\title{
LE MONDE
}

AVANT IA

\section{CREATION DE L'HOMME}




\section{CEUVRES DE CAMILLE FLAMMARION}

\section{ASTRONOMIE POPULAIRE}

Ouvrage couronné par l'Académie française. 1 beau vol. gr. in -8 jésus de 840 pages, illustré de 360 grar., chromolithographies, cartes célestes, etc. Soixante-quinzième mille. Prix : broché, $19 \mathrm{fr}$.

\section{LES ÉTOILES \& LES CURIOSITÉS DU CIEL}

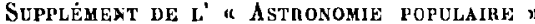

Description complète du Ciel, étoile par étoile, constellations, instruments, Catalogues, etc. 1 vol. grand in-8 ${ }^{\circ}$, illustré de 400 figures, cartes|er planches. Quarantieme mille. $12 \mathrm{fr}$

\section{LES TERRES DU CIEL}

Description astronomique, climatologique, géographique des planètes qui gravitent avec la Terre autour du Soleil et de l'êtat probable do la vie à leur surface. 1 volume grand in-8 ${ }^{\circ}$

lllustré de photographies célestes, vues telescopiques, 400 figures. Quarante-cinquieme mille. $12 \mathrm{fr}$.

\section{DANS LE CIEL ET SUR LA TERRE}

Tableaux ot Harmonies.

Edition de luxe, grand in-16 carré, ornée de 4 eaux-fortes : $5 \mathrm{fr}$

\section{LA PLURALITÉ DES MONDES HABITES}

Au point de yue de l'Astronamie, de la Physiologie et de la Philosophie naturelle. 33 édition. 1 vol. in-12. 3 fr. 50.

Le méme ouvrage, edition bijou: $4 \mathrm{fr}$.

\section{LES MONDES IMAGINAIRES \& LES MONDES REELS}

Revue des therories humaines sur les habitants des astres. Q0: édition. 1 vol. in-12. $3 \mathrm{fr} .50$.

\section{RÉCITS DE L'INFINI}

Lumen, histoire d'une Ame. - Histoire d'une comète. - La rie universelle et éternelle. $11^{\circ}$ édition, 1 vol in-12, 3 fr. sio

\section{DIEU DANS LA NATURE}

Ou le Spiritualisme et le Matérialisme devant la Science moderne. $20^{*}$ édition, 1. fort vol. in-12, avec le portrait de l'auteur. $4 \mathrm{fr}$.

\section{CONTEMPLATIONS SCIENTIFIOUES}

Nouvelles études de la Nature et exposition des onvres éminentes de la Science contemporaine. $4^{e}$ édition, $1 \mathrm{vol}$ in-19.3 $\mathrm{fr}, 50$

\section{VOYAGES AÉRIENS}

Journal de bord de douze voyages seientifiques en ballon, arce plans topographiques. 1 vol. in-19. 3 fr. 50

\section{LES DERNIERS JOURS D'UN PHILOSOPHE}

pak Sir HUMphry DaYy. Ouvrage traduit de l'anglais et annoté. 1 vol. in-12. $3 \mathrm{fr}$. 50

\section{HISTOIRE DU CIEL}

Histoire populaire de l'Astranomie et des différents systemes imaginés pour expliquer l'Tnivers. 4 édition. 1 vol, grand in-8 8 . $9 \mathrm{fr}$.

\section{ASTRONOMIE SIDÉRALE : LES ÉTOILES DOUBLES}

Catalogue des étoiles multiples en mouvement, contenant les observations et l'analyse des mouvements 1 vol. in $-8^{\circ} .8 \mathrm{fr}$.

\section{LES MERVEILLES CÉLESTES}

Lectures du soir a l'usage de la jeunesse. 89 grer, et 3 cartes célestes $\left(4^{e}\right.$ mille). 2 fr. 25.

\section{PETITE ASTRONÓMIE DESCRIPTIVE}

Pour les enfants, adaptée aux besoins de l'enseignement, par C. DELoN. 100 fig. 1 fr. $\mathbf{2 5 .}$

\section{L'ASTRONOMIE}

Revue mensuelle d'Astronomie populaire. Progres de la Science, observations, etc. Abonnement annuel : $12 \mathrm{fr}$.

Grande Carte céleste (1" 20) contenant toutes les étoiles visibles à l'œil nu. . . 6 fr. Globe gèographique de la planete Mars. . . . . . . . . . . . . 5 fr.

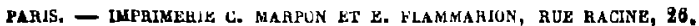


IRIS - LILLIAD - Université Lille 1 


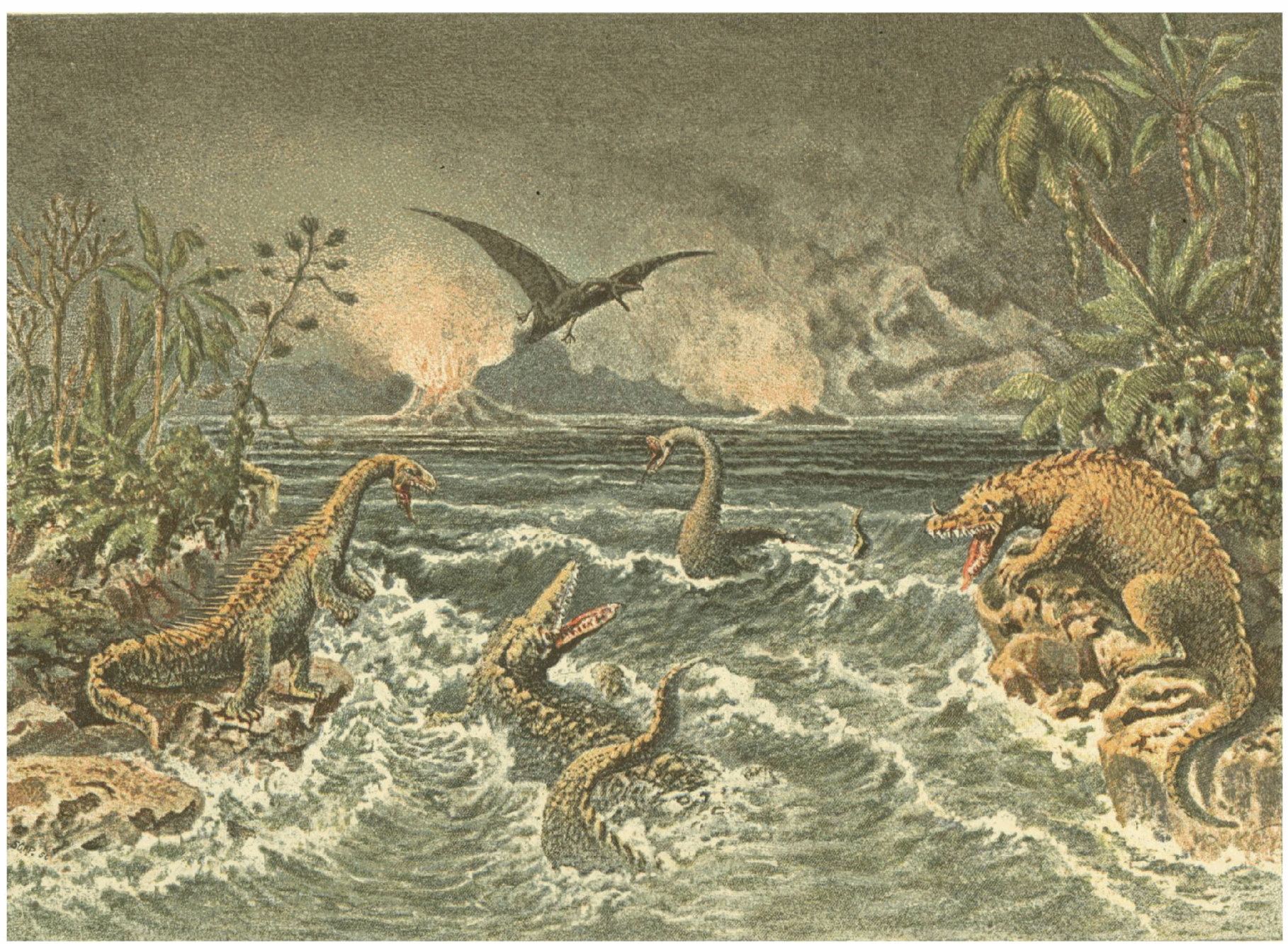

SCÈNE DU MONDE PRIMITIF PENDANT LA PÉRIODE SECONDAIRE 


\section{CAMILLE FLAMMARION}
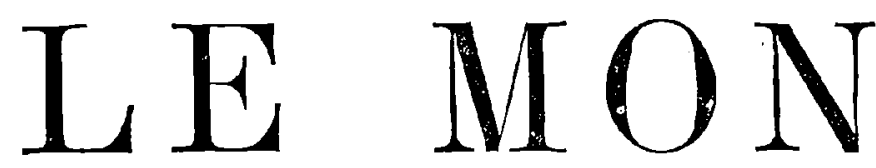

$\mathrm{DF}$

AVANT I.A

\section{CRÉATION DE L'HOMME}

ORIGINES DE LA TERRE

ORIGINES DE LA VIE. - ORIGINES DE L'HUMANITÉ

OIVIAGE ILLUSTRÉ DE 400 GRAVURES SUR BOIS

B CARTES GÉOLOGIQUES ET 5 AQDARELLES

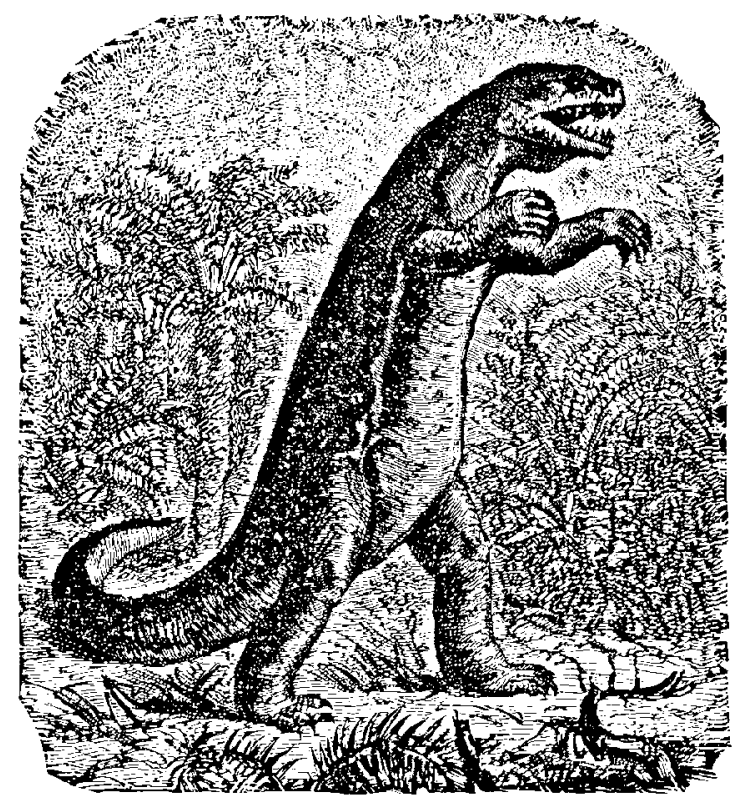

\section{PARIS}

G MARPON ET E. FLAMMARION, ÉDITEURS RUE RACINE, 26 , PRÉS L'ODKOON

\section{6}

Tous droits résurvés. 
IRIS - LILLIAD - Université Lille 1 


\section{AVERTISSEMENT DES ÉDITEURS}

S'il est une question qui ait toujours intrigué et même passionné la curiositć humaine, t'est assurément celle de l'origine du Monde, de l'origine des Êtres et le l'origine de l'Humanité elle-même. La science a dans tous les sièclo interrogé la nature dans l'espérance de déchiffrer l'énigme du grand mystère. Buffon a sondé les époques de la création. Laplace a découvert la loi générale qui a présidé à la formation des mondes. Lamarck a mis en lumière la parenté et la filiation des êtres. Cuvier a r\$suscité les fossiles ensevelis depuis des millions d'années. Darwin a montré comment les espèces se sont succédé et et comment elles sè transforment. Depuis un quart de siècle surtout, les efforts de tous ley naturalistes semblent concentrés sur cette question de l'origine des Êtres et des premières manifestations de la vie sur notre planète. Il semble aujourd'hui qu'à l'ordre du génie humain tous les monstres antédiluviens aient tressailli dans leurs tombeaux et qu'ils se soient levtrs pour venir reconstituer eux-mêmes les scènes grandioses des âges disparus et montrer à l'Homme ses lointains ancêtres.

Ce tableau du Ilonde avant la création de l'Homme, Zimmermann avait entrepus de le tracer dans un ouvrage qui est resté célèbre, mais qui est lepuis longtemps épuisé en librairie. Depuis un quart de siècle que zette œuvre a été écrite, la science a fait d'ailleurs des pas de géant. Mussi, les nouveaux Éditeurs de cet ouvrage ont-ils prié M. Camille Fammarion de l'examiner avec soin et d'en donner une édition élevésau niveau' des progrès actuels de la science. Lc savant astronome, auquel ces études de cosmogonie ont toujours été familières par la parenté qu'elles offrent avec les bases mêmes de la doctrine de la Plualité des Mondes, avait à peine commencé ce travail de revision quil s'est aperçu que l'œuvre de Zimmermann méritait d'être entièremnt refondue. En fait, il se trouve que pas une seule page de l'ouvrage rriginal n'est restée.

L'œuvre de lacréation se déroule ici, pour la première fois, sans lacunes, depuis la ormation de la nébuleuse solaire jusqu'à l'apparition de l'humanité ellemême. L'auteur a voulu aborder de face le problème des origines de litumanité aux yeux des plus éminents critiques, sa solution est établi sur des bases absolues et incontestables, et au licu d'être grossière or humiliante, comme on le craignait, cette solution radicale se trouveștre à la plus grande gloire de l'humanité, et en même temps éminemment spiritualiste.

Pour satisfair à tous les désirs déjà exprimés, les Éditeurs ont cru devoir donne à cette nouvelle publication la forme populaire mais relativemert luxueuse - qui a ćté accucillie avec tant d'enthousiasme par les inombrables lecteurs de l'Astronomie populaire et des Terres du Ciel. 
IRIS - LILLIAD - Université Lille 1 


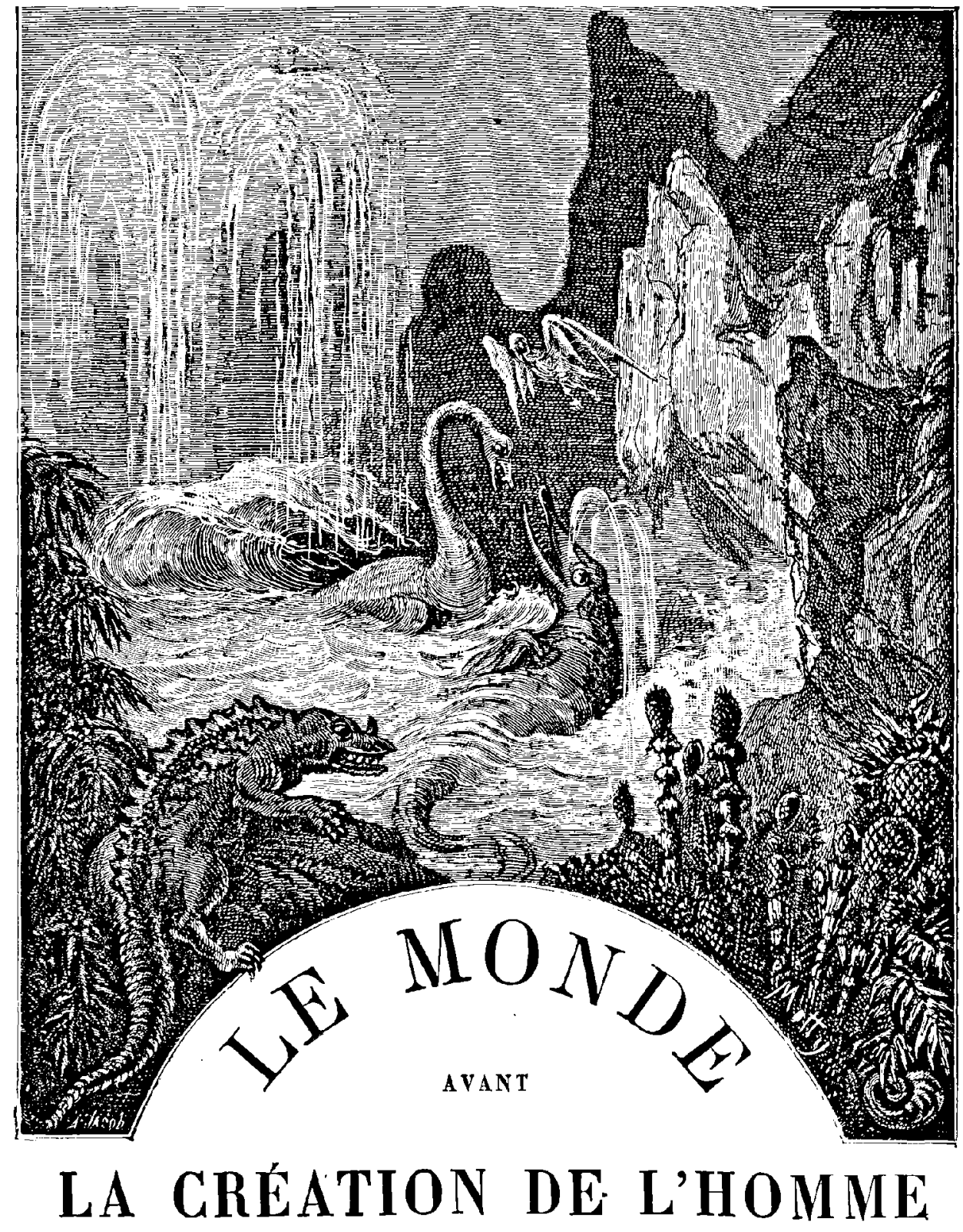

\section{CHAPITRE PRÉLIMINAIRE}

LES PREMIERS JOURS DE LA TERRE

Il fut un temps oủ l'humanité n'existait pas. La Terre offrait alors un aspect tout différent de celui qu'elle présente de nos jours. Au lieu de la vie intelligente, laborieuse et active qui circule à sa LE MONDE aVANT LA CRÉation DE L'HOMME 
surface; au lieu de ces villes populeuses, de ces villages, de ces habitations; de ces champs cultivés, de ces rignes, de ces jardins; de ces routes, de ces chemins de fer, de ces navires, de ces usines, de ces ateliers; de ces palais, de ces monuments, de ces temples; au lieu de cette incessante activité humaine qui exploite actuellement toutes les forces de la nature, pénètre les profondeurs du sol, interroge les énigmes du ciel, étudie les événements de l'univers et semble concentrer sur elle-mêrme l'histoire entière de la création; il n'y avait que des forêts sauvages et impénétrables, des fleuves coulant silencieusement entre des rives solitaires, des montagnes sans spectateurs, des vallées sans chaumières, des soirs sans rêveries, des nuits étoilées sans contemplateurs. Ni science, ni littérature; ni arts, ni industrie; ni politique, ni histoire; ni parole, ni intelligence, ni pensée. Alors, les drames et les comédies de la vie humaine étaient inconnus sur notre planète. L'affection comme la haine, l'amour comme la jalousie, la bonté comme la méchanceté, l'enthousiasme, le dèvouement, le sacrifice, tous les sentiments, nobles ou pervers, qui constituent la trame de l'étoffe humaine, n'étaient pas encore nés ici-bas. Les citoyens de la patrie terrestre existaient sans lo savoir et travaillaient sans but. C'ètaient le lourd mastodonte écrasant sous ses pas les fleurs déjà écloses dans les clairières, le colossal megatherium fouillant de son museau les racines des arbres, le mylodon robustus rongeant les branches basses des cèdres, le dinotherium giganteum, le plus grand des mammifères terrestres qui aient jamais vécu, plongeant ses longues défenses au fond des eaux pour en arracher les plantes féculentes; c'étaient aussi les singes mesopithèques et dryopithèques, qui gambadaient avec agilité sur les collines de la Grèce antédiluvienne, et comfnençaient la famille sur les hauteurs du Parthénon.

En ces temps reculés, Paris sommeillait dans l'inconnu de l'avenir. Une antique forèt avait étendu son manteau sombre sur la France entière, la Belgique et l'Allemagne. La Seine, dix fois plus large que de nos jours, inondait les plaines où la grande eapitale développe aujourd'hui ses splendeurs; des poissons qui n'existent plus se poursuivaient dans ses ondes; des oiseaux qui n'existent plus chantaient dans les îles; des reptiles qui n'existent plus circu- 
laient parmi les rochers. Autres espèces animales et végétales, autre température, autres climats, autre monde.

En remontant plus loin encore dans l'histoire de la Terre, nous rencontrerions une époque oú Paris et la plus grande partie de la France étaient plongés au fond des eaux, où la mer s'étendait de Cherbourg à Orléans, à Lyon et à Nice, où la surfạce de l'Europe ne ressemblait en rien à ce qu'elle est actuellement, où la faune et la flore différaient si étrangement de celles qui leur ont succédé, que sans doute, les habitants de Vénus ou de Mars nous ressemblent davantage. D'épouvantables ptérodactyles aux larges ailes sautaient dans le ciel, vespertillons des rèves de la Terre, et ces dragons volants, ces chauves-souris géantes, étaient alors les souverains de l'atmosphère. Le dimorphodon macronyx; le crassirostris et le ramphorynchus, aussi barbares que leurs noms, perchaient sur les arbres, s'aidaient des pieds et des mains pour grimper sur le haut des rochers, s'élançaient dans les airs en ouvrant leurs parachutes membrancux et se précipitaient dans les eaux comme des amphibies. En mème temps, les sauriens gigantesques, l'ichthyosaure et le plésiosaure se combattaient au sein des flots agités, remplissant l'air de leurs hurlements féroces, monstres macrocéphales aux larges màchoires, dont la taille ne mesurait pas moins de dix et douze mètres de longucur. (On a compté jusqu'à deux mille soixante-douze dents dans la tête de quelques-uns de ces dinosauriens.) L'iguanosaure et le mégalosaure animaient la solitude des forèts, au sein desquelles des arbres gigantesques, des fougères arhorescentes, des sigillaires, des cycadées et mille conifères, élevaient leurs cimes pyramidales, ou arrondissaient leurs dômes de verdure. Des iguanodons, de la forme du kangourou, atteignaient quatorze mètres de longueur : en appuyant leurs pattes sur l'une de nos plus hautes maisons, ils auraient pu manger au balcon d'un cinquiéme étage... Quelles masses prodigieuses! quels animaux et quelles plantes, relativement à notre monde actuel! Ces êtres fantastiques valent bien ceux que l'imagination humaine a inventés, dans les centaures, les faunes, les griffons, les hamadryades, les chimères; les goules, les vampires, les hydres, les dragons, les cerbères; et ils sont réels : ils ont vécu, au sein des primilives forêts; ils onit-vu les Alpes, les Pyrénées, sortir lentement de la mer, s'élever au-dessus 
des nues et redescendre. Ils ont marché dans les avenues ombreuses de fougères et d'araurarias. Paysages grandioses des âges disparus! nul regard humain ne vous a comtemplés, nulle oreille n'a compris vos harmonies, nulle pensée n'était éveillée devant vos magiques panoramas. Pendant le jour, le soleil n'éclairait que les combats et les jeux de la vie animale. Pendant la nuit, la lune brillait silencieuse au-dessus du sommeil de la nature inconsciente.

Depuis la naissance de la Terre, depuis l'époque reculée où, dẻtachée de la nébuleuse solaire, elle exista comme planète, oủ elle se condensa en globe, se refroidit, se solidifia et devint habitable, tant de millions et de millions d'années se sont succédécs, que l'histoire tout entière de l'humanité s'évanouit devant ce cycle immense. Quinze ou vingt mille ans d'histoire humaine ne représentent certainement qu'une faible partie de la période géologique contemporaine. En accordant (ce qui est un minimum) cent mille ans d'âge à l'époque actuelle, que ses caractères vitaux signalent comme étant la quatrième depuis le commencement de notre monde, et qui porte en géologie le nom d'époque quaternaire, l'àge tertiaire aurait duré trois cent mille ans, l'âge secondaire douze cont mille, et l'époque primaire plus de trois millions d'années. C'est, au minimum, un total de quatre millions sept cent mille années depuis les origines des espèces animales et végétales relativement supérieures. Mais ces époques avaient été précėdées elles-mêmes d'un âge primordial, pendant lequel la vie naissante n'était représentée que par ses rudiments primitifs, par les espèces inférieures, algues, crụstacẻs, mollusques, invertébrés ou vertébrés sans têtes, et cet àge primordial parait occuper les çinquante-trois centièmes de l'épaisseur des formations géologiques, ce qui lui donnerait à l'échelle précédente cinq millions trois cent mille ans pour lui seul!

Ces dix millions d'années $\mathrm{d} u$ calendrier terrestre peuvent représenter l'âge de la vie. Mais la genèse des préparatifs avait été incomparablement plus longue encore. La période planétaire antérieure à l'apparition du premier être vivant a surpassé considérablement en durée la période de la succession des espèces. Des expériences judicieuses conduisentà penser que pour passer de l'état liquide à l'état solide, pour se refroidir de $2000^{\circ} \grave{a} 200^{\circ}$, notre globe n'a pas demandé moins de trois cent cinquante millions d'années! 


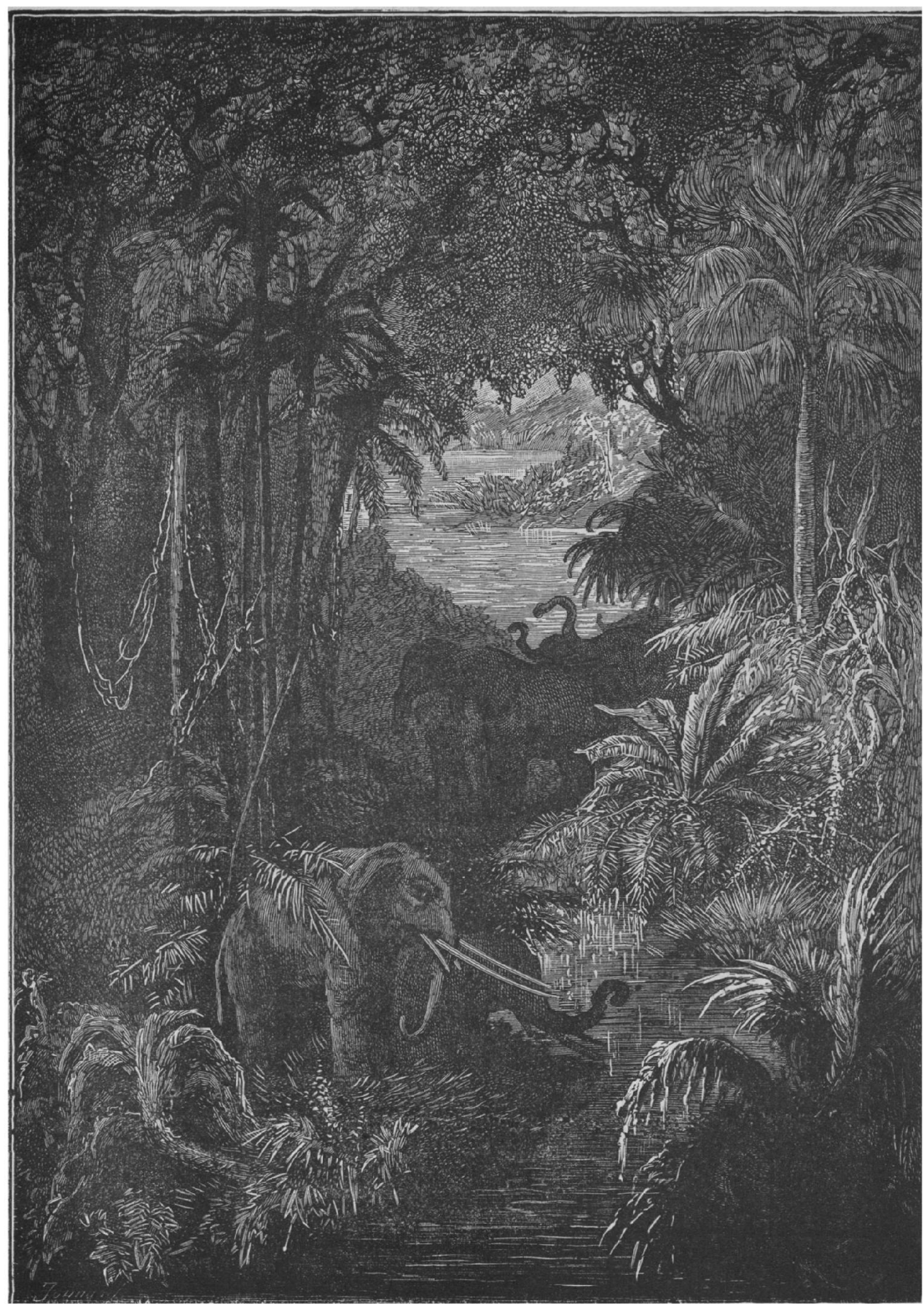

Foréts sauvages et impénétrables..... le lourd mastodonte écrasait sous ses pas les fleurs déjà écloses dans les clairières.... 
Quelle histoire que celle d'un monde! Essayer de la encevoir, c'est avoir la noble ambition de s'initier aux plus profonds et plıs importants mystères de la nature, c'est désirer pénétrer dans le conseil des dieux antiques qui s'étaient partagé le gouvernement de l'univers. Et comment ne pas s'intéresser à ces merveilleuses conquetes de la science moderne, qui, en fouillant les tombeaux de la Terre, a su ressusciter nos ancêtres disparus! A l'ordre dı génie humain, ces monstres antédiluviens ont tressailli dans leurs noirs sépulcres, et, depuis un demi-siècle surtout, ils se sont levés de leurs tombeaux, un ì un, sont sortis des carrières, des puits de mine, des tunnels, de toutes les fouilles, et ont reparu à la lumière du jour. De toutes parts, péniblement, lourdement, léthargiques, brisés en morceaux, la tète ici, les jambes plus loin, souvent incomplets, ces vicux cadavres, déjà pétrifiés au temps du déluge, ont entendu la trompette du jugement, du jugement de la science, et ils sont ressuscités, se sont réunis comme une armée de légions ètrangères de tous les pays et de tous les siècles, et les voici qui vont défiler devant nous, étranges, bizarres, inattendus, gauches, maladroits, monstrueux, paraissant venir d'un autre monde, mais forts, solides, satisfaits d'eux-mèmes, semblant avoir conscience de leur valeur et, nous disant dans leur silence de statues: « Nous voici, nous, vos aïcux; nous, vos ancêtres; nous, sans lesqucls vous n'existeriez pas. Regardez-nous et cherchez en nous l'origine de ce que vous êtes, car c'est nous qui vous avons faits. Vos yeux, avec lesquels vous sondez l'infiniment grand et l'infiniment petit, en voici les premicrs essais, modestes, rudimentaires, mais bien importants, car si ces premiers essais n'avaient pas réussi chez nous, vous seriez aveugles. Vos mains, si élégantes, si savantes, voici de quelles pattes elles sont le perfectionnement: ne riez pas trop de nos pattes si vous trouvez vos mains utiles et agréables. Votre bouche, votre langue, vos dents, tout cela est délicat, charmant, très gentil, mais ce sont nos gueules, nos museaux, nos crocs, nos becs, qui sont devenus votre bouche. Vos ccurs battent doucement, mystérieusement, et ces palpitations humaines, que nous ne connaissons pas, vous procurent, dit-on, des émotions si profondes, si intimes, que parfois vous donneriez le monde entier pour satisfaire la moindre d'entre elles; eh bien, voici comment la circulation du sang a commencé, 
voici le premier cour qui a battu. Et votre cerveau, vous vous admirez en lui, vous saluez en lui le siège de l'âme et de la pensée, vous en appréciez à ce point l'incomparable sensibilité, que c'est à peine si vous osez en approfondir la délicate structure; or, votre cerveau, c'est notre moelle, la moelle de nos vertèbres, qui s'est développée, perfectionnẻe, épurée, et sans nous le géologue, l'astronome, le naturaliste, l'historien, le philosophe, le poète, n'existeraient pas. Oui, nous voici : saluez vos pères! »

Ainsi parleraient tous ces fossiles, les singes, les prosimiens, les marsupiaux, les oiseaux, les reptiles, les serpents, les amphibies, les poissons, les mollusques, et ils diraient vrai, car l'homme est la plus haute branche de l'arbre de la nature, ses racines plongent dans la terre commune, et l'arbre qui porte ce beau fruit est formé par toutes ces espèces, en apparence si différentes, en réalité voisines, parentes, sœurs. - Ils sont ressuscités, et le naturaliste les classe.

Et quel est l'être intelligent et curieux, quel est le penseur, quel est mème le simple lecteur de feuilletons et de romans populaires, qui ne préférerait, un instant au moins, à une lecture inutile, celle de ce grand livre de la nature, ouvert pour tous les yeux, si intéressant par sos révélations, si captivant par ses surprises, si supérieur à toutes les fictions et à tous les con tes? qui ne préférerait cet admirable livre de la nature à tous les autres? qui n'aimerait s'initier directement à ce grand mystère de l'origine de l'hornme, de la Genèse de la T'erre et du berceau de l'univers? Est-il un sujet qui nous touche de plus près, qui puisse intéresser davantage notre curiosité intelligente?

Etudier l'histoiro de la Terre, e'est étudier à la fois l'univers et l'homme, car la Terre est un astre dans l'univers, et l'homme est la résultante de toutes les forces terrestres. Il n'est pas un produit du miracle : il est l'enfant de la nature.

Personne ne peut plus croire aujourd'hui que le monde ait été sréé en six jours il y a six mille ans, que les animaux soient subitement sortis de lerre à la voix d'un Créateur, tout formés, adultes, et associés par couples de mâles et femelles, depuis l'éléphant jusqu'à la puce et jusqu'aux microbes microscopiques; que le premier cheval ait bondi d'une colline; que le premier chêne ait été créé séculaire. Personne ne peut plus admettre non plus que l'humanité ait 
commencé par un couple de deux jeunes gens créés de toutes pièces à l'âge viril, placés dans un jardin préparé pour les recevoir, au milieu des fleurs et des fruits mùrs. Sans doute, c'était là une mythologie à la fois charmante et terrible. Adam naissant à l'âge de vingt ou trente ans, s'ennuyant bientôt d'être seul, Jéhovah lui détachant une côte pendant son sommeil et en formant le corps de

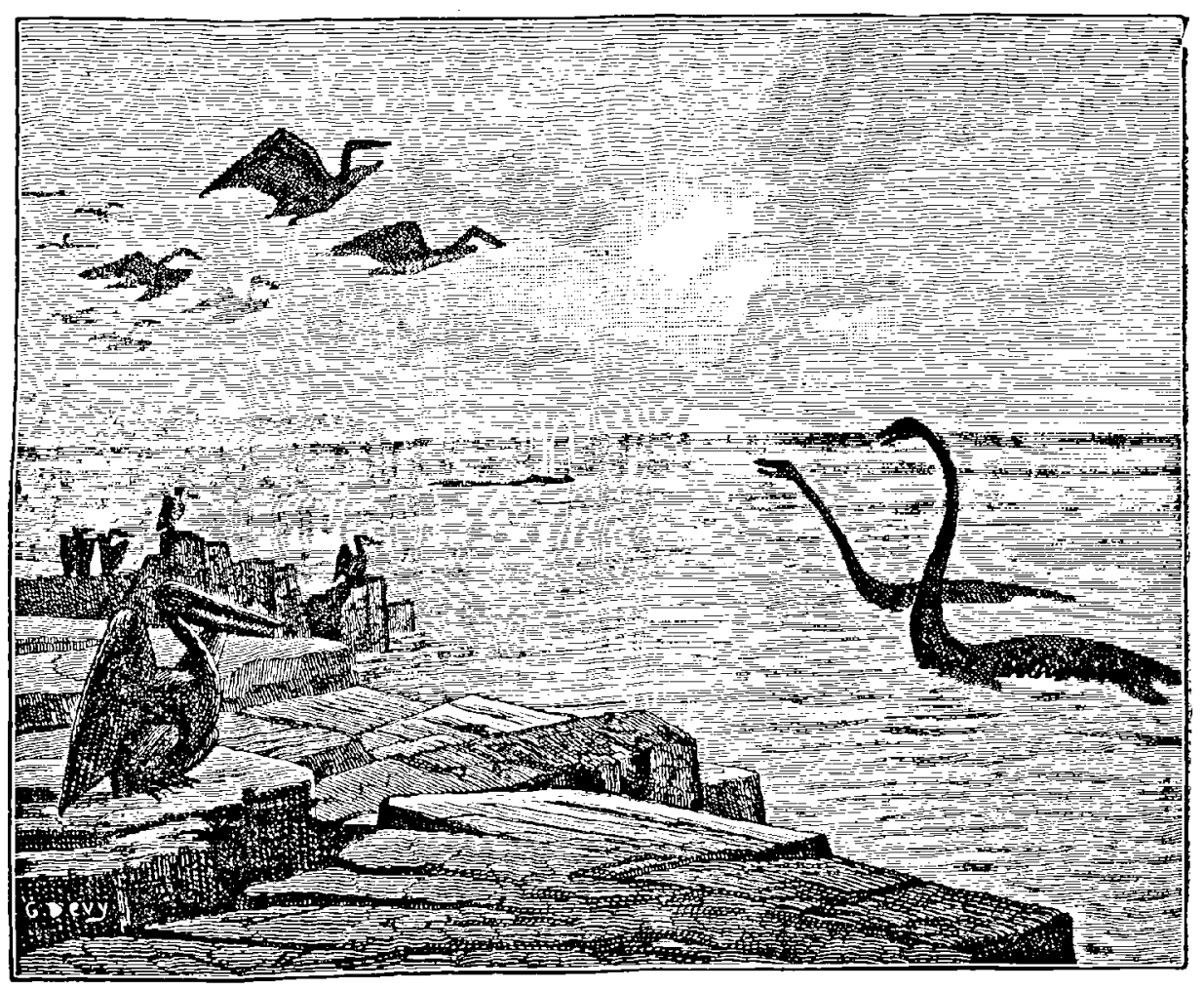

Au lieu de Paris, c'était la mer... des ptérodactyles aux larges ailes sautaient dans le ciel.

là première jeune fille. Dieu se promenant dans le jardin pendant les chaleurs de l'après-midi et les grondant d'avoir succombé à la tentation pour laquelle il venait de créer Éve, les enfants de ce premier couple étant maudits dès leur naissance et le déluge arrivant pour les punir de leurs prévarications. Noé enfermant dans un bateau un couple de toutes les espèces d'animaux, etc. Tout cela est original, mais naif, et les amis du miracle doivent regretter que ce 


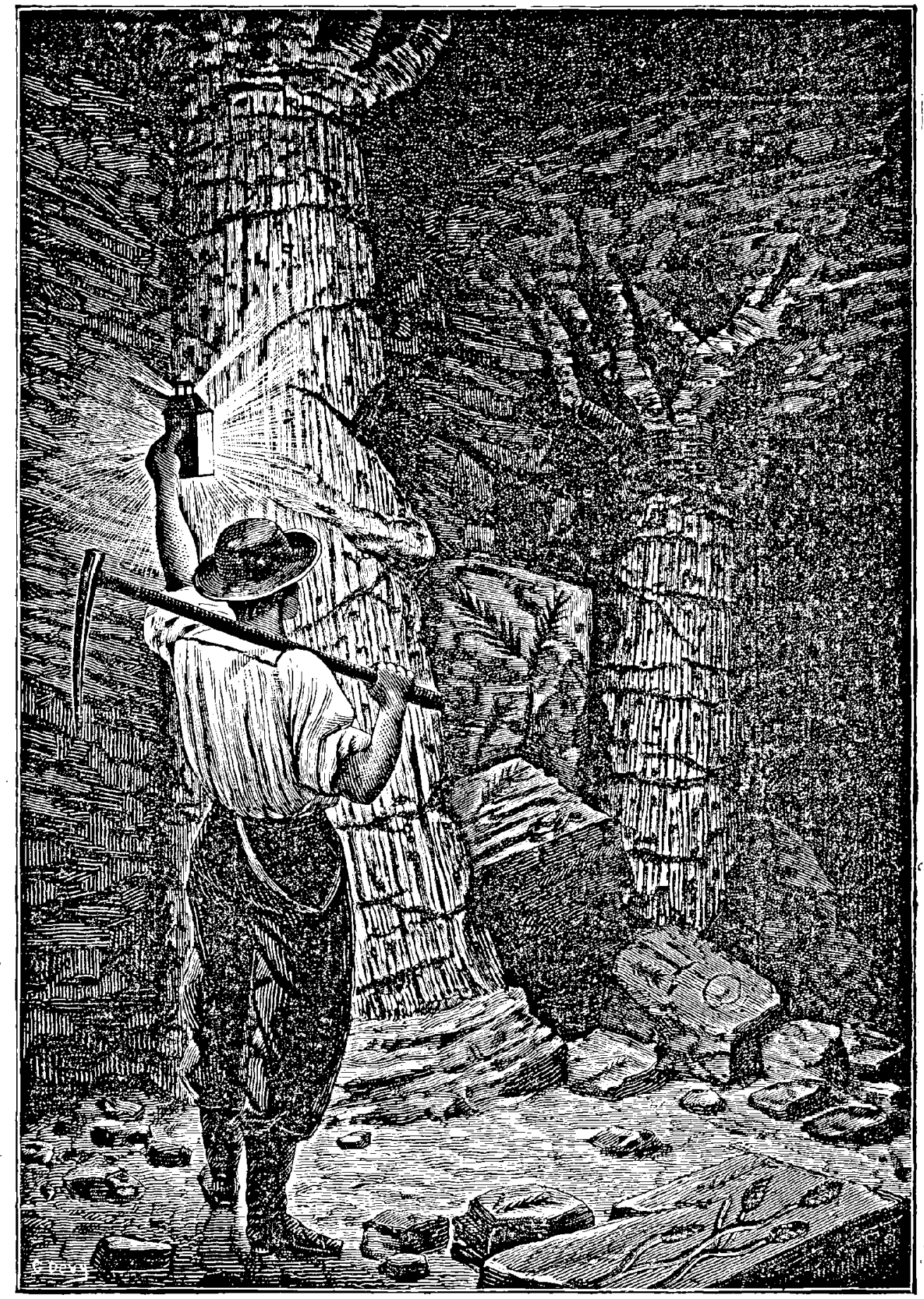

- Au sein des mines profondes, le houilleur rencontre avec étonnement les vieilles forèts ensevelies.

LE MUNDE avaNt La CRÉation DE L'HOMage 
ue puisse pas etre vrai. Mais nul n'ignore aujourd'hui que Dieu n'a pas crée les animaux qui existent actuellement et qu'ils ont été précédés par des espèces primitives, différentes, mais non étrangères, inconnues du temps de Moïse; nul n'ignore que notre globe est très ancien et que ses couches géologiques renferment les fossiles des âges disparus; nul n'ignore qu'anatomiquement le corps de l'homme est le même que celui des mammifères; nul n'ignore que nous possédons encore des organes atrophiés, qui ne nous servent à rien, et qui sont les vestiges de ceux qui existent encore chez nos ancêtres animaux; nul n'ignore que chacun de nous a été, avant de naitre, pendant les premiers mois de la conception dans le sein de sa mère, mollusque, poisson, reptile, quadrupède, la nature résumant en petit sa grande œuvre des temps antiques; nul n'ignore enfin que toutes les espèces vivantes se tiennent entre elles comme les anneaux d'une même chaine, que l'on passe de l'une à l'autre par des degrés intermédiaires insensibles, que la vie a commencé sur la Terre par les êtres les plus simples et les plus élémentaires, par des plantes qui n'ayant ni feuilles, ni fleurs, ni fruits, peuvent à peine porter le titre de plantes, par des animaux qui n'ayant ni tète, ni sens, ni muscles, ni estomac, ni moyens de locomotion, méritent à peine le nom d'animaux, et que lentement, irisensiblement, par gradation, suivant l'état de l'atmosphère et des eaux, la température, les conditions de milieux et d'alimentation, les êtres sont devenus plus vivants, plus sensibles, plus personnels, micux spécifiés, plus perfectionnés, pour aboutir finalement à ces fleurs brillantes et parfumées qui sont l'ornement des modernes campagnes, aux oiseaux qui chantent dans les bois... pour aboutir surtout à l'être humain, le plus élevé de tous dans l'ordre de la vie. Oui, nous avons nos racines dans le passé, nous avons encore du minéral dans nos os, nous avons hérité du meilleur patrimoine de nos aieux de la série zoologique, et nous sommes encore un peu plantes par certains aspects : ne le sentons-nous pas au printemps, aux jours ensoleillés où la sève circule avec plus d'intensité dans les artères des petites fleurs et des grands arbres?

L'ètre humain, le roi de la création terrestre, n'est pas, d'ailleurs, aussi isolé, aussi nettement détaché de ses ancêtres, aussi personnel, aussi intellectuel qu'il le parait. Il est, au contraire, très varié lui- 
mème dans ses manifestations. Sur les quatorze cent millions d'ètres humains qui existent autour de ce globe (et qui se reproduisent sans un seul instant d'arrèt, afin do donner à la nature près de cent mille naissances par jour), combien n'en est-il pas qui vivent sans faire jamais œuvre d'intelligence?

En fait, il y a, non seulement dans les contrées sauvages, non seuloment chez les tribus de l'Afrique centrale, chez les Samoyèdes ou les habitants de la Terre-de-Feu, mais encore chez les peuples civilisés, des millions d'êtres humains qui ne pensent pas, qui ne se sontjamais demandé pourquoi ils existent sur la Terre, qui ne s'intéressent à rien, ni à leurs propres destinées, ni à I'histoire de l'humanité, ni à cclle de la planète, qui ne savent pas oú ils sont et ne s'en inquiètent pas, en un mot qui vivent absolument comme des brutes. Les hommes qui pensent, qui existent par l'esprit, sont une minorité dans notre espèce. Leur nombre néanmoins s'accroît de jour en jour. Le sentiment de la curiosité scientifique s'est éveillé et se développe. Le progrès qui s'est manifesté avec lenteur dans le perfectionnement des sens et du cerveau de la série animale se continue, et nous le voyons à l'œuvre dans notre propre espèce, autrefois rude, grossière, barbare, aujourd'hui plus sensible, plus délicate, plus intellectuelle. L'homme change, plus rapidement peut-être que nulle autre espèce. Celui qui reviendrait sur la Terre dans cent mille ans n'en reconnaîtrait plus l'humanité.

Déjà, si nous comparions aujourd'hui l'un des boulevards de Paris, la salle de l'Opéra un soir de brillante représentation, une nuit de bal, un harmonieux concert, une séance de l'Institut, une armée en campagne, etc., avec les réunions primitives de nos ancôtres de l'âge de pierre, nous ne pourrions nous empêcher de reconnaître un progrès manifeste en faveur de notre époque, non seulement au moral, mais encore au physique. Ce ne sont plus les mèmes hommes ni les mêmes femmes. L'élégance de l'esprit et celle du corps se sont affinées. Les muscles sont moins forts, les nerfs sont plus développés. L'homme moderne est moins massif, moins rude; insensiblement, le cerveau domine. La femme moderne est plus artiste, plus fine; elle est aussi plus Jlanche, sa chevelure est plus longue et plus soyeuse, son regard est plus clair, sa main plus petite, son indolence plus voluptueuse. De temps à autre, 
des invasions barbares bouleversent tout et arrètent l'énervement. Mais ce n'est qu'un arrêt et un tourbillon. L'ensemble est emporté vers l'inconscient désir du mieux, vers l'idéal, vers le rêve. On cherche. Quoi? Nul ne le sait. Mais on aspire, et l'aspiration entraine l'humanité vers un état intellectuel toujours plus avancé, jamais satisfait. Le cràne moule le cerveau, et le corps moule l'esprit.

L'exercice dés membres développe ceux qui agissent le plus; cenx qu'on oublie diminuent, finissent mème par s'atrophier. On pourrait juger des møurs d'une époque par la stature des individus. Quoique, de nos jours, on puisse encore soutenir, avec une vraisemblance apparente, que " la force prime lẹ droit», les esprits sont dẻjà assez avancés pour sentir que c'est lì un axiome complètement faux. Le jour viendra où il n'y aura plus ni armées, ni guerres, où l'homme se sentira couvert de honte en voyant qu'íl ne travaille que pour nourrir des régiments, et ou la France, l'Europe, le monde entier délivré, respirera librement en sceouant et jetant au fumier ce manteau de lèpre, de sottise et d'infamie qui s'appelle le budget de la guerre.

Non, celui qui reviendrait sur la Terre dans cent mille ans n'en reconnaîtrait plus l'humanité. Aucune de nos langues n'aura subsisté : on parlera un tout autre langage. Aucune de nos nations. Aucune de nos capitales. Une civilisation brillante aura éclairé l'Afrique centrale. L'Europe aura passé par-dessus l'Amérique pour aller retrouver la Chine. L'atmosphère sera sillonnée d'aéronefs supprimant les frontières et semant la liberté sur les Etats-Unis de l'Europe et de l'Asie. De nouvelles forces physiques et naturelles auront été conquises... et peut-ètre quelque télégraphe photophonique nous fera-t-il converser avec les habitants, des planètes voisines.

La Terre change sans cesse, - lentement, car sa vie est longue, - mais perpétuellement. Ici la mer ronge les falaises et s'avance dans l'intérieur des terres ; là, au contraire, les fleuves charrient du sable, forment des deltas, des estuaires et voient avancer leurs rives dans la mer; les pluies et lés vents font descendre les montagnes dans les fleuves et dans l'Ocèan; les forces souterraines en soulèvent d'autres; les volcans détruisent et créent; les courants de la mer et 


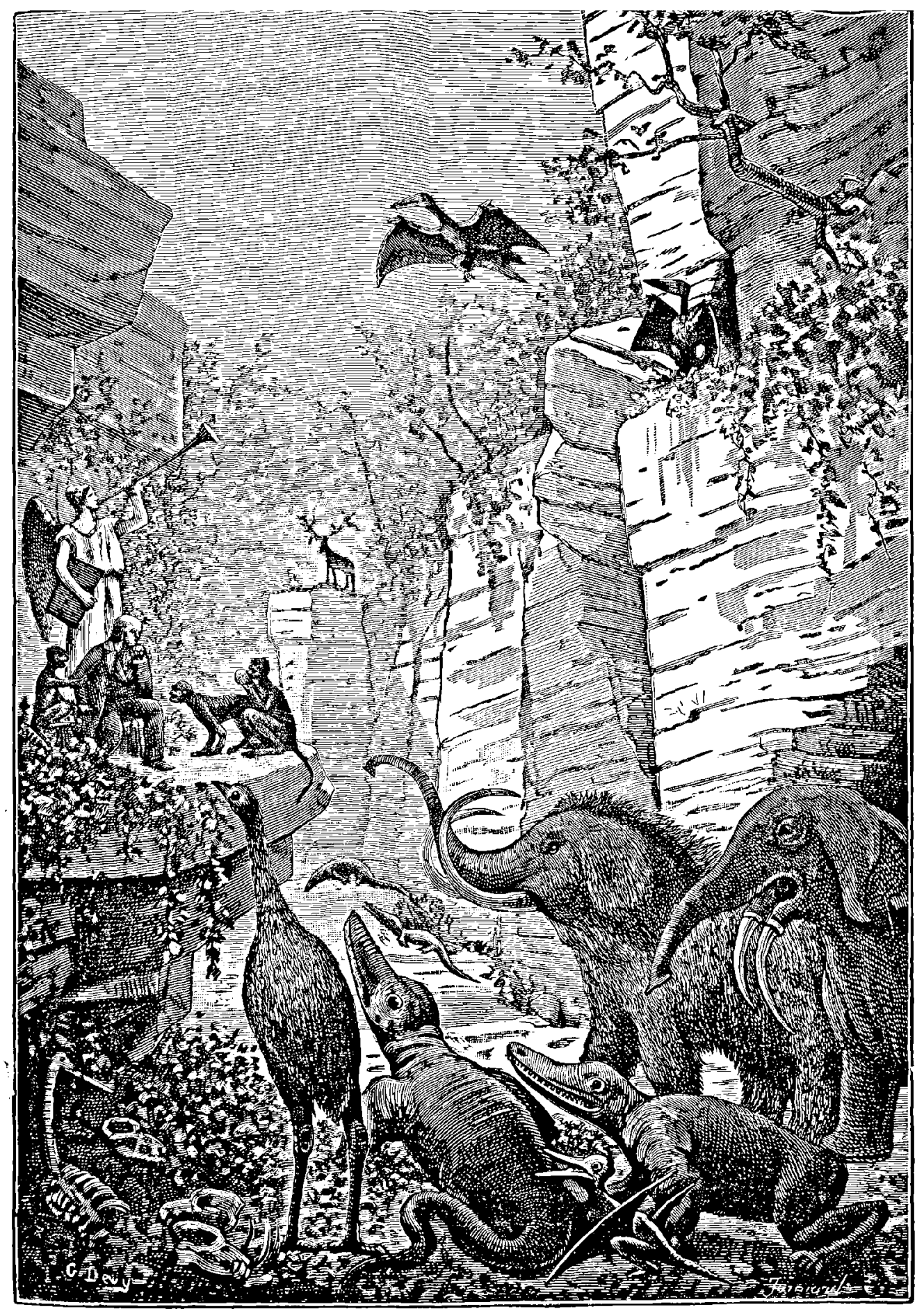

La trompette du jugement de la science a sonné. Ils sont ressuscités, et le naturaliste les classe. 
de l'atmosphère modifient les climats ; les saisons varient pèriodiquement; les plantes se transforment, non seulement par la culture humaine, mais encore par les variations de milieux; les oiseaux des villes construisent aujourd'hui leurs nids avec les débris des manufactures ; les cités humaines naissent, vivent et meurent; un mouvement prodigieux emporte toute chose en son cours; en ces heures charmantes du soir où, sur le penchant des collines solitaires, nous fuyons les bruits du monde pour nous associer aux mystérieux spectacles de la nature, à l'heure où le soleil vient de descendre dans son lit de pourpre et d'or, oủ le croissant lunaire se détache, céleste nacelle, sur l'océan d'azur, et où les premières étoiles s'allument dans l'infini, alors il nous semble que tout est en repos, en repos absolu, autour de nous, et que la nature commence à s'endormir d'un profond sommeil ; cet aspect est trompeur; dans la nature, jamais de repos, toujours le travail, le travail harmonieux, vivant et perpétuel; la Terre semble immobile : elle nous emporte dans l'espace avec une vitesse de 26500 lieues à l'heure; onze cent fois la vitesse d'un train express; la Lune parait arrètéo ': clle nous suit dans notre cours autour du Soleil ct tourne autour de nous en raison de plus de mille mètres par seconde; en agissant à chaque instant par son attraction pour déranger notre globe, le tirer en avant ou en arrière, produire les marées, etc.; les étoiles nous paraissent fixes : chacune d'elles vogue avec une rapidité vertigineuse, inconcevable, parcourant jusqu'à deux et trois cent mille lieues ì l'heure; le soleil semble couché, il brille toujours, sans avoir jamais connu la nuit, s'enveloppe de flamboiements intenses el lance incessamment autour de lui, avec ses effluves de lumière et de chaleur, des explosions de feu s'élevant à quatre et cinq cent mille kilomètres de hauteur et retombant en flammes d'incendie sur l'océan solaire qui toujours brüle; le fleuve qui est $\dot{a}$ nos pieds est calme comme un miroir : il coule, coule toujours, ramenant sans cesse à l'Océan l'eau des pluies qui toujours tombe, des nuages qui toujours se forment, des vapeurs de l'Océan qui toujours s'élèvent; l'herbe sur laquelle nous sommes assis paraît n'ètre qu'un tapis inerte : elle pousse, elle croît, elle grandit, et jour et nuit, sans un instant de repos, les molécules d'hydrogène, d'oxygène, d'acide carbonique, s'y combattent ou s'y com- 
binent dans une activité perpétuelle; l'oiseau se tait dans les bois: sous le chaud duvet de la eouveuse les œufs sont en vibration profonde et bientôt les petits vont éclore; et nous-mèmes, qui contemplons en rêvant ce grand spectacle de la nature, nous nous croyons en repos et nous sommes portés à croire que pendant notre propre sommeil la nature se repose en nous : erreur, erreur profonde : notre cœur bat, envoyant à chaque battement la circulation du sang jusqu'aux extrémités des artères, nos poümons fonctionnent, régénérant sans cesse ce fluide de vie, les molécules constitutives de chaque millimètre de notre corps se poussent, se juxtaposent, se marient, se chassent, se substituent sans un instant d'arrèt, et si nous pouvions étudier au microscope les tissus de nos organes, nos muscles, nos nerfs, notre sang, notre moelle, et surtout la fermentation de chaque parcelle de notre cerveau, nous assisterions à un travail intime permanent, faisant vibrer nuit et jour chaque point de notre ètre, depuis le moment de notre conception jusqu'à notre dernier soupir - et au delà, car, l'âme envolée, ce corps retourne, molécule par molécule, à la nature terrestre, aux plantes, aux ani- maux et aux hommes qui nous succédent: rien ne se perd, rien ne se crée, nous sommes composés de la poussière de nos ancêtres, nos petits-fils le seront de la nôtre.

Tout change, tout se métamorphose. Il n'y a jamais eu plus de création qu'aujourd'hui. La Cause première ne s'est pas éveillée un beau jour, après une éternité d'inaction, pour créer le monde : elle est la force initiale mème de la nature; dès le premier moment de son existence, elle agit. L'Univers est coéternel à Dieu et infini comme lui. En vain mille religions diverses ont eu l'audace naïve d'inventer des dieux à l'image de l'homme, en vain l'une d'entre elles ose-t-elle prétendre que l'homme peut créer Dieu à son tour et le manger ou le mettre dans sa poche:ce sont là d'inqualifiables extravagances. Dieu est l'Infini et l'Inconnaissable. L'Univers est en création perpètuelle. Des genèses de mondes s'allument actuellement dans les cieux; des agonies s'éteignent artour des vieux soleils, et des cimetières de planètes défuntes circulent dans la profondeur des nuits étoilées. Les comètes vagabondes qui gravitent de systèmes en systèmes sèment sur leur passage les étoiles filantes, cendres 'de 
mondes détruits, et le carbone, germe des organismes à venir. Toute planète a son enfance, sa jeunesse, son âge mùr, sa vieillesse, sa mort. Le jour viendra où le voyageur errant sur les rives de la. Seine, de la Tamise, du Tibre, du Danube, de l'Hudson, de la Néva, cherchera la place où Paris, Londres, Rome, Vienne, New-York, Saint-Pétersbourg auront, pendant tant de siècles, brillé capitales de nations florissantes, comme l'archéologue cherche la place où

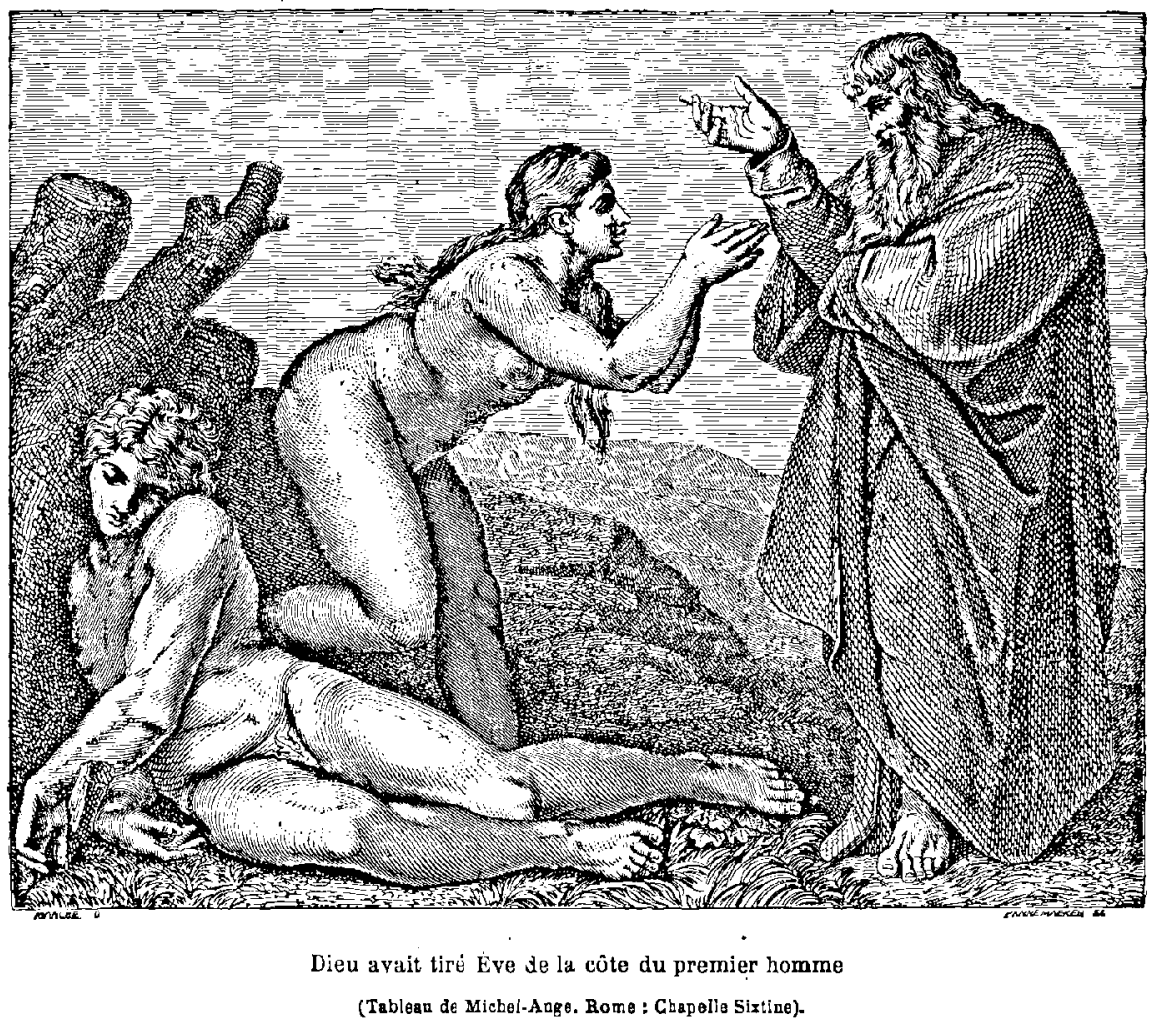

Ninive, Babylone, Tyr, Sidon, Memphis, Ecbatane resplendissaient autrefois au sein de l'activité, du luxe et des plaisirs. Le jour viendra où l'humanité, plusieurs fois transformée, descendra la courbe de son progrès, s'éteindra avec les derniers éléments vitaux de la planète, et s'endormira du dernier sommeil sur une Terre désormais déserte et solitaire, oủ l'oiseau ne chantera plus, où la fleur ne fleurira plus, où l'eau ne coulera plus, où le vent ne soufflera plus, oü le blanc suaire des dernières neiges et des dernières glaces s'al- 


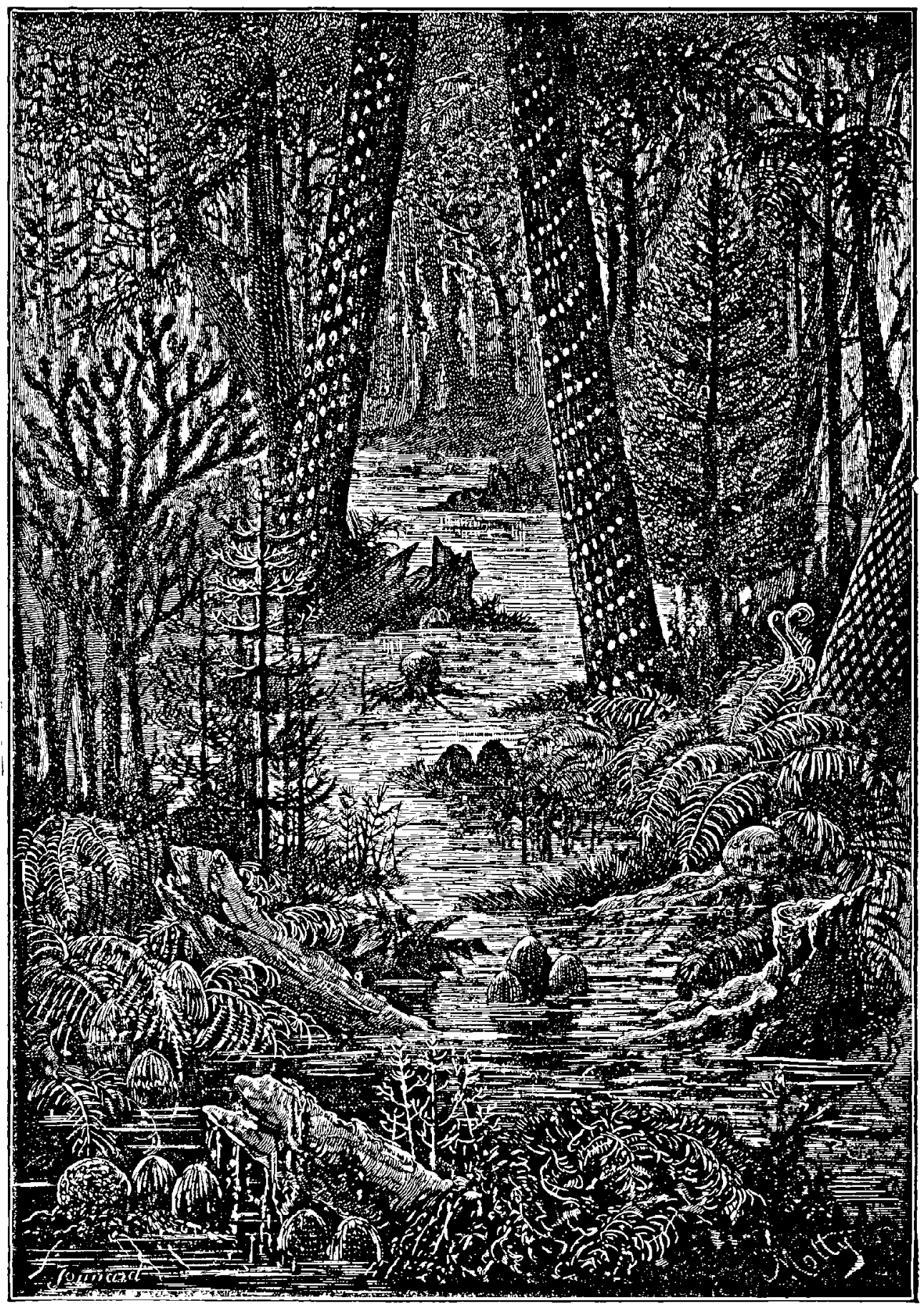

Paysages grandioses des áges disparus! nul regard humain ne vous a contemplés, nulle oreille n'a compris vos harmonies... 
longera sinistrement depuis les pôles jusqu'à l'équateur. Et le Soleil, notre grand, notre puissant, notre beau, notre bon Soleil, s'éteindra lui-même au centre de son système. Nul tombeau, nulle pierre mortuaire, nulle épitaphe ne marquera la place où l'humanité tout entière aura vécu, la place où tant de nations puissantes, tant de gloires, tant de travaux, tant de bonheurs et tant de malheurs se seront succédé... et cette place mème n'existe pas, car la Terre, depuis sa naissance, 'emportée dans son tourbillon autour du Soleil qui vogue lui-même avec tout son système parmi les étoiles, la Terre où nous sommes n'est pas passée deux fois par le même chemin depuis qu'elle existe, et le sillage éthéré que nous venons de parcourir ensemble depuis une heure, ce sillage de 26500 lieues se referme derrière nous pour ne jamais, jamais se rouvrir devant nos pas.

La loi suprème du progrès régit tout, emporte tout. Nous n'y songeons pas, mais nous marchons en avant avec rapidité, et loin de nous désoler en certaines époques de défaillance, nous devons être satisfaits du chemin parcouru. Qu'est-ce que deux siècles, trois siècles, dans l'histoire? C'est six, huit, dix générations ; c'est un jour. Or, en France même, en 1619, au XVII sic̀cle encore, sous Louis XIII et sous Richelieu (c'est d'hier), le philosophe Vanini n'a. t-il pas été brúlé vif à Toulouse pour ses opinions religieuses, peu diffèrentes de celles que nous venons d'émettre tout à l'heure? On lo promena par la ville, en chemise et la corde au cou (c'était par une froide journée d'hiver) ; on voulut le forcer à abjurer ses idées, ce qu'il refusa; on le fit monter sur l'échafaud, au milieu d'une populace vociférante; le bourreau enfonça de force les tenailles dans sa bouche, lui arracha la langue jusqu'à la racine et la jeta au feu, et la douleur lui fit pousser un cri si déchirant que tous les assistants en frémirent; enfin on le brûla et l'on jeta ses cendres au vent. Est-ce que de telles exécutions pourraient encore se produire de nos jours? Peut-être, dans les violentes commotions politiques, sous l'exacerbation des guerres civiles ou internationales, mais non de sang froid, tranquillement, légalement, pour des opinions philosophiques ou religienses. La liberté de conscience est une conquête définitive acquise au progrès. A la même époque, Jordano Bruno montait sur le bủcher en pleine Rome, au milieu d'une fête 
publique, pour avoir proclamé une doctrine absolurrent conforme à la nôtre : la Pluralité des Mondes et l'inconnaissabilité de Dieu; en 1634, Urbain Grandier, curé de Loudun, était brùlé vif comme sorcier; en cette époque d'intolérance, des milliers de victimes expirèrent sur les bûchers, Jeanne d'Arc en tête, et le peuple, le peuple ignorant et stupido applaudissait. Ce tomps-là est passé, et bien passé. L'Inquisition (quoiqu'elle existe toujours) ne 'condamnerait plus aujourd'hui Galilée à abjurer l'hérésie du monvement de la

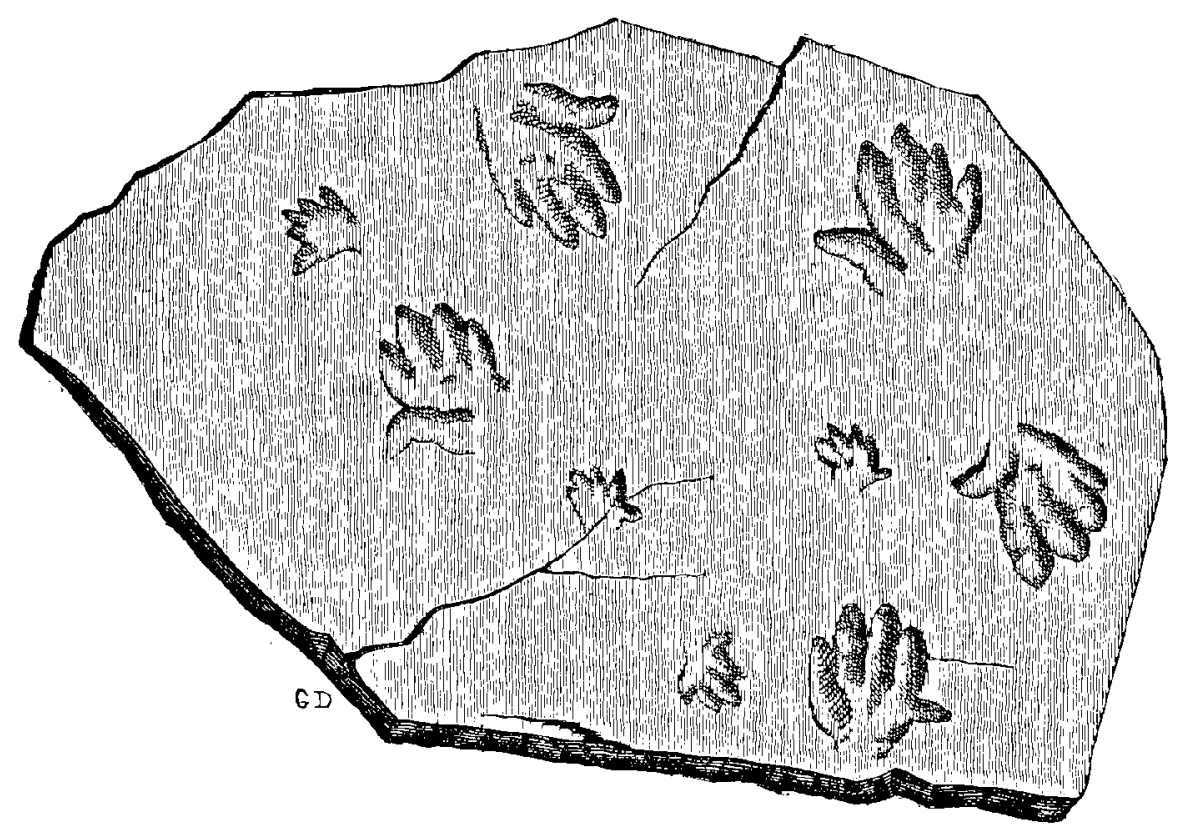

Fig. 8. - ... On retrouve la trace de leurs pas... (Empreintes fossiles du Labyrinthodon.)

Terre. La science, l'agrandissement de la pensée humaine, l'affranchissement des consciences, la liberté, emportent l'humanité dans l'apothéose de lia lumière.

Oui, le monde marche vers un iđéal sans cesse plus élevé; les mnurs s'adoucissent, les esprits s'éclairent, l'humanité progresse, dans son ensemble comme dans chacun de ses membres. Pouvonsnous admettre que cette loi universelle du progrès chez tous les ètres soit sans but, que l'existence même des choses soit sans but, que l'humanité terrestre marche vers un apogée idéal pour ne rien laisser du tout. après elle, et que chacun de nous ne 
soit qu'un accident fortuit, un feu follet qui s'éteindra comme il est venu ; que l'Univers entier, en un mot, et tous les êtres, éminents ou obscurs, heureux ou malheureux, sages ou fous, bons ou méchants, vertueux ou crimincls qui le composent, depuis notre infime planète jusqu'aux profondeurs les plus reculées de l'espace infini, pouvons-nous admettre que tout existe sans cause et sans but? Nous ne le pensons pas. Ce serait triste, ce serait noir. Dans cette conception mécanique de l'univers, tout ne serait qu'illusion, fantasmagorie, mensonge, il y aurait plus de logique dans la moindre pensée humaine que dans l'ensemble de la nature, et nous n'aurions plus qu'à cesser de penser pour nous rendre dignes de notre fin. Quelle étrange doctrine! Mais non : toute âme doit vivre éternellement, en progressant toujours.

L'histoire de la Terre porte en elle-mème le plus magnifique, le plus éloquent témoignage en faveur de la loi du Progrès qui soit accessible à nos obscrvations. Elle est en quelque sorte le progrès lui-même incarné dans la vie, depuis le minéral jusqu'à l'homme. Notre planète a commencé par ètre une nébulosité informe, qui graduellement s'est condensée en globe. Cette nébulosité gazeuse, d'une densité incomparablement plus faible que l'air que nous respirons, cette immense boule de vent, était formée d'un gaz sans doute primitivement homogène, plus léger que l'hydrogène mème. L'attraction mutuelle de toutes les molécules vers le centre, la condensation progressive qui en résulta, les frottements et la transformation de cette chute centripète en chaleur, les premic̀res combinaisons chimiques naissant de ce développement de calorique, l'influence de l'électricité, l'action multiple et diverse des forces de la nature dérivant en quelque sorte les unes des autres, amenèrent la formation des premiers éléments, de l'hydrogène, de l'oxygène, du carbone, de l'azote, du sodium, du fer, du calcium, du silicium, de l'aluminium, du magnésium, et des divers autres minéraux qui paraissent tous formés géométriquement comme s'ils étaient des multiples de l'ćlément primitif dont l'hydrogène scmble être la première condensation. Les espèces minérales se sont séparées successivement.

Ces mèmes substances qui constituaient notre planète primitive lorsqu'elle brillait, étoile nébuleuse; cet oxygène, cet hydrogène, ce 


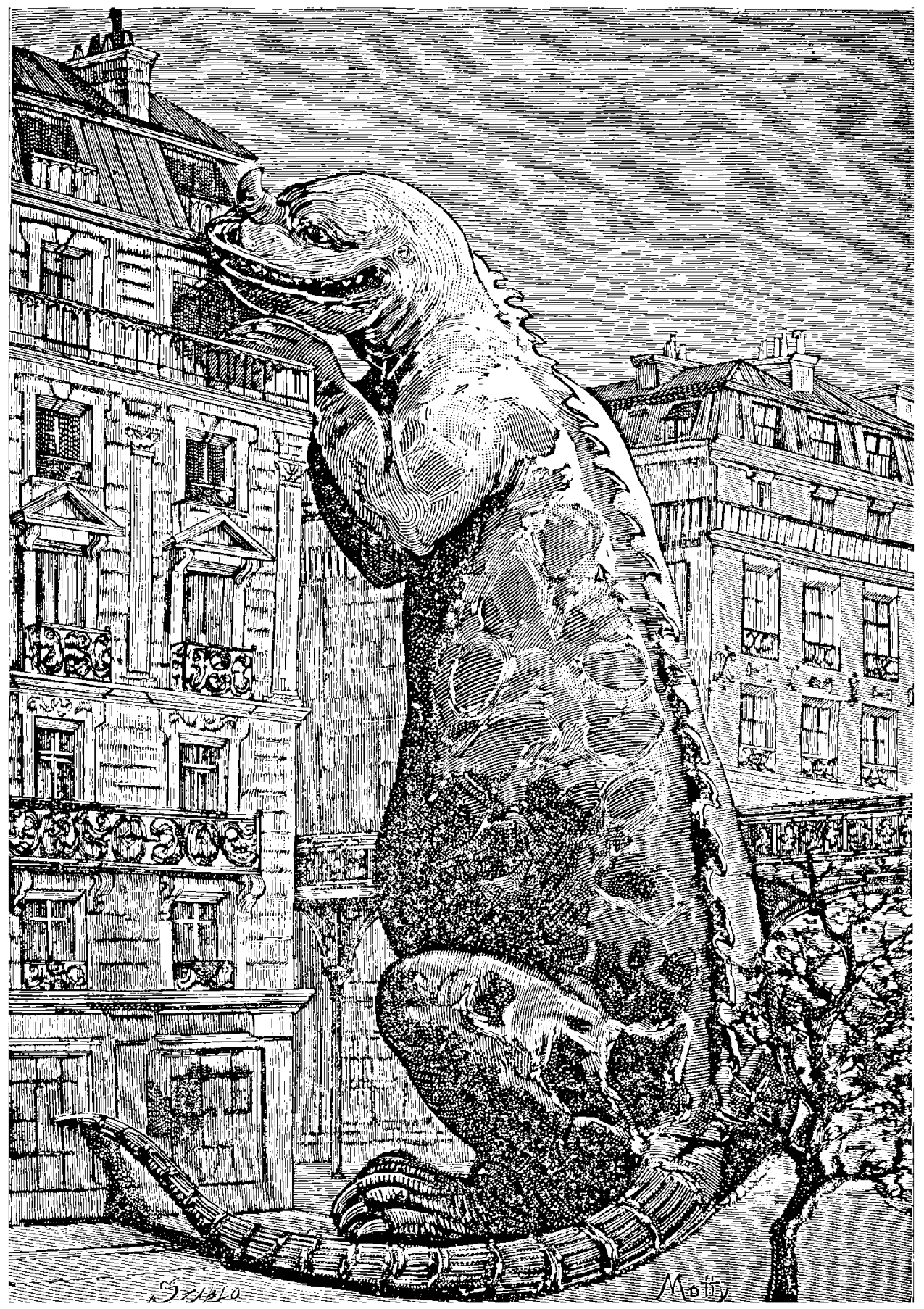

... En appuyant leurs pattes sur une de nos plus hautes maisons, ils auraient pu manger au balcon d'un cinquième étage... 
sodium qui brûlaient, feux ardents, comme ils brùlent aujourd'hui dans les flammes du Soleil, se sont combinés d'une tout autre façon après l'extinction de la Terre comme étoile. Le feu est devenu l'eau. Physiquement, ce sont les extrêmes ; chimiquement, c'est le même élément. L'Océan qui roule encore aujourd'hui ses flots tout autour du globe, est formé d'hydrogène, d'oxygène et de sodium.

L'observateur de l'espace aurait pu voir notre planète briller d'abord à l'état de pâle nébuleuse, resplendir ensuite comme un soleil, devenir étoile rouge, étoile sombre, étoile variable aux fluctuations d'éclat, et perdre insensiblement sa lumière et sa chaleur pour arriver à l'état dans lequel nous observons aujourd'hui Jupiter.

Déjà la Terre tournait sur elle-mème et autour du Soleil. Lorsque la température de l'éclosion fut abaissée, lorsque les vapeurs atmosphériques se condensèrent, lorsque la mer primitive s'étendit tout autour du globe, au sein des convulsions volcaniques de l'enfance terrestre, parmi les déchirements de la foudre et les éclats du tonnerre, dans les eaux tièdes et fécondes, les premières plantes, les premiers animaux se formèrent par des combinaisons du carbone, semi-solides, semi-liquides, pâteuses, malléables, dociles, mobiles et changeantes. Ces premiers ètres sont des cellules primitives ou de simples associations de cellules, des algues, des fucus, des annélides, des objets gélatineux, des mollusques : ce sont encore des minéraux, autant que des plantes et des animaux, ce sont des zoophytes, des coraux, des éponges, des madrépores, des crustacés. Les premiers animaux ne sont que des plantes sans racines. Par le perfectionnement séculaire des conditions organiques de la planète, par le développement graduel de quelques organes rudimentaires, la vie s'améliore, s'enrichit, se perfectionne. Pendant l'époque primordiale, on ne voit que des invertébrés flottant dans les eaux encore tièdes des mers primitives. Vers la fin de cette époque, pendant la période silurienne, on voit apparaitre les premiers poissons, mais seulement les cartilagineux : les poissons osseux ne viendront que longtemps après. Pendant la période primaire commencent les grossiers amphibies et les lourds reptiles, les lents crustacés. Des îles s'élèvent du sein des ondes et se couvrent d'une végétation splendide. Mais le règne animal est 
encore bien pauvre. Pendant des millions d'années tous les habitants de la Terre ont été sourds et muets; les premiers animaux apparus sur ce globe, ceux qui occupent aujourd'hui le bas de la série, sont tous dépourvus de voix; la voix ne commence qu'au milieu de l'âge secondaire, et l'oreille ne s'est formée que beaucoup plus tard. Pendant des millions d'années aussi, animaux et plantes ont été sans sexe. Les premières manifestations de cet ordre sont pauvres, mal définies, sans ardeurs (amours de poissons). Mais graduellement la vie progresse, se perfectionne. Bientôt le règne animal se diversifie en espèces distinctes et nombreuses. Les reptiles se sont développés : l'aile porte l'oiseau dans les airs; les premiers mammifères, les marsupiaux, habitent les forèts. Pendant l'àge tertiaire, les serpents se détachent tout à fait des reptiles en perdant leurs pattes (dont les soudures primitives sont encore visibles aujourd'hui), le reptile-oiseau, archéoptérix, disparait aussi, les ancêtres des simiens se développent sur les continents en même temps que toutes les fortes espèces animales. Mais la race humaine n'existe pas encore. L'homme va apparaittre, semblable à l'animal par sa constitution anatomique, mais plus élevé dans l'échelle du progrès et destiné à dominer un jour le monde par la grandeur de son intelligence. L'esprit humain brille enfin sur la Terre, contemple, percoit, réfléchit, pense, raisonne. Dans l'histoire de la planète, l'homme a été le premier entretien de la Nature avec Dieu.

Chaque couche de terre dans les champs et les bois, sur le versant des montagnes ou au fond des vallées, chaque banc de pierre dans les carrières, chaque dépôt de la mer ou des fleuves nous montre la succcssion lente des époques de la nature et l'œuvre séculaire de la vie terrestre. Il n'y a pas bien longtemps encore, on croyait le monde créé littéralement en six jours, et des écrivains, tels que Bernardin de Saint-Pierre entr'autres, pensaient sérieusement que les êtres dont nous voyons les débris dans les entrailles de la Terre n'ont récllement pas vécu et que le monde a été fait tout vieux. Des forèts seraient nées en pleine croissance, abritant des animaux qui n'auraient pas eu d'enfance; les oiseaux de proie auraient dévoré des cadavres qui n'avaient point eu de vie. « On y a vu des jeunesses d'un matin et des décrépitudes d'un jour. » Quelle différence de grandeur, entre cette mesquine 
conception du monde et celle qui vient d'ètre résumée! Fn tenant compte seulement de la vie à ciel découvert, dans les intervalles de submersions océaniques, les habitants de Londros ne sont que les seconds locataires de leur contrée, les Parisiens n'en sont que les troisiémes occupants, et les Autrichiens de Vienne ont été précédé par trois espèces d'êtres appartenant pour ainsi dire à trois créations différentes.

Les couches géologiques du globe terrestre, que nous retournons

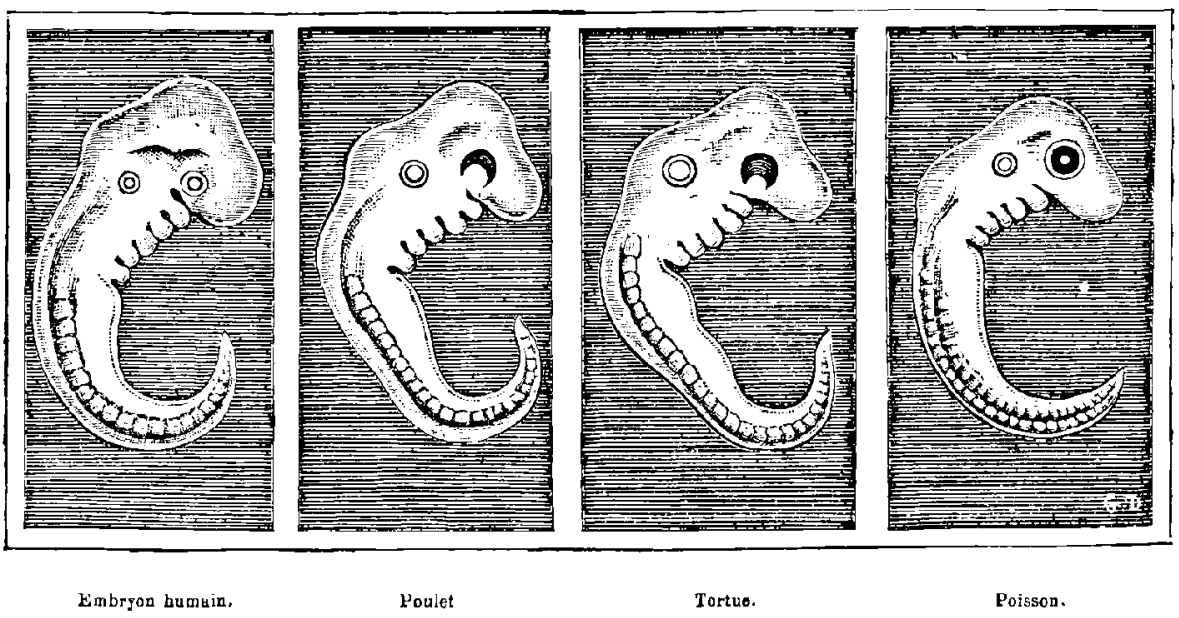

Fig. 10. - ... Chacun de nous a été, dans le sein de sa mère, moliusque, poisson, reptile, quadrupède. (Embryons comparés).

aujourd'hui comme les feuillets d'un livre, nous montrent ainsi cette succession de fossiles ensevelis. Les espèces se sont succédées en se développant graduellement, comme les rameaux d'un mème arbre. Elles dérivent d'une même source; elles se rattachent entre elles comme les anneaux d'une mème chaîne; elles appartiennent au même ordre de choses; elles réalisent le même programme.

Mais n'anticipons pas sur les spectacles qui vont se dérouler devant nos yeux. Il importe, maintenant que nous avons pris un avant-goût de ces grandioses problèmes, d'entrer immédiatement dans le cœur de notre sujet. Comment la Terre où nous sommes s'est-elle formée? Quelle fée a veillé sur son berceau ? Est-elle vraiment fille du Soleil ? Est-elle vraiment mère de la Lune ? Quels 


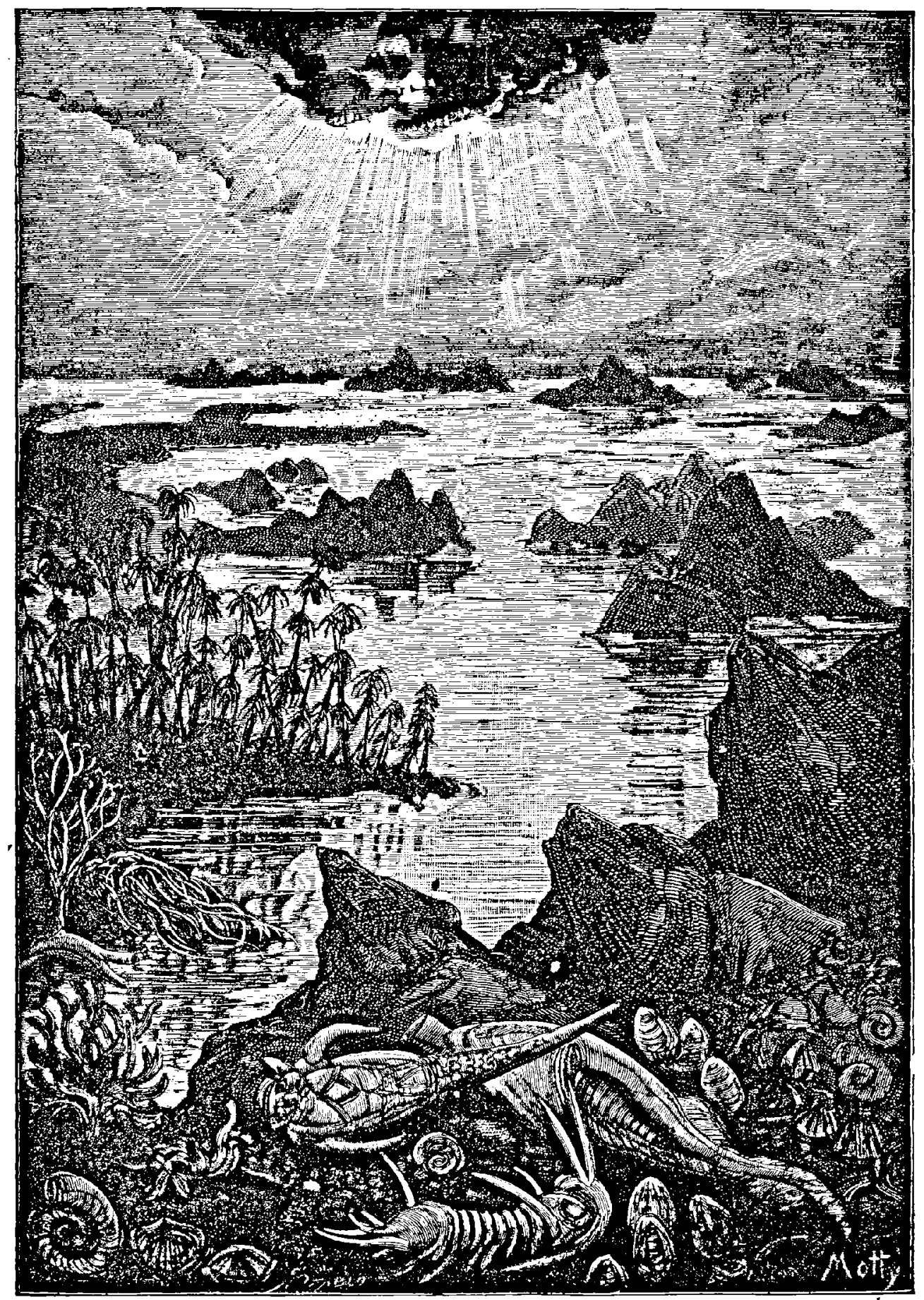

Durant ces millions d'années, les premiers habitants du globe élaient muets, sourds et sans sexo.

LE MONDE AVANT LA CREATION DE L'HOMML 
liens de parenté rattachent notre planète à ses sœurs? Comment les. forces de la Nature ont-elles pu donner naissance à toutes ces merveilleuses espèces d'animaux et de plantes qui animent et embellissent la surface de notre monde? Quel est le plus ancien de l'œuf ou de la poule? Qu'est-ce que l'œuf humain? Quel sein l'a recu? Quelle virilité l'a fécondé ? Quelle Ève a conçu. le premier enfant? Sous quel soleil a-t-il grandi ? Quelles harmonies ont bercé ses premiers rèves ? Quels tableaux, quels paysages, quelles scènes ont orné les jours de la Terre, depuis les antiques et fabuleuses périodes de la genèse primordiale jusqu'à la première association de familles humaines dans les cavernes de l'âge de pierre, jusqu'aux premières chasses du rhinocéros tychorinus, de l'ours spelæus, du cerf à bois gigantesque; jusqu'au premier duel, jusqu'au premier crime, jusqu'aux premiers combats à l'aide de bâtons noueux, de massues grossières, d'arınes en silex taillés et de flèches d'obsidienne? Quels déluges, quels volcans, quels effondrements, quelles transformations ont changé la face du globe dans les vieux temps préhistoriques?... Autant de questions, autant de captivants sujets d'études pour tois les amis de la Science et de la Nature.

Le voile du temple est déchiré. Pénétrons dans l'auguste sanctuaire de la Création. 


\section{LIVRE PREMIER}

LE COMMENCEMENT DU MONDE

IRIS - LILLIAD - Université Lille 1 
IRIS - LILLIAD - Université Lille 1 


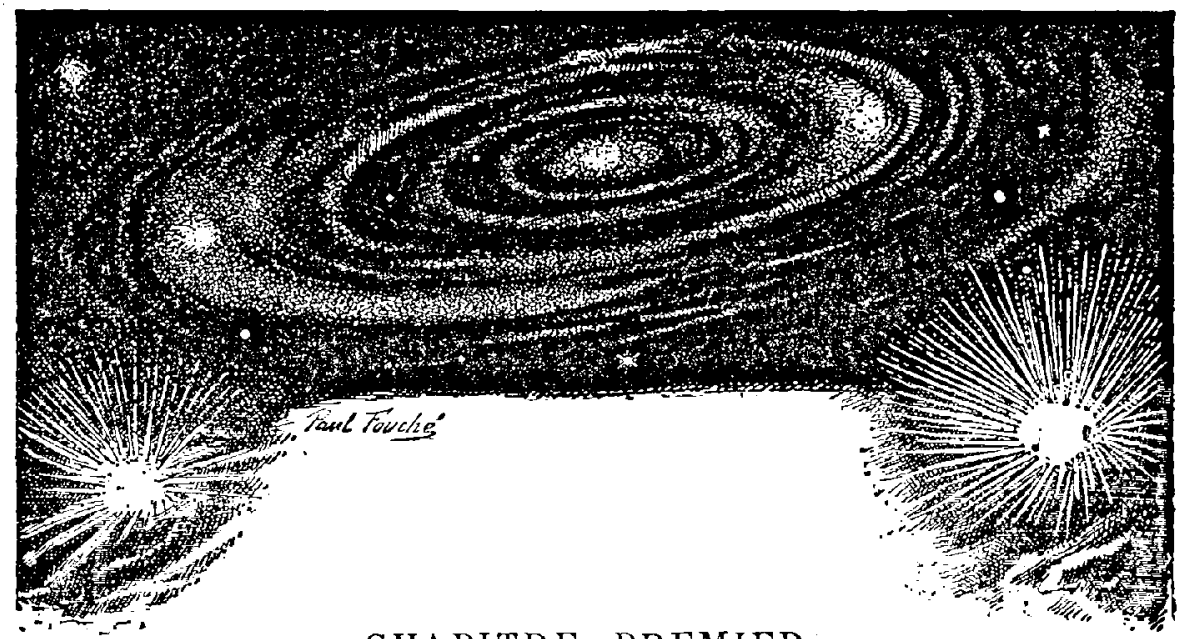

CHAPITRE PREMIER

LA GENISE DES MONDES. - LES NËBULEUSES.

Porté par les apparences à considérer la Terre comme représentant le monde entier, et à ne voir dans le Soleil, la Lune, les planètes et les étoiles que des astres lointains, moins importants que la Torre, et tournant autour d'elle comme des satellites subalternes, l'homme s'est accoutumé à donner le titre de monde au globe que nous habitons et à associer aux destinées de ce globe celles de l'univers tont entier. Pour lui, " le commencement du monde on « le commencement de lia Terre " constituaient un seul et même fait, exprimaient une seulè et même idée; "la fin du monde » ou " la fin de la Terre " représcntaient également le même acte cosmologique. L'univers avait commencé avec la Terre et devait finir avec elle; mieux encore : il avait été eréé et mis au monde exprès pour elle; la Terre était faite uniquement pour l'homme; l'homme était le souverain de l'univers et les périodes de la nature etaient indissolublement associées aux destinées de la race humaine.

Les conquêtes de l'Astronomie ont radicalement transformé cette étroite interprétation du spectacle de la nature; elles l'ont agrandie, éclairée et transfigurée. Nous savons aujourd'hui que la Terre où nous sommes est loin de constituer à elle senle l'univers tout entier; nous savons qu'elle n'est qu'une province du système solaire; qu'elle est la troisième des planètes qui circulent autour 
du Soleil; qu'entre elle et le Soleil il y a deux globes, Mercure et Vẻnus, gravitant comme elle autour de l'astre illuminateur; qu'au delà d'elle, on connait encore cinq planètes importantes: Mars, Jupiter, Saturne, Uranus et Neptune, sans compter toute une république de petits mondes situés entre Mars et Jupiter, et sans compter aussi les satellites qui, tels que la Lune, qui accompagne la Terre, les deux lunes de Mars, les quatre de Jupiter, les huit de Saturne, celles d'Uranus et de Neptune, complètent la grande famille du Soleil.

L'histoire de la Terre, quelque importante qu'elle nous paraisse, et quelque intéressante qu'elle soit pour nous, n'est qu'un chapitre, qu'une page, qu'un paragraphe de l'histoire générale de l'univers. Si la Terre et son humanité n'existaient pas, l'univers suivrait son cours comme il le fait; avant l'existence de notre monde, les étoiles brillaient déjà dans les profondeurs de l'espace, et, chacune étant un soleil, ces innombrables flambeaux versaient déjà dans l'étendue leurs rayons de lumière et de chaleur; nous recevons seulement aujourd'hui des rayons de lumière partis de ces sources lointaines longtemps avant la naissance du premier homme terrestre; après la mort de notre planète et de son humanité, les étoiles continueront de briller au ciel, les soleils de l'avenir continueront d'éclairer d'autres terres et d'autres cieux, et l'univers marchera comme de nos jours.

C'est l'histoire de la Terre que nous venons d'entreprendre dans cet ouvrage; mais elle touche par son origine et par ses ramifications à celle du système solaire tout entier. Il est impossible de considérer notre planète isolément, au moins en ce qui concerne ses origines, car en réalité elle n'est pas isolée, et si nous voulions en imagination la créer tout d'une pièce, sans nous occuper du Soleil ni des autres planètes, nous serions certainement à côté de la vérité. Or, que cherchons-nous? La vérité. Personne n'a assisté à la création de la Terre. Aucun témoin oculaire ne peut raconter comment ces grandioses événements se sont passés. Il faut donc, si nous voulons savoir quelque chose, que nous nous entourions de toutes les données, de tous les documents, de toutes les sources d'informations qu'il nous est possible de recueillir. Comme le fruit vient de la fleur, la fleur de l'arbre, comme la vie de l'arbre a ses racines dans 
le terrain qui le porte, ainsi les origines de la Terre ne peuvent se découvrir que par l'étude de sa situation dans le système auquel elle appartient.

Le premier coup d'œil jeté sur cette situation et sur l'ensemble du système solaire met en évidence des faits bien significatifs. Considérons avec attention l'ensemble de ce système ( $f g$. 13). Ce plan est tracé à l'échelle de 1 millimètre pour 10 millions de lieues. Le Soleil est au centre; mais il n'a pu être dessiné, parce que, mesurant 345500 lieues de diamètre, il n'aurait à cette échelle qu'un trentième de millimètre. La planète la plus proche de l'éblouissant foyer, Mercure, tourne dans sa lumière à la distance de 15 millions de lieues, - Vénus à 26 millions, - la Terre à 37 millions, - Mars à 56 millions, - les petites planètes vers 100 millions, - Jupiter à 192 millions, - Saturne à 355 millions, - Uranus à. 710 millions, et Neptune, la plus éloignée que nous connaissions, à la distance de 1150 millions de lieues du mème centre.

Toutes ces planètes voguent autour du Soleil, dans le mème sens (en sens contraire du mouvement des aiguilles d'une montre) comme on le voit sur la figure, et le Soleil tourne également sur lui-même, et dans le même sens. Ce premier fait est très important dans la question qui nous occupe. Il nous montre tout d'abord qu'il y a une unité d'origine et de plan dans le système solaire et une certaine parenté à découvrir entre les différents membres de cette famille. Le Soleil régit tout ce groupe de planètes qui gravite autour de lui. Il ne les a pas rencontrées et conquises au passage et au hasard, car dans ce cas elles circuleraient, comme les comètes, dans tous les sens et dans toutes les directions. Mais elles ont la même origine que lui, elles lui restent assujetties, elles roulent dans le même plan, dans la même surface, pour ainsi dire, comme des billes qui tourneraient sur une table autour d'un boulet central.

Le Soleil les domine toutes par sa masse et sa grandeur, et il pèse sept cent tois plus que toutes les planètes ensemble et trois cent vingt-quatre mille fois plus que la Terre seule. Il. est un million deux cent quatre-vingt mille fois plus gros que notre planète, ce qui lui donne une densité beaucoup moindre, puisqu'il ne'pèse que trois cent vingt-quatre mille' fois plus. Cette densité est 
environ le quart de la notre : il faudrait qu'il se condensat quatre fois

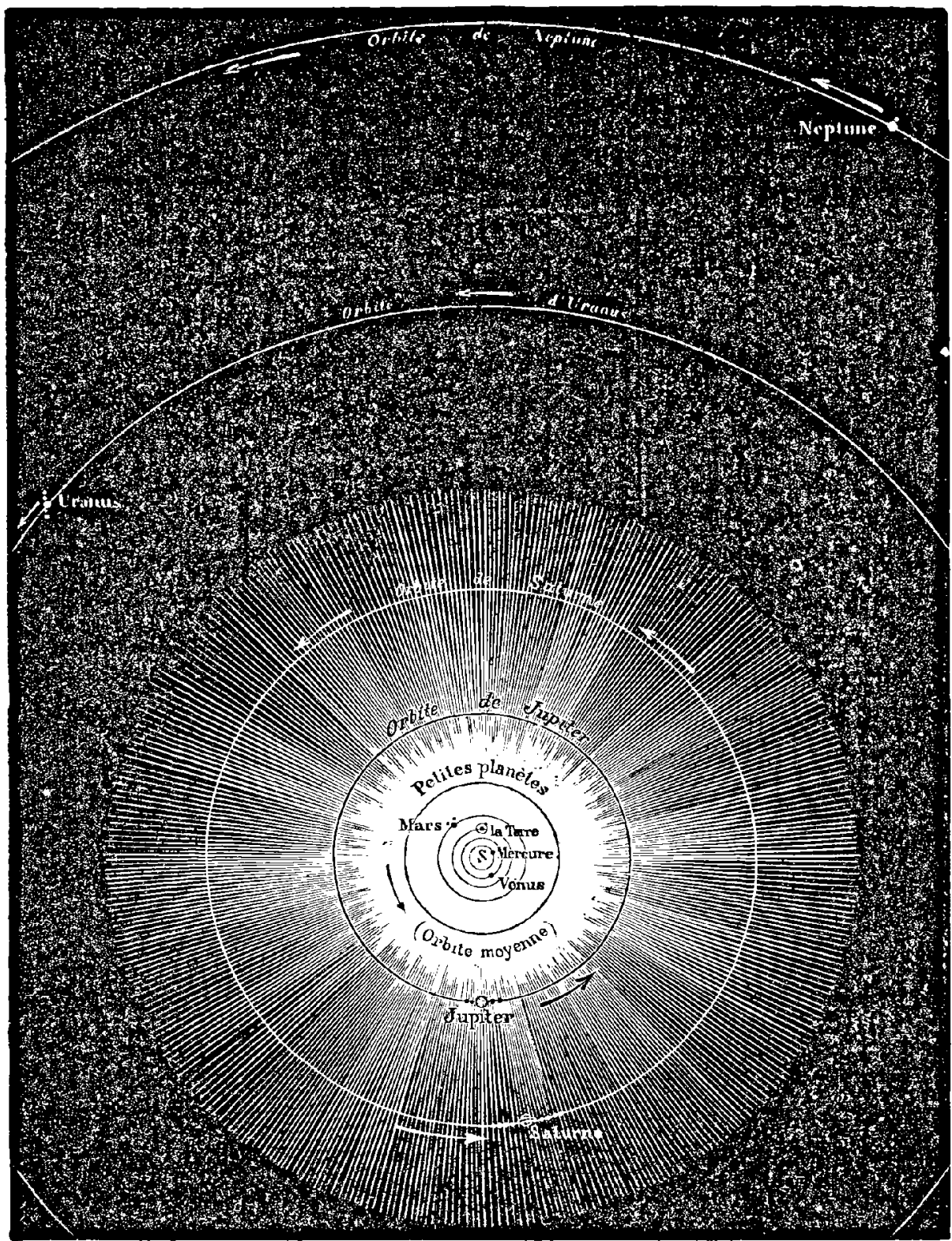

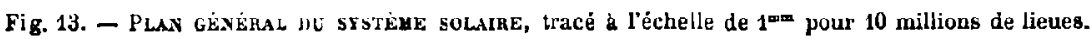

plus qu'il ne l'est pour qu'un mètre cube de sa substance constitutive, par exemple, eùt la méme densité qu'un mètre cube de terre. 
On jugera de l'importance du Soleil comparativement aux différentes planètes par l'examen de la figure suivante, sur laquelle nous avons représcnté la grandeur relative des principaux globes du

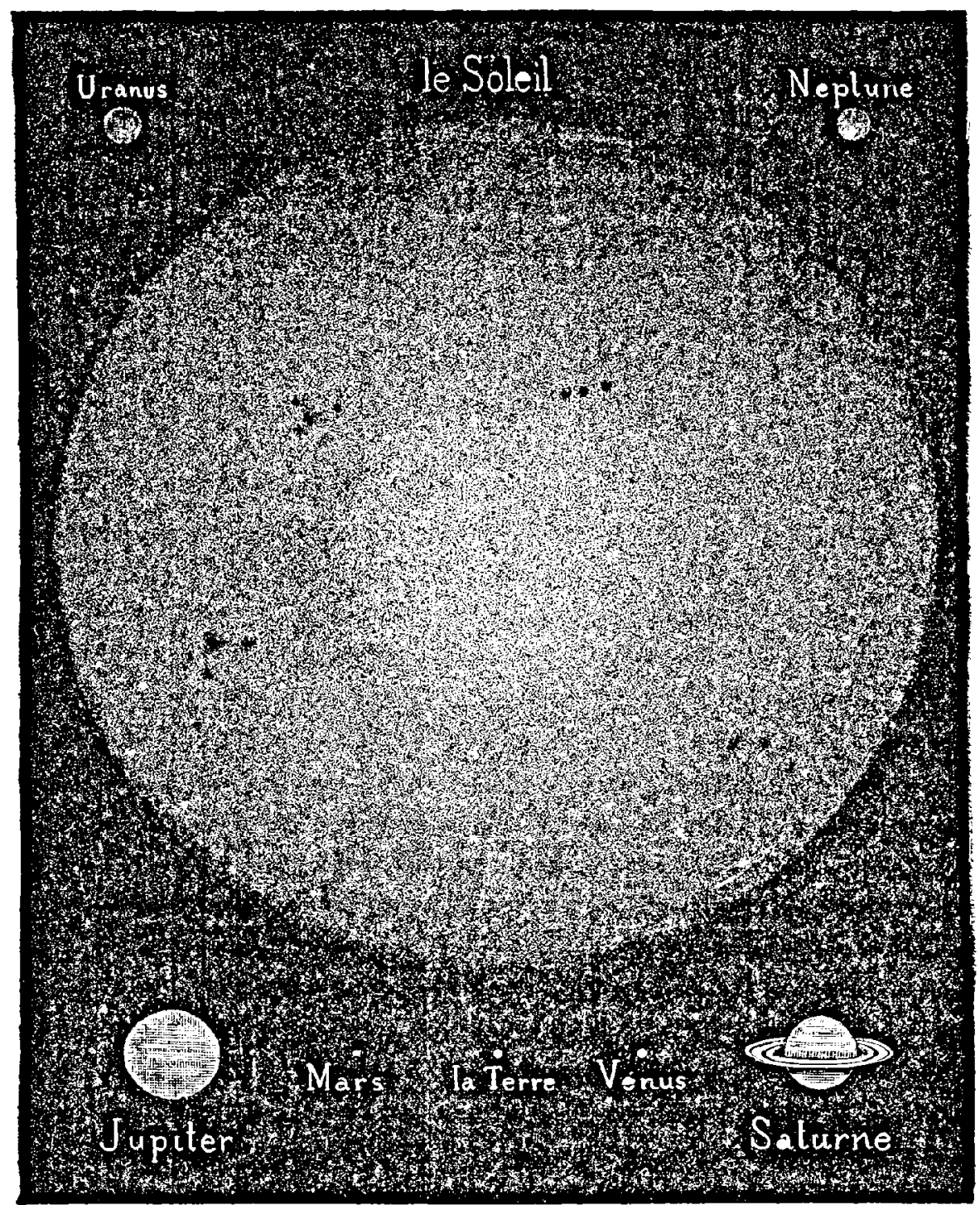

Fig. 14. - Grandeur comparée du Soleil et des principaux mondes de son système.

système solaire. On peut remarquer que Jupiter est environ onze fois plus large que la Terre en diamètre et le Soleil, à son tour, onze fois plus grand que Jupiter :

LE MONDE AYANT LA GRÉATION DE L'HOMME 


\begin{tabular}{rrrrr}
\hline & & Terre. & Jupiter. & \multicolumn{1}{c}{ Solesl. } \\
Diamètre. . . . . . . . & 1 & 11 & 108 \\
$-\quad$ en kilomètres. . & 12742 & 140000 & 1382000
\end{tabular}

Jupiter, Saturne, Uranus et Neptune sont des mondes considérables. La Terre, Vénus et Mars sont beaucoup moins importants; Mercure est plus petit encore, et les petites planètes qui gravitent entre Mars et Jupiter sont très exiguës.

Les phénoménes que nous observons chaque jour à la surface du Soleil prouvent que ce n'est pas un corps solide, comme la Terre ou la Lune, mais liquide ou gazeux. Cette surface est en mouvement perpétuel, comme un précipité chimique, et l'on remarque au télescope qu'elle est composée d'une granulation mobile qui se déplace en obẻissant à des courants et qui change incessamment de forme et d'éclat. Ici naissent des taches dont les dimensions surpassent parfois de beaucoup le diamètre de la Terre, qui s'agrandissent, se développent, se brisent, se modifient de mille facons pour s'évanouir après quelques semaines, parfois quelques jours - parfois aussi plusieurs mois, - en se fondant dans l'intensité lumineuse de l'astre éblouissant. Là se forment des nuages plus brillants que le Soleil lui-mème, qui généralement entourent les taches et les dominent à une grande hauteur. Ailleurs encore on assiste à des explosions de vapeurs brûlantes et de gaz lumineux, si violentes, si gigantesques, si prodigieuses, qu'elles s'élancent à des centaines de milliers de kilomètres de hauteur dans l'atmosphère ardente de l'astre du jour pour s'évanouir en nuages roses ou retomber en pluies de feu sur l'océan solaire, toujours cnflammé d'un feu qui ne s'éteint jamais.

Quelle est la cause de cet état physique du Soleil ? Quelle est la source de cette lumière et de cette chaleur? Il y a évidemment en œuvre ici l'une des grandes lois de la nature, car l'astre qui nous éclaire n'est pas une exception dans l'univers : toutes les étoiles sont des soleils; l'immensité infinie est peuplée de millions et de millions de soleils.

Il faut donc que cet état physique, cette fluidité, cette mobilité, cette vibration calorifique, lumineuse, électrique aient une cause naturelle, simple, générale. Une combustion chimique, une conflagration d'éléments, un incendie, ne sont pas d'une généralisation applicable à l'innombrable armée des étoiles, ni d'une durée en 
rapport avec celle de chaque système. D'un siècle à l'autre, ces tem. pératures solaires ou stellaires ne doivent ni s'épuiser ni sensiblement diminuer. Il faut qu'elles proviennent du mode même de la formation des mondes.

Eh bien ! le cicl nous offre lui-méme des indices de ce mode de formation. Il n'y a pas seulement des étoiles au ciel; en balayant ses plages de zone en zone, le télescope rencontre çà et là des sortes de nuages cosmiques peu lumineux, des nébuleuses, de formes très variées, qui paraissent isolées dans les profondeurs de l'espace et qui semblent attendre la fécondation de l'avenir.

Ces créations sont nombreuses. Quoiqu'elles soient en général peu apparentes, vagues et diffuses, cependant on en a déjà découvert et catalogué plus de cinq mille. C'est peu, sans doute, relativement au nombre des étoiles. Mais on ne les voit certainement pas toutes; on n'a probablement découvert que les plus avancées en stage, les plus lumineuses.

Les nébuleuses sont relativement isolées, comme si cllos avaient rassemblé cn elles toute la matière cosmique environnante. Il y a moins d'étoiles autour d'elles que dans la moyenne de l'étendue céleste, et celles que l'on voit dans leurs environs sont probablement devant ou derrière elles, en deçà ou au delà, relativement à notre rayon visuel. Le patient William Herschel, qui en a découvert plus de deux mille cinq cents à lui seul, avait l'habitude de dire à son secrètaire (sa sœur, miss Caroline Herschel), lorsque les étoiles devenaient rares dans le champ du télescope : « Préparez-vous à écrire, les nébuleuses vont arriver ๖.

Grâce aux ingénieuses méthodes de l'analyse spectrale, la chimie céleste a pu analyser ces nébuleuses et constater qu'elles sont gazeuses. Il ne faut pas les confondre avec les amas d'étoiles, qui portent quelquefois aussi le nom de nébuleuses à cause de leur aspect dans les instruments de faible puissance; lorsqu'on eût reconnu leur nature, ces amas d'étoiles avaient d'abord fait penser qu'il n'y avait pas de nébuleuses réelles et que ces pâles lueurs perdues dans l'infini étaient toutes des agglomérations d'étoiles, si éloignées de nous, si resserrées par la perspective, que les plus puissants télescopes ne parvenaient pas à en séparer les composantes. Nous savons aujourd'hui que ces deux espéces sidérales existent. D'une part, il y á des 
amas d'étoiles, dont un grand nombre ne sont résolubles que dans le champ des plus puissants télescopes, dont plusieurs aussi ne seront résolus que par les progrès de l'optique future. D'autre part, il y a des nébuleuses gazeuses, absolument dépourvues d'étoiles, et déjà le spectroscope découvre la nature chimique des gaz et des vapeurs qui les composent.

L'une des plus belles d'entre elles, par sa grandeur et son éclat, l'une des plus importantes par ses dimensions réelles, et en même temps l'une des plus intéressantes par les études dont elle a èté l'objet, est sans contredit la nébuleuse d'Orion, que l'on découvre presque à l'œil nu dans le ciel et dont une jumelle suffit pour constater la présence. Tout le monde connait la magnifique constellation d'Orion, qui resplendit pendant nos longues nuits d'hiver, règnant au sud entre Sirius à ses pieds et les Pléiades à sa tête. Dans cette constellation, la ceinture ou baudrier, est marquée par trois étoiles brillantes alignées en ligne droite, mais obliquement, que l'on appclle aussi " les Trois Rois mages », « le Râteau, » etc. Eh bien, regardez attentivement au-dessous de ces trois étoiles, vous remarquerez un petit groupe d'ètoiles serrées, pouvant représenter une épée suspendue à la ceinture, ou un manche de râteau, etc. Lá, une bonne jumelle, ou mieux une petite lunette d'approche vous montrera la plus belle nébuleuse du ciel.

Cette nébuleuse est si brillante qu'elle se laisse facilement photographier. Nous reproduisons ici l'une des meilleures photographies qu'on en ait obtenue ('). On remarque dans l'intérieur de la nébulosité une étoile quadruple (qui devient même sextuple dans les puissants instruments) et plusieurs étoiles épárses. Il est probable que l'ètoile multiple lui appartient; mais il n'est pas probable que toutes les autres fassent partie du mème système : plusicurs peuvent ètre en deçà ou au delà, et sont visibles soit devant elle, soit à travers elle. Le point important pour la question qui nous occupe est que cette nébuleuse est visiblement condensée vers ses régions cen-

1. Cette photographie a été faite le 30 janvier 1883, par M. Common. Voy. la Revue mensuelle d'Astronomie populaire, année 1883, p. 277. Voir aussi, pour la description de cette nébuleuse et le moyen facile de trouver tous ces astres dans le ciel : Flammarion, Lea Étoiles et les Curiosités du Ciel. On peut reconnaftre cette nébuleuse à l'aide d'une simple jumelle. 
trales. Elle s'ètend en réalité dans le ciel, vag̉ue, diffuse, transparente, beaucoup plus loin que la photographie ne le montre.

La partie centrale la plus lumineuse de cette vaste nébulosité occupe dans le ciel une surface égale au disque apparent de la Lune; mais on peut la suivre de part et d'autre, à l'est et à l'ouest, au

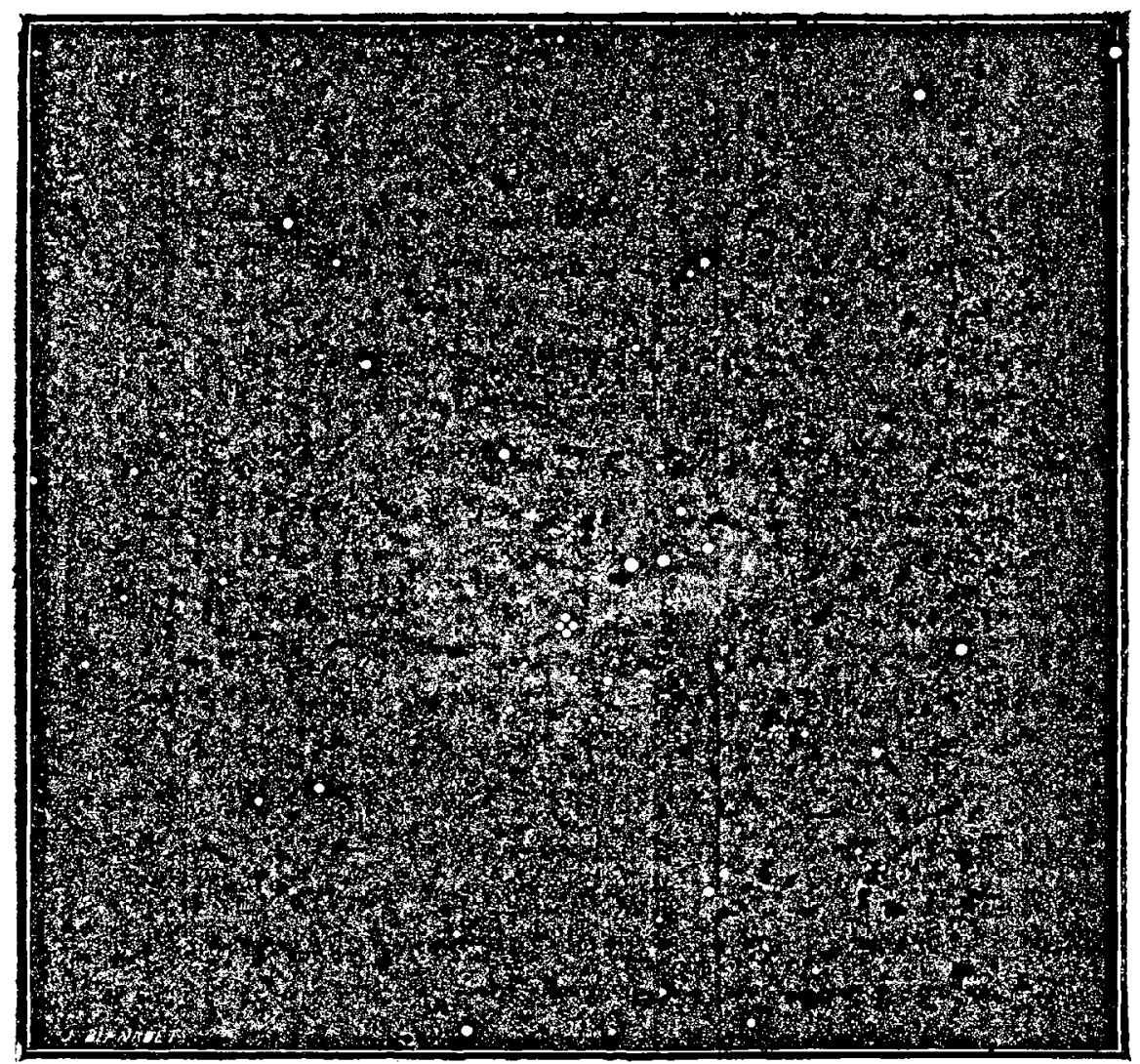

Fir. 1ă. - Ja nébuleuse d'Orion, d’après une photographie directe. - Matière cosmique prirnitive en condensation.

nord et au sud, sur une étendue dix fois 'plus large. Avec son disque apparent, la Lune, qui n'est qu'à 96000 lieues d'ici, mesure 870 lieues de diamètre. Le Soleil, qui ne parait pas plus grand, mais qui est quatre cent fois plus éloigné que la Lune, est aussi quatre cent fois plus large en réalité, et mesure 345500 lieues de diamètre. La nébuleuse d'Orion, en admettant qu'elle ne soit pas 
plus éloignée de nous que les étoiles les plus proches, qu'elle soit, par exemple, à la distance de la $61^{\circ}$ du Cygne, serait déjà d'une étendue qui tient du prodige : à la perspective de cet éloignement, la largeur de la Lune équivaudrait à 133 milliards de lieues ! C'est déjà 3700 fois plus que la distance qui nous sépare du Soleil. Mais nous venons de voir que la nébulosité est dix fois plus vaste encore! Elle s'élendrait donc sur une étendue de 1330 milliards de lieues... Un train express courant avec la vitesse constante de soixante kilomètres à l'heure n'emploierait pas moins de dix millions d'an. nées pour traverser ce brouillard $1 . .$.

Voilà plus qu'il n'en faut pour créer, non pas seulement un monde, mais un et plusieurs systèmes de monde. De quoi est-elle composée? De gaz, et déjà dans ce gaz lumineux on croit avoir reconnu de l'hydrogène et de l'azote. Ses différences d'intensité lumineuse montrent que la densité de ce gaz n'est pas la mème partout et que plusieurs condensations partielles s'opèrent. On remarque même à quelque distance au nord (au-dessous) une condensation isolée qui commence. Les lois de la nature agissent. L'attraction s'exerce : les régions les plus denses attirent les autres Peut-être se disloquera-t-elle en plusieurs foyers, peut-être est-elle destinée à former plusieurs univers.

Une nébuleuse composée d'un gaz ainsi disséminé peut-elle arriver à former un ou plusieurs soleils, un ou plusieurs systèmes de mondes?

En admettant que primitivement une matière nébuleuse occupant tout l'ensemble du système solaire, jusqu'à l'orbite de Neptune et au delà, ait une ténuité extrème, le mathématicien et physiologiste Helmoltz a calculé quolle quantité de chaleur aurait èté engendré par une condensation arrivant à former le Soleil, la Terre et les pla. nètes. Le résultat du calcul donne 28 millions de degrés centigrades, en prenant la chaleur spécifique de la masse condensante comme égale à celle de l'eau. Ainsi la chute seule des molécules de la nébu. leuse primitive vers un centre d'attraction aurait suffi pour produire une chaleur dé millions et de millions de degrés centigrades.

Chacun sait aujourd'hui que le mouvement se transforme en chaleur et que la chaleur n'est elle-même qu'un mode de mouvement. 'Lorsque, le marteáu à la main, nous enfonçons une pointe 
de fer dans une pièce de bois, le mouvement musculaire de notre bras se communique à la pointe à l'état de mouvement visible, et elle s'enfonce graduellement. Mais si nous continuons de frapper lorsqu'elle est complètement enfoncée, que devient le travaill accompli? On croyait autrefois qu'il était perdu: c'était là une erreur. Le mouvement se communique toujours à la pointe de fer, seulement au lieu d'être visible, c'est du mouvement invisible, du mouvement moléculaire : le métal s'échauffe et toutes ses molécules se mettent à vibrer plus ou moins vite. La chaleur n'est que du mouvement invisible, du mouvement moléculaire ('). En comprimant, dans un tube de verre, une colonne d'air au dixième de son volume, on l'élève à la température du charbon ardent.

Une pierre qui tomberait de la distance de Neptune sur le Soleil emploierait 10628 jours ou 29 ans environ pour franchir cette distance de 1150 millions de lieves, et, partie du repos, tombant avec une vitesse grandissante, elle arriverait sur le globe solaire avec une vitesse de 600000 mètres parcourus pendant la dernière seconde. Cette vitesse, mille fois supérieure à celle d'un boulet, serait telle qu'en touchant le Soleil, celui-ci fût-il un bloc de glace, le mouvement obligé de s'arrêter et de se transformer en chaleur, ferait non seulement fondre instantanément la pierre comme de l'huile, mais encore la réduirait en vapeur, et le choc échaufferait considérablement la place oủ elle aurait atteint le Soleil. La chaleur engendrée par le choc serait neuf mille fois supérieure à celle qui serait produite par la combustion d'un morceau de houille du même poids que cette pierre, quelle qu'elle soit.

Si la Terre tombait dans le Soleil, elle y arriverait en 64 jours, et la chaleur produite par son choc serait telle qu'elle élèverait notablement la température du Soleil tout entier. En fait cette chaleur produite équivaudrait à celle que cet astre rayonne pendant 95 ans. Et l'on sait quelle consommation colossale s'opère en cet intense

1. La chaleur nécessaire pour élever de 1 degré centigrade la température de 1 kilogramme d'eau représente exactement la force nécesssaire pour élever 424 kilogrammes à 1 mètre de hauteur ou pour élever l kilogramme à 424 mètres.

La capacité calorifique du plomb étant le trentième de celle de l'eau, une balle de plomb tombant d'une hauteur de 424 mètres engendrerait, par l'arrét de son mouvement de chute, une chaleur suffisante pour élever sa propre température de 30 degrés. Sa vitesse, en arrivant au sol, serait de 91 mètres par seconde. 
foyer! la chaleur émise par le Soleil, à chaque seconde, est égale à celle qui résulterait de la combustion de onze quatrillions six cent mille milliards de tonnes de charbon de terre brülant ensemble; elle ferait bouillir par heure deux trillions neuf cent milliards de kilomètres cubes d'eau à la température de la glace !...

Que le mouvement provienne d'un grand corps ou d'un petit corps, qu'il soit arrêté brusquement ou graduellement, par frottements, le résultat est le mème : il se transforme en chaleur.

Supposons toute la matière du Soleil, des planètes et de leurs

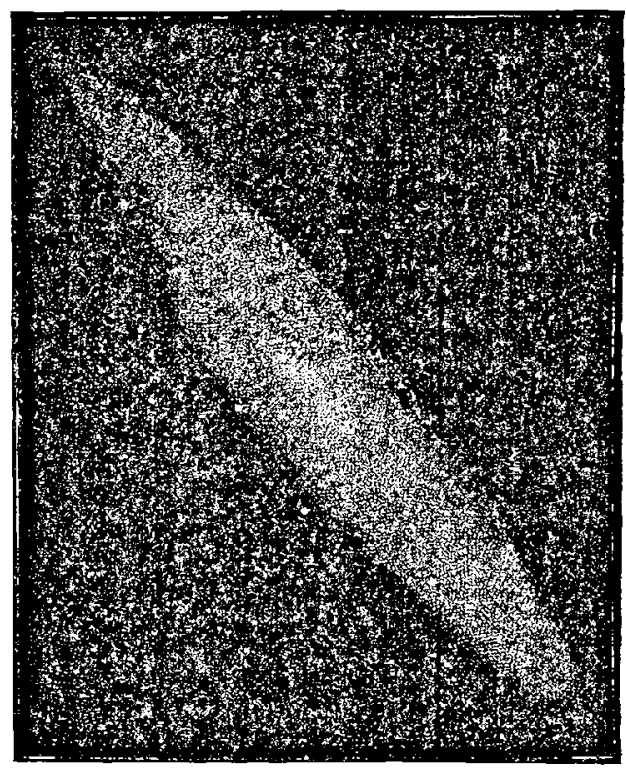

Fig. 16.

La nébuleuse d'Andromède. Condensation vers un eentre. satellites uniformément répartie dans l'espace sphérique cmbrassé par l'orbite de Neptune, il en résulterait une nébuleuse gazeuse, homogène, dont il est facile de calculer la densité. Comme la sphère d'eau d'un pareil rayon aurait un volume égal à plus de 300 quatrillions de fois le volume terrestre, la densité cherchée ne serait plus qu'un demitrillionième de la densité de l'eau. La nébuleuse solaire ainsi dilatée serait 400 millions de fois moins dense que l'hydrogène à la pression ordinaire, lequel est, comme on sait, le plus léger de tous les gaz connus (il pèse 14 fois moins que l'air : dix litres d'air pèsent 13 grammes, dix litres d'hydrogène ne pèsent pas un gramme).

Nous avons vu tout à l'heure que la gravitation de toutes les molécules de cette nébuleuse vers un centre de condensation suffirait pour produire une chlleur de 28 millions de degrés.

La nature nous met donc pour ainsi dire entre les mains les matériaux qui lui servent pour la création des mondes, et non seulement les matériaux, mais encore les moyens qu'elle emploie. Si nous ne savions pas comment les arbres grandissent et arrivent à 
leur complet développement, une promenade dans une forêt 'nous l'apprendrait en nous montrant des arbres de tous les âges, de petits arbrisseaux de quélques années, de hantes futaies, en pleine croissance éncore, et des arbres séculaires qui déjà descendent vers Ia vicillesse et la décadence: Eh bien, la contemplation du cicl nous donne la même lecon pour la naissance, la vie et le développement des mondes. Nous voyons des nébuleuses, comme celle d'Orion, qui n'ont encore ancune forme, qui sont très étendues, très disséminées,

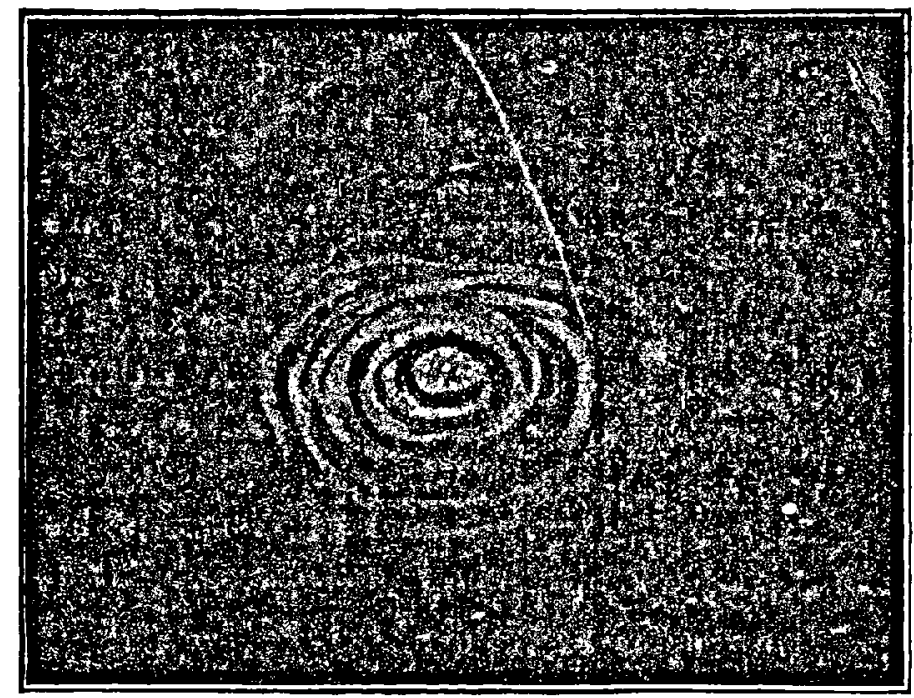

Fig. 17. - Nébuleuse du Lion, montrant des anneaux níbu،eux. Image de la formation des mondes.

et présentent néanmoins déjả des centres de condensation. Nous en voyons d'autres, comme celle d'Andromède $(f g .16)$ qui offrent une figure plus régulière, plus géométrique. Il est bien probable que c'est là une nébuleuse circulaire qui se présente à nous très obliquement. La condensation centrale est très marquée. Comme celle d'Orion, et plus facilement encore, elle est visible pour tous ceux qui veulent la voir, dans une simple jumelle de spectacle, ou mieux, dans une lunette d'approche. Lorsqu'on l'observe à l'aide de puissants télescopes, elle perd un peu de cette régularité apparente et des lambeaux de pâles clartés semblent flotter et s'étendre au loin. C'est cette nébuleuse que le curé Derham prenait pour un

LE MONDE aVANT La CRÉATION DE L' hoMME 
endroit aminci du firmament, devenu assez transparent pour laisser passer au travers la lumière du paradis...

D'autres nébuleuses manifestent plus clairement encore les procédés de la nature dans cette grande œuvre de la création. Ainsi, par exemple, celle de la constellation du Lion (fig. 17) montre un foyer central très brillant, plus loin un foyer secondaire qui commence, et autour du foyer central des zones de condensation, des anneaux nébuleux faisant deviner un mouvement de rotation et une sorte d'enroulement en spirale d'anneaux consécutifs.

On trouve dans la constellation du Dragon une nébuleuse particulièrement intéressante, parce qu'elle est la première dont l'analyse chimique ait éét faite (Huggins, 1864). Depuis cent cinquante ans, en effet, les astronomes ètaient fort embarrassés pour décider s'il existe de véritables nébuleuses gazeuses, et l'intérèt du sujet n'a fait que grandir depuis que William Herschel a exprimé la pensée que ces amas sont des portions de la matière primitive qui s'est condensée en étoiles, et qu'en les étudiant, nous étudions en mème temps quelques-unes des phases par lesquelles les soleils et les planètes ont passė.

Le spectre de cette nébuleuse, autant du moins que les données acquises permettent de l'affirmer, ne peut être produit que par la lumière émanèe d'une matière à l'état de gaz. On pouvait donc en conclure; dès ces premières observations, que la lumière de cette nébuleuse n'émane pas d'une matière solide ou liquide incandescente, comme la lumière du soleil et des étoiles, mais d'un gaz lumineux. L'examen des lignes de ce spectre montre que la plus importante d'entre elles occupe une position très voisine des raies les plus brillantes du spectre de l'azote. La plus faible des raies coïncide avec la raie verte de l'hydrogène. Mais la raie moyenne du groupe des trois lignes qui forment le spectre de la nébuleuse n'a son identique dans aucune des raies intenses des spectres des éléments terrestres connus. Il y a là un ètat de la matière inconnu pour nous. On voit un spectre continu excessivement faible provenant du centre de la nébuleuse, d'un noyau très petit, mais plus brillant que le reste de la masse. L'observation nous apprend à peu prè̀s certuinemént que la matière du noyau n'est pas à l'ćtat de gaz,' comme celle de la nébulosité qui l'entoure. Elle consiste en une- 
matière opaque qui peut exister à l'état de brouillard incandescent, formé de particules solides ou liquides.

Le résultat nouveau et inattendu auquel venait de conduire l'examen spectroscopique de cette nébuleuse frappa de surprise les astronomes et les engagea à étudier attentivement les autres créations analogues qui sont disséminèes dans l'étendue des cieux. Le résulţal de cette analyse a été qu'un grand nombre de nébuleuses sont composées de véritables gaz, - de gaz flamboyants visibles à des millions de milliards de lioues d'ici!

Lors donc que nous observons cette pâlle nébulcuse bleuâtre situẻe au pôle de l'écliptique, nous savons que c'est là un amas de matic̀re gazcuse incandescente, déjà muni d'un noyau central de condensation, et nous devinons dans cette lueur lointaine l'ardente genèse d'un nouveau monde. Nous assistons d'ici à la création!... Là brille déjà un embryon de soleil ; là se prépare un système plan:taire. Que dis-je! le rayon li:mineux qui nous arrive en ce moment de cette région de l'infini en est peut-être parti

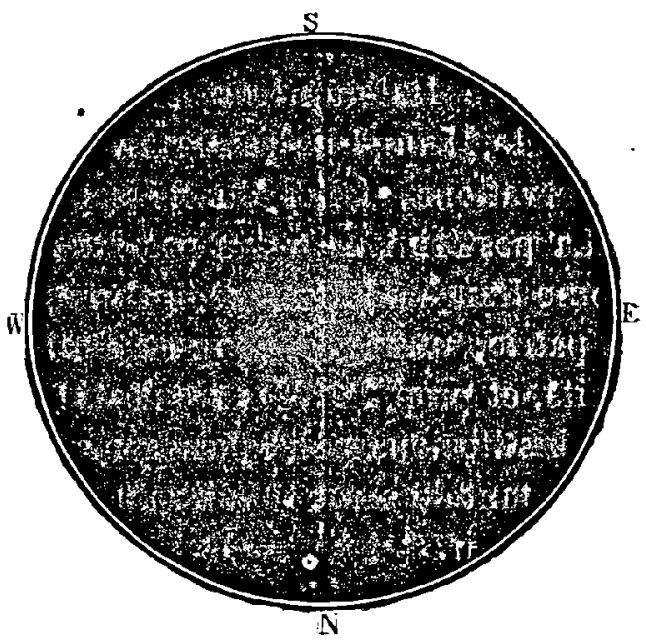

Fig. 18 - Nébuleuse du Dragon. Point central de condensation et vaste atmosphère. il y a plusieurs millions d'années, et peut-ètre qu'en ce moment une ou plusieurs planètes sont déjà formées, fécondées, habitées, et peut-être qu’il y a là aussi des yeux qui nous contemplent, et pour lesquels, notre his= toire étant également en retard de plusieurs millions d'années, notre système solaire n'est encore qu'une nébuleuse circulaire, vue justement de face: ils se demandent si un jour notre nébuleuse deviendra soleil et planètes et ne se doutent pas que nous existons déjà et que nous pourrions leur répondre! Voix du passé, 'vous devenez maintenant les paroles de l'avenir, tandis que le présent, l'actuel, disparait pour les regards échangés à travers les vastes cieux, à travers l'infini, à travers l'éternité ! 
Voici un autre exemple pris dans le ciel et qui est plus caratéristique encore.

Le 22 août 1794 , pendant une belle nuit d'ètẻ, l'astronome Jẻrôme de Lalande (qui a plus fait en quelques années à lui seul, pour la connaissance et les progrès de l'astronomie stellaire, que tous les Observatoires officiels de son époque réunis), l'astronome Lalande, dis-je, observait en son modeste observatoire de l'École militaire en com. pagnie de son neveu Le Français de Lalande. Ils notaient au passage les petites étoiles de la constellation du Verseau, et en remarquèrent une, entr'autres, de $7^{\mathbf{0}} \frac{1}{2}$ grandeur, dont ils déterminèrent la position. Six années plus tard, le 25 octobre 1800, on l'observait de nouveau au même instrument, et on l'estimait de $8^{\circ}$ grandeur. G'est l'étoile qui porte les numéros 40765 . et 40766 du grand Catalogue de Lalande, lequel ne renferme pas moins de quarante-sept mille observations, faites du 27 septembre 1791 au 15 janvier 1801 . a La postérité ne verra pas sans intérêt, écrivait l'éminent astronome français lui-même, qu'au milieu des convulsions qui agitaient la patrie, un travail long et pénible s'exécutait dans le silence des nuits, et préparait des résultats faits pour durer plus longtemps que les institutions politiques pour lesquelles on s'agite si fort et l'on verse tant de sang. „ Voila un jugement sain sur la politique, quelle quelle soit.

Mais revenons à notre étoile. Cette étoile n'en est pas une, malgrè son aspect stellaire. Des observateurs exercés peuvent la voir passer dans le champ de leur instrument sans y prendre garde : elle ressemble seulement à une étoile qui n'est pas exactement au foyer. Mais si on l'examine avec attention, on constate qu'on n'arrive jamais à lui donner la netteté d'un point brillant sans dimensions. En effet, c'est une nébuleuse (').

1. Déjà William Herschel l'avait reconnue comme telle, il y a plus de cent ans, en septembre 1782. Il l'avait qualifiée de " nébuleuse planétaire's et comparée au disque de Jupiter; elle est inscrite sous le numéro I de sa quatrième classe, et on la désigne généralement, en abrégé, sous le chiffre H. IV, I. Sir John Herschel la décrit dans les termes suivants : Admirable - aspect planétaire - très brillante - petite - elliptique. Lord Rosse et Lassell l'ayant examinée à l'aide de leurs puissants télescopes reconnurent qu'elle est environnée d'un anneau que nous voyons par la tranche, ce qui rappelle un peu l'aspect de Saturne. (Le ciel offre d'autres nébuleuses analogues qui se trouvent de face et dont nous voyous l'anneau circulairement.) Toute mip̣uscule qu'elle nous paraissse, 
Si sa forme est singulière, sa constitution chimique est peutètre plus curieuse encore. En effet, les recherches spectróscopiques conduisent à la conclusion, que cette nébuleuse est entièrement gazeuse, composée d'une masse de gaz lumineux.

Nous avons done là sous les yeux, à n'en pas douter, un système solaire en formation. Nous. assistons à la genèse d'un monde, à la créatión d'un univers lointain.

Des différents gaz, c'èst l'azote et l'hydrogène qui dominent dans le spectre de cette genèse.

La plupart des autrés nébuleuses planétaires et annulaires ont offert les mêmes rẻsultats à l'analyse : ce sont de véritables nébuleuses gazeuses qui, tout en se condensant autour d'un centre, nous donnent une image de la genèse de la Terre et des Planètes par la formation d'anneaux nébuleux se détachant du foyer central.

A quelle distance cetie nébuleuse se trouve-t. elle de notre atome terrestre?

Selon toute probabilité, elle est beaucoup

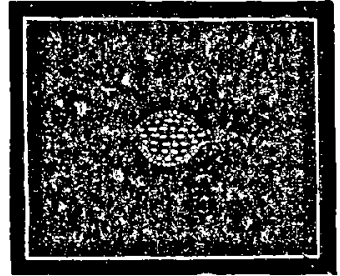

Fig. 19.

La nébuleuse saturnierne du Verseau. plus éloignée que les étoiles les plus proches.

En 1871 et 1872, M. Brunnow, astronome royal d'Irlande, directeur de l'Observatoire de Dublin, essayant de mesurer la parallaxe d'une nébuleuse analogue (celle du Dragon), a trouvé pour résultat une valeur si faible qu'elle ne correspond à aucune parallaxe sensible.

Nous resterons donc certainement en deçà de la vérité èn sup-

elle est sans contredit l'une des nébuleuses les plus remarquables que la vision télescopique ait su découvrir.

Le grand mesureur de nébuleuses, d'Arrest, de l'observatoire de Copenhague (descendant d'une noble famille chassée de France sous Lovis XIV par l'absurde révocation de l'édit de Nantes), la contempla avec admiration et la mesura pendant les nuits des 23 juillet 1862, 7 aoùt 1863 et 6 novembre 1864. Nebula planetaris, écrit-il, insigni splendore, capta culminans inter nubes. * Il la qualife comme brillant e d'une insigne splendeur *. Ses mesures lui donnent $23^{\prime \prime}$ de longueur sur $18^{\prime \prime}$ de largeur. * Elle brille d'une clarté bleuâtre, ajoute-t-jl, et présente un appendice nẻbuleux. *

Le diamètre de Saturne étant en moyenne de $18^{\prime \prime}$ et s'élevant à $20^{\prime \prime}$ lorsque la planète passe en opposition, on voít que la grandeur apparente de cette nébuleuse est un peu supérieure à celle -de Saturne. On peut la vair, comme étoile, avec une petite lúnette, et la recónnaitre comme nébulfuse avec une lunette de moyenne puissance, si le ciel est bien pur et affranehi de la clarté gènanté du clair de lune. 
posant que cette charmante et singulière petite nébuleuse ne soit pas plus éloignée de nous que l'étoile la plus proche de notre hémisphère, la $61^{\circ}$ du Gygne, dont la parallaxe est, comme chacun le sait, de $0^{\prime \prime}, 511$, et dont la distance est, par conséquent, de 404000 fois celle qui nous sépare du Soleil (37 millions de lieues), c'est-à-dire de 15 trillions de lieues, en nombre rond. Répétons-le, notre nébuleuse est certainement plus éloignce. Mais admettons le chiffre le plus modeste pour servir de base à notre raisonnement.

Eh bien, à la distance de la $61^{\circ}$ du Cygne, une longueur de 37 millions de lieues est réduite à $0^{\prime \prime}, 511$, c'est-à-dire à une demi-seconde environ. Notre nébuleuse mesure, avons-nous dit, $23^{\prime \prime}$ de longueur sur $18^{\prime \prime}$ de largeur. Considérons-la, en nombre rond, comme une sphère de gaz de $20^{\prime \prime}$ de diamètre. A cette distance, cette longueur correspond à 40 fois environ lạ distance qui nous sépare du Soleil.

Or, nous savons que la planète extérieure de notre système, Neptune, tourne autour du Soleil à la distance de 30 fois celle de la Terre. Notre nébuleuse étant au minimun plus large que le demidiamètre de l'orbite de Neptune, et étant, selon toute probabilité plus large que le diamètre entier de cette orbite, nous devons la considérer réellement comme occupant un espace au moins aussi. vaste que celui de notre système solaire tout entier.

Mais sait-on ce qu'une sphère du diamètre de l'orbite de Neptune représente? Les volumes des sphères sont entre eux comme les cubes des rayons. Neptune décrivant sa circonférence à 6420 fois le demi-diamètre du Soleil, le volume du Soleil est à celui de cette sphère dans le rapport de 1 à 6420 multiplié deux fois par lui-mème, ou de 1 à 264609000000 .

Ainsi ce globe de gaz est au moins 264 milliards de fois plus gros que notre Soleil, lequel est lui-mème 1280000 fois plus gros que la Terre..., c'est-ḋ-dire que cette minuscule petite nébuleuse est, an minimum, 338 quatrillions 896 trillions 800 mille millions de fois plus volumineuse que le globe sur lequel nous vivons!

Et, ne nous lassons pas de le répéter, c'est bien là un minimum; car, selon toute probabilité, cet objet céleste est beaucoup plus éloigné que nous ne le supposons; il peut être, il doit ètre, non pas sculement des centaines de quatrillions, mais des quintillions, des sextillions de fois plus immense que la Terre. 
Comment contempler cette « ètoile nébuleuse » passant tranquillement dans le champ du télescope au milieu du silence de la nuit? comment regarder cette lointaine lumière, sur laquelle dẻjà se sont arrêtés les regards des Herschel, des Lalande, des lord Rosse, des Lassell, des d'Arrest et de tant d'astronomes dont les yeux sont au-; jourd'hui fermés, sans ètre pénétré de sa formidable grandeur, sans . deviner les mouvements de gravitation qui l'agitent, sans songer aux radiations lumineuses, calorifiques, électriques, aux forces latentes qui s'éveillent en cette aurore, sans entrevoir les importantes des-, tinées qui l'attendent sur la vaste scène de l'Univers ?... Voilà ce que nous étions, Terre, Lune, Soleil, Planètes, il y a des millions d'années. C'est l'embryon d'un nouveau monde. Qui sait quels germes d'avenir dorment dans ce céleste berceau?

Cette genèse sidérale n'est pas un mythe. Tout le monde peut la voir. Cherchez quelque soir au-dessous de la constellation du Petit Cheval, à droite del'étoile $\vee$ du Verseau, et vous la reconnaitrez, pâle étoile de $7^{\circ}$ à $8^{\circ}$ grandeur, et vous la saluerez, création inaccessible, mystérieuse enfant du Cosmos, fleur à peine éclose dans les jardins du Ciel.

A l'époque où la fleur aura donné son fruit, dans les siècles futurs où la nébuleuse aujourd'hui gazeuse sera condensée en soleil et en planètes, il est probable que notre soleil actuel sera vieux, usé, èteint, que notre planète aura depuis longtemps cessé de vivre, et que l'antique histoire humaine sera à jamais évanouie dans le dernier sommeil.... Pourtant, alors comme aujourd'hui, il y aura des soleils, et des mondes, des printemps et des étés, une voûte céleste peuplée, de splendeurs, un univers non moins beau, non moins riche, non moins glorieux que celui dont la lumière enchante aujourd'hui nos. regards et nos pensées.

Mais pourquoi parler de l'avenir? Peut-étre cette nébuleuse du Verseau, peut-être ses sœurs du Lion, d'Andromède, d'Orion, sontelles éloignées à une telle distance de nous, que leur lumière emploie des millions d'années à nous arriver, et depuis l'époque oú sont partis de leur sein les rayons lumineux qui nous apportent aujourd'hui leur photographie, peut-ètre sont-elles déjà devenues des soleils et des systèmes. 


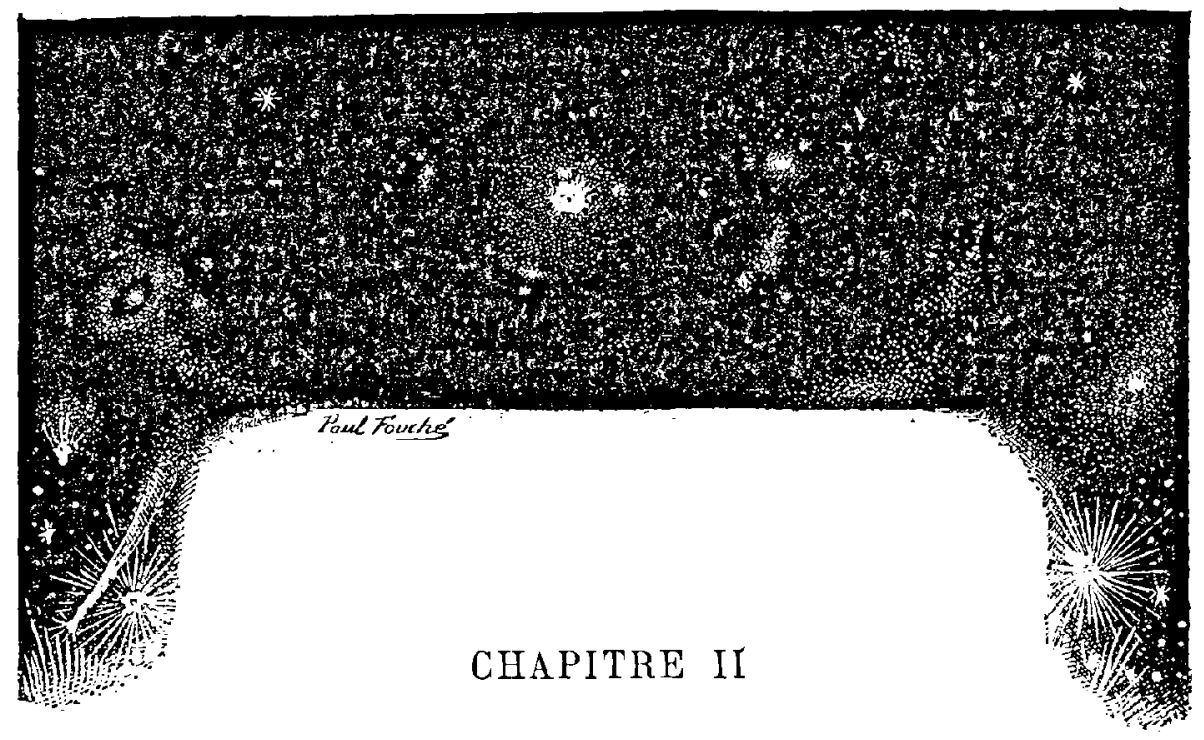

LA FORMATION DU SYSTEME SOLAIRE

Ainsi, d'après l'ensemble des témoignages de la nature et de la science, les nébuleuses sont la genèse des mondes. La matière cosmique primitive étant donnée, chaque atome attirant chaque atome, en vertu des lois de la gravitation universelle, la réunion de deux atomes suffisant pour commencer un centre d'attraction, on conçoit très bien que des centres de condensation se. forment dans les nébuleuses gazeuses mème les moins denses, que les unes deviennent irrégulières, multiples, partagées, et donnent naissance à plusieurs systèmes différents ou à des soleils associés, comme nous le voyons dans les étoiles doubles, triples, quadruples, multiples, que d'autres deviennent régulières, sphériques, isolées, et donnent naissance à des soleils simples analogues à celui qui nous éclaire. Notre système solaire appartient certainement à l'ordre des formations régulières. L'union de ses différents membres, la simplicité de son organisation, l'homogénéité de son ensemble, l'harmonie de ses mouvements, tout nous prouve que la nébuleuse qui lui a donné naissance n'était pas l'une. de ces nébuleuses irrégulières, doubles, multiples, comme le ciel en offre tant d'exemples, 
mais une création analogue à celle du Verseau, dont nous venons de résumer l'existence.

Maintcnant, de quelle façon une nébuleuse peut-elle donner naissance d̀ un soleil et à un système planétaire?

Représentons-nous un amas de matière cosmique, isolé et animé d'un mouvement de rotation sur-lui-mème. Ge mouvement, de rotation a été la résultante de tous les mouvements moléculaires qui

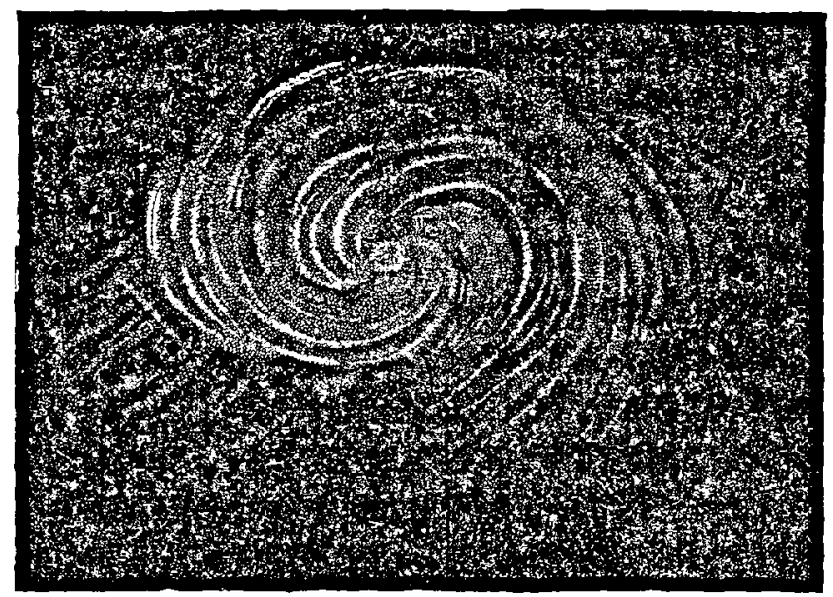

Fig. 21. - La nébuleuse en spirale de la constellation des Chiens de chasse, montrant le résultat des mourements intërieurs.

ont commencé à agir dès l'origine même de la condensation et d'une attraction centrale. Il décide d'ailleurs de son isolement et de sa forme globulaire. Ce mouvement de rotation n'est pas une invention de la théorie pour les besoins de la cause; nous avons la preuve qu'il existe dans les nébuleuses de cet ordre, par leur aspect même. Revoyez un instant la nébuleuse du Lion, représentée plus haut (p. 41) et considérez anssi la merveilleuse nébuleuse en spirale de la constellation des Chiens de chasse, reproduite ci-dessous, et vous aurcz sous les yeux la nature prise sur le fait. Dans cette dernière formation, notamment, nous voyons d'immenses spires lumineuses partir d'un centre pour se dérouler dans l'espace, et l'on croit mème deviner par les traînées qu'elle laisse derrière elle, le sens de la direction de son mouvement propre à travers l'immensité. 
Le Soleil paraît s'être formé au centre d'une condensation de ce genre. Il est sphérique, peu ou point aplati à ses pôles, et tourne lentement sur lui-même, si lentement même que la force centrifuge créée par ce mouvement de rotation est à peine sensible. Mais la nébuleuse gazeuse dont il est la condensation centrale tournait avec lui, et, dans cette nébuleuse, la vitesse de rotation est d'autant plus grande que l'on considère un point plus éloigné du centre. Au taux de la vitesse actuelle, un point éloignè du Soleil à la distance de 36,4 (le demi-diamètre du Soleil étant pris pour unité), c'est-àdire à cinq millions six cent soixante-six mille lieues, qui tournerait avec le Soleil, marquerait la limite extrême de son atmosphère. A cette distance, la force centrifuge créée par ce mouvement serait précisément égale à la pesanteur vers le Soleil, et toute molécule situéc au delà cesscrait d'appartenir au Solcil, s'échapperait sur la tangente comme la pierre lancée par la fronde. Cette distance est environ le tiers de celle de Mercure.

Si le Soleil avait tourné avec sa vitesse actuelle à l'époque où sa nébulosité, ou son atmosphère, s'étendaient jusqu'à cette distance, la zone extérieure de cette nébuleuse se serait détachée et aurait donné naissance à une planète. Alors, au lieu d'être sphérique, cette nébuleuse eût èté fortement aplatie, approchant de la forme d'une lentille, le rapport du diamètre équatorial au diamètre polaire étant de 3 à 2.

Les planètes ont pu naitre successivement de zones détachées de la nébulense solaire, en commençant par Neptune, la plus extérieure, et en finissant par Mercure, la plus intérieure. Mais si elles se sont formées de la sorte, ce n'est point du Soleil lui-mème, du noyau solaire proprement dit, car à chacun de ces détachements dus à la force centrifuge, le Soleil étendu jusqu'aux orbites planétaires eût dù ètre non sphérique, mais elliptique, lenticulaire, et l'on ne roit pas pourquoi il serait redevenu sphérique, sa vitesse n'ayant pu que s'accroitre toujours avce la condensation. Ce n'est pas du Soleil même que les planètes se seraient détachées, c'est de la nébulosité qui l'aurait environné en tournant avec lui, c'est de son atmosphère.

Il faut done que dans le centre de la nébuleuse le Soleil se soit condensé d'une manière en quelque sorte indépendante, se soit 
formé et ait pris sa vie propre en constituant un globe relativement isolé au milieu de l'immense nébuleuse. Le mouvement de rotation sera toutefois resté commun à l'astre central et à sa nébuleuse. A l'époque lointaine où s'est détachée la zone extérieure qui aura donné naissance à Neptune, la nébuleuse s'étendait jusqu'à l'orbite de cette planète, c'est-à-dire à 1100 millions de lieues et tournait en 165 ans : à la distance de Neptune, la force centrifuge produite par cette vitesse de mouvement est précisément égale à l'attraction vers le Soleil ; elle est de $0^{\mathrm{mm}}, 0065$, c'est-à-dire de 65 dix-millièmes de millimètre; si de là un corps tombait sur le Soleil, il ne parcourrait que cette minime quantité pendant la première seconde de chute, et, de même, si l'attraction solaire était suspendue, un corps tournant avec la vitesse de Neptune s'échapperait de l'orbite et s'éloignerait de cette mème quantité pendant la première seconde.

Toutes les planètes sont dans ce même cas. Aux distances respectives oủ ellẹs tournent autour du Soleil, si on arrêtait leur mouvement, elles tomberaient précisément vers le Soleil de la même quantité dont elles s'éloigneraient si l'attraction de l'astre central était supprimée. La vitesse de leur marche développe justement une force centrifuge qui tend à les éloigner de la quantité même dont le Soleil les attire. C'est là le secret, très simple, de l'équilibre du système du monde.

Ainsi, si l'on supprimait l'attraction du Soleil, la Terre, au lieu de tourner autour de lui, continuerait son cours en ligne droite, s'éloignant du Soleil de près de 6 millimètres dès la première seconde, et s'en irait se perdre dans la nuit glacée des profondeurs de l'espace. D'autre part, si l'on supprimait son mouvement, la force centrifuge disparaissant, cette planète obẻirait à l'attraction solaire et tomberait en ligne droite sur l'astre central, avec la vitesse de 6 millimètres également (exactement $5^{\mathrm{mm}}, 87$ ) pendant la première seconde.

Mais tracons un petit tableau de ces vitesses et de leurs conséquences au point de vue qui nous intéresse spécialement ici. Ce petit tableau est particulièrement instructif en lui-même. Il nous donne une idée du mouvement et de la vie, de la force en jeu dans le mécanisme du système du monde. 


\section{VITESSES DES PLANĖTES SUR LEURS ORBITES}

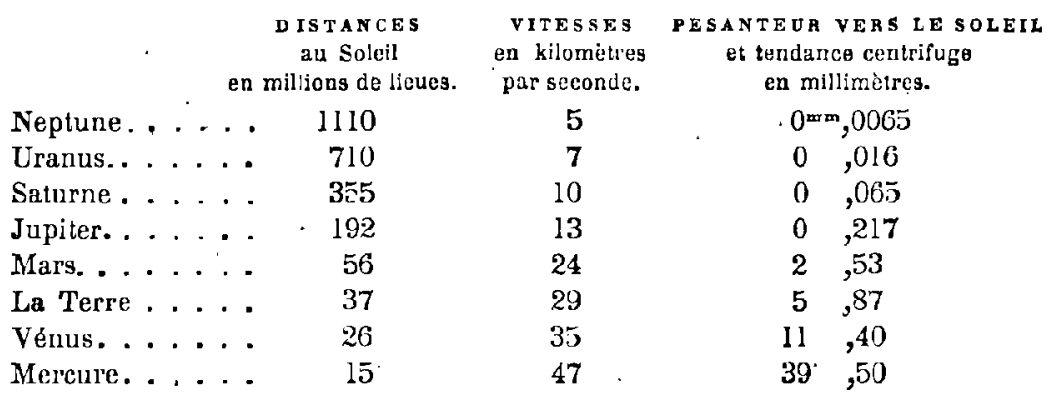

Il faut que nous nous représentions par la pensée toutes les planètes tournant ainsi. On le voit, Mercure se maintient, en tournant autour du Soleil à la distance moyenne de 15 millions de lieues, parce qu'il vogue au taux de 47 kilomètres par seconde. Cette vitesse crèe une force centrifuge qui tend à l'éloigner du Soleil en raison de $39^{\mathrm{mm}} \frac{1}{a}$ par seconde, valeur égale à la quantité dont il tomberait vers le Soleil pendant la première seconde de chute si ce mouvement était supprimé. Il en est de mème pour chaque planète, chacune selon sa distance.

La nébuleuse primitive s'étendait jusqu'au delà de l'orbite de Neptune (et même fort au delà, car il existe au moins une planète trans-neptunienne). Les zones de vapeurs qui ont donné naissance aux planètes ont-elles été abandonnées simplement par la nébuleuso en voie de condensation, ou bien se sont-elles formées dans l'intérieur même de la nébuleuse?

Les deux hypothèses sont admissibles. Des zones de condensation ont pu se produire dans l'intérieur de la nébuleuse. Elles tournaient tout d'une pièce avec la nébuleuse elle-même. En se resserrant graduellement vers leur point de plus grande condensation, chacune de ces zones peut avoir donné naissance à une planète.

Les zones extérieures, plus vastes, ont donné naissance aux quatre colossales planètes de notre système, qui sont plus volumineuses et moins denses que la Terre, et qui tournent plus rapidement sur, elles-mémes. En deçà de Jupiter, le plus important de tous les mondes de la famille solaire, il semble que la zone ait été empèchée 
de se condenser en un seul globe, car elle a donné naissance à une innombrable quantité de provinces célestes dont on en a déjà découvert plus de deux cent. Ces petites planètes, qui gravitent entre Mars et Jupiter, sont elles-mêmes distribuées en zones caractéristiques, accumulées le long de certaines lignes, éparses, rares, le long d'autres lignes, et complètement absentes le long de certaines routes célestes remarquables par ces vides ou lacunes. Ces zones désertes sont celles oủ circuleraient des planètes en des périodes égales à la moitié, au tiers ou au quart de la révolution annuelle de Jupiter, proportions simples qui ramèneraient périodiquement les mèmes perturbations et balayeraient l'espace sans y rien laisser. Ciest donc à la puissance perturbatrice de Jupiter que l'on doit l'absence d'une grosse planète dans son voisinage. Le tyran n'eùt pas supporté de rival.

La vitesse des diffèrentes parties d'une roue ou d'un disque en mouvement étant d'autant plus grande que l'on est plus éloigné du centre, les parties extérieures des

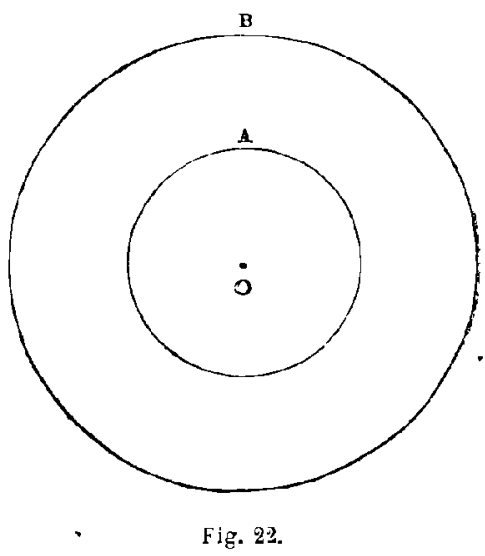

La vitesse augmente avec la distance au centre. zones de condensation tournaient plus vile que les parties intérieures. Dans la roue o a B, par exemple, le point $\mathrm{B}$, deux fois plus éloigné du centre que le point $\Delta$, tourne deux fois plus rapidement. Les circonférences augrnentent dans la même proportion que les rayons. Il en résulte que lorsque ces zones se sont condensées en planètes, ces planètes ont été animées d'un mouvement de rotation dirigé dans le mème sens que le mouvement général de la nébuleuse sur elle-même, c'est-à-dire en sens direct, la vitesse extérieure de chaque zone détachée étant plus grande que la vitesse intérieure. Telle est aussi, sans doute, la raison primitive pour laquelle les planètes éloignées sont à la fois les plus volumineuses et les plus rapides en rotation, leurs zones productrices ayant été plus larges, et la différence de vitesse entre l'extérieur et l'intérieur de ces zones ayant été très grande. La figure suivante donne une idée de ce procédé. 
Il serait difficile de concevoir que ces anneaux pussent rester à l'état d'anneaux. Il faudrait pour cela qu'ils fussent d'une homogénéité parfaite, que nulle région d'entre eux ne fût plus dense que les autres, et que des perturbations extérieures empèchassent aucun amoncellement durable de matière. Mais en vertu de l'attraction, ces anneaux tendent généralement à se resserrer vers des régions momentanément plus denses et à perdre la stabilité théorique de

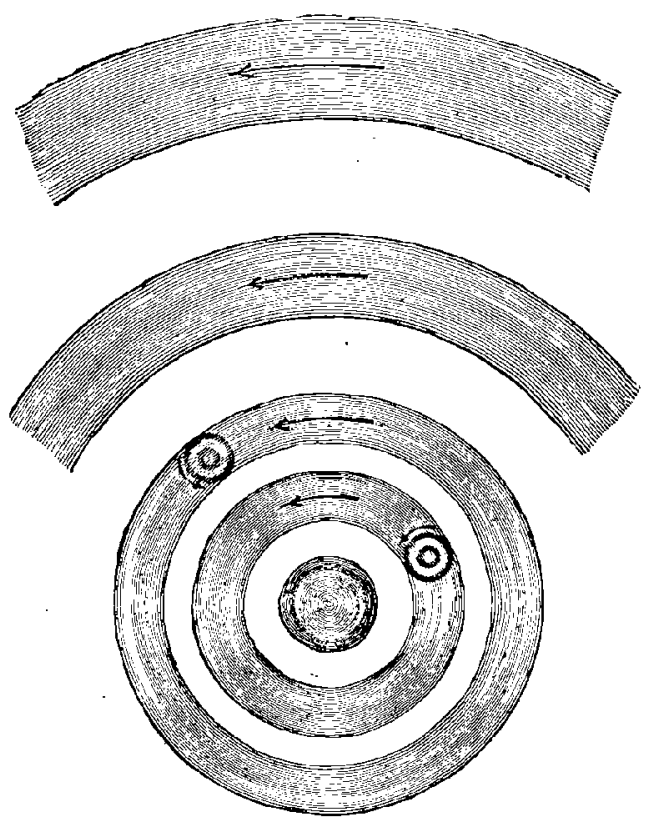

Fig. 23, - Formation d'anneaus nébuleux et origine des condensations planétaires.

leur équilibre, et peu à peu une masse sphérique nébuleuse formée en un point quelconque finit par rassembler tous les matériaux de l'anneau.

Chacune de ces nébuleuses secondaires va maintenant reproduire en petit ce qui s'est passé en grand dans l'ensemble du système. Elle tournera sur elle-même avec une vitesse croissante à mesure qu'elle se condenscra ct qu'clle se rapetissera $\left({ }^{4}\right)$. Alors des

1. L'accélération du mouvement à mesure qu'une nébuleúse se rapetisse, ou à mesure que dans un système on se rapproche du centre s'exprinue en mathématique par la loi des aires qui s'énonce ainsi : Les surfaces balayées par les lignes menées des planètes au Soleil, sont proportionnelies aux temps employés à les parcourir. (Voy. l'explication et 
anneaux pourront se former pour donner naissance à des satellites, et ces anneaux primitifs et ces satellites seront d'autant plus nombreux que la planète aura une matière plus étendue et aura tourné plus vite.

Ainsi la Lune est née de la Terre et chaque satellite est né de sa planète centrale. Peut-être les satellites pourraicnt-ils encore donner naissance à leur tour à des satellites secondaires. Mais nous n'en avons pas d'exemple dans notre système solaire. Sans doute, nos satellites étaient-ils trop denses ou en rotation trop lente, dès l'origine, pour avoir pu se fractionner de nouveau. Nous connaissons des exemples de ce genre en d'autres régions du ciel : ce sont des systèmes quadruples, dans lesquels un corps céleste tourne autour d'un plus gros, qui tourne lui-mème autour d'un autre, lequel emporte à son tour ce système triple autour d'un soleil plus fort et plus éloigné.

Que, dans la nébuleuse solaire dont nous essayons de raconter l'histoire, des zones de condensation, annulaires ou partielles, se soient formées intérieurement, ou qu'elles se soient formées extérieurement, à la limite où la force contrifuge faisait équilibre à l'attraction générale, le résultat a été le mème. Étant admis, comme il est rationnel de le penser, que la nébuleuse tournait tout d'une pièce autour de son centre, les vitesses de rotation s'accroissant avec la distance, les bords extérieurs des zones tournant plus vite que les bords intérieurs, les planètes ainsi formées ont été entraínées dans un mouvement de rotation direct, comme nous l'avons dit tout à l'heure.

Cette théorie, formulée pour la première fois au siècle dernier par le philosophe Kant et par le mathématicien Laplace, explique d'une manière satisfaisante l'ensemble des mouvements planétaires. Il semble que la nature elle-même y ait mis son empreinte et qu'elle ait laissé dans notre propre système la trace de son œuvre

la figure, Astronomie populaire, p. 278.) Mais un moyen extrêmement simple de s'en rendre compte est d'enrouler autour de son doigt un fil terminé par un petit poids. A mesure que le fil se raccourcit en s'enroulant, le mouvement devient plus rapide; à mesure qu'il s'allonge en se déroulant il devient plus lent. Voilà toute la \& loi des aires * et tout le secret de l'accroissement des mouvements planélaires à mesure qu'on s'approche du Soleil. 
par l'aspect du monde de Saturne, qui roule dans le ciel accompagné d'une couronne d'anneaux toujours subsistants. Ces anneaux, toutefois, ne sont pas gazeux, ni liquides, ni solides, mais ils paraissent constitués de corpuscules distincts tournant ensemble autour de la planòte et maintenus par le réseau d'attraction des satellites extérieurs. Ils ne sont qu'une image modifiée du mode de formation des corps célestes, et il n'est pas probable qu'ils se réunissent jamais en une seule masse pour la constitution d'un satellite. Ce sont déjà, eux-mèmes, en chacune de leurs corpuscules, de véritables satellites, détachés de la planète, isolés, circulant, non comme

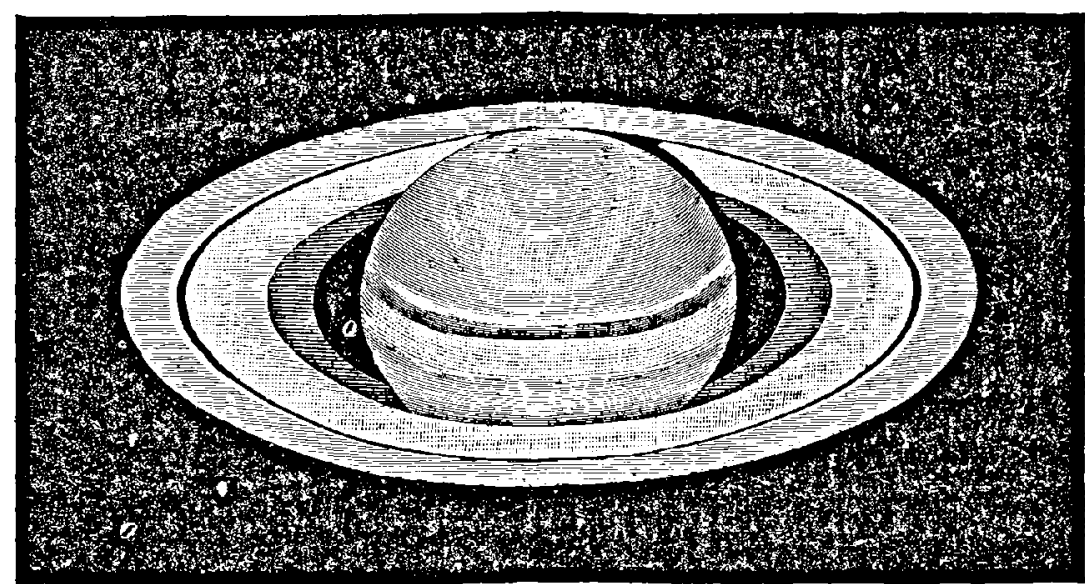

Fig. 24. - Le monde de Saturne et ses anneaux.

une atmosphère, mais comme des corps célestes indépendants, le bord extérieur de l'anneau tournant moins vite que le bord in térieur, suivant le décroissement de l'attraction en raison du carré de la distance.

La théorie que nous venons d'exposer est simple et rationnelle. Elle n'explique pas toutefois certaines particularités de notre système.

Ainsi, elle ne nous donne pas la raison de l'inclinaison des planètes sur leurs orbites. D'après ce que nous venons de voir, les planètes devraient ètre placées droit sur leurs orbites, et non obliquement. Leurs mouvements de rotation ayant pour cause première la différence de vitesse entre le bord extérieur et le bord intérieur 
de la zone en condensation, l'axe de rotation devrait ètre franchement perpendiculaire au plan dans lequel chaque planète se meut autour du Soleil. C'est ce qui existe, il est vrai, pour la plus importante des planètes, pour Jupiter, mais les autres sont toutes plus ou moins inclinées. Chacun sait, par exemple, que l'axe de rotation de la Terre est incliné de $23^{\circ} \frac{1}{2}$ et que e'est cette inclinaison qui est la cause des saisons.

On se rendra compte de cetétat de choses à l'inspection du dessin ci-dessous, qui représente l'inclinaison comparée de la Terre et de

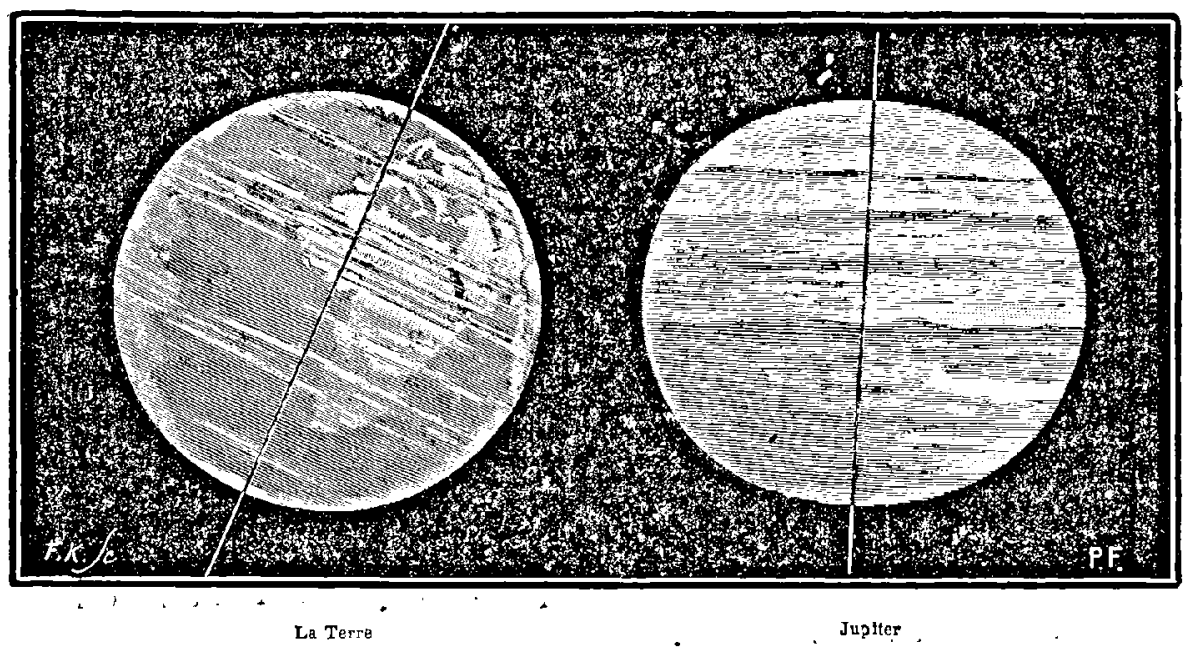

Fig 20̈. - Inalinaison comptrée de l'axe do la Terce et de laxe de Jupiter.

Jupiter (on a dessiné la Terre aussi grosse que Jupiter pour permettre d'apprécier facilement cette inclinaison). Jupiter est presque droit : son inclinaison n'est que de $3^{\circ}$. La Terre, au contraire, est fortement inclinée.

Th bien, les autres planètes sont inclinées comme la Terre, et plusieurs le sont beaucoup plus. Voici ces diverses inclinaisons :

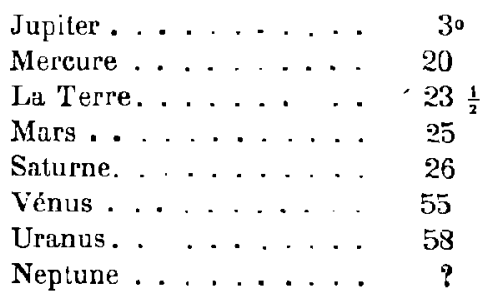

I.E MONDE AYANT LA CRÉATION DE L'HOMHE

Satellites : $93^{\circ}$

146 
Les inclinaisons de Mercure, la Terre, Mars et Saturne ne diffèrent pas considérablement entre elles et sont comprises entre $20^{\circ}$ et $26^{\circ}$. Les saisons sont à peu près de la mème intensité relative sur ces quatre planètes, quoique différant au point de vue de la température moyenne comme au point de vue de la longueur. L'inclinaison de Vénus, de $55^{\circ}$, est beaucoup plus forte, comme on peut en juger à l'aspect de la figure 26 .

Uranus est encore plus incliné. D'après les dernières observations ( $\left.{ }^{1}\right)$, l'axe de rotation qui, pour Jupiter, n'est incliné que de $3^{\text {o }}$ sur la perpendiculaire au plan dans lequel il se meut, pour la Terre de $23^{\circ} \frac{1}{2}$ et pour Vénus de $55^{\circ}$, cet axe, disons-nous, est incliné de $58^{\circ}$. Mais ce qu'il y a de plus surprenant, e'est que le système de ses quatre satellites est plus incliné encore et descend jusqu'à $98^{\circ}$, c'est-à-dire au delà de l'angle droit, ce qui fait qu'ils circulent presque perpendiculairemont au plan de l'orbite. L'axe polaire d'Uranus fait avec l'axe de révolution de ses satellites (ou, ce qui revient au mème, l'équateur d'Uranus fait avec le plan de révolution des satellites) un angle de $41^{\circ}$ environ, la planète tournant sur elle-même en un plan tout différent de celui de ses satellites. De plus, cette inclinaison de $98^{\circ}$, fait que les satellites, tout en tournant presque perpendiculairement, sont plutôt rétrogrades que directs. Il y a lì une anomalie très remarquable et qui a fait pencher d'une étrange manière les axes de rotation.

Nous ne savons pas encore dans quel sens Uranus tourne sur luimème, si c'èst en sens direct ou en sens rétrograde.

Le système de Neptune est encore plus accusé : son inclinaison descend jusqu'à $146^{\circ}$ et le mouvement de ses satellites est franchement rétrograde.

Ce sont là des faits astronomiques que la théorie cosmogonique exposée plus haut n'explique pas $\left({ }^{2}\right)$. Il importait néanmoins de ne pas les laisser passer sous silence.

1. Voy. l'Astronomie, Revue mensuelle d'Astronomie populaire (Paris, GauthierVillars), numéro d'août 1884, observatians faites à l'Observatoire de Paris par MM. Hexry.

2. Voy. Haye, Revue mensuelle d'Astronomie, nos de mai et juin 1884. M. Faye pense que la formation du système solaire s'est faite autrement a partír d'Uranus, que pour Neptune et Uranus les anneaux cosmiques se sont formés extérieurement à la nébuleuse solaire tandis que pour Saturne et les autres planètes plus rapprochées ils se seraient 
Il est probable que ces inclinaisons ont en pour cause le mode de formation mếme de chaque planète, par la condensation, non immédiate et uniforme, mais graduelle et en plusieurs fois, de la zone nébuleuse originale. Les adjonctions successives des masses diffuses ont dù faire changer le centre de gravité comme le plan du mouvement. Les perturbations extérieures n'ont pas été non plus sans action.

La théorie n'explique pas non plus pourquoi la Lune, née de la

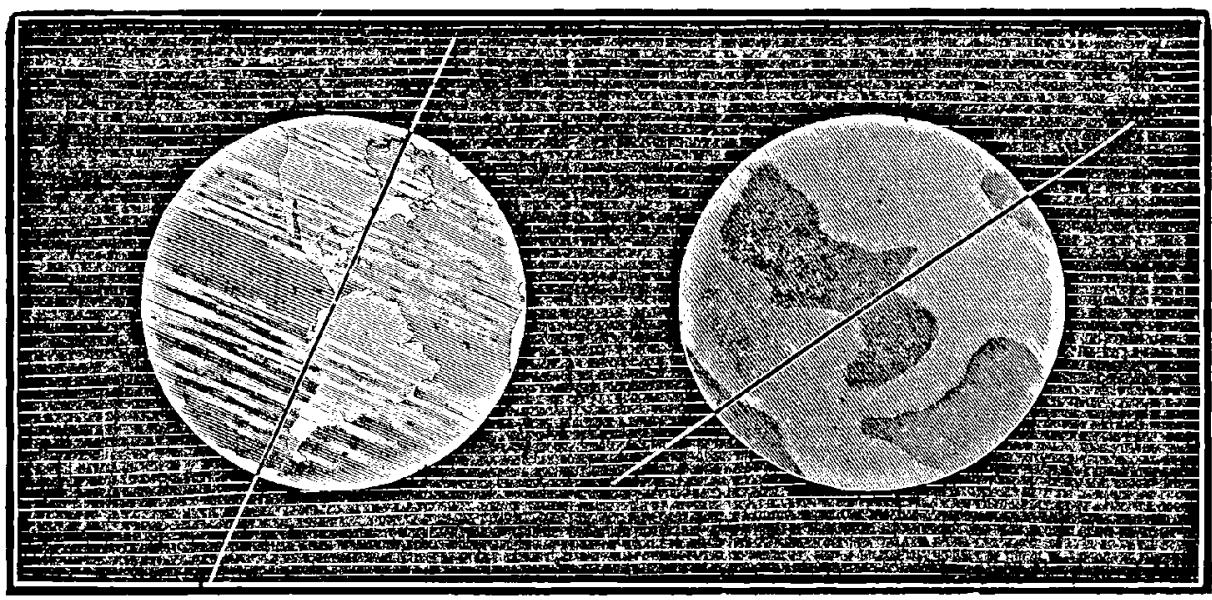

La Terre

Vénus

Fig. 26. - Inclinaison comparée de l'axe de la Terre et de l'axe de Vénus.

nébuleuse terrestre, présente toujours la même face à la Terre, tandis que les planètes, mème les plus proches du Soleil, tournent sur elles-mèmes avec indépendance. On peut répondre, sans doute, que la Lune a primitivement tourné sur elle-même, et que c'est la Terre qui l'a arrêlée en agissant par les marées lunaires comme un frein, de même que de nos jours les marées terrestres produites par la Lune tendent à ralentir le monvement de rotation de la Terre. Mais le Soleil a dù produire sur Mercure des marées analogues et aurait dù, en vertu du mème principe, arrêter son mouvement de rotation. Elle n'explique pas non plus pourquoi l'un des deux satellites de Mars tourne plus vite que la planèle elle-même : il fait le tour de

formés intérieurement. Mais cette différence ne rend pas compte de la perpendicularité du système d'Uranus ni des inclinaisons planétaires. 
la planète en 7 heures 39 minutes, tandis qu'elle emploie 24 heures 37 minutes à accomplir son propre mouvement de rotation (').

Nous ne savons pas tout. Mais telle que nous l'avons exposée, cette théorie rend compte de l'ensemble des différents corps du système solaire et de leur unitẻ d'origine. C'est déjà beaucoup. Nous devons nous estimer heureux d'avoir su trouver les liens de parenté qui rattachent les nébuleuses aux soleils, de savoir comment une nébuleuse peut former un soleil et un système de mondes, de pouvoir assister par la pensée à l'éclosion de la Terre dans le sein de la nébuleuse solaire et à l'éclosion de la Lune dans le sein de la nébuleuse terrestre. L'analyse spectrale, qui nous permet aujourd'hui de lire dans les rayons de lumière l'histoire chimique des astres, confirme l'unité du système du monde, et même l'unité de l'univers, en nous montrant les éléments terrestres répandus sur les autres planètes et jusque. dans les étoiles, et en affirmant l'unité de composition du Cosmos.

Ou a mème essayć de reproduire par une expérienco de laboratoire la théorie de la formation des mondes que nous venons d'esquisser. M. Plateau, phrsicien belge, est le promier auteur de cette expérience, que l'on reproduit souvent dans les cours de physique.

Au milieu d'un vase de verre rempli d'cau-de-vie, ayant la pesanteur spécifique de l'huile avec laquelle on veut faire l'expérience, on place un siphon se terminant en pointe et rempli d'huile, comme ci-dessous.

On tient l'extrémité du siphon au milieu du verre, puis on retire le doigt de l'embouchure supérieure pour livrer passage à l'huile. Immédiatement on voit celle-ci se montrez à l'extrémité opposée sous la forme d'une goutte. La goutte grossit, alteint les proportions d'un pois, d'une noisette et, si l'expérience est bien faite, jusqu'à la dimension d'une noix ordinaire. Telle est donc la forme que prend un liquide livré à lui-mème, indépendant de tout obstacle.

Si maintenant on fait tourner un pareil globe d'huile sur son axe, sa forme change : il devient un sphéroïde aplati aux deux extrémités les plus rapprochées de l'axe. L'expérience se fait aisément avec les gouttes d'huile dans l'eau-de-vie. On attache un bouton de métal que l'on fait tourner à l'aide d'un rouage. On descend ce bouton au milieu du mélange d'esprit-de-vin et d'eau. Le rouage est maintenu hors de l'eau et disposé

1. La vitesse actuelle de la rotation du Soleil est aussi une objection contre la théorie. (Voy. Revue mensuelle d'Astronomie populaire, fév. 1885, article de Maurice Fovehé, sur l'hypothèse de Laplace. 
de telle sorte que la tige et le bouton qui la termino ne fassent que tourner sur leur axe, sans autre mouvement ou secousse. - Tout étant ainsi préparé, on laisse la goutte d'huile s'échapper du siphon et descendre sous le bouton. Elle forme immédiatement un petit globe autour de celui-ci et d'une partie de la tige. Si alors on fait tourner lentement sur son axe la tige de métal, la goutte de liquide acquiert une partie de ce mouvement, dont la vitesse va en croissant. Aussitôt que la rotation de la goutte d'huile devient visible, celle-ci change de forme; elle s'aplatit comme une orange ou comme les planètes, et en accélérant adroitement la rotation, on peut aller jusqu'à faire en sorte que le diamètre de la

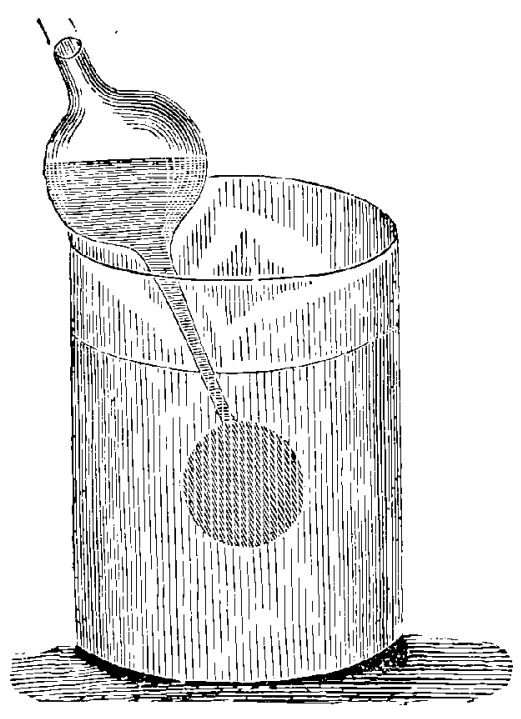

Fig. 27. - Goutte d'huile au repos.

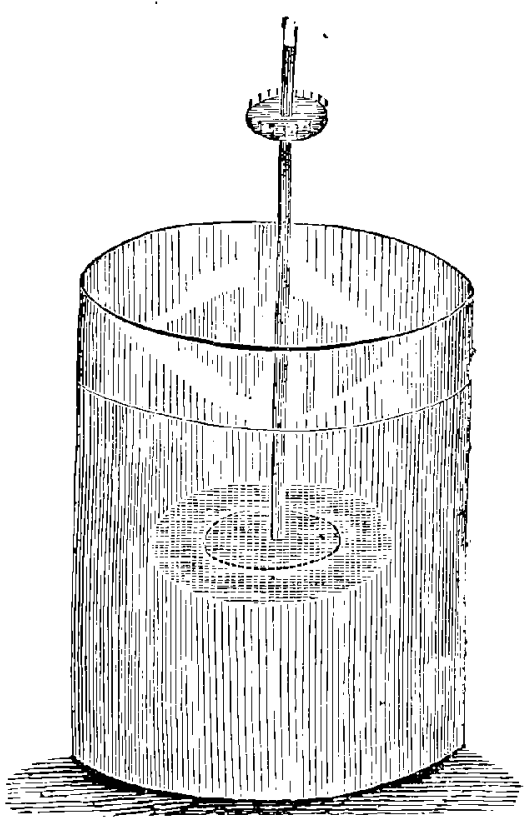

Fig. 28. - Goutte d'huile en mouvement.

goutte d'huile atteigne le double de la longueur de son axe. Mais si l'on va au delá, la cohésion cesse, la zone extérieure se détache et la goutte d'huile devient semblable à la planète Saturne.

Cette ingénieuse expérience montre en pratique ce que la théorio enseigne, que la rotation des cor'ps à l'état liquide modifie leur forme en raison de leur volume et de la vitesse de leur rotation. La Terre a, comme on le sait, la forme d'une sphéroïde légèrement aplatie aux pỏles.

De ce qui précède, il résulte que le corps terrestre a été jadis liquide ou mou, c'est-à-dire plastique. La Terre a dì prendre la forme d'un globe et, par suite de la rotation, s'aplatir aux extrémités de son axe. La température de la planète, liquide par son noyau et gazouse par son atmosphère, était alors de plusieurs milliers de degrés. 
Les diverses plảnètes ne se sont ni formées en même temps ni refroidies simultanément. Leur création ne date pas du même jour, et elles rı'ont pas le même âge relatif. Ainsi, relativement à la Terre, Jupiter est beaucoup plus jeune : il n'est pas encore arrivé à l'état de stabilité de notre planète; son atmosphère cst encore chargée de vapeurs ct de nuages et se montre soumise à des perturbations incessantes; il se passe là des phénomènes météorologiques quotidiens que la chaleur solaire serait incapable de produire à cette distance et qui sont entretenus par la température propre à Jupiter, encore actucllement très élevéc; depuis quelques années surtout, l'observation assidue des astronomes a mis en évidence des faits caractéristiques qui nous font assister de loin à la formation de la surface d'un monde : une tache rouge d'une grande étendue (plus vaste que la Terre entière) s'est formée audessus de l'équateur et est restée fixe au mème point depuis sept années ('), tournant avec la planète, dans son rapide mouvement de rotation, de $9^{\mathrm{b}} \mathbf{5 5 ^ { \mathrm { m } }}$, mais restant immobile à la même place du globe ; elle a pâli lentement et s'est graduellement effacée; ce ne pouvait être un nuage ni un accident météorologique, puisqu'elle est restée pendant cinq annèes fixe au mème point; elle appartient à la surface mème du globe, et il est probable qu'il s'agit là d'un continent en formation. Jupiter est actuellement ḋ son âge primordial.

Les étoiles, soleils de l'infini, qui parsc̀ment l'immensité, se présentent également à nous dans leurs différents âges. Elles se partagent essentiellement en quatre types: $1^{\circ} \mathrm{les}$ étoiles blanches, comme Sirius, Véga, Rigel, Procyon, Altaïr, etc., dont le spectre montre surtout l'hydrogène incandescent et manifeste une température extrèmement élevée, ce sont les plus jeunes; $2^{\circ}$ les jaunes d'or, telles que notre propre soleil, Capella, Arcturus, Pollux, Aldébaran, etc., dans lesquelles on voit en dissociation le sodium, le fer, l'hydrogène, le magnésium, et dont la température est moins ćlevéc que colle des soleils précédents, ces astres paraissent être dans la force de l'âge; $\therefore$ les étoiles orangées, comme Antarès et d'autres moins brillantes, dont le spectre se montre formè de fortes lignes sombres et de traits

1. Voy. Flammarion, Les Terres du Ciel, p. 506. 
lumineux, atmosphères absorbantes, hydrogène rare, sodium, fer, magnésium, carbone (un grand nombre de ces étoiles sont variahles, ainsi que celles de la classe suivante); $4^{\circ}$ les étoiles rouges et sombres, qui sont très peu brillantes, généralement invisibles à l'œil nu, et dans lesquelles le spectroscope permet de reconnaitre le caractère des composés du carbone, probablement des oxydes

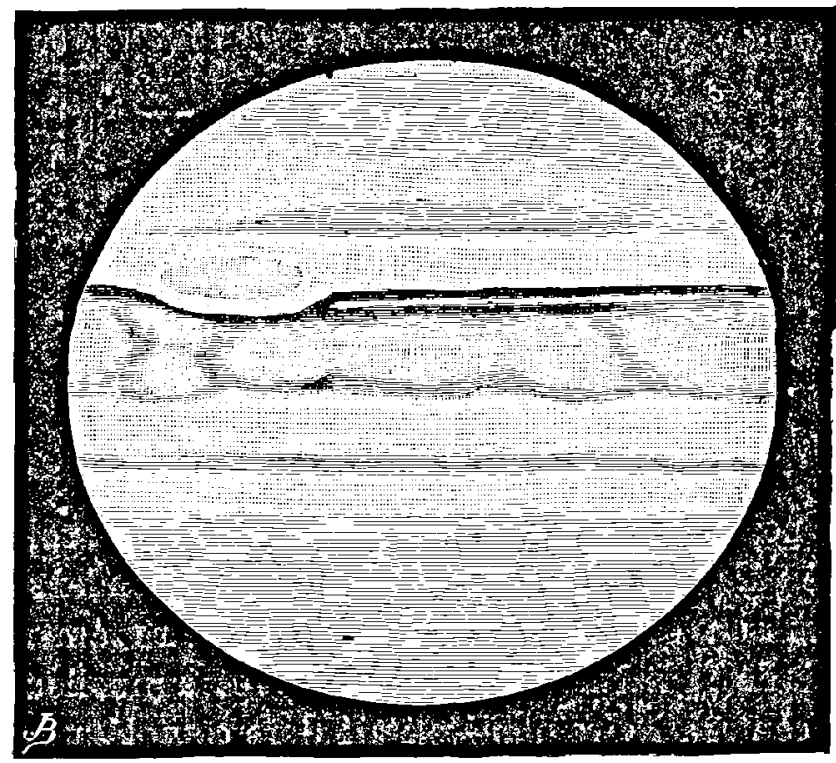

Fig. 29 .

Jupiter est un monde en sa genèse. Tache rouge observée q̧ 1878 à 1884.

gazeux, ce qui indique des soleils à basse température : ce sont sans doute là des astres qui s'oxydent, qui sont prêts à s'éteindre. Ainsi, le ciel nous montre ses créations à toutes les époques de leur histoire. Il y a dans le ciel comme sur la Terre des berceaux et des tombes. Heureux qui pourrait lever le voile de ces berceaux et faire l'horoscope des mondes à venir. Plus heureux encore celui qui, dans les astres en agonie et parmi les mondes défunts, saurait deviner la résurrection et découvrir par quels mystérieux procédés la nature rend son œuvre eternelle. 


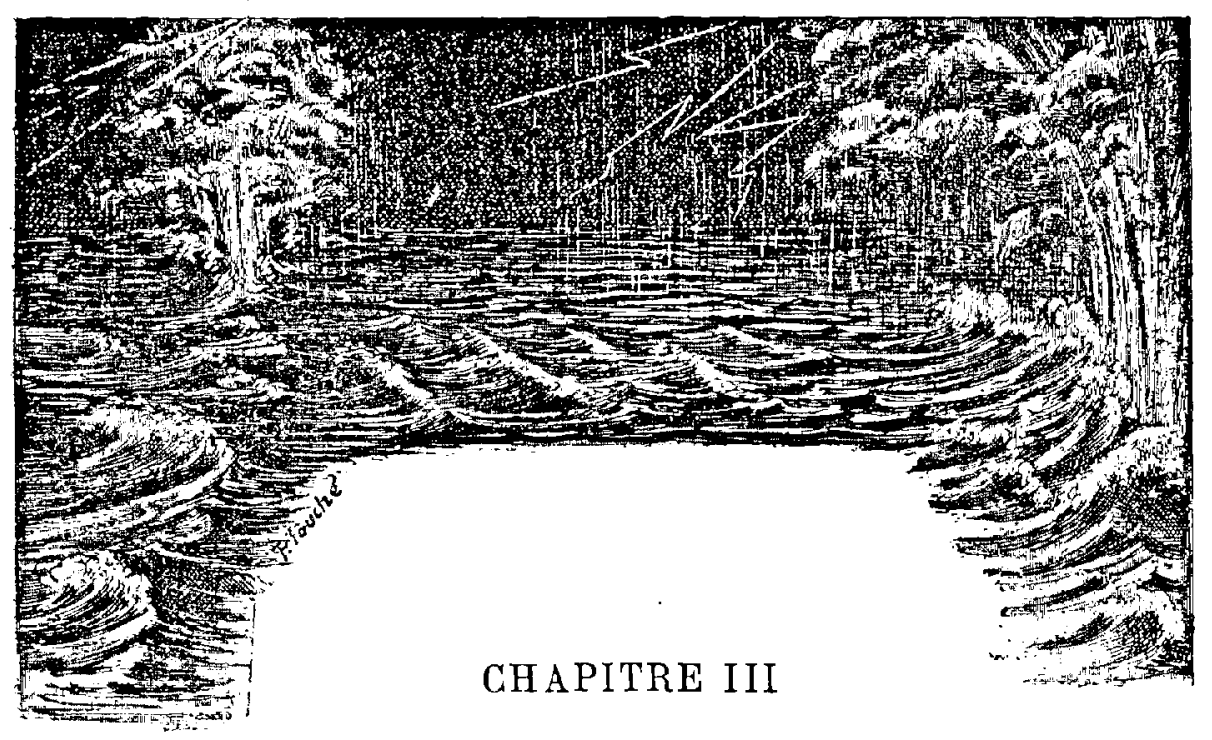

IA NAISSANGE DE LA TERRE

Dans la noire immensité des cieux la nébuleuse solaire brillait d'une clarté pâle et diffuse, et tandis qu'elle se condensait graduellement vers son centre, la nébuleuse terrestre émanée de son sein, brillait de la mème clarté en tournant annuellement autour de ce foyer central. Notre planète était alors complètement gazeuse; elle ne possédait ni noyau solide, ni mème aucune couche liquide; ce n'était en quelque sorte qu'une atmosphère, considérablement plus légère que l'air que nous respirons. Sa température originelle était égale à celle de la zone solaire dans le sein de laquelle elle s'est formée. Elle augmenta encore par l'effet de sa propre condensation. Obéissant aux lois de la gravitation, les molécules se resserrèrent de plus en plus vers le centre. Sa forme sphérique se définit de micux en micux. La nébuleuse devint soleil et brilla d'une resplendissante lumière.

La théorie mécanique de la chaleur montre que la seule condensation en globe, des particules constitutives de notre planète, a dù produire une chaleur de 8988 degrés centigrades. Durant cette première période notre berceau répandait au loin son éclatant rayonnement. La Terre brillait alors dans l'espace comme un soleil enveloppé d'une pâle nébulositè. 
Alors les' obscrvateurs placés dans' les univers lointains auront pu voir, à l'époque solaire de notre planète, une étoíle double composée de deux asties de grandeur différente; le plus grand était notre propre Sóleil; le plus petit était la.Terre, la Terre-Soleil. Sans doute mème ce système était-il double; triple, quadruple, multiple, plusieurs autres planètes áyant été solcils à'la même époque que notre Terre. Mais comme il est probable que Vénus ét

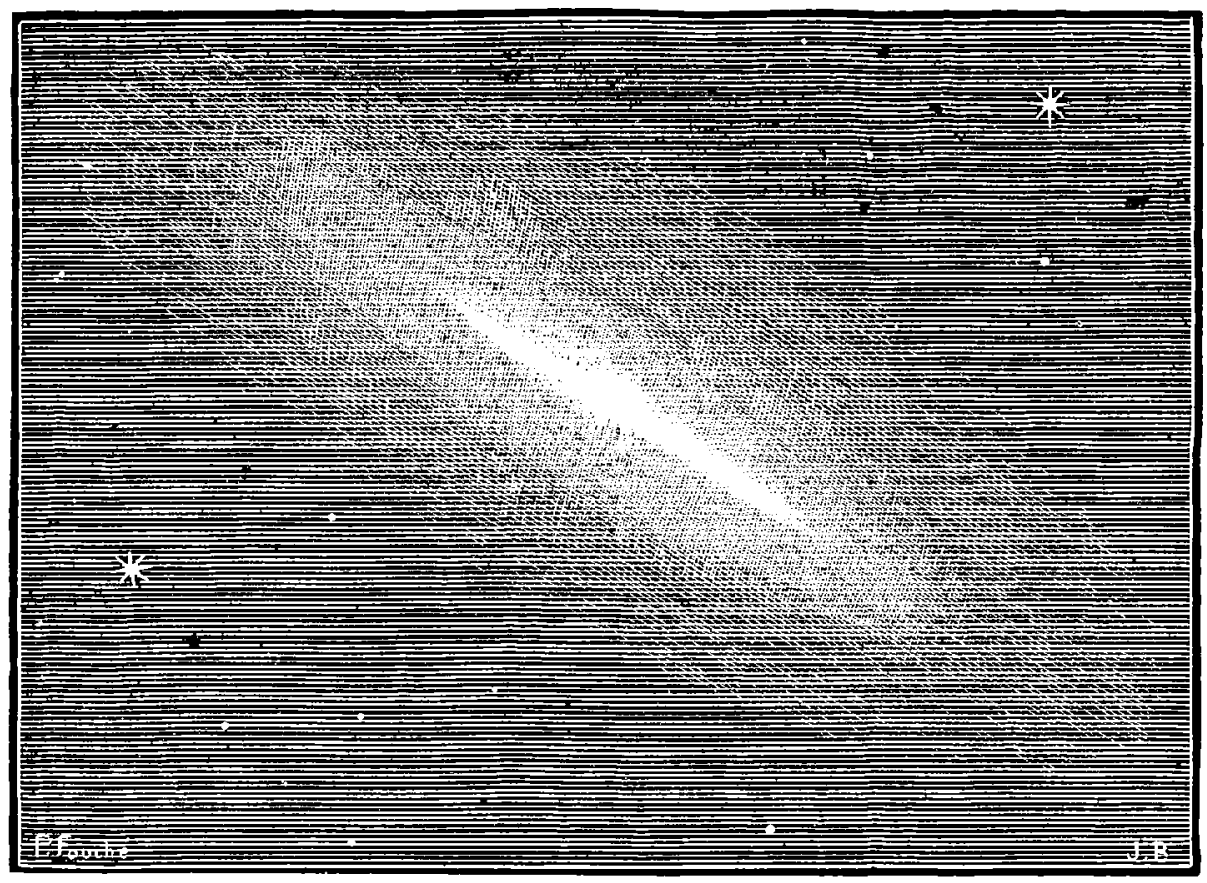

Fig. 31. - La Terre brillait alors dans l'espace comme un soleil enveloppé d'une pảle nébulosité.

Mercure étaient encore nébuleux lorsque la Terre était déjà soleil, il y eut une époque oủ, dans le champ du télescope, les observateurs lointains auront pu voir le Soleil et la Terre sous l'aspect de la figure 32.

Pendant bien des siècles, notre globe brilla, soleil éblouissant, foyer de réactions chimiques puissantes, donnant naissance à des taches ct à des éruptions gigantesques, analogues aux phénomènes que nous voyons s'accomplir tous les jours à la surface de notre Soleil. Elle était alors, selon toute probabilité, moins volumineuse

LE MONDE aXaNt ta CRÉtion de I'HOMne. 
que notre Soleil actuel; mais elle était considérablement plus grande qu'elle n'est de nos jours; sans doute s'étendait-elle jusqu'au delà de l'orbite de la Lune, avec un diamètre trente à quarante fois plus large que son diamètre actuel, très légère de densité et entièrement gazeuse.

Mais l'espace dans lequel se meuvent les mondes est froid et obscur. Sa température normale parait être de $270^{\circ}$ au-dessous de zéro. C'est un froid si intense que les uranolithes, qui en sont imprégnés, le gardent dans leur scin malgré leur échauffement superficiel dans leur passage si rapide à travers l'atmosphère tcrrestre : lorsqu'on les ramasse après leur chute, on se brúle les doigts en les touchant, mais lorsqu'on les casse, l'intérieur est si glacè qu'il brûle, lui aussi, plus encore que l'extérieur. (Cette remarque a été faite, notamment, le 14 juillel 1860, lors de la chule de l'uranolithe de Dhurmsalla, dans les Indes.)

Au milieu de ce froid, le rayonnement du Soleil-Terre finit par s'épuiser; ni sa condensation progressive, ni ses combustions chimiques, ni la chute de malériaux ou des poussières cosmiques qui durent lui arriver des restes de la nébuleuse solaire environnante et des diverses parties de l'espace ne suffirent à l'entretien de ce rayonnement calorifique et lumineux. Le globe terrestre, de gazeux devint liquide, liquide brùlant, mais moins lumineux. De blanche et resplendissante qu'elle était d'abord, l'ètoile-Terre se colora de rayons jaunes d'or, puis orangés, rougeâtres et sombres. Une atmosphère épaisse, lourde, tourmentée, une atmosphère d'usine et de laboratoire l'enveloppa de ses tourbillons. La Terre s'éteignit.

Elle s'éteignit comme soleil, mais c'était pour entrer dans l'aurore de sa vie.

C'est durant cette période primordiale que la Lune s'est formée, émanation de la nébuleuse terrestre, comme la Terre s'était formée, émanation de la nébuleuse solaire. La Lune appartient à la Terre comme la Terre appartient au Soleil. Elle tourne autour de notre planète en 27 jours 7 heures, comme nous tournons autour du Soleil en 365 jours 6 heures; elle nous accompagne, satellite fidèle; elle circule mensuellement autour de nous, tournant dans le même sens que nous tournons nous-mèmes, c'est-à-dire de l'ouest vers 
l'est, et presque dans le plan de notre équateur (l'inclinaison est de $5^{\circ}$ ); son extrait de naissance est encore inscrit dans son mouvemont, et son origine terrestre se décèle dans tous ses caractères; elle pèse quatre-vingt fois moins que là Terre, et est cinquante fois plus petite : sa densité est les six dixièmes de celle de la Terre.

Elle a dù se former d'unc zone nébuleuse détachée vers le plan de l'équateur de la nébuleuse terrestre à une époque où le mourement de rotation de la Terre s'était considérablement accéléré et ètait devenu beaucoup plus rapide qu'il n'est de nos jours, car la Lune est si proche de nous et son attraction est si puissante, qu'elle produit des marées considérables, et que ces marées agissant comme un frein, en sens contraire du mouvement de rotation de notre globe, ont retardé ce mouvement comme elles le retardent encore aujourd'hui, et dans

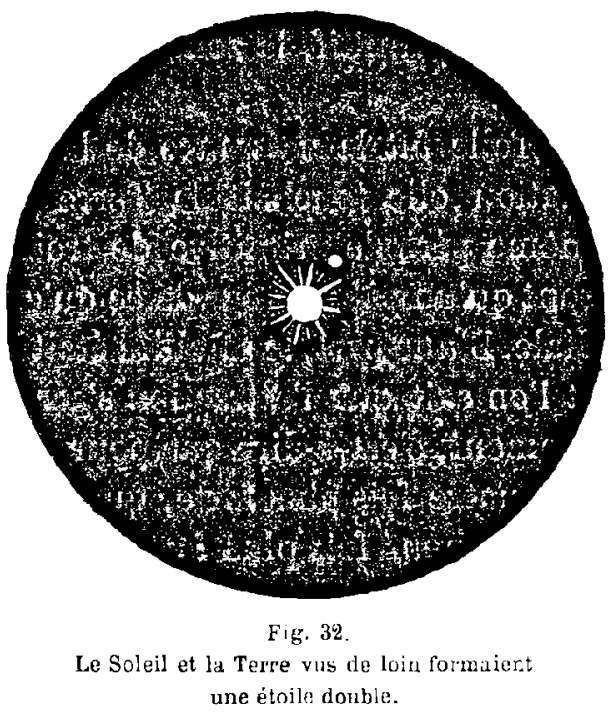
des proportions beaucoup plus grandes.

Des calculs judicieux, récemment faits par Darwin fils, semblent conduire à la conclusion que la naissance de la Lune remonterait à environ cinquante millions d'années, époque à laquelle le mouvement de rotation de la Terre sur elle-même se serait accompli en trois heures seulement ( $\left.{ }^{4}\right)$. $\Lambda$ vant la naissance de la Lune, la Terre subissait déjá des marées, mais des marées seulement produites par l'attraction du Soleil, et qui renflaient la nébuleuse terrestre le long de sa zone équatoriale en faisant tourner une sorte de bourrelet fluide le long de cette zone. D'autre part, le rapide mouvement de rotation de notre planète sur elle-mème produisait le long de cette mème zone équatoriale une force centrifuge très puissante, et pour

1. Voyez L'Astronomie, Revue mensuelle d'Astronomie populaire, numéro. de novembre 1884 . 
détacher de la nébuleuse terrestre une portion relativement considérable, la moindre cause pouvait suffire. Le Soleil a été cette cause. Une coïncidence de forte marée avec la tendance centrifuge aura rendu indépendante de l'attraction terrestre une partie de cette zone en équilibre instable, graduellement amoindrie par des vibrations diurnes consécutives, comme un pendule; la Terre aura repris sa forme globulaire et les matériaux détachés se scront rassemblés en une mème masse exerçant à son tour sa propre attraction sur toutes ses parties constitutives, en même temps que, gardant son mouvement primitif, la zone détachée continua de tourner autour de la Terre.

Telle fut la naissance de la Lune. Aux premiers jours de sa formation elle touchait la Terre et tournait autour d'elle en cette même période primitive de trois heures. Nos marées actuelles ne sont qu'un pâle vestige de ce qu'elles étaient en cette époque primordiale. D'une part, le satellite était beaucoup plus proche de la planète, et l'on sait que l'attraction s'accroît en raison du carré du rapprochement, c'est-à-dire que pour une distance deux fois moindre, elle est quatre fois plus forte, que pour une distance trois fois moindre, elle est neuf fois plus forte, et ainsi de suite. D'autre part, le globe terrestre, au lieu d'être solidifié et d'avoir sa surface partagée en continents et en océans, était entièrement fluide : les marées agissaient donc entièrement sur lui et faisaient constamment tourner un bourrelet autour de lui. Actuellement, nos insignifiantes marées, en faisant le tour du globe en sens contraire du mouvement de rotation de la Terre, agissent comme un frein qui retarde ce mouvement et augmente la durée du jour de 22 secondes par siècle. Alors, les gigantesques marées primitives, qui inondaient tout le globe deux fois par jour sur leur passage, agissaient avec une énergie incomparablement plus puissante pour ralentir ce mouvement, lequel, de trois heures, arriva à quatre, à cinq, à douze, et finalement à vingt-quatre. Le retardement du mouvement de la Terre est accompagné de celui de la Lune, et, par cela mème, d'un éloignement graduel de notre satellite.

En même temps, les marées produites par la Terre sur la Lune étaient beaucoup plus fortes que celles produites par la Lune sur la Terre, puisque la planète est 80 fois plus pesante, plus forte que le 
satellite. Elle a fini par enrayer tout á fait le mouvement de rotation de la Lune et par l'arrêter. Maintenant la Lune tourne autour

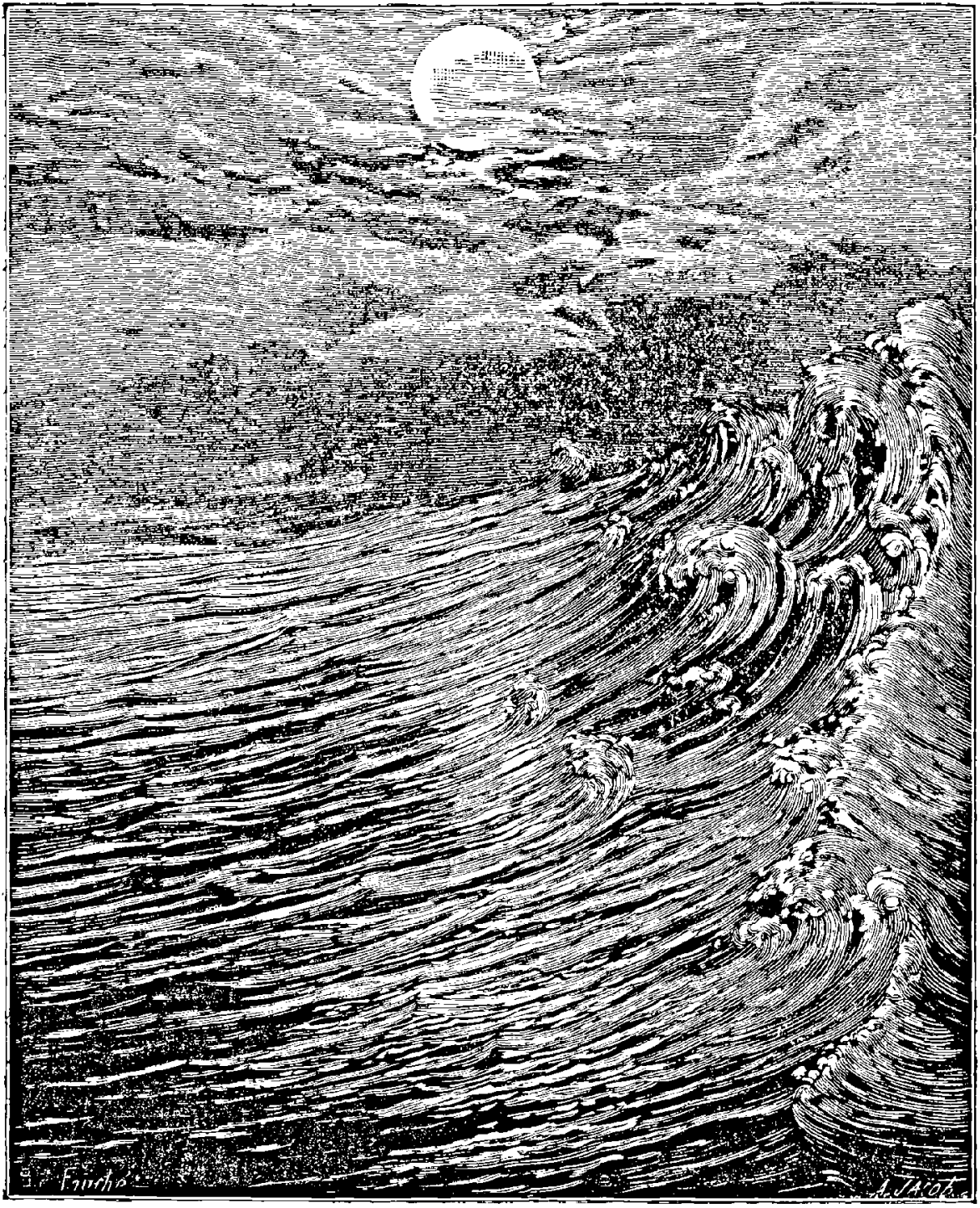

Fig. 33. - A lorigine, la Lune plus proche de la Terre encore fluide, procuisait des marées formidables.

de nous en nous présentant toujours la même face. De plus, elle n'est pas parfaitement sphérique, mais un peu allongée dans la direction de la Terre. Il n'y a plus de marées sur la Lune; et lors 
mème que le globe lunaire serait couvert d'eau, il n'y en aurait pas davantage puisque, relativement à la Terre, la Lune est arrêtée sur son axe.

Ainsi, depuis sa naissance, la Lune a été en s'éloignant lentement de la Terre et en tournant de moins en moins vite, et réciproquement le mouvement de rotation de la Terre a été en se ralentissant. Les marées continuent d'agir comme un frein et de le ralentir. Il est probable que le temps viendra où à son tour la Lune aura arrètè le mouvement do rotation de notre planète, l'aura rendu égal au mois lunaire, en foręant aussi notre globe à présenter toujours la même face à la Lune. Si les océans terrestres durent assez longtemps pour que les marées puissent produire ce résultat, la révolution de notre satcllite autour de nous scrait alors allongée à 58 jours, et nous I'aurions plus sur la Terre que six jours par an, chaque jour étant de 1400 heures! Le calendrier serait considérablement simplifié, nos mœurs et nos habitudes singulièrement transformées. Mais notre petit séjour ambulant est sous l'influence de tant d'autres causes cosmiques qu'il ne serait pas philosophique de n'en considérer qu'une seule.

Deux planètes semblent, dans notre système, nous donner une image de ces temps primitifs, car, tout en étant nées avant la Terre et plus anciennes qu'elles, elles ont mis beaucoup plus de temps à se condenser et sont relativement plus jeunes qu'elle aujourd'hui. Nous voulons parler des deux mondes les plus volumineux du groupe solaire, de Jupiter et Saturne. Les lunes de Saturne sont encore tout proches de leur planète génératrice et leur naissance n'est certainement pas ancienne. Il y a plus. Les anneaux qui circulent autour du globe de Saturne sont composés de petits corps réunis dans un tourbillon, et ces particules constitutives, qui tournent rapidement autour de la planète, sont agrégées en zones plus denses le long de certaines lignes, disséminées, éparses, raréfiées, en d'autres points. On remarque même une zone absolument vide, qui sépare les anneaux en deux parties distinctes, et oủ ces particules sont absentes. On peut penser que ces anneaux si étranges sont les embryons de deux satellites futurs, ce qui porterail a dix le nombre des compagnons de Saturne. On peut penser aussi que la Lune, ainsi que les satellites des autres planètes, ont 
été formés suivant un procédé analogue, par une zone équatoriale détachée de la planète et graduellement rassemblée en globe en vertu de l'attraction mème de ses particules constitutives.

La durée de la période de formation des planètes a dépendu pour chacune d'elles de la quantité de matière qui les a composées, et la période de refroidissement a dépendu de l'élévation de la température du globe primitif, de son volume et de sa surface, ce à quoi il faudrait encore ajouter la différence de nature minérale des terrains formés, et celle des atmosphères, dont l'enveloppe protectrice est plus ou moins efficace, suivant sa transparence pour la chaleur. C'est par la surface extérieure qu'un globe céleste se refroidit. Ainsi, le volume de la Terre est 49 fois plus grand que celui de la Lune; mais la surface de notre planète n'est que treize fois plus grande. La Lune a donc, de ce chef, une faculté de refroidissement presque quatre fois plus rapide que celle de la Terre, et, en effet, elle s'est refroidie plus vite que nous.

D'après l'ensemble des causes qui ont présidé à la formation de la Terre, notre planète a dù passer par une température excessive, du mème ordre que celle du Soleil; puis, les principes de combustion épuisés, elle a commencé à se refroidir tout en se condensant encore, de gazeuse elle est devenue liquide, et l'époque arriva où la surface se figeant commença à se solidifier. Notre globe se refroidit ainsi de siècle en siècle, le refroidissement s'opérant naturellement de l'extérieur à l'intérieur.

Le refroidissement est-il complet aujourd'hui ? Depuis les millions d'années qu'il s'opère, est-il arrivé à son dernier degré? Une chaleur intérieure existe-t-elle encore dans le sein de notre planète? A-t-elle une action quelconque sur la vie qui rayonne à la surface du globe? En se mouvant depuis tant de siècles dans un espace plus que glacé, dans un espace dont la température normale paraît ètre de $270^{\circ}$ au-dessous de zéro, la Terre n'a-t-elle pas aujourd'hui son cœur glacé ? Quelle est actuellement la température intéricure du globe terrestre? C'est là une question du plus haut intérêt, que nous étudierons dans tous ses détails, et à laquelle nous consacrerons un chapitre spécial, exposant tous les documents acquis par la science sur la constitution intérieure de notre planète; sur les températures observées dans les mines, tunnels, sources thermales, 
volcans, etc. Mais l'histoire de la Terre se déroule en ce moment devant nos yeux, et nous entrons dans l'une des phases décisives de sa destinée.

Tont le monde 'sait que les trois états des corps, l'état solide, l'état liquide et l'état gazeux' sont uniquement cáusés par de simples différences de température. Voici, par exemple, un bloc de glace. Que sa température soit portée au degré de la glace fondante $\left(0^{\circ} \mathrm{du}\right.$ thermomètre centigrade), et 'ce bloc va cesser d'ètre solide pour devenir liquide et couler en eau : ce sont simplement ses molécules qui s'éloignent mutuellement' les unes des autres, cessent d'être agrégées et subissent l'action de la pesanteur. Échauffons maintenant cette, eau au degré de l'ébullition $\left(100^{\circ}\right.$ du thermomètre centigrade) et elle se transformera en vapeur. Dans les trois cas, ce corps n'est pas chimiquement changé; c'est toujours de l'eau; mais l'aspect physique est bien différent : dans le premier état, c'est un minéral solide; dans le second, c'est un fluide; dans le troisième, c'est un gaz qui, rapidement, devient invisible. Prenons un morceau de fer, élevons-le à la température de $1500^{\circ}$, et il fondra comme de l'eau., Prenons un morceau de zinc, à $450^{\circ}$ il devient liquide; à $1300^{\circ}$ il devient gazeux, etc., etc.

Les diverses substances qui constituent le globe terrestre ne sont devenues liquides, puis solides, qu'aux époques où, pour chacuné d'elles, lo refroidissement a été suffisant. Les combinaisons, auxquelles sont dus tous les corps composés, n'ont pu se produire ellesmèmes que par. les abaissements consécutifs de la température primordiale. Les liquides que la chaux tenait en suspension dans l'atmosphère à l'état de vapeur commencèrent à se précipiter en pluies de diverses natures. Aucun théoricien jusqu'ici n'a suivi ces diverses précipitations de notre atmosphère, qui ont dù avoir lieu à mesure que le refroidissement forçait chacune des substances primitivement en, vapeur, de retomber en liquide sur le noyau central. Ainsi, vèrs la température de 350 degrés thermométriques, les pluies de mercure ont commencé; les pluies d'eau n'ont été possibles que quand l'atmosphère n'était plus qu'à 100 degrés. A quelle époque ont commencé les précipitations des autres substances, soit simples, soit composées? Quelles étaient au milieu de tous ces matériaux hétérogènes les réactions chimiques de ce vaste laboratoire 


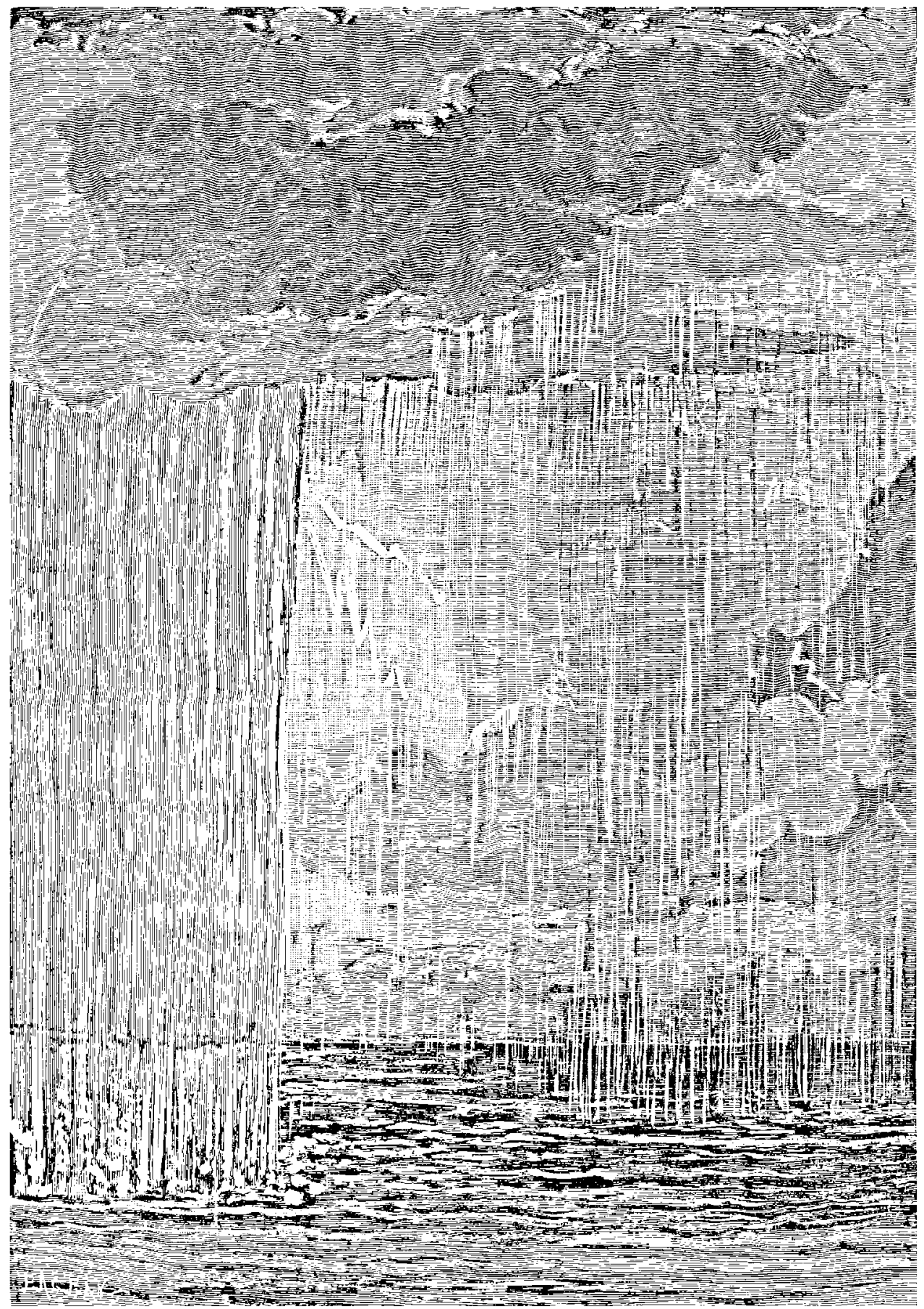

La formation de l'atmosphère. Première condensation des eaux.

LE MONDE AVANT LA GRÉation DE L'HOMME 
atmosphérique, à l'équateur, vers les pôles et dans les régions intermédiaires? Il y avait là toute la genèse d'un monde.

Peu à peu la surface du noyau terrestre se solidifia par le refroidissement, et prit une épaisseur capable de servir de fond et de bassin aux eaux et aux liquides, lesquels abandonnèrent sans retour l'atmosphère pour former les mers des divers âges. Ces dépôts fluides réagirent, ainsi que l'atmosphère elle-même, sur les malières combustibles ou salifiables de la partie solide. Par un refroidissement prolongé du noyau, et par suite de sa réduction à un plus petit volume, la croûte enveloppante portèe sur un noyau devenu trop étroit se brisa à plusieurs époques dont les périodes devinrent d'autant inoins fréquentes, que cette croùte prit plus d'épaisseur et de solidité.

Pendant ce lent refroidissement, toutes les substances gazeuses qui constituaient la planète primitive ne passèrent pas, sans exception, à l'état liquide ou à l'état solide. Il reste tout autour du globe une enveloppe gazeuse considérable, formée par un mélange de l'oxygène avec l'azote, conservés à l'état de gaz permanents. C'est l'air que nous respirons. Cette atmosphère, d'abord immense, s'étendant jusqu'à la Lune (alors, du reste, moins éloignée de nous) et chargée, non seulement des quantités prodigieuses de vapeur d'eau qui se sont plus tard condensées en océans et en mers, mais encore de toutes les vapeurs et de tous les gaz des minéraux futurs, s'est, de siècle en siècle, transformée et purifièe, et de nos jours nous avons le privilège de posséder et de respirer cet air transparent qui nous donne l'azur des cieux, la beauté des perspectives aériennes, qui tempère la lumière du jour, qui nourrit si délicatement les plantes et les ètres, et dont le voile, assez épais pour empècher le refroidissement complet des nuits et des hivers, reste encore assez léger pour nous permettre la vue des étoiles et l'étude de l'univers. Nous n'y pensons pas. Mais si l'atmosphère avait été seulement un peu différente, un rien eût suffi pour nous envelopper d'une brume perpétuelle, et cette enveloppe opaque de quelques kilomètres eùt suffi pour nous isoler du reste de l'univers et pour tenir l'humanité dans l'esclavage de l'huître assoupie au fond de la mer.

La surface du globe devait être alors d'un rouge de feu. L'atmosphère de vapeurs qui pesait sur elle était le siège d'évaporations, de 
courants ascendants, de condensations supérieures, de pluies diluviennes et d'évaporations nouvelles qui, pendant des siècles et des siècles, firent de notre monde un gigantesque lahoratoire de chimie où tous les éléments furent d'abord confondus. Les formidables dégagements d'électricité produits par ces transformation de la chaleur et du mouvement criblaient l'atmosphère et les eaux d'éclairs et de conflagrations électriques, et le voyageur céleste qui eủt pu passer non loin de ce chaos fantastique aurait été assourdi par les éclats effroyables d'un tonnerre perpétuel, se repercutant nuit et jour entre les nues déchirées et les flots agités de cette flamboyante gerièse. Peut-être à cette époque la Lune était-elle habitée; peut-ètre ses observateurs ont-ils assisté à ces combats titaniques des éléments en fureur rivalisant d'énergie pour prendre la domination d'un nouveau monde.

Mais, plus rapprochée de la Terre, la Lune produisait par son attraction puissante des marées colossales, d'autant plus étendues que nul continent n'étant encore figé, le sol liquide ou pâteux obéissait tout entier à l'influence luni-solaire. De l'ouest à l'est, tout autour du globe, marchait l'ondulation íormidable, en mème temps que la lourde atmosphère subissait elle-mème des marées plus gigantesques encore. La fournaise était agitée sans trève par la main de la nature. Ce n'était pas un monde; c'était un océan de fou, de flammes, do fumées, de vapeurs, d'orages et de tempêtes.

Cependant, en roulant dans l'espace glacé, la planète se refroidissait réellement. Le jour arriva où, vers les pôles, d'abord, là oủ les marées étaient moins violentes et venaient s'éteindre, où le mouvement diurne et la 'force centrifuge qu'il engendre étaient moins sensibles, où un calme relatif permettait en quelque sorte aux époques de la nature de se recueillir sur elles-mèmes, le jour vint où la surface de ce globe liquide et encore brùlant commença à se figer, à se solidifier. Les pôles avaient alors la mème température que l'équateur. La chaleur terrestre dominait de beaucoup celle qui pouvait être reçue du Soleil; elle était de plusieurs centaines de degrés, et elle était la mème pour toutes les régions du globe. 11 n'y avait alors ni climats, ni saisons, quoique la situation de la Terre 
relativement au Soleil et son inclinaison fussent peu différentes de ce qu'elles sont de nos jours. Mais la fournaise bouillonnait dans sa propre chaleur.

Les premières solidifications qui arrivèrent dans les régions polaires purent ètre de quelque duree. Mais celles qui se formèrent dans les autres régions du globe, et surtout dans les zones tropicales et équatoriales, furent pendant longtemps soulevées et brisées par les marées. Elles formèrent des scories flottant sur l'océan de feu, tour à tour rongées, fondues et reformées. La surface, néanmoins, devenait visqueuse jusqu'à une cortaine profondeur; elle n'était plus liquide comme l'eau, mais prenait de la consistance, ressemblant à celle de la poix ou du fer que l'on retire de la fournaise pour le travailler. Avec les siècles, les scories flottantes se multiplièrent, se soudèrent, s'étendirent, et enfin le premier sol fut formé.

Mais pas pour longtemps. A peine formé, les réactions de la fournaise intérieure contre ce premier obstacle aux dégagements des vapeurs et des gaz le brisèrent de crevasses, le criblèrent de bulles et de volcans, tandis que les marées intérieures l'ondulaient, le soulevaient et le brisaient encore. Comment cette première croùte eít-elle pu résister anx vagues de cet océan de feu?.Qui pourrait imaginer les déchirements effroyables, les débordements, les convulsions de ces premières années? Pandémonium en feu, sur lequel de gigantesques titans se combattaient dans le délire d'une atmosphère incandescente.

Les flots liquides qui se faisaient jour à travers les premières fractures de l'écorce primitive et qui vinrent se figer au dehors et se solidifier étaient des flots de granit. Ce sont là les premières montagnes.

Lorsque le reiroidissement devint suffisant pour permettre l'existence de l'eau à l'état liquide, les vapeurs commencèrent à se résoudre, et les premières gouttes d'eau tombèrent. Mais dans cette température voisine de 100 degrés (et même supérieure à cause de la pression atmosphérique plus puissante), à peine tombées, ces pluies s'évaporaient de nouveau. C'étaient de véritables pluies d'eau bouillante. Il y eut là une longue période de pluies. L'évaporation ramenait vite l'eau, à l'état de vapeur, dans les hauteurs de l'atmo- 
sphère, régions refroidies par leur rayonnement vers l'espace glacé, et là elles se condensaient de nouveau en nuages pour retomber on pluies et continuer ce même cycle perpétuel. Ce combat de l'eau et du feu dura des siècles et des sièeles, an milieu des formidables dégagements d'électricité, des orages, des éclairs et des tonnerres. Il hâta le refroidissement de la surface. Le jour vint où, la majeure partie des vapeurs étant condensées, une couche d'eau de plusieurs kilomètres d'épaisseur s'étendit sur la surface entière du globe.

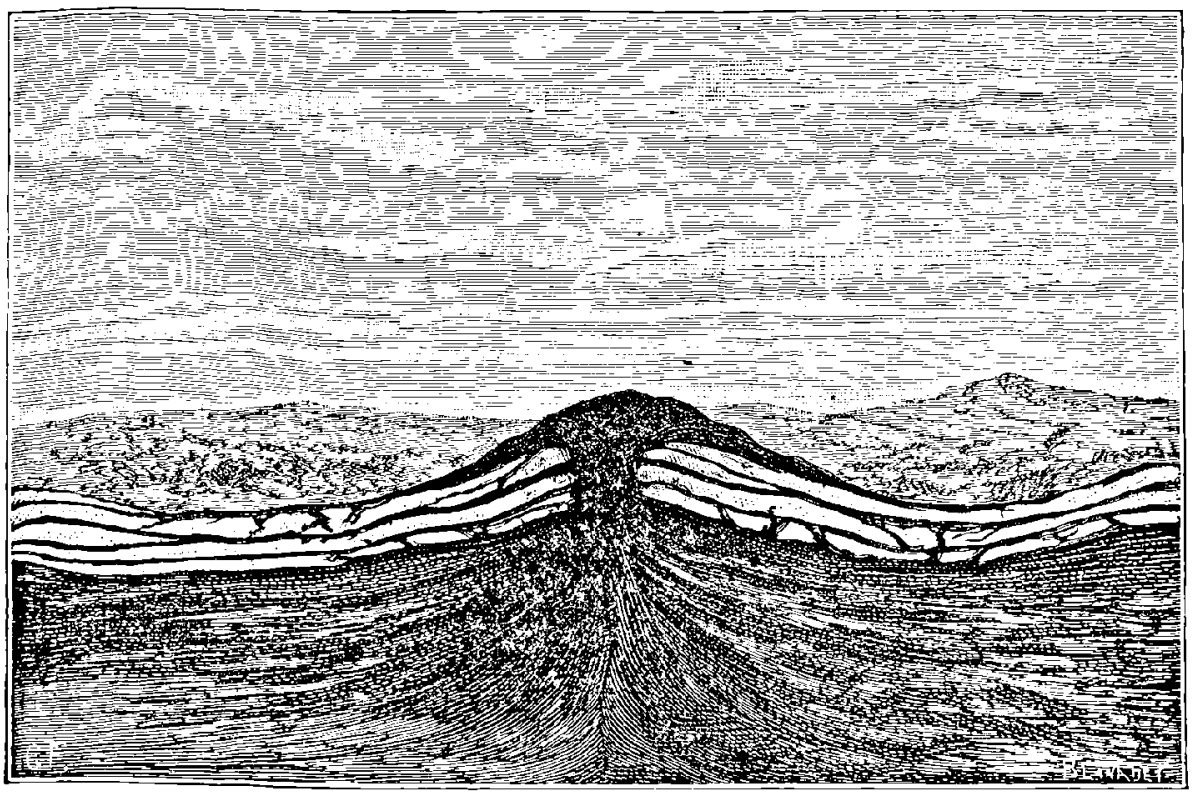

Fig. 3ü. - Les premiers soulèvements de la croưte terrestre : le granit.

La première écorce solidifiée du globe, celle qui forma le sol de la première mer universelle, et qui, par ses soulèvements, donna naissance aux premières îles et aux premières montagnes, était composée de granit. Ce minèral doit son nom à son aspect (ce nom vient de l'italien grano, grain) à raison de sa structure granulée. Il est composé de feldspath, de quartz et de mica. L'eau, froide ou chaude, et l'acide carbonique de l'air, décomposent facilement le feldspath, qui est un silicate à base d'alumine, de potasse et de soude. L'action chimique et mécanique des eaux agitées des mers primitives désagrégea ces silicates, et le fond des mers se couvrit de 
sable, de vase, de débris, étendus en bancs, en couches d'abord horizontales. Le granit et le gneiss, ces roches primitives, subirent là une première modification.

L'action de la chaleur est visible sur ces premières couches. Les argiles ainsi déposées prirent sous l'actiou de la chalcur une structure feuillée ou schisteuse, c'est-à-dire formées de feuillets faciles à séparer, comme dans les ardoises. Ces schistes, premiers sédiments connus, reposent immédiatement sur les terrains d'origine ignée. Durant cette première phase de son existence, notre planète était partout recouverte d'une couche d'eau tiede et vaseuse, au fond de laquelle se déposaient ces produits de la désagrégation du granit. Les premiers soulèvements faisaient émerger du niveau des eaux, comme des îles solitaires, les cimes des boursouflures de granit, qui à leur tour étaient rongées par les pluies, les vents et les orages.

Ce terrain primitif, que l'on trouve à la base de toutes les couches géologiques, montre généralement quatre bancs superposés : tout en bas le granit; au-dessus, le gneiss, qui n'est, du reste, qu'une variété du granit, dans laquelle le mica prédomine; ensuite le micaschiste, qui est déjà une couche schisteuse; enfin l'étage des schistes en général. Dans ces conches, on n'a jamais rencontrè aucun fossile, pas la moindre coquille, pas la moindre plante. La vie n'était pas encore apparue à la surface de la Terre.

Par les fissures, les crevasses, les déchirures produites en cet âge primordial, sous l'influence de la chaleur intérieure, des métaux fondus dans l'ardente fournaise se sont projetés en filons plus ou moins épais. On y trouvo du fer, de l'or, de l'argent, du cuivre, de l'ètain, des pierres précieuses telles que le grenat et le rubis. Il est probable qu'au-dessous du granit existent dans l'intérieur du globe d'immenses quantités de fer et de métaux très denses.

Les schistes inférieurs, qui reposent immédiatement sur le granit, sont bleus, et ceux qui vinrent plus tard se déposer sur les premiers sont verts (ardoises). Tout le monde a remarqué, soit dans les tranchées de chemins de fer, soit dans les pays de montagnes, les bancs de roches inclinés qui restent pour notre âge moderne l'indice des soulèvements de l'écorce terrestre arrivés en ces temps primitifs. Les couches dont nous venons de parler ont èté naturellement déposées horizontalement au fond des eaux. Lorsqu'on les 
rencontre inclinées, c'est qu'elles ont été soulevées par les forces souterraines ou bien que, des vides s'étant formés dans l'intérieur du globe par son refroidissement et sa contraction, elles sont tombées par leur propre poids. Les deux causes, du reste, ont agi. Or toutes les fois qu'en traversant une série de couches inclinées on peut arriver jusqu'au granit, on est aussi certain de trouver la surface de cette dernière roche bombẻe ou inclinée elle-même dans le mème sens, qu'on le serait en entrant dans une pièce dont tous les meubles seraient penchés, de trouver le plancher incliné dans le mème sens. Il y a mieux : les couches que l'on observe sur le granit d'une montagne indiquent l'époque de son soulèvement. $\mathrm{Si}$, par exemple, on ne retrouve que les schistes bleus sans les ardoises vertes, c'est un témoignage que le soulèvement du granit a eu lieu immédiatement après la formation du premier dépôt et avant le second. Si les bancs d'ardoises se retrouvent au-dessus des schistes bleus, c'est que le soulèvement a eu lieu plus tard. Et ainsi de suite. L'examen des Alpes et des Pyrénées prouve que ces montagnes ont subi plusieurs mouvements d'ascension et de descente. Quelquefois ce ne sont point les couches précédentes qui reposent en contact avec le granit, mais des dépôts sédimentaires beaucoup moins anciens. L'explication n'en est pas difficile. Qu'une ile de granit se soit élevéc au-dessus de la mer primitive avant la formation des couches schisteuses dont nous venons de parler, et qu'elle se soit ensuite abaissée au fond des flots (ces alternatives de mouvements ne sont pas rares dans l'archipel gree et en Italie): dans ce cas, l'île granitique se recouvrira seulement des dépôts des àges moins anciens.

On retrouve en Bretagne, dans le Finistère et la Vendée, les schistes bleus dont nous parlions tout à l'heure : ce sont là les plus anciens terrains de l'Europe, et probablement du monde entier. On en retrouve aussi en Angleterre, dans le Cumberland. Les ardoises vertes manquent en Bretagne et se rencontrent dans le comté de Galles et dans l'Amérique du Nord. On trouve les gneiss et les micaschistes dans le Lyonnais, le Limousin, la Lozère, les Cévennes, l'Auvergne, la Bretagne, la Vendée. Maigres pour l'agriculture, mais féconds pour le mineur, ces terrains sont riches en métaux. 
La période dont nous venons d'esquisser à grands traits l'histoire, a employé des millions d'années à s'accomplir.

Éloquentes et précieuses sont les archives de la Terre. Les clairvoyantes investigations des géologues ont découvert jusqu’a des empreintes fossiles de gouttes de pluie, comme on le voit sur notre figure 36. Ces gouttes étaient tombées sur du sable qui s'est pètrifié en grès. Autre témoignage non moins curieux : en exploitant a Chalindrey (Haute-Marne) une carrière de grès infraliasique, on a trouvé des bancs qui conservent sur une large sur-

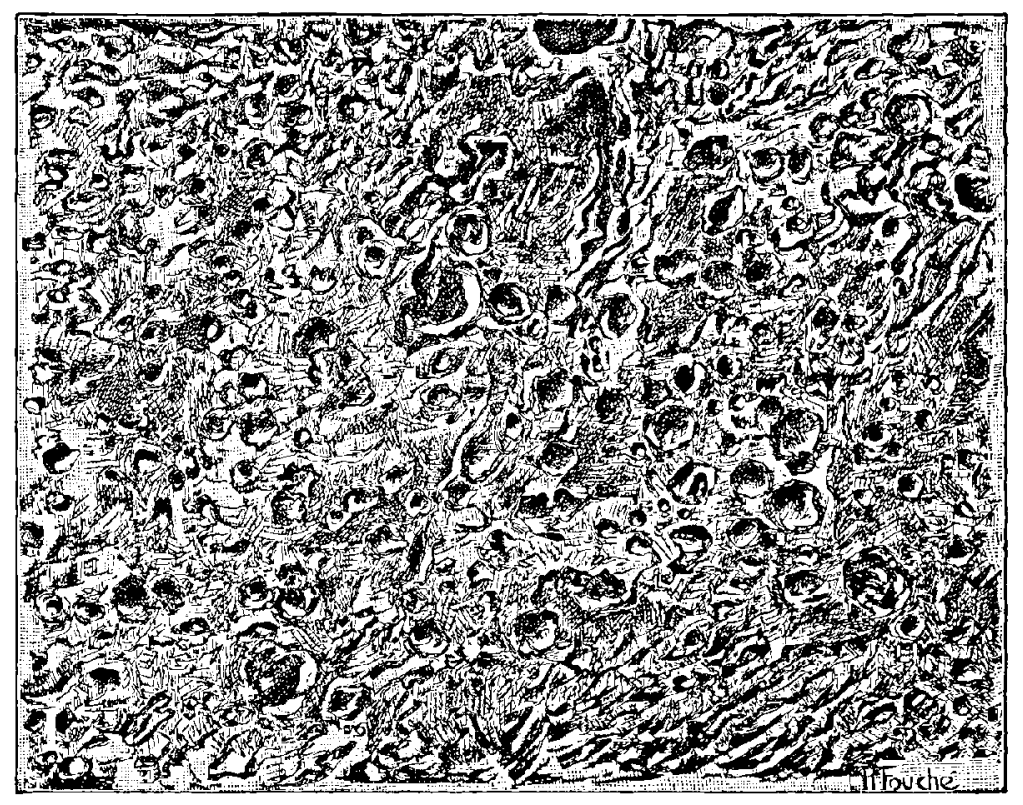

Flg. 36. - Empreintes fossiles de gouttes de pluie tombées il y a des millions d'années.

face les traces de l'ondulation des eaux ( $f g .39)$. Des pétrifications du même genre ont été trouvées près de Boulogne-sur-Mer.

Pendant la longue durée des siècles de l'époque primaire, nous sommes sur une planète intéressante aux points de vue astronomique et géologique, mais sur une planète sans vie. Pas un animal, pas une plante I Rien qu'un désert. Eau ou rochers. Pas une mousse sur ces rochers. Pas un mollusque dans ces eaux. Ce n'est mème pas la mort, puisque la vie n'y a jamais existé. Est-ce bien la Terre? En vain chercherait-on à reconnaitre la configura- 


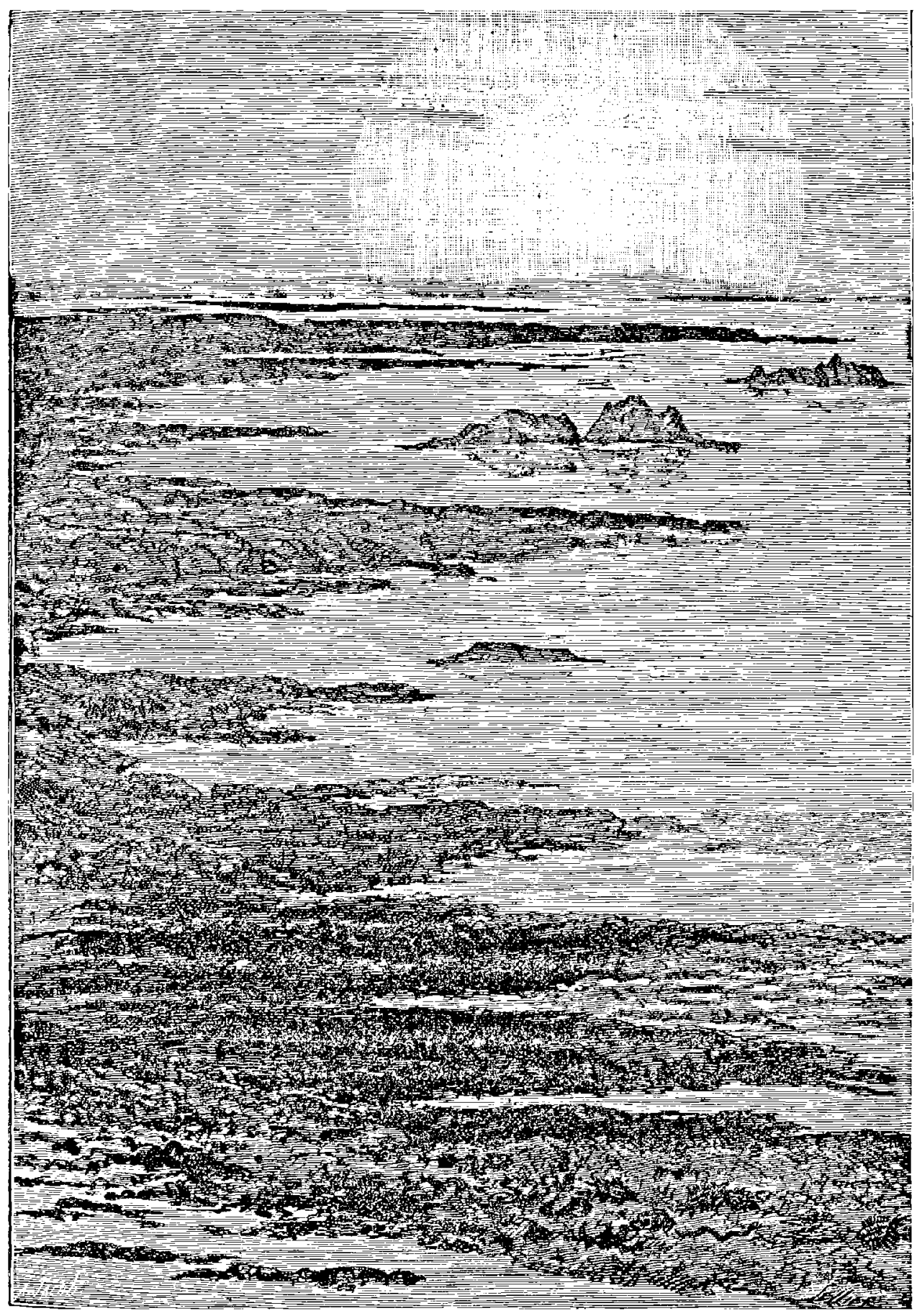

Les premières fles, arides et nues, sortirent des eaux....

LE MONDE AVANT LA GRÉATION DE L'HOMHE 
tion gẻographique qui la caractérise. Ni Europe, ni Asie, ni Afrique, ni Amérique. Seulement la mer, partout la mer, avec quelques iles de granit. Une immense marée fait deux fois par jour le tour du

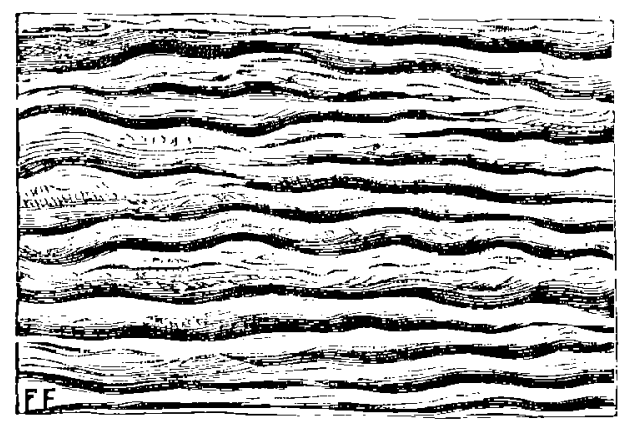

Fig- 38. - Ondulations laissées par les eaux et pétrifiées.

globe. Presque partout, presque toujours, le ciel est couvert. La pluie tombe, le tonnerre gronde, les éclairs sillonnent les nues, le vent souffle et la tempête agite les flots. Mais les éléments de la vie se préparent. Aux heures de calme, dans le fond des eaux tièdes, un clairvoyant prophète pourrait découvrir quelques traces d'une gelée féconde qui n'est déjà plus absolument inanimée. 


\section{LIVRE II}

\section{L'AGE PRIUORDIAL}

IRIS - LILLIAD - Université Lille 1 
IRIS - LILLIAD - Université Lille 1 


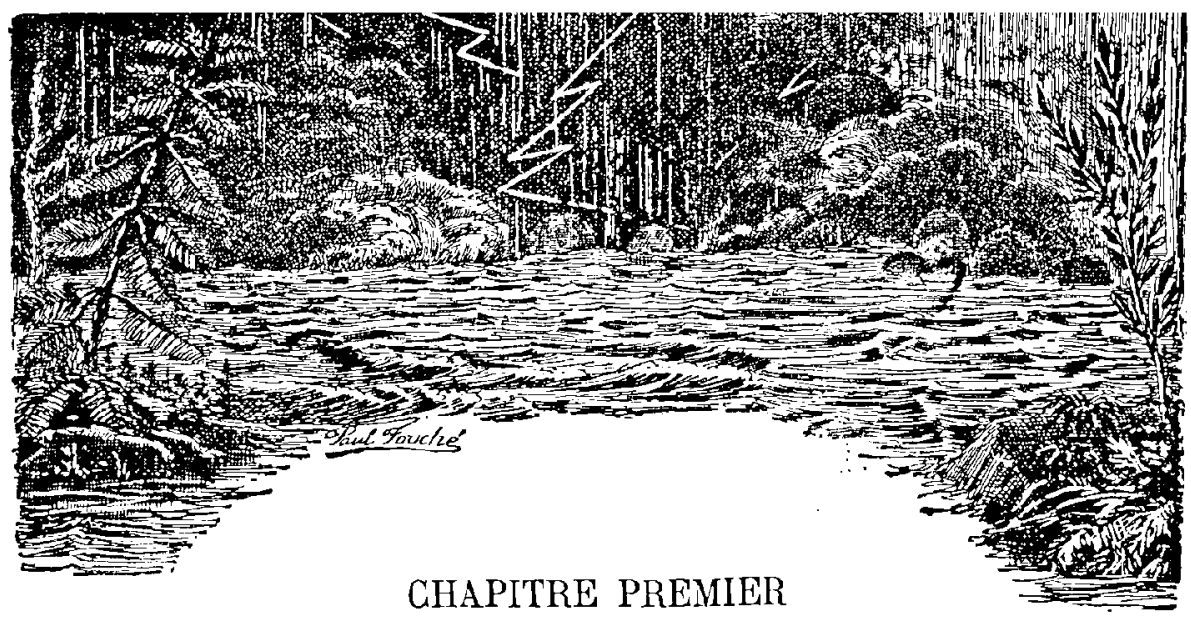

LES ORIGINES DE LA VIE

Parenté et filiation des êtres. Arbre généalogique de la vie terrestre.

Transformation séculaire des espèces.

Au sein des solitudes infinies, la nature semble se recueillir dans l'cxorde du grand mystère de la création de la vie. Il n'y a pas encore un scul être vivant à la surface de la Terre : ni hommes, ni animaux, ni plantes. L'eau, l'eau partout, l'eau toujours. Dans son sein va germer la vie. Au-dessous de la mer universelle, les minéraux se sont solidifiés en une mince couche, incessamment soulevée et abaissée par les marées, mobile, élastique, d'épaisseur variée, qui déjả s'est crevassée, ressoudée, brisée, reformée, et a livré passage aux premières éruptions de granit, aux premières îles. C'est eneore un radeau flottant sur le globe en fusion. Mais de siècle en siècle il prend plus de consistance. Le refroidissement accroit son épaisseur. Les îles primitives subissent de leur côté l'influence des agents atmosphériques, des vents, des pluies, des alternatives de soleil et de nuit, et, en se désagrégeant lentement, vont répandre au fond des mers les premiers dépôts sédimentaires. La température est encore fort élevéề G'est à peine si l'on pourrait percevoir une différence entre l'hiver et l'été, entre minuit et midi. Cette température terrestre est encore aussi élevée que celle que la planète reçoit du Soleil, mais elle ne la surpasse plus. Les saisons vont commencer, ainsi que les alternatives de la nuit et du jour. Le Soleil reste, pen- 
dant les plus beaux jours, encore voilé par l'atmosphère constamment chargée de vapeurs, de nuages et de pluies; lui-mème n'est pas encore parvenu à la période astrale qui lui donnera le disque lumineux, net et défini, sous lequel nous le connaissons à notre époque : il est encore enveloppé d'une atmosphère nébuleuse absorbant une partie de son rayonnement, et surtout il est immense, occupant peut-être encore tout l'orbe de la planète Vénus, deux cents fois plus large en diamètre que nous ne le voyons aujourd'hui, vague et peu lumineux. Mais insensiblement, de siècle en siècle, il se formera lui-méme et marchera vers la gloire de l'avenir, inau. gurant son rôle d'astre illuminateur, de foyer des demeures planétaires, de soutien du système du monde. L'atmosphère terrestre se purifiera, et, un jour, dans un avenir encore lointain, l'azur du ciel apparaîtra dans les éclaircies de l'orage apaisé.

G'était bien là, en effet, un monde tout différent de celui que nous habitons aujourd'hui. Aucun regard n'était ouvert pour le contempler; aucun être n'était né pour le sentir. Les lles émergées des flots, les premières montagnes, étaient arides et nues : pas un arbre, pas un buisson, pas un brin d'herbe, pas uno mousse. Les roches grises régnaient, solitaires, au-dessus des eaux, reflétant les nuances des rayons ou des ombres qui glissaient aux diverses heures du jour suivant les éclaircies du ciel, recevant les pluies diluviennes et les coups de foudre, illuminées pendant la nuit par de sinistres éclairs qui frappaient pour ne rien tuer, tandis que la Lune, immense et sans phases, brillant de sa propre lumière, encore incandescente elle-mème, répandait sur les flots les lueurs fauves de son lointain incendie.

Qu'est-ce que la vie? Comment les innombrables espèces animales et végétales sont-elles apparues à la surface de ce monde? Depuis combien de temps existent-elles? Chacune d'elles a-t-elle été l'objet de la création directe du Pouvoir suprême? ou bien sontelles parentes et dérivent-elles de quelques souches originaires? Jusqu'à notre époque, la science classique, a généralement enseigní que les espèces sont différentes les unes des autres et invariables, et que la Nature a eu en vue dans son œuvre, non la durée des indi. vidus, mais celle des espèces. On s'est accordè à adopter la classification suivante pour le règne animal. 
CLASSIFICATION DU RÈGNE ANIMAL ,

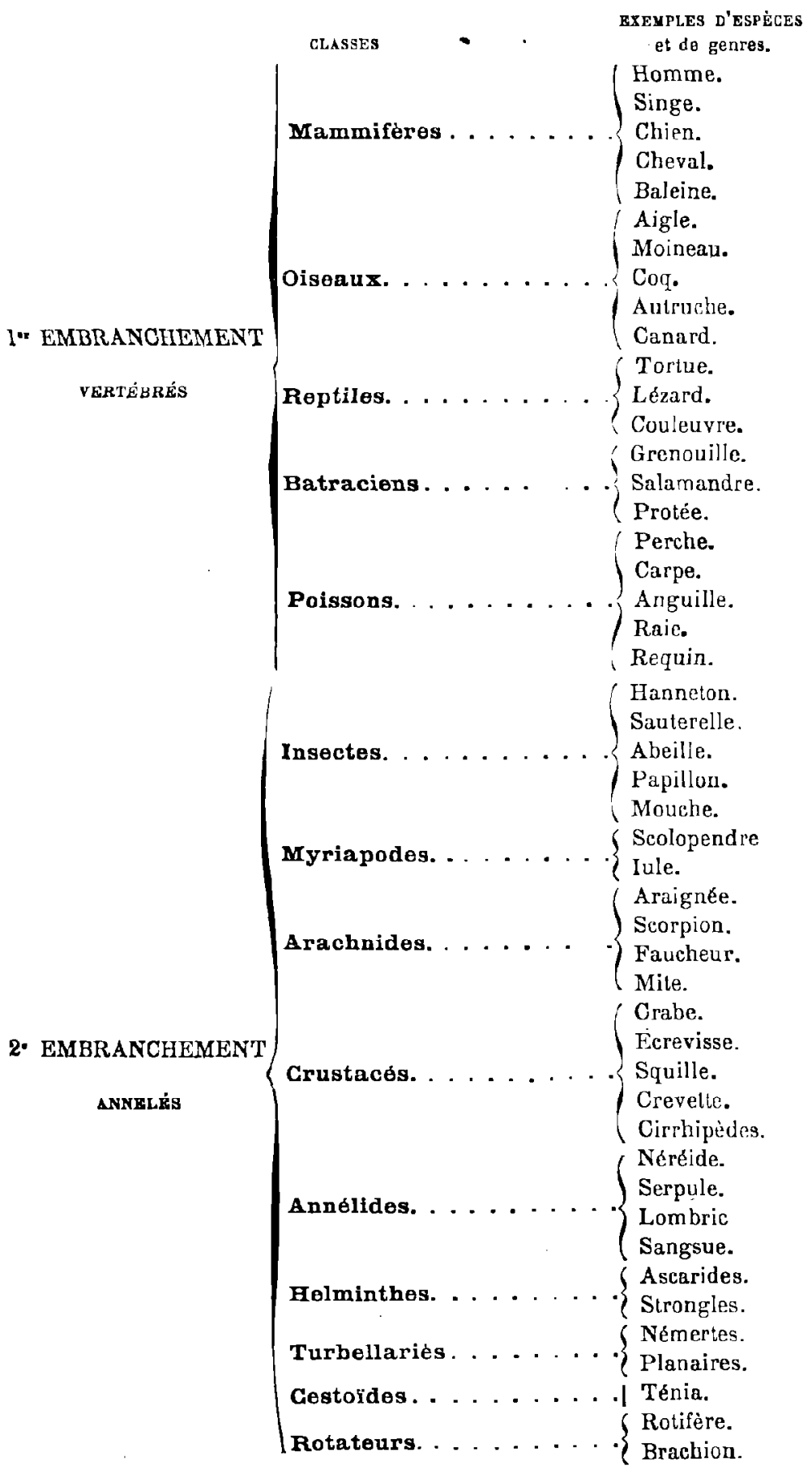




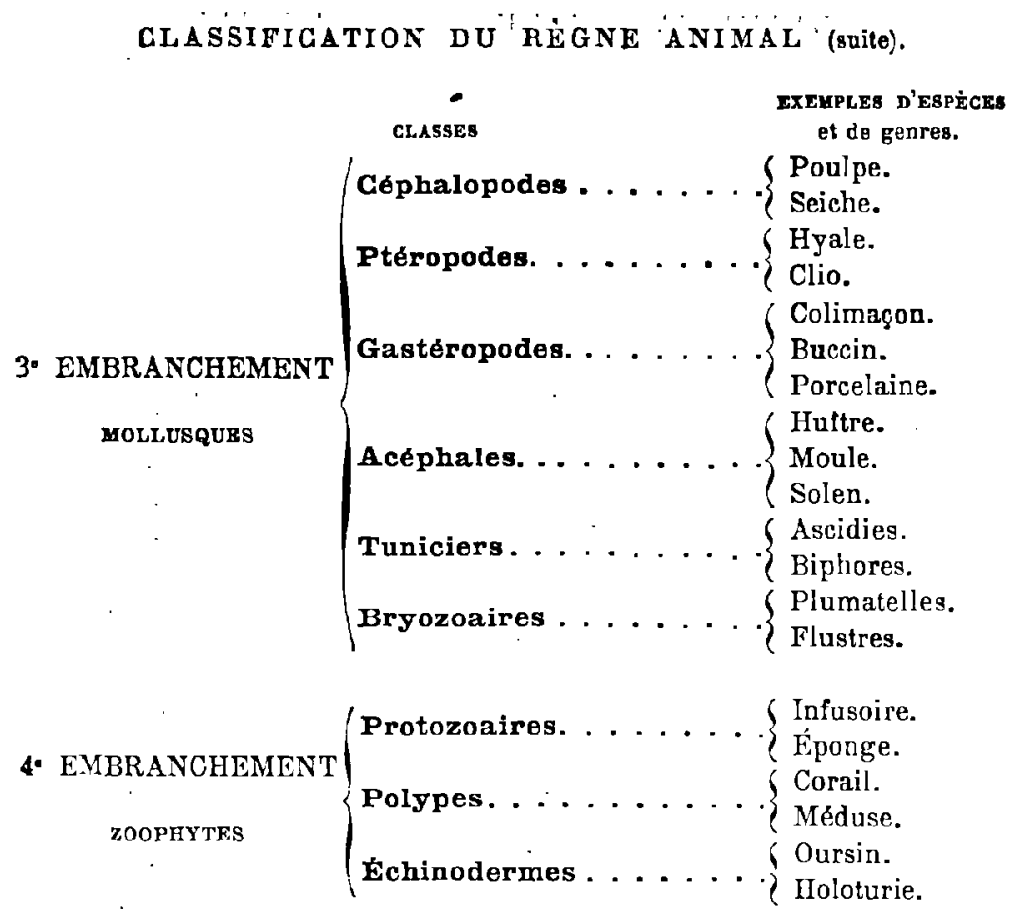

Pour Buffon, Lacépède, Guvier, Agassiz, Flourens et tous les professeurs classiques d'histoire naturelle, le tableau précédent représente des espèces réelles et invariables et une classification réelle dans la nature. C'est là une erreur capitale. Non seulement, pour la nature, l'espèce n'est pas d'une importance essentielle dans l'organisation vitale de la planète, mais encore on peut dire qu'en réalité l'espèce n'existe pas, ce qui est la contre-partie de tout ce qu'on enseignait dans les écoles. Dans la nature, il n'y a que des individus; ces individus se modifient suivant les conditions d'existence auxquelles ils sont soumis; ces modifications se continuent de générations en générations et se transmettent par voie d'hérédité. Le règne animal forme une seule unité. Le règne végétal forme une autre unité. Ces deux règnes tiennent l'un à l'autre par leurs racines originaires. Telle est la grande vérité entrevue il y a deux mille ans par Aristote, incomprise et combattue pendant bien des siècles, posée scientifiquement par Lamarck, naturaliste français trop méconnu, en 1801 et surtout en 1809 dans sa Philosophie zoologique, prouvèe par Geoffroy-Saint-Hilaire en 1830 et surabondamment 


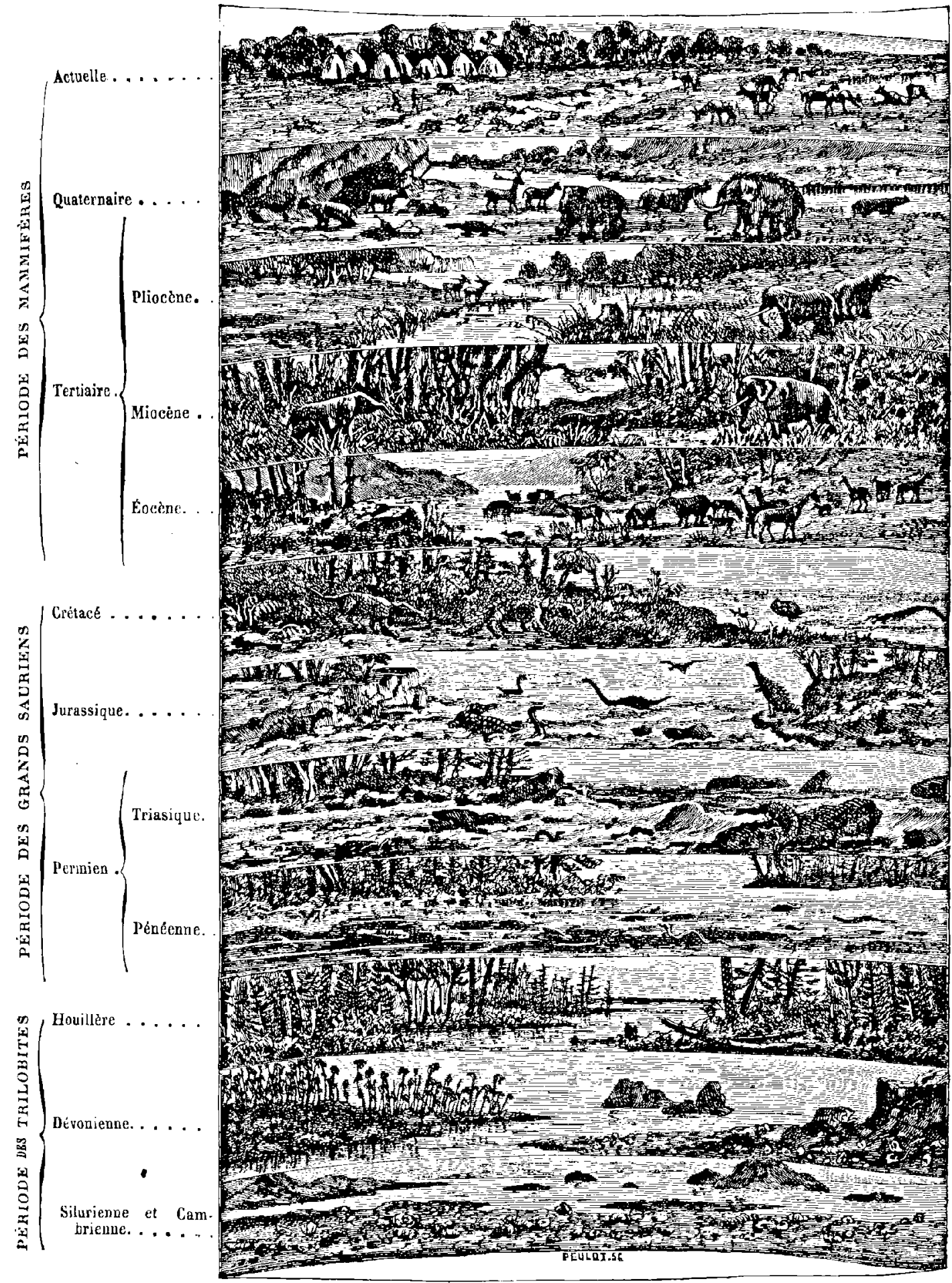

DÉvelopPEMENTS PhOGRESSIFS DE LA FLURE ET DE LA FAUNE ACX AGES SUCCESSIFS DE IA TERRE

LE MONDE AVANT LA CRÉATION DE L'HOMME 
démontrée en 1859 par Darwin, Wallace, et depuis par leurs successeurs.

Nos classifications sont utiles pour nos études; mais elles sont purement apparentes, artificielles, et n'existent pas dans la nature. Tout change constamment, mais lentement. Nos classifications ne nous paraissent invariables que parce que nous ne connaissons qu'un instant dans l'immense durée des siècles. « Si la durée de la vie humaine, écrivait Lamarck, ne s'étendait qu'à la durée d'une seconde, et s'il existait une de nos pendules actuelles, montée et cn mouvement, chaque individu de notre espèce, qui considérerait les aiguilles, ne les verrait jamais changer de place dans le cours de sa vie. Les olsservations de trente générations n'apprendraient rien de bien évident sur le déplacement de ces aiguilles, car le mouvement n'étant pas celui qui s'opère pendant une demi-minute serait trop peu de chose pour être bien saisi; et si des observations beaucoup plus anciennes apprenaient que cette même aiguille a réellement changé de place, ceux auxquels on l'affirmerait n'y croiraient pas et supposeraient quelque erreur, chacun ayant toujours vu ces aiguilles aux memes points du cadran 2 .

Sans doute, lorsque nous regardons d'un œil superficiel les êtres vivants, si dissemblables, qui peuplent notre planète, il semble qu'ils soient complètement étrangers les uns aux autres ainsi qu'à nous-mèmes. Lorsque nous examinons les fossiles, tous ces êtres qui ont précédé l'homme et qui sortent aujourd'hui de leurs tombeaux, ne semblent-ils pas des monstres? Pourtant ils sont rattachés à nous par des liens originels qui, de jour en jour, se font mieux apprécier.

Il est intéressant de nous rendre compte tout d'abord du fait des variations apportées dans la forme et la structure des ètres par leur manière de vivre et l'influence des milieux au scin desquels ils sont oblirés de vivre. Nous allons examiner successivement l'influence dos divers changements du milieu ambiant qui modifient l'organisition des végétaux et des animaux, savoir l'ean, l'air, la lumière et la chaleur, en prenant pour guide l'exposé magistral fait par le professeur Charles Martins dans son Introduction à l'édition moderne de la Philosophie zoologique de Lamarck. 
$1^{0}$ Infiufavae ne l'eau. - L'action de l'eau sur les végétaux est des plus ćvidentes. Lamarck cite la renoncule aquatique. Cette plante est, en effet, singulièrement modifiée par son séjour dans l'eau : 'les feuilles submergées sont finement découpées et comme capillaires; celles qui s'élèvent au-dessus de la surface liquide sont arrondies et simplement lobées; suivant que les feuilles ont séjourné plus ou moins dans l'eau, suivant que celle-ci est courante ou stagnante, elles présentent toutes les transitions imaginables entre ces deux extrèmes, et les botanistes en ont fait des espèces et des variétés sans nombre. Les feuilles submergées de la châtaigne d'eau sont également capillaires, les feuilles aériennes no le sont pas. Dans ces renoncules, r'action de l'eau amène la disparition partielle du parenchyme de la feuille. I e dernier terme de celte modification se voit sur une naïadée de Madagascar, l'ouvirandra fenestralis: dans celte plante aquatique, la fcuille immergée se réduit à une fine dentelle à mailles quadrilatères formées par des nervures longitudinales et des cloisons transversales.

La sagittaire doit son nom à ses feuilles aéricnnes, qui ont exactement la forme d'un fer de flèche, mais, lorsqu'elles sont plongées dans une eau courante, clles forment de longs rubans ondulants suivant le fil de l'eau. Le plantain d'eau offre la même modification: dans les eaux courantes, ses feuilles ovalaires deviennent rubanaires et flottantes. Le jonc lacustre n'a point de feuilles, il n'a que des gaines rougcâtres terminées par un petit limbe : quand la plante est dans une cau peu profonde, celles-ci avortent complètement; mais dans une rivière ce limbe se développe, s'allonge et atteint quelquefois une longrueur de un à deux mètres. Ce sont là autant de preuves de variation.

Les feuilles floltantes du nénuplarar jaune sont étalées à la surface de l'eau; ce sont des disques arrondis, mais les feuilleš submergées sont presque transparentes et bosselées comme celles du chou pommé. Ces deux modifications morphologiques, la forme rubanaire et la forme bosselée, deviennent constantes et permanentes dans les plantes marines : la première dans les laminaires, les zostères, les cymodocées, la seconde dans les ulvacées.

Un autre effet de l'eau, c'est de favoriser la formation de lacunes, qui renferment de l'air. Ainsi les rameaux de l'utriculaire portent de petites vessies aériennes appelées ascidies. Dans l'aldrovandia vesiculosa, ce sont les feuilles elles-mèmes; dans certains fucus, ce sont les frondes qui deviennent vésiculeuses. Le pétiole des feuilles aériennes du trapa natans, du pontederia-crassipes, se remplit également d'air. De même, les tiges d'un grand nombre de plantes aquatiques, les nymphoa, les nelumbium, les jussiæa, l'aponogeton dystachion, les pilulaires, les joncs, sont creusées de grandes lacunes aériennes cloisonnées. L'eau a même le pouvoir de transformer certains organes et de les adapter à des 
fonctions complètement différentes de celles qu'ils remplissaient originairement. La jussiæa repens est une plante aquatique produisant de longs rameaux ou stolons, maintenus à la surface de l'eau par des corps cylindriçues, spongieux, d'un blanc rosé, qui jouent le rôle de ces vessies gonflées d'air qu'on fixe sous les aisselles d'un nageur inexpérimenté; ces stolons se garnissent de fleurs s'épanouissant au-dessus de l'eau. Les corps qui souticnnent ces rameaux fleuris sont des racines transformées par l'action de l'eau. La tige même devient quelquefois spongieuse et se remplit d'air. Dans l'eau, les feuilles de la mème plante sont lisses, obovales, et acquièrent une longueur de dix centimètres de long et deux de large, tandis que, sur un terrain sec ou desséché, elles sont étroites, aiguës, longues d'un centimetre au plus et couvertes de poils. Ces deux formes d'une même plante ont été considérées comme deux espéces distinctes. Ainsi l'eau imprime à l'organisme végétal des modifications profondes qui se traduisent non seulement dans les formes extérieures, mais même dans la structure anatomique.

L’influence de l'eau sur la forme et l'organisation des animaux n'est pas moins remarquable; on reconnaît surtout par l'étude des batraciens que les branchies, appareils respiratoires des animaux aquatiques, sont dues à l'influence d'un milieu liquide. Chez certains d'entre eux, les branchies sont temporaires : ainsi les tètards de la grenouille et du crapaud respirent par des branchies, mais à mesurc que les pattes poussent et que la queue scrvant de nageoire se résorbe, les poumons se développent et les branchies s'atrophient : l'animal, d'aquatique guiil ciait, devient amphibie. Les tritons vivant dans l'eau pendant la première période de leur vie respirent par des branchies, plus tard ils se tiennent habituellement sur le bord des mares: les branchies disparaissent, des poumons les remplacent; cependant, si l'on force ces animaux à rester dans l'eau, la métamorphose ne s'accomplit pas. Les protées des lacs souterrains de la Carniole, ayant à la fois des poumons et des branchies, peuvent respirer dans l'air comme dans l'eau. On connaît sous le nom d'axolotl, un gros tètard à branchies extérieures, vivant dans le lac qui avoisine la ville de Mexico. Ln grand nombre de ces animaux ayant été donnés au Muséum d'histoire naturelle de Paris, la plupart ne se modifièrent pas; mais le 10 octobre 1865, M. Auguste Duméril remarqua que plusieur's présentaient des taclıes jaunes, leur crête caudale s'atrophiait, ainsi que les branchies, et le 6 novembre, de jeunes axolotls s'étaient transformés en un triton du genre amblystoma, dont les espèces habitent l'Amérique du Nord, c'est-à-dire en un animal amphibie respirant par des poumons dépourvus de branchies et à queue cylindrique. Le même savant eut l'idée de couper les branchies d'un certain nombre d'axolotls. Quelques-uns se métamorphosèrent en tritons, d'autres restèrent à l'état de têtards. Ajoutons que, ces axolotls se multi- 
pliant, ce fait nous démontre que la reproduction bien connue des protées ne prouve en aucune manière qu'ils ne soient pas les tètards d'un reptile encore inconnu. Il existe encore des animaux qui ne sont probablement que des ètres n'ayant pas subi toutes leurs métamorphoses; exemple les ménobranches, qui ont, comme le protée, des branchies extérieures et quatre pattes. Tout le monde connait la rainette, cette petite grenouille verte qui se tient habituellement sur les feuilles des plantes aquatiques : elle pond des ceufs d'où éclòt un tètard; mais un Ilaturaliste, M. Bavay, a observé une espèce des An-

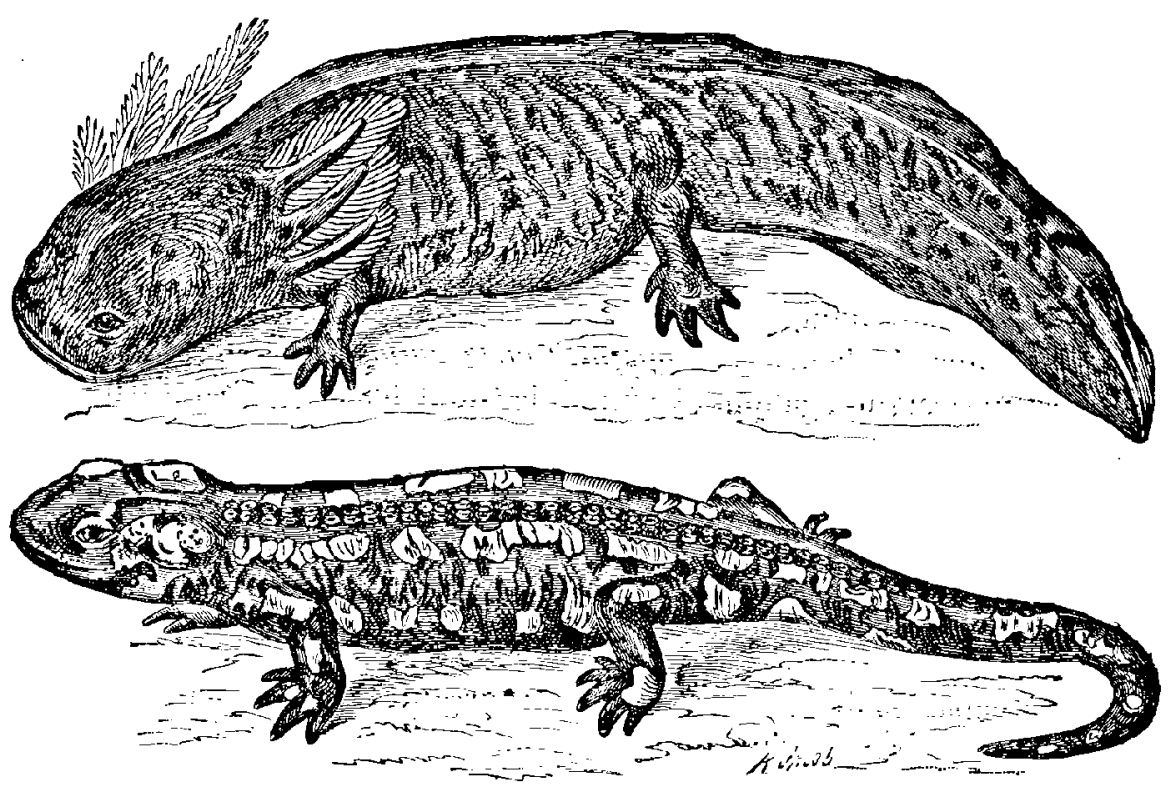

Fig. 41. - L'axolotl du Mexique avant et après sa transformation

Métamorphoses d'un animal aquatique sespirant par les branchies, en un reptile de terre ferme.

tilles où la métamorphose s'accomplit dans l'œuf mème. Celui-ci contient un têtard muni d'une queue et de branchies, et pourtant au bout de dix jours il en sort une rainette sans queue, sans branchies et respirant par des poumons. Blumenbach avait déjà constaté le mème fait sur le crapaud pipa de Surinam. Ces métamorphoses, accomplies tantòt hors de l'œuf, tantôt dans l'œuf même, nous éclairent sur les métamorphoses des animaux supéricurs, qui parcourent dans le sein de leur mère les différentes phases de leur développement sérial à partir d'unc classe d'animaux inférieurs à celle dont ils font partie.

Il existe dans l'ordre des mammifères carnassiers un groupe de petits animaux, parfaitement naturel, connu sous le nom d'animaux vermiformes: il comprend la marte commune, la fouine, le putois, la belette, etc.: La marte commune, effroi des poulaillier's européens, depuis la Méditer- 
ranée jusqu'à l'Océan glacial, est un animal esscntiellement terrestre; dans ce même genre se rencontre pourtant une forme aquatique tellement voisine, que Linné, Cuvier et beaucoup d'autres zoologis!es la considéraient comme une espèce du genre marte; c'est la loutre d'Europe, dont la distribution géographique est la même que celle de la marte commune. La loutre, en effet, est une marte amphibie qui se nourrit de poissons, de grenouilles, d'écrevisses, tandis que sa congénère mange les poules, les perdreaux et les petits lapins. Les deux animaux se ressemblent prodigieusement : la dentition est la même ainsi que le pelage; tous deux, bas sur jambes, ont des membres terminés par des doigts armés d'ongles cruchus; mais, la loulre cherchant sa proic dins les eaux, ce nouveau milieu a imprimé à son or granisalion des différences peu apparentes à l'extérieur et néanmoins très réelles. Ainsi les doigts, libres dans la marte, sont unis par des membranes dans la loutre. La queue, au lieu d'èlre cylindrique, est aplatie de huut en bas comme celle d'un castor, et dans le ventre un grand sinus veineux permet au sang de s'y accumuler lorsque l'animal, plonireant sous l'cau, suspend sa respiration pendant quelque temps. La loutre est donc une marle amphibie, comme le desman est une musureigne également amphibie, dont les doigts sont palmés et dont le terrier s'uuvie sous l'eau.

Dans les carnivores dits aruphibies, tels que les phoques et les morses, nous trouverons l'exemple de grands animaux dont l'existence est encore plus aquatique : aussi les modifications de l'organisme sont-elles plus profondes que dims la loutre. Ces carnassiers amphibies forment la transition des mammiféres terrestres aux cétacés, mammifères marins complètement incapables de se mouvoir sur un terrain solide. Lamarck avait été très frappé par la vue d'un phoque vivant. Les pieds de derrière jouent pour la natation le même rôle que la nageoire caudale des cétacés et des poissons. A terre, le phoque progresse par bonds de la totalité du corps, s'appuyant seulement sur l'avant-bras, sans faire usatre de ses membres comme instruments de progression; les extrémités postérieures sont appliquées sur les parties latérales du corps. Or, lorganisation du phoque est celle du chien. La dentition est analogue, la langue lisse chez l'un et chez l'autre, le canal intestinal caractérisé par un cœcum court; ils se nourrissent tous deux de chair, sans être exclusivement carnivures. Les doigts sont telminés par des ongles; la douceur, l'intellirence, la sociabilité et les sentiments d'affection pour l'homme sont aussi développés chez le phoque que chez le chien. Voilà pour les analogies; mais, soit que l'on considère le chien comme une forme terrestre dérivée du phoque, ou le phoque comme une forme amphibie du chien, toujours est-il que les modifications dues au milieu uqueux sont les suivantes. Le corps du phoque est plus allongé que celui du chien, cylindroïde, beaucoup plus large en avant qu'en arrière; le poil est court et ras, les doigts, très longs, sont 
réunis par des nembranes, les os du bras et de la cuisse, de l'avant-bras et de la jambe sont courts et forts, les membres postérieurs dirigés d'avant en arrière parallèlement à la queue. Les narines peuvent se fermer quand l'animal plonge, et la parotide, devenue moins nécessaire, est atrophiée; l'animal mangeant toujours dans l'eau, la sécrétion salivaire est devenue inutile. - Lo chien de Terro-Neuve, essentiellement nageur et employé dans certains pays au sauvetage des individus en danger de se noyer, a les doigts palmés, et transmet à ses petits par hérédité cette conformation, indice chez tous les animaux de l'action prolongée de l'eau sur leurs extrémités digitales.

Dans la classification des oiseaux, on comprend habituellement sous le nom d'échassiers et de palmipèdes tous ceux dont les doigts sont plus ou moins réunis par des membranes, c'est-à-dire palmés; mais, si l'on étudie ces animaux avec plus d'attention, on reconnaît qu'on peut les considérer comme des formes aquatiques d'autres espèces terrestres. Ainsi les palmipédes longipennes, les albatros, les frégates, les cormorans, correspondent aux grands rapaces, tels que les aigles et les vautours. Les mouettes, les pétrels sont les analogues des faucons et des milans. Les sternes ont été appelées hirondelles de mer, tant l'analogie est évidente entre ces deux genres. Les hérons, les cigognes, les flamants rappellent les autruches et les casoars. Les cygnes, les oies et les canards sont d'excellents voiliers et de parfaits nageurs, la marche seule leur est difficile. Ainsi les doigts palmés, indices d'une vie essentiellement aquatique, ne sont pas liés au reste de l'organisation, ils sonl uniquement le résultat d'une natation prolongée. Voici quelques exemples : parmi les oies, l'anseranas a les doigts presque libres; le bec-en-fourrcau est une véritable mouette, mais dont les doigts ne sont pas palmés; la poule sultane et la bécasse aux doigts libres ressemblent singulièrement à la macreuse et à l'avocette aux cloigts palmés. La cigogne et le flamant, la grèbe et le plongeon, sont des genres très voisins : les doigts sont plus ou moins libres dans les premiers, réunis dans les seconds. Enfin, les pingouins et les manchots sont, par rapport aux autres oiseaux, ce que les phoques et les morses sonb aux autres mammifères ; étant presque entièrement aquatiques, ils présentent des modifications analogues à celles des mammifères amphibies; leur corps est allongé comme celui des phoques, les membres postérieurs sont dirigés comme chez eux d'avant en arrière dans le prolongement de l'axe du corps. Chez les macareux, les ailes très réduites soutiennent encore l'animal dans les airs pendant quelques instants ; mais dans le grand pingouin et les manchots, elles deviennent complètement impropres au vol. Chez ces derniers, les plumes avortent et ressemblent à des écailles; l'aile n'est plus qu'une rame avec laquelle l'oiseau se meut dans les eaux. Chez le phoque, ce sont les mains, chez les manchots ce sont les ailes qui sont devenues des organes remplissant la fonction des nageoires des 
poissions, et inversement chez ceux-ci dans quelques espèces, les poissons volants, par exemple, les nageoires pectorales très développées permettent à l'animal de 's'élancer hors de l'eau et de décrire dans l'air une trijectoire assez longue pour échapper à ses ennemis.

De tous les fäits qui viennent d'être énumérés, on peut et on doit conclure que les modifications de l'organisation des animaux aquatiques s'opèrent sous linfluence du milieu qu'ils habitent et non pas en vertu d'une harmonie préétablie entre cette organisation et le milieu dans lequel l'animal serait destiné à vivre.

$2^{\circ}$ INFLUENCE DE L'AIR. - Lamarck ne craint pas d'attribuer à l'air toute l'organisation des oiseaux, l'adhérence des poumons avec la colonne vertébrale, la perforation de ces poumons, la pénétration de l'air dans tout le corps de l'animal et le développement des plumes. Toutes ces particularitès sont pour lui le résultat des efforts faits par l'animal pour se soutenir dans un milicu aérien.

L'illustre naturaliste avait remarqué, que, chez les animaux qui vivent sur les arbres et qui s'élancent de l'un à l'autre, la répétition de cet exercice pendant une longue suite de générations a amené le développement d'une membrane en forme de parachute, étendue de chaque còté du corps, depuis le membre antérieur jusqu'au membre postérieur. Ainsi, parmi les écureuils, on connail maintenant sept espèces désignées sous le nom d'écureuils volants, munies de ce parachute qui leur permet de se laisser choir sans danger du haut des arbres qu'ils habitent. Dans les marsupiaux frugivores, on distingue également un groupe d'animaux australiens qui sont munis d'un parachute. Enfin chez les galéopithèques, animal intermédiaire entre les singes et les chauves-souris, ce parachute s'étend depuis le cou jusqu'à la queue et forme un véritable manteau; en le déployant, le singe volant peut, s'élancer d'un arbre d̀ l'autre. Chéz les chauves-souris, le même appareil existe : il so complète par une véritable aile membraneuse : les os du métacarpe et les doigts, le pouce excepté, sont très longs; une seconde membrane se continuant avec le parachute, réunit ces os entre eux. L'animal ainsi organisé, vole aussi longtemps et aussi rapidement qu'un oiseau.

De Blainville et d'autres, avaient déjà constaté l'étroite analogie qui unit les oiseaux aux reptiles, analogie justifiée dans les idées de Lamarck et de Darwin par l'hypothèse très probable queles oiseaux ne sont que des reptiles transformés. Il y a plus, l'histologie ou anatomie microscopique prouve que la plume de l'oiseau et l'écaille du reptile sont originairement identiques, et que la plume n'est. qu'une écaille plus développée. Les plumes avortées des manchots ressemblent à des écailles de reptiles. Ajoutons que, parmi les reptiles, le dragon volant est soutenu par un parachute semblable à celui des écureuils et des ṕhalangers volants. Ainsi donc, s'il est encore impossible, dans l'état actuel de nos 


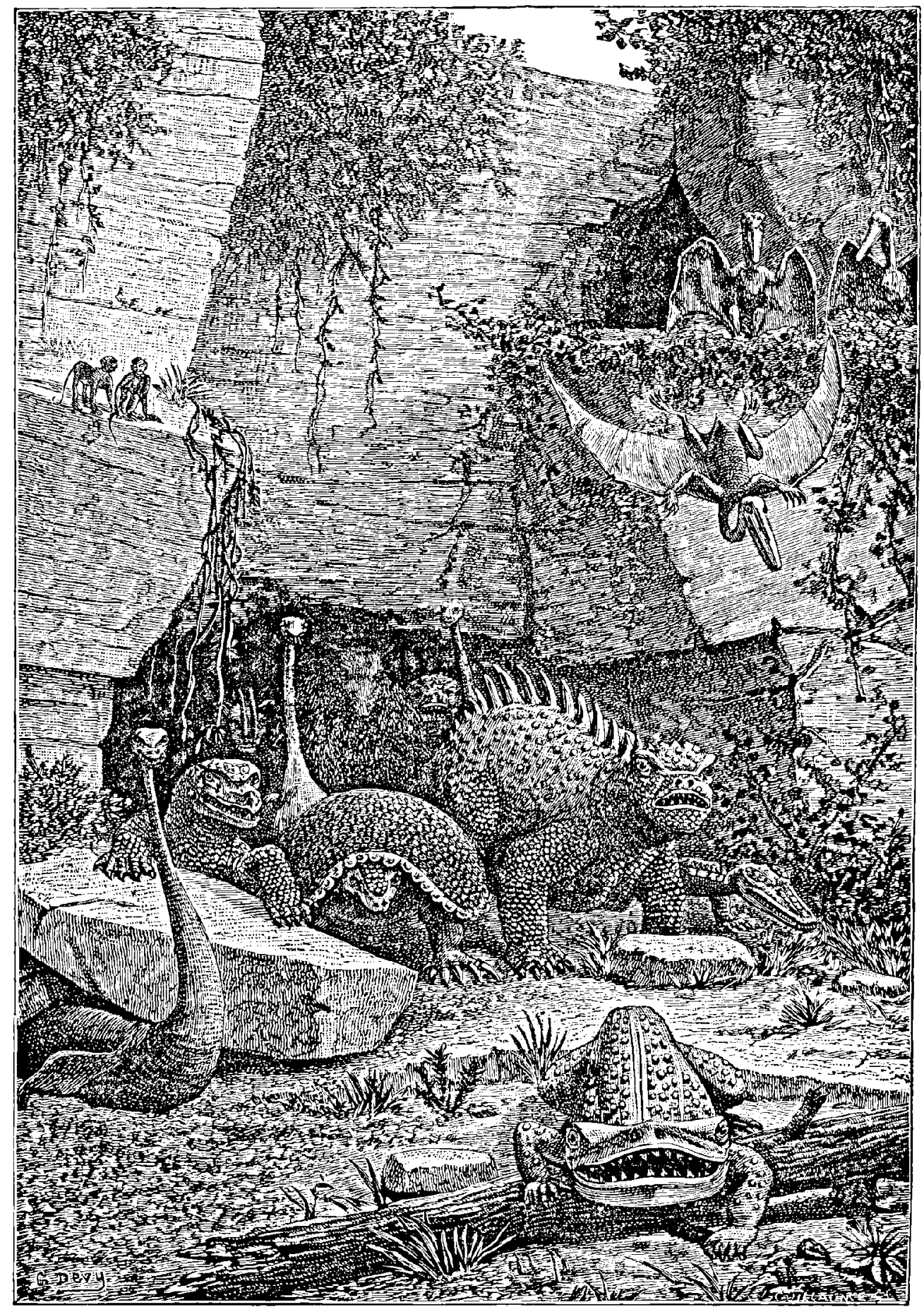

Tous ces ètres qui out précédé l'homme et qui sortent aujourd'hui de leurs tombeaux ne semblent-iis pas des monstres? Pourtant ils sont rattachés à nous par des liens originels. 
connaissances, de démontrer comment l'air a pu modifier si profondément l'organisme des oiseaux, on voit poindre déjà les premiers indices qui permettront de le faire sans s'appuyer sur une adaptation préconçue de l'organe à la fonction qu'il remplit.

$3^{\circ}$ Influence dF ra tumière. - La lumière est indispensablè aux végétaux. Sous l'influence de cet agent, la matière verte ou chlorophylle se forme, l'acide carbonique de l'air est décomposé, et le carbone, base du tissu vógétal, est fixé. Dans l'obscurité, la plante languit, s'étiole, les entre-nœuds s'allongent, les feuilles se développent à peine, les fleurs et les fruits avortent, les mouvements, tels que ceux des feuilles de la sensitive, sont abolis; aussi, quelques plantes parasites exceptées, la lumière est-elle une condition nécessaire de la vie végétale. Certaines fleurs ne s'épanouissent que sous l'action d'une. lumière très vive. Vainement on leur prodigue la chaleur dans les serres du Nord de l'Europe; elles ne fleurissent pas ou fleurissent mal, tandis que, déjà dans le midi de la France et dans les climats du soleil, elles se couvrent de fleurs tous les ans, malgré une température plus basse et moins égale que celle des scrres d'Angleterre ou de Hollande. Toutes les plantes cherchent la lumièro; placées dans une chambre éclairée, elles so dirigent vers les fenêtres, dans une cave obscure vers le soupirail.

La lumière est moins indispensable aux animaux; leur respiration en est indépendante, tous peuvent vivre dans une demi-obscurité, et beaucoup dans une obscurité totale; leurs fonctions s'accomplissent, ils vivent et se reproduisent, seulement leur peau, leurs liquides et leurs tissus ne se colorent pas; ils s'étiolent comme ceux des plantes. Tous les animaux du Nord ont les couleurs mates, sauf le blanc, qui est quelque fois très pur, surtout on hiver. Ce sont toujours les parties les plus exposées à la lumière qui sont le mieux colorées, le dos et les flancs dans les mammifères, les oiseaux, les reptiles et les poissons. Dans les coquilles, le contraste est encore plus flappant; celles qui vivent dans la vase ou dans la mer à de grandes profondeurs ont les couleurs ternes et uniformes.

Liće intimement à l'organe de la vue, sans lequel les animaux n'en auraient pas la perception, la lumière exerce sur cet organe une action puissante. Dans l'obscurité, les yeux des animaux s'atrophient; à la lumière, ils se perfectionnent et s'améliorent par l'exercice. Les aigles, les vautours, les faucons, roient à des distances énormes : c'est la vue et non l'odorat qui leur signale une proie éloignée. La direction constante de la lumière détermine même le déplacement de l'œil lorsqu'il est placé de façon à ne pas pouvoir remplir ses fonctions. En voici la preuve. Les raies sont des poissons carnivores, jouant dans les eaux le même rôle que les oiseaux de proie dans les airs; leur corps aplati est horizontalement symétrique, et les deux yeux sont placés sur la face dorsale de la tête. Dans les pleuronectes, la plie, le turbot et la barbue, 
la symétrie est au contraire verticale, comme celle des poissons ordinaires; mais le corps, étant aplati latéralcment, ces poissons nagent sur le côté, se cachent dans le sable, couchés, la plie sur le côté gauche, le turbot sur le côté droit, et happent ainsi placés le fretin qui passe audessus d'eux. Quand ces êtres sont adultes, les deux yeux sont situés l'un près de l'autre du côté de la tête qui regarde en haut; cependant originairement, dans l'enfance, ces yeux étaient l'un à droite, l'autre à gauche de la tête, comme chez les autres poissons; mais avec l'âge l'œil situé du côté qui repose sur le sable, étant sans usage, se déplace et traverse les os du crâne pour venir faire saillie près de l'œil placé du côté éclairé de l'animal! C'est ce qui a été mis hors de doute par un zoologiste danois très distingué, M. Steenstrups. Cetle migration d'un organe ' inutile dans sa position normale, pour venir occuper une place ou il puisse exercer ses fonctions, est un des faits les plus caractéristiques de l'action de la lumière sur l'économie vivante. Nous aurons la contre-partie de ce fait lorsque nous parlerons tout à l'heure de l'influence d'une obscurité prolongée sur l'organe de la vue.

$4^{\circ}$ Influexce de la chaleur. - Il suffira de mentionner l'influence de la chaleur pour que le lecteur se rappelle immédiatement les faits innombrables qui prouvent la puissance de cette forme du mouvement. Le sauvage qui adore instinctivement le soleil et le savant qui démontre que cet astre est la source unique de la chaleur et de la vie sur la Terre en sont aussi convaincus l'un que l'autre. Tout organisme, pour se développer, pour vivre, pour se reproduire, exige une certaine température, supérieure à celle de la glace fondante; le degré varie, mais au-clessus et au-dessous de certaines limites, fixes pour chaque espèce, tout s'arrète, tout meurt. Comparez en imagination les régions polaires, ensevelies sous un linceul de glace qui ne laisse à découvert que de pelits intervalles revètus d'une végétation uniforme de lichens, de mousses ct d'herbes rabougries, avec la végétation luxuriante des contrées intertropicales où la chaleur, la lumière et l'eau conspirent pour activer les forces vitales de la plante. Là les fougères deviennent des arbres et les arbres sont gigantesques. Comparez encore la faune terrestre des contrées arctiques, réduite à quelques animaux de couleur terne, survivants de l'époque glaciaire, el à des oiseaux voyageurs réfugiés temporairement dans ces régions reculées, avec la faune nombreuse, variée, multicolore, qui remplit en tout temps la forêt tropicale. Vers le pôle, la vie s'éteint; elle déborde sous les tropiques. La plante même semble animée, les animaux pullulent et disputent à l'homme la possession du sol; les uns, formidables par leur taille ou les armes dont ils sont pourvus, les autres, redoutables par leur nombre, semblent ligués pour l'exclure du domaine où ils se multiplient sans cesse. Aussi toutes les influences dont nous avons parlé sont-elles sans action, si la chaleur est absente. La lumière, 
l'atmosphère et l'eau seraient impuissantes pour faire germer et développer la plante, si la chaleur n'intervenait pas dans une mesure appropriée aux besoins de chaque espèce. Sans chaleur, l'animal périt dans le sein de sa mère ou dans l'ouf, et cette chaleur mème a sa source éloignée dans le Soleil. Sous l'influence des rayons solaires, un des éléments de l'air est décomposé, l'autre absorbé; la matière verte et les autres principes immédiats se déposent dans le tissu des végétaux; ceux-ci nourrissent l'animal dont ils maintiennent la température; cette chaleur active les fonctions, engendre les mouvements, préside à la reproduction et à toutes les modifications organiques par lesquelles les animaux se transforment, depuis la monade jusqu'à. l'homme. Transformation des forces physiques, transformation des espèces organisées, même phénomène sous deux aspects, ou plutôt la première une prémisse, la seconde une conséquence. Affirmer l'une et nier l'autre est radicalement illogique. Le physicien et le naturaliste ne sauraient se contredire, et la physiologio expérimentale confirme les jugements de l'histoire niturelle. " En modifiant les milieux nutritifs et évolutifs, a dit Glaude Bernard, et en prenant la matière organisée en quelque sorte à l'état naissant, on peut espérer d'en changer la direction évolutive et par conséquent l'expression finale. Je pense donc que nous pourrons produire scientifiquement de nouvelles espèces organisées, de même que nous créons de nouvelles espèces minérales, c'est-à-dire que nous ferons apparaitre des formes organisées qui existent virtuellement dans les lois organogéniques, mais que la nature n'a point encore réalisées. „ Ainsi parle notre premier physiologiste, et l'on voit qu'il est d'accord avec Lamarck, Geoffroy-SaintHilaire et Darwin, qui, en étudiant le monde organisé vivant et fossile, sont arrivés à la mème conclusion.

$5^{\circ}$ Organes atrophiés devenus indtiles. - S'il est vrai que l'influence de certains milieux, l'eau, l'air ou la lumière, détermine le développement des organes correspondants, qui augmentent de volume par un exercice habituel et se transmettent ainsi perfectionnés des ascendants aux descendants par voie de génération successive, il l'est également que ces mêmes organes diminuent de volume, c'est-à-dire s'atrophient ou mème disparaissent, si, lo milieu venant à changer, l'organe roste sans emploi. C'est ce que Lamarck a parfaitement exprimé lorsqu'il a dit : \& Le défaut d'emploi d'un organe devenu constant par les habitudes qu'on a prises, appauvrit graduellement cet organe et finit par le faire disparaitre et même l'anéantir. ”

Les botanistes avaient apprécié avant les zoologistes l'importance de ces organes rudimentaires. De Candolle, dans la première édition de sa Théorie élémentaire de la botanique, publiée en 1813, consacre un chapitre spécial à l'avortement des organes. Les épines des arbres et des arbrisseaux sont des branches avortées. Sous l'influence d'un mauvais sol, de la 
sécheresse ou du voisinage affamant d'un grand nombre d'autrẹs végétaux, elles restent courtes, dures et pointues. Transportez le prunier épinellx d'une haie dans un jardin, cultivez-le, fumez-le, les épines s'allongeront sous formes de rameaux feuillés et il ne s'en produira plus de iouvilles.

? 7 ite jeune branche de lilas est terminée par trois bourgeons, mais tou†ou: les deux bourceons latéraux se développent, celui du milieu resserré entre les deux autres ne s'accroît pas, et la branche se bifurque au lieu de se trifurquer. A part les avortements dus à la compression, au développement exagéré des organes voisins, ou à une nutrition insuffisante du végétal, la cause prochaine des autres nous échappe, et tient probablement à des circonstances héréditaires de végétation. Linsi les acacias à phyllodes de l'Australie ont dés feuilles composées dans leur jeunesse, et

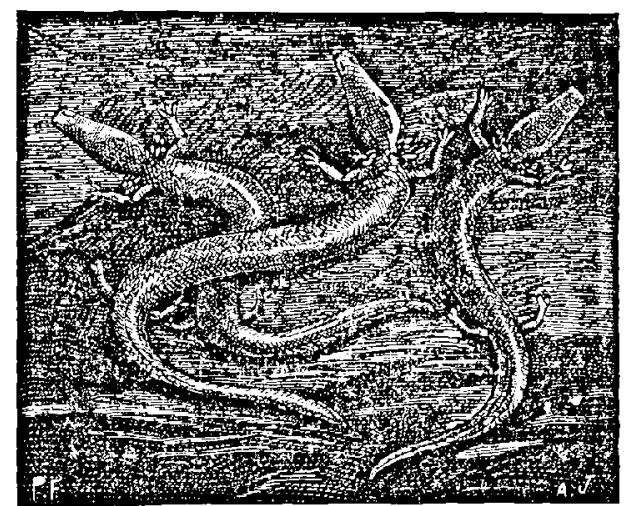

Fig. 49. - Exemple de transformation des races et d'atrophie des ouganes : le a'eptile-poisson aveugle des grottes de la Carniole.

l'acacia heterophylla en conserve toute sa vie un certain nombre, tandis que dans les autres espèces les folioles avortent toutes, et la feuille se réduit à un pétiole élargi, simulant les feuilles simples de nos saules indigènes.

Chez les animaux, les causes d'atrophie sont bien plus évidentes; c'est, comme Iamarck l'avait parfaitement compris, lo manque d'exercice d'un organe, pat suite d'un changement dans le milieu ambiant ou dans les habitudes de l'animal. Rien de plus instructif à cet égard que l'influence de la lumière sur l'organe de la vue. Un animal plongé constamment dans l'obscurité ne se dirige plus au moyen de ses yeux, mais à l'aide du tact; alors les yeux diminuent de volume, s'enfoncent dans l'orbite, sont recouverts par la peau, finissent par s'atrophier et même par disparaîlre. Ces dispositions se transmettent héréditairement des parents à leur progéniture, et l'on voit des espèces, munies de leurs yeux quand elles vivent à la lumière, devenir aveugles quand elles se tiennent habi- 
tuellement dans l'obscurité. Ainsi, dans la taupe ordinaire, animal souterrain, l'œil étant recouvert par la peau percée d'un tout petit canal oblique, la vision doit être très imparfaite. Deux espèces de spalax qui habitent la Russie méridionale, le chrysochlore du cap et le cténomys de l'Amérique du Sud dont la vie est souterraine comme celle de la taupe, présentent la mème organisation. On connait des reptiles aveugles, tels sont, parmi les lézards scincoidiens, le typhline de Cuvier, et, parmi les serpents, les typhlops, qui vivent sous terre comme nos lombrics. Parmi les batraciens, on peut citer la grande sirène lacertine, qui habite les marais fangeux de la Caroline du Sud et passe une partie de sa vie enfoncée dans la vase : cet animal a sur la tête deux petits yeux ronds recouverts d'une peau à demi transparente. Signalons encore les cécilies, dont l'organisation se rapproche beaucoup de celle des poissons, le protée ( $\left.{ }^{1}\right)$ des lacs souterrains de la Carniole, le sirédon, espèce de batracien à tête et à corps de poisson et à pattes de grenouille des grottes de Mammouth aux ktatsUnis, et le poisson cyprinodon des mêmes grottes. Dans les protées des lacs souterrains de la Carniole, qui peuvent servir de type de ces races transformées, Charles Vogt a trouvé sous la peau le globe oculaire avorté, de la grosseur d'une petite tête d'épingle, mais dépourvu de muscles et de ses membranes d'enveloppe : il a pu suivre le nerf optique jusqu'au cerveau.

Les poissons qui vivent constamment dans des eaux souterraines deviennent aveugles. Ce fait s'observe dans tous les ordres de cette grande classe : ainsi, chez les salmones, l'amblyopsis des cavernes de l'Amérique du Nord a des yeux microscopiques recouverts d'une peau non transparente; parmi les silures, nous nommerons le silurus cœcuticus, quelques anguilles (apterichys cœcus) et les myxinoïdes parasites. Les crustacés podophthalmes sont ceux qui, à l'instar des homards et des langoustes, ont un œil pédiculé, c'est-à-dire porté sur un support mobile. Quelquesuns sont aveugles : l'œil a disparu, le support est resté. Des crustacés appartenant à la section des entomostracés vivent en parasites sur d'autres animaux ; jeunes, ils nagent librement dans l'eau et sont munis d'yeux bien conformés; mais lorsqu'ils se cachent sous les écailles ou s'enfoncent entre les branchies des poissons, ils se trouvent dans la condition des animaux des cavernes : les yeux, ne fonctionnant plus, s'atrophient, et l'animal devient et reste aveugle toute sa vie.

1. Nous reproduisons ici (fig. 42), d'après un dessin de sir Humphry Davy, le proteus anguinus, singulier reptile-poisson de la grotte d'Adelsberg que l'illustre chimiste a visitée et a décrite en détail dans son ouvrage Les derniers jours d'un philosophe. Cet habitant des lacs souterrains de la Carniole est devenu complètement aveugle par l'arrèt d'exercice des organes de vision dans ce milieu obscur, et est présenté depuis Iongtemps comme un type remarquable d'espèce intermédiaire entre les reptiles et les poissons et de transformation des organes par le milieu ambiant. (Voy. l'ouvrage précédent, édition française, p. 247, et La Pluralité des Mondes habités, p. 119). 
Les insectes nous offrent les exemples les plus nombreux d'espèces aveugles habitant les cavernes, tandis que leurs congénères vivant à l'air libre ne le sont pas. Parmi les coléoptères de la famille des carabiques se trouve le genre trechus : ce sont de petits animaux se tenant habituellement sous des pierres ou sous des amas de feuilles mortes. Dans les grottes de la Carniole, on en compte quatre, qu'on a réunies dans le genre des anophtalmus, mais qui ne different des autres que par l'absence des yeux. Il en est d'autres qui portent à la place de l'œil disparu une tache ovale derrière les antennes. On a trouvé de ces insectes aveugles dans les cavernes de tous les pays, Pyrénées, Amérique du Nord, etc. On peut, avec Charlos Vogt, résumer la question en disant que partout ces insectes sont caractérisés par l'absence des yeux, une coloration moindre, la mollesse relative du corps et la diminution des ailes. Des faits que nous venons de citer, il est impossible de ne pas concluré que c'est la lumière qui entretient et développe l'organe de la vision; dans l'obscurité, celui-ci disparaît, et l'on est invinciblement amené à penser, comme Lamarck, que c'est le milieu qui créo et maintient les organes : le milieu changeant, ils s'évanouissent sans retour.

Ce que nous avons dit de l'œil s'applique à tous les appareils; quelle que soit la nature des fonctions qu'ils accomplissent, l'exercice les développe, le manque d'usage les atrophie, et ces modifications se transmettent par hérédité. Nous nous servons généralement beaucoup moins du bras gauche que du bras droit, aussi celui-ci est-il plus gros, plus lourd, et toutes ses partics, os, muscles, nerfs, artères, sont-clles plus fortes que celles du côté opposé; ces différences existent déjà chez le nouveauné. Chèz les autruches, animaux trop lourds pour pouvoir s'élever dans - les airs, les jambes se sont fortifiées et allongées, les ailes ont diminué et ne font plus qu'office de voiles lorsque l'oiseau court dans le sens du vent. Chez le casoar et l'aptérix, les ailes sont réduites à un rudiment inutile caché sous les plumes du corps, parce que le genre de vie de ces animaux est complètement terrestre: se nourrissant de vermisscaux ct de petits reptiles, ils courent, mais ne volent pas.

On a vu que chez les oiseaux tout à fait aquatiques, tels que les manchots et les pingouins, ces mêmes ailes se sont converties en nageoires; par contre, dans les poissons volants, les nageoires pectorales ont assez d'envergure pour qu'ils puissent s'élancer hors de l'eau et se soutenir quelque temps dans l'air, afin d'échapper à leurs ennemis. Ces nageoires présagent pour ainsi dire les ailes des animaux et des chauvessouris. Au contraire, dans les anguilles, les lamproies et les myxines dont le corps cylindrique et allongé glisse facilement dans l'eau, les nagenires pectorales et ventrales, devenues inutiles, disparaissent, la nageoire caudale suffit seule à la natation. Dans une foule d'insectes, les ailes n'existent que chez le mâle, sont incomplètes ou avortées chez la 
femelle. Les males du papillon des vers à soie, qui sont élevés dans les magnaneries, n'exerçant plus leurs ailes en volant à l'air libre, cellesci ont diminué de génération en génération, et actuellement ces mâles ont des ailes trop courtes et incapables de les soutenir; ils battent des ailes, mais ils ne volent plus. Dans l'ìle de Madère et celles qui l'avoisinent, les insectes coléoptères sont souvent emportés par les vents et jetés à la mer où ils périssent; ils se tiennent cachés tant que l'air est en mouvement : aussi les ailes se sont-elles amoindries. Cette disposition est devenue héréditaire, et sur cinq cent cinquante espèces répandues dans ces îles, il y en a deux cents qui sont incapables de soutenir un vol prolongé. Sur vingt-neuf genres indigènes, vingt-trois, proportion énorme! se composent d'espèces aptères ou munies d'ailes imparfaites.

L'ensemble de ces faits fera comprendre aux personnes étrangères à l'étude des sciences naturelles pourquoi les zoologistes, quand ils veulent s'exprimer rigoureusement, disent toujours: les oiseaux. volent parce qu'ils ont des ailes, et non pas: les oiseaux ont des ailes pour voler. La première proposition exprime un fait simple, évident, indiscutable; la seconde se complique de l'hypothèse des causes finales et suppose une prédestination de l'animal à un certain genre de vie. En fait, c'est le genre de vie qui détermine le développement ou amène l'atrophie des organes; ceux-ci sont actifs ou inactifs suivant les circonstances et les conditions au milieu desquelles l'animal se trouve placé. Une loi universelle de progrès, de développement, de perfectionnement, d'ascension vers le mieux, de transformation de la matière brute en matière animée et en substance pensante est profondément inscrite dans le caractère de la nature entière : les êtres sont menés par cette loi, s'élèvent et se transforment par le fait même de leur existence.

Continuons l'étude des organes avortés. Dans une classe d'animaux, les uns terrestres, les autres aquatiques, celle des reptiles, ce sont les pattes qui disparaissent. Les crocodiles et les lézards en ont quatre : chez les seps, elles sont très courtes; dans les bimanes et les bipèdes, il n'y en a plus que deux; dans le pseudopus, elles se réduisent à de petits tubcrcules, dernière trace des membres postérieurs. Chez l'orvet, il n'y a plus de menbres, mais on trouve sous la peau les os de l'épaule et le sternum; enfin ces os mèmes disparaissent dans les serpents. Cependant chez le boa on remarque encore deux os en forme de cornes, réminiscence clu bassin des sauriens. Lamarck ne craint pas d'expliquer cette disparition des membres par l'habitude de ramper, de se glisser sous les pierres ou dans l'herbe, qui existe déjà chez les lézards; il fait remarquer avec raison qu'un corps aussi allongé que celui d'un serpent n'aurait pas été convenablement soutcnu par quatre pattes, nombre que la nature n'a jamais dépassé dans les animaux verlóbrés. Un serpent rampe à l'aide 
de ses côtes, devenues des organes de progression. L'allongement exagéré du corps a produit l'amoindrissement de l'un des poumons, tandis que l'autre se prolonge jusque dans le ventre. Mème chez les mammi-

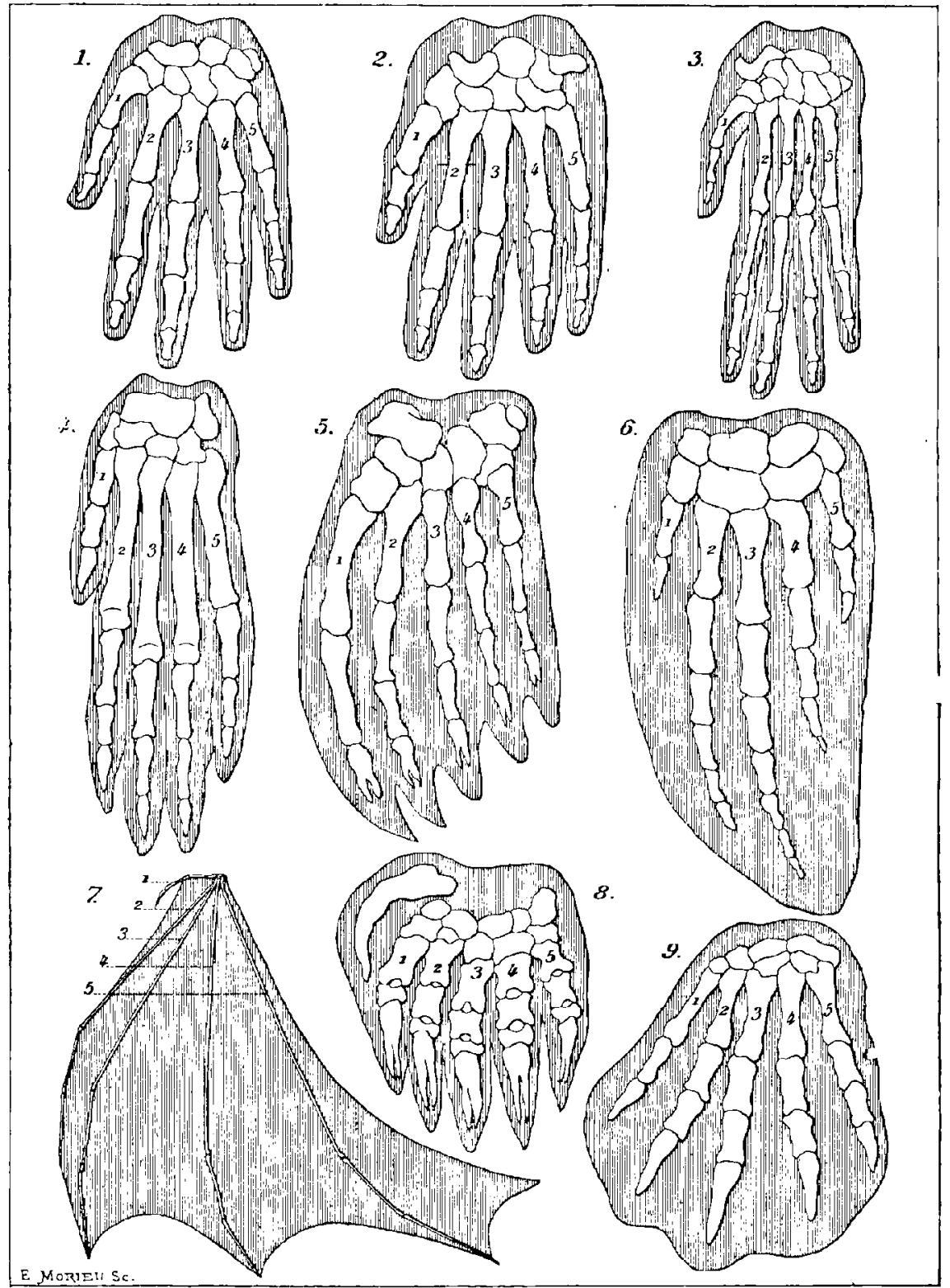

Fig. 43. - Unité organique el parenté des êtres

1. Main bamairo (le contour extérieur représente la chair). - 2. Gorille. - 3. Orang. - 4. Chïgn. - 5. Zhoque. - 6. Daujhin. 7. Chauve-souris. - 8. Taupe. - 9. Ornitherynque. 
fèrés, les plus parfaits des animaux, les organes avortés et inutiles ne sont pas rares; ainsi la plupart de ces animaux présentent les trois types dentaires, savoir des incisives, des canines et des molaires. GeoffroySaint-Hilaire avait déjà remarqué que chez la baleine, où les dents sont remplacées par des fanons, les germes des dents avortées sont cachés dans l'épaisseur de la mâchoire du foetus ; depuis, le môme savant les a retrouvées dans le bec des oiseaux. Les ruminants ont un bourrelet. calleux à la place des incisives supérieures, mais le germe des dents existe dans le fœtus. Il en est de même chez les lamantins, qui n'ont d'incisives ni en haut ni en bas; se nourrissant uniquement de plantes marines, ils n'en faisaient point usage, et ces dents ont fini par dispa. raître.

Les organes avortés qui existent chez L'romme, et dont il peut tous les jours conslater l'inutilité, semblaient être naguère encore autant de preuves de l'unité de plan qui a présidé à la création du règrne animal. De mêmo, disait-on, qu'un architecte soucieux de la symélrio met de fausses fenètres, ou rappelle sur les ailes d'un édifice les motifs de la façade principale, de mème le Créateur, en laissant subsister ces organes, nous dévoile l'unité du plan qu'il a suivi. Dans les idées de Lamarck et de ses successeurs, ces organes rudimentaires n'ont point cette signification purement intellectuelle; ils se sont atrophiés faute d'usage. La présence de ces vestiges d'organes chez l'homme, auxquels ils sont inuliles, prouve seulement que son organisation se lie intimement à celle du règne animal, dont il est la dernière et la plus parfaite émanation. Nous possédons sur les côtés du cou un muscle superficiel appelé peaucier; c'est celui avec lequel les chevaux font vibrer leur peau pour chasser les mouches qui les importunent: chez nous, les vêtements; chez les sauvages, les peaux, les corps gras, ou l'argile dont ils s'enduisent le corps, rendent ce muscle inutile, aussi s'est-il tellement aminci qu'il ne peut plus imprimer à la peau le moindre mouvement. Il en est de même des muscles qui meuvent l'oreille du cheval, du chien et d'autres animaux; nous les possédons, mais ils ne nous servent à rien: placée sur les còtés et non pas au sommet de la tête, notre oreille ne saurait diriger l'ouverture de son pavillon vers tous les points de l'horizon pour recueillir les sons qui en émanent. Autre exemple encore : on remarque à l'angle interne de l'œil un petit replis rose qui fait partie du dessin de l'œil humain; c'est la trace de la troisième paupière des oiseaux de proie, qui leur permet de fixer le soleil, sans fermer les yeux.

Il y a plus, ces organes rudimentaires peuvent être non seulement inutiles, mais encore nuisibles. Le mollet est formé par deux muscles puissants qui s'insèrent au talon par l'intermédiaire du tendon d'Achille; à côté d'eux se trouve un autre muscle long, mince, incapable d'uno action énergique, le plantaire grêle. Ce muscle, ayant les mèmes attaches que 
les jumeaux, semble un mince fil de coton accolé à un gros câble de navire; pour nous, il est sans utilité, et la rupture de ce muscle, causée par un effort pour sauter ou par un faux pas, donne lieu à l'accident douloureux connu sous le nom de coup de fouet, et dont la guérison nécessite un repos prolongé. Chez le chat, le tigre, la panthère, le léopard et leurs cousins, ce muscle est aussi fort que les doux jumeaux, et rend ces animaux capables d'exécuter des bonds prodigieux quand ils s'élancent sur leur proie. Autre exemple dans les herbivores, le cheval, le bœuf et certains rongeurs : le gros intestin présente un grand appendice en forme de cul-de-sac, appelé cœcum, qui se rattache au régime purement herbivore de ces animaux; chez l'homme, dont la nourriture n'est pas exclusivement végétale, le cœecum se réduit à un petit corps cylindrique dont la cavité admet à peine une soie de sanglier ; c'est l'appendice vermiforme. Inutile à la digestion, puisque les aliments n'y pénètrent pas, il devient un danger, si par hasard un corps dur tel qu'un pépin ou un fragment d'arète de poisson vient à s'y introduiro; le cas arrive, et il en résulte d'abord une inflammation, puis la perforation du canal intestinal, accidents suivis d'une péritonite souvent mortelle.

Ces exemples pour ainsi dire personnels doivent suffire pour montrer le rôle et la signification des organes atrophiés. Chez l'homme et chez les mammifères supérieurs, ces rudiments sont une réminiscence de l'organisation d'un animal placé plus bas dans l'échelle des êtres; mais dans les vertébrés inférieurs, ils sont quelquefois l'indication d'un perfectionnement futur. Ainsi les traces des membres chez le pseudopus précèdent le développement de ces membres dans les tortues. Le pouce des galagos et des larsiers annonce l'apparition de la main parfaite des singes et de l'homme, etc.

En un mot, le règne animal tout entier, vivant et fossile, nous présente les mèmes phénomènes que l'évolution embryonnaire de l'être qui, partant de la cellule, complète peu à peu son organisation et s'élève graduellement jusqu'à l'échelon occupé par les deux êtres qui lui ont donné naissance. Cetto évolution se manifeste également dans la série des animaux dont les couches géologiques nous ont conservé les restes. Les plus anciennes ne contiennent que des invertébrés et des poissons; les reptiles, les oiseaux et les mammifères apparaissent successivement dans leur ordre hiérarchique, et l'homme termine enfin cette série ascendante. Toutes les mythologies en ont próvu la continuation en imaginant les anges, êtres plus parfaits' que l'homme, intermédiaires entre lui et son Créateur ( ${ }^{\mathbf{1}}$ ).

Cette filiation naturelle des ètres a été établie par Lamarck au commencement de ce siècle, combattue par les savants officiels,

1. Charles Martins. Introduction à la Philosophie zoologique de Lamarck. 
enterrée dans la conspiration du silence, et reprise par Darwin, qui l'a victorieusement et définitivement démontrée. En même temps que Lamarck la soutenait en France, Gœthe la proclamait en Allemagne dans un magnifique langage:

« Les êtres se modèlent d'après des lois éternelles, écrivait-il, et toute forme, fùt-elle extraordinaire, recèle en soi le type primitif. La structure de l'animal détermine ses habitudes et le genre de vie réagit puissamment sur toutes les formes. Par là se révèle la régularitė du progrès qui tend au changement sous les pressions $\mathrm{du}$ milieu extérieur.

a Au fond de tous les organismes, il y a une communauté originelle; au contraire, la différence des formes provient des rapports nécessaires avec le monde extérieur. Il faut donc admettre une diversité originelle simultanée, et une métamorphose, incessamment progressive, si l'on veut comprendre les phénomènes constants et les phénomènes variables.

a Nous en sommes arrivés à pouvoir affirmer sans crainte que toutes les formes les plus parfaites de la nature organique, par exemple les poissons, les amphibies, les oiseaux, les mammifères, ét, au premier rang de ces derniers, l'homme, ont tous été modelés sur un type primitif dont les parties les plus fixes en apparence ne varient que dans d'étroites limites et que tous les jours encore ces formes se développent et se métamorphosent en se reproduisant.

a Si l'on examine les plantes et les animaux placés an bas de l'échelle des êtres, on peut à peine les distinguer les uns des autres; nous pouvons donc dire que les êtres, d'abord confondus dans un état de parenté oủ il se différenciaient à peine les uns des autres, sont peu à peu devenus plantes et animaux, en se perfectionnant dans deux directions opposées, pour aboutir les unes à l'arbre durable et immobile, les autres à l'homme qui représente le plus haut degré de mobilité et de libertẻ ».

Geoffroy-Saint-Hilaire comprit cette grande doctrine de l'unité de plan réalisée dans un développement graduel, et la soutint avec éloquence. Mais il fut combattu et vaincu par Guvier, esprit fermé au progrès et dont l'influence sur la science française a été fatale, malgré ses immortels travaux en paléontologie. Lorsque cette doc- 
trine revint en France après avoir passé par l'Angleterre, elle parut nouvelle, tant elle avait été soigneusement étouffée par le baron

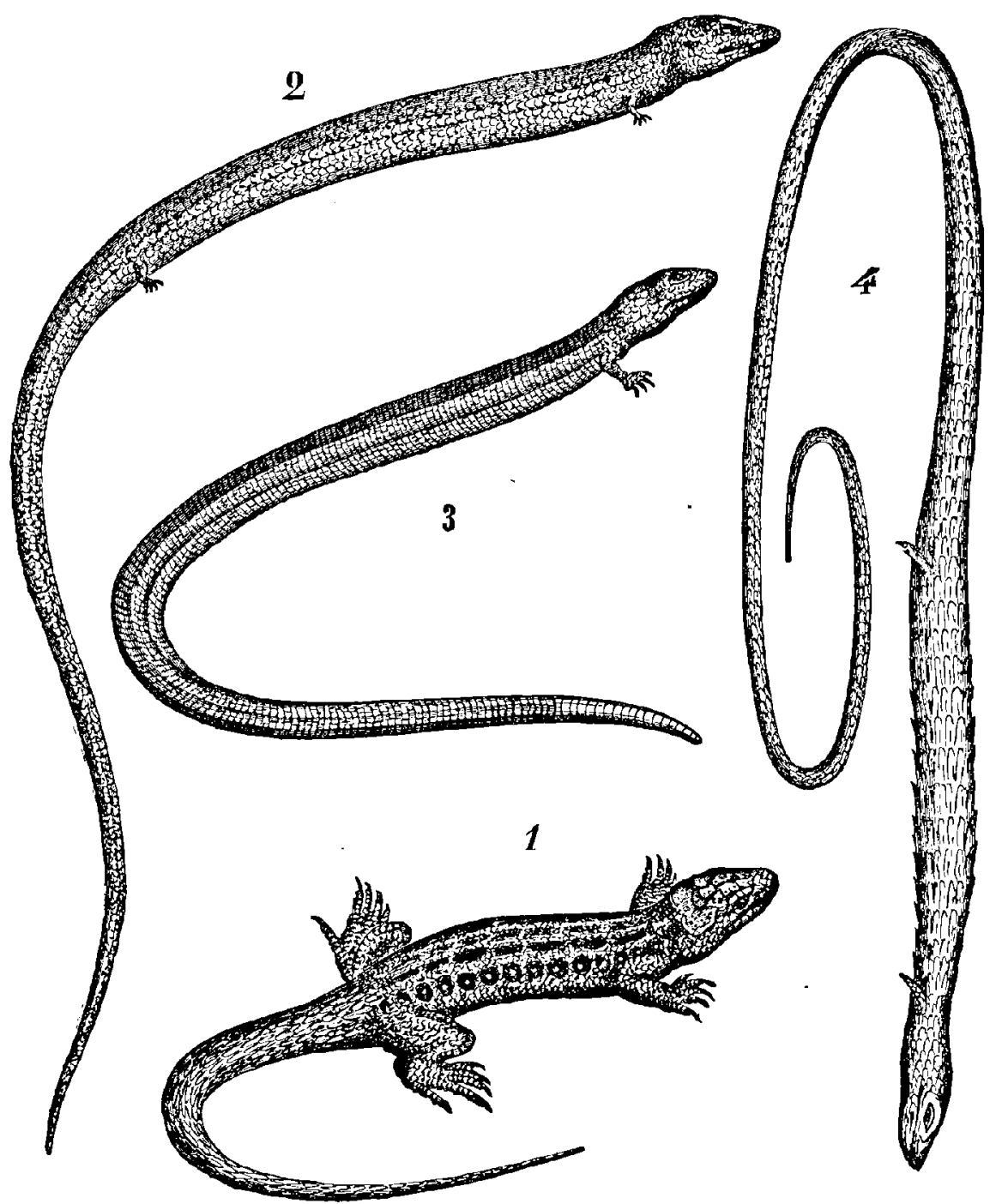

Fig. 44. - Transformation des espèces: La chute des pattes.

4. Le lézard vulgaire. - Q. Le seps. - 3. Le lézard cannelé. - 4. Le lézard monodactyle.

Cuvier, secrétaire perpétuel de l'Académie des sciences, professeur an Muséum d'histoire naturelle et au Collège de France, conseiller d'État, pair de France, etc., etc. ' il affirma et imposa officiellement 
la théorie des révolutions du globe et des créations successives. Comme Buffon, Daubenton, Lacépède, il affirmait l'immutabilité absolue des espèces.

Les idées préconçues empêchent vraiment de voir les choses comme elles sont. En feuilletant, ces jours derniers, une grande. èdition des œuvres de Buffon et Lacépède, qui orne notre bibliothèque, et en comparant entre eux près de trois mille dessins d'animaux de tout genre, qui composent son atlas, depuis les mollusques, les poissons et les reptiles jusqu'à l'homme, il nous semblait que ce qui était le plus frappant dans ces figures, ce n'était pas la diversité des espèces, mais plutôt leurs similitudes et leurs innombrables points de contact. On passe de l'une à l'autre en comprenant de mieux en mieux la vérité de l'antique adage : Natura non facit saltus. Considérez, par exemple, entre autres la reproduction que nous avons faite ( $f g$. 44) d'après cet atlas mème, de quatre lézards observés au point de vue de ce que nous pourrions appeler " la chute des pattes » ou la transformation du lézard en serpent. Dans le premier (le lézard vulgaire), la construction anatomique porte son caractère évident. Dans le second (le seps) les pattes sont réduites à un rudiment presque imperceptible. Dans le troisième il ne reste plus que deux rudiments de paltes sur quatre, et dans le quatrième il n'en reste plus que la place pour ainsi dire. Les pattes n'ont pas poussé aux serpents pour en faire des sauriens : elles sont tombées des sauriens pour en faire des serpents. Plusieurs serpents en portent encore les vertèbres atrophiées.

Darwin a défini la doctrine de la transformation séculaire des espèces et de leur filiation d'une origine commune en désignant sous le nom de sélection naturelle la méthode employèe par la nature, et cette définition en deux mots est entrée pour beaucoup dans le succès récent de la doctrine. Mais ce n'était là que mẹttre une désignation nouvelle à la place de l'influence des milieux de Lamarck, d'autant plus, qu'en réalité, la nature clle-même ne fait pas de choix, ou de sélection: les causes produisent des effets, et voilà tout.

Mais voyons, exposée par lui-même, l'œuvre de Darwin dans l'élucidation du grand mystère, « le mystère des mystères », comme l'exprimait Humboldt. 
Quand on réfléchit au problème de l'origine des espèces, on songeant aux rapports mutuels des êtres organisés, à leurs relations embryologiques, à leur distribution géographique et à d'autres faits analıgues, il semble réellement incroyahle qu'un naturaliste n'arrive pas à conclure tout d'abord que chaque espèce ne peut avoir élé crééo indépendamment mais doit descendre, comme les variétés, d'autres espèces. Néanmoins une telle conclusion, serait-elle fondée, ne saurait être satisfaisante jusqu'à ce qu'il fût possible de démontrer comment les innombrables espèces qui habitent ce monde ont été modifiées de manière à acquérir cette perfection de structuro et cette adaptation des organes a leurs fonctions qui excile à si juste titre notre admiration.

Au premier abord, il peut paraître difficile d'admettre que les organes et les instincts les plus complexes aient été perfectionnés, non par des moyens supérieurs bien qu'analogues à la raison humaine, mais par l'accumulation de variations innombrables, quoique légères, et dont chacune a été utile à son possesseur individuel. Néanmoins cette difficulté ne peut arrêter la science si l'on admet les propositions suivantes :

G'est d'abord que les organes et les instincts sont, à un degré si faiblo que ce soit, variables;

G'est qu'il existe une concurronce vitale universello ayant pour effet de perpétuer chaque utile déviation de structure ou d'instinct;

G'est enfin que chaque degré de perfection d'un organe quelconque peut avoir existé, chacun de ces degrés étant bon dans son espèce.

L'homme ne produit pas la variabilité, il expose seulement, et, souvent sans dessein, les animaux domestiques et les plantes cultivées à de nouvelles conditions de vic, et alors, la nature agissant sur l'organisation, il en résulte des variations. Mais ce que nous pouvons faire et ce que nous faisons, c'est de choisir les variations que la nature produit, et de les accumuler dans la direction qui nous plaît. Nous adaptons ainsi, soit les animaux, soit les plantes, à notre propre utilité ou même à notre agrément. Un tel résultat peut être obtenu systématiquement ou même sans conscience de l'effet produit, il suffit que sans avoir aucunement la pensée d'altérer la race, chacun conserve de préférence les individus qui, à toute époque donnée, lui sont le plus utiles. Il est certain qu'on peut transformer les caractères d'une espèce en choisissant à chaque génération successive des diffórences individuelles assez lécrères pour échapper à des yeux inexpérimentés, et co procédé électif a été lo principal agent dans la production des races domestiques les plus distinctes et les plus utiles. Que plusieurs des races produites par l'homme aient, dans une largre mesure, le caractère d'espèces naturelles, il n'en faut d'autres preuves que les inextricables doutes où nous sommes si quelques-unes d'entre elles sont des variétés ou des espéces originairement distinctes.

Il n'est aucune bonne raison pour que les mộmes principes qui ont 
agi si efficacement à l'état domestique n'agissent pas à l'état de nature. La conservation des races et des individus favorisés dans la lutte perpétuellement renouvelée au sujet des moyens d'existence, est un agent toutpuissant et toujours actif d'élection naturelle. La concurrence vitale est une conséquence nécessaire de la multiplication en raison géométrique plus ou moins élevée de tous les êtres organisés. La rapidité de celte progression est prouvée, non seulement par le calcul, mais par la prompte multiplication de certaines espèces d'animaux ou de plantes pendant une suite de saisons favorables, ou lorsqu'elles sont naluralisées en de nouvelles contrées. Il naît plus d'individus qu'il n'en peut vivre : un grain dans la balance peut déterminer quel individu vivra et lequel mourra, quelle variété ou quelle espèce s'accroîtra en nombre et laquelle diminuera ou sera finalement éteinte. Comme les individus de mème espèce entrent à lous égards en plus étroite concurrence les uns onvers les autres, la lutte est en général d'autant plus sévère entre eux. Elle est presque également sérieuse entre les variétés de la mème espèce, et grave encore entre les espèces du même genre; mais la lutte peut exister souvent entre des êtres très éloignés les uns des autres dans l'échelle de la nature. Le plus mince avantage acquis par un individu, à quelque âare ou durant quelque saison que ce soit, sur ceux avec lesquels il entre en concurrence, ou une meilleure adaptation d'organes aux conditions physiques environnantes, quelque léger que soit ce perfectionnement, fera pencher la balance.

Parmi les animaux chez lesquels les sexes sont distincts, une certaine rivalité entre les máles est fréquente et même permanente. Les individus les plus vigoureux ou ceux qui ont lutté avec le plus de bonheur contre les conditions physiques locales, laisseront généralement la plus nombreuse progéniture. Mais leur succès dépendra souvent des armes spéciales ou des moyens de défense qu'ils possèdent, ou même de leur beauté, et le plus léger avantage leur procurera la victoire.

En admettant que le témoignage géologique soit extrèmement incompiet, tous les faits qu'il nous offre sont à l'appui de la théorie de descendance modifiée. Les espèces nouvelles ont apparu sur la scène du monde lentement et par intervalles successifs; et la somme des changements effectués dans des temps égalax est très différente dans les différents groupes. L'extinction des espèces et des groupes entiers d'espèces qui a joué un rôle si important, est une suite presque inévitable du principe d'élection naturelle ; car les formes anciennes doivent être supplantées par des formes nouvelles plus parfaites. Ni les espèces isolées, ni les groupes d'ezpèces, ne peuvent reparaître quand une fois la chaine des générations régulières a été rompue.

La théorie d'élection naturelle, avec ses conséquences, les extinctions d'espèces et la divergence des caractères, est la seule qui ronde raison de 


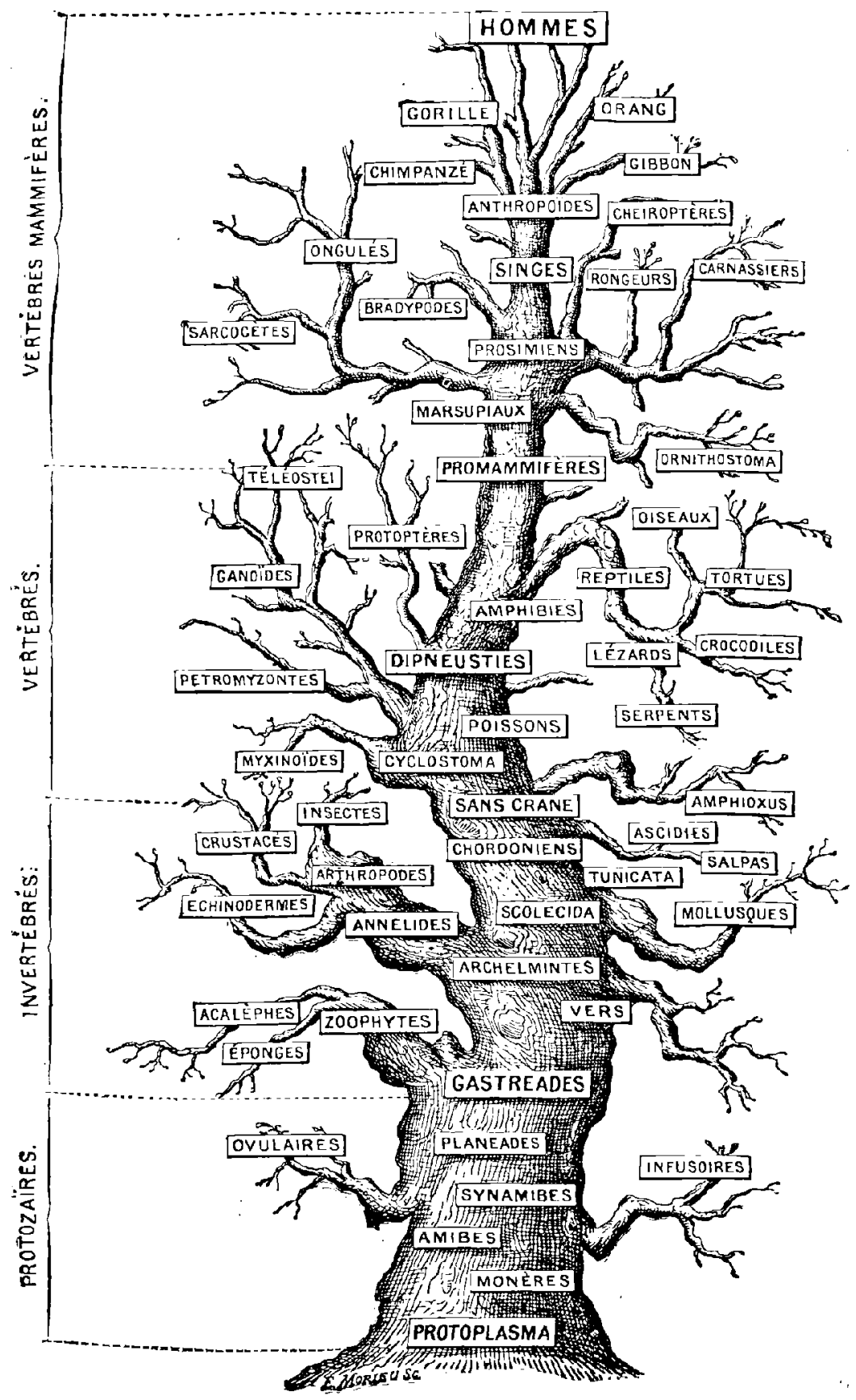

Fig. 45. - ARBRE GŔNÉALOGIQUE DE LA VIE TERRESTRE.

LE MONDE AVANT LA CBÉATION DE L'HOMNE. 
l'arrangement si remarquable de tous les êtres organisés, présents et passés, en un seul grand système naturel, formé de groupes subordonnés à d'autres groupes avec des groupes éteints qui tombent souvent entre des groupes actuels. C'est quo les affinités réelles des êtres organisés sont dues à l'hérédité ou à la communauté d'origine. Le système naturel est un arbre généalogique dont il nous faut découvrir les lignées à l'aide des caractères les plus permanents, quelque légère que soit leur importance vitale.

La disposition des os est analogue dans la main de l'homme, dans l'aile de la chauve-souris, dans la nageoire de la tortue et dans le pied du cheval; le même nombre de vertèbres forment le cou de la girafe et celui de l'éléphant; ces faits, et un nombre infini d'autres semblables, s'expliquent d'eux-mêmes dans la théorie de descendance lentement et successivement modifiée.

Tout le règne animal est sans doute descendu de quatre ou cinq types primitifs, tout au plus, et le règne végétal d'un nombre égal ou moindre.

L'analogie conduirait même un peu plus loin, c'est-à-dire à la croyance que tous les animaux et toutes les plantes descendent d'un seul prototype ; tous les êtres vivants ont beaucoup d'attributs communs: leur composition chimique, leur structure cellulaire, lours lois de croissance, et leur faculté d'être affectés par des influences nuisibles. Ghez tous, autant qu'on en peut juger par ce que nous en savons de nos jours, la vésicule germinative est la même; de sorte que chaque individu organisé part d'une méme origine. Mème si l'on considère les deux divisions prineipales du monde organique, c'est-à-dire le règne animal et le règne végétal, nous voyons que certaines formes inférieures sont si parfaitement intermédiaires en caractères, que des naturalistes ont disputé dans quel royaume elles devaient être rangées; comme le professeur Asa Gray l'a remarqué, " les spores et autres corps reproducteurs de beaucoup d'entre les algues les moins élevées de la série, peuvent se targuer d'avoir d'abord les caractères de l'animalité et plus tard une existence végétale équivoque. "Ainsi, en partant du principe d'élection naturelle, avec divergence de caractères, il ne semble pas incroyable que les animaux et les plantes se soient formés de quelque forme inférieure intermédiaire. Si nous admettons ce point de départ, il faut admettre aussi que tous les êtres organisés qui ont jamais vécu peuvent descendre d'une forme primordiale unique. Mais cette conséquence est principalement fondée sur l'analogie; et il importo peu qu'elle soit ou non acceptée. Il en est autrement de chaque grande classe, telle que les vertébrés, les articulés, etc. ; car ici nous avons dans les lois de l'homologio et do l'em. bryologie, etc., des preuves toutes spéciales que tous descendent d'un parent unique.

D'éminents auteurs semblent pleinement satisfaits de l'hypothèse que 
chaque espèce ait été indépendamment créée. A mon avis, ce que nous connaissons des lois imposées à la matière par le Gréateur, s'accorde mieux avec la formation et l'extinction des ètres présents et passés par des causes secondes, semblables à celles qui déterminent la naissance et la mort des individus. Quand je regarde tous les ctres, non plus comme des créations spéciales, mais comme la descendance en ligne directe d'ètres qui vécurent longtemps avant que les premières couches du système silurien fussent déposées, ils me semblent tout à coup anoblis. Préjugeant l'avenir du passé, nous pouvons prédire avec sùreté qu'aucune espèce vivante ne transmeltra sa ressemblance inaltérée aux àges futurs, et qu'un petit nombre d'entre elles enverront seules une postérité quelconque jusqu'à une époque très éloignée ; car le système de groupement des êtres orcanisés uous montre que le plus grand nombre des espèces de chaque genre n'ont laissé aucun descendant, mais se sont entièrement éteintes. Nous pouvons mème jeter un regard prophétique dans l'avenir jusqu'à prédire que ce sont les espèces communes et très répandues, appartenant aux groupes les plus nombreux de chaque classe, qui prévaudront ultérieurement, et qui donneront naissance à de nouvelles espèces dominantes. Cornme toutes les formes vivantes actuelles sont la postérité linéaire de celles qui vécurent longtemps avant l'époque silurienne, nous pouvons être certains que la succession régulière des génórations n'a jamais été interrompue, et que par conséquent jamais aucun cataclysme n'a désolé le monde entier. Nous pouvons aussi en conclure avec toute confince, qu'il nous est permis de compter sur un avenir d'une incalculable longueur. Et comme l'élection naturelle agit seulement pour le bien de chaque individu, tout don physique ou intellectuel tendra à progresser vers la perfection.

Quel intérèt ne trouve-t-on pas à contempler un rivage luxuriant, couvert de nombreuses plantes appartenant $\grave{a}$ de nombreuses espèces, avec des oiseaux chantant dans les buissons, des insectes volligeant a l'entour, des aunélides ou des larves vermiformes rampant à travers le sol humide; si l'on songe en mème temps que toutes ces formes èlaborées avec tant de soin, de patience, d'habileté, et dépendantes les unes des autres par une série de rapports si compliqués ont toutes été produites par des lois qui arissent continuellement autour de nous! Ces lois, prises dans leur sens le plus large, nous les énumérerons ici : c'est la lo: de croissance et de reproduction; c'est la loi d'hérédité, presque impliquée dans la précédente; c'est la loi de variabilité sous l'action directe ou indirecte des conditions extérieures de la vie et de l'usage ou du défaut d'exercice des organes; c'est la loi de mulliplication des espéces en raison géométrique qui a pour conséquence la concurrenco vitalo et l'élection naturelle, d'où suivent la divergence des caractères et l'extinotion des formes spécifiques. 
Il y a de la grandeur dans une telle manière d'envisager la vie et ses diverses puissances, animant a l'origine quelques formes ou une forme unique sous un souffle créateur. Et tandis que notre planète a continué de décrire ses cycles perpétuels, d'après les lois fixes de la gravitation, d'un si modeste berceau sont sorties des formes sans nombre, de plus en plus belles, de plus en plus mervéilleuses, qui vont en se développant dans une évolution sans fin (").

Ainsi parle Darwin lui-même, résumant cette loi universelle et désormais incontestable de la parenté, de la fraternité de tous les ètres. Tous les faits judicieusement observés en histoire naturelle viennent témoigner en faveur de cette unité organique. Nous avons déjà remarqué plus haut (p. 24) la parenté entre l'homme et les animaux signalée par le témoignage actuel de notre propre embryologie. Nous y reviendrons plus tard, ainsi que sur les témoignages fournis par l'anatomie comparée. Mais dans la nature tous les renseignements sont précieux et il n'y a rien d'insignifiant. Ainsi, par exemple, la main de l'homme n'est pas arbitraire mais rattachée morphologiquement aux pattes des animaux qui nous paraissent les plus étrangers. Dans la main du gorille, dans celle de l'orang, dans la patte du chien, dans le sabot du cheval, dans la nageoire pectorale du phoque et du dauphin, dans l'aile de la chauve-souris, dans la pioche de la taupe et mème dans les pattes du plus imparfait des mammifères, l'ornithorynque, on retrouve partout et toujours le mème nombre d'os et la même construction. Cette comparaison, que nous avons reproduite d'après Hæckel ( $f g$. 43), est significative pour tous ceux qui savent lire.

Les diverses formes des ètres ne sont que les résultats de transformations lentes. C'est, en grand, ce qui se produit en petit dans la physionomie humaine et dans les allures des individus selon leur genre de vie et leurs facultés dominantes. Un penseur, un savant, un poète, un théologien, un artiste, un magistrat, un commerçant, un militaire, un ouvrier, un moine, un sacristain, un viveur, un parasite, un joueur, un escroc, un voleur, un malfaiteur, portent chacun sur leur physionomie et dans leur manière d'être des témoignages non équivoques de leur situation sociale. On rencontre

1. Darwiw, De l'origine des espèces ou des lois du progrès chez les êtres organisés. 
très souvent dans le monde des êtres chez lesquels le cerveau semble atrophié. Le chercheur porte une tête pensive légèrement inclinée; celui dont la cervelle est vide et légère porte la tête altière et pose un peu à la façon du paon. L'ouvrier a des muscles, le poète et le musicien ont des nerfs, l'observateur a des yeux, et sur chaque visage, l'âme se reflète dans sa manifestation réelle. Multipliez ces nuances par des siècles d'hérédité et de dévcloppement et vous aurez une image de la transformation des espèces.

L'examen des fossiles qui caractérisent les différentes couches de terrains géologiques montre que les formes organisées vont en se simplifiant à mesure que l'on descend et que l'on retrouve des couches de plus en plus anciennes. Sans doute, tous les êtres fossiles sont loin d'avoir été retrouvés. Les fouilles que l'homme a faites dans l'écorce terrestre ne représentent qu'une surface insignifiante. Les types découverts sont comme des médailles de divers siècles : on en a retrouvé quelques-unes, mais il en manque un grand nombre. Pourtant elles suffisent pour reconstituer la marche générale de l'histoire, et, remarque significative, chaque médaille nouvelle que l'on met au jour vient précisément se placer aux lacunes laissées en blanc et servir de trait d'union entre deux espéces qui paraissaient trop éloignées l'une de l'autre et se séparer dans l'arbre généalogique. Ainsi l'on descend jusqu'aux couches primitives, où l'on ne trouve plus aucun fossile de végétal ou d'aṇimal ressemblant à ceux qui existent aujourd'hui, mais précisément des types élémentaires très inférieurs qui ne représentent pour ainsi dire que des réunions de cellules sans organisation.

Tous les êtres vivants sont pareils entre eux. Non seulement on peut passer d'une espèce à l'autre, chez les animaux comme chez les végétaux, sans avoir jamais d'abíme à franchir, sans trouver de vides entre elles, mais encore on constate que les espèces les plus perfectionnées peuvent être rattachées de proche en proche aux espèces les plus simples, comme des extrémités des diverses branches d'un arbre gigantesque on descend aux branches inférieures dont toutes les autres dérivent. Il y a plus. Lorsqu'on arrive aux animaux comme aux plantes primitifs les plus élémentaires, on voit qu'à leur tour ils ne sont pas aussi séparés entre eux que le sont les animaux supéricurs des plantes supérieures, et qu'au contraire 
ils se rapprochent à un tel point que l'on ne sait plus si l'on doit les nommer des animaux ou des plantes. Ce sont des êtres intermédiaires, qui ne sont ni animaux ni plantes, mais les deux à la fois, sous une forme tont élémentaire, et qui les rapproche meme du minéral. En fait, tels de ces êtres primitifs sont à la fois minéraux, plantes et animaux; par exemple, les coraux, les éponges et un grand nombre de zoophytes.

Dans l'état actuel de la science, on peut déjà se représenter la filiation générale des espèces et esquisser l'arbre généalogique de la vie terrestre. C'est ce qu'a fait récemment le naturaliste Hiekel dans le tableau figuré que nous avons reproduit plus haut (fg. 45). Cette filiation n'est pas encore établie dans toutes ses branches, mais l'ensemble est déjà démontré par l'accord de toutes les sciences naturelles réunies : géologie, paléontologie, anatomic, embryologie, physiologie, etc. Nous venons d'esquisser cet ensemble, nous allons pénétrer dans l'analyse des origines et chercher d'abord comment la vie a commencé sur notre planète errante. Mais le fait capital, celui de l'unité et de la parenté de tous les êtres vivants est désormais fondé sur des bases inébranlables.

Les espèces sont dérivées les unes des autres par suite de transformations naturelles lentement accomplies; elles ne sont ni immuables ni même durables; elles naissent comme variétés, vivent et disparaissent lorsque les conditions de leur existence mettent en péril leur vitalité. Nous avons vu déjà disparaître plusieurs espèces depuis les temps historiques même. Lo dinornis a cessé de vivre à la Nouvelle Zélande, l'æpiornis à Madagascar, le dronte et plusieurs espèces de tortues aux îles Muscareignes. La baleine disparait rapidement. Les troupeaux d'aurochs qui habitaient la Gaule du temps de Jules César ont disparu. Plusieurs races humaines, notamment celle des Tasmaniens, se sont éteintes sans retour. Pendant ce temps, d'autres grandissent et arrivent à leur apogée. Toutes ces transformations de la vie terrestre s'accomplissent naturellement, sans révolutions géologiques, sans cataclysmes et sans miracles.

On le voit, tout nous prouve l'unité de l'arbre généalogique de la vie et la filiation naturelle des ètres depuis le vers de terre jusqu'à l'homme. L'embryologie, qui nous montro l'homme lui-mème commencant son existence par un ouf et par des phases correspon- 
dant aux formes animales d'où sont issus ses ancêtres; l'anatomie comparée, qui montre l'identité de son squelette avec celui des vertćbrés supérieurs; la physiologie qui nous montre dans le cerreau le développement progressif de la moelle épinière et dans chaque organe un résultat de l'exercice de facultés graducllement grandissantes; l'histoire naturelle dans toutes ses branches, qui nous montre chez les plantes comme chez les animaux la variation des organes et des formes produite par les changements de milieux, de conditions d'existence, d'alimentation, de respiration, de lumière, de température, etc., et se transmettant par hérédité, ainsi que l'atrophie et la disparition des organes devenus inutiles; la paléontologie, qui nous montre les fossiles èchelonnés du simple au composé et se succédant de période en période en accusant un lent et perpétuel progrès dans le développement des espèces; la géologie et l'histoire de la Terre, qui nous montrent l'harmonie des périodes avec les espèces vivantes et mettent les causes à côté des effets; tout nous prouve cette unité grandiose, cette universelle fraternité.

Telle est la théorie de la transformation des espèces, de leur filiation et de leur origine, aujourd'hui irrévocablement établie par les travaux des grands naturalistes, a la tête desquels se placent Lamarck, Geoffroy-Saint-Milaire et Darwin. Ne pas l'accepter, c'est fermer les yeux à la lumière. Dans l'état actuel de nos connaissances, lorsque vous entendez quelqu'un tourner en ridicule la parenté de l'homme avec le singe et avec les autres espèces animales, tenez pour démontré que vous avez devant vous ou un ignorant, ou une personne de mauvaise foi, ou un cerveau muré; et ne vous donnez pas la peine de discuter. Cos esprits rétrogrades mettent la noblesse où elle,n'est pas, dans la décadence d'un type primitif plus ou moins parfait, au lieu de la reconnaitre, de l'admirer et de la saluer dans LE PROGRÈs. 


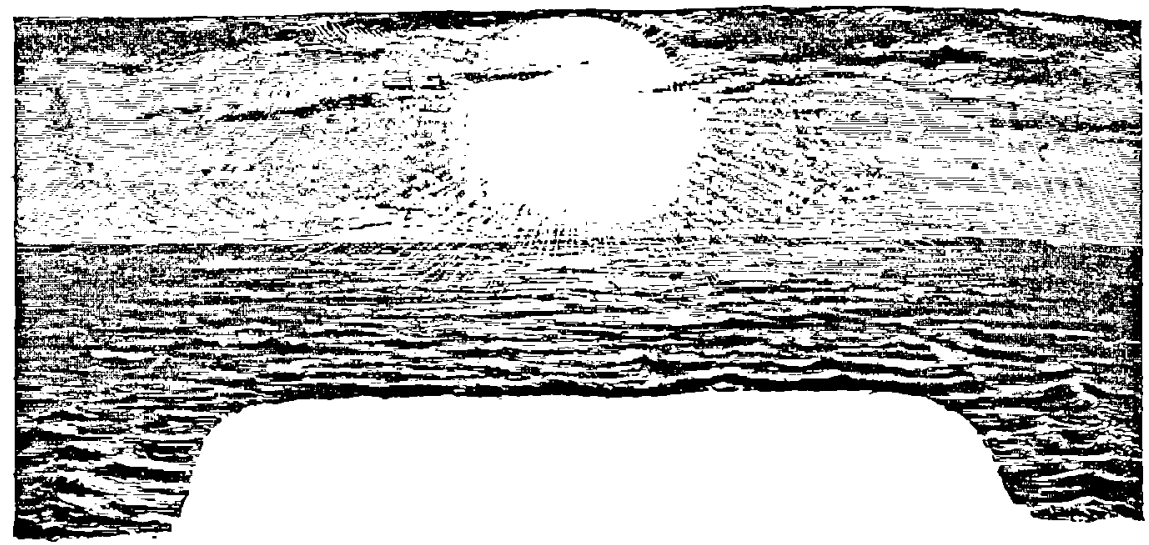

GHAPITRE II

LES ORIGINES DE LA VIE

Comment la vie a-t-elle commencé ? L'organisme élémentaire.

Nous arrivons ici à la question capitale par excellence. Que les espèces animales d'une part, les espèces végétales d'autre part, dérivent, comme des branches et des rameaux de deux troncs primitifs, c'est ce qui doit être accepté comme entièrement conforme à tous les enseignements directs de la nature elle-même. Que ces deux arbres généalogiques soient voisins par leur origine et aient les mêmes racines, c'est ce que nous pouvons également admettre, en interprétant ces enseignements dans leur étendue générale. Mais, reculons aussi loin que nous le voudrons, à travers les âges, les filiations organiques et leurs transformations, nous n'en sommes pas moins conduits à aboutir à un moment où la vie a dù commencer. La vie ne pouvait exister, même en germes, à l'époque où la Terre était soleil, et brillait incandescente dans les solitudes de l'espace. Il ne pouvait exister là ni germos de plantes, ni germes d'animaux, ni molécules organiques quelconques. Les éléments chimiques étaient eux-mêmes dissociés. Avant d'être soleil, notre planète, comme nous l'avons vu, était à l'état gazeux, faisant partie de la nébuleuse solaire. En remontant plus haut encore, nous atteignons une époque à laquelle la substance qui devait dans l'avenir constituer la Terre et ses habitants était raréfièe à un tel degré que le vide le plus absolu de nos machines pneumatiques serait du 


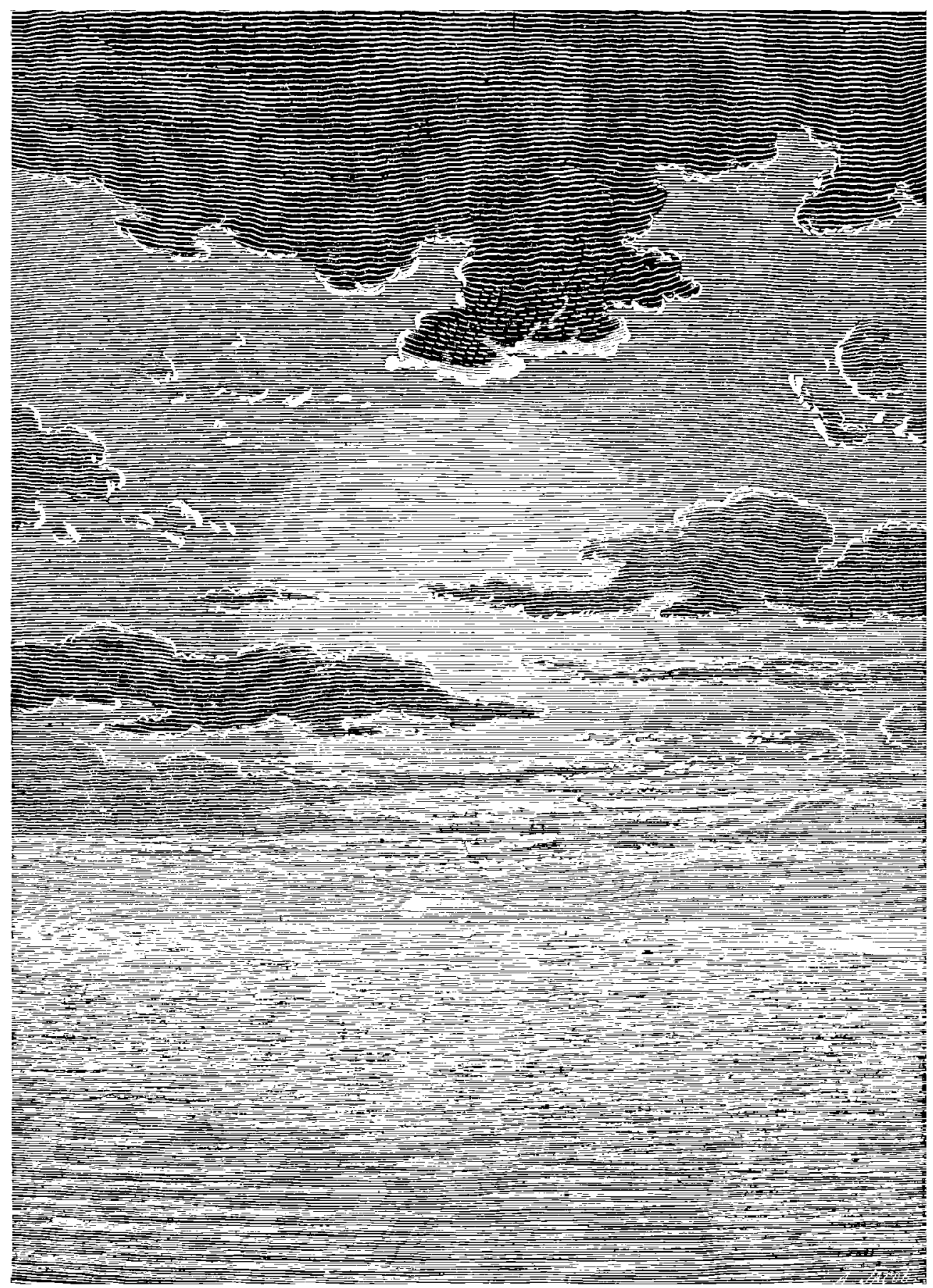

... Sous l'immense soleil des premiers âges, l'eau, l'euu partout, l'eau tonjours.. Dans son sein va germer la vie.

LE MONDE AYANT LA CRÉtion DE L'HOMME 
plomb en comparaison, presque impondérable et presque aussi transparente que l'espace pur. Il est impossible d'imaginer que les germes de la vie aient pu exister déjà dans ces conditions, à moins de faire une hypothèse un peu hardie.

Cette hypothèse consisterait à supposer que les germes primitifs de la vie sont des atomes spéciaux, des atomes vivants, existant au même titre que les atomes de carbone, d'oxygène, d'hydrogène, d'azote ou de fer. On admet, en chimie et en mécanique, que les atomes sont indestructibles. De là à les supposer éternels, la distance n'est pas très grande. Si les atomes ont existé de toute éternité, et si l'origine de la vie réside dans la propriété de a l'atome vivant » d'attirer à soi d'autres atomes pour en constituer des molécules organiques, il suffirait d'attendre que les conditions convenables fussent réunies pour assister à la formation naturelle de la première cellule organique.

Mais cette hypothèse n'est pas probable. Sans doute, il n'y a pas vraiment d'atomes d'hydrogène, d'oxygène, de carbone ou de fer, mais seulement des molécules de ces corps, c'est-à-dire des agglomérations spécifiques, distinctes, variées, d'atomes primitifs, qui, eux, ne sont ni de l'hydrogène, ni de l'oxygène, ni du fer, etc. Les corps que la chimie appelle sịmples sont très probablement des composés, des édifices d'atomes élémentaires. Dans cette vue de l'univers, il n'y aurait qu'un genre d'atomes primitifs, tous les atomes étant identiques.

La substance cosmique primordiale doit etre simple, formée d'atomes homogènes, dernier terme de la réductibilité de la matière. Les corps considérés comme simples par la chimie peuvent ètre, doivent être des agglomérations d'atomes, des molécules différant entre elles par leur volume, leur forme et leur poids. La molécule d'hydrogène pèse 8 fois moins que la molécule d'oxygène, 14 fois mains que celle de l'azote, 31 fois moins que celle du phosphore, 100 fois moins que celle du mercure. Mais tout porte à croire que ce sont vraiment lá des molécules et non des atomes, et que leurs différences de propriétés proviennent de leurs différences de constitution atomique.

A leur tour, ces molécules, en se réunissant, forment des particules de corps autrefois réputés simples et aujourd'hui connus comme composés. Deux volumes d'hydrogène combinés avec un 
volume d'oxygène créent de l'eau. 21 parties d'oxygène mélangées à 79 parties d'azote créent de l'air. Tous les corps qui nous environnent, inorganiques ou organiques, sont des composés, des associations, des combinaisons de molécules fournies par les divers corps appclés simples en chimie.

Partout et en tout, dans scs moindres détails comme dans les plus grandes lignes de l'architecture du cosmos, la nature procède du simple au composé. Nous sommes donc autorisés par son enseignement mème à remonter, dans la recherche de l'origine des choses, jusqu'à la plus extrême simplification qu'il soit possible d'imaginer, et sans doute n'atteindrons-nous mème pas encore la simplicité primordiale.

A l'origine du système solaire, la substance cosmique primitive dont il est constitué était formée d'atomes homogènes, simples, élémentaires; l'état actuel de l'univers est dù aux arrangements ultérieurs de ces atomes entre eux.

Nous admettons en principe que les molécules des corps considérés encore aujourd'hui comme simples par la chimie sont composées d'atomes, et que leurs diversités spécifiques proviennent du mode d'arrangement de ces atomes primitifs réalisé dans la formation de chaque molécule.

Ces modes d'association ne sont pas arbitraires, mais causés par les forces de la nature, telles que l'attraction (quelle que soit son essence), la chaleur, la lumière, l'électricité, le magnétisme et les autres modes de mouvement atomique. Il n'est donc pas surprenant que les mèmes combinaisons d'atomes aient été réalisées en des mondes différents et même en des systèmes de mondes différents, et que l'analyse spectrale ait constaté la présence du fer, de l'hydrogène, du sodium, du magnésium, de l'eau mème et du carbone, ainsi que d'autres éléments existants sur la Terre, dans le Soleil, les étoiles, les planètes et los comètes. Les lois de la nature sont partout les mêmes, quoique appliquées sous des formes variées. Mais ces mèmes atomes primitifs simples et élémentaires, peuvent aussi s'être associés en d'autres genres de molécules n'existant pas sur la Terre. Et, en effet, le spectroscope révèle dans Saturne, dans Uranus, dans certaines nébuleuses, l'existence de corps inconnus qui n'ont pas leurs analogues dans la chimie terrestre. Dans le spectre solaire, 
les raies de l'hélium prouvent qu'il y a sur le Soleil des corps absolument étrangers à ceux que nous connaissons sur la Terre.

Les associations géométriques d'atomes ont créé les molécules originaires des espèces inorganiques, l'hydrogène, l'oxygène, l'azote, le carbone, le fer, le soufre, le phosphore, l'arsenic, l'aluminium, l'antimoine, l'argent, l'or, le plomb, le zinc, le cuivre, l'étain, le mercure, etc.

Les associations de molécules, parmi lesquelles se signalent en première ligne les molécules de carbone et les particules d'eau et d'air, ont pu, dans le développement du même principe naturel, produire les premières substances organiques. La force qui, primitivement, est purement mécanique dans les mouvements des atomes élémentaires ou dans celle des astres, atomes de l'espace immense, devient affinité, force physico-chimique, dans les associations de molécules entre elles, force vitale dans la constitution des organismes végétaux et animaux, et plus tard force pensante chez les animaux et chez l'homme (l'âme humaine, consciente d'elle-même et responsable, n'arrivera sur la Terre que dans les temps modernes). Il n'y a sans doute qu'une force, comme il n'y a qu'un genre d'atomes. Mais cette force se diversifie, comme la substance, et ses diverses manifestations peuvent à leur tour se transformer les unes dans les autres, la somme d'ènergie restant la mème, comme la quantité de matière, rien ne venant du néant et rien ne s'anéantissant.

L'analyse des.tissus animaux et végétaux prouve directement qu'ils sont formés de molécules inorganiques. Buffon et plusieurs naturalistes ont cru qu'il existait des molécules organiques; mais on a reconnu depuis que c'était là une erreur. Il n'y a pas de molécules organiques. Comme fait incontestable et absolument démontré, les êtres vivants sont composés de molécules inorganiques, parmi lesquelles dominent l'eau, l'air, le carbone et autres substances primitivement non organisées.

Allons un peu plus loin. Si l'on examine en détail ces tissus animaux et végétaux, on constate qu'ils sont formés de globules muqueux soudés ensemble. Ces globules albuminoïdes, désignés techniquement sous le nom de cellules, sont de petits œufs microscopiques, dans lesquels on peut distinguer ce qui caractérise tous 
les œufs : une enveloppe, un liquide et un noyau. C'est là l'élément essentiel de construction de tous les êtres vivants, végétaux comme animaux. Tous, encore aujourd'hui (y compris l'homme), naissent d'un ceuf microscopique, d'une simple cellule.

Nous sqmmes donc conduits, par l'étude directe de la nature, à admettre que la vie a commencé sur la Terre par la formation de cellules élémentaires. Mais comment, et de quelles substances ces cellules se sont-elles formées?

Malgré le scepticisme apparent de ceux qui prétendent qu'il est interdit à la nature humaine de remonter à la recherche des causes premières, cette question de l'origine de la vie est trop capitale pour n'avoir pas préoccupé tous les esprits soucieux de la connaissance de la vérité. On est allé parfois très loin en chercher la solution. C'est ainsi que sir William Thomson a émis l'hypothèse que les premiers germes de la vie ont pu etre apportés sur notre planète par les étoiles filantes et les uranolithes, considérés comme ruines de mondes détruits flottant dans l'espace et rencontrant par hasard dans les déserts du vide les mondes à ensemencer. L'hypothèse est originale, mais peu probable, quoi qu'il ne soit pas du tout impossible qu'un morceau de planète défunte tombe du ciel et nous apporte quelque germe non stérilisé. Mais les conditionss d'habitabilité des divers mondes sont si différentes entre elles que lors même qu'une telle occurrence se produirait, il n'est point dit pour cela que l'endroit de la mer ou des continents où l'uranolithe arriverait serait un champ tout préparé pour faire fructifier la semence extra-terrestre. Les étoiles filantes arrivant dans l'air et s'y désagrégeant seraient peut-être plus sûres; mais la chaleur produite par la rapidité de leur pénétration dans l'atmosphère les fond et les brûle, à moins qu'elles n'aient un volume relativement considérable. D'ailleurs, une telle hypothèse ne fait que reculer la difficulté. Si la vie nous venait d'un autre monde, la question serait de chercher comment elle est née sur ce monde antérieur, et ainsi de suite.

Revenons donc à la question elle-même. D'après les considérations qui précèdent, nous avons pour la résoudre les documents concordants fournis par divers ordres d'études : l'examen des fossiles appartenant aux terrains les plus anciens; l'examen de l'arbre généalogique des espèces végétales et des espèces animales; 
l'examen de la formation actuelle des êtres organisés et des substances qui les constituent.

L'un des résultats les plus importants de la science moderne a été de constater, comme nous venons de le voir, qu'il n'y a pas de matière organique spéciale, et que végétaux et animaux sont composés d'éléments inorganiques, que l'on connait d'ailleurs, et qui sont, par ordre d'importance : l'eau (c'est-à-dire l'oxygène et l'hydrogène), l'air (c'est-à-dire l'oxygène et l'azote), le carbone, la chaux, la silice, le sel, le phosphore, le soufre, le fer. Tous les êtres vivants, quels qu'ils soient, depuis l'homme jusqu'd la plante la plus élémentaire, sont formés de matériaux inorganiques. Ce qui les distingue des minéraux, ce n'est pas la composition, la substance, mais le mode spécial d'arrangement, qui en fait des corps ni solides, ni liquides, ni gazeux, cornme les corps inorganiques, mais des corps semi-solides, semi-liquides; cet état spécial est dủ surtout à l'eau, qui existe en grande quantité dans tous les êtres organisés et qui, par son union avec les éléments constitutifs de leur substance, joue un rôle de premier ordre dans l'explication des phénomènes de la vie ( $\left.{ }^{4}\right)$.

C'est là un fait très important pour la solution du grand problème. En voici un sccond qui n'est pas moins significatif, c'est que ces êtres se reproduisent. Mais il faut savoir interpréter cette faculté et ne pas se laisser illusionner par les apparences.

On croit généralement que tous les êtres vivants, hommes, animaux, végétaux, naissent aujourd'hui d'un père et d'une mère, et l'on voit là une objection insurmontable à la formation spontanée d'un premier être vivant. C'est là une erreur. Il n'y a que les êtres supérieurs qui se reproduisent par la génération sexuelle. Les ètres élémentaires se reproduisent par simple fractionnement. Considérons, par exemple, les monères, les amibes, les zoophytes, les polypes, etc. Qu'observons-nous chez un grand nombre d'entre eux? Tout simplementiceci : l'organisme se partage en deux moitiés égales, dès que par la croissance il a atteint un certain volume; puis cha-

1. Les organismes primitifs ne sont pour ainsi dire que de l'eau imprégnée d'éléments associés. Chez certaines méduses, le corps contient 99 p. 100 d'eau, et seulement 1 p. 100 de matière solide. Chez l'homme, le corps renferme dans ses tissus 70 p. 100 d'eau et sulement 30 p. 100 de matière solide. 
cune des deux moitiés s'accroît et devient un individu complet. Et ainsi de suite. On rencontre le même mode de reproduction chez certains annelés. C'est, du reste, là le mode constant de reproduction de la cellule elle-mème, c'est-à-dire de l'élément constitutif. A l'origine, il n'y avait ni végétaux ni animaux, mais seulement des cellules, ou moins encore, peut-être les monères d'Haeckel.

Les monères (') sont les êtres les plus simples qui aient encore été observés. Elles ont été découvertes en 1864, dans la Méditerranée, dans la délicieuse baie de Villefranche, près de Nice $\left(^{2}\right)$, par Haeckel, professeur de zoologie à l'Université d'Iéna; ce sont de petites boules muqueuses, invisibles à l'œil nu, ou très petites, et ne dépassant que rarement 1 millimètre de diamètre. Elles sont formées

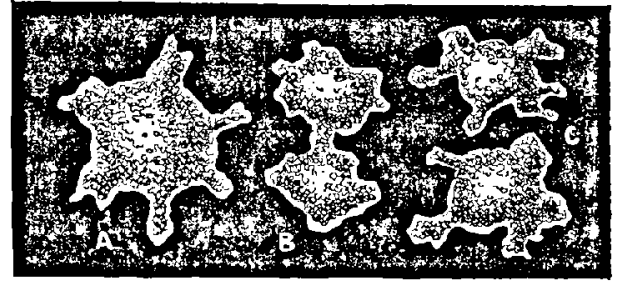

Fig. 48. - Les premiers organisues, la monère, d'après Haeckel.

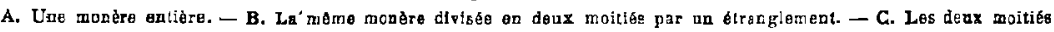
se sont séparées et constituent maintenant des individus indépendacts.

d'une substance carbonée albuminoïde et se soudent ensemble comme les molécules végétales d'une feuille; on les rencontre, réunies sous forme de petites masses gélatineuses, sur les rochers et dans la mer. C'est un organisme sans organes : ni tête, nï membres, ni estomac, ni cœur, ni système nerveux ou musculaire. Matière sans structure, simple, homogène, ce grain vivant est aussi bien plante qu'animal. Il est d'une vitalité surprenante, et on l'a trouvé dans les abìmes océaniques jusqu'à 8000 mètres de profondeur. Il est sphérique, ce qui est la forme élémentaire par excellence. Il est mobile. Quand il se met en mouvement, il se forme à sa surface des saillies digitèes, des espèces de petits pieds informes, qui lui permettent de se déplacer. Il se nourrit sans bouche, sans tube digestif, sans estomac, par endosmose, comme les iplantes, la nourriture à absorber pénétrant par conlact jusque

1. Étymologie : Movos, seul.

2. D'oû l'auteur éerit précisément ces lignes (féyrier 1885). 
dans son intérieur. Pour se reproduire, il se divise en deux parties qui se forment à la suite d'un étranglement, comme on peat's'en rendre compte à l'examen de la petite figure précédente.

$\therefore$ Ce mode de reproduction n'est qu'un excès de croissance de l'organisme qui dépasse son volume normal. Ce procédé primitif, la- fissiparité, est, à proprement parler, le procédé dę multiplications le plus gẻnëral, le plus répandu; en effet, c'est par ce simple mode de division que, se reproduisent les cellules, ces individns orgániques rudimentaires dont l'agglomération constitue la masse de la plipart des, organismes, sans en excepter. le corps humain. Considèrons, par exemple, avec le mème auteur, ce qui arrive dans un œuf de mammifère. Voici $(f g .49)$ l'un de ces œufs. En sommc,

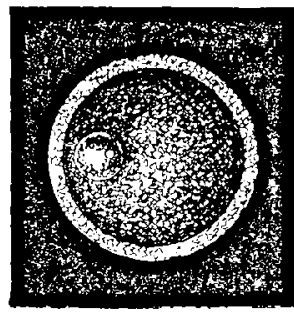

Fig 49.

ouf de mammifère. c'est une simple cellule. Le tour est une membrane enveloppant la substance gélatineuse, dans laquelle on remarque un petit noyau ou vésicule germinative.

Dans le premier stade de la création de l'ètre vivart, cette vésicule germinative se divise par fissiparité en deux noyaux, puis la matière cellululaire, le jaune de l'œuf, suit le mouvement (fg. 50, A). De même les deux cellules se divisent à leur tour en quatre (B), celles-ci en huit (C), en scize, en, trentedeux, et enfin, il en résulte un amas sphérique ressemblant à une framboise (D). Ainsi commence, encore aujourd'hui, chaque être vivant, l'homme compris.

Celte même propagation par fissiparité, peut ètre observèe chez un grand nombre d'infusoires, comme le représente la figure 51. Dans l'espace de quelques jours, on voit naître, dans un verre d'eau de mer, plusieurs millions d'individus produits par ce procédé d'extrème simplicité.

A la reproduction par division ou fissiparitẻ se rattache de très près la reproduction par bourgeonnement, si répandue dans le règne végétal et dans certaines classes inféricures du règne anlimal, zoophytes, méduses hydrostatiques, vers; polypes, etc. Ici déjà se manifeste une différenciation. Tandis que dans le premier cas les deux ètres issus du partage de la cellule primitive sont frères et égaux, dans la reproduction par bourgeonnement, le second indi- 
vidu est un produit du premier, qui peut être considéré comme son gériérateur; il est plus petit, et il a besoin de grandir pour devenir:égal au premier.

C'est ainsi que les choses ont commencé. Les organismes in-

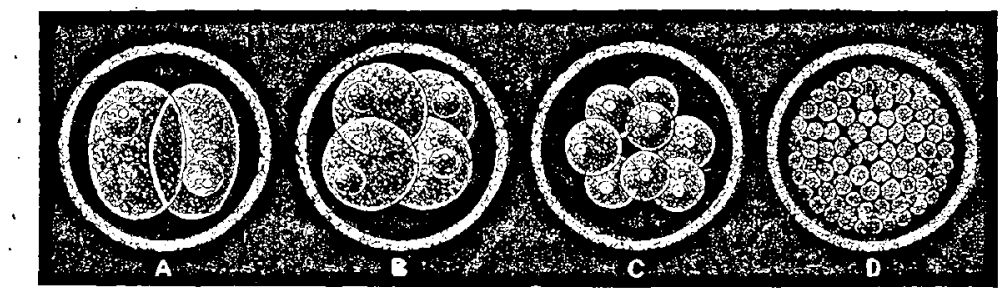

Fig. 30. - Premiers stades de la création d'un mammifère :

L'euf ou celiule se divise en deux, en quatre, en huit, ete, et finit par produire un amas sphérique analogue à une framboise.

férieurs, végétaux et animaux, n'ont pas de sexe. Pendant.des millions d'années ils se sont reproduits par fractionnement, par bourgeonnement, et ensuite par germes. L'existence des sexes, puis leur séparation en deux individus distincts, ne sont arrivés que fort
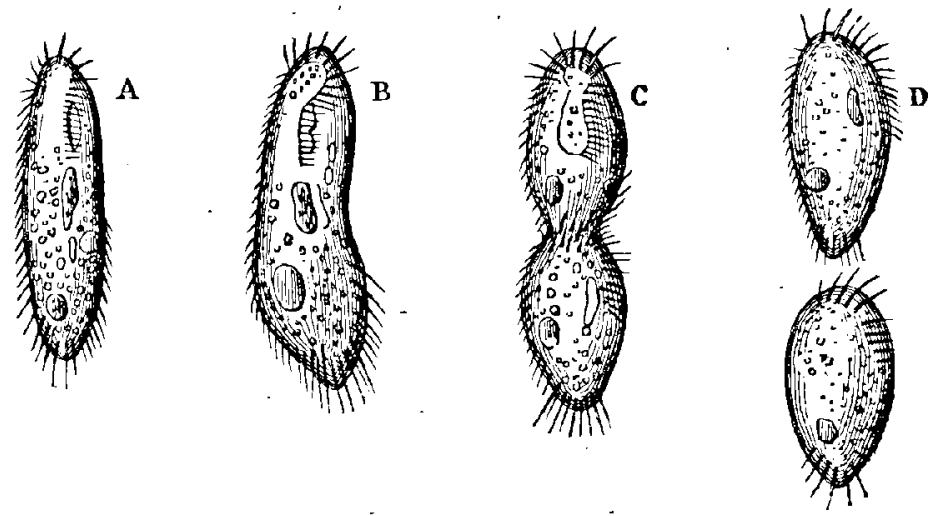

Fig. 51. - Propagation d'un infusoire par division spontanée.

tard dans l'histoire de la création. L'hermaphrodismé a précédé pendant longtemps la séparation des sexes : il existe encore aujourd'hui dans la majorité des plantes et chez certains animaux inférieurs (le colimacon, la sangsue, le lombric et beaucoup d'autres vers). La séparation des sexcs existe par contre chez les plantes su- 
périeures, mimosées, sensitives, orchidées, vallisnérie, chanvre, saules, peupliers, marronniers, dattiers, etc. D'ailleurs la génération sans sexe et la génération par sexe ne sont pas séparées par une grande distance, et la seconde vient de la première en passant par la génération alternante. La reproduction virginale ou parthénogénèse existe chez un grand nombre d'insectes parfaits (tout le monde connait celle des pucerons). On remarque des variantes assez curicuses. Ainsi, chez les abeilles, les œufs de la reine donnent naissance à des individus mâles (faux-bourdons) s'ils n'ont pas été fécondés, et à des abeilles femelles s'ils l'ont èté.

D'après ces études analytiques d'histoire naturelle, l'antique objection fondée sur l'idée que les ètres animés proviennent tous de parents générateurs n'a pas de valeur scientifique intrinsèque, puisque pendant une longue série de siècles les habitants primitifs du globe sont nés sans parents. La difficulté d'admettre la formation de cellules organiques élémentaires n'est plus aussi grande qu'elle le paraissait lorsqu'on enfermait le monde vivant dans un cercle trop étroit. Cette formation parait à peine plus compliquée (quoique toute différente) que celle des minéraux qui cristallisent en formes géométriques admirables, de ces produits chimiques qui, dans des conditions déterminées de saturation et de température, donnent naissance à ces merveilleux arrangements de molécules dont le microscope nous a fait connaître la grandeur et l'harmonie.

Les moneres de IIaeckel sont les organismes les plus simples et les plus élémentaires que l'on ait encore observés. On peut leur adjoindre les microzymas (') découverts et etudićs depuis 1857 par M. Béchamp, alors professeur à la Faculté de médecine de Montpellier. Ce sont des granulations moléculaires, microscopiques, que l'on a d'abord considérées comme des moisissures, qui agissent chimiquement pour intervertir le sucre en dissolution, pour former la mère du vinaigre, en un mot pour faire fermenter les productions organiques, que M. Béchamp trouve dans l'air, dans l'eau, dans les animaux, dans les végétaux, dans les minéraux même et dans les fossiles, et qu'il regarde comme des organismes vivants et indestructibles. Tandis que la cellule elle-même se constitue et se dé-

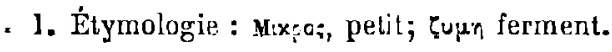


compose, par conséquent n'est pas simple et ne survit pas à la mort des organismes qu'elle a formés, le microzyma serait l'élément primitif de la cellule elle-mème, la forme vivante réduite à sa plus simple expression, ayant la vie en soi, sans laquelle la vie ne se manifeste nulle part. Ces granulations organiques, découvertes depuis en Allemagne, y ont reçu le nom de « micrococcus ». C'est leur réunion en alignements qui produit les bactéries. D'après l'auteur, ces êtres ne sont pas étrangers aux organismes, comme des germes extérieurs qui apporteraicnt les maladies; ils font partie intégrante essentielle de tous les corps vivants et sont l'origine même de la vie dans tous les êtres. Les microbes en forme du chiffre 8 de M. l'asteur ne seraient autres que des mycrozymas accouplés deux à deux. En un mot, les microzymas évolueraient en cellules, en oufs, en bactéries, en microbes, et seraient le substratum mème du monde organique tout entier. Ils sont classés avec raison parmi les infiniment petits; car leur grandeur est de l'ordre des millièmes de millimètres.

Sans doute, la nature intime de ces organismes n'est pas encore bien définie, et leur exiguïté mème cst une difficulté presque insurmontable. Mais, qu'ils portent vraiment en eux la vie indestructible, comme l'affirme le savant qui les a étudiés, ou qu'ils servent seulement à la constitution élémentaire des êtres, ils avaient droit de cité ici et devaient être présentés à nos lecteurs dans cet exposé indépendant et sincère de tous les éléments scientifiques qui peuvent contribuer à l'élucidation du grand problème de l'origine de la vie.

Mais, monères, microzymas, cellules, amibes, organismes rudimentaires, sont formés de quelque chose. Ce quclque chose, leur substance, possède une certaine activité que ne possèdent pas les minéraux. Eh bien! c'est là la première substance vivante, la plus élémentaire et la plus simple de toutes : on lui a donné le nom de protoplasma (') : les physiologistes constatent qu'elle existe à la base de tous les tissus, végétaux et animaux.

Le protoplasma est une substance appartenant au groupe chimique des albuminoïdes, c'est-à-dire composée par une combinaison du carbone avec l'hydrogène et l'azote, éléments primitifs mêmes de

1. Étymologie : $\pi \rho \omega \tau \sigma \sigma$, premier, et $\pi \lambda \alpha \sigma \mu \alpha$, formation. 
la planète. A ces éléments, dont les proportions varient, s'ajoutent souvent le soufre, le fer et le phosphore ('). Tout chimique, minéral, élèmentaire qu'il soit, le protoplasma vit, naìt, s'accroit, se reproduit et meurt, se nourrit, est sensible, se meut même et réagit contre les excitations qui viennent le provoquer. G'est cette substance qui, en se modifiant de façons diverses, sert à l'édification des tissus et des organes de tous les êtres vivants. Quand les êtres vivants meurent, leur substance se décompose et retourne au monde inorganique auquel elle avait été empruntée.

La sensibilité a été le point de départ de la vie, le grand phénomène initial d'où sont dérivés tous les autres, aussi bien dans l'ordre physiologique que dans l'ordre intellectuel et moral. Les plantes sont sensibles, comme les animaux (différences de degré seulement); le protoplasma est sensible, et c'est en cela surtout qu'il diffère des substances inorganiques qui lui ressemblent le plus.

Les monères, qui habitent encore aujourd'hui l'eau salée, ne sont composées que d'un simple grumeau protoplasmique. Ce sont les êtres les plus simples que nous connaissions. La vie a commencè à l'époque où le globe terrestre était entièrement environné des eaux tièdes de l'océan primordial. Les premiers êtres vivants, très probablement analogues aux monères actuelles, étaient habitants de la mer. D'enx sont venues les plantes aquatiques et terrestres, les êtres qui ne peuvent plus vivre aujourd'hui que dans l'eau douce des lacs, des rivières et des fleuves, ainsi que toute la flore et toute la faune qui décorent et animent aujourd'hui la terre ferme des continents. Encore aujourd'hui les êtres sont surtout composés d'eau.

L'enseignement tout entier de la nature répond donc à la question posée tout à l'heure. Nous savons que les premiers organismes se sont formés dans les eaux tièdes de la mer primitive et n'ont été que des corpuscules gélatineux sans formes, sans structure,

1. D'après Lieber Kühn, la formule de l'albumine serait $\mathrm{C}^{210} \mathrm{H}^{382} \mathrm{Az}^{78} \mathrm{O}^{78} \mathrm{~S}^{3}$, c'est-d̂-dire qu'une particule d'albumine serait composée de 240 molécules de carbone, 392 d'hydrogène, 75 d'azote, 75 d'oxygène, 3 de soufre, et comprendrait par conséquont 786 molécules de divers corps simples. Elle est relativement grosse et on l'estime à trois millionnièmes de millimètre de diamèlre environ. On ne la voit pas encore au microscope, quoiqu'on parvienne déjà à distinguer des lignes ne mesurant que cinq millionnièmes de millimètre de diamètre et des objets mesurant 10 millionnièmes ou 1 cent millème. 
des corps chimiques dans lesquels les propriétés spéciales du carbone, surtout la demi-fluidité et la souplesse indéfinie des composés albuminoüdes, ont commencé une différenciation capitale avec les produits exclusivement minéraux el ont inauguré les phínomènes de la vie.

Leurs formes rudimentaires et presque indécises nous apparaissent, pour employer la seule image qui soit assez expressive,

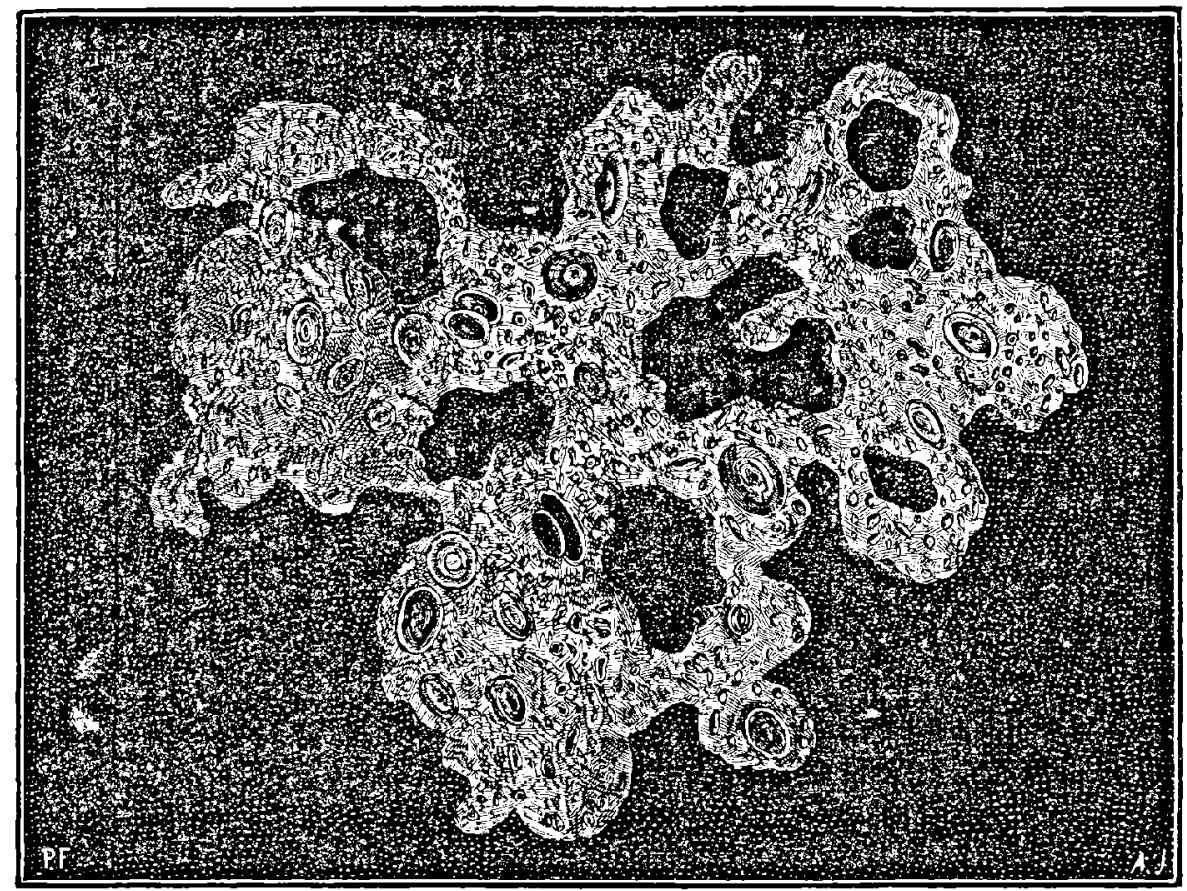

Fig. วั2. - LRS ORIGINSS DZ LA VIR. - Protoplasma recueilli dans les profondeurs de la mer (gr. : 700 diamétres).

comme les premiers pas hésitants de la vie qui vient de naître. Chez eux, la cellule, telle qu'on la définit avec son noyau et sa membrane d'enveloppe, n'existe pas encore. G'est presque dire que l'individualité n'existe pas non plus ou n'existe qu'à peine. La vie est encore à I'état confus. La substance protoplasmique fluctuante et amorphe ne nous donne qu'à peine l'idée d'ètres réels.

Pendant l'exploration du fond de l'Océan faite pour la première pose du câble transatlantique, on trouva, mêlée au limon gris qui forme ce fond, une masse gèlatineuse informe, contenant des cor- 
puscules calcaires. Cette gélatine fut conservée dans l'alcool. Le professeur Huxley reconnaissant en elle du protoplasma amorphe, la désigna comme l'être, le monérien le plus rudimentaire, sous le nom de Bathybius Hreckelii.

Les mémorables explorations sous-marines faites en 1868 et 1869 par MM. Thompson et Carpenter sur les navires Ligthning et Porcupine, qui renversèrent toutes Jes idées classiques enseignées sur l'absence de vie dans les profondeurs de la mer, découvrirent à trois et quatre mille mètres sous la surface des flots ce pro. toplasma consistant en une grande quantité de matière gélatineuse, organique, dans une proportion assez considérable pour donner au limon une certaine viscosité. Si l'on agite ce limon avec de l'espritde-vin à un faible degré, des flocons très fins se déposent, ayant l'aspect d'une substance muqueuse et coagulée. Si un peu de ce limon, dont la nature visqueuse est des plus évidentes, est placé dans une goutte d'eau de mer sous le microscope, on peut ordinairement apercevoir, au bout de quelque temps, un réseau irrégulier de matière albuminoïde, avec contours nettement dessinés et qui ne se mêle pas avec l'eau : on peut voir comment cette masse visqueuse modifie peu d̀ peu sa forme et comment les granules englobés et les corps étrangers y changent leur situation relative. Cette substance est done susceptible d'un certain degré de mouvement, et il ne peut y avoir aucun doute qu'elle ne manifeste des phénomènes d'une forme de la vie très élémentaire. On a représenté plus haut ( $f g .52$ ), d'après l'ouvrage de ces navigateurs (Les abimes de la mer), un fragment de cette substance.

Toutefois, on resta longtemps sceptique sur la nature et sur l'existence même de cet ètre trop rudimentaire. Les chimistes ayant montré que l'alcool versé dans l'eau de mer détermine un précipité visqueux, on assimila la substance en question à un précipité de ce genre. Mais en 1875, un naturaliste allemand, M. Bessels, l'observa de nouveau dans une expédition américaine au pôle Nord, à une profondeur de 92 brasses, dans le détroit de Smith. Ces masses étaient purement et simplement constituées par du protoplasma, auxquelles se trouvaient être mélés accidentellement quelques corpuscules calcaires.

Les monères ne sont que du protoplasma. « Un grumcau de 
gelée, écrit M. Perrier, voilà tout ce que montrent en elles nos microscopes les plus puissants. Mais cette gelée est vivante : on la voit à chaque instant changer de forme, s'emparer d'autres infusoires, les dissoudre et les incorporer dans sa propre substance. Il apparaît dans le liquide qui l'entoure semblable à ces légers filaments qui ondulent dans un verre d'eau au-dessus d'un morceau de sucre qui fond ». Nous l'avons dit, les monères sont de petites sphères. Lorsqu'elles ont besoin de se déplacer, il leur pousse des rayons qui leur servent de pieds. On en connaît déjà plusieurs espèces. Elles constituent des individus qui sont comme autant de cellules, si l'on peut appeler cellules des masses nues ei sans noyaux. Ces petites boules vivantes ont, disons-nous, des cils ou lobes, pseudopodes rudimentaires, courts, irréguliers, qui s'avancent en saillio dans tous les sens, se raccourcissent et rentrent mème, quand ce rudiment d'ètre n'en a plus besoin. Le mode de locomotion est un mouvement de reptation qui s'effectue par l'allongement d'un lobe, lequel prend un point d'appui par son extrémité et se raccoureit ensuite pour entrainer le corps entier, semblant alors glisser comme une goutte d'huile chasscé par un souflle sur une lame de verre polie. Lorsqu'un rayon de soleil vient frapper le vase qui contient un de ces ètres, celui-ci se dirige toujouirs du côté de la lumière. L'élasticité du protoplasma vivant, sa dilatation et sa contraction sous l'influence de la chaleur dégagéc par sa respiration, suffisent à rendre compte du mécanisme de ces mouvements. Signalons encore, parmi les monères, le myxodictyum sociale. Là, le protoplasma constitue des individualités distinctes, de petits grumeaux plus ou moins sphériques, entourés de toutes parts de pseudopodes ramifiès et rayonnants, qui se reproduisent par fissiparité, comme nous l'avons vu plus haut, mais restent réunis en colonies par leurs filaments. On se rendra compte de leur aspect par la figure suivante ( $f g .53)$, reproduite d'après l'ouvrage de Perrier sur les colonies animales.

Ce sont là les êtres primitifs. L'organique vient de l'inorganique. La force vitale est née de la force physico-chimique.

L'électricité n'a probablement pas été étrangère à cette progression de la matière; aux conditions préparées par la chaleur, la pression des eaux, la densité, elle a ajouté celle qui donne aux molécules la faculté des mouvements internes. Encore aujourd'hui, 
elle joue un rôle peu étudié, mais important, dảns les phénomènes supérieurs de la vie. Le prophète qui eût été contemplateur de la Terre en cette époque primordiale n'eût pas olservé sans émotion cette ardento genèse qui allait créer un nouveau monde. Sous l'immense soleil des premiers âges, l'eau, l'eau partout, l'eau toujours... Dans son sein va germer la vie!

Certes, cette fécondation de la planète n'est pas en elle-même une simple opération chimique, pas plus qu'une combinaison n'est une opération mécanique : c'est qualque chose de plus. La vie est une forme nouvelle du mouvement; elle est une création naturelle produite par les conditions chimiques qui l'ont déterminée. Mais il n'y a pas ici une simple opération chimique, il y a autre chose, une nouvelle forme de mouvement. "Par' les. changements incessants qui s'accomplissent dans leur composition, par les mouvements dont ils sont le siège, par leur faculté de se nourrir, de se diviser en individualités distinctes, de se reproduire, les protoplasmes se distinguent nettement de toutes les substances chimiques, dirons-nous avec M. Edmond Perrier, ils constituent une classe de substances tout à fait à part. Entre les substances vivantes et les composés chimiques, la distance est grande. Mais on sait aujourd'hui que la vie existe avec tous ses caractères dans une classe de substances tout aussi simple, au point de vue de la structure, que les composés chimiques $i$.

- Pour le penseur qui cherche à pénétrer les secrets de la nature, ill n'est pas plus surprenant de voir les combinaisons du carbone donner naissance à des corpuscules gélatineux que de voir les cristaux arborescents d'une solution saline grandir et se développer à mesure que l'eau s'évapore, l'arbre de Saturne s'élever lorsqu'on abandonne une lame de zinc suspendue dans une dissolution d'acétate de plomb, la vapeur d'eau dessiner des fougères sur les vitres d'une fenêtre gelée, les fleurs hexagonales de la neige se former dans l'air, le soufre cristalliser en rhomboèdres, lo bismuth en hexaèdres, l'or et le cuivre en octaćdres pyramidaux, etc., etc. La différence qui sépare les produits organiques des produits inorganiques ne consiste pas dans la nature matérielle de leur composition, car la composition de tous les êtres vivants est purement chimique et formée des mèmes éléments que 
celle des corps inorganiques; cette différence réside dans la souplesse de leurs tissus, dans leur faculté d'ètre pénétrés par le milieu ambiant et de s'accroitre intérieurement par intussusception, au lieu de le faire extérieurement par juxtaposition comme les cristallisations chimiques, dans les formes qui les spécifient et dans l'aptitude à changer de forme (s'allonger, se raccourcir, se molfvoir), qui résulte de ces diverses propriétés. La différence essentiollc réside surtout dans la faculté de reproduction; mais, comme nous l'avons vu, cette faculté a commencé à se manifester par un

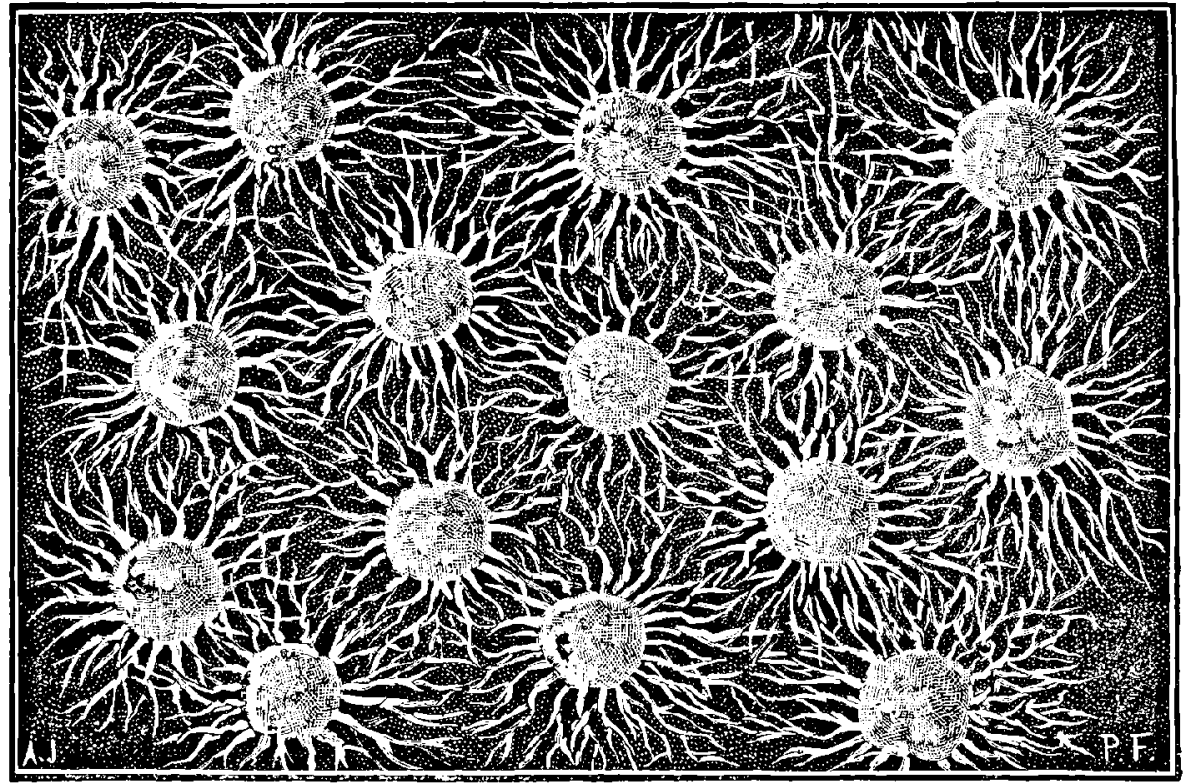

Fig. 53. - Les premiers organismes. - Association de monères.

simple partage de l'objet accru. Certes, on ne peut qualifier ni d'animal ni de végétal un corpuscule organique aussi rudimentaire qu'un grain de protoplasma; mais il diffère néanmoins essentiellement des autres produits chimiques, et il est véritablement l'cuf de la vie qui, dans l'avenir, se répandra à la surface de la Terre.

Pour la nature, il n'y a ni chimie, ni physique, ni mécanique, ni astronomie, ni météorologie, ni botanique, ni zoologie, pas plus qu'il n'y a d'espèces cosmographiques, minérales, végétales ou animales. Ce sont là des classifications inventées par les hommes pour séparer les objets d'étude et faciliter cette étude elle-mème. Quoi- 
qu'un grand nombre de savants se laissent illusionner et prennent leurs propres inventions pour des réalités, il importe de ne pas être dupes d'une erreur qui détruirait pour notre esprit la simplicité splendide de la nature. Pour elle, le monde organique est, comme le monde inorganique, le développement d'un même être; une vaste unité embrasse l'ensemble entier des choses.

L'univers a existé pendant longtemps dans un état purement mé. canique, nébuleuse en actirité, mouvements d'atomes, gravitation universelle. La chaleur, la lumière, l'électricité, les formations de molécules ont donné naissance à l'état physique, pendant lequel la planète est sortie de son berceau nébuleux. Les combinaisons, les affinités, ont amené l"êtat chimique : les conditions de la vie se préparaient. A ces trois âges, dérivés les uns des autres, a succédé l'état organique, issu tout naturellement aussi de l'âge qui l'avait précédé.

Du jour où par le développement mème de la genèse terrestre les conditions de la vie ont été réunies, il eût été aussi difficile au protoplasma de ne pas se former qu'à un produit chimique de ne pas obéir aux conditions qui le déterminent. Et du jour où la vie est apparue avec sa propriété caractéristique de reproduction perpétuelle, elle devait s'étendre et se multiplier sur toute la surface du monde. De même que la lumière, la chaleur, l'affinité chimique, le mouvement moléculaire, la vie agit sans cesse et ne s'éteint plus. Jusqu'au dernier jour de la Terre elle animera la nature, en se transformant à l'infini, mais en ne s'annihilant jamais. Et quelle force irrésistible! Il faut vivre : c'est le premier cri de tout ètre arrivant en ce monde, et qu'il appartienne à la plante, au mollusque, au poisson, au reptile, à l'oiseau ou au vertébré supérieur, cet ètre est à peine arrivé à l'âge adulte, qu'une loi suprême s'impose à lui, le pénètre d'inconscients désirs et lui fait pressentir les instants de mystérieuse volupté sans lesquels le flot de la vie s'arrèterait dans son cours. Il ne suffit pas de vivre, il faut encore perpétuer la vie.

A dater de cette époque, notre planète est transformée. Jusqu'ici, elle appartenait au monde minéral, sourd, muet, aveugle, inconscient; désormais elle porte la vie, et le premier sentiment confus d'existence personnelle qui vient de se manifester dans la formation des premiers organismes va s'illuminer et grandir pour atteindre un jour les nobles degrés du monde intellectuel et moral. 
G'est dans les mers que la vie a commencé; c'est là qu'elle est toujours la plus abondante. Les eaux possèdent beaucoup plus d'habitants que la terre ferme. Sur une surface moins variée que celle des continents, la mor renferme dans son scin une exubérance de vie dont aucune autre région du globe ne pourrait donner l'idée.

La vie s'épanouit au nord comme au midi, à l'orient comme à l'occident. Partout les mers sont peuplées; partout, au sein de l'abime, s'agitent et s'ébattent des créatures qui se correspondent et s'harmonisent; partout le naturaliste trouve à s'instruire et le philosophe à méditer. Les profondeurs de l'Océan, ses plaines et ses montagnes, ses vallées et ses obscurités, ses ruines mème sont animées et embellies par d'innombrables êtres organisés. Ce sont d'abord des plantes solitaires ou sociales, droites ou flottantes, étalées en prairies, groupées en oasis, ou rassemblées en immenses forets. Ces plantes protègent et nourrissent des milliers d'animaux, qui rampent, qui courent, qui nagent, qui volent, qui s'enfoncent dans le sable, s'attachent à des rochers, se logent dans des crevasses ou se construisent des abris; qui se recherchent ou se fuient, se poursuivent ou se battent, se caressent avec amour ou se dévorent sans pitié. Nos forèts terrestres n'entretiennent pas, à beaucoup près, autant d'animaux que celles de la mer. L'Océan qui est pour l'homme l'élément de l'asphyxie et de la mort est, pour des milliers d'animaux, un élément de vie et de santé. Il y a de la joie dans ses flots; il y a du bonheur sur ses rives; il y a du bleu partout (').

Aux grandes profondeurs, la température des eaux est sensiblement la mème (vers $0^{\circ}$ ) pour toutes les latitudes, depuis l'équateur jusqu'aux régions glacées des pôles. Les plus intenses agitations de la surface ne s'étendent pas à plus de 25 mètres de profondeur, d'où il résulte que les végétaux et les animaux, en descendant plus ou moins, suivant le froid ou les mouvements qui les trouble, peuvent toujours trouver un milieu qui leur convienne.

Les colosses que l'on rencontre dans la mer, la baleine, le cachalot, le rorqual, le narval, le dauphin, le requin, ne constituent pas la population la plus importante des profondeurs aquatiques. L'Océan est peuplé de légions innombrables d'infiniment petits,

1. Moquin-Taxdon. Le monde de la mer. 
d'infusoires microscopiques si minuscules qu'une gouttelette de liquide en contient plusieurs millions. Toutes les eaux en présentent, les donces comme les salées, les froides comme les chaudes. Les grands fleuves en charrient constamment des quantités ènormes dans la mer. Le Gange en transporte, dans l'espace d'une année, une

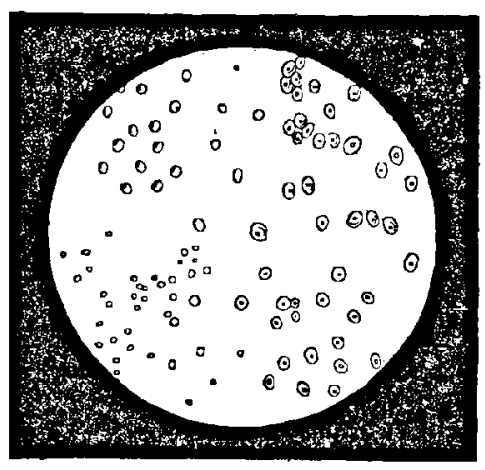

Fig. 54. - Infusoires élémentaires. Nonades. masse égale à six ou huit fois la valcur de la plus haute pyramide d'Égypte. Parmi ces animalcules, on en a compté déjà plusieurs centaines d'espèces diffirentes.

Près des deux pôles, là où de grands organismes ne pourraient exister, on rencontre encore des myriades d'infusoires. Ceux qu'on a observés dans les mers du pôle austral, pendant le voyage de James Ross, offraient une richesse loute particulière d'organisations inconnues jusqu'alors et d'une élégance remarquable. Dans les résidus de la fonte des glaces, qui flottent par $70^{\circ}$ de latitude, on a trouvé près de cinquante

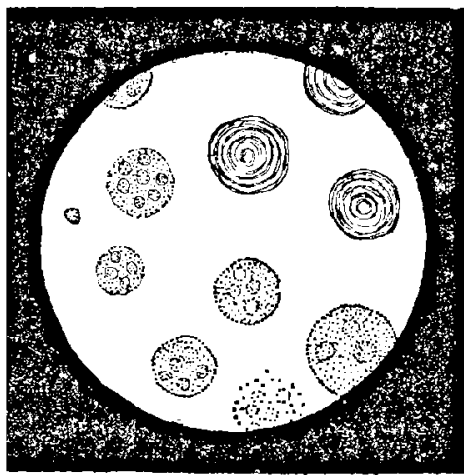

Fig 65. - Infusoires élémentaires. Volvores. espèces différentes (Ehhrenberg).

A des profondeurs de la mer, qui dépassent les hauteurs des plus puissanles montagnes, chaque couche d'eau est animée par des phalanges innombrables d'imperceptibles habitants (Humboldt).

Oui, voilà bien le berceau de la vie, et voilà bien les premiers ètres qui aient vécu. L'Océan a èté ce berceau, et la substance gélatineuse dont les infusoires sont composés a èté cette première gelée féconde. Encore aujourd'hui, les infusoircs sont à la fois les animanx les plus nombreux de la nature et ceux dont la force vitale est la plus énergique. Considérons, par exemple, les amibes (fig. 56). Imaginez-vous une gout telette de matière demi-solide, demitransparente, demi-gélatineuse, homogène, douée de mouvement 
volontaire. Elle s'agite dans divers sens, se dilate ou se resserre, adopte les figures les plus irrégulières et les plus inattendues. Quand on place l'animalcule sur le porte-objet d'un microscope, il glisse comme une gouttelette d'huile, se déforme et se reforme. Véritable protẻe, il est, suivant les moments, circulaire, oblong, échancré, lobé, étoilé, et même tout à fait rameux (Moquin-Tandon).

Les radiolaires peuvent leur être comparécs. On les rencontre dans la Méditerranée, surtout sous le beau ciel de Messine, flottant réunies en masses de gelée molle, diaphane, incolore. Leur dimension est à peu près celle d'un point (.). Si l'on essaye de les saisir
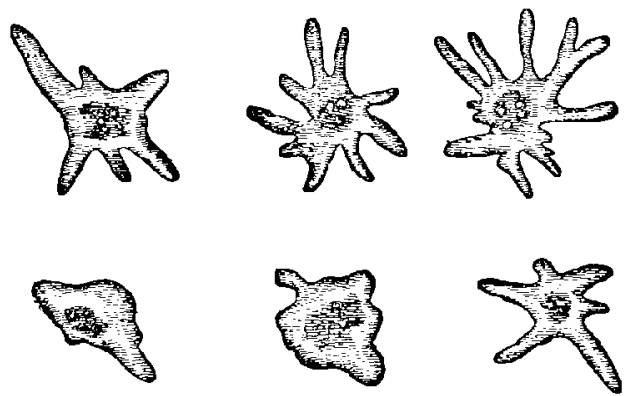

Fig. 56. - Infusoires élẻmentaires. - Amibes.

avec une pince, elles se déchirent; si l'on tente de les pêcher au filet, elles restent collées aux mailles.

Les monades ( $f g .54)$, semblent n'être que des molécules de substance absorbante, des atòmes agités, des points qui se meuvent: elles mesurent un trois-millième de millimètre de diamètre.

Les volvoces $(f g .55)$ roulent et tournoient constamment sur eux-mêmes. Ce sont de petites boules vivantes.

En général, ces infusoires sont pourvus de cils qui les entourent et leur servent à tout, mouvement, alimentation, respiration, etc.

Ces êtres possèdent, en quelque sorte, la vie dans chacun de leurs éléments. Müller a vu une kolpode se résoudre en molécules jusqu’à la sixième partie du corps, puis ce sixième se mit à nager « comme si de rien n'était ». Ils offrent bien d'autres genres de décompośition. Si l'on approche de la goutte d'eau dans laquelle ils nagent une barbe de plume trempée dans de l'ammoniaque, dit Moquin Tandon, l'animalcule s'arrête, mais continue à mouvoir ses cils. Tout à coup, sur un point de son contour, il se fait une échancrure qui s'agrandit 
peu à peu, jusqu'à ce que l'animal entier soit fondu, ou, pour mieux dire, dissous. Si l'on ajoute une goutte d'eau pure, la décomposition est brusquement enrayée, et ce qui reste de l'animalcule recommence à se mouvoir et à nager, toujours comme si de rien n'était!

Des rotifëres oubliés pendant plusieurs années dans un grenier, desséchés et morts pour toujours, peuvent revivre le plus facilement du monde : il suffit de les mouiller.

Tous ces petits êtres peuvent ètre comptés parmi les plus anciens de la planète. Sous toutes les latitudes et à toutes les profondeurs, on trouve en immenses bancs de pierre les foraminifères fossiles. Paris lui-même en est presque entièrement bâti. Les carrières de Gentilly les renferment à raison de 20000 par centimètre cube, ou de 20 milliards par mètre cube! Quand nous passons près d'une maison en démolition ou d'un édifice en construction, le nuage de poussière que nous respirons en passant nous en fait avaler des milliers. Ces infiniment petits ont construit des îles, des montagnes et ont joué un rôle plus considérable dans la formation de la terre que les animaux les plus puissants et, en apparence, les plus importants. Nous demanderons à tous ces petits êtres, dans le chapitre suivant, la leçon qu'ils sont en état de nous donner sur l'histoire de la vie à la surface de notre planète; le point capital pour nous était d'abord de déterminer les origines de cette vie.

Ainsi, pour résumer en quelques mots tous les documents qui précèdent : Nous connaissons aujourd'hui les origines de la vie sur la Terre; nous savons que tous les etres vivants, sans en exepter l'homme, sont parents entre eux et descendent de cette origine; nous savons aussi que cette origine et une humble substance organique issue des conditions physico-chimiques qui lui ont donné naissance; nous savons enfin que la LoI $\mathrm{Dt}$ PROGRÈs régit la création entière.

Telle a été, d'après l'enseignement de toutes les sciences comparées, l'origine de la vie sur notre planète, origine dont le développement et les transformations ont successivement donné naissance à la merveilleuse diversité qui nous environne. Cette création naturelle des espèces vivantes froisse quelques sentiments respectables, ayant leur source dans une interprétation étroite et mal dirigée du sentiment religieux. Pour l'esprit qui sait le comprendre, 
le progrès des êtres, depuis le minéral jusqu'à l'homme, est le plus sublime des poèmes, et la noblesse d'une telle origine, qui de l'argile s'élève jusqu'à l'ange, est incomparablement plus fière et plus digne de respect que la chute et la décadence de tous les êtres, qui auraient été créés séparément et parfaits, par la main mème d'un dieu humain, par couples adultes auxquels l'ordre de se reproduire eùt été immédiatement intimé. Cette origine miraculeuse n'explique rien d'ailleurs, ni les instincts, ni l'hérédité, ni les variations observées, ni les filiations, ni les parentés, ni les arrêts de développement, ni les organes atrophiés, et elle se pose en contradiction formelle avec l'enseignement tout entier de la nature. Mais nous disons, de plus, que la doctrine scientifique qui vient d'être exposée n'est combattue que par des esprits étroits et rétrogrades qui ne s'appuient même pas sur les traditions dont ils se prétendent les défenseurs. En effet, ce n'est que depuis peu de temps que l'Église condamne l'hypothėse d'une génération spontanée primitive. La scolastique chrétienne, saint Thomas d'Aquin en tète, croyaient à la génération spontanée, ct sur une échelle autrement vaste. D'ailleurs la Bible ne parle pas autrement. Écoutons-là :

" Dieu dit: Que la terre produise de l'herbe verte qui porte de la graine, et des arbres fruitiers qui portent du fruit chacun selon son espèce et qui renferment leur semence en eux-mêmes pour se reproduire sur la terre. Et cela so fit ainsi (Genèse, I, 11).

- Dieu dit encore : Que les eaux produisent des animaux vivants qui nagent dans l'eau (Id., I, 20).

" Dieu dit aussi : Que la terre produise des animaux vivants, chacun selon son espèce, les animaux, les reptiles et les bêtes sauvages. Et cela se fit ainsi $(I d ., I, 24)$. n

A ceux donc qui prétendent servir la cause de l'Église en jetant l'anathème sur les efforts laborieux des savants qui parviennent $\dot{a}$ remonter aux origines tant cherchées, nous conseillerons d'étudier d'abord un peu plus sérieusement l'histoire de leurs propres doctrines, et de se souvenir qu'ils auraient peut-être déjà mieux fait de se taire le jour où, à propos de Galilée, ils ont déclaré « hérétique 》 la croyance au mouvement de la Terre. 


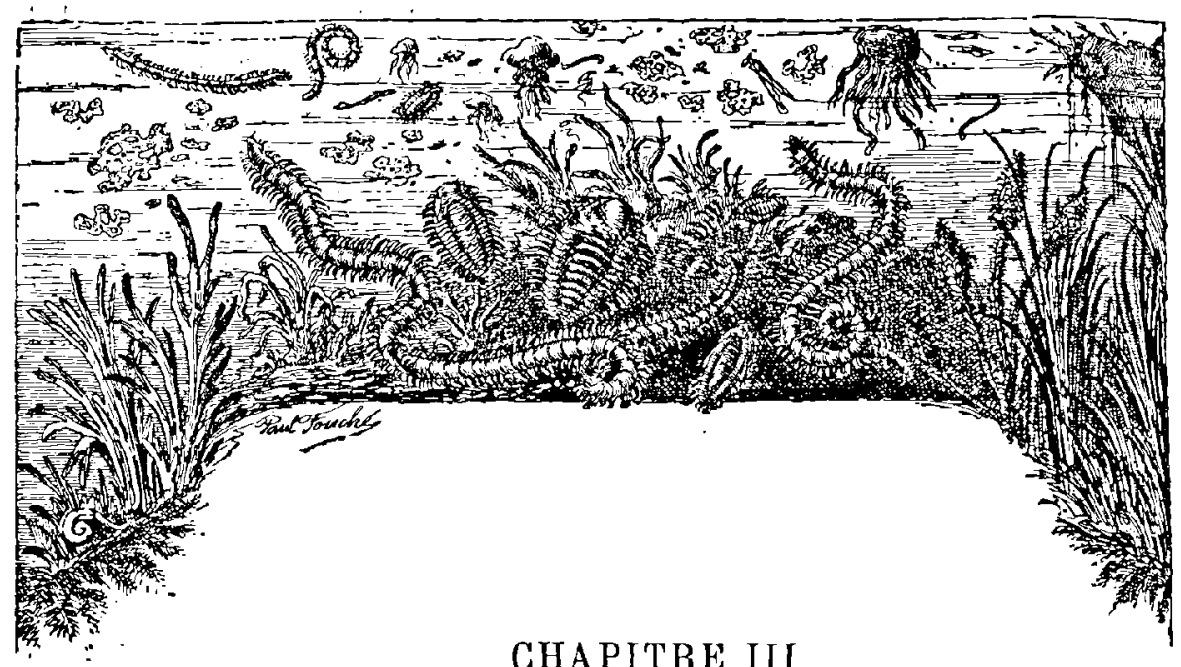

GHAPITRE III

DEVELOPPEMENT ET PROGRESION DE LA VIE

Grâce aux travaux considérables effectués dans ces derniers temps par les sciences biologiques, nous sommes parvenus par la réunion et la comparaison de toutes ces conquêtes scientifiques qui se complètent les unes par les autres, à soulever un coin du voile qui cachait le mystère enseveli depuis tant de siècles sous les secrets en apparence impénétrables de la nature; nous venons d'assister à la formation naturelle des premières substances organiques, dérvant de la combinaison des substances chimiques antérieures, lesquelles avaicnt dérivé elles-mèmes des associations physiques et mécaniques des molécules; nous avons suivi par la pensée la métamorphose graduelle de la nébuleuse terrestre, depuis l'état gazeux, transparent, pour ainsi dire impondèrable, de son origine primordiale, jusqu'à l'édification atomique des molécules des corps réputés simples, jusqu'aux affinités, aux combinaisons variées, a ux transformations de force et de matière, jusqu'au berceau de la vie, et jusqu'aux premiers organismes, plantes et animaux.

Cette primitive substance organique une fois formée ne va pas rester stérile. Obéissant à la loi du Progrès, elle va subir elle-mème des transformations ayant pour effet le développement graduel de la vie, la variété des formes organisées, le perfectionnement des êtres. Des physiologistes distingués, Flourens en tête, ont cru et 


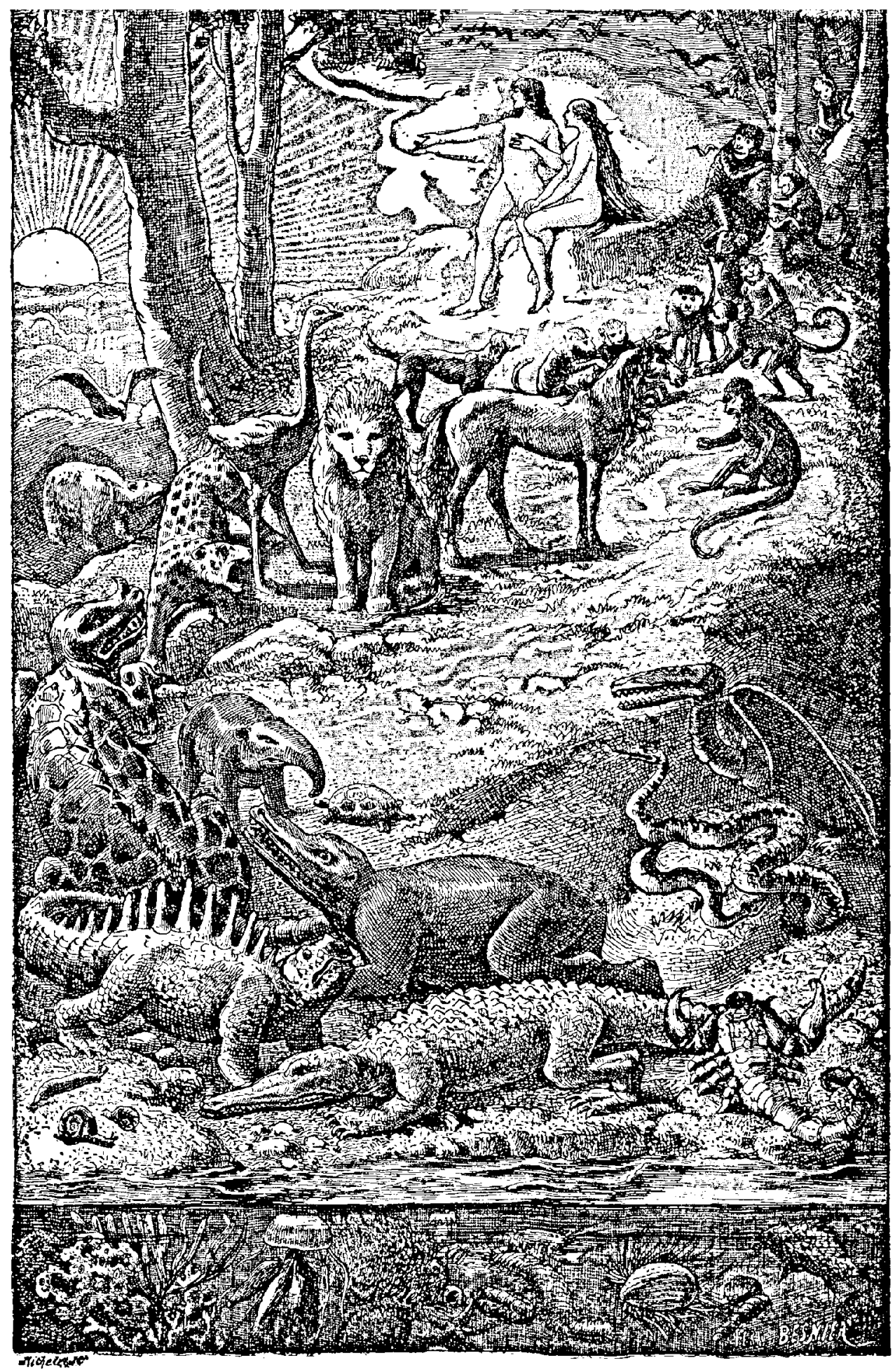

LASCENSION DH LA VIT

LE MONDE aYAYT IA CRÉation DE L'HOMME 
enseigné que la quantité de vie sur le globe était une quantité constante ('). C'est là une grosse erreur. A l'origine de la vic, il n'y avait aucune variété dans les êtres, aucune espèce différente d'une autre. Le nombre des espèces s'est accru de siècle en siècle par des différenciations dans les formes organisées, et le nombre des êtres vivants a été en s'accroissant de gẻnérations en générations. Depuis la première formation du protoplasma, la quantité de vie, le nombre et la variété des êtres vivants, ont été en augmentant suivant une progression irrégulière mais constante.

Qu'est-ce que LA VIE?

Les définitions ne manquent pas. Mais le plus souvent elles ne disent rien de plus que ce mot lui-méme " La vie est le contraire de la mort ", lit-on dans l'Encyclopédie. Vraiment, il était inutile que Diderot et d'Alembert associassent leurs génies pour aboutir à ce jeu de mots. — "La vie est un principe intérieur d'action». selon Kant; sans doute, mais cette définition ne nous apprend pas grand'chose. - Tout le monde connaît la fameuse définition de Bichat: "La vie est l'ensemble des fonctions qui résistent à la mort. » Pour l'un des créateurs de l'anatomie, c'est lá une conception au moins singulière, car elle revient a dire que les fonctions et les propriétés des corps vivants sont en antagonisme perpétuel avec les propriétés physiques et chimiques ordinaires, ce qui est diamétralement le contraire de la vérité. Aussi Claude Bernard, en constatant que les doctrines vitalistes ont succombé par l'erreur essentielle de leur principe de dualisme et d'antagonisme entre la nature vivante et la nature inorganique a-t-il pris soin d'ajouter les remarques suivantes: "Si nous voulions exprimer que toutes les fonctions vitales sont la conséquence nécessaire d'une combustion orga-

1. J'étudie la vie daus les êtres vivants, et je trouve deux choses : la première, que le nombre des espèces va toujours en diminuant depuis qu'il y a des animaux sur le globe, et la seconde, que le nombre des individus, dans certaines espèces, va toujours, au contraire, en croissant; de sorte que, à tout prendre, et tout bien compté, le total de La quantité de vie, j'entends le total de la quantité des êtres vivants, reste toujours à peu près le mème. De la longécité humaine et de la quantité de vie sur le globe, par P. Flocrens, membre de l'Académie française, secrétaire perpétuel de l'Académie des Sciences, professeur au Muséum, etc., etc., 1856, p. 104. Cette affirmation est une erreur: le nombre des espèces a été en augmentant depuis l'origine de la vie, et la quantité de vie augmente. 
nique, nous dirions : la vie, c'est la mort, la destruction des tissus. $\mathrm{Si}$, au contraire, nous voulions insister sur cette seconde face du phénomène de la nutrition, que la vie ne se maintient qu'à la condition d'une constante régénération des tissus, nous regarderions la vie comme une création exécutée au moyen d'un acte plastique et règénérateur opposé aux manifestations vitales. Enfin, si nous voulions comprendre les deux faces du phénomène, l'organisation ct la désorganisation, nous nous rapprocherions de la définition donnée par de Blainville : " $L a$ vie est un double mouvement interne de décomposition à la fois général et con$\operatorname{tinu}\left({ }^{4}\right) . »$

Toutes ces définitions ne nous satisfont pas. Essaierons-nous d'en donncr une autre ? Oủ tant d'esprits supérieurs ont échoué, la tentative serait assurément téméraire, et, après tout, le mot de vie est un de ces termes axiomatiques qui portent leur explication en eux-mèmes et que nulle définition ne saurait rendre plus clairs qu'ils ne le sont eux-mèmes. Cependant, si chacun conçoit sans explication la différence qui sépare un être vivant d'un èlre' mort, un être organisé d'un être inorganique, il n'en est pas moins désirable de savoir en quoi consiste la vie considérée en ellemême.

La vie est une force qui régit la substance suivant une constitution et une forme déterminées par le germe. L'être vivant est un édifice qui se renouvelle sans cesse et dont la durée est limitée par l'impulsion évolutive du germe et par l'entretien dù à la nutrition. La vie se renouvelle par la génération.

Du jour où le premier grumeau de protoplasma s'est formé, la vie a ajouté quelque chose à la Terre, quelque chose qui ne se pèse . pas, sans doute, quelque chose d'impondérable, mais enfin un élément nouveau, une forme nouvelle d'activité, une valeur que la planète ne possédait pas encore : la vie, la sensibilité, et plus tard la penséc. Puis le perfectionnement de la vie a sans cesse continué d'ajouter quelque chose à la nature. L'influence de la lumière et la formation du nerf optique; l'influence du son etla formation du nerf auditif, le lent développement des cinq sens, la formation et le

1. Cladde Bernard, La Science expérimentale, Paris, 1878, p. 199. 
développement du système nerveux, la naissance des premières impressions ressenties, la conscience du moi, d'abord vague et obscure, plus tard et graduellement mieux définie, l'impressionnabilité, la pensée, la mémoire ont été autant d'acquisitions lentes et progressives de l'être vivant. Tout cela n'existait pas sur notre planète avant la naissance de la vie. Tout cela existe aujourd'hui, C'est donc bien l'histoire d'une création continuelle que nous écrivons ici.

Les savants qui, à l'exemple d'Haeckel, croient que la vie n'est qu'une fonction mécanique, un mode particulier de mouvement appartenant à l'ordre physique et chimique, se trompent. La propriété évolutive de l'œuf qui produira un mammifère, un oiseąu ou un poisson n'est ni de la physique ni de la chimie. L'activité directrice de la plante et de l'animal, qui assimile au corps vivant les molécules d'air, d'eau, de carbone, etc., puisées dans le milieu extèrieur, qui les désassimile et les rejette, qui entretient l'organisme dans sa force et dans sa beauté, n'appartient pas davantage à la mécanique, à la physique ou à la chimie, quoique les phénomènes vitaux leur appartiennent entièrement et soient régis par elles. Il y a quelque chose de plus.

Aussi bien nous permettrons-nous de ne pas admettre avec l'éminent physiologiste Claude Bernard que a la force métaphysique évolutive par laquelle nous pouvons caractériser la vie soit inutile à la science parce qu'étant en dehors des forces physiques elle ne peut exercer aucune influence sur elles » ni qu'il.faille « séparer le monde métaphysique du monde physique phénoménal qui lui sert de base ('). „ Nous pensons que la vie n'est pas une force métaphysique, mais une activité physique dont la science de l'avenir déterminera certainement la formule. Descartes et Leibnitz, en considérant les animaux comme des automates et les âmes comme des entités divines entièrement étrangères aux corps n'ont certainement pas deviné les progrès acquis dès aujourd'hui dans la connaissance des origines de la vie.

La force qui fait vivre la plante, l'animal, l'homme, est une transformation (à nos yeux une épuration, un mode supérieur) des

1. Claude Bernard, La Science expérimentale, p. 211. - Id. p. 427. 
forces naturelles, chimiques et physiques, en activité dans le monde inorganique. Depuis Lavoisier, l'antique fiction de la vie comparée à une flamme qui brille et s'éteint a cessé d'être une métaphore pour devenir une réalité. Ce sont identiquement les mèmes conditions chimiques qui alimentent le feu dans la nature inorganique et la vie dans la nature organique : c'est l'action de l'oxygène. Mais de mème que ce n'est pas l'acide d'une pile électrique ou les propriétés du. cuivre et du zinc qui font qu'une horloge électrique indique les heures, de méme a la matière n'engendre pas les phénomènes manifestés par la vie; elle en est le substratum et ne fait que donner aux phénomènes leurs conditions de manifestation. $D$

Les combinaisons chimiques et les affinités des molécules entre elles sont néos après la période purement mécanique de la genèse terrestre et sont dérivées.des conditions par lesquelles la matière et les forces venaient de passer. Elles aussi avaient dójà ajouté quelque chose - et beaucoup - au monde brut de l'âge primordial. Les premières formations organiques du protoplasma, dérivées à leur tour des combinaisons chimiques antérieures ont commencé la vie. Il n'y avait alors ni âmes ni pensées. La pensée, chez les animaux inférieurs, chez les insectes, par exemple, ou mème chez les premiers vertébrés, poissons et reptiles, a été incontestablement le produit naturel du développement des sens et de leurs perceptions. Pourquoi créerions-nous d'avance des âmes étrangères aux corps, et dont nous n'avons aucun besoin pour l'explication des choses tant que l'humanité n'est pas apparue ?.Et même, une fois l'humanité dégagée de sa chrysalide animale, pourquoi créerions-nous si vite des âmes immortelles, qui ne sauraient que faire de leur immortalité?

On le voit, notre conception actuelle de la nature doit être toute différente de celles qui étaient nées jusqu'ici d'une connaissance moins avancée des œuvres de la nature elle-mème. La vie a commencé par une simple substance chimique à peine imprégnée de ce que nous appelons aujourd'hui les propriétés vitales, et le germe, la cause productrice de ces organismes primitifs n'a été autre chose qu'une heureuse réunion d'éléments combinés pour déterminer ce nouveau mode d'activité dans l'œuvre de la création. De mème que 
l'électricité sort des éléments d'une pile préparée, ainsi la force vitale est née spontanément du grand laboratoire de la nature. Le protoplasma subit à son tour des influences qui l'élèveront graduellement au-dessus de son humble origine. Par sa faculté de se nourrir, il se développe et se divise, ce qui a été le premier mode de génération. Il ne mérite mème pas encore le titre de plante; mais enfin il vit, renouvelle son tissu et se reproduit.

Cette gelée vivante, cet albuminoïde, ce composé gélatineux de carbone, d'hydrogéne, d'azote et d'oxygène, s'imprégnera bientôt d'autres substances minérales, de soufre, de phosphore, de sel, de fer et se modifiera dans sa forme et dans ses allures. Ainsi le protoplasma en se subdivisant en individus différents les uns des autres donnera naissance aux monères, aux radiolaires, aux foraminifères, aux premiers végétaux cryptogames, aux myxomycètes, aux champignons, aux èponges, aux algues, etc., etc.

Nous avons fait connaissance avec les différentes espèces de monères déjà étudićes par les progrès si rapides de la science contemporaine, et nous avons viu que l'on distigue déjà entre elles diverses espèces, telles que la monère de Villefranche (la première découverte) à laquelle on a donné le nom de protogenes primordialis (sa forme est simplement sphérique et sa taille est de 1 millimètre de diamètre en moyenne),- la protamæba primitiva, qui parait encore plus simple, n'a aucune forme définie et en change sans cesse, et ne dépasse guère quelques centièmes de millimètre, - le bathybius Haeckeli, découvert dans les profondeurs de la mer, - le myxodictyum sociale, dont nous avons reproduit plus haut ( $/ 2 g .53$, p. 137) les associations coloniales, - la monobia confluens, analogue à la précédente, mais moins riche comme nombre d'individus associés et comme dimensions d'individus, - l'Haeckelina gigantea, qui offre l'aspect d'étoiles à plusieurs branches et atteint parfois un centimètre de diamètre,- les vampyrilla et les protomonas, qui vivent sur les conferves et les algues,-la protomyxa, que l'on trouve en grande quantité sur les coquilles rejetées par la mer le long des rivages, etc., etc. Tous ces êtres primitifs se reproduisent ordinairement par simple division de leur corps en deux parties égales; cependant les trois dernières espèces que nous venons de nommer se comportent autrement. A une certaine époque de leur exis- 
tence, elles rétractent leurs petits filaments qui leur servent à la fois d'organe de locomotion et de préhension, leurs pseudopodes, et se transforment en boules. La couche extérieure de ces boules devient plus résistante que celle du protoplasma, et forme une

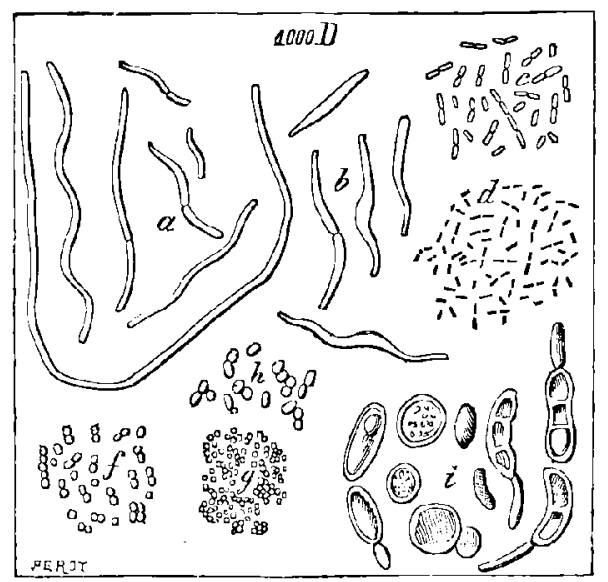

Fig. 59. - Microbes atmosphériques, grossis 1000 fois en diamètre $: a, b$. Vibrions; $c, d$. Bactéries; $f, g, h$. Micrococcus divers; $i$. torules variées.

sorte d'envéloppe dans I'intérieur de laquelle le protoplasma se divise en un grand nombre de petites masses globuleuses. Puis l'envcloppe se rompt et tout part. C'est la création des zoospores,
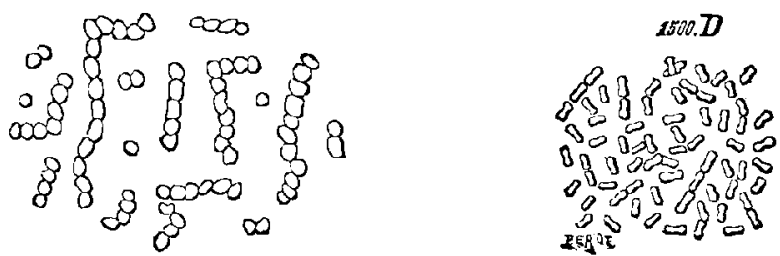

Fig. 60.

1. Bacilles en forme da micrococcus, grossis 1000 fois en diamètre.

2. Bacterium commun, grossis 1500 fois en diamètre.

dont chacun devient un monde; c'est l'origine d'un second mode de génération.

Les microbes, dont on parle tant depuis quelques années surtout, paraissent n'être, eux aussi, que des monères. Ils représentent la vie rudimentaire, primitive, ni végétale, ni animale, mais la vie disséminée à l'infini. On croit retrouver en eux le 
premier enthousiasme de l'enfance de la force vitale. On né s"imagine pas, en général, l'innombrable quantité d'ètres qui pullulent partout dans les airs et dans les eaux. En moyenne, chaque mètre cube de l'air qu'on respire à Paris en renferme de trois à quatre mille. Mais ceux-ci sont de création (ou tout au moins de transformation) récente, puisqu'ils appartiennent aux agglomérations humaines comme parasites et pullulent dans les lieux habités pour disparaitre en pleine mer et sur les montagnes. Leur vitalité est pro-

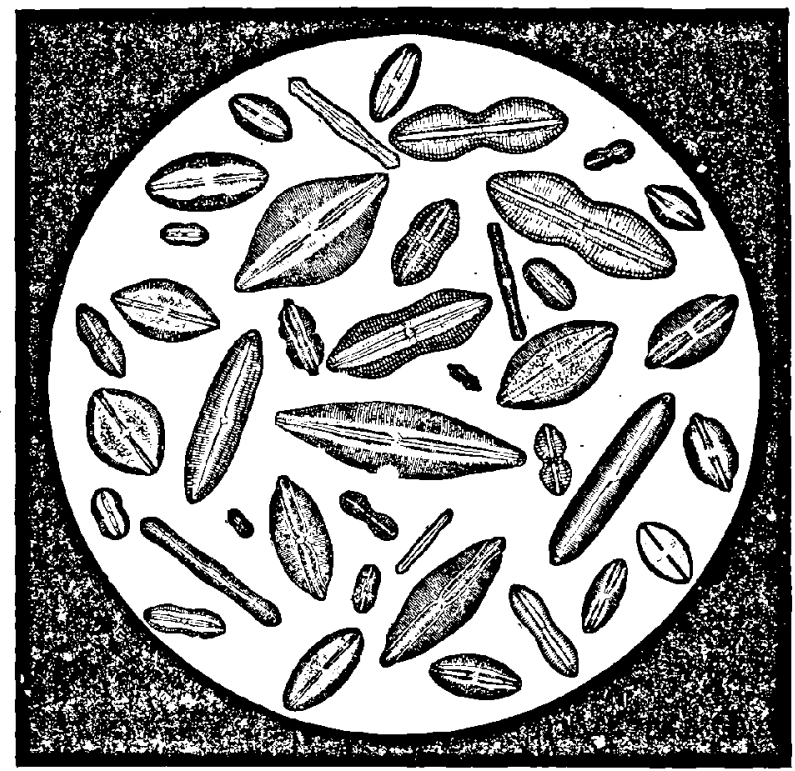

Fig. 61. - Diverses formes de Diatomées.

digieuse, de mème que celle de la plupart des infusoires. Une seule bactéric peut, en vingt-quatre heures, produire seize millions cinq cent mille hactéries! Certains infusoires ne peuvent pour ainsi dire pas mourir. Spallanzani a ressuscité, en les humectant, des rotifères desséchés depuis trente ans (')!

La formation de l'arbre généalogique du règne animal, comme

1. Nous avons reproduit plus haut, p. 15I, les formes les plus répandues de ces êtres microscopiques en suspension dans l'air, d'après les observations faites par le $\mathrm{D}^{\mathrm{r}}$ Mjquel à l'observatoire de Monlsouris. Ce sont bien. là des organismes élémentaires analogues à ceux qui ont dû apparaitre à la surface de la Terre dès les origines de la vie. Leur nombre est considérable dans les lieux habités. Presque nul en pleine mer et au sommet 
celle de l'arbre généalogique du règne végétal, a été longue et lente. "Il a fallu bien des perfectionnements, écrit le professeur Edmond Perrier, dans son important ouvrage sur les Colonies animales, avant que certaines monères, gardant toute leur vie la membrane d'enveloppe qui protège temporairement le protoplasma de quelques-unes d'entre elles, soient devenues capables de demander directement à l'air et à l'eau, plus ou moins chargés de matières minćrales, les éléments de leur constitution. Ge jour-

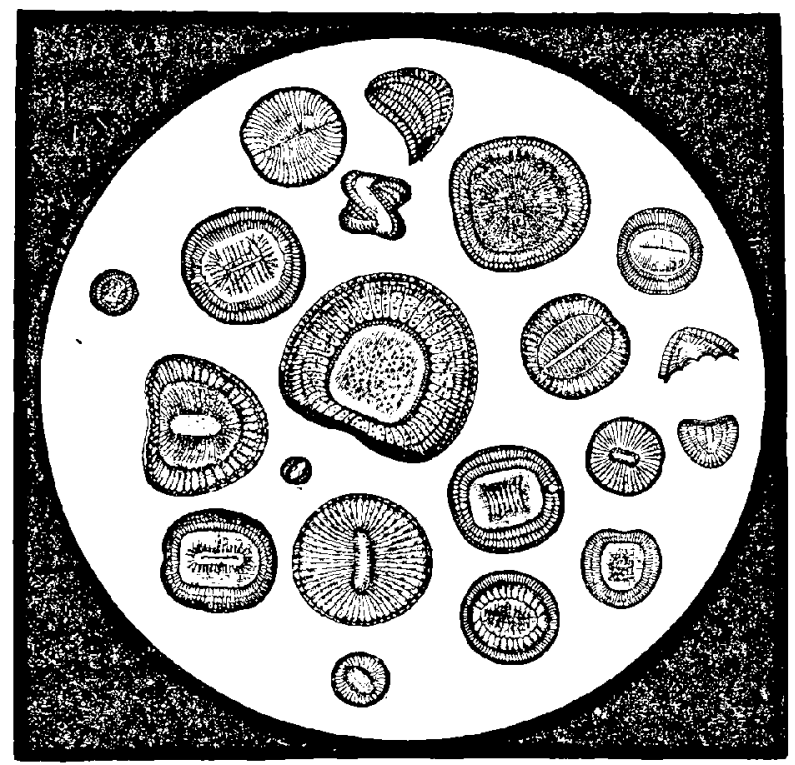

Fig. 62. - Diverses formes de Diatomées.

là, le règne végétal a fait son apparition sur la Terre. Pas plus que le règne animal, il ne s'est formé subitement; longtemps les

des montrgnes, il augmentè rapidement dans les villes populeuses, comme on peut s'en rendre compte par la curieuse statistique suivante :

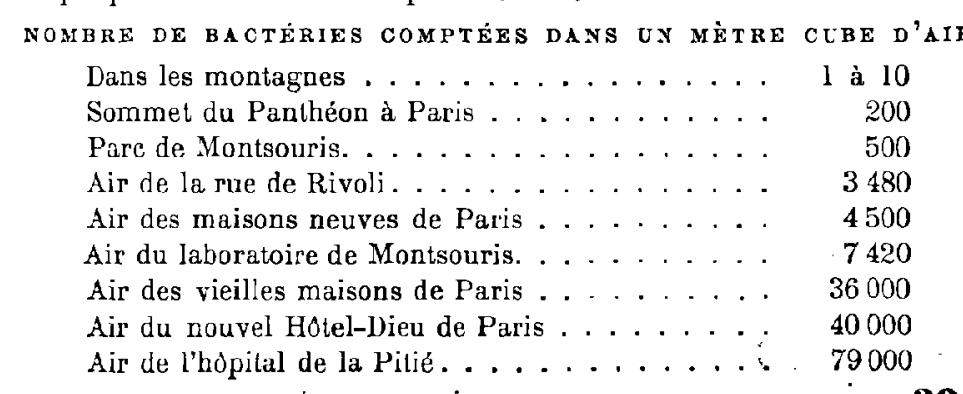

LE MONDE AVANT LA CRÉATION DE L'HOMNE 
monères ont été les seuls habitants de ce globe, et c'est d'elles que sont lentement sortis, se développant simultanément côte à côte, les êtres qui devaient plus tard couvrir le sol de son vert manteau ou donner aux prairies comme aux forêts leurs innombrables habitants. »

Les végétaux n'ont pas été les ancètres des animaux. Ce sont là deux mondes distincts l'un de l'autre, quoique ayant la même origine. Il eùt pu se faire que les animaux existassent seuls, ce

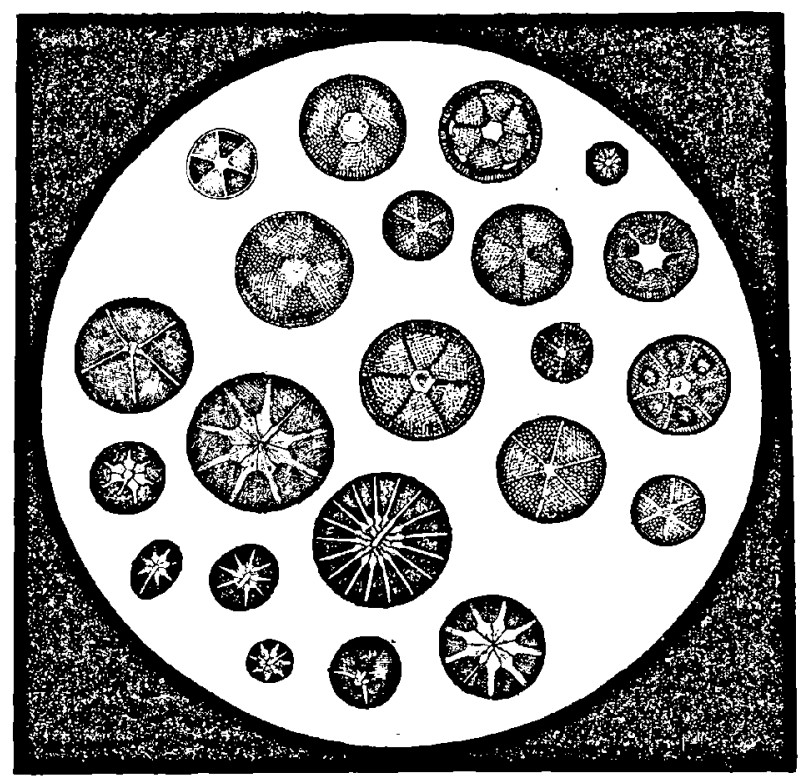

Fig. 63. - Diverses formes de Diatomées.

qui serait arrivé si aucun organisme primitif ne s'ètait fixé au sol. Il eùt pu se faire aussi que les végétaux existassent seuls, ce qui serait arrivé si tous les organismes primitifs s'étaient formés du sol, soit à l'air libre, soit au fond des eaux. Il eùt pu se faire encore que le règne animal, comme le règne végétal, prissent des développements tout à fait différents de ceux qu'ils ont pris, ce qui serait arrivé si les conditions organiques de la planète, éléments chimiques, chaleur, pesanteur, densité, lumière, etc., eussent été différentes de ce qu'elles sont. Les formes de la vie à la surface des autres mondes doivent ètre toutes différentes de ce qu'elles sont ici. Et comment les imaginer? Imaginerions-nous des arbres, des 
fruits et des fleurs, s'il n'y avait pas de règne végétal sur notre planète?

Ce qui doit peut-être le plus nous frapper dans l'étude des premiers êtres organisés qui se soient formés sur notre planète, c'est leur extrème petitesse : la plupart d'entre eux sont microscopiques. Les débuts de la force vitale ont été des plus humbles à tous les égards, comme si la nature n'avait pu que s'essayer d'abord en petit, comme si elle n'avait pas osé s'élancer tout d'un coup trop loin du règne

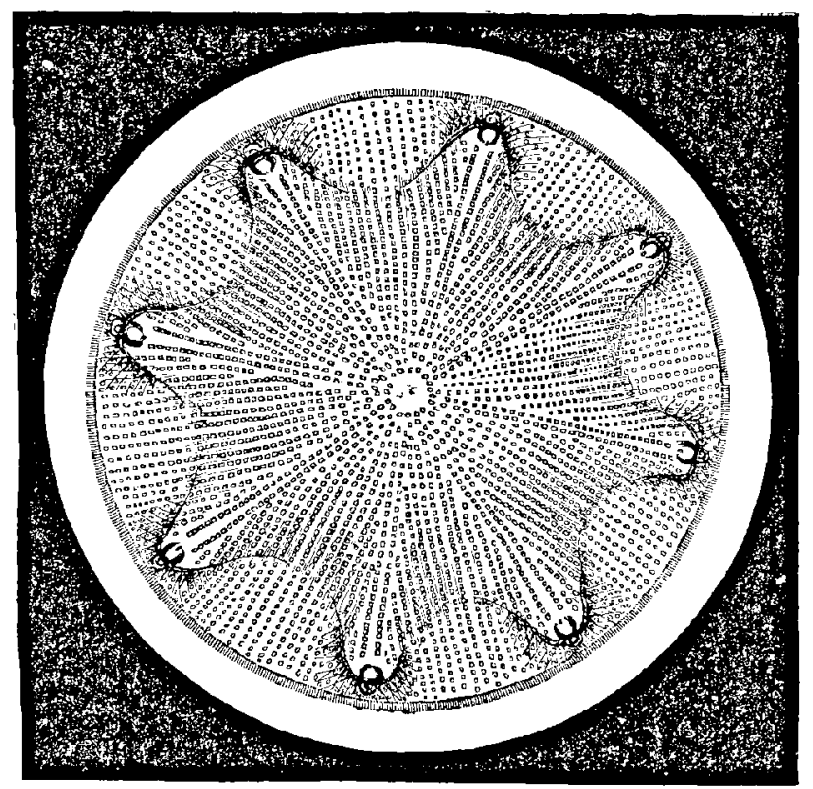

Fig. 64. - Diatomée $(g r:=400$ diamètres $)$.

inorganique. Minerve n'est pas sortie tout armée de la tète de Jupiter. Mais si les individus ne sont pas grands, ils sont nombreux, ou, pour mieux dire, ils sont innombrables. Certains terrains sont entièrement formés des fossiles microscopiques de ces êtres anciens, dont un grand nombre d'espèces ont traversé les âges jusqu'à nous. Ehrenberg a trouvé dans un centimètre cube de craie plus de cinq cent mille momies de foraminifères; Max-Schultze a évalué le nombre de ces squelettes contenu dans 30 grammes de sable du port de Gaëte à un million et demi. Or ils se sont accumulés en telle quantité qu'ils forment de véritables montagnes. Des îles entières, par exemple les Barbades, en sont presque exclusivement 
composées. La craie est formée de débris de protozoaires et de microphytes, animaux et plantes microscopiques; on a beau l'écraser, le pilon est trop grossier pour atteindre ces infiniment petits. Dès l'année 1842, Ehrenberg examinant au microscope un fragment de la surface crayeuse d'une carte de visite glacée ne mesurant pas plus d'un demi-millimètre carré, et le grossissant environ deux cents fois, y découvrait la mosaïque reproduite ici (fig. 65). Les foraminifères, les diatomées, les galionelles, les bacillarièes sont entassès par myriades de myriades dans les terrains calcaires et siliceux, à tel point que, d'après Ehrenberg, un ponce cube peut en contenir jusqu'à quarante millions. Les diatomées, dont les formes sont si élégantes $(f g .61$ à $64 \hat{y}$, sont les carapaces siliceuses de plantes élémentaires, d'algues qui abondent dans les anciens terrains et qui existent encore dans les mers actucles. Leurs espèces sont très nombreuses, comme on peut s'en rendre compte par la diversité des formes reproduites. Ici, les molécules se groupent encore géométriquement, comme dans les produits chimiques.

Les foraminifères, ainsi nommés parce que leurs carapaces siliceuses sont criblées de trous; les radiolaires, qui portent des rayons, des épines, des cils tout autour d'eux sont, comme les monères, tout simplement formés de protoplasma, et leurs squelettes minuscules sont de la silice, comme le cristal de roche, ni plus, ni moins. Dujardin leur avait donné le nom de rhizopodes, parce que leurs cils, qui leur servent de pieds, ressemblent à des racines. Ces filaments organiques arrètent, par leur simple contant, comme ceux des monères et amibes, les infusoires ou les petits crustacés qui flottent autour d'eux, les saisissent, les enveloppent de leur réseau mucilagineux, les dissolvent et s'en nourrissent. Les foraminifères sont microscopiques; les radiolaires atteignent parfois la grosseur d'une tète d'épingle. Les premiers enlèvent lá silice à l'eau ambiante; les seconds sécrètent du carbonate de chaus. Les uns comme les autres continuent de vivre de nos jours dans les profondeurs de la mer. Ces êtres primitifs ne sont pas entièrement sortis du monde inorganique. Le carbonate de chaux se cristallise, chez les radiolaires, suivant des formes géométriques, troublées et. dérangées par l'influence chimique du protoplasma albuminoide; 
mais enfin suivant des formes géomélriques, comme la neige, comme la glace, comme les cristaux, etc. Foraminifères et radiolaires revètent des milliers, des myriades de formes différentes. Ils n'ont pas de sexe et se reproduisent par bouturage, comme beaucoup de végétaux. Il semble qu'ils n'aient eu en eux aucun élément de progrès, ni rivalités, ni combats pour la vie, car ils ont traversé les siècles sans beaucoup changer, et n'ont pas fait souche d'espèces plus parfaites.

Ces petits êtres méritent déjà le titre d'animarx. Les amibes,

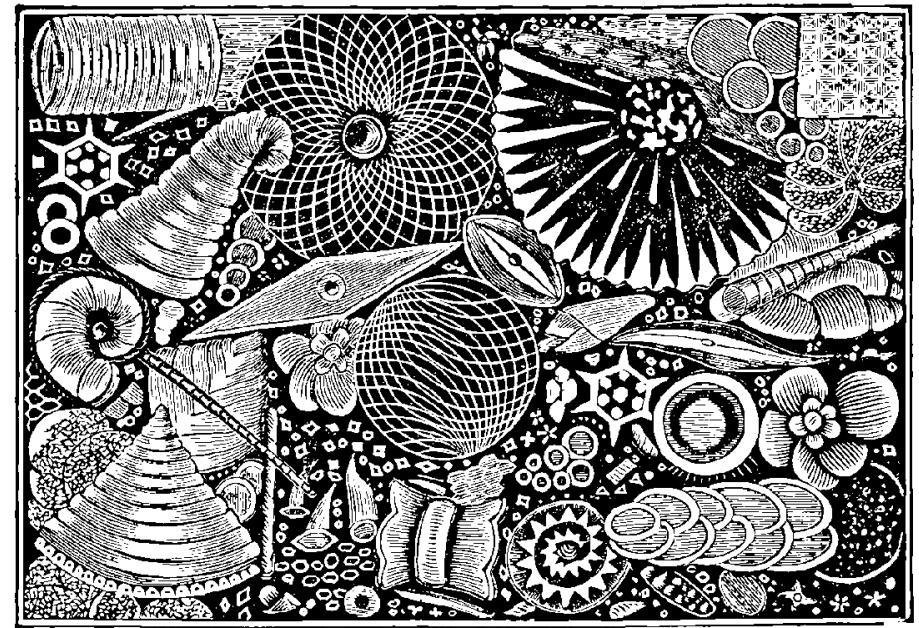

Fig. 65. - Coquilles de ia craie prise sur une carte de visite glacée (Ehrenberg, 18.42).

avec lesquels nous avons fait plus haut connaissance (p. 141) qui ne sont que du protoplasma condensé en noyau et se reproduisent par une simple division en deux parties, ne méritaient pas ce titre, pas plus que celui de végétaux. Un premier progrès est réalisé lorsque le protoplasma devient apte à sécréter une enveloppe membraneuse au sein de laquelle il se divise de manière à donner naissance à des zoospores plus ou moins nombreux. L'enveloppe est-elle de nature albuminoïde, l'organisme qui l'a produite se rapproche du règne animal ; est-elle, au contraire, de la nature de la cellulose, l'organisme tend à se rapprocher du règne végétal. Les substances albuminoïdes sont toujours plus ou moins flexibles, la cellulose est résistante; il suit de là que les mouvements du protoplasma pourront encore se manifester au dehors dans le premier cas; ils ces- 
seront d'être apparents dans le second. G'est pourquoi tous les animaux sont capables de se mouvoir, tandis que le plus grand nombre des végétaux sont toute leur vie immobiles ( $\left.{ }^{4}\right)$.

Antérieurement à ce progrès, les organismes n'étaient ni animaux ni végétaux, quoiqu'ils fussent déjà plus compliqués que les

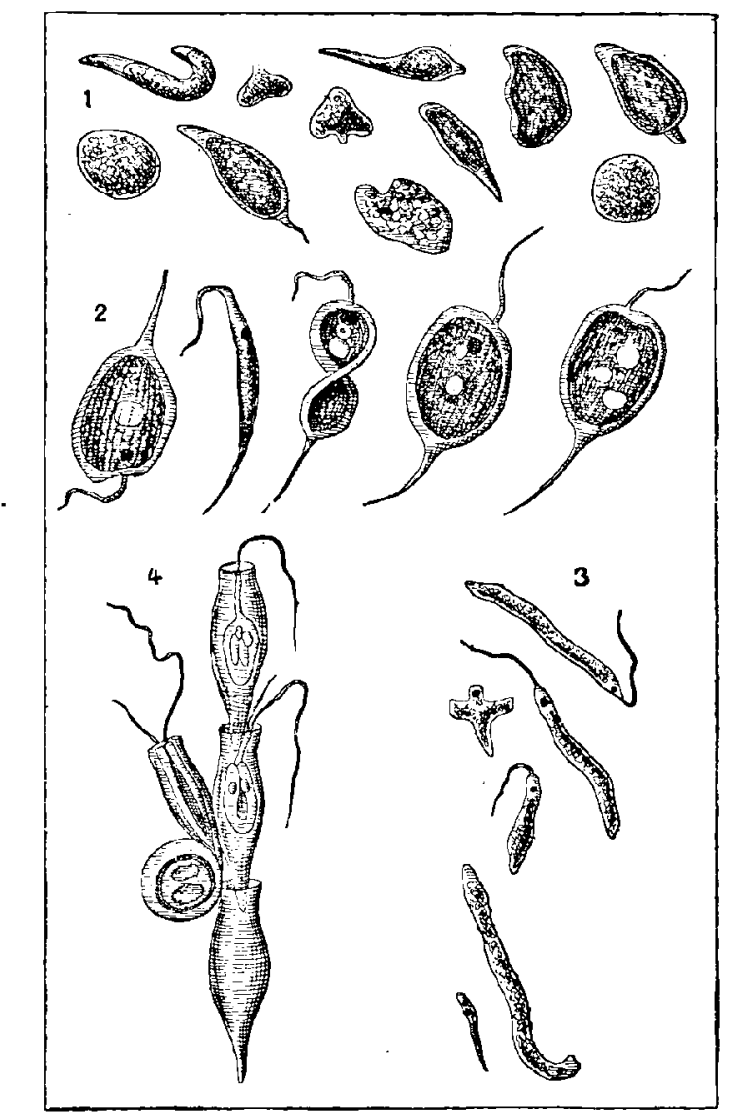

Fig. 66. - Protistes (intermédiaires entre les animaux ot les végétaux).

Infusolres lagelliferes, d’après Edmond Perrier. - 1. Astasies. - 2. Phacus. - 3. Euglènez. - 4. Dlnobryon sertularia.

monères et les amibes. Il en reste encore aujourd'hui de nombreux descendants, que tout le monde peut étudier. Les infusoires flagellifères, ainsi nommés parce qu'en général ils portent une sorte de fouet à leurs extrémités, appartiennent à ces êtres intermédiaires, à ces protistes, qui ne sont ni l'un ni l'autre. Ils affectent toutes

1. Evmond Perrier. Les Colonies animales. 
sortes de formes. Les uns $\left(f g .66 \mathrm{n}^{\circ} 1\right)$, sont ovoïdes et rougeâtres ; les autres $\left(\mathrm{n}^{\circ} 2\right)$, sont aplatis en forme de feuilles; d'autres $\left(\mathrm{n}^{\circ} 3\right)$, sont allongés en forme de bâtonnets; d'autres encore $\left(\mathrm{n}^{0} 4\right)$ vivent dans des étuis, ramifiés en colonies arborescentes. Plusieurs organismes de ce groupe contribuent à la coloration rouge que présente parfois la pluie ou la neige, coloration attribuée jadis à du sang par la

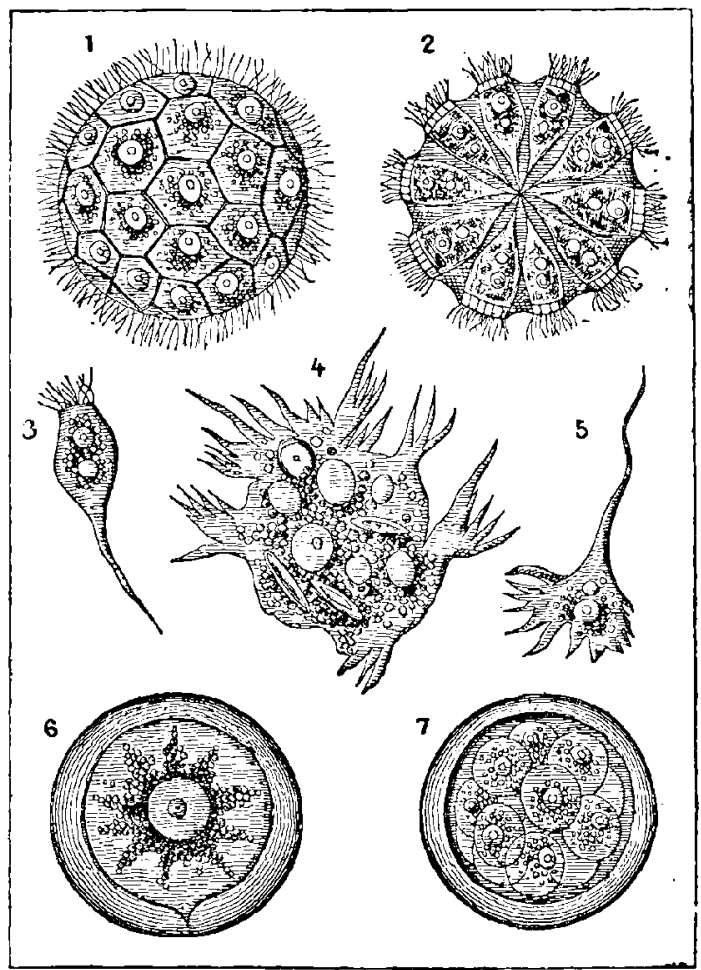

Fig. 67. - Protistes, êtres intermédiaires. La magosphæra planula.

superstition du peuple effrayé. On en rencontre assez souvent sur les substances amylacées, sur le pain, et autrefois lorsqu'on voyait ppparaitre ces taches rouges sur les hosties, on les attribuait à des nanifestations de la colère divine.

A la mème classe d'êtres intermédiaires, appartient la magosphæra planula, découverte en 1869 par Haeckel dans la mer du Nord. C'est une petite sphère composée de trente-deux pyramides réunies par leurs sommets ( $f g .67, \mathrm{n}^{\circ} 1$; le $\mathrm{n}^{\circ} 2$ montre une tranche passant par le centre). A l'aide des cils vibratils, elle nage en tour- 
nant, comme le volvox. A un certain moment, la sphère se désagrège, les cęllules mises en liberté s'en vont, revêtant des formes et des grandeurs variées $\left(n^{\circ} 3\right.$, 4 et 5$)$, puis elles prennent la forme sphérique et ressemblent à de petits oufs ( $\left.n^{\circ} 6\right)$. Ces œufs n'ont pas besoin d'ètre fécondés. Chacun d'eux se subdivise en 2, 4, 8, 16 et 32 cellules $\left(n^{0} \%\right)$ et reproduit un organisme analogue à celui d'où il est sorti. Et ainsi de suite.

Ces organismes ne sont ni végétaux ni animaux, quoique composés des mêmes matériaux; ils n'ont aucun des caractères distinctifs de l'un ou de l'autre règne. $\Lambda u$ même ordre d'ètres primitifs appartiennent aussi les myxomycètes, connus sous le nom de " champignons de la tannée » ou "fleurs du tan » qui se développent abondamment pendant l'été sur les amas de copeaux de chêne ou de hêtre. Ce sont des masses muqueuses orangées qui émettent des prolongements anal gues aux pseudopodes des amibes, se réunissent et offrent $11: 1$ aspect rappelant celui des batybius ( $f g .56$, p. 141), peuvent se déplacer et se nourrissent en absorbant des matières étrangères. Co sont sans doute là les ancêtres des champignons qui, eux; sont déjà des végétaux (très élémentaires).

La noctiluque miliaire et les peridinium, auxquels est due en grande partie la phosphorescence

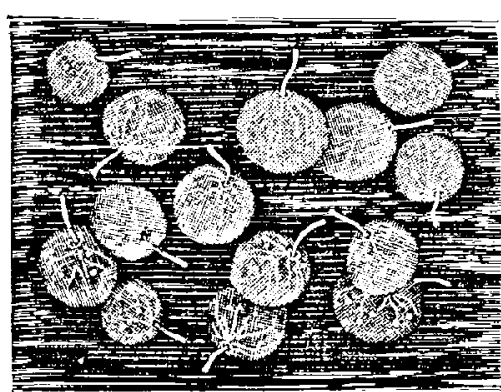

Fig. 68.

La noctiluque miliaire. de la mer, sont aussi des organismes intermédiaires, ni mollusques, ni plantes. Tous ceux qui ont passé un mois de vacances en été, sur les bords de l'Océan, connaissent ce beau phénomène. C'est surtout après les journées chaudes et orageuses qu'il est très intense. L'eau de la mer est comme imprègnée de ces organismes microscopiques. Dans trente centimètres cubes d'eau on a compté jusqu'à 25000 noctiluques. En ces heures ardentes, principalement sur le passage des barques et des navires la mer s'illumine de tous ces feux. Pendant la nuit on croit voir une naïade glisser sur les ondes et faire jaillir la phosphorescence. Ce protiste n'est en quelque sorte 
qu'un globule de gelée transparente. Il suffit d'agiter l'eau pour voir jaillir des myriades d'étincelles : en se plongeant les bras dans un seau d'eau de mer on voit ce feu léger courir en doux frémissements le long de la chair : nous en avons souvent fait l'expérience sur les côtes de France, notamment à Pornichet, au Croisic, à Guérande, etc.

Ce sont lì les véritables zoophytes, les animaux-plantes ou, pour mieux dire, les protistes, ni animaux, ni plantes, les premiers essais de la nature aspirant aux facultés futures de la vie.

Plus avancées que les organismes précédents sont les éponges,

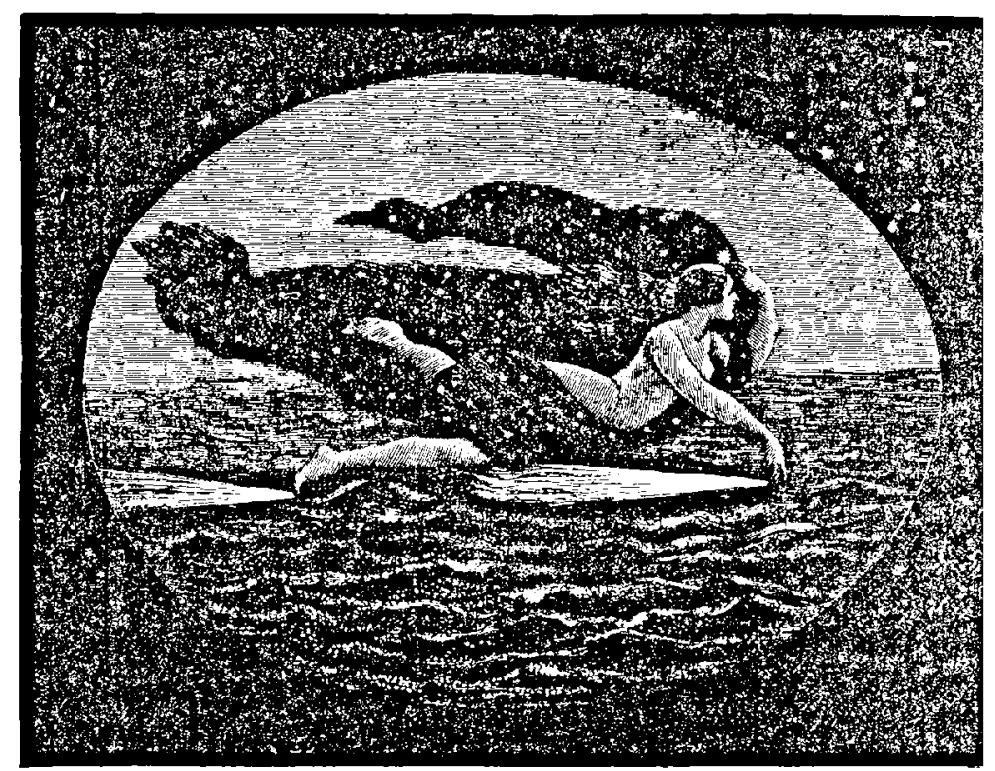

On croit voir une narade glisser sur les ondes et faire jallir la phosphorescence.

qui flottcnt encore à la limite entre les deux règnès, sont attachées au sol marin commedes plantes, mais se nourrissentà la facon des animaux. L'éponge est une société d'amibes et d'infusoires flagellifères qui perdent leur individualité pour se fondre dans la masse commune. Celle-ci vit, ressent des impressions, peut se contracter ou se dilater, reçoit l'eau qui vient la nourrir, la fait passer à travers son corps et la chasse. C'est comme une urne percée de trous, à travers lesquels l'eau circulerait sans cesse, un tissu mouvant qui a déjà une certaine individualité obscure. Elle se reproduit elle-même, donne naissance à des cellules amiboïdes (comme chez les magosphæra), qui flottent 
dans l'eau, et vont s'accrocher à quelque aspérité du sol pour former une nouvelle éponge. Toutefois, il n'y a pas encore ici de génération sexuée, ni par conséquent de caractères définitifs d'espèces.

Ces caractères vont apparaitre chez les hydres, en même temps qu'un remarquable développement de la force vitale('). Ici, l'individualité est beaucoup plus accusée que dans les organismes précédents. Les hydres, ou polypes d'eau douce, se rencontrent dans les flaques d'eau; elles ont la forme générale d'un petit cornet dont l'cxtrémité pointue scrait pourvue d'une sorte de ventouse permettant à l'animal de se fixer sur les bois, plantes ou corps submergés; l'ouverture du cornet est hérissée de petits bras ou tentacules. La nourriture que le polype absorbe entre et sort par cette même ouverture. Pour se déplacer, l'animal courbe son corjs en are (comme certaines chenilles), se colle la bouche contre l'objet sur lequel il s'appuie, détache son pied, le ramène vers la bouche, la

1. Ces petits êtres sont très voraces et très redoutables pour leurs voisins de même taille. Dans les vésicules formant saillie sur la surface des bras, et ouvertes par le haut, se trouvent sles hameçons à trois pointes, dirigées en arrière et attachées à un long filament, très flexible et tordu en spirale; le polype peut, à volonté lancer et retirer ces hameçons, dont le nombre est considérable. Quand un infusoire arrive à proximi ié de l'hydre guettant sa proie, les tentacules l'enlacent, les hameçons l'accrochent et l'entrajnent dans la gueule du petit monstre. Aucun animal sur terre, même parmi les bêtes fauves les plus redoutables, n'est muni d'armes aussi dangereuses que ce polype presque imperceptible, dont la voracité et la puissance digestive sonl également sans exemple.

On a pu observer, à laide du microscope, que ces animaltules, aprés avoir dévoré leur proie, en rejettent, au bout de quelques minutes, les restes complètement dèfigurés et dépouillés de leur substance nutritive; parfois ils engloutissent des corps plus gros qu'eux-mèmes; alor's on voit l'ouverture buccale, puis le cylindre creux qui forme le corps du polype, se dilater jusqu'au triple du volume ordinaire; si l'animal dévoré est formé d'une carapace, le suc dissolvanl, contenu dans l'estomac du polype, la ramollit et la fail digérer.

Remarque curieuse, pourlant, cette puissance digestive ne s'exerce que sur des corps étranger's, jamais sur des corps de polypes. Unobservateur attentif, Trembley, en a recueilli la preuve irrêfragable. Un polype avait avalé, en mème temps que sa proie, une de ses propres tentacules: au bout dequelques instants, pendantque la proie se dissolvait dans le corps transparent du polype, son bras sorlit inlact de l'ouverture buctale. Le Hollandais Harting raconte un trait encore plus surprenant, au sujet de l'inculnérabilite des polypes. Deux de ces animalcules se disputaient une proie; aucun des deux ne voulait lacher prise; le plus fort finit par avaler le plus faible en méine temps que la proie laquelle il se cramponnait. On croira sans doute que l'un et l'autre furent digérés; point du tout: le vainqueur rejeta peu après les restes de son repas, et avec eux sortil, sain et sauf, l'autre polype; il tournoya quelques instants dans l'eau, comme pour se rincer, puis reprit a chasse, et avala à son tour des animaux plus petits que lui, absolument comme s'il n'avait pas éprouvé le moindre accident! 
pose de nouveau plus loin, et ainsi de suite. Quelquefois il va plus vite, par une série de culbutes consécutives.C'est ordinairement pour marcher vers la lumière, qu'ellos aiment beaucoup, quoiqu'elles n'aient pas d'yeux, que les hydres exécutent ces mouvements; mais c'est aussi pour chercher leur proie. Il y a donc ici une personnalité incontestable.

Cependant, quels ètres bizarres! On peut les couper en morceaux sans porter atteinte à leur vitalité, au contraire : d'une seule hydre on en fait ainsi deux, trois, quatre, cinq, dix, qui se porteront à merveille. On peut, d'autre part, los retourner commo un gant sans nuire en aucune façon à leur digestion : la surface exté-
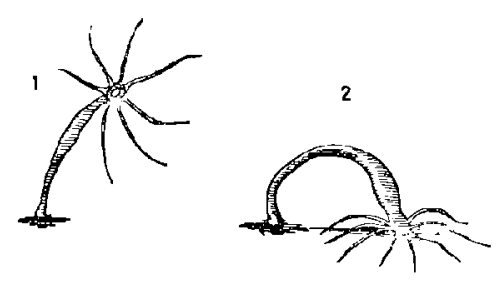

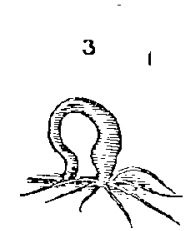

Fig. 70. - L'hydre d'eau douce et son mode de locomotion.

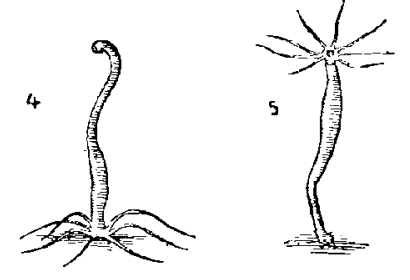

rieure du corps devient tout de suite estomac. On peut anssi les souder ensemble, les greffer comme des branches d'arbres, etc.

« Une hydre est-elle coupée en deux moitiés dans le sens de si longueur, dit M. Perrier, chacune des deux moitiés ne met pas plus de vingt-quatre heures pour se refermer de manière à constituer une hydre nouvelle capable de saisir une proie et de la digérer. Si l'on coupe une hydre par le traver's, en deux jours la moitiẻ antérieure s'est refait un pied, et la moitié postérieure a déjà poussé de nouveaux bras. Si, au lieu de ne donner qu'un coup de ciseaux, on en donne deux de manière à partager l'hydre en trois morceaux, il ne faudra pas plus de huit jours à chacun de ces tiers d'hydres pour redevenir liydre complète. Que l'on essaye de couper une hydre longitudinalement en deux moitiés, puis de diviser encore par le travers chacune de ces moitiés en deux; l'hydre est alors écartelée : mais en huit jours chacun des fragments a reconstitué un polype parfait. On peut découper l'hydre en un nombre do rondelles superposées qui n'est limité que par l'impossibilité de saisir avec des ciseaux un corps trop petit, chacune de ces rondelles refait 
encore un être, à la seule condition d'attendre qut les parties en voie de restauration aient atteint une taille suffisamment con. sidérable. Trembley a réussi à tailler dans une hydre cinquante morceaux, et à fabriquer ainsi, aux dépens d'un mème individu, cinquante hydres nouvelles! $\gg$.

On peut aussi, comme nous le remarquions tout à l'heure, retourner cet étrange animal sans mettre sa vie en péril. Chez les éponges, la couche cellulaire interne, l'entoderme, diffère essentiellement de la couche externe, l'exoderme. "L'entoderme des éponges, écrit encore le mème auteur, est formé de monades flagellifères, l'exoderme est formé d'amibes, et ces deux sortes d'éléments se distinguent déjà chez la larve. L'entoderme et l'exoderme de l'hydre se ressemblent, an contraire, d'une facon presque complète. L'une des plus célèbres expériences de Trembley témoigne même d'une facon indiscutable de leur intime analogic. On peut à volonté faire, aussi souvent qu'on le désire, de l'entoderme d'une hydre son exoderme et inversement. Il suffit pour cela de retourner comme un doigt de gant le double sac qui constitue le polype. Pour que l'animal continue à vivre, il faut alors que son exoderme, qui lui servail de peau, se mette à digérer les aliments; que son entoderme, qui jouait le rôle de muqueuse digestive, devienne, au contraire, la partie tout à la fois protectrice et sensible du corps. Quel bouleversement plus complet peut-on apporter dans un organisme? Il semblerait que l'hydre dùt cent fois en mourir. Ce retournement est cependant sans aucune espèce de gravité pour ce singulier animal. Pendant quelques heures, le patient semble à la véritè mal à l'aise, il tente mème des efforts, assez souvent couronnés de succès, pour recouvrer sa position primitive. Mais, s'il n'y parvient pas, il fait très vite contre mauvaise fortune bon cœur : au bout de deux jours tout au plus, on le voit étendre ses bras pour pêcher et manger copieusement; il répare le temps perdu. L'exoderme s'acquitte fort bien de ses nouvelles fonctions et l'entoderme, devenu la peau, ne lui cède en rien sous ce rapport. Rien ne saurait évidemment mieux prouver l'identité primitive de ces deux tissus que la facilité avec laquelle on les transforme l'un dans l'autre. $>$

On peut faire avaler un polype par un autre : l'avalé n'est pas digéré, au contraire, les deux polypes ne tardent pas à se débarrasser 
mutuellement l'un de l'autre et à vivre aussi tranquillement que si rien n'était arrivé. Si pourtant, avant de faire avaler un polype par l'autre on a pris soin de retourner celui qui doit entrer dans le corps de son confrère, les deux surfaces internes vont se trouver en contact; dès lors, elles se soudront, et au bout de quelques jours les deux êtres n'en feront plus qu'un, qui vivra comme si de rien n'é-

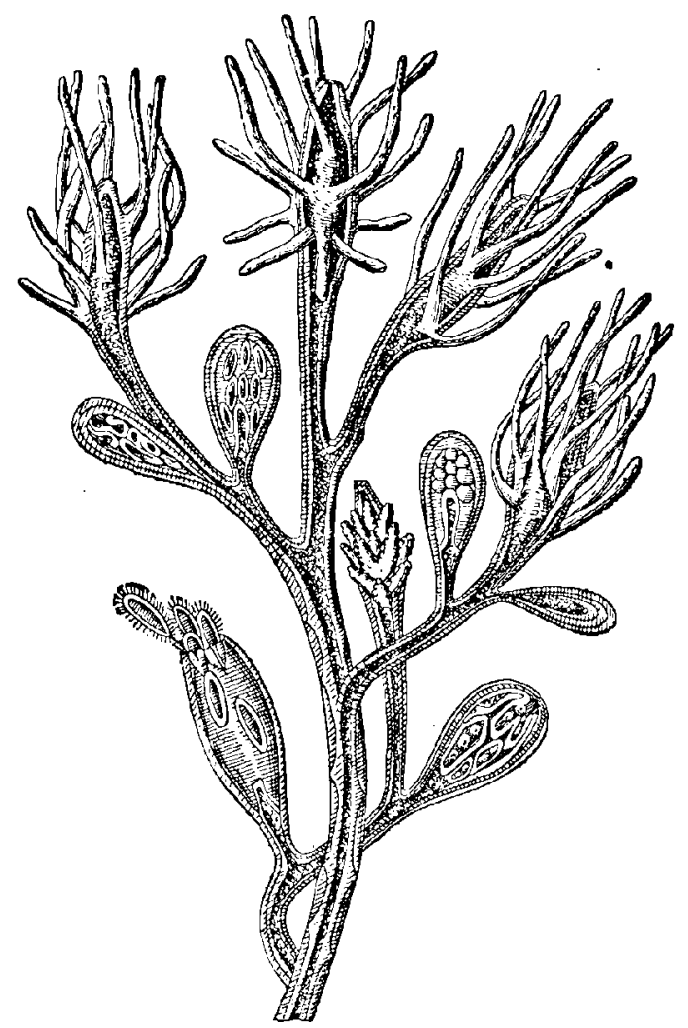

Fig. 71. - Hydraires d'eau douce. - Colonie de Cordylophora lacustres, d'après Edmond Perrier. (On roit comment les bou:geons animés s'échsppert.)

tait!... On voit combien ces tissus élémentaires primitifs s'adaptent aux changements de milieux et se transforment. Leurs propriétés physiologiques, leur composition chimique, la forme même des éléments qui les composent se modifient plus ou moins profondément, et c'est là l'une des sources les plus fẻcondes de diversification du règne animal.

Les hydres se reproduisent par bourgeonnement : une petite hydre pousse sur le corps de la première et s'y développe, puis s'en 
détache et vit séparément. Quelquefois des hydres portent deux, trois, quatre ou cinq petits à différents degrés de dèveloppement. Il n'y a pas encore de sexes; les enfants poussent selon' la nourriture que le polype a absorbée et selon l'élévation de la température : c'est plutôt végétal qu'animal. Quelquefois, surtout chez les espèces marines, les polypiers forment mème de véritables touffes arborescentes. Mais ces êtres tendent déjà à s'élever vers la génération sexuée. Dans les derniers jours de l'été, on peut souvent remarquer, entre autres chez les cordylophora ( $f g .71$ ), un mode de reproduction différent du précédent. Les jeunes polypes qui poussent, comme nous venons de le dire, au lieu de se développer en individus, se transforment en petits sacs sphériques dont les uns contiennent de petits œufs et les autres des glandes mâles. Ces organes sont des individus modifiés en vue de la reproduction. C'est un nouveau pas de fait par la nature dans ses manifestations vitales.

Ce progrès, cet acheminement vers la création des sexes, sert de transition, dans l'arbre généalogique de ces êtres primitifs, entre les polypes et les méduses, ces singulières plaques de gélatine que tout le monde a vues abandonnées par le reflux de la mer sur les rivages ou rencontrées à l'état d'hémisphères flottant dans les eaux. Pendant longtemps les naturalistes ont cherché à découvrir le mode de naissance de ces mollusques; on les avait soigneusement distinguẻes des polypes sous le titre d'acalèphes ( $x \times x \lambda r, \varphi n$, ortie : les Grecs les nommaient ainsi à cause des démangeaisons produites par leur contact visqueux): or, elles sont au contraire les filles des polypes. Elles naissent de ccrtains polypes, des seyphistomes, par une série de transformations bizarres que l'on peut résumer ainsi : le polype hydraire nommé scyphistome, assez semblable aux hydres d'eau douce, se change en un autre polype tout différent, nommé strobile; celui-ci s' transforme en une espèce de pile d'assiettes creuses, et chacune d" celles-ci se détache et n'est autre chose qu'une méduse. Celles-ci grandissent, leur ombrelle s'élargit, se frange et se complique de bras et de filaments Arrivées à l'àge adulte, elles ont des œufs el des glandes, pondent ces œuls, et ceux-ci donnent naissance à des polypes hydraires d'où sortiront de nouvelles méduses. Ce ne sont pas lí des métamorphoses comme chez les insectes (qui, alors, n'existaient pas encore), ce sont de curieux produits de génération 
alternante et indécise. Quelles sont les causes de ces alternances? Les hydres naissent des œufs fécondés, les méduses naissent des hydres sans fécondation préalable, par une simple segmentation du corps, par bourgeonnement et détachement.

Toutes les méduses ne se ressemblent pas. Il y a une multitude de formes différentes, et quoique toutes soient rattachées aux hydres

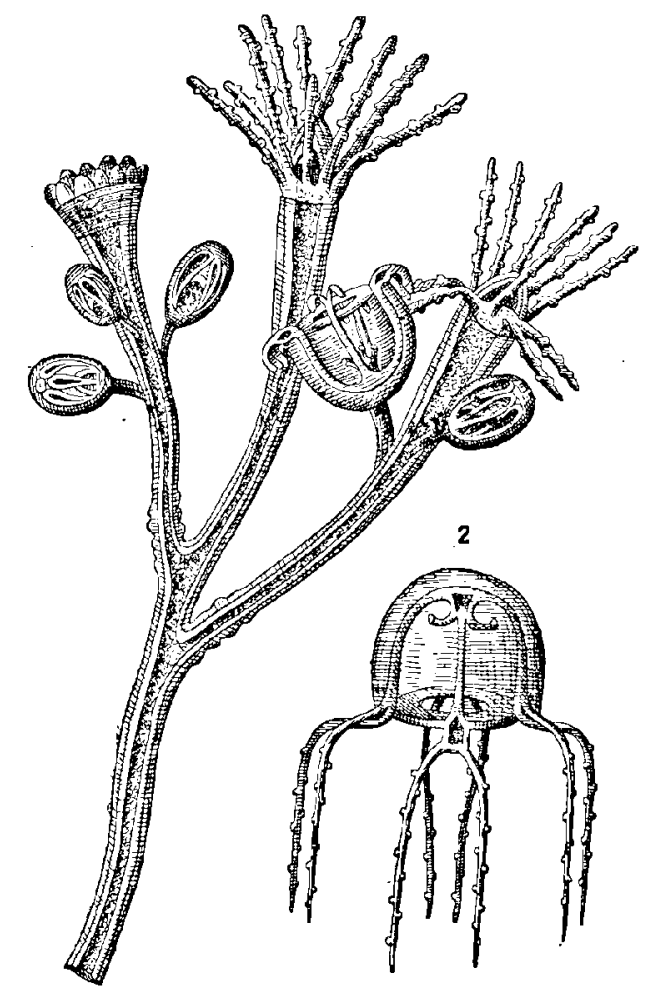

Fig. 72. - La formation des méduses (colonie de Bougainvillier ramosa), d'après Perrier 1. Le Polype nomrricier porta des méduses à divers états de développeinent. -2 . Méduse détachée.

par leur naissance, toutes ne naissent pas de la même façon. Les petites méduses en forme de cloche ne viennent pas, comme les grandes méduses en forme de champignon, par segmentation d'un strobile; elles poussęnt comme des fleurs sur des hydres en colonies arborescentes; d'au tres naissent au bout des raméaux, d'autres sous forme de grappes ou de collerettes; puis elles se détachent et flottent dans les eaux. Ne croirait-on pas voir là des plantes marines, des rameaux, des bourgeons et des fruits? Comment ne pas leur con- 
tinuer le titre de zoophytes? La méduse est à l'hydre ce que la fleur est à la feuille; son ombrelle est une corolle monopétale qui a même été polypétale dans sa jeunesse. De même que la fleur est formée de feuilles modifiées qui se sont groupées en rayons par suite de leur rapprochement sur l'axe qui les porte, de me̊me la méduse est formée de polypes hydraires modifiés, qui ont pris une
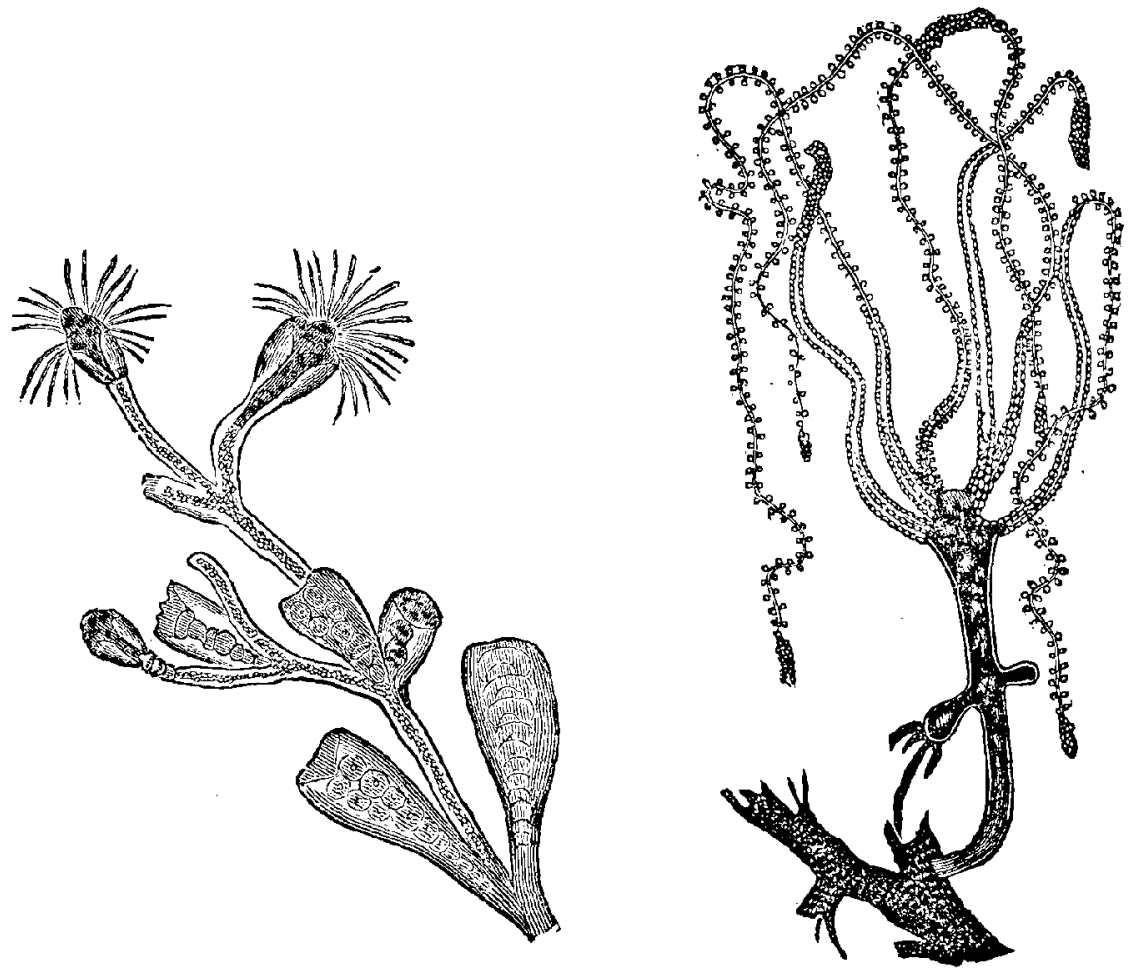

Fig. 73. - Polypes. - 1. Hydre campanulaire. - 2. Hydre brune.

disposition rayonnante par suite du raccourcissement de la distance qui les sẻparait à l'origine.

Ne croirait-on pas aussi, lorsqu'on voit les polypes représentés ici, que l'on a des plantes sous les yeux? Ils n'offrent pourtant d'autre rapport avec les végétaux que leur adhérence à un point fixe, à la façon des coraux.

Ces plantes-animaux, dont la forme, la nature mème varientsi complètement suivant les conditions d'alimentation, de température, d'existence, sont une grande leçon de la nature. L'hydre d'eau douce, habituellement solitaire, fonde des colonies lorsqu'on la 
place dans un milieu riche en nutrition et en température. "Quels arguments plus précieux pourrait-on recueillir en faveur de la mutabilité des formes spécifiques? Les polypes hydraires nous montrent déjä comment un organisme simple, peut revètir les formes

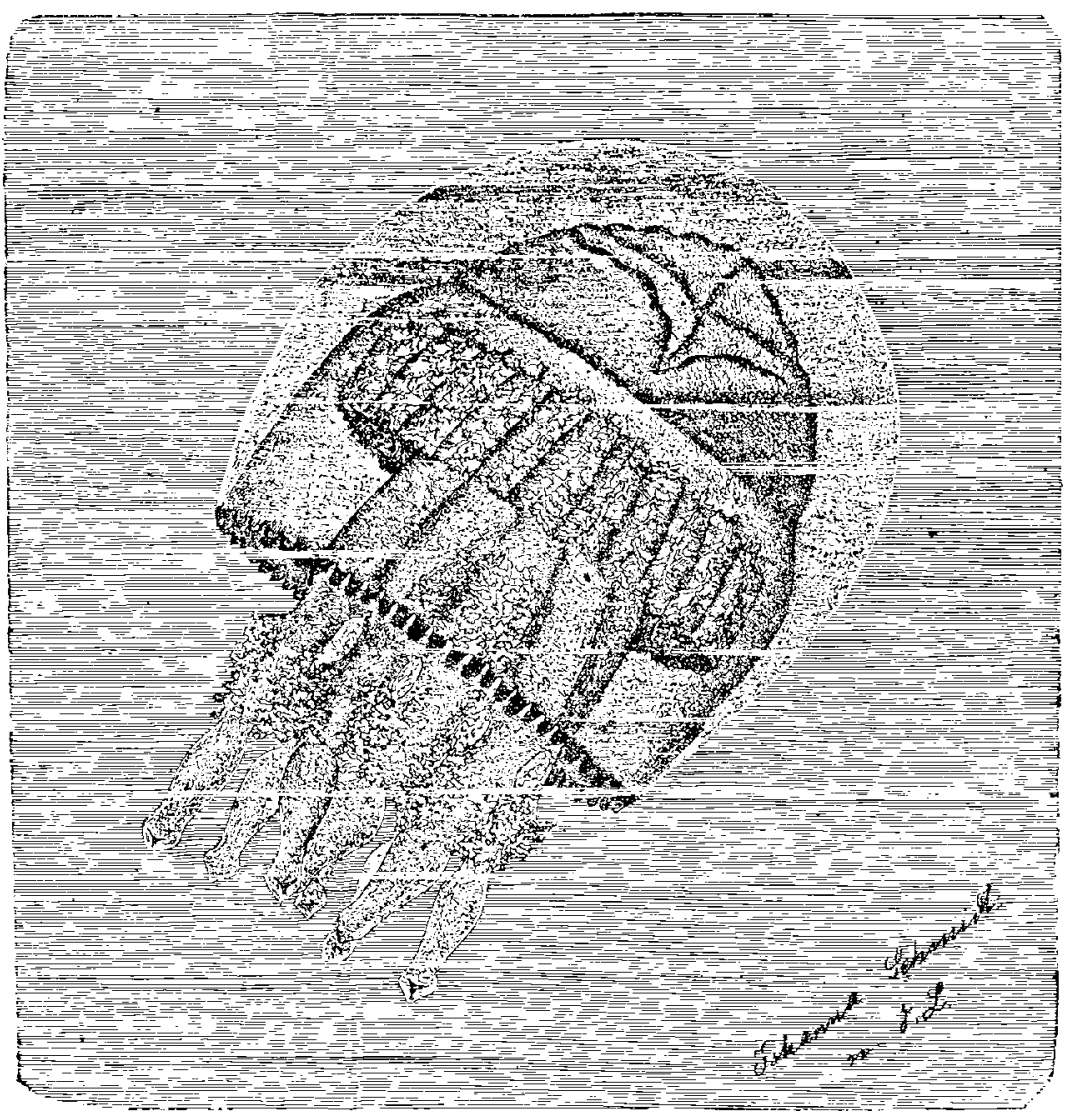

Fig. 74. - Ètres primitifs. - La méduse Rhizostome.

les plus diverses, redescendre l'échelle de l'organisation ou la remon. ter; ils nous permettent, encore de nos jours, de suivre pas à pas cette merveilleuse métamorphose (Edmond Permien, Les Colonies animales). ”

Le mème titre d'animal-plante peut être donné, et la même révélation latente peut être demandée au polypier du corail qui élève au sein des mers des édifices de fleurs brillantes et sécrète des matérianx de construction tels que des îles entières sont exclusive- 
ment formées de leurs banes massifs et solides. Ce sont des colonies plus ou moins nombreuses dont chaque citoyen construil sa demeure et l'habite. Ces innombrables branches du corail dont les entrelacements forment comme un tissu de forêt minérale, ontété longtemps une énigme pour la science, et la beauté de leurs couleurs a inspiré les plus gracieuses descriptions. On sait aujourd'hui que ce sont des colonies de polypes, dont la diversité de forme et de propriétés organiques n'est pas moins éloquente que chez les précédents. Comme eux, toutefois, ils se composent essentiellement d'un tube dont l'épanouissement peut ètre considéré comme une bouche et dont l'intérieur peut ètre qualifié d'estomac. Beaucoup de tentacules servant de petits bras. Toujours pas de tête. La faculté de voir et celle d'entendre ne sont pas encore nées. Des cinq sens, celui du toucher existe seul ; celui du goût commence. Monde obscur, quoique en pleine lumière, n'ayant encore qu'une vague conscience de lui-même, végétatif plutôt qu'animé. Quelques muscles; les nerfs ne sont qu'à l'état rudimentaire, sans grande sensibilité. Chaque petit polypier vit séparément; mais sa vie semble se confondre dans l'existence morne et aveugle de la colonie à laquelle il appartient comme partie intégrante. Comme chez les méd uses, la multiplication se produit à l'aide de petits œufs et de petits corpuscules fécondants, ce qui commence aussi les sexes, mais encore à l'état rudimentaire et sommeillant dans une profonde insensibilité. Ces êtres sont hermaphrodites sans le savoir. Sentent-ils même quelque chose de la vie? Les polypes bryozoaires sont, dans cette classe d'organismes, des créatures si étranges que la vie parait pour eux de la dernicre indifférence. Quelquefois l'un absorbe l'autre sans que celui-ci minifeste la moindre résistance. Quelquefois le polype meurt au fond de sa loge et est aussitôt remplacé par un autre, créé par cette logge elle-mème : c'est une maison qui enfante ses propres locataires!

Comme si la nature s'essayait lentement dans son cuvre du développement de la vie, à côté des organismes que nous venons de décrire, et un peu plus haut dans l'échelle organique, se placent les tuniciers, dont l'enveloppe est formée de cellulose, commeles plantes, dont le tube digestif a deux ouvertures, une pour l'entrée de l'eau nutritive et une pour la sortie (l'hydre n'en a qu'une, voy. p. 162) et qui, en plus des organes de digestion et de reproduction possède un ap- 
lusques ne sont encore, en quelque sorte, que des sacs vivants, mais ils vivent déjà un peu plus complètement que les précédents. Le pareil de circulation et un rudiment de ccur. Ges sortes de petits molplus remarquable est que ce rudiment de cour, sans valvules, sans orcillettes, sans ventricules, n'a pas encore de direction déterminée pour la circulation du sang (et quel sang!) : il bat pendant un certain temps dans un sens, s'arrête, puis se met à batlre en sens inverse, de sorte que les vaisseaux qui jouaient le rôle d'artères dans

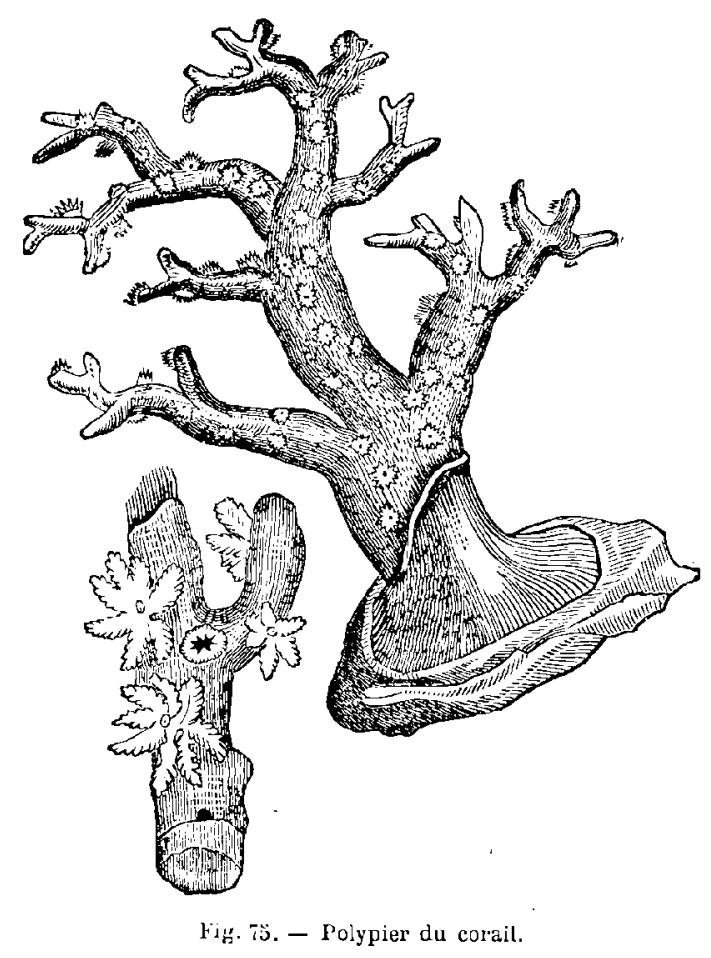

le premier cas, jouent le rôle de veines dans le second, et ainsi de suite. L'animal respire, et son appareil respiratoire (branchies) est constitué aux dépens de la partie antérieure du tube digestif. Il semble que de tous les animaux sans vertèbres, ccux-ci soient les plus proches voisins des vertébrés et représentent la souche d'oú se sont élevés les premiers vertébrés. Quant à son mode d'alimentation, ce sont toujours les cils vibratiles dont il est fourvu qui amènent vers la bouche l'eau chargée de particules alimentaires. Leurs 
formes et leurs dimensions offrent la plus grande variété. Plusieurs espèces sont microscopiques; quelques-uns sécrétent de petites coquilles protectrices ; d'autres, comme les pyrosomes, jouissent de la propriété d'être phosphorescents et répandent même, lorsqu'ils sont dans toute leur activité vitale, une très vive lumière rougo; les uns sont entièrement libres et passent leur vie à nager; d'autres se fixent sur les rochers ou dans le sol des grèves sablonneuses : ce sont les ascidies, qui abondent sur nos plages et qui atteignent parfois la dimension d'un ouf de poule; elles se collent sous les pierres comme des morceaux de gélatine et si on retourne la pierre lancent de l'eau tout autour d'elles.

Ghez ces êtres, la génération est aussi confuse, aussi irrégullière, en quelque sorte aussi hésitante, que la circulation. Ils sont hermaphrodites, portent les deux sexes, donnent naissance à des œufs, les fécondent, et de l'œuf éclot, non pas le fils, mais le petit-fils de l'animal qui l'a pondu, le fils n'apparaissant dans l'wuf que pour s'y reproduire et y mourir aussitôt! L'œuf se forme pour reproduire un être qui ne verra jamais le jour, les enveloppes de cet muf sont à la fois le berceau et le tombeau d'un organisme qui se reproduit à leur intérieur en demeurant à l'état de foetus et dont les restes lentement résorbés servent d'aliments à la génération nouvelle, seule destinée à paraître au dehors. Ge fait, aussi bizarre et aussi mystérieux que certain, est d'un haut enseignement pour la théorie de l'évolution. Il nous montre que ces êtres appartiennenta à une époque capitale de l'histoire de la nature, à la période pendant laquclle la force vitale a franchi, après mille essais et mille hésitations, le passage qui sépare les mollusques des animaux soutenus par un squelette, les invertébrés des vertẻbrés.

La nature a déjà parcouru une longue voie dans l'élaboration de toutes les formes organiques précédentes. Cependant, nons n'avons eu jusqu’a présent sous les yeux que des êtres informes végètant dans les profondeurs de la mer. Les uns sont de petites boules gélatineuses nageant à l'aide de leurs cils vibratiles qui leur servent à tout, les autres sont collés au fond de la mer ou contre les rochers, les autres se sont associès en colonies et forment des espèces d'arbres vivants. Ils ont bien déjà un tube digestif, des organes d'assimilation, de reproduction et de circulation sanguine, des muscles et des nerfs, 
mais ils n'ont aucune symétrie, ni avant, ni arrière, ni droite, ni ganche. Il serait superflu d'ajouter que jusqu'à présent mème, la tête n'existe pas. Jusqu'ici, tous les ètres sont aveugles, sourds et muets.

Un rudiment de tête, un commencement de symétrie, va se montrer chez les vers, dont les ancètres habitaient la vase des mers et des rivages. Ce mollusque diffère des précédents par deux caractères : il est allongé et il se déplace. C'est un polype libre (pas toujours encore; exemple: le tænia). Considérons un instant le plus simple ver de torre. Le seul fait de ramper constitue déjà pour lui une supériorité. Il est formé d'anneaux égaux, c'est vrai, et son accroissement de longueur n'est obtenu que par un accroissement dans le nombre de ces anneaux, dont chacun peut également devenir une tête ou une queue. Tous ces ćléments sont égaux. Mais le

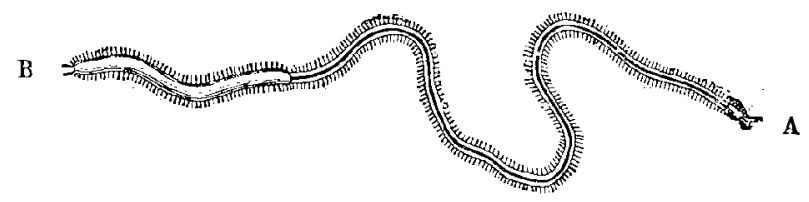

Fig. 76. - Les indécisions primitives de la génération.

Syllis amica composée de deux parties, l'antélieure sans sexe, la seconde sexuéc.

seul fait que l'anneau antérieur est chargé d'absorber le premier la nourriture qui doit traverser le ver tout entier place cet anneau en des condilions telles que ses moyens de perception sont constamment sollicités à agir et à se développer. C'est une bouche qui marche, qui a une certaine responsabilité vis-à-vis de l'alimentation de la colonie, qui doit toujours ètre en avant et au bas pour chercher dans lo sol ce qu'il y a de meilleur, etqui par ce fait même commence une symétrie pour l'organisme: uno pièce antérieure, une face ventrale, une face dorsale, une gauche et une droite.

La tète va prendre une fonction spéciale. Elle rencontrera des obstacles, sera quelquefris appelée à combattre, se trouvera parfois fort exposéc. Sa résistance et sa force augmenteront graduellement. Cependant cet organe n'acquiert pas encore une importance telleInent essentielle qu'if ne puisse renaitre de ses propres racines s'il a été mutilé. Coupez la tête à un ver de terre, elle repoussera; partagez un ver en deux parties, chacune des deux parties se complétera, mème la partie postérieure qui devra s'ajouter un appareil 
de circulation et un cerveau. Chez les naïs, qui habitent les eaux douces, la force vitale est encore plus intense, car elle est pour ainsi dire individualisée dans chaque anneau : à l'aide de ciscaux très fins, coupez cet annelé en autant de parties que vous voudrez, chacmne d'elle se munira d'une tête et d'une queue et formera un animal en parfait état de vitalité.

Les annélides représentent le type des colonies animales, de la construction d'individus par juxtaposition d'organismes élémentaires. Quelquefois elles atteignent des proportions considérables; certaines eunices mesurent $1^{\mathrm{m}} 50$ de longueur sur près de trois centimètres de largeur, et sont composées de plusieurs centaines d'anneaux; il en est de mème de certaines espèces de vers des pays chauds. On rencontre souvent dans la mer des annélides si longues que la queue n'est pour ainsi dire plus en communication directe avec la lête, et qu'elles se mordent elles-mèmes sans paraitre s'en apercevoir. Les nais et les déro se reproduisent par simple bourgeonnement: quarante ḋ soixante anneaux poussent successivement, puis l'animal se coupe spontanément en deux, ot une tète se forme à l'anneau antérieur du nouvel être; mais, ce qu'il y a de plus remarquable, c'est qu'à la fin de l'année, à l'automne, ce mode de reproduction s'arrête pour faire place à la génération sexuée. Certaines néréides sont plus curieuses encore peut-être: elles sont composées de deux individus soudés bout à bout, l'un sans sexe, l'autre sexué. Il en est de mème des syllis (voy. fig. 76). Vraiment la nature semble avoir essayé tous les moyens avant de se fixer. A l'époque de ces essais, il semble qu'elle était encore loin de s'ètre décidée pour le mode de génération qui conviendra le mieux.

Plus tard, chez les insectes, la reproduction sera réservée à l'ẹtre parfait, au papillon sorti de la chrysalide, et les larves ne pourront plus se reproduire. Ici, les larves se reproduisent et la métamorphose qui commence n'est pas encore faite. L'indépendance des anneaux est souvent telle que chez un même animal les uns peuvent être mâles et les autres femelles, les uns sexués, les autres stériles (spirorbes, autolytes, etc.).

Insensiblement la tête se forme, quoique assez irrégulièrement. Le rudiment du cerveau se trouve dans le premier anneau chez les 
innélides, dans le troisième et quelquefois le quatrième chez los lombrics; la bouche occupe le second anneau chez les annèlides. Les cils vibratiles sont devenus des antennes, des organes de préhension. Les yeux, des yeux rudimentaires apparaissent; ce sont des nerfs, sensibles à la lumière, qui commencent à se développer, et souvent aux dcux extrémités de l'annélide, $\dot{a}$ la queue comme à la tête, autour des anneaux extrêmes. La nematonereis contorta, l'oria armandi, les fabricius, ont généralement deux yeux sur le segment anal; les amphicorines, les myxicoles en ont quatre, l'amphiglena mediterranea six ou huit. Il est à remarquer que cette particularité s'observe surtout chez les annélides dans lesquelles la tête a été détournée de son rôle primitif, du rôle de cicerone de la colonie, par le développement d'un volumineux panache respiratoire. Les amphicorines et les myxicoles quittent volontiers leur tube pour courir à l'aventure; ils en sortent la queue la première, la dirigent toujours en avant, et semblent traîner après elle le reste de la colonie. L'anneau postérieur s'est donc réellement emparé d'une des fonctions essentielles de la tête, ou plutôt les rôles que remplit ordinairement une tête se sont partagés entre les deux extrémités du corps : la tête digestive, celle qui porte la bouche, est demeurée à l'extrémité qui correspond au côté antérieur des autres vers; la tête sensitive s'est transportée à l'extrémité postérieure, gènée qu'elle était dans l'exercice de ses fonctions ('). Les tæenia, vers solitaires, parasites attachés à un organisme, n'ayant jamais besoin de chercher leur nourriture, qui leur arrive toute seule, n'ont pas de tête du tout, mais seulement une sorte de ventouse, un scolex qui reproduit le corps du ver en donnant naissance à des anneaux consécutifs. Ce que nous venons de dire des yeux peut être appliqué aux organes de l'ouie, qui commencent également à paraitre, rudiments d'impression auditive que l'on rencontre tantôt sur le premier segment (oria armandi), tantôt sur le second (amphicorine coureuse), tantôt sur le troisième (amphicorine argus), tantôt sur le quatrième (wartelia). Mais insensiblement les organes, les sens, vont se localiser à la partie antérieure du corps où leurs fonctions d'avertisseurs les appellera de plus en plus.

\section{Edmond Perrier. Les Colonies animales.}


Ainsi graduellement nous assistons au développement el à la progression de la vie, chaque détail de la formation des organismes nouveaux se présentant à notre attention comme une révélation des origines d'où sont issues toutes les créatures actuellement vivantes. Lorsque nous arrivons aux insectes, nous voyons en eux la même structure originaire : ce sont des anneaux plus ou moins réunis et soudés. Les myriapodes, on bètes à mille pattes que tout le monde connait, ne possèdent, en général, que neuf anneaux à leur sortie de l'œuf; les autres anneaux poussent successivement à la partie postérieure du corps; mais l'individualisation est déjà plus complète : les deux moitiés d'une scolopendre coupée par le travers peuvent vivre encore pendant quelque temps et se mouvoir comme deux animaux distincts; mais elles finissent par succomber l'une et l'autre sans s'ètre complétées. Le mode de génération devient essenticllement sexuel.

Chez tous les insectes, le corps se compose de trois parties caractiristiques : la tête, le thorax et l'abdomen; la tête est formée d'anneaux soudés, le thorax toujours de trois et l'abdomen de six à douze. Chez les araignées, la distinction des anneaux n'est visible que pendant la période embryonnaire. L'unité d'origine est flagrante.

Mais n'allons pas si vite, afin de concevoir judicieusement la marche des choses dans ce lent et grandiose développement de la vie. Du mème ordre organique que les êtres précédents, primitifs comme eux, et comme eux caractérisant ]ès débuts de l'organisation terrestre, sont les échinodermes ('), astéries ou étoiles de mer, oursins, crinoïdes, holothuries, etc. Ils possèdent encore les deux modes de reproduction (par sexes et sans sexes), c'est-à-dire que d'une part ils ont des œufs et que d'autre part ils se multiplient par bourgeonnements. Des pècheurs souvent contrariés de voir les étoiles de iner pulluler dans leurs parages, les coupent par morceanx lorsqu'ils les saisissent accrochées à leurs filets et en rejettent les morceaux à la mer; ils créent ainsi quatre ou cinq astéries au lieu d'une. Ils peuvent se déplacer lenternent, à l'aide de leurs petites tentacules érectiles. Les astéries et les oursins ont des yeux rudimentaires : ce sont des taches pigmentaires rouges, situées à la face

1. Etymologie: Exเvos, hérisson et pux, peau (ètres à la peau hérissée). 
infërieure des rayons, immédiatement au-dessous des tentaeules terminaux. La lumière s'y réfracte fortement. Ils méritent à peine ce titre, mais, en fait, ce sont déjà des yeux.

Les étoiles de mer ou astéries sont, originairement, des polypes linéaires, des vers, soudés par la tète au centre de l'ètoile. Le bras d'une étoile, détaché au disque central, repousse tout entier. Les cinq bras (ou davantage chez certaines espèces) repoussent également. Chaque bras vit et peut, à son tour, donner naissance à un

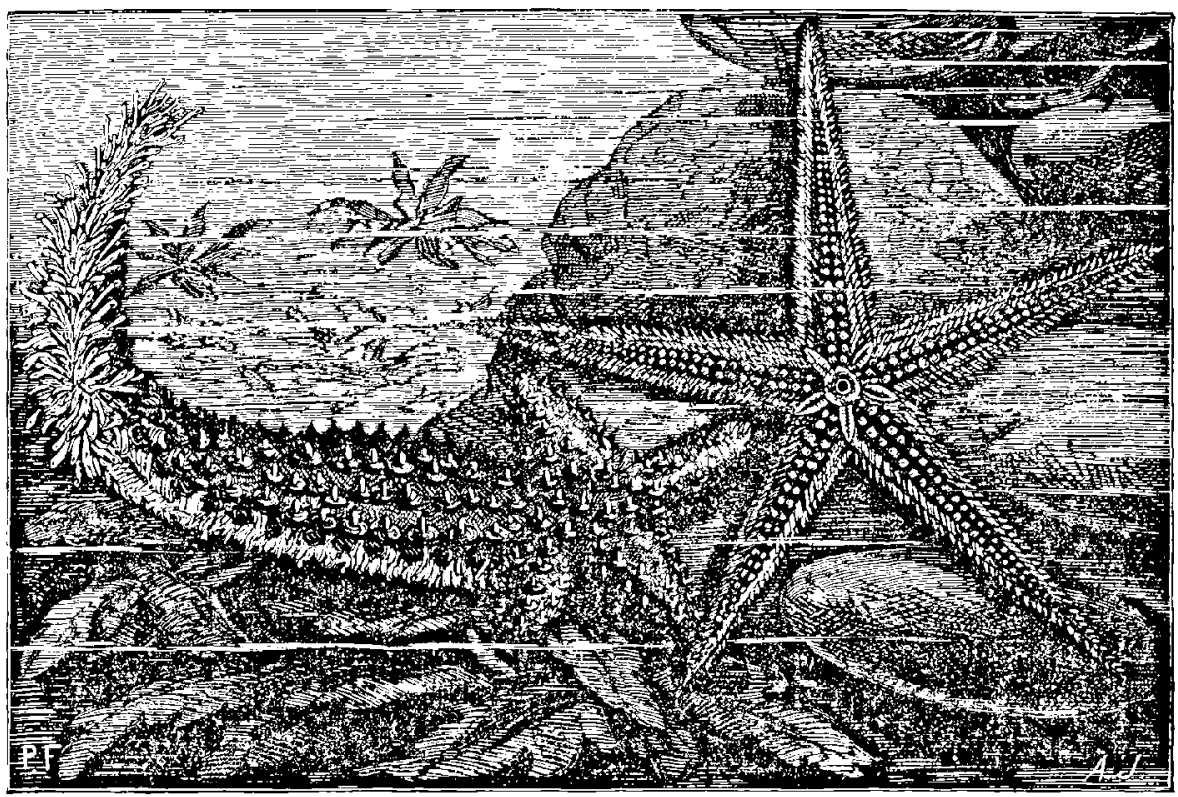

Fig. 77 - Astérie en pleine reproauction de ses rayons. - Astérie normale.

bourgeon qui devient disque central et reconstitue l'astérie. La force vitale est toujours répandue dans l'ensemble de l'ètre. Il n'y a pas encore de tête ni d'appareil respiratoire. Ne croit-on pas voir la nature s'essayer de toutes les facons les plus inimaginables?

Les mollusques proprement dits, les céphalopodes, qui marcḩent sur la tête, poulpes, pieưrres, etc.; les gastéropodes, qui marchent sur le ventre, escargots, limaces, etc.; les acéphales, qui n'ont pas de tète, huîtres, moules, etc., paraissent descendre des vers annelés, d'après les recherches de M. Perrier. Sclon ce naturaliste, tous ces mollusques marchent sur un appendice de leur tête, les bras du céphalopode, le pied aplati du gastéropode et le 
pied linguiforme de l'acéphale seraient tous trois des dépendances de la tête du mollusque; leurs formes proviendraient des conditions au sein desquelles ils ont dû vivre. Les mollusques et les annélides céphalobranches seraient les uns et les autres' les descendants d'êtres habitant des tubes, n'ayant de rapports avec le monde extérieur que par les orifices de ceux-ci et surtout par leur orifice antérieur : l'anatomie prouve cette relation. Les acéphales seraient dos gastéropodes dégénérés, chez lesquels la tête n'ayant plus aucune fonction à exercer s'est atrophiée et résorbée dans l'ensemble du mollusque. Les brachiopodes qui, comme les acéphales, sont enfermés dans une coquille bivalve, mais en diffèrent beaucoup au point de vue de l'anatomie intérieure, descendraient des annclides par une autre lignée, et seraient restés les plus rapprochés de la souche commune.

Chez les mollusques, les systèmes nerveux et musculaire sont encore très rudimentaires. Le système nerveux consiste en deux colliers entourant l'œesophage et sur lesquels sont dissimulés les ganglions; le système musculaire n'a pas d'organes de soutien. L'une des propriétés particulières des téguments des mollusques est celle de sécréter des substances solides formant leurs coquilles si variées, et qui sont pour eux des organes de soutien indépendants du système musculaire. Les organes des sens prennent graduellement un grand développement. Le toucher a acquis une certaine délicatesse. L'odorat se distingue progressivement du goùt. L'ouie a pour appareil des vésicules contenant dans leur intérieur des autolytes. L'oil possède une rétine, un cristallin, un iris, la sclérotique, la choroïde, le corps ciliaire et l'humeur vitrée. La partie du corps qui porte les yeux est ordinairement la base des tentacules; souvent aussi ils se trouvent aux extrémités. Ils ont tous un cœur ou un appareil circulatoire qui en tient lieu. Ils sont sexués et se reproduisent par œufs, mais les sexes ne sont pas touiours séparés en deux individus différents : chez les céphalopodes, poulpes, sciches, les sexes sont séparés; chez les gastéropodes ils sont réunis; presque tous les gastéropodes sont hermaphrodites : limaces, escargots, limnées, murex, cyprées, etc. Les hélices, colimaçons ou escargots, sont hermaphrodites, c'est-à-dire que chaque individu est pourvu des deux sexes, mais la réunion intime des deux étres est 
nécessaire pour la reproduction, chacun d'eux agissant en même temps comme mâle et comme femelle. Ce sont là autant d'essais de la nature que le philosophe doit apprécier.

A la froutière des vertébrés et des invertébrés, on rencontre l'amphyoxus "le vénérable amphyoxus ", comme le salue Haeckel, qui n'est ni limace, comme le croyait le premier naturaliste qui l'étudia (Pallas, 1778), ni poisson, comme le déclarait le zoologiste Costa en 1834. En fait, cet être diffère beaucoup plus de tous les poissons que ceux-ci ne diffèrent de l'homme. C'est un vertébré sans cràne.

L'amphyoxus vit sur les plages marines sablonneuses, en partie

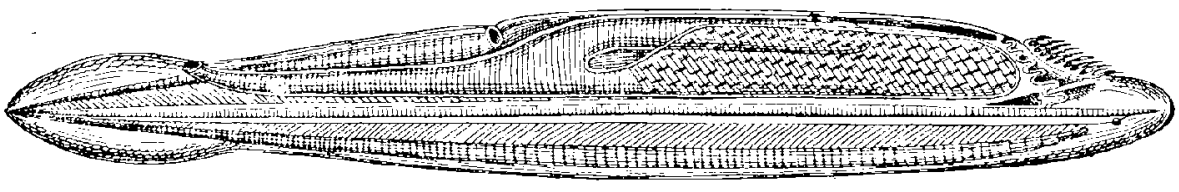

Fig. 78. - L'amphyoxus, vertébré sans tète, intermédiaire entre les invertébrés et les vertébrés.

enfoui dans le sable, et est très répandu dans les diverses mers; on le trouve dans la mer du Nord, sur les côtes de l'Angleterre, sur celles de la Méditerranée, au Brésil, au Pérou, à Bornéo, en Chine, un peu partout. Son corps est mou, sans aucune partie solide, sans aucun organo pétrifiable, long de cinq centimètres environ, blan-

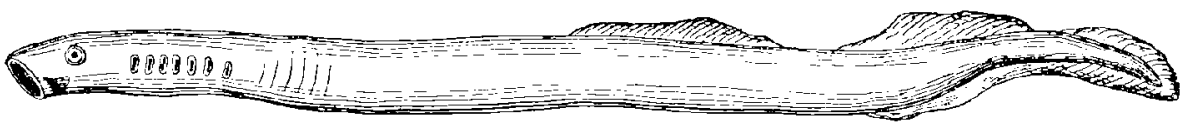

Fig. 79. - La Lamproie, poișson primitif rudimentaire.

châtro ou légèrement teinté de rose : il a la forme d'une lancette étrcite pointue aux deux bouts. Nulle trace de membres. Un tube cylindrique forme l'axe de son corps; ce trube loge le système nerveux central, et représento en principe la colonne vertébrale. Les organes principaux des vertébrés sont là sous leur forme la plus rudimentaire. Une petite tachè pigmentaire. placée en avant, à l'extrémité du tube nerveux, paraît etre lo rudiment de l'œil ; à côté, une petite fossette commence sans doute l'organe olfactif; l'ouie n'existe pas encore; pas de cerveau du tout. L'anatomie de cet être curieux montre en lui lancétre le plus probable 
des vertébrés : il serait le dernicr descendant de la race antique des vertébrés dépourvus de tête; les naturalistes pensent avoir trouvé là l'intermédiaire tant cherchè entre les invertébrés et les vertébrés, le plus proche parent du premier type disparu des vertébrés.

Immédiatement après cet ancêtre peuvent ètre classés les poissons à crâne les plus primitifs, par exemple les cyclostomes, dont la lamproie (fg. 79) fait partie. Leur corps est allongé, cylindrique, vermiforme, dépourvu de membres; leur bouche toute ronde n'a pas encore de dents ; leur peau est nue et sans écailles. Point de squelette osseux. Mais déjà un commencement de branchies et dé̉à un commencement de cerveau.

A mesure que nous avançons dans l'examen des organismes, nous allons voir l'ètre s'individualiser davantage, la vie se localiser en quelque sorte, les éléments constitutifs des animaux perdre leurs propriétés primitives pour s'abandonner à la direction commune de l'être cérébral, de plus en plus personnel et dominant. Les vertébrés, mammifères, oiseaux, reptiles, batraciens, poissons, sont essentiellement constitués par un édifice de vertèbres, qui protège la moelle épinière, se termine par un crâne formé luimême de vertèbres modifiées, lequel renferme le cerveau, qui n'est qu'un épanouissement de la moelle épinière. Nés des invertébrés, issus sans doute mème des plus humbles d'entre eux, des vers annelés, dont l'anatomie offre les plus significatives analogies avec celle des vertébrés infẻrieurs, l'embranchement si considérable des vertébrés, à la tête duquel règne l'homme lui-même, nous apparait comme le déploiement le plus complet de la vie à la surface de notre planète. Dans son analyse, on trouve l'explication, non seulement de la forme revêtue par les étres, mais encore de la disposition et de la place de chaque organe du corps. La tête, les appareils'si délicats de la vue et de l'ouïe, l'individualisation du cceur, des ooumons, des reins, se sont constitués graduellement et progressive,ment. La forme de chaque ètre, extérieure ou intérieure, provient do son genre de vie et de celui de ses ancètres. Nous avons vu que pendant des siècles et des siècles, les organismes se sont reproduits par hourgeonnement et fissiparité. Puis nous avons ru apparaitre, chez des êtres qui continuaient de se repro- 
duire par ce mode primitif, des organes donnant naissance, les uns à de petits cuff, les autres à de petites glandes de fécondation. Alors commenco la génération sexuée, alternant avee la précédente chez les mèmes individus, et se manifestant sur des organismes qui portent à la fois ces deux rudiments de sexes et sont hermaphrodites. Bientôt elle se trouve le plus souvent séparée sur deux

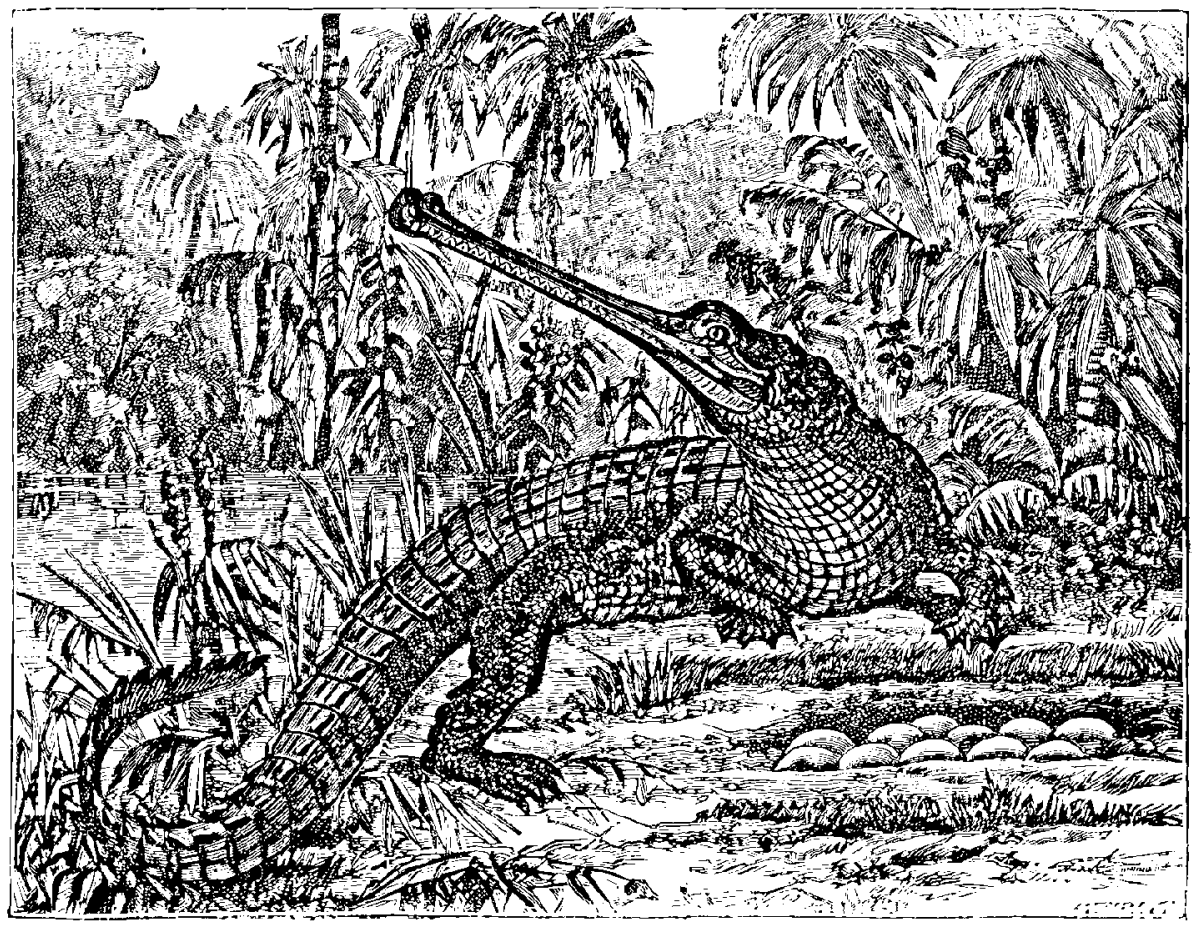

Fig. 80. -- La génćration vivipare vient de la gènération oviparc. Quadrupedes ovipares : Crocodile ol ses ceufs.

individus différents, qui devront se rapprocher, revenir à leur unité primitive, pour assurer la durée de l'espèce, et c'est précisément ce mode de génération sexuée qui différenciera le plus les êtres et créera les espèces. Ia pusition de ces organes dans le voisinage de ceux qui servent à l'excrétion des substances inutiles à l'organisme I'est sans doute pas fort heureuse; elle provient, de proche en proche, de la constitution des vers de terre eux-mèmes, chez lesquels on voit les primitifs organes de reproduction associés aux organes de sécrétion et identiques à eux comme conformation. Chez 
les annélides, les produits de la génération, œufs ou zoospermes, se formant dans tous les canaux du corps, trouvent dans ces petits canaux d'excrétion un passage tout préparé pour arriver au dehors. Le perfectionnement séculaire de l'animalitẻ n'a pas encore effacé cette origine.

La multiplication par œufs, ła génération ovipare, s'est lentement établie, d'une manière en quelque sorte inconsciente d'abord; puis clle a régné jusqu'au jour où elle s'est transforméc elle-même en génération vivipare. A partir de cet établissement de la génération sexuée, tont être vivant vient d'un œuf fécondé, a un père et une mère. Mais le père et la mère ne sont pas pour cela forcés de se connaître. Les poissons répandent leurs œufs dans les eaux : un jour ou l'autre ces œufs sont fécondés sans que le poisson qui passe par là ait jamais connu la mère de ces cufs. Il y a quelques exceptions, notamment pour les raies, les squales, qui sont entre les ovipares et les vivipares, l'œuf éclosant dans le ventre de la mère, comme chez les yipères; mais tel est le mode impersonnel et froid de la génération des poissons. Dans d'autres cas, coinme chez les grenouilles, chez les salamandres aquatiques, etc., le père ct la mère se rapprochent, mais sans se toucher, et les oufs reçoivent néanmoins la fécondation avant d'ètre pondus ou au moment même où ils le sont (4). L'union intime de deux êtres, le mariage naturel, momentané ou durable, sont des produits du progrès à travers les âges. Cette tendre union, déjà remarquable chez un grand nombre d'oiseaux, a commencé parmi les espèces ovipares, au nombre desquelles on peut compter un très grand nombre de quadrupèdes. Les tortues, les lézards en général, les crocodiles, les grenouilles, les serpents, les couleuvres non vipères, les oiseaux, sont ovipares. On peut suivre le développement de la génération ovipare depuis les insectes les plus humbles jusqu'aux mammifères. Ceux-ci sor.t vivipares; mais encore ici, chacun sait que dans le sein de la mère tout être vivant a commencé par un œuf. La viviparité n'est que l'oviparité perfectionnée; elle est même encore indécise chez les premiers mammifères, chez les marsupiaux qui portent leurs enfants dans une poche extérieure, et surtout chez les monotrèmes,

1. Yoy. LACÉPÈDE, Histoire naturelle des quadrupèdes ovipares, art. Salamandre. 
ornithorinque et échidné. Ainsi, sous quelque point de vue que nous l'envisagions, nous voyons dans la vie terrestre tout entière le développement d'un seul et même arbre généalogique.

Les quadrupèdes ovipares forment la transition entre la génération par œufs et les générations par petits vivants; on ne sait mème pas encore au juste aujourd'hui si l'ornithorinque pond toujours des ceufs ou met parfois au monde des petits vivants. Les marsupiaux, sarigues, kangourous, pétrogales ( $/ \mathrm{g} .81$ ), ctc., paraissent être les plus anciens mammifères du globe, avec les monotrêmes, chez lesquels le sein commence par une simple glande mammaire à peine visible; ils semblent être le résultat de la première tentative de la nature s'essayant à produire des mammifères. Ces ètres arrètés dans le développement de la vie no mettent au monde que des petits à peine commencés, qui finissent de se former après être nés. La mère saisit avec ses lèvres ses petits, nés non viables par euxmèmes, et les dépose dans la poche qu'elle porte devant son ventre. $L \dot{a}$, ils se greffent chacun à un mamelon assez semblable à une vossie allongée, et y restent adhérents jusqu'à ce que leurs membres et leurs organes soient développés. Cette poche marsupiale est comme un second utérus dans lequel s'achève leur évolution. Lorsqu'ils marchent tout seuls, les petits n'oublient pas ce nid, et à la premic̀re alerte ils s'y réfugient; ils y passent pour ainsi dire toute leur enfance. On le voit, nous assistons graduellement au développement de tous les organes : On peut suivre pas à pas la formation du sein, depuis l'humble monotrème jusqu'à la splendide Vénus de Milo; le perfectionnement de la tète, depuis le ver vulgaire jusqu'à l'Apollon ou l'Antinoüs; comme celui du corps tout entier, de chacun de ses organes, de l'œil, de l'oreille, de la main, etc., etc. Petit à petit tout arrive, tout progresse, tout se perfectionne. Comment a-t-on pu rester si longtemps sourd à ces enseignements universels de la nature?

La force vitale, d'abord répandue dans tout l'organisme, va en se centralisant avec le perfectionnement des êtres. C'est là un autre fait auquel il importe de donner aussi la plus haute attention. Nous avons déjà vu que dans la tribu des annélides, on peut couper une nais en deux, trois, quatre, dix, vingt, autant de morceaux qu'on le voudra, sans empêcher de vivre cet' être qui n'est qu'une association 
d'éléments vitaux excessivement petits dont chacun possède sa vitalité propre: trente morceaux de naïs font simplement trente naiss différentes; chacun se fabriquera rapidement une tête, une queue et de nouveaux anneaux. Nous avons vu aussi que certaines longues annélides se mordent la queue sans s'apercevoir qu'elles s'attaquent à leur propre personne-laquelle personne, au surplus, n'a presque pas conscience d'elle-mème. - Nous avons vu encore qu'en partageant une hydre en morceaux, soit longitudinalement, de haut en bas,

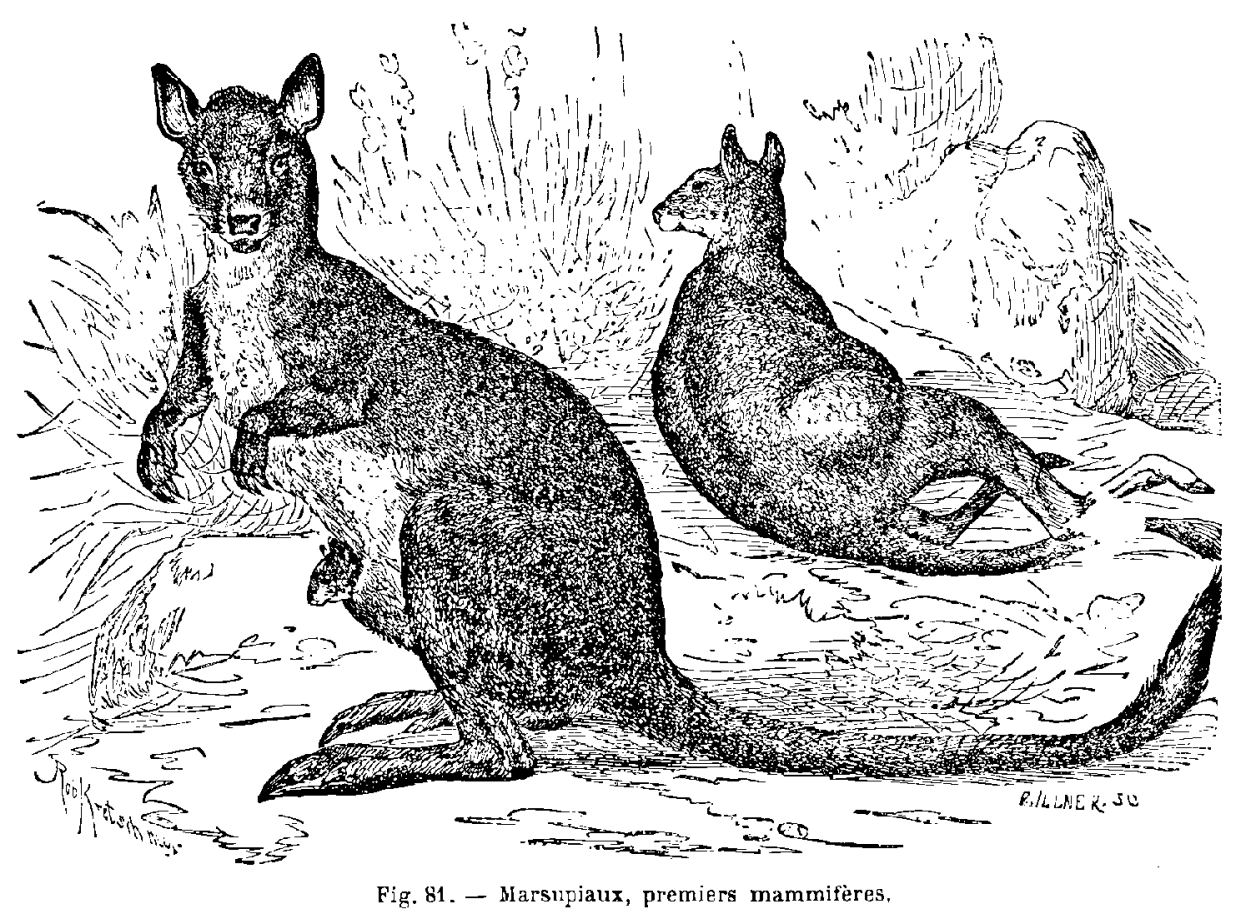

Los noaveaux-nés, g'étant pas encore tont a faitt tormés, sont congervés dans une poche.

soit transversalement, soit des deux facons, on ne la tue pas, au contraire, on la multiplie, chaque pièce devenant une nourelle hydre parfaitement vivante; que, d'autre part, on peut la retourner cormme un gant sans lui faire plus de mal, l'épiderme extérieur deve. nant très vite estomac, et réciproquement; que, d'autre part encore, on peut greffer ces animaux ou ces morceaux d'animaux les uns sur les autres et les forcer à vivre à la façon d'un seul, etc., etc. Le lombric ou ver de terre n'a déjà plus cette vitalité générale, mais pourtant on peut encore lui couper la tête : elle repousse. Charles 
Bonmet (1) ayant coupé douze fois la tête à un même ver l'a vue repousser douze fois. Chaque rayon d'une ètoile de mer a sa vie propre : on peut le détacher, il continue de vivre et reformera. l'astérie tout entićre; l'étoile, de son côté, reformera sus rayons. A mesure rue nous avançons dans le perfectionnement des etres, cette force vitale qui appartenait d'abord indistinctement à chaque élément constitutif de l'organisme, se localise et acquiert la conscience de son existence. D'abord obscure, cette conscience s'établit

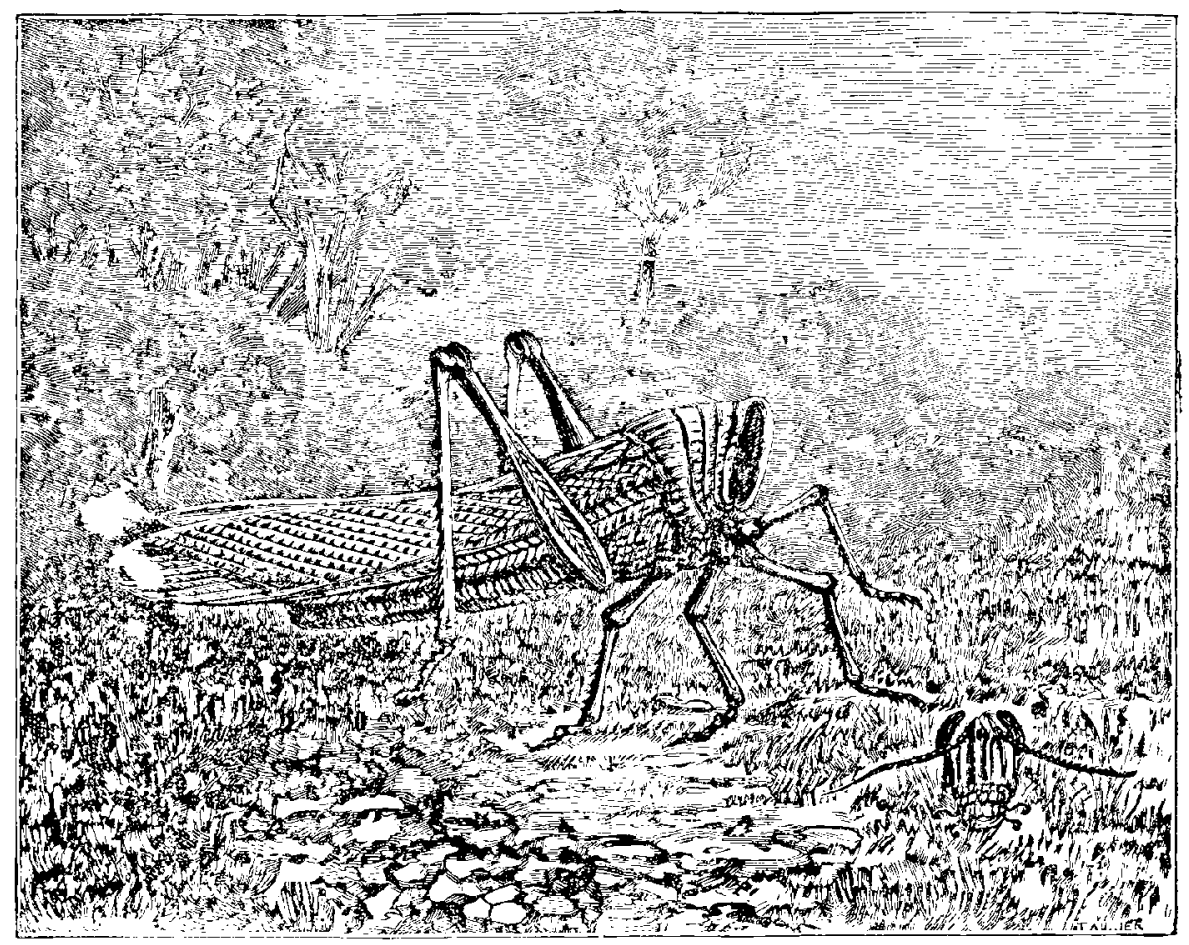

Fig. 82. - Sauterelle décapitée, vivant au bout de quinze jours.

graduellement et se personnifie. Toutefois la vitalité des éléments ne disparait pas pour cela; elle diminue et s'éteint lentement. Tous ceux qui ont été enfants (et qui ne l'a pas été?) se souviennent de l'in-

1. Charles Bonnet était un philosophe plutớt qu'un naturaliste de profession. On prut en dire aulant de I,eibnitz écrivant sa protogée, de Gothe an nonçant le transformisme, de Lamarck enseignant sa philosophie zoologique, de Geoffroy Saint-Hilaile et de tous les grands esprits pour lesquels les progrès des sciences naturelles représentent autre chose que des classifications d'école. 
différence singulière avec laquelle le lézard laisse sa queue dans la main qui croyait le saisir : plutôt que d'être pris tout entier, il n'hésite pas un seul instant à perdre cet ornement, sachant probablement que la partie détachée se reformera. Gette partie détachée vit elle-mème pendant plusieurs minutes, remue, s'agite, se retourne, comme si elle cherchait son propriëtaire disparu. L'animal reconstitue sa queue, d'abord en deux ou trois mois, dans son tissu, ensuite, au bout de deux ans, dans ses vertèbres mêmes (expériences de M. Charles Legros). Chez les salamandres, les pattes repoussent aussi bien que la queue, et mème les yeux et une partie de la tête. On a observé également la régénération de la queue chez les loirs. Chacun sait aussi que les pattes et les antennes de l'écrevisse repoussent et que c'est pour cette raison qu'elles sont si souvent d'inégales grosseurs et d'inégales longueurs. Il en est de mème chez les homards, les crabes, etc.; ici on a même constaté la régénération des yeux. Les mollusques, notamment les céphalopodes, régénèrent aussi leurs membres détruits.

Parmi les insectes, les sauterelles sont douées d'une vitalité prodigieuse, qui date certainement aussi de ces époques primitives pendant lesquelles la nature enfantait la vie sous toutes ses formes à la surface de la Terre. Il y a quelques années, j'ai eu l'occasion de faire sur ce point des expériences assez curieuses et tout à fait caractéristiques. G'était à Nice, dans un jardin où ces insectes font le désespoir des jardiniers. Sans rapporter ici en détail ces expériences qui n'ont pas duré moins d'un mois, je résumerai celles qui se rattqchent directement à la question que nous traitons en ce moment.

Sur 31 sauterelles décapitées, toutes ont vécu quarantehuit heures, aussi alertes que si on ne leur avait fait subir aucune opération, 29 ont vécu trois jours, 23 quatre jours, 10 cinq jours, 4 six jours, 2 sept jours; le huitième jour, la dernière était encore très nerveuse et presque féroce; je voulus la prendre, comme j'avais pris successivement ses compagnes défuntes, pour l'enlever de la boite, elle sauta si énergiquement qu'elle me laissa dans la main la patte que j'avais saisie. Cette lutteuse vécut encore six jours. Treize jours après la décapitation, en l'exposant au soleil, elle remuait encore la patte sauteuse qui lui restait, et même les petites pattes. En fait, elle ne mourut que quinze jours après avoir été décapitee! 
Ainsi, ces créatures peuvent vivre longtemps sans tête. Elles peuvent vivre également entièrement vidées de tous leurs organes, et mème empaillées : vidées, et cm yaillées ou non, cinq jours; vidées et décapitées, quatre jours. La tête seule, détachée, peut vivre pendant vingt-quatre heıres, remuant les antennes et les mandibules. La tête avec le premier anneau peut vivre pendant trente heures. La tête avec les deux premiers anneaux vit pendant trois jours. Le premier anneau seul séparé de la tête et du corps, vit plusieurs heures. Le troisième anneau et l'abdomen, c'est-à-dire, à proprement parler, le corps de la sauterelle, meurt immédiatement. Ainsi, les centres vitaux sont répandus dans la tête et les deux premiers anneaux et sont absents du troisième. Ces ëtres sont, au surplus, d'une indifférence apparente des plus singulières; lorsqu'on leur coupe la tête, lorsqu'on les dissèque tout vivants, Iorsqu'on leur arrache les entrailles, ils ne manifestent aucun mouvernent convulsif. Une sauterelle qui a la tête coupée depuis huit jours ne le sait probablement pas : elle est sans doute plutôt gênée par la faim qu'autrement.

Gette vitalité peut être observée chez un grand nombre d'animaux; mais elle se localise dans le cerveau et le cœur à mesure qu'on s'éléve dans la série animale. On sait, entre autres, que les deux moitiés d'ùne grenouille coupée en deux ne meurent pas immédiatement : la moitié antérieure, la tête et les deux premières pattes, se sauve dans les herbes, tandis que la moitié postérieure garde toute sa sensibilité; il n'est pas rare de voir, dans les expériences de laboratoire, une grenouille décapitée écarter avec sa patte la pince qui la fait souffrir. Il n'est pas rare non plus de voir dans les basses-cours un volatile auquel on vient de trancher la tête pour satisfaire un désir du cuisinier, s'envoler au loin et inonder de sang tout le trajet de son agonie. Une anguille écorchée et coupée en morceaux s'agite singulièrement, comme si chaque segment restait doué d'une vie propre. Un cœur de tortue arraché de la poitrine de l'animal continue de battre pendant plusieurs heures encore. Nous avons vu plus haut qu'on peut enlever le cerveau aux animaux inférieurs et qu'il repousse; l'expérience peut être faite sur des animaux relativement supérieurs, sur des oiseaux, sur des pigeons. Les lobes cérébraux ayant été enlevés chez un pigeon, l'animal 
perd immédiatement l'usage de ses sens et la faculté de chercher sa nourriture. Toutefois, si l'on ingurgite la nourriture à l'animal, il peut survivre, parce que les fonctions nutritives sont restées intactes tant que leurs centres nerveux spéciaux ont été respectés. Peu à peu le cerveau se régénère avec scs éléments anatomiques spéciaux, et, à mesure que cette régénération s'opère, on voit les usages des sens, les instincts et l'intelligence de l'animal revenir (').

Si le lecteur a bien voulu suivre avec nous cette étude, un pen longue peut-être, mais qui se compose tout entière de documents d'observation rigoureuse et positive, sur le développement et la progression de la vie, il aura surtout été pénétré de l'idée que tout se tient, dans cette grande cuvre de la nature, depuis le minéral jusqu'à l'homme; oui, nous le répétons, depuis le minéral. Ainsi, par exemple, un morceau de cristal brisé se cicatrise et se refait à la façon d'un tissu végétal ou animal, quoiqu'il y ait une distance considérable entre ces trois substances. Il résulte à ce propos, des recherches de M. Pasteur, que «lorsqu'un cristal a été brisé surl'une quelconque de ses parties et qu'on le replace dans son eau-mère, on voit, en même temps que le cristal s'agrandit dans tous les sens par un dépôt de particules cristallines, un travail très actif avoir lieu sur la partie brisće ou déformée, et en quelques heures il a satisfait, non seulement à la régularité du travail général sur toutes les parties du cristal, mais au rétablissement de la régularité dans la partie mutilée. »

Dans cette série ininterrompue des manifestations de la nature créatrice, depuis les périodes mécanique, physique et chimique, antérieures à la vie, jusqu'aux siècles modernes illustrés par l'intelligence et par la pensée, il n'y a aucune solution de continuité, aucun hiatus, aucun changement de plan, aucun abîme infranchissable, aucune création spontanée de toutes pièces, aucun apport étranger aux effets antérieurs. La nature terrestre tout entière est construite sur le mème plan et manifeste l'expression permanente de la mème idée. Lorsqu'on arrive à l'homme, on ne se trouve pas non plus en face d'un abîme infranchissable. L'homme est fils de

1. Claude Ijernakd. La Science expérimentale. Les fonclions du cerveju. 
la nature au même titre que les productions précédentes. Il est ruttaché par des liens oriøinaires et indissolubles aux êtres qui l'unt précédé, aux minéraux, aux végétaux et aux animaux. Nous examinerons plus loin quel a été son ancêtre le plus direct. Mais en terminant cette étude synthétique sur l'ensemble, il importe que nous comprenions bien cette parenté naturelle de l'homme avec la rie terrestre tout entière.

L'esprit comme le corps sont des produits de l'activité vitale, lentement ot graduellement acquis. La vie se concentre de plus en

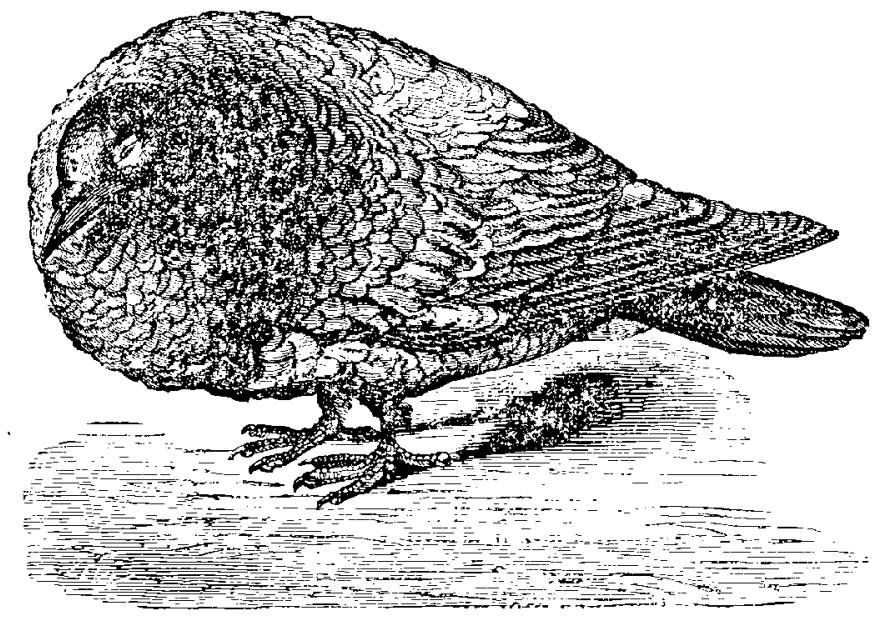

Fig. 83. - Pigeon après l'ablation des lobes cérébraux. (Lo cervesu repoussera et linteligonco reparaltra.)

plus dans le coeur et dans le cerveau, la conscience se localise de plus en plus dans le cerveau et se personnific, s'individualise; mais ce n'est point pour cela un monde nouveau, e'est la continuation et le développement de l'ancien monde.

Nous remarquions tout à l'heure qu'un cœur de tortue continue de battre après avoir été arraché do l'animal; il en est de même du cceur humain. En enlevant le ccur d'un supplicié quelques minutes après l'exécution; on observe des battements qui persistent pendant plus d'une heure, an nombre de quarante à quarante-cinq par minute, alors même que le foie, l'estomac, l'intestin ont été enlevés. M. Robin a mème vu sur un corps décapité, une heure après l'exécution, à la suite d'une excitation faite sur la poitrine à l'aide de la pointe d'un scalpel, le bras droit qui en était 
fort écarté se rapprocher rapidement du corps et la main se porter vers la poitrine pour la défendre. Il y a quelques années, un témoin compétent d'exécutions faites au Japon vit avec effroi les yeux de la tête d'un décapité, tombée sur le sable, le regarder fixement et le suivre quinze à vingt secondes après la décollation ( $\left.{ }^{4}\right)$.

Les membres, les organes, ne se renouvellent plus chez l'homme comme chez les animaux inférieurs, précisément à cause de l'importance, de l'individualité qu'ils ont acquise; mais les tissus se réparent encore naturellement, les plaies se cicatrisent, les chairs se referment; par la greffe on a déjà pu reconstituer certaines parties d'organes, et mème on sait que la transfusion du sang a déjà permis d'empècher de mourir et de prolonger normalement l'existence chez certaines personnes gravement atteintes dans la perte de cet élément.

A mesure que la centralisation s'accentue, à mesure que la

1. Voici les curieuses observations faites par ce témoin, M. le doeteur Petitgand, dans les conditions exceptionnellement favorables où le hasard l'avait placé :

- Sans perdre un seul instant de vue le condamné que je m'étais promis d'observer, dit-il, et même à l'exclusion de ses compagnons, j'échangeai, au sujet de cet homme, quelques paroles à haute voix avec l'officier chargé de procéder à l'exécution, et je remarquai que, de son côté, le patient m'examinail avec la plus vive attention. Les préparatifs terminés, je me tins à deux mètres de lui ; il s'était agenouillé et, avant de baisser la tête, il avait encore échangé avec moi un rapide regard.

Frappée d'un seul coup de sabre, la tète tomba à $\mathbf{l}^{\mathbf{m}} 20$ de moi, sans rouler, comme 1l arrive d'ordinaire; mais la surface de section s'appliquant immédiatement sur le sable, l'hémorragie se trouva ainsi accidentellement réduite au minimum.

A ce moment, je fus effrayé de voir les yeux du supplicié fixés franchement sur les miens. N'osant croire à une manifestation consciente, je décrivis vivement un quart de cercle autour de la tète gisant à mes pieds, et je dus constater que les yeux me suivaient pendant ce mouvement. Je revins alors à ma position première, mais plus lentement cetle fois; les yeux me suivirent encore pendant un instant fort court, puis me quittèrent subitement. La face exprimait à ce moment une angoisse manifeste, l'angoisse poignante d'une personne en état d'asphyxie aiguë. La bouche s'ouvrit violemment, comme pour un demier appel d'air respirable, et la tête, ainsi déplacée de sa position d'équilibre, roula de côté.

Cette contraction des muscles maxillaires fut la dernière manifestation de la vie. Depuis le moment de l'exécution, il s'était écoulé quinze à vingt secondes.

De ces faits, je crois pouvoir conclure que la tête, séparée du corps, est en possession de toutes ses facultés, tant que l'hémorragie ne dépasse pas certaines limites et que la proportion d'oxygène dissous dans le sang est suffisante pour l'entretien de la fonction nerveuse, c'est-à-dire pendant quelques instants très courts et ne pouvant guère excéder la moitié d'une minute. C'est le temps pendant lequel le supplicié a pu lever les yeux sur moi, suivre mes mouvements autour de sa tête, et reconnaitre la personne qui avait altiré son attention quelques instants avant le supplice. ? 
conscience s'individualise, les actes primitifs s'effacent et s'accomplissent instinctivement, indépendamment de toute volonté. Le cœur bat, les poumons respirent, l'estomac digère sans que nulle volonté ait à s'en mêler; et c'est fortheureux, car dès que la volonté cesse d'ètre inconsciente pour devenir personnelle, la régularité des actes les plus essentiels à la vie serait singulièrement compromise (surtout chez l'homme). Graduellement la pensée est centralisée dans le cerveau, graduellement l'être acquiert la conscience de son individualité psychologique, de son moi.

Cette personnalité de l'ètre, cette conscience, ce moi, a commencé dès les rangs les plus humbles de l'animalité (1).Le mollusque,

1. Elle a même commencé dans le monde des plantes, lequel est loin d'être aussi inerte qu'il le paraft. Rappelons comme témoignages les observations et appréciations suivantes, extraites de notre ouvrage Contemplations scientifiques :

< La plante est un être qui personnifie, sous un type spécial, la force inconnue à laquelle nous avons donné le nom de vie, force d la fois universelle et individuelle, qui respire dans la création tout entière. Et ce type de vie, quelque différent qu'il soit du' type humain, n'en est pas moins complet et plein d'intérét par lui-même.

La plante respire, la plante mange, la plante boit; la plante sommeille. Elle respire, comme nous, l'air atmosphérique qui enveloppe le globe d'un duvet d'azur, et sa respiration s'effectue à l'inverse de la nơtre : elle consomme l'acide carbonique, élément mortel pour nous, et a précisément pour role de rétablir sans cesse l'équilibre des principes de l'air.

Elle mange et boit; ses aliments sont l'eau, le carbone, l'ammoniaque, le soufre, le phosphore. L'organisation merveilleuse de ses racines et de ses feuilles lui permet de prendre et même d'aller chercher ses principes nutritifs dans l'air et dans le sol, aussi loin que ses bras pcuvent s'étendre. - - Elle sommeille : la plupart suivent docilement la nature et dorment du coucher au lever du soleil; mais d'autres, belles paresseuses, veillent tard, osent à peine se lever avant midi, et meme ne s'éveillent pas du tout s'il doit pleuvoir.

Un rapport secrét relie la plante à la lumière; l'heure de leur réveil et de leur épanouissement varie selou les familles; il en est qui suivent les saisons et les fluctuations de la température; d'autres semblent se conformer, en filles plus saumises, à la marche apparente du soleil et gardent des habitudes rêgulières. C'est sur celles-ei que Linné a construit l'horloge de Flore, que tout le monde connait.

La plante jouit sans contredit de facultés électives, et sait apprécier la nourriture qui lui convient. Ecoutez, par exemple, cette histoire :

Sur les ruines de New-Abbey, dans le comlé de Galloway, croissait un érable au milieu d'un vieux mur. Là, loin du sol au-dessus duquel le monecan de picrres s'élevait. encore de quelques pieds, notre pauvre érable mourait de faim, faim de Tantale, puisqu'au pied même du mur aride s'étendait la bonne et nourrissante terre.

Qui dira les sourds tressaillements de l'être végétal qui lutte contre lá mort, ses tortures silencieuses et ses muettes langueurs galvanisées par la convoitise? Qui saura raconter ici en particulier ce qui se passa dans l'organisme de notre pauvre martyr; quelles attractions s'établirent, quelles facultés s'aiguisèrent, quelles impérieuses lois se révélèrent, quelles vertus enfin furent créées ?... Toujours est-il que notre érable, érable 
le poisson, le reptile, savent qu'ils existent, défendent leur existence envers et contre tout, rapportent le monde entier à leur petite personnalité. Ils commencent à penser déjà. La pensée se déve-

énergique et aventureux s'il en fút, voulant vivie à tout prix et ne pouvant attirer la terre à lui, marcha, lui, l'immohile, l'enchainć, ver's cette terre lointaine, objet de ses ardents désirs.

Il marcha? non; mais il s'étira, s'allongea, tendit un bras désespéré. Une racine improvisée pour la circonstance fut émise, poussée au grand air, envoyée en reconnaissance, dirigée vers le sol, qu'elle atteignit... Avec quelle ivresse elle s'y enfonça! L'arbre était snuvé désormais. Nourri par cette racine nouvelle, il se déplaça, laissa mourir celles qui vainement plongeaient dans les décombres; puis, se redressant peu d̀ peu, il quitta les pierres du vieux mur et vécut sur l'organe libérateur, qui bientôt se transformia en un tronc véritable. Que pensez-vous de cette persistance? Ne trouvez-vous pas que cet instinct ressemble fort à l'instinct animal, et méme, osons l'avouer, à la volonté humaine?

Un illustre bataniste du XVIIIs siècle, Duhamel, raconte qu'un jour il fit creuser un fossé entre une allée d'ormes et un champ fertile, afin d'intercepter le passage aux racines et d'en préserver le champ. Or, quelle décision prirent ces infortunés végétaux auxquels on coupait ainsi les vivres? Ils firent prendre un détour aux racines qui n'avaient pas été tranchées; elles descendirent le long du talus, passèrent sous le fossé el retournèrent à leur table permanente. C'était à la fois pour retrouver leur aliment accoutumé et pour éviter la lumière; car, remarque digne de l'intérêt du philosophe, il y a dans les plantes deux parties bien distinctes: l'une, terrestre, qui fuit la lumière; l'autre, aérienne, qui la cherche, la réclame et la boit par tous ses pores.

La poésie a souvent comparé les fleurs et les femmes? J'aimerais mieux prendre la Plante en elle-même pour cette comparaison. N'est-elle pas l'image de la femme, de la femme qui, par sa solidité morale et sa valeur, doit fixer fortement les racines de la famille dans un sol choisi, et, en mème lemps, s'élever elle-même comme une tige parfumée vers la beauté, ver's la lumière, et porter l'homme et l'enfant dans cette ascension vers l'idéal?

De la lumière ! de la Iumière! s'écriait Gothe au moment de rendre le dernier soupir. Ce cri de l'ame, cette aspiration d'un symbolisme sublime qui devrait rayonner sur le front de toutes les intelligences humaines; cette soif de lumière, c'est la supplication incessante de la plante aérienne, de la tige aux feuilles verdoyantes, de la fleur à la corolle parfumée.

Tramsportons une plante, un plant de capucines, dans l'intérieur d'une pièce éclairée par une seule fenétre: nous verrons bientót loutes les feuilles retourner leur face supérieure du côté de celte fenêtre.

Un grand nombre d'observateurs, - au nombre desquels j'aimerais me placer, si je ne préférais Uranie à Cérès, à Flore et à Pomone, - - un grand nombre d'observateurs, dis-je, ont constaté ce grand fait de la tendance vers la lumiore. On a répandu des graines sur du coton imbibé flottant à la suriace d'un vase d'eau, et transporté ce vase en divers points d'une pièce éclairée seulement par une lucarne latérale : les petites racines se dirigeaient vers la partie obscure de la chambre, les tigelles s'infléchissaient, tendant leur front vers le pur baiser de la lumière.

Ces êtres primitifs, innocents et enveloppés d'une demi-somnolence, me rappellent les petits enfants au berceau, qui, distinguant à peine encore les couleurs et les objets tournent cependant obstinément leur tête chercheuse vers le jour, et tendent leurs faibles bras vers la clarté, comme s'ils se souvenaient d'une destinée lumineuse voilée par un rêve... 
loppe avec la conscience du moi. Personne ne met plus en doute aujourd'hui l'intelligence des animaux. L'observation des mœurs, l'analyse des actions volontaires et des manifestations diverses du sentiment chez les singes (encore trop peu éludiés jusqu'ici), les chiens, les fourmis, les chats, les éléphants, les abeilles et, du reste, un peu dans toutes les espèces animales, démontre sans réplique qu'à côté et au-dessus de l'instinct héréditaire l'âme des bêtes est douée de toutes les facultés dont s'enorgueillit l'âme humaine, à des degrés divers, généralement fort inférieurs, mais qui toutefois, en certains cas, se sont montrés supérieurs relativement même à la moyenne des âmes humaines. Il n'est pas rare de voir, mêne chez les peuples civilisés, des parents prouver par leurs actes que leur

Ah! comme elles aiment la lumière, ces plantes aux sensations inconnues, et comme elles s'élèvent sans cesse pour la ravir! C'est un singulier et admirable contraste que l'humilité de ces êtres et Ia splendeur de leur désir. N'avez-vous pas vu parfois, dans une cave obscure et humide, de misćrables plantes languissantes et décolorées, des... pommes de terre, s'il faut dire le nom, pâles et étirées, germer, lancer une tige opiniâtre et fervente, qui se dresse, monte, s'accroche à la muraille... et s'élève avec persévérance jusqu'au soupirail où l'attire le jour?

On a vu une pauvre petite plante souterraine, dont le nom est une humilité, la clandestine, parasite de la famille des orobanchées, qui ne s'élève ordinairement qu'd queJques centimètres, se dresser et grandir a la hauteur prodigieuse de cent vingt pieds, pour franchir l'espace qui la séparait d'une lucarne au fond d'une mine de Mansfeld.

Ln observateur a constaté qu'un jasmin héroïque traversa huit fois une planche trouée qui le séparait de la lumière, et que l'on retournait vers l'obscurité après chaque nouveau mouvement de la fleur pour observer si à la fin celle-ci ne se lesserait pas.

Que penser surtout de la sensitive, que le plus léger attouchement suffit pour frapper de stupeur et abaltre dans une sorte de léthargie? Quelle délicatesse de sensation dans ces plantes! On voit sous les tropiques des champs entiers de véritables sensitives. Le bruit des pas d'un cheval les fait contracter au loin comme si elles en étaient effrayées. Elles se baissent précipitamment à l'approche d'un homme; et l'on a vu une légère secousse se propager d'un trait comme un signal d'alarme dans les colonies de ces végélaux sensibles qu'un importun effarouchait. L'ombre d'un nuage suffit pouŕ produire une animation manifeste au milieu de leurs groupes. Elle est presque nerveuse, la sensitive. Les narcotiques affaiblissent sa sensibilitê comme ils affaiblissent la notre. Arrosée avec de l'opium, elle s'endort et devient insensible. Lne décharge électrique la tue. Et cependant, chose merveilleuse, on parvient à l'apprivoiser! Desfontaines en avait placé une dans une voiture; effrayée des cahos, elle se replia d'abord craintivement sur elle-mème, puis, peu ả peu, elle s'accoutuma et reprit sa tranquillité. Mais si la voiture s'arrêtait, elle semblait s'étoner de nouveau, avait peur et se contractait. ?

Nous irions beaucoup plus loin encore dans l'appréciation de la vie et de la personnalité de la plante, si nous appelions l'attention de nos lecteurs sur les faits et gestes des plantes carnivores. Mais ce n'en est pas ici le lieu.

Sous ces manifestations d'une vie inconnue, le philosophe ne peut s'empècher de reconaaître dans le monde des plantes un chant du chœur universel.

LE MUNDE AVANT LA GREATION DE L'HOMME 
affection et leur dévouement pour leurs enfants sont fort au-dessous de ce que l'on observe chez les chats, les lions et les tigres. Il n'est pas rare non plus de rencontrer des hommes moins intelligents que des fourmis, moins bons que des chiens, moins fins que des singes, qui, en un mot, " n'ont rien pour eux », sont incapables de la moindre initiative ni de comprendre quoi que ce soit.

Les Boschismans, les Andamans, les Hottentots, les Papous, gisent en un état si rudimentaire d'intelligence que l'on pourrait croire qu'ils ne pensent pas du tọt. Un grand nombre de ces tribus n'ont aucun mot pour dire animal, plante, son, couleur, et exprimer d'autres idées aussi simples, tandis qu'elles ont des expressions spécialcs pour désigner chaque animal, chaque plante, chaque son, chaque couleur. La faculté d'abstraire leur manque absolument. Ils savent compter jusqu'à cinq; au delà, ce n'est plus un nombre, c'est la multitude. D'autres peuplades sauvages comptent jusqu'à dix, jusqu'à vingt: plusicurs animaux ont èté beaucoup plus loin. On voit dans l'Asie méridionale et dans l'Afrique orientale des tribus qui vivent absolument à l'état de réunions transitoires, à la façon des singes, sans avoir encore le sentiment de la vie de famille, du mariage, qui sont les bases de la civilisation humaine. Les nègres encore à demi-simiens qui vivent dans les hautes régions du Nil sont, au rapport de plusieurs missionnaires, absolument rebelles à toute idée quelconque, non seulement incapables de réflexion, mais encore incapables de reconnaissance, par conséquent à cet égard inférieurs aux chiens. Il suffit de lire les récits des voyageurs qui ont observé ces peuplades primitives pour juger de leur état d'infériorité morale et intellectuelle.

$\mathrm{Si}$, d'ạutre part, on analyse les procédés psychologiques mis en usage dans les raisonnements des animaux, dans les manifestations de leurs volontés et de leurs sentiments, on reconnait que, comme nous, ils concluent par voie d'iuduction et de déduction. Ce n'est. qu'une différence de degré, mais non une différence de nature. L'enfant n'arrive à raisonner qu'avec une grande lenteur, et ses premiers modes de raisonnement sont aussi des rapports et des comparaisons. Un enfant d'un an est encore un petit animal à ce point de vue; ses facultés intellectuelles sont encore à l'état de germes et elles $r_{1}$ e se développeront que graduellement. D'abord, 
véritable petit singe, il voudra tout imiter, et ce sera lá la première cause de son progrès. Puis il commencera à juger, très simplement, des causes et des effets, et généralement il jugera très juste. Ensuite on arrive à le tromper de mille façons différentes, et malheureusement notre fausse éducation sociale enveloppe l'adolescent d'erreurs et de prójugés, l'instruit mal et l'empêche de s'élever' libręment dans la voie du Progrès.

Aussi súrement que les premières combinaisons chimiques sont nées des associations des molécules entre elles, que les affinités chimiques sont dérivées de ces combinaisons, que les organismes primitifs élémentaires avec leurs propriétés vitales sont dérivées de ces affinités; aussi sûrement l'âme végétative, cause de la vie, s'est graduellement formée par le progrès des organismes, l'âme animale, source des phénomènes de conscience et de volonté, est un dévcloppement de l'âme végétative, et aussi sùrement aussi l'âme humaine est un perfectionnement de l'âme animale.

La nature immense est lá devant nous. Notre devoir est de l'étudier sous tous ses aspects, d'entendre toutes ses voix, et d'interpréter aussi fidèlement que possible tous ses enseignements. Devant certaines difficultés, qui parfois paraissent insurmontables, un grand nombre de philosophes croient trancher les questions en imitant l'autruche qui se cache la tête dans le sable pour ne plus rien voir : ce n'est pas là une solution.

Mais il ne faudrait pas croire pour cela que la science ait jamais dit son dernier mot, ni que l'étude de la nature s'arrête à la surface des choses ou aux phénomènes mécaniques, physiques, chimiques et biologiques. Les facultés de l'âme humaine, et le sentiment luimème avec toutes ses aspirations, appartiennent de droit à l'étude de la nature et ne sont pas en dehors du cadre de la science.

Or, sans qu'il soit nécessaire d'interroger individuellement ici chacun de nos lecteurs, il est aussi certain que deux et deux font quatre que si le chapitre que nous venons d'écrire sur a le développement et la progression de la vie s et qui devait nous conduire graduellement du protoplasma jusqu'à l'homme s'arrêtait ici, nul d'entre eux ne serait satisfait.

Pourquoi ? Parce que chacun de nous sent qu'il n'est pas seulement un animal, de mème que tout animal n'est pas seulement 
un végétal, et que tout végétal n'est pas seulement une substance chimique minérale.

Dans l'animal, déjà, et surtout dans l'animal supérieur, l'âme témoigne qu'elle est une force directrice et non pas une propriété. La matière qui constitue le corps a des propriétés chimiques, physiques, etc., et ces propriétés agissent constamment dans l'organisme. Un ètre vivant subit, comme tous les autres, par exemple, les effets de la pesanteur, et les lois de la mécanique sont en jeu dans le mouvement du muscle qui soulève un bras comme dans Ia chute d'un aliment de la bouche à l'estomac. Mais ce ne sont pas ces propriétés de la matière qui donnent à un être vivant son existence, sa forme, sa vitalité, sa personnalité. Prenons ici un exemple cité par Glaude Bernard.

" Si dans une horloge électrique, dit-il, on enlevait l'acide de la pile, on ne concevrait pas que le mécanisme continuât de marcher; mais, si l'on restituait ensuite convenablement l'acide supprimé, on ne comprendrait pas non plus que le mécanisme se refusât à reprendre son mouvement. Cependant on ne se croirait pas obligé pour cela de conclure que la cause de la division du temps en heures, en minutes, en secondes, indiquées par l'horloge, réside dans les qualités de l'acide ou dans les propriétés du cuivre ou de la matière qui constitue les aiguilles et les rouages du mécanisme(') $)$.

Et ailleurs :

“ Les phénomènes de création organique des êtres vivants me semblent bien de nature à démontrer que la matière $n$ 'engendre pas les phénomènes qu'elle manifeste. Flle n'en est que le substratum et ne fait absolument que donner aux phénomènes leurs condilions de manifestation $\left({ }^{2}\right)$.

Et ailleurs encore :

" Il faut bien se garder de confondre les propriétés de la matière avec les fonctions qu'elles accomplissent. Ne trouverait-on pas absurde de dire que les fibres musculaires de la langue et celles du larynx ont la propriété de parler et de chanter, et celles du diaphragme la propriété de respirer? Il en est de mème pour les fibres et cellules cérébrales : elles ont des propriétés générales d'innervation et de conductibilité, mais on ne saurait leur attribuer pour cela la propriété de sentir, de penser ou de vouloir $\left({ }^{3}\right)$ s.

1. Clatne Bernard. La Science expérimentale, p. 126. - 2. Id., id., p. 133.

3. Id. Discours de réception à l'A cadémie fi'ançuise. 
La vie existe et agit. Elle a produit la pensée. La pensée aussi existe; c'est une force qui a conscience de soi, qui sent, qui veut et qui agit. Elle n'est point matière. Le corps et le mouvement sont de purs phénomènes : le premier n'est qu'une image de la substance, le second une image de l'action; mais l'un et l'autre sont des effets de la force. En dernière analyse, c'est la force que nous trouvons. Nous l'avons vue naitre, humble, faible, sourde, inconsciente, dans le protoplasma. Nous l'avons vue grandir insensiblement, s'affirmer, gouverner, régner dans le magnifique développement $d u$ règne animal. Nous la voyons à son apogée dans l'homme (à son apogćc terrestre, car, en d'autres mondes, en des conditions plus parfaites, elle peut être incomparablement plus élevée et plus grande). La pensée hurnaine est le résumé de toutes les énergies de la nature, puisqu'elle se les est toutes assimilées.

Ainsi l'âme humaine n'a pass été créće tout d'une pièce et n'a pas été infusée dans un corps créé également tout d'un coup. C'est là de la mythologie. Nous voyons, nous constatons, que l'être humain tout entier, organisme et pensée, s'est formé lentement, graduellement, de siècle en siècle. Encore aujourd'hui, il continue de se perfectionner en délicatesse nerveuse et en puissance cérébrale, en méme temps que l'être pensant s'agrandit dans son savoir, dans son jugement et dans sa raison. Cet être pensant, d'abord simple affinité minérale, plus tard centre d'attraction organique, âme végétative, âme animale, est immatériel comme les forces qui se rnanifestent à nous dans l'attraction des astres entre eux, dans la pesanteur, dans la lumière, dans la chaleur, dans l'électricité, et appartient à cet ordre des invisibles et des impondérables qui réside dans le milieu éthéré dont l'univers matériel parait n'être qu'une condensation. Aucun physicien, aucun astronome n'a jamais vu l'èther; aucun ne doute pourtant de son existence, puisque c'est en lui qu'il faut remonter pour trouver toutes les causes de mouvement et de transmission de mouvement. La substance animique n'est pas matiere, mais force, et, comme toutes les forces, a sans doute son principe d'action dans l'éther. On peut penser que l'éther est la substance des âmes.

L'essence de la force nous est inconnue. Nous ne savons pas du tout en quoi elle consiste. Nous tenons une pierre dans la main; 
elle tombe : où est le lien invisible qui l'a tirèe vers la terre? Notre planète tourne avec rapidité autour du Soleil : où est la fronde qui la fait tourner? Voici un polyèdre de cuivre qui se forme, une étoile de neige, une fleur de glace, où est la main qui juxtapose les molécules suivant des formes déterminées? Les éléments semblent obceir à un rythme mystérieux qui les dirige, chacun suivant ses fonctions, comme autrefois, disait-on, les villes de marbre se bâtissaient elles-mèmes aux sons de la lyre d'Orphée... Versons dans une solution limpide de sulfate de potasse une solution également claire de sulfate d'alumine: le mélange se trouble et nous voyons aussitôtapparaître des myriades de petits cristaux scintillant comme des diamants, et qui ne sont autres que des cristaux d'alun : chacun de ces petits diamants d'un millimètre est composé de 94 molécules groupées suivant une admirable symétrie, et en quelques secondes plusieurs milliards de ces édifices ont été créés! Voit-on la force qui les a édifiés ?.. Voici deux graines, de la grosseur de deux lentilles; au point de vue physique et chimique, elles sont identiques; pourtant l'une donnera naissance à une petite plante qui n'atteindra pas l'automne, et l'autre à un arbre gigantesque qui dominera les années et les siècles : en quoi consiste la différence des deux germes? dans une force invisible qui gouvernera de sa naissance à sa mort l'évolution du végétal... Tous les cufs se ressemblent à l'origine; entre ceux d'où sortiront un poisson, une souris, un éléphant ou un homme, il y a similitude de structure, et pourtant quelles différences de destinées! Or toutes ces différences sont dans la force latente invisible incorporée en chacun d'eux... L'œil ne voit pas tout. A parler rigoureusement, il ne voit mème rien de ce qui existe en réalité, du moins rien tel que cela existe. Le fond des choses, ce n'est pas la matière, c'est la force. L'univers est un dymanisme.

La science ne condamne done pas nos sentiments, nos aspirtions et nos espérances. Au contraire, elle les constate, elle les enregistre, et son devoir sera de les expliquer et de les justifier. Une science encore incomplète, comme celle que l'homme a acquise depuis si peu de temps qu'il travaille, laisse encore bien des solutions dans l'ombre. Une science plus avancée nous rapprochera de plus en plus de la vérité et apportera de plus en plus de lumeère 
autour de nous. La croyance en l'existence de Dicu et en l'immortalité de l'âme humaine n'est pas mise en péril par les théories dont nous venons de nous faire l'interprète; au contraire, la science conduirait plutôt à donter de l'existence de la matière; du moins poulvons-nous ètre certains que l'univers matériel n'est pas du tout ce qu'il nous parait être : le monde visible est composé d'atomes invisibles régis par des forces immatérielles.

Mais il importe que tous les esprits sincères qui ont quelque souci de la vérití soicnt profondément pénétrés de cet axiome : on ne sait que ce que l'on sait, c'est-ì-dire ce que l'on a appris. En dehors de la science, toute solution ne peut être que nulle, fausse ou mensongère. Aucune révélation directe de Dieu n'est jamais rien venue nous apprendre sur quoi que ce soit. Le plus grand empèchement à la marche du progrès, ce n'est peut-être pas encore l'ignorance, ce sont les fausses solutions données par de prétendus interprètes de la Divinité, et encore aujourd'hui la moitié de l'humanité pensante est égarée, par les principes mèmes de son éducation première. Elle croit tenir la vérité quand elle ne s'accroche qu'à l'illusion, comme l'aéronaute suspendu dans l'espace aux derniers lambeaux de l'aérostat qui se dégonfle et se déchire. La vraie force ascensionnelle de l'humanité, c'est la science, - la science générale, s'entend - l'étude de la nature dans toute son étendue, l'analyse des facultés humaines aussi bien que la connaissance de la construction de l'univers. Sans doute, cette science n'est l'esclave d'aucune secte ni d'aucun système; mais elle n'est point pour cela matérialiste ni athée; elle est, au contraire, essentiellement spiritualiste, beaucoup plus qu'aucune religion, car elle n'a jamais inventé de dieux rapetissés al niveau des passions humaines, et elle ne le fera jamais; son œuvre est de nous élever sans cesse vers l'idéal, de nous faire admirer dans la nature des lois et des forces dont l'essence réside, toujours mystérieuse, dans le domaine de l'invisible et de l'infini. 


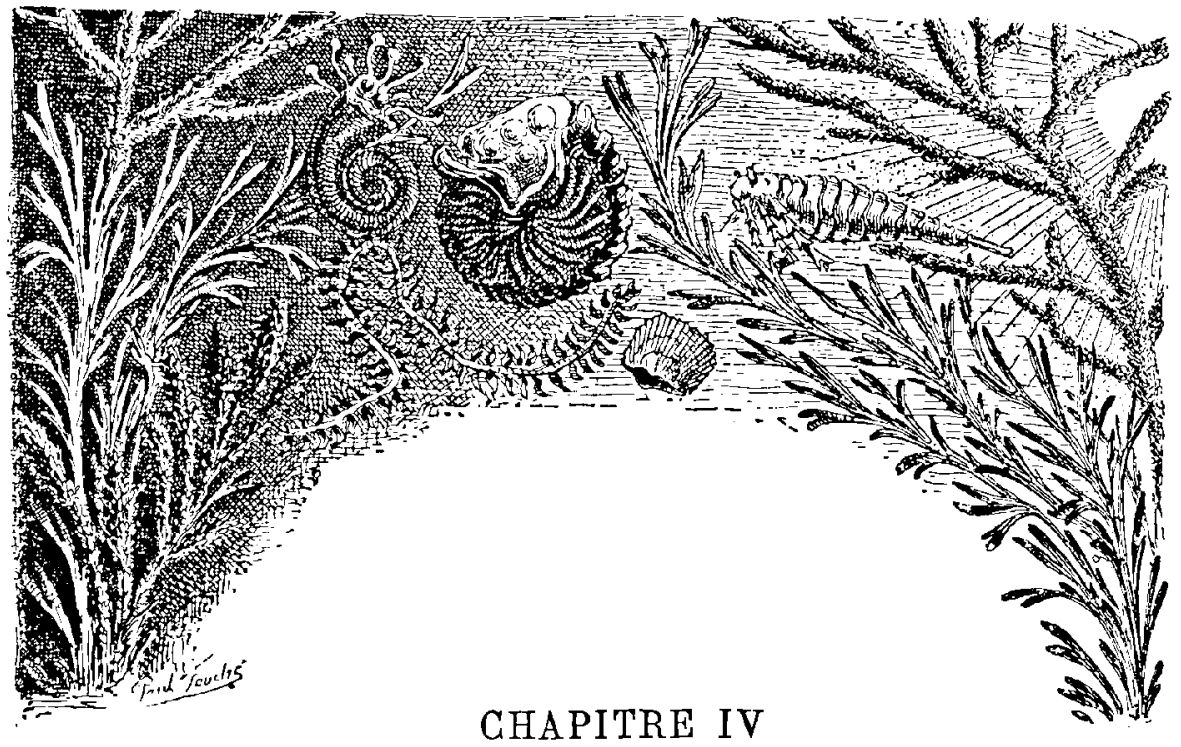

FREMIÉRES PLANTES ET PREMIERS ANIMAUX

Les plus anciens fossiles. - Périodes laurentienno, cambrienne et silurienne.

Les descriptions et les tableaux qui précèdent ont esquissé à grands traits l'histoire physiologique de la Terre. Son histoire géologique va maintenant se dérouler sous nos yeux parallèlement aux scènes précédentes. Nous avons assisté à l'origine mème de la vie, à son développement graduel, à sa progression splendide à la surface du monde, depuis l'humble protoplasma chimique jusqu'à l'âme humaine. Nous allons retrouver dans les fossiles appartenant à chaque terrain les témoignages irrécusables de la marche progressive de la vie depuis les temps les plus anciens jusqu'à nos jours.

Déjà nous l'avons vu, le globe terrestre proprement dit, qui s'est condensé de la nébuleuse solaire, a été pendant des siècles et des siècles à l'état d'incandescence, s'est refroidi lentement, s'cst d'abord figé à la surface, puis durci, comme un métal fondu qui se refroidit et se solidifie: ce globe a été dépourvu de tonte espèce de vie, et l'on ne saurait retrouver en lui aucune trace d'organismes quelconques. Lorsque l'atmosphère qui l'environnait se füt condensée, que les vapeurs refroidies furent devenues liquides, que les caux ainsi formées eurent constitué les mers, que la température 
de ces eaux fût descendue vers $60^{\circ}$, les éléments chimiques qui flottaient dans ces eaux, les combinaisons du carbone, donnèrent naissance aux premiers organisınes. Ces premiers organismes, gélatineux, albuminoïdes, n'ont pu se fossiliser et ètre conservés pour l'instruction des siècles futurs. Les premiers fossiles sont ceux des ctres qui, ensevelis dans le fond vaseux de la mer, ont été sous-

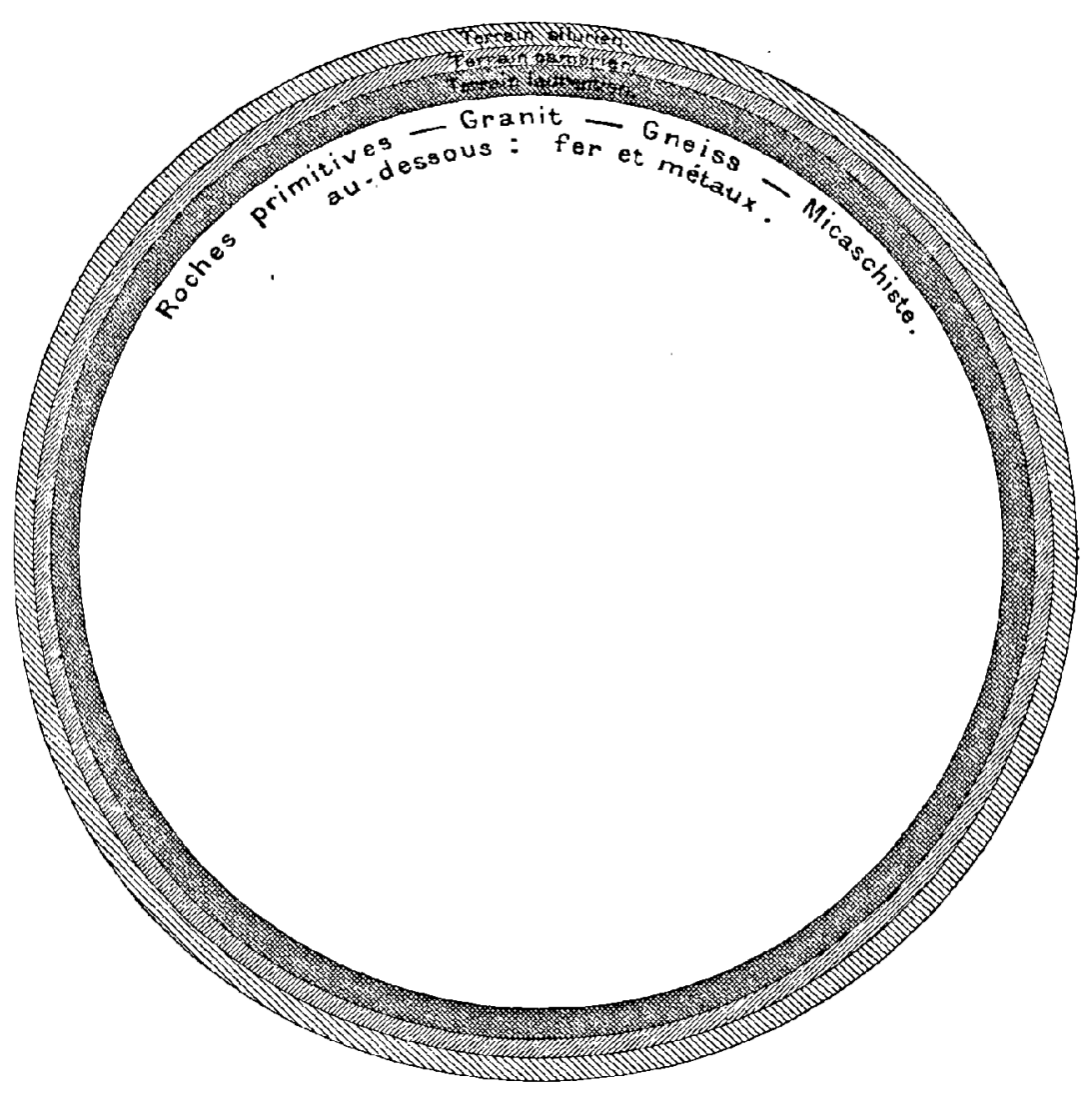

Fig. 83̈. - Premiers terrains dẻposés sur le globe minéral primitif après son refroidissement. Epoque primordiale de la vie.

traits aux influences destructives des animaux contemporains, de l'eau et de l'air, et se sont trouvés dans un sol de constitution telle qu'ils pussent s'y pétrifier. Dans un sol perméable, dans les sables ou les grès, par exemple, la fossilisation, qui marche de pair avec le durcissement du sol, se fait autrement que dans les terrains imperméables, comme les argiles. Quelquefois l'animal est simple- 
ment moulé et il n'en reste que la forme, bien fidèle, il est vrai, mais enfin la forme seulement. En d'autres cas, chacune de ses molécules, pour ainsi dire, fait place à une molécule minérale correspondante fournie par le terrain qui presse sur le cadavre, sur le squelette, coquille ou autre, et l'absorbe. D'autres fois, il y a simultanément enveloppement et pénétration des coquilles par le calcaire; d'autres fois encore il y a comme attraction de la pyrite ou bisulfure de fer autour des fossiles ou mème dans leur intérieur. En somme les êtres sont conservés, mais non sans subir des transformations moléculaires plus ou moins considérables. Si le dépôt protecteur offrait une imperméabilité absolue, ils pourraient être conservés intégralement à travers les siècles et les siècles. C'est le cas du limon constamment glacé de la Sibérie, où des cadavres entiers de mammouths ont été retrouvés sans aucune altération, la chair même et les poils étant conscrvés dans toute la fraîcheur de la vie; c'est aussi le cas des insectes pris dans la résine et dans l'ambre. Mais ce sont là de rares exceptions.

Comment se sont formés les terrains?

Le globe primitif, le globe antérieur d̀ la vie, se compose sans doute principalement de fer. La densité de la planète $(5,5$, ou cinq fois et demie celle de l'eau prise comme unité) prouve qu'elle est formée d'éléments plus lourds que ceux qui existent dans la constitution de son écorce. Le granite pèse entre 2,6 et 2,7. Il en est de même du gneiss, du quartz et des micaschistes. La densité de l'ardoise est de 2,6 à 2,9 ; celle du basalte de 2,8 à 3,1 , celle du calcaire lithographique de 2,7, celle du grès de 2,2, celle du marbre de 2,6 à 2,8, celle du gypse ou pierre à plàtre de 2,2. Tout cela est très inférieur à la densité moyenne de la Terre, et si notre planète était surtout composée de roches granitiques, elle ne pèserait pas trois fois plus qu'un globe d'eau de mèmes dimensions, tandis qu'elle pése cinq fois et demi plus. - Gette différence dans la densité de la Terre aurait d'assez curieuses conséquences. Ainsi, nous pèserions beau. coup moins; avec la mème force musculaire, nous serions beaucoup plus légers; la Lune tournerait moins vite autour de nous et les mois seraient plus longs, etc., etc. Tout se tient dans l'unité de la nature.

Les masses de fer natif amenées parfois, comme en Sibérie, des 
profondeurs du globe à la surface du sol,'les phénomènes du magnétisme terrestre, la composition des fers tombés du ciel (lesquels peuvent fort bien avoir été lancés par la Terre, hors de sa propre attraction, durant les temps primitifs) sont autant de témoignages qui viennent s'ajouter au fait de la densité du globe pour nous conduire à admettre que le fer entre pour une grande partie dans les matériaux constitntifs de notre planète. Sa densité $(7,2)$ est précisément celle qui convient pour donner le poids qu'elles doivent avoir aux couches intérieures du globe.

Reportons-nous un instant encore à l'époque où la Terre ayant terminé sa phase solaire, ayant perdu sa lumière et sa chaleur, entrait dans sa phase planétaire, globe liquide encore en fusion mais se refroidissant.

Les parties les plus légères de la masse fondue, celles que leur poids spécifique obligeait à s'élever à la surface, étaient en mème temps composées des substances les plus réfractaires, et si quelques métaux légers s'y mêlaient aux éléments du groupe des pierres, e'ètaient des métaux facilement oxydables et destinés à se transformer immédiaternent en bases pour s'unir à la silice et à l'alumine. A mesure donc que la perte de chaleur par rayonnement faisait des progrès, cette espèce d'écume siliceuse ne pouvait manquer de se solidifier par parties. Il est vrai que la solidification des matières pierreuses ayant on général pour effet d'accroitre leur densité, lés premières plaques solides étaient destinées à s'enfoncer d'abord, au lieu de surnager sur le bain liquide. Mais cette descente ne pouvait les entrainer très loin : car les matières en fusion étant superposées par ordre de densités, un moment arrivait bien vite où chaque plaque solide trouvait autour d'elle une nappe fondue de méme poids spécifique. Alors sans doute elle subissait une nouvelle fusion, partielle ou même totale ; mais c'ètait nécessairement aux dépens de la chaleur latente des masses avoisinantes, et cet effet, se reproduisant sur toute la surface du globe à la fois, ne pouvait manquer de produire, à un certain moment, la prise en masse d'une écorce sphérique composée du mélange des matériaux les plus légers avec d'autres ayant appartenu à des nappes un peu moins superficielles. Le granite fondu se solidifia lorsque la température de la surface du globe descendit à 1500 degrés. 
Avant que cette écorce fût consolidée, toute l'eau de nos océans existait à l'état de vapeur dans l'atmosphère primitive, dont la pression était, de ce fait, 250 ou 300 fois supérieure à ce qu'elle est aujourd'hui, influant à coup sùr, d'une manière marquée sur le mode de solidification de l'écume siliceuse. Avec l'eau se trouvaient aussi en vapcurs plusicurs substances volatiles, actuellement fixées dans la nappe océanique ou dans l'écorce, notamment des chlorures et des fluorures alcalins.

Or, à peine la croùte était-elle formée que les éléments volatils, désormais privés de toute communication avec le foyer de chaleur qui les maintenait à l'état gazeux, ont dù commencer à se condenser. On devine aisément ce que pouvaient être la puissance de cristallisation et celle de dégradation dans ce premier océan, si riche en principes actifs et porté à une température voisine de l'ébullition. De là, sans doute, un remaniement surtout chimique, mais en partie aussi mécanique, des éléments de la croûte à peine consolidée, ce remaniement s'effectuant dans un liquide mobile, l'action de la pesanteur y devait déterminer une stratification dont il est possible d'ailleurs que des traces aient existé déjà dans les premières plaques solides, en raison des efforts de tension qu'elles pouvaient avoir à supporter avant la prise en masse. De plus, les minéraux de l'écorée" mairtenus en quelque sorte en suspension ou tout au moins à l'état dé pâtes visqueuses, ne pouvaient échapper aux phénomènes de concentration moléculaire qui se manifestent dans toutes les masses hétérogènes douées d'une certaine mobilité. Il semble donc admissible qu'il s'y soit fait une sépara. tion plus ou moins complète des divers éléments et cela, de préférence, suivant des amas lenticulaires allongés dans le sens harizontal. Enfin cette première croùte devait offrir, au début, une très faible résistance et, à chaque instant, les masses demeurées par-dessous à l'état liquide ou pâteux y pouvaient être injectées en veines ou en massifs, prenant part à la constitution de l'ensemble et modifiant par leur contact les parties encaissantes.

Telle est l'idée que nous pouvons nous faire des conditions au milieu desquelles a dù se constifuer cette écorce, destinée à servir de soubassement à toute la série sédimentaire, en même temps 


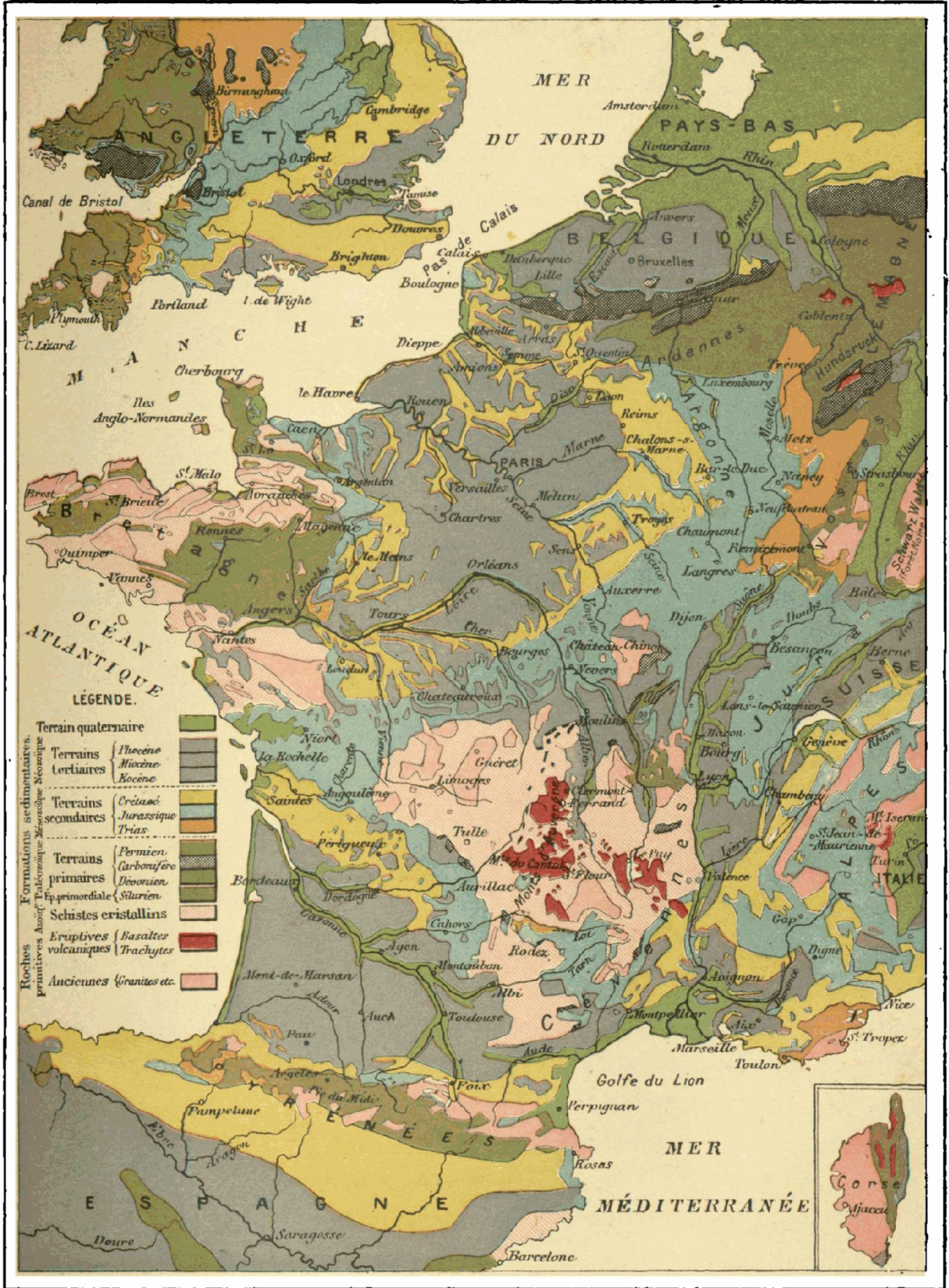

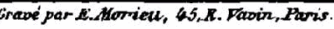


IRIS - LILLIAD - Université Lille 1 
qu'elle emmagasinait, en quelque sorte, à l'abri des influences extérieures, les matériaux des futures formạtions éruptives ( $\left.{ }^{4}\right)$.

Cette écorce du globe, ce terrain primitif, c'est, comme nous l'avons déjà entrevu, du granite, du gneiss, du micaschiste, roches dans lesquelles dominent le quartz, le feldspath et le mica. On retrouve ce terrain primitif partout, dans toutes les contrées, sous toutes les latitudes, et servant de base aux couches de sédiments qui se sont formées depuis dans les eaux de la mer et qui se sont déposées au-dessus de lui. Tandis que ces couches de sédiments sont très variées, ne se rencontrent pas partout, manquent en certaines régions, se localisent plus ou moins dans leur distribution et dans leur proportionnalité, le terrain primitif existe partout dans les profondeurs du sol. Il représente donc sûrement la surface de notre planète à l'époque où les eaux se sont condensées et où la vie élaborait ses principes de constitution.

Sur cette roche universelle et primitive, dont la surface a été sensiblement modifiée par les agents extérieurs, la pression des eaux, l'oxygène de l'air, la chaleur interne qui lui arrivait encore, etc., sur ce soubassement fondamental, antérieur à la vie, se sont déposés les terrains contemporains de la vie.

L'origine de ces terrains de sédiment $\left(^{2}\right)$ est toute diffèrente de celle des premiers. Ce sont des dépôts, des détritus, des apports, étrangers à la constitution intérieure de la planète. La pluie, les vents, le soleil, le froid, désagrègent insensiblement tout ce qui leur est exposé. A peine les premières îles rocailleuses, encore dépourvues de toute espèce de tapis végétal, avaient-elles èmergé du sein de l'Océan, à peine les premiers rochers de granite, de gneiss, étaientils sortis des eaux, à peine les premières montagnes s'élevaientelles dans les airs, que ces effets de désagrégation commencèrent à se produire. Les pluies donnèrent naissance aux sources, les sources aux ruisseaux, aux rivières, aux torrents, plus tard aux grands fleuves. Les eaux roulèrent les pierres, les réduisirent en fragments, en galets, en sable. Tout le long des rivages, la mer rongeant les falaises produisait en même temps sur une vaste

1. A. DI LapparmNT, Traité de Géologie.

2. Étymologie : Sédimentum, état de ce qui est assis, posé, déposé. 
ètendue les galets et les sables. Le flux et le reflux des marées modifiait, deux fois par jour, la limite et la configuration des rivages. De tout cet ensemble de faits il s'ensuit que les éléments de la surface du sol, réduits en fragments plus ou moins fins, sont allés se déposer au fond de l'Océan, des cours d'eau, des lacs ou des estuaires, en emportant avec eux tous les débris qui s'y trouvaient mélangés. Tel est le mode de formation des terrains de sédiments, et tel est le mode général employé par la nature pour la conservation des fossiles.

Tous les terrains de sédiment ne se ressemblent pas. Les uns ont été formès par du sable très fin restant longtemps en suspension dans les eaux calmes et se déposant avec une extrême lenteur sur un fonid horizontal. Les autres, comme le grès ou pierre de sable (sandstone des Anglais, sandstein des Allemands) résultent de l'agglutination d'un sable par un ciment quelconque: on distingue les grès quartzeux, les grès ferrugineux, les grès argileux ou grauwackes, les grès psammites, les grès calcarifères, etc. D'autres encore, et ceux-ci se rencontrent presque partout, sont des conglomérats variés, des dépôts agglomérés de galets, cailloux, silice, oxyde de fer, etc., emportés par les eaux et soudés plus ou moins solidement. On leur donne aussi le nom de poudingues. D'autres encore, comme les schistes, sont des dépôts argileux; d'autres sont des formations calcaires, composées de carbonate de chaux provenant très souvent exclusivement de coquilles entassées. A cet ordre appartient la craie, roche friable que tout le monde connait et que le microscope résout en un agrégat d'une infinité de particules de protozoaires et de microphytes: on y trouve des fragments de foraminifères, avec des débris de polypiers, d'échinodermes, de mollusques, associés à des restes siliceux de radiolaires, d'eponges et de diatomées. Certains calcaires sont entièrement formés par une accumulation de petites carapaces de crustacés d'eau douce, tels que les cypris. La cristallisation des calcaires produit les marbres, dans lesquels on remarque souvent de belles coquilles rendues bien visibles par le polissage. Le tripoli est entièrement formé de diatomées, algues siliceuses microscopiques, bacilles, galionelles, etc. La houille ou charbon de terre est un terrain de sédiment formé de débris de végétaux compacts ensevelis sous une puissante pression. 
Ces couches se sont superposées les unes au-dessus des autres suivant leur ordre dę succession. Les restes d'animaux et de végétaux que l'on y rencontre ont appartenu à des êtres qui vivaient aux époques pendant lesquelles ces couches se sont formées, et, à part de rares exceptions, qui habitaient non loin des lieux où on les retrouve, car de longs transports les usent et les brisent. La plupart du temps, l'organisme est conservè par substitution moléculaire et entièrement pétrifié : il ne reste rien de lui comme substance; mais sa forme extérieure et intérieure, son individualité organique est admirablement préservée. Les dépôts augmentent par le haut, naturellement; leur âge est done d'autant plus ancien qu'ils sont situés d̀ une plus grande profondeur.

Comme vue d'ensemble, on donne avec raison aux roches primitives, granite, gneiss, micaschiste, qui représentent les matériaux cristallins du noyau du globe autrefois brûlants et antérieurs à toute vie, la qualification d'azoüques ('), et aux premiers dépôts sédimentaires qui se sont effectués après la condensation des eaux, le titre de paléozoüques $\left(^{2}\right)$. La classification est ainsi très logiquement établie : $1^{\circ}$ avant l'apparition de la vie; $2^{\circ}$ depuis cette apparition.

La science des fossiles est toute moderne. On a été longtemps, pendant des siècles et des siècles, sans vouloir admettre que ces débris d'animaux et de végétaux aient pu vraiment appartenir autrefois à de véritables êtres vivants. C'étaient, disait-on, des jeux de la nature, produits, sous l'influence variable des constellations, du soleil, de la lune et des planètes, par une force plastique mystérieuse inhérente au globe terrestre. Ce ne fut guère que dans la première moitiè du seizième siècle que les phénomènes géologiques commencèrent à fixer l'attention. A celte époque, une vive controverse s'éleva en Italie, au sujet de la vraie nature et de l'origine des coquilles marines et d'autres fossiles organisés, que l'on trouve en abondance dans les terrains de la péninsule. L'illustre peintre Lćonard de Vinci, qui, dans sa jeunesse, avait conçu le plan

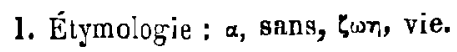

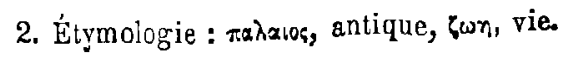




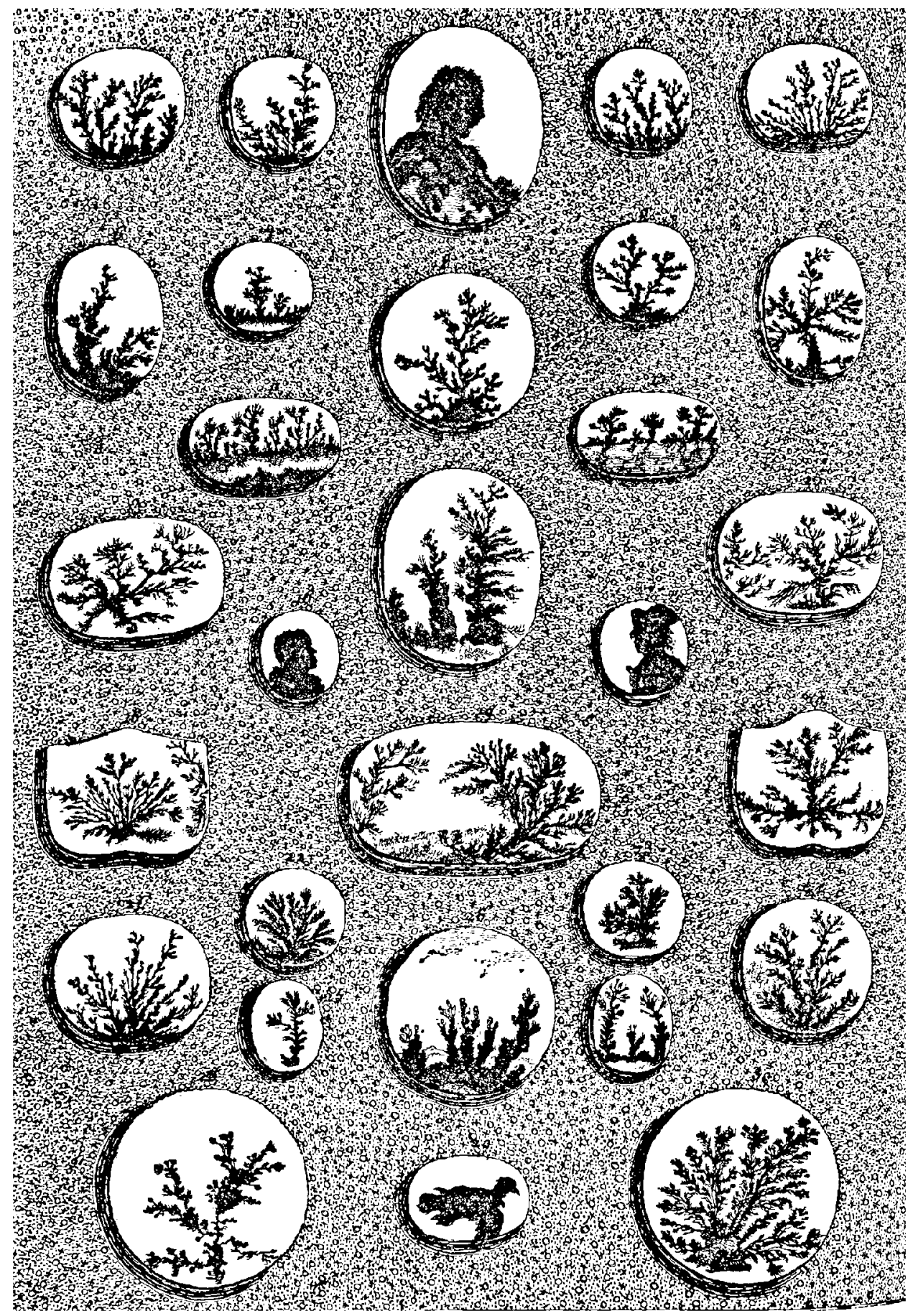

FIG. 86, - AGATHES POATANT DE SINGULIËES FIGURES NATERELLES 


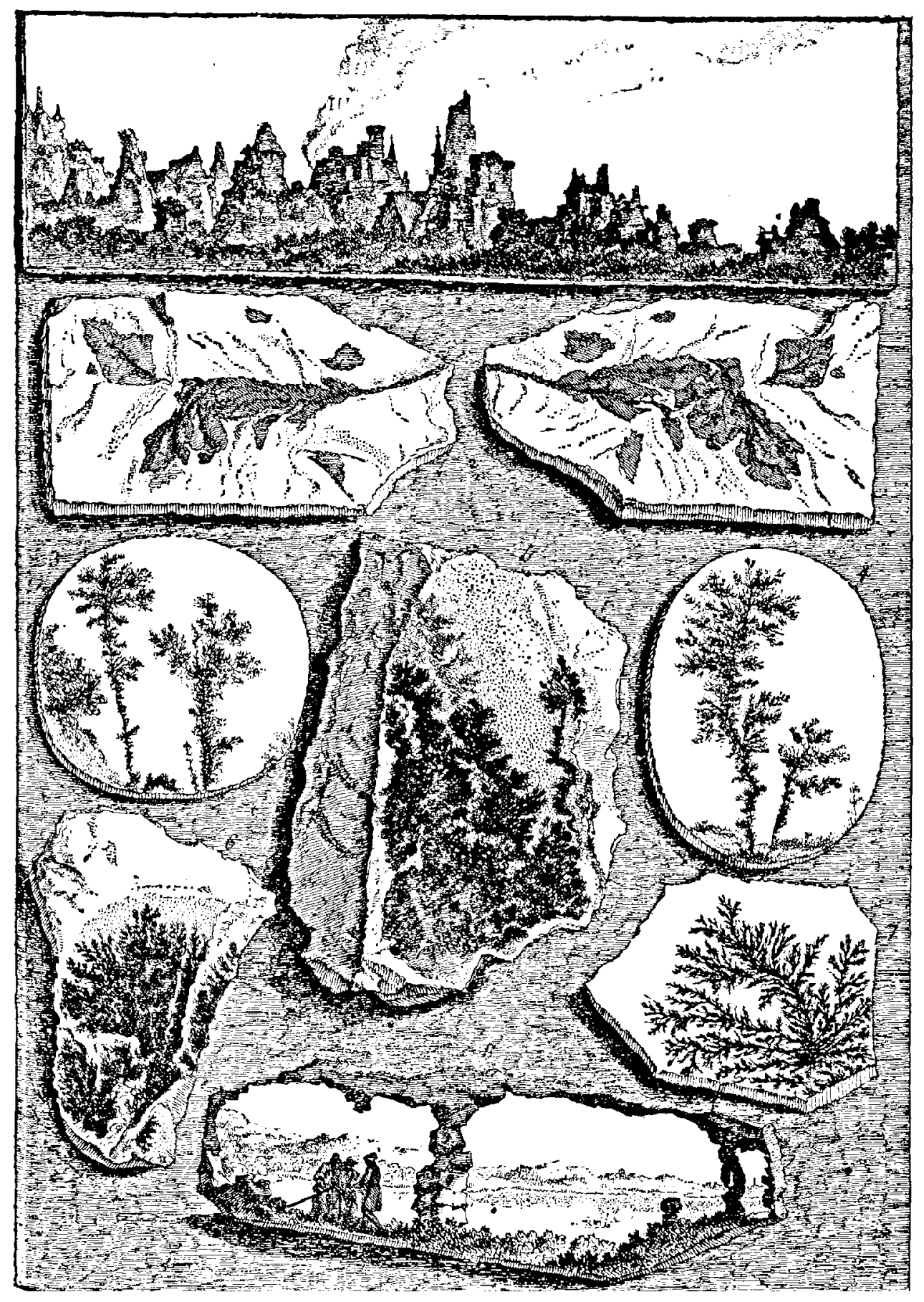

FIG. 87, - CURIEUSES PIFRRES ARBORISEES 
de plusieurs canaux navigables qu'il exécuta dans le nord de l'Italie, fut un des premiers à raisonner d'une manière saine et logique sur le sujet en question. "Le limon des rivières, dit-il, a recouvert les coquilles fossiles et a pénétré dans leur intérieur, lorsqu'elles étaient au fond de la mer près des côtes. On prétend que ces coquilles ont été formées sur les collines par l'influence des étoiles, mais je demande si l'on voit aujourd'hui les étailes former sur les collines des coquilles d'âges et d'espèces différentes? Comment, d'ailleurs, les étoiles expliqueraient-elles l'origine du gravier, que l'on rencontre à diverses hauteurs, et qui se compose de galets qui semblent avoir été arrondis par le mouvement de l'eau courante ? Comment, enfin, expliquer, par une telle cause, la pétrification, sur ces mèmes collines, des feuilles, des plantes, et des crabes marins? „Les fouilles faites en 1517 , pour les travaux de réparation de la ville de Vérone, mirent au jour une multitude de pétrifications curieuses, et fournirent matiere aux spéculations de divers auteurs, parmi lesquels nous citerons Frascatoro. Celui-ci déclara que, dans son opinion, les coquilles fossiles avaient toutes appartenu à des êtres vivants, qui avaient jadis vécu sur les lieux mêmes où l'on trouvait alors leurs dépouilles. Il démontra combien il était absurde d'avoir recours à la “ force plastique »de Théophraste, qui avait le soi-disant pouvoir de donner aux pierres des formes organiques, et prouva, à l'aide d'arguments non moins puissants, qu'il était ridicule d'attribuer la situation des coquilles en question au déluge mosaïque, comme le soutenaient obstinément quelques-uns.

Mais ces idées judicieuses ne furent pas comprises, et tout le talent et la force de raisonnement des savants se dépensèrent inutilement, pendant trois siècles, à discuter ces deux questions simples et préliminaires, savoir : premièrement, si les débris fossiles avaient jamais appartenu à des créatures vivantes; et secondement, si, ce principe admís, tous les phénomènes ne pouvaient pas s'expliquer par le déluge de Noë. Jusqu'à l'époque dont nous parlons, la croyance, généralement admise dans le monde chrétien, ćtait que l'origine de notre planète ne remontait pas à plus de six mille ans, et que, depuis la création, le dẻluge avait été l'unique catastrophe qui eût opéré un changement considérable à la surface de 
la terre. D'un autre côté, l'opinion que la dissolution finale de notre système était un événement auquel on devait s'attendre prochainement était presque aussi généralement répandue. La fin du monde avait dù arriver en l'an mille; mais cette fameuse année s'était passée sans catastrophe ainsi que les suivantes et, depuis cinq cents ans, les moines jouissaient paisiblement des riches concessions de terre que leur avaient faites de pieux donateurs, sans que l'on reconnut l'erreur de la prophétie.

Bien qu'au seizième siècle, il fut devenu nécessaire d'interpréter plus largement certaines prédictions concernant le millénaire, et d'assigner une date plus éloignée à la future conflagration du monde, on trouve dans les spéculations des anciens géologues, une allusion constante à l'arrivée prochaine d'une telle catastrophe. Quant à tout ce qui regarde l'ancienneté de la Terre, les opinions des siècles d'ignorance se maintinrent sans la moindre modification. La première tentative faite dans le but d'effacer, à l'aide de preuves physiques, un article de foi si généralement reconnu, excita une alarme considérable; mais grâce à l'esprit de tolérance relative qui existait parmi le clergé italien, il fut permis de discuter ce sujet en toute liberté. Les prêtres eux-mêmes se mêlèrent à la controverse, se prononçant souvent pour différentes solutions de la question. Tout en déplorant la perte de temps et de travail qui furent consacrés à la défense d'opinions insoutenables, il faut reconnaitre que, dans cette polémique, on déploya bien moins d'acrimonie que darns celle qui éclata, deux siècles et demi plus tard, de ce côté-ci des Alpes, parmi certains écrivains.

Ce système de disputes scolastiques, encouragé dans les Universités du moyen âge, avait malheureusement conduit à des habitudes d'interminables argumentations; ces combats intellectuels ayant pour but et objet la victoire non la vérité, on en était venu à préférer souvent des propositions absurdes et extravagrantes, par cela seul qu'elles exigeaient plus d'habileté pour être soutenues.

Toute théoric, quelque bizarre et subtile qu'elle fût, était sûre d'avoir ses parlisans, pourvu qu'elle se rapportât à quelque idée populaire. André Mattioli, botaniste éminent, défendit l'opinion qu'une certaine matière grasse, mise en fermentation par la cha- 


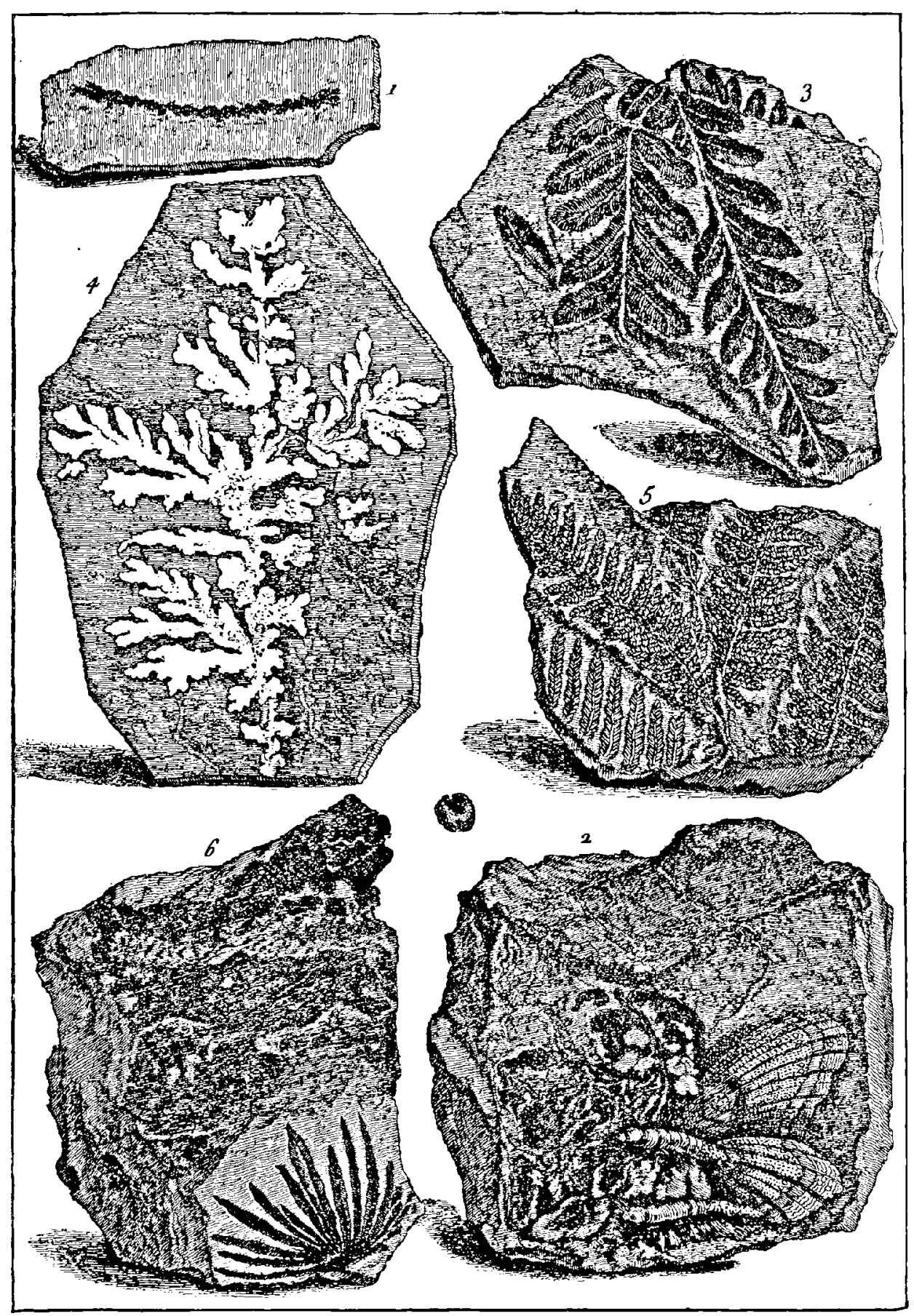

Fig. 88. - ARDOISES POATANT DES PETRIFICATIONS(170́1). 


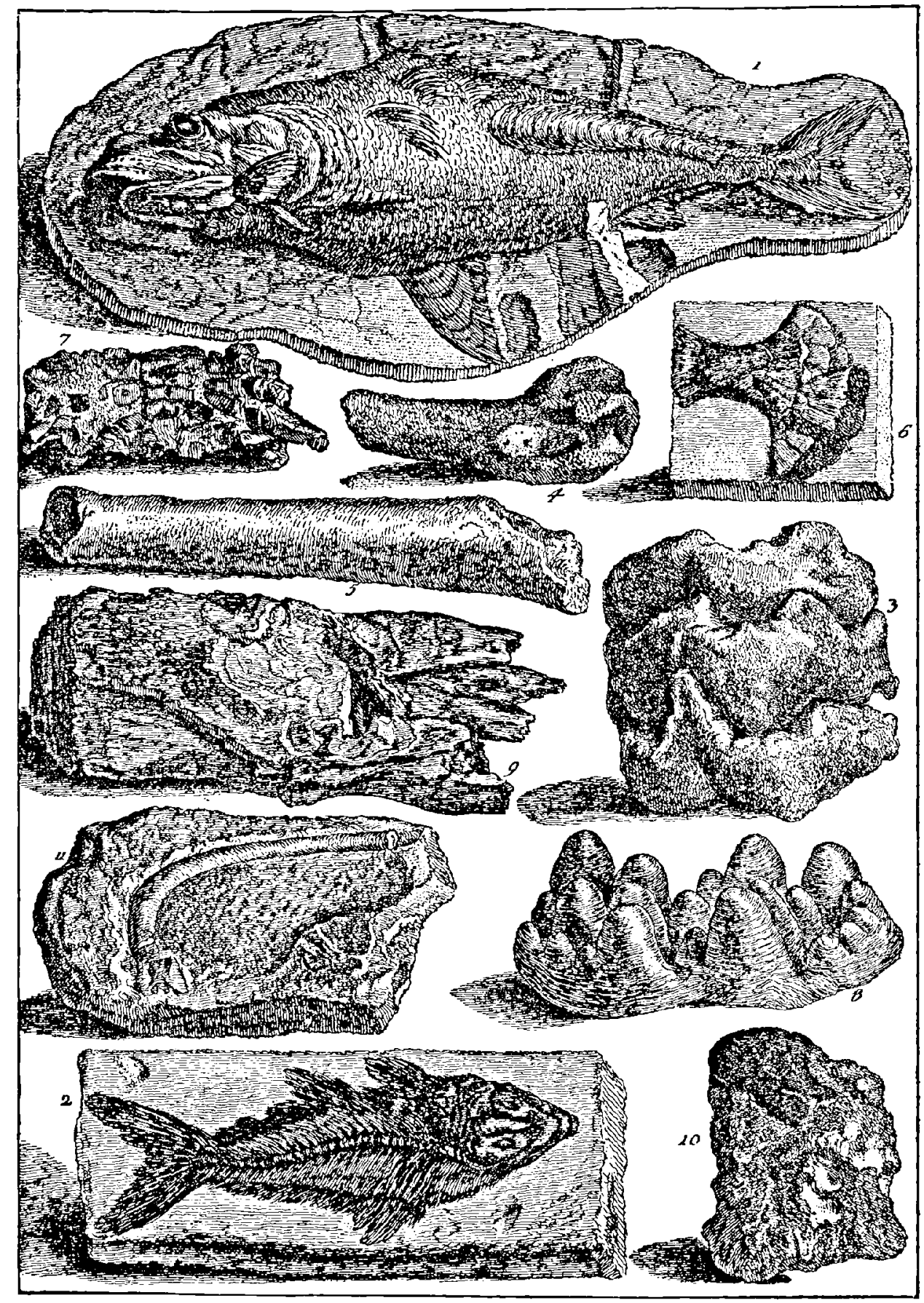

FIG, 89. - COLIECTIONS DE FOSSILES GRAVÉS DÉS 1751. 
leur, donnait naissance à des formes organiques fossiles. Cependant, d'après ses propres observations, il en était venu à conclure que les corps poreux, tels que les os et les coquilles, pouvaient être convertis en pierre, comme étant perméables à ce qu'il appelait le « suc lapidifiant ». De même, Faloppio, de Padoue, imagina que les coquilles pétrifiées étaient produites par fermentation, dans les lieux mêmes où on les trouve, ou que, dans certains cas, elles avaient acquis leurs formes par la suite a des mouvements tumultueux des exhalaisons terrestres ». Bien que professeur d'anatomie fort distingué, il enseigna que certaines défenses d'èléphants, déterrés de son temps, dans la Pouille, n'étaient autre chose que des concrétions terrestres; et, conséquent avec ces principes, il aila jusqu'à considérer les vases du Mont-Testaceo, à Rome, comme n'étant probablement que des impressions naturelles qui s'étaient modelées dans le sol! Animé du même esprit, Mercati, qui publia, en 1574, des figures très exactes des coquilles fossiles conservées par le pape Sixte V, dans le musée du Vatican, exprima l'opinion que ces coquilles n'étaient tout simplement que des pierres dont la configuration particulière devait ètre attribuée à l'influence des corps célestes. Olivier de Crémone les considérait comme de sirrples jeux de la nature. On alla jusqu'à dire que les nummulites trouvées en Égypte étaient des provisions de lentilles accumulées par les Pharaons pour la nourriture des esclaves employés à la construction des pyramides, et pétrifiées!

Quelques-unes des conceptions fantasques de ces temps furent jugées moins déraisonnables que les autres, par cela qu'elles se trouvaient quelque peu d'accord avec la théorie de la génération spontanée d'Aristote, enseignée alors dans toutes les écoles. Des hommes imbus, dès leur première jeunesse, de l'idée qu'une grande partie des plantes et des animaux vivants avaient été formés par le concours fortuit des atomes, ou qu'ils avaient pris naissance dans la matière organique corrompue, pouvaient facilement se persuader que les formes organiques, souvent imparfaitement conservées dans l'intérieur des roches solides, devaient leur existence à des causes également obscures et mystérieuses ( ${ }^{4}$ ).

1. Lyell, Principes de Géologie. 
Mais l'indépendance allait se faire jour. Bernard Palissy observe directement la nature et parle : « Un potier de terre, qui ne savait ni latin, ni grec, fut le premier, dit Fontenclle, qui, vers la fin du XVI ${ }^{\circ}$ siècle, osa dire dans Paris, et à la face de tous les docteurs, que les coquilles fossiles étaient de véritables coquilles déposées autrefois par la mer dans les lieux où elles se trouvaient alors, que des animaux, et surtout des poissons, avaient donné aux pierres figurées toutes leurs différentes figures; et il défia hardiment toute l'école d'A ristote d'attaquer ses preuves ».

Ce simple ouvrier touche aux questions les plus élevées de la science, et quelquefois il les résout. Il a rósolu celle des coquilles fossiles.

a Et parce qu'il se trouve, dit-il, des pierres remplies de coquilles, jusques au sommet des plus hautes montagnes, il ne faut pas que tu penses que lesdites coquilles soient formées comme aucuns disent que la nature se joue à faire quelque chose de nouveau ». Il ajoute: ‘ Quand j'ai eu de bien près regardé aux formes des pierres, j'ay trouvé que nulle d'icelles ne peut prendre forme de coquilles ni d'autre animal, si l'animal mesme n'a basti sa forme $»$. - " Il faut donc conclure, dit-il encore, que, auparavant que ces dictes coquilles fussent pétrifiées, les poissons qui les ont formées estoyent vivants dans l'eau,..... et que, depuis, l'eau et les poissons se sont pétrifiés en un mesme temps; et de ce ne faut douter ».

Cependant, on continuait de douter. Quoique dès 1669 Sténon cût donné l'explication des terrains de sédiment et des fossiles, Fontenelle, Buffon, Voltaire, hésitent sur la nature des fossiles et ne devinent pas le mode de formation des terrains de sédiments. On écrit pourtant un très grand nombre de traités spéciaux sur les fossiles même. Dans l'un d'eux, que nous avons actuellement sous les yeux ("), l'auteur anonyme, membre de la Société royale de Londres et de l'Académie de Montpellier; range parmi les fossiles les minéraux, pierres, cailloux, marbres, sels, bitume, charbon de terre, qu'il appelle « fossiles naturels à la terre », et les arbres, branches, racines, fruits, fougères, coquilles, poissons, vertèbres, dents, os, « qui se sont pétrifiés dans les entrailles de la

1. Oryctologie, ou traité des pierres, minéraux et fossiles, Paris, 1755. 
terre, ont été déplacés et disséminés par le déluge universel » et il les qualifie de a fossiles étrangers à la terre ». Cet ouvrage est illustré d'un grand nombre de planches admirablement gravées, et nous n'avons pu résister au plaisir d'cn reproduire ici pour nos lecteurs quelques-unes des plus remarquables. Ces spécimens offrent encore un autre intérèt, c'est qu'ils représentent précisément la transition entre l'époque où l'on considérait tous les objets figurés dans les pétrifications comme des jeux de la nature et celle où l'on a su distinguer les véritables fossiles des effets parfois si curieus produits par le hasard dans la contexture de certaines pierres. La première de ces planches $(f g .86)$ représente des spécimens de dentrites copiées fidèlement sur la collection du cabinet de l'abbé de Fleury. " La dentrite, dit l'auteur, est une agathe transparente, d'un gris sale, avec des traits jaunes, rouges ou noirs, qui représen. tent des arbrisseaux, des buissons, des mousses, des bruyères et autres feuillages: c'est ce qui lui a fait donner le nom de picre arborisée, du mot grec devòov, qui veut dire arbre. » Puis il explique en détail l'aspect de chacune de ces trente petites vignettes. - La seconde planche ( $f g .87$ ) représente des pierres arborisées non moins curieuses que les précédentes. Sur ces pierres, la seconde, qui est fendue en deux et montre des empreintes de plantes, parait porter une véritable pétrification de fossile; les autres sont certainement des " jeux de la nature »; sur la première on remarque une ville en ruine avec des clochers, des terrasses, de la fumée, un grand ciel ; sur la dernière on voit une grotte au bord de la mer, avec un pilier principal qui la partage en deux, et un groupe de trois hommes paraissant causer cnsemble. L'auteur prend le soin de déclarer que e l'imagination ou le burin du graveur n'ont rien ajouté. „- La troisième planche $(f i g .88)$ représente des fossiles de plantes et d'animaux, conservés dans des ardoises. D'après l'auteur, le $n^{\circ} 4$ serait un' simple a jeu de la nature $n$; mais nous savons aujourd'hui que c'est bien réellement là un fossile végétal. Enfin la quatrième planche ( $f g .89)$ réunit des spécimens de fossiles d'animaux aussi curieux qu'incontestables. On trouve dans le même ouvrage un grand nombre d'ammonites, de coquilles, de térébratules, d'oursins, etc., etc., recneillis en divers points de la France.

Insensiblement la science des fossiles se dégage du profond 
mystère qui l'avait toujours enveloppée. Les travaux de Stenon, de Pallas, de Saussure, de Werner, de Deluc, de Hutton, de Playfair, de Smith, de Léopold de Buc, de Humboldt, de Guettard, de Cuvier surtout, de Brongniart, de d'Orbigny, de Blainville, de Lyell, d'ílie de Beaumont et de leurs émules, la conduisirent graduellement au degré de science positive qui la caractérise aujourd'hui et qui en a fait une branche essentielle de la géobgie. Cuvier a été vraiment le créateur de la paléontologie (1). Dès lors, les esprits les plus retardataires eux-mèmes cessèrent de douter de la nature des fossiles, et tout le monde fut conduit à reconnaître en eux les débris d'animaux et de plantes ayant vécu pendant la succession des époques antérieures à l'apparition de l'homme et ayant été conservés dans les terrains de sédiment successivement déposés.

Cette élaboration fut longue, comme on le voit. Pourtant dès le temps des Romains, Ovide avait écrit:

Vidi, ego, quod fuerat quondam solidissima tellus

Esse freium; vidi factas ex aquore terras;

Et procul a palago conche jacuere marine

Et vetus inventa est in montibus anchora summis.

J'ai vu ce qui avait été une terre ferme céder la place à la mer;

J'ai vu en revanche des terres se former aux dépens des ondes. Loin de l'Océan gisent des coquilles marines;

On a trouvé un ancre de forme antique au sommet d'un mont ( $\left.{ }^{2}\right)$.

Mais la vérité ne s'impose aux hommes que lentement; la vue ne s'acclimate que graduellement à la pleine lumière.

Dans cet historique de la géologie, il ne serait peut-être pas inopportun de remarquer combien les esprits supérieurs agrandissent tous les sujets qu'ils traitent. Quelquefois mêrne, à force d'élargir l'horizon et de reculer le but, ils ne l'atteignent jamais; mais sur leur route ils font d'abondantes moissons, et ces richesses, qui semblaient d'abord accessoires, acquièrent souvent plus d'importance que n'aurait pu en avoir l'objet principal. C'est ce qui nous frappe, à propos des fossiles, lorsque nous nous souvenons que Leibniz, chargé en 1680 par le duc ErnestAuguste d'écrire l'histoire de la maison de Hanovre, du duché de Brunswick, voulut commencer cette histoire par celle du pays,

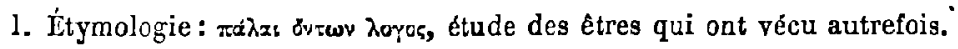

2. Metamorphoses, XV, 262-265.

LE MONDE AVANT LA CRÉaTION DE L'HOMNE 
puis celle du pays par sa géologie, puis cette géologie par celle de la Terre entière, si bien qu'il écrivit sa Protogée, ou Traité de la formation et des révolutions du globe, comme introduction à l'histoire du Hanovre, et finalement en resta là,... sans mème arriver au déluge. Ce petit livre est, dans tous les cas, incomparablement plus important et plus intéressant que n'eût été l'histoire d'une dynastie quelconque de ducs, de roitelets, ou d'empereurs. Comme Stenon, Leibniz comprend la vérité inscrite dans les annales de la nature; il déclare que les fossiles sont les restes pétrifiés d'animaux antédiluviens, et à ceux qui objectent que les ammonites aient jamais vécu par la raison que les mers actuelles n'en fournissent plus, il répond " que d'abord on n'a pas exploré les dernières profondeurs des mers et leurs abîmes; que le nouveau monde nous présente une foule d'animaux auparavant inconnus, et qu'enfin il est présumable qu'à travers tant de révolutions un grand nombre de formes animales ont été transformées. „- On le voit, le génie de Leibniz avait devancé de deux siècles les progrès de la science. - Mais revenons à l'histoire de la Terre, à la formation des terrains.

Les plus anciens terrains de sédiment sont ceux qui reposent sur les roches primitives, sur le squelette minéral de la planète. Ils représentent les dépôts formés pendant la période primordiale et se divisent en trois étages. Ils n'ont pas conservé leur horizontalité primitive et sont plus souvent bouleversés, disloqués que réguliers. La coupe du globe terrestre $(f g .85)$ qui indique leur ordre de succession, n'est que théorique et rarement réalisée dans la pratique ; mais cet ordre de succession n'en est pas moins certain et incontestable.

On s'accorde à considérer comme représentant l'AGE PRIMORDiL ces trois plus anciennes couches, désignées sous les noms de terrains laurentien, cambrien et silurien. Le premier doit son nom à ce que les fouilles principales qui l'ont fait reconnaitre ont èté entreprises dans la région du fleuve Saint-Laurent, au Canada; le second au mot Cambria, nom breton du pays de Galles en Angleterre, oủ cette sorte de terrain a été très étudiée; le troisième à cette particularité que la peuplade celtique des Silures, qui combattit avec gloire lors de l'invasion de l'île anglaise par les Romains, habitait 
le comté de Shropshire où ces couches sédimentaires sont très ètendues. C'est assurément là une nomenclature bizarre et peu scientifique. Mais la science est comme l'histoire : elle a commencé par des faits isolés et sans rapports entre eux, qu'un regard général pent réunir plus tard en synthèse, mais qui d'abord ne sont point logiquement reliés ensemble et dont les désignations primitives ne sont pas inspirées par un même plan. Un jour, probablement, on remplacera ces termes géographiques incohérents, ainsi que ceux que nous aurons l'occasion de rencontrer dans le cours de cet ouvrage, par des termes géologiques ou chronologiques; mais, en attendant, l'historien de la nature est obligé de s'en servir, et pour que le leeteur fùt au courant des choses il était utile d'en donner l'explication.

Nous étudierons, au chapitre suivant, le mode de formation de ces terrains et nous chercherons à pénétrer directement à travers les époques de la nature; nous verrons comment les oscillations de l'écorce du globe ont soulevé les couches géologiques inférieures et les ont fait affleurer à la surface du sol où le naturaliste peut les analyser.

L'épaisseur respective de ces trois terrains peut donner une idée de la durée proportionnelle des périodes pendant lesquelles ils se sont formés. On a pu constater que le terrain laurentien n'a pas moins de neuf kilomètres d'épaisseur. Le terrain cambrien a montré une épaisseur de six mille mètres, et le terrain silurien une épaisseur de huit mille. G'est donc une épaisscur totale de vingt-trois kilomètres, entièrement formée par les dépôts de la mer. Or tous les autres terrains plus récents que l'on retrouve sur les anciens et qui correspondent aux époques consécutives, primaire, secondaire, tertiaire et quaternaire, n'atteignent pas cctte épaisseur, car ils ne paraissent pas surpasser vingt kilomètres. La conséquence est que, d'après cette première indication, l'âge primordial a surpassé à lui seul en durée celui des quatre périodes plus récentes qui arrivent jusqu'à nous.

D'après l'ensemble des comparaisons faites, d'après le temps que les pluies et les vents emploient à désagréger les reliefs du globe, que les ruisseaux, les rivières et les fleuves mettent à les conduire à la mer, et que les substances tenues en suspension dans les eaux emploient à se déposer au fond, on peut arriver ì se former une idée approximative de la durée réelle de ces âges préhistoriques. 
Notre vie est si éphémère, l'histoire des pcuples est elle-mème si rapide, que nous avons toujours une tendance à réduire les œuvres de la nature à l'échelle de notre mí̛rocosme, et parce qu'un siècle nous parait long, nous sommes originairement convaincus qu'il est long, en réalité, pour la nature elle-même. Mais 'rètude directe de l'univers, dê $e^{\circ} \mathrm{s}^{2}$ mouvements, de ses transformations hous prouve que nos impressiơns sont personnelles à nos êtres trop éphémères et que dans histoire de l'univers les siècles sont moins que des secondes dans $\frac{\$}{4}$ notre vie. Cependant, malgré tout, nous sommes conduitşà prendre pour base de raisonnement une limite très étroite mais compréhensible pour nous. Notre mémoire historique est si courte qu'en accordant une durée de cent mille ans, par exemple, à l'âge quaternaire, contemporain de l'espèce humaine, c'est-à-dire à l'âge de l'humanité elle-même, nous çpaignons d'cxagérer. Pourtant il est dès maintenant certain que nous sommes audessous de la vérité. L'humanité a nécessairement existé pendant d'immenses périodes de temps avant de commencer l'histoire, avant de s'élever à la notion du langage précis et de l'écriture, avant de se réunir en peuples capables d'acquérir une mémoire historique. Quoiqu'il en soit, admettons cette base ⿳亠丷⿵冂⿱十口nimum de cent mille ans poụr la durée de l'âge actuel, depuis les origines de l'humanité jusqu'à nos jours,

Eh bien! dans cette appréciation trop modeste, et, répétons-le, inférieure à la réalité, la période tertiaire aurait duré 460000 ans, la période secondaire 2300000 , la période primaire 6420000 et la période primordiale 10720000 , comme on peut s'en rendre compte par le petit tableau suivant:

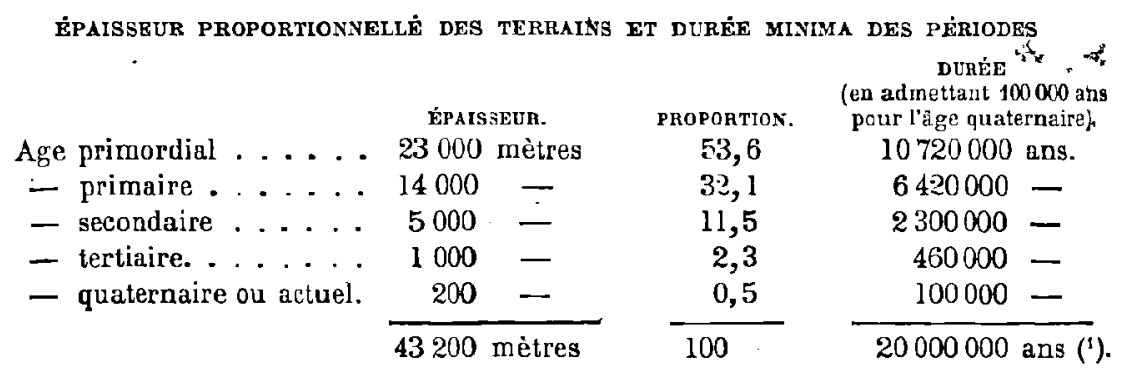

(1) Nous répétons que ces chiffres n'ont aucune valeur absolue et ne peuvent servir que d'indication pour apprécier l'échelle probable des temps antiques. Ils sont au-dessous de la rẻalité. 


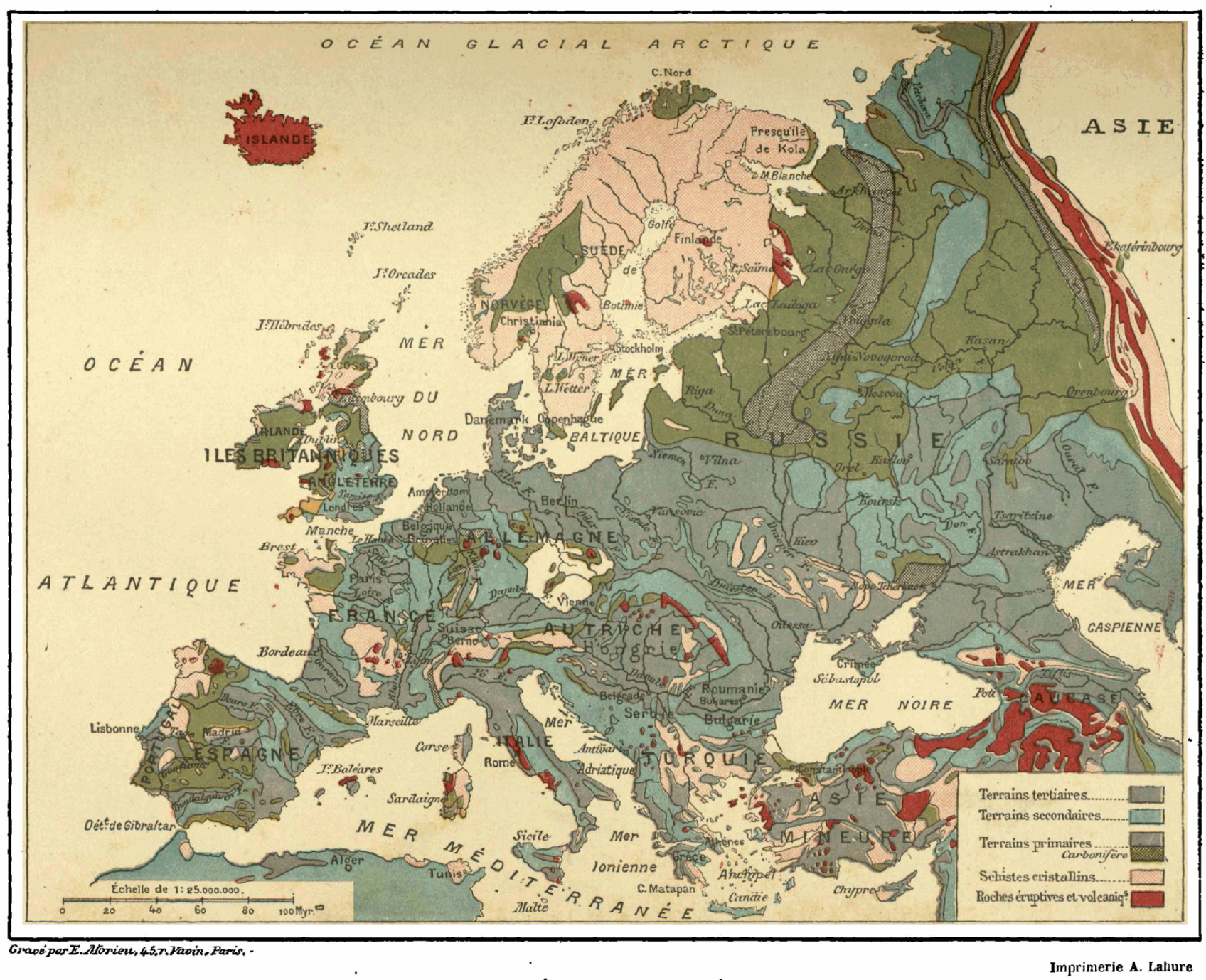

CARTE GÉOLOGIQUE DE L'EUROPE 
IRIS - LILLIAD - Université Lille 1 
Nous avons adopté ici les données discutées et acceptées par Maeckel pour les épaisseurs relatives des terrains, comme résumant l'ensemble des observations faites. Les chiffres présentés par les divers géologues varicnt à certains égards, mais le résultat définitif reste à peu près le mème, quant à l'immense étendue de la durée de ces époques de la nature.

Examinons maintenant de plus près l'âge primordial dont la description nous occupe en ce moment, et voyons quels sont les vestiges de plantes et d'animaux qu'on y découvre.

Cet âge primordial est représenté en géologie, comme nous

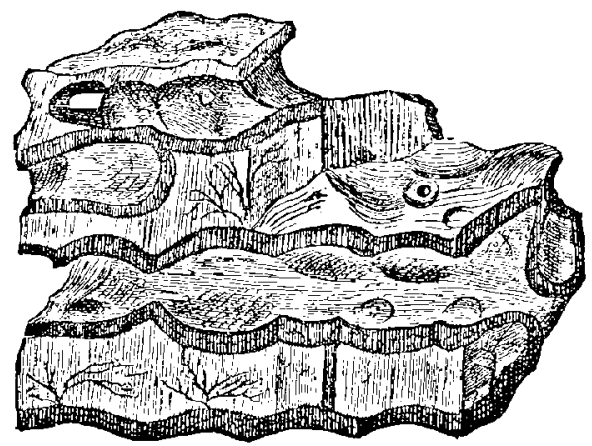

Fig. 90. - Les plus anciens dépôts sédimentaires : schistes laurentiens, Eazoon canadense.

l'avons vu tout à l'heure, par les terrains laurentien, cambrien et, silurien, superposés dans l'ordre de leur formation et offrant les épaisseurs proportionnelles suivantes:

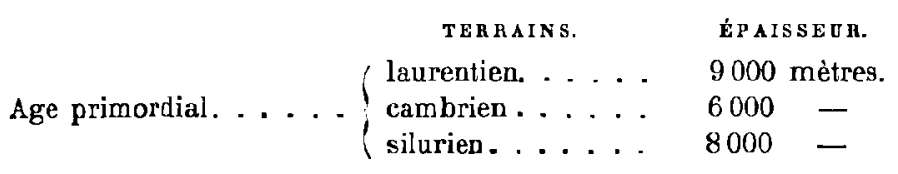

On n'a encore ricn trouvé de certain jusqu'aujourd'hui dans le terrain laurentien. Ces schistes du Canada ont paru à plusieurs géologues (Dawson, Carpenter, etc.) formés de dépôts organiques, et certaines traces qu'ils présentent ont même été regardées par eux comme des restes d'organismes rudimentaires; on a même donné à ces roches énigmatiques le nom symbolique d'eozoon (") "ou organismes de l'aurore "; mais l'authenticité de ces objets

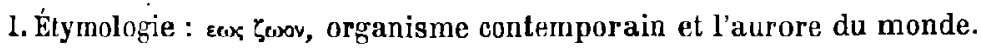


est très contestable et tout porte à croire que ce sont plutôt de simples minéraux que des pétrifications d'êtres ayant vécu. Nous ne nous permettrons donc pas de les inscrire au nombre des fossiles, n'admettant ici que les résultats scientifiques suffisamment démontrés. Toutefois, quoiqu'on n'ait encore rien trouvé de certain dans le terrain laurentien, c'est sans aucun doute pendant cette période que les premiers organismes ont dù se former. La présence du graphite en nids de substance charbonneuse presque pure atteste qu'il existait déjà là des amas assez considérables de substance organique végétale. Darwin pensait mème que la vie primordiale devait être déjà très répandue, et que cette première période organique a été " plus longue que toute celle qui s'est écoulée depuis ». Ainsi, nous sommes incontestablement ici, an seuil de l'édifice de la vie.

Les explorations géologiques ayant à peine dépassé la millième partie de la surfuce du globe, il n'y a rien de surprenant à ce qu'on ait trouvé si peu de fossiles appartenant au berceau mème de la vie terrestre; d'autre part ces couches primitives ont été chauffées et modifiées dans leur structure mème par la chaleur intérieure du globe, de sorte que la grande majorité des restes d'êtres vivants ont été détruits par cette transformation mème. Cependant on ne doit pas désespérer de voir les documents arriver au jour avec les explorations des géologues et prouver avec certitude que la vie a commencé pendant l'époque laurentienne.

Il n'est pas inutile de remarquer ici, tontefois, que les premiers organismes gélatineux n'avaient pas assez de consistance pour se fossiliser ; du moins leur transformation et lcur conscrvation à l'état fossile eussent-elles été soumises à des conditions difficiles à réunir et n'est-il pas surprenant que leurs spécimens deviennent d'autant plus rares que les terrains sont plus anciens.

Ce terrain laurentien représente une longue période de dépôt au fond des eaux, une longue période de siècles, car il n'a pas moins de neuf kilomètres d'épaisseur. Les estimations les plus faibles établissent, au minimum, pour la durée de cet âge, plusieurs millions d'années. Ces calculs ne peuvent ètre précis, les dépôts s'effectuant plus ou moins lentement suivant les distances aux rivages, suivant les profondeurs, ct les alternances ayant varié 
avec les périodes d'exhaussement et d'affaissement. En géologie, on est loin des certitudes et des précisions de l'astronomie.

Los premiers vestiges certains d'êtres organisés ont été trouvés dars le terrain cambrien, principalement en Angleterre et en Suède. Ge sont des empreintes de plantes marines rudimentaires et d'animaux marins non moins rudimentaires, des algues, des annèlides,

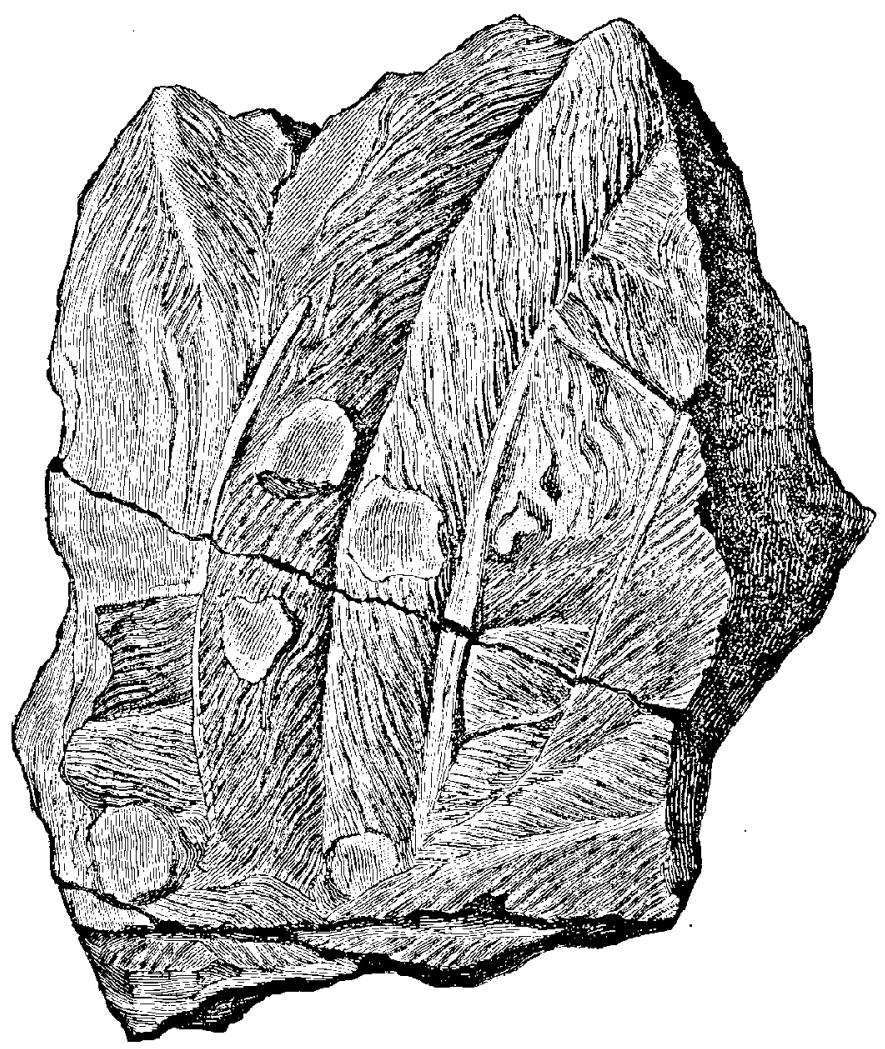

Fig. 91. - Les organismes problematiques des anciennes mers Bilohites.

des mollusques, des éponges, des polypiers, des échinides. Devant ces premières empreintes, l'esprit hésite à dẻcider si ce sont des algues ou des tubes d'annélides, ou seulement des trainées d'objets purement inertes promenés par le remou des vagues et ayant ravé le fond vaseux. Tout semble mystérieux, voilé dans l'éloignement, et pourtant on sent qu'on ne peut attribuer au hasard ces caractères indéchiffrables et qu'il y a là des traces des premières plantes et des premiers animaux. 
Les organismes problématiques des anciennes mers, les bilobites, les gyrolithes, les vexillées, les lophyties que l'on retrouve fossilisés en demi-relief dans les terrains primitifs, notamment dans le silurien, et dans lesquels un certain nombre de gẻologues et de naturalistes ne voient que des traces pétrifiées de passages d'ani-

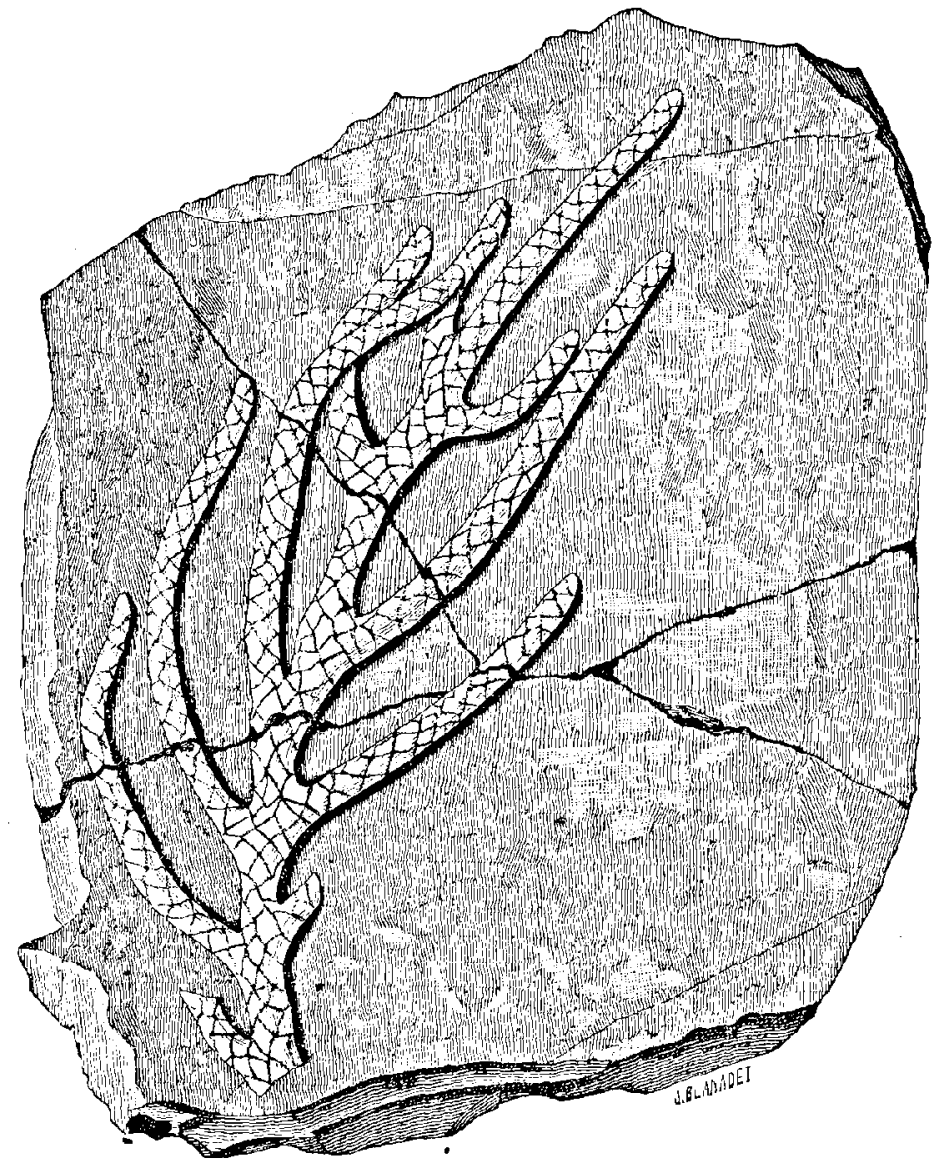

Fig. y9. - Les organismes problématiques des anciennes mers: Brachyphyluan gracilc.

maux, des empreintes ou des pistes conservées après le durcissement du sol sur lequel elles auraient été laissées, sont très prohrblement, d'après les laborieuses recherches du marquis de Saporta, de véritables organismes, très élémentaires, offrant déjà le caractère des vëgètanx, et sans doute les ancêtres des algues. On peut admettre que couchées soit à plat soit dans une direction oblique, ces premières plantes marines ètaient appliquées contre le sol 
sous-marin, qu'elles constituaient sur la vase du fond des amas superposés ou entre-croisés, sortes de colonies rampantes occupant une parlie des ancicnnes mers et s'y multipliant de façon à se trouver parquées sur certains points, chaque type ou mème chaque
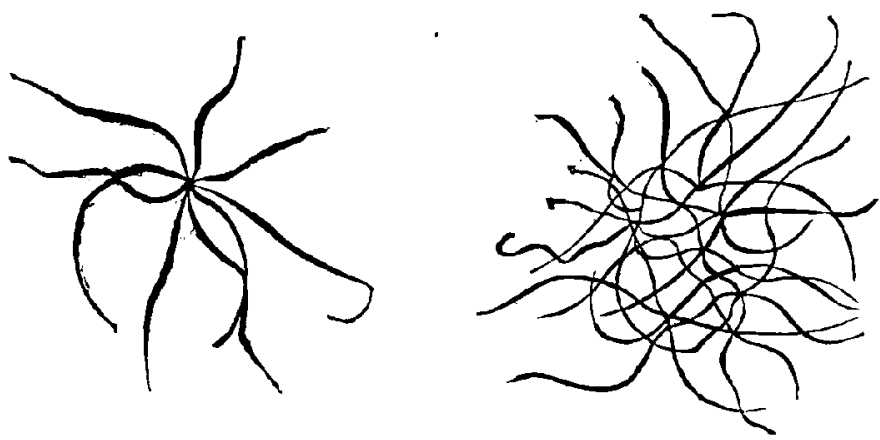

Fig. 93. - Premières plantes : algues.

espèce s'y multipliant. De mème que l'on constate la prédominance des cryptogames vasculaires au sein des premières flores terrestres; de même que l'on proclame la prédominance ou le règne des pois-

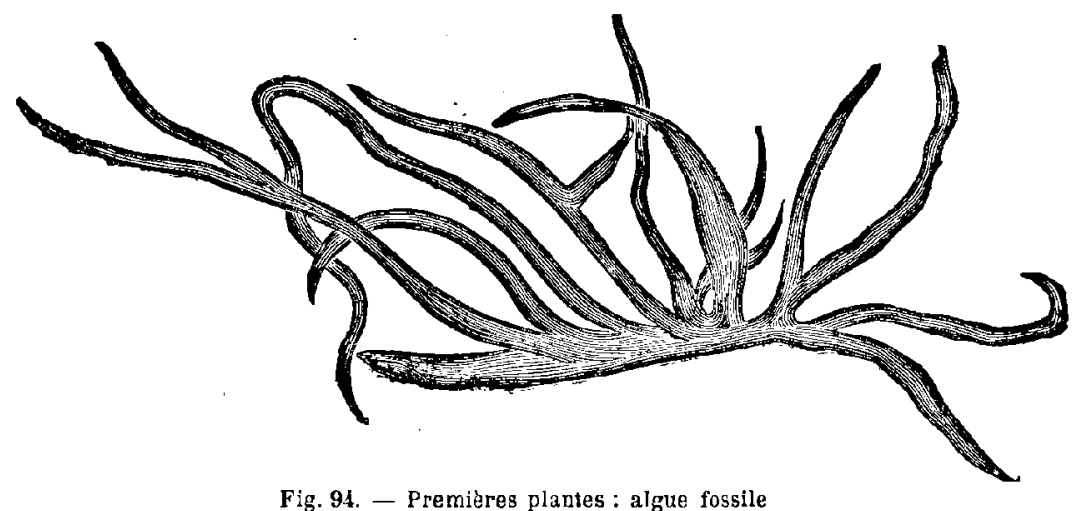

sons cartilagineux relativement aux poissons osseux développés plus tardivement; de même que l'on affirme la prédominance des reptiles comme ayant précédé les autres classes de vertébrés à respiration pulmonaire, et celle des marsupiaux comme ayant devancé les mammifères placentoïdes; de même il aurait existé, au fond des anciennes mers, une prédominance longtemps acquise aux algues unicellulaires. Elles auraient compris à l'origine des types d'une grande vigueur végétative. Nous reproduisons ici $(f g .91$ et 92$)$, 
d'après M. de Saporta ('), deux spécimens remarquables de ces végétaux primitifs : lo bilobites Goldfussi et le brachyphyllum gracile. Le premier a été trouvé à Pontréau (Ille-et-Vilaine) dans le grès armoricain, et appartient au muséum de Paris; le second a étẻ trouvé dans les calcaires lithographiques de Cirin et appartient au muséurm de Lyon.

Les algues, toutefois, deviennent rapidement si nombreuses que l'on donne parfois le nom d'époque des algues à l'âge primordial. Sont-ce des plantes? Leur formation est bien élémentaire. De simples filaments partent d'un point central comme dans la figure 93. Aussitôt que plusieurs plantes de ce genre se rassemblent, comme

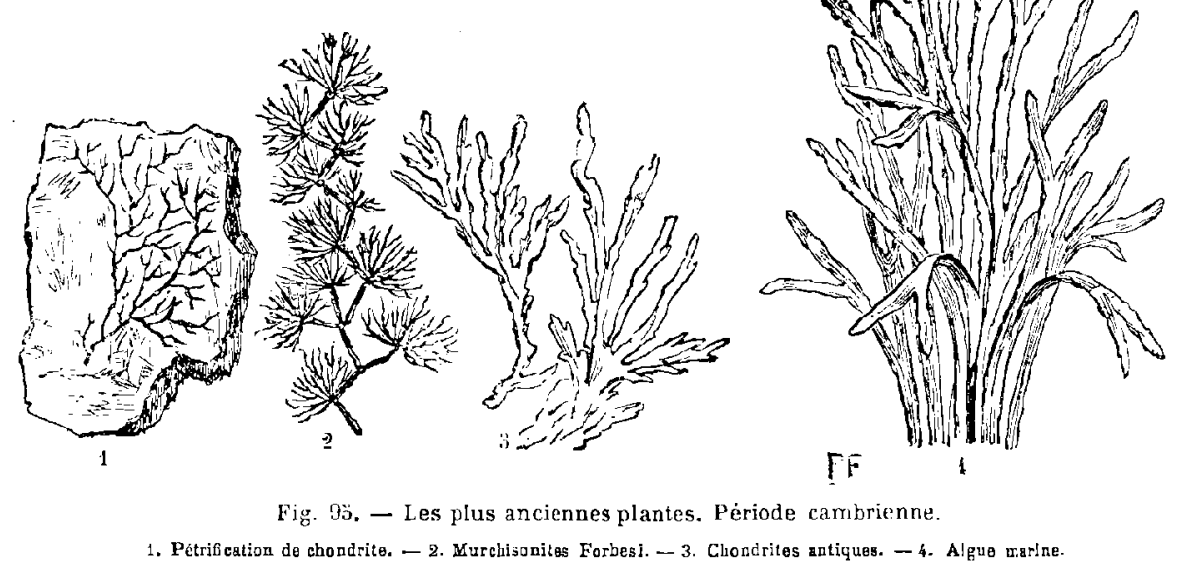

dans la deuxième figure, il se forme une espèce de tissu, une sorte de limon glutineux, demi-transparent qui, examiné au microscope, se divise en une quantité de filaments invisibles à l'œil nu. Les fucus que la mer renferme en quantités innombrables sont beaucoup plus vigoureux et plus solides. Ce sont toujours des cellules accolées, sans racines, mais formant dans la mer par leur accumulation, un tissu serró qu'un navire a parfois quelque peine à traverser.

Ces premières plantes sont ce qu'il y a au monde de plus simple

1. I) Saporta. Les Organismes problématiques des anciennes mers. 
et de plus élémentaire. Ce ne sont, pour ainsi dire, que des tubes aplatis, sans fenilles, sans fleurs et sans fruits (voy. fig. 95). Elles vivaient et se développaient au sein des eaux tièdes des mers primitives. Il n'y avait pas encore de terre ferme; à peine quelques iles commençaient-elles à émerger de la surface des flots.

Il n'y avait à cette époque ni saisons ni climats, la température

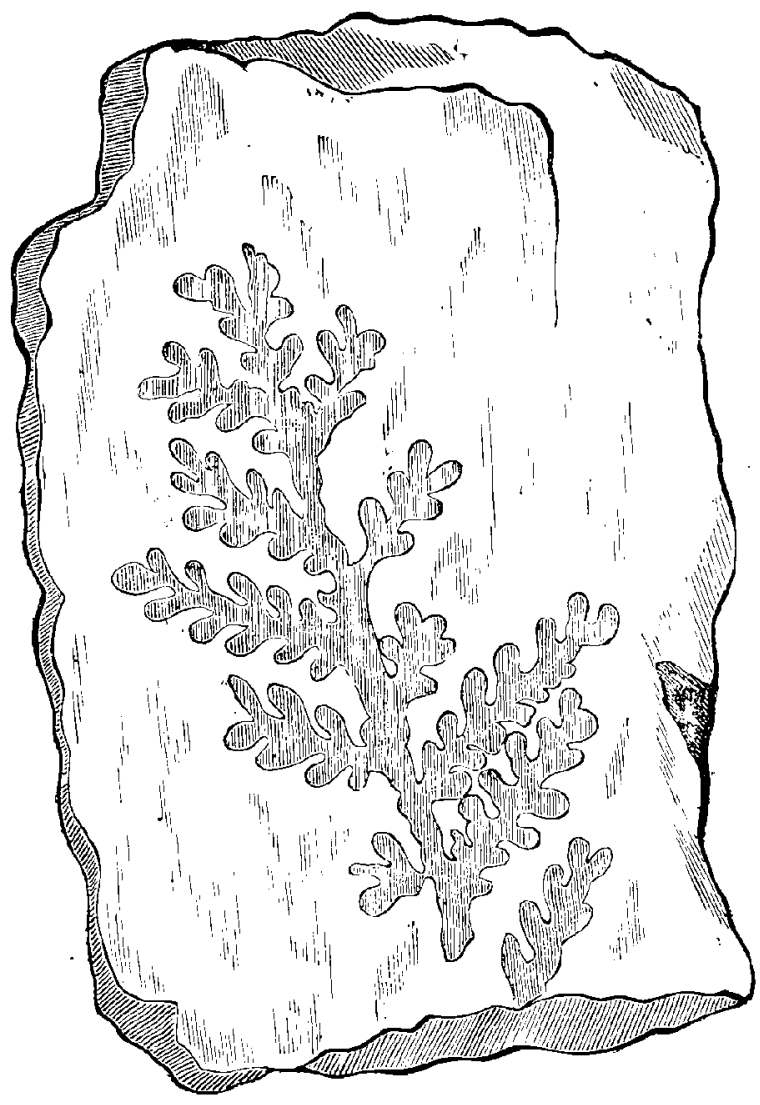

Fig. 96. - Empreinte fossile de plante prinitive.

de l'écorce du globe étant encore supérieure à la chaleur qui pouvait ètre reçue du Soleil, et le globe offrait aux pộles les mêmes conditions d'existence qu'à l'équateur. Le fait des marées, beaucoup plus fortes dans la direction du Soleil et de la Lune, donnait même aux régions que nous nommons tropicales et tempérécs une agitation superficielle qui allait en s'éteignant vers les pôles. Les régions polaires étaient donc, de ce chef, mieux favorisẻes que les ẹ́qua- 
toriales, d'autant plus que cette mème attraction du Soleil et de la Lune, en agissant avec plus d'intensitè sur le noyau liquide intérieur

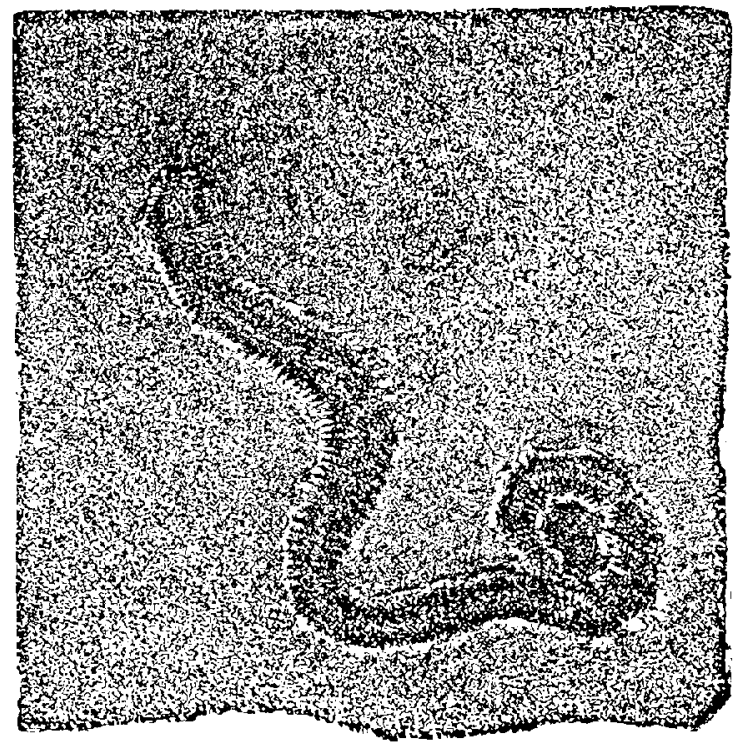

Fig. 97. - Les plus anciens animaux : empreinte d'annélide à l'époque cambrienns.

dans les régions équatoriales que dans les polaires, dut permettre à l'écorce terrestre d'acquérir une plus grande stabilité en ces der-

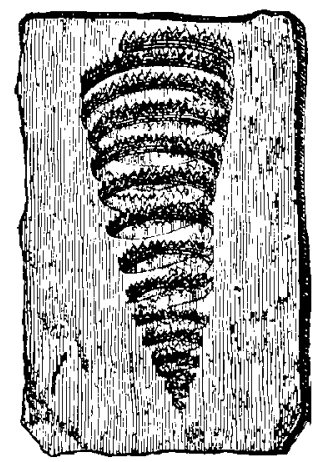

Graptolithus turricalsus

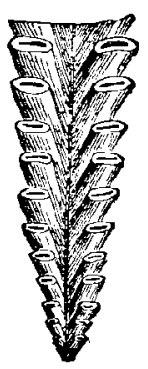

Diprion pristis

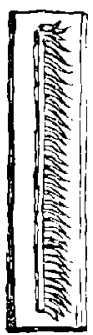

Mocograptus.
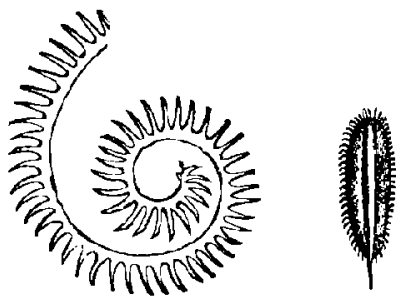

hastrite peregrinus.

Phyllogngtat

Fig. 98. - Les plus anciens animaux. Période cambrienne.

nières régions. On peut donc penser que les premiers organismes vivants se sont formés dans la tranquillité des mers polaires, éclairées alors par un soleil gigantesque. 11 est hautement probable, en effet, que pendant la période laurentienne oú la vie parait avoir fait son 
apparition, le Soleil n'était pas encore condensé beaucoup au dedans de l'orbite de Vénus. Il est probable que l'on n'a pas encore trouvé les véritables premiers organismes, soit végétaux, soit animaux,

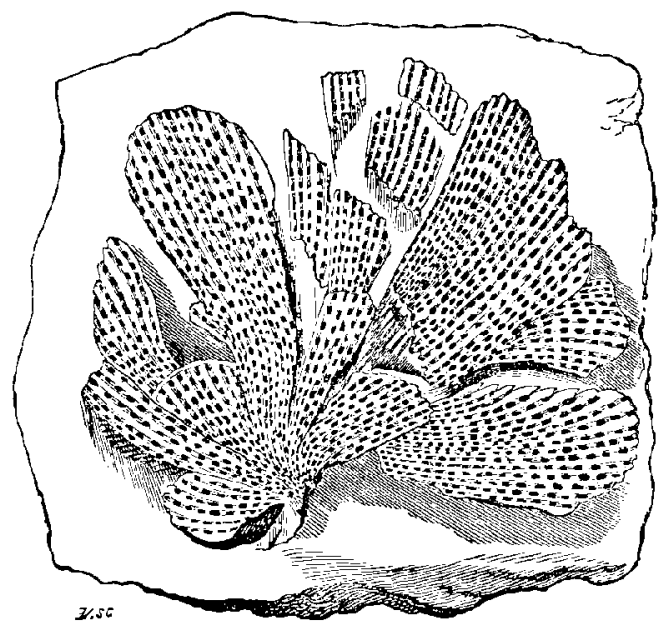

Fig. 99. - Les plus anciens animaux. - Fossile du mollusque bryozoaire Fenestella tenuiceps.

et qu'on les trouvera dans les terrains laurentiens non encore explorés.

Les premiers animaux sont également des animaux marins. On

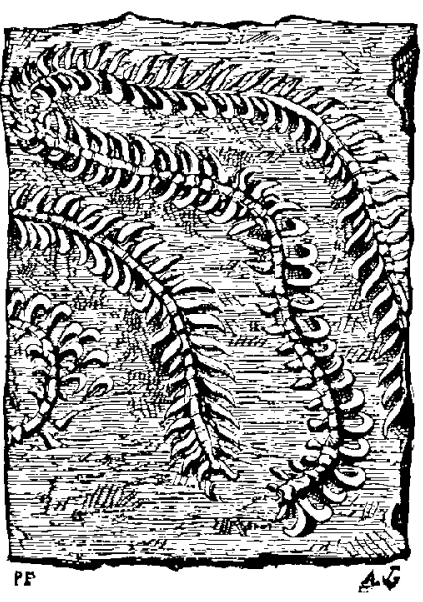

Nereites cumbriengis.

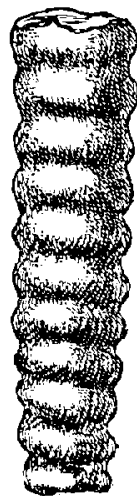

Orthoceras vohemieum

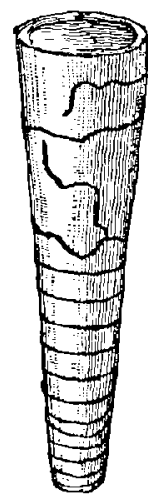

Orthocurus régulare

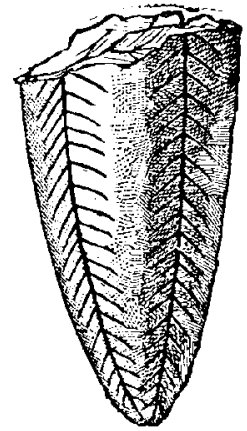

Conularia pyramidata.

Fig. 100. - Les plus anciens animaux. Période cambrienne et silurienne.

a trouvé dans les fossiles cambriens des annélides qui semblent appartenir aussi bien au règne végétal 'qu'au règne animal : ce ne sont, eux aussi, que des tubes articulés flottant dans les 
eaux, comme les algues leurs contemporaines ( $f g .97)$. On rencontre aussi, en très grand nombre, des graptolites, polypiers très simples composés de tubes enroulés et dentelés dont chaque cellule était sans doute animée ( $f i g .98, \mathrm{n}^{\text {os }} 1$ et 2) des monograptus $\left(n^{0} 3\right)$, des rastrites $\left(n^{\circ} 4\right)$, des phyllograptus $\left(n^{0} 5\right)$. Ce sont des protozoaires extrèmement simples, des agglomérations de loges soudées entre elles, des hydraires rudimentaires formées de protoplasma. C'est le commencement des polypes, et l'on s'étonne que la vie ait pu animer des formes aussi bizarres. Les mèmes terrains primitifs renferment aussi de petites coquilles auxquelles on a donné le nom de lingules (ce sont les premier's. mollusques brachiopodes) et des mollusques bryozoaires renfermés dans des cellules pierreuses agrégées en colonies, dont notre figure 99 offre un spécimen.

Déjà le terrain cambrien a fourni une cinquantaine d'espèces végétales ou animales (ou plutôt origines des deux règnes) parmi lesquelles dominent les algues unicellulaires, les annélides, les brachiopodes, los spongiaires et les polypiers. Dans le terrain silurien dominent les graptolithes, les millépores et surtout, comme nous allons le voir, les trilobites.

En effet, une légion d'êtres nouveaux arrive et se répand avec une diffusion extraordinaire : ce sont des crustacés connus sous le nom de trilobites, qui n'existent plus depuis longtemps: ils ont disparu pendant l'époque carbonifère, il y a des millions d'annécs. Les trilobites pullulaient dans les-mers primitives, et on les retrouve très facilement lorsque dans les falaises ou dans les tranchées à travers les montagnes, on les recherche pendant quelques heures dans les terrains qui les renferment. Ils sont notamment très répandus dans le département de Maine-et-Loire, dans les couches siluriennes des carrières de Trélazé, près d'Angers.

De cette antique époque date aussi le polypier du corail qui a jouć un rôle important dans la formation de la Terre, et dont les colonies séculaires ont créé à elles seules des îles immenses. 0n remarque, parmi les zoophytes, le genre des hémicesmites, en forme de poires, échinodermes, oursins, holoturies. C'est à peine si ces êtres méritent le titre d'animaux. Plusieurs, parmi les mollusques, n'ont pas encore de tête et ne peuvent pas se mouvoir, comme les huitres 
dont on retrouve les ancêtres; d'autres ont une sorte de tête et un rudiment de tube digestif; mais une seule ouverture sert pour l'introduction et l'expulsion des aliments, comme chez les échinodermes; d'autres, comme les vers, ont un commencement d'organisation générale, encore la plupart des organes des sens leur man-
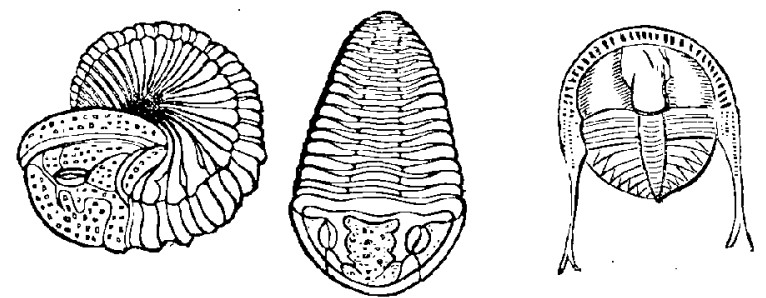

Fig. 101.-Animaux marins primordiaux : Trilobites.

quent-ils et ne peuvent-ils se déplacer que par reptation, en rétrécissant et allongeant successivement leur système d'anneaux. L'ordre des fossiles suit l'ordre de la progression de la vie exposé au chapitre précédent.

Cette ćpoque primordiale a occupé, comme nous l'avons vu, bien des millions d'années. Pendant cette longue durée, les pre-

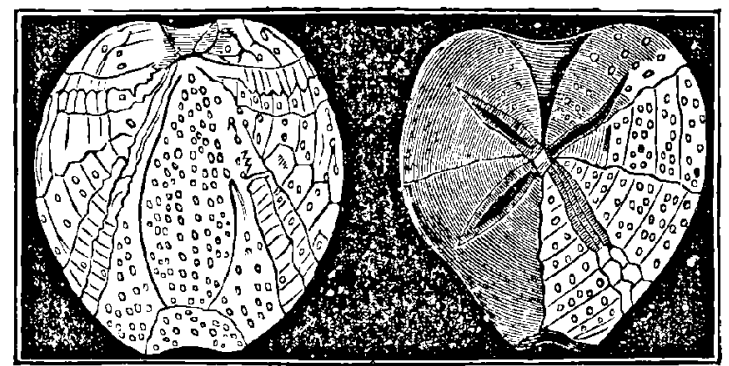

Fig. 102. - Fossiles d'échinodermes.

mières espèces animales, toutes rudimentaires qu'elles étaient, manifestent néanmoins des progrès relatifs. Certainement, il n'y a pas encore un seul animal à vertèbres, et toute la création organique est limitée à l'ordre des invertébrés, et mème parmi ceux-ci les insectes n'existent pas encore. Il n'y a done, dans toute la populition primordiale du globe, ni mammifères, ni oiseaux, ni reptiles, ni batraciens, ni poissons, ni insectes. Mais parmi les invertébrés, le progrès marche. Nous n'en sommes plus au protoplasma primitif, 
iux plaques de gélatine flottant dans les eaux, aux simples associations de cellules, aux algues ou aux annélides. Les trilobites ont déjà une tète, un corps, une queue et probablement des pattes, mais celles-ci étaient minces et faibles, car elles ne se sont pas fossilisées. Sur cette tête mème, on reconnait la trace des yeux. Ce sont là sans doute les premiers yeux qui aient existé sur notre planète, yeux rudimentaires, vagues, méritant à peine ce titre, mais enfin nerf optique et rétine. Ces arthropodes (1) primitifs, très inférieurs organiquement à nos crabes et à nos écrevisses, occupent le premier rang parmi les animaux marins de l'époque silurienne; ils multiplient à profusion leurs familles, leurs espèces, puis ils

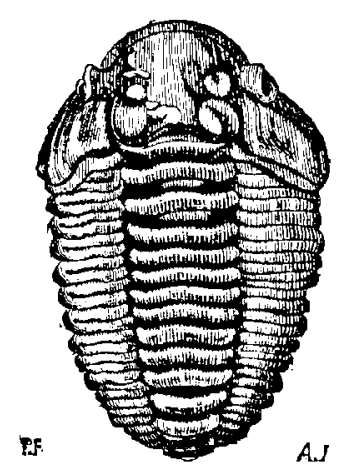

Fig. 103. - Le roi des mers primordiales: Trilobite calymène.

disparaissent brusquement à l'époque de la houille, et sont à peine représentés aujourd'hui par les limules. On a retrouvé deux autres crustacés relativement aussi élevés dans l'échelle des êtres, le pterygotus bilobus et l'eurypterus remipes; le premier est reprèsenté plus loin $(f g .104)$ à demi grandeur naturelle . ils avaient également une tête munie d'yeux et peut-être furent-ils les premiers habitants des eaux douces. Les eaux douces, issues de la pluie, commencèrent avec les montagnes, les sources et les premières rivières.

Les crustacés étaient encore représentés par d'autres espèces dans la faune silurienne. Outre toutes les variétés de trilobites, les calymènes, les dalmanites, les trinucleus, etc., etc.; outre les pterygotus et les eurypterus, on pourrait encore citer les peltocaris, les

1. Étymologie : $\alpha$ p $\theta$ por articulation et roòs pied. 
ceratiocaris, les primitia, les beyrichia, les aristozoe, les callizoe. Mais nous n'écrivons pas ici un traité de paléontologie, et nous ne devons pas oublier les grandes lignes de l'histoire de la Terre pour nous égarer dans les détails. Remarquons pourtant que les céphalopoles atteignent, surtout dans la seconde partie de la période, un développement considérable : on en compte plus de 1600 espèces, parmi lesquelles il faut citer les nautilides. Plusieurs orthocéres sont de taille géante et mesurent jusqu'à deux mètres de longueur. Les ptéropodes, les gastéropodes, les brachiopodes sont très nom-

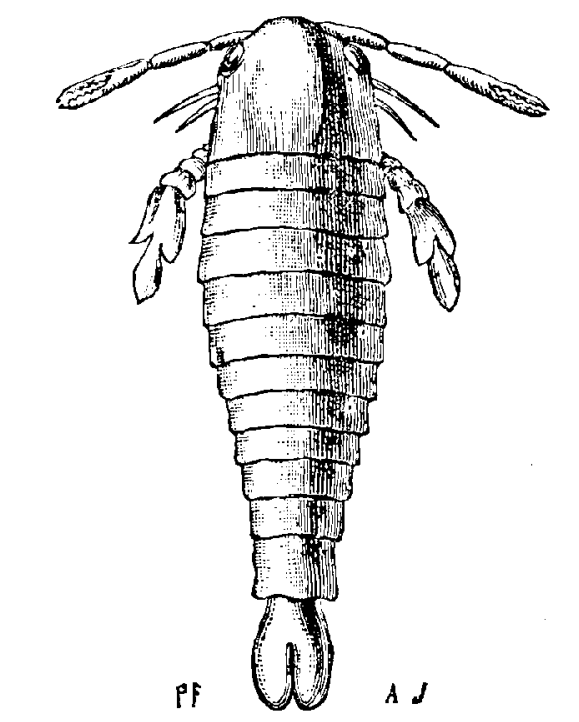

Fig 104. - I'reuiers animaux : le Perngotus bitobus

brcux, nous en reproduisons plusieurs types (fig. 106). On rencontre aussi des polypiers, des hydrocoralliaives, des éponges et des méduses. La classe des échinodermes est représentée par les crinoïdes, singuliers ètres dont la plupart sont fixés ậ sol par une tige flexible, rectiligne, composée d'un grand nombre de discues empilés les uns sur les autres et connus sous le nom d'entroques. D'abord très courtes, ces tiges ont acquis un grand développement pendant la période jurassique. Notre figure 106 en représente deux types remarquables, l'ichtyocrinus de la période silurienne, et l'apiocrinus de la période jurassique.

Les fossiles de crinoïdes forment parfois, presque à eux seuls, la masse de puissantes assises, et ils ont donné leur nom à toute 
une couche géologique, le calcaire à entroques. Ils étaient, en effet, prodigieusement nombreux dans les mers primitives : ils tapissaient leurs profondeurs de véritables prairies animées et présentaient alors une immense variété de formes souvent d'une. extrême élégance. Presque tous les crinoïdes de cette époque etaient fixés au sol : une longue tige flexible, formée d'articles nombreux (c'étaient précisément les entroques des anciens naturalistes), supportait une toulfe d'appendices écalement articulés, parfois ramigiés à l'infini et qui pouvaient s'ćtaler au-dessus de la tige comme les feuilles pennées de certains palmiers, ou se res*errer facilement les uns contre les autres, s'enroulant de mille facons, comme les pétales d'une fleur pendant son sommeil. Quelques-uns de ces crinoïdes avaient plus d'un mètre de longueur, et la tige de ccrtains Pentacrinus dépassait cinquante pieds.

L'histoire des crinoïdes commence avec l'histoire même du glole, par des formes rudimentaires dont les élements sont parents de ceux qui ont constitué les holothuries, les oursins, les encrines, les ophiures et les étoiles de mer. Certaines formes anciennes ressemblent, en effet, à des étoiles de mer dont tous les bras se seraient rclevés sur le dos et soudés par leur extrémité, ou à des oursins qui seraient fixés au sommet d'un pédoncule.

$\Lambda$ près avoir eu une époque d'extraordinaire prospérité durant la période secondaire, les crinoïdes ont rapidement décliné dans les periodes suivantes; cependant il en reste encore aujourd'hui un certain nombre d'espèces : les comatules, les pentacrinus, les bathycrinus, etc.

Tous les crinoïdes vivent à des profondeurs considérables : le pentacrinus caput meduse à $\mathbf{2 5 0}$ ou 300 brasses au-dessous du niveau de l'Océan, le rhyzocrinus lafotensis depuis 100 jusqu'à 900 , le bathycrinus gracilis à 2435 brasses ('). Dans ces régions que les mouvements des tempètes efleurent à peine, que n'atteisnent pas les variations de température extérieure, où le solcil n'envoie plus que de faibles rayons, où les organismes phosphorescents répandent sculs une lueur d'étoiles, la vie a pu échapper aut modifications profondes que lui ont incessamment imprimées

1. La longueur de la brasse est de $1^{m} 6 \cong 4$ 
les conditions si variables et si variées de la surface. Là elle a pu suivre sans secousse la lente et graduelle évolution du globe; c'est dans le fond des mers que se sont perpétués jusqu'à nous, avec leur forme initiale, les êtres pour qui la vie dans de telles conditions avait été originairement possible. La difficulté d'attcindre les habitants de ces sombres abimes les a longtemps soustraits à notre investigation, mais on sait aujourd'hui, grâce surtout aux recherches d'Agassiz et de ses élèves, qu'ils sont fort nombreux et que dans certaines régions les pentacrinus couvrent le sol sous-marin d'une végétation d'un nouveau genre ('). Ils ont peu changé depuis des millions d'années qu'ils existent, parce que les conditions de la vie en ces profondeurs océaniques ont peu varié elles-mêmes. Les organismes qui se transforment, au point de devenir aériens, d'aquatiques qu'ils étaient d'abord, sont ceux qui, voisins des rivages ou de la surface, ont été graduellement conduits à vivre dans un milieu différent du milieu primitif. Lorsqu'ils ont pu s'y acclimater, ils se sont transformés insensiblement et indéfiniment, à mesure que les conditions d'existence se sont ellesmèmes différenciées. Lorsqu'ils n'ont pt s'y. conformer, ils ont disparu.

En même temps que les échinodermes, les mollusques et les crustacés sont très nombreux à la fin de la période silurienne. On retrouve aujourd'hui une immense quantité de coquilles de cette époque. Ce sont les trilobites ét les nautiles qui dominent, avec leur lête déjà formée et bien complète. Le progrès marche d'âge en âge. Les premiers poissons apparaitront dans les earx à la fin de la période, juste à l'époque où elle fait place à la période dévonienne qui lui succède, et dans les îles déjà émergćes et déjà couvertes de végétaux, principalement de lycopodes, apparaîtront en même temps les premiers animaux à respiration terrestre, sous la forme des scorpions.

Par les soulèvements de l'écorce du globe, les terrains cambrien et silurien ont été portés à fleur dú sol sur plusieurs points de l'Europe et ont été l'objet d'importantes études. En Angleterre, l'épaisseur du cambrien dépasse 6000 mètres et celle du silurien

1. Perrier. Les Colonies animales. 
atteint 8000 . En Suède, au contraire, le silurien n'a que 600 mètres. En Bohême il s'intercalle entre des roches éruptives. Un fait bien remarquable est que les mèmes êtres vivants, aujourd'hui fossiles, ont apparu simultanément dans toutes les régions siluriennes, de sorte que l'ordre zoologique est le mème quelle que soit l'épaisseur du terrain. Les mèmes genres se rencontrent en Suéde, en Angleterre, en Bohême, aux Etats-Unis, au cap de Bonne-Espérance et jusqu'au détroit de Barrow et à l'ile Melville, sous le $76^{\circ}$ degré de latitude nord; plusieurs espèces, telles que le graptolite murchisonü, le calymène mocropthalum sont communs à des localités séparées par tout le diamètre terrestre ( ${ }^{(1)}$. Il y avait partout la mème température.

Le terrain silurien est rarement horizontal. Il a subi tous les
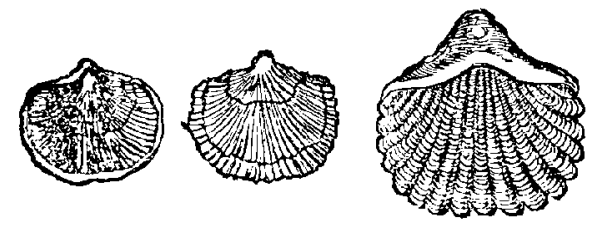

Orhis olegantula.

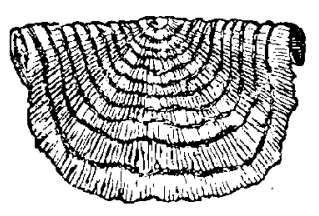

Stropoomens.

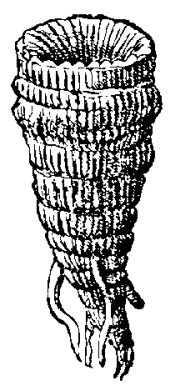

Omplygas

PLg. 103. - Les premiers animaux. Coquiles fossiles de hrachiopodes de lá póriode silurienne.

effets des soulèvements et affaissements de l'écorce du globe arrivés depuis ces temps primitifs; on l'a mème retrouvé avec ses fossiles jusqu'a 5000 mètres de hauteur dans les Andes de l'Amérique. Durant cette longue époque primordiale, les mers s'étendaient encore sur le globe presque tout entier. A peine quelques iles étaientelles émergées. Ainsi, l'Europe presque entière était encore sous les eaux, depuis l'Espagne jusqu'aux monts Ourals. Il eut été difficile de deviner alors quelle serait un jour la configuration géographique de la Frauce. Une partie de la Bretagne était soulevée, ainsi que l'Auvergne, les Alpes, le Jura et quelques îlots dans les Pyrénées; mais les régions où Paris, Rouen, le Havre, Orléans, Tours, Bordeaux, Avignon, Marseille, Nice, Turin, Genève, Belfort, Dijon,

1. Contejean. Élèments de géologie de paléontologie. 


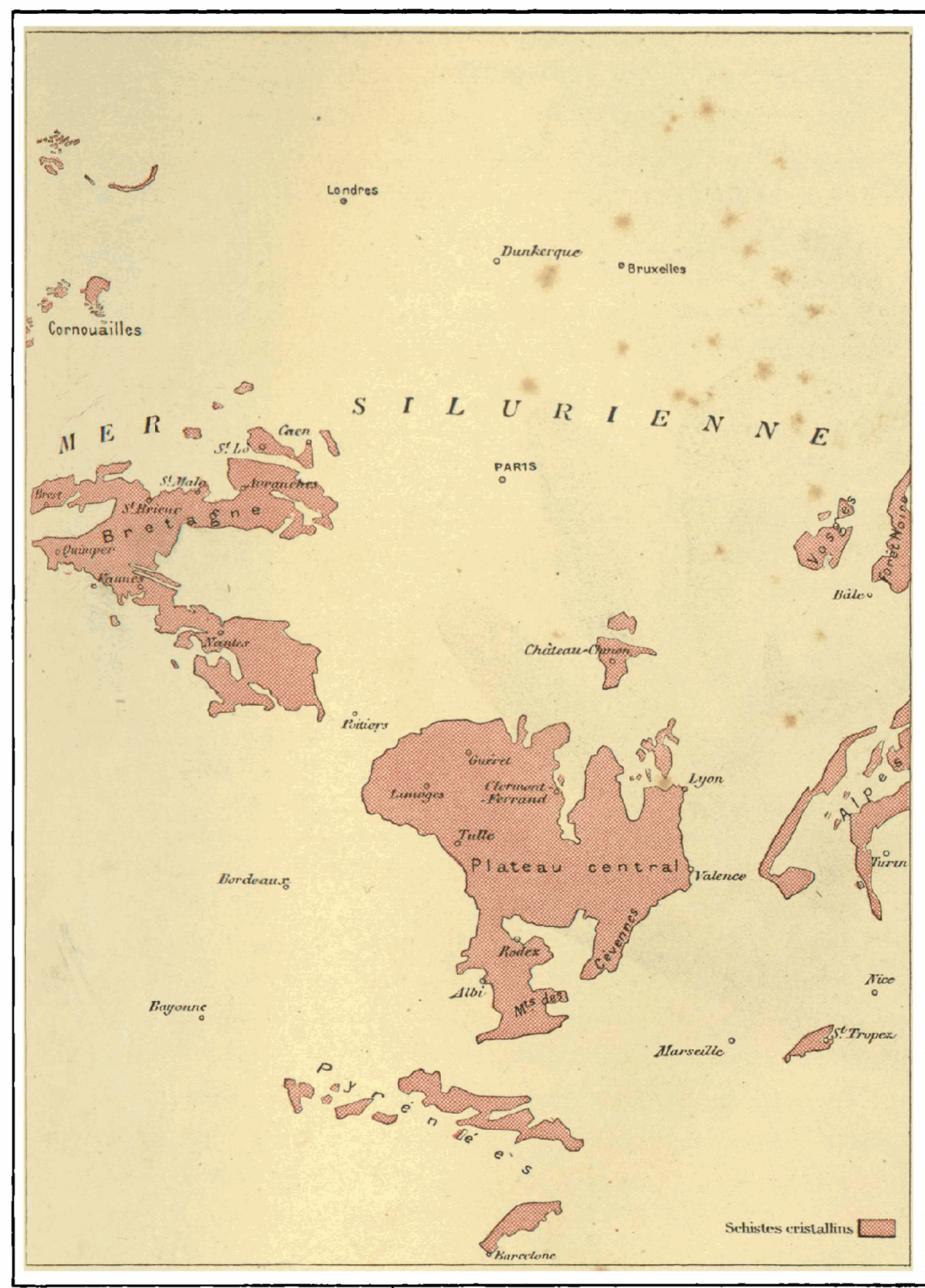

Orwe par killoreeu, K. Vaven 45, Paris

FORMATION GRADUELLE DES TERRAINIS

FRA NG:E

Terrains primitifs 
IRIS - LILLIAD - Université Lille 1 
Troyes, Amiens, Lille, Bruxelles devaient s'élever plus tard comme foyers divers de l'activité humaine, étaient alors immergées sous les flots de la mer silurienne. Brest, St-Brieuc, St-Malo, Quimper, Vannes, Nantes, Limoges, Clermont, 'Tulle, Rodez, Le Puy, Autun

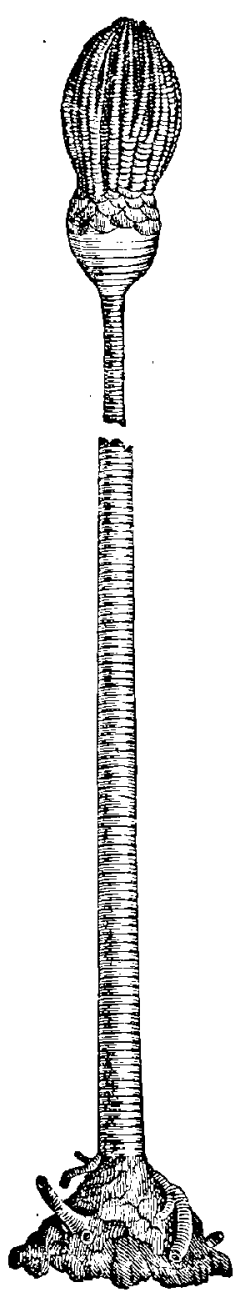
étaient déjà sorties des eaux. Notre carte I montre ce qu'était la France à l'époque de la mer silurienne, et notre carte II montre l'Europe à la même époque. L'Islande, formée des terrains éruptifs de l'époque primordiale, la Laponie, la Finlande, une partie de la Suède et de la Norvège, une partie de l'Écosse et de l'Irlande, de l'Espagne, de la Suisse, de la Corșe, de la Sardaigne, de la Bohême, de la Turquie planaient au-dessus des solitudes de la mer ; mais, comme Paris, Londres, Madrid, Lisbonne, Rome, Vienne, Prague, Berlin, St-Pétersbonrg, Constantinople, dormaient au fond de l'Océan, et au-dessus d'eux s'agitaient au sein des ondes nos ancetres végétaux et animaux de

$a$

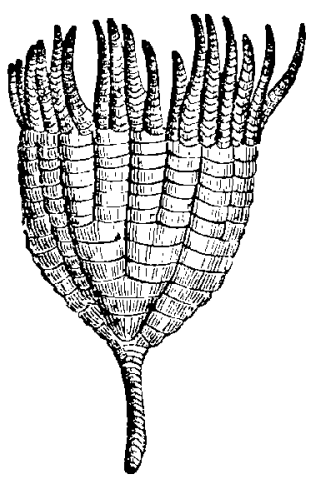

b

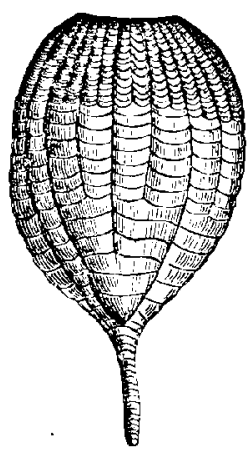

Fig. 106. - Les premiers animaux - Échinodermes : crinoïdes.

1. Apiocrinus Royssjanus. - z. Ichthyocrinus laris : a las bras onverts, $b$ les bras fermés.

l'époque silurienne, qui préparaient par leurs labeurs séculaires l'œuvre féconde de la vie future.

Ce grand spectacle est éloquent pour celui qui sait le comprendre. Il nous montre dès le premier coup d'aeil les âges relatifs des 
montagnes. Les Alpes sont plus anciennes que les Pyrénées. A l'époque où le granite du Mont-Blanc, du St-Gothard, de la Yungiruu élevait déjà sa tête au-dessus des nues, les Pyrénées dormaient encore au fond des eaux; elles sont filles de l'époque secondaire et postérieures de plusieurs millions d'années à l'exhaussement des Alpes. A cette époque lointaine, quelques massifs seulement s'élevaient comme de petites îles, surtout vers la base méditerranéenne des Pyrénées; mais les eaux circulaientlibrement dans cet archipel et la configuration géographique de l'Espagne n'était pas mieux dessinée que celle de la France. La Méditerranée n'existait pas davantage, pas plus que la mer Noire, la Caspienne, la Baltique ou la Manche: un seul océan s'étendait sur le globe. Les Alpes dominaient déjà l'Europe, et sans doute même étaient-elles beaucoup plus élevées qu'aujourd'hui, car elles paraissent être redescendues et avoir subi plusieurs alternatives d'exhaussement et d'affaissement.

Dans ces mers régnaient les phalanges, les légions de trilobites. Armé de son bouclier aux trois lobes, ce petit crustacé fut le premier qui osa se mouvoir librement, visiter des lieux différents, chercher de nouveaux rivages à travers l'univers inconnu.

Il fut aussi le premier des êtres qui eût des yeux capables do voir. Avant lui, tout être naissait aveugle, restait aveugle, comme si la nature encore informe n'eùt voulu se donner en spectacle à aucun être vivant. Qu'était-ce, en effet, que ces taches colorées, ces points souvent imperceptibles qui tenaient la place des yeux dans le groupe naissant des zoophytes et des annélides? Ne dirait-on pas qu'à de pareils témoins la nature a voulu rester encore cachée? Tout ce qu'ils peuvent faire est de discerner la lumière des ténèbres, le jour de la nuit. C'est pour eux le comble de l'existence et de la connaissance. Ces premiers êtres organisés palpent le point qu'ils occupent; ils ne le voient pas.

Enfin vient le trilobite; il a un véritable organe de vision, autrement qu'à l'état rudimentaire. Et ce premier œil, informe, réticulé, à la surface bosselée, que vit-il en s'ouvrant dans l'abime? Des mollusques flottants de petite taille, point de poissons encore, ni de reptiles, ni de vertébrés d'aucun genre, mais de nombreux zoophytes, coraux, crinoïdes, lingules, étoiles de mer, parmi lesquels 
il cherchait sa nourriture. Pour échapper à ses ennemis (car il en avait déjà), il so roulait en boule et se laissait emporter par l'Océan aveugle. On a compté jusqu'à vingt métamorphoses successives de ce premier des crustacés à travers les formes diverses de son cxistence.

Il vivra assez pour rencontrer à la fin, le regard fixe, l'ceil déja presque achevé des grands mollusques céphalopodes; tout l'organe de la vision a été développé, perfectionné sans relâche, d'époque en époque, depuis le point coloré des zoanthaires jusqu'aux deux gros youx des ammonites et des bélemnites, qui se rapprochent de ceux des vertébrés. Déjà dans chaque coin de l'abîme, il y a un œil ouvert, au fond des mers primordiales. Il regarde, il voit. La nature vivante a cessé d'être aveugle.

Le trilobite, ancêtre des crustacés, fut aussi l'un des premicrs êtres qui disparut du monde naissant, au sein de l'univers qui s'entr'ouvre, il annonce, il publie que tout sera changement,. instabilité; que les formes des organisations passeront, comme la figure da monde; que la durce n'appartient à aucun être. Son bouclier aux trois lobes ne l'a pas défendu contre les atteintes du temps; ainsi, non seulement les individus meurent, mais aussi les espèces et méme les genres.

A l'extrémité la plus reculée de l'horizon des âges, cette mer silurienne a déjà ses révolutions. Elles sont cachées dans les gouffres ou la vic sous-marine se développe loin de la lumière libre du jour. Point de continent encore, peut-être déjà quelques deltas ou des plages, ou des îlots nus, rasant au milieu d'une eau profonde; ces points battus des flots marquaient la place-future de l'Angleterre, de la Russie, de la Bohême, du Canada.

Nulle créature ne s'est encore aventurée hors des mers tièdes; cà et là, des tẹmpîtes jettent súr la rive une algue déracince, un coquillage bivalve, que le flot reprend et rend à l'Océan. Nìl ètre ne s'est essayé à vivre sur la terre qui manque presque partout; nul témoin n'a encore levé la tète au-dessus de la mer et osé regarder en facc l'univers; tout être vivant reste plongé et perdu dans l'abime. Les eaux seules sont habitées.

Cette contemplation du passé nous fait revivre au milieu des âges disparus. Comment tenir sans émotion ces fossiles dans nos 
mains, sans songer qu'ils ont été les premiers êtres vivants de notre planète, sans essayer de revivre en ces siècles antiques? Les hommes qui nous ont précédés n'avaient sous leurs yeux que l'univers actuel. Ils ne connaissaient que les étres organisés qui sont leurs contemporains, et ils ne devinaient pas qu'il ait pu jamais en exister d'autres. Leur horizon était renfermé dans le moment de la nature présente. L'idée ne leur venait pas qu'il y eût une éternité visible, pétrifiée derrière eux. Leurs sentiments, leurs jugements, leurs systèmes étaient jetés đans le moule du monde qu'éclaire le soleil d'aujourd'hui. Ou si, par hasard, ils soupçonnaient que d'autres formes eussent jamais passé sur la terre, c'étaient pour eux des chimères, des hydres, des centaures auxquels ils n'attribuaient que la réalité douteuse que l'imagination prète à ses monstres. L'astronomie nous a révélé l'espace; la géologie nous révèle le temps.

Voici maintenant qu'au milieu de la surprise de tous, le monde présent, contemporain, n'est plus le senl que nous puissions voir de nos yeux et toucher de nos mains. Un autre univers vient de nous être révélé qui nous est donné par surcroit. Un passé incommensurable s'ouvre devant nous, peuplé d'habitants dont nous n'avions aucune idée. Les visions des poètes primitifs et des prophètes, gorgones, dragons, sphinx sont surpassées par la réalité! Elles prennent un corps et s'appellent ptérodactyles, plésiosaures, dinothériums, etc.

«Il n'est pas possible, remarque ici avec éloquence Edgard Quinet, il n'est pas possible qu'un tel changement, non seulement dans la conception, mais dans la possession du monde matériel, un si immense domaine ajouté soudainement au domaine de l'homme, une si prodigieuse richesse ajoutée à sa richesse, la borne de son champ d'héritage déplacée, reculée toùt à coup à l'infini, et, pour tout dire, le don gratuit d'une nature toute neuve conservée dans la mort, n'influent sur sa manière de concevoir et la vie et là mort, et le présent et l'avenir, et, sa place à lui-mème à la tête des êtres organisés.

"A l'époque secondaire, si les reptiles avaient parlé, ils auraient dit : Nous sommes les rois du monde. Nul etre ne s'élève au-dessus de nous, nul autre que nous ne sait ramper. En vain une plèbe 


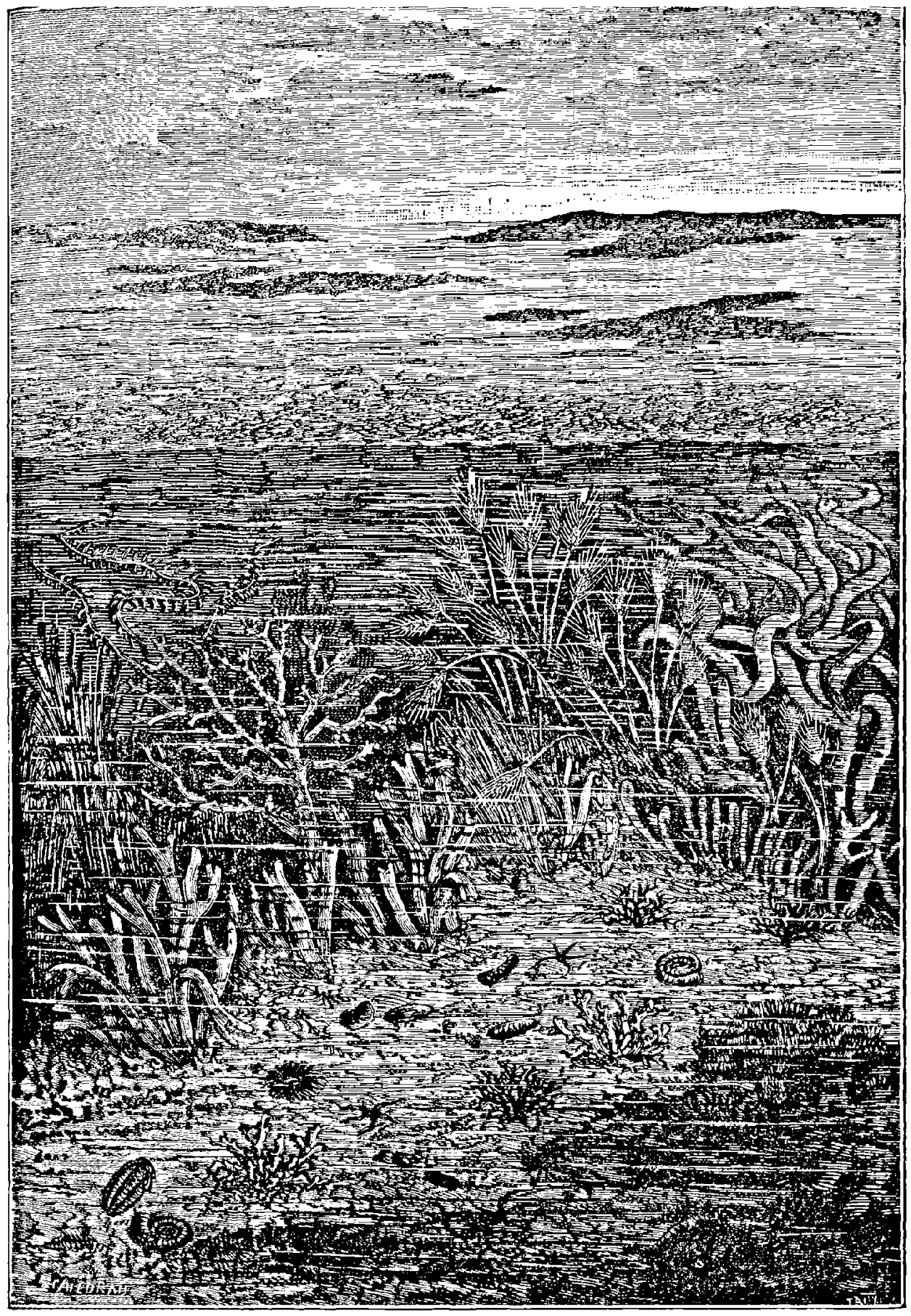

LES PREMLRS JOURS DE L'EPOQUE SILURIENTE : LES EAUX SECLES SONT HABITÉES

LE MONDE AYANT LA CREATION DE L'HUMME

31 
infinie de créntures inférieures, rayonnés, mollusques, poissons s'épuisent à monter jusqu'aux reptiles. Le reptile est la créature préférée, la forme suprème, divine; le monde s'arrête à lui. Que sont toutes les organisations inférieures primaires, au prix de la sienne. En lui s'achève et se couronne le monde.

« Dans l'époque tertiaire, si les grands mammifères avaient parlé, ils auraient dit : L'Univers a fait un pas, nous en sommes le faite. Comment les reptiles ont-ils pu croire un instant que le monde s'arrèterait à cux ? Ils sont bons pour marcher sur le ventre; mais nous avons relevé la tête. Nous' sommes les dominateurs légitimes; qui pourrait comprendre qu'une organisation apparaisse supérieure à la nôtre? C'est vers nous que gravitaient aveuğlément toutes ces vies ébauchées qui s'essayaient à vivre. Mais nous avons touché le but sins craindre qu'aucun être nous dépossède jamais, nous pouvons de siècle en siècle tranquillement brouter la terre ou nous dévorer les uns les autres.

"Vient cnfin la période quaternaire; l'homme parait, il dità son tour : Tout le monde s'est trompé ici-bas, excepté moi. Les reptiles ont cru au règne divin des reptiles; les mammifères à celui des mammifères. Erreur, extravagance de la plèbe de la création. Il n'y a de roi légitime que moi. C'est pour me fuire place que tous ces monarques d'un jour sont tombés, depuis les trilobites cuirassés, depuis les royales ammonites jusqu'aux grands vcrtébrés. Moi seul, je suis le dominateur suprème en qui s'achève toute vie; ou plulôt il n'y a aucun lien entre les vies antérieures et la mienne. L'Univers est fini, les temps sont consommés. Dieu s'est épuisé en moi : je suis le dernier fils de sa vieillesse.

a Ce point de vue scra chaque jour plus difficile à soutenir; tant de dynasties organiques qui ont passé pourraient bien finir par persuader l'homme qu'il est lui-mème un monarque éphémère, et que le moment viendra où il sera détrôné.

« Lorsque je vois cette lente progression, depuis le trilobite, premier témoin effaré du monde naissant jusqu’à la race humaine, et tous les degrés vivants de l'universelle vie s'ítager l'un sur l'autre, tous ces yeux ouverts, ces pupilles d'un pied de diamètre qui cherchent la lumière, toutes ces formes qui se haussent l'une sur l'autre, tous ces êtres qui rampent, nagent, marchent, courent, 
londissent, volent au-devant de l'esprit, comment puis-je croire que cette ascension soit arrêtée à moi, que ce travail infini ne s'étende pas au delà de l'horizon que j'embrasse?

"Quand je refais, en idee, ce voyage infini de gradins en gradins, dans le puits de l'Éternel, je ne peux me contenter de ce que je suis. Moi aussi jo demande des ailes. Je conçois des séries futures et inconnues de formes et d'êtres qui me dépasseront en force et en lumière, autant que je dépasse le premier né des anciens océans.

"Alors, jo m'explique ce prodige d'orgueil et d'humilité qui est tout l'homme. Orgueil en face des ètres antérieurs qui gravitent ohscurément vers lui; humilité en face des ètres supérieurs dont il porte en lui la substance, et dont il sent intérieurement le battement d'ailes ('),, .

Lentement, progressivement, l'arbre de la vie grandit et se dévcluppe. On observe un parallélisme évident entre l'évolution du règne végétal et celle du règne animal. Les plus anciennes plantes connues sont les algues marines élémentaires, de mème que les plus anciens animaux sont des organismes marins. Il est bien remarquable que le régne végètal ait suivi dans son développement, comme le règne animal, précisément l'ordre indiqué par la physiologie : c'est là un fait capital et irréfragable, contre lequel aucun argument théorique ne saurait prévaloir. Si les fossiles conservés dans les terrains laurentien, cambrien et silurien nous montraient des végétaux supérieurs, des arbres, des fleurs ou des fruits analogues aux plantes actuelles, il serait permis de contester les principes exposés depuis la première page de ce livre. Mais, comme le règne animal, le règne végétal a suivi ponctuellement la progression lente que nos lecteurs ont été appelés à apprécier dans les études qui précẻdent. Les végétaux les plus simples, les cryptogames, sont les plus anciens, et ce sont les seuls que l'on rencontre dans les couches géologiques de l'époque primordiale; les plantes plus perfectionnées, les phanérogames, ne sont arrivées sur la scène du monde que beaucoup plus tard. Les cryptogames

1. Edgard Quinet : La Création. 
sont dans l'histoire de la planète comme dans la physiologie végétale, la souche et le point de départ de tous les végétanx.

Nous rencontrons à l'origine de toutes les plantes une substance protoplasmique encore amorphe, mais possédant les attributs essintiels de la vie. C'est la mème substance qui a formé les premiers animaux, et dans le végétal le plus perfectionné, le plus éloigné du point de départ, le souvenir de cet état primitif est conservé. A l'intérieur des cellules végétales, le protoplasma, véritable amilie (roy. p. 141), se contracte et respire ḋ la manière animale. Les

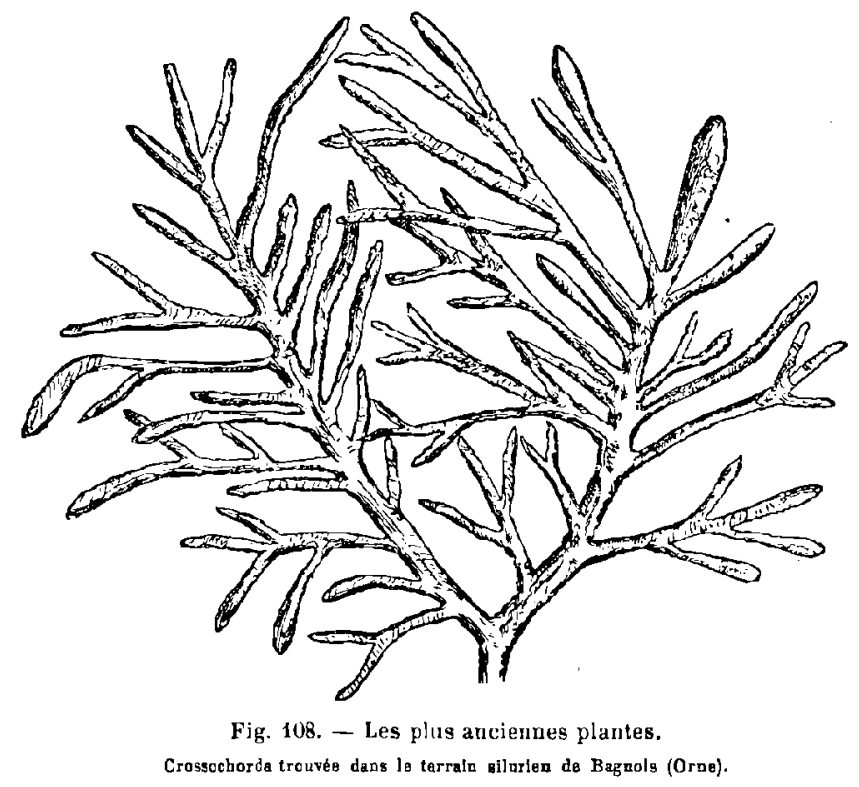

plantes carnirores, les plantes qui mangent des insectes s'en ressouviennent au point d'être presque animées; les sensitives subissent l'influence des anesthésiques. Les premières plantes, les algues unicellulaires, les champignons, qui déjả sont leurs parasites, les lichens, qui résultent de l'union des champignons ascomycètss avec les algues inférieures, rie sont que des agglomérations de cellules protoplasmiques.

C'est avec raison qu'on a donné le nom d'âge des algues i l'èpoque primordiale, car elles n'ont pas tardé à se répandre dans les mers primitives, et ce sont aussi les premières plantes qui, se trouvant sur les rivages, se sont légèrement modifiées pour pouvoir virre sans beaucoup d'eau, ou mème seulement dans un air imprégús 
d'humidité. Celles qui sont restées au fond des eaux, dans des conditions presque invariables, n'ont pas eu à se transformer, et telles elles existaient il y a des millions d'années, telles nous les retrouvons aujourd'hui. Ces protophytes (premières plantes) offrent toutefois, dès la fin de l'époque silurienne, une grande variété de formes et de dimensions. Aux espèces signalées plus haut, aux bilobites ct aux algues primordiales on peut adjoindre les crossochorda (fg. 108), trouvées dans le silurien inférieur de Bagnols (Orne) et de l'Écosse, qui ne sont guère aussi que des cylindres, des

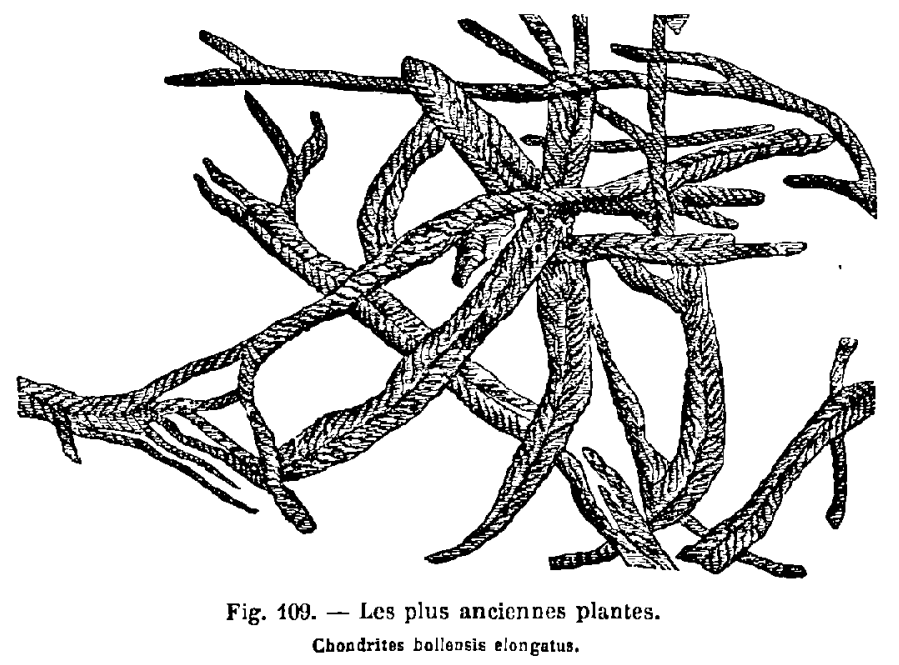

tubes entrelacés comme les algues actuelles de la mer de Sargasses; les arthrophycus que l'on a trouvées à tous les étages du silurien, et qui se composent de tubes divergeant d'un pied do souche, les eophytons qui ressemblent aux bilobites, les siphonées, et surtout le groupe important des chondrites, qui, commençant à l'époque silurienne, ont disparu vers le milieu de l'époque tertiaire : ce sont des ramifications de cylindres (fig. 109). Les algues supérieures (characées, phéosporées, fucoïdées et floridées) ne sont venues que longtemps après les premières. N'écrivant pas ici un traitẻ de botanique, nous ne nous égarerons pas dans les details; mais il importait d'esquisser complètement l'ensemble du tableau. Le point capital était de savoir que la vie végétale a commencé comme la vie animale, par les organismos maritimes les plus élémentaires. La végétation aérienne procède tout entière des protophytes 
aquatiques. Diverses algues ont abandonné les eaux pour prendre possession du sol émergé, s'établissant d'abord dans les stations humides et souvent inondèes, se dispersant ensuite de proche en proche en soumettant l'agrégat cellulaire primordial à des influences modificatrices diverses. Sous l'influence du noureau milieu, les tissus cellulaires, primitivement homogènes, donnèrent naissance à des téguments nouveaux. Les fonctions d'alsorption ou de nutrition gazeuse prenant une énergie toujours plus grande, des régions spéciales se façonnèrent spécialement dans ce but. D'une part, les mousses, les épatiques, prirent naissance, d'autre part, les fougères, les ophioglossćes, les équisétacées, calamites, etc. Les premières plantes ont été les cryptogames : les phanérogames et tout l'admirable règne végétal actuel en sont la descendance ( $\left.{ }^{\mathbf{1}}\right)$.

Les premiers végétaux terrestres, de mème que les premiers animaux à respiration aérienne, n'arrivent qu'à la fin de la période silurienne. Dans les ardoises d'Angers, le professeur Morière, de Caen, a trouvé une très belle empreinte de fougère, que l'on a nommée Eopteris Morieri, et que nous reproduisons ici $(f g .110)$ d'après M. de Saporta. On a retrouvé aussi, dans le silurien de Cincinnati, des sigillaires, des lycopodes et des calamites. Ce sont là les plus ancienries plantes terrestres connues : elles remontent ì la période silurienne. L'organisation déjả complexe du règne végétal, lors de son début apparent à la surface du sol, fait présumer l'existence d'une période, demeurće inconnue, de végétaux terrestres beaucoup plus simples que les fougères, les calamariées et les sigillaires. Lorsque les pluies étaient pour ainsi dire perpétuelles à la surface, lorsque la chaleur encore sensible des eaux provoquait une évaporation incessante, des végétaux d'une structure élémentaire ont dù couvrir le sol. Ces plantes primitives vivaient sans doute à la façon des algues que la marée ne délaisse que pour les recouvrir de nouveau; comme celles-ci, elles demeuraient plongées dans un bain à peine interrompu. C'est à la suite d'une longue série de siècles qu'elles ont dû revêtir les formes que róvèlent les plus anciennes empreintes. Durant le temps où se développèrent les schistes, les

1. Marion et Saporta, L'Évaluation du régne végétal. Les cryptogames. 
quartzites et les calcaires des systemes laurentien, cambrien et silurien, l'air a dù s'épurer, les pluies cesser à la fin d'être continues pour devenir intermiltentes, et l'atmosphère, tout en demeurant chaude et brumeuse, se constituer une seconde mer suspendue au-dessus de l'Océan. Alors aussi la végétation terrestre a dú élaborer des formes et des organes appropriés à des circonstances nouvelles. Pour la première fois, les végétaux ont présenté des feuilles, émis des racines, diversifié la structure de leurs tissus et acquis la beauté qui résulte d'une symétrie de plus en plus rigoureuse des parties aussi bien que la force qui nait de l'énerrie croissante des fonctions vitales.

"L'eau constitue un milieu auquel la plupart des organismes inférieurs se trouvent nécessairement adaptés. Des classes entières d'animaux et de plantes, comme les algues, les zoophytes, la majorité des mollusques et tous les poissons vivent confinés dans cet élément, qu'ils ne pcuvent quilter sans périr. Non seulement l'eau sert de véhicule aux gaz respirés par ces ètres, mais elle baigne ces derniers et les pénètre; le système aquifère des moll usques comprend mème tout un ensemble d'ouvertures et de canaux. C'est là, il faut bien le dire, un des caractères les mieux prononcés d'infériorité relative. Prenons les algues aussi bien que les animaux mous, nous verrons qu'à peine retirés đe l'eau, ces organismes se dessèchent et perdent par l'évaporation le liquide qui maintient en cux la circulation et la vie. Ces êtres purement aquatiques meurent promptement une fois retirés de l'eau; mais on conçoit qu'une atmusphòce très humide soit presque l'équivalent d'un milieu liquide. C'est ainsi que les cloportes, quoique respirant par des branchics comme les autres crustacés, vivent à l'air sous les pierres et dans l'hcrbe mouilléc. Les lichens et les mousses, bien que terrestres, ne végètent que sous l'influence de l'eau. Inertes tant que l'air reste sec, ces plantes suspendent pour ainsi dire le cours de leur existence; leur vie s'arrête pour reprendre sa marche dès que l'humidité leur rend la souplesse et la virgueur. La lenteur de la vérétation des lichens, dont la plaque ne s'aceroît que par la périphèrie, est vraiment incroyable. Un siècle entier amène chez eux peu de changement, et tel lirhen, que nous regardons avec dédain, remonte, par son âgre, au delà des temps historiques. 
" L'air humide a été sans doute la voie par laquelle la vie a retiré autrefois ses productions du sein de l'eau pour les établir à la surface du sol. Les fougères, qui sont les plus anciennes plantes terrestres dont on ait connaissance, ne prospèrent jamais autant que dans une atmosphère brumeuse. D'autre part, la différence entre le milieu aquatique et le milieu atmosphérique a dù originairement se réduire à presque rien. L'air obcurci de vapeurs, se: résolvant en pluies continuelles, offrait aux plantes et aux animaux des conditions d'existence sensiblement analogues à celles qu'ils

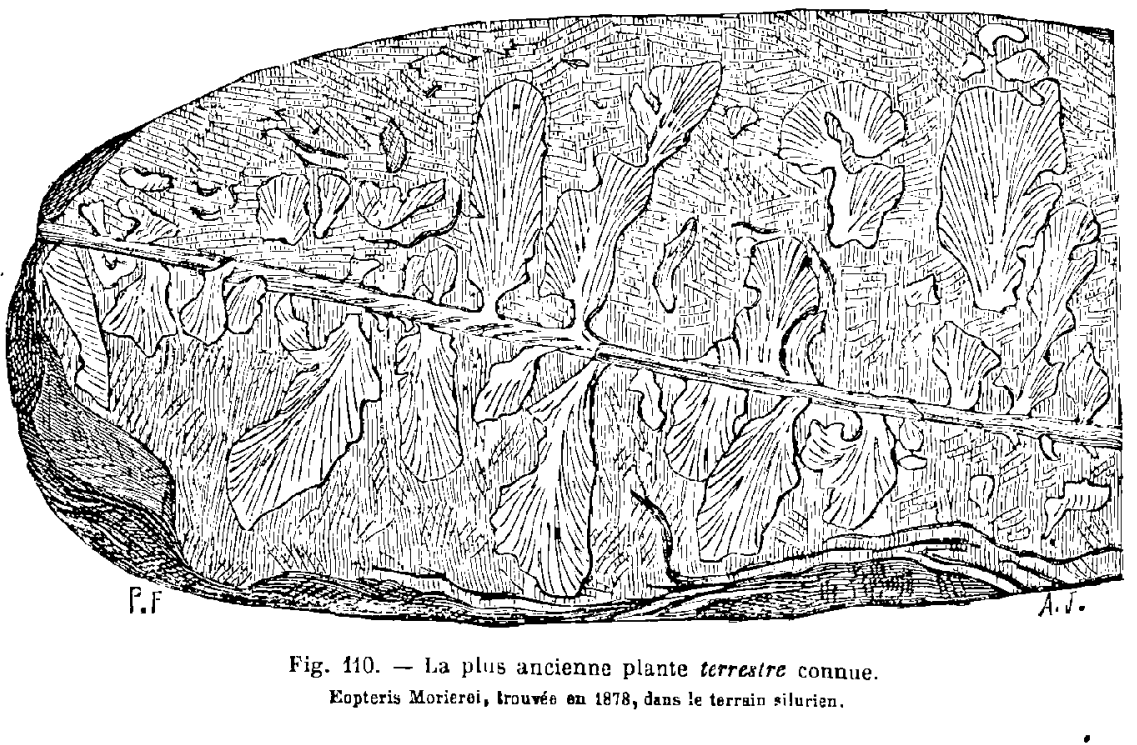

rencontrent au milieu mème des flots. Le mollusque pulmoné, celui chez lequel les branchies se trouvent remplacées par des poches à air et qui respire hors de l'eau, n'est parvenu à ramper à terre qu'ả force de précautions. Animal à la peau molle et nue, il ne saurait cheminer sur le sol sans perdre les mucosités qui suintent de son corps et servent à faciliter sa rnarche. Aussi, pour ne pas s'épuiser promptement, il habite des retraites obscures et humides d'où il ne sor't que la nuit ou par les jours de pluic, et pour ceux qui possédent une coquille le danger de s'exposer à l'air est si pressant qu'ils ne manquent pas de se clore hermétiquement, soit en secrétant une humeur visqueuse, soit en usant d'un opercule. Retirés au fond d'une retraite etroite, mais sùre, les mollusques à coquilles 
attendent parfois durant des mois et des saisons les occasions favorables; ils demeurent inertes tant que l'humidité ne les tire pas de leur torpeur; on a même pu voir quelquefois avec étonnement les animaux de certaines collections de coquilles, étiquetés et classés depuis des années, sortir de leur repos sous l'influence d'un bain et reprendre inopinément le mouvement et la vie. D'abord aquati-

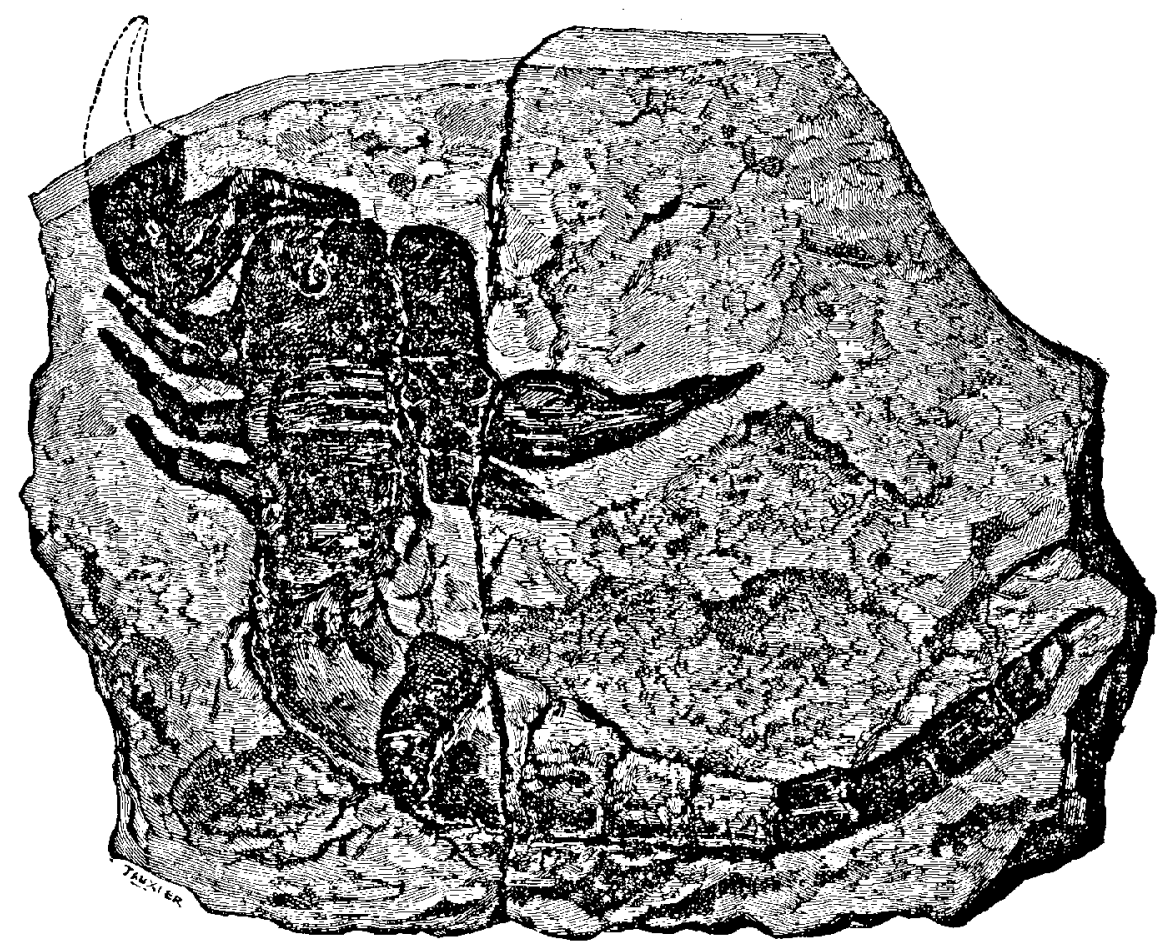

Fig. 111. - Le plus ancien animal terrestre connu. - Scorpion fossile trouvé en 1884 dans le terrain silurien.

ques, les animaux et les plantes, n'ont pu s'établir à l'air qu'à l'ide de moyens détournés, de ce qu'on pourrait nommer des subterfuges, c'est-à-dire en recherchant l'eau en dehors des lieux où cet élément se rassemble en masse. Pour former des ètres définitirement aériens et terrestres, la vie a concu des plans plus complexes et d'una exécution plus longue. Elle y est arrivée principalement par la respiration pulmonaire chez les animaux vertúbrés, et chez les plantes par le jeu combiné d'un ensemble d'organes qui sont inconnus ou rudimentaires dans les végétaux inférieurs, tels 
que les racines chargées de puiser les matériaux de la sève et les feuilles remplissant le rôle de branchies aériennes ('). D

Il y a quelques années, on doutait encore de l'existence d'animaux à respiration aérienne à la fin de la période silurienne. Tout récemment, en 1884, un naturaliste suédois, M. Lindstrom, de Stockholm, a trouvé un scorpion fossile dans le terrain silurien supérieur de l'île de Gotland (Suède). C'est le plus ancien animal terrestre qui ait encore étẻ découvert. (Les libcllules qui jusqu'ici remontaient à la plus haute antiquité avaient été trouvées dans le ter. rain dévonien du Canada.) Nous en reproduisons ici la photographie fidèle. Il diffère des scorpions actuels en ce que les quatre paires de pattes thoraciques, qui sont grosses et pointues, ressemblent aux pattes des embryons de plusieurs autres trachéates. Cette forme de pattes n'existe plus chez les scorpions fossiles de l'époque carbonilère, chez lesquels ces appendices ressemblent à ceux des scorpions de nos jours. La queue est pointue. En même temps, un autre naturaliste, M. Hunter, reconnaissait la véritable nature d'un autre scorpion trouvé par lui, en 1883, dans la couche silurienne supérieure de l'Écosse. Il est remarquable que ces deux spécimens d'animaux qui ne vivent aujourd'hui que dans les pays chauds ont été trouvés sous les latitudes boréales de la Suède et de l'Écosse. Les clirnats n'existaient pas encore.

Les scorpions sont des invertébrés appartenant à l'embranchement des annelés et à la classe des arachnides, qui succèdent à la classe des crustacés dans la classification du règne animal (voy. p. 87). C'est le signal de l'apparition des animaux terrestres. En même temps, dans les eaux encore tièdes, vont apparaitre les premiers vertébrés, les poissons. La nature continue graduellement son œuvre.

Quelle affirmation plus nette, plus magnifique, de la loi du progrès pourrions-nous demander à la nature. Par toutes ses voix elle nous donne, en tout et partout, le même enseignement. « Appliqué à la nature vivante, dirons-nous avec M. de Saporta, le progrès est simplement une marche quj s'opère dans une direction déterminèe, suivant le sens du mot latin progredi,

1. De. Saporta. Le Monde des Plantes avant l'apparition de l'homme. 
s'avancer. L'organisme s'avance : en s'avançant il se modifie et se complique plus ou moins; de là le perfectionnement qui n'est que le progrès relatif et comparé. Le perfectionnement absolu est le résultat possible mais non pas nécessaire de cette manière de procéder. Le progrès demeure ainsi un phénomène essentiellement relatif pour chaque être et pour chaque série d'êtres en particulier, puisque le mode de progression n'étant pas le même pour tous, est loin de produire pour tous les mêmes effots. Mais si l'on considère l'ensemble des ètres, le progrès en ressort comme étant la base mème et l'essence du plan général des choses créées; c'est le ciment qui relie toutes les parties de l'édifice et sans lcquel il s'écroulerait aussitôt pour s'en aller en poussière. Partir de l'algue et du mollusque inférieur ou mérne de plus bas encore pour aboutir à l'homme et à l'homme intelligent, moral et religieux, n'est-ce pas constater le plus magnifique et le plus incontestable enchainement de progrès. L'être unicellulaire, incrte à force de simplicité organique, se montre au seuil de la création tont entière; puis à mesure que les siècles se déroulent par myriades, à travers d'innombrables vicissitudes, les êtres se mu'. tiplient, se compliquent, se spécialisent, se ramifient; ils acquièrent peu à peu la force, la souplesse, la diversité; ils s'écartent toujours davantage les uns des autres; leurs opérations se compliquent de même que leurs organes; leurs facultés se localisent; leurs instincts se prononcent; l'intelligence parait la dernière, comme un soleil d'abord faible qui se lèverait à l'horizon et dissiperait enfin les nnages. Quel spectacle que l'exécution de ce plan qui se poursuit inexorablement, comme un drame éternel marchant d'acte en acte, de scène en scène, pour aboutir à un inévitable denouement, celui où nous devenons acteurs nous-mêmes, en pleine possession de nos destinées et conscients du rôle qui nous a été dévolu. Tout cela paraît grand, simple, facile à exposer, et cependant rien n'a été plus complexe, plus entremèlé de détours et d'irrégularités. »

On nous accuse de manquer d'orgueil, de fierté, de dignité, en interprétant humblement ces grandes leçons de la nature, en admettant que tout marche et s'élève vers une destinée lumineuse, que les êtres vivants, comme les arbres et les fleurs, sont partis 
de très bas pour s'élever très haut. Quelle accusation irréfléchie! N'y a-t-il pas plus de mérite à monter qu'à descendre? L'homme n'est-il pas plus noble, plus grand, plus admirable d'avoir su se dégager de la chrysalide animale et ouvrir ses ailes en plein ciel, que si vraiment il était tombé d'un état de perfection archangélique dont une impardonnable sottise l'aurait fait choir à jamais? Entre l'enseignement unanime de la nature, la logique et le bon sens d'une part, et la négation de la science, la fable et l'imagination d'autre part, est-il encore permis d'hésiter? Nos. 


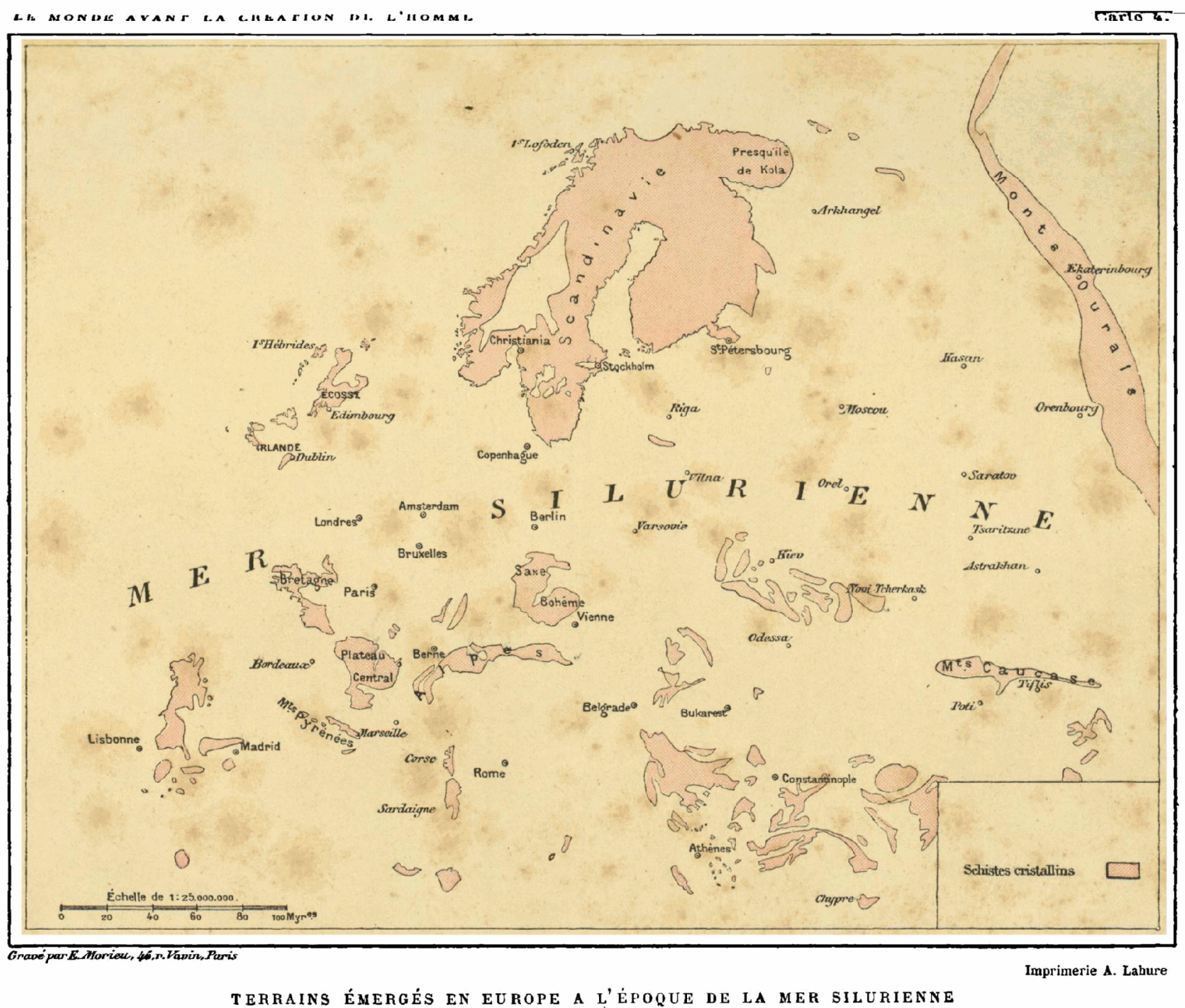


IRIS - LILLIAD - Université Lille 1 


\section{LIVRE II]}

LAGE PRIMAIRE

IRIS - LILLIAD - Université Lille 1 
IRIS - LILLIAD - Université Lille 1 


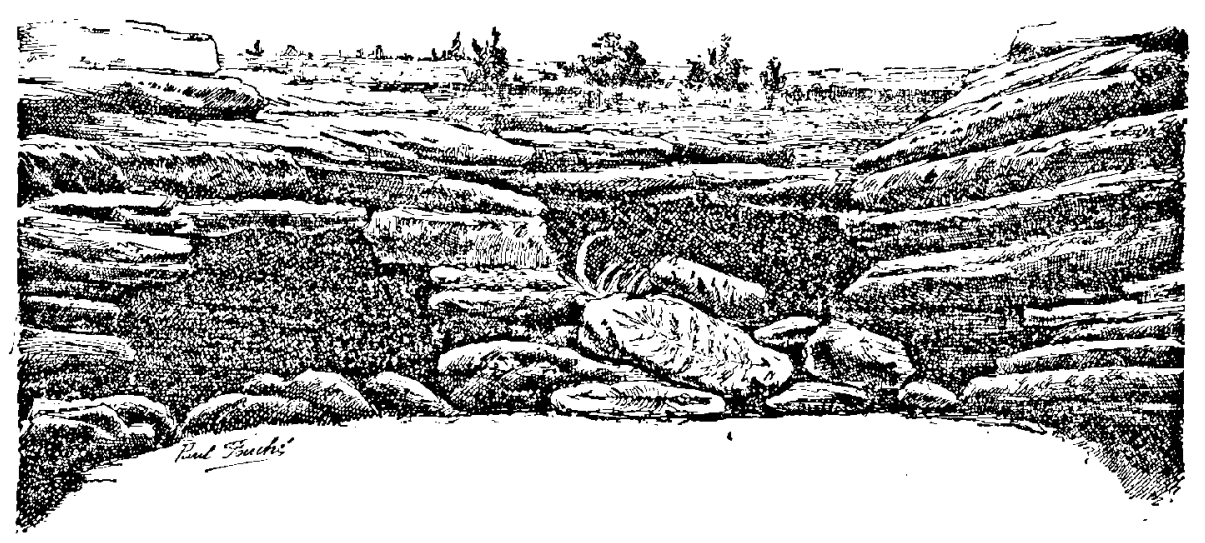

CHAPITRE PREMIER

LES EPOQUES DE LA NATURE

La formation des terrains. - Leur classification.

Dans un manuscrit arabe du septième siècle de l'Hégire (XIII ${ }^{e}$ siècle de notre ère), conservé à la Bibliothèque nationale de Paris, l'auteur, Mohamed Kazwini, met dans la bouche d'un personnage allégorique l'originale légende que voici :

Passant un jour par une ville très ancienne et prodigieusement peuplée, je demandai à l'un de ses habitants depuis combien de temps elle était fondée. - " C'est vraiment, me répondit-il, une cité.puissante, mais nous ne savons depuis quand elle existe, et nos ancètres, à ce sujet, ètaient aussi ignorants que nous. »

Cinq siècles plus tard, je repassai par le mème lieu, et ne pus apercevoir aucun vestige de la ville. Je demandai à un paysan, occupé à cueillir des herbes sur son ancien emplacement, depuis combien de temps elle avait été détruite: "En vérité », me dit-il, " voilà úne étrange question. Ce terrain n'a jamais été autre chose que ce qu'il est à présent. " - " Mais n'y eût-il pas ici anciennement, lui répliquai-je, une splendide cité ? —— « Jamais, me répondit-il, autant du moins que nous en puissions juger par ce que nous avons vu, et nos pères même ne nous ont jamais parlé d'une pareille chose. " 
- A mon retour, cinq cents ans plus tard, dans ces mèmes lieux, je les trouvai occupés par la mer; sur le rivage stationnait un groupe de pêcheurs, à qui je demandai depuis quand la terre avait èté couverte par les eaux? - a Est-ce là, me dirent-ils, une question à faire pour un homme comme vous? Ce lieu a toujours été ce qu'il est aujourd'hui. ๖

Au bout de cinq cents années, j'y retournai encore, et la mer avait disparu; je m'informai d'un homme que je rencontrai seul en cet endroit, depuis combien de temps le changement avait eu lieu, et il me fit la même réponse que j'avais eue précédemment.

Enfin, apres un laps de temps égal aux précédents, j'y retournai une dernière fois, et j'y trouvai une cité florissante, plus peuplée et plus riche en monuments que la première que j'avais visitée, et lorsque je voulus me renseigner sur son origine, les habitants me répondirent: « La date de sa fondation se perd dans l'antiquité la plus reculée; nous ignorons depuis quand elle existe, et nos pères, à ce sujet, n'en savaient pas plus que nous. »

C'est bien là l'image de la brièveté de la mémoire humaine et de la petitesse de nos horizons dans le temps comme dans l'espace. Nous sommes portés à croire que la Terre a toujours été ce qu'elle est; nous ne nous représentons qu'avec difficulté les transformations séculaires qu'elle a subies pendant les millions et millions d'années qui ont précédé l'apparition de l'homme ; la grandeur de ces temps nous écrase, comme en astronomie la grandeur de l'espace.

A l'époque à laquelle nous arrivons dans cette histoire dè la Terre, la vie est déjà très répandue au sein des eaux, qui recouvrent encore la presque totalité du globe. Elle consiste surtout en plantes primitives, rudimentaires, en mollusques et en crustacés. Elle se développe. Les espèces qui demeureront dans des conditions invariables, ou peu variables, par exemple au fond de la mer, se perpétueront sans beaucoup changer, et un grand nombre d'entre elles arriveront jusqu'à nous. Celles qui se trouveront vers les rivages, ou déjà sur la terre ferme, auront à subir des variations dans leur mode d'existence, respiration, alimèntation, température, lumière, etc., etc., elles s'y acclimateront en se transformant, ou 
périront si le changement est trop considérable ou trop brusque. Plusieurs géologues ont donné le nom de " période de transition »à l'époque à laquelle nous arrivons; mais, en fait, toutes les époques sont des périodes de transition : on passe constamment, indéfiniment, d'une phase à une autre. Il arrive souvent aussi qu'en politique on qualifie de période de transition l'époque en laquelle nous vivons actuellement, parce qu'en effet nous sommes là pour remarquer les changements qui s'opèrent autour de nous- non seulement. pour les remarquer, mais encore pour les subir, car le progrès des idées et de la liberté ne marche pas sans faire de victimes, et chacun paye son tribut à l'ascension de l'humanité vers un état que l'on dósiro sans cesse plus perfectionné. - Mais en fait, dans l'histoire de l'humanité comme dans celle de la nature, toutes les époques sont des périodes de transition, de passage d'un état vers un autre plus élevé. Heureux quand ce ne sont pas des chutes ou des reculs! Il faut reconnaître d'ailleurs que si les nations grandissent, arrivent $\dot{a}$ une apogée, puis déclinent et meurent, le patrimoine de l'humanité considérée dans son ensemble, s'enrichit et s'agrandit de siècle en siècle. La série des transitions fait, sans contredit, constarnment avancer l'humanité.

Nous oublierons donc ce terme de période de transition pour ne conserver que son nom géologique. Cette période, qui vient immédiatement après la póriode silurienne décrite au chapitre précédent, et qui commence une seconde ère dans l'histoire de la nature, l'ère pnimalne, a reçu le nom de période dévonienne, parce qu'on a spécialement étudié pour la première fois (Murchison et Sedgwick, 1837) les terrains qui en renferment les fossiles en Angleterre dans le comté de Devonshire. Ces couches sont aussi désignées quelquefois sous le nom de vieux grès rouge, à cause de leur aspect.

Mais il importe que nous nous rendions compte géologiquement de cette succession des terrains et des couches paléontologiques. Jusqu'à présent, nous avons surtout contemplé, étudié, la naissance et le développement de ra vie, tant animale que végétale, nous avons assisté aux premières scènes du spectacle de la nature et nous avons vu apparaitre les organismes primitifs qui ont commencé sur notre planète l'ère de l'ascension vitale dont l'homme 
occupe le sommet. Il est intéressant pour nous maintenant de voir comment les terrains se superposent et de suivre la marche de la nature dans le dépôt consécutif de ces couches au sein desquelles on a retrouvé les vestiges des êtres disparus.

Construisons done d'abord un tableau d'ensemble de la succession de ces terrains et de ces âges, en commençant par les plus anciens, par ceux que nous connaissons déjà pour les avoir visités aux chapitres précédents.

\section{TABLAAU DES PÉRIODES PALÉONTOLOGIQUES}

ou des

GRANDS CYCLES DE L'HISTOIRE ORGANIQUE DE LA TERRE

I. Premier cycle. - Age primordial.

Age des Acraniens et des Algues.

1. Age primordial ancien . . . . ou Période laurentienne

2o Age primordial moven ....... ou Période cambrienne.

3o Age primordial récent. . . . . . ou Période silurienne.

II. Deuxième cycle. - Age primalre.

A gie des Proissons et des Fougeres.

4. Age primaire ancien ....... ou Période dévonienne.

5o Age primaire moyen . : . . . . . ou Période carbonifère.

6o Age primaire récent. . . . . . . ou Période permienne.

III. Troisieme cycle. - Age secondaire.

Age des Reptiles et des Arbres a feuilles persistantes.

7. Age secondaire ancien. . . . . . ou Période triasique.

3. Age secondaire moyen ....... ou Période jurassique.

9. Age secondaire récent. . . . . . . on Période crétacée.

IV. Quatrième cycle. - Age tertiaire.

Age des Mammitêres et des Arbres a saisons.

10. Age tertiaire ancien ........ ou Période éocène.

11. Age tertiaire moyen........ ou Période miocène.

12. Age tertiaire récent. . . ..... ou Période pliocène.

V. Ginquiéme période. - Age quaternaire.

Age des Hommes, des Plantes cultivées et des Animaux domestiques.

13' Age quaternaire ancien ....... ou Période glaciaire.

14. Age quaternaire moyen ...... ou Période post-glaciaire.

15. Age quaternaire récent ...... ou Période de la civilisation.

Les terrains se superposent dans le même ordre. Donnons-en le tạbleau et la coupe, en plaçant naturellement en bas les terrains 
inférieurs, suivant l'ordre normal de leur succession dans l'histoire de la nature.

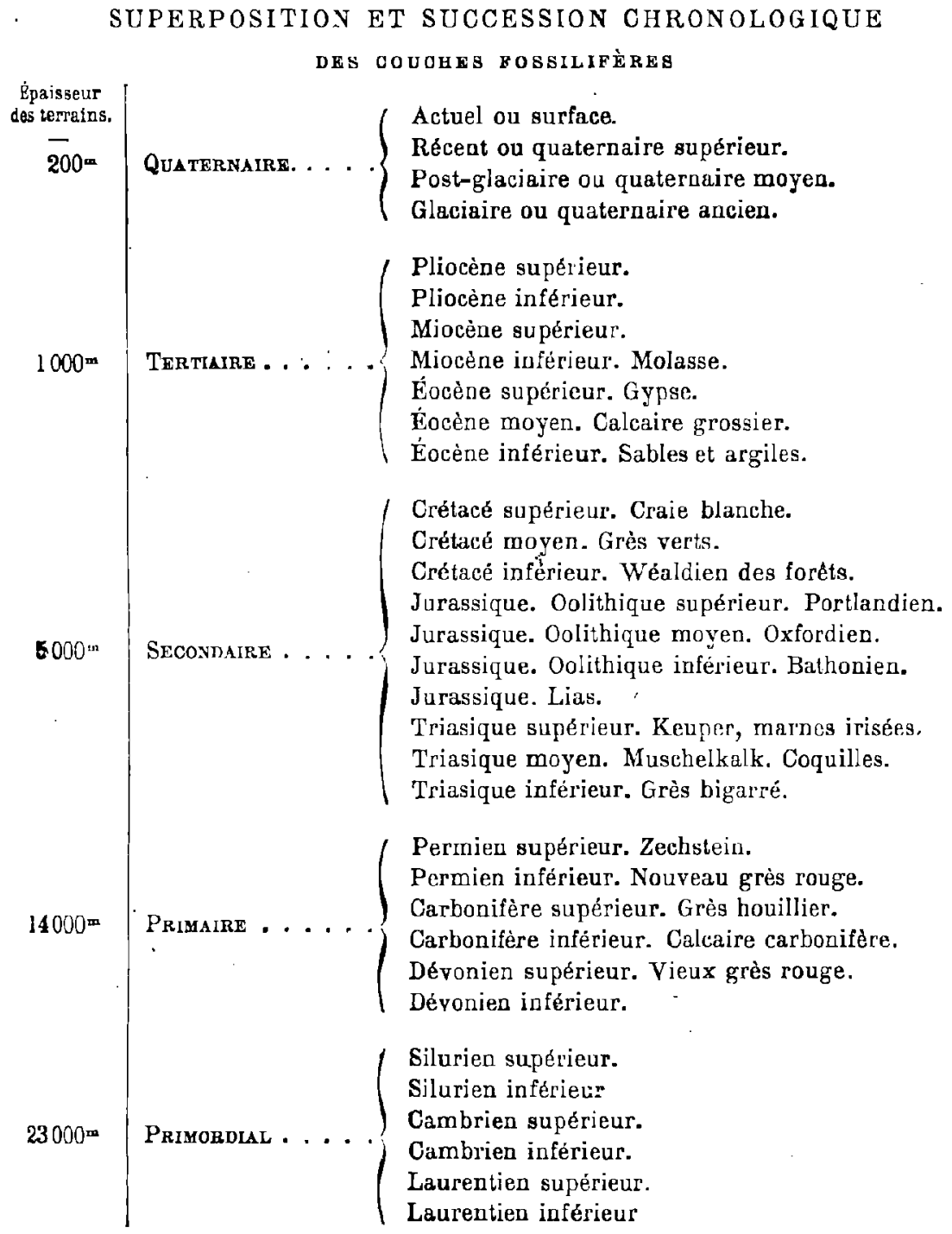

Ces couches reposent sur le terrain primitif du globe, granite, etc., dans lequel on n'a trouvé aucun vestige de vie. Entre le granite et le terrain laurentien inférieur se trouvent, comme nous l'avons vu, le gneiss, le micaschite et les schistes qui paraissent du granite transformé par la pression, la chaleur, l'eau, les 
sels, les éruptions, dislocations, mélanges, etc., en un mot par les conditions d'activité mème de cette époque primitive.

Cette succession des terrains qui composent l'écorce du globe est représentée ici (fig. 113), avac l'épaisseur relative observée des diverses formations. C'est là une coupe théorique. Comme nous l'avons vu, il est extrèmement rare que l'on rencontre dans leur

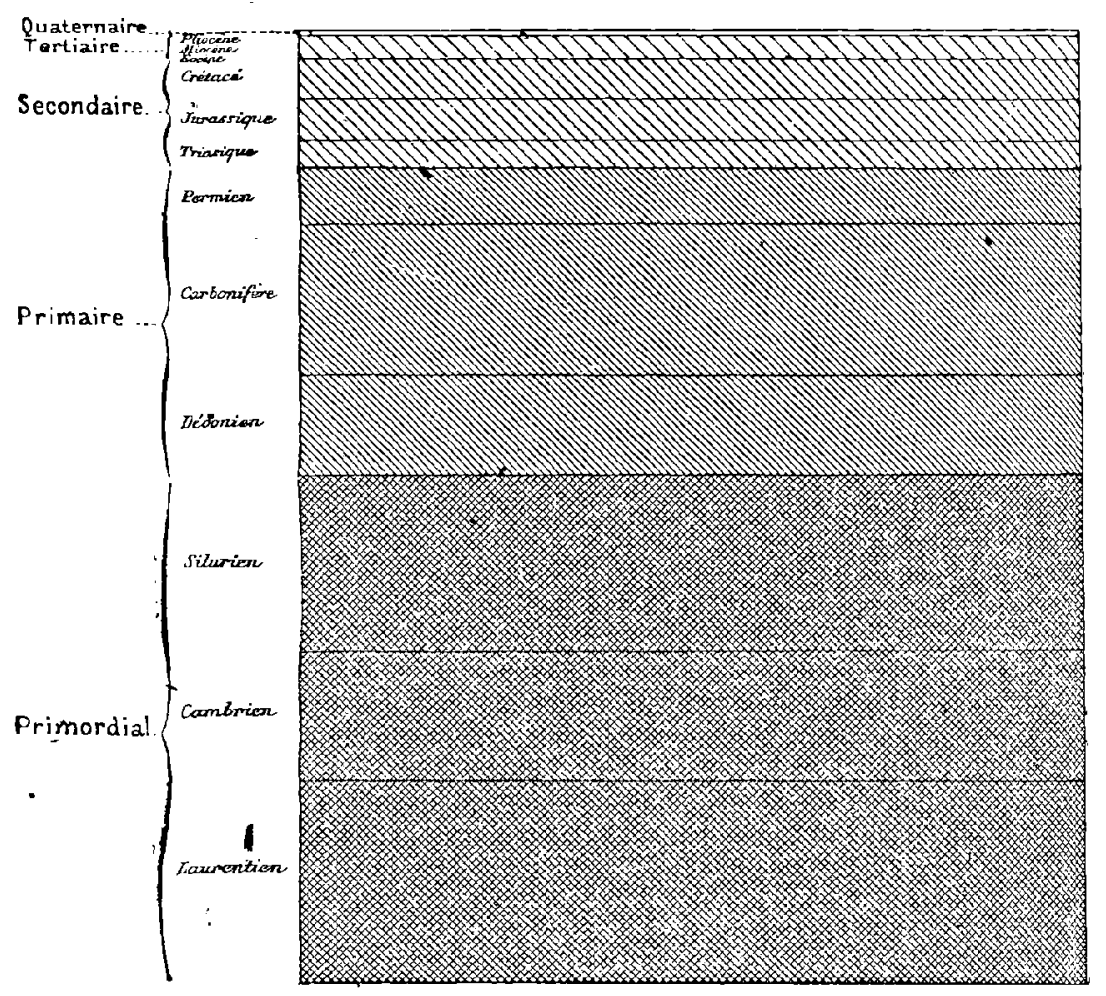

Fig. 113. - Épaisseur comparative des terrains géologiques.

ordre primitif ces couches horizontales et parallèles ; presque partout elles ont èté dérangées, inclinées, disloquées, par les exhaussements, les affaissements, les tremblements de terre, les glissements, les révolutions diverses dont la surface de notrp planète a été le théâtre depuis l'origine des temps. Mais l'ordre n'est jamais renversé, les successions se montrent toujours dans l'ordre reconnu, qui est celui dans lequel la nature a opéré elle-même.

Si nous voulons nous représenter tout l'ensemble avec ses détails, il est nécessaire de ne pas nous arrêter à la coupe rigoureuse des épaisseurs relatives et de. donner plus d'importance aux terrains 


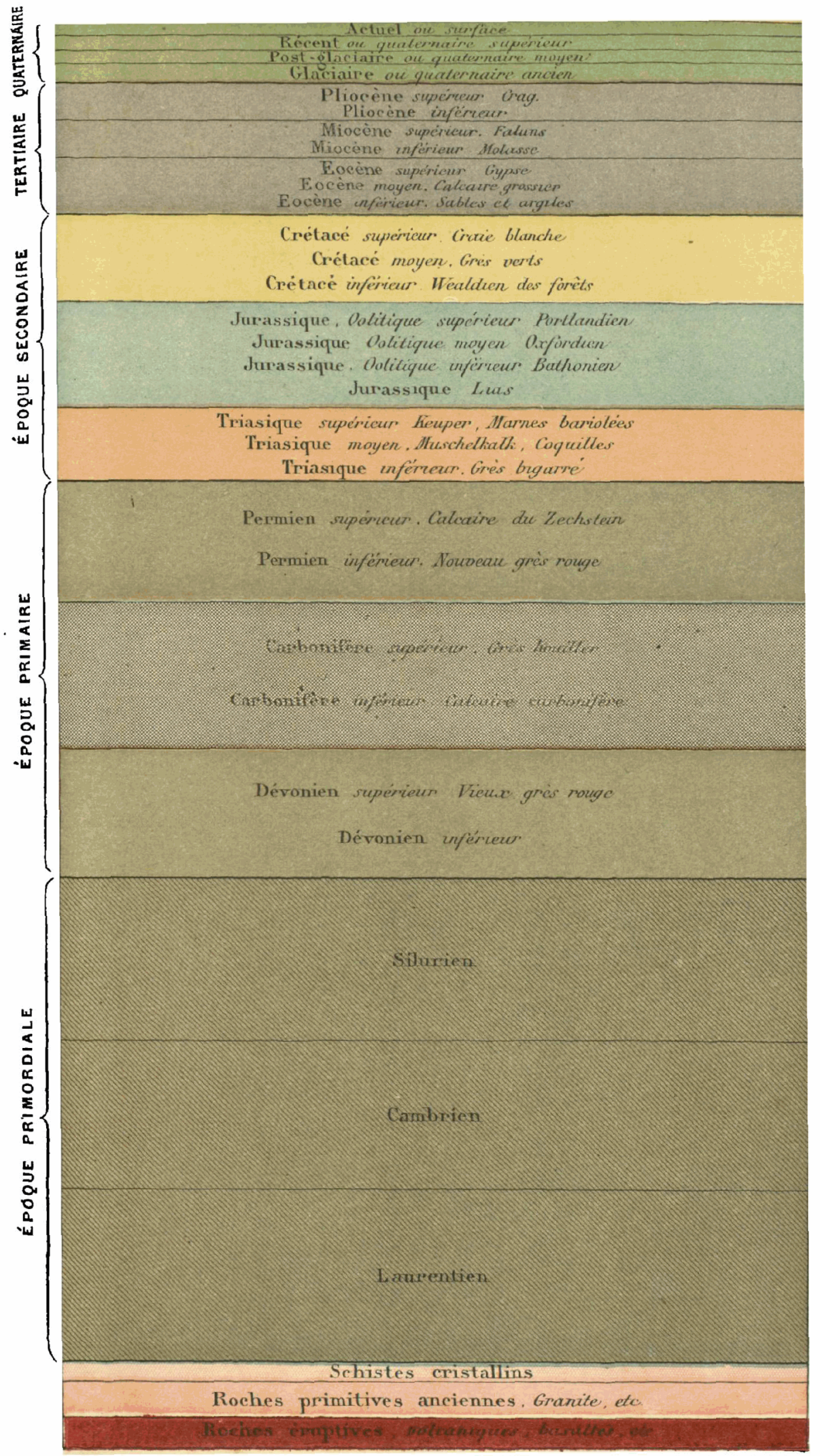


IRIS - LILLIAD - Université Lille 1 
modernes. C'est ce que nous avons fait (voy. Carte $n^{\circ} 3$ ). En examinant cette coupe générale de l'écorce du globe on se rendra compte de la succession totale des terrains, depuis l'origine mème jusqu'à nos jours.

Tout le monde sait qu'au-dessous de la terre arable sur laquelle poussent les champs, les prés et les bois on rencontre, à une très faible profondeur, des terrains rocailleux d'une autre nature, des roches plus ou moins dures, des pierres, du calcaire, du sable, de la craie, de l'argile, etc. La terre végétale n'est jamais bien épaisse: on la trouve souvent réduite à quelques décimètres seulement, et mème sur certains rochers elle ne dépasse pas quelques centimètres. Dans les hautes montagnes, elle est complètement absente. Dans les plaines et les vallées elle atteint ses plus grandes épaisseurs. La couche superficielle du sol est le produit actuel des causes en action : ici l'humus des bois accroit lentement l'épaisseur de la terre végétale, là l'industrie humaine ajoute des engrais de fertilisation, plus loin les pluies entrainent sur les terrains inférieurs tout ce que les terrains supérieurs contenaient de bon au point de vue de la fertilité; ailleurs les rivières en débordant répandent un limon sur les prairies; et ainsi se modifie sans cesse la surface du globe.

$\mathrm{Au}$-dessous de cette couche superficielle se rencontrent les bancs minéraux dont nous venons de parler, suivant une superposition correspondant à l'ordre successif de leur formation. Dans tout cet ensemble, la composition géologique montre presque partout des alternances de grès, de calcaire et d'argile. Depuis la surface du sol cultivé jusqu'aux roches les plus profondes, toute la substance terrestre se compose de trois éléments principaux : la silice, le carbonate de chaux et l'alumine ou argile. La silice a produit le quartz, la pierre meulière, le silex, le sable des rivages et des dunes; l'albumine a produit par ses mélanges les argiles et les marnes; le carbonate de chaux a produit la pierre calcaire (la plus répandue de toutes les substances minérales de l'écorce terrestre), les pierres de nos carrières, la craie, les marbres et les grès. Viennent ensuite les métaux, généralement injectés en filons. Ces substances jouent un rôle important dans l'habitation de l'homme sur la planète et dans les manifestations matérielles de la civilisation. 
Ces couches se sont formées avec une lenteur extrême. En un an, en dix ans, en cent ans, le dépôt géologique condensé au fond d'une eau tranquille ou vers les rivages des mers est presque nul. Depuis longtemps, les géologues admettent d'un commun accord que les diverses formations s'échelonnent en série historique. Les strates superposées répondent à des périodes successives de l'histoire organique terrestre, pendant lesquelles elles se sont déposées au fond des mers à l'état de limon. Peu à peu, ce limon s'est pétrifié; après nombre d'émersions et de submersions alternantes, ces roches se sont exhaussées en montagnes. Toutes les montagnes, à l'exception du granite et du gneiss, sont constituées de roches primitivement formées au fond des mers.

Encore aujourd'hui, les couches de sédiment continuent à se déposer au fond des eaux, comme aux temps antiques. L'action de l'oxygène de l'air sur les roches les plus dures, la chaleur qui sèche et fendille, les alternatives de chaleur et de froid, le vent, l'orage, la foudre, les tempêtes, les trombes, les pluies, les inondations, décomposent les roches, les dénudent, réduisent les minéraux à l'état de sable. Rien n'y résiste, ni le granite, ni le fer, ni les plus dur's métaux. Le pouvoir dissolvant de la pluie seule, de l'eau chargće d'acide carbonique, est énorme. Les sculptures de pierre et de marbre faites aux monuments du moyen âge ou de la renaissance, il y a quelques siècles seulement, sont rongées au point que parfois les motifs en sont devenus méconnaissables. La cathédrale de Limoges, bâtie de granite il y a seulement quatre cents ans, est déjà vermoulue sur un centimètre d'épaisseur le long de sa face nord exposée aux vents régnants et aux pluies. Notre-Dame de Paris est toute rongée sur sa face sud, parce qu'à Paris ce sont les vents du sud et du sud-ouest qui amènent la pluie. Dans les carrières où les pierres de la cathédrale de Limoges ont été extraites, la couche altérée atteint ${ }^{\prime \prime} 1^{m} 60$. Les pluies entrainent toute cette poussière, tout ce sable, et les rivières les transportent à la mer, où ils se déposent chargés des débris végétaux et animaux qu'ils ont entrainés. Des dépôts analogues se forment dans les laes et au fond des vallées où les cours d'eau aboutissent. Des dépôts d'une autre nature ont actuellement lieu. dans l'Océan : les sondages opérés pour la pose du câble transatlantique nous ont 
appris qu'une vase blanche, composée de corps organiques d'une nature identique à ceux qui constituent la craie que l'on trouve à diverses profondeurs dans toute la France et dans presque toute l'Europe est actuellement en voie de se déposer sur des espaces bien plus étendus que l'Europe entière.

L'épaisseur relative des diverses couches permet d'évaluer approximativement la durée relative des diverses périodes. Pourtant on serait mal fondé à conclure de la durée de la formation d'une couche d'un décimètre d'épaisseur, par exemple, qu'une couche d'un mètre représente juste dix fois plus de temps et une couche de cent mètres mille fois plus, car les conditions de formation des diverses couches sont très variables. Nous pouvons seulement, de l'épaisseur, de la puissance, d'une formation, déduire approximativement la longueur relative de la période à laquelle elle correspond.

Mais on oublie trop que la durée de la vie humaine est une minuscule échelle de comparaison pour mesurer de telles grandeurs et que les temps historiques de l'humanité tout entière ne sont qu'un instant évanouissant en face de la prodigieuse immensité des temps géologiques. L'homme est naturellement conduit à se scrvir, comme mesure du temps, de l'espace compris entre sa naissance et sa mort, et cette mesure instinctive a exercé une influence considérable sur notre conception générale de la nature, depuis Moïse et Jésus jusqu'à Bossuet et Cuvier. Un homme âgé de quatre-vingts ans a vécu 29219 jours. Inaginons que cette vie soit réduite à sa millième partie, soit à 29 jours, et que tous les phénomènes de notre existence soient accélérés dans la même proportion. Dans ce cas, un homme arrivant à la fin de ses jours rı'aurait observé qu'une seule révolution de la Lune: il dirait donc que notre satellite tourne a lentement » autour de la Terre, tand is que nous disons qu'il tourne « vite » parce que nous savons qu'il fait plus de douze tours par an. Le même observateuir ne connaîtrait le changement des saisons que par tradition, et il se pourrait que bien des générations d'hommes semblables eussent disparu depuis cette période de grand froid que nous nommons l'hiver.

Réduisons encore ces 29 jours à leur millième partie. La durée de la vie de notre octogénaire serait alors de 40 minutes (c'est 
celle de certains éphémères). Le changement du jour et de la nuit lui serait inconnu, et s'il avait assez de pénétration pour remarquer que pendant sa vie le soleil s'est un peu déplacé vers l'ouest, il n'aurait aucune raison de croire assurément que ce soleil se couchera jamais et reviendra par l'est.

Nous pourrions, en sens inverse, supposer la durée de la vie humaine mille fois plus longue et ses impressions physiques mille fois pius lentes qu'elles ne le sont réellement, si lentes, que l'impression du jour et de la nuit disparaitrait et que le soleil, par la rapidité de son mouvement pour une telle lenteur d'impression, apparaitrait, non plus sous la forme d'une sphère en mouvement lent, mais sous l'aspect d'un anneau lumineux traversant le ciel de l'est à l'ouest. On sait que, dans l'ètat actuel des choses, l'impression lumineuse demeure un dixième de seconde dans notre rétine avant d'arriver à l'esprit, et que si, par exemple, nous faisons tourner devant nous un charbon ardent avec une vitesse de plus de dix tours par seconde, nous voyons un anneau lumineux continu. Notre conception du monde extérieur serait toute différente de ce qu'elle est si ces impressions employaient cinq ou dix minutes pour arriver de la rétine au cerveau.

Un ètre doué de raison dont la vie ne durerait qu'un jour aurail une toute autre conception de l'univers que celui qui vivrait cent ou mille ans, et par conséquent la mesure par laquelle ce dernier apprécierait l'univers scrait toute différente de celle du premicr.

L'exiguite de l'homme au point de vue du temps est la mème qu'au point de vue de l'espace. Qu'est-ce que la taille de l'homme comparée à celle de la Terre? La taille moyenne de l'homme est de $1^{\text {"7}} 70$, et le diamètre du globe terrestre est de 12742208 mètres. Mais qu'est-ce que la grosseur de notre minuscule planète relativement à celle du gigantesque Soleil, un million deux cent quatrevingt mille fois plus volumineux qu'elle! Et pourtant notre soleil n'est qu'une petile étoile. La distance qui nous sépare de la Chine nous paraft considérable: que sont ces quelques milliers de kilomètres à côté des 148 millions de kilomètres qui nous séparent du Soleill Mais, à son tour, qu'est-ce que cette étape du Soleil comparée à celle de l'étoile la plus proche, qui équivaut à deux cent vingt mille étapes comme celle d'ici à l'astre du jour! Et, à son tour, que 


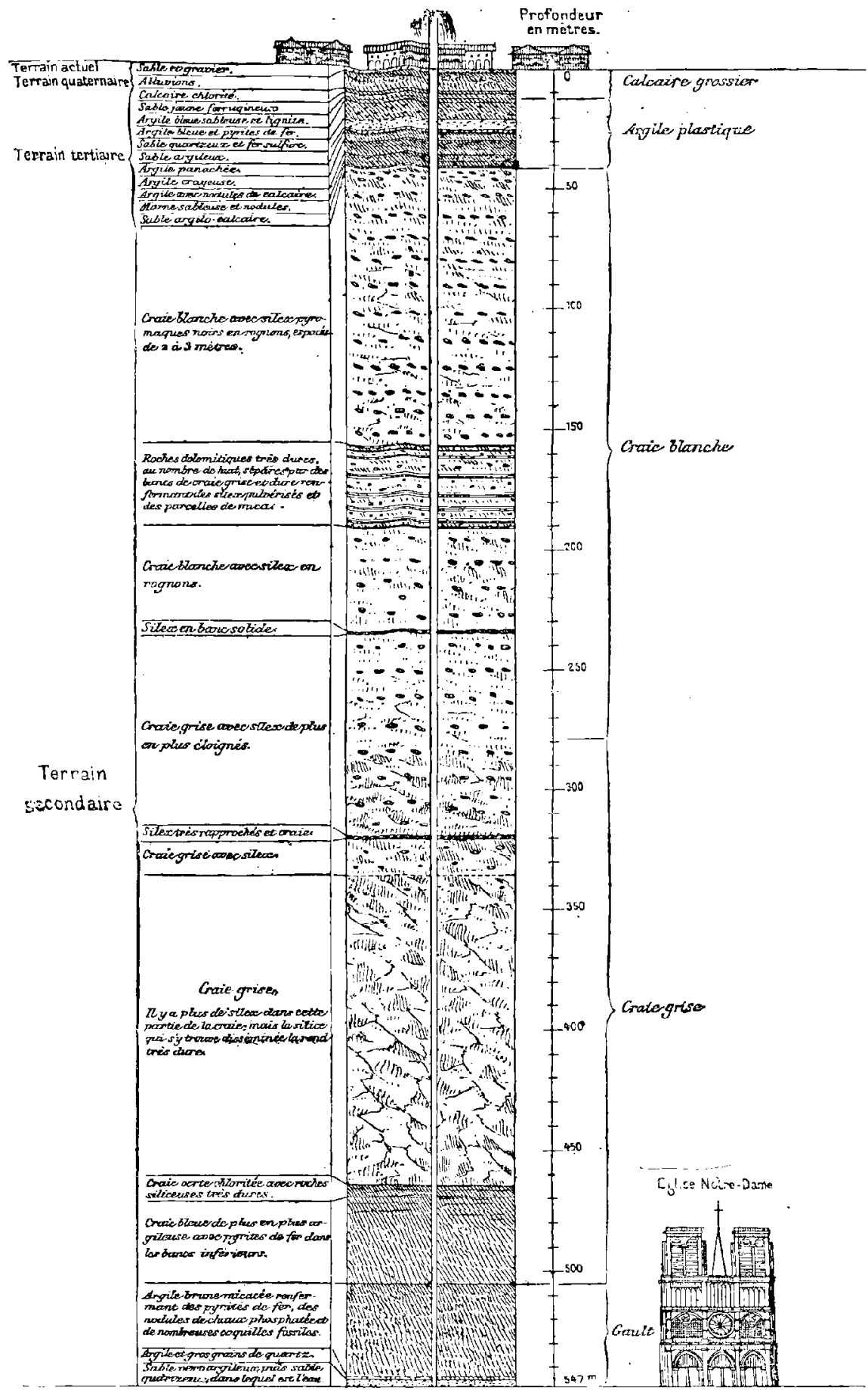

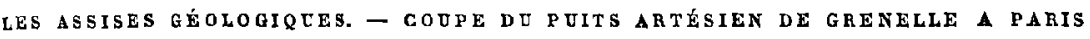


devient cette distance de huit mille milliards de lieues comparativement aux infinis des distances intersiderales!

Pour chercher à apprécier les phases de l'histoire de la Terre, il faut donc que nous jugions à leur exiguïté (on pourrait presque dire à leur néant) les impressions humaines relatives au temps. Un siècle n'est presque rien dans cette histoire. Nos impres. sions de durée, de " longucur ", de " lenteur » sont relatives à notre existence éphémère, rien de plus. En fait, cent millions d'années, un million de siècles, ce n'est pas long.

Non seulement une immense durée de temps a été nécessaire pour la formation successive des dépôts sédimentaires et pour leur pétrification en roches compactes et dures, mais encore cette mème durée n'a pas été moins indispensables pour le soulèvement des montagnes, qui, telles que les Alpes et les Pyrénées, les Andes et les Cordilières, s'élèvent à quatre, cinq, six, sept et huit mille mètres au-dessus du niveau de la mer. A part certaines exceptions, restreintes, semble-t-il, aux opérations d'ordre volcanique et $\dot{a}$ des causes locales de soulèvement, les exhaussements et les dépressions du sol semblent ne s'opérer qu'avec une extrème lenteur. De plus, ils ne sont ni réguliers ni graduels, mais se montrent soumis à des alternatives et des oscillations. Quoique, d'ailleurs, les irrégularités de la surfice terrestre nous paraissent énormes, relativement à la dimension du globe, elles sont presque insignifiantes.

Nous l'avons déjà dit - mais il importe d'appuyer sur ce fait afin que chacun conçoive clairement et complètement le mode de formation des couches géologiques - tous les terrains de sédiment ont été constitués aux dépens de l'écorce du globe: ils sont le produit de sa désagrégation séculaire et sont la stratification, la pétrification de la poussière du temps. S'ils ont quarante-trois mille mètres d'épaisseur en totalité, depuis la période laurentienne jusqu'à l'àge actuel (Voy. p. 220), ce sont là quarante-trois mille mètres d'enlevés successivement à la surface des roches émergées au-dessus du niveau de la mer. L'écorce du globe aux dépens de laquelle se sont formés tous les terrains de sédiment était donc déjả d'une grande épaisseur pendant la longue durée des temps géologiques. En fait, l'écorce solide du globe s'est accrue, dès l'époque primordiale, en deux sens opposés: en bas, par la solidificaticin 
graduelle et l'augmentation d'épaisseur due au refroidissement, en haut par l'accumulation des terrains de sédiment dans les bassins des mers; mais ce second accroissement d'épaisseur doit plutôt être considéré comme un nivellement que comme un accroissement réel, puisqu'il s'eflectue aux dépens des montagnes, des irrégularités extérieures et de tout ce qui est soumis à l'influence des agents atmosphériques.

La coupe géologique dessinée ici $(f g$. . 115) nous donne une idéo exucte du mode de formation de cos terrains. Dans un bassin plus ou moins profond, mer ou lac, les débris enlevés aux roches extérieures par les agents atmosphériques de toute nature se sont successivement déposés. Leur nature minérale, leur densité, leur épais-

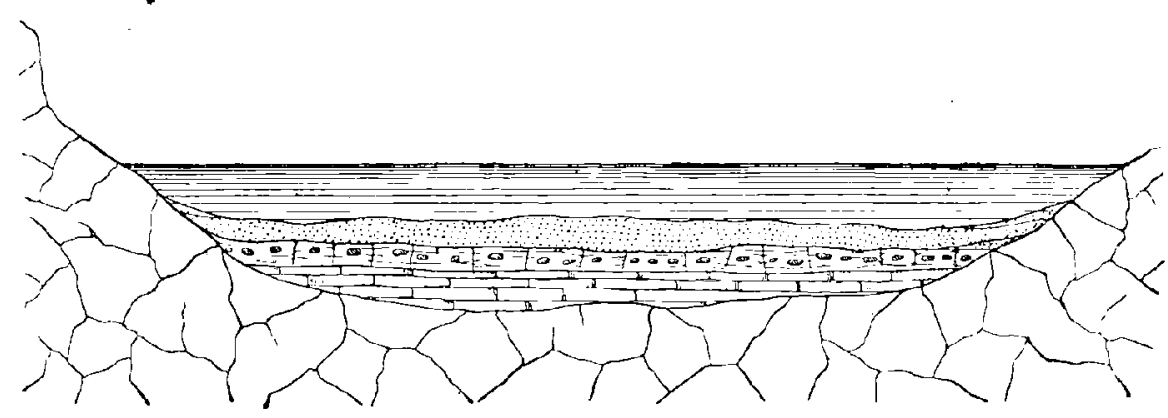

Fig. 115. - Mode de formation des terrains de sédiment.

seur dépendent de la nature des roches dont elles sont la désagrégation, des conditions dans lesquelles elles se sont déposées, du temps qu'elles ont mis à se tasser en couches plus ou moins compactes et des circonstances variées qui leur ont donné naissance.

Originairement, ces couches déposées au fond des eaux ont été horizontales ou faiblement inclinées. Mais nous avons vu que le globe terrestre a été primitivement en fusion, roulant dans l'immensité à l'état de sphère liquide lumincuse, et que son refroidissement a commencé par la surface, la température normale de l'espace étant plus que glaciale : 270 degrés au-dessons de zéro. La pellicule figée, la première couche granitique a commencé par la juxtaposition et la soudure des glaces flottantes de granite durci, et longtemps elle resta cxtrêrnement mince. Pendant des siècles et des siècles, elle a obèi docilement aux plus légers mouvements du globe liquide interne et a subi des marées, des oscillations, des sou- 
lèvements et des dépressions de toute nature. Lorsqu'elle fut deve. nue plus épaisse et plus solide, clle n'ondula plus aussi docilement, mais pourtant elle ne put résister aux poussées souvent intenses venant de l'intérieur et causées par les opérations chimiques, par les changements d'équilibre dus à la condensation, par l'emprisonnement d'un globe de feu dans une coque d'argile, d'eau et d'air. Des soulèvements relativement insignifiants comparés à la grandeur et $\dot{z}$ l'étendue du globe terrestre modifièrent successivement la surface. Les roches éruptives anciennes, encore pâteuses ou mème - liquides soulevèrent l'écorce solidifiée qui pesait sur elles et se firent jour à travers des fractures qui mesurent souvent plusieurs

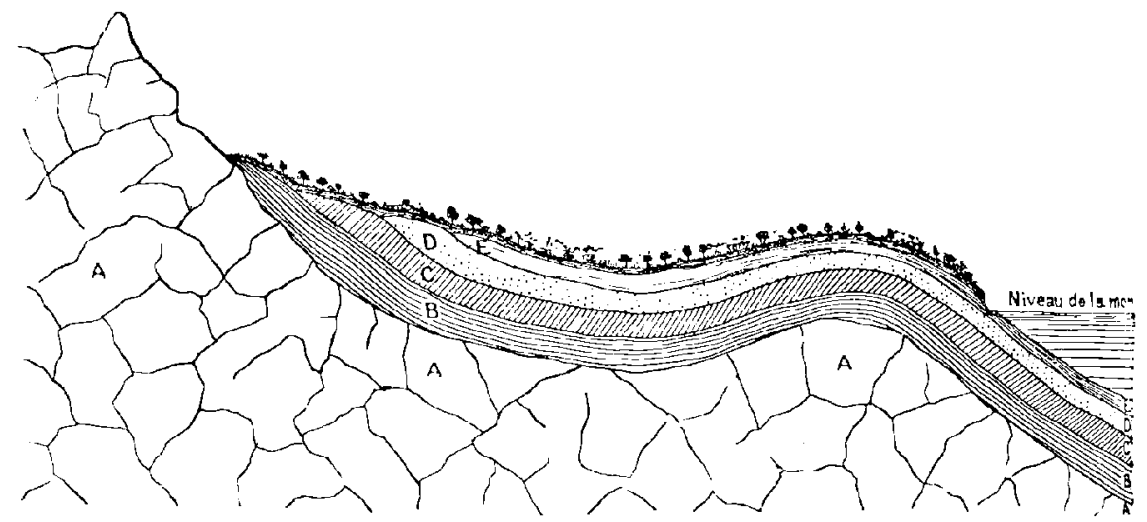

Fig. 116. - Soulèvement des terrains de sédiment.

A. Roches éruptives, grenīte, syénitos, porpliyre, ete, - B. Terraias primordiaux. - C. Terrains primalres. D. Terrains secondairgs, - E. Terrairs tertiaires.

kilomètres et même plusieurs lieues de largeur. On se rendra compte de ce mode de soulèvement à l'examen de la coupe tracie ici (fig. 116). Les Alpes, les Pyrénées, les Vosges, les massifs de l'Auvergne et de la Bretagne ne sont pas formés autrement.

Il résulte de ces soulèvements, qui ont été variés, consécutifs, alternatifs, que depuis l'origine de la vie la surface tout entière du globe a été soumise à toutes les variations imaginables. Il nous serait impossible de mettre le pied sur un point qui n'ait pas été l'objet de plusieurs remaniements pendant la longue durée de l'histoire de la nature. Tous les points du globe, sans exception, ont été une ou plusieurs fois couverts d'eau. La plupart ont eté non pas seulement soulevés une seule fois, mais alternativement soulevés, abaissés, et soulevés encore. On trouve, ici ou là, toutez 
les espèces de terrain à fleur de sol, les primaires et secondaires, aussi bien que les tertiaires et les quaternaires. Du reste, l'aspect des carrières a déjà rendu familiers à tous nos lecteurs la disposition des couches de terrains par banes consécutifs, comme on le voit ci-dessous.

Si tous les points de la surface du globe ont été travaillés par la main de la nature, tous ne l'ont pas été également. Le naturaliste

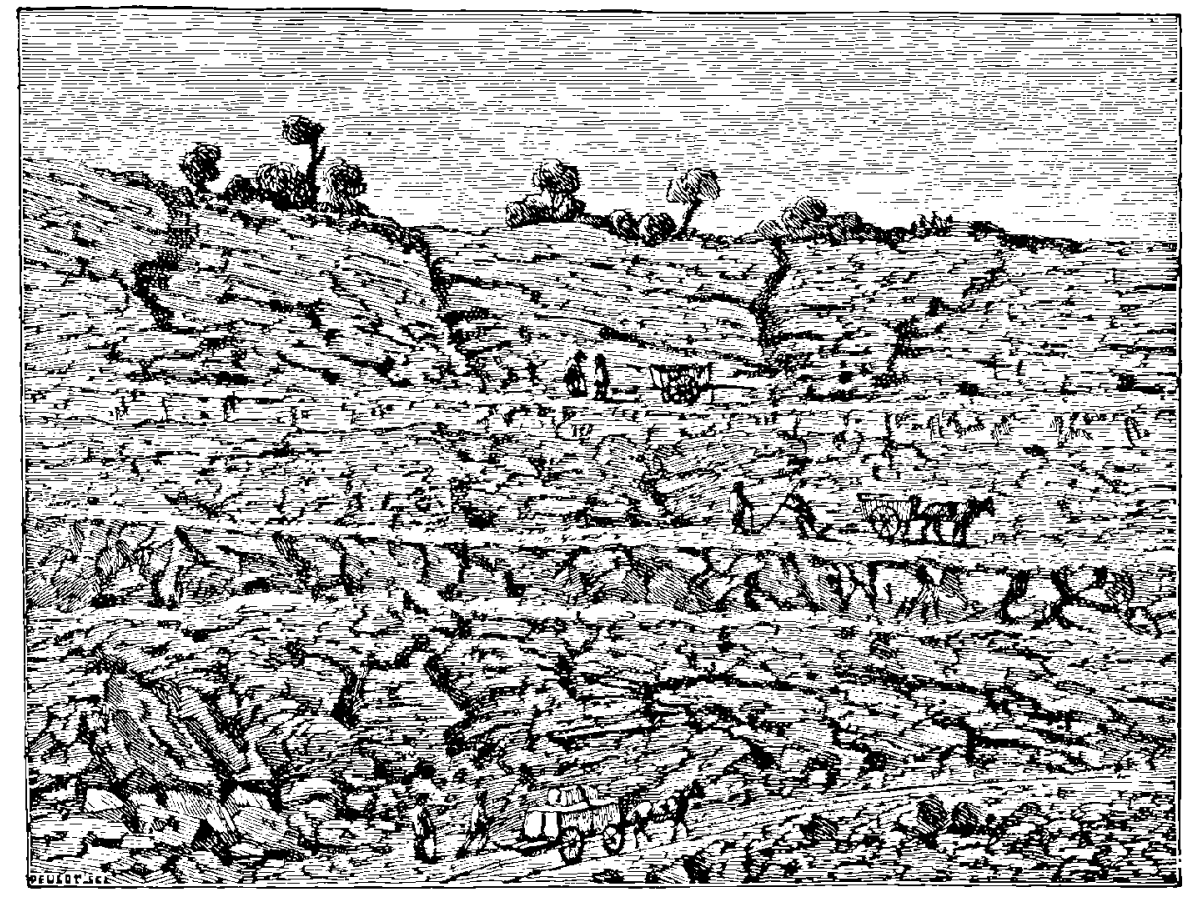

Fig. 117. - Une carcjère. - Couches de roches supperposées.

comme le géologue y remarquent la plus grande variété. En général, les pays de montagnes sont constitués par soulèvements des roches primitives qui ont tout disloqué pour s'élever dans les airs; les pays de collines sont les contreforts des massifs précédents, formés par le soulèvement des terrains secondaires appuyés sur les terrains primaires contigus aux roches primitives, tandis que les régions de plaines sont posées sur les terrains tertiaires plus éloignés du point de soulèvement. Les coupes géologiques représentées figures 118 et 119 montrent cette disposition.

Les pays de plaine offrent eux-memes une grande variété de 
constitution. Souvent des alluvions provenant des débordements d'un fleuve voisin ont couvert ces plaines d'un limon nivelé comme l'eau d'une mer. Souvent, au contraire, un fleuve traversant la région primitivement plane, les rivières qui y aboulissent et leurs affluents ont usé le sol et, surtout à la suite des saisons de pluies et des torrents, désagrégé la plaine, creusé des vallées et transformé l'aspect primitif du sol. Mais les couches stratifiécs qui forment le

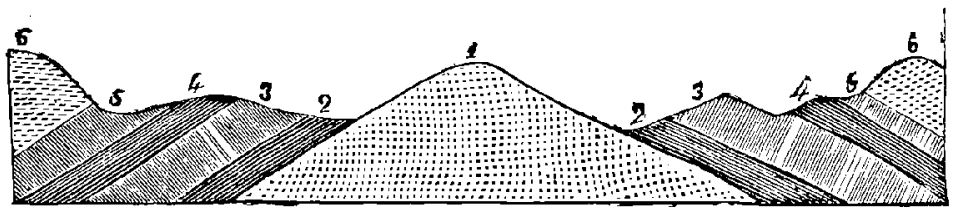

Fig. 118. - Exemple de soulèvement es des inclinaisons qui en résultent.

sous-sol de ces vallées, et celles qui forment les collines sculptées par lo creusement des terrains d'alentour, sont restées dans les conditions originelles de leur dépôt, c'est-à-dire horizontales et régulièrement superposées les unes au-dessus des autres. Ainsi, pour prendre un exemple bien proche de nous et longuement ètudié, la plaine sur laquelle Paris est bâti repose sur des terrains tertiaires formés de couches horizontales, et ces couches horizontales se

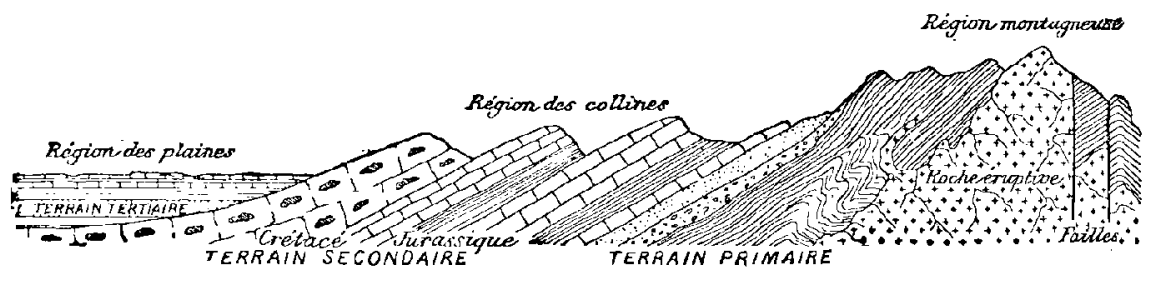

Fig-119. - Soulevement des terrains stratifiés, bases des diverses régions.

continuent dans la composition des collines de cette règion. Ce sont les eaux, ce sont les débordements torrentiels de la Seine aux temps préhistoriques qui ont déblayé le terrain sur lequel la grande capitale repose aujourd'hui, et qui ont fait de Montmartre du mont Valérien, etc., des collines rongées tout autour et aujourd'hui isolées. La coupe au travers de la vallée de la Seine (fig. 120) montre ce creusement de la vallée de Paris dù à l'action destructive des eaux torrentielles et violentes, ainsi qu'en témoignent les dépôt de limons, de sables et de graviers qu'elles ont laissé sur leur pareours. 
Si l'on creuse le sol au-dessous de Paris, on traverse successivement toute la série des terrains qui se sont superposés pendant les périodes quaternaire, tertiaire, secondaire et primaire. Le puits artésien de Grenelle a commencé par traverser le sol superficiel ou actuel, formé de terre végétale et de poussière de la grande ville, de détritus divers représentant sur un mètre environ d'épaisseur le produit de l'âge actuel. Puis on traversa une couche de sables, graviers, cailloux roulés, galets amenés par les alluvions de la Scine pendant la période quaternaire et désignés anciennement sous la dénomination générale de diluvium parce qu'on les attribuait au "déluge universel », tandis qu'ils sont dus simplement à l'action des cours d'eau. Ce sont là des terrains d'atterrissement formés pendant l'époque quaternaire, contemporains de l'homme primitif de

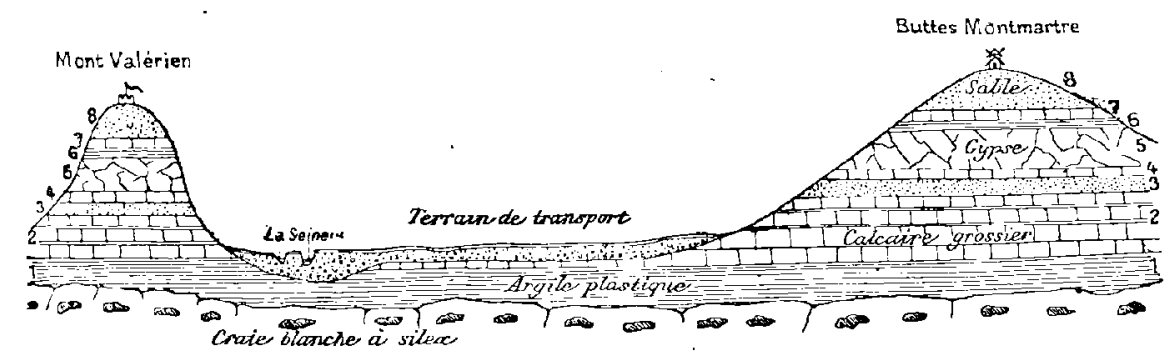

Fig. 190. - Goupe au travers de la vallée de la Seine, montrant la disposition des couches stratifées.

1. Argile plastiqua - 2. Calcaire grossier. - 3. Sables anciens. - 4. Calcaira d'eau douce. - 5. Gypse.

6. Marnes rertes. - 7. Meulières. - 8. Sables récents.

l'àge de la pierre, du mammouth, du rhinocéros tichorhinus, de l'elephas primigenius. On a trouvé, à Paris même, et à Grenelle même, des ossements fossiles du mammouth, ¿̀ 3 mètres de la surface, d'hippopotames à 5 mètres, et d'elephas primigenius à 7 mètres. On y a trouvé aussi (à Grenelle même) des os de renne, des silex taillés et des ossements humains, notamment sept crânes d'une race primitive dolichocéphale. Ces débris fossiles d'une race humaine inférieure habitant alors la vallée de la Seine ont été rencontrés à $1^{\mathrm{m}} 40$ seulement de profondeur et appartenaient à des corps qui ont été jetés là par une crue de la Seine, avec toute l'alluvion. - Ces premières couches traversées par le puits artésien mesurent, tout compris, $9^{\mathrm{m}} 65$, à partir de la surface du sol.

On arriva ensuite au terrain tertiaire, d'abord à un calcaire chlorité, avec coquilles, de $0^{\mathrm{m}} 85$ d'épaisseur, puis à des couches d'ar- 
gile alternant avec des bancs de lignite et des sables, le tout descen. dant jusqu'a $41^{\text {m}} \tilde{3} 4$ de profondeur.

Vint ensuite le terrain secondaire, avec ses craies diverses. Quoiqu'on eût traversé plusieurs nappes d'eau coulant sur des lits d'argile ou à travers les sables, on avait pour but, dans l'établissement de ce puits, d'atteindre une nappe d'eau puissante, et notamment celle qui, d'après la théorie, devait descendre de la Bourgogne et du plateau de Langres et suivre les couches géologiques qui, en forme de cuvette, passcnt au-dessous de Paris pour se relever ensuite. On les atteignit, après des efforts inouïs, mille obstacles imprévus, sept ans et deux mois de travail ('), à la profondeur de 547 mètres, après

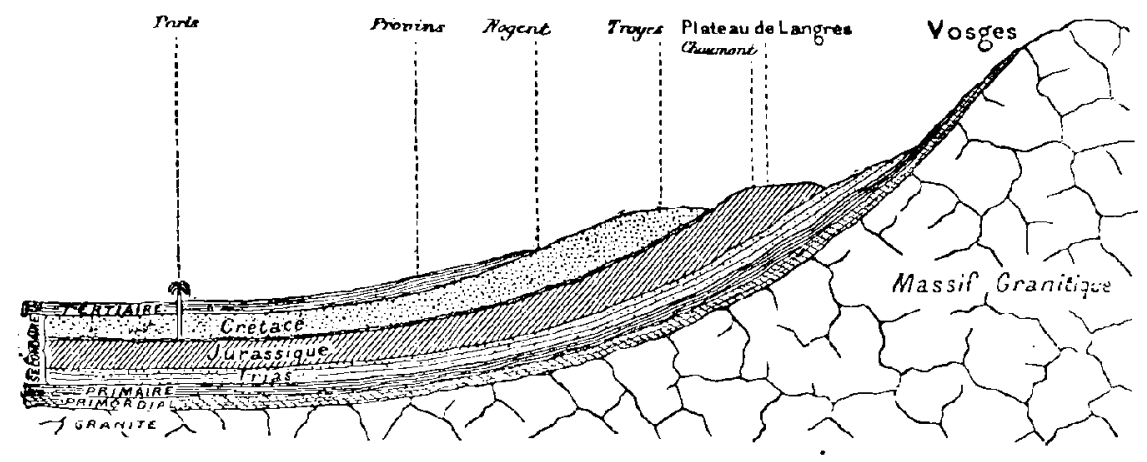

Fig. 121. - Coupe du bassin de la Scine, du puits artésien de Grenelle-Paris au plateau de Langres.

avoir traversé 238 mètres de craie blanche, 227 mètres de craie grise, verte on bleue, et 40 mètres d'argile gault, le tout appartenant aux terrains secondaires. Nous avons reproduit plus haut (p. 265), la coupe aussi curieuse qu'instructive de ces terrains traversés par le tube du puits artésien de Grenelle.

Si l'on continuait de descendre, on trouverait, au-dessous du crétacé, en partie déjà traversé par le puits artésien, les couches des terrains jurassique et triasique des premiers temps de la période

1. Le travail de forage, commencé le 30 décembre 1833 , atteignit la nappe d'eau le 26 février 1841 ; on commença ensuite le tubage, qui fut terminè le 30 novembre 1842. Cette ouvre fait le plus grand honneur à la persévérance de l'ingénieur Muloł. Le prix de revient a été de 362432 franes; les 548 mètres de tubes en cuivre galvanisé pèsent 12000 kilos et se composent de trois calibres différents, le supérieur de $0^{\text {m, }}, 50$, le moyen de $0^{\mathrm{m}}, 33$, l'inférieur de $0^{\mathrm{m}}, 17$. Le rapport d'A rago (1842) donne pour le débit de l'eau : 1100 litres par minute à 32 mètres au-dessus du sol, 1620 litres à 16 mètres ế 2200 litres à la surface du sol. La température de l'eau est de $27^{\circ}, 7$. 
secondaire, puis l'époque primaire, et enfin l'époque primordiale reposant sur son soubassement normal de gneiss, de micaschistes et de granite.

Comme on le voit, Paris est construit dans une sorte de cuvette, sur un lit formé par le terrain tertiaire modelé sur l'ondulation du

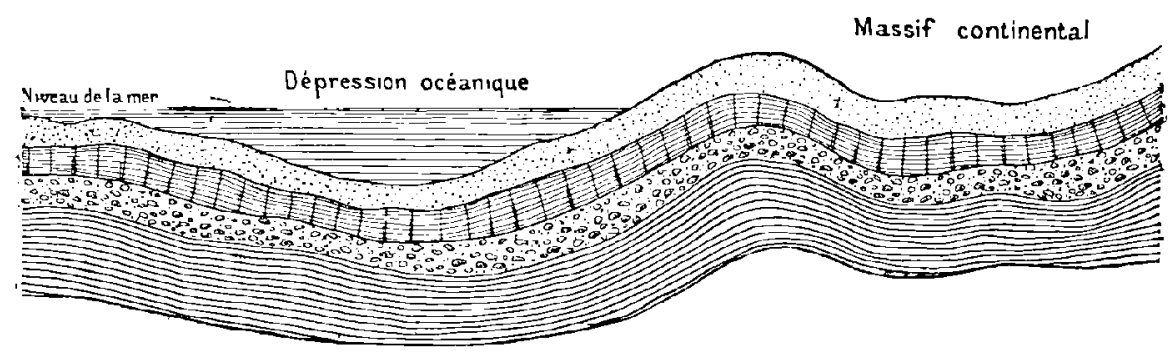

Fig. 122. - Ondulations, soulevements et dépressions dans l'écorce du globa,

terrain secondaire. La conche supérieure de ce terrain secondaire, qui passe sous Paris, le crétacé, arrive à la surface du sol, à l'est, à Chầlons, à Troyes; au sud, vers Auxerre, Bourges et Tours; à l'ouest, vers Le Mans et Dreux; au nord, vers Amiens et Creil, comme on peut s'en rendre compte sur notre carte géologique de la France.

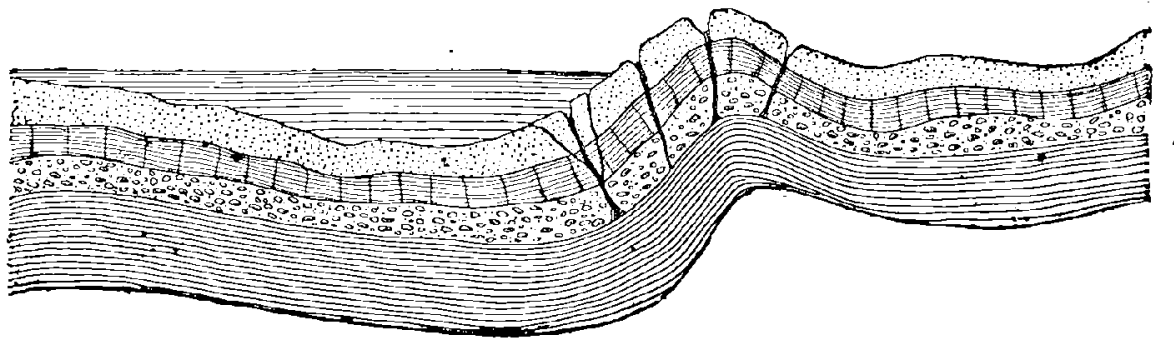

Fig. 123. - Fractures dans l'écorce du globe.

La couche inféricure, le jurassique, a produit les montagnes de l'Argonne, le plateau de Langres, les collines de la Bourgogne, et se prolonge par Nevers, Chateauroux, La Rochelle, pour remonter au nord dans la direction de Caen. Le terrain primitif a formé les Ardennes, les Vosges, l'Auvergne, la Vendèe et la Bretagne. Paris est placé au centre de cette circonvallation. La coupe du hassin de Paris (fig. 121) indique la disposition de ces couches et montre comment l'eau du puits artésien est alimentée par une nappe aquifère 
glissant le long des sables secondaires qui recouvrent le jurassique depuis le plateau de Langres jusqu'è Paris.

De mème que nous avons vu, dans les chapitres précédents, com* ment les différentes espèces végétales et animales qui petuplent aujourd'hul notre planète sont filles de lạ mème nature, parentes entre elles, effets de causes physiques aujourd'hui analysées par la science, de mème nous pourrions remarquer ici que l'histoire de l'humanite est en rapport immédiat avec la nature des terrains sur lesquels elle vit. Non seulement la valeur économique de ces terrains,

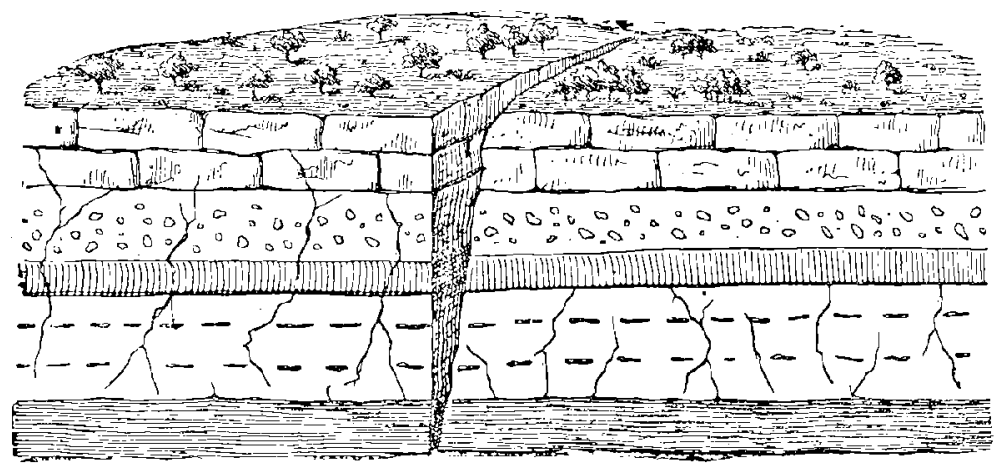

Fig. 124. - Exemple de fracture simple.

au point de vue de la culture, de l'alimentation, des végétaux qui y croissent, des animaux qui y vivent, des matériaux de construction et de tout ee qui concerne les conditions d'existence des habitants, a exercé l'action la plus directe et la plus constante sur lo caractère des hommes et sur les destinées locales de chaque pays, mais encore on peut presque lire l'histoire de France tout entière sur le sol de la patrie. Et il en serait de même pour tous les autres peuples. Plus d'une fois les historiens se sont demandé pourquoi Lutèce est devenue la capitale de la France. Sa position est loin d'ètre centrale, et Bourges est beaucoup mieux placée à cet égard. Flle n'est point la plus ancienne cité de ces contrées; Marseille, puis Lyon étaicnt florissantes à l'époque romaine où Lutèce n'était encore qu'un villagge de pècheurs, et pourtant Marseille ef Lyon n'ont été que les étapes de la civilisation prenant son vol pour aller resplendir de Rome à Paris. Le rôle politique de la capitale de la France n'est dû ni au hasard ni à la volonté humaine, mais à la situation géologique que 
nous venons de décrire et qui fait descendre naturellement vers Paris comme vers un centre d'attraction toutes les sources de fertilité. "Cette capitale, dirons-nous avec Ėlie de Beaumont, n'a pris naissance, et surtout n'a grandi, là où elle se trouve, que par l'effet de circonstances naturelles résultant, en principe, de la structure intérieure de notre sol. On en trouve le reflet dans le groupement des intérêts et des populations, de même qu'on voit la différence des climats influer sur les lois des différents peuples ». L'ile de France est unc véritable oasis, entourée par des terrains moins privilégiés au point de vue des cours d'eau et de la végétation, et,

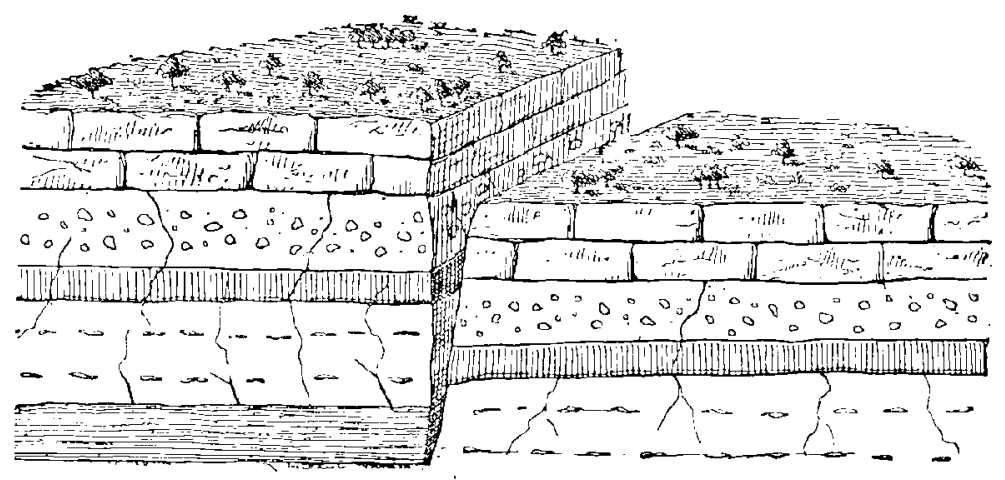

Fig. 12:5. - Fracture suivie d'une dénivellation.

comme si la nature avait pris soin de tout prévoir, elle a ajouté à cette oasis d'excellents matériaux de construction. Ainsi tout se ticnt dans la nature, les effets suivent les causes, ot malgré ses brillantes facultés d'iniliative et son amour de la iibcrté, l'homme est originairement, au même titre que les plantes et les animaux, enfant de la Terre qui lui a donné le jour.

Ainsi se sont succédé et superposé les uns sur les autres les terrains formés d'âge en âge sous l'action des agents atmosphériques, chacun ayant porté sa flore et sa faune spéciales, et chacun en conservant les vestiges fossiles. L'épaisseur de chaque couche géologique varie suivant les conditions mèmes de sa formation, ici elles sont riches et puissantes, là elles sont minces et pauvres, ailleurs elles manquent mème tout à fait, par suite des soulèvements et des dislocations. Mais nous avons vu au chapitre précédent qu'en additionnant toutes les épaisseurs déjà explorées, on arrive au chiffre 
total de 43000 mètres, depuis la surface actuelle jusqu'au fond du terrain laurentien, jusqu'au squelette granitique du globe.

L'humanité habite donc, en fait, sur un cimetière de quarante kilomètres d'épaisseur; nous marchons sur les dépouilles des êtres innombrables, grands et petits, qui ont vécu avant nous, sur un entassement funéraire de millions et de millions d'années, sur les dépôts lentement amoncelés par les siècles antiques, depuis les origines de la vie jusqu'à nos jours; nous foulons sous nos pieds la poussière des âges évanouis... Comment pourrions-nous, connaissant ces choses, faire désormais un seul pas sur la Terre sans respect!

L'histoire de la nature se continue sous nos yeux. A l'époque

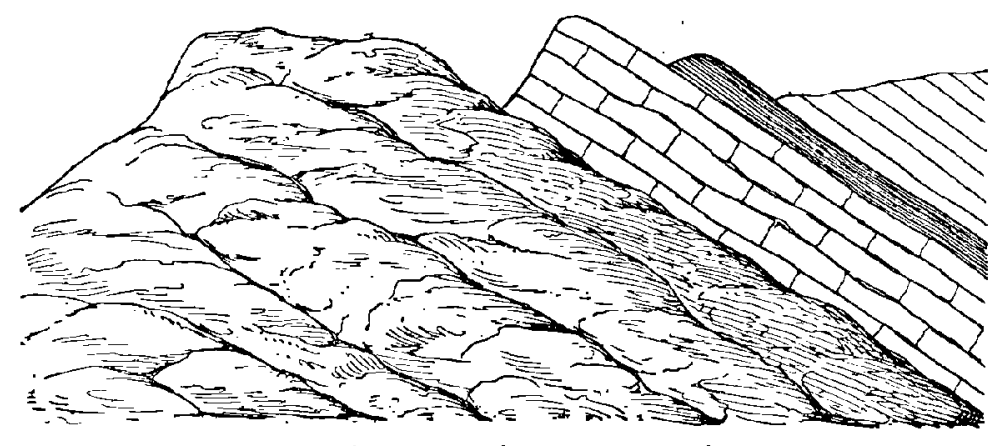

Fig. 126. - Couches relevées sur une masse éruptive.

actuelle, que l'on peut appeler l'âge de l'humanité - et qui ne fait que commencer, quoiqu'elle date déjà de plus de cent mille ans, car l'humanité prouve par sa grossièreté et sa barbarie qu'elle n'a pas encore attcint l'âge de raison - à l'époque actuelle, disons-nous, notre planète continue de rouler dans l'espace comme pendant les époques anté-humaines, entourée de ses éléments d'activité et de vitalité ; les générations se suivent et se succèdent, sur le taux de 86400 par jour, en moyenne, pour la surface entière du globe, soit d'une mort et d'une naissance par seconde, le nombre des naissances étant toutefois un peu plus grand que celui des morts; les corps retournent à la terre, ou, pour parler plus exactement, à l'atmosphère, car la chair et les os eux-mêmes ne sont guère que de l'eau et de l'air, de l'air condensé, et presque tout s'évapore ; les hommes sont tour à tour formés des mêmes éléments, qu'ils partagent fraternellement d'ailleurs avec les animaux et les plantes; tel d'entre 
nous peut posséder dans son corps une molécule qui circula jadis dans le corps de Phryné ou de Lucrèce Borgia, ou quelque atome ayant appartenu au cerveau de César ou de Napoléon; le saule vermoulu qui végète au bord du ruisseau exhale de l'oxygène qui va ètre respiré pạr l'enfant jouant au milieu des fleurs; la molécule d'acide carbonique échappée de la poitrine du vieillard à l'agonie va nourrir la rose du parterre, le myosotis ou la violette; de vie en mort et de mort en vie tout se transforme, tout se métamorphose.

Ce n'était point une terre autre que celle-ci, celle qui fut foulée par nos antérieurs des époques tertiaire, secondaire et primaire. Il

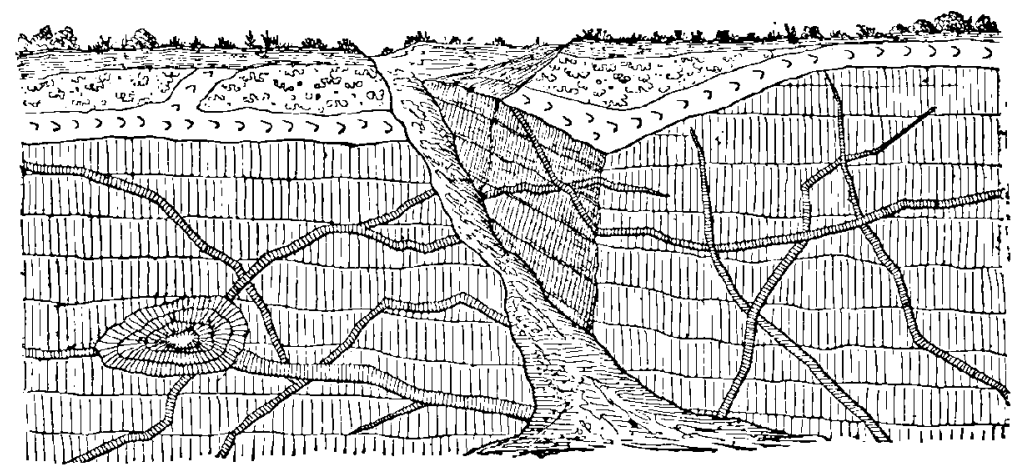

Fig. 127. - Exemple de filons éruptifs ả travers les roches stratifiées.

n'est besoin d'aucune révolution fántastique, d'aucun déluge universel, d'aucun cataclysme, d'aucune destruction ni d'aucune création pour expliquer la formation des couches géologiques et les différences qui les caractérisent. Les choses ne pouvaient pas se passer autrement. La première pellicule solidifiée tout autour du globe chaud, pâteux, liquide, a subi docilement les moindres ondulations, les moindres frémissements de ce globe, et la sphère n'a pu rester rigoureusement unie. Mais ces premiers plissements se sont eux-mêmes modifiés. Le globe terrestre en se refroidissant se condense, se contracte, diminue de volume. L'écorce est obligée de se plisser d'une manière un peu différente pour rester appuyée sur le noyau; d'une part, elle s'affaisse; d'autre part, elle se relève; d'autre part encore, elle subit des fractures, les matières éruptives enfermées tendent à se faire jour, à s'échapper, et les premières 
èruptions s'élèvent à la surface. Les eaux, descendant toujours aux plus has niveaux, se réunissent dans les dépressions les plus profondes, etc., etc. On peut sc représenter la formation de l'écorce du globe, ses plissements, l'origine des montagnes, des continents et des bassins maritimes, les soulèvements, les affaissements, les éruptions, les filons et toutes les transformations de terrains par la série de coupes géologiques (fig. 122. à 127) qui complètent l'exposé précédent en l'expliquant par l'aspect mème des choses. La géologie, comme l'astronomie, est désormais un livre ouvert pour tous ceux qui veulent se donner le plaisir de le lire.

On se rend compte ainsi facilement de l'état dans lequel les divers terrains se présentent à notre vue. Les soulèvements, les dislocations, les ruptures, ont amené à fleur du sol les roches les plus anciennes et les mettent en évidence pour les études des géologues, sans qu'il soit nécessaire de descendre dans les profondeurs du sol. Le profil d'une contrée comme la France montre tous les genres de terrains, déplacés par des causes lentes ou rapides, mais plus généralement par des causes lentes et graduelles.

Tous ces phénomènes se continuent de nos jours, et chacun de nous peut lire actuellement dans le livre de la nature - s'il a appris à y lire. - Encore aujourd'hui la surface de la Terre se transforme, telle contrée s'exhausse lentement, telle autre s'abaisse, ici la mer gagne sur le rivage, ailleurs elle recule sous l'avancement des terres, telle montagne se dénude, telle vallée se comble, telle colline glisse avec tout ce qu'elle porte, etc., etc. Il suffit d'observer pour apprécier toutes ces transformations et pour vivre en communauté avec les actes de la nature. Cet important sujet, du plus haut intérèt scientifique et philosophique, fera l'objet du chapitre suivant; il importe de nous occuper ici de cette étude générale, qui constitue la base même de la géologie. 


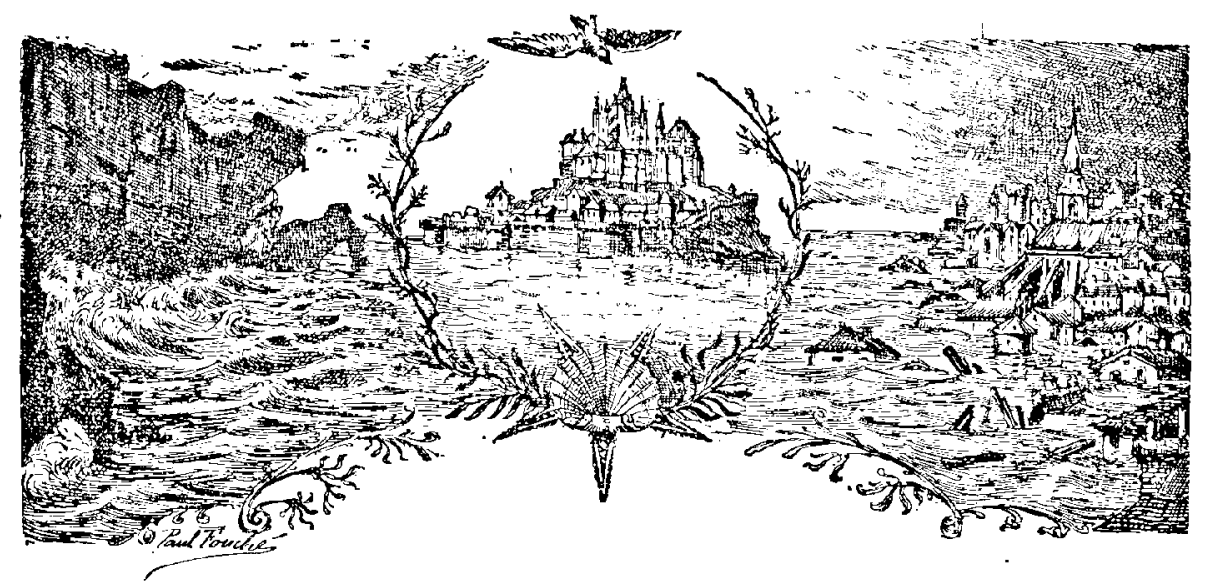

CHAPITRE II

LES TRANSFORMATIONS ACTUELLES DU SOL

Variation des rivages. - Embouchures et Deltas.

Action des cours d'eau. - Oscillations lentes. - Soulèvements. '- Depressions.

La terre et la mer. - La nature continue son œurre.

Insensiblement tout change, tout se transforme autour de nous. Le sol lui-même, que nous sommes accoutumés à considérer comme le type de ce qui est solide par excellence, le sol lui-mème, varie sans cesse. La nature continue son cuvre. En appréciant ce qu'elle accomplit sous nos yeux, nous allons entrer en relation directe avec les procédés qu'elle a employés pour sculpter le globe sur lequel nous vivons. Etudions-la toujours directement : c'est la méthode la plus simple et la plus sûre pour arriver à la connaissance de la vérité.

C'est une erreur classique d'enseigner qu'il y a des époques géologiques spéciales qui représentent la création du monde et ont cessẻ d'agir. L'époque actuelle est « géologique » aussi bien que celles qui l'ont précédée. Le jour viendra où nous serons reculés dans l'histoire comme le sont les ptérodactyles et les ichtyosaures.

Et d'abord, considérée dans son ensemble, la surface de la Terre varie sans cesse. Les pluies, la gelée, la chaleur, lo vent, les 
orages, les tempètes, les ruisseaux, les torrents, désagrègent les sommets des montagnes, dont les matériaux sont détachés, entrainés, brisćs, charriés, broyés, finalement réduits en sables et transportés dans la mer par les embouchures des fleuves. D'autre part, la mer ronge constamment ses rivages, produit des falaises de plus en plus élevées en pénétrant les continents, et exhausse son fond par les matériaux détachés. D'autre part encore, Jes forces intéricures du globe continuent d'agir : certaines régions se soulèvent lentement tandis que d'autres s'abaissent. Essayons de passer en revue, aussi brièvement que possible, les témoignages variés et multipliés des changements qui s'accomplissent autour de nous, non point, comme le font trop souvent les historiens de la nature, en allant chercher nos exemples aux antipodes, mais en choisissant ceux que la majorité de nos lecteurs peuvent constater par eux-mêmes et ont, pour ainsi dire, sous la main.

Les observations qui vont suivre permettent de poser ici deux principes : $1^{\circ}$ la mer gagne partout où il y a des falaises; $2^{\circ}$ elle recule à l'embouchure des fleuves. Dans le premier cas, elle mine les falaises qui s'écroulent en galets; dans le second cas, le fleuve apporte des sables, exhausse le fond de la mer et la fait reculer. Ces deux principes souffrent, il est vrai, des exceptions, car d'une part les courants de la mer et l'action des vagues poussèes par le vent peuvent faire avancer l'eau dans l'intérieur des terres ou se servir des galcts pour former des cordons littoraux, et d'autre part les sables eux-mèmes peuvent contrebalancer la tendance d'un fleuve. Mais, en général, ces deux causes agissent avec efficacité, et à elles séules elles suffiraient pour transformer la géographie de notre planète, même en dehors des soulèvements et dépressions. Examinons les faits.

Tout le "monde," par exemple, connaît le Havre. Précisément cette région peut scrvir de type pour un grand nombre d'autres analogues. On sait que cette ville, très moderne, n'a pas encore quatre siècles d'existence et qu'elle n'a été fondée qu'en 1516 par Francois $\mathrm{I}^{\mathrm{er}}$. Toute cette plaine sur laquelle cette importante cité s'est si rapidement élevée, a été formée par les alluvions de la Seine et les dépôts de sable rejetés par la mer aux grandes marécs, 
le tout en partie resté à l'état de marais jusqu'en ce siècle mème. La Seine charrie des sables qui tendent à exhausser son fond, ot lentement elle les dépose à son embouchure jusqu'd une grande distance dans l'intérieur de la mer. Mais aux jours de grandes marées et de tempêtes, la mer repousse ces dépòts et modifie incessamment le sous-sol. 'Le résultat définitif est un avancement des rives du fleuve et une diminution dans le domaine de la mer. Autrefois, les navires pouvaient arriver jusqu'à IIarfleur. On a montré pendant longtemps les anneaux de fer qui servaient à les amarrer, et nous avons vì nous-mème, en 1865, au milieu d'un

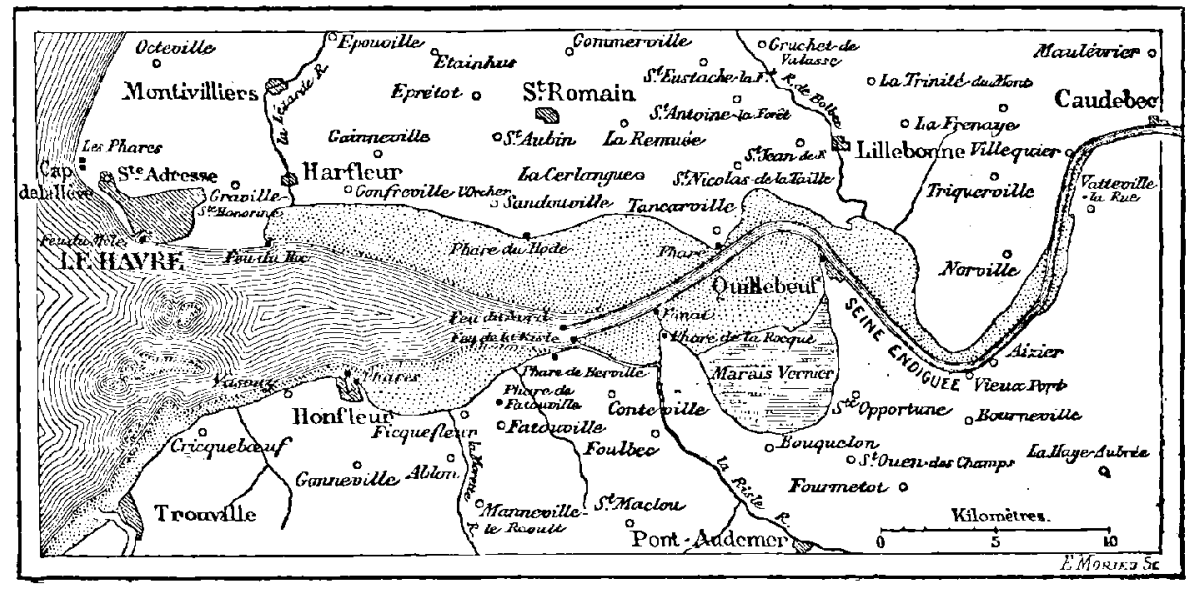

Fig. 129. - L'embouchure de la Seine.

jardin, un mur au pied duquel les eaux de la marée arrivaient encore an XVI siècle. Malgré les digues, le mascaret des grandes marées a encore une action très efficace pour modifier les rivages du fleuve, depuis Quillebeuf jusqu'au delà de Caudebec, et c'est cette violente poursuite des eaux douces par les eaux amères qui a le plus agi pour contrebalancer l'action du fleuve. La rive droite de la Seine s'allonge, très lentement, au delà du Havre; la rive gauche s'allonge assez rapidemient, en ce sens que la plage sablonneuse de Trouville s'élargit de plus en plus dans la mer. Des hauteurs d'Ingouville on distingue nettement le lit jaune de la Seine dans la mer verte, jusqu'au delà de Trouville.

Nos lecteurs trouveront ici (fig. 129) le plan actuel de l'enLE NONDE AVANT LA CRÉATION DE L'HOMME 
bouchure de la Seine, sur lequel on peut se rendre compte des courants et des sables, et $(f g .130)$, le plan du Havre avant la fondalion de la ville ('). Tout ce rivage est aujourd'hui transformé. D'abord la Seine a élargi ce littoral par'le dépôt de ses sables. Harffeur était, au XV siècle, un grand port. Une flotte espagnole de quarante vaisseaux et trois galères $\mathrm{y}$ stationnait en 1405. «Les navires y entrent par l'embouchure d'une rivière qui la traverse (la Lézarde), écrivait l'un des commandants, et la mer en enveloppe la moitié; l'autre moitié est couverte par une bonne muraille flanquée de fortes tours et par un fossć à escarpes maçonnées et rempli d'eau. " Depuis cette époque, les atterrissements, les sables ont envahi cet ancien port, dont la Seine s'éloigne au taux moyen de deux mètres par an depuis quatre cents ans. Harfleur est une ville morte, enfermée dans les terres, et qui n'a plus que le souvenir de sa splendeur passée. Le Havre l'a remplacée, puis tuée. Là où passe actuellement le chemin de fer, des navires ont navigué. Loi'squ'on creusa le canal de Harfleur, en 1667, on détcrra vers l'église de Graville, la quille entière d'un navire qui avait 80 pieds de long. En 1868, en construisant les nouvelles formes sèches dans l'ancienne citadelle du Havre, on trouva de gros arbres au-dessous du niveau des vives eaux actuelles : des forêts ont abrité des nids sur ces terres aujourd'hui submergées par la mer. Quatre ports existaient en cette région lorsque François ${ }^{\text {er }}$ fonda le Havre : Harfleur; un peu plus bas, les Neiges; plus loin encore Leure (voy. la fig. 130); et au delà du Havre actuel, au pied du cap de la Hève, le Chef-de-Caux. Le dernier a disparu parce que la mer a pris la place de la terre, les trois autres parce que la terre a pris la place de la mer. Le Havre subirait le même sort que cos trois derniers si le travail incessant de l'homme ne combattait désormais l'ouvre de la nature.

Le Chef-de-Caux dont nous venons de parler était le caput caleti, la tête des Calètes qui occupaient la Normandie au temps de César, et dont Lillebonne (autre ville morte) était la capitale. - Lin 1345, l'importance de ce port était telle qu'il fournissait à la flotte de Philippe de Valois trois vaisseaux de guerre, un de plus

1. Voy. F. DE Connck, Le IIavre, son passé, son présent, son avenir. 
que Fécamp, un de moins que Cherbourg. En 1364, on plaç, par

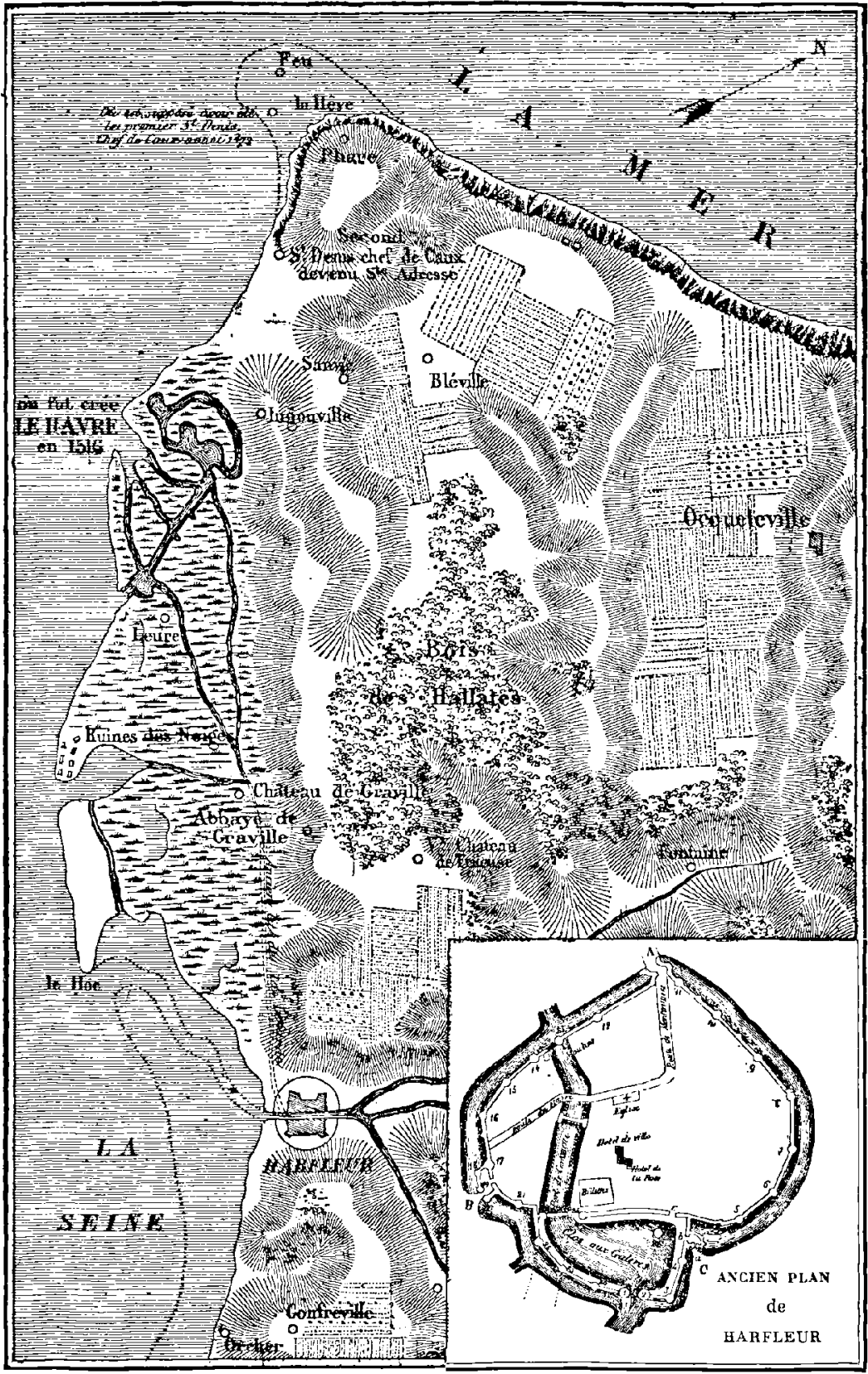

Fig. 130. - L'embouchure de la Seine il y a quatre cents ans, avant la fondation du Havre.

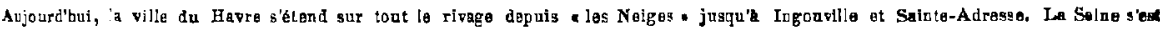
silomitro. 
ordre de Charles V, un feu pour faciliter le commerce des Castillans " qui apportaient au Quief-de-Caux, à Leure et à Harfleur, des vins, du blé, de la cire, du sel et des cuirs mégissés à Cordoue. „Ce fut l'un des premiers phares de France. La ville et le phare ètaient au sommet de la falaise qui, alors, se continuait à quatorze cents mètres environ au delà du rivage actuel, jusqu'au banc de l'Éclat, que l'on distingue encore aujourd'hui à marée basse et qui n'est qu'à quelques mètres au-dessous de l'eau. En 1372, peu de temps, comme on le voit, après l'établissement du phare, la mer ayant rongé les falaises, une partie du pays s'écroula et fut submergée, notamment le phare, le cimetière et l'èglise, consacrée à saint Denis. Une ordonnance royale de janvier 1373 en décida le rétablissement. L'église fut rebâtie où elle est aujourd'hui, au pied du vallor. Fn 1491, il est encore question du Quief-de-Caux comme d'un port militaire à défendre contre les Anglais. La mer a continué de ronger les falaises; le phare a dù être reculé de siècle en siècle : les deux tours que l'on voit aujourd'hui ont été élevées en 1775, et il est probable que la mer les atteindra dans le courant du siècle prochain ('). La petite ville de Saint-Denis-Ghef-de-Caux s'est reculée, elle aussi, de siècle en siècle; elle y a perdu tous ses anciens souvenirs et jusqu'à son nom : c'est aujourd'hui Sainte-Adresse ( ${ }^{2}$ ).

L'érosion de la falaise par les vagues de la mer suffit entièrement pour expliquer la diminution du rivage. Sans les a épis », solides charpentes de bois que l'on entretient pour garantir la falaise de Sainte-Adresse, elle diminuerait encore plus vite, d'autant plus qu'une partie de la côte glisse lentement sur un lit de terre glaise. Sans que nous le remarquions, tout change autour de nous, par l'influence mème des causes actuelles. Et ce sont là, simplement,

1. Depuis l'année 1865, nous passons de temps en temps quelques jours dans la villa d'un philosophe éclairé, qui préfère la contemplation solitaire de la nature à la fréquentation bruyante de l'humanité, au milieu de ce cadre, à la fois granliose el charmant, des falaises du cap de la Hève. D'année en année, quelques heures d'observation suffisent pour permettre de constater l'envahissement graduel de la mer et les transformations lentes du littoral.

2. L'or'gıne du nom de Saint-eAdresse est assez curieuse. Un yaisseau allait périr dans une tempête; l'équipage désespéré se bornait à invoquer saint Denis : « Mes amis, s'écria le capitaine, ce n'est pas saint Denis qui nous sauvera, c'est sainte adresse. Allons! du courage! Une heureuse manœuvre amena le navire au port, et le nom de Sainte-Adresse fit fortune. 
ce que l'on appelait autrefois « les révolutions du globe. " L'examen attentif de notre figure 131, due à un naturaliste du Ilavre

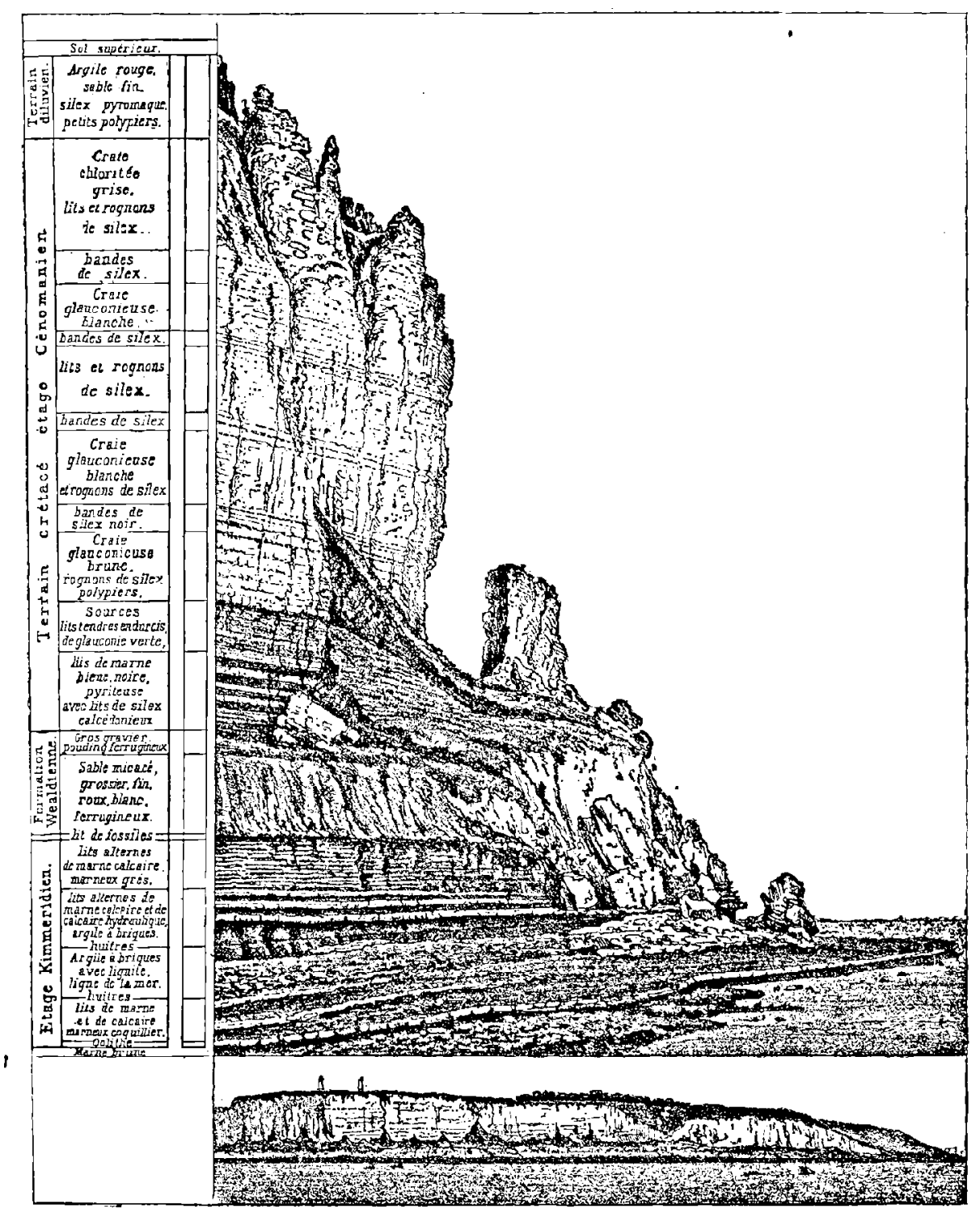

Fig. 131. - Le cap de la Heve et sa constitution géologique.

(A. Lesueur), suffira pour montrer comment en minant la base de la falaise, surtout aux jours de tempètes et de grandes marées, la mer désagrège ces bancs géologiques, composés de craie, de 
marne et d'argile, laisse surplomber des murs verticaux (qui mesurent ici cent mètres de hauteur au-dessus du niveau des eaux), dont elle ne tarde pas à délayer de nouveau la base et à faire effondrer les assises séculaires. Cette œuvre de la mer a donné un grand pittoresque à ces rivages. Il est des heures de lumières et d'ombres, surtout en automne, vers le coucher du soleil, où le spectacle de l'immensité des eaux contemplé de ces hauteurs à pic qui s'avan. cent en cap au milieu des flots, donne à l'homme l'impression simultanée de sa petitesse et de sa grandeur; de sa petitesse, comme rouage microscopique du mystérieux mécanisme de la nature; de sa grandeur, comme esprit s'élevant par l'exercice de ses facultés à la conception de l'histoire mème de ce vaste univers dont il fait partie intégrante.

Depuis la fin du onzième siècle, il y a là 1400 mètres de dévorís par l'avancement de la mer; c'est près de deux mètres par an.

Primitivement, les rivages de toutes les mers étaient peu inclinés: c'est l'érosion qui a produit ces murailles verticales et ces falaises, dont le désagrègement incessant donne naissance aur galets de ces plages. On remarque mème une différence caractéristique entre le mode d'érosion, le profil, des falaises rongécs graduellement par l'action lente d'une mer à niveau constant, comme la Méditerranée, où les marées sont insensibles, et celui des falaises de l'Océan. Dans le premier cas, les roches lavées par les flots et dénudées présentent un profil simple (fig. 132); dans le second cas ( $f g .133)$, le profil est double, dessiné par les niveaux de haute et de basse mer. Il y a là l'effet d'une action mécanique des eaux facile à saisir. Sur les plages sablonneuses, les sables sont rejetés par la mer, et généralement la mer perd de son domaine.

Malgré les différences dues à l'attraction des continents, aux variations dans la pression atmosphérique, aux effets divers des marées sur le littoral, on peut considérer le niveau des mers comme à peu près constant, et c'est la meilleure ligne de repère à laquelle on puisse se rapporter. Lorsqu'on observe une différence de niveau, constatée d'un siècle à l'autre, sur un rivage quelconque, on doit scientifiquement admettre que ce n'est pas la mer qui a changé de niveau, mais le sol lui-même. La mer garde constamment le mème niveau moyen, parce que l'eau qui tombe, sous forme de pluie ou 
de neige, est égale à celle qui s'élève de la mer par évaporation, et il n'en peut pas être autrement, puisque les nuages sont précisément formés par la vapeur d'eau enlevée à la mer et à toutes les eaux par la chaleur solaire. L'égalité entre l'évaporation et Ja précipitation est un équilibre naturel, qui ne peut pas ne pas être. Pourtant, il n'y a pas fort longtemps que ce circuit est apprécié dans sa véritable nature. Comme on ne voit pas la vapeur d'eau qui, sous forme invisible, s'élève de la mer dans les hauteurs de l'atmosphère, on ne devinait pas d'oủ viennent les nuages, d'où vient la pluie, d'où viennent les sources, les ruisseaux, les rivières et les fleuves. Au siècle dernier encore, le géologue Vallisneri dut combattre les théories de Burnet, Whiston et Woodward; « il se trouva forcé de soutenir, dit Lyell, contre saint Cérôme et contre quatre autres ínterprètes de la Bible, sans compter les professeurs de théologie, que les sources ne dérivent pas de la mer en passant par des siphons souterrains et des cavités, et en perdant leur salure en chemin, cette théorie n'ayant été imaginée que dans le but de se conformer au témoignage des Ecritures. »

On estime à environ $1^{\mathrm{m}} 50$ la hauteur de la pluic qui tombe chaque année sur i'ensemble du globe. Par conséquent, telle est précisément la quantité qui s'évapore pour former les nuages. L'Océan s'abaisserait d'année en année si l'eau était emportée en dehors de la Terre. Mais elle retombe en pluie sur l'Océan luimème, ou lui est restituée par les cours d'eau qui lui ramènent l'eau des pluies. Lorsqu'il pleut, une partie de l'eau tombée retourne immédiatement à l'atmosphère par évaporation; le reste pènètre les terrains jusqu'à la rencontre d'une couche d'argile imperméable. Là, elle glisse sur cette couche et finit généralement par affleurer à la surface de la terre, et former une source. Telle est l'origine de toutes les sources, de tous les ruisseaux, de toutes les rivières, de tous les fleuves. Il y a des sources à tous les niveaux, depuis le voisinage des sommets montagneux jusqu'au fond de la mer. Cette évaporation, cette condensation en nuages dans les hauteurs de l'air, et cette précipitation en pluic constitue, en fait, un immense alambic naturel. La chaleur solaire employée pour élever cette quantité d'eau à la hauteur moyenne des nuages est égale au travail qui serait réalisé par quinze cent milliards de 
chevaux travaillant sept heures par jour... La Terre entière ne suffirait pas à les nourrir!

Comme le sel ne s'évapore pas, l'eau des nuages, des pluies, des sources et des cours d'eau, est de l'eau douce, de l'eau distillée par le soleil. L'eau normale, l'eau de la mer, est salée, parce qu'elle est formée par de l'hydrogène, de l'oxygène et du chlorure de sodium. Elle pourrait être, d'ailleurs, d'une toute autre composition. L'océan

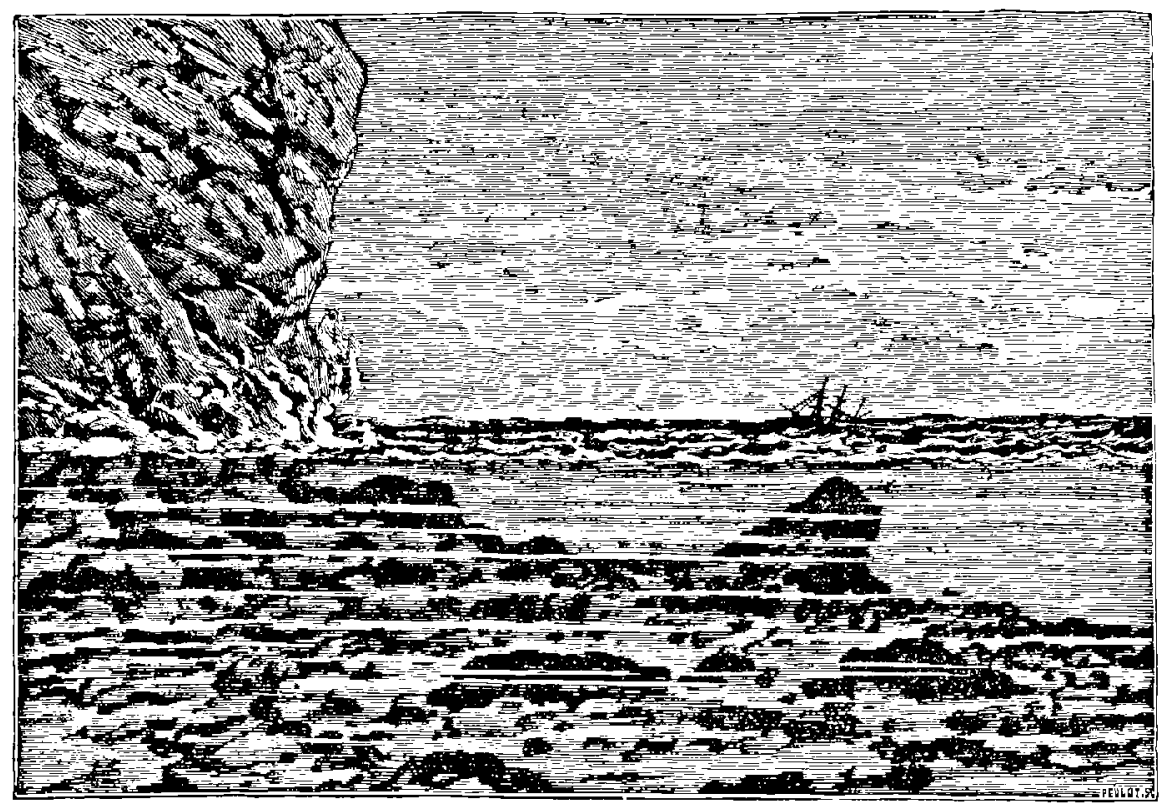

Fig 132. - Falaise méditerranéenne.

de feu qui brûlait autour du globe terrestre était composé d'hydrogène, d'oxygène et de sodiun, comme colui qui brûle actuellement autour du soleil, et dans son ardente atmosphère flottaient les vapeurs de tous les éléments qui existent actuellement sur notre planète.

Une infinitésimale partie de l'eau des pluies ne retourne pas à la mer, parce qu'elle ne trouve pas, en pénétrant le sol, de couche absolument imperméable qui l'y ramène. Elle s'enfonce profondément dans l'intérieur du globe, arrive à saturer les roches, forme les eaux minérales, descend dans les régions chaudes où elle donne naissance à des vapeurs et à des explosions, et, dans tous 
les cas, est perdue pour la surface. La mer diminue done un peu de siècle en siècle; mais en dix siècles, en mille, deux mille oin trois mille ans, cette diminution est insensible pour l'observation, et pour la mémoire humaine, le niveau des mers reste constant (1).

A son origine, qu'il prenne'sa source dans les glaciers, comme le Rhin, le Rhône, le $\mathrm{Pô}$, la Garonne, ou dans les ruisseaux des montagnes, comme la Seine, la Loire, la Dordogne, etc., tout fleuve

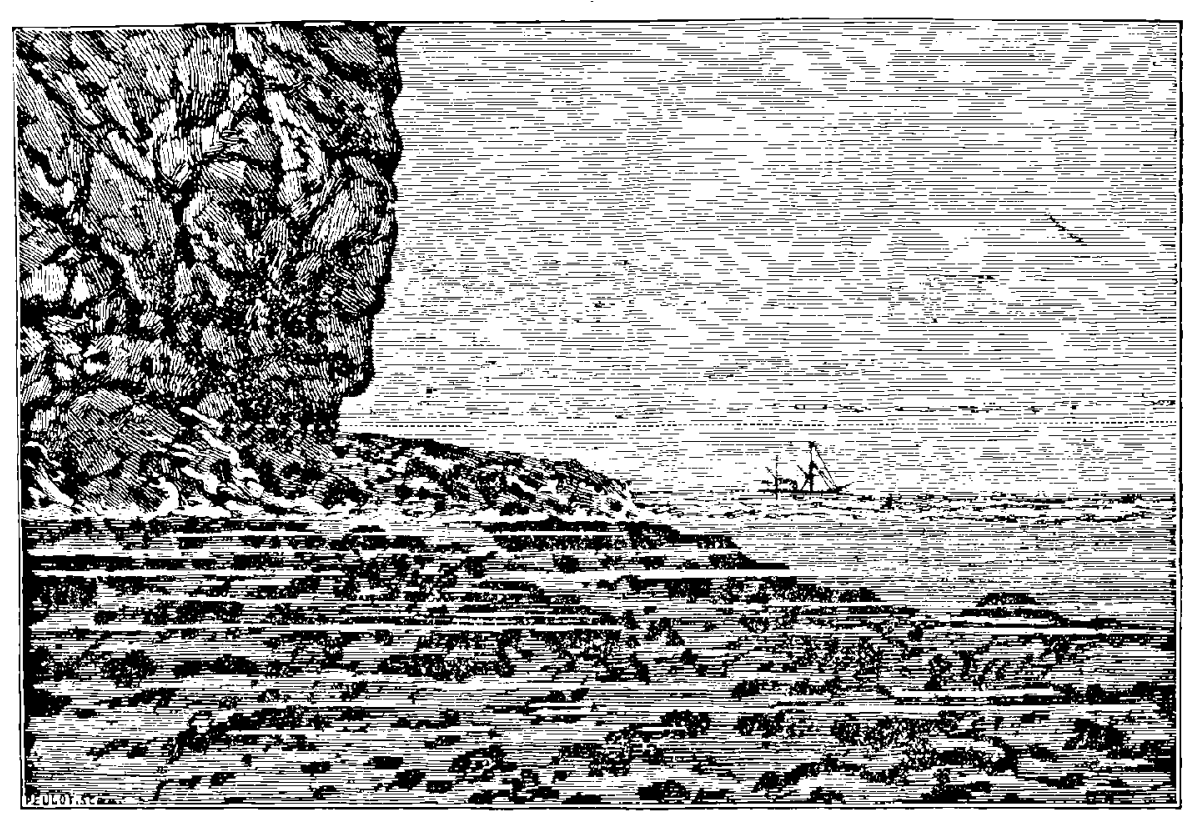

Fig. 133. - Falaise de l'o céan.

1. En certaines régions, certes, l'évaporation est beaucoup plus grande que la moyenne générale. Ainsi, par exemple, il ne pleut presque jamais sur la mer Rouge ni aux environs, et l'èvaporation y est tellement active qu'une couche de 7 mètres d'épaissenr y est enlevée chaque année sous forme de vapeur. Cette mer serait desséchée depuis longtemps et remplacée par une vallée de sel cristallisé si elle n'ètait pas alimentée par la mer des Indes et l'Océan. Dans nos climats mème, l'évaporation est telle que s'il n'y avait pas de sources pour alimenter la Seine sur son parcours, elle s'évaporerait tout entière le long de son trajet de Paris au Havre.

Le niveau de la mer Rouge est le même que le niveau moyen des mers, à cause de sa communication avec l'Océan, et, pour la même raison, il en est de même de celui de la Méditerranée, quoique son évaporation surpasse d'un tiers environ l'apport des fleuves.

La mer Caspienne étant fermée a perdu son niveau par évaporation, et a baissé de cent mètres; la mer Morte a baissé de quatre cents mètres; leur niveau est constitué désormais par l'équilibre entre leur évaporation et la pluie qu'elles reçoivent.

LE MONDE AVANT La CRÉATION DE L'HOMMÉ 
suit une pente rapide, qui lui donne un cours torrentiel dans la saison des pluies, et le conduit à dégrader les terrains le long dcsquels il se précipite. Il creuse des vallées, détache des rochers, roule des pierres, broie les matériaux qu'il charrie, et finit par entrainer dans ses eaux une grande quantité de sable et de limon. La partie supérieure de son cours est une zone de dénudation, d'érosion; la scconde, dans laquelle le courant est assez rapide pour entraîner les matériaux, mais plus régulier et plus large, est une zone de compensation: il ne creuse plus son lit, mais ne le comble pas; la troisième, dans laquelle la pente devient insensible et se rapproche de la grande plaine maritime, est une zone de dépôt, d'alluvion. Ainsi, par exemple, le Rhône, qui prend sa source dans les Alpes, à 1760 mètres d'altitude, arrive au lac de Genève après avoir suivi une pente moyenne de $7^{\mathrm{m}} 40$ par kilomètre. A son entrée dans le lac, il laisse déjà tant de dépôts que le lac de Genève diminue rapidement de longueur et de profondeur: les habitarits de cette extrémité du lac le constatent d'une généra'ion à l'autre. De Genève à Lyon, la pente n'est plus que de 1 mètre par kilomètre; de Lyon à Beaucaire, elle est de $0^{\mathrm{m}} 40$, de Beaucaire à Arles elle est réduite à $0^{\mathrm{m}} 12$; de Arles à la mer il ne reste en tout qu'un mètre de pente pour cinquante kilomètres, c'est-à-dire qu'il n'y a presque plus de pente du tout, la largeur du fleuve atteint sur certains points plusieurs kilomètres, sa vitesse, si grande à Genéve et même encore à Lyon, est presque réduite à rien, et tous les sables s'étendent en nappe que les vagues et les courants de la mer modifient sans cesse. - C'est là le type de tous les fleuves et du travail des eaux pour modifier la surface de la planète. Les uns, comme la Seine, la Gironde, la Tamise, l'Hudson, le Saint-Laurent, conservent une vitesse assez grande et sont assez heureusement balayés par les courants de la mer, pour garder libres leurs embouchures, ct permettre à de vastes ports de s'y établir: le Havre, Bordeaux, Londres, New-York, Québec ; les autres, comme le Rhône, le Pô, le Nil, le Danube, charrient si lentement leurs sables qu'ils exhaussent insensiblement leur fond et oblitèrent tout passage.

L'examen de l'embouchure du Rhône apporte les plus intéressants documents sur cette même question géologique et historique 
de la variation des rivages. L'histoire d'Aigues-Mortes, entre autres, est particulièrement remarquable, non point, comme on le croit généralement, que la mer se soit retirée depuis l'époque où saint Louis s'y est embarqué pour les Croisades, mais parce que l'embouchure du Rhône a subi là des transformations significatives. La mer s'est retirée, en effet, mais non comme on l'enseigne généralement: pas du tout au point du littoral le plus voisin d'AiguesMortes, de 4 kilomètres à l'embouchure du Petit-Rhône, et de 10 kilomètres à l'embouchure du Grand-Rhône. Quant à AiguesMortes, saint Louis s'est embarqué en 1248 et 1270 dans l'ancien chenal qui conduisait les eaux du Rhône à la mer et qui a gardé le nom de «canal-viel», et aboutissait au «Grau-Louis » (voy. fag. 134). Les plus anciennes cartes nous montrent Aigues-Mortes baignée par l'eau de ces nombreux bras du Rhône aujourd'hui atterris et désignès sous le nom de Rhônes morts. Après avoir jeté longtemps ses eaux à l'ouest d'Aigues-Mortes, dans l'étang de Mauguio, le grand fleuve s'cst peu à peu arancé vers l'est, les anciens Rhônes ont été remplacés par le Rhône vif, celui-ci par le Petit-Rhône, et enfin le grand courant a fini par s'établir dans le Rhône d'Arles actuel. Les embouchures du fleuve se sont déplacées de l'ouest à l'est. On montre le long des remparts d'Aigues-Mortes les traces des anneaux de fer où l'on amarrait les navires, mais c'était l'eau du Rhône et des étangs qui venait baigner ces murs (ccux-ci, du reste, ne datent pas de saint Louis, mais de son fils Philippe le Hardi ; quand saint Louis, désireux de posséder un port sur la Méditerranée, acheta, en 1248, au Inonastère de Psalmodi, Ia ville d'Aigues-Mortes et son territoire, il $\mathbf{y}$ avait déjà des étangs et marais entre cette cité et la mer; à cette époque, Psalmodi était une île monastique entourée par le Rhône.)

On sait que le Rhône se partage en deux branches principales au-dessus d'Arles. La branche orientale ou grand Rhône, se jette dans la mer à l'est du golfe de Fos, le bras occidental ou petit Rhône se divise lui-mème en deux bras pour former le delta de la Camargue, l'oriental se jette dans la mer non loin du village des Saintes-Maries et l'occidental à dix-sept kilomètres de là à l'ouest. Anciennement, le petit Rhône passait à Aigues-Mortes, et plus anciennement encore il allait se jeter dans l'étang de Mauguio. Au- 
jourd'hui presque tout est endigué, et de Beaucaire même un canal descend par Saint-Gilles et Aigues-Mortes jusqu'à la mer. L'industrie humaine a modifié l'œuvre de la nature. Malgré les digues, toutefois, les bouches du Rhòne continuent de se transformer rapidement d'année en année; le grand bras actuel n'existe que depuis cent cinquante ans, et il est destiné à changer de place aussi bien que tous les autres bras. Tout le sol est presque au niveau de la mer, et ce sont les atterrissements du fleuve qui l'ont formé. Le Rhône apporte annuellement $\dot{a}$ son embouchure dix-huit $\dot{a}$ vingt millions de mètres cubes de sable et de vase et s'avance graduellement. Les vagues de la mer, surtout aux jours de tempètes, chassent à leur tour ce sable et dessinent la configuration du rivage sous la direction $d u$ vent dominant (est-sud-est vers ouest-nordouest. On a construit des tours à son embouchure: on en compte aujourd'hui quatre à cinq de chaque côté; la dernière, élevée en 1737, surr le rivage même, en est aujourd'hui à plus de sept kilomètres. C'est là un témoignage que le lit du Rhône s'est prolongé peu à peu dans la mer par des atterrissements successifs. C'est le contraire de ce qui se passe au cap de la Hève pour les phares.

Toute la côte de la Camargue n'avance pas ainsi; au contraire, l'action prédominante de la mer produit sur différents points du rivage des érosions considérables. Sans les apports incessants du Rhône, la côte de la Camargue et tout le littoral sablonneux du delta finiraient par disparaitre. Les contours et les variations du rivage sont donc le résultat d'une lutte permanente entre le fleuve qui le nourrit et la mer qui l'appauvrit. L'envahissement de la mer est très sensible au phare de Faraman : construit en 1836, à sept cent mètres environ de la mer, cet édifice est atteint aujourd'hui par les eaux.

L'avancement de la grande bouche du Rhône est à peu près de soixante mètres par an, et comme la direction du fleuve est exactement opposée au choc de la grosse mer du large, les atterrissements sont remaniés sur place et servent aux berges du fleuve. Tout à côté, 1a plage de Faraman, rongée par la mer, recule de quinze mètres par an aujourd'hui : au siècle dernier, l'érosion était du double. 
Tout le golfe du Lion, depuis les Pyrénées jusqu'à Marseille, offre des témoignages de la variété d'action des éléments dans la modification permanente du globe ('). Il y a deux mille ans, avant la domination romaine et pendant cette domination, un nombre considérable de villes florissantes étaient échelonnées le long de ce golfe : Illiberris, à l'embouchure du Tech; Ruscino, sur la

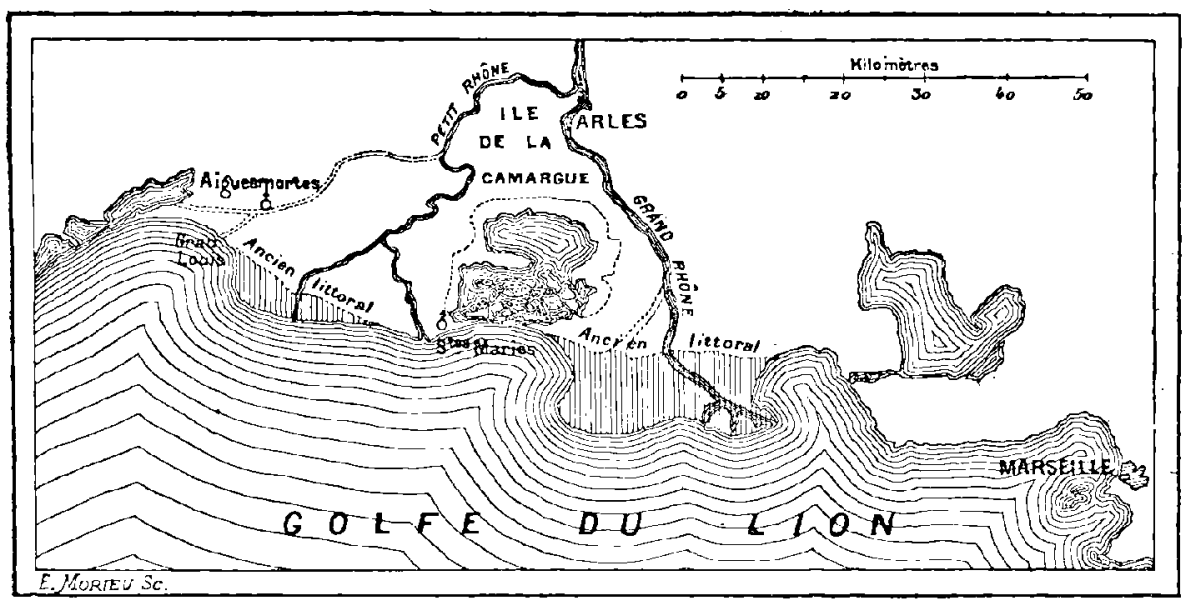

Fig. 131. - L'embouchure du Rhône.

Tèt; Narbonne, sur l'Atax; Agde, sur l'Hérault; Aigues-Mortes, Saint-Gilles, Héraclée, Rhodanusia et Arles, sur les différents

1. La plage des Saintes-Maries, où une tradition qui ne parait pas sans fondement fait débarquer, six ou sept ans après la mort de Jésus-Christ, Marie-Madeleine, son amie, accompagnée de plusieurs membres de la famille du maitre (notamment la scur de sa mère, Marie Jacobé, mère de Jacques le Mineur, et Marie Salomé, mère des apótres Jacques et Jean, ainsi que Lazare le ressuscité et Marthe sa sœur), la plage des SaintesMaries, disons-llous, existait déjà au commencement de notre ère, et sur ce point le littoral paruît avoir peu changé. Tne hypothèse récente explique cetle tradition par un souvenir du séjour de Marius et de sa prophétesse Marthe sur le même rivage, cent cinquante ans avant notre ère, et par un bas-relief antique taillế dans le rocher, près des Baux, désigné sous le nom de trémaz̈é et représentant trois personnages debout, drapés de longues tuniques. De ce document romain dédié à Marius, l'imagination populaire aurait fait un document chrétien, et les trémaïé seraient devenus les trois-maries : de telles défigurations ne sont pas rares aux premiers siècles du christianisme. L'llypothèse est admissible. Cependant des documents écrits remontant au cinquième siècle et une tradition constante n'cn désignent pas moins l'embouchure du Rhone comme ayant été le lieu de débarquement de Marie-Madeleine et de plusieurs parents du prophète. Le fait n'est pas absolument invraisemblable, étant données les traversées perpétuelles qui se faisaient alors comme aujourd'hui entre l'Orient et Marseille; d'autre part encore, nul n'ignore combien le culte de Marie-Madeleine est ancien dans les églises de France. 
bras du Rhône. Quatre de ces florissantes cités ont entièrement disparu, et il n'en reste que des ruines. Les autres sont mortes et leur état actuel n'est que l'ombre de leur splendeur passée. Autrefois, les cours d'eau étaient profonds et navigables, au moins à leur embouchure; et le long du rivage des lagunes analogues à celles de Venise étaient ouvertes à la navigation. Mais le lit des fleuves s'élève lentement. Alimentées autrefois

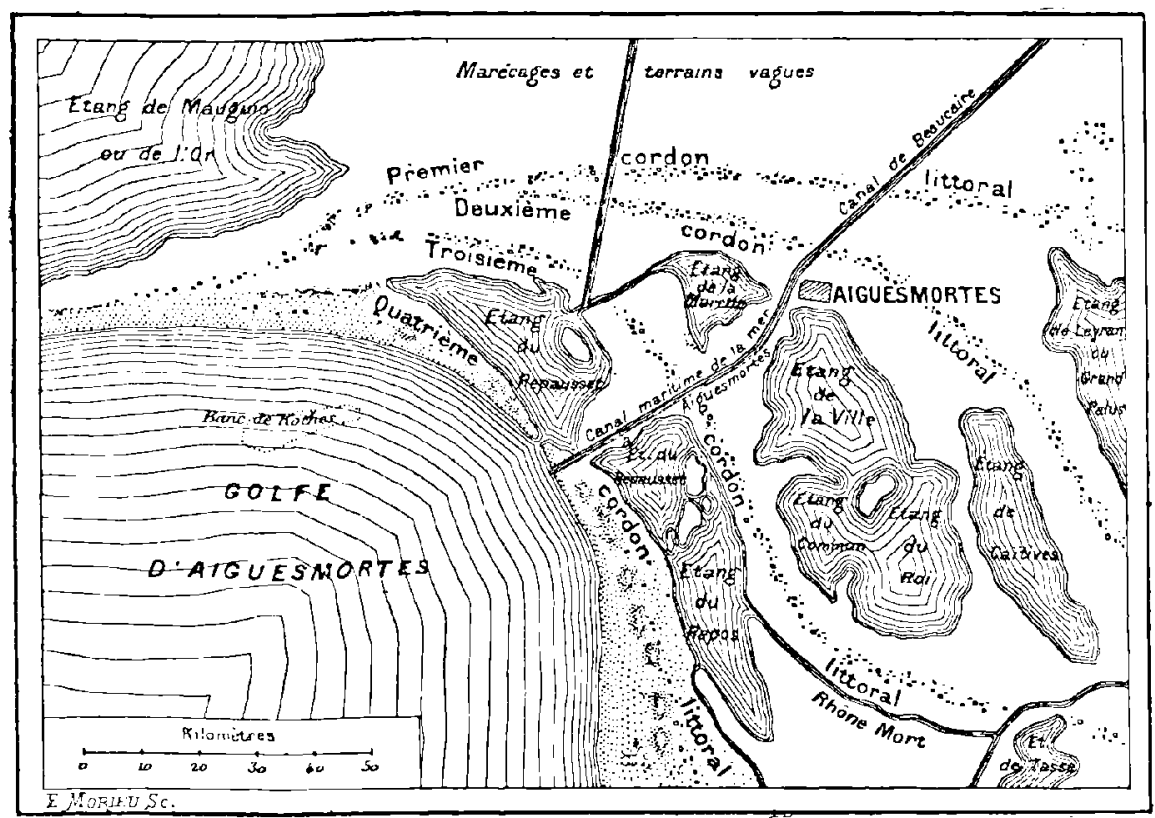

Fig. 135. - Les cordons littordux et le leut retrait de la mer.

par leurs fleuves respoctifs, nćes pour ainsi dire de la lagune, ces villes ont décliné et sont mortes avec elles. Les forêts ont été maladroitement détruites par l'homme. Les lagunes so sont changées en étangs, les étangs en marais fiévreux. Depuis plusieurs siècles on essaie de dessécher la plus grande surface de ces marais, mais la végétation n'y trouve pas encore une terre assez ferme. Insensiblement l'ancien domaine maritime fera place au domaine agricole (').

On jugera des atterrissements apportés par le Rhône pendant

1. СН. LentuÉrio. Les villes mortes du golfe du Lion. 
les temps historiques, à l'inspection du petit plan ( $f \mathrm{~g}$. . 134) reproduit ici (1).

Si nous voulions remonter jusqu'aux temps préhistoriques, nous constaterions que la mer s'est lentement retirée et que cette rétrogradation peut être directement appréciée par les quatre cordons

1. D'après M. Lenthéric. Certains savants sont en désaccord sur ce point; M. Desjardins, entre autres, pense que le rivage s'est avancé pour ainsi dire tout d'une pièce, beaucoup plus régulièrement, et trace ce rivage, au IV c siècle de notre ère, par une ligne presque horizontale, quoique sinueuse, menée de Fos à Aigues-Mortes. Nous penchons plutốt pour le tracé adopté ici, jugeant toujour's, naturellement, avec l'impartialité Ja plus absolue.

La plupart des questions qui sont l'objet de nos recherches dans le présent ouvrage, sont en voie de solution pour la science contemporaine; plusieurs peuvent être acceptées comme résolues; plusieurs, au contraire, ne le sont pas encore définitivement. La connaissance du «Monde avant la création de l'homme» est aussi nouvelle, en vẻrité, que celle des « Terres di Ciel », ef sur plusieurs points même la géologie est moins a.vancéc que l'astronomie. Il est quelquefois difficile de se décider, lorsque indépendant de tout préjugé antérieur, on a fait, comme Descartes, table rase pour n'accepter que ce qui est démontré. Dans la question capitale de l'origine de la vie, nos lecteurs scientifiques ont pu juger comme nous que le fruit est mutr et que notre opinion peul ètre légitimement fixée. Ici, dans l'appréciation des changements survenus à la surface du globe, et des causes actuelles qui continuent d'agir, les plus laborieuses comparaisons de documents ne suffisent pas toujours pour autoriser une conclusion affirmative. Ainsi, par exemple, l'un des plus illustres géologues de notre siècle, Lyell, assure (Principes de Géologie, I, 562) que \& le plus remarquable monument qui prouve l'accroissement du delta du Rhône depuis l'épóque des Romains, est le grand et bizarre détour de l'ancienne voie romaine qui allait d'Ugernum (Beaucaire) à Biterrae (Béziers) en passant par Nemausus (Nîmes). Il est évident, déclare-t-il, qu'à l'époque où ce chemin fut construit, on ne

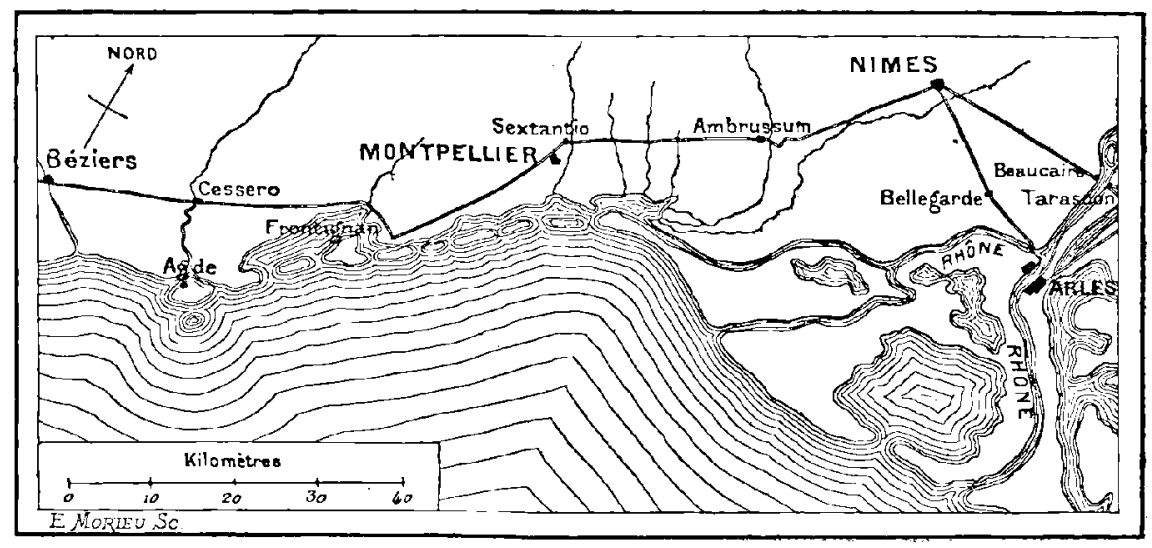

Fig. 136. - Voie romaine de Beaucaire à Béziers

pouvait, comme on le fait à présent, traverser le delta en ligne droite, et que la mer ou des marais occupaient alors l'cspace qui est devenu terre ferme». Eh bicn, nous avons beau examiner cette voie romaine, nous ne trouvong rien de surprenant à ce qu'on 
littoraux qui dessinent les anciens rivages. Ces cordons, toutefois, ne sont pas anciens : ils appartiennent à l'époque géologique actuelle ou quaternaire; tout le terrain du delta du Rhône est, du reste, quaternaire.

On conçoit facilement que la tendance des fleuves à leur embouchure soit d'allonger le continent aux dépens de la mer et de déposer progressivement les débris arrachés aux montagnes par les torrents et pulvérisćs. Co mouvement suffit pour transformer lentement la configuration géographique des diverses contrées. L'exemple de l'embouchure du Pô, en Italie, est des plus caractéristiques et des mieux étudiés. Examinez, entr'autres, la petite carte ci-dessous (fig. 137), vous remarquerez dès le premier coup d'œil l'échancrure dessinće dans la mer adriatique par les alluvions dues aux bouches du Pô. La ville d'Adria, qui a donné son nom à l'Adriatique, était à son origine, du temps des Etrusques, il y a environ trois mille ans, sur le rivage même de la mer. Elle est aujourd'hui éloignée à 26 kilomètres du point le plus proche : l'Adige et les divers bras du Pô chassent insensiblement le rivage; l'embouchure principale du fleuve est actuellement à 35 kilomètres du méridien d'Adria. L'avancement de la terre dans la mer, est sur ce point, de soixante-dix mètres par ari. Le fleuve apporte

l'ait fait passer par l'importante ville de Nìmes, cité considérable, toute romaine d'ailleurs (séjour de plusieurs empereurs), plulòt que par le désert du rivage, lors même que le rivage eût été le méme que de nos jours, et nous sommes persuadé que la plupart de nos lecteurs partageront notre avis à l'inspection de ce tracé. Une grande route dans ces parages eût été à peu près inutile et son absence ne prouve rien. - On lit quelques lignes plus loin dans le même auteur: ce qui prouve encore la grande ètendue de la terre ferme qui s'est formée depuis les Romains, c'est qu'ils n'ont jamais parlé des eaux thermales de Bàarue comme étant dans le dela; quoiqu'ils connussent parfaitement celles d'Aix ainsi que d'autres plus éloignées et qu'ils y attachassent, comme à toutes les sources chaudes, une grande importance. Les eaux de Balaruc doivent avoir jailli autrefois sous la mer. , Or, allez à Balaruc (qui, par parenthèse, n'est pas dans le delta du Rhơne, mais dans le département de l'Hérault, près de Frontignan) et l'on vous montrera la place des anciens bains romains, que Lyell ne connaissait pas, puisqu'ils n'ont été découverts qu'en 1863, mais dont le tẻrnoignage négatif ne prouverait rien comme on voit. - Ouvrez Buffon: Théorie de la Terre, vous y lirez: «Aigues-Mortes qui est actuellement à plus d'une demi-lieue de la mer, était un port du temps de saint Louis. \& Et c'est là l'opinion commune. Nous avons vu qu'il n'en est rien. Etc., etc.

Nous avons fait nos efforts pour dégager la vérité au milieu d'un grand nombre de documents contradictoires, et pour apporter la plus grande précision possible dans cette étude intéressante, mais à peine mûre et laboricuse. 
annuellement $42 \pi 60000$ mètres cubes de limon, soit $1^{\mathrm{m}} 36$ par seconde (Lombardini). C'est un fleuve travailleur des plus actifs, à cause des Alpes et de leurs torrents; le Danube, qui a cinq fois la masse d'eau du Pô, ne porte à la mer que 35500000 mètres cubes d'alluvions par an.

Les digues commencées dès le XIII ${ }^{\mathrm{e}}$ siècle garantissent, il est. vrai, le pays, des inondations annuelles auxquelles il était exposé, mais le fond du lit s'exhausse lentement, et actuellement la surface

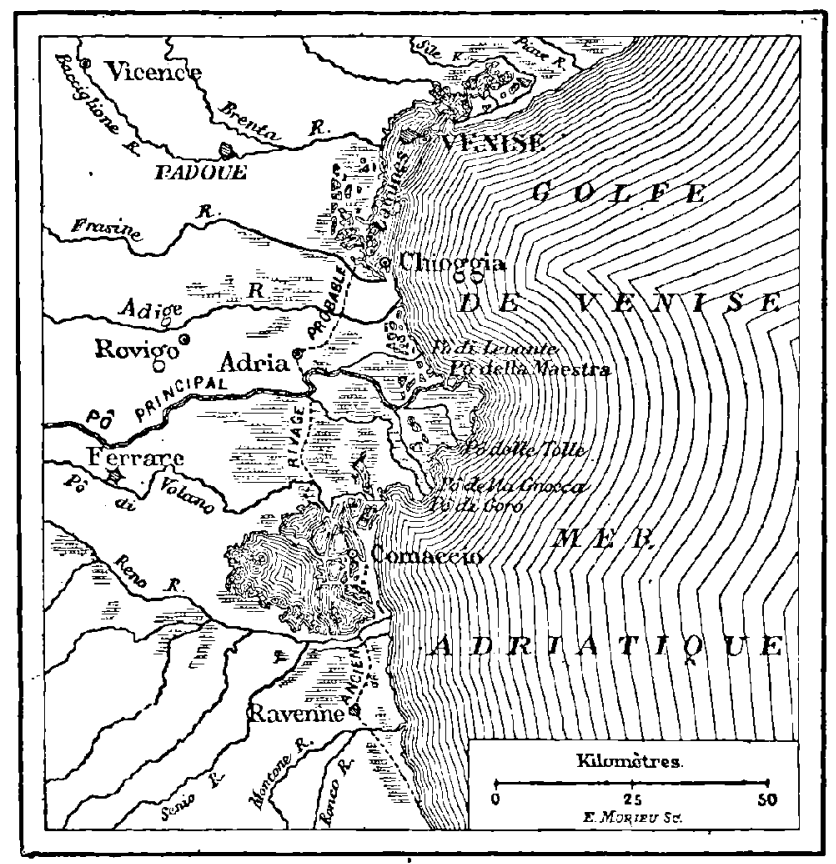

Fig. 13̄̆ - Diminution graduelle de la mer à l'embouchure du Pô.

des eaux du Pô est - non pas plus élevée que le toit des maisons de Ferrare, comme l'ont écrit Prony et Cuvier, - mais néanmoins un peu supérieure au sol des régions adjacentes; dans les grandes crues, comme celles de 1870 et 1872 , elle arrive à deux ou trois mètres au-dessus du niveau du pavé. Lorsqu'après les saisons de pluics une rupture s'ourre dans ces digues, les inondations qui en résultent répandent partout la ruine et la mort sur leur passage. Lorsqu'ils ne sont pas détruits par la violence de l'irruption, les points habités deviennent des iles. - Un jour, visitant la 
ville de Ferrare (automne de 1872), une rupture des digues du Pô amena les eaux tout autour des remparts et nous dủmes attendre près d'une semaine le rétablissement des communications interrompues. - D'aprẻs la comparaison des documents, nous avons tracé sur la petite carte de cette région ( $f g .137)$, l'ancien rivage probable d'il y a trois mille ans. A sa fondation (mème époque), Ravenne était également port de mer; elle l'était encore sous Auguste, qui l'agrandit et en fit un port militaire : elle est aujourd'hui à sept kilomètres de la mer.

On reçoit la mème impression si l'on examine l'embouchure du Tibre, à Ostie, près de Rome. Ostie, comme tout le monde le sait, veut dire bouche. Ce port a été établi dès l'origine de Rome, par Ancus Martius, à l'embouchure même du fleuve. Actuellement les ruines de l'antique Ostia se trouvent à quatre mille mètres de l'embouchure du fleuve. C'est de ce port que partit pour l'Espagne la flotte de Scipion l'Africain. De 80000 habitants, la population est tombée à 50 pauvres infortunés qui désertent même en été, à cause de la malaria. Le village moderne a été fondé en 830, par Grégoire IV, un peu au-dessus de l'ancien, ensablé. En 1569, on construisit au bord de la mer la tour San Michele, qui en est aujourd'hui éloignée de sept cents mètres (et mème de quinze cents si l'on considère l'embouchure du fleuve). Dès le temps de l'empire romain, on fut obligé de creuser le port et le canal de Fiumicino pour remplacer l'embouchure ensablée du fleuve. D'après Rozet, l'avancement du delta du Tibre est en moyenne de $3^{\mathrm{m}} 90$ par an depuis le point de repère pris en 1662. Le nivean de la mer n'a pas changé $\left({ }^{4}\right)$. On peut se rendre compte du déplacement du rivage par la petite carte ci-dessous ( $f g .138$ ).

Les anciens n'ignoraient pas ces changements, dont les atterris-

1. On jugera de ces transports de sable par les calculs suivants :

La Loire fait passer à Nantes chaque année 400000 mètres cubes de sable charrićs dans 24 milliards de mètres cubes d'eau.

La Garonne fait passer par an à Marmande 2850000 mètres d'alluvion emportés dans 25 milliards de mètres cubes d'eau.

De 1847 a 1867 , soit en vingt ans, on a enlevé du lit de la Seine, sur 42 kilomities de longueur, en aval de Rouen, 60 millions de mètres cubes de sable. Le volume moyen d'eau de mer refoulée, par marée, en amont des sables entraínés, peut être évalué á environ 30 milions de mètres cubes, et le volume moyen des eaux douces descendantes est de 20 millions. 
sements du Nil en Egypte leur offraient un exemple si remarquable. Il y a 2400 ans, Hérodote écrivait que les prêtres d'Égypte regardaient déjà leur pays “ comme un présent du Nil. "Selon lui, le delta serait d'époque récente. Homère parle de Thèbes commesi elle eùt été seule en Egypte et ne fait aucune mention de Memphis. Jadis les branches du fleuve qui se jettent dans la mer à Canope et $\dot{a}$ Péluse étaient les principales et la côte s'étendait presque en ligne droite de l'une à l'autre, comme on le voit sur les cartes de Pto-

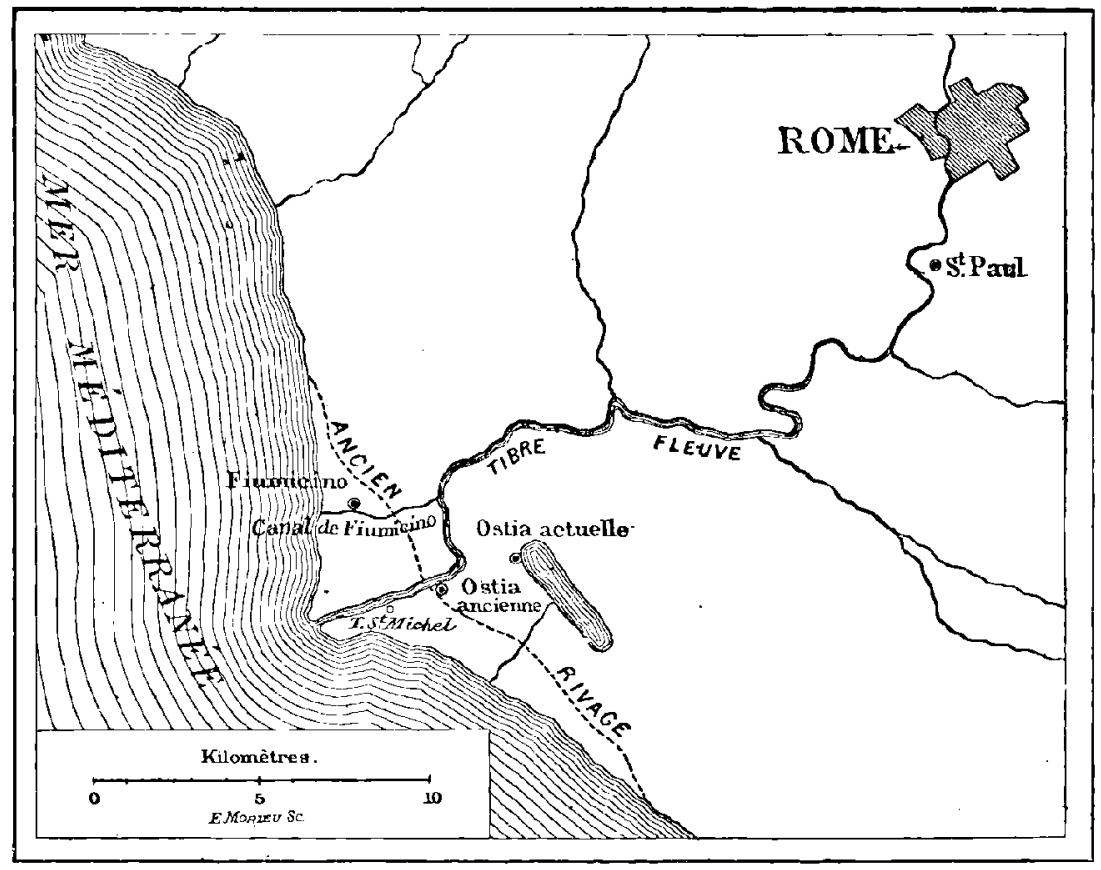

Fig. 138. - Diminution graduelle de la mer à l'embouchure du Tibre.

lémée. Maintenant Canope et Péluse sont en ruine dans l'oubli du passé, les bouches principales du fleuve se sont rapprochées l'une de l'autre et portent depuis deux mille ans les eaux dans la direction de Rosette et de Damiette, cités bâties au bord de la mer il y a moins de mille ans et qui en sont dèjà reculées à huit kilomètres. C'estle Nil lui-même qui a donné sa forme circulaire à labase du delta, laquelle mesure près de trois cents kilomètres de développement; la superficie actuelle du delta est de 22276 kilomètres carrés. On a calculé que si tout le limon apporté par les bouches du Nil était 
uniformément rejeté sur le littoral, celui-ci avancerait d'environ quatre mètres par année; mais cette avance est fort irrégulière et le fleuve tend à abandonner presque toutes les alluvions sur ses campagnes riveraines et à exhausser le sol; les agriculteurs modifient aujourd'hui sensiblement l'œuvre de la nature par les colmatages, la culture industrielle et les pompes à vapeur ( $\left.{ }^{4}\right)$. Nous avons tracé sur la carte actuelle des bouches du Nil (fig. 139) la ligne de l'ancien rivage d'après Ptolémée, lequel, comme on le sait, était égyptien et habitait le pays.

Le Mississipi et le Gange sont plus remarquables encore. Le premier a poussé ses alluvions jusqu'à quarante kilomètres dans la mer; le Gange et le Brahmapoutra versent dans la baie du Bengale un milliard cent trente-deux millions de mètres cubes de terre par an!

Nous pourrions facilement multiplier ces exemples. Nous avons choisi les principaux comme types caractéristiques; nos lecteurs peuvent eux-mèmes leur en adjoindre d'autres: il suffit d'examiner une carte de département riverain pour remarquer les échancrures formées dans la mer par les alluvions des embouchures de fleuves et de rivières (ex. : le Var, l'Hérault, la Vire, l'Orne, la Dives ( ${ }^{2}$ ), la Touque, etc.). Il va sans dire que cet avancement ne se produit que lorsque rien ne s'y oppose efficacement; beaucoup d'embouchures présentent un aspect contraire, par suite de la configuration géologique des roches, de courants maritimes ou mème d'affaissements du sol; mais le résultat est le mèrne : transformation séculaire. Il y a bien peu de points qui n'aient pas changé du tout, seulement depuis les temps historiques.

1. Le travail des fleuves dans les atterrissements est destiné à diminuer d'année en année, par suite de l'ulilisation des eaux par les agriculteurs. Le Po sert déjả à l'irrigation de centaines de milliers d'bectares : cinquante-cinq millions de mètres cubes d'eau par jour lui sont empruntés pour les cultures de la Lombardie et de la Vénitie. La Durance est utilisée pour la fertilisation de la Provence; le Gange livre les six sepliènes de ses eaux pour servir trois millions d'etres humains; dans le riche delta du Nil, cinquante mille puits d'arrosement ne cessent de fonctionner aux dépens du fleuve et de ses canaux. Les cours d'eau sont déjà bus en partie et détournés avant d'arriver à la mer.

2. A Dives, la mer s'est retirée de deux kilomètres depuis l'époque (1066) où Guillaume, duc de Normandie, s'y embarqua avec 400 navires et 67000 hommes d'armes pour aller conquérir l'Angleterre : de vastes prairies occupent aujourd'hui l'emplacement de l'ancien port. 
Par ce travail des eaux, les montagnes s'abaissent et le fond des mers s'exhausse. La Durance roule dans ses eaux jusqu'à 63 millièmes de limon, la Garonne 10 millièmes, le Rhin 6 millièmes, l'Indus de 2 à 5 millièmes. Ce sont là des maxima, après les crues et les torrents. Il y a des jours où le Danube verse dans la mer jusqu'à 1250000 mètres cubes de terre! D'après une comparaison judicieuse des divers apports des fleuves, M. Élisée Reclus est conduit à admettre qu'il y a environ dix kilomètres cubes de terre de jetés pur an dans la mer par l'ensemble de tous les cours d'eau. Réparti

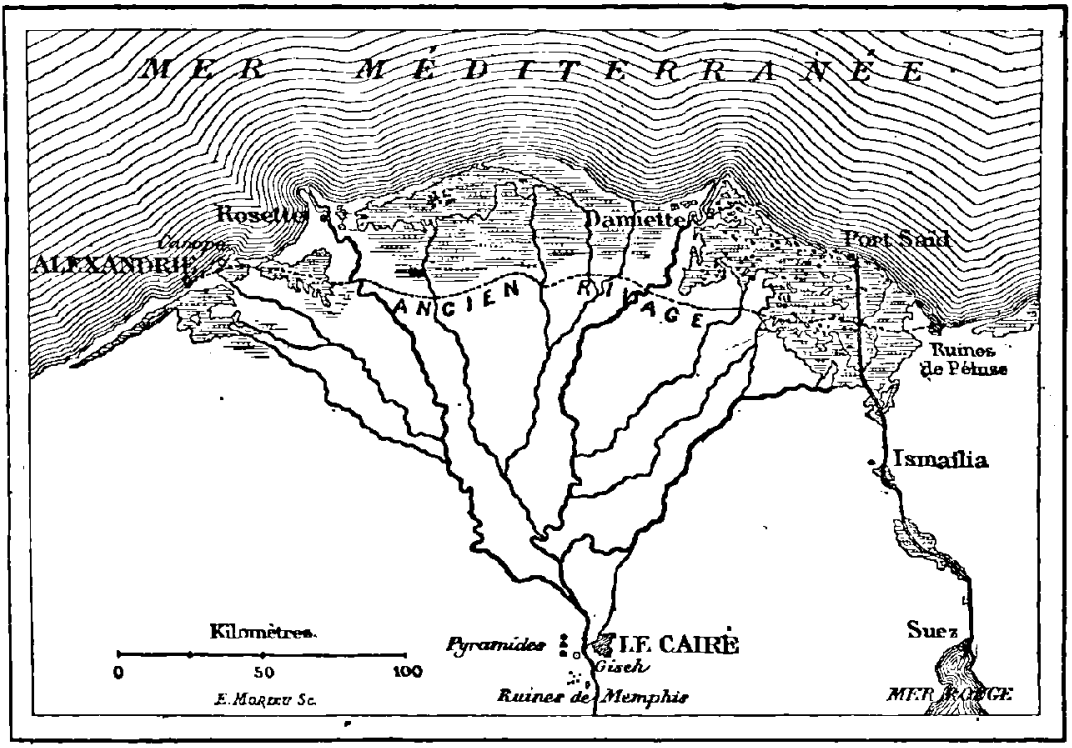

Fig. 139. - Diminution graduelle de la mer a l'embouchure du Nil.

sur le fond de la mer, ce dépôt s'élèverait de 1 centimètre en 341 ans, ou de 1 mètre en 341 siècles et 1000 mètres en 34 millions d'années. Les eaux réunies de tous les fleuves et de toutes les rivières ne forment qu'une très faible quantité comparativement à l'eau des océans. En admettant que la profondeur moyenne des mers soit de cinq kilomètres, la quantité d'eau que roulent actuellement les cours d'eau n'égalerait celle qui remplit les abîmes de l'Océan qu'après un laps de cinq millions et demi d'années.

Inexorablement, avec le temps, la surface du globe change entièrement. Si aucune cause intérieure ne produisait de soulèvements du 
sol ou de dépressions, le globe terrestre finirait, avec la seule action des equx, par ètre complètement.uni comme un boulet et recouvert uniformément d'une couche d'eau de quelques centaines de mètres d'épaisseur. Mais nous verrons tout à l'heure que le niveau du sol n'est pas éternel non plus. L'action des dépôts n'en est pas moins efficace de siècle en siècle. Le jour viendra où la Méditerranée, par exemple, ne sera plus qu'un enchaînement de lacs, et, plus tard encore, qu'un gigantesque fleuve. La mer d'Azof se transforme graduellement en rivière par le lent rapprochement de ses bords. Le golfe de Venise ne sera plus un jour que le prolongement de la vallée du Pô, et les deux grands bassins de la Méditerranée, séparés par la barre sous. marine qui rejoint la Sicile à l'Afrique, formeront deux lacs de plus en plus rétrécis, dont les eaux alimenteront le plus grand fleuve du monde. Alors le Dnieper, le Danube et le Pô en soront de simples tributaires; peut-être même que le Nil, déjà si peu considérable à son embouchure, perdra toute son eau par l'évaporation avant de pouvoir atteindre le fleuve Méditerranée et deviendra un cours d'eau entièrement continental, comme le Chari, l'Haouach et le Jourdain ( ${ }^{1}$ ).

C'est ce qui parait ètre actuellement arrivé déjà pour la planète Mars qui, plus ancienne que la Terre, n'a plus aucun ocćan, mais seulement des méditerranées, des fleuves et des canaux (").

Tout ce que nous venons de dire pour le travail des eaux apportant à la mer des terrains de sédiment, allongeant les continents, modifiant les rivages, peut être appliqué aux lacs et mème à la transformation perpétuelle des vallées. Ainsi, par exemple, le Rhòne, que nous venons de voir avancer de soixante mètres par an en moyenne dans la Méditerranée a modifié d'une manière peutêtre plus sensible encore le lac Léman, qu'il a, du reste, créé luimẻme.

Le fleuve accomplit aux deux extrémités du bassin d'un lac, des travaux, contraires en apparence, mais ayant également pour résultat de réduire la superficie des eaux. En amont, il exhausse

1. ÉLisḱe Rechus. La Terre, I, 525.

2. Voy. la carte géographique de la planète Mars, dans nos Terres du Ciel et. le petif Globe gèographique de Mars que nous avons récemment publié. 
graduellement son lit et gagne sur le lac en le comblant d'alluvions; en aval, il abaisse le seuil, et, par ce déversoir incessamment agrandi, écoule peu à peu la masse liquide; à la fin, les deux lits. d'amont et d'aval se rencontreront à mi-chemin, et le lac aura cessé d'exister. C'est là le double phénomène qui se produit depuis des siècles dans le lac Léman. Jadis cette nappe en forme de croissant s'élendait en amont jusqu'au point où se trouve aujourd'hui Saint-Maurice, à 22 kilomètres en amont du lac, et se prolongeait en aval, par d'étroits bassins, jusqu'an fort de l'Écluse, à 15 kilomètres de la sortie du Rhône. On peut se rendre compte par la pe-

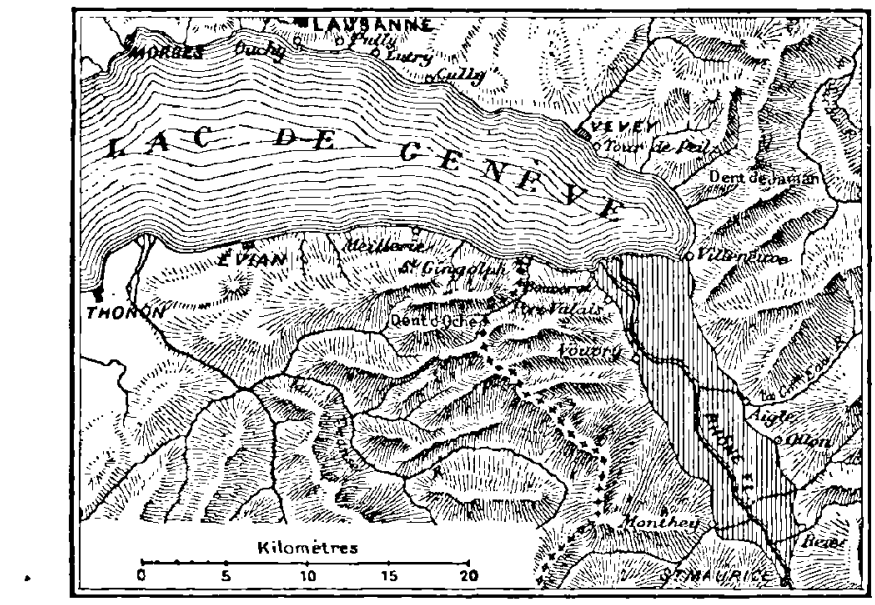

Fig. 1.40. - Diminution graduelle du lac de Genève par les atterrissements du Rhône.

tite carte ci-dessus (fig. 140) de tout le terrain perdu déjà par le lac, depuis sa formation en vertu des atterrissements du Rhône. Les sédiments fluviatiles, sables ou graviers de grosseur moyenne, s'accumulent en strates superposées comme les feuillets d'un livre que le géologue peut retourner. Ces couches de formation contemporaine s'étendent chaque année sur un gigantesque plan incliné de plus de trois kilomètres de longueur; la profondeur du lac, entre Vevey et Saint-Gingolph étant de 180 mètres, ces strates peuvent ètre considérées comme presque horizontales. Depuis huit siècles seulement, Port-Valais est reculé de huit kilomètres. Ce sont là autant de documents significatifs qu'il faut savoir interprèter.

Non seulement ce travail des eaux transforme graduellement 
la configuration géographique du globe, mais il joue encore le plus grand rôle dans la constitution géologique des terrains et dans la conservation des débris d'ètres vivants. Dans le delta du Gange, et du Brahmapoutra, qui ne mesure pas moins de 166400 kilomètres carrés, sur lesquels les deux fleuves déposent leurs sédiments sur une épaisseur de 60 à 70 centimètres par siècle, on rencontre des crocodiles de diverses espèces. Ces animaux pullulent dans l'eau saumâtre, sur toute la ligne des bancs de sable où l'accroissement du delta est le plus rapide. On les voit réunis par centaines dans les criques ou se chauffant au soleil sur les hauts fonds. Ils attaquent les hommes et le bétail, se jetant sur les imprudents qui se baignent dans le fleuve et sur les animaux domestiques ou sauvages qui viennent s'y abreuver. « J'ai été témoin assez souvent, dit Colebrooke, de l'horrible spectacle d'un cadavre flottant, saisi par un crocodile avec une telle avidité que le monstre, pour mieux tenir sa proie, restait à moitié hors de l'eau. "Le géologue ne manquera pas de remarquer, écrit Lyell à ce propos, à quel point les mœurs et la distribution de ces sauriens les exposent à être enfouis dans les couches horizontales du limon fin qui sont déposées chaque année sur plusieurs centaines de kilomètres carrés dans la baie de Bengale. Les habitants du pays qui viennent à se noyer ou à ètre jetés dans l'eau sont la proie de ces reptiles voraces et l'on peut supposer que les débris des sauriens eux-mèmes sont continuellement ensevelis dans les nouvelles formations. D'un autre côté, le nombre des corps d'Indous appartenant à la classe pauvre que l'on jette annuellement dans le Gange est si considérable qu'on ne peut manquer de rencontrer dans le limon fluviatile, quelques-uns de leurs os ou quelques débris de leurs squelettes.

Ces dépôts deviennent des roches, et les débris qu'ils conservent se fossilisent graduellement. La nature minérale, la densité, l'épaisseur, la couleur, la dureté des couches stratifiées dérivent de la nature des terres transportées et de la vitesse des eaux qui les déposent. L'arrangement stratifié qui domine si généralement dans les dépôts aqueux est dù le plus souvent à des variations dans lé degré de rapidité de l'eau courante qui, lorsqu'elle se meut avec une vitesse donnée ne peut entrainer que des particules d'une certaine grosseur et d'un certain poids. Il suit de là que, selon que la 
force du courant augmente ou diminue, les matériaux déposés en

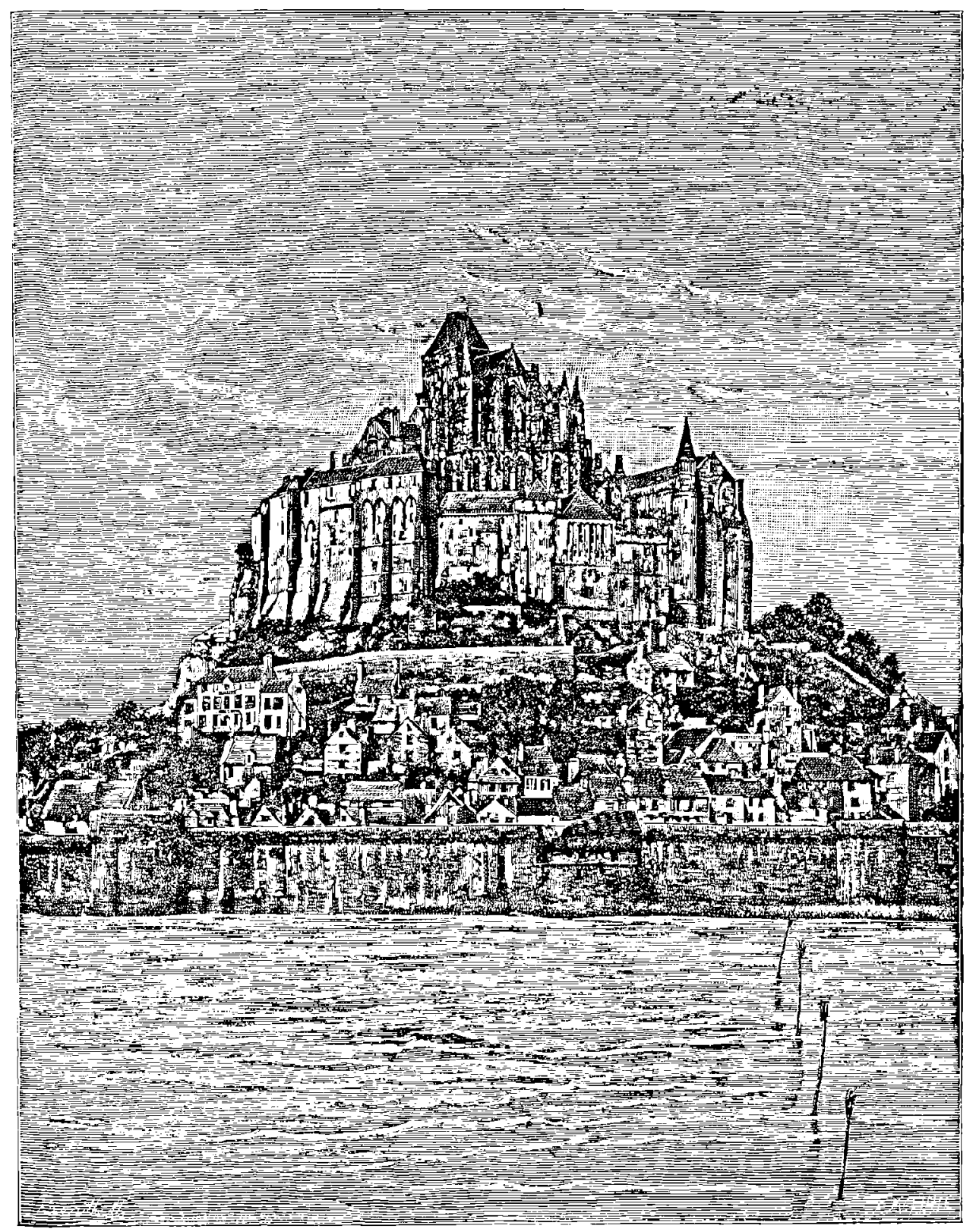

LE MONT-SAINT-HICHEL

couches successives sur différents points sont grossièrement assortis, suivant leurs dimensions, leurs formes et leur pesanteur spéciI. MONDE AVAVT LA CHÉTION DE L'HOMNF. 
fique. Diverses circonstances donnent lieu à des variations. Ainsi à telle époque de l'année, c'est du bois qui est transporté et à telle autre c'est du limon. D'autrefois, quand le courant atteint son maximum de volume et de vitesse il peut répandre des cailloux sur une certaine surface où se déposent, lorsque les eaux deviennent basses, un sédiment fin et des précipités chimiques. On peut observer la formation actuelle de toutes les espèces de terrains au fond des fleuves, aux confluents, dans les lacs, les deltas et les embouchures. Au fond de l'Allier se forment d'une année à l'autre des pierres assez dures; au fond de la Marne, de la Meuse et de la Seine on en trouve d'autres, souvent assez singulières de formes, de formation contemporaine également. Les rivières torrentielles produisent surtout des conglomérats: on en trouve partout aux environs de Nice et presque sur tout le littoral de Toulon à Gènes.

Nous remarquions au commencement de ce chapitre (p. 262) qu'en posant le câble transatlantique on a trouvé au fond de l'Océan une vase blanche composée de corps organiques d'une nature identique à ceux qui constituent la craie, et qui se forme actuellement. Il en est de même un peu partout. Erenberg a compté 6000 carapaces dans une once de sable de l'Adriatique; d'Orbigny en a compté 484000 dans un gramme de sable des Antilles. Ce sont là des faits actuels qui nous montrent directement le mode d'opération de la nature.

Mais ne nous laissons pas entrainer trop loin dans ces considérations, car il importe que nous embrassions autant que possible sous un même coup d'œil l'ensemble des causes actuelles de transformation du sol. Nous arrivons ici, sans quitter la question des rivages, à une autre cause de transformation qui n'est pas moins importante que les précédentes. C'est celle des soulèvements et des dépressions du sol. Ce sujet a été très discuté, souvent même avec passion. Aujourd'hui nous avons entre les mains des documents rigoureux et positifs. Exposons-les méthodiquement, et toujours en commençant par les points les mieux accessibles à l'observation.

A toutes les opérations géologiques séculaires dues à l'œuvre quotidienne et normale du cours d'eau, ajoutons maintenant cette autre cause qui vient souvent s'ajouter aux précédentes. Le sol n'est pas 
stable lui-même : en certains points il s'abaisse, en d'autres régions il s'élève.

Considérons, par exemple, la célèbre baie du Mont-Saint-Mich@l. Au temps de la conquête romaine el pendant les premiers siècles do notre ère, une immense forêt couvrait toute cette région: c'était la forêt de Scissey, dans laquelle s'établirent de nombreux monastères, entre autres celui de Taurac (qui fut détruit au VI ${ }^{\mathrm{e}}$ siècle par les soldats du roi Clother). Le Mont-Saint-Michel, qu'on appelait alors « le Mont-Tombe », s'élevait au milieu comme un mausolée et se trou-

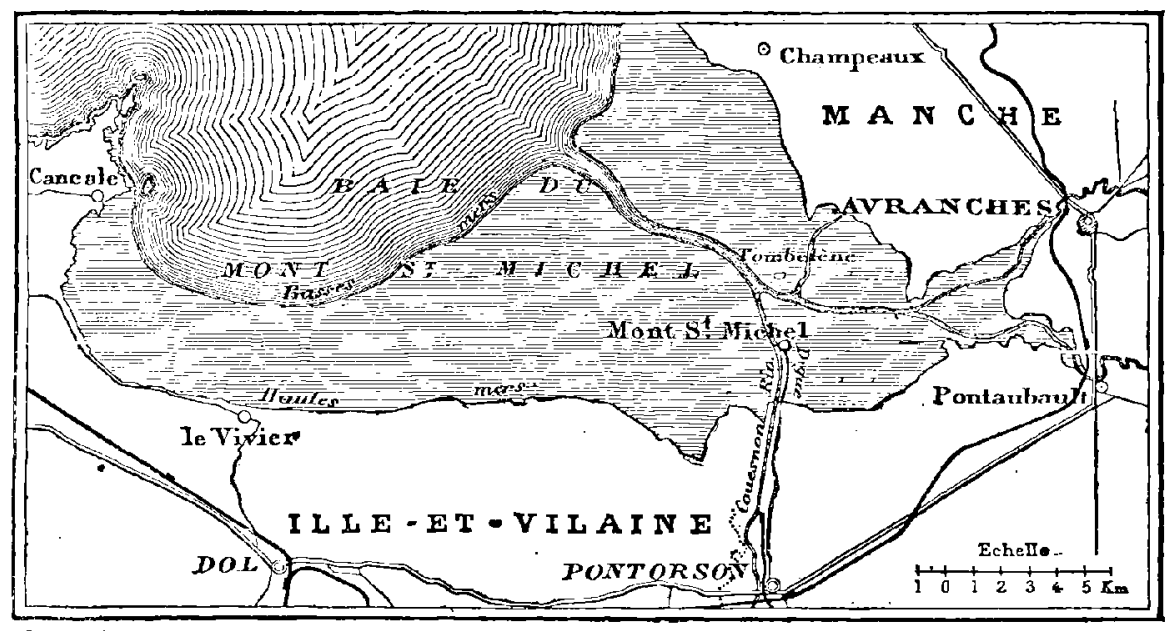

E. Hellé.

Fig. 142. - La biie du Mont-Saint-Minhel aux hautes et basses mers.

vait à environ vingt kilomètres de la mer. Chacun sait qu'il est aujourd'hui isolé au milieu d'une plage absolument nue, recouverte deux fois par jour, aux grandes inarées, sous les flots de la mer (qui s'avance jusqu'aux digues, à plus de deux kilomètres, et s'étend en largeur sur plus de trente kilomètres, comme on peut s'en rendre compte sur notre petite carte $(f g .142)$. Dans toute cette région, en deçà comme au delà de la plage recouverte par les grandes marées, on rencontre à une faible profondcur des trones d'arbres de toutes les essences.

Un mánuscrit du dixième siècle, ou peut-être mème du neuvième, expose que le Mont-Saint-Michel a perdu depuis Iongtemps la forêt dont il était entouré, que Dieu a transformé cette région pour suivre ses vues et préparer le culte du saint archange, et que 
Ia mer a tout balayé "pour faire un beau chemin aux pèlerins » qui, de toutes parts, affluent et viennent rendre témoignage aux miracles ('). La première abbaye élevée au culte de saint Michel par Autbert, évêque d'Avranches, avait été inaugurèe en 709, et déjà la mer entourait le mont, puisque les chroniques de l'abbaye mettent ces paroles mêmes dans la bouche de l'archange : in pelago " dans la mer et que toutes les anciennes chartes qualifient le mont in periculo maris « au péril de la mer $»$.

On a retrouvé, en 1822, à la suite d'une tempête qui avait bouleversé la grève, à dix pieds au-dessous du niveau habituel des sables, une chaussée pavée en pierres plates, vestige d'une ancienne voie romaine à travers le sol marécageux de l'antique forèt.

D'après l'ensemble des observations, nous pouvons admettre qu'en l'an 709 le niveau des plus hautes marées s'élevait à environ 12 mètres au-dessus du niveau actuel des plus basses mers. Or, ce niveau des plus hautes marées s'élève maintenant à $15^{\mathrm{m}} 50$. On peut

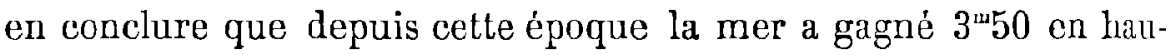
teur verticale, c'est-à-dire, en fait, que le sol a baissé de cette quantité, ce qui indiquerait une dépression de 33 centimètres par siècle $\left({ }^{2}\right)$.

Un récit dı VI* siècle fait mourir le même jour (15 avril 565), dans la baie du Mont-Saint-Michel, les deux évèques saint Pair (saint Patern) et saint Escouvillon (saint Scubilio), allant à la rencontre l'un de l'autre à la veille de leur mort. Ce jour-là, veille de la nouvelle lune, la marée était déjà forte, et arrivait à six heures du soir. lls furent arrètés dans leur tentative de rencontre par une largeur de mer d'un peu plus de quatre kilomètres « fere tria millia

1. Voy. Cuisvemont. Les mouvements $d u$ sol, p. 350.

2. La baie du Mont-Saint-Michel est l'un des points les plus admirables pour la contemplation comme pour l'élude des marées, et nous y passons souvent quelques jours anx époques de grandes marées d'équinoxe. Alors c'est un grandiose spectacle que l'arrivée de la mer venant submerger toute la contrée sous une immense nappe d'eau. Elle envahit deux fois par jour l'entrée de la ville féodale et submerge la grande rue jusqu'au-dessus de « l'hotel Poulard s. On ne peut alors sortir de la ville qu'en bateau. Les choses ne devaient pas être ainsi à l'époque où l'on a construit ces rues et pavé la ville. Il y a lá une preuve manifeste de dépression. Le Mont-Saint-Michel tout entier diminue lentement de hauteur. - Pour la description du spectacle des grandes marées observé dans cette fameuse baie du Mont-Saint-Michel, voir notre ouvrage Dans le Ciel et sur la Terre, perspectives et harmonies, p. 197. 
Aujourd'hui, le bras de mer qui forme l'estuaire commun du Couesnon, de la Sélune et de la Sée n'a pas moins de douze kilomètres. Là aussi, l'abaissement du sol est de $3^{\mathrm{m}} 50$ à 4 mètres.

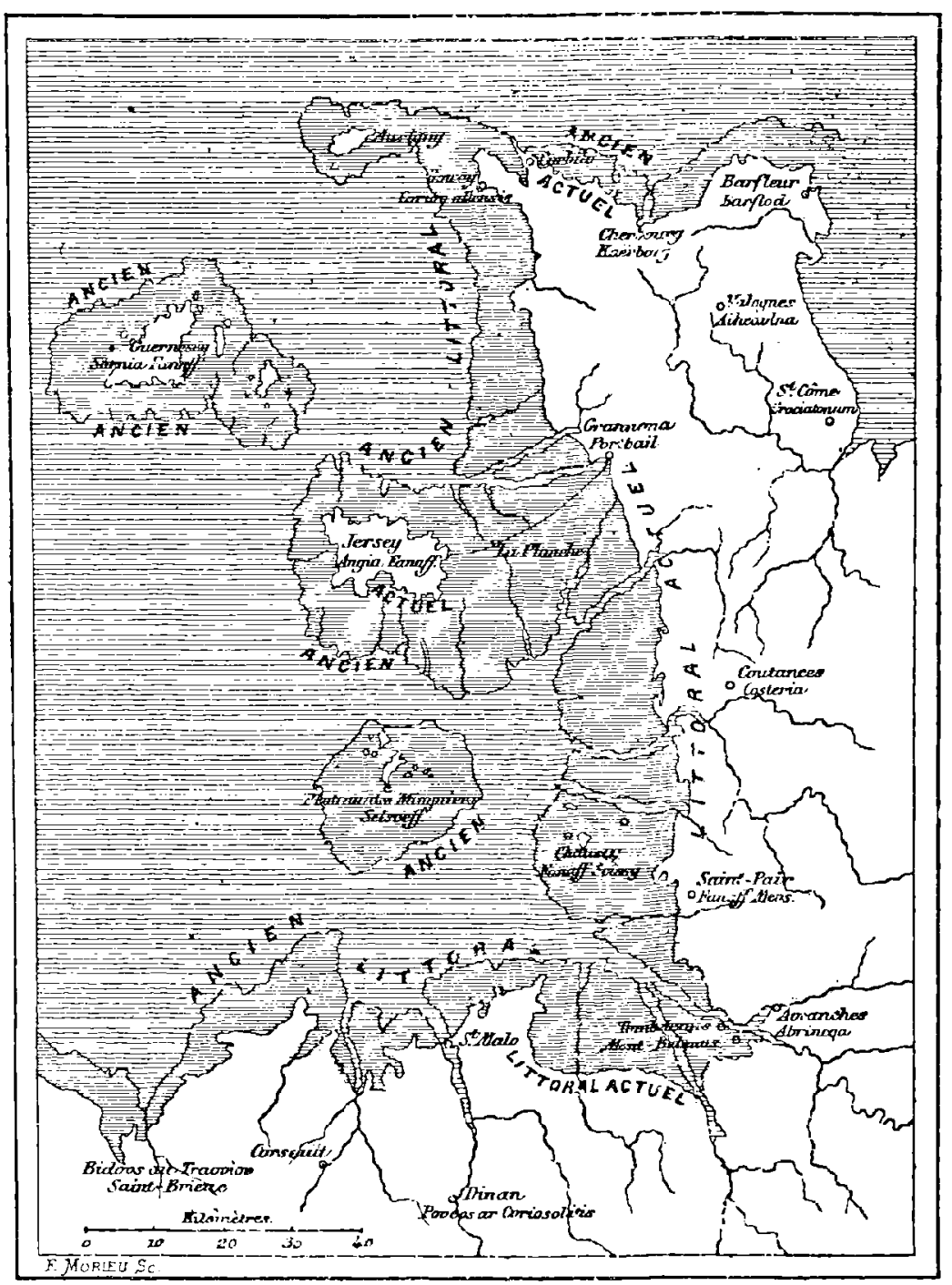

Pig. 143. - Carte des envahissements de la mer, Normandie et Bretagne, d'sprès le document très ancien trouvé en 1714 par Deschamps-Vadeville au Mont-Saint-Michel.

Sur tonte la baie de Dol s'étendait aussi, pendant les premiers siècles de notre ère, la forêt de Kauquelunde, yoisine de la forèt de Scissey, celles de Cantias et de Goat-Is. Une autre, non moins vaste, 
existait au sud de Chausey, aujourd'hui groupe d'llots battu par les vagues. La vaste plaine qui s'étend autour du mont Dol continue de s'abaisser graduellement et n'est garantie de l'invasion de la mer que par les digues du littoral, le long desquelles la mer rejette heurcusement des bourrelets de sable qui les consolident. Mais il n'en faut pas moins donner issue, à marée basse, aux cours d'eau répan. dus sur six cent mille kilomètres carrés. Le sous-sol est saumâtre. On trouve dans le marais de Dol tous les vestiges des forêts ensevelies : chenes, châtaigniers, cerisiers, peupliers, etc. Depuis le XIII" siècle, sept paroisses ont disparu sous l'envahissement de la mer, les bourgs de Tommen, Mauny, Saint-Louis, Santrte-Manie, SaintSigolas-du-Bourgneuf, La Feillette et Saint-Étienne-de-Paluel, ce dernier en 1630 seulement.

Au douzième siècle, la gracieuse rivière de la Rance, qui descend de Dinan à Dinard et à Saint-Malo, ne mesurait, au pied de la cité d'Aleth (Saint-Servan), que 70 mètres environ de largeur, à mer oasse, bien entendu. Aujourd'hui, au même point, entre Dinard et Saint-Servan, au plus bas flot, elle mesure près de 1100 mètres. Toute cette vallée est descendue sous les flots, ainsi que les prairies qui s'étendaient entre Saint-Malo et Césembre, aujourd'hui ile isolée en face de Saint-Enogat.

Les traditions ont gardé le souvenir que l'ile de Jersey était rat. tachée au continent pendant les temps historiques, et que mème du temps des premiers évèques (saint Lô, mort en 365 et ses premiers successeurs) les habitants de l'île étaient tenus de fournir à l'archidiacre une planche pour passer, à basse mer, une rivière ou un chenal d'écoulement des eaux salées. L'examen des cartes marines conduit à confirmer cette tradition. Il fait discerner dans la mer un isthme par lequel Jersey a dû conserver pendant un temps son dernier lien avec la terre ferme. a Nous avons pu suivre cet isthme, écrit M. Chèvremont, bien que fortement dèmantelé par les courants, dans la direction de Saint-Germain (France) à Graville (Jersey). Sur cette direction, dans une longueur de 32 kilomètres, une série de plateaux rocheux sous-marins permet de reconstruire sans lacunes le passage que la subsidence du sol a fait descendre sous la mer et que les courants ont profondément ravinée. $n$

On est ramené, par là aulisi, à admettre un affaissement de 
quatre mètres environ, depuis la fin de l'époque gallo-romaine. Les roches dépassaient un peu le niveau de la mer aux basses eaux, et les terres qui remplissaient leurs interstices et les recouvraient y permettaient un passage. La communication a pu se maintenir entre l'île et le continent comme elle a existé jusqu'au XV siècle entre Saint-Malo et Césembre, entre Saint-Servan et Dinard. Les a prairies de Césembre » ont été l'objèt de querelles entre le domaine public et le chapitre seigneurial jusqu'en 1437; depuis, elles ont été définitivement submergées.

Le mème témoignage nous est donné par la communication qui rattachait la forêt de Scissey à Jersey par les Ecrehous. Ce passage devint une île qui fut donnée aux moines du Val Richer pour ! bâtir une église, parce que les habitants ne pouvaient plus venir entendre la messe à Portbail, la mer ayant séparé l'île du continent en 1203. De cette île alors très peuplée, il ne reste plus qu'ur amas de rochers sur lesquels on peut encore distinguer, à marée basse, les ruines de la vieille chapelle.

Au surplus, tous ces témoignages historiques sont confirmés par un document découvert en 1714 au Mont-Saint-Michel par l'ingénieur Deschamps-Vadeville, qui représente les envahissements de la mer depuis Saint-Brieuc jusqu'à Barfleur. Cette carte porte la date de 1406, mais par l'aspect des caractères et par l'examen des termes employés, elle paraît être la copie d'une carte écrite au XIII siècle d'après un original plus ancien encore et sans doute du IX siècle. Nous reproduisons ici ce curieux document, d'après l'édition qu'en a donnée $M$. Chèvremont. Sans attacher aux détails une précision qu'ils ne comportent certainement pas, on peut considérer cette carte comme représentant le dessin d'ensem. ble de ce que devaient ètre les rivages de la Gaule au commencement de notre ère, d'après les traditions encore vivantes au IX' siècle. A Jersey et à Guernesey la mer couvre aujourd'hui de 15 mètres d'eau le sol sur lequel des bois et des prairies existaient en 1340, d'après le cadastre de l'époque. La dépression conclue serait de trois mètres par siècle.

La mer ronge également ses falaises sur le littoral du Calvados (notamment à Courseulles) et presque tout le long de cette côto. M. Quénault a trouvé près de Gaen, à six mètres au-dessous du 
niveau des plus basses mers d'équinoxe, des débris de canots du $X^{a}$ siècle. Ce serait un affaissement de deux mètres par siècle environ.

Au large de Cherbourg, le sol sous marin est recouvert de restes encore debout d'une vaste forêt, appartenant à des espèces végétales actuellement vivantes. On peut en voir de remarquables fragments au Muséum d'bistoire naturelle de Paris. Nous avons retrouvé des débris analogues au nord de l'lle des Glénans (Finistère).

En 1871, nous avons placé le long de la falaise de la cité de Limes, près de Dieppe, des pierres qui en marquaient le bord. Douze ans plus tard, il n'en restait plus que quelques-unes : la falaise avait perdu environ 20 centimètres.

Dans la baie de Douarnenez existait anciennement une ville célèbre, la ville d'Is, dont la légende du roi Gradlon a illustré la fin si tragique. Aux premiers siècles de notre ère, cette cité était encore florissante, quoique déjà menacée par la mer et protégée par des digues. On rapporte à l'année 444 l'invasion des eaux qui englouti. rent définitivement ces populations. On voit encore aujourd'hui, à basse mer, de vieux murs qui portent le nom de a Mogher-Greghi, ” murailles des Grecs.

Cette histoire de la submersion de la ville d'Is mérite de nous arrêter un instant, quoique les documents que nous réunissons ici pour la première fois sous les yeux de nos lecteurs soient si nombreux que tous nos efforts tendent, comme on peut s'en apercevoir, à limiter avec parcimonie notre récit à ces documents eux-mêrnes, afin de ne pas trop allonger ce chapitre pourtant capital. Exposons en quelques mots cette tradition significative :

G'est sur les bords désolés de la baie des Trépassés (Finistère) que l'on retrouve les vestiges de l'antique cité. Plusieurs routes anciennes aboutissent aujourd'hui à la mer et se prolongeaient autrefois dans la haie de Douarnenez. Les traditions bretonnes racontent que la cité d'Is était défendue contre l'Océan par des digues puissantes, dont les écluses étaient ouvertes une fois par mois sous la présidence du roi pour donner passage au trop plein des cours d'eau. La ville était luxueuse, le palais somptueux, la cour adonnée à tous les plaisirs. La fille du roi, la prin. cesse Dahut, était belle, coquette et licencieuse, et malgré l'austérité paternelle, se livrait à de folles orgies. Gradlon avait promis d'imposer son autorité et d'arrêter les scandales de sa fille, mais l'indulgence pater- 


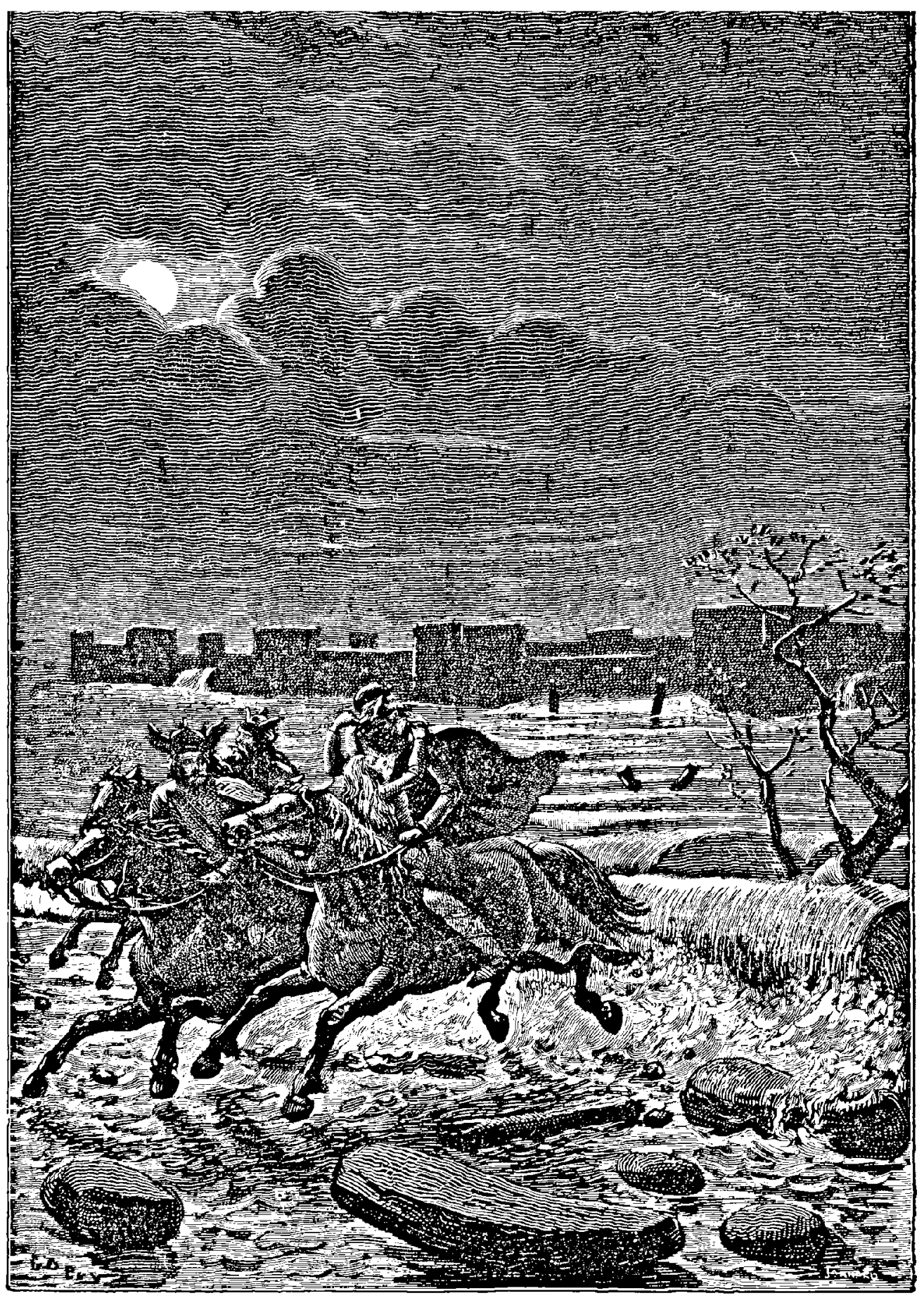

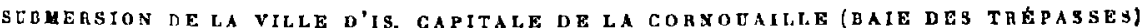
A U Y SIECLE UE NOTRE ÉRE.

LE MONDE AVANT LA CRÉATION DE L'HUMHE 
nelle l'avait toujours emporté dans son cceur. La jeune princesse forma un complot pour s'emparer de l'autorité royale, et lo vieux roi ne tarda pas à être relégué dans le fond de son propre palais. Elle présida aux cérémonies et mẻme à l'ouverture des écluses, et ello eut la fantaisie de les ouvrir elle-même un jour de grande marée!... C'était le soir; le roi! vit arriver devant lui saint Guénqlé, l'apôtre de la Bretagne, qui venait lui annoncer l'imprudence de sa fille: la mer pénétrait dans la ville, la tempête la poussait devant ello, et il n'avait plus qu'à fuir, la ville entière étant destinée à disparaître. Gradlon voulut encore sauver son enfant des suites de sa folle imprudence : il l'envoya chercher, la prit en croupe sur son cheval et, suivi de ses officiers, se dirigea vers les portes de la cité. Au moment où il les franchissait, un long mugissement retentit derrière lui; il se détourna et poussa un cri! A la place de la ville d'Is s'étendait une baie immense sur laquelle se reflétait la lueur des étoiles. Mais les vagues arrivaient sur lui, frémissantes. Elles allaient l'atteindre, et le renverser, malgré lo galop des chovaux, lorsqu'une voix cria : « Gradlon! si tu ne veux périr, débarrasse-toi du démon que 11 portes derrière toi . Dahut terrifiée sentit ses forces l'abandonner, un voile s'étendit sur ses yeux, ses mains, qui serraient convulsivement lit poitrine de son père, se glacèrent et retombèrent : elle roula dans les flots. A peine l'eurent-ils engloutie qu'ils s'arrètèrent. Quant au roi, it arriva sain et sauf à Quimper et se fixa dans cette ville, qui devint la capitale de la Cornouaille.

C'est là une légende assurément; mais cette légende recouvre un fond de vérité : la submersion incontestable d'une grande ville au $V^{*}$ siècle de notre ère.

A la ville d'Is on peut ajouter, comme exemple de régions submergées par les envahissements de la mer, la cité d'Herbadicia, près Nantes, dont parle Grégoire de Tours (elle était sous sa juridiction), et qui fut engloutie de son temps, vers 580 ; - celle de Tolente, non loin de Brest; - celle de NazAdo, près d'Erquy; - celle de Gandorne, dans la plaine de Dol, qui disparut au temps de Charlemagne. Depuis l'embouchure de la Loire jusqu'au Finistère, il n'est pas une côte où l'on ne rencontre des villes submergées, pas une grève au fond de laquelle on ne retrouve des vestiges d'habitations. Le littoral du Morhiban paraît être descendu de cinq mètres à Closmadeuc.

Il y avait des forêts, sur le rivage de Dunkerque, occupant les plages baignées aujourd'hui par la mer. La plage d'Etaples contenait un si grand nombre d'arbres ensevelis dans le sable que l'État 
a mis en adjudication le droit de les extraire. Des fondations romaines ont été découvertes à Sangatte. On a retrouvé à l'onest de Calais les restes d'une forêt submergée, au milieu de laquelle on a reconnu des ossements d'aurochs et des coquilles d'eau douce, ce qui prouve qu'à une époque géologique récente la côte était plus élevée que de nos jours. A cette époque, au commencement de la période quaternaire, lo Pas-de-Galais n'était pas encore ouvcrt aux eaux de l'Océan qui se précipitent dans la mer du Nord, l'Angleterre était encore rattachée à la France.

La Belgique et la Hollande descendent lentement; le sol des villes bâties non loin du rivage est au-dessous du niveau de la mer, mème aux plus basses maries; en plusieurs points, le niveau des hautes mers surpasse les toits des maisons. Si ces régions sont encore continentales et habitées, elles le doivent, non a la nature; mais aux digues construites par les hommes, et cela depuis les origines même de l'histoire des " Pays-Bas » qu'une admirable persévérance maintient contre la menace de l'élément marin. On en aura l'impression en se souvenant des principaux faits de cet ordre accompli sur ces rivages :

Le golfe de l'Artois, au fond duquel on a trouvé des médailles romaines mélangées à la tourbe, s'est formé du $\mathrm{III}^{\mathrm{a}}$ au Ve siècle de notre ère, de Calais à St-Omer et Nieuport.

Aux douzième et treizième sièçle, destruction du rivage des PaysBas : 140000 victimes;

En 1282, invasion de la mer dans le lac Flevo et formation du Zuyderzéc;

En 1321, cent.mille victimes en Hollande;

En 1421, soixante-douze villages engloutis à l'embouchure de la Neuse;

En 1427, 55 autres villages submergés en Hollande et 13 dans la contrée de Dol;

En 1503, la mer arrive jusqu'à Bruges;

En 1570, rupture des digues de l'embouchure de la Meuse, cent mille victimes;

En 1531, extension de la mer de Harlem;

En 1717, nouvelle irruption en Hollande, 12000 victimes, l'affaissement du sol est de dix mètres au-dessous de la haute mer;

En 1775, nouvelle irruption et nouveaux désastres;

En 1834, fin du nord-strand danois. 
Les chroniques des Pays-Bas ont conservé les récits les plus lamentables de ces terribles envahissements de la mer sur un sol qui descend tonjours. Dans les seules années 1421,1427 et 1146 , plus de deux cents villages de la Frise et de la Zélande furent engloutis. Pendant longtemps on continua de voir sortir des eaux les sommets des tours et les pointes des clochers. Depuis les Commentaires de César, tous les récits sont d'accord pour toute cette contrée. L'île des Bataves, habitée du temps de Tacite, est aujourd'hui au-dessous des basses mers.

Il n'est pas rare de retrouver ces ruines englouties. En 1869, nous avons vu, à l'embouchure de l'Escaut, du pont du bateau qui faisait le service d'Anvers, des ruines très distinctes submergées à une grande profondeur.

Le sol s'abaisse également sur le littoral des départements du Nord et du Pas-de-Calais. A Calais, les rues ne se trouvent plus qu'à un Inètre au-dessus des hautes marées, et le sol cultivé descend jusqu'à la limite du flot; à Dunkerque, la hauteur des rues n'est plus que de 60 centimètres et les champs sont labourés jusqu'à un mètre en contre-bas de la mer; à Furnes, à Ostende, les rues sont encore plus basses, et le niveau des polders ne cesse de s'abaisser; près des bouches de l'Escant, ce niveau est de 3 mètres et demi au-dessous des hautes marées; pendant les fortes tempêtes de l'ouest, la vague de houle est sur la plage de Hollande à $\mathbf{5}$ mètres et demi au-dessus du pavé d'Amsterdam.

Le Zuyderzée ou mer du Sud, qui s'ètend sur 196670 hectares au nord-est d'Amsterdam et n'a que de faibles profondeurs (1 à 8 mètres) n'a été formé qu'au treizième siècle. Il est probable que le travail de l'homme le desséchera pour le faire servir à l'agriculture, comme on y a réussi pour la mer de Haarlem, qui mesurait pourtant $21 \mathrm{ki}-$ lomètres de longueur sur 10 de largeur et 4 mètres de profondeur et contenait 724 millions de mètres cubes. Sa formation est toute récente. Au temps de Tacite, son emplacement était occupé par de la terre ferme et plusieurs lacs, dont le plus grand est désigné, par Pomponius Méla, sous le nom de lac Flevo. A cette époque, l'Issel se jetait dans ces eaux intérieures, et, continuant son cours, atteignait la mer du Nord entre les îles appelées aujourd'hui Vlieland et 
Schelling. C'est au treizième siècle que la mer envahit ces laes, submergea ces terres et combla le Zuyderzée.

En avant du Zuyderzée, existaient, sur le littoral de la Hollande, une chaine de 23 lles, restes prohables d'une ancienne terre submergée. On n'en retrouve plus aujourd'hui que seize fragments, rongés, dissèminès et abaissés d'année en année.

On observe des faits analogues sur les rivages de l'Océan, à l'em-

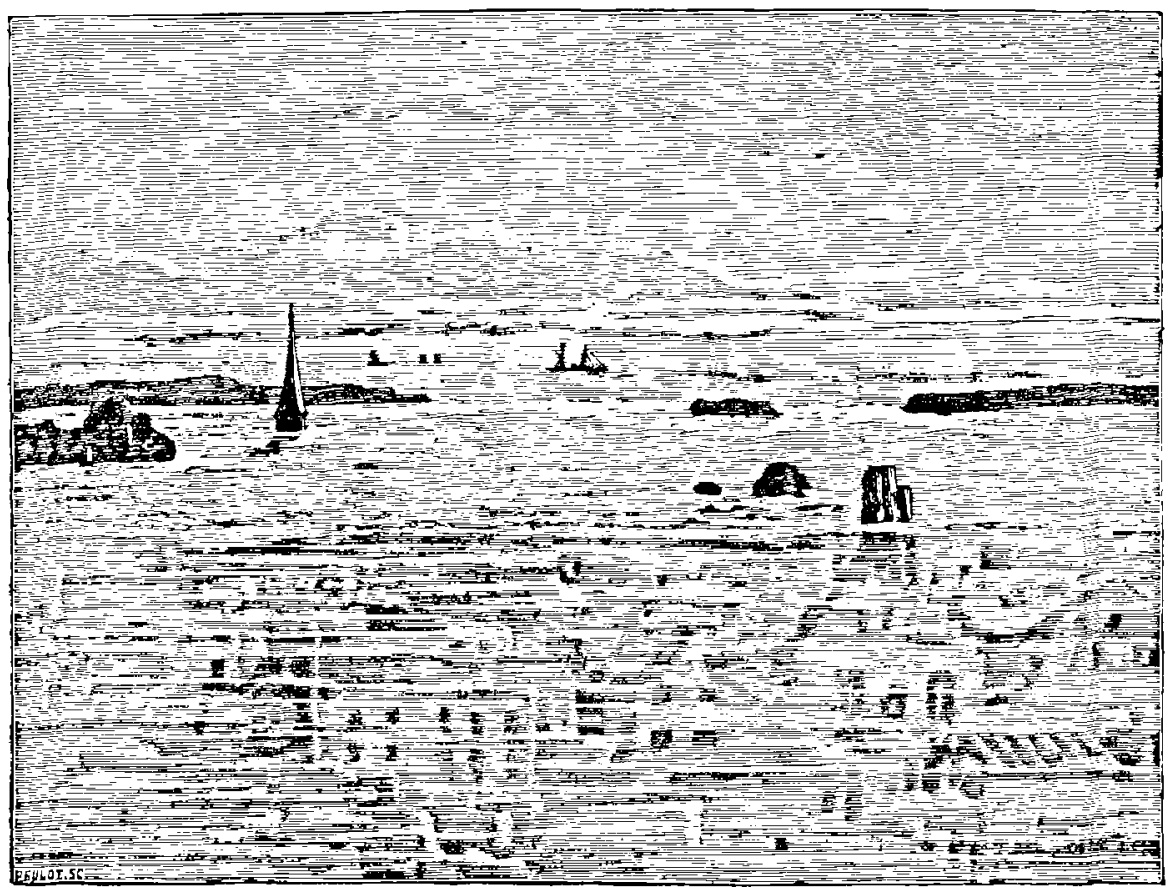

Fig. 145. - Villages de Zélande engloutis sous l'irruption de la mer.

bouchure de la Gironde. Il suffit de comparer les cartes hydrographiques dressées en 1752 avec celles de 1842, pour constater que, dans cet intervalle si court (90 ans), la mer a pris 1200 mètres á la pointe de Grave. En 1774, la ligne de haute mer à Soulac était à 950 mètres de l'église; en 1818, elle était à 650 mètres; et en 1865 , à 560 mètres seulement.

Lo rocher de Gordouan, sur lequel s'élèvo la célèbre tour, faisait autrefois parlie du continent; en l'an 1500, il n'en était encore séparé, à marée basse, que par un passage étroit et guéable. Au- 
jourd'hui, sa distance au rivage est de sept kilomètres, et l'on n'aborde plus à la tour qu'aux bassès marées. De siècle en siècle, cette terre s'est rétrécie pour n'ètre qu'un rocher découvrant à mer basse. On a même pu mesurer d'une manière exacte, mathématique, quel a été le taux de l'abaissement annuel. En effet, la portée des feux du phare de Cordouan ayant constamment diminué a cause de l'abaissement graduel du fanal lui-mème, il a fallu exhausser de nouveau la tour pour donner à la lumière la mème portée qu'il y a un siècle. L'abaissement du sol est de 3 centimètres par an, 3 mètres par siècle.

La pointe de Grave est un exemple d'autant plus remarquable de l'envahissement de la mer, que le travail d'érosion des vagues est aidé par l'affaissement du sol. De 1826 à 1860, le rivage a reculé de 750 mètres. Continuant son œuvre, la mer aurait aujourd'hui détruit toute la pointe et changé le lit de la Gironde en lui ouvrant une seconde embouchure si d'immenses travaux de défense, sourent renversés par les tempêtes, mais toujours réparés avec intellijence et persévérance, n'avaient, depuis 1860, opposé un obstacle efficace aux conquêtes de l'élément liquide. Toutes les constructions élevées depuis le commencement du siècle à l'extrémité de la pointe ont dì être successivement démolies et réédifiées dans l'intérieur de la presqu'île. L'ancien fort qui défendait l'entrée de la Gironde a été renversé par les vagues, et l'on apercoit encore, aux plus basses marées d'équinoxes, des canons gisant dans le sable. La hauteur de l'eau est actuellement de dix mètres le long de la ligne du rivage de 1826. De 1818 à 1846, la largeur du détroit qui sépare Cordouan de la péninsule du Bas-Médoc s'était exactement accrue d'un dixième. A la fin du XVI' siècle, lorsque Louis de Foix travaillait à la construction du phare de Cordouan, l'ile était assez grande pour porter tout un village d'ouvriers; actuellement ce n'est qu'un rocher découvrant à basse mer. - Malgré tous les efforts, le sol illustré et enrichi par les meilleurs vignobles de France diminue malheureusement de siècle en siècle.

L'île d'Aix, en face de Rochefort, jusqu'alors attachée au continent, s'en est séparée vers l'an 1400; aujourd'hui elle en est distante de plusieurs kilomètres.

Il en est'de mème à Arcachon et sur la côte des Landes, jusqu’ả 
l'Espagne. L'envahissement de la mer est très sensible à Saint-Jeande-Luz. La ville s'étendait autrefois au nord : un couvent de bénédictins qui occupait ce quartier est submergé et détruit, à l'exception de deux puits dont la maçonnerie a résisté et oủ l'on peut encore puiser de l'eau douce. La mer avance de 2 mètres par an.

Dans la Méditerranée à l'extrémité de l'Adriatique, Venise est

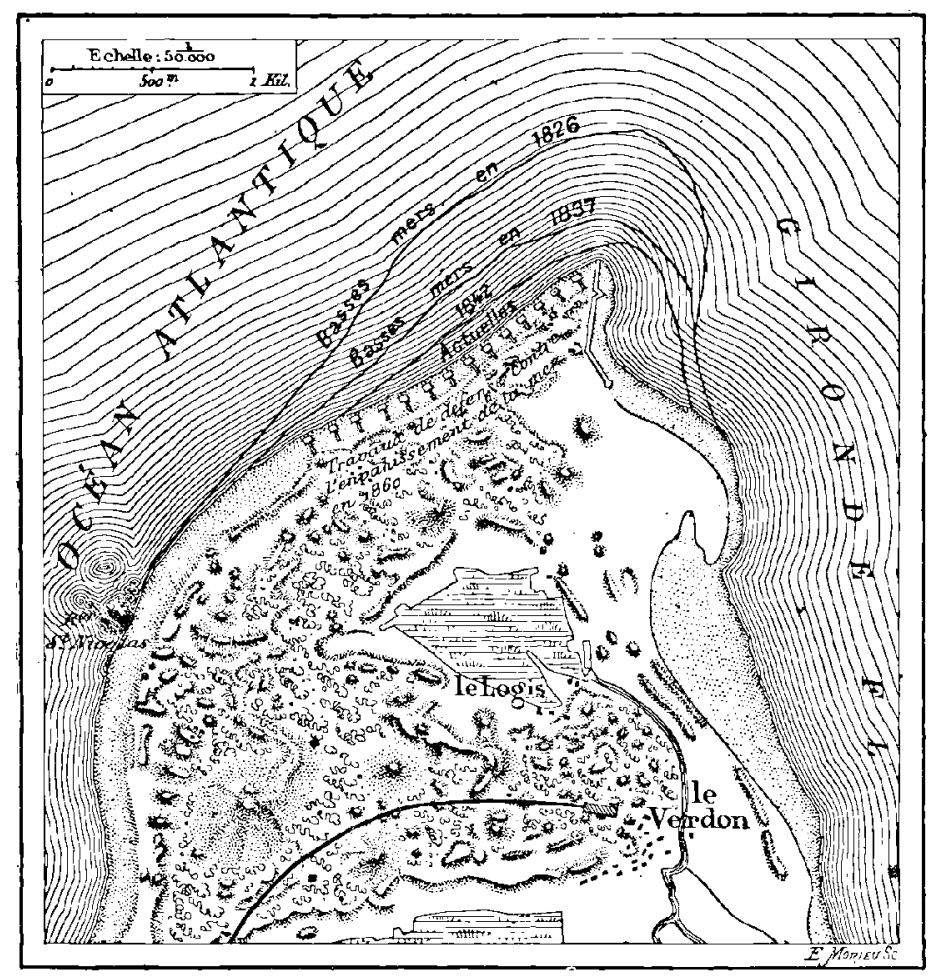

Fig. 146. - Les envahissements de la mer a la pointe de Grave.

un exemple de l'affaissement graduel du sol : on peut l'évaluer à $0^{\mathrm{m}} 155$ par siècle. Le pavage de la place Saint-Mare, qui a déjà été exhaussé, est de temps à autre submergé par les eaux qui arrivent par infiltrations aux époques de hautes mers : en 1873, nous avons mesuré une épaisseur d'eau de 20 contimètres au-dessus des dalles. En 1732 , on a exhaussé le pavé de $0^{\mathrm{m}} 34$ au-dessus de l'ancien pavé de briques.

Ainsi, l'on ne peut plus conserver aucun doute à l'égard de l'affaissement graduel du sol de la Hollande, de la Belgique, de la Normandie, de la Bretagne et d'une partie du littoral océanique 
de la France. Quel est le degré de cet affaissement? Les uns (M. Quénault) l'évaluent à 2 mètres par siècle et concluent que dans dix siècles la Normandie et la Bretagne se seront abaissées de 20 mètres, que « tous les ports de la Manche et de l'Océan seront détruits » et qu'un peu plus tard " Paris sera devenu une ville maritime, en attendant qu'il soit englouti, dans une vingtaine de

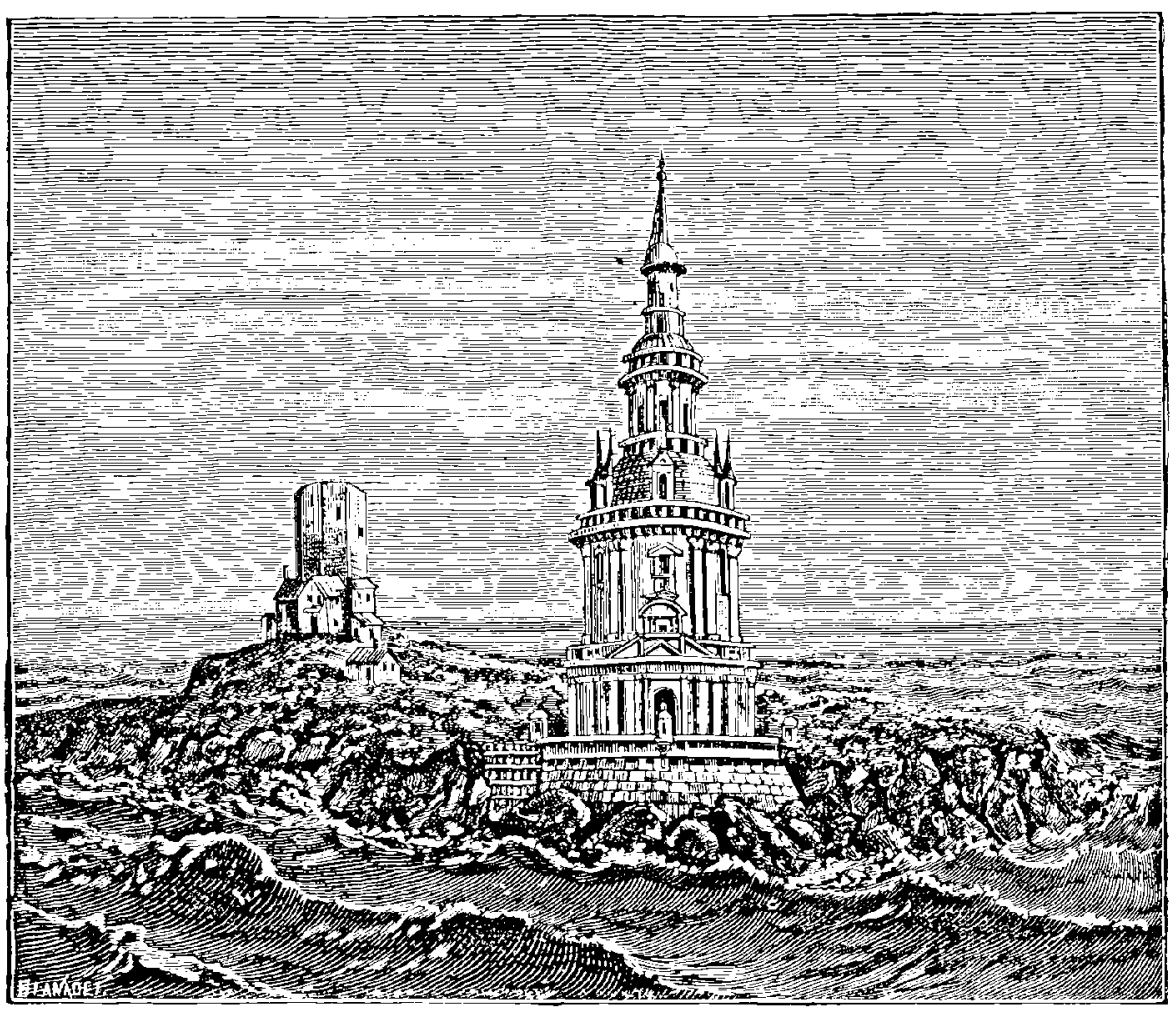

Fig. 147. - Le phare de Cordouan et son île au selzième siècle.

siècles $»$ : cette appréciation parait trop forte. Les autres (M. Chòvremont) sont moins alarmistes et reportent à une date sept fois plus éloignée les effets qui viennent d'être décrits. Mais ce n'est là qu'une question de degré. Le fait en lui-mème est désormais acquis à la science. Dans un certain nombre de siècles, Paris sera devenu port de mer par l'œuvre même de la nature, puis cetto même contrée descendra lentement sous les eaux de la mer, moins que ce mouvement de dépression ne s'arrète pour se changer en oscillation contraire, ce qui est possible, mais ce que rien ne 
nous autorise à prévoir. Actuellement, la Seine, à Paris, n'est qu'à 26 mètres au-dessus du niveau moyen de la mer. Alors un explorateur sous-marin distinguerait, dans le crépuscule des eaux, les ruines de

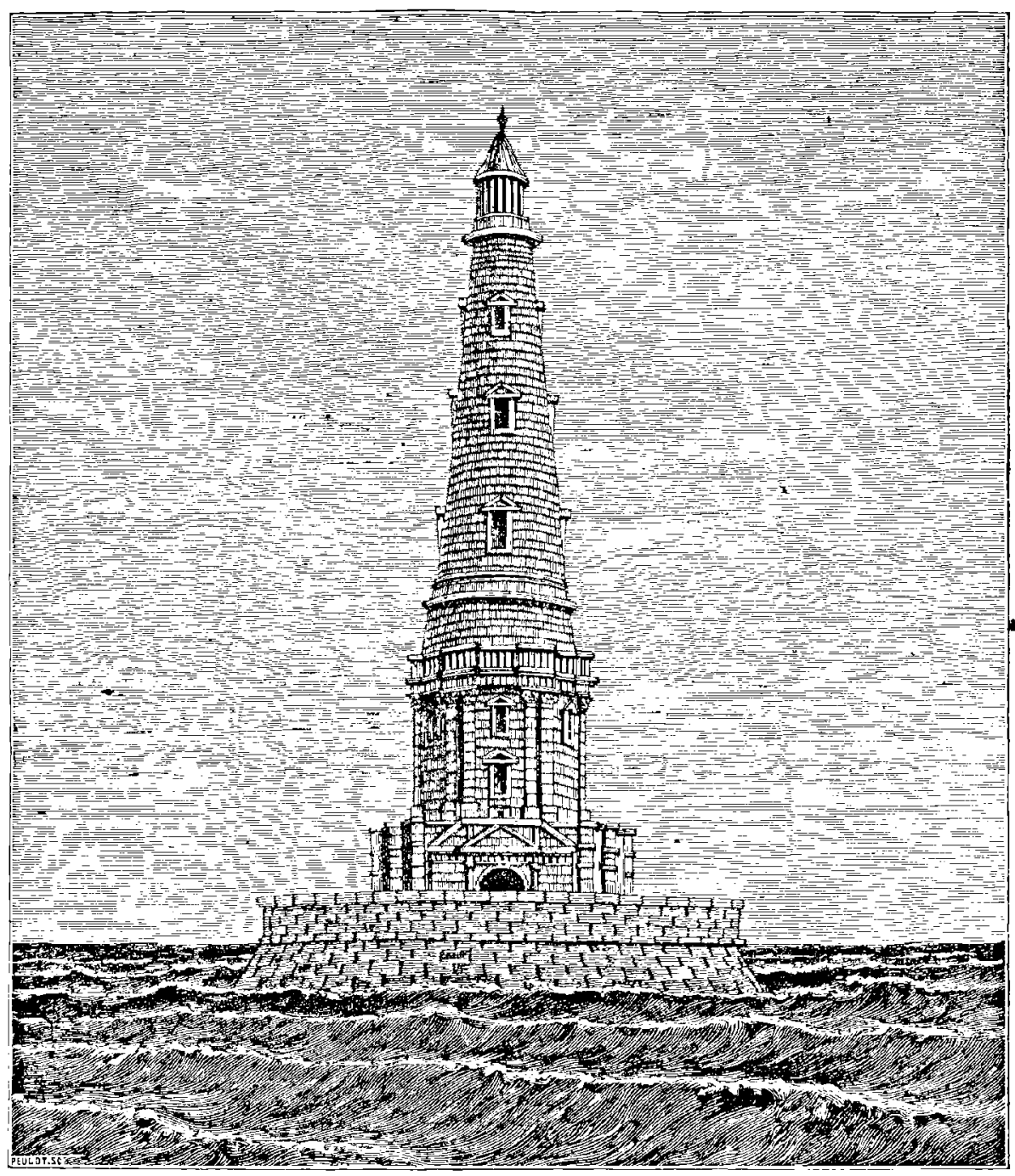

Fig. 148. - Le phare de Cordouan aujourd'hui.

ce qui fut Paris. En ces siècles à venir, toutefois, le Panthéon, l'Observatoire, l'Arc de l'Étoile, les édifices futurs de Montmartre, du Père-Lachaise, des Buttes-Chaumont et du Mont-Valérien domineraient la mer parisienne comme les derniers témoins des âges éva- 
nouis. Mais il est hautement probable que notre brillante capitale ne vivra pas aussi longtemps, et que dans quatre, cinq ou six mille ans d'ici elle sera déjà oublièe par le changement des foyers de civilisation et leur transport au delà de l'Atlantique.

Ce sont là autant de tèmoignages de l'áffaissement du sol. Dans la grande majorité des cas signalés, cet affaissement est certain, notamment en ce qui concerne la Hollande, la baie du Mont-SaintMichel, Venise, Cordouan, etc. En d'autres cas, l'abaissement du sol se complique de l'érosion des rivages par les vagues de la mer. En d'autres cas, cette érosion existe seule, l'extension des eaux ne prouve pas toujours un changement de niveau : exemple le cap de la Hève.

Comme nous l'avons vu, indépendamment de tout changement de niveau, le littoral est rongé presque partout où la falaise est minée par la mer. En Angleterre, la côte qui borde l'estuaire de la Tamise offre de nombreux exemples du mème genre. L'île de Sheppey, dans le comté de Kent, perd près d'un hectare par an, et si la dégradation actuelle se continue, le temps n'est pas éloigné où l'ile entière sera détruite. Plus loin, vers l'est, on voit l'église de Reculver, qui était à 1600 mètres de la mer à l'époque d'Henri VIII. En 1781, il restait encore un espace considérable entre lo mur du cimetière et la falaise; en 1804, une partie du cimetière fut entrainée; en 1831, Lyell vit des ossements humains et un morceau de cercueil en bois qui sortait du talus éboulé; actuellement, l'église ne subsiste, depuis longtemps abandonnée pour le culte, que grâce à une digue artificielle de pierres et de pilotis qui la protège. Nous reproduisons plus loin deux figures prises en 1781 et 1834, qui montrent bien cet empiètement de la mer.

Sur la côte du Suffolk, la ville de Dunwich, qui fut jadis le port le plus considérable de cette région, a été entièrement délruite par l'érosion des falaises sur lesquelles elle était bâtie. La destruction, commencée au XI ${ }^{\circ}$ siècle, était finie au XVIII".

A Harwich, à Folkstone, à Saint-Léonard, à Hastings, à Newhaven, le rivage est rongé par la mer, qui s'avance sur plusieurs points de plus de cent mètres par siècle.

L'érosion de certaines côtes anglaises est aujourd'hui si bien 
connue qu'on en ticnt compte dans les actes de vente en l'évaluant à un mè̀tre par an en moyenne.

On peut constater des transformations analogues sur tous les rivages. A Gallipoli (Turquie d'Europe), au nord des Dardanelles, entre autres, on connaît un remarquable exempie $(f g .149)$ de l'érosion séculaire du littoral par les flots de la mer.

L'homme peut quelquefois mettre un frein à la destruction des

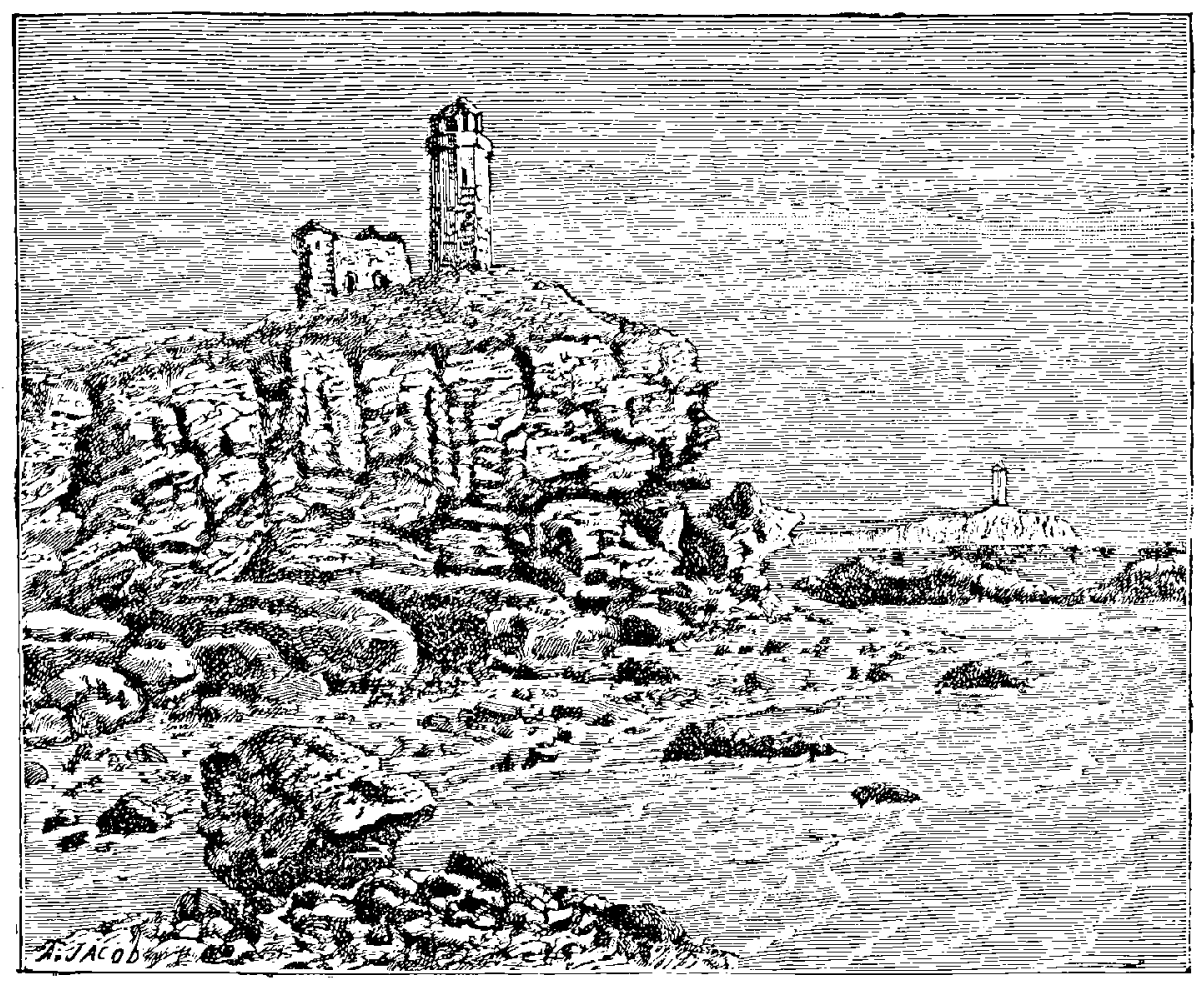

Fig. 149. - Les envahissements da la mer : Rivage rongé par les flots à Gúlijoli.

falaises en empèchant les vagues d'arriver jusqu'à la base et de la miner. Non loin de Douvres s'élève la célèbre fạlaise que les Anglais ont consacrée à Shakespeare en souvenir de la belle description qu'il en a donnée dans « le Roi Lear ». Pour sauver ce promontoire historique, les coteaux voisins, les maisons qu'ils portent, le chemin de fer, etc., on a fait sauter à la mine toute la partie supérieure de la. roche dont la base était ravagée, quelque chose comme un milliard de kilos, qui, secoués par neuf mille kilos de poudre, s'écroulèrent 
- avec fracas et créèrent un banc de sept à huit hectares, qui forme talus et arrête pour plusieurs siècles la destruction de la falaise, rongée déjà de près de deux kilomètres depuis dix-huit siècles.

Si l'érosion de la mer le long des falaises continentales est sensible d'une génération à l'autre et presque d'année en année, à plus forte raison peut-on suivre plus facilement encore son cuvre sur les falaises des îles. Certaines îles escarpées, autrefois très

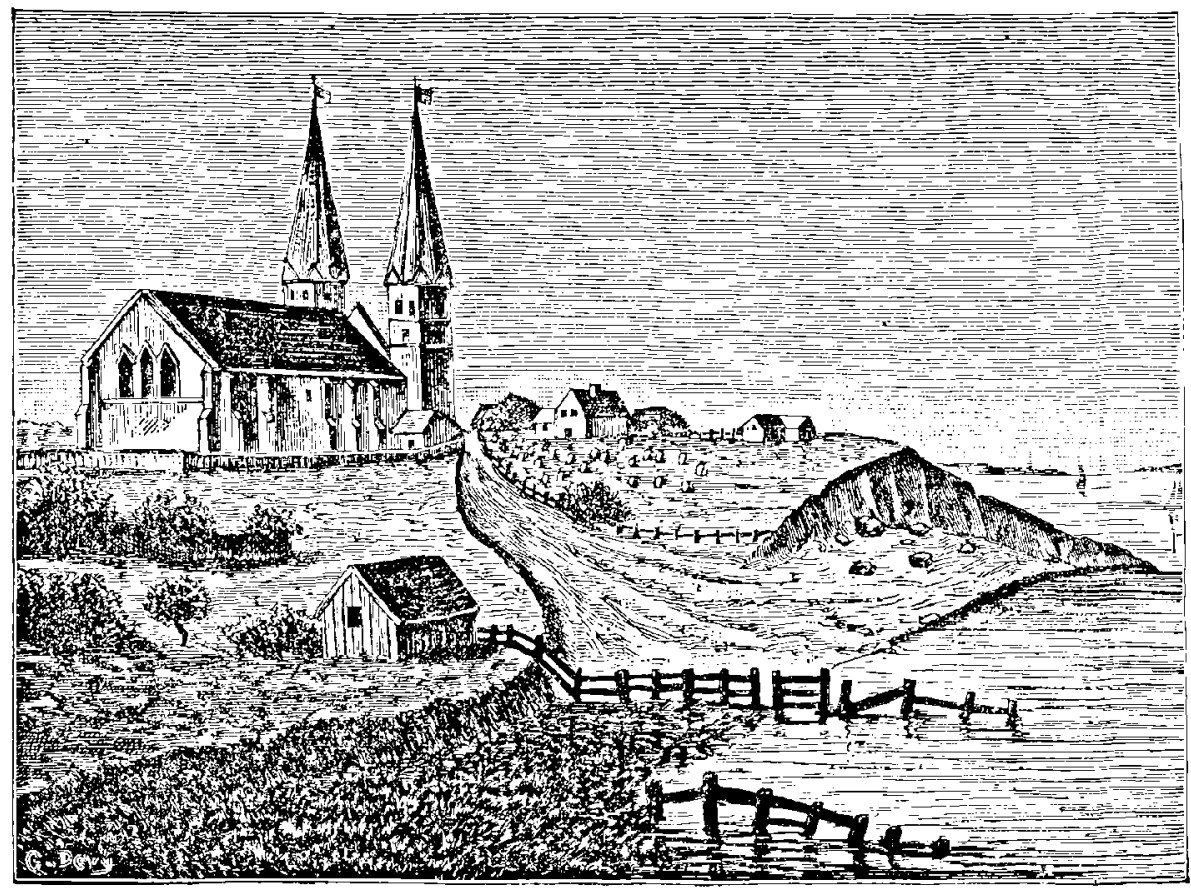

Fig. 1\%̃0. - Les empiétements de la mer : L’ẻglise de Reculver en 1781.

vastes, ont presque entièrement disparu. Dans la mer du Nord, par exemple, on peut citer l'île d'Helgoland ou Halligland, composée de grès bigarnés, entourée sur tout son pourtour d'une falaise de soixante mètres de hauteur. Au onzième siècle, elle s'ètendait sur un espace de 900 kilomètres carrés, ètait très fertile, riche en céréales, en bestiaux et en volatiles. Aujourd'hui il ne reste plus rien qu'un banc de deux kilomètres de long sur six cents mètres de largeur en moyenne, de maigres pâturages et quelques champs de pommes de terre. Nous pourrions signaler un grand nombre d'autres exemples analogues. 
$\mathrm{Si}$, d'une part, la mer empiète sur la terre ferme; d'autre part, et en bien des régions, la terre ferme empiète sur le domaine maritime. Nous avons déjà cité comme exemples les embouchures des fleuves. En voici d'autres qui paraissent dus à une élévation du sol.

En Bretagne, entre la Loire et la Vilaine, le bourg de Batz, encore si curieux à visiter aujourd'hui, le Croisic et le Pouliguen formaient autrefois une ile. Peu à peu l'espace compris entre l'île et la

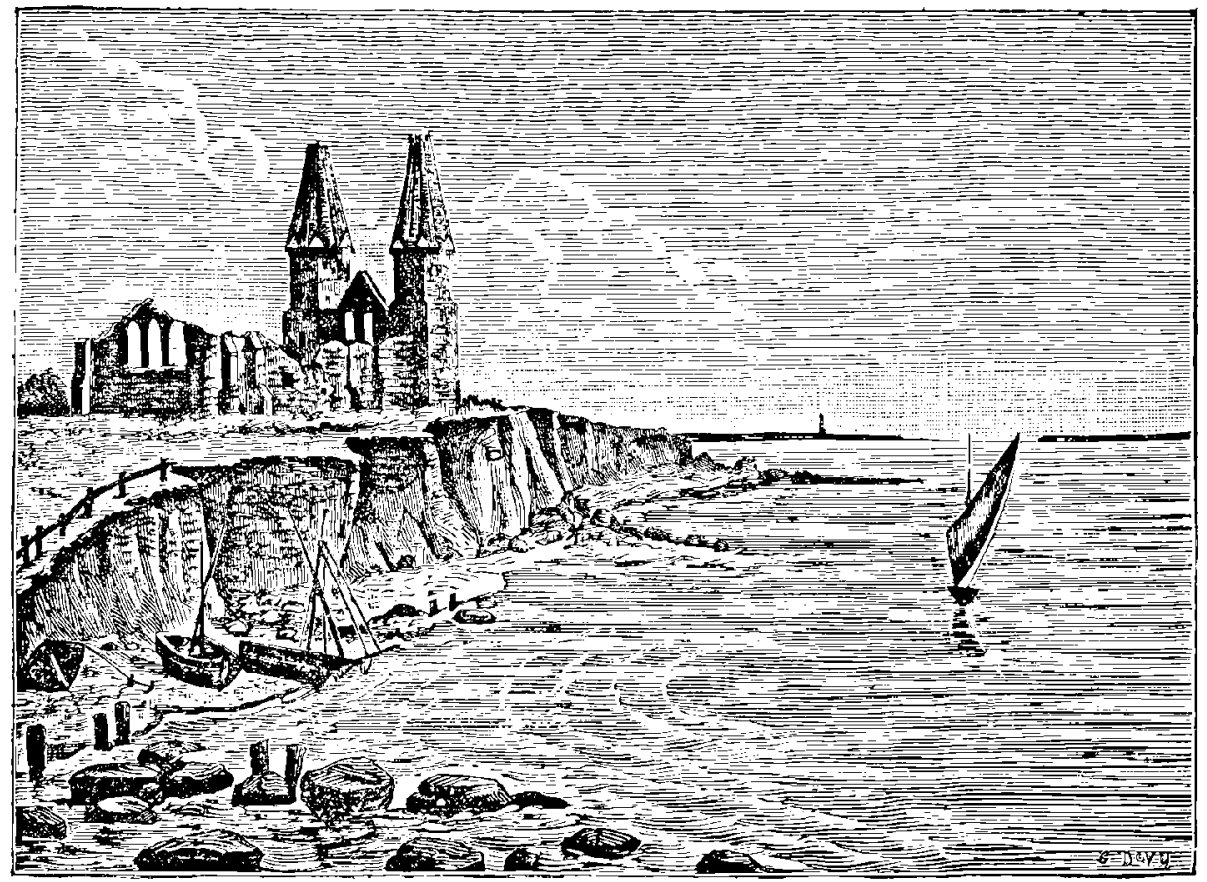

Fig. 151. - Vue de l'église de Reculver en 1834.

terre ferme s'est converti en marais. Strabon rapporte que cette île était habitée par des prètresses samnites qui se livraient à toutes les pratiques d'une religion cruelle et insensée. Les marais salants ont été abandonnés par la mer. Peut-être y a-t-il ensablement.

A Garnac, le célèbre pays des menhirs, d'après des comparaisons que nous avons faites sur d'anciens cadastres, la mer se retire lentement.

A Hennebont, le pied des tours de l'antique enceinte était autrefois baigné par la mer. Il s'est produit là, sur le Blavet, le méme effet qu'à Harfleur sur la Seine. 
A Brouage, non loin de Rochefort et de l'embouchure de la Charente, la mer s'est retirée et a fait place à des marais salants. On attache aujourd'hui les bêtes de somme aux mêmes anneaux où les marins amarraient les embarcations de Richelicu à l'époque du siège de La Rochelle (1627). La petite ville de Brouage, maintenant abandonnèe à cause de son insalubrité, ne reçoit plus dans ses fossés que lës eaux des plus fortes marées.

A Rochefort, les cales de construction établies du temps de Louis XIV seraient trop hautes aujourd'hui de $1^{\mathrm{m}} 25$ environ; de plus, dans les marais salants qui produisent ces monticules blancs de sel marin que rien ne préserve de l'action des pluies, on reconnait que d'annéo en année le sol se soulève et que, pour faire entrer les eaux mères qui doivent donner le sel, on est obligé de se rapprocher de la côte, laissant ainsi une ligne d'anciens bassins d'évaporation qui, sous le nom de marais gâts, forme une large lisière derrière les bassins qui travaillent aujourd'hui.

Au sud de l'embouchure de la Loire, l'île de Noirmoutiers, anciennement île isolée, est aujourd'hui presqu'île à marée basse et s'agrandit par suite du dépôt des sables. Il en est de même de l'île de Bouin. Depuis cent ans, la commune de Bourgneuf a gagné cinq cents hectares. L'anse de l'Aiguillon parait être le reste de l'ancien golfe du Poitou, qui s'étendait au loin dans les terres jusqu'à Niort, Luçon et Courçon; l'apport des alluvions marines, les dépôts de la Sèvre niortaise, de la Vendée et du Lay, et peut-être aussi un soulevement du littoral, ont fait gagner environ cinq cent mille hectares au continent depuis une époque relativement récente : on calcule que la mer abandonne chaque année trente hectares, et si le mouvement continue, un siècle suffira pour transformer en terre ferme ce que l'Océan garde encore du vieux golfe poitevin.

Sur la côte de la Vendée, près de la pointe de l'Aiguillon, les moines de Saint-Michel-en-l'Herm possédaient un immense domaine avec des pêcheries et des élèves de chevaux, qui portaient leurs revenus ou plutôt ceux de l'abbé à plusieurs centaines de mille francs. Ils étaient fort jaloux des conquêtes que le changement de configuration de la côte leur permettait de faire sur l'Océan; aussi, pour que l'autorité royale ne vint pas leur disputer ces extensions 
de territoire, leurs titres de propriété portaient : confrontant à l'ouest à l'Amérique, l'Océan Atlantique entre deux. On voit qu'il y avait une large part pour les terrains soulevés ou abandonnés par la mer. Quant au passage dans l'île de Noirmoutiers, Henri IV, qui n'était rien moins que poltron, n'osa pas le tenter un soir de lempête, et passa une nuit fort incommode dans la cabane du batelier, quoique certaines attractions de son goût l'attendissent dans l'île. Aujourd'hui ce trajet se fait sur des chevaux ou sur des ânes, par tous les temps possibles.

A toutes ces causes de variations des rivages, nous devons encore ajouter les dunes de sable poussées par le vent de la mer. En certaines régions elles agissent avec une singulière activité. Sur le littoral des Landes de Gascogne, par exemple, les vagues de la mer jettent chaque année six millions de mètres cubes de sable ! Ge sable, poussé par le vent, forme des collines, parfois même des montagnes. L'une d'entre elles (celle de Lascours) s'élève jusqu'à 80 et mème 89 mètres de hauteur. En Afrique, sur les plages basses où l'Océan vient baigner le grand désert du Sahara, les dunes du cap Bojador et du cap Vert atteignent une élévation de 120 à 180 mètres. On a vu de siècle en siècle des villages engloutis sous cette fine poussière. des étangs repoussés graduellement et surélevés, des transformations topographiques considérables. Dans les dunes de Gascogne, on connaît les villages de Lislan, de Lélos, engloutis tout entiers; on n'en retrouve même plus l'emplacement. Le bourg de Mimizan a été sauvé à temps par des palissades et des plantations. Les dunes de la Teste avancent de vingt à vingt-cinq mètres par an. L'homme les arrète aujourd'hui par des plantations qui s'opposent à la prise du vent.

Lorsqu'il y a rivalité efficace, équilibre moyen, entre le rent de la mer et le vent venant de terre, les dunes restent stationnaires : ce qu'elles gagnent un jour, elles le perdent le lendemain. Mais si le vent de la mer domine sensiblement, elles gagnent sans cesse en étendue et forment des collines ambulantes qui s'avancent inexorablement dans l'intéricur des terres. C'est ainsi qu'aux environs de Saint-Pol-de-Léon (Finistère), les dunes de Santec recouvrent aujourd'hui un canton qui, jusqu'en 1666. était habité et fertile; on 
voyait encore, au commencement de ce siècle, le clocher et quelques cheminées émergeant au-dessus des sables. Le mouvement de progression des dunes s'était élevé à 537 mètres par an! On s'est décidé à les arrèter par des plantations de pins maritimes.

A Escoublac, près de Pornichet (Loire-Inférieure), nous avons en vain cherché, il y a quelques années, les ruines de l'ancien bourg enscreli sous les dunes depuis un siècle. La montagne de sable est

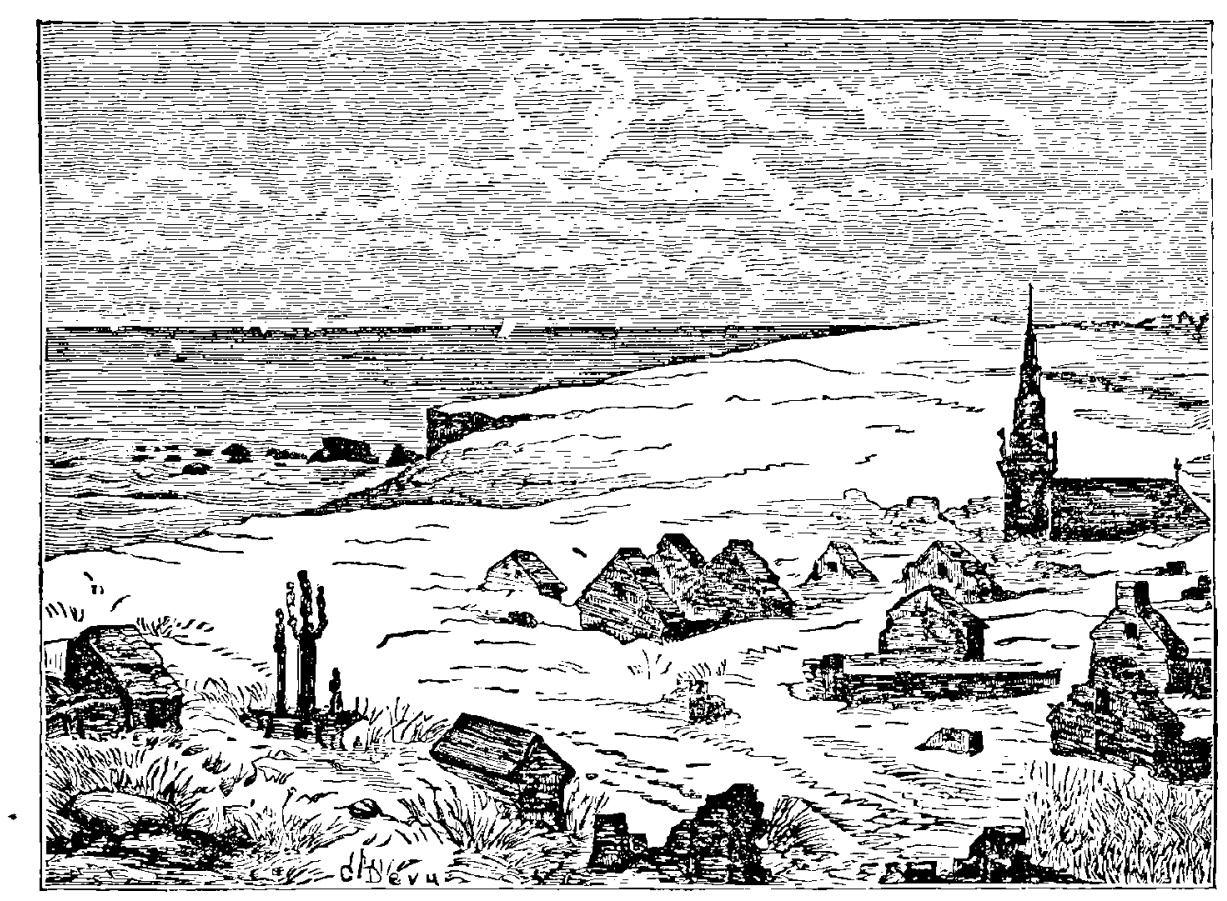

Fig. 152. - Village enseveli sous les dunes.

aujourd'hui couverte de sapins. Chassés impitoyablement par l'envahissement des sables qui, grain à grain (on pourrait dire goutte à goutte), venait les submerger, les habitants de l'ancien bourg abandonnèrent définitivement leurs demeures en 1779 et s'installèrent dans le village actuel, plus éloigné de la mer. Il reste encore une ferme, vers la limite de l'ancien Escoublac. Quoique la submersion ne se soit effectuée qu'avec lenteur et ait laissé aux habitants du pays tout le temps nécessaire pour s'installer un peu plus loin, des traditions sont restées qui donnent un aspect tragique à l'événement. 
Les aieules racontaient encore naguère, à leurs petits-enfants, qu'un soir deux étrangors se présentèrent au bourg et y demandèrent l'hospitalité : c'étaient un vieillard vénérable et une jeune femme d'honnête figure, mais si pauvres, qu'auprès d'eux les briérons (les pauvres ouvriers qui exploitent la brièrej, avaient paru des “ négociants" Ils allèrent de porte en porte sans pouvoir obtenir ni un morceau de pain pour leur souper, ni une botte de paille pour la nuit. Quand ils eurent dépassó la dernière maison, tous deux s'arrêtèrent. Le vieillard semblait indigné et

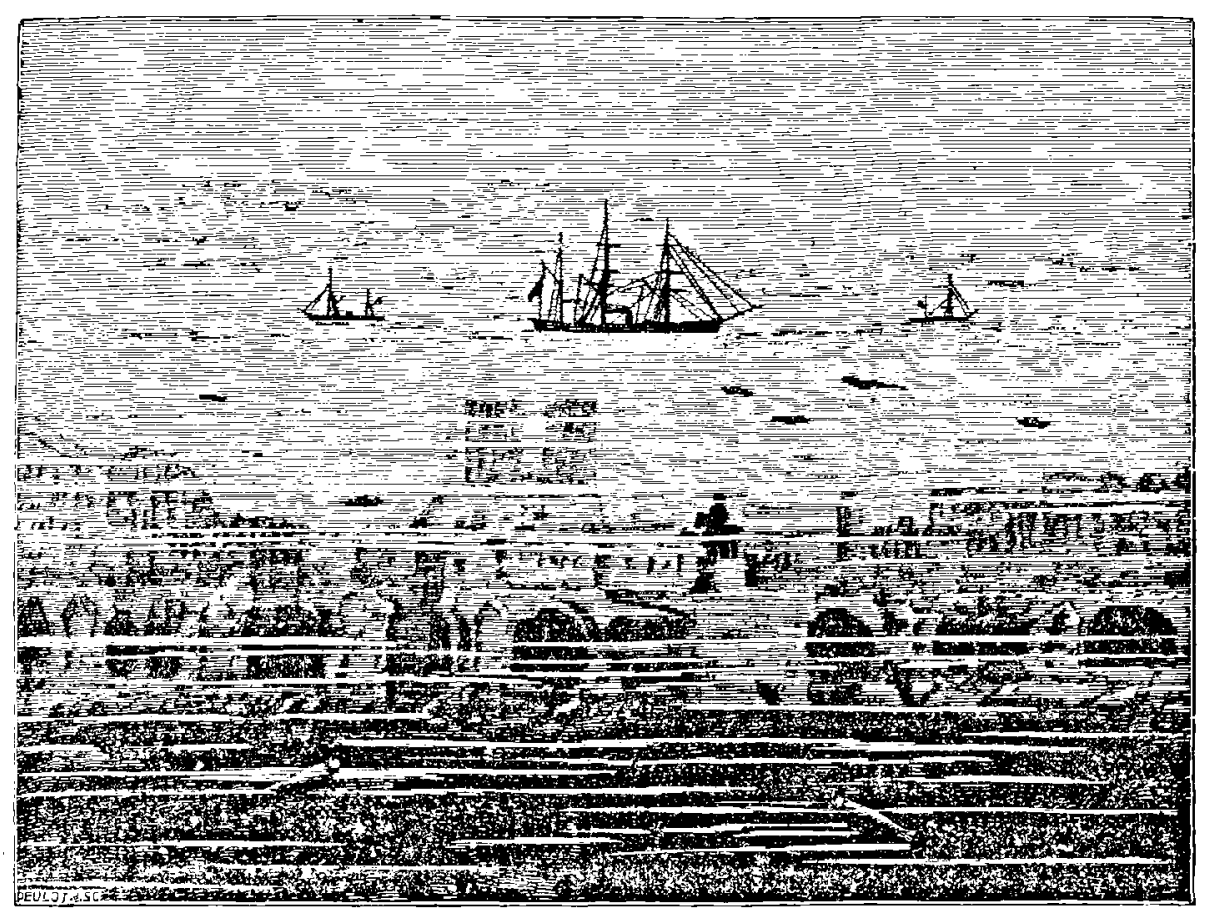

Fig. 153. - Paris sous les eaux.

la femme pleurait, non pas sur elle, mais sur ceux qui avaient été sans pitié. Alors elle joignit les mains comme pour demander gràce; mais san compagnon arracha trois brins de sa barbe qu'il souffla vers la mer, puis la femme et lui s'envolèrent dans le ciel! A peine avaient-ils disparu qu'il s'éleva un vent d'ouest tel qu'il n'en n'avait jamais soufflé depuis la création du monde. Il roulait dans l'air des nuées de sable si épaisses, qu'un homme avait peine $\dot{a}$ y fourrer le bras, et que le lendemain, au soleil levant, le bourg avait disparu. On n'apercevait plus que le coq du clocher, qui se trouvait au niveau du'sol. Les gens comprirent alors quo lo vieillard et la pauvre femme repoussés la veille étaient Dieu le père et 
la vierge Marie, qui avaient voulu éprouver les gens d'Escoublac, et qui les avaient punis de Ieur manque de charité.

L'église actuelle d'Escoublac date de 1782. Au moyen âge, le village s'appelait Episcopi lacus (le lac de l'Évêque), et il ešt probable que le lac ou étang auquel ce nom fait allusion, occupait l'emplacement actuellement marqué par les marais salants.

Le travail de la nature sur les rivages est, comme on le sait, très complexe. Quelquefois les débris des falaises, réduits en galets, puis en sable, sont entraînés au loin le long des rivages par les courants de marée qui vont en former des bancs et des dépôts. C'est ce qu'on voit, sur les côtes de la Manche, à l'embouchure de la Somme, au promontoire du Hourdel, sur les rivages des Flandres, de la Hollande et de l'Angleterre orientale. Ce qui est pris aux falaises par l'érosion est rendu plus loin en bancs de sable et en galets. Notre figure 154 montre un exemple remarquable de ces remaniements de rivages par les galets rejetés par la mer en cordons successifs, tel qu'on peut l'observer à Cayeux, sur le littoral du département de la Somme.

Sur ce littoral, Cayeux, St-Valery, le Crotoy, etc., la mer se retire. Au treizième siècle encore, les barques à fond plat pouvaient remonter à la marée jusque sous les murs d'Abbeville. Il y a là plusieurs anciens ports abandonnés. Les premières maisons bâties à Cayeux, sur le bord de la mer, en sont maintenant à plus de trois cents mètres : en 1879 l'administration du domaine maritime considérant le relais de mer comme lui appartenant, a vendu la bande de terrain nouvellement formée entre le bourg et la plage. Depuis le Crotoy jusqu'a Boulogne on peut suivre sur les cartes le retrait graduel de la mer. La Canche était navigable au XIII siècle jusqu'à Valloire; Montreuil-sur-Mer était un port : il est à quinze kilomètres de la mer; le Marquenterre est une plaine entièrement conquise sur la mer, etc.

Les courants de la mer, la direction des vents, le cours des sables charriés aux embouchures des fleuves, agissant de concert sur certains points, modifient leur configuration, non toujours d'une manière régulière, mais parfois en changeant d'allure suivant la variation des circonstances. Il y a encore là un autre aspect de la question. On peut en signaler comme type le cap Ferret, dans le 
bassin d'Arcachon. Gràce au courant de marée, il s'est avancé de 1768 à 1826, dans l'intérieur de la mer, de cinq kilomètres en 58 ans, c'est-à-dire de 86 mètres par an ou de 20 à 25 centimètres par jour! Puis le mouvement s'est arrèté, le courant a changé et le cap a rétrogradé. En 1854́, l'extrémité du cap avait rétrogradé de 1800 mètres. Maintenant, elle empiète de nouveau sur la mer dans

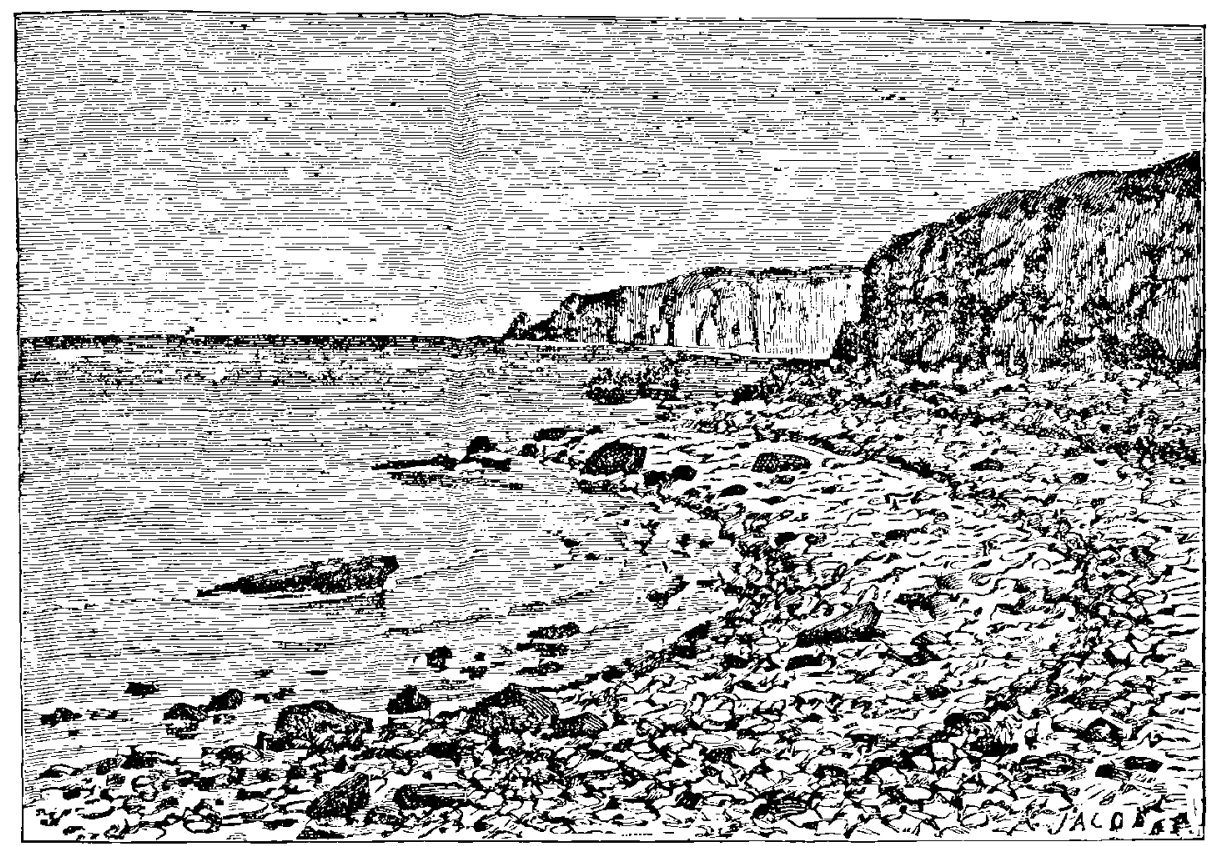

Fig. 154. - Plage de galets rejetés en cordons par la mer à Caycux (Somme).

la direction du sud. Bancs de sables, flèches et lagunes sont des jouets pour les eourants de la mer. (Voy. la fig. 155.)

Mais ne nous attardons pas sur les détails, et revenons aux oscillations lentes du sol.

Parmi les faits qui mettent le mieux en évidence les variations lentes mais sủres de niveau du sol, on doit citer la Suède et toute la péninsule scandinave, qui s'élève d'un côté tandis qu'elle s'abaisse. de l'autre. Dès l'année 1730, l'astronome suédois Celsius (celui anquel on doit la graduation du thermomètre centigrade) avait conclu du témoignage des paysans et des pècheurs que le golfe de Bothnie diminue d'amnée en année de profondeur et d'étendue; les vieillards lui montraient les divers points de la côte où la mer arrivait 
au temps de lcur enfance; les noms de lieux, la position plus ou moins continentale d'anciens ports abandonnés, les débris de bateaux trouvés loin de la mer, les chants populaires, ne pouvaient laisser aucun doute sur la diminution de la mer. Cet abaissement du niveau des eaux était-il récl? Etait-ce la mer qui avait baissé ou

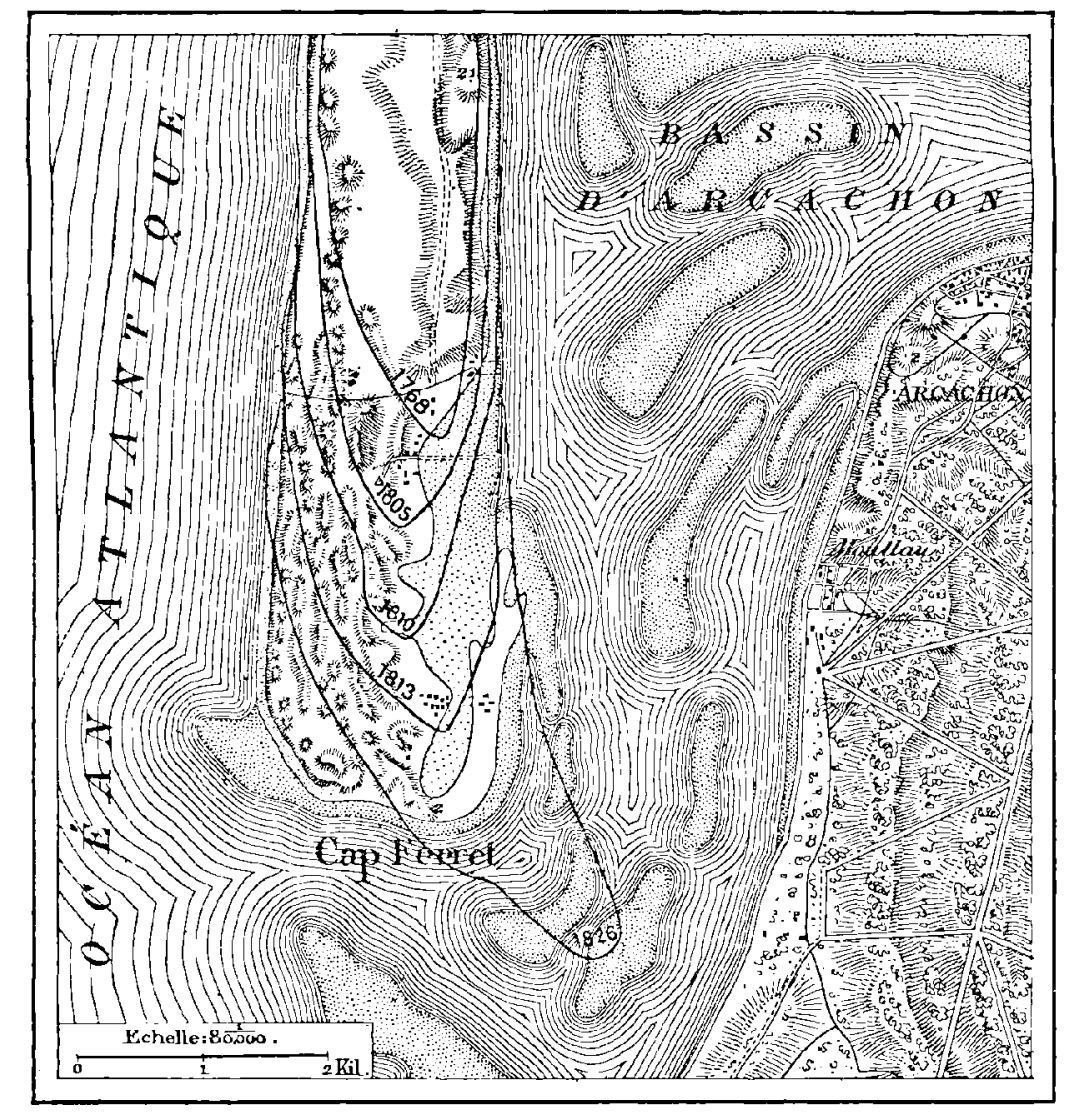

Fig $193 .-T_{1}$ ansformation des ryages : Fitat actual et displacenents rapides du cap Ferret, près d'Arcachon.

le sol s'était-il élevé? A cette époque encore l'opinion unanime étail que le sol était l'élément solide et invariable par excellence, et Cclsius, comme les savants de son époque, attribuèrent le fait à une diminution des eaux de la mer Baltique. L'année suivante, en 1731, en compagnie de Linné, il traça une ligne de repère à la base d'un rocher de l'île Lœfforund, non loin de Gefle, et treize ans plus tard il put constater que la différence de niveau s'élevait à $0^{\mathrm{m}} 18$. Il fut 
accusé d'impiété par les théologiens de Stockholm et d'Upsal, qui affirmaient l'invariabilité de la création, et mème le Parlement fut appelè à trancher la question par un' vote! Les représentants du peuple et la noblesse eurent le bon sens de se reconnaitre incompétents; mais le clergé et les bourgeois déclarèrent hérétique l'opi-

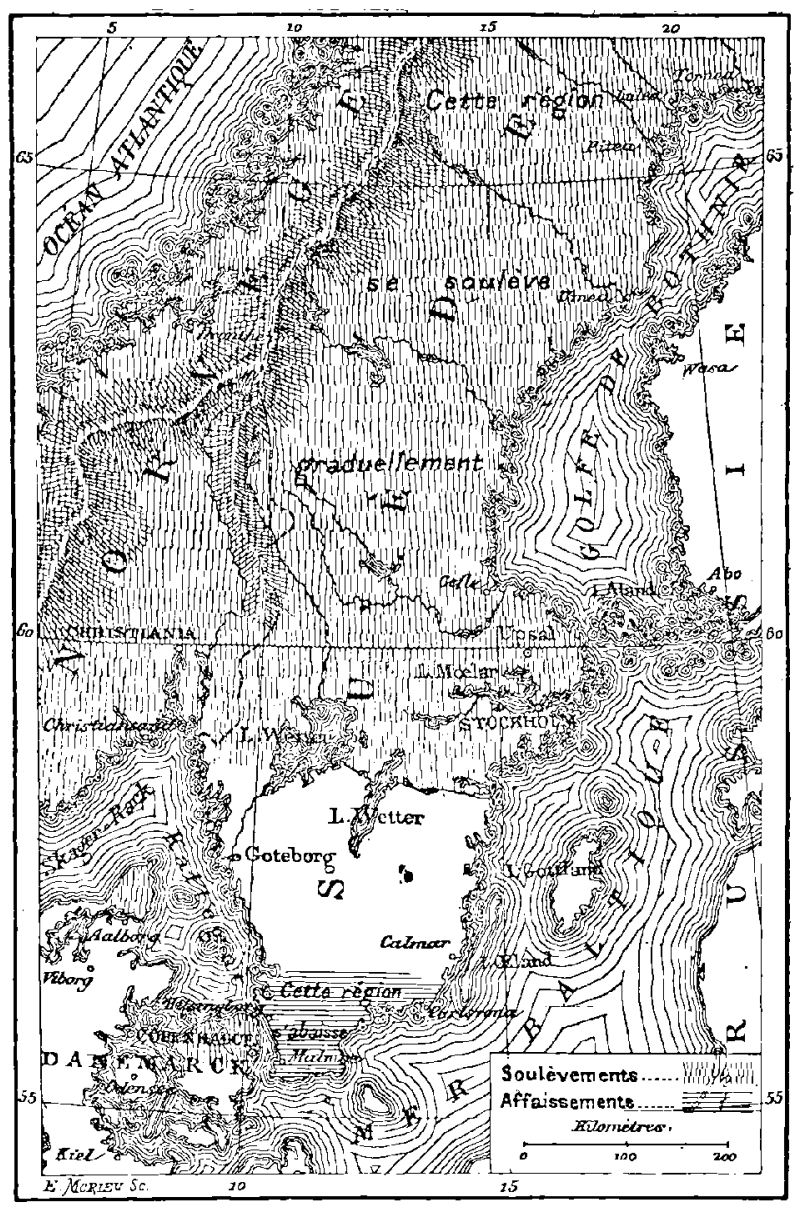

Fig. 10̈6. - Soulevements et affaissements constatés en Suede.

nion nouvelle et la condamnèrent! Vraiment, l'histoire de la vanitó religieuse restera toujours la plus curieuse des histoires!

Les théologiens suédois n'empèchèrent, toutefois, la Terre ni de tourner ni de changer. Depuis le temps de Celsius et de Linné on a continué les observations et on a constaté qu'en effet la terre suédoise s'èlève sensiblement vers le nord tandis qu'elle s'abaisse vers 
lo sud. La ligne de démarcation s'étend de la côte suédoise à celle du schleswig-Holstein, au delà de Bornholm et de Laland. D'après les derniers relevés (1884), la côte nord s'est élevée de $2^{\mathrm{m}} 10$ pendant les 153 années qui séparent l'année 1731 de l'année 1884.

Par contre, la pointe terminale de la péninsule scandinave, la Scanie (de même que le Jutland), s'enfonce graduellement sous les eaux. D'anciennes forêts situées au bord de la mer sont englouties et continuent de descendre. Plusieurs rues de Trelleborg, Istad, Malmöe, sont aujourd'hui remplies d'eau : cette dernière ville s'est abaissée de $1^{\mathrm{m}} 55$ depuis les observations de 1731.

On trouve jusqu'à 27 mètres de hauteur des amas de coquilles marines, identiques avec celles qui vivent actuellement dans ces mers.

En ouvrant les canaux qui font communiquer le lac Molar avec la mer, près de Stockholm, on mit au jour d'anciens vaisseaux snterrés. En coupant une colline on retrouva une habitation consruite en bois, ensevelie à 15 mètres de profondeur sous des sables, les argiles et du gravier.

Des forêts en voie de submersion analogues à celles des côtes de la Scanie se voient en Cornouailles et en Devonshire (Angleterre) : à marée basse on trouve des souches très nombreuses d'arbres variés, aoircies par l'ensevelissement, et du terreau dans lequel on recueille des noisettes, des branches, des feuilles, quelquefois mème le corselet d'un scarabée et des ossements. Ces souches ont toutes la position verticale naturelle aux arbres : la submersion doit avoir eu lieu lentement et sans aucune secousse.

De Kessing à Cromer (Norfolk) une forêt de 64 kilomètres de longueur est visible dans la mer à marée basse, composée de troncs d'arbres restés debout et attachés encore par leurs racines; plusieurs d'entre eux mesurent do soixante à quatre-vingt-dix centimeirres de diamètre, et les lits d'argiles qui les renferment contiennent une énorme accumulation de matière végétale. On les voit toutes les fois qu'à marée hasse les vagues ont déblayé les sables et galets qui les recouvrent.

A Plumstead, à Dagenharn, et dans d'autres parties de la Tumise, entre Woolwich et Erith, on pent reconnaître à marée basse les restes d'une forèt submergée sur laquolle le fleuve coule aujourd'hui. 
C'est du reste là un fait très anciennement connu. Décrit dès le milieu du siècle dernier par le capitaine Perry, il a été spécialement étudié en 1817 par Guekladd et vérifié en 1883 par l'Association scientifique anglaise : on a retrouvé, au-dessous de six à huit pieds d'alluvions, un sol formé de branches, de feuilles, de traces d'arbres et d'ossements d'animaux de l'époque actuelle. Cet affaissement est récent, comme tous les précédents. La ville de Londres est bâtie sur une ancienne forèt habitée autrefois par des races d'animaux dont on a retrouvé les restes.

Ainsi, sur toutes ces côtes, les vestiges de forêts sous-marines sont incontestables et prouvent l'affaissement du sol. Les documents sont nombreux. Nous nous bornons à signaler les principaux. Or ces faits de dépressions et de soulèvements ne sont pas spéciaux à notre époque; ils se sont produits autrefois comme de nos jours, et ils expliquent les variétés du relief de la croùte du globe.

Le Groënland, aujourd'hui couvert de glace et parsemé de ruines, était autrefois une « terre verdoyante » comme son nom l'indique. Après les voyages effectués par Erik le Rouge en 983 et en 986, le pays, très fertile, au moins le long du littoral, ne tarda pas à être colonisé. Aujourd'hui, les glaces couvrent plus de la moitié des deux milliards de kilomètres carrés que représente sa surface. Il s'est soulevé après la póriode glaciaire, et ce soulèvement a porté à l'altitude de 50 mètres des bancs de coquilles identiques à celles qui vivent actuellement dans la mer voisine. L'expédition qui vient d'être faite (1879 à 1883) par ordre du gonvernement danois signale entre autres une ruine du moyen âge, située sur un écueil, à Igaliko, qui s'est tellement affaissée que la mer en baigne le pied. La côte occidentale du pays subit un abaissement lent, absolument certain, dont la mesure, toutefois, ne nous parait pas clairement exprimée (').

C'est non loin du Groënland que se trouve, sur les anciennes car- ' tes marines, la " Terre submergée de Buss », vers $57^{\circ}$ de latitude et $30^{\circ}$ de longitude, dont on ne retrouve plus aucune trace aujourd'hui.

1. Yoy. Journal des savants, juin 1885, p. 364 ; * Cet abaissement a été à Lich tensfeld, depuis 1789 , de $1^{m} 88$ à $2^{m} 51$. " - Veut on dire que l'abaissement avait déjà été mesuré à $\mathrm{l}^{\mathrm{m}} 88$ en 1789 et est aujourdhui de $2^{\mathrm{m}} 5 \mathrm{l}$, ou que depuis 1789 il est égal a une quantité comprise entre $1^{\mathrm{m}} 88$ et $2^{\text {t5 }} 51$ ? 
Il y a là actuellement 748 brasses d'eau, au-dessus d'une montagne sous-marine tout antour de laquelle la profondeur descend jusqu'a 1200 brasses environ de part et d'autre. Cependant, cn 1777 encore, les cartes marines signalent là un écueil pour les navigateurs. Cet écueil datait sans doute du siècle précédent. En remontant plus haut, on trouve au XIV siècle, en 1380, la relation de deux nobles Vénitiens, Nicolas et Antonio Zeni qui, emportés par une ternpête, ont été recueillis là par une population chrétienne habitant une grande île, l'ouest Friesland, sur laquelle existaient « cent villes et cent villages ». Cette île est-elle la terre submergée de Buss ou une

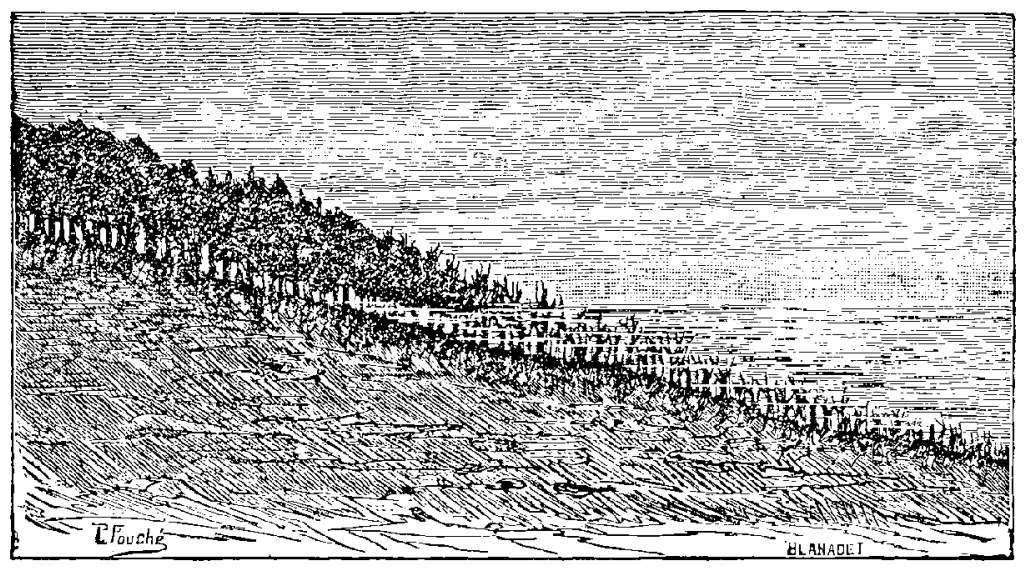

Fig. 1307. - Forèt en voie de submersion sur les rivages de la Suède.

partie du Groënland lui-même? L'histoire est muette. Mais, sclon toute probabilité, il y a là une île submergée.

On se rendra compte de l'ensemble de ces grands mouvements d'oscillations du sol à l'examen de la carte ci-dessous (fig. 158), sur laquelle sont indiqués les changements les mieux constatés. On y voit s'abaisser la côte occidentale du Groënland, l'extrémité méridionale de la Suède, la Prusse, le Hanovre, la Hollande, la Belgique, la Flandre, la Picardie, la Normandie, la Bretagne (excepté du Blavet à la Loire : la Vendée, le Poitou, la Saintonge; paraissent plutôt s'élever que s'abaisser), les Landes et la Gascogne jusqu'á l'Espagne; le littoral de l'Adriatique, le delta du Nil et la région du canal de Suez, les bouches de l'Indus et le delta du Gange. - Dans les Amériques, la côte orientale de l'Amérique du Nord, entre la Flo- 
ride, Terre-Neuve et le Brésil, de l'embouchure de l'Amazone jusqu'au Pornahyba: la vallée des Amazones s'est laissée envahir par l'océan jusqu'à 500 kilomètres, et les Andes qui portent Quito parais-

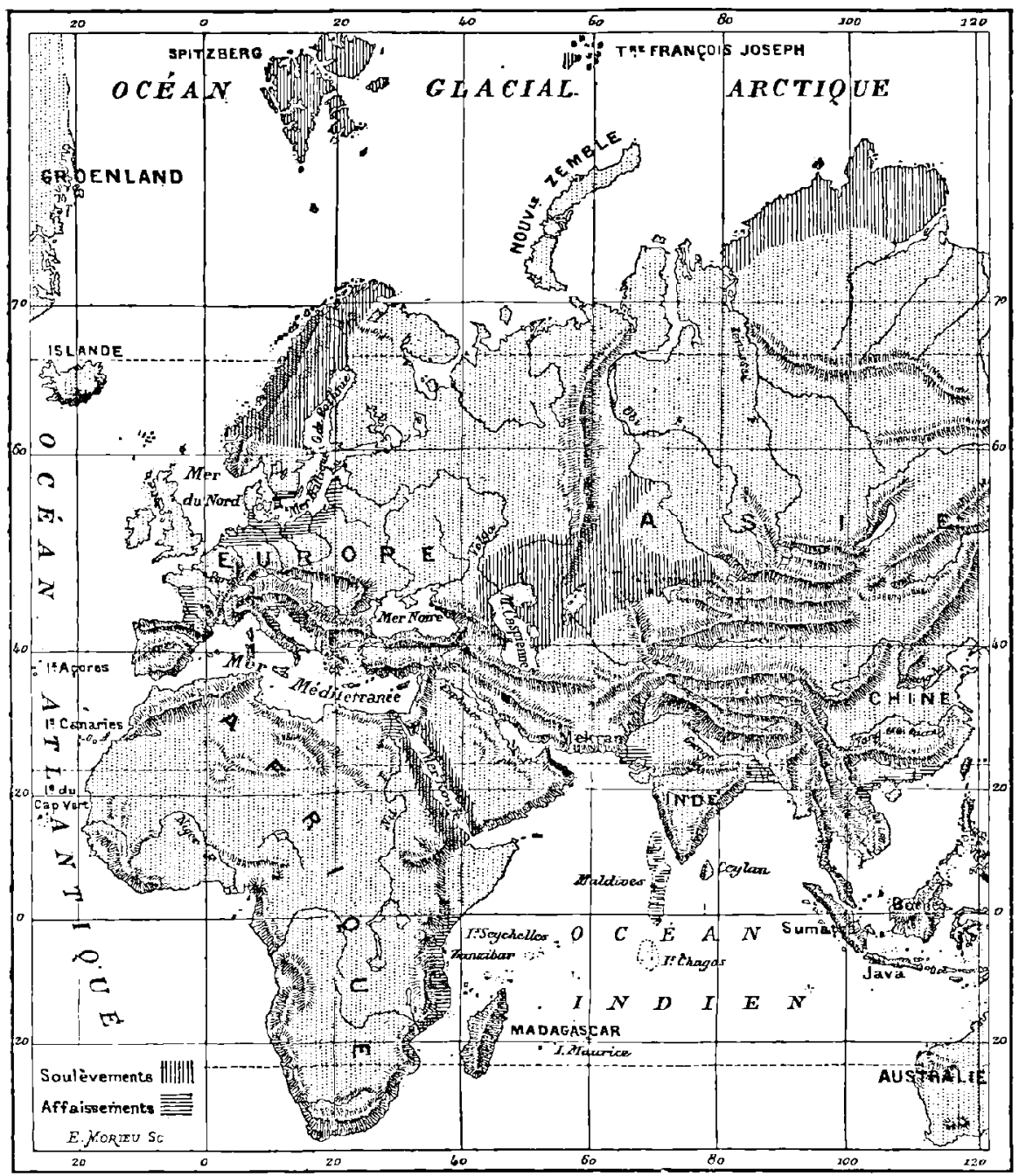

Fig. 138. - Carte gé1ėrale des soulèvements et affaissements du sol en voie d'accomplissement.

sent descendre lentement.- Sur cette même carte, on remarquera, au contraire, que le Spitzberg, la côte orientale de la Sibérie, Ia Norvège et les Alpes Scandinaves, l'Écosse, la Sardaigne, la Tunisie, les deux rives de la mer Rouge et le Turkestan, sont en voie d'exhaussement.

LE MONDE AVANT LA CRÉation DE L'HUMME 
L'Angleterre était autrcfois réunie à la France. La constitution géologique des terrains est la méme de part et d'autre du détroit; les mèmes formations correspondent, et les soulèvements observés en France dans le relief du sol se continuent en Angleterre de l'autre côté de la Manche. L'Angleterre ne contient en propre pas une seule plante, pas un seul animal qui ne soit venu du continent. C'est au Pas-de-Calais que s'est opérée la réunion des eaux de l'Atlantique avec celles de la mer du Nord : la distance du rivage français au rivage anglais n'est encore aujourd'hui que de 22 kilomètres, et la plus grande profondeur ne surpasse pas 57 mètres. Si l'on y plaçait Notre-Dame de Paris, les tours dépasseraient assez le niveau des eaux pour que l'on pût encore sonner les cloches. Comment et à quelle époque le détroit s'est-il ouvert? C'est ce qu'il serait difficile de décider; mais ce n'est pas géologiquement ancien, et c'est pendant l'époque actuelle, peut-ètre mème depuis l'origine de l'humanité. Les courants de marée peuvent avoir suffi, un jour de violente tempete, pour ouvrir le passage. Il continue de se creuser. Une première carte du fond de la Manche, construite par Baach en 1737 et publiée par Desmarets en 1751, porte 29 brasses comme maximum entre Douvres et Calais; encore laisse-t-elle subsister sur toute la largeur du détroit un haut fond de 19 brasses. La brasse est de $1^{\mathrm{m}} 62$. Nous aurions donc, au maximum, 47 mètres pour la plus grande profondeur sur la ligne de Galais à Douvres, en 1737. La carte publiée en 1876, à propos du projet de tunnel sous-marin entre la France et l'Angleterre, indique pour ce même maximum 57 mètres. D'après ces comparaisons, le canal se serait creusé de dix mètres en 139 ans. Il n'y a là rien d'absolu, attendu que les sondages du siècle dernier n'étaient pas très précis ; cependant on ne peut s'empècher d'en conclure au moins le fait d'un abaissement certain. Remarquons encore que, précisément sur ce pareours, surtout entre Folkstone et le eap Gris-Nez, on rencontre des bancs qui affleurent presque, l'un, le Varne, arrive à dix mètres au-dessous de la surface (et même à six et à cinq); l'autre, le Colbart, arrive à cinq mètres en certains points. La direction et la force des courants, d'une part, la nature des roches d'autre part, agissent de facons diverses dans ce creusement du détroit, mai: l'aspect général conduit bien à con. 
clure que la séparation est géologiquement récente. L'isthme de Calais-Douvres est encore visible.

En même temps qu'il se creuse, le détroit s'élargit. La falaise du cap Gris-Nez, point français le plus rapproché des côtes anglaises, recule actuellement de 25 mètres par siècle. Il en a été de mème près de Douvres, comme nous l'avons vu.

De la mème manière, l'Irlande a été séparée de la Grande-Bretagne pendant la période géologique et zoologique actuelle.

De même que l'Angleterre était autrefois réunie à la France, de même l'Afrique était rattachée à l'Europe. Le détroit de Gibraltar
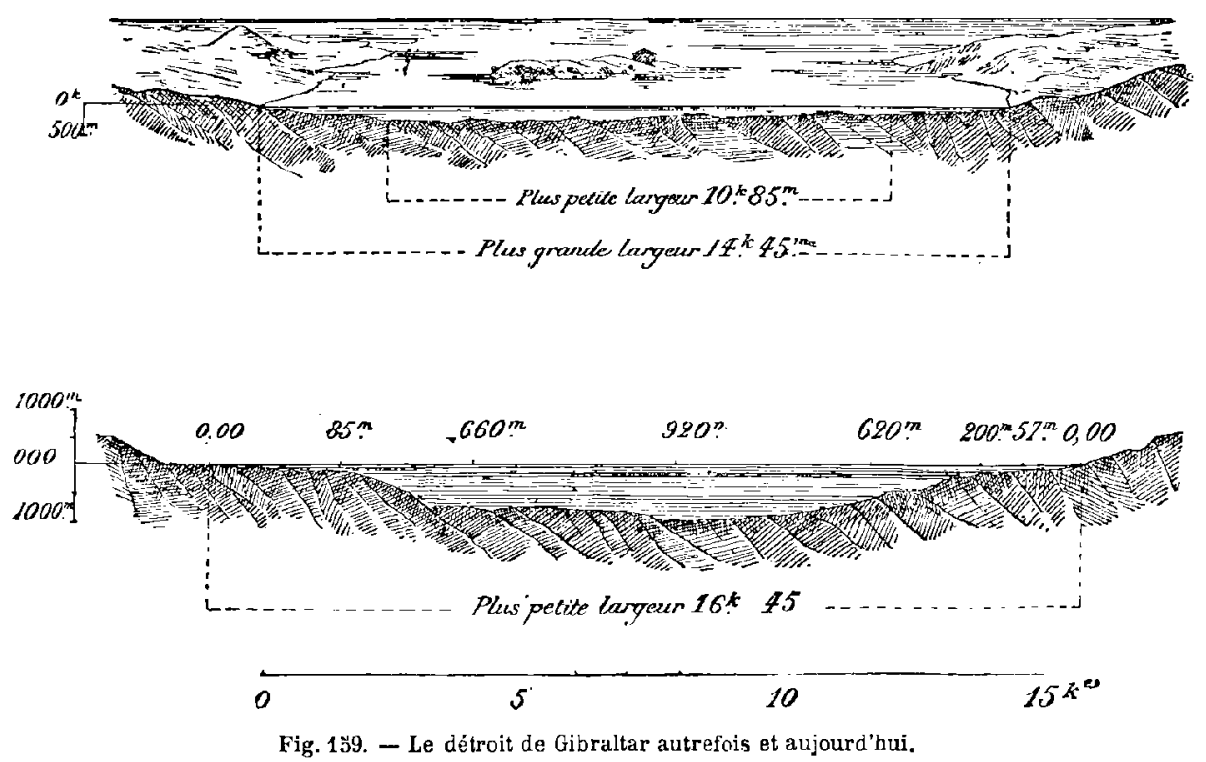

I'a pas toujours existé, pas plus que la Manche. Les anciens s'en étaient doutés par la forme des denx rivages symétriques, et ils attribuaient à Hercule la puissance d'avoir ouvert le passage entre l'Océan et la Méditerranéc. Salluste regarde mème comme une fâcheuse nouveauté d'avoir donné en géographie deux noms différents à l'Afrique et à l'Europe. De même que le Pas-de-Calais, le détroit de Gibraltar ne cesse de s'élargir sous la triple action des météores aériens, des vagues de tempêtes et du couranit qui sort d'une mer pour se porter dans l'autre. L'antuque risunion de l'Afrique à l'Europe est constatée zoologiquement par ce fait, que le nord de l'Afrique n'a pas une seule espèce de mollusques vivants 
qui lui soit particulière et que tous les types de ces animaux trouvés sur les pentes de l'Atlas sont originaires de l'Espagne.

Ce détroit, désigné dans l'antiquité sous le nom de “Colonnes d'Hercule » à cause des gigantesques massifs montagneux qui le bordent de part et d'autre sur la côte européenne comme sur la côte africaine, ce détroit, disons-nous, s'élargit et s'approfondit de siècle en siècle. Pline, Pomponius Mela, Avienụs parlent d'une et

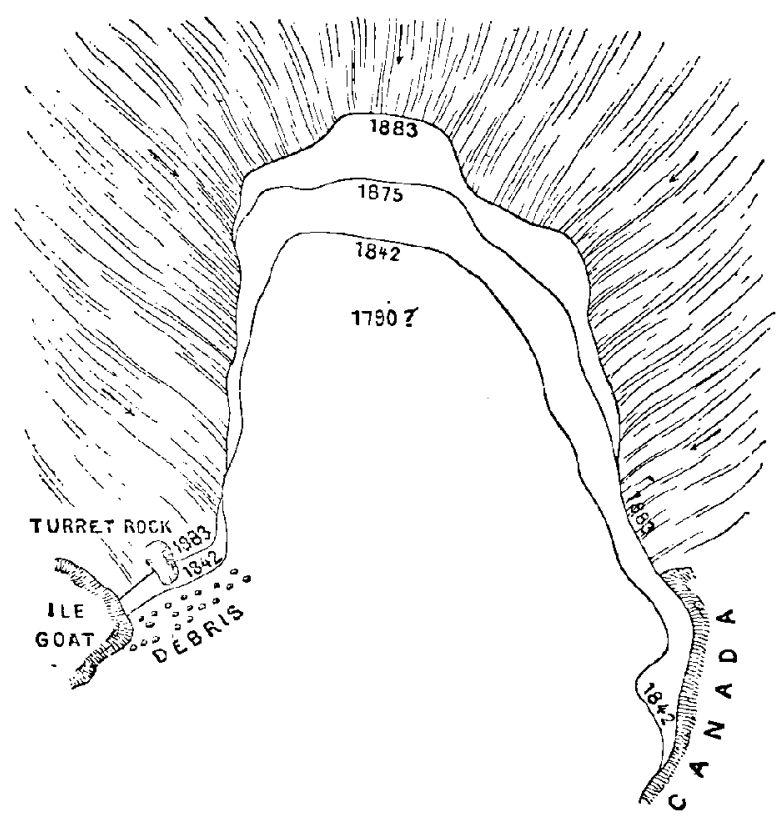

Fig. 160. - Recul graduel de la cataracte du Niagara

même plusieurs îles boisées qui l'entrecoupaient; un temple y avait été bâti en l'honneur d'Hercule. D'après Pline, la plus petite largeur du détroit aurait été de 10 à 11 kilomètres, et la plus grande largeur de 14 kilomètres et demi. Actuellement la plus petite largeur est de 16 kilomètres. La mer a englouti la ville de Belon, à trois lieues à l'est de Tarifa, et, dans la baie même de Gibraltar, une partie de la ville de Carteya

Combien de terres ont disparu depuis les origines mémes de l'humanité ! Tous ceux qui aiment la littérature ont lu dans Platon les belles pages qu'il a consacrées au souvenir de l'Atlantide, de ce continent mystérieux qui existait autrefois entre l'Europo et l'Amé- 
rique et sur lequel une antique humanité a vécu. Les comparaisons géologiques nous montrent qu'à l'époque miocéne, les plantes et les animaux étaient les mêmes en Europe et en Amérique, quoiqu'ils diffèrent si complètement aujourd'hui. On peut en conclure, avec vraisemblance, qu'à cette époque, le continent disparu qui a donné son nom à l'Océan Atlantique, devait être rattaché par des îles à l'Europe comme à l'Amérique. Les Guanches des Canaries ont

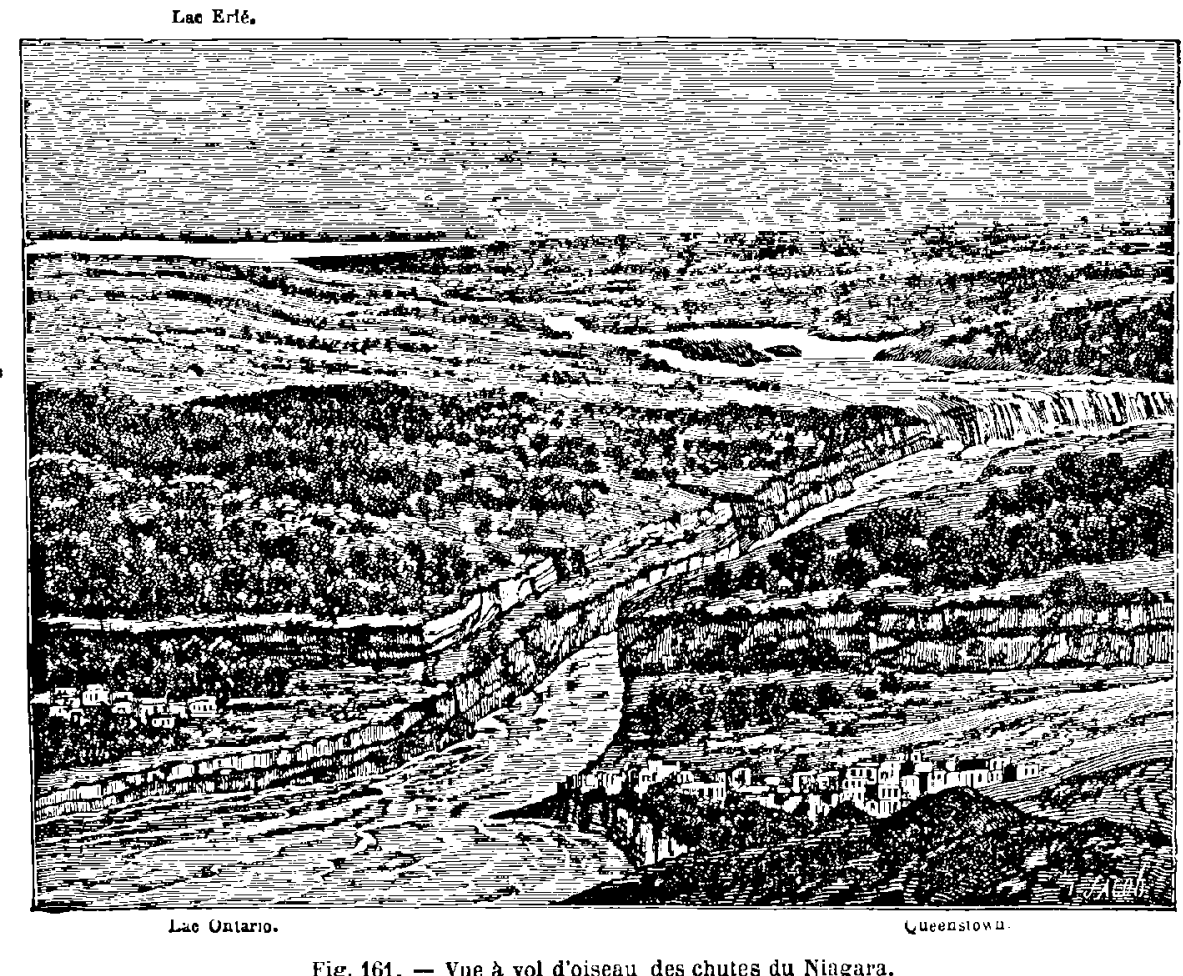

mème été regardés comme les descendants directs de l'humanité primordiale qui peuplait l'Atlantide.

L'île de Madagascar est sans doute aussi un fragment de, monde disparu, un restant de continent descendu sous les flots. Quoique assez rapprochée de l'Afrique, elle en diffère par sa zoologie et sa botanique; sa faune et sa flore lui appartiennent en propre, et elle possède mème des familles entières, notamment de serpents et de singes, qui n'ont pas d'autres représentants sur la planète.

L'île de Ceylan est dans le même cas. Elle appartenait sans 
doute, avec Madagascar et les Seychelles, à un ancien continent émergé à la place de l'Océan Indien.

La plupart des Antilles, mème les dernières terres, paraissent être émergées d'un continent sans rapport avec l'Amérique du Nord. Tout le monde sait que la Nouvelle-Zélande forme à elle seule un monde à part, dont la flore et la faune ont un caractère essentiellement original. $\mathrm{Ni}$ ses espèces fossiles, ni ses espèces vivantes, ne ressemblent à celles de l'Australie ou de l'Amérique du Sud.

J'après les fossiles si remarquables trouvés à Pikermi : hipparions, antilopes, girafes, mastodontes, rhinocéros, dinothériums, machairodus, la Gréce doit être le reste d'un ancien continent, portant de vastes forêts et de plantureuses prairies, s'étendant sans doute jusqu'à l'Afrique à travers les espaces marqués de nos jours par les îles de l'Archipel et la mer de Crète.

Tout change, tout se transforme, avec une rapidité plus ou moins grande. Qui ne connaît - de réputation tout au moins - la chute splendide du Niagara! C'est là un magnifique exemple de l'excavation progressive d'une vallée profonde dans la roche dure. Ce fleuve coule sur un plateau élevé dans lequel le bassin du lac Érié forme une dépression. Le point où il sort de ce lac a près de 1600 mètres de largeur, et un niveau de cent mètres supérieur à celui du lac Ontario, qui se trouve distant d'environ 48 kilomètres. En sortant du lac Érié, sur les 25 premiers kilonètres de son cours, le Niagara est limité par des bords qui sont presque de niveau avec le pays plat adjacent, comprenant à l'ouest le haut Canada, et à l'est l'État de New-York; ils ne sont nulle part à plus de 9 à 12 mètres au-dessus de la surface générale de la contrée. Le fleuve, d'une largeur qui est parfois de 4800 metres, accidentelloment entrecoupé d'îles basses et boisées, forme, en les côtoyant, un courant aux eaux claires, unies et tranquilles; sa pente n'étant, sur une étendue de plusieurs kilomètres, que de $4^{\mathrm{m}} 50$; il ressemble, dans cette partie de sa course, à un bras du lac Érié. Mais il ne tarde pas à changer complètement de caractère, et, lorsqu'il approche des Rapides, il commence à courir en écumant sur un lit de calcaire rocheux et inégal, et parcourt ainsi un espace de 1600 mètres environ, jusqu'à ce qu'enfin arrivé aux chutes, il se précipite perpendiculairement d'une hauteur de 50 mètres. Une île, située au 
bord même de la cataracte, divise le Niagara en deux nappes d'eau; la plus grande mesure 530 mètres de largeur, et la plus petite 180 . Après s'être précipitée dans un bassin d'une profondeur considérable, l'eau s'engage avec une grande rapidité dans un canal étroit d'une forte pente, sur une étendue de onze kilomètres. Ce ravin, n'offrant entre ses murs qu'une distance de 200 à 400 mètres, la largeur du fleuve, sur ce point, contraste d'une manière frappante avec celle qu'il a au-dessus. Cette énorme tranchée, dont la profondeur est de 60 à 90 mètres, se termine brusquement à Queenstown en un escarpement, ou longue ligne de falaises intérieures, faisant face au nord du côté du lac Ontario. A sa sortie de la gorge creusée dans cet escarpement, le Niagara entre dans une plaine dont le niveau est à si peu de chose près le même que celui du lac Ontario, que les onze kilomètres à parcourir entre Queenstown et les bords de ce lac n'offrent qu'une pente de 12 centimètres environ.

La vue de ces chutes inspire l'idée d'une destruction constante et progressive; la partie du bassin qui a été l'œuvre des cent cinquante dernières années ressemblant précisément, sous le rapport de la profondeur, de la largeur et du caractère, au reste de la gorge qui s'étend au-dessous sur une longueur de onze kilomètres, il est tout naturel de conclure que le ravin entier a été creusć de la même manière, par suite de la rétrogradation de la cataracte.

On vient de calculer tout récemment (Wesson, 1885) le taux de rétrogradation du Niagara, que Bakewell avait déjà ètudié sur place en 1829 et Lyell en 1841. Nous reproduisons ici ( $f g .160)$, d'après la carte officielle des États-Unis, les lignes de repère de cette rétrogradation pour la branche canadienne. Elle s'accomplit d'une manière inégale et irrégulière; mais de 1842 à 1883, elle s'est élevée à 253 pieds anglais, c'est-à-dire à 77 mètres, soit $1^{\mathrm{m}} 88$ par an. A ce taux, il n'y aurait pas plus de six mille ans que la cataracte aurait commencé à rétrograder à partir de l'escarpement de Queenstown. Lyell avait, sur une base moins vaste, admis seulement $0^{\mathrm{m}} 30$ par an, ce qui reculerait à trente-cinq mille ans l'órigine de la rétrogradation. Auparavant, l'immense fleuve coulait dans un lit différent, dont on retrouve les traces non loin du lit actuel.

Ces mouvements, ces changements, passent inaperçus pour 
l'homme, observateur d'un jour, parce que notre vie est trop rapide, et d'ailleurs occupée par de tout autres sujets, moins intéressants, pour la plupart, que l'étude de la nature. Combien. d'hommes vivent intellectuellement? Combien se demandent même où ils sont et se rendent compte du pays qu'ils habitent?

Nous avons vu tout à l'heure que toutes les montagnes sont len. tement usées par les agents atmosphériques. Si l'on n'est pas frappé de cet abaissement, c'est parce qu'il s'effectue avec une extrême lenteur et que la base de nos observations est très restreinte. Mais que nous ayons sous les yeux d'anciens souvenirs historiques, et aussitôt l'œuvre des siècles parle aux yeux. En arrivant à Rome, la « ville aux sept collines », la première impression que nous avons reçue en contemplant le panorama du haut de l'Observatoire du Capitole, a été de « chercher » les sept collines. Elles sont descendues, leurs débris séculaires ont comblé les vallées intermédiaires (notamment. le Forum, si considérablement exhaussé), et ce ne sont plus aujour-, d'hui que de simples ondulations. Le fond de toutes les villes s'élève avec le temps. Sous Louis XII, on montait un escalier de treize marches pour entrer à Notre-Dame de Paris. Aujourd'hui, la place du Parvis est de niveau avec le pavé de l'église.

A Paris même et aux environs, la Bièvre était autrefois une rivière importante, dans laquelle les castors étaient trés nombreux (c'est même de leur nom ancien qu'elle a pris son nom). Aujourd'hui, la Bièvre n'est plus qu'un cours d'eau insignifiant, un ruisseau qui ne mérite le titre de rivière qu'aux jours de grandes crues.

Plus anciennement dans l'histoire, ou pour mieux dire aux temps préhistoriques, la Seine, incomparablement plus vaste qu'elle n'est de nos jours, s'étendait, fleuve immense, sur plusieurs kilomèlres de largeur à Paris même, et s'élevait jusqu'à la hauteur de 60 mètres — et mème de 63 mètres, - à 37 mètres au-dessus de son niveau actuel, dont l'altitude est de 26 mètres. M. Belgrand a mème pu reconstituer cet ancien lit du fleuve dans les deux cartes que nous reproduisons plus lọin. On a retrouvé ses alluvions jusqu'à ces hauteurs. Le fleuve a creusé les vallées jusqu'au point où nous les voyons aujourd'hui.

Transformation perpétuclle! Ici, les eaux creusent le sol, plus loin elles l'exhaussent en abandonnant le limon charrié aux 


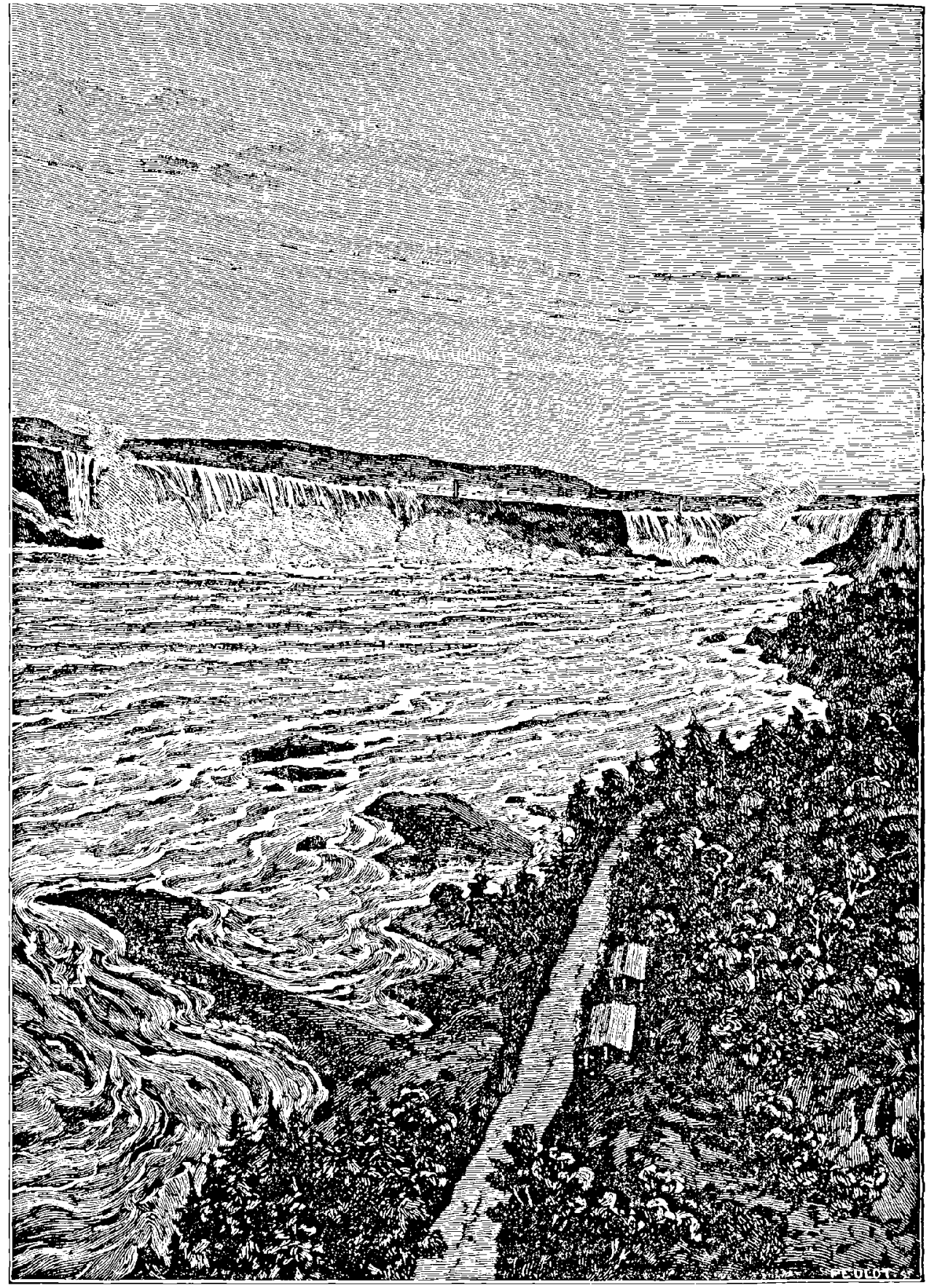

CHUTE DU NIAGARA

LE MUNUE AVANT LA CRÉtTION DE L'HOMME 
époques d'inondations ou en faisant un lit des matériaux enlevés aux montagnes par les pluies. Il suffit de regarder pour reconnaitre partout les traces actuelles de dénivellation des terrains lentement minés. Les couches d'alluvions modernes occupent des espaces considérables, et mesurent souvent plusieurs mètres d'épaisseur. Tout récemment encore nous le constations dans la vallée de la Meuse - en des lieux qui nous sont chers - non loin de la source de cette rivière, entre Bourmont et Montigny-le-Roi. Presque tous les ans la rivière déborde et recouvre de ses eaux limoneuses plusieurs centaines d'hectares. On peut estimer à deux millimètres l'épaisseur annuelle du limon abandonné après les crues en certaines régions de la valléc, tant par la rivière elle-mème que par les terres descendues des collines en bordure : c'est deux mètres en mille ans, trois mètres au moins depuis l'époque romaine. On a trouvé des fers à cheval de petit module, des casques et divers objets alors abandonnés à la surface du sol, enterrés aujaurd'hui à deux mètres de profondeur, et nous avons déterré nous-même (août 1855) à trois mètres au-dessous du niveau de la prairie, un chêne charrié et abandonné là depuis les origines de l'histoire de France, sans doute. Des fossiles jurassiques, térébratules, rynchonelles, bélemnites, huîtres, et autres coquilles antédiluviennes, entraînées par les eaux ou charriées pour les remblais de la voie ferrée, viennent confondre les époques géologiques en ajoutant leurs restes à ceux de l'époque actuelle. Le niveau de la vallée s'élève, le relief des collines s'abaisse, et l'histoire du monde écrit une de ses pages dans le paysage changeant ou sous l'indulgente affection du grand-père et de la grand'mère les jeux de notre enfance s'envolaient dans l'azur, - fugitive image de la fugacité de toutes choses et de la mobilité mème de l'éternelle nature.

Partout nous pouvons observer ces transformations plus ou moins lentes. Certains exemples sont encore plus remarquables que tous les précédents. Nous voudrions pouvoir les signaler tous.

Dans le divin golfe de Naples, sur ce rivage enchanteur où les souvenirs de l'histoire s'unissent aux beautés de la nature pour bercer la pensée, on s'arrête, au milieu des ruines de Pouzzole, devant l'ancien temple de Jupiter Sérapis, curieux témoignaga de l'instabilité du sol. Ce temple, édifié vers l'an 105 avant J.-G. sur le 
rivage de la mer, mais fort au-dessus du niveau de ses eaux, décoré de marbres précieux par Septime Sévère, entre les années 194 et 211 de notre ère, cmbelli et enrichi encore par Alexandre Sévère entre les années 222 et 235, fut ruiné par Alaric et ses Goths en 410, et par Genséric en 445. Ce sont là des vicissitudes humaines. Mais ce qui nous intẹ́resse le plus, c'est l'nuvre de la nature.

Le sol sur lequel le temple est bâti s'est abaissé au-dessous du niveau de la mer. Les trois belles colonnes de marbre qui en

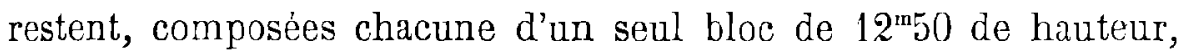
sont descendues avec le pavé et les substructions du temple au point d'ètre immergécs jusqu'à $6^{\mathrm{m}} 30$ de hauteur. Pendant cette période de submersion, qui s'est effectuće au moyen âge et était terminée au XV $\mathrm{XV}^{\circ}$ siècle, la portion supéricure de la partie immergée a été attaquée, sur une hauteur de $2^{\mathrm{m}} 70$, par des mollusques lithophages (mangeurs de pierres) qui vivaient alors dans la mer, comme aujourd'hui, et qui ont criblé ces colonnes de petits trous au fond desquels on trouve encore leurs coquilles. Les perforations sont si considérables en profondeur qu'elles témoignent d'un séjour prolongé des lithophages dans les colonnes, car à mesure que ces animaux croissent en âge et en volume, ils agrandissent proportionnellement leur demeure. La portion inférieure des colonnes est restée intacte, parce qu'elle plongeait dans le fond de la mer rempli do vase et de scories volcaniques jusqu'à la hauteur de $3^{\mathrm{m}} 60$. (Nous reproduisons plus loin $f g$. 165, d'après Lyell, Principes de géologie, un beau dessin de ces ruines.)

A la fin du $X V^{e}$ siècle, ce sol si remarquable par son instabilité commença à effectuer un mouvement contraire, à se relever lentement et graduellement. Un document daté d'octobre 150.3 porte que Ferdinand et Isabelle, souverains de Naples, accordent à l'université de Pouzzole une portion de terrain « d'où la mer est en voie de se retirer ", et depuis cette époque on peut suivre sur les documents contemporains l'exhaussement graduel de cette plage.

Puis, de nouveau, ce mouvement d'élévation s'est arrèté. En 1749, le temple était entic̀rement sorti des eaux et tout le terrain environnant était à sec.

En 1807, l'architecte Nicolini, chargé de la réparation de ces ruines, ne vit jamais le pavé recouvert par la mer, excepté quel- 
quefois lorsque le vent du sud soufflait avec force. Mais le sol commençait à redescendre de nouveau. De 1822 à 1838, les observations montrèrent que l'abaissement s'effectuait à raison de 25 millimètres tous les quatre áns, si bien qu'en 1838 on prenait chaque jour du poisson sur cette partie du pavé où, en 1807, il n'y avait jamais eu une goutte d'eau quand le temps était calme. En 1857

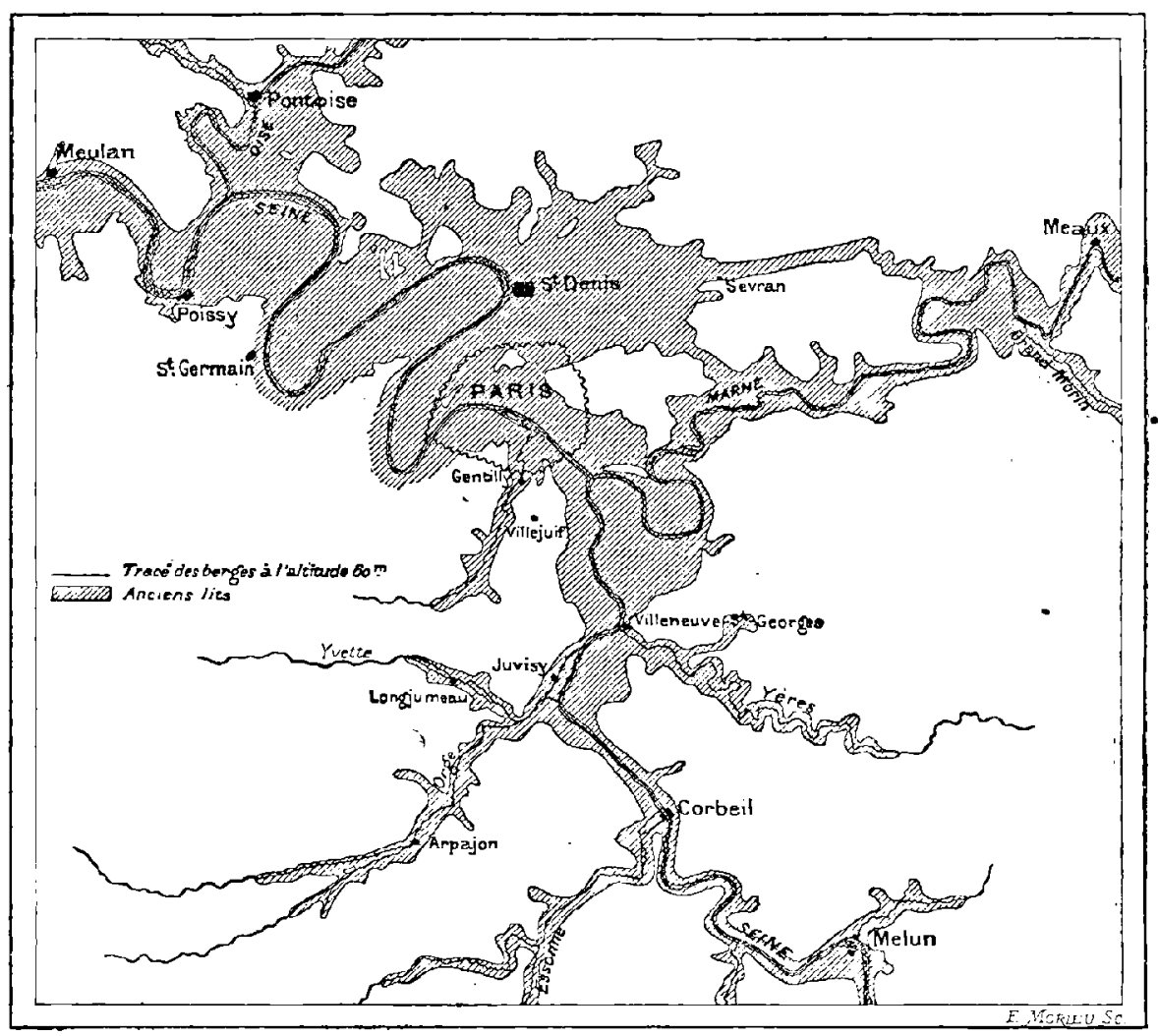

Fig. 163. - La Seine aux temps préhistoriques.

et 1858 , Lyell trouva qu'il y avait environ $0^{\mathrm{m}} 60$ d'eau sur le pavé. Le sol continue de descendre ( $\left.{ }^{1}\right)$.

Ces curieuses oscillations du sol constatées par le temple de Sé-

1. Je trouve dans mes notes de voyage que le 13 décembre 1872 il y avait « environ deux mètres d'eau à la base des trois belles colonnes », et je laisse cette note telle qu'elle est, quoique cette profondeur me paraisse considérable en examinant la question. Peutêtre avait-on fait là quelques travaux qui auront retenu les eaux de pluies. Quoiqu'il en soit, cette dépression du rivage se continue. 
rapis sont visibles dans toute cette contrée. A Pouzzole méme, le temple de Neptune et le temple des Nymphes sont actuellement sous les eaux de la mer; deux voies romaines sont submergées; des lits de coquilles se voient le long du rivage, et de l'autre côté de Naples, à Sorrente, on a découvert une route, avec des fragments de constructions romaines, à une certaine profondeur sous la mer. Dans l'île de Capri (l'antique Caprée, de trop famense mémoire) un des palais de Tibère est depuis longtemps couvert par les eaux.

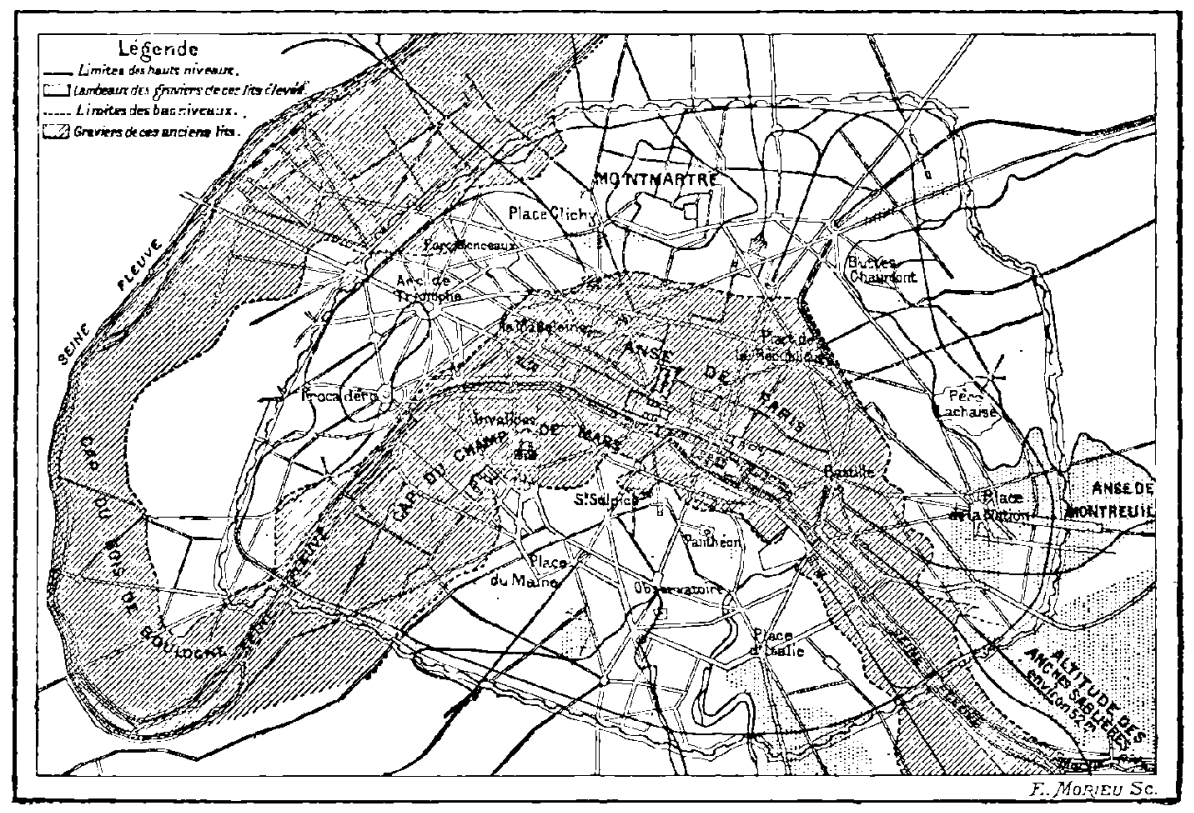

Fig. 161. - La Seine sur l'emplacement de Paris aux temps prébistoriques.

On peut admettre, avec Babbage et Lyell, que l'action de la chaleur est, d'une maniére oll d'une autre, la cause du phénomène auquel se rattache le changement du niveau du temple. La source chaude que possède ce temple, la position qu'il occupe ḋ contiguitté immédiate de la Solfatare, sa proximité du Monte-Nuovo, les eaux thermales des bains de Yéron, sur le rivage opposé du golfe de Baïa, les sources bouillantes, les anciens volcans d'Ischia d'un côté et le Vésuve de l'autre, sont autant de circonstances, parmi une multitude d'autres, qui paraissent militer en faveur de cette conclusion. Si l'on compare, en effet, les dates des principales 
ascillations avec l'histoire de la région, on remarque une certaine connexité entre chaque période de soulèvement et un développement local de la chaleur volcanique, tandis que chaque période de dépression concorde avec un état de repos ou d'assoupissement des causes ignées souterraines. Ainsi, par exemple, avant l'ère chrétienne, lorsque les nombreux volcans d'Ischia faisaicnt souvent éruption, et que l'Averne et autres points des champs Phlégréens étaient réputés pour leur aspect et leur caractère voleanique, le sol sur lequel repose le temple de Sérapis se trouvait à une certaine hauteur au-dessus des eaux. A cette époque, le Vésuve était regardé comme un volcan éteint; mais lorsque, après le commencement de l'ère chrétienne, les feux de cette montagne vinrent à se rallumer, on n'eut plus à signaler une seule éruption dans l'île d'Ischia ou dans les environs du golfe de Baïa. Le temple était alors en voie d'abaissement. A une période suivante, le Vésuve resta presque à l'état de repos pendant les cinq siècles qui précédèrent la grande explosion de 1631, et, dans cet intervalle, des éruptions se manifestèrent à la Solfatare en 1198, à Ischia en 1302, et le Monte-Nuovo se formait en 1538. Durant ces phénomènes, les fondations sur lesquelles repose le temple étaient en voie de se relever. Enfin le Vésuve reprit toute son activité, qu'il n'a jamais perdue depuis, et pendant tout ce temps l'aire du temple, autant qu'on peut le savoir par son histoire, a toujours subi un mouvement de dépression.

Ces phénomènes semblent d'accord avec l'hypothèse que lorsque, 1a chaleur souterraine augmentant d'intensité, la lave se forme sans trouver une issue facile par une grande ouverture comme celle du Vésuve, la surface incombante est soulevée dans cette région; tandis que cette mèrne surface est abaissée lorsqu'au-dessous d'elle les roches se contractent en se refroidissant, et que les laves se solidifient lentement en diminuant de volume.

Le Monte-Nuovo, cette curieuse montagne, de 132 mètres de hau. teur et de 2400 mètres de circonférence $\dot{a}$ la base, qui s'éleva en une seule nuit sur l'emplacement de l'ancien lac Lucrin est, à elle seule, un type géologique du plus haut intérêt. Pendant 492 ans le Vésuve était resté à peu près endormi (tandis que l'Etna avait manifesté la plus violente activité), et pendant près de cent ans encore, 
juscqu'en 1631, il ne donna aucune éruption. Le 29 septembre 1538, après deux jours de tremblements de terre incessants, le sol du rivage s'éleva légèrément, mais assez pour faire retirer la mer, qui laissa à sec une longueur de deux cents pas environ, sur laquelle restèrent une quantité de poissons. A l'endroit où se trouve aujourd'hui le Monte-Nuovo on vit, dans l'après-midi, le sol s'affaisser d'abord de quatre mètres environ, puis s'èlever lentement et, on quelques heures, s'ouvrir et vomir des flammes, des pierres et des cendres. Le soir, le feu jaillissait avec violence, lançant, comme un volcan, des blocs énormes avec un bruit effroyable. Tout le pays fut bientôt inondé sous une pluie de cendres et de pierres ponces. Pendant toute la nuit ce furent dans la nowvelle montagne des tonnerres terribles et des flammes s'élançant vers le ciel au milieu de la plus formidable projection de pierres et de boues. Deux récits de témoins oculaires, qui nese connaissaient pas et dont les manuscrits ont été retrouvés beaucoup plus tard, constatent que le nouveau volcan lançait des masses de terre et de pierres « aussi grosses que des bœufs » jusqu'a deux mille quatre cents mètres de hauteur. Le lendemain matin, au jour, on s'aperçut qu'une haute montagne était sortie du sol. " Les malheureux habitants de Pouzzole, écrit un témoin oculaire, fuyaient, ayant la mort peinte sur le visage; les unf emportaient les enfants dans leurs bras, les antres trainaient après eux des sacs remplis de leurs effets, d'autres conduisaient du côté de Naples des bestiaux chargés de leur famille; d'autres encore emportaient des quantités d'oiseaux tombés morts ou des poissons trouvés sur le rivage ».

" Cette èruption, écrit un autre témoin oculaire, dura denx jours et deux nuits sans interruption; le troisième jour elle cessa et je montai avec un grand nombre de personnes au sommet de la nouvelle colline. Au sommet s'ouvrait un cratère énorme, de 400 mètres environ de circonférence : les pierres qui y étaient retombées ressemblaient à des bulles se dégageant d'une eau en ébullition. Le quatrième jour l'éruption recommença et le septième elle redevint très violente; plusieurs personnes qui étaient sur la montagne furent renversées et tuées par les pierres ou étouffées par la fumée. „ - Le fait le plus remarquable peut-être est que le cratère intérieur descend presque jusqu'à la base de la montagne: le fond, à 126 mètres 
du haut, n'est qu'a $5^{\text {m}} 70$ au-dessus du niveau de la mer. C'est un cratère analogue à ceux de la Iune.

Toute cette région des champs phlégréens est, du reste, de formation volcanique. C'est la, comme on le sait, l'emplacement des Enfers de Virgile. On y voit encore le lac Averne, la Solfatare, l'an-

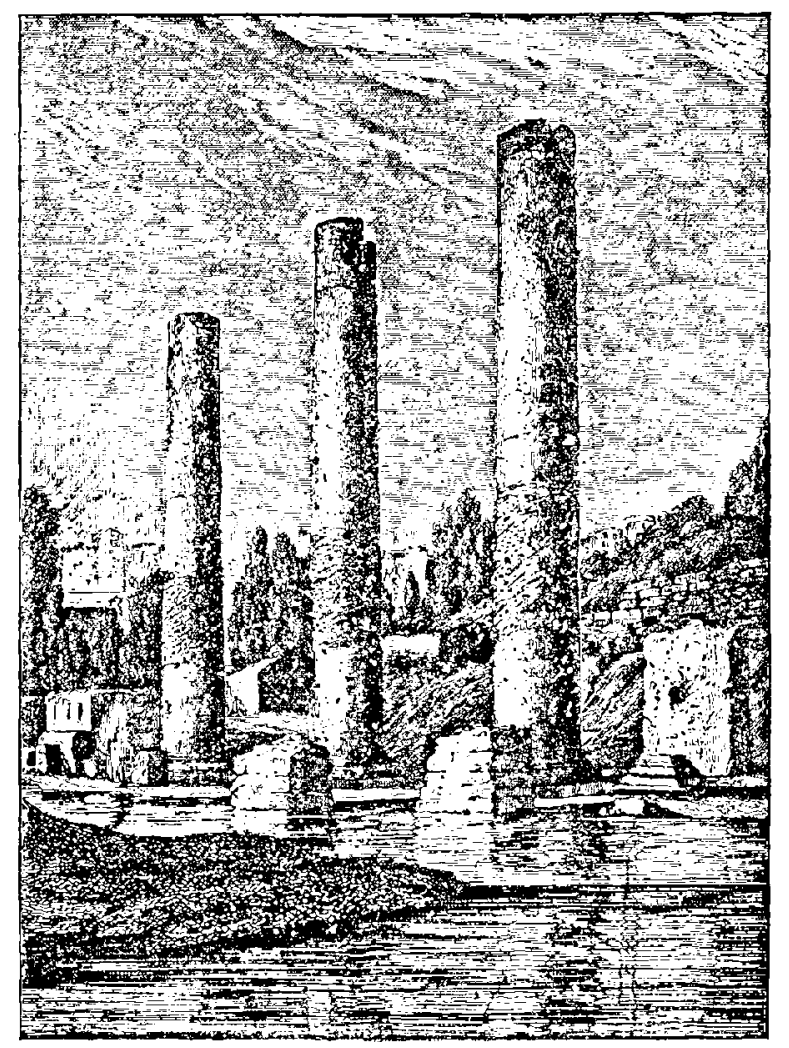

Fig. 163. - Le temple de Sérapis à Pouzzole.

tre de la Sibylle, etc. C'est là aussi que se trouve la célébre grotte du Chien; dans laquelle un malheureux chicn est asphyxié par l'acide carbonique invisible qui baigne le sol sur un pied d'épaisseur environ tandis qu'à la hauteur de la tête on respire l'air ordinaire. Là aussi se trouvent les étuves de Néron, galerie, dans une montagne, dont la température est de $55^{\circ}$ : un enfant nu prend un seau vide et des æufs crus, s'enfonce dans la galeric et revient au bout de trois minutes, son seau plein d'eau chaude, ses cufs cuits, tout son corps rouge 


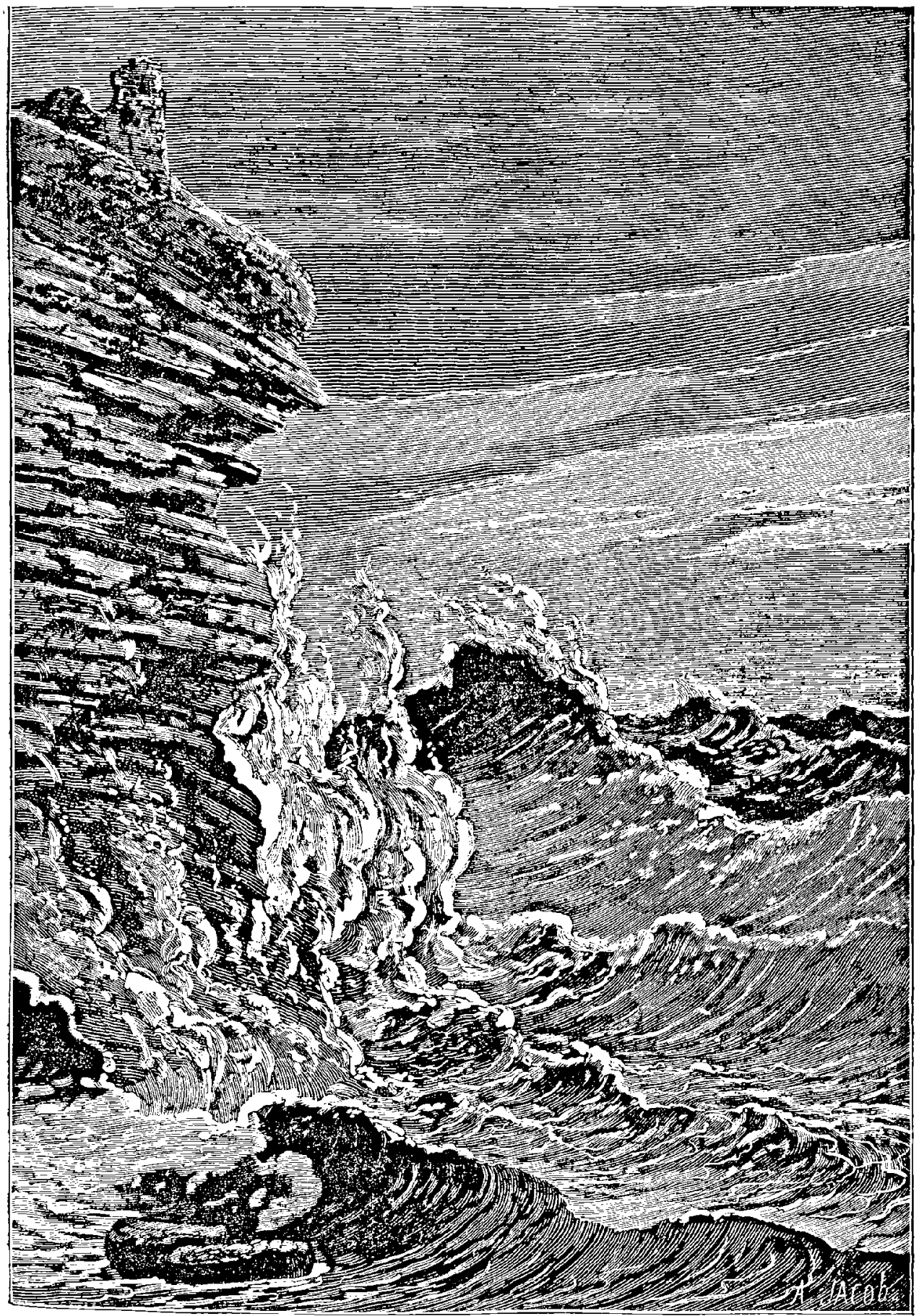

LA TEMPĖ

IE MONDE AVANT LA CRÉaTION DE L'HONIIE 
comme une écrevisse. Non loin de lá aussi, la montagne de la Solfatare est si creuse qu'en frappant du pied le sol tremble jusqu'à une grande distance. Toutes ces régions sont dans un état d'instabilité remarquable. Lyell écrit que le sol de la chambre où la Svbille de Cumes rendait ses oracles est recouvert de « quelques millimètres d'eau $»$. Au mois de décembre 1872 , on y avait de l'eau jusqu'à la cointure, et nous n'avons pu y pénétrer que porté sur les épaules d'un cicerone.

Ne nous perdons pas dans les détails, quelqu'intéressants qu'ils puissent être. Sans doute, ce serait peut-être le lieu de décrire ici les trarriques destructions causées par les volcans et les tremblements de terre, depuis l'ensevelissement d'Her'culanum, de Pompéi et de Stabia, l'an 79 de notre ère, jusqu'à la dernière catastrophe d'Ischia (juillet 1883). Mais nous ne devons pas oublier le sujet capital de cet ouvrage, et le point important ètait d'établir clairement pour tous les veux que mille causes diverses agissent actuellement avec efficacité pour transformer incessamment la surface du globe.

Remarquons encore ici, que de toutes les actions destructives dues aux agents atmosphériques ou géologiques, à part les tremblements de terre et les plus violentes éruptions volcaniques, les tempêtes exercent une action à la fois continuelle et formidable. D'année en année, sans trève, elles concourent à la destruction des rivages. Il faut les observer des bords de l'Océan, de la presqu'île de Quiḅeron, par exemple, des rivages voisins de Carnac, de l'anse de la Torche ou de la baie des Trépassés. Les vagues arrivent immenses et puissantes, sous une couleur sombre que l'on ne retrouve jamais dans les vagues écourtées et heurtées de la Méditerranée. Cependant c'est peutètre encore du haut du cap de la Ilague, an raz Blanchard, ou des caps de la Hève et d'Antifer que le spectacle est le plus grandiose, quoique ces points d'observation appartiennent à la Manche. On voit sous un ciel sinistre et par un vent intense qui apporte à l'oreille tous les cris gutturaux de la mer en fureur, on voit ar'river du large l'armée des vagues blanchissantes qui viennent se ruer à l'assaut des rochers. Elles bondissent, se heurtent entre elles, reculent, reviennent et se précipitent sur les écueils, débris des falaises inférieures, avec un acharnement qui ne fail que redoubler leur fureur. Tout ce 
qui peut être détáchédu roc est lavé, délayé, désagrégé, emporté, et le squelette reste dénudé avec des formes souvent fantastiques, , comme on le voit à Etretat. Les rochers eux-mémes ne tardent pas à être démolis et réduits en galets, pour peu qu'ils laissent de prise à l'introduction de l'eau. Les vagues se servent des débris eux-mèmes pour les lancer en projectiles contre les murs qu'elles assiègent. Lorsque les vagues du large peuvent arriver directement jusqu'au pied mème de la falaise, elles se précipitent lourdement contre sa base, comme autrefois les béliers dont les assiégeants ébréchaient les anciennes tours, et elles ébranlent la montagne elle-même, qui tremble sous leurs coups répétés. Malheur à la barque, malheur au navire entrainé par la tourmente vers les côtes! Un scul choc sưfit pour broyer et livrer à l'assaut des lames l'édifice en apparence si solide, qui tombe par morceaux comme un châtean de cartes.

La puissance des vagues de tempêtes est considérable. Irritées par les écueils et les obstacles, on les a vues s'élancer parfois sur les rochers jusqu'à vingt, cinquante et même cent mètres de hauteur, en poussière écumante qui retombe dans l'air. On a constaté des pressions s'élevant jusqu'à 35000 kilogrammes par rnètre carré! Des blocs de pierres énormes placés comme travaux de défense devant des digues et pesant plusieurs milliers de kilogrammes, sont parfois roulés, déplacés, lancés même comme des jouets par la tempète furibonde; à Cherbourg, les plus lourds canons de remparts ont été déplacés. La terre tremble au loin, jusqu'à plusieurs centaines de mètres du rivage - et mème jusqu'à 1500 mètres pour des appareils de mesure très délicats. Ce mouvement de la terre cansé par les vagues agit efficacement en faveur de la stratification des dépòts du littoral, comme on l'a reconnu par des coupes géologiques faites à travers des terrains tout récents et déjá stratifiés.

Nul n'a oublié l'ancien adage: Gutta cavat lapidem: la goutte d'eau creuse la pierre, non par sa violence, mais en tombant souvent. Les deux effets s'ajoutent dans l'œuvre de la nature. L'action délayante et dissolvante des eaux de pluie agit avec une grande efficacité pour modifier la surface du sol, creuser lentement des gouffres, produire des tassements et des glissements. A Lons-leSaulnier, par exemple, les effondrements du sol ne sont pas rares 
par cette cause : la statistique scientifique a déjả enregistré ceux de $1703,1712,1738,1792,1814,1836$ et 1848. M. Fournet, qui a fait une étude spéciale de cette localité, pense qu'une sorte de fleuve souterrain circule sous la ville et mine peu à peu les marnes. Pendant l'affaissement de 1792, un moulin disparut comme par enchantement, des maisons descendirent dans un abime et furent recouvertes de quinze mètres d'eau. Lorsqu'on voulut ensuite combler le précipice pour assurer la stabilité des rues voisines, on y jeta 15711 tombereaux de matérianx sans arriver à le combler !

On retrouve cette action des caux dans les dégradations annuelles de la surface sur les points qui y sont le plus directement exposés. Dans la forêt de Compiègne, par exemple, la voie

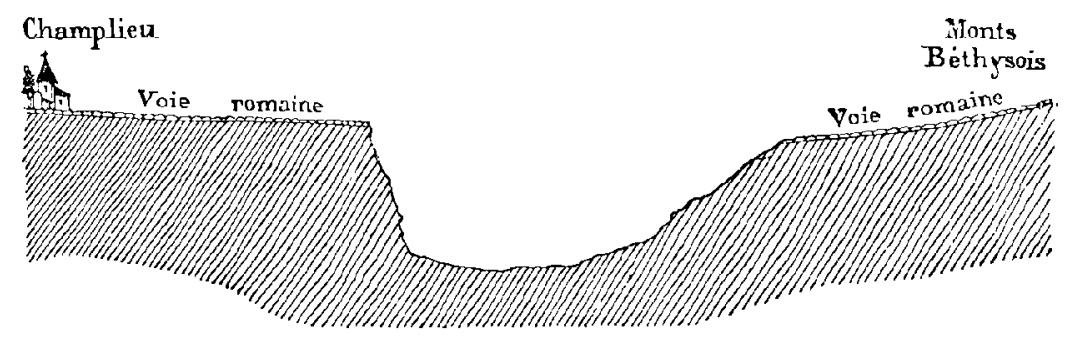

Fig. 167. - Dégradation produite par les edux à trarers la voie romaine de Soissons à Senlis

romaine de Soissons à Senlis traverse, en sortant de la forèt, la plaine de Champlieu et la coupe obliquement. Or, la dénudation produite par les eaux a fini par enlever la voie sur une partie de son parcours et par creuser un vide, témoin irréfragable de cette action des caux (fgr. 167).

Un autre exemple bien remarquable de l'action des eaux a èté observé en Géorgie, près de Milledgeville. Lorsque Lyell visita cette contrée, en 1846, il remarqua qu'en vingt ans l'eau avait creusé un ravin de seize mètres de profondeur sur cinquante-quatre mètres de largeur et trois cents mètres de longueur dans un terrain qui, étant resté boisé antérieurement, n'avait subi aucune altération sensible. Lorsqu'il fut déboisé, des fentes de neuf centimètres se produisirent dans l'argile, par suite de la chaleur solaịre, et à la saison des pluies, l'eau commença à élargir la fente principale. I'artant de lá pour attaquer sans discontinuité les 
plans inférieurs, son action érosive finit par creuser cet énorme ravin.

Une statistique faite récemment (1885) aux États-Unis, établit qu'en moyenne les pluies enlévent 385 kilogrammes de matières par an et par hectare aux pentes des montagnes pour les charrier dans les vallées, les rivières et en partie dans la mer.

Et que dirons-nous des éboulements de montagnes dus à l'action des eaux? Quoique assez peu importants au point de vue géologique, ces phénomènes frappent par leur puissance destructive et le souvenir s'en conserve par tradition pendant de longs siècles, Aucun événement n'est de nature à saisir plus fortement l'imagination populaire. Les roches escarpées ou surplombantes qui restaient suspendues au-dessus des campagnes, se détachent tout à coup et glissent sur les pentes; elles soulèvent en s'écroulant un nuage de poudre semblable anx cendres vomies des volcans; d'horribles ténèbres se répandent dans la vallèe naguère si riante, et l'on ne connait le cataclysme que par le tremblement du sol et le terrible fracas des blocs qui s'entrechoquent et se brisent. Quand le nuage de poussière se dissipe enfin, on voit un amas de roches et de décombres là où s'étendaient des pâturages et des cultures; le torrent de la vallée est obstrué et changé en lac boueux, la muraille de rochers a perdu son ancienne forme; et sur ses flanes d'ou s'écroulent encore quelques débris, on distingue, à vives arêtes, l'énorme paroi de laquelle s'est détaché tout un pan de montagnes. Dans les Pyrénćes, les Alpes et les autres grandes chaînes, il est peu de valices où l'on ne rencontre ces témoins.

Les principales catastrophes de ce genre, qui ont eu lieu pendant les siècles de l'ère actuelle dans les montagnes de l'Europe, sont connucs. Au sud de Plaisance, en Italic, l'antique ville romaine de Velleja, fut engloutie vers le sixième siècle par les éboulements du mont bien nommé de Rovinazzo; le grand nombre d'ossements, de monnaies, de documents précieux que l'on a trouvés dans les ruines, prouve que la chute soudaine des rochers ne laissa pas mème aux citoyens le temps do se sauver. De même le château de Tauretunum et le bourg voisin, situés sur la rive méridionale du lac de Genève, dans la vallée supérieure du Rhône, furent complètement écrasés en 563 par une chute de rochers : une terrible 
vague produite par le déluge de pierres, et peut-être aidée par le tremblement du sol, parcourut les rivages opposés du lac et balaya toutes les habitations; de Morges à Vevey, toutes les villes du littoral furent démolies, et l'on ne commença de les rebâtir que dans le siècle suivant; Genève fut mèmıe en partie recouverte par les eaux, et le pont du Rhòne emporté. D'après Troyon et Morlot, ces désastres auraient été causés par un éboulis dont on voit encore les traces sur une montagne qui domine la vallée du Rhône, immédiatement en amont de son delta. Il en serait résulté la formation d'un lac temporaire, et lors de la destruction da barrage, l'inondation aurait dévasté les rives du Léman; toutefois, l'exhaussement des eaux produit par la débâcle soudaine d'un réservoir situé en aval de la porte de Saint-Maurice, r'aurait pu avoir qu'une faible importance relative sur le niveau du Léman. Pour expliquer le désastre; il faut admettre que le pan de la montagne est tombé dans le lac mème.

C'est par centaines que l'on compte les grands éboulements de rochers qui ont eu lieu, durant les siècles historiques, dans les Alpes et les montagnes voisines. En 1248, quatre villages situés à la base du mont Granier, non loin de Chambéry, furent engloutis sous d'énormes amas de ruines calcaires que les eaux ont depuis diversement ravinés et sculptés en forme de monticules; de petits lacs, connus sous le nom d'abimes, sont épars au milieu de ces anciens débris que recouvrent aujourd'hui les cultures. En 1618, l'éboulement du Monte-Conto ensevelit les 2400 habitants du village de Plurs, près de Chiavenna; deux des cinq pies des Diablerets s'écroulèrent, l'un en 1714, l'autre en 1749, recouvrirent les pâturages d'une couche de cent mètres de débris, et barrant les cours du torrent de Lizerne, formèrent les trois lacs de Derborence qui existent encoro. De même, le Bernina, le Righi, la Dent-deMayen ont recouvert de leurs décombres de vastes étendues de terrains cultivés; un pan de la crête supérieure de la Dent-du-Midi s'est écroulé, menaçant d'arrèter le Rhône en amont de Saint-Maurice, et longtemps des ouvriers durent travailler au déhlaiement des roches, avertis par la voix du canon, quand une chute s'annonçait et qu'il leur fallait chercher un lieu de refuge.

Mais la chute d'un pan du Rossberg, le 2 septembre 1806, est, 
de toutes les catastrophes de ce genre, celle qui a laissé le plus terrifiant souvenir. Cette montagne, située au nord du Righi, au centre de l'espace péninsulaire formé par les lacs de Zug, d'Égeri et de Lowerz, consiste en couches d'un conglomérat compacte reposant sur des lits d'argile, que délayent les eaux d'infiltration. A une époque inconnue, l'éboulis d'un contrefort avait déjà écrasé le village de Rotten; mais, en 1806, la catastrophe fut plus terrible encore. La saison qui venait de s'écouler était pluvieuse, et les strates d'argile s'étaient graducllemont changées en une masse boueuse : à la fin, les roches supérieures, venant à manquer d'appui, commencèrent à glisser sur les pentes en sonlevant les terres devant elles comme la proue d'un navire soulève l'eau de la mer. Soudain, la débâcle cut lieu. En un moment l'énorme masse, avec ses forêts, ses prairies, ses hameaux, ses habitants, s'abattit dans la plaine; les flammes produites par le frottement des roches entre-choquées s'élancèrent en gerbes de la montagne ouverte; l'eau des couches profondes, tout à coup transformée en vapeur, fit explosion, et des quantités de pierres et de boue furent lancées comme par la bouche d'un volcan. Les charmantes campagnes de Goldan (la vallée d'Or) et quatre villages qu'hahitaient près de mille personnes disparurent sous l'entassement de débris, le lac de Lowcrz fut comblé cn partic, et la vague furieuse que l'éboulement lança contre les rivages jusqu'à vingt mètres de hauteur, balaya toutes les habitations. La catastrophe s'était accomplie d'une manière tellement rapide que les oiscaux avaient été tués dans l'air. La partie de la montagne éboulée n'avait pas moins de quatre kilomètres de long sur 320 mètres de largeur moyenne et 32 mètres d'épaisscur : c'est une masse de plus de quarante millions de mètres cubes.

Ln éboulement moins considérahle, mais étudié avec plus de soin, eut lieu dans une autre partie de la Suisse, dans la vallée de Serıft, en 1881 ; c'est le cataclysme qui détruisit une moitié du village d'Elm. L'imprévoyance humaine fut la cause de ce désastre. En cet endroit, les carriers s'étaient attaqués, depuis des siècles peutêtre, à des escarpements d'ardoise dont la pente était assez forte, et les travaux se poursuivaient sans qu'on se donnât la peine d'étayer la roche. Bien avant que l'écroulement eut lieu, on s'attendait à la catastrophe : une crevasse s'était formée dans le sol au-dessus des 
carrières, et chaque année devenait plus large et plus profonde. Enfin la rupture se fit : la masse rocheuse de dix millions de mètres cubes s'écroula soudain sur le village d'Unterthal et vint se heurter obliquement aux flanes d'une montagne opposée, qui rejeta de nouveau dans la plaine l'énorme avalanche de pierres. Une colonne d'air précédant l'éboulis faisait tourbillonner devant lui les chalets, les arbres et les hommes, tandis qu'à côté du courant de pierres, l'atmosphère restait parfaitement calme, et que le foin ne s'envolait même pas des meules empilées dans les prairies. Dans la plaine, les ardoises et les terres, s'étalant à la manière des courants de la lave, glissaient sur le sol presque uni avec une vitesse de 120 mètres par seconde (').

Nous nous trouvions alors à Interlaken (autre exemple des transformations du sol, car toute cette plaine verdoyante n'est qu'une alluvion réconte) et visitant le lieu du désastre quelques semaines plus tard nous fùmes témoin de la terreur des habitants et de leur stoïcisme voisin de l'indifférence. Singulier mélange de sentiments opposés! A peine une catastrophe a-t-elle jeté le deuil dans une contrée que sur les ruines mêmes on s'empresse de rebâtir les demeures, sans s'éloigner de la montagne toujours menaçante. On se fonde sur la brièveté de la vie. Et, en effet, ce ne sont que les arrière-petits-fils qui recevront un nouvel éboulement.

Ces chutes ne sont que des phénomènes de second ordre, comparativement aux résultats que produit l'action lente des agents atmosphériques, des glaces et des eaux torrentielles. Ce sont là les travailleurs infatigables qui, par leur œuvre incessante, ont élargi les premières failles ouvertes dans l'épaisseur des roches, et qui ont creusé tout ce réseau de couloirs, de cirques, de combes, de défilés, de cluses, de vallons et de vallées dont les innombrables ramifications donnent tant de variété à l'architecture des montagnes. Par ce travail continué sans relâche les hautes cimes sont lentement abaissées, et les matériaux enlevés aux pentes vont s'établir au loin dans les plaines de continents et dans les eaux de la mer.

La température agit sur le sol, la chaleur dilatant les corps et le

1. Élisé Reclis, La Terre, I, p. 205. 


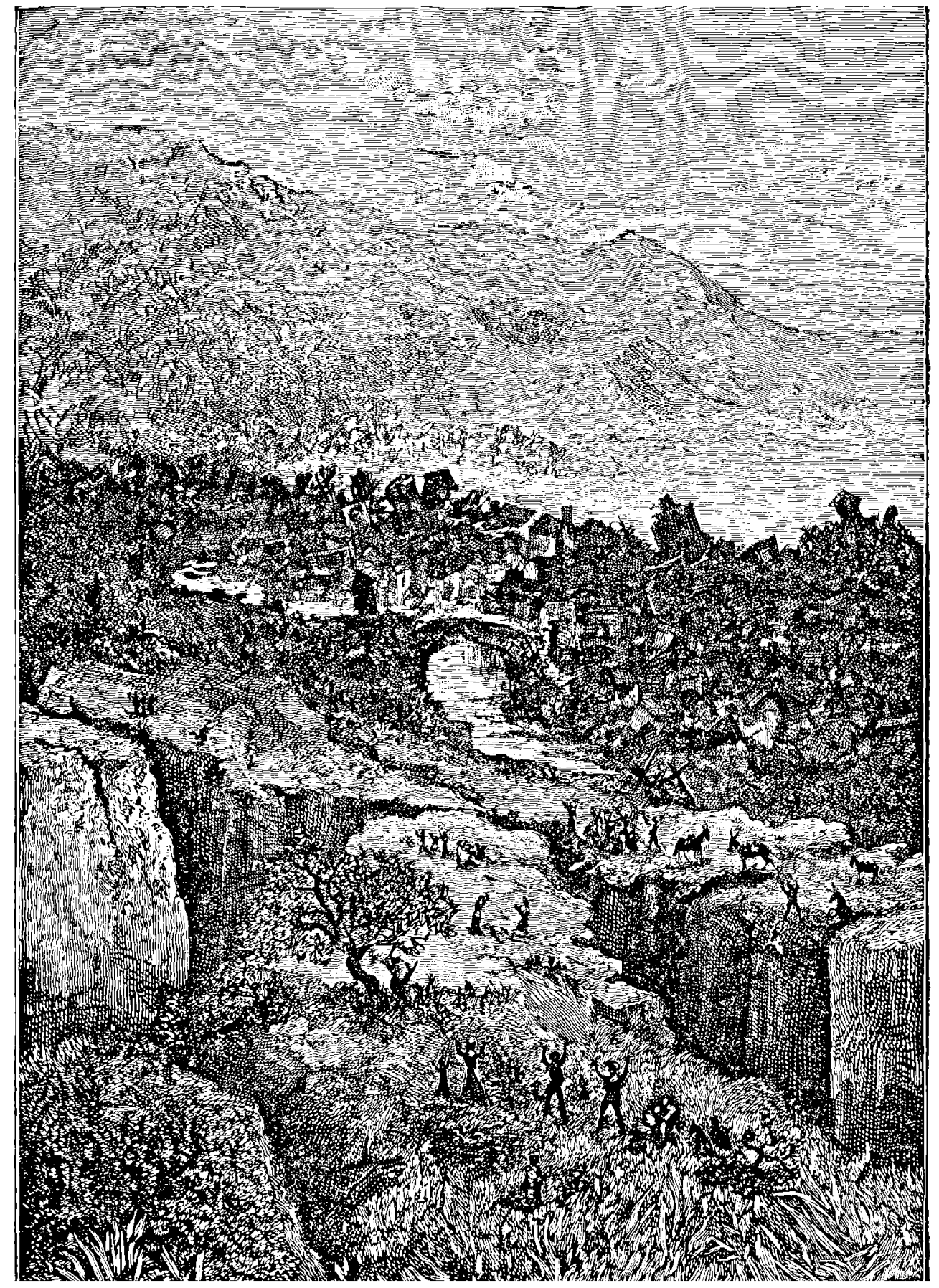

LE THEMHLEMENT DE TERBE 
froid les resserrant. Pendant le jour, les molécules des rochers se dilatent sous l'influence des rayons solaires; la nuit, elles se contractent par suite du rayonnement nocturne, de sorte que la masse totale s'élève et s'abaisse d'une quantité qui n'est pas toujours inappréciable aux instruments. D'après un grand nombre d'observations faites d'heure en heure, jour et nuit, en diverses saisons, à notre Observatoire de Juvisy, nous avons constaté que la température de l'intérieur des murs varie annuellement depuis $\mathbf{4}^{\circ}$ (et peut-être davantage) au-dessous de zéro, jusqu'à $37^{\circ}$ au-dessus. Cet écart de 41 degrés centigrades produit une différence de volume sensible dans les matériaux constitutifs des murs, pierres, fer et bois, d'où il résulte que tous les édifices sont plus élevés, plus longs, plus larges et plus épais lo soir que le matin et à la fin de l'été qu'à la fin de l'hiver. Pendant l'été, on observe parfois des différences de $10^{\circ}$ à $12^{\circ}$ à douze heures d'intervalle pour le milieu même de l'épaisseur du mur. Les molécules constitutives de tous les murs - en apparence si solides - de toutes les maisons, ne se touchent pas, d'ailleurs, et sont en mouvement constant. A l'Observatoire de Santiago (Chili), situé sur une colline, les observations de M. Moesta ont montré que la colline s'élève et s'abaisse alternativement dans l'espace de 24 heures. La température intérieure du sol peut amener de notables variations à la surface; Babbage a calculé qu'un écart de $50^{\circ}$ affectant les terrains sur une épaisseur de huit kilomètres détermine un mouvement de sept mètres à la surface.

Des phénomènes analogues peuvent ètre déterminés par d'autres causes. En Irlande, la colline qui porte l'Observatoire d'Armagh s'élève sensiblement après les pluies, puis, lorsqu'une évaporation active a fait disparaitre l'eau qui gonflait los pores, elle s'abaisse de nouveau. A l'Observatoire de Genève, les niveaux ont indiqué à M. Plantamour une oscillation annuelle correspondant à la température; l'oscillation, assez forte dans le sens Est-Ouest, l'est un peu moins dans le sens Sud-Nord. A l'Observatoire de Neuchâtel, M. Hirsch a constaté que la colline du Mail sur laquelle il est situé oscille annuellement autour de la verticale : elle tourne chaque été de gauche à droite et chaque hiver de droite à gauche; de plus, depuis sa fondation (1859), l'Observatoire et sa base s'inclinent graduellement vers l'ouest, sans doute par suile d'un glissement du terrain. 
Si ces mouvements du sol se rapportent à des observatoires, ce n'est pas que ces établissements soient moins solidement établis, moins stables que les autres constructions humaines, au contraire; c'est simplement parce que des observations précises y ont été faites. Nous pouvons en conclure avec certitude que partout le sol ter. restre est en mouvement et en transformation.

Un autre exemple des èlévations et affaissements du sol est offert, pour le fond des mers, par les îles de coraux, ou atolls. Ges îles en forme d'anneaux sont construites par les coraux, qui ne peuvent prospérer qu'à une faịle profondeur au-dessous du niveau

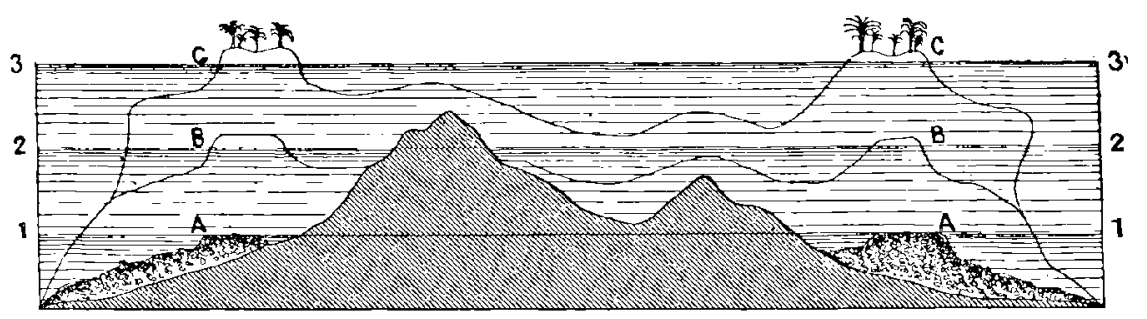

Fig. 170. - Coupe verticale à travers une ile de coraux, montrant ses phases successives.

de la mer, et qui ne peuvent pas non plus vivre plus haut que la crête des vagues. Lenr élévation est donc constamment en rapport avec celle du niveau des eaux. Si une île, autour de laquelle les coraux se sont établis, vers le niveau du balancement des marées, est en voie d'affaissement, les coraux grandiront comme des arbres à mesure que leur base descendra, et ils se maintiendront toujours au niveau des eaux. Quand l'île aura disparu, ils dépasseront son sommet et s'élèveront sous la forme d'un anneau plus ou moins régulier. On se rendra compte des diverses phases du développement d'un récif de coraux par la $\mathrm{fg}$. 170, qui représente trois niveaux successifs $(1,2,3)$ de la mer, correspondants à l'affaissement d'une île. L'île descendant, la profondeur d'eau au-dessus d'elle augmente progressivement; c'est comme si le niveau de la mer s'élevait, et l'île de corail atteint en mème temps les hautcurs correspondantes A, B, C. On rencontre dans l'Océan Pacifique et dans l'Océan Indien des îles de coraux qui se sont élevées ainsi, par le seul travail des polypiers, jusqu'à plus de mille mètres de hauteur verticale, presque à pic. 
Ce sont là, indépendamment de leur caractère góologique, d'admirables formations naturelles. Le récif suffit pour arrêter les vagues de la mer la plus agitée; l'eau bouillonne en blanche écume le long des récifs et les signale de loin aux marins, tandis que l'intérieur de l'atoll reste calme comme un lac. $\Lambda$ travers l'onde translucide, sous l'intense soleil du midi, on voit la forêt rose fleurir au fond des eaux; par légions et par myriades, les fleurs du corail multiplient leurs brillantes étoiles ; tout est joie, Iumière et vie dans ces nouveaux jardins des Hespérides; la mousse multicolore elle-même qui comble les intervalles est composée de millions d'animalcules coralliaires. Les petits architectes vivent et travaillent sans relâche. La tempête peut arracher d'énormes blocs : nuit et joụr la population vivante répare les pertes, en grandissant toujours. Aucun colosse dans le règne animal, aucune persćvérance dans le règne humain n'ont jamais rien édifié qui puisse rivaliser avec les îles immenses lentement élevées par le corail au sein des mers.

On le voit, l'application des causes actuelles à la transformation perpétuelle du globe terrestre explique tous les changements observés à la surface de ce globe; les temps géologiques n'ont pas ditféré des nôtres comme nature d'opération, mais seulement comme degré, et notre époque deviendra, elle aussi, pour l'avenir, une époque " géologique »; on retrouvera, à l'état fossile, les vestiges de l'âge dans lequel nous vivons, et peut-être alors la race humaine plus avancée en laquelle nos successeurs se seront graduellement transformés ne daignera-t-elle pas accorder le titre d'humains à nos squelettes fossiles trop grossiers et trop barbares pour l'élégance des beautés futures.

Mais de ce que les causes actuelles suffisent pour tout expliquer, ce n'est pas à dire pour cola que les transformations se soient toujours effectuées par des procédés lents et silencieux. Il y a réellement, de temps à autre, dans la nature comme dans l'humanité, de véritables révolutions. Les inondations, maritimes ou fluviales, souvent formidables, les éruptions volcaniques, les tremblements de terre, les cyclones, les tempètes, les orages, les glissements de terrains, les débâcles des glaces, sont autant de phénomènes dont 
l'étendue reste, il est vrai, localisée ì certains districts, mais qui n'en ont pas moins une action réelle, et souvent considérable, pour concourir à la modification incessante du globe. Herculanum, Pompéi, Stabia, ont été englouties sous les cendres du Vésuve. Bien des cités ont été renversées par des secousses de tremblements de terre, détruites par des inondations, ravagécs par des cyclones. Qui ne se souvient historiquement de la catastrophe de Lisbonne en 1755? Qui ne se souvient personnellement des plus récentes : inondations de Murcie en 1879; tremblement de terre d'Ischia (28 juillet 1883,

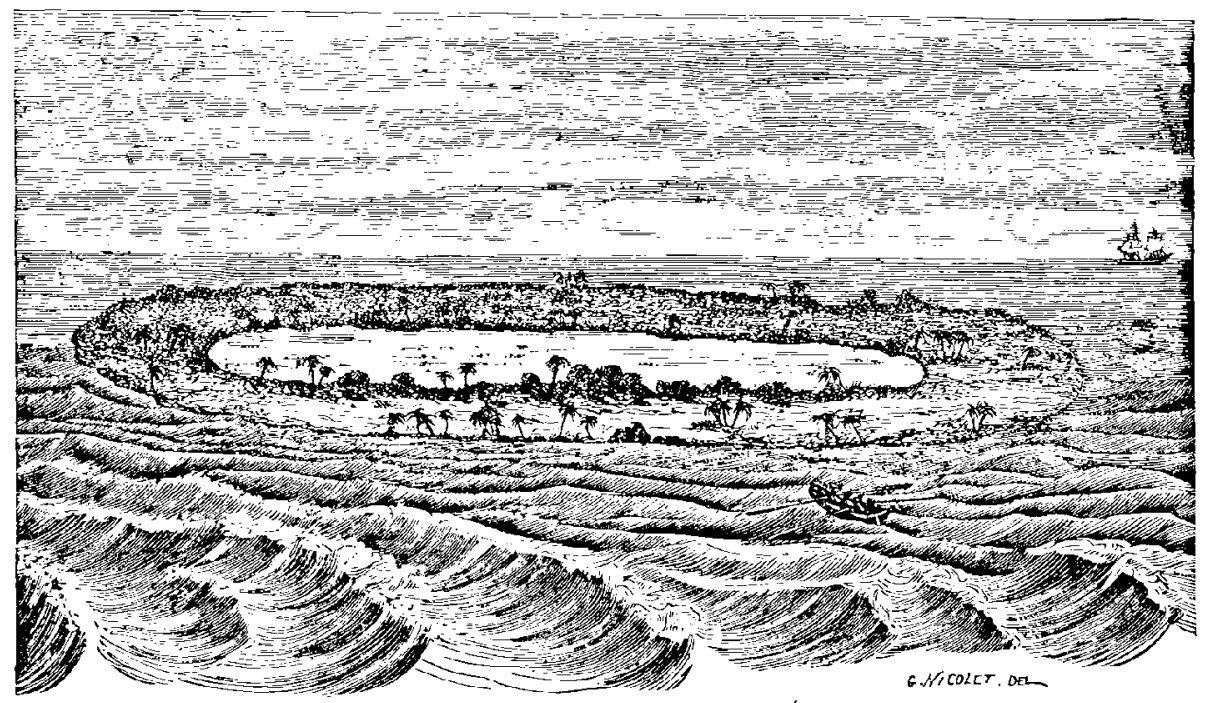

Fig. 171. - Une île de Coraux.

2443 victimes); éruption de Krakatoa (26-27 aoùt 1883, 40000 victimes); tremblement de terre d'Espagne (25 décembre 1884, 2500 victimes); tremblement de terre de l'Asie centrale, vallée de Cachemire, Baramula (17 juin 1885, 2700 victimes). L'éruption de Krakatoa a été, selon toute probabilité, le plus grand phénomène géologique de l'histoire entière de l'humanité ( $\left.{ }^{9}\right)$. Ge volean formidable du détroit de la Sonde a arraché des entrailles de la Terre plus de dixhuit milliards de mètres cubes de matières, dont les deux tiers sont retombées en dedans d'un cercle de quinze kilomètres de rayon, et dont le reste a été disséminé sous forme de vapeur d'eau peut-être

(1) Cette qualification n'est pas exagérée. Voy. notre Revue mensuelle d'Astronomie populaire, année 1884 . 
dissociée, d'hydrogène, de fines poussières, à de tolles hauteurs dans l'atmosphère qu'une année plus tard l'élévation des lueurs crépusculaires produites par ces poussières planait encore à 70 kilomètres? Le bruit de la détonation a été entendu jusqu'aux antipodes du volcan! La commotion marine a traversé les océans et est arrivée jusqu'aux côtes de France! L'ébranlement atmosphérique a été tel qu'il a fait le tour du monde en trente-cinq heures et l'a recommencé deux fois: tous les thermometres des observatoires ont baissé au passage de l'onde atmosphérique. Ce violent cataclysme, sans précédent dans l'histoire de l'humanité, a modifié tout le détroit de la Sonde, fond de la mer, îles, rivages, etc.; et les modifications se continuent actuellement (1885) par les courants de la mer et par la continuité des éruptions de Java. L'éruption du Skaptar Jokul, en 1783, vomit des fleuves de lave tels que leurs volumes réunis représentent une masse égale à celle du Mont-Blanc! On ne saurait douter que ces causes diverses aient eu dans tous les siècles de l'histoire de la Terre une action réelle pour engloutir des cadavres d'ètres vivants et les conserver plus ou moins complètement ainsi que pour modifier la surface du globe dans toutes ses parties.

Sans admettre avec Cuvier un cataclysme diluvien effroyable qui aurait entièrement transformé les continents il y a cinq ou six mille ans, et tout en expliquant un grand nombre des transports et des dépôts par les torrents et les alluvions, on ne peut rejeter absolument les traditions et les souvenirs antiques relatifs au déluge de Noë ou de Deucalion. L'exagération orientale du récit biblique (et celle des commentateurs occidentaux, qui est beaucoup moins excusable) a conduit un grand nombre d'esprits éclairés, mais sceptiques, à tout rejeter sur le compte de la fable et à rester sourds aux voix du passè. C'est là un autre genre d'exagération dans lequel il est sage de ne pas tomber. Les traditions anciennes sont trop concordantes pour que nous puissions douter d'une inondation formidable arrivée vers cette époque dans la région du mont Ararat, en Arménie. Sans doute, les premières tribus humaines qui commençaient à s'éveiller là à l'aurore de la civilisation ont-elles eu à subir une submersion produite par l'une des trois mers qui circonscrivent cette contrée (mer Caspienne, mer Noire et Méditerranée) ou plus simplement peut-être par l'Euphrate. Remarquons à ce propos que la réunion du 
Tigre et de l'Euphrate date de l'époque humaine; en soixante ans, le delta de ces rivièrés avánce actuellement de trois kilomètres, et l'on admet qu'il a empiété d'environ 64 kilomètres sur le golfe persique dans le cours des vingt-cinq derniers siècles. Quoi qu'il en soit, de tels cataclysmes existent dans l'histoire et font partie des causes que nous venons d'apprécier pour nous rendre compte de la transformation séculaire de notre planète.

A toutes ces transformations actuelles du sol, déjà si innombrables, nous devrions encore ajouter ici celle des climats, qui surpasse toutes les précédentes en importance, par son influence sur les métamorphoses séculaires de la vie végétale et animale. Les courants de la mer, en se modifiant avec les variations de niveau des bas fonds et des rivages, ouvertures et élargissements des isthmes, agrandissement des détroits, destruction des caps, élévation des terres, abaissement des températures suivant les hauteurs, les courants de la mer, disons-nous, suffiraient à eux seuls pour modifier considérablement le climat des diverses contrées. Sans l'océan et sans le gulf-stream, par exemple, qui vient baigner de ses eaux tièdes les rives de la France, de l'Angleterre, de la Hollande, de la Suède, nos contrées seraient beaucoup plus froides qu'elles ne lt sont, et au lieu de recevoir des vents d'ouest chauds et féconds comme ceux qui se déversent sur la France, nous aurions à Paris le climai de Cracovie, de Poltava ou des Cozaques du Don. De plus, la quantité d'eau qui tombe annucllement sur chaque pays dépend de l'évaporation des mers, de la direction des vents, du relief du sol, et son action sur la vie varie avec la constitution géologique des terrains sur lesquels elle tombe et avec l'état de leur surface. Tout cela change. De plus encore, l'obliquité de chaque région relativement aux rayons du Soleil varie légèrement d'année en année; le climat de Paris, par exemple, oscille entre celui d'Orléans et celui d'Amiens, et peut-être davantage si l'oscillation de l'obliquité de l'écliptique est plus forte qu'on ne ne le croit. Nous aurons lieu d'examiner plus loin cette importante question de la variation séculaire des climats. Il y aurait aussi à discuter les variations possibles de la latitule, que de récentes observations semblent accuser, ainsi que les changements de l'horizontale signalés par le pendule et par les niveaux... Mais nos lecteurs sont désormais surabondarn- 
ment édifićs sur le principe, et nous n'abuscrons pas plus longtemps de leur persévérante attention.

Cet exposé général a dépassé de beaucoup les limites habituelles d'un chapitre. Cependant il ètait du plus haut intérêt pour nous de réunir en un même enscmble tous ces faits, qui doivent désormais servir de base à notre connaissance géologique de la planète. Ils établissent clairement que sous nos yeux mèmes l'œuvre de la création - c'est-à-dire de la transformation perpétuolle des choses et des ètres - se continue, nous invitant à juger du passé par le présent, à voir dans les événements actuels l'explication de tout ce qui s'est accompli depuis la nébuleuse terrestre, depuis le protoplasma, depuis la première plante, depuis le premier animal, jusqu'à l'état actuel de la nature - et l'image de tout ce qui s'accomplira jusqu'aux âges les plus reculés de l'avenir. Les effets continueront de suivre les causes. L'avenir est en germe dans le présent comme le présent était en germe dans le passé. Celui qui saurait lire le langage des atomes devinerait dès aujourd'hui l'ètat futur de la Terre et de l'humanité. Qu'il nous suffise d'avoir constaté, d'avoir compris, les transformations actuelles du sol, et de savoir que " le monde avant la création de l'homme » a été produit, entretenu, graduellement trạnsformé par les mêmes causes naturelles qui continuent d'agir sous nos yeux.

Chez les êtres vivants, cette transformation est une épuration, une ascension, un progrès vers une perfectibilité indéfinie. L'histoire d'un monde est l'arbre généalogique de son progrès. 


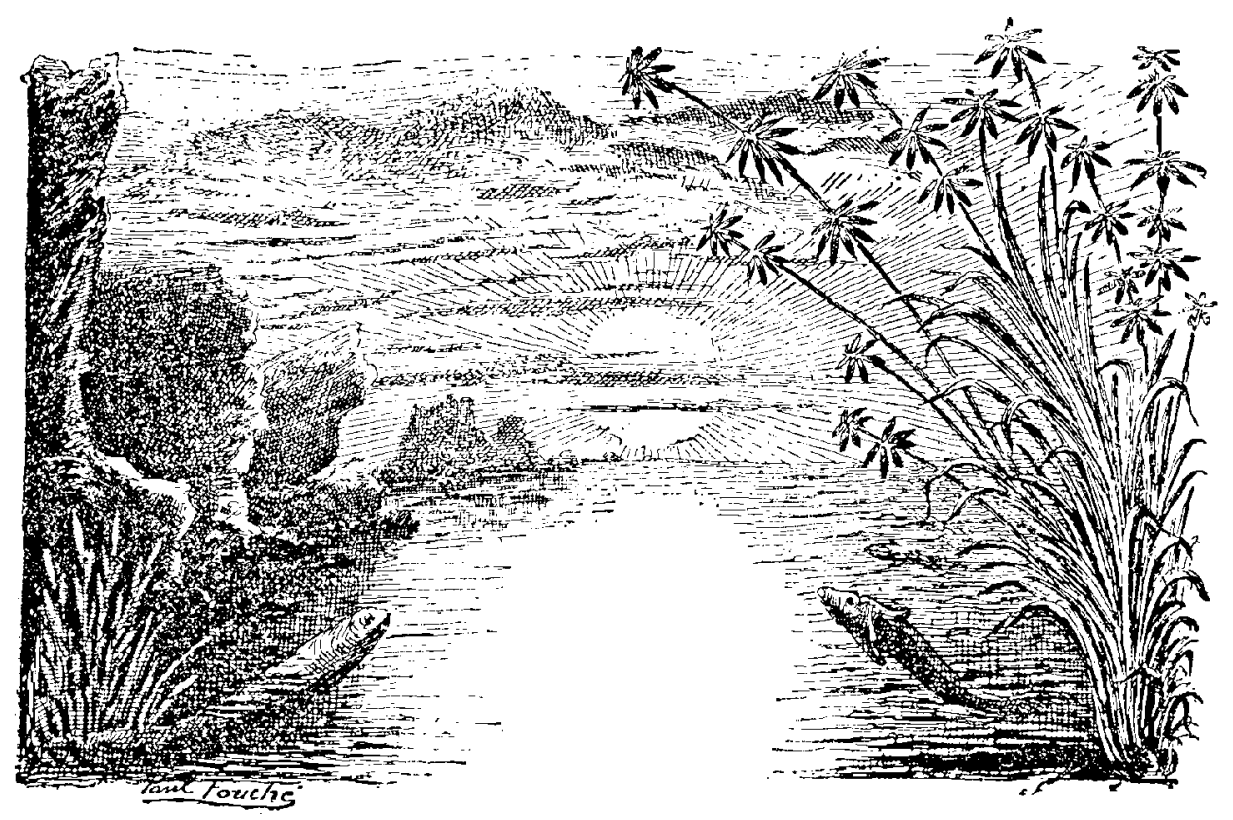

GH APITRE III

LE DÉVELOPPEMENT DE LA VIE

La naissance des poissons. - La période dévonienne.

Les documents nombreux et variés que nous venons d'exposer et de comparer dans le but de comprendre exactement le mode de formation des terrains et l'œuvre permanente de la nature dans la métamorphose incessante du globe ne doivent pas nous avoir fait oublier l'époque à laquelle nous nous sommes arrêtés dans cette description générale du monde anté-humain. Au contraire, cette exposition nous a permis de nous rendre compte des voies et moyens employés par la nature dans l'organisation d'une planète telle que la nôtre. Admis dans le laboratoire de son cuvre, initiès aux secrets de sa puissance, nous apprécions dans sa simplicité grandiose le travail géologique qui incessamment s'accomplit, et au-dessus de cette transformation de tous les jours, nous voyons s'élaborer en mème temps l'ascension graduelle du règne végétal et du règne animal dans l'harmonie des choses et des ètres. Tout se modifie lentement, avec les conditions mème de la vie. Il en a toujours été ainsi, sans révolutions fantasmagoriques, sans brusques

LE MONDE AVANT LA CRÉATION DE L'HOMME

17 
changements de décors. L'univers n'est pas un théàtre de carton et le Gréateur n'est pas un auteur dranatique: l'univers est une œuvre en un perpétuel devenir; Dieu en est la pensée. L'étude patiente des faits révèle des enchainements entre toutes les formations géologiques, entre toutes les organisations végétales ou animales. A la fin de sa vie, ayant eu le temps de beaucoup observer et de beaucoup méditer, le grand géologue D'Omalius d'Halloy écrivait: “ J'ai peine à croire que l'auteur de la nature ait à diverses époques fait périr tous les êtres vivants pour se donner le plaisir d'en créer de nouveaux qui, sur les mêmes plans généraux, présentent des différences successives, tendant à arriver aux formes actuelles. » L'ancienne et théâtrale interprétation de l'œuvre de la nature doit faire place aujourd'hui à une conception plus conforme à la simplicité comme à la grandeur des faits observés.

Toutes les cosmogonies primitives chantent que la Terre est a fille de l'Océan ». Ce n'est point un mythe; c'est la réalité même.

Nous avons vu la vie apparaître an sein des eaux tièdes de l'époque primordiale, sous forme d'organismes très petits et très simples, sortes de grumeaux de gélatine associẻs, protistes, infusoires, diatomées, algues, bilobites, chondrites, mollusques bryo. zoaires, zoophytes, polypiers, échinodermes, brachiopodes, trilobites, etc. Les premières îles ont commencé à émerger du sein des mers, et sur les premiers rivages, bas et humides, les mollusques marins et les plantes marines ont commencé à s'aventurer, essayant de s'acclimater à de nouvelles conditions d'existence. Dans l'air humide, sous une lourde et tiède atmosphère, les fougères vont acquérir leurs feuillages opulents, et déjà sur le sol dégagé des eaux on voit apparaitre des annelés, crustacés et arachnides, crabes et scorpions.

Mais jusqu'à présent, pendant ces millions d'années d'existence, durant la longue série des périodes laurentienne, cambrienne et silurienne, la planète terrestre n'a pas encore été animée à sa surface par un seul être d'ordre supérieur. Le règne végétal n'est représenté que par des cryptogames, le règne animal par des invertébrés. Dans la multitude de ces plantes, pas une fleur, pas un fruit, pas un arbre véritable; le regard de l'observateur n'aurait pu découvrir ni la plus modeste rose sauvage, ni bluets, coquelicots, pervenches ou 
lisorons; ni un saule, ni un chène, ni un boulcau, ni un peuplier: rien de ce qui constitue aujourd'hui la beauté de nos paysages. Ce n'est que de la mousse, parfois très haute, arborescente, et plutôt jaune que verte. Dans la multitude de ces animaux on n'aurait pu découvrir non plus aucun de ceux qui représentent de nos jours la plus importante population de la Terre, pas un quadrupède, pas un oiseau, pas un reptile, et mème pas un poisson!

Monde étrange et bizarre, et pourtant contenant en germes tout ce qui existe aujourd'hui. C'est déjà la Terre, notre patrie ; ce n'est ni la Lune, ni Vénus, ni Mars, ni Jupiter, ni Saturne. Le sort en est jeté. La voie est ouverte. Le monde marche. La nature sans cesse agissante développe graduellement son œuvre. Plus une minute de repos. Nuit et jour chaque atome gravite vers l'attraction qui le gouverne; chaque moléeule cherche la lumière, la chaleur, la fécondité ; chaque être désire un idéal invisible et ne veut mourir qu'après s'ètre approché de son rêve.

Jusqu'ici, la nature est restéc muette. Elle a commencé à voir par le trilobite :jusqu'à lui elle semble être restée aveugle; avec lui l'œil s'est ouvert à la lumière, et, de progrès en progrès, cet organe va se perfectionner et s'animer pour devenir un jour l'œil de l'aigle... de la gazelle... du chien... du lion qui contemple..., l'œil de l'homme qui pense ou le regard de la femme qui aime... Jusqu'ici aussi, tous les etres vivants sont restés sourds et muets; le nerf auditif va se former, vibrer pour la première fois, donner graduellement naissance à l'oreille; le larynx, la langue vont permettre aux sons de se produire, d'abord inarticulés, puis graduellement modifiés de modulations variées ; ils siffleront dans la voix du serpent, rugiront dans celle de la bète fauve, chanteront dans celle du rossignol et aboutiront au langage humain qui par sa richesse, son éloquence ou son charme, a porté l'humanité dans sa voie intellectuelle, créé le langage écrit, fondé les traditions et l'histoire, patrimoine des àges disparus et, en fixant la pensée, imprime dans la race humaine son véritable caractère de noblesse et de grandeur. L'œil et l'oreille, voir et entendre, puis parler ! Quel progrès sur l'époque primordiale où la nature, malgré la lumière naissante et les bruits du vent ou des flots, était restée pendant tant de siècles absolument aveugle et sourde! L'analyste, le penseur, s'il ne marehe plus sur le sol 
que pénétré d'un profond respect pour cet amoncellement de la poussière des siècles vécus, est pénétré d'un sentiment plus intime encore au souvenir de tous les progrès accomplis : il a de la reconnaissance pour les premiers yeux, aujourd'hui pétrifiés, qui se sont ouverts ici-bas, pour les premiers êtres qui ont frémi au bruit de l'orage et de la tempéte, ont entendu quelque chose, ont essayé de crier !... Peut-être, en lisant ces lignes, de nobles personnages confits en un sot orgueil souriront-ils de pareils sentiments. Ils se vanteront de ne rien devoir à leurs précurseurs, de ne rien avoir conservé de naturel dans leurs facultés. Ne les contrarions pas. Ni l'épiderme des roses, ni la pureté du lys, ni le parfum des prairies, ni l'ombre solitaire des bois, ni l'azur du cicl, ni la fougue de l'orage, ni la fraîcheur des eaux, ni le gazouillement du ruisseau, ni les hattements d'ailes autour des nids, ni le chant de la fauvette, ni l'inaltérable affection du chien, ni la grâce des jeunes chats qui jouent, ni la finesse du singe, ne leur ont rien donné, ne leur ont rien laissé. Isolés sur la scène de la nature, ils sont même redevenus aveugles et sourds, ayant des yeux pour ne plus voir et des oreilles pour ne plus entendre. Laissons-les dans lour isolement, et renvoyons-les à Pascal, qui, déjà, à l'aurore du règne des sciences naturelles, a ćcrit sans y mettre trop de réticences, au fronton de leur petite église: "Qui veut faire l'ange fait la bête. .

La période dévonienne, fille et héritière de la période silurienne, inauguratrice de l'âge primaire, marque un progrès considérable dans le monde organique: les premiers vertébrés apparaissent dans les eaux, comme leurs précurseurs invertébrés; ce sont des poissons.

Les poissons sont les plus humbles, les plus rudimentaires, les plus primitifs des animaux à vertèbres, et leur apparition paléontologique à l'origine des vertébrés est un argument qui vient s'unir à tous les précédents en faveur de la théorie de l'évolution graduclle des ètres vivants.

Leur cerveau est très petit et représente ce qu'il y a de moins élevé parmi les vertébrés; leur moelle épinière est rudimentaire, leur système nerveux peu développé; ils n'ont pas encore d'organes de préhension; la moitié de leur puissance réside dans leur bouche; la tête est assez bien formée, l'odorat est très sensible 
l'œil voit bien, l'oreille commence, .certains poissons perçoivent même des sons délicats; mais ils ne possèdent pas encore la voix : la nature a cessé d'ètre sourde, mais elle n'a pas encore cessé d'être muette, et tous les êtres vivants restent silencieux. Lente élaboration du progrès! Les sexes existent et sont séparés sur des individus distincts; mais, dans ces animaux à sang froid, cette séparation n'implique pas la douce loi du rapprochement. Ils ne connaissent pas cette attraction, réservée aux enfants de l'avenir; le désir, ils l'ignorent; le sentiment affectif né de l'union, mème passagère, ou seulement du désir, ils ne le connaissent pas. Incapables d'amour, ils sont aussi incapables d'affection maternelle, paternelle ou filiale. Quelle distance du poisson à l'oiseau ! Et que la nature a encore de degrés à monter! Tout poisson reste isolé. Manger ou ètre mangé : voilà toute sa destinée. La femelle sémera des milliers d'œufs dont les quatre-vingt-dix-neuf centiemes seront perdus pour l'œuvre de la vie; elle les abandonne comme un fardeau superflu et n'a nulle préoccupation de l'avenir; ils lui deviennent. aussi étrangers que s'ils étaient tombés du ciel. Le mâle passe quelque jour au-dessus de ces oufs et laisse échapper une liqueur qui les féconde; il ne les connait pas davantage, et ce ne sont pas ses enfants: ce sont ceux de la nature. Pauvres amours! Pauvre vie!

Et pourtant! quelle supériorité déjà sur le mollusque qui rampait péniblement à la surface du sol aquatique ! quelle légèreté ! quelle liberté! Heureux, dit-on, comme un poisson dans l'eau! Sans doute; tout est relatif. S'il ne connait pas nos ardeurs, il ne connait pas non plus nos chagrins. Il glisse dans l'azur transparent, visite des plages, plonge au fond des mers, mobile comme l'onde sa mère, vrai fils de l'onde, et parfois mème s'aventure dans l'eau douce des fleuves pour visiter de nouveaux pays. C'est déjà une royauté. Quelle merveille de voir, par des mouvements de queue aussi insensibles, par une souplesse inimitable, le poisson aux reflets argentés glisser avec agilité dans les eaux, changer de route, fondre sur sa proie, planer au sein des flots ou se laisser bercer comme une fleur vivante selon le courant de l'élément liquide. Mème en dormant, il flotte encore. Et quelles merveilleuses couleurs dans les mers tropicales! Le poisson est une nouvelle étape de la force vitale vers la lumière et vers la liberté. 
Là aussi, il y a des degrés. Les premiers poissons n'avaient ni cette élégance ni cetle légèretẻ qui nous charment aujourd'hui. Eux aussi ont progressé, et beaucoup. Les plus anciens poissons fos. siles découvorts dans les terrains de l'époque primaire, sont des poissons cuirassés. Ils ont élé conservés dans l'étage dévonien, première couche de l'époque primaire - revoir la description des terrains, p. 257, et les tableanx, p. 258 et 259, - lequel étage dévo. nien affleure à la surface du sol, en Angleterre (comté de Devonshire, Shropshire, Herefordshire, etc.,) en France (Ardennes, Orne, Cotentin, Sarthe, Mayenne, Ille-et-Vilaine, Vosges, plateau central,
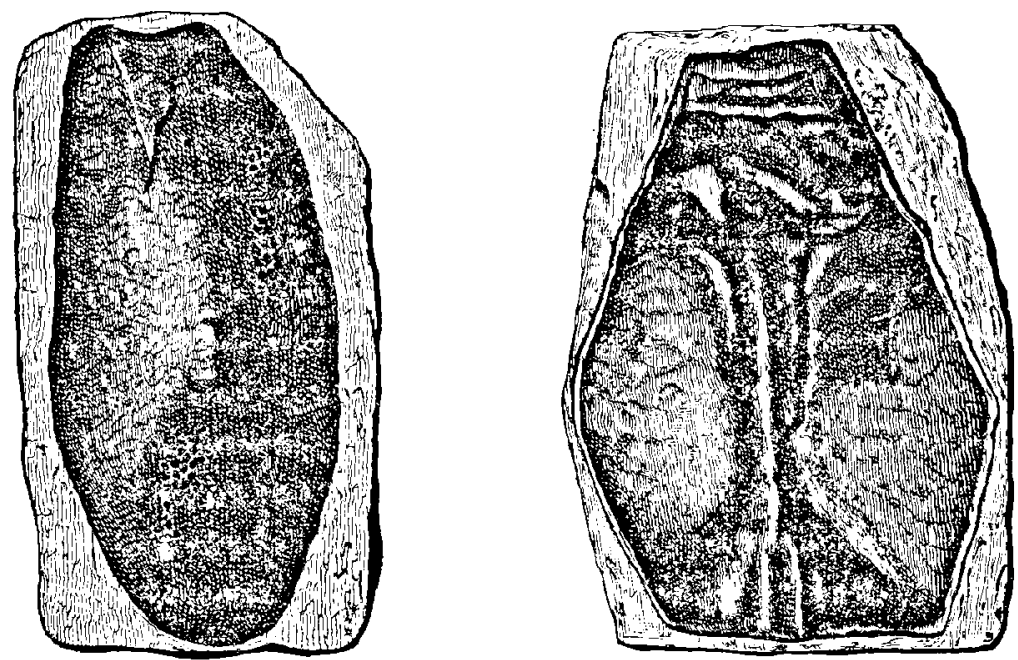

Fig. 173-171. - Les premiers poissons. Période dèvonienne. Seaphaspis Lioydil ot Pteraspla rostratns (Grandonr naturolio):

Languedoc, Pyrénées), Allemagne (bords du Rhin, Nassau, Westphalie), Espagne (Asturies), etc. Ces premiers poissons cuirassés ont reçu le nom de ganoüdes ('), parce qu'ils avaient plus d'apparence que de réalité, en ce sens que leur ossification était incomplòto, qu ils étaicnt faibles ot quo leur corps était protégé par de grandes plaques et des écailles osseuses couvertes d'un émail brillant. Ainsi, chez ces premiers poissons, le squelette était inachevé. Sont-ce mème déjà des poissons? Ne sont-ce pas des cousins des crustacés? Examinez-les vous-mêmes et jugez. Nous en reprodui-

I. Étymologie : భavos, éclat, Eıôos, apparence. 
sons deux ici ( $/ g .173$ et 174) d'après M. Gandry, le scaphaspis

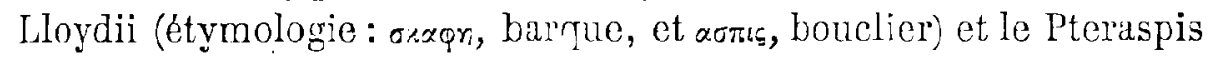

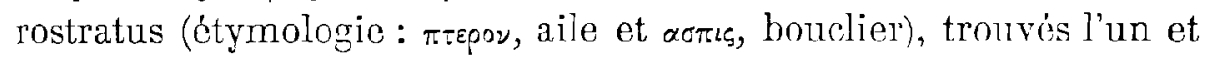
l'autre dans le dévonien inféricur de Grodley (Herefordshire). Pour prouver que ce sont là des poissons d'un caractère tout à fait initial qui marquent le passage de l'invertébré au vertébré, il suffit, dit M. Gaudry, de rappeler l'histoire de leur découverte. « En 1835, dans son grand ouvrage sur les poissons fossiles, Agassiz attribua leurs débris à des poissons. Un peu plus tard, Rudolphe Kner prétendit que ce n'étaient pas des restes de poissons; il supposa que c'ètaient des coquilles internes de mollusques, analogues à l'os de la seiche. En effet, si l'on compare le tracé d'un os de seicho et celui de la plaque singulière qui représente la carapace du scaphaspis, on ne peut manquer d'être frappé de leur ressemblance apparente. En 1856, M. Ferdinand Romer exprima l'opinion que la pièce attribuće par Kner à un mollusque provenait d'un crustacé, et il considéra la plaque d'un scaphaspis du dévonien de l'Eilel comme un os de seiche; il l'inscrivit sous le nom de paleoteuthis (ancien calmar). Deux ans après, M. Huxley étudia la structure des plaques du scaphaspis et déclara que c'étaient bien des os de poissons. Mais, pour enlever tous les doutes, il fallut que M. Ray Lankester eut, en 1863, la bonne fortune d'obtenir un morceau de pteraspis, genre voisin du scaphaspis, qui avait, contre sa plaque, des écailles semblables à celles des poissons. On ne saurait s'étonner que d'éminents naturalistes, comme Kner et Roemer, aient cru ces poissons primitifs plus près des invertébrés que des vertébrés. En effet, des vertébrés, qui justifient leur nom, devraient avoir des vertèbres; lo scaphaspis n'en montre pas plus de traces que l'amphyoxus de nos mers actuelles. Les vortébrés ont leurs membres soutenus par des pièces solides; le scaphaspis et leurs alliés n'ont ancun vestige de ces pièces ou d'un os interne quelconque; ils ont seulement une ou plusieurs plaques qui forment, périphérie, un lambeau de cuirasse, comme chez les crustacés ('). D

Ainsi se confirme sous tous ses aspects la théorie des enchainements du monde animal at du développement graduel des êtres.

1. Gatdru, Fossiles primaires. 
Nous avons vu, au chapitre de la physiologie (p. 179), que l'amphyoxus, vertébré sans cràne, marque physiologiquement le passage des invertébrés aux vertébrés. La paléontologie est en parfaite concordance avec la théorie physiologique : les poissons, les ganoïdes primitifs, appartiennent au type de l'amphyoxus, si rudimentaire, comme nous l'avons vu. Aux deux spécimens précédents ajoutons encore leus contemporains trouvés dans le dévonien
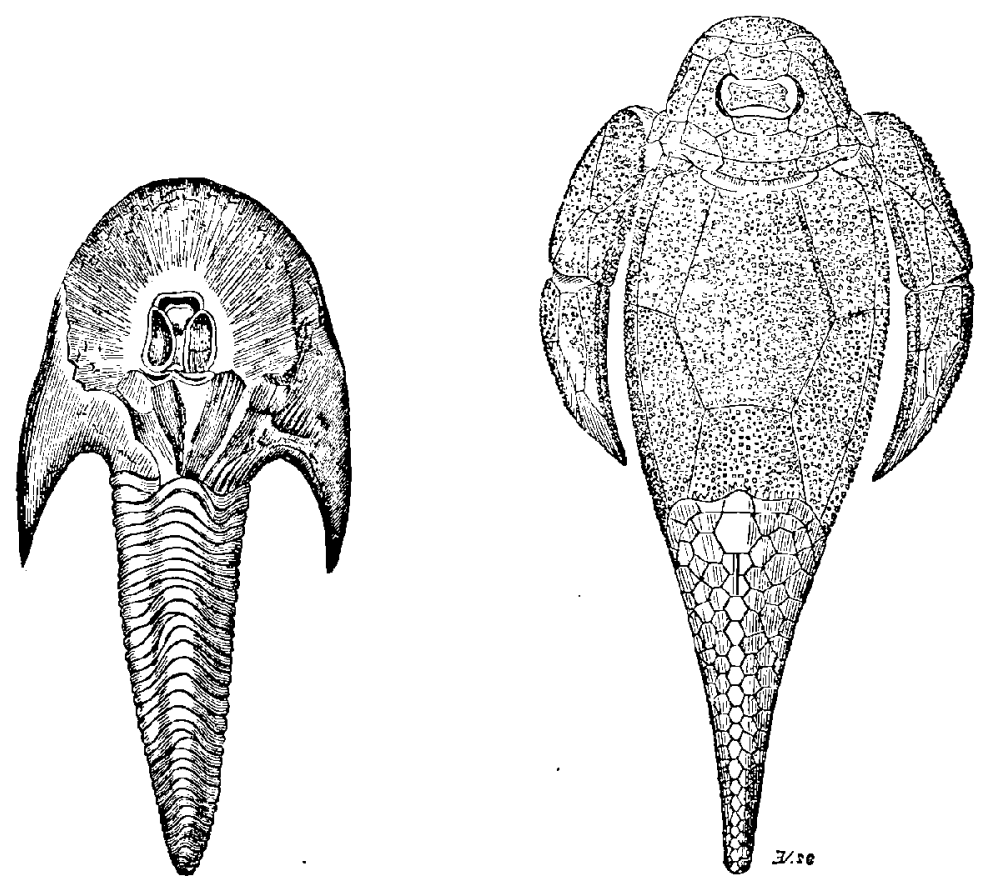

Fig. 17j̀-176. - Les premiers poissons. - Période dévonienne. Cephalaspia Lyelli et Pterichtys Milleri (1/2 grandeur naterelle).

inférieur, le cephalaspis ( $\left.{ }^{4}\right)$ et le pterichtys, dessinés ci-dessus. Ce sont également des poissons, mais si différents de tous ceux qui existent actucllement, qu'on est embarrassé pour décider s'il convient de les ranger dans la sous-classe des poissons osseux ou dans celle des cartilagineux. Ils sont dépourvus de vertèbres et d'os internes. Vainement chercherait-on dans leur tête les dispositions des poissons actucls: on voit un bouclier ou il est impossible de tracer les divisions des os du crâne; sa forme rappelle celle des

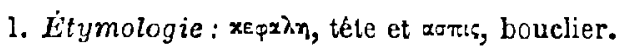




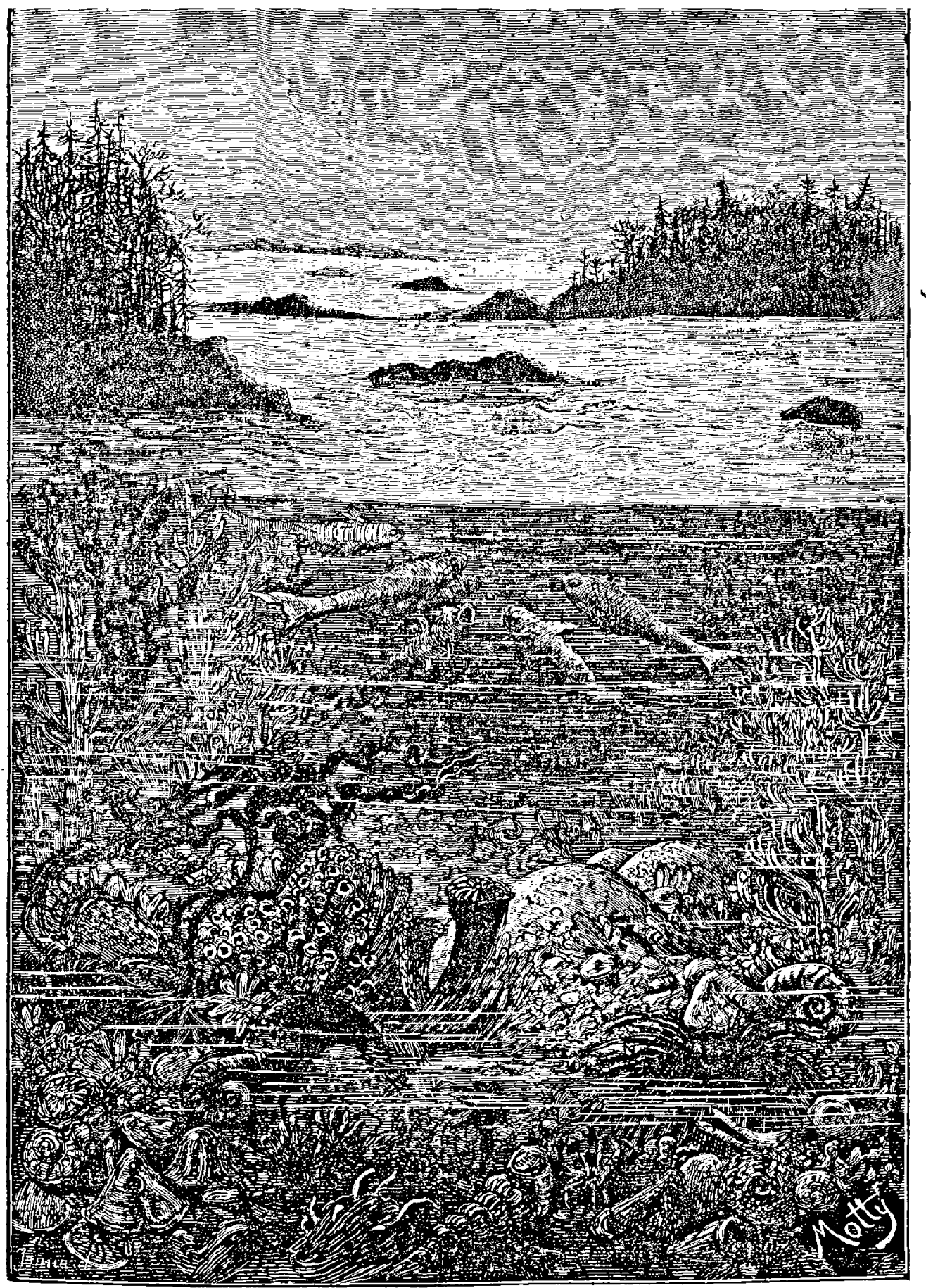

LES PRINCIPAUY HABITANTS DE LA TERRE PENDANT LA PÉRIODE DÉYONIENAE.

LE MONUE AVANT LA CREATION DE L'HONMF. 
trilobites. Ainsi le trilobite que nous avons vu plus haut (p. 232), roi des mers primordiales, a pour successeur un poisson qui lui ressemble et qui partage sa royauté dans le gouvernement des mers primaires. L'arbre généalogique de la vie se montre à l'observateur duns toutes ses ramifications.

Parmi ces premiers poissons, remarquons aussi les pterichtys (') qui ne sont pas moins étranges. "Il est impossible de rien voir de plus bizarre dans toute la création, écrivait Agassiz à propos de cet animal primitif. Le mème étonnement qu'éprouva Guvier en examinant pour la première fois les plésiosaures, qui semblaient porter un défi à toutes les lois de l'organisation, je l'ai éprouvé moi-mème lorsque M. Miller me fit voir les échantillons qu'il en avait ramassés ». Le géologue Miller, qui fit cette découverte - et bien d'autres - et qui a aujourd'hui sa statue dans son pays natal, en técosse, non loin de la chaumière où il est né, était un ouvrier carrier : en cassant des picrres du terrain dévonien, il y trouvait des poissons fossiles; son esprit en fut émerveillé, et un jour il laissa la pioche pour prendre la plume et créer l'une des branches de la paléontologie. Comme la vie elle-mème, le patrimoine scientifique de l'humanité a commencé par les plus humbles travailleurs, et ce sont eux encore, eux toujours, qui contribuent à l'élévation lente et progressive de l'édifice des connaissances humaines.

Nous avons reproduit plus haut $(f g .176)$ ce singulier poisson primitif. Sa bizarrerie est telle qu'on a attribué les carapaces qu'on en découvrait, tantôt à des insectes, tantôt à des crustacés, tantôt à des tortues. Ils ont une colonne vertébrale, mais elle n'est pas endurcie; la moitié extérieure du corps est enfermée dans une cuirasse et leurs pattes paraissent plutôt faites pour sauter que

1. Étymologie : $\pi \tau \varepsilon p o v$, ailes, et $x^{0 \vee \varsigma}$, poisson.

Par ces étymologies, nos lecteurs peuvent remarquer que ces désignations en apparence barbares ne sont autre chose que la traduction grecque de l'aspect de l'animal. On remplace deux ou trois mots par un seul, grammaticalement construit. Ft c'est mème plus clair lorsqu'on connât l'ëtymologie. Au lieu de dire : « apparence et éclat \$, « tête et bouclier \$, aile et poisson 》, on exprime la même pensée en grec modernisé. C'est comme en médecine, au lieu de dire qu'on a mal à la tête, on dit qu'on a de la " céphalalgie 》, une souffrance d'entrailles devient de la e gastralgie », le rhume de cervean s'appelle - coryza \$. C'est déjà une première satisfaction pour le médecin de nommer en gree la maladie de son client, et trop souvent..., c'est tout ce qu'il peut faire pour la guérir.-. 
pour nager; la moitié postérieure porte des écailles et des nageoires. “ On pent dire, écrit M. Gaudry, que cet être bizarre est partagé en deux parties, une antérieure par laquelle il se rapproche des invertébrés, el une postérieure par laquelle il appartient aux vertébrés ». Toujours les indécisionśs primitives de ld nature avançant très lentement dans son cuvre.

On trouve aussi dans les terrains dévoniens un genre de poissons plus élevé que les précédents dans l'ordre des vertéhrés, le

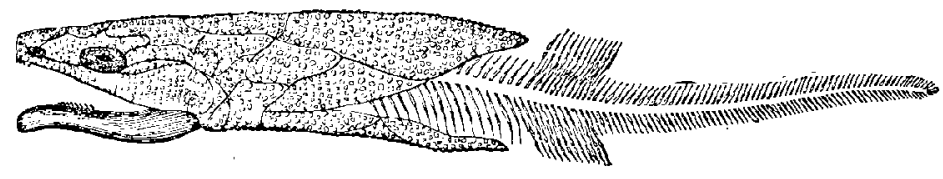

Fig. 178 - Les premiers poissons.

Restauration du squelette du coccosteus decipiens, d'après M. Gaudry.

coccosteus ( 1 ) dont M. Gaudry a restauré le squelette ( $f g$. 178). La partie postérieure du corps était tout à fait nue; la partie antéricure était cuirassée très solidement. C'est ce qui a fait dire à Richard Owen: "Coccosteus était armé comme un dragon français avec un fort casque et une courte cuirasse; nous voyons ses restes dans l'état où l'on pourrait un jour rencontrer ceux de quelques-

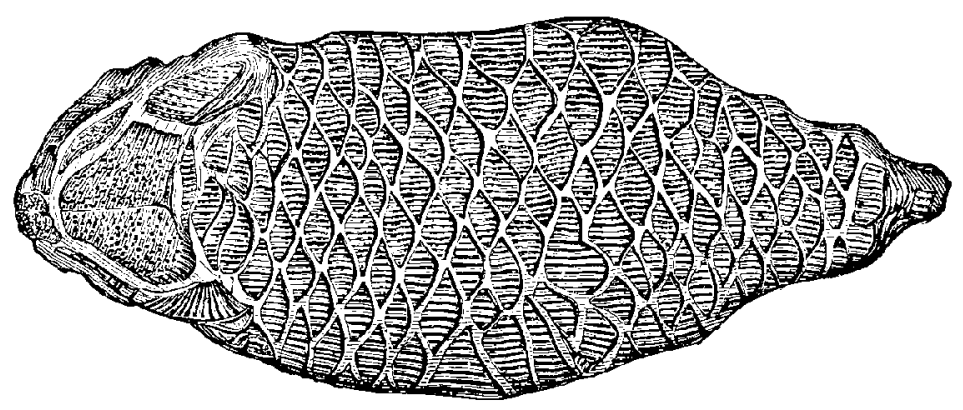

Fig. 179. - Les premiers poissons. L'hnloptychus Andersoni.

uns des soldats de la vieille garde de Napoléon, qui, ayant été ensevelis tout habillés, seraient déterrés, dans le champ fatal de Barodino ou sur les rives de la Dwina ». M. Gaudry pense avec Owen que sans doute ce poisson cachait dans la vase la partie postérieure de son corps, laissée sans défense, et cite à ce propos l'exemple

1. Étymologie : xoxxos, grain, ortiov, os, ì cause des granulations de la surface des os. 
d'un petit poisson de l'Inde, le Pimelodus gulio, dont le corps est nu et dont la tète porte un casque très dur, lequel s'enfonce dans la vase, attend qu'un poisson passe an-dessus de lui et le tue d'un solide coup de sa tête cuirassée ('). Signalons encore, avec M. Contejean, parmi les plus curieux de ces poissons primitifs, l'holoptychus Andersonii ( $f g .179$ ).

Tous ces poissons primitifs différaient beaucoup des poissons actuels par leurs carapaces antérieures, par leur aspect général, par les divers détails de leur organisation, et par la forme de leur

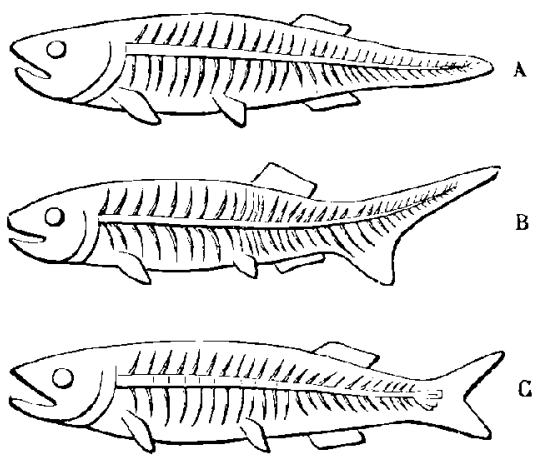

Fig. 180. - Transformation de la queue des poissons, d'après MI. Gaudry.

queue. Le savant auteur des "Enchaînements du monde animal » a très ingénieusement comparé les types de la variation de la queue du poisson suivant celle de la colonne vertébrale. Dans le premicr type $(f g .180 \mathrm{~A})$ la queve est simple, la colonne vertébrale diminue graduellement comme dans une queue de rat ou de lézard; dans le second type (B), cette colonne s'est relevée et agrandie et il en reste nne queve d'un aspect irrégulier; dans le troisième type (C) elle est devenue bifurquée et sert de gouveruail perfectionné, ce qui donne aux poissons modernes leur grâce et leur agilité. Or on constate que bien que certains genres du premier type se soient perpétués jusqu'à nos jours (comme les anguilles) ils ont cu leur règne souverain pendant les âges primaires, que les seconds ont dominé pendant les temps secondaires et que les troisièmes caractérisent les époques plus récentes.

- 1. Arbrrt Gaudry. Les enchainements du monde animal. Fossiles primaires. 
Nous avons remarqué plus haut (p. 24) que l'cmbryologie nous prouve la parenté des êtres en nous plaçant sous les yeux la ressemblance de l'embryon humain avec ceux des autres etres vivants. Les recherches de M. Alexandre Agassiz, fils de Louis Agassiz, ont confirmé l'accord des développements paléontologiques et embryogéniques: actuellernent, les poissons traversent depuis l'état embryonnaire jusqu'à l'état adulte les mêmes phases par les-

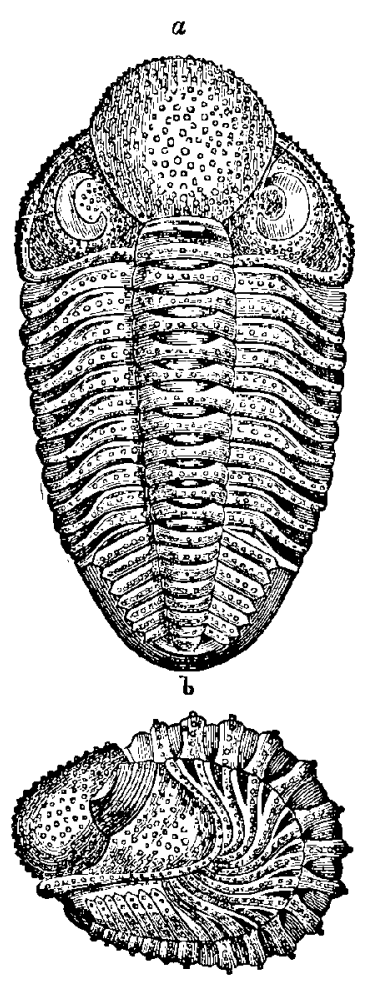

Fig. 181. - Crustacés de la période dévonienne. Phacops latifrons. - a. L'adirnal élendu. - b. Euroule.

quelles ils ont passé depuis les temps primaires jusqu'aux temps actuels.

Ainsi, comme nous venons de le voir, la période dévunienne doit être inscrite dans les annales de l'histoire de notre planète comme ayant èté marquée par un pas décisif dans la marche du progrès, par la naissance des premiers vertébrés, des poissons. Dans les chapitres précédents nous avions vu naître les invertébrés, zoophytes, polypes, échinodermes, foraminifères, brachïopodes, 
bivalves, gastropodes, céphalopodes, mollusques divers, articulés, crustacés. Maintenant les poissons animent les eaux, dérivant sans doute, par une transformation graduelle, des vers, dont les mollusques et les crustacés ont formé deux dérivations assez proches parentes. Bientôt nous allons être témoins de nouveaux progrès. Les poissons donneront naissance aux amphibies, les amphibies aux reptiles, les reptiles aux serpents d'une part, aux oiseaux d'autre part, tout cela par une gradation lente et insensible. La lenteur est extrème. Il est plus facile de suivre les progrès d'un écolier que ceux d'une espèce animale, quoique les premiers soient, en fait, plus considérables que les seconds; il est, par excmple, plus facile de suivre les progrès de Pierre Simon Laplace, fils d'un pauvre paysan de Beaumont-en-Auge, enfant studieux, grandissant dans le travail de la pensée et devenant en moins d'un demi-siècle l'immortel auteur de la Mécanique céleste, formulant en termes précis les lois invisibles retenues cachées jusqu'alors dans la majesté de la nature, concevant et exprimant les forces qui, dans le passé comme dans le présent et dans l'avenir, régissent les mouvements des corps célestes, il est plus facile, disons-nous, de suivre la transformation d'une intelligence ainsi grandissante que celle d'une anguille acquérant des nageoires ou d'un lézard perdant ses pattes. Pourtant, la distance n'est-elle pas incomparablement plus grande?

En même temps que les premières espèces de poissons, assez grossières, comme nous venons de le voir, se développent au sein de la mer, les crustacés, surtout les trilobites, dominent et règnent encore comme pendant les siècles de la période silurienne; mais ils commencent pourtant à sentir qu'ils doivent céder la place à leurs successeurs. Signalons le phacops latifrons ( $f g$. 181), qui rappelle le trilobite calymène. Avec les trilobites de toutes tailles et de toutes formes, les pterygotus, les eurypterus avec lesquels nous avons fait connaissance en étudiant les hôtes primitifs des temps siluriens, on retrouve parmi les fossiles dévoniens les stylonorus ( $\left.{ }^{\prime}\right)$, dont la queue était pointue comme un stylet, les slimonia $\left({ }^{2}\right)$, les

1. Étymologie: orùos stylet; oupa, 'queue.

2. Nom donné en l'honneur du géologue écossais Slimon 
xiphosures (1), dont la limule actuelle est un type conservé, les hemiaspis limuloïdes $\left({ }^{2}\right)$, non moins singuliers que les précédents

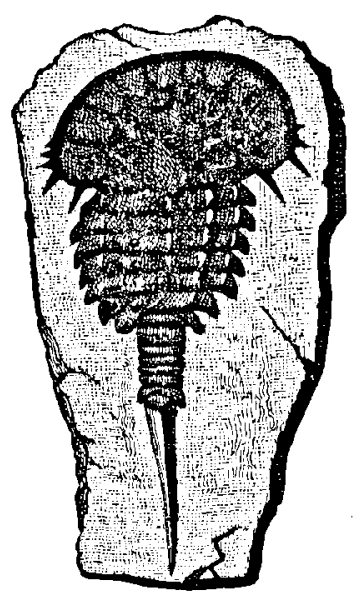

Fig. 182. - Crustacé de l'époque déyonienne. L'hémiaspis limuloüdes (grandeur naturelle).

par leur forme si bizarre (fig. 182). Un certain nombre de ces crustacés et de ces articulés atteignaient de fortes dimensions : on a

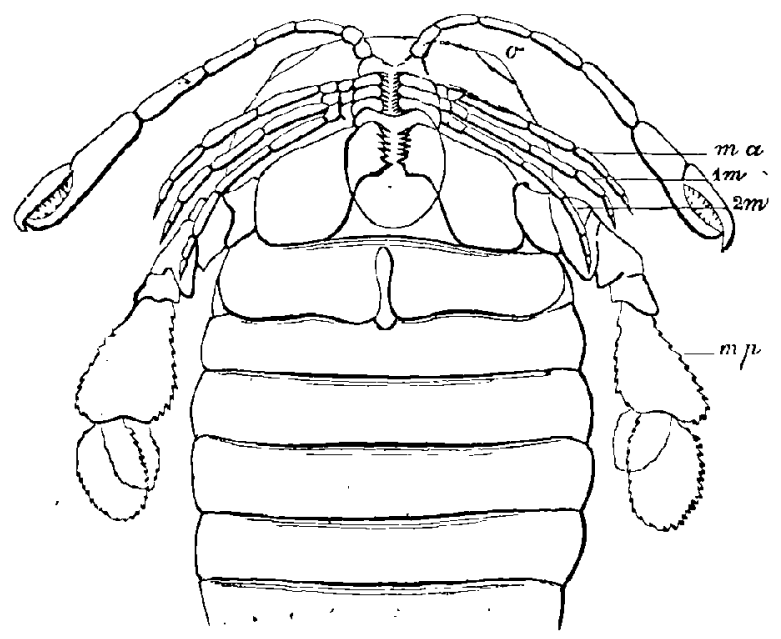

Fig. 183. - Détails des cuisses-máchoires du pterygotus anglicus. (1)20 de grandeur naturelle).

trouvé dans le dévonien d'Écosse une espèce de pterigotus qui ne, mesure pas moins de $1^{\mathrm{m}} 80$ de longueur et dépasse incomparable-

1. Étymologie: šsor, épée; oupx, queue.

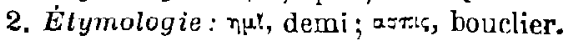


ment la taille des plus grands homars actucls. On a donné le nom de mérostomes (1), à un certain genre fort curieux, d'entre ces crustacés, qui, à l'exemple des pterygotus, se servent de leurs jambes à la fois pour marcher et pour se nourrir. Ils nous montrent, remarque à ce propos M. Gaudry, un curieux procédé

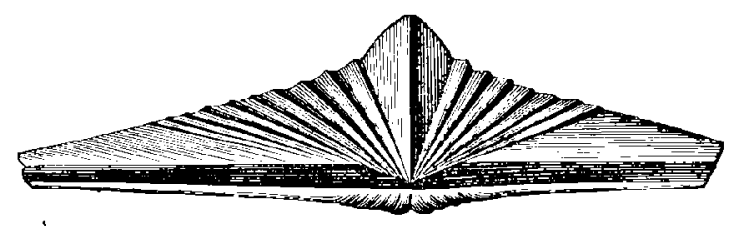

Fig. 184. - Mollusques brachiopodes de la période dévonienne. Spirifer macropterus.

d'économie employé par la nature dans un temps oủ elle n'était pas riche comme elle l'est aujourd'hui. A leur extrémité, les
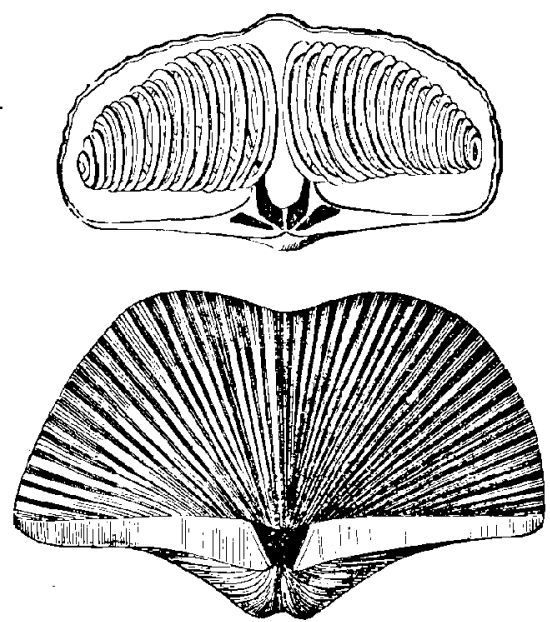

Fig. 185. - Mollusques brachiopodes de la jériode dévonianne. Spirifer strialus.

appendices céphaliques $(f g .183), m a, 1 m, 2 m, m p$, remplissaient les fonctions de pattes; leur base munie de denticules jouait le rôle de mâchoires. Singuliers organes que ces cuissesmâchoires! Tout a bien changé depuis...

Outre les poissons primitifs et les légions de crustacés, les mers sont peuplées de mollusques brachiopodes beancoup plus nom-

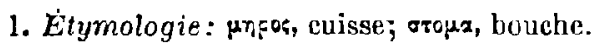


breux que de nos jours. Aux types de la période silurienne (voy. p. 236) il faut ajouter les curieux spirifer (fig. 184 et 185), les
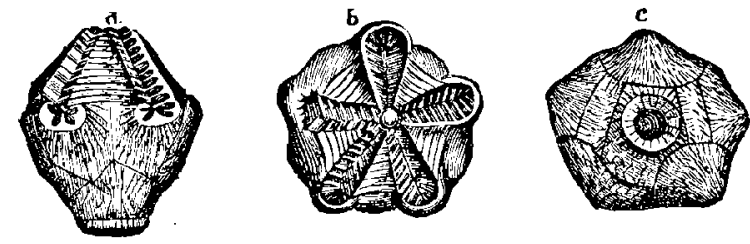

Fig. 186. - Mollusques brachiopodes de la période dẻvonienne. Haploerinus mespiliformls. - a. Va de profi. - b. Ka dessus. - c. En dessous.

haplocrinus ( $f g .186)$ et les calceola ( $f g .187)$. Ces mollusques sont caractéristiques de l'époque. On doit leur ajouter les ptéropodes
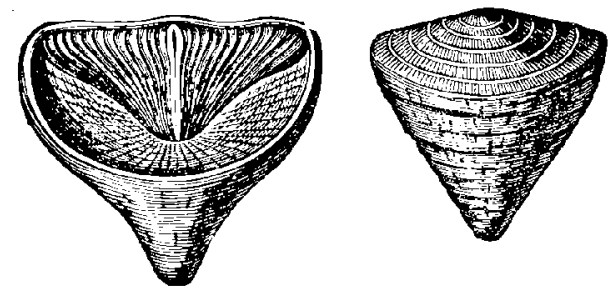

Fig. 187. - Mollusques brachiopodes de la période dévonienne. Calcoola Saudallna.

(fig. 188 à 190), des nautilides et des clyménies ( $f g .191$ ), ainsi que les crinoïdes encore très répandus. - Voilà bien des mots grecs
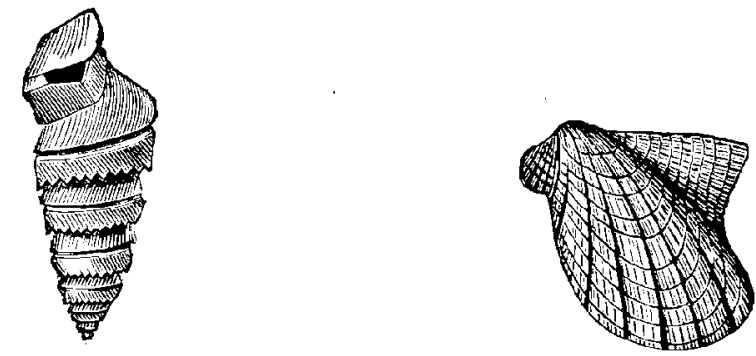

Fig. 188-189. - Mollusques ptéropodes de la période dévonienno. Murchisonia intermedia. Aricula taballa.

d'aspect assez barbare pour notre belle langue française! et nous demandons humblement pardon à nos lecteurs - et à nos lectrices - du manque d'harmonie de certaines scènes de cette grande épopée.

En résumé, dirons-nous avec M. Contejean, la faune dévonienne LE MONDE aVANT La Gréation de L'HOMaIE 
n'est que la continuation de la faune siluriesne, mais avec une tendance marquée au perfectionnement. Quelques espèces passent de l'une à l'autre période; un très grand nombre des genres siluriens sont représentés, à l'époque dévonienne, par des formes nou-

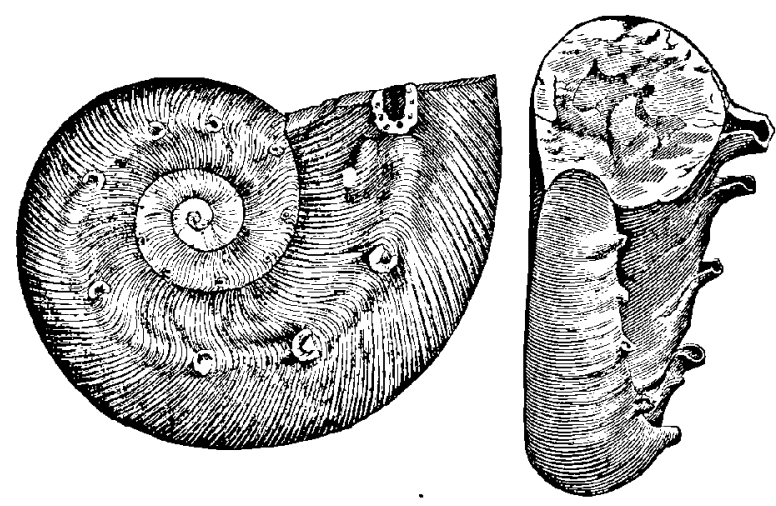

Fig. 190. - Mollusques ptéropodes de la période dévonienne. Cirrus spinosus.

velles; plusieurs s'éteignent, et cenx qui apparaissent montrent souvent une plus grande complication de structure. Cette faune, qui comple déjà plus de cinq mille espèces, constitue un ensemble

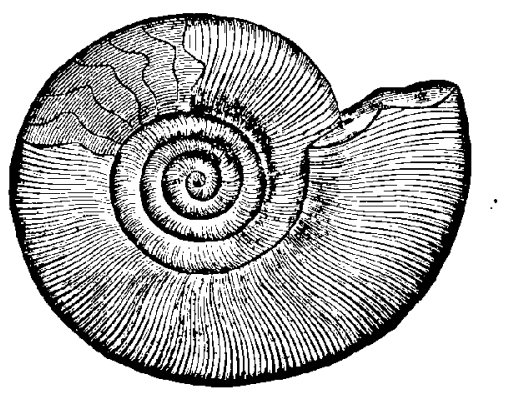

Fig. 191. - Mollusques nautilides des mers dévoniennes. - Clyménie.

comparable à l'une des trois grandes faunes siluriennes, et cependant plus riche peut-ètre qu'aucune de ces dernières; de sorte qu'au point de vue paléontologique le terrain dévonien n'équivaut guère qu'au tiers du terrain silurien. Aussi les subdivisions en sontelles moins générales, moins naturelles, et varient-elles davantage en nombre et en importance suivant les localités.

$\mathrm{Si}$, dans son ensernble, l'histoire du monde présente le spectacle 
d'un progrès, il faut se garder de croire que toutes les classes se soient développées d'une manière continue pendant la durée des temps géologiques. Les ptéropodes, les céphalopodes, les ostracodes, les branchiopodes, les mérostomes, les insectes (comme nous allons le voir), ont atteint, à l'époque primaire, une grande perfection et mème une taille plus considérable que dans l'époque actuelle. " Un des résultats les plus curieux des étndes paléontologique, écrit M. Gaudry, a èté de montrer que chacune des époques du

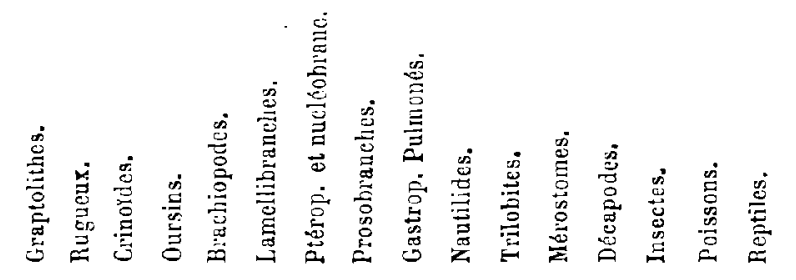

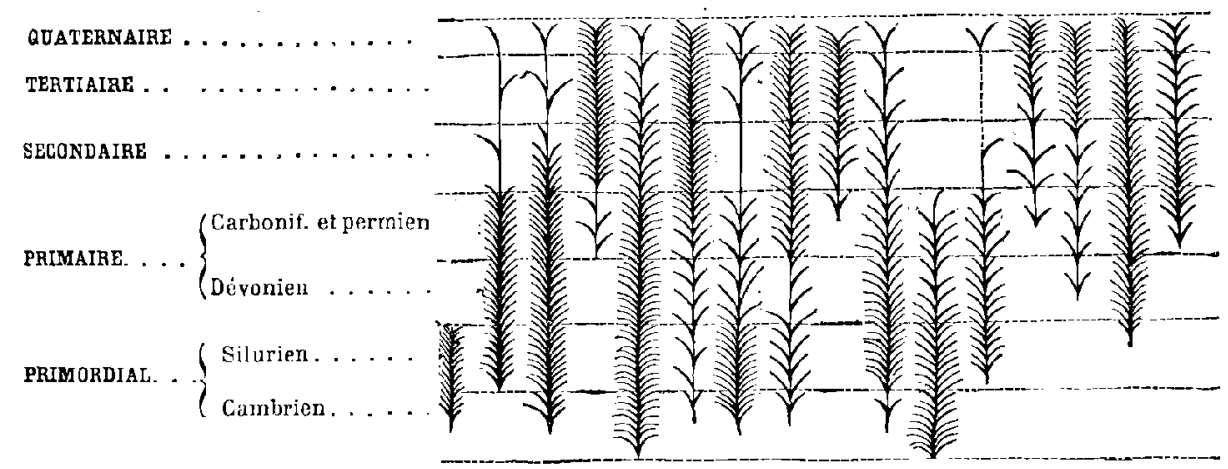

Fig. 192. - Développement et variation des animalx primaires à travers les âges.

monde a eu ses épanouissements particuliers; elle a eu des etres qui ont été faits par elle; avec elle, leur règne a commencé; avec elle leur règne a fini. On s'en rendra compte en jetant les yeux sur la figure 192, oì est indiquée la marche suivie par le développement d'une partie des animaux primaires; chaque groupe est représenté par un rameau plus ou moins fourni, selon que le développement a été plus ou moins grand. On voit dans ce tableau combien les graptolites ont été éphémères; nés dans le cambrien, ils n'ont pas dépassé le silurien; quelques-uns des polypes hydraires des époques plus récentes ont pu en provenir, mais alors ils ont cessé d'ètre des graptolithes, de sorte qu'on doit dire que la forme graptolithe est restée confinée aux anciennes époques. Les rugueux ont eu leur extension dans les temps primaires; il est rraisem- 
blable que plusieurs ont été la souche des corallaires de la période secondaire, puisqu'ils se lient à eux d'une manière insensible, mais sans doute tous n'ont pas servi de progéniteurs. Quelques-uns des tabulés des terrains anciens, tels que l'heliolites, paraissent les ancêtres des alcyonaires actuels; au contraire, la michelinia, l'halysites et plusieurs autres sont restés spéciaux aux formations primaires.

"Les ptẻropodes et les nucléobranches primaires ont pu être les ancêtres de ceux qui sont venus après eux; néanmoins, ils ont tellement changé qu'on ne risque pas de confondre les genres anciens avec les genres nouveaux. Sauf le nautilus, aucune forme de la famille nautilide, qui a eu jadis une extrême fécondité, n'est représentè de nos jours. Les trilobites, dont les variations ont attesté une si étonnante plasticité pendant les temps cambriens et siluriens, ont diminué dans le carbonifère, et leur dernière espèce a été trouvée dans le permien. Les mérostomes ne sont plus représentés anjourd'hui que par le genre limule; ce n'est pas pour produire ce survivant isolé que se sont épanouis dans les temps primaires tant, de singulières créatures des groupes xiphosuridé et euryptéridé. Jo crois que plusieurs des poissons anciens ont été les prototypes des poissons actuels; mais quelques-uns d'entre eux, tels que le pterichthys, le cephalaspis, le coccosteus forment une population étrange confinće dans les temps primaires. Les reptiles labyrinthodontes caractérisent la fin du primaire et le commencement du secondaire. Ces fossiles, qui ont été spéciaux à certaines périodes de l'histoire de la Terre, rendent de précieux services aux géologues pour la détermination des terrains. Ils méritent bien le nom de médailles de la création 》( 1 ).

Les insectes ont fait leur apparition à cette même époque; mais ils n'ont guère laissé de fossiles, on le conçoit sans peine. On a retrouvé des ailes de névroptères, du genre des éphémères, dans l'étage dévonien du Canada. L'un de ces ancêtres nommé platephemera $\left({ }^{2}\right)$ était gigantesque et mesurait, parait-il, plus de vingt centimètres quand il étalait ses ailes; un autre offrait quelques traits d'organisation intermédiaire entre les éphémères et les libel-

1. A. Gaudry, Les Enchainements du monde animal. Fossiles primaires, p. 290.

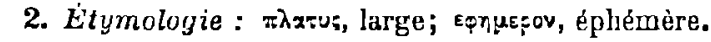


lules ; un troisième n'a de ressemblance avec aucun type connu, et un quatrième (le xononeura antiquorum) présente cette particularité d'offrir des vestiges d'un appareil stridulent analogue à celui des grillons actuels. Il est remarquable que ce soient là des insectes à la fois aquatiques et aẹ́riens. L'air va s'animer de fleurs vivantes; l'aile se forme; ils n'ont pas encore la voix, ils ne l'auront jamais; mais pourtant ils ne sont déjà plus muets : la nature

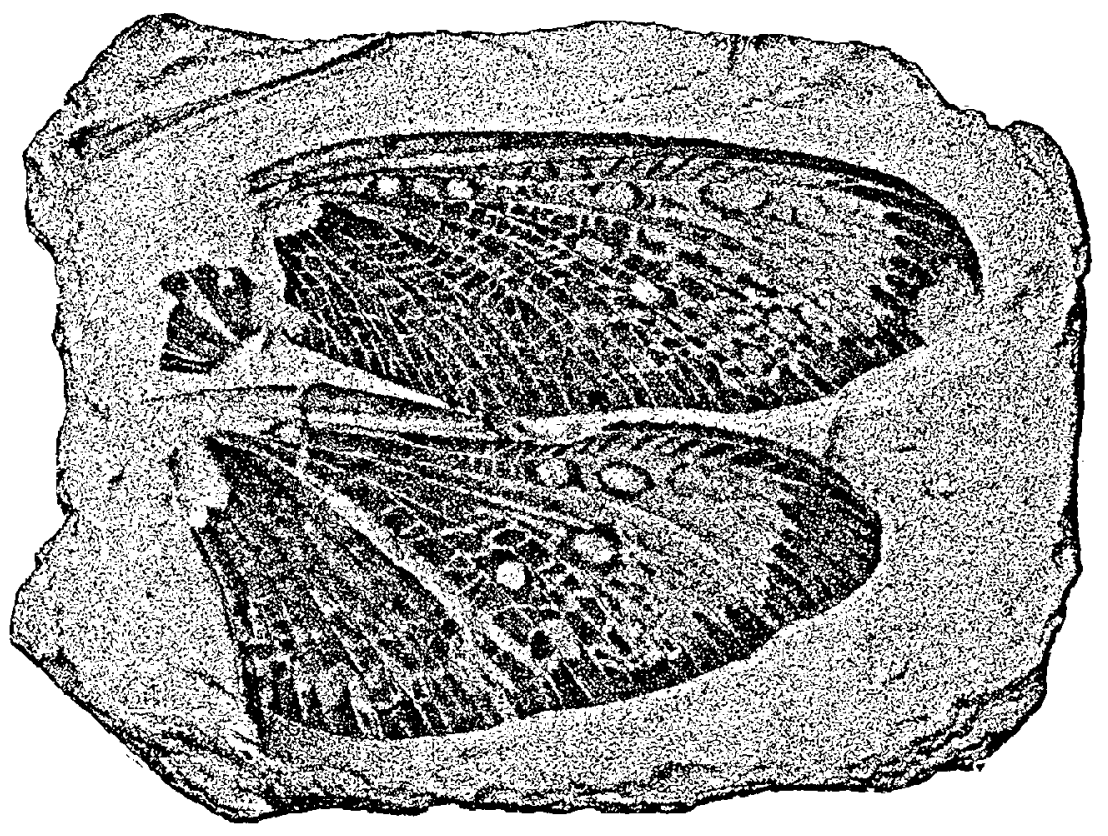

Fig. 193. - Les premiers insectes. - Ailes fossiles de lamproptilia Grand'Euryi.

Trouve dans ies houilières de Commentry. (Gradour naturelle.)

entre dans une nouvelle phase. Le seul fait de l'existence de ces insectes névroptères à l'époque dévonienne prouve qu'ils ont eu des précurscurs moins parfaits qu'eux-mèmes ('). L'élégante demoiselle des eaux n'est pas sortie d'un rayon de soleil; elle a eu des ascendants plis grossiers, fils des annèlides.

Que les insectes soient sortis les uns des autres et successivement aient donné naissance, de proche en proche, aux innombrables variétés qui les représentent, c'est ce dont il est difficile de

1. Au moment où nous corrigeons cette épreuve (septembre 1885), nous apprenons que M. Douvillé, professeur à l'École des Mines, vient précisément de trouver l'aile d'un insecte dans le silurien moyen de Jurques (Calvados). Cet insecte était une espèce de blatte. 
douter lorsque d'une part on compare leurs analogies, et lorsque, d'autre part, on réfléchit au nombre des espèces déjà connues. Les coléoptères, à eux seuls, comprennent au moins cent mille espèces, les diptères autant, les hyménoptères quatre-vingt mille, les hémiptères cinquante mille, les lépidoptères vingt mille, les anoploures dix mille, les névroptères autant, les orthoptères six mille : c'est un total de 376000 espèces d'insectes, papillons, mouches, puces, punaises, fourmis, charancons, asticots, vers des fruits ou du fromage, que les théologiens - avant que l'éfude directe de la nature eût établi la parenté de tous les ètres entre

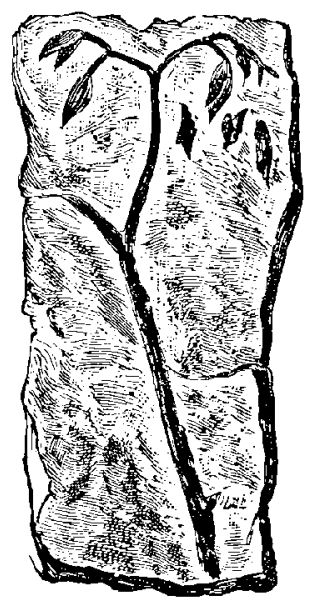

Fig. 194. - Les plus ancieures plantes. Psylopbiton princeps. - Terrains silurieng el dévoriens,

eux, - obligeaient l'Étre suprème à avoir créé lui-même par couples de chaque espèce.

Voici donc les insectes au monde, issus, selon tọte probabilité, des annélides de l'èpoque primordiale. Ils vont prendre un rapide essor et se développeront magnifiquement, pendant la période qui va suivre, en môme temps qúc le règne végétal. On a truuvé récemment, dans le terrain houiller de Commentry, le beau specimen que nous reproduisons ici (fig. 193) d'après M. Ch. Brongniart. Il appartenait à la famille des platyptérides ( ${ }^{4}$ ).

Déjà les plantes commencent à s'acelimater hors de l'eau, dans les marécages et sur les îles basses. La terre ferme s'accroit d'ail-

1. Étymologie: $\pi \lambda a r o s$, large; $\pi \tau s p o \gamma$, aile. 
leurs insensiblement par les soulèvements et les émersions lentes, et peu à peu la végétation l'envahit. Ce ne sont plus seulement des algucs ou des plantes tout à fait élémentaires ; mais déjà apparais-
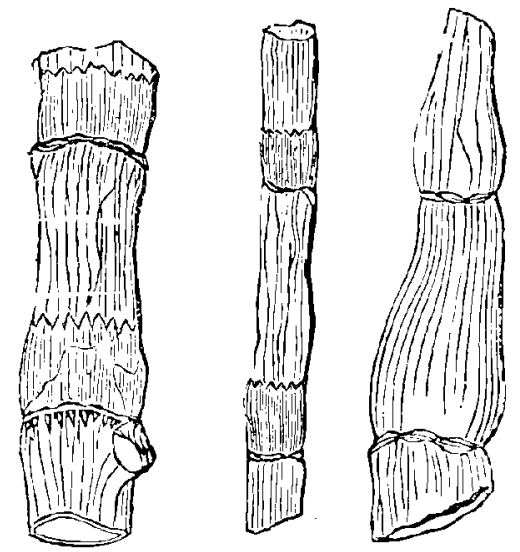

Fig. 195. - Débris fossiles de plantes primitives. Équisétacées de la périodo dévonienne.

sent les fougères, les lycopodes, les sigillaires, les équisétacées. Toutefois, la nature n'est pas encore sortie des cryptogames: ces

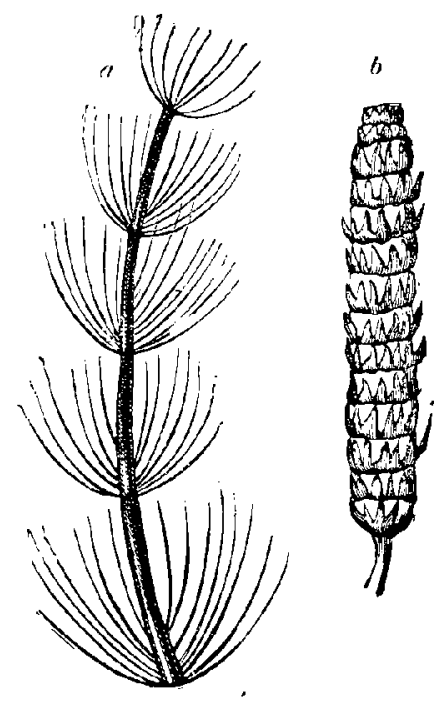

Fig. 196. - Plantes primitives. Calamites.

a. Rameau. - b. Épi frugifère.

plantes règnent en souveraines dans les eaux et sur les iles, et nul prophète n'oserait deviner les richesses réservées à la végétation de l'avenir. 
Dans le dévonien inférieur, an-dessus du silurien dans lequel nous avons remarqué les plantes primitives, algnes variées, bilobites, eophyton, etc., on rencontre le psylophiton étudié dans les terrains du Canada par M. Dawson, et dont nous représentons ici (fig. 194) un rameau d'après M. Crié. C'était une espèce de lyco-

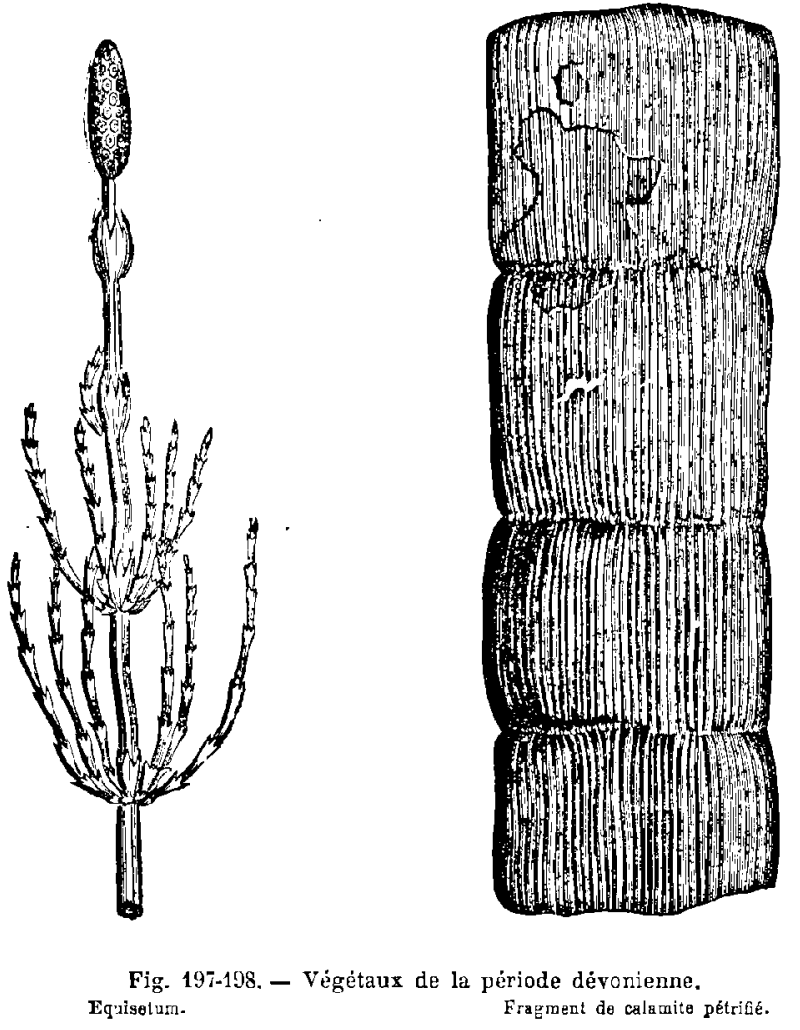

pode. Tous ces plus anciens végétaux ont èté trouvés dans le nord, comme les premiers animaux : Canada, Scandinavie, Russie, Angleterre. Nous verrons bientòt qu'à cette époque reculée il n'y avait encore ni saisons ni climats, que la température était la mème sur le globe entier, et que probablement c'est dans les calmes régions polaires que la vie a commencé.

Tout le monde connât les prêles, ou queues de rat, plantes en forme de joncs, dures, dépourvues de feuilles, que l'on trouve un peu partout, surtout dans les régions non cultivées, aux bords des ruisseaux solitaires. Cette plante a servi de type à la famille régé- 
tale désignée sous le nom des équisétacées ('), à cause de la forme des rameaux, qui ressemblent à de la soie de cheval. C'est là une plante primitive, qui date de l'époque dévonienne. Ces humbles prêles, dont la taille n'excède pas aujourd'hui quelques décimètres, s'élevaient alors à sept et huit mètres de hanteur, comme de gigantesques asperges, et dominaient par leur nombre la population végétale des premières forêts. Ciryptogame rudimentaire, encore peu éloignée des algues primitives, quoique terrestre, à peine plis com-

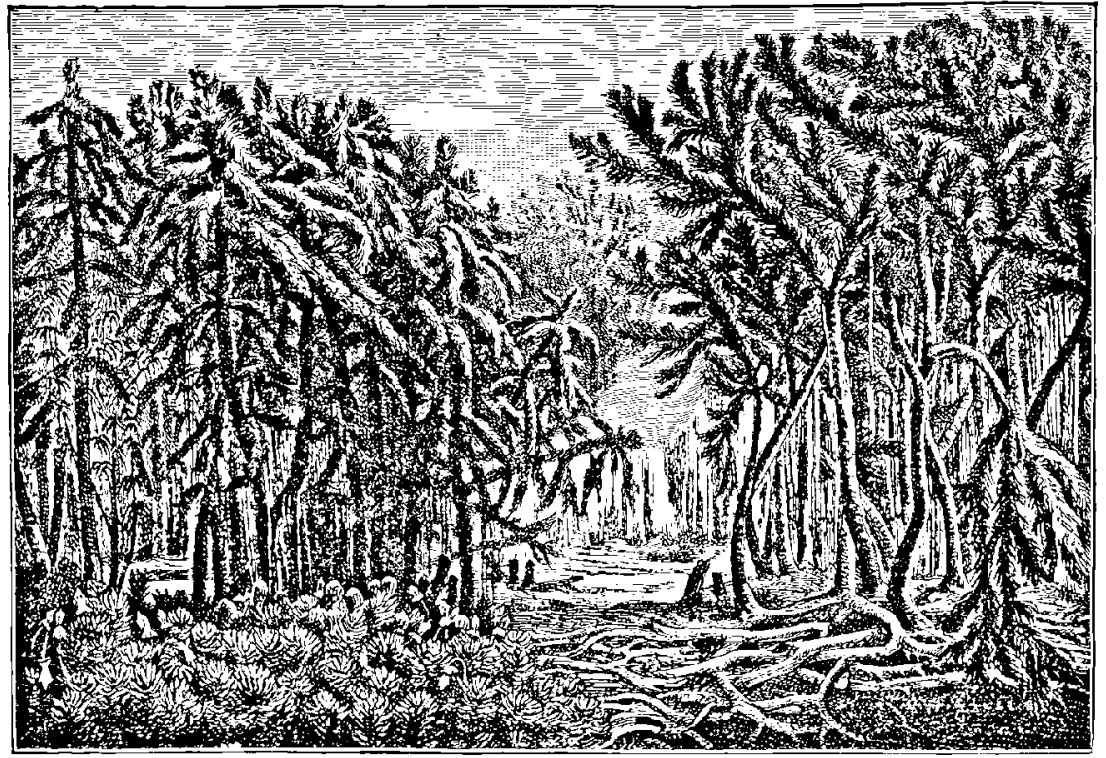

Fig. 199. - Les premières forèts. - Période dévonienne.

pliquée que les lichens, les mousses et les hépatiques, l'équisètacée commence, avec la fougère, le développement du monde végétal. G'est aussi par gradation, comme le règne animal, que le règne végétal se crée. L'ère des cryptogames ouvre la série, pour ètre suivie plus tard par celle des phanérogames, gymnospermes et angiospermes. On a retrouvé parmi les fossiles dévoniens des débris (fg. 195) qui ont appartenu à des équisétacées de dix mètres de hauteur. Ces plantes devaient offrir un aspect analogne à celui de l'equisetum représenté figure 197. Ces premières forêts possédaient,

1. Etymologie: Equus, cheval; sela, soie. 
outre les calamites (fg. 196), espèces de roseaux gigantesques mesurant pluș d'ụn décimètre de diamètre, dont notre figure 198 représente un échantillon fossile, des bornia, des cordaïtes, des antholites, dẹs lycopodiacées, parmi lesquels on doit citer surtout les lépidoden-

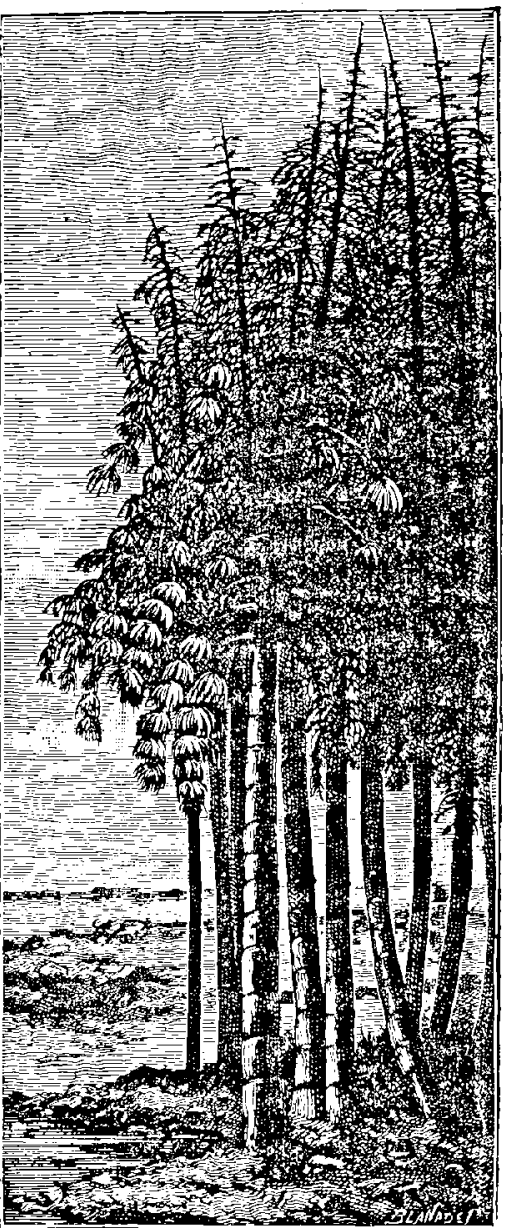

Fig. 200. - Les premiers arbres. Groupe de calamitea. drons qui, pendant la période suivạnte, atteindront vingt-cing et trente mètres de hauteur. Aujourd'hui les lycopodes sont des mousses! On jugera de l'aspect de ces premiers arbres par le groupe de calamites représenté ici $(f g .200)$, ou mieux encore par notre figure précédente (199), dans laquelle on a essayé de rétablir une forèt de cette époque.

Dans ces forêts silencieuses, pas un oiseau, pas un reptile, pas un quadrupède, pas une bête sauvage. Rien de tont cela n'existe encore. Les hôtes des bois sont absents. Cerfs, chevreuils, sangliers, loups, renards ou écureuils; lions, tigres, jaguars, panthères ou chacals; crocodiles, lézards ou grenouilles; aigles, vautours, conḍors, corbeaux, perdrix ou paons; oiseaux chanteurs, rossignols, pinsons ou fauvettes : aucun n'est encore de ce monde. Si l'on entend remuer, c'est quelque scorpion dans les pierres, quelque blatte entre les feuilles ou quelque grillon frottant ses élytres. Quelques insectes, quelques mouches, commencent à bourdonner dans l'atmosphère lourde et orageuse. Mais la vie est encore presque tout entière - dans les eaux, douces et salées. La lumière du jour n'est pas encore intense: le soleil n'est pas encore brillant: il est immense, mais nébuleux; le ciel azuré, lumineux et pur n'existe 
pas encore; la différence entre le jour et la nuit n'est pas considérable, ni sous le rapport de la lumière, ni sous le rapport de la chileur; notre planète ne connaît encore ni les saisons ni les climats.

Le Soleil ne versait pas encore une éblouissante lumière à la surface de la Terre. Autrefois, pendant les âges azoïques - sans vie - ou peut-être même pendant les âges protozaïques au - commencement méme de la vie - lo jour no différait pas de la nuit, quoique la planète tournât déjà sur son axe, parce que la faible lumière émise par la nébuleuse solaire n'arrivait pas jusqu'à la surface de la Terre, et que notre globe, d'ailleurs, resta longtemps lui-même à l'état de soleil, lentement éteint, puis environné de vapeurs absorbantes. Maintenant, à l'époque dévonienne, et même depuis longtemps, dès l'époque silurienne, le jour diffère de la nuit, il y a déjà une certaine lumière : nous le savons par la seule existence des yeux des trilobites, des crustacés, des mollusques ęt des poissons. L'œil ne pourrait pas exister sans la lumière : l'origine meme de l'œil réside dans l'impression lumineuse. Nous pouvons en conclure que certainement la nébulense solaire était alors déjà très condensée.

Mais nous allons étudier cette importante question en arrivan à la splendide période carbonifère. 


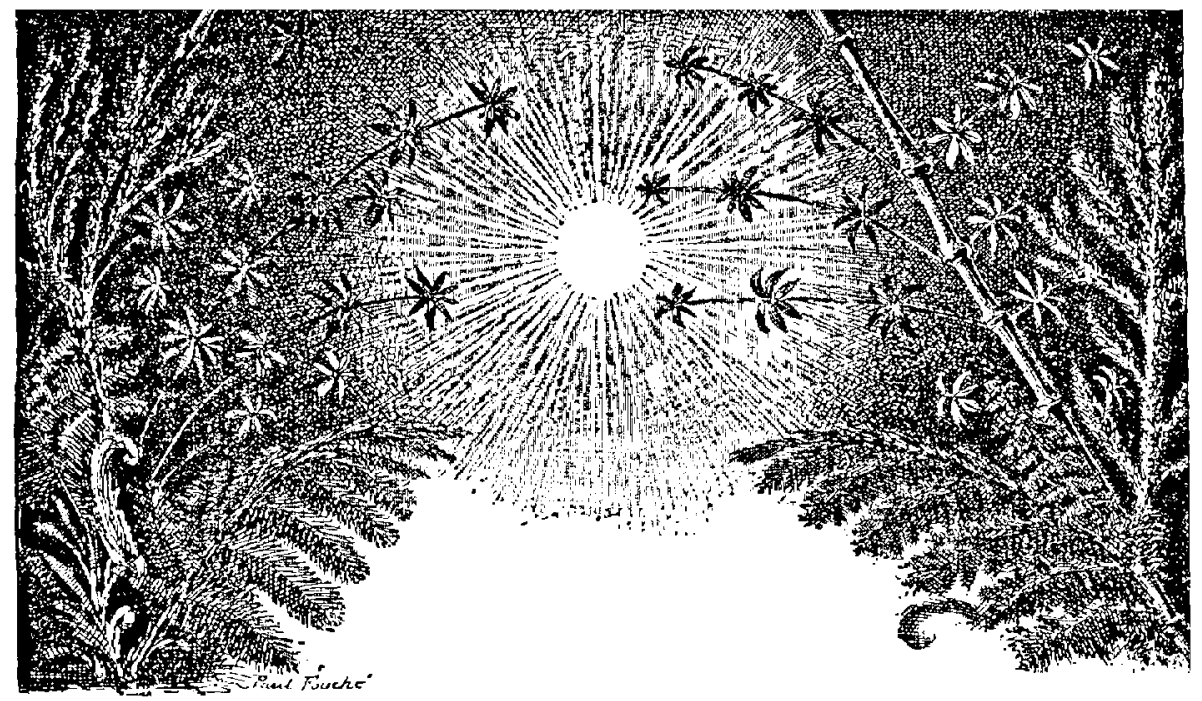

GIIAPITRE IV

LA PÉRIONE GARBONIFÉRE

Développement du règne végétal. - Iles et continents. $\rightarrow$ Climats insulaires. Absence de saisons. - La nébuleuse solaire. - L'atmosphère, la chaleur et l'humidite. - Les plantes et les arbres. - Forèts antiques. Animaux qui los habitaient.

Pas un astre n'est en repos dans l'immense univers; pas un atome n'est arrèté dans le sein du plus dur minéral; pas une molécule n'est inmobile dans le corps d'une plante ou d'un animal; pas un globule de sang ne cesse de circuler dans nos artères; toujour's, en tout et partout, la force invisible et infatigable s'exerce avec une activité perpétuelle; les mondes se transforment; les soleils s'allument et s'éteignent; la Terre où nous sommes varie d'un siècle à l'autre; les êtres qui la peuplent varient corrélativement avec ces conditions mêmes, et, de plus, en vertu de leur propre activité, il n'en pourrait être autremenl, et l'histoire de la T'erre n'est que le tablean de sa transformation perpétuelle.

Les îles qui ont émergé de l'océan universel, pendant les siècles vénérables dont nous venons de nous faire l'historien, ont invité l'activité des premières plantes et des premiers animaux à s'exercer 
en des conditions nouvelles, et nous avons vu des plantes marines devenir plantes d'eau douce, puis s'acclimater à l'atmosphère humide des bas-fonds. C'est le long des rivages qu'elles s'essayent à leur condition nouvelle. Des feuilles poussent qui leur permettront de respirer l'air au lieu de rester immergées ou flottantes. Leurs frères, les animaux marins ou aquatiques, commencent aussi à vivre sous de faibles épaisseurs d'eau ou même au dehors. Des insectes voltigent déjà à la surface des eaux; des blattes, des sauterelles, des grillons, des termites rampent, sautent et se glissent sous les premiers feuillages. L'atmosphère est lourde. C'est presque encore de l'eau. La chaleur est étouffante. Il pleut continuellement.

Quelles précieuses conditions pour le règne végétal! A l'origine de la vie, nous l'avons vu, il n'y avait ni plantes ni animaux, et les conditions vitales de la planète n'eussent permis ni les uns ni les autres: il y avait du protoplasma flottant au sein des eaux, des amibes, des protistes, ancetres des animaux comme des plantes. La vie s'est ensuite bifurquée en deux branches longtemps presque soudées, comme si elles eussent regretté la séparation, mais enfin séparées, qui ont abouti à des ramifications aujourd'hui bien éloignées l'une de l'autre, car une grande distance apparente distingue actuellement, par exemple, le bœuf de l'herbe qu'il broute : pourtant, originairement, ils ont le mème ancêtre, et même pour les yeux de l'analyste ils sont loin d'être aussi différents l'un de l'autre qu'ils le sont pour le pâtre qui conduit le troupeau. Avec les débuts de la période carbonifère, le règne végétal a fait des progrès rapides, grâce aux conditions exceptionnelles de fécondité qui marquèrent cette phase importante de l'histoire de la Terre.

La chaleur intérieure du globe traversait encore l'écorce et entretenait une haute température dans l'atmosphère. Tous ceux qui ont fait l'ascension du Vésuve, de l'Etna ou de quelque volcan savent, il est vrai, qu'une faible épaisseur de scories et de cendres suffit pour intercepter la chaleur, et chacun sait aussi qu'un peu de cendres dans le creux de la main suffit pour permettre d'emporter de l'âtre un charbon ardent sans se brüler. Cependant la chaleur filtre pour ainsi dire par des interstices invisibles. Au mois de décembre 1872, une ascension au Vésuve brúla en partie les semelles de nos chaussures; la chaleur de la cendre était assez 
forte pour faire cuire des œufs; en remuant un peu plus bas à l'aide d'un bâton ferré, on mettait au jour la lave rouge, durcie, mais assez chaude pour y allumer un cigare. Or la température de la lave volcanique ne dépasse pas un millier de degrés; celle du globe primitif devait être au moins neuf ou dix fois plus élevée, car la théorie mécanique de la chaleur enseigne que la seule condensation de toutes les molécules du globe terrestre de l'état nébuleux à l'état de densité actuelle, a dú donner naissance à une chalęur de $89880^{\circ}$, sans compter celle qui a dù être produite par les combinaisons chimiques et les combustions. Par les fissures, par les éruptions, par les dislocations et même à travers l'écorce mince, à peine solidifiée, impréġnée d'eau, cette chaleur intérieure arrivait dans l'atmosphère, qui ne lui permettait pas de rayonner et de se perdre dans l'espace. Le pouvoir absorbant d'une molécule de vapeur' aqueuse est seize mille fois supérieur à celui d'une molécule d'air sec. Nous venons de voir que l'atmosphère était alors imprégnée de vapeurs et que les pluies étaient presque continuelles. Remarquons encore qu'il n'y avait pas de continents, mais seulement des îles, et que la Terre entière jouissait d'un climat marin, sorte d'universel gulf-stream. En de telles conditions, la température de la surface du globe était éminemment appropriée au développement de la végétation primitive, et, de plus, elle était la même aux pôles qu'à l'équateur, puisqu'il n'y avait pas encore de saisons.

Les saisons sont dues, comme nos lecteurs le savent ('), à ce que la Terre tourne autour du Soleil en ayant son axe incliné. Pendant la moitié de l'année un pôle est très penché du côté du Soleil et pendant les six autres mois il est penché du côté opposé. De là résultent les longues nuits d'hiver comme les longs jours d'été, les grands froids polaires, les saisons opposées et disparates (c'est ce dont on se souviendra facilement à l'inspection de notre fig. 201). Les lois de la mécanique céleste établissent que l'inclinaison de l'axe ne varie que de quelques degrés, et que pendant l'époque primaire elle n'était pas très différente de ce qu'elle est de nos jours. D'ailleurs, eût-elle été très différente, si le Soleil avait eu alors comme aujourd'hui une action prépondérante sur la chaleur

1. Astronomie populaire, p. 35, et surtout Les Terres du Ciel, p. 402. 
terrestre, les climats auraient existé : les rayons solaires arrivant perpendiculairement sur les régions équatoriales auraient versé là une chaleur beaucoup plus élevée que sur les régions polaires où ils n'arrivent plus qu'obliquement, en raison de la sphéricité du globe, et ne font que glisser. Or c'est ce que dénie le témoignage des végétaux de l'époque carbonifère. Les mêmes espèces de plantes qui habitaient les régions équatoriales habitaient aussi les régions polaires. On a retrouvé jusqu'au Spitzberg et jusqu'aux plus extrêmes latitudes septentrionales explorées par̀ l'homme (amiral Narès, expédition de 1878 au pôle nord, terre de Grinel, par $82^{\circ} 40^{\prime}$ de lati-

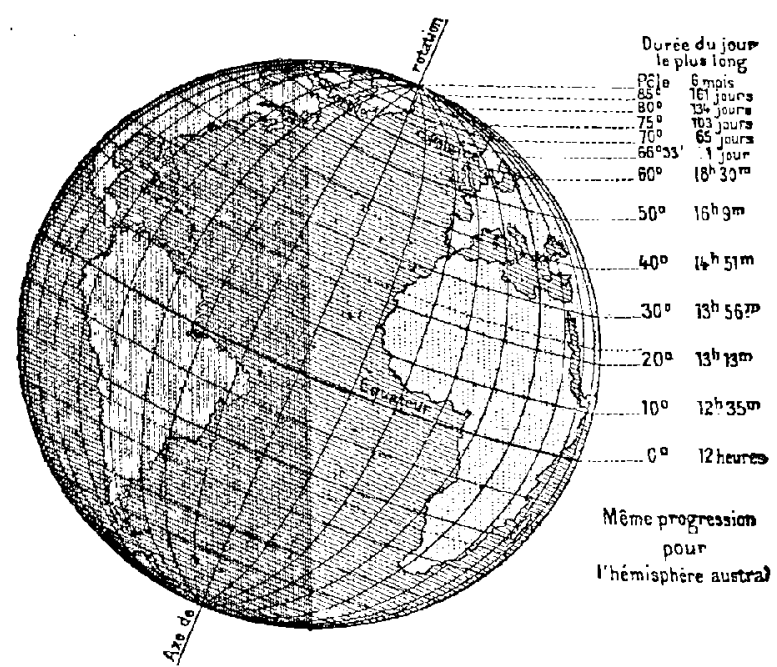

Fig. 202. -- Les saisons sur la Terre. - Position de la Terre au solstice de juin.

tude boréale) le mème calcaire carbonifëre, et jusqu'au $76^{c}$ parallèle les mèmes houilles qu'en France et aux États-Unis, en Chine, dans le bassin du Zambèze (Afrique) et dans l'Amérique du Sud. De plus, la flore terrestre tout entière n'est composée que d'arbres à feuilles persistantes; il n'y a pas encore d'arbres à saisons. Les tiges d'arbres fossiles de cette éporque ne montrent pas les couches concentriques annuelles formées chaque printemps, et par lesquelles on recon11ait l'âge des arbres.

C'est là un fait capital et de la plus haute inportance pour l'histoire de notre planète. On en peut conclure avec certitude qu'à cette époque $i l$ n'y avait pas encore de saisons. Le Soleil n'ajon- 
tait que peu ou point de chaleur à celle de la Terre, car la température à laquelle végètent les fougères arborescentes, les lycopodes, les cycadées, est comprise entre 20 et 25 degrés, et n'était pas plus élevée en Afrique qu'au Spitzberg.

Le Soleil était alors gigantesque, mais encore nébuleux et n'émettant qu'une faible lumière. Que l'anneau cosmique dont la Terre est une condensation globulaire se soit formé dans l'intérieur de la nébuleuse solaire originelle, comme le suppose M. Faye, ou

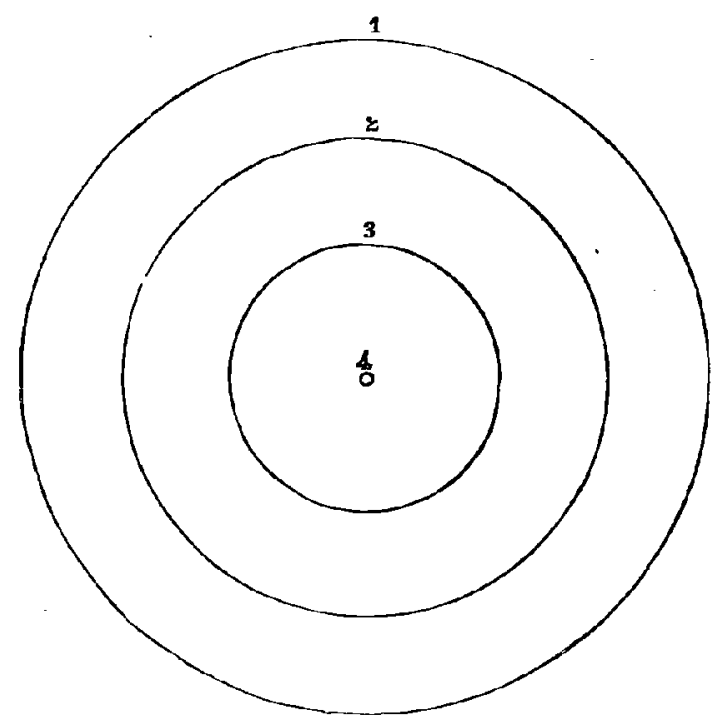

Fig. 203. - Condensation progressive du Soleil à partir de l'orbite de la Terre.

$$
\begin{aligned}
& \text { 1. Orbite de la Terre- Diamètre }=74 \text { millliong do lienas. } \\
& \begin{array}{llll}
\text { 2. Orbite de Vénus. } & \text { Diamètre }=52 & - & - \\
\text { 3. Orbite de Mercura. } & \text { Diamètre }=28 & - & -
\end{array} \\
& \text { 4. Le diancètá actuel du Soleil est de } 345 \text { 500 lieues. } \\
& \text { fCrelles : } 1 \mathrm{~mm}=1 \text { million de lienes. } \\
& \text { (Doublée pour le Soleil.) }
\end{aligned}
$$

à l'extérieur, comme le supposait Laplace, le résultat est le même en ce qui concerne l'immense volume du Soleil pendant les périodes primitives de l'histoire des planètes. L'astre solaire a abandonné la zone de l'orbite terrestre, puisqu'il ne l'atteignait plus, et s'est rétracté graduellernent à travers les orbites de Vénus et de Mercure successivement, à des millions d'années d'intervalles, ses dimensions ont passé par les limites des courbes 1,2 et 3 tracées ci-dessus ( $f g .202$ ), et aujourd'hui elles sont réduites à un point relatif, le diamètre actuel du Soleil n'étant que de 345500 lieues, tandis que celui de 
l'orbite de Mereure est de 28 millions, celui de l'orbite de Vénus de 52, et celui de l'orbite terrestre de 74. Les diamètres des orbites de la Terre, de Vénus et de Mercure, comparés à celui du Soleil pris pour unité, sont entre eux comme les nombres 214, 153, 83 et 1.

Pour se représenter non seulement les dimensions réclles, mais en mème temps les dimensions apparentes du Soleil vu de la Terre aux époques où il remplissait entièrement l'orbite de Vénus ou celle de Mercure, il suffit de reconstruire ici les figures 103 et 152 des

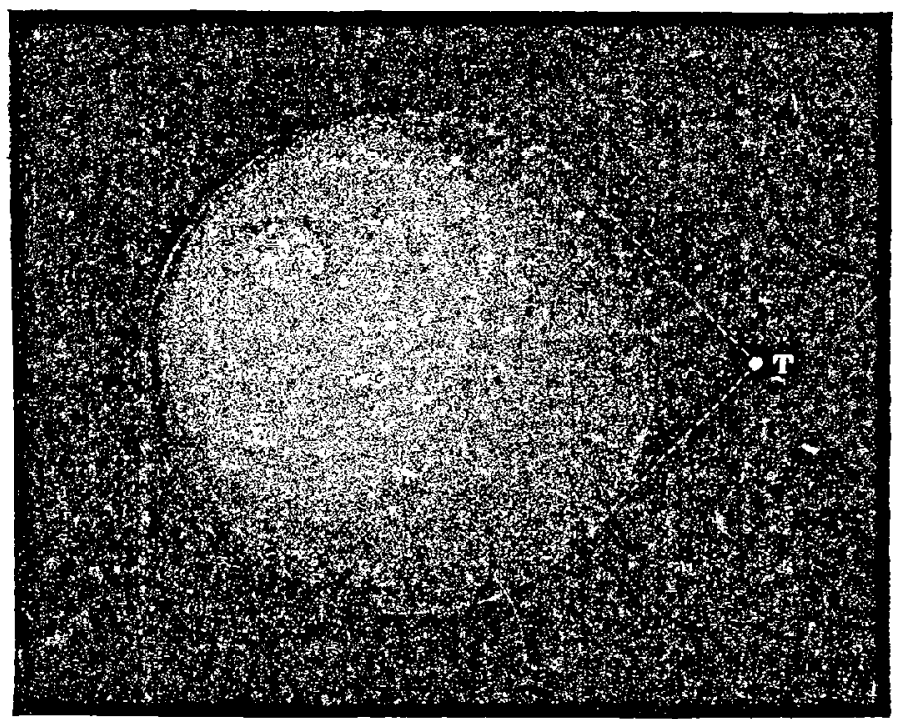

Fig. 204. - La nébuleuse solaire vue de la Terre lorsqu'elle arriva à l'orbite de Vénus.

Terres $d u$ Ciel, en los adaptant à cet aspect spécial de la question. Dans la première (Voy. $f g$. . 203), le disque solaire atteignait la dimension angulaire d'un angle droit; c'est-à-dire qu'il occupait la moitié entière du ciel depuis l'horizon jusqu'au zénith : 90 degrès! soit 169 fois son diamètre actuel. Si, dès cette époque, la phase - Jaire était déjà assez avancée pour donner naissance à une faible lumière, le faisceau conique des rayons solaires dépassait les pôles dans leur position la plus inclinée (solstices), et, par conséquent, la Terre pouvait tourner dans l'illumination solaire en ne subissant qu'une nuit peu étendue et de faible durée. Les pôles étaient éclairés toute l'année aussi bien que l'équateur, et il n'y avait pas de zone glaciale. (Voy. la fig. 204, dans laquelle la Terre est dans la même 
situation que $f g$. . 203, mais agrandie.) La chaleur comme la lumière solaire devaient alors être très faibles; mais la distance du Soleil à la Terre n'était que de onze millions de lieues an lieu de trente-sept (en admettant que l'orbite terrestre fût peu différente en position de ce qu'elle est de nos jours), et comme la chaleur ainsi que la lumière augmentent en raison inverse du carré de la distance, la quantité reçue était beaucoup plus grande que de nos jours relativement à la quantité émise. La cosmogonie primitive de chaque planète est passée par des situations analogues (').

A mosure que la nébuleuse solaire se resserra, le cône des rayons reçus par notre planc̀te s'allongea et la différence s'accentua graduellement entre les pôles et l'équatcur. L'inçlinaison de l'axe de rotation de la Terre étant de $23^{\circ} \frac{1}{2}$, lorsque le disque solaire fut diminué jusqu'à $47^{\circ}$, c'est-à-dire au double de cotte inclinaison, ses rayons atteignaient encore aux solstices la ligne actuelle des cercles polaires, comme l'a fait remarquer M. Blandet, de sorte qu'aucun cercle de latitude n'était exposé à accomplir toute sa rotation diurne dans l'ombre, qu'il'n'y avait pas encore do nuits de vingt-quatre heures pour les pôles et pas encore de zones glaciales (Voy. $f . g .205$ ).

En arrivant à l'orbite de Mercure, la nébuleuse solaire offrait les dimensions représentées figure 206. L'angle soustendu par l'astre immense était encore de 45 degrés, moitié de celui de l'orbite de Vénus, et remplissait encore les conditions requises pour éclairer le globe terrestre jusque près des pôles. A dater de cette époque seulement, l'inclinaison de l'axe de rotation du globe a commencè à agir sensiblement pour la distinction des saisons, si toutefois la chaleur d'origine terrestre ne surpassait pas encore celle d'origine . solaire. Dans cette phase, la Terre était éclairée à peu près comme on vient de le voir dans le diagramme de la figure 205.

L'effet de l'immense disque solaire, vu de la Terre, devait être

1. Grandeurs apparentes de la nébuleuse solaire pendant sa condensation :

Vue de Neptune a l'orbite d'Uranus . . . . . . . . . . . . . . $80^{\circ}$

Vue d'Uranus a l'orbite de Saturne.................. $60^{\circ}$

Vue de Saturne a l'orbite de Jupiter. . . . . . . . . . . . . . 67

Vue de Jupiter aux quatıe condensations puincipales des anneaux d'astérơles $86^{\circ}, 80^{\circ}, 74^{\circ}, 70^{\circ}$

Vue de ces quatre condensations à l'orbite moyenne de Vars. . . . . . . . $31^{\circ}, 59^{\circ}, 69^{\circ}, 80^{\circ}$

Vue de Mars a l'orbite de Ia Terre. . . . . . . . . . . . . $88^{\circ}$

Vue de la Terre à l'orbite de Yénus. . . . . . . . . . . . . . 90

Yue de Vénus à l'orbite moyenne de Norcurc. . . . . . . . . . Găn 
étrange. Car, s'ètendant sur une longueur de 90 degrés, lorsqu'après son lever son bord inférieur touchait encore l'horizon, son bord supérieur atteignait déjà le zénith. En raison de la perspective do la forme surbaissée de la voûte apparente du ciel, e'était le ciel lui-

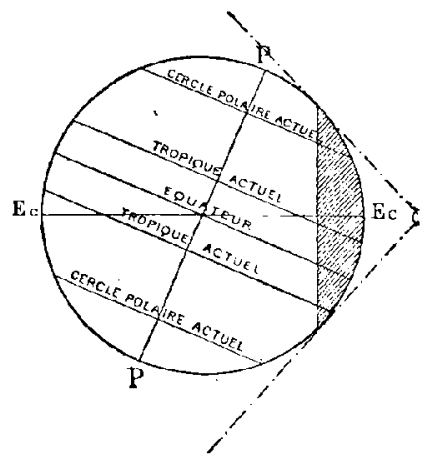

Fig. 203ั. - Éclairement de la Terre â l'époque où la nébuleuse solaire arrivait à l'orbite de Vénus.

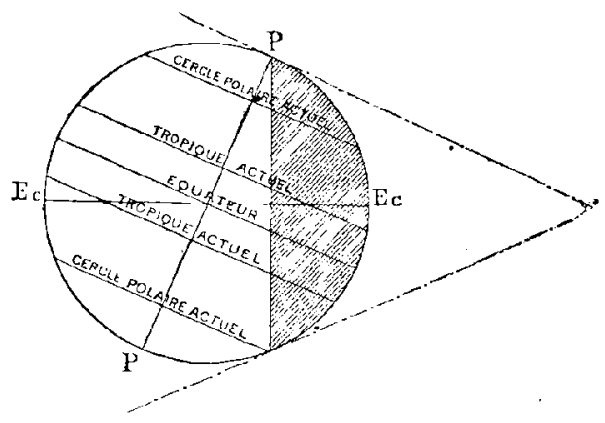

Fig. 206. - Éclairement de la Terre pour un Soleil de $47^{\circ}$

même qui devait sembler fait d'un seul Soleil dans toute sa partie orientale, comme un tiers de four chand et lumineux, les deux autres restant froids et obscurs. Sí, au lieu de la surface du ciel, nous considérions, pour essayer de la représenter par le dessin, une

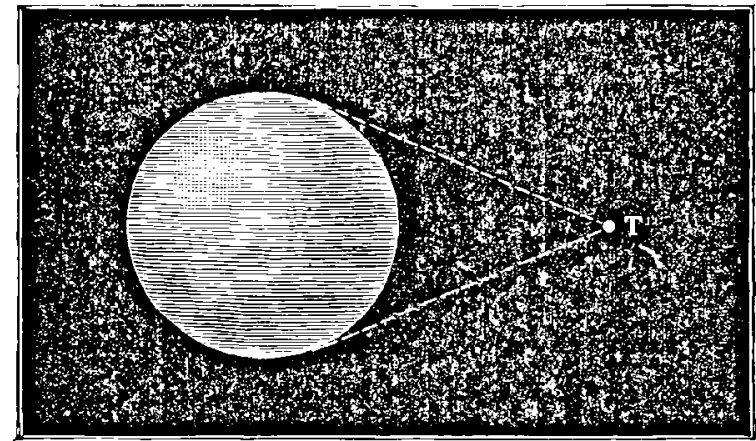

Fig. 207. - La nébuleuse solaire vue de la Terre lorsqu'elle arriva à l'orbite de Mercure.

coupe de ce ciel, nous anrions une voute ( $f g .207$ ) sur laquelle paraitrait glisser une plaque de lumière $a b$, s'étendant de l'horizon jusqu'au zénith, au milieu de la matinée, et planant à midi comme un cercle immense sur tout le sommet du ciel. Si faible qu'ait èté le rayonnement calorifique et lumineux de cet astre immense, il 
u'a pu manquer, par sa constance et par sa durée, d'avoir une action puissante sur le développement de la végétation des premiers âges.

Les deux causes ont agi on mème temps. D'une part, la chaleur intérieure du globe a cntretenu une haute température dans l'atmosphère ambiante jusqu'à l'époque où l'écorce devint assez épaisse pour òtre imperméable à cette chaleur, comme elle l'est depuis longtemps; d'autre part, le Soleil, en se condensant, a éclairé une surface de plus en plus petite, jusqu’à ce que ses rayons devinssent presque parallèles et n'éclairassent plus qu'un seul hémisphère. Nous disons presque, parce qu'ils ne le sont pas encore et ne le seront du reste jamais. Lo Soleil étant 108 fois plus large que la Terre, en diamètre, le faisceau des rayons qui arrivent à notre planète a la forme d'un cône, et l'ombre de la Terre dans l'espace finit en pointe à la distance de 1380000 kilomètres en moyenne. L? réfraction de l'atmosphère allonge encore l'éclairement à l'avantage de l'hémisphère obscur. Mais, néanmoins, dès l'origine de la radiation solaire, la quantité reçue par la Terre a été plus grande à l'équateur qu'aux pôles, et climats et saisons ont eu une tendance de plus en plus marquée à se constituer d'âge en âge. Puisque, pendant l'époque primaire, les végétaux disséminés sur toute la surface du globe n'indiquent aucune trace de saisons et témoignent d'une température uniforme de $25^{\circ}$ a $30^{\circ}$ sur le globe entier, nous devons en conclure qu'à cette époque la chaleur terrestre était encore de beaucoup prédominante sur la chaleur recue di Soleil.

Il y a huit ou dix millions d'années, vers le milieu de l'époque primaire, les conditions de stabilité du système du monde n'étaient pas absolument les mèmes que de nos jours. Le Soleil était plus voluminenx, son centre de gravité, ainsi que celui du système solaire, occupaient des situations géométriques différentes des positions modernes, et peut-être aussi, en vertu de la translation séculaire dans l'espace, le système solaire était-il soumis à des influences stellaires différentes de l'état de choses actuel. Il n'est pas démontré que l'ohliquité de l'écliptique ait été la même que de nos jours, ni que le pôle géographique ne change pas de place à la surface du globe dans un intervalle de temps aussi considérable (des expériences récentes sembleraient conduire à la conclusion contraire), ni que 
la variation séculaire de l'excentricité de l'orbite terrestre (') ne surpasse pas les limites calculées et ne détermine pas des effets plus sensibles sur les saisons; et l'on ne peut pas assurer non plus que le jeu des forces intéricures en action dans le sein du globe terrestre, aidé par les marées luni-solaires ou mème par des attractions extérieures, ne puisse faire varier les positions de l'axe du monde. Tout change ( $\left.{ }^{2}\right)$, dans l'ordre cosmique aussi bien que dans l'ordre terrestre individuel. Loin donc d'éprouver la moindre difficulté à admettre

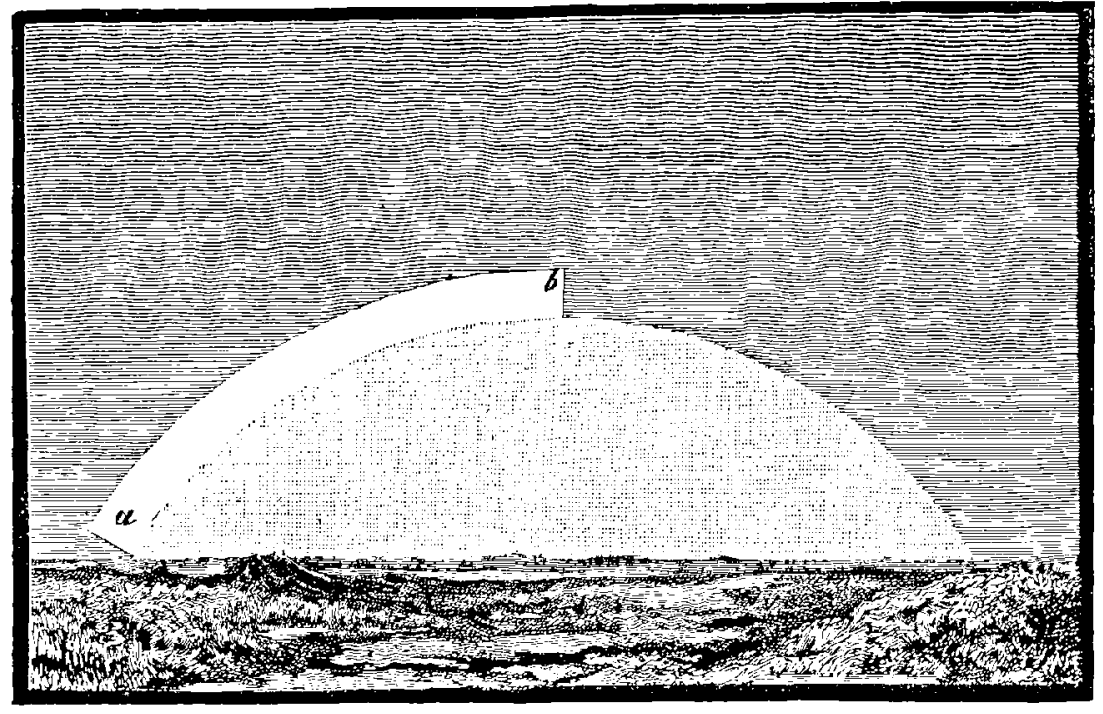

Fig. 208. - Étendue du Solell sur le firmament, lorsqưil atteignait l'orbite de Vénus.

pour ces époques reculées une terre différente de celle que nous lıabitons aujourd'hui, nous devons être tout disposés à concevoir qu'il n'en pouvait ètre autrement.

L'important pour nous est de retrouver les phases réelles de l'antique histoire du monde. Or, l'astronomie, la géologie et la paléontologie s'accordent pour nous apprendre que les saisons n'ont commencé que fort tard dans la vie terrestre, et que pendant les temps primitifs les climats étaient les mêmes aux pôles qu'à l'équateur. Et comme nous venons de le voir, non seulement ces sciences

1. Voy. cette variation pour deux cent mille ans dans notre ouvrage Les Étoiles et les Curiosites du Ciel, p. 773.

2. Voy. l'exposition des dix principaux mouvements de la Terre dahs Les Terres du Ciel, liv. IV, ch. ler. 
nous apprennent qu'il en a été ainsi, mais encore clles nous expliquent pourquoi.

Atmosphère épaisse, lourde, pluvieuse; température uniforme, constante, chaude; marées considérables; éruptions du feu intérieur; orages fréquents; tempètes formidables; l'aspect de la Terre était bien différent de celui de notre époque. Les témoins de cette primitive nature seront des êtres grossiers, énormes, puissants, dans le scin desquels s'ébaucheront les perfectionnements des âges futurs.

Simples, sans ornements, sans fleurs, sans parfums, les plantes vont absorber cette atmosphère nutritive, grandir sans bornes, atteindre des proportions géantes. Le Soleil n'a pas d'éclat; les oiseaux ne chantent pas encore; un morne silence enveloppe la terre; les insectes seulement bourdonnent et se multiplient dans l'ombre épaisse des forêts grandissantes, forêts immenses dont rien n'arrêtera l'extension: elles vont pour la première fois vêtir la planète d'un inextricable tapis de verdure, depuis l'équateur jusqu'aux pôles. Nul prophète ne saurait deviner l'existence future des déserts de glace ou des neiges éternelles qui, sur les montagnes comme aux régions polaires, feront dans l'avenir reculer la vie en lui imposant des bornes infranchissables.

Si l'on se transporte par l'imagination dans ces vastes solitudes primitives, on est saisi d'un sentiment indéfinissable en présence de l'invariable monotonie des formes. L'absence totale de fleurs et d'animaux supérieurs devait contribuer à jeter sur la nature un voile d'universelle tristesse; pas un seul oiseau n'égayait la forèt, dont les profondeurs n'étaient visitées par aucun mammifère. L'air embrasé était rempli de vapeurs suffocantes s'échappant du sol, et le silence de la nature n'était troublé que par le bruit de la pluie, le fracas et les sifflements du vent à travers les arbres! La Terre était encore probablement couverte d'épaisses nuées provenant de la haute température du sol, qui réduisait en vapeur beaucoup plus d'eau qu'aujourd'hui; le climat de la planète ne dépendait pas seulement du Soleil, mais bien aussi de la chaleur même du globe, comme le prouve la présence des mêmes formes de plantes jusqu'à l'extrème nord.

Les naturalistes suédois Nordenskioeld et Malmgren ont décou- 
vert, pendant l'été de 1868 , à Bären-Insel $\left(74^{\circ} 30^{\prime}\right.$ lat. nord), dans les houilles et les roches immédiates, dix-huit espèces de plantes dont quinze sont identiques à celles des couches les plus inférieures des gisements carbonifères. Cette ancienne flore houillère de Bären-Insel a de grands caractères identiques à ceux de la flore des Vosges et de la Forèt-Noire. Ce sont d'abondants Lepidodendrons. A l'ombre de ces arbres vivaient des fougères à grandes feuilles (Cardiopteris frondosa et polymorpha). La flore des îles Parry paraît avoir eu le même aspect; on y a découvert de nombreux gisenients de charbon, et, parmi les végétaux qu'on y a constatés, se trouve le Knorria acicularis de l'île Melville (baie de Bridport, $70^{\circ}$ lat. nord); elle a été signalée aussi à Bären-Insel, et se rencontre dans les houilles de Silésie.

La faune marine arctique a le même caractère. Ce sont de nomhreuses espèces de mollusques provenant de la mer de l'époque houillère de la zone arctique, et qui se rencontrent dans la môme formation en Europe; quelques-unes mème ont été trouvées sous les tropiques. Ainsi on a recueilli le Spirifer Keillshavii à Bären-Insel, au Spitzberg, dans le Nord-Albert-Land, à Petschora, et ailleurs dans l'Inde; le Productus costatus au Spitzberg, en Russie, en Angleterre, dans le noord de l'Amérique, dans l'Inde et en Australie; le Productus Humboldtii, au Spitzberg, en Russie et dan's le sud de l'Amérique. Il en est de même du Productus sulcatus qui a été observé à Melville-Insel, à $76^{\circ}$ nord, et du Spirifer cristatus trouvé au Spitzberg, et qui a une vaste aera. Outre ces mollusques, le Spitzberg fournit des coraux qu'on rencontre à Klaas-Billen Bay ( $78^{\circ} 40^{\prime}$ lat. nord), dans de grands blocs calcaires.

Tout nous prouve qu'alors la chaleur prépondérante sur la Terre n'était pas comme aujourd'hui celle du Soleil.

La zone polaire devail jouir d'une température bien plus élevée qu'actuellement; comme nous l'avons vu, la présence des mêmes espèces sous les latitudes de $40^{\circ}$ ¿ $76^{\circ}$ nord permet de conclure qu'il y avait une grande égalité dans la température du globe. D'autre part, le caractère universel de la flore houillère révèle un sol marécageux et une atmosphère chargée de vapeurs; or, e'est seulement dans les parages humides des tropiques que se rencontrent aujourd'hui des formes de végétaux qui s'en rapprochent. 
On doit remarquerque les fougères et les Lycopodiacées de nos jours croissent le plus souvent sous l'ombre épaisse des forèts, et qu'elles demandent biens moins que les Phanérogames l'action directe des rayons du Soleil. C'était, sans nul doute, le cas pour leurs ancêtres primitifs; et comme elles forment la grande majorité des plantes de la flore houillère, nous comprenons qu'elles aient pu vivre et prospérer sous un ciel toujours couvert. Il en est de mème pour les quelques insectes connus de cette époque, car ils sont, pour la plupart, nocturnes, tels que les termites et les blattes (').

Cette uniformité générale de la température est encore démontrée par cet autre fait que l'on a retrouvé jusque dans les régions arctiques, notamment près de la Pointe-Barrow, le grand polypier constructeur lithostrotion; ce qui prouve qu'en ces temps reculés la mer aretique était une mer à coraux et que jamais la température n'y descendait au-dessous de $+20^{\circ}$.

La pensée n'a qu'à se laisser emporter à travers un lointain aussi reculé, dirons-nous avec M. de Saporta; elle contemplera des plages basses, au sol mouvant et imbibé, à peine assez élevè pour former aux flots de la mer l'accès des lagunes intérieures, dominées par des hauteurs peu hardies et souvent voilées par une brume épaisse, se prolongeant à perte de vue et ceignant d'une verdure épaisse une nappe dormante aux contours indécis. Ce fut là le berceau des houillères; des myriades de ruisseaux limpides, alimentés par des pluies intarissables, se déversaient des pentes voisines et des vallées supérieures, comme autant d'affluents de chacun de ces bassins. Si l'on avait longtemps vécu sur leurs bords, on aurait vu, par une sorte de roulement, non exempt de monotonie, les fougères ou les calamariées, les lépidodendrées, les sigillariées et les cordaïtées se succéder ou s'associer dans des proportions très diverses. On aurait remarqué dans le port raide et nu des calamites, dans la. tenue en colonne des sigillaires, dans l'inextricable lacis des fougères entremèlées, bien des sujets d'étonnement; mais la grâce infinie des fougères arborescentes avec leur couronne de feuilles géantes; la beauté régulière des lépidodendrons, la souplesse et la légèreté des astérophyllites; le jeu d'une lumière caressante, tami-

1. Oswild Hark, Le Monde primilif de la Suisse. 


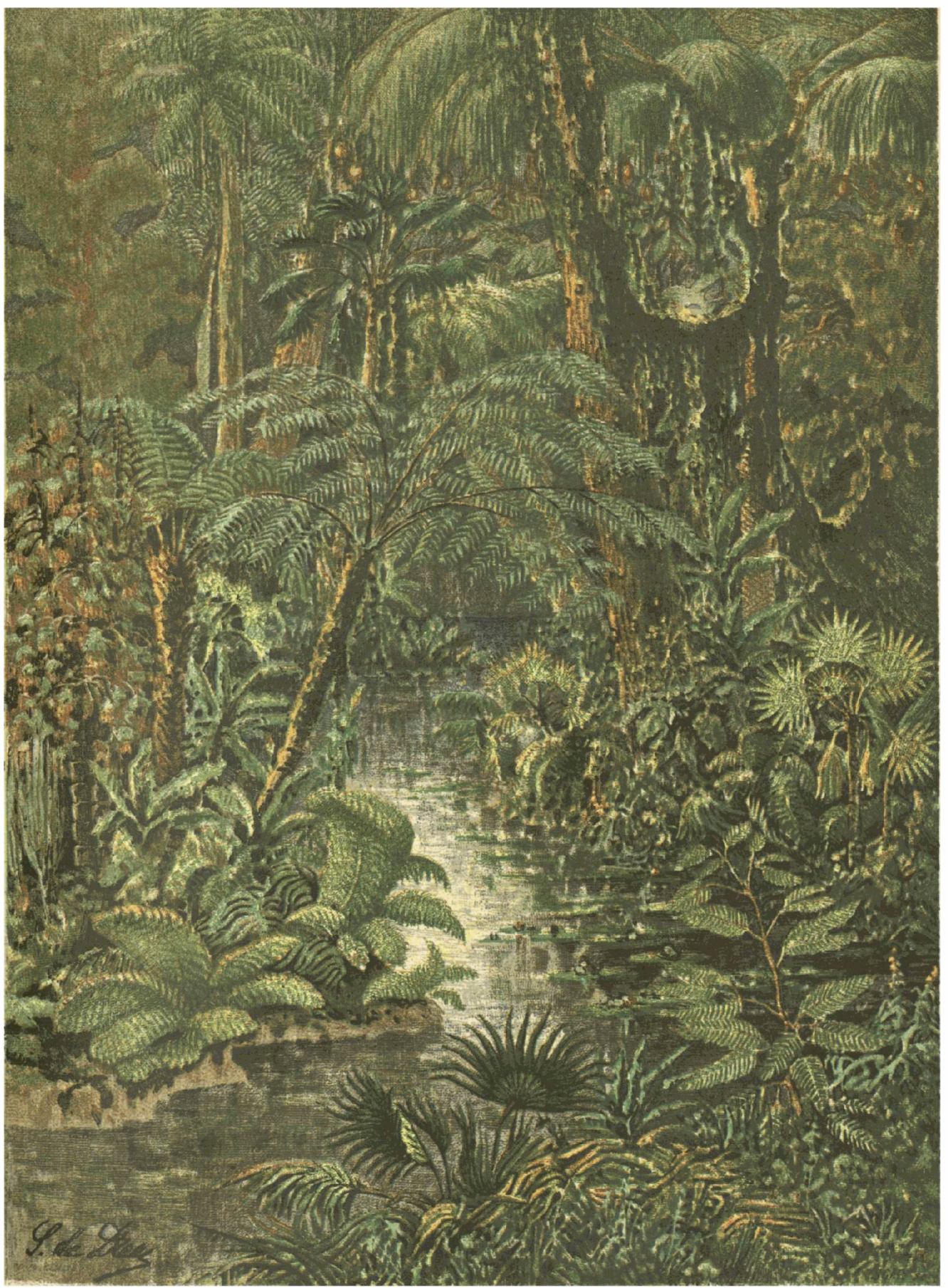

Cbromotypograplie Suas.

\section{PAYSAGE ANTÉDILUVIEN}

UNE FORETT DE L'ÉPOQUE GARBUNIFĖRE 
IRIS - LILLIAD - Université Lille 1 
sée à travers des ombrages si pleins d'opposition, auraient amené une surprise dont aucun spectacle terrestre ne saurait de nos jours donner l'idée. Pourtant, un contraste, qu'il faut bien sigualer, scrait de nature à détourner l'esprit de son enchantement, et l'admiration excitée par la vue de tant de merveilles ne serait pas exempte de tristesse. Adolphe Brongniart, un de ceux qui ont le plus contribué à dévoiler cette surprenante époque des houilles, n'a pas manqué de faire ressortir ce que l'aspect des paysages d'alors avait de morne et de dur. Parmi ces tiges de calamites, de lépidodendrons, de sigillaires, érigées avec tant de raideur, divisées, suivant des lois

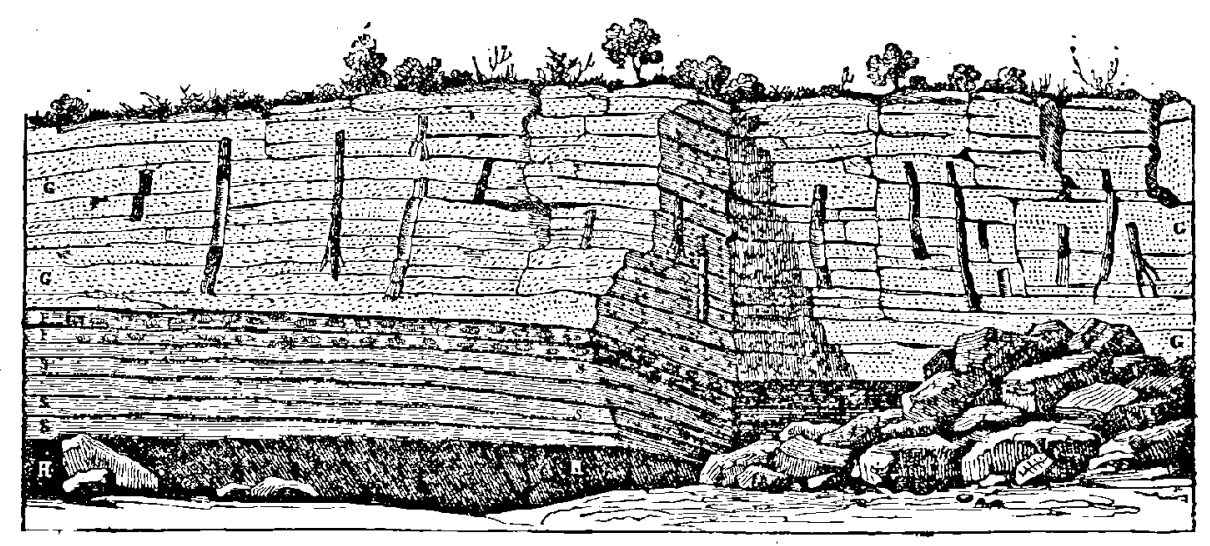

rig. 2uy. - Arbres fossiles trouvés debout dans les houillè'es des mines de Saint-Etienme.

presque mathématiques, dont les feuilles pointues ou coriaces se dressent de toutes parts, aucune fleur ne se montrait encore. Les organes sexuels étaient réduits aux seules parties indispensables; privés d'éclat, ils ne se cachaient sous aucune enveloppe ou s'entouraient d'écailles insignifiantes. La nature, devenue peu ḋ peu opulente, a rougi plus tard de sa nudité; elle s'est tissé des vêtements de noce : pour cela, elle a su assouplir les feuilles les plus voisines des organes fondamentaux, elle les a transformées en pétales; elle en a varié la forme, l'aspect, le coloris. En compliquant ainsi des appareils d'abord réduits aux seules parties les plus essentielles, elle a créé la fleur, comme la civilisation a créé le luxe, en le faisant sortir peu à peu des nécessités de l'existence améliorée et embellie.

On pense depuis longtemps, et malgré certaines objections nous LE MONDE AYAXT La CREATION DE' L'HOMUE

$5: 2$ 
pouvons continuer d'admettre que l'atmosphère de l'époque houillère ètait très chargíe d'acide carbonique et que cette époque doit toujours être considérée comme celle de la purification de l'atmosphère. Celle-ci a cédé son excès de carbone à une puissante végétation, développée, sur les premiers continents définitivement émergés, à la faveur d'une température tropicale et d'une lumière abondante, quoique diffuse. Dans les conditions ordinaires, ces plantes, en se décomposant, eussent restitué à l'atmosphère l'acide carbonique qu'elles lui avaient enlevé. Mais les débris végétaux étaient, au fur et à mesure de leur chute, enfouis sous l'eau et la vase, et leur transformation lente, opérée à l'abri de l'air, maintenait dans la houillo qui en résultait la presque totalité du carbone. En même temps, des masses considérables de calcaire se déposaient dans les régions pélagiques, fixant une quantité correspondante d'acide carbonique. On comprend dès lors que le changement incessant dans la composition du milieu ambiant et, sans doute aussi, dans le mode de transmission de la lumière, ait pu influer constamment sur la végétation terrestre et que celle-ci ait reflété, par la rapide succession de ses types, les phases diverses do la transformation atmosphérique.

De ce que les conditions physiques de l'époque houillère ont été les mêmes sur tout le globe, il ne s'ensuit pas qu'on doive s'attendre à rencontrer de la houille sous toutes les latitudes. En effet, nous avons vu que les plus grandes accumulations de matières végétales s'étaient faites sur le bord des continents existants à l'intérieur desquels le combustible minéral ne pouvait se former que dans des dépressions assez circonscrites. Le pourtour des continents de l'époque houillère définit donc les espaces où l'on peut aujourd'hui s'attendre à rencontrer du charbon de terre en gisements étendus. Au delà des lagunes, dans la direction du large, il devait se faire exclusivement des dépôts calcaires, comme le calcaire carbonifère et le calcaire a fusulines.

Cela posé, les faits observés permettent de croire qu'une mer immense s'étendait, à l'époque houillère, au nord du $76^{\circ}$ parallèle ('). Ce u'est qu'au sud de cette limite, dans les îles de Melville,

I. De Laprarent, Traité de Géologie. 
Bathurst et Prince Patrick, qu'on commence à observer les dépòts de houille. On n'en rencontre pas non plus dans les régions tropicales de l'hèmisphère nord, sans doute immergées à cette époque. D'après cela, une zone s'étendant de l'est à l'ouest sur toute la Terre, mais limitée au sud par le $40^{\circ}$ et au nord par le $76^{e}$ parallèle, embrasserait assez exactement toutes les régions de l'hémisphère borèal pourvues de combustible permo-carbonifère. Mais les choses paraissent s'être passées difléremment sur l'hémisphère austral, où les dépôts du Zambèze sont sitnès sous le $16^{e}$ degré de latitude, ceux de l'Australie s'étendant de $25^{\circ}$ à $35^{\circ}$ de latitude sud. Ainsi l'on peut croire qu'à l'époque houillère, comme aujourd'hui, les terres australes étaient a la fois moins étendues et plus rapprochées de l'équateur que les terres boréales (').

Le terrain carbonifẻre comprend une puissante série de dépôts, atteignant, dans certaines régions, dix et même douze mille mètres d'épaisseur, où prédominent, avec la houille, des grès et des conglomèrats souvent fort épais, accompagnés des schistes argileux au sein desquels sont conservés, à l'état d'empreintes, les débris de la végélation carbonifère; à de nombreuses reprises, au milieu de ces roches arénacées et schisteuses qui représentent les dépôts effectués dans les lagunes et les bassins lacustres houillers, viennent s'intercaler des bancs de calcaire, où se trouve concentrée la faune marine de l'époque. On compte parfois une centaine de couches de houille en supcrposition régulière le long d'une seule verticale.

Ce terrain représente donc une époque de longue durée pendant laquelle les principales modifications ont porté surtout sur la flore terrestre. C'est donc à cette flore qu'il faut s'adresser pour établir des divisions dans cet ensemble.

L'étude des bassins houillers européens ayant révélé l'existence de trois flores successives, l'époque carbonifère a pu ètre divisée de la sorte en trois parties, caractérisées chacune par une flore spéciale :

I. - La première phase dans le développement de cette flore remarquable est marquée par la prédominance des lycopodiacées

1. Dr Saporta, Le Monde des plantes 
(Lépidodendrons) et des fougères herbacées au feuillage découpé (Sphénoptéris).

II. - La seconde par celle des sigillaires et des calamites associées à de grandes fougères arhorescentes (Pécoptéris).

III. - Dans la troisième phase, la prépondérance appartient aux fougères, aux cordaïtes ainsi qu'aux plantes verticillées de marais (Annularia).

C'est également, dans cette troisième phase, qu'apparaissent les walchia, qui prédomineront plus tard dans les forêts permiennes.

Considérée au point de vue des manifestations de l'activité interne du globe, l'époque carbonifère a été marquée encore par une fait important. En France, dans toutes les régions, telles que la Bretagne, les Vosges, le Plateau central, le massif des Maures et de l'Esterel, qui avaient toujours été le siège favori des éruptions, le sol s'est entr'ouvert, à diverses reprises, et a livré passage aux roches porphyriques; aux roches granitoüdes essentiellement cristallines, dont les émissions s'étaient poursuivies avec les diorites jusqu'au sommet du dévonien, ont ainsi succédé des roches présentant leurs éléments cristallins, non plus soudés entre eux et solidement agrégès par simple juxtaposition, mais disséminés dans une pâte d'apparence compacte, qui ne comprend plus de cristaux nettement spécifiés. Ce fait est général et s'est étendu à tout le globe. C'est là l'indice certain d'un ralentissement marqué dans la puissance chimique déployée jusque-là par le foyer interne pour la formation des roches éruptives (').

Mais pénétrons un instant dans l'étude spéciale des mines de houille.

La houille est le produit d'une accumulation de matières végétales décomposées et transformées. On retrouve en elle les débris, les restes, les tiges, les feuilles, les empreintes, des arbres de ces forèts antiques. Chimiquement analysée, elle se montre composée de carbone, d'hydrogène et d'oxygène, c'est-à-dire des substances constitutives des tissus végétaux. En movenne, la houille renferme 83 p. 100 de carbone, 6 p. 100 d'hydrogène, $51 / 2$ p. 100 d'oxygène, plus des traces d'azote et de soufre. Certains morceaux d'anthracite ont donné jusqu'au 95 p. 100 de carbone.

1. Chr. VILAIN. Géologie stratigraphique. 
On peut dire littéralement que la chaleur qui chauffe les locomotives venant du carbone fixé dans les forèts de l'époque primaire n'est autre que la chaleur primitive du globe et la chaleur solaire elle-mème. Cette antique chaleur était emmagasinée dans les houillères : nous la remettons aujourd'hui en liberté en utilisant sa

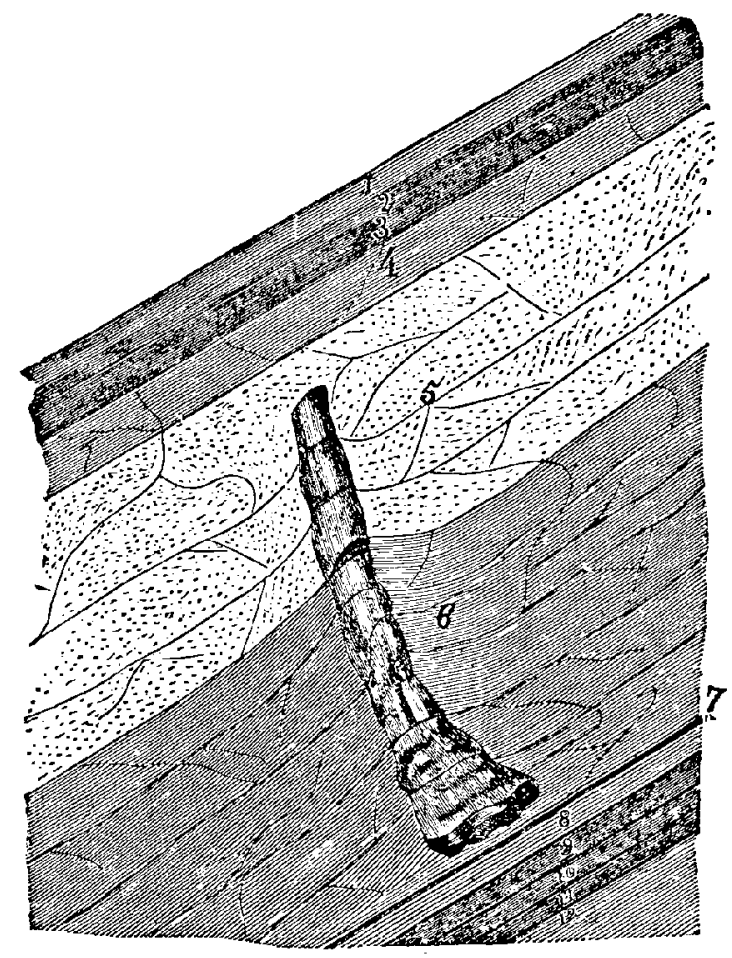

Fig. 210. - Arbre fossile trouvé à 217 mètres de profondeur (Mines dAnzin).

force sous une autre forme, et nous rendons à la nature les réscrves qu'elle avait conservées.

Ces forèts de la période carbonifère ont-elles été ensevelies sur place? Comme on voit, de nos jours encore, la tourbe se former dans les marais, la houille serait-elle de la tourbe primitive, opulente, épaisse, serrée sous les couches ultérieures de sédiment, et pétrifièe? Ou bien est-elle formée de résiđus végétaux entraînés par les eaux et déposés an fond des bassins? La seconde théoric a été la première imaginée par les géologues; elle a été ensuite détrônée par sa rivale, lorsqu'on eut découvert des arbres presque fossilisés 
debout; puis, depuis quelques années, surfout depuis les travaux spéciaux de MM. Grand'Eury et Fayol, elle a reconquis la faveur générale, parce qu'elle explique mieux l'ensemble des fäits observés.

Dans l'ouvrage capital d'Élie de Beaumont sur la Carte géologique de la France, on remarque notamment (Tome I, p. 510 et 763) les deux dessins caractéristiques que nous avons reproduit plus haut ( $f g .209$ et 210) et qui représentent, le premier, les arbres fossiles de la carrière du Treuil, terrain houiller de Saint-Titienne, et le second l'un des plus beaux arbres fossiles trouvés dans les mines d'Anzin. Ces arbres fossiles sont perpendiculaires au sol des couches, e'est-à-dire dans la position naturelle de leur vie vègétale, et ont suhi l'inclinaison de cos mêmes couches, géologiquement soulevées. On remarque que les couches de grès, qui se sont successivement déposées horizontalement en enterrant ces arbres, sont relevées autour de ces tiges, comme du sable qui s'amoncelle autour d'un pieu. Ces arbres fossiles sont surtout des calamites; on ne leur retrouve pas de racines, et ils se montrent cassés en haut comme en bas. Celui des mines d'Anzin mesurait cinq mètres de hauteur (l'échelle de la figure est de 1 centimètre pour un mètre), $1^{\mathrm{m}}, 13$ de diamètre à la base, et encore $0^{\mathrm{m}}, 40 \mathrm{a}$ son extrémité supérieure. Il a èté trouvé, en 1836, à 217 mètres audessous de la surface dı sol et à 140 mètres au-dessous de la surface supérieure du terrain houiller. On a trouvé plusieurs spécimens non moins remarquables, dont plusieurs ont été conservés (et peuvent se voir à l'entrẻe du musée de Valenciennes).

Lorsque Alexandre Brongniart mit en évidence les arbres fossiles des mines de Saint-Ettienne, il crut retrouver.là « une véritahle forêt fossile de végétaux monocotylédons, d'apparence de bambous ou de grands équisetums comme pétrifiés sur place. "Élie de Beaumont et Dufrénoy écrivaient à ce propos : "Les galets nombreux qui entrent dans la composition des terrains houillers, les grès qui en constituent les principales couches, font généralement regarder les terrains houillers comme formés à la manière des terrains de transport; et on a supposé que la houille elle-même est, dans le plus grand nombre de cas, le produit de l'accumulation de végétaux transportés et enfouis. Cette théorie de la formation des terrains houillers, en apparence si naturelle, est loin cependant 
d'expliquer la plupart des phénamènes qu'ils présentent. On remarque que les arbres fossiles traversent les différents strates dont se compose l'assise du grès. Souvent mème ces surfaces de séparation sont marquées par un glissement horizontal, peu étendu il est vrai, mais suffisant pour rompre, dans plusieurs points, la continuité de ces tiges, en sorte que les parties supérieures sont comme rejetées de côté et ne font plus suite aux inférieures.

« La disposition singulière de ces arbres au milieu du grès fait naturellement supposer qu'ils ont été enfouis sur place et sans changer de position; mais comment ces arbres ont-ils pu croitre, tandis qu'il se formait un dépôt qui les enfouissait graduellement? Peut-être le sol a-t-il été soumis à un enfoncement progressif qui, en abaissant la base de ces végétaux aussitôt qu'elle était entourée par les matières charriées, les a, pour ainsi dire, fossilisécs au fur et à mesure de leur croissance.

" Cette circonstance, jointe à la presque impossibilité de concevoir des transports de bois assez épais pour produire, par leur décomposition, une couche de houille, nous conduit à admettre que, dans la plupart des cas, les houilles ont été formées sur place par l'enfouissement successif de végétaux qui recouvraient le sol houiller, et qui se sont succédé, suivant les phénomènes naturels de la vie, d'une manière assez analogue à ce qui se passe dans les tourbières. "

Et plus loin, comparant l'un des arbres fossiles d'Anzin à la houille enviromnante, les éminents géologues ajoutent : "Les fissures qui séparent, les unes des autres, les diverses assises d'argile schisteuse, coupent l'arbre transversalement; c'est dans ces partios qu'il s'est détaché en sections cylindriques. Il était placé perpendiculairement aux bancs de l'argile schisteuse, qui sont inclinés de $33^{\circ}$ vers le sud. La partie qui a dù contenir les racines était dirigée en bas et placée à 1 mètre au-dessus de la veine-boulangère. Les diverses assises du schiste offrent, à son approche, une légère courbure qui se relève vers le haut, comme si la matière, encore molle, avait subi, en se solidifiant, un retrait ou un tassement qui n'aurait pu se faire près de l'arbre aussi aisément qu'ailleurs.

« L'intérieur de ce fossile est rempli d'une matière analogue à 
celle des couches environnantes, disposées en couches parallèles, mais concaves, qui se relèvent du centre vers la circonférence; ce qui peut faire présumer que ce fossile était creux, et que la matière introduite dans son intérieur y aura éprouvé un tassement comme à l'extérieur. Le remplissage extérieur de la tige est séparé du schiste qui l'environne par une pellicule de charbon de cinq millimètres d'épaisseur, colorée de diverses nuances qui paraissent dues à la présence de sulfures d'oxydes métalliques et de carbonate de chaux. Cette couche de charbon semble avoir été seule douée de végétation. La matière schisteuse, tant extérieure qu'intérieure, qui est en contact avec elle, a conservé l'empreinte de sa configuration, qui diffère, par les dessins qu'on y remarque, de l'arbre de la fosse de Bleuse-Borne.

" Cette pellicule de houille est évidemment la matière mème du végćtal, qui était presque creux ou rempli intérieurement d'un tissu lâche, très spongieux et très facilement destructible, comme le sont de nos jours beaucoup de grands végétaux des contrées tropicales. La matière plus solide de l'enveloppe extérieure s'est sans doute transformée en houille par une élaboration très lente qu'elle a subie dans le sein de la terre. La houille qui compose les couches, et qui est presque entièrement identique avec celle de ces pellicules, ne saurait avoir une autre origine.

" En outre, ces troncs perpendiculaires à la surface des couches sont, à eux seuls, une preuve démonstrative du changement de position qui a donné à ces mèmes couches l'inclinaison qu'elles nous présentent. Dans l'origine, les couches s'étaient formées dans une position horizontale, et les troncs des arbres qui leur sont perpendiculaires ètaient verticaux. Depuis, les couches et les arbres ont été inclinés cnsemble. Ici, l'inclinaison n'a été que d'environ 30 degrés; ailleurs, elle a été de 60 , de 80 et de 90 degrés, et quelquefois même elles ont été renversées au delà de la verticale. L'horizontalité presque rigoureuse que doivent avoir affectée, dans le principe, les couches sédimentaires, peut, d'ailleurs, se conclure d'observations d'une nature différente. "

On pouvait croire, en effet, à des forèts ensevelies sur place, à des sédiments ultéricurs et à des soulèvements de l'ensemble. Mais pourtant l'absence de racines était un fait assez grave. 
ll est plus sûr de revenir à la promière théorie, à celle des transports. La perpendicularité des troncs aux couches qui les portent ne prouve pas leur développement sur place. Il existe à Commentry un banc où les tiges de calamodendron et de psaronius abondent au point de simuler une forct fossile; mais si l'on compte ces restes, on reconnait qu'il y a cent fois plus d'arbres couchés que debout; de plus, lorsqu'ils sont debout, ce n'est jamais dans les couches de houille, mais dans les grès, ou, parfois, dans les schistes. Comment ont-ils été transportés? Les arbres houillers, avec leurs trones mous et cylindriques couronnès, seulement au sommet, par une ombelle de feuilles, étaient tout à fait propres à conserver, dans le flottage, la verticalité de leurs tiges. Charriés au milieu de sédiments gros-

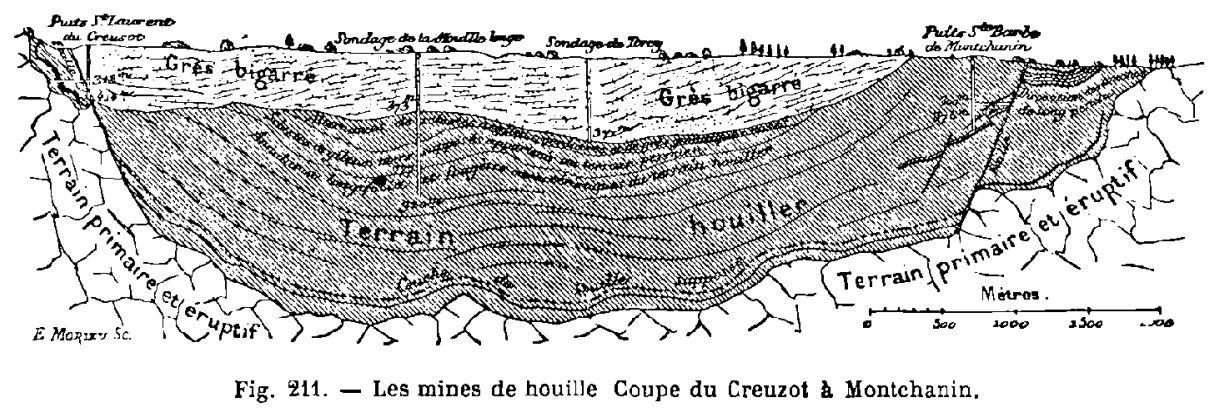

siers, ils devaient s'enfoncer peu à peu au sein d'une matière assez résistante pour les soutenir; au contraire, si le courant n'emportait que de la boue, destinée à former du schiste, les tiges, une fois enfoncées, devaient tendre à se coucher sur le fond. C'est, dı reste, ce qui arrive dans le domaine des grands fleuves, tels que le Mississipi, où des sapins entiers, charriès avec leurs branches, s'enfoncent verticalement dans les alluvions du delta. Ajoutons que M. Fayol a trouvé à Commentry une tige verticale dont la racine était en haut et qui ne pouvait avoir été amenée dans cette position que par flottage.

Ce flottage résulte-t-il de la chute ou du glissement de débris végétaux, entrainnés par la pluie à une très faible distance de leur lieu d'origine et venant former, au-dessus d'une terre basse ou d'un marécage, une accumulation que des sédiments d'alluvion pourront plus tard recouvrir, quand le sol aura subi un affaissement? Ou bien les couches de houille ne sont-elles pas elles-mêmes des alluvions, 
jetées par des torrents, pèle-mèle avec de la vase ou du gravier, dans l'eau profonde d'un lac et s'y stratifiant à la manière des dépôts des deltas? D'après les travaux de MM. Grand'Eury et Fayol, nous devons regarder la houille comme étant formée de résidus végétaux posés à plat et se recouvrant mutuellement, comme s'ils s'étaient amassés sur un plan horizontal, dans une situation tellement uniforme qu'on y doit reconnaitre l'action permanente d'un liquide servant de véhicule. Les résidus sont des fragments de troncs, d'écorces, de tiges, et des rameaux, des lambeaux de feuilles, tantôt très variées, tantôt homogènes; ainsi la grande couche de Decazeville est formée d'écorces de Calamodrendron et plusieurs des couches de Saint-Étienne sont presque exclusivement constituées par des écorces de Cordaïtes. Ces dernières, transformées en houille, gardent encore des épaisseurs de cinq, six et sept centimètres, qui montrent ce que devait ètre la puissance de développement de ces végétaux à l'état vivant.

Des torrents chargés de gravier, de vase et de débris végétaux, dèbouchent dass l'eau profonde et tranquille d'un lac, où les matériaux se séparent suivant leurs densités; les galets et les graviers tombent en couches très inclinées tout près de l'embouchure, tandis que les vases vont plus loin, se stratifient suivant une pente plus adoucie et qu'à leur pied, dans une situation voisine de l'horizontale, se déposcnt les végétaux. Ainsi les progrès continucls du delta amènent l'ensevelissement de l'alluvion végétale sous de nouvelles couches de sédiments et, si l'apport de débris de plantes continue, la couche de combustible, plus ou moins régulière, se prolongera sur le fond, bien que ses diverses parties ne soient pas contemporaines et représentent les apports successifs de crues consécutives. De cette manière, la qualité de la couche se ressentira des variations du régime etl'on pourra y rencontrer tous les degrès possibles, depuis la houille pure (c'est-à-dire la matic̀re végétale excmpte de détritus minéraux) jusqu'au schiste bitumineux (c'est-à-dire jusqu'à la vase détritique un peu mélangée de plantes et de débris) (').

Combien d'années, combien de siècles représentent ces dépôts et ces transformations? Il serait assurément difficile de le supputer.

1. De Lapparent Traité de Géologie. 
Quelle ne devait pas ètre l'activité végétale de cette époque? D'après les calculs d'Elie de Beaumont, tout le charbon que pourraient fournir nos forèts actuelles ne formerait tout au plus, sur l'ótendue des houillères exploitées, qu'une couche de 16 millimètres én cent ans!

Des centaines de milliers d'années sont ici en présenre, reculées à des millions d'années derrière nous. Ces événements géologiques nous reportent loin, quoique déjả tant de siècles se soient succédé depuis les temps où notre planète était un globe en fusion commençant à se redroidir. On se souvient involontairement ici de l'image des bouddhistes. Pour donner une idée de l'antiquité de la Terre et de sa durée, ces penseurs comparent notre globe à une montagne de diamant que l'on essuierait une fois par siècle avec une légère étoffe de coton. Quand sera-t-elle usée?... Fort heureusement pour nous, la science humaine va plus vite que l'histoire de la Terre.

Depuis un demi-siècle qu'ils sont nés, les chemins de fer ont apportė une lumière inattendue sur le développement de la géologie, par les tranchées et les tunuels qu'ils ont creusés à travers les diverses couches de la surface du globe. Mais de toutes les espèces de terrains, ce sont les terrains carbonifères qui ont été les mieux ètudiés, les plus recherchés, à cause de la valeur intrinsèque de leur exploitation industrielle. (Nous n'avons pas à parler ici des mines de diamants, de pierres précieuses, d'or, d'argent, de métaux divers, parce qu'elles appartiennent à des terrains primitifs, à des filons éruptifs, d'origine antérieure à la vie et étrangers au sujet de cet ouvrage.) On connait non seulement les mines de charbon qui affleurent à la surface du sol, mais on a encore recherché, au prix des plus grands efforts, celles qui peuvent se trouver à une faible profondeur et permettre l'exploitation. Cette exploitation elle-même a une limite : lorsque la profondeur de la couche de houille est telle que les dépenses faites pour aller la chercher deviennent égales ou supéricures au prix de vente, les plus intrépides s'arrêtent. Ainsi, par exemple, en examinant la coupe de la figure $12 \mathrm{~L}$ (p. 272), faite à travers le bassin de la Seine, et celle du puits artésieñ de Grenelle (p. 265), on conceit qu'en arrivant au terrain primaire qui passe au-dessous de Paris on puisse y trouver de la houille, mais 
aussitôt on reconnait que les frais d'exploitation laissent à l'état chimérique tout projet d'aller la chercher ( $\left.{ }^{(}\right)$.

Cette grande valeur du charbon de terre, d'autant plus précieux qu'il n'est pas inépuisable -- et que mème, selon toute probabilité, on aura tout brùlé d'ici à trois siècles - a conduit à connaitre les gisements qui n'arrivent pas jusqu'à la surface du sol et qui sont recouverts de terrains modernes tout différents. Ainsi, à Valenciennes, à Anzin et en Lorraine, les mines sont recouvertes par des terrains modernes, tandis que dans le plateau central de la France elles arrivent jusqu'à fleur du sol. Celles des Flandres passent sous la Manche et descendent en Angleterre. (On peut voir sur notre carte géologique de France les principales mines de houille de notre pays.) La Belgique, l'Angleterre, les Etats-Lnis, la Russie, la Chine, sont,

Nord.

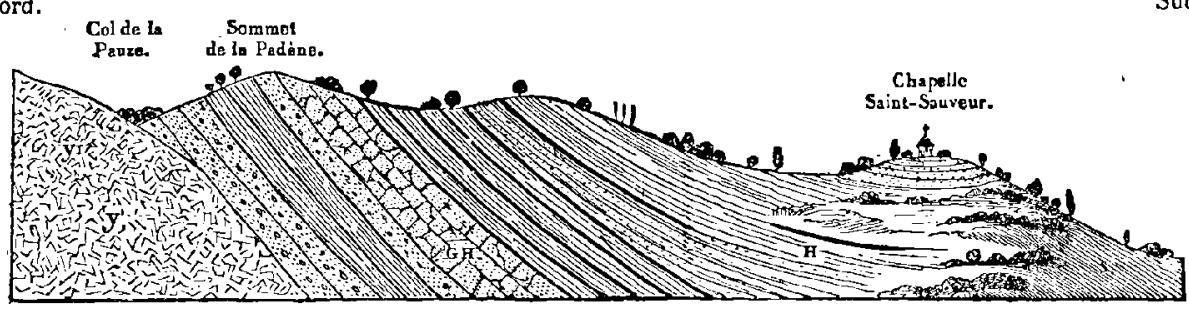

Fig. 212. - Coupe du terrain houiller de Saint-Gervais, près Lodève.

comme on le sait, très riches en mines de houille $\left(^{2}\right)$. Le terrain houiller s'étend sur plus d'un tiers de la Russie d'Europe, couvrant un bassin aplati dont le bord vient s'appuyer d'une part entre la mer Blanche et Moscou, et de l'autre contre les montagnes de l'Oural. Sa constitution géologique (calcaires marins) montre qu'à

1. La distance n'est pas toujours le seul obstacle. Il y a, non loin des mines d'Anzin, à Marly, près de Valenciennes, une couche de houille qui paraît digne de solliciter l'ambition des actionnaires. Elle reste inexploitée, principalement à cause des inondations souterraines qui l'envahissent et dont on n'a pu se rendre maître.

2. La superficie des tèrains houillers en exploitation s'élève à trente mille lieues carrées de qualre kilomètres au côté, chacune valant seize hectares. On peut estimer à deux cent millions de tonnes de mille kilogrammes la quantité de houille extraite en moyenne chaque année de l'ensemble des mines du monde entier. L'Angleterre seule entre pour la moitié dans ce chiffre et la France pour le dixième. L'armée des mineurs se chiffre par trois cent cirquante mille hommes en Angleterre, cent mille en France, autant en Allemagne, cinquante mille en Belgique. Le chiff le de cette armée sonterraine, qui combat pour les travaux de la paix, pour l'industrie et pour les progrès de l'humanitè, s'élève à près d'un million d'hommes. 
la fin de l'époque carbonifère une mer s'étendait sur la Russie, alors que l'Europe occidentale, en grande partie émergée, était couverte de lacs et de marécages d'eau douce arrosant les pieds des végétaux géants.

Lorsque les couches carbonifères viennent affleurer à la surface du sol, elles ne s'étendent point pour cela sur de vastes espaces, mais descendent assez vite, plus ou moins obliquement, jusqu'à une certaine profondeur. C'est par des puits verticaux et par des galeries inclinées que les mineurs parviennent à extraire le précieux

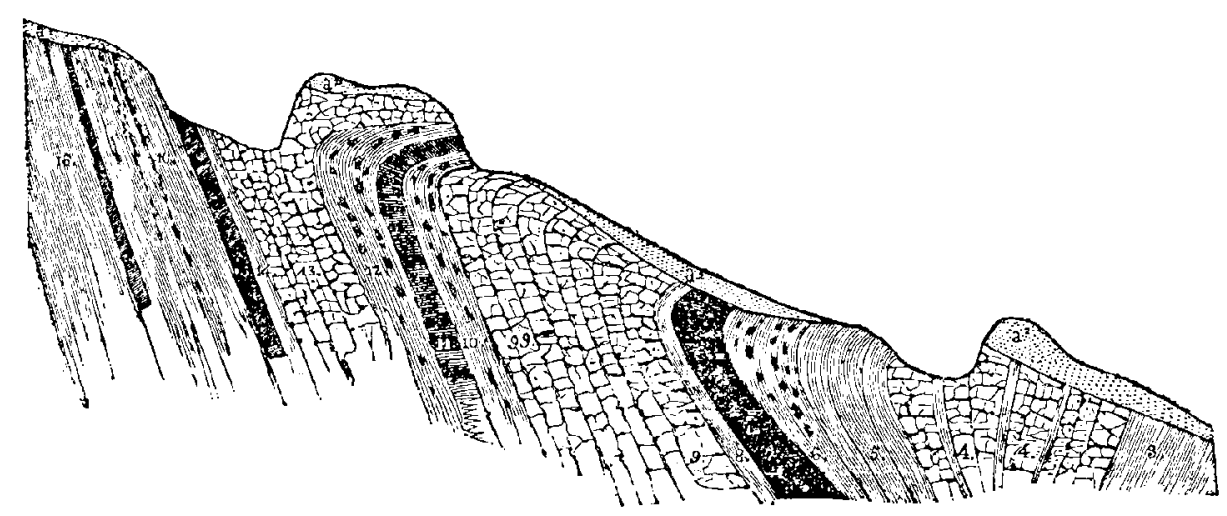

Fig. 213. - Position des couches de houille à la carrière de Fins (Allier).

combustible et à le livrer à la consommation, au prix d'une vie d'abnégation et de fatigues qui n'est presque jamais récompensée. Malgré des bénéfices souvent prodigieux, le travail du mineur n'est pas associe aux chances, et lors mème que ce soldal de l'abîme donne en exemple une vie laborieuse et dévouée, il est rare qu'il arrive à une vieillesse tranquille. Lorsqu'il est sorti sain et sauf de tous les accidents de la vie souterraine, feu grisou, éboulements, inondations, etc., ses poumons n'en sont pas moins imprégnés de poussière charbonneuse, sont devenus noirs et durs, et cessent de fonctionner normalement; le sang est mal renouvelé, et la lumière du jour, dont il espérait jouir quelques années, n'éclaire plus qu'un corps débile regrettant presque sa seconde patrie. Si, en nous confiant au train rapide qui nous emporte à travers les provinces et met aujourd'hui Nice aux portes de Paris, on, dans la grande cité, le soir, en admirant l'ètincelante illumination qui rivalise avec celle 
du jour, nous songeons à la formation de la houille à laquelle nous devons ces racrveilles; nous pouvons, nous devons associcr dans notre souvenir un sentiment de sympathie envers ce soldat de l'abime et son pacifique champ de bataille.

La profondeur des mines de houille descend parfois jusqu'à cinq cents, six cents, huit cents mètres, et les galeries, tracées à la boussole, s'étendent souvent jusqu'à cinq et six kilomètres.

En général, ces bassins houillers ont la torme de cuvettes, plus ou moins vastes, plus ou moins épaisses, plus ou moins profondes; mais ici encore on ne pourrait établir de règle, à cause des nombreuses dislocations de terrains et de la varièté mème des conditions originaires de la production de la houille. Plusieurs géologues distinguent le calcaire carbonifère du terrain houiller qui repose au-dessus, souvent séparé par une couche de grès stérile. Il serait difficile de supputer le nombre des alternatives de submersion d'eau marine ou d'eau douce représentées par les nombreux feuillets houillers successifs. Dans l'énorme couche qui s'ètend de Valenciennes à Liège, on a compté, sur une épaisseur de trois cents mètres, cent cinquante-six feuillets superposés, parmi lesquels on reconnaitt jusqu'à sept invasions marines représentées par des calcaires noires à productus et à goniatides. Certains feuillets ne mesurent que quelques décimètres d'épaisseur. D'autres, comme à Commentry, n'ont pas moins de vingt-cinq mètres. En Belgique, certaines couches sont replićes en forme de $Z$, si bien qu'un mème puits vertical traverse souvent trois fois le mème feuillet. C'est souvent couché, le corps replié, le cou tordu, que l'ouvrier mineur doit remonter obliquement les veines de houille en désagrégeant péniblement à la pioche toute l'épaisseur combustible. Quelquefois nous sommes resté des journées entières dans ces profondeurs, témoin des travaux qui courbent en un rude labeur ceux qui, le soir, venaient encore chanter, en posant leurs petits enfants sur leurs genoux : « Ma lampe est mon soleil, tous mes jours sont des nuits $» .$. . Nos lecteurs se rendront compte de ces variétés de gisements, de dislocations de terrains et de transformations par les coupes dessinées ici ( $f g .210$ à 213). La première est une coupe du Creusot à Montchanin, tracée par M. Simonin : elle montre toute la richesse de ce vaste bassin; la seconde (fig. 211) montre les 
inclinaisons et les alternatives de houille, de schiste et de grès; la troisième montre que parfois elles arrivent mêmo à devenir verticales; la quatrième met en évidence des irrégularités et des dénivellations plus remarquables encore : ces trois dernières sont empruntées au travail officiel d'Elie de Beaumont (Explication de la carte géologique).

La houille n'existe pas seulement dans les terrains de l'époque primaire dont nous étudions en ce moment l'histoire. Le combustible fossile se troure dans tous les terrains; mais il est de moins en moins pur et compacte, ou bien occupe des surfaces de moins en moins étendues, à mesure qu'on remonte ou descend l'échelle géologique, à partir du terrain houiller proprement dit. C'est que ce terrain a été le seul où les conditions botaniques et climatologiques aient permis une grande accumulation des végétaux qui ont produit la houille. Ces végétaux ont ensuite disparu ou changé peu à peu de nature jusqu'à revêtir les formes qu'ils ont actıellement.

Toutefois, par l'effet de circonstances particulières, la véritable houille compacte, bitumineuse, collant au feu, a pu se former dans tous les terrains, et non pas seulement dans le terrain houiller, comme le veulent quelques savants trop absolus. Il faut done admettre, à l'exemple des anciens géologues, les houilles anciennes et récentes. Se refuser à cette elassification serait fermer les yeux à la réalité. Encore moins convient-il de baptiser du nom irrévérencieux de lignite, qui ne rappelle que le bois, lignum, les véritables houilles des terrains plus modernes que le terrain houiller. Ces terrains furent souvent le théâtre, même à l'époque tertiaire, d'une végétation tropicale, et les palmacites, ou palmiers fossiles, ont été les précurseurs des palmiers des régions torrides actuelles.

a En Toscane, la formation carbonifère ancienne ne se montre nulle part. " Il n'y a pas de houille en Etrurie ", disaient done les géologues en l'an de grâce 1839. Cette assertion vint aux oreilles d'un sieur Lenzi, gros fermier de la Maremme, qui avait mis un jour à nu, le long d'un ravin, un affleurement de charbon. Il fit part de sa découverte à des capitalistes de Livourne, qui visitèrent les lieux, et, sans s'inquiéter de ce qu'en penserait la géologie, mirent l'affaire en actions. Le grand duc lui-même, le vieux Léopold 
s'émut, et appela la discussion. Grand mouvement dans le camp des géologues. "C'est de la houille », disaient les uns. "C'est du lignite », répondaient les autres. Au Congrès scientifique de Pise, la querelle s'échanffa; on manqua de se jeter les échantillons à la tête. Le public, qui écoutait aux portes, ne comprenait rien au débat, et demandait avant tout s'il existait du charbon et s'il brûlait bien. Ce qu'il y eut de particulier dans tout ceci, c'est que ce lignite, comme on persistait à le nommer, avait toutes les propriétés des meilleures houilles, même celle de donner du coke. A quoi les géologues orthodoxes répondaient que puisqu'il donnait du coke, ce ne

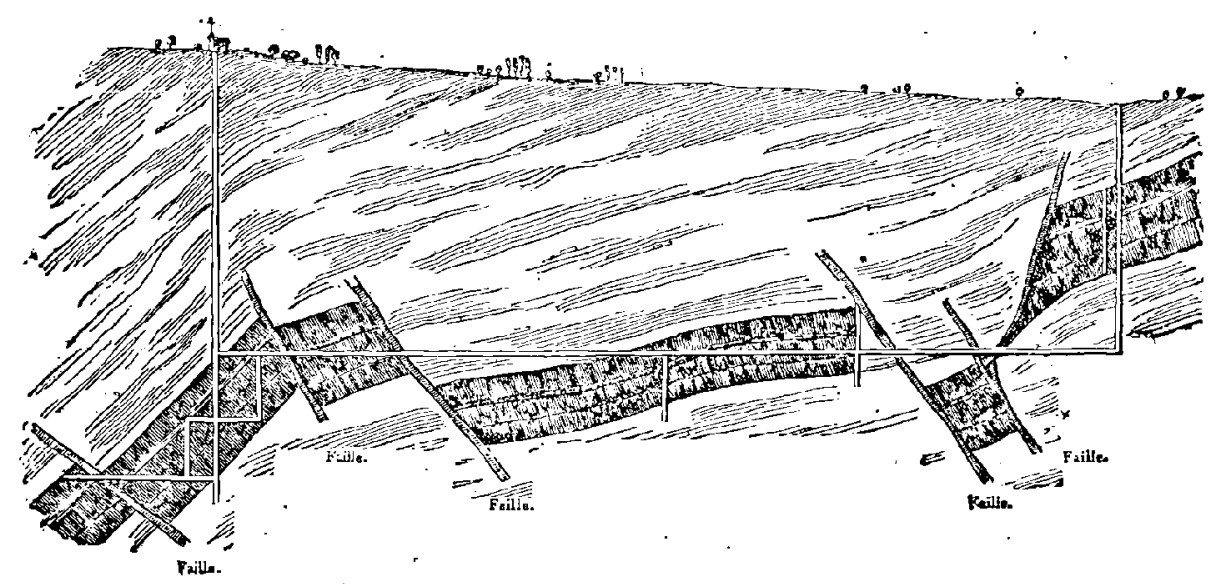

Fig. 214. - Coupe de la couche de houille de Montceau-les-Mines, suivant une ligne parallele a la direction de son inclinaison.

pouvait être du lignite, mais bien de la houille anglaise achetée à Livourne et jetée exprès au fond du puits! Cela fit baisser les actions; car il reste toujours quelque chose de la calomnie, comme disait Basile. La lutte dura longtemps; les congrès scientifiques se la transmirent de l'un à l'autre, et je ne sais pas si elle est aujourd'hui entièrement vidée. Ce que je puis aftìmer, c'est que les pauvres actionnaires ne se sont jamais relevés du coup que leur ont porté les géologues ( $\left.{ }^{4}\right)$ D.

Mais revenons aux plantes des temps primitifs auxquelles nous sommes redevables de la formation des houilles.

Nos lecteurs remarqueront ici ( $f g .214)$ un fort intéressant docu-

1. Simonin. La Vie souterraine ou Les Mines et les Mineurs. 


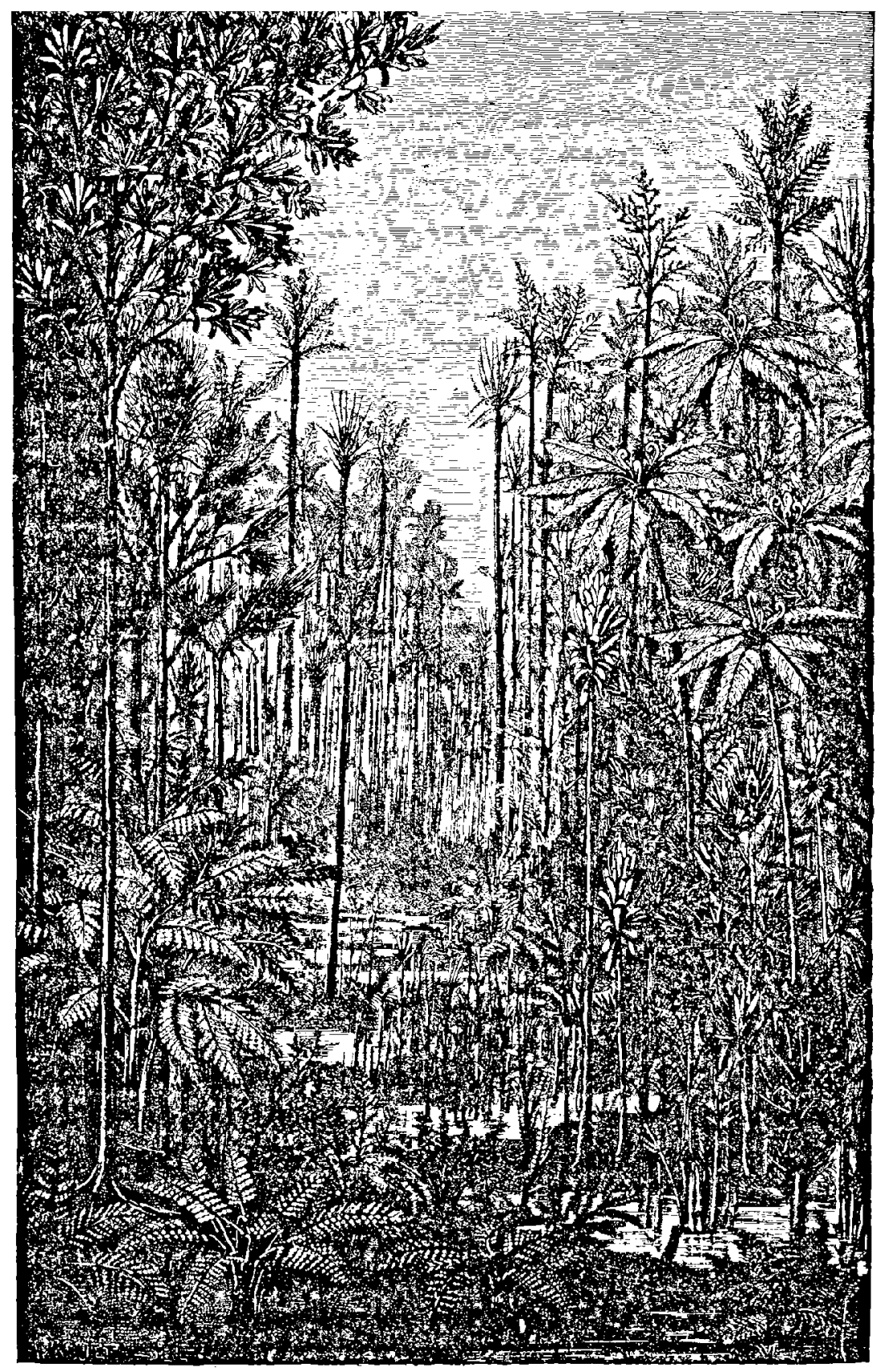

FORÈT DE L'F́POQUE GARBONIFÉRE

Be:taurée d'aptès M. Grand'Eury, per M. L. Marchand.

LE MONDE aYaNt LA GRÉation DE l'HOMME 
ment dú à M. Marchand, représentant une forèt de l'époque carbonifère restaurée sur les documents publiés par M. Grand'Eury. Au milieu de ccs riches fougères au feuillage si finement découpé, ce que l'auteur admire le plus, ce sont les plus humbles cryptogames dont il s'est fait l'éloquent défenseur, celles qui se cachent an sein des eaux ou celles que leur petitesse rend invisibles. \& Le groupe des cryptogames, dit-il (4), contient les plantes les plus grandes et les plantes les plus petites. On y trouve des végétaux tels que, suivant Schleiden, il en faut 111500000 réunis pour atteindre le poids d'un gramme (de telle sorte que chacun pèse la millionième partie d'un milligramme et qu'il en tient 41000 millions sur un pouce carré). Il y en a de plus petits encore! A côté on trouve des Macrocystis dont un échantillon mesuré par IIumboldt avait 500 mètres de longueur; la flèche de la cathédrale de Strasbourg trois fois superposée donnerait une hautcur de 460 mètres seulement; il s'en faudrait donc de 40 mètres pour qu'elle égalât celle du Macrocystis en question. De telles plantes seraient dignes du nom de géantes, si leur grosseur était en rapport avec leur longueur; il n'en est rien: leurs tiges sont relativement minces et flexibles pour leur permettre de flotter au gré des flots.

( Les cryptogames se rencontrent partout: dans les eaux, sur la terre, dans le sol, dans les airs, dans les corps vivants, dans les corps morts. Leur rôle dans l'économie du globe terrestre est de la plus haute importance.

"Les eaux sont remplies de ces cryptogames qu'on appelle algues; les fleuves, les rivières, les étangs, les eaux stagnantes en nourrissent d'innombrables quantités; les mers en sont pour ainsi dire tapissées; elles donnent naissance dans leurs profondeurs à des forêts qui, par la multiplicité des formes et la beauté des couleurs, ne le cèdent en rien aux forêts des terres émergées. Lorsque l'œil ne distingue plus rien dans ces eaux, si l'on s'arme d'une loupe on découvre de nouveaux paysages : bientôt la loupe ne suffit plus; on veut voir encore, on s'aide du microscope, et l'on s'aperçoit que c'est en vain que, par des grossissements de plus en plus puissants, on élargit son horizon, car on découvre toujours de nonvelles végè-

1. L. Marchand, Botanique criptogamique. 
tations, et l'on pressent que la nature réserve de ce côté un infini à sonder. De mème, en sens inverse, les perfectionnements du télescope, tout en nous faisant pénétrer de plus en plus loin dans les profondeurs du ciel, nous le montrent partout parsemé de soleils et de mondes nouveaux.

« Toutes ces cryptogames, petites et grandes, vivent, et c'est de leurs vies plus encore que des nôtres, peut-être, qu'est faite celle de la Terre. En les voyant à l'œuvre, on comprend quelle grande part lcur revient dans les phénomènes qui se passent sur notre planète : en soutirant, pour vivre, l'acide carbonique des eaux surchargées de bicarbonate, elles font du carbonate de chaux insoluble qui se dépose, et préparent ainsi des couches de pierre à bâtir, au milieu desquelles elles laissent leurs débris comme témoignage de la part qu'elles ont prises au travail. Certaines autres agissent sur l'acide silicique; elles l'emmagasinent, s'en servent pour se construire des enveloppes protectrices, et se multipliant avec une rapidité vertigineuse, elles arrivent à former des rochers qui s'élèvent rapidement; les générations qui se succèdent s'établissent sur les cadavres de celles qui ont vécu et qui restent là enveloppés de coquilles siliceuses leur servant de linceul. C'est ainsi que se forment un grand nombre de roches et de terres.

« D'autres fois, ces petites cryptngames aquatiques, charriées par les fleuves, viennent échouer leurs cadavres en si grande quantité qu'elles enlizent les embouchures de ces cours d'eau. Aux bouches de l'Oder et de maint autre fleuve, dans le port de Wismar, sur la barre de Pillau, la vase est formée en partie, ou mème pour un tiers ou la moitié, d'espèces vivantes en multitudes incalculables. C'est à un million de mètres cubes qu'il faut évaluer les masses de ces infiniment petits qui se déposent chaque siècle dans le port de Pillau. Et rappelons que ces cryptogarnes sont de celles dont il faut 41000 millions pour couvrir 1 pouce carré.

" A peine les roches viennent-elles émerger, que d'autres cryptogames s'en emparent : ce sont, en général, des lichens. Attachées aux roches, elles décomposent les plus dures. Ces plantes singulières, qu'on rencontre partout où il y a un terrain à préparer pour permettre l'établissement de végétaux d'ordre plus élevé, algues par partie et champignons par l'autre, sont aptes à toute espèce de tra- 
vail; aussi les trouve-t-on partout, végétant sur le quartz, les grès, les schistes ardoisier's, les basaltes, les porphyres des volcans éteints et, même, jusque sur les laves à peine refroidies de ceux qui sont encore en éruption. Toutefois il est bon de remarquer que les cryptogames ont toutes des habitudes aquatiques; elles sont toutes plus ou moins hydrophiles; c'est à peine si les plus élevées en organisation se hasardent dans les lieux un peu sees, celles que nous avons signalées dans les déserts brûlants sont des lichens qui n'y meurent pas, mais qui n'y vivent que lorsqu'ils rencontrent quclque humidité. On sent chez toutes comme un lien secret de parenté avec les algues dont, sans doute, elles sont sorties. Les rhizocarpes sont aquatiques; les hépatiques le sont presque : il leur faut un air saturé d'humidité, et les sphaignes ne vivent que dans nos marécages, où elles entassent leurs générations pour former la tourbe. Les mousses n'exigent pas tant d'eau, mais la plupart veulent l'ombrage des bois; de mème pour les isoëtes, les lycopodes et les prêles, toutes aiment un sol humide. In n'y a que les fougères qui deviennent terrestres, à condition toutefois, pour le plus grand nombre, que l'atmosphère soit fortement chargée de vapeur d'eau.

« Si, au licu de nous en tenir à la simple exploration de la surface du globe, nous fouillons un peu les profondeurs du sol, nous nous apercevons rapidement que les phénomènes naturels auxquels nous assistons ne sont que la continuation non interrompue de ceux qui se sont passés aux ćpoques qui nous ont précédés. Le mème travail se faisait, le mème fonctionnement s'opérait, l'équilibre vital s'établissait par l'action combinèe d'éléments fabricateurs et d'éléments consommateurs; mais, à en juger par les témoins qui restent de ces âgés, tout le travail était fait par les cryptogames, les pharénogames n'étant apparues que plus tard à la surface du globe, pour les aider d'abord, les suppléer ensuite, et, enfin, tenter de les remplacer dans leur fonction cosmique. ”

Pondant les longs siècles de l'époque carbonifère, la force vitale de la plinète terrestre était surtont repsésentée par deux grands systemes d'organisations : dans les eaux, les poissons; sur la terre, les plantes.

La tendance divine vers l'incessant perfectionnement n'a pas 
encore produit les espèces supérieures, ni dans le règne animal, ni dans le règne végétal; mais elle s'est magnifiquement manifestée déjả par les degrés ascendants qui s'étendent du règne minẻral aux poissons et aux insectes d'une part, aux fougères ou aux sigillaires d'autre part. Elle continuera d'agir en un essor incomparablement

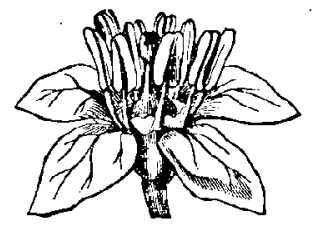

Fig. 216. Fleur de Boswellia.

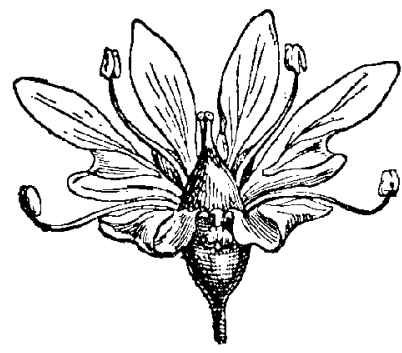

Fig. 217. Fleur de Coriandre.

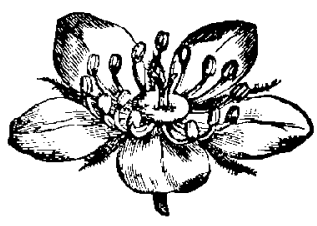

Fig. 218. Fleur d'Aigremoine.

plus lumineux encore lorsqu'à travers les âges elle donnera naissance aux plantes nerveuses ou carnivores, à la sensitive ou au

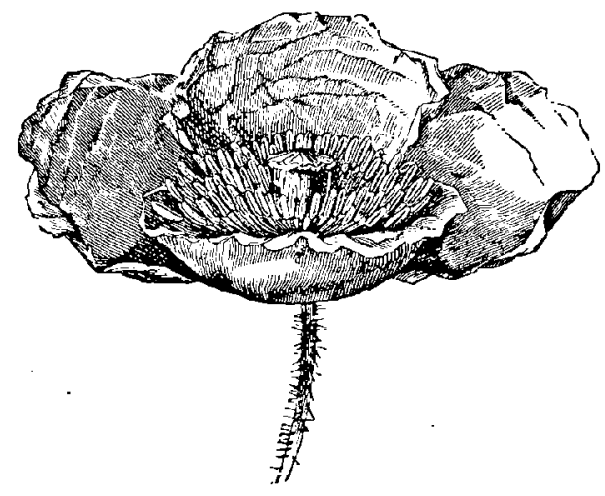

Fig. 219. - Fleur de Pavol.

drosera, et, parallèlement, aux oiseaux, aux mammifëres et à la race humaine.

A l'époque à laquelle nous sommes arrivés dans cette étude de la Terre antérieure, ce sont les plantes qui font les progrès les plus rapides, et la nature elle-même nous invite à nous arrêter un instant pour admirer ce curieux monde végétal, et l'apprécier à sa valeur réelle, si ètrangement méconnue. Aux yeux d'un grand 
nombre d'humains, le monde des plantes semble étranger au système général de la vie terrestre; leur perpétuel silence, leur immobilité, leur modestie, les laissent passer inaperẹues. Pourtant elles ne sont pas moins intéressantes à connaitre que les animaux euxmêmes, elles sont vivantes, et il eût pu se faire qu'elles existassent seules sur notre planète et que la race supérieure - celle qui eût remplacé la race humaine - fût une race végétale.

Souvenons-nous d'abord, pour bien les apprécicr, que les plantes peuvent être partagées en deux grands embranchements : les GRYPtoganes et les phanérogunes. Les premières sont des plantes humbles, peu brillantes, dépourvues de fleurs a ces couchettes nuptiales $"$, et leur nom vient précisément de cet état ( $\left.{ }^{4}\right)$; les organes de la génération comme ceux de la reproduction sont invisibles, microscopiques, latents, si bien cachés, si discrets, que naguère encore d'éminents botanistes doutaient de leur existence et proposaicnt d'appeler ces végétaux agames, c'est-ì-dire privés de génération. Parmi ces plantes cryptogames, nous pouvons citer les algues, les champignons, les moisissures, les mousses, les lichens, les lycopodes, les fougères. En fait, il n'y a pas plus chez clles que chez les phanérogames de génération spontanée, mais comme chez les animaux primitifs dont les pages précédentes ont exposé l'histoire, le mode de génération reste encore rudimentaire, fluctuant, indécis, et n'a pas attcint le perfectionnement de la séparation absolue des sexes et de la nécessité du rapprochement de deux êtres distincts et complémentaires l'un de l'autre.

Point de fleurs, point de coquetterie, point de parfums, point d'ivresse, point d'attractions, point d'attouchements: amours de mollusques, de crustacés, de poissons !

Mais la nature s'élève vers un idéal à la fois plus poétique et plus sensible. Des cryptogames sortiront les phanérogames, comme des invertébrés sortiront les vertébrés. Les phanérogames sont les plantes supérieures, à noces brillantes ( $\left.{ }^{2}\right)$, possédant des organes de génération visibles à l'œil nu pour la plupart d'entre elles: les organes mâles, appelés étamines, portent les éléments fécondants, le pollen; l'organe femelle, désigné sous le nom de pistil, porte

1. Étymologie : xơurzós, caché; $\gamma \alpha \mu \circ \varsigma$, noce.

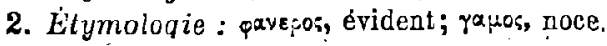


les ovules destinés à ètre fécondés et à donner naissance à une nouvelle plante. Les phanérogames se partagent en deux grandes sections : les gymnospermes et les angiospermes; le caractère essentiel des premières est d'avoir les ovules nus et, pour les arbres, du bois composé de fibres disposées par couches concentriques, comme les cycadées et les conifères; le caractère essentiel des secondes est d'avoir les ovules enfermés dans un petit sac nommé ovaire; les angiospermes se partagent à leur tour en deux classes : les monocotylédones, chez lesquelles la feuille primaire de l'embryon, ou cotylédon, est isolée, et dont le bois ne s'accroît pas par couches concentriques (exemple: palmiers, bananiers, balisiers, roseaux, jacinthe) et les dicotylédones, chez lesquelles les feuilles primaires de l'embryon sont au. nombre de deux, opposées l'une à l'autre, et où le bois, pour les arbres, s'accroit par couches concentriques, comme celui des gymnospermes, et est formé de fibres et de vaisseaux (cxemple : chênes, ormcaux, acacias, fenouil, thym, haricots, etc.) Mais évitons les détails : nous n'écrivons pas ici un traité de botanique.

Apprécions cependant la vie réelle des plantes en nous initiant un instant à leurs mœurs et à leurs sensations.

Voici des fleurs ( $f g .216$ à 219). Dans la corolle on remarque au centre un filet renflé à sa partie inférieure ; c'est le pistil ou organe femelle; le renflement inférieur est l'ovaire, contenant les ovules; le bout du pistil s'appelle le stigmate.

Autour de ce pistil ou corps central on remarque les étamines, ou organes mâles, au nombre de cinq ou davantage (leur nombre est variable, et le pistil, lui aussi, peut être unique ou multiple, suivant les espèces de plantes). Ges étamines sont constituées par un support en forme de colonnette qui se termine par un renflement nommé anthère. G'est la partie essentielle de l'organe, e'est elle qui renferme le pollen ou poussière fécondante.

On se rendra compte du mécanisme de la fécondation des fleurs à l'in '-ection des petites figures ci-dessous, qui montrent différents aspects de la constitution organique de la fleur. La figure 220 offre une fleur de kalmia, dans l'ètat de repos des étamines, avant la fécondation, la figure 221 montre cette méme fleur au moment de la fẻcondation, les étamines ètant venues se poser sur le stigmate du 
pistil, et la figure 222 fait connaitre une fleur compliquée, mais qui n'en cst pas moins éloquente par ses mouvements, la loasa lateritia, sur laquelle on voit toutes les étamines se diriger vers le stigmate qui les attire.

Pour que la fécondation s'opère, il faut que le pollen aille toucher les ovules. Les ovules non touchés par cette substance fécondante restent stériles comme s'ils étaient d'inertes grains de sable.

Au moment de la fécondation, l'anthère s'ouvre et lance du pollen sur le stigmate femelle. Un tube très fin sort de chaque grain de pollen, pénètre dans le stigmate, traverse le pistil dans toute sa longueur pour aller chercher les ovules qui l'attirent, et là, par un contact mystérieux, les pique, les féconde. A partir de ce moment l'embryon commence : l'ovule fécondé devient une graine et l'ovaire un fruit. Adieu la fleur, adieu ses parfums, adieu sa beauté. Le beau a fait place au vrai, l'agréable à l'utile. Le but de la nature est accompli. Dans la vie transitoire des fleurs et des êtres se perpétue la vie éternelle de l'univers vivant; - la vie éternelle, ou pour mieux dire, la vie ascendante. Du champignon elle s'élève à la rose; l'argile tend vers l'ange.

Qui pourrait raconter la sensation de la fleur dans le scin do laquelle glisse le tube prolifique qui doit, qui veut s'allonger jusqu'aux ovules encore endormis dans l'inconnu! lls portent en eux le germe de la vie; mais ce germe ne s'éveillera pas s'il n'est touché. Le stigmate de la jeune fleur est mouillé de gouttes sucrées; la fleur entière est imprégnée de tous ses parfums ; le tube pollinique subit une telle attraction que dans certaines plantes (exemple: digitale pourprée) il atteint une longueur de 33 millimètres, soit onze cents fois lo diamètre du grain de pollon d'où il est sorti! Il est vrdi qu'il y met un temps parfois considérable : six heures chez certaines graminées, douze heures dans la zosthère marine, un jour dans certaines naïades, trois jours dains le glaïeul, cinq dans l'orme, un mois pour l'oranger et le citronnier, quatre mois (fóvrier à juin) pour le noisetier, un an même chez ıes pins. Aux approches de la fécondation, la température des fleurs s'élève sensiblement; dans les arums on peut facilement la sentir à la main: cette augmentation de chaleur est due, comme dans le 
corps humain; à une absorption considérable d'oxygène. Il y a lả des phénomènes physiologiques devant lesquels nous passons inattentifs, mais qui ne sont pas aussi èloignés qu'ils le paraissent de ceux qui constituęnt les plus importantes phases de la vie chez les animaux supérieurs et même dans l'humanité.

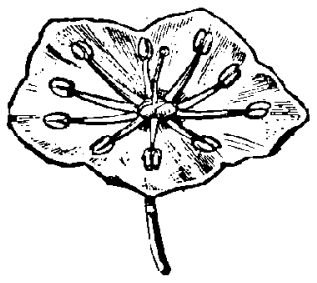

Fig. 220. - Fleur de Kalmia. Élamines apart la fecondation.

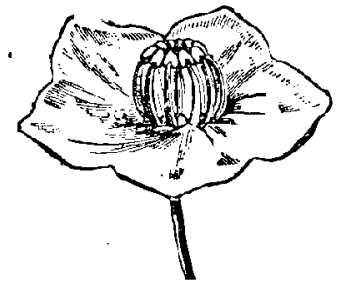

Fig, 221. - La mème fleur. Etamires posées sur le stigmate du moment de la fécondation.

Nous supposons, avec raison sans doule, que ce sont là des sensations sourdes, confuses, presque insensibles. Qui sait? sur des

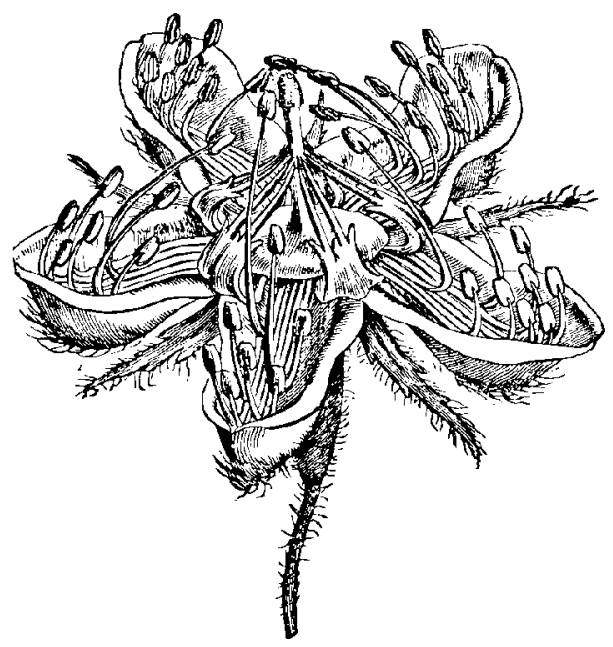

Fig. 222. - Loasa lateritia : étamines se portant vers le stigmate pour la fécondalion.

mondes plus délicats que le nôtre, les joies, les plaisirs, le bonheur ont peut-être atteint un tel degré d'intensité, que pour les êtres qui les ressentent, nos jouissances les plus vives sont anx leurs ce que celles des plantes sont aux nôtres.

L'œuvre de la rature est une magnifique unité. En fait, botanique et zoologie se touchent - physiologie et sensation - biologie et paléontologie - géologie et biologie - géographie et botanique 
- astronomie et géologie - hommes, oiseaux, reptilos, poissons; algues, roseaux, fougères, chênes; air, ear, pierres, ciel et terre; univers et atomes - tout se touche, tout se tient, tout ne fait qu'un.

En lançant dans l'espace, après la pluie, l'arc-en-ciel aux sept couleurs, la nature semble nous donner la loi des contrastes, nous montrer que les extrêmes se touchent et que tout n'est que transition. Cherchez la séparation dẹ couleurs du spectre solaire, à l'aide d'un prisme très dispersif, agrandissez-le, comme vient de le faire M. Thollon, jusqu'à lui donner douze et quinze mètres de longueur : il vous sera de toute impossibilité de trouver la zone précise où le rouge fait place à l'orangé, l'orangé au jaune, le jaune au vert, etc. Pourtant le vert diffëre assurément du rouge, comme le violet du jaune, ou le bleu de l'orangé. Les couleurs sont l'image de la parenté de toutes les espèces, vógétales et animales, dans l'immense unité de la vie terrestre.

Depuis longtemps les sexes sont séparés chez les animaux, et cette séparation est une cause très active de perfectionnement et de progrès. Ils ne le sont pas encore chez toutes les plantes, et même la séparation est l'exception. Ils ne le seront sans doute jamais, parce que les plantes ne marchent pas et que cette séparation est plutôt une cause d'infériorité. Le progrès s'accomplit de préférence chez les plantes monoïques, douées des deux sexes à la fois. La stature de la fleur est en rapport avec la longueur relative des étamines et du pistil. Le moyen le plus sûr d'assurer la fécondation étant que le pollen soit situé au-dessus de l'organe femelle, afin qu'en tombant par sa propre maturité il soit reçu sur le stigmate, chez les fleurs droites, les étamines sont plus grandes que le pistil et le couronnent. Voyez au contraire le fuchsias, dont les fleurs sont pendantes et renversées : le pistil descend longuement au-dessous des étamines, et lorsque le pollen s'échappe des anthères, il tombe naturellement sur le stigmate. Ghez un grand nombre de fleurs (exemple: la rue, l'épine-vinette, la parnassis, le mahonia), les étamines se mettent en mouvement au moindre contact; aussitôt qu'on les touche, qu'un insccte les frôle, elles s'abattent vivement sur le stigmate. Aussi les insectes jouent-ils un rôle très important dans la fécondation des fleurs. En s'introduisant dans 
leurs corolles, ils mettent en activité les étamines, qui, très sensibles, arrivent instinctivement en contact avec le stigmate. Les abeilles, les bourdons, les papillons s'imprègent de pollen en allant chercher le miel dans la corolle des fleurs, et, se transportant sur d'autres fleurs, leur laissent ce pollen qui les fẻconde beaucoup plus vite qu'elles ne l'eussent été sans cette intervention. Chez les plantes à sexes séparés, comme les dattiers, les marronniers, le chanvre, l'épinard, le melon, la fécondation est même impossible sans l'aide des insectes ou du vent. On connait l'histoire de ce dattier femelle, planté à Otrante, qui resta stérile jusqu’à l'époque où un dattier mâle situé à Brindes put élever sa cime au-dessus des arbres voisins et confier au vent la précieuse poussière fécondante. On a parfois remarqué des plantes d'un même sexe se reproduisant elles-mèmes; mais on a découvert qu'elles portaient alors quelques fleurs de l'autre sexe.

La vallisnérie, plante des eaux que tout le monde connait, est peut-être la plus curieuse d'entre ces plantes à sexes séparés. Les fleurs femelles sont portées par un.long filet qui leur permet d'arriver jusqu'à la surface de l'eau, d'y étendre leurs charmes, et d'y flotter dans une gracieuse indolence. Les fleurs mâles passent leur vie à leurs pieds, sans jamais s'élever assez pour les atteindre. Mais à l'époque des noces, elles s'échappent brusquement des spathes qui les enfermaient et s'èlèvent comme de petits ballons jusqu'au lit nuptial. Alors les anthères répandent leur pollen, les fleurs femelles le reçoivent et sont fécondées. Puis, enroulant en spirale les longues tiges qui les portent, elles disent adieu au monde et à la lumière ct redescendent au fond des eaux pour y mùrir le fruit de ces silencieuses amours.

Plus élevées encore dans l'organisation sont les plantes à mouvements spontanés ou provoqués, qui possèdent, à leur façon, des nerfs et des muscles et sont douées de facultés supérieures à celles d'un grand nombre d'animaux primitifs. Telles sont, entre autres, la desmodie oscillante, la sensitive, le drosera, la dionée attrapemouches, l'aldrovandia, le drosophyllum, la pingnicula, l'utricularia, etc. La plus remarquable et la plus étudiée dans ses multiples fonctions est peut-être le drosera, type si singulier des plantes carnivores. Nous sommes si généralement accoutumés à croire que 
les plantes vivent « de l'air du temps », se contentent de respirer par leurs feuilles et de se nourrir des sucs de la terre par leurs racines, que nos notions habituelles sur la douceur et l'innocence du règne végétal paraissent confondues lorsque nous entendons parler d'une plante qui mange et qui digère à la facon d'un animal. Examinez pourtant le drosera, qui habite les marais tourbeux et les prairies spongieuses et dont les feuilles couvertes de tentacules sécrètent des gouttes de liqueur brillant au soleil, ce qui a fait donner aussi à cette plante le nom de rosée du soleil: ros-solis. Lorsqu'un insecte, une mouche, un papillon, voire même une libellule, vient se poser sur la feuille, tous les tentacules (au nombre de 130, 150, 200, parfois mème 260) s'abaissent lentement sur l'insecte et l'emprisonnent. Lors même qu'il s'est posé sur le bord de la feuille, il n'en est pas moins saisi par les tentacules et insensiblement amené au centre. Une sécrétion visqueuse l'englue et il ne tarde pas à mourir. Puis la plante le mange, littéralement, c'est-àdire qu'elle l'absorbe et qu'elle le digère, en vertu d'un suc gastrique de même ordre que celui qui fonctionne dans notre estomac. La plante carnivore sécrète un ferment analogue à la pepsine, et qui se comporte absolument comme elle dans la digestion. On peut lui donner à manger de la viande crue, de la viande rôtie, des fragments d'œufs durs, des cartilages, mème des os 1 Elle ne rejette presque rien. Cet être est d'une puissance digestive phénoménale. On ne peut observer les actes du drosera sans se croire en face d'un animal d'organisation inféricure embrassant sa proie avec ses bras, ou d'une pieuvre d'un nouveau genre.

L'espace nous manque pour nous étendre davantage sur ces plantes sensibles. Il serait du plus haut intérêt de nous arrêter un instant encore sur les dionées, qui broient sans pitiè les mouches imprudentes un instant posées sur elles et les dévorent sans autre forme de procès, les byblis, les aldrovandia, et les espèces analogues. Mais le grand objet de nos études nous presse. Il était important, en décrivant la période carbonifëre, l'ère par excellence du règne végẻtal, d'apprécier ce règne dans sa réalité vivante, de sentir qu'il n'est pas étranger au svstème vital de notre planète, qu'il est beaucoup moins èloigné du règne animal que les apparences ne portent à le croire, et que, non seulement par son origins, 
mais encore par ses manifestations graduelles, il est le frère de son voisin plus heureux et plus riche. Lorsque nous nous occuperons des origines de l'esprit humain, nous verrons que, mème an point de vue des facultes mentales, la plante n'est pas aussi inerte, aussi impersonnelle qu'on le suppose. La faim, la soif, la santé, la ma-

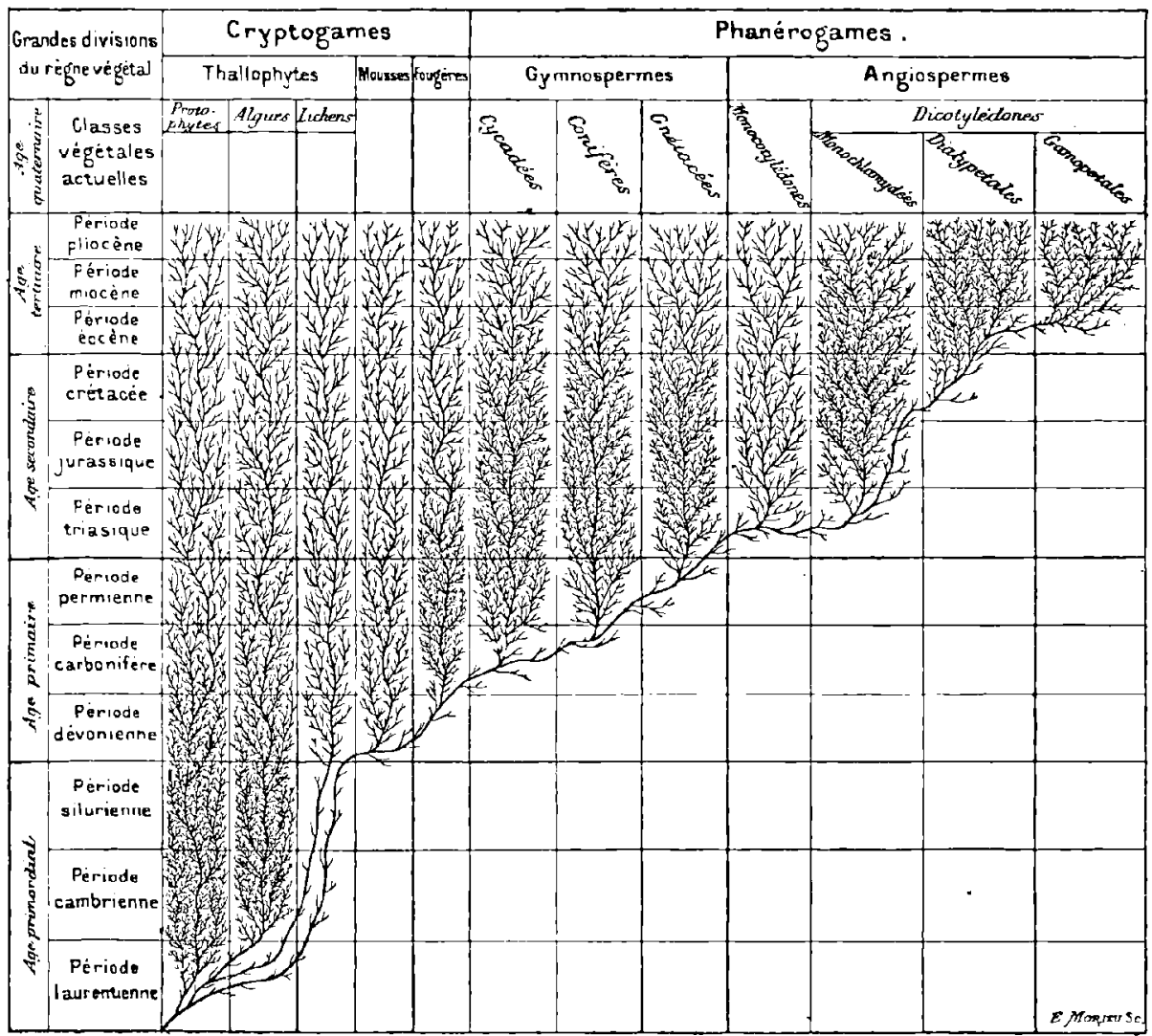

Fig. 223 - Arbre généalogique du règne végétal.

ladie, les variations de force et d'activité, la gourmandise, le désir, lamour même, ne sont pas des sensations étrangères aux plantes; elles en connaissent au moins l'impression rudimentaire.

Les plantes supérieures ne sont arrivées que très tard sur la scène du monde, comme les animaux supérieurs, et rien ne nous empèche de penser que dans l'avenir il n'en existera pas de plus élevées encore que celles-ci, car le règne végétal progresse comme le règne animal et comme le règne humain. Les phanérogames angiospermes sont de 
date récente: les monocotylédones n'ont commencé qu'à l'époque triasique et les dicotylédones à l'époque crétacée. Pendant les temps carbonifères, le monde végétal est composé de cryptogames : les gymnospermes s'annoncent.

On se rendra compte du développement et du perfectionnement graduel du règne végétal à travers les âges, par le tableau résumé ici (fig. 223) d'après celui de Haeckel. On voit, sous un mème coup

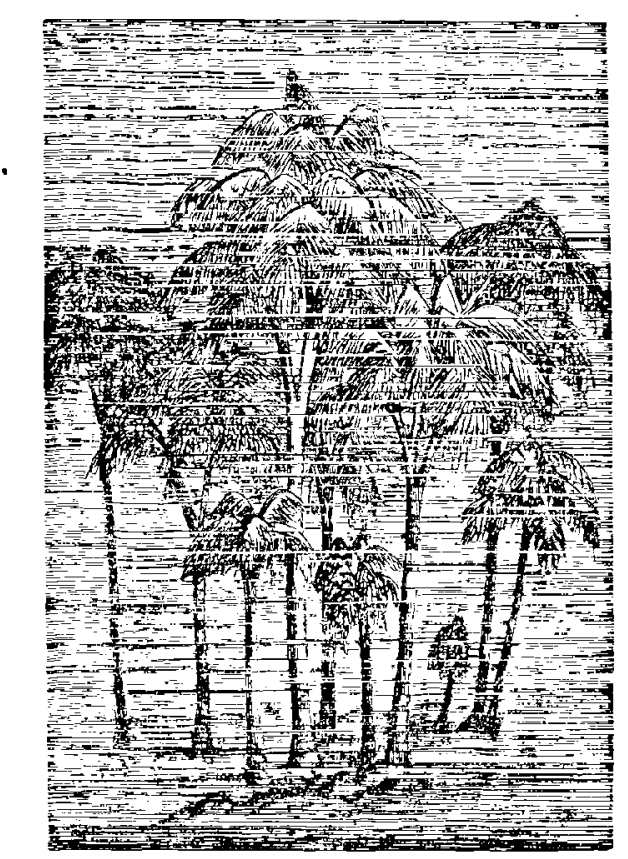

Fig. 224. - Lessonia fucescens (Algues), d'après M. L. Marchand.

d'œil, que pendant l'âge primordial, il n'y avait encore que des crypto. games primitives, des protophytes et des algues; que pendant l'âge primaire, la période dévonienne donne naissance aux lichens, aux mousses, aux premières fougères, aux lycopodiacées, calamariées, équisétacées, qui se développent surtout pendant la période carbonifère; que dans la période carbonifère naissent les gymnospermes cycadées, qui se rattachent de près aux fougères, puis, dans la période permienne des conifères, qui dominent dans l'âge secondaire. On voit aussi que les angiospermes ont commencé par les plantes monocotylédones, durant la période triasique, tandis que les dico- 
tylédones ne se sont montrées qu'à la fin pour occuper le milieu de l'âge tertiaire et arriver jusqu'à nous. C'est surtout au point de vue de l'ensemble de cet arbre généalogique que nous publions ce tableau. Il n'est point nécessaire que nos lccteurs pénètrent dans los détails de la botanique pour le comprendre. Il suffit qu'ils se repré-

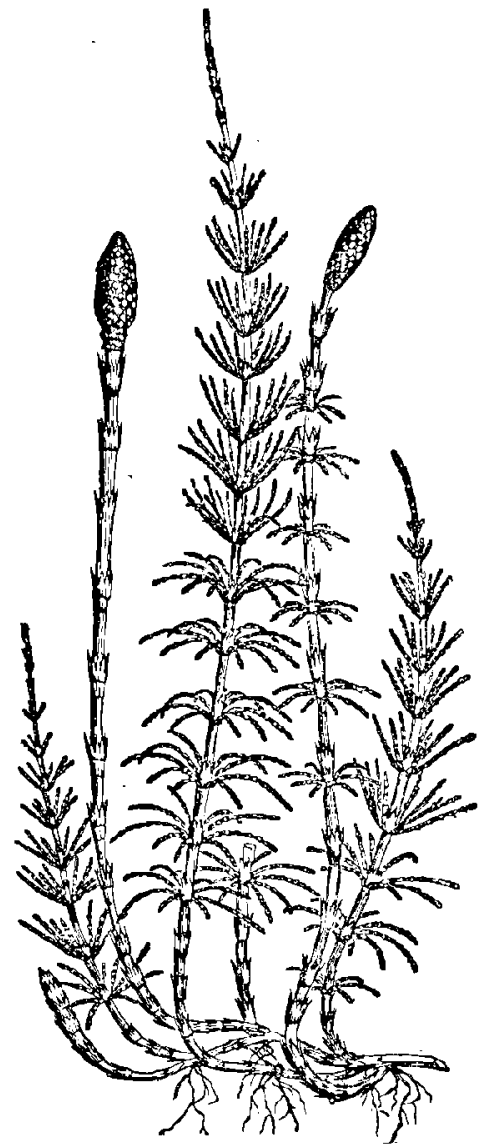

Fig. 225. - Equisetum sylvaticum (Prêles).

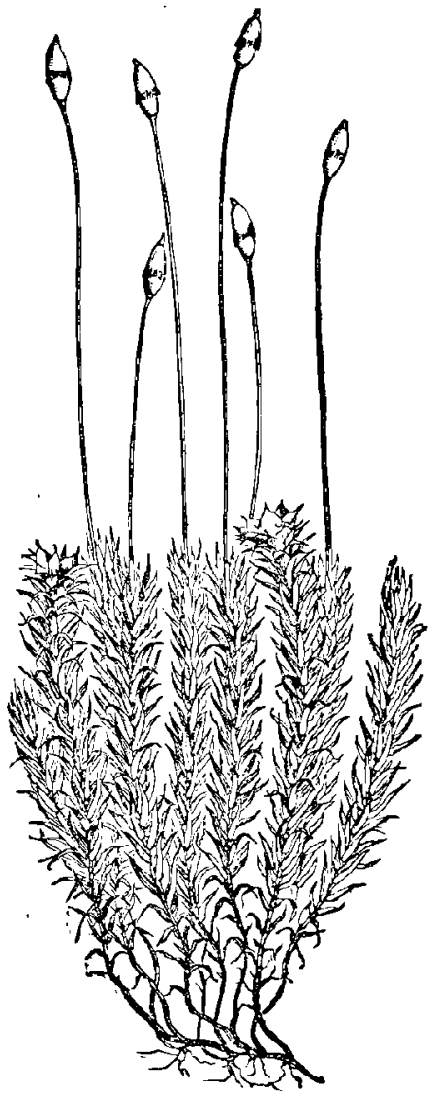

Fig. 226. - Polytrichum commune (Mousses).

sentent la filiation des espèces végétales dérivant naturellement les unes des autres, comme nous l'avons vu pour le règne animal. Désormais nos lecteurs connaissent les grandes lignes de l'architecture de la vie terrestre, les vérités fondamentales du " monde avant la création de l'homme $n$.

Lentement, graduellement, le règne végétal grandissait, se perfectionnait, s'adaptant aux conditions organiques de la planète et à 
leur propre perfectionnement. La période carbonifère a été celle de son expansion la plus rapide. Dans l'abondance et la fécondité de cette végétation primitive, au sein des eaux tièdes, sur les îles d peine émergées, dans les bas-fonds saturés d'humidité, on pouvait reconnaitre les genres les plus divers de la flore cryptogamique, des algues relativement perfectionnées ( $f g$. 224), des prêles élégantes (fig. 225), des mousses (fig. 226). Elles règnaient en soluveraines et formaient pour ainsi dire le tissu mème des terrains sur lesquels

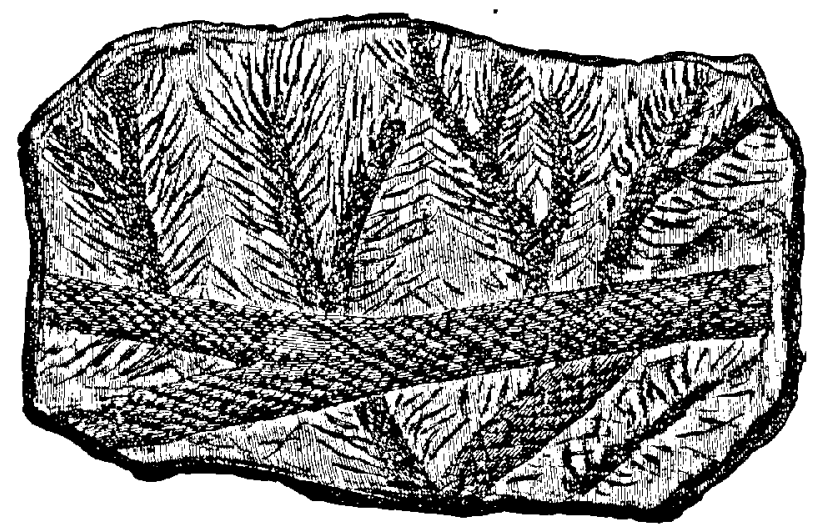

Fig. 227, - Rameaux fossiles de Lépidodendron.

vont croitre les gigantesques lycopodiacées. « De ces formes rudimentaires où le protoplasma est à nu, dépourvu qu'il est de membrane cellulaire, écrit M. Marchand, on monte aux formes qui touchent aux phanérogames, auxquelles on passe insensiblement. En suivant pas à pas le développement du monde des végétaux on a le sentiment d'un perfectionnement qu'on voit s'accomplir. »

Ces vẻgẻtaux inférieurs, ces mousses, ces prèles, grandissent, arrivent à mesurer plusieurs mètres de hauteur. On a même trouvé dans le terrain carbonifère des calamites, prẻles gigantesques, équisétacées, s'élevant à dix et douze mètres. (On a remarqué plus haut les beaux fragments recueillis dans les mines de Saint-Étienne et d'Anzin.)

Mais ce n'était là que le prélude des forèts splendides dans lesquelles vont dominer les lépidodendrons, les sigillaires et les fougères arborescentes. Les lépidodendrons appartiennent à la famille des Iycopodiacées,qui n'est plus représentée aujourd'hui que par nos 


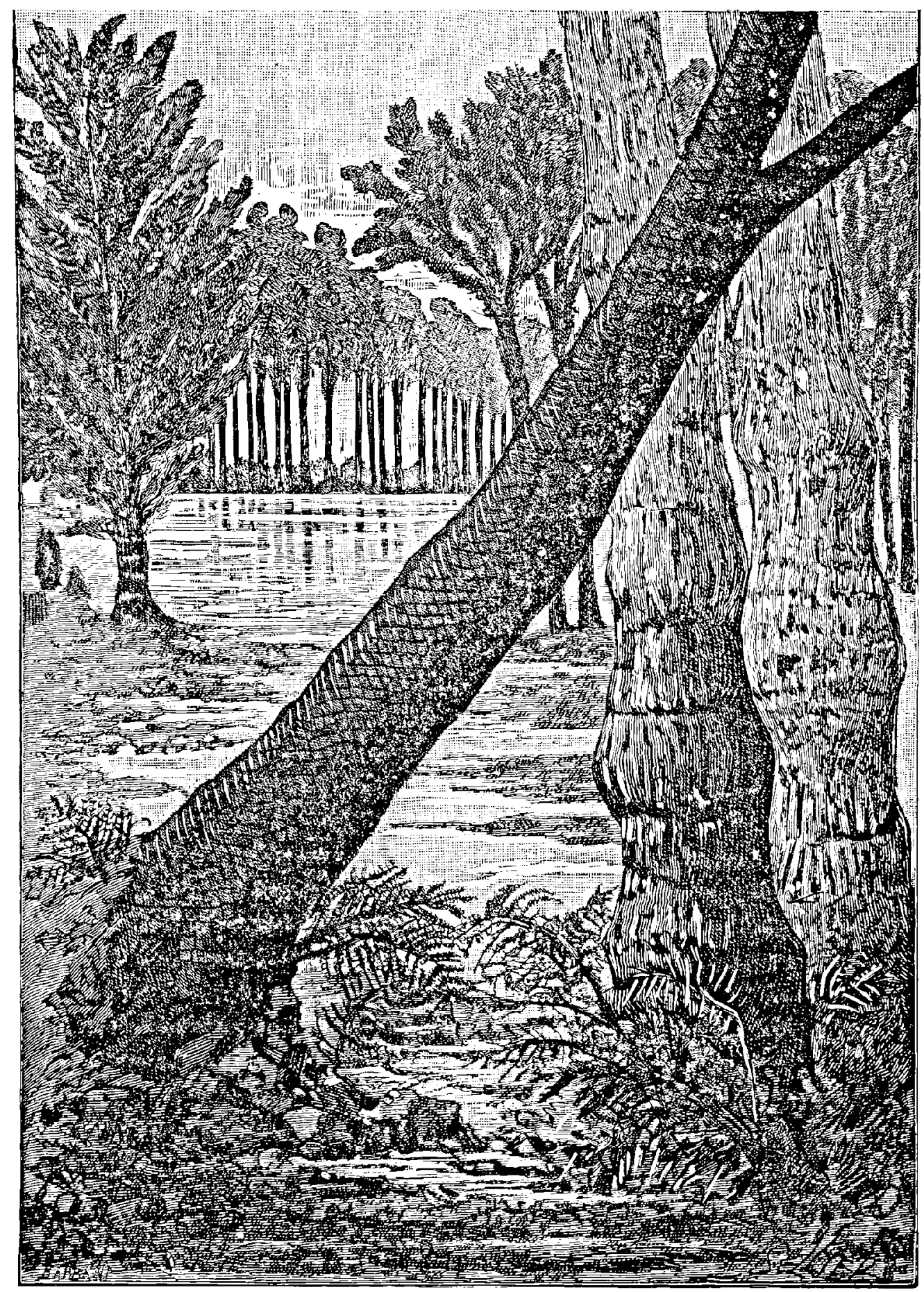

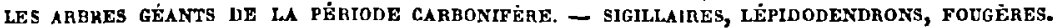
(Hauteur $=30$ et sol mêtres.)

LE MONDE AYANT LA CRÉation DE L'HOMME 
humbles lycopodes. Ils atteignaient alors des dimensions prodigieuses, et leur élégance rivalisait avec leur force. Déjà, dans les. vestiges retrouvés au milieu des houilles, on devinait à la fois cette force et cette élégance. Lorsqu'ils furent mieux connus et qu'on sut les apprécier à leur réelle valeur, on trouva que ces fragments appartenaient à des arbres merveilleux mesurant jusqu"a trente mètres de hauteur et un mètre et demi de diamètre. L'écorce

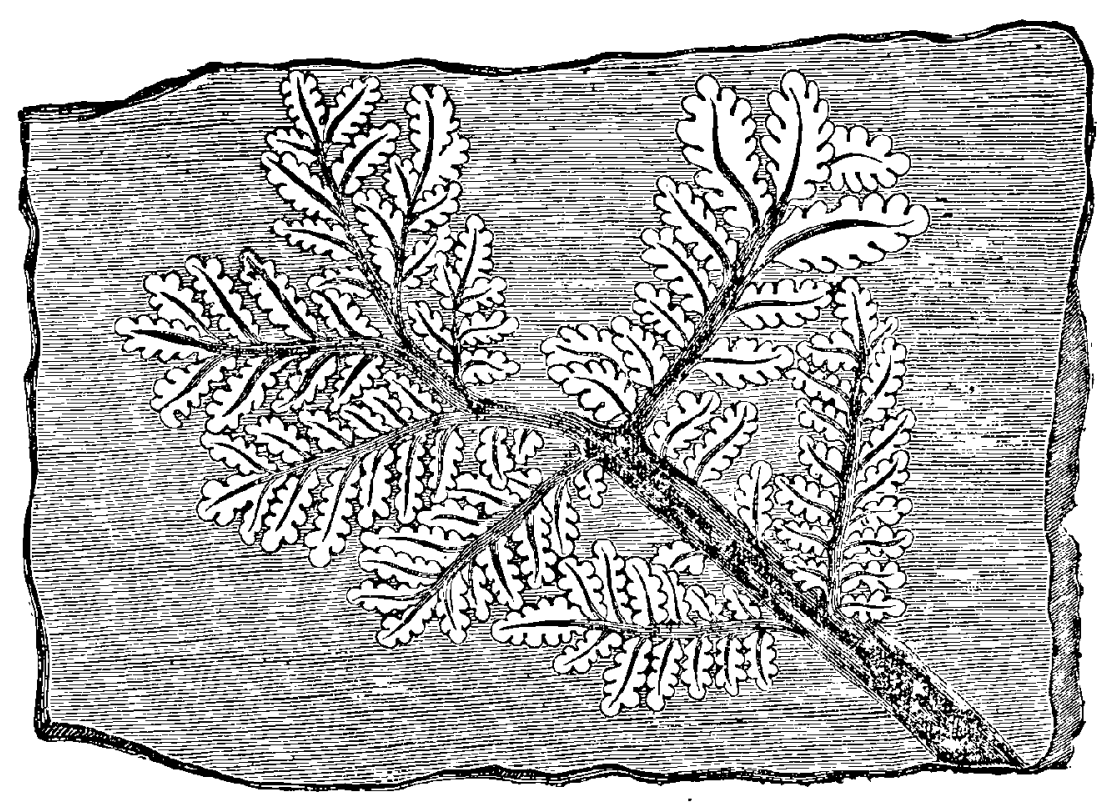

Fig. 229. - Empreinte fossile de fougère.

de ces arbres' gigantesques était remarquablement belle (on peut on juger par les fragments ci-dessous ( $f$ g. 230-231), gravée, ciselée de losanges fort élégants. On a retrouvé juscqu'à la forme exacte de leur tige et de sa structure intérieure : il y avait au centre une espèce de moelle, comme dans les calamodendrons ( $f g$. 232-233) leurs contemporains. On voit qu'il n'y avait pas de couches concentriques annuelles, comme celles qui nous permettent aujourd'hui de compter les années de l'âge d'un arbre, de reconnaître son oricntation lorsqu'il vivait, et même de distinguer ses années de souffrance et ses années de prospérité. La restauration qui a été faite de ces arbres (voy. p. 441) nous permet aujourd'hui de nous rendre compte de leur aspect et de leur stature. 
Aux calamites et aux lépidodendrons il faut adjoindre, comme représentant la flore cryptogamique fossile de ces âges reculés, les fougères qui, dans ces riches conditions de prospérité, deviennent arborescentes. Au lieu de s'élever à peine à quelques mètres de hauteur, comme de nos jours, mème dans les régions tropicales, elles atteignaient douze et quinze mètres et formaient de véritables arbres. Les nombreux spécimens qu'on en retrouve dans les couches

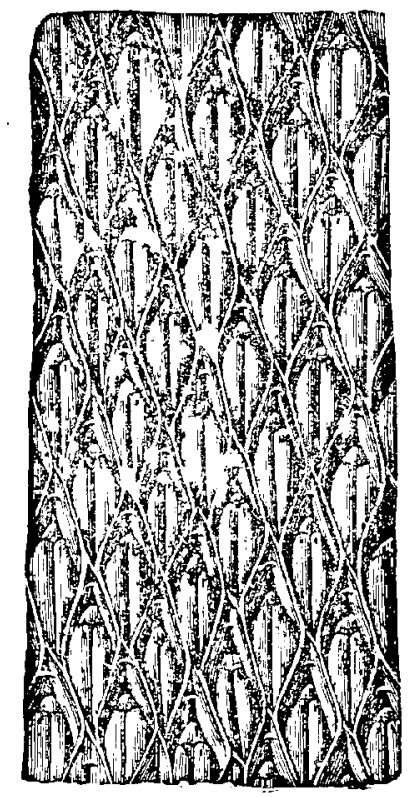

Fig. 2:30.

Ecorce du hépidodendron aculeatum.

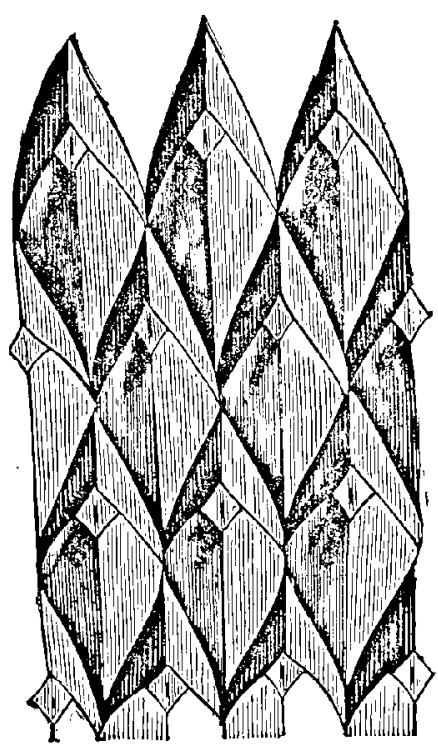

Fig. 231. Écailles de lépidodendrons.

carbonifères révèlent la variété et la richesse de formes qui les distinguaient. Elles étaient extrêmement nombreuses et ont régné en souveraines pendant les longs siècles de l'époque paléozoïque, pendant les premiers âges de la vie à la surface du globe. Le dessin publié plus haut (p. 425) rappelle la haute élégance de leurs formes predominantes.

Mais peut-être aucun végétal de ces temps antiques n'égalait-il encore comme singularité et comme aspect les arbres gigantesques et bizarres, absolument perdus aujourd'hui, désignés sous le nom de sigillaires. Ces arbres, qui atteignaient et dépassaient peut-être 
quarante mètres de hauteur, semblent nous conserver le souvenir des types intermédiaires entre les cryptogames et les phanérogames, car ce sont presque déjà des phanérogames gymnospermes. Ils ressemblent aux cycadées et aux conifères. Ils rn'ont pas de couches annuelles, et leurs ovules ne sont pas protégés par un ovaire. "Les gymnospermes, écrit ḋ ce propos M. de Saporta, sont

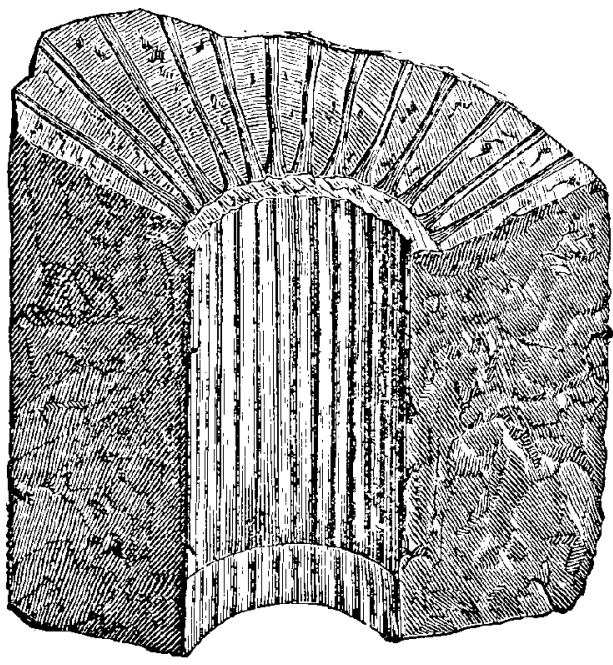

Fig 232.

Fragment de tige de calamodendron.

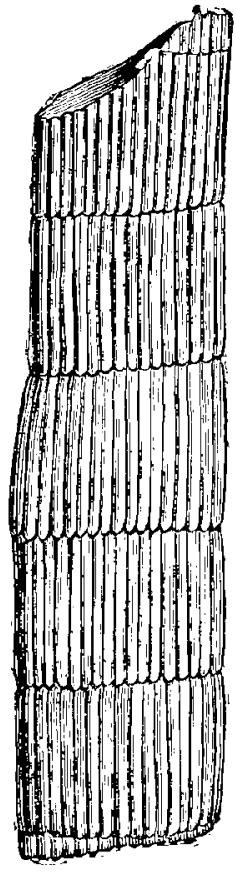

Fig. 233.

Moelle pétrifiée d'un calamodendron.

des phanérogames imparfaites, ou mieux encore plus simples, moins éloignées des cryptogames que les angiospermes, ou phanérogames proprement dites. Celles-ci ne se manifesteront que beaucoup plus tard, et surtout elles ne parviendront pas de longtemps à saisir la prépondérance. $\left.»()^{4}\right)$

On le voit, la marche de la nature est toujours la même : du simple au composé, de l'imparfait au perfectionné, de la pauvreté à la richesse; en un mot l'ascension, le perfectionnement, le progrès.

1. Nous pouvons considérer les sigillaires comme des végétaux cryplogames, se reproduisnt an moyen de spores. (Voy. Zkiluer. Comptes randus de l'Académie des sciences du 30 juin 1884.) 
Dès les premières découvertes de troncs de sigillaires, on fut surpris de l'arrangement régulier de certaines cicatrices ovales tout autour de ces belles tiges cylindriques ( $f g$. 234-235), et c'est même cette particularité qui inspira le nom sous lequel on les désigne, à cause de cette ressemblance avec des sceaux (Sigillum). Ces énormes végétaux étaient soutenus par des racines puissantes (Stigmaria) qui s'étendaient parfois souterrainement jusqu'à quinze et vingt mètres de la base de l'arbre. On ne connait pas encore avec certitude l'aspect que ce colosse pouvait avoir; cependant il ne pouvait
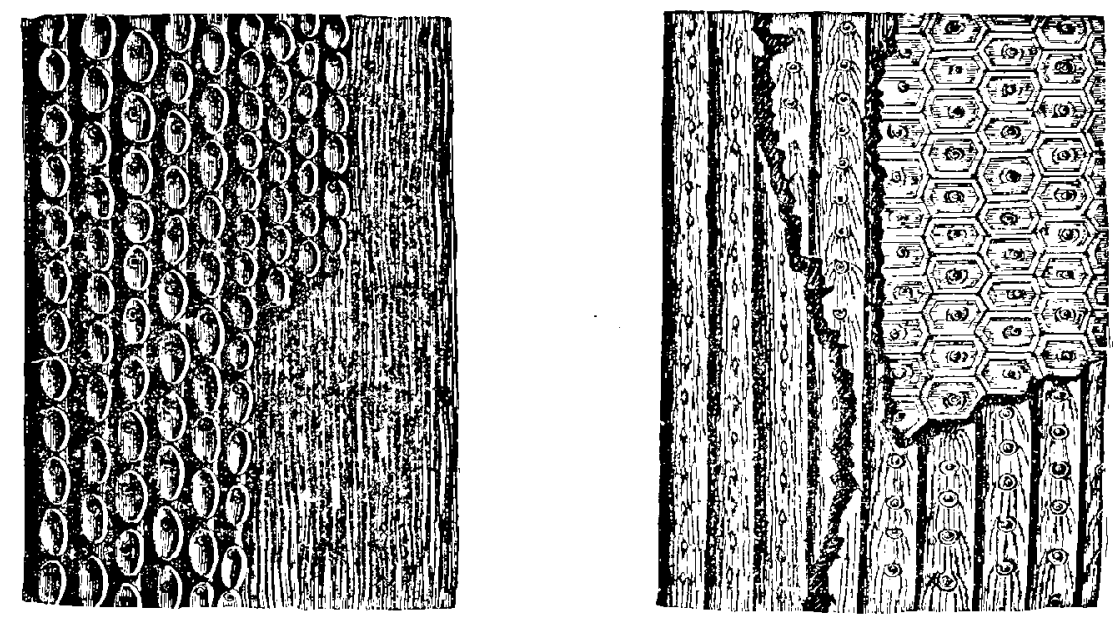

Fig. 23.1 et 235. - Ĺcorce fossile de Sigillaires. (Sigil laria tressellala el Davreuxii).

pas s'éloigner beaucoup de la forme représentée plus haut (p. 441), ot devait ressembler aux cycadées qui existent encore actuellement. Quant à ses dimensions, elles sont certaines.

D'autres arbres do cettc famille sont cuirassés du haut en bas de boucliers hexagonaux, qui tous portent en mème temps les traces des feuilles; ou bien ces sortes d'écussons sont trois fois plus longs que larges, et.ne portent les attaches des feuilles qu'à l'angle supérieur, ce qui produit une configuration analogue, mais pourtant très distincte.

Lne autre forme également singulière, celle des stigmarias, qui a beaucoup d'affinité avec celle que nous venons de décrire, a donné lieu à maintes erreurs, jusqu'à ce que l'on eût découvert le mot de l'énigme. 
Dans les terrains houillers, on trouvait les énormes tiges plus ou moins courbées, mais jamais tout à fait droites, d'une espèce étrange; ces arbres se faisaient surtout remarquer par leur écorce ondulée,

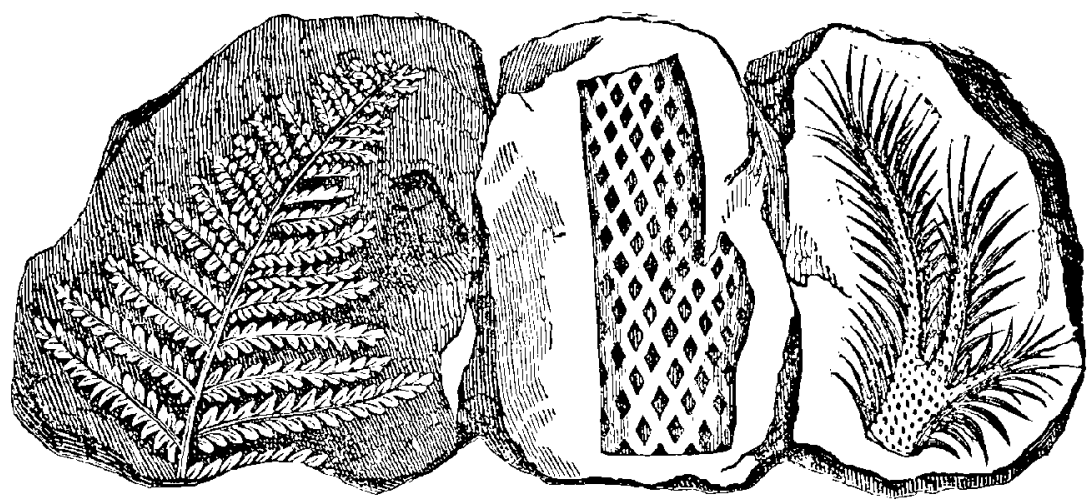

Fig. 236. - Empreintes fossiles d'une fougìre, d'un tronc de lépidodendron et d'une branche du mème arbre.

par un rétrécissement très rapide du tronc, et enfin par des marques, de la grosseur d'un pois, qui s'enroulaient autour de la tige en spirales régulières. Ces marques étaient de petits sceaux, des empreintes

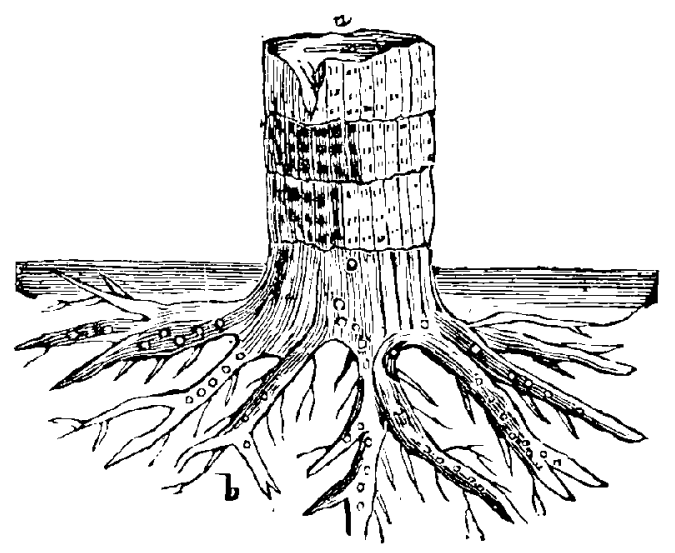

Fig. 237 - Racines de sigillaire : stigmaria.

de feuilles qui, dans les sigillaires (comme dans nos beaux palmiers et nos fougères), sortaient du tronc mème; mais ces feuilles ne semblaient en aucune facon appartenir à la mème famille. De plus amples recherches firent découvrir des souches portant de pareilles feuilles, ligneuses, cylindriques; c'étaient les pétioles plutôt que 
les feuilles. Enfin, on trouva un trone magnifique de sigillaire, portant encore ses racines, et il fut constaté que ce qu'on avait appelé stigmaria, considéré comme un tout, comme un arbre isolé, n'était autre chose que la racine du sigillaria. On a pu remarquer plus haut $(f g .237)$ cette souche avce ses racines, telle qu'on en trouve en abondance, depuis que l'on observe plus attentivement les fossiles, et qu'on s'occupe avec plus de soin de leur conservation.

Toute cette espèce a disparu avec la flore primitive; nais les

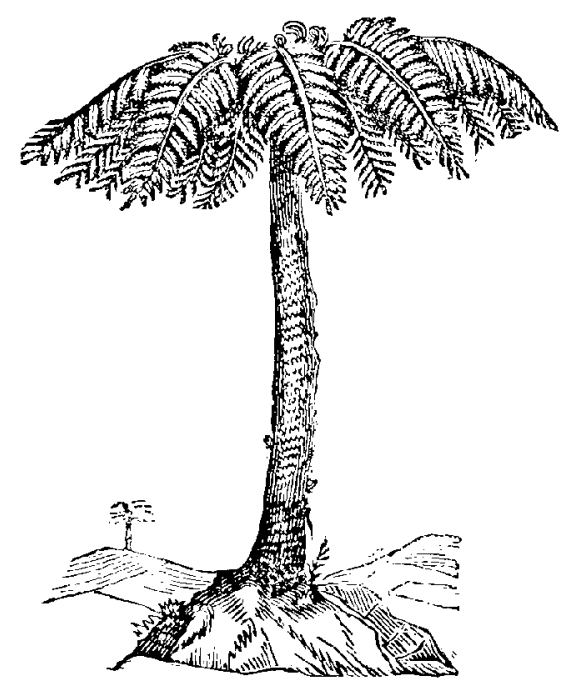

Fig. 238. - Fougère arborescente.

sigillaires se transforment en fougères, les plus belles plantes arborescentes de cette famille. Ce que nous appelons aujourd'hui de ce nom n'est plus qu'un pâle vestige de ces splendides végétaux d'autrefois. Le dessin ci-dessus donne une idée de l'aspect d'ensemble d'un arbre de cette nature. Ce n'étaient point des palmiers, malgré la ressemblance : les feuilles des fougères sont bipennées, parfois mème tripennées; de plus, les jeunes feuilles des fougères naissent en grand nombre à la fois et sont enroulées comme des cheveux dans des papillotes, tandis que les feuilles des palmiers naissent l'une après l'autre et s'élancent d'une tige droite rappelant la forme d'une queue de billard, qui se termine presque en pointe à l'extrémité. 
Les fougères, comme les sigillaires, sont des plantes qui, outre l'ombre et l'humidité, aiment la chaleur, car toutes celles qu'on a trouvées révèlent un climat tropical

Les arbres fossiles ne datent pas de la mème époque que les houilles; ils sont plus récents. Cependant quoique les plantes transformées en silice n'appartiennent pas à la formation houillère, elles sont incontestablement des produits de la période du grès

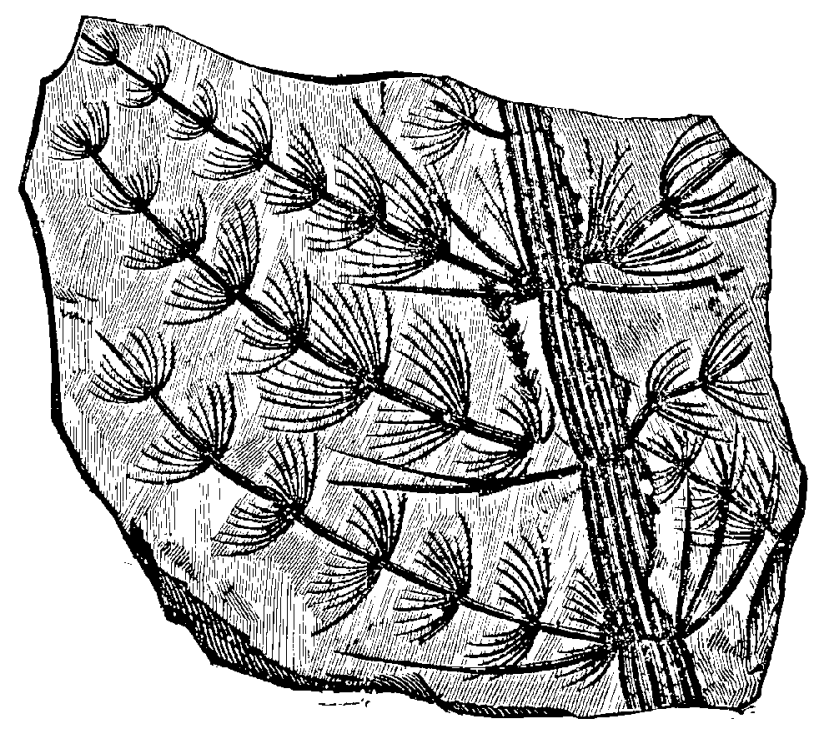

Fig. 939. - Ramealı fossile d'asterophyllite equisetiformis.

rouge, qui suit immédiatement. Peut-ètre ces végétaux, s'étant développés à l'époque de la formation houillère, sans être incinérés ou carbonisés, ont-ils été retenus à la surface, recouverte de sable et d'argile; puis, la substance siliceuse se sera séparée du mélange pour se déposer dans les fibres ligneuses, ou bien, le carbone y étant rare, s'y substituer, molécule à moécule et n'en conserver que la forme, le carbone servant de matière colorante. C'est ainsi que nous trouvons en abondance ce que nous appelons du bois fossile, transformé en agate, en calcédoine, en pyromate, et il est merveilleux que toutes les fibres, toute la texture de la plante, la pulpe, etc., aient conservé leur forme, alor's que la substance elle-même a complètement disparu.

On retrouve des couches entières de bois pétrifiè. L'hôtel de 


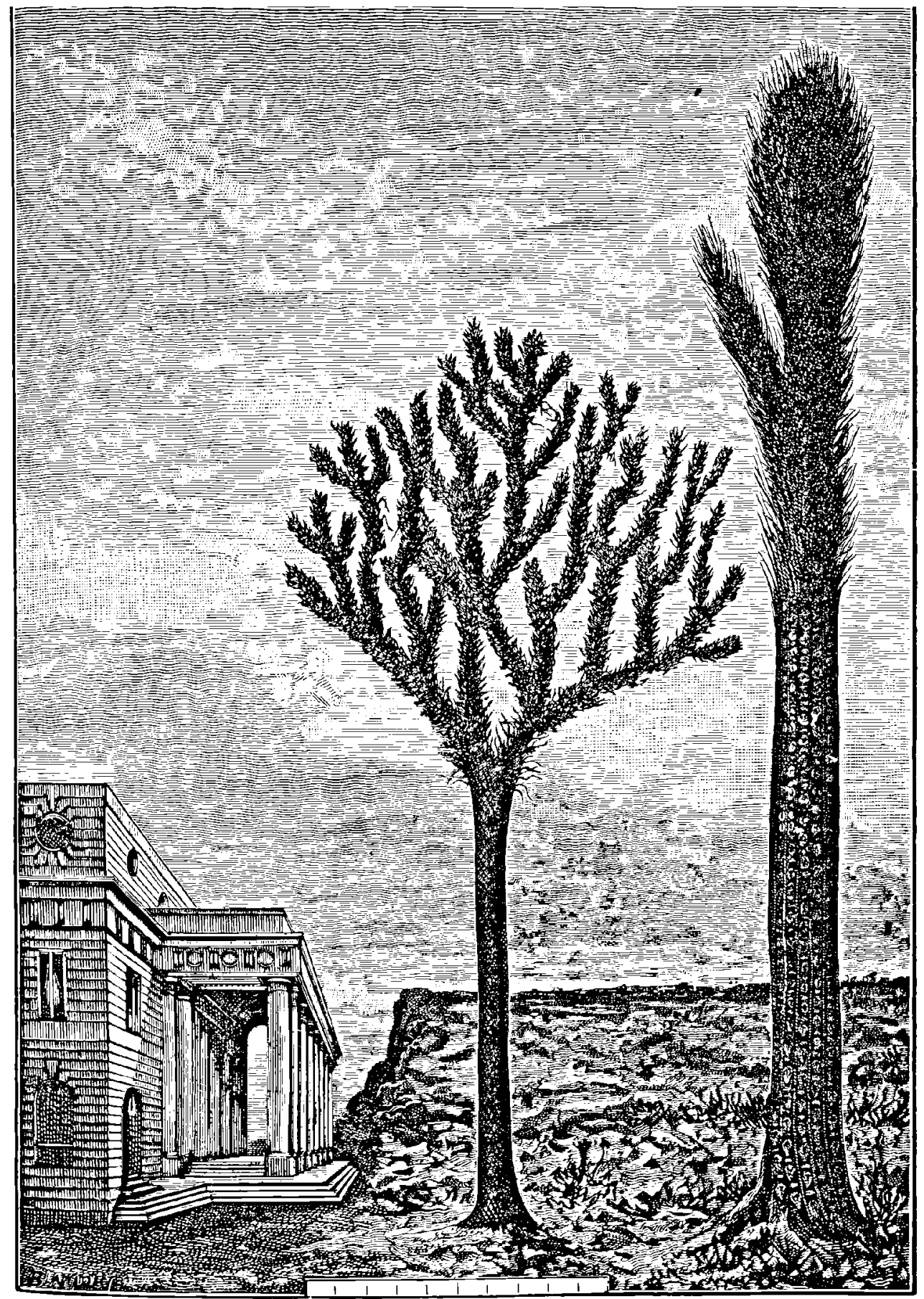

\footnotetext{
W.. RESGUSCITŔS DE NOS JOURS, CES ARBRES GEANTS FERAIENT ONE ETRANGE FIGURA... (Lepidadendron de 30 m ot Sigillatre do $40 \mathrm{~m}_{\text {. }}$ )
}

LE MONDE AYANT LA CRÉATION DE L'HOMME 
ville de Nordhausen renferme un escalier en grès, dont chaque fragment indique, de la facon la moins équivoque, qu'il a été primitivement de bois, et, micux encore, que sa masse s'est accumulée d'année en année en couches ligneuses, formées des fibres, des tiges et des branches; sur d'autres points, on trouve la masse ligneuse transformée en agates superbes, parfois transparentes, parfois opaques et teintes des couleurs les plus variées. Sur Ia terre
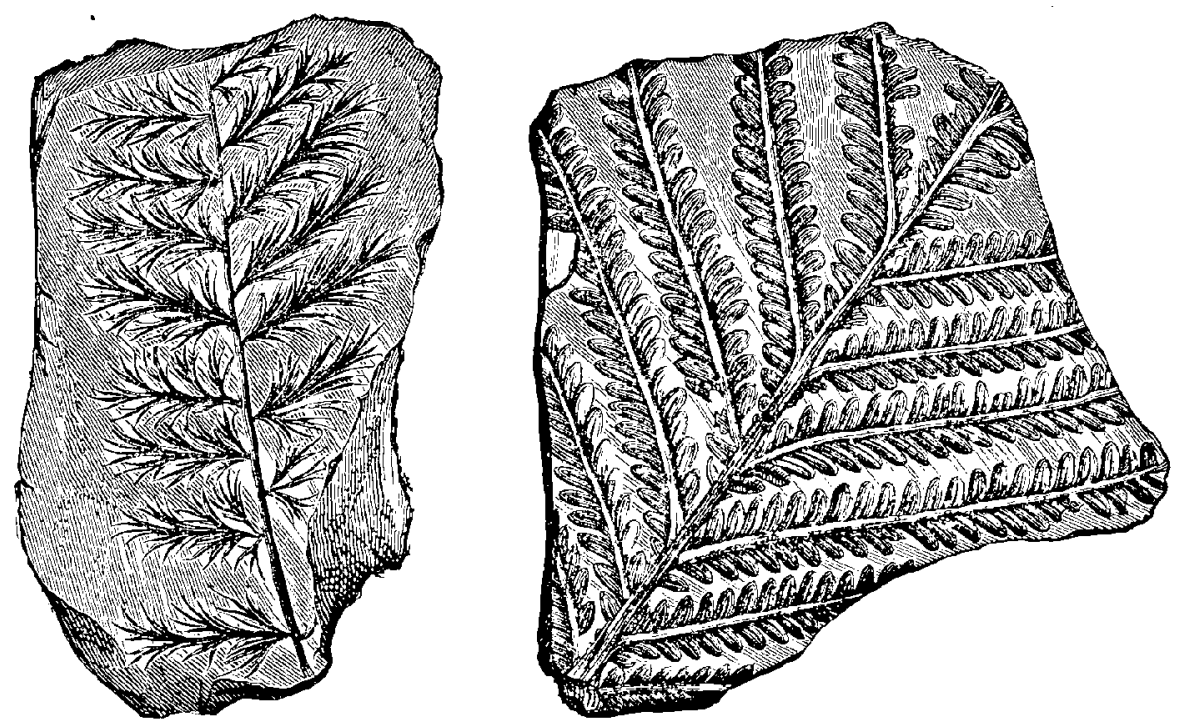

Fig. $2 k 1$ et 2 เ2. - Rameaux fossiles de fougères. (Spbenopteris acutiloha. Callipteris conferta.)

de Van Diémen, il existe, dans le vallon de Derwent, une forèt d'arbres pétrifiés et transformés en opales. Une des curiositès naturelles les plus merveilleuses, qui attirent l'attention des géologues visitant ces contrées, est sans contredit cette vallée des arbres pétrifiés. Nulle part peut-être on ne rencontre plus belle pétrification de bois et nulle part la structure originelle des tissus ne s'est mieux conservée. Tandis que l'extérieur offre une surface luisante et homogène, pareille à celle d'un sapin revêtu d'écorce, l'intérieur se compose de couches concentriques qui paraissent tout à fait compactes et de même nature, mais se laissent parfaitement fendre dans toute leur longueur.

- «Le plus remarquable de ces arbres, écrit sir James Ross, surgit verticalement d'une couche de lave bulleuse, du haut d'un rocher 
qui domine de 70 pieds le niveau de la rivière. L'arbre lui-même n'a que six pieds de haut et mesure an sommet 15 pouces de diamètre. Non loin dẹ là s'en trouve un autre, planté dans une sorte de cheminée naturelle, beaucoup plus longue que la souche et dont les empreintes indiquent que, dans le vide qu'elle renferme, l'arbre se continuait jadis. Cet espace vide a sept pieds de long. Comme tous les arbres pétrifiés, ceux-ci sont verticaux; d'où il semble résulter qu'ils étaient encore en pleine croissance lorsque la lave ardente les atteiguit, consumant les feuilles et les branches, et ne trouvant qu'à une certaine profondeur du végétal une résistance suffisante pour ne pas le carboniser et peut-être pour se refroidir. Il serait intéressant de rechercher les racines, dont l'existence démontrerait que les arbres sont encore à leur place primitive; peut-être cependant ont-ils été amenés debout par le flot brûlant, semblable au glacier qui entraîne avec lui les objets enfermés dans ses flancs. $D$

L'île de Kerguelen et les pétrifications qu'on y a trouvées sont mentionnées par sir J. Ross dans le récit qui précède. Voici ce qu'il en dit ailleurs :

“ Au sud du port (le port de Noöl, dans l'ìle de Kerguelen), se trouve le renarquable rocher décrit par Cook et dont le profil occupe une si grande place dans son dessin de la baie. C'est une énorme masse de basalte, de cinq cents pieds d'épaisseur, beaucoup plus récente que le rocher sur lequel elle repose et d'où elle parait avoir surgi à l'état mi-liquide, à une hauteur de six cents pieds au-dessus du niveau de la mer. C'est entre ces deux roches, d'ancienneté différente, que l'on a trouvé des arbres pétrifiés; on en a déterré un de plus de sept pieds, que l'on a expédié en Angleterre. Quelques fragments de ce bois pétrifié paraissaient encore si vivaces qu'il fallut se livrer à un examen très attentif, pour se convaincre que c'était de la pierre qu'on avait sous les yeux. Leur degré de pétrification varie depuis la houille très combustible, jusqu'au silex capable d'ẹtamer le verre. Tne couche de schiste, de plusieurs pieds d'épaisseur, déposée sur les arbres, parait en avoir empéché la carbonisation, lors de l'invasion de la lave. Un des caractères géologiques les plus curieux de cettê île est précisérnent qu'on y trouve des couches de 
houille superposées, d'une épaisseur variant de quelques pouces ḋ plusieurs pieds. »

L'écrivain anglais, au lieu de décrire la stratification de ces roches, ajoute ici que, sans savoir si l'abondance de la houille dans ces îles permet d'en former un oljet de trafic, il croit les couches assez riches pour en tirer de quoi établir un dépôt de combustible à l'usage des vapeurs de passage. Ce détail est plus intéressant pour les commerçants que pour les géologues. L'intérèt principal de ce récit, c'est qu'au-dessus de la formation houillère et des couches qui la recouvrent, des pétrifications siliceuses ont été trouvées, aussi bien à l'extrémité sud de la Nouvelle-Hollande (terre de Van Diémen), qu'à la distance d'un quart de la circonlérence du globe, sous la même latitude; dans l'île de Kerguelen, aussi bien que dans le centre de l'Allemagne (').

Dans le grès rouge et au-dessous de cette roche, on trouve des arbres pétrifiés pénétrés d'une masse siliceuse, et transformés en calcédoine; ces trones, coupés transversalement, sciès en plaques et polis, donnent des carreaux de luxe pour tous les usages, aussi beaux que l'agate et la col'naline.

Mais revenons à l'époque houillère.

Comme les sigillaires, les cardoites, aujourd'hui disparues, ouvraient l'ère des gymnospermes, dont les cycadées et les conifères sont les représentants actuels, et elles aussi formaient des arbres de quarante mètres de hauteur, ramifiés seulement au sommet et couverts de feuilles énormes, mesurant un mètre de longucur. Ces longues feuilles arrondies se trouvent en grand nombre dans tout le terrain houiller, surtout dans les couches supérieures.

Signalons encore ccrtaines conifères, les walchia, voisins des araucarias actuels, les annularièes des marais, plantes herbacées flottantes, les astérophyllites ( $f g .239)$ dont on avait fait un genre de la famille précédente, mais qui appartiennent aux calamodendrons. Tous ces végétaux sont caractéristiques des terrains carbonifères, et nous reportent aux âges disparus pendant lesquels la plus grande partie des îles émergées étaient recouvertes de ces. hautes et impénétrables forêts, à peine éclairées par la lumière

1. Les plantes transformées én silice, qu'on a trouvées en Europe, sonl généralement des fougères. 
diffuse du soleil naissant. Nos lecteurs se rendront compte de cet ensemble à l'aspect de nos dessins. Sur le grand tableau (p. 441); les arbres géants de droite sont des sigillaires, celui qui semble tomber à travers le paysage est un lépidodendron; à gauche, on remarque un calamite et au dernier plan des fougères. Déjà ils ont pu se retrouver au milieu de ces forêts fossiles dès les premières pages de cet ouvrage (p. 9) cn voyant les restes de sigil-

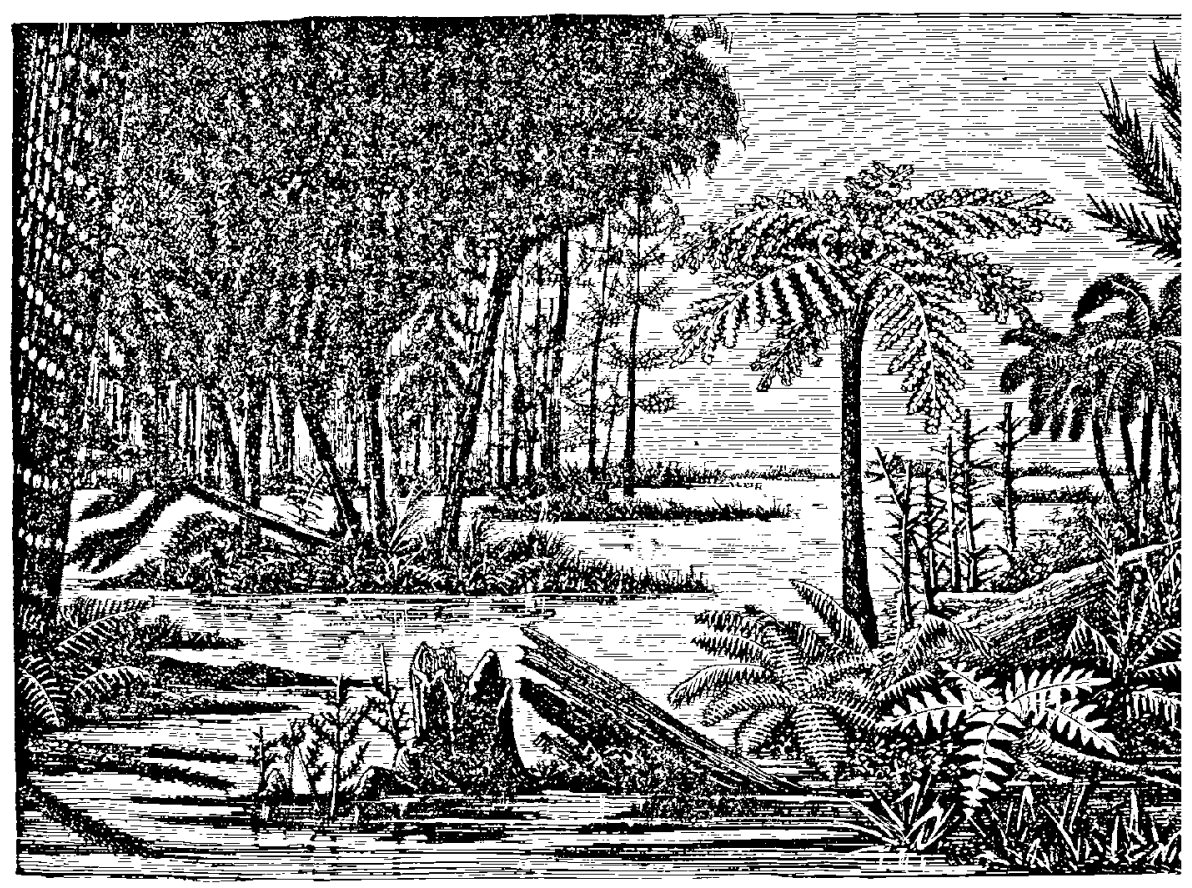

Fig. 243. - Un paysage de l'époque houillère.

laires, de calamites, de lépidodendrons, de fougères dégagés par la pioche du mineur au fond des mines de houille, et déjà aussi ils ont pu admirer l'une de ces forêts restaurées (p. 17) en un tableau qui nous remet en face de ces siècles évanouis. Mais e'est surtout en contemplant le magnifique paysage de l'époque carbonifère interprété par l'aquarelle ( $p l$. II) (') que nos lecteurs pourront le mieux se rendre compte de la nature de ces forêts immenses croissant autant dans les eaux que sur un sol dejà

1. Cette planche en couleur doit être placée par le relieur en regard de la page 408 et la planche I au frontispice du volume, en face du titre. 
végétalisé par la multitude des plantes amoncelées dans ce sol depuis des siècles. Ce paysage donne une idée aussi exacte que possible de ce que devait être l'aspect de la Terre pendant l'époque de la formation des houilles.

Ressuscités de nos jours, ces arbres géants feraient une étrange figure. Le dessin publié plus haut (p. 449) montre quel effet ils produiraient si quelques-uns d'entre eux se dressaient encore à la lumière de notre soleil. Nous avons là sous les yeux un lépidodendron. de trente mètres et un sigillaire de quarante, comme les forêts houillières en comptaient des milliers.

Telle était la flore qui embellissait notre planète eu ces temps antiques où se préparaient les opulentes houillères découvertes dans les âges modernes par les investigations de l'industrie humaine; le règne végétal, comme on vient de le voir, a fait des progrès gigantesques et rapides. Il n'en a pas été de mème du règne animal. Les forces de la nature semblent surtout avoir été appliquées à l'extension et au dévcloppement de la vie végétale.

Les espèces de poissons qui caractérisent la période précédente, la période dévonienne, se continuent pendant celle-ci, et sont représentées par les poissons ganoïdes avec lesquels nous avons fait connaissance. Ils prennent un grand développement, deviennent plus variés de formes, et atteignent une grande taille, comme le megalicthys ( $\left.{ }^{4}\right)$. D'après les vestiges découverts, certaines espèces de ces poissons devaient respirer à la fois par des branchies, comme les poissons ordinaires, et par des poumons, comme les vertébrés terrestres, ce qui leur permettait de vivre dans la vase desséchée.

Les mollusques se transforment. Ce qui domine, ce sont des brachiopodes connus sous le nom de productus ( $f g .244$ et 245), espèces bombées de très grande taille. Ceux des périodes précédentes sont en décadence, à l'exception des spirifer et de quelques autres. Les acéphales déclinent aussi, mais les gastéropodes se relèvent. Les zoophytes changent peu. On rencontre des échinodermes, des oursins à plaques hexagonales, de structure assez élégante $(f g .246)$, des étoiles de mer, nées aussi de l'époque silu-

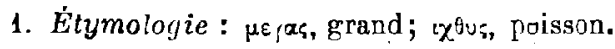


rienne, et des crinoïdes ( $f g .247$ ) qui se multiplient particulièrement durant cette période. (On en connait plus de cinq mille espèces fossiles.)

Dans l'embranchement des annelés, les crustacés subissent des variations sensibles; les trilobites disparaissent presque entière-
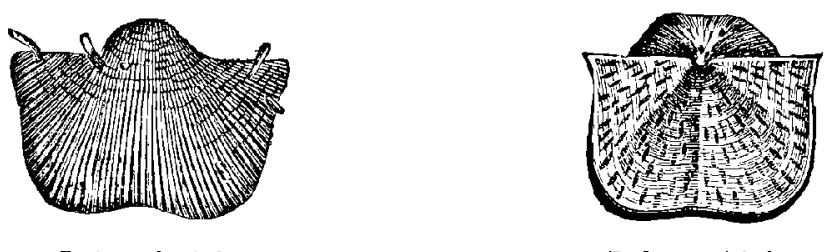

Fig. 244-215. - Brachiopodes de la période carbonifère.

ment; les arachnides, scorpions, se multiplient. Nous avons signalé plus haut (p. 249) un scorpion trouvé dans le terrain silurien. No6 lecteurs trouveront à la page suivante ses successeurs du terrain
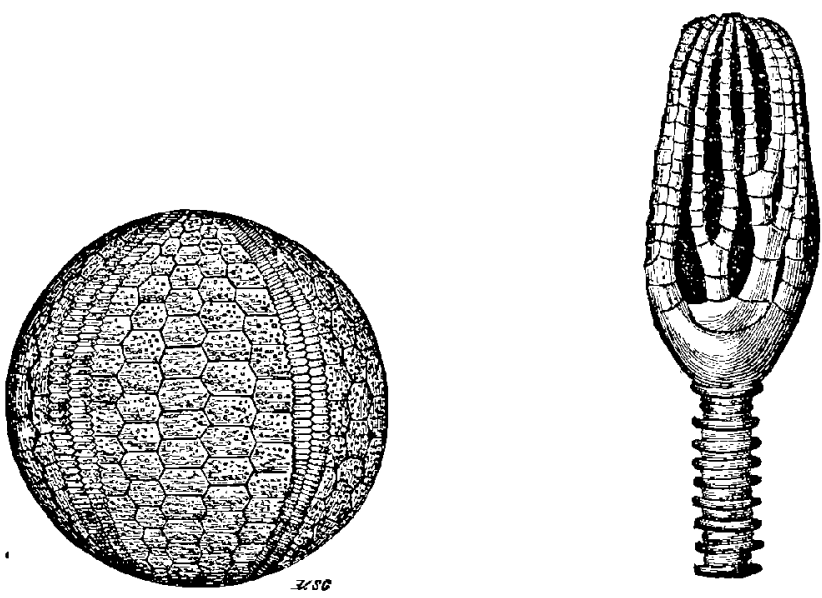

Fig. 246-247. - Oursins ct crinoïdes de l'époque carbonifère.

houiller. Les animaux à respiration aérienne deviennent de plus en plus nombreux. Comme les arachnides, les plis anciennes myriapodes ont été découvertes dans le terrain houiller. Mais ce sont les insectes qui prennent le plus rapide développement.

Yaguère encore, on n'avait retrouvé qu'un très petit nombre d'insectes fossiles, et seulement dans les couches secondaires et surtout lertiaires. Jusqu'en 1878, par exemple, dans tous les pays 
du monde, on n'avait recueilli que cent vingt débris d'insectes fossiles; depuis 1878, on a découvert, en France, dans les mines de houille de Commentry (Allier) plus de treize cents échantillons,

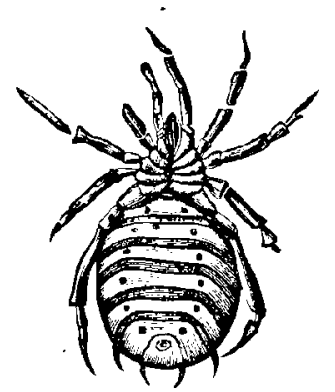

Fig. 218. - Araignẻe fossile (Eopbrynus (1) Prestricli) Troupée dans lo terrain houiller do Dudley, pue en descous pour montrer les ouvertures (stomates) de la respiratiod. (Grazdeur naturelle.)

grâce surtout au dévouement scientifique éclairé du directeur de ces mines, M. Fayol. Comme nous l'avons vu au chapitre précédent, on en a découvert quelques-uns dans le terrain dévonien, et cette année même (1885), dans le silurien De plus, le corps d'un insecte étant naturellement d'une conservation difficile, en général on ne trouvait guère que des ailes; les insectes de Commentry sont, an contraire, dans un état remarquable de conservation; beaucoup d'entre eux sont complets,ce qui permet d’apprécier plus sùrement

leurs affinités zoologiques.

Tous les insectes trouvés jusqu'aujourd'hui dans les terrains primaires sont ou des orthoptères, ou des névroptères ou des hémiptères, moins élevés en organisation que les hyménoptères, les diptères et les lépidoptères; leur corps encore primitif, et pour ainsi

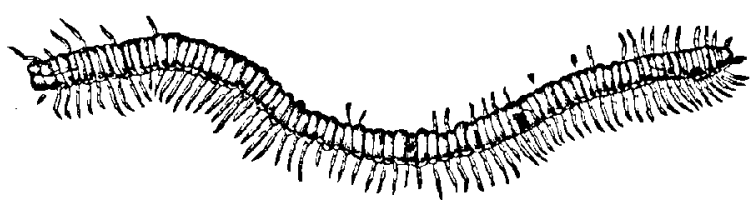

Fig. 249. - Myriapodo fossile (Euphoberia (2) Brownii) trouve dans le terrain houiller de Glasgow, (Trois querts de grandeur.)

dire d'une seule pièce, comme choz les myriapodes, n'offre pas cette segmentation bien séparée, nette et élégante, de la tête, du thorax et de l'abdomen, que l'on admire chez les hyménoptères et leurs émules. Une blatte, un grillon, une sauterelle, un termite, un fulgore, une libellule mème (tous primaires), sont moins avancés en organisation qu'un papillon aux ailes écailleuses, une abeille et une fourmi. Dans l'ordre du progrès, il est naturel que les orthoptères aient précédé les hyménoptères.

1. Etymologie: Ews, aurore; థ̣uvos, bête venimeuse.

2. Étymologie : eu, bien; pobspros, effrayant. 
Ce sont les ancêtrès des blattes, des mantes, des grillons, des sauterelles, des termites, des libellules, qui existaient dans les forêts de l'époque carbonifère. On connait, depuis longtemps déjà, les blattes (fig. 250) découvertes par Oswald Heer, dans le terrain carbonifère de la Suisse. Parmi ces insectes antiques, plusieurs sont remarquables par leurs dimensions. On a retrouvé notamment des ailes de 33 centimètres de longueur appartenant au meganeuræ (') monyi. Le titanophasma $\left({ }^{2}\right)$ mesurait 25 ccntimètres de long sans les antennes : aucun insecte actuel n'atteint cette dimension. Signa•

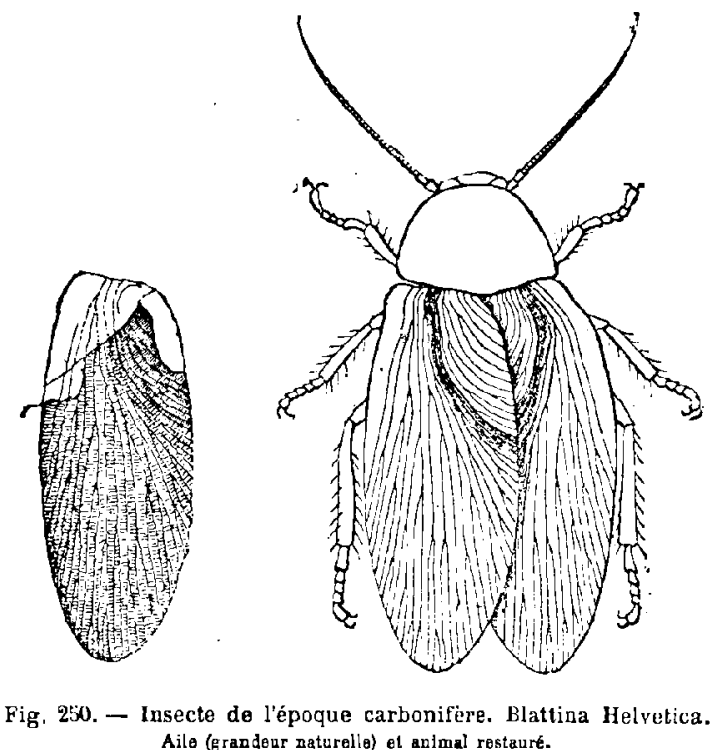

lons aussi le genre des corydaloïdes, petits insectes amphibies munis à la fois de trachées et de stigmates, qui, par conséquent, respiraient l'air en nature et l'air tenu en dissolution dans l'eau $\left({ }^{3}\right)$. Nos lecteurs pourront juger de l'état remarquable de conservation de ces fossiles, âgés de plusieurs millions d'années, par le fac-simile du protophasma (") Damasii reproduit ici ( $f g .251)$, à demi-grandeur. L'œil, les antennes, les plus délicates nervures des ailes, sont admirablement conservés.

1. Étymologie : $\mu \varepsilon \gamma \alpha$, grand; veurav, aile.

2. Étymologie : тเтхv, géant; parix, spectre.

3. Voy. Ch. Brongniart, Revue scientifique du 29 août 1885.

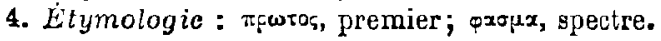

LE MONDE AVANT LA CRÉATION DE L'HOMDE 
Il suffit de songer à ces insectes, de les ressusciter par la pensée au milieu des splendides forêts de cette époque, de se souvenir de la délicatesse des sensations recues par ces antennes et par ces yeux aux mille facettes, pour apprécier la grandeur de l'œuvre déjà accomplie par la nature depuis les âges lointains où les organismes problématiques des anciennes mers flottaient seuls dans l'Océan sans îles de la période cambrienne.

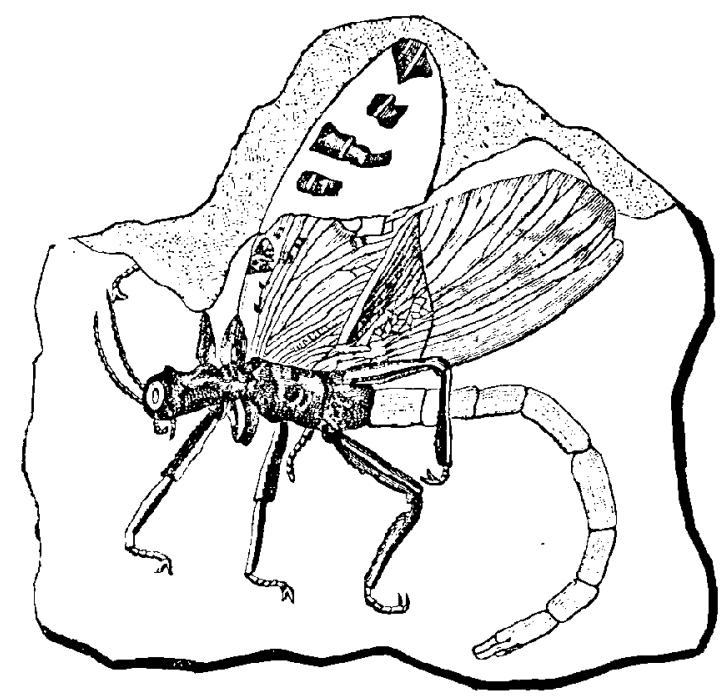

Fig. Đis1. - Insecte de l'époque carbonifère. Protophasma Damasii. (Demi-grandeur.)

Dans l'arbre généalogique de la vie terrestre (voy. p. 113), les insectes ont eu pour ancêtres les vers. Ils le sont encore un peu pendant la première période de leur existence. Je ne me souviens pas d'avoir éprouvé une plus grande surprise, étant enfant, que le jour où je retrouvai une boîte de petits vers à pèche, oubliée dans un jardin, et où, en l'ouvrant, je vis les vers disparus et remplacés par une collection de belles mouches : je n'en croyais pas mes yeux, je me lançai dans l'entomologie des insectes d'un jardin, et pendant plusieurs années ma passion dominante (celle d'un enfant de sept à neuf ans) fut de piquer sur un carton les papillons attrapés, de les laisser pondre (ce qu'ils ne manquaient pas de faire pendant leur supplice), d'enfermer précieusement lcs œufs, d'assister à l'éclosion des chenilles, de les nourrir, de les voir se transformer en chrysa- 
lides, et d'épier les jours de douce chaleur printanière où mes petites momies s'éveillaient, remuaicnt, s'agitaient, brisaient leur enveloppe et s'envolaient en joyeux papillons. Quelles questions, quelles idées s'agitent dans un petit cerveau qui veut connaitre le pourquoi et le comment des choses! Petite cervelle, chrysalide elle-même, qui aspire à l'éclosion de ses ailes... Hélas! devant l'infini des choses à connaitre, sommes-nous beaucoup plus instruits à 70 ans qu'à 7 ?...

Il se cache là - dans les métamorphoses des insectes - un mystère plus profond qu'il ne le parait encore. La larve, la chrysalide, le papillon, sont le même ètre! Qui pourrait s'en douter si on ne le constatait par l'observation mème. Eux-mèmes ne le savent point. .

Sans doute, cette métamorphose est, comme l'état embryonnaire de tout ètre vivant à l'éclosion de l'œuf, une réminiscence de ce. qui s'est passé dans la biologie terrestre pendant les longs siècles de la formation de chaque espèce. De mème que l'homme, le mammifère, le poisson, passent rapidement par les phases ancestrales avant d'acquérir leur état définitif, ainsi l'embryologie des insectes leur métamorphose - nous est un témoignage contemporain des origines disparues.

Déjà si riche par tous les éléments qui précèdent, la période carbonifere parait encore avoir été contemporaine de la naissance des reptiles. On a retrouvé dans les terrains houillers des batraciens ressemblant à des salamandres et à des grenouilles, dont quelquesunes mesuraient plus de deux mètres de longueur. De cette époque aussi datent les labyrinthodontes, qui représentent le passage entre les batraciens et les reptiles. Nous allons faire connaissance avec eux en ètudiant la période permienne, pendant laquelle ils ont pris un rapide-développement pour se prẹparer an règne qui leur était réservé sur le monde terrestre de l'époque secondaire. 


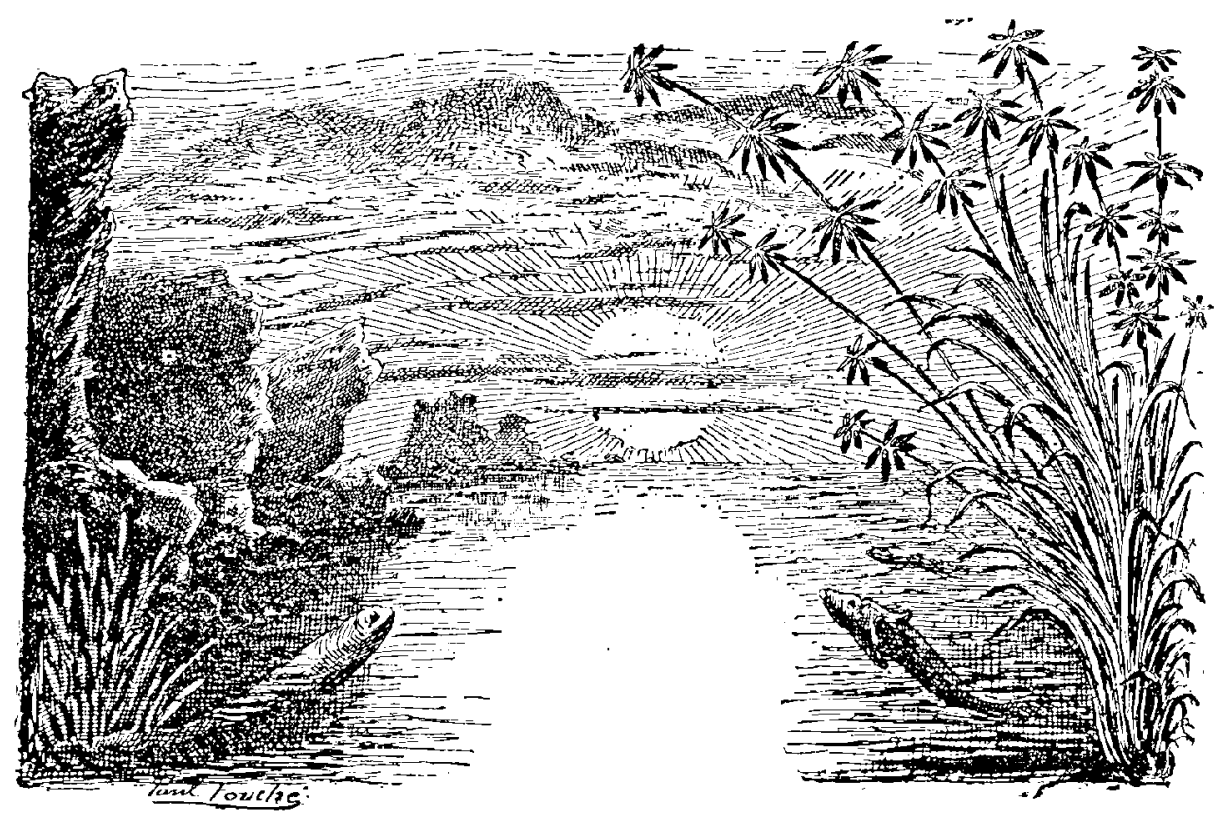

CHAPITRE V

FIN DES TEMPS PRIMAIRES

La période permienne. - Batraciens et reptiles.

La période à laquelle nous arrivons marque la fin des premiers âges, la fin de l'enfance de la Terre et de ses êlres élémentaires, la. fin du règne des invertébrés dans le monde animal et des cryptogames dans le monde végétal, et elle prépare l'adolescence de la planète, la domination rayonnante dont vont être désormais investis les vertébrés et les phanérogames. Le progrès marche. Les humbles vont céder la place aux forts. Lentement, graduellement, la matière s'épure par son élaboration mème. La sensibilité est née. Bientôt la penséc, d'abord chrysalide inconsciente, s'éveillera, se reconuaitra, prendra son essor

Considérée au point de vue organique aussi bien qu'au point de vue physique, la période permienne n'est que le développement de la période carbonifère, leurs terrains se trouvent intimement associés l'un à l'autre, et parfois mème on les confond en une mème désignation : permo-carbonifère. Toutefois, ce ne sont plus des houilles; ce sont des calcaires et des grés, dépourvus de combustibles, reposant en couches plus ou moins épaisses sur les terrains houillers. 
Nous avons vu plus haut que les terrains houillers offrent une étendue considérable en Russie et occupent plus du tiers de la Russie d'Europe. Il en est de même des terrains permiens, qui affleurent sur d'immenses espaces dans le comté de Perm: de là leur nom. Cet étage géologique est quelquefois aussi désigné sous le nom de pénéen, à cause de la pauvreté de ses fossiles. Permien et pénéen sont deux termes identiques pour désigner une même espèce de terrain et une mème époque de l'histoire de la Terre.

En France, ce terrain affleure en plusieurs régions. Sur le plateau contral, si riche, comme nous l'avons vu en couches de houille, le terrain permien recouvre parfois ces couches avec une épaisseur de neuf cent à mille mètres de grès, de poudingues et de schistes noirs bitumineux d'où l'on extrait du pétrole (Morvan, Autun, Épinac, etc.) On le trouve également au Creuzot, à Blanzy, à Lodève (Hérault), ainsi que dans les Vosges où il occupe le fond des vallées qui, sur la bordure orientale de cette belle région montagneuse découpent profondément les chaînes secondaires: là, il repose directement sur le gneiss, qui forme le sous-sol de ces vallées, et se mélange avec des éraissions de porphyre qui sont arrivées à l'époque où toute cette partie orientale des Vosges était couverte de forèts permiennes (fougères, cordaïtes, etc.), dont on exhume aujourd'hui les débris silicifiés. Ge tcrrain permien occupe en France une surface plus importante qu'on ne le croyait encore il y a quelques années. On en a retrouvé récemment ( $\left.{ }^{4}\right)$ dans les départements de l'Aveyron et de l'Hérault (Roquetaillade, Saint-Victor, etc.), composés de schistes argileux reposant sur le terrain houiller, mesurant jusqu'à deux cents mètres d'épaisseur et contenant des fossiles de poissons, de batraciens et de plantes. On a retrouvé également $\left({ }^{2}\right)$ ce même terrain dans la Loire-Inférieure, à Teillè, mesurant cent mètres d'épaisseur, reposant aussi sur le terrain houiller, et contcnant entre autres des fougères et des cordaïtes. Ainsi, à l'époque qui nous occupe, la mer s'étendait sur toutes ces régions.

Plantes, animaux sont encore ce qu'ils étaient pendant la période précédente, mais prêts à faire place à des types plus per-

1. Académie des sciences, séance du 13 juillet 1885 : M. Bergeron.

2. Même séance : M. Bureau. 
fectionnés. Le milieu change. Cependant il n'y a pas encore de saisons sur notre planète et le soleil n'est pas encore très brillant. La température reste partout tropicale et uniforme. Le relief du sol subit des dénivellations, des changements de niveau dus au refroidissement intérieur et à la contraction du globe. " Au commencement de cette nouvelle phase, écrit M. Contejean dans son précieux Traité de géologie, un affaissement général ramène la mer sur une grande partie du sol européen, notamment en Russie, au centre de l'Allemagne, au sud-ouest de l'Angleterre, au pied des Vosges, etc. De puissants conglomérats s'accumulent dans les mers : ils constituent le nouveau grès rouge des géologues. Au-dessus, et pendant une période de calne relatif, se déposent les calcaires magnésiens connus en Allemagne sous le nom de zechstein (calcaire fétide). Telle est, dans l'Europe centrale et occidentale, la composition la plus ordinaire d'u terrain permien, d'ailleurs extrêmement variable. Sur une infinité de points, des injections et des émanations souterraines introduisent dans les mers des éléments minéralogiques assez divers, mais en général funestes à la vie; par exemple les cuivres de Thuringe et de la Russie, les gypses et le sel gemme de la Russie et des États-Unis, la magnésie de partout. Aussi, sous le rapport de la composition minéralogique, le terrain permien ressemble-t-il beaucoup plus à celui du trias, qui lui succède, qu'aux terrains qui l'ont précédé ; mais l'inverse a lieu si l'on compare les faunes et les flores. Sauf en Russie et aux États-Unis, où persiste la tranquillité des époques précédentes, les mouvements du sol et les bouleversements des couches sont fréquents; aussi rien de plus variable que la puissance du terrain permien, qui est de 250 mètres aux États-Unis, qui atteint 700 mètres en Bohème et qui dépasse 1200 mètres en Saxe. Les assises inférieures s'appuient tantôt sur le terrain houiller, tantôt sur les schistes cristallins ou sur le granite, ce qui indique un empiétement des mers. Rarement il se trouve en concordance avec les formations plus anciennes sur lesquelles il repose, mais les couches du trias le recouvrent presque partout sans aucune différence de stratification. Ainsi, sous le rapport de la stratigraphie, lo terrain permien se montre indépendant des époques antérieures, et intimement lié aux subséquentes, et le contraire a lieu si l'on ne 
considère que la paléontologie. Il en rósulte que les époques ne sont pas mieux délimitées que les terrains, et même que certaines divisions de moindre importance. Leur distinction est fondée sur les caractères des faunes et des flores, et nullement sur de brusques séparations stratigraphiques, minéralogiques ou paléontologiques. Cette période marque bien la fin d'une grande époque géologique, puisque pendant sa durée, s'éteignent la plupart des types paléozoïques, soit parce qu'ils sont arrivés à leur terme naturcl, soit à cause de l'improprièté du milieu. Quelques-uns cependant, mais en assez petit nombre, continuent à subsister : aucune des formes nouvelles qui caractérisent l'époque secondaire ne fait son apparition. Il est done extrêmement naturel de fixer à la fin du terrain permien le terme de l'époque paléozoïque.

« La faune permienne compte à peine trois cents espèces connues. Tous les groupes se trouvent en grande décadence, et subissent des réductions énormes, au moins en Europe et aux ÉtatsUnis. Les polypiers, les crinoïdes et les échinides ne comptent qu'un très petit nombre de genres. Presque tous les brachiopodes paléozoiques ont disparu; quelques-uns se montrent pour la dernière fois: tels sont les atrypa, camarophoria, orthisina, chonetes, productus, jadis si riches en espèces. Désormais cet ordre ne se relèvera plus de sa décadence, et sera toujours primé par les mollusques proprement dits, gastéropodes et acéphales. Les céphalopodes sont réduits aux genres nautile, orthocère et cyrtocère, et les crustacés ne figurent plus que pour mémoire, représentés par le dernier des trilobites, par quelques limules et quelques cypridines. Les poissons ganoïdes se maintiennent et, dans le nombre, les palæoniscus (voy. $f g$. 254) sont remarquables par la variété de leurs espèces et l'abondance des individus. En résumé, la faune permienne est caractérisèe par certains brachiopodes (terebratula elongata, spirifer alatus, productus horridus, productus cancrini, etc.), par certains acćphales, des genres mytilus, schizodus, monotis; par les palæoniscus aux écailles striées et ponctuées et par des batraciens et des reptiles appartenant aux genres zygosaurus, palæosaurus, thecodontosaurus, proterosaurus, etc. (').

1. Voilà encore bien des noms d'aspect répulsif, et sans doute plus d'un lecteur passe en courant sur ces expressions sans les lire. Pourlant il faut bien nommer les habitatns 
Considérée d'une manic̀re générale la faune permienne forme un ensemble indivisible, comparable à l'une des faunes siluriennes; de sorte que les subdivisions du terrain varient selon les licux, et correspondent seulement $\dot{a}$ des changements dans la nature minéralogique des assises. L'analogie est très grande avec la faune carbonifère, malgré les discordances de stratification. Dans les contrées, où celles-ci n'ont pas lieu, aux États-Unis par exemple,
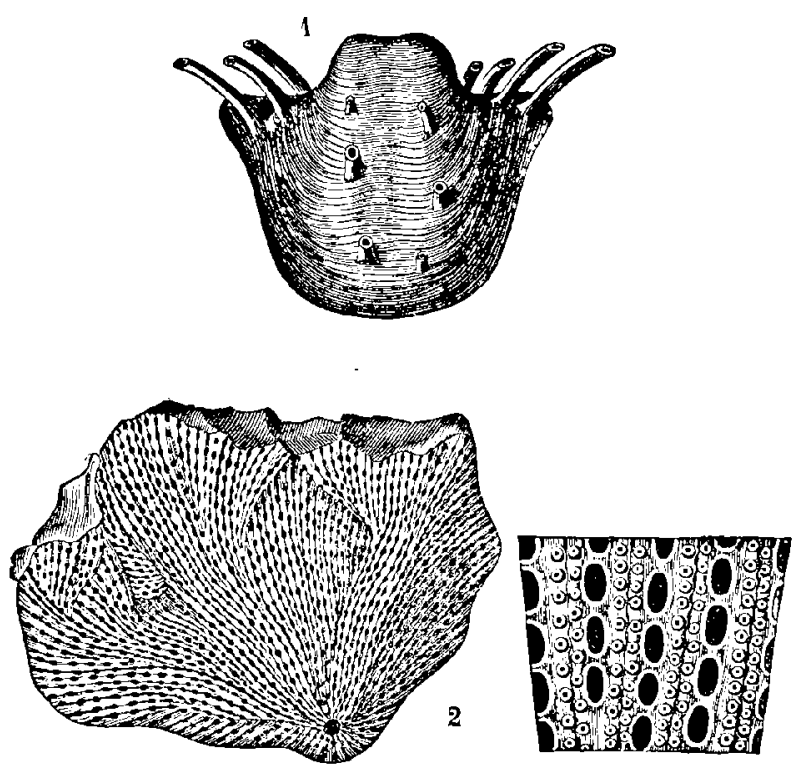

Fig. 253. - Mollusques de la période permienne.

1. Productus borridus. - 2. Fenestella rotlformin, avee fragment grossl.

les fossiles carbonifères paraissent se mèler aux fossiles permiens sur une assez grande épaisseur de couches.

Le développement de la vie sur la Terre se continue régulièrement, comme celui d'un arbre gigantesque, dont les branches mères précèdent les branches secondaires, quoique certains rameaux présentent une croissance rapide tandis que d'autres se ralentissent

de la Terre pendant ces époques reculées, et il serait aussi difficile de supprimer ces noms que de prétendre écrire l'histoire de l'humanité sans appeler par leurs noms sous lesquels nous les connaissons F'o-Hi, Aseth, Hoang-Ti, Osymandias, Sésostris, Moïse, Sargon, Tcheou-Kong, Sardanapale, Nabuchodonosor, Confucius, Pythagore, Jésus-Christ, Mahomet, Charlemagne, Copernic, Képler, Newton, Louis XIV, Napaléon, etc. Il faut avouer pourtant que les paléontologues auraient pu mettre plus d'élégance dans leurs dénominations. 
ou même s'arrètent dans leur marche ascendante. Revoyons un instant le tableau publié plus haut (page 87) de la classification du règne animal. Au-dessus des trois embranchements des zoophytes, des mollusques et des annelés, tous invertébrés, nous avons celui des vertébrés. Or, pendant les époques primordiale et primaire dont nous terminons ici l'histoire, nous avons assisté à l'apparition successive des êtres appartenant à ces trois embranchements. La correspondance entre la classification anatomique et l'évolution naturelle s'est manifestée non sculement dans les grandes lignes, mais encore dans les détails : c'est ainsi que les plus perfectionnès des invertébrés, les arachnides, les myriapodes, les insectes, les

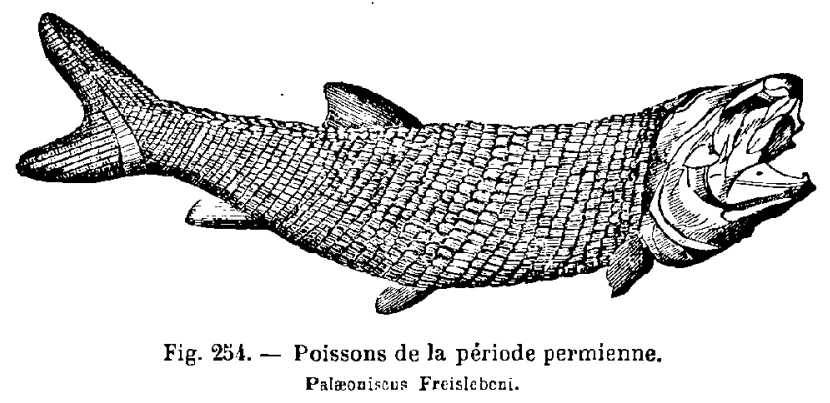

annelés en général, sont arrivés les derniers, longtemps après les zoophytes et les mollusques. De mème, nous avons vu l'ordre des vertébrés commencer par les plus rudimentaires, les poissons. Cet ordre supérieur de la biologie terrestre se partage, comme nous l'avons vu, dans les classes suivantes :

\section{PoIssons \\ BATRAGIENS \\ Reptiles \\ OISEAUX \\ MAMMIFÈRES}

Nous avons vu naitre la première de ces classes. Nous allons assister maintenant au développement de la seconde.

Les batraciens ne sont ni des poissons ni des reptiles. Un peu plus avancés que les poissons comme système nerveux, sensibilité et intelligence, ils le sont moins que les reptiles. On lcur donne aussi la qualification d'amphibiens, parce qu'ils peuvent vivre dans l'eau, comme les poissons, et dans l'air, comme les reptiles. 
Nos lecteurs connaissent ces distinctions générales. Cependant, pour que la clarté soit aussi complète que possible, sans nous perdre toutefois dans les détails techniques, signalons les types principaux caractérisant l'une et l'autre classe. Aux batraciens (1) appartiennent les grenouilles, les rainettes, les alytes, les crapauds (réunis sous la dénomination d'anoures, ou « sans queue »), ainsi que les salamandres, les tritons, les euproctes, les protées (réunis sous la désignation d'urodèles ou à̀ queue visible»). Aux reptiles $\left({ }^{2}\right)$, appartiennent les serpents, les lézards ou sauriens, les crocodiles, les tortues.

Les batraciens respirent l'air dissous dans l'eau, au moyen de branchies, au moins pendant les premiers temps de leur vie. Les reptiles respirent l'air en nature, au moyen de poumons, à toutes les périodes de leur existence. Les batraciens présentent, en outre, constamment des métamorphoses; de mème que les poissons, ils sont anallantoïdiens, c'est-à-dire que les embryons sont dépourvus de membrane allantoïde. Ils subissent des métamorphoses analogues à celles qui sont si générales chez los invertébrés; au moment où ils quittent l'œuf, les batraciens n'ont pas encore achevé leur complet développement, et ne possèdent pas l'organisation de leurs parents; ils ne l'acquièrent que plus tard, alors qu'ils passent de l'état larvaire à l'état adulte. Au commencement de leur vie leur existence est celle des poissons; ils sont essentiellement aquatiques. Leur conformation subit des modifications considérables “ Tantôt, écrit Carl Vogt, les membres font entièrement défaut, tantôt la forme du corps se rapproche de celle d'un disque, elle est aplatie et élargie par des organes de locomotion très développés. Chez les céciliés, qui vivent à terre et sont dénués de membres, le corps ressemble entièrement à celui d'un ver de. terre. Les amphiumes, qui, au contraire, se tiennent toujours dans l'eau, ont la queue comprimée latéralement, très allongée, et servant aux mouvements de natation. Les pattes présentent tous les degrés de développement; d'abord incapables de soutenir le corps, elles se garnissent ensuite d'ongles qui sont presque atro-

1. F́tymologie : Bхт; $\times \chi^{2}$, grenouille.

2. Etymologie : reptum, supin de repere, ramper. 
phiés. Parfois les membres antérieurs existent seuls, et sont alor's détachés de charque côté du cou sous forme de petits moignons; d'autres fois ce sont les membres postérieurs qui seuls sont visibles. Chez les anoures, la quoue s'atrophie et disparait complètement dans l'animal adulte.

La conformation extérieure des amphibiens ou batraciens prouve qu'ils sont organisés pour vivre alternativement dans l'eau et dans l'air, mais montre cependant des variations de forme considéralıles conduisant à celles des animaux terrestres disposés pour ramper. grimper et sauter.

Bien que fort simple, le système nerveux central est cependant supérieur à celui des poissons. Le cerveau est toujours petit, surtout relativement à la moelle épiniẻre, car il est court et étroit; c'est ainsi que, dans la salamandre, le poids des centres nerveux est 3 , comparé à la masse totale du corps, 380, l'encéphale n'étant représenté que par 1. Comme les poissons, les balraciens sont ovipares et pondent des œufs ('). Les vivipares n'arriveront que plus tard sur la scène du monde.

De mème que les reptiles, les batraciens prospèrent avant tout sous un climat chaud et humide : ils sont particulièrement abondants dans les régions tropicales et intertropicales du nouveallmonde. Dans les forêts vierges, ils trouvent pendant toute l'année l'humidité et la chaleur si nécessaires à leur développement. Les immenses forèts de l'Amérique du Sud et de l'Asic méridionale servent de repaire à des quantités innombrables d'espèces; au sein de ces forêts, l'eau déposée dans les creux des arbres, sur les feuilles, dans la mousse qui partout tapisse le sol, est essentiellement favorable à l'íclosion de leurs œufs, au développement de leurs larves $\left({ }^{2}\right)$.

Ces conditions d'habitabilité sont précisément celles de l'époque permienne : elles convenaient aux batraciens comme aux fougères, aux sigillaires et à l'opulente régétation de ces temps primitifs.

De mème que nous avons qualifié la période dévonienne de

1. Pourlant la salamandre atra (batracien urodèle) est vivipare et met au monde des petits dépourvus de branchies et destinés à vivre immédiatement hors de l'eau. Mais avant leur naissance ils ont des branchies et une queve nalatoire.

2. Breng. Les Reptiles et les Batraciens. Édition de E. Sauvage. 
période des poissons, parce que e'est pendant ces temps que leur existence s'est affirmée, de mème que la période carhonifère mérite avant tout de caractériser le règne des plantes, de mème nous pourrions regarder la période permienne comme celle du développement des batraciens, sous une atmosphère humide et chaude. Sans doute, les batraciens et les reptiles datent de la période carbonifẻre, jeut-ètre même des temps dévoniens, mais ils ne se développent.

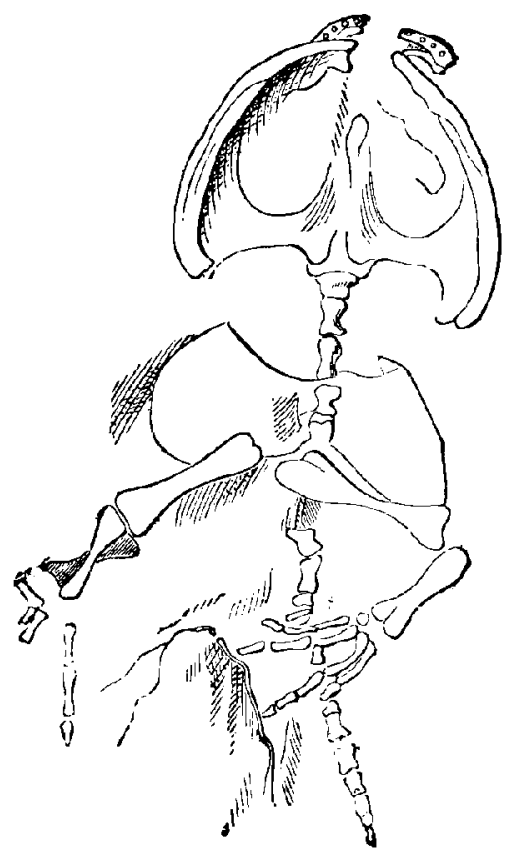

Fig. 255. - Les premiers batraciens. Raniceps de Lyell.

que maintenant et les seconds ne règneront que pendant l'époque secondaire, et surtout aux temps jurassiques. "Pendant plus de trente-quatre ans, écrit Charles Lyell, ce fut un axiome recu en paléontologie qu'il n'avait pas existé de reptiles avant la période permienne, avant le calcaire magnésien; mais à la fin de 1844, cette barrière préconçue fut renversée, et des reptiles carbonifères, terrestres et aquatiques de plusieurs genres virent le jour. On discute mème encore en ce moment la question de savoir si certains restes d'un enaliosaurus (c'était peut-être un grand labyrinthodon) n'ont pas été découverts dans le terrain houiller de la Nouvelle- 
Écosse, et si certains grès des environs d'Elgin, en Écosse, contenant des os de lacertiens, de crocodiliens et de rhynchosauriens, ne devraient pas se rapporter au grès rouge, c'est-à-dire au groupe dévonien. Néanmoins, aucun vestige de cette classe, n'a été encore découvert dans des roches aussi anciennes que celles dans lesquelles on a trouvé les premiers poissons. „)

Dès 1863, Dawson a fait connaître plusieurs batraciens et reptiles, notamment une espèce qni a reçu le nom d'hylonomus, à vertèbres bien ossifiées qui aurait èté capable de respirer hors de l'eau, de grimper et de sauter dans les arbres. Huxley a signalé, dans le houiller de la GrandeBretagne, divers reptiles, parmi lesquels on peut citer l'anthracosaure, animal long de deux mètres, trouvé dans une houillère du bassin de Glascow. En 1844, le docteur King a reconnu dans le houiller de Greensburg, en Pensylvanie, des empreintes . d'un énorme animal, le batrachopus; les traces des pas de derrière mesuraient près d'un pied de long, et par conséquent dépassaient en grandeur celle des labyrinthodontes triasiques. Ces empreintes indiquaient une bète qui avait une respiration aérienne, car, d'après leur mode de fossilisation

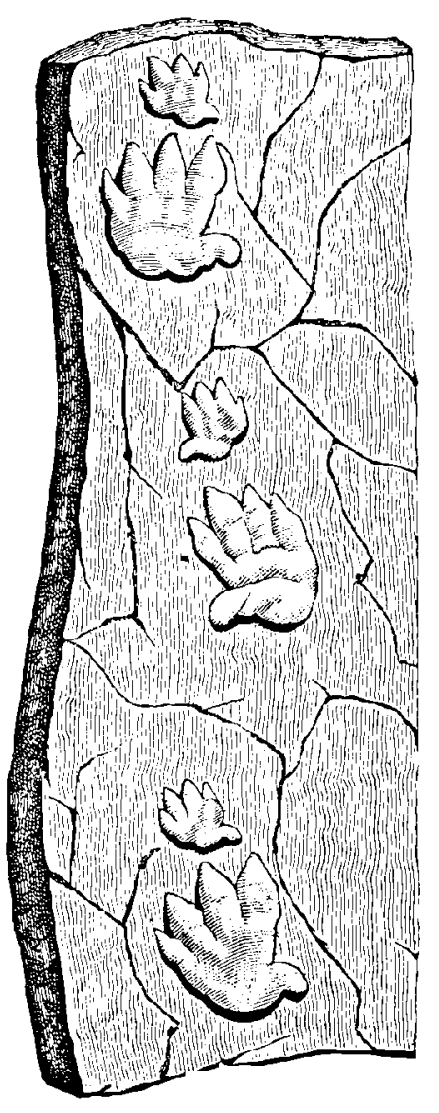

Fig. ㄴ. 2.6i. - Empreintes de pas laissés par le Chirotherium.

il est évident qu'elles ont été faites par un quadrupède marchant sur l'argile molle d'un rivage, que cette argile s'est desséchée au soleil et s'est crevassée. Ensuite du sable a dû recouvrir l'argile et enfin lo sable se sera changé en grès.

Certaines empreintes de pas de reptiles encore plus anciens ont été observées par Lea dans la Pensylvanie, à 520 mètres plus bas que celles de Greensburg; on a pensé qu'elles pourraient appartenir au Dévonien. 
Ainsi, ces plages étaient alors peuplées de batraciens aux formes etranges, qui ont laissé des traces de leur existence non seulement par des débris de leur squelette osseux et de leur couverture écailleuse, mais encoro par les empreintes de pas qui se rencontrent nombreuses sur les grès maintenant consolidés ( ${ }^{\mathbf{1}}$ ).

Sur une plage unie, limoneuse, non seulement les animaux laissent les traces de leur marche, mais la pluie elle-mème, tombant à larges gouttes, y imprime son action en $\mathrm{y}$ creusant une multitude de petites cavités arrondies. Sous l'influence de la chaleur solaire, toutes ces traces durcissent. Si maintenant nous supposons qu'à la marée suivante, un retour des eaux marines amène, sur la plage desséchée, de nouveaux sables fins, ce dépôt se moulera dans les moindres creux et, se desséchant à son tour, ces moules en lelief resteront en témoignage du passage des animaux et des effets de l'averse.

Tels sont les faits qui, observés en de nombreux points sur des plaques de grès des terrains carbonifères et permiens sont venus attester, non seulement le passage d'animaux sur les plages de l'époque, mais aussi que des pluies abondantes s'y sont déversées.

Ces empreintes de pas appartiennent à des batraciens qui ont laissé, sur les plages sablonneuses du continent carbonifère, non seulement ainsi des traces de leur passage, mais des portions de leur squelette, en particulier de grandes plaques osseuses, comparables à celles qui forment la cuirasse des crocodiles actuels, ainsi que des dents coniques à structure compliquée, qui leur a valu le nom de labyrinthodontes. Leur grande taille, l'armure de plaques osseuses

1. On nous a même signalé il y a quelques mois (MM. Joseph et Noël Gérard, Jean Viesen, à Boncelles (Belgique), une découverte presque incroyable, que nous ne publions ici que sous bénéfice d'inventaire. En creusant, en 1869, un puits de mine, au Grand Horez, à Flémalle-Grande, près de Liège, on aurait trouvè à plusieurs reprises, à 250 et 300 mètres de profondeur, de pelits crapauds aveugles, frêles, de couleur verdatre, ayant les jambes d'arrière fort longues, et vivants. Remontés à la surface du sol, ils auraient encore vécu deux et trois jours. Les signalaires ci-dessus s'affirment comme témoins oculaires.

Si le fait est authentique, il serait intéressant d'examiner si ces batraciens n'ont pu venir du dehors par les infiltrations des eaux, ou même avoir été transporiés là à l'état d'coufs, par les eaux souterraines. S'ils sont aveugles, on a peut-être affiaire à une race souterraine, comme nous I'avons vu pour les bitratiens de la Carniole. Que des crapauds puissent vivre des années enlières dans des pierres, e'est ce qui est prouvé par de nombreuses observations. 
qui recouvrait leur corps, leurs mâchoires ornèes de dents puissantes, leur tête cuirassée, ont fuit de cette famille ancienne de batraciens, aujourd'hui disparue, la plus singulière de la faune primaire ( $\left.{ }^{4}\right)$.

Auprès de Lodève, dans le département de l'Hérault, ces carrières de grès bigarrés, qui sont exploitées pour dalles et pavés, renferment de nombreuses empreintes de ces pas de labyrinthodontes triasiques, si bien conservées qu'on peut y reconnaitre tous les détails de la peau écaillcuse de ces animaux singuliers. Leur taille atteignait plusieurs mètres de long: leurs membres étaient courts, mais robustes, et la disproportion relative entre les pattes de derrière puissantes, et celles plus grêles du devant, indiquent un reptile sauteur, à la manière des brataciens modernes $\left(^{(2}\right)$.

Les empreintes dont il s'agrit ont été laissées par un animal qui avait quatre mains, ce qui lui a fait donner le nom de chirotherium (3). Ses membres antéricurs étaient beaucoup plus petits que les postérieurs, qui avaient à peu près la forme d'une grosse et lourde main d'homme, avec cette différence que les doigts itaient encore plus courts et plus gros; la longueur de ses pattes postérieures était de 22 à 24 centimètres, plus du double des antérieures. Le chirotherium èlait un labyrinthodonte géant.

On sait que, chez tous les animaux, le ponce tourné en dedans, et le petit doigt en dehors. Si l'homme marchait à quatre pattes, les pouces des mains et des pieds suivraient une mème direction.

En examinant la figure 256, on remarque une disposition contraire. Les pouces sont évidemment tournés en dehors. Il s'agit sans doute ici non d'empreintes directes, mais de contre-empreintes produites par le sable déposé sur les pistes. Ce reptile marchait, comme le cheval, en tenant les pieds très rapprochés de la ligne médiane du corps.

La grandeur si différente des extrémités de ces animaux a fait

1. Étymologie $: \lambda \times \beta \beta_{i}=40 ;$ labyrinthe, oồv dent. Ces premiers quadrupèdes ont été nommés ainsi parce que les labyrinthodontes du trias, qui ont été étudiés les premiers, ont des dents d'une structure si compliquée que leurs plis et replis (Voy. fig. 257) donnent l'jée d'us labyrinthe. Cetle désignation est fâcheuse, d'un caractère trop étroit.

2. Ch. VÉLAIN. Géologie stratigraphique.

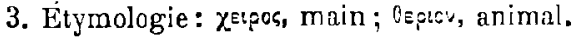


penser qu'ils devaient avoir de l'affinité avec les kangourous ; mais ces derniers ne marchent point, ils ne font que sauter sur leurs pattes de derrière, se servent de leurs membres antérieurs pour prendre leur nourriture, et ne les posent à terre qu'accidentellement. Les batraciens, au contraire, ont les extrémités en forme de mains et de grandeur très différente; il résulte de ces faits que le chirotherium a dù être un amphibie de l'ordre des batraciens, uno espèce de grenouille, ou, pour mieux dire, de salamandre gigantesque, car il avait une queue.

Dès le terrain carbonifère, avec des batraciens qui rappellent un

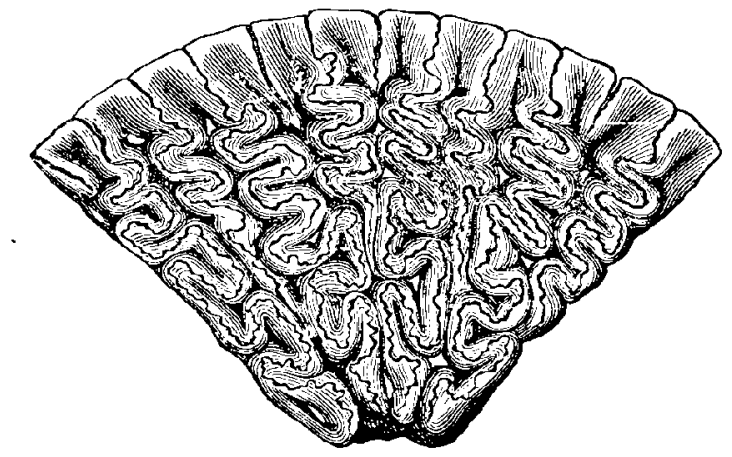

Fig. 257. - Quart de dent de labyrinthodonte, section transversale, grossie.

peu ceux qui vivent aujourd'hui (tels sont les raniceps, les parabatracus) et avec des sauriens, tels que le dendrepeton et l'hylerpeton, minuscules vivaient les labyrinthodontes proprement dils.

Jans le terrain permien qui, géologiquement, fait directement suite au terrain carbonifère, les reptiles et les batraciens sont plus nombreux, tant en Europe que dans l'Amérique du Sud. C'est ainsi que Cope a découvert dans le permien du Texas et de l'Illinois jusqu'à quatorze genres et vingt-huit espèces de reptiles, six genres et sept espèces de batraciens stégocéphales ou labyrinthodontes.

Chez les labyrinthodontes les plus anciens, le cråne est complètement cuirassé, aussi ces animaux ont-ils èté désignés sous le nom de'ganocéphales : la surface externe du crâne est généralement couverto de vermiculations souvent très prononcées qui rappellent l'aspect des crocodiles de l'époque actuelle. Ce crâne est 
tantôt allongé, ainsi qu'on le voit chez le cricotus, le trématosaure, l'archégosaure; tantôt plus trapu, plus raccourci, comme dans le genre américain éryops et dans les genres européens actinodon et mastodontosaure.

Chez les trématosaures, le crâne, par sa forme, rappelle celui du crocodile, tandis que chez les cricotus des terrains permiens du Texas et de l'Illinois, le museau, bien distinct du crâne, est long et rétréci. Les membres sont faibles en comparaison de la taille.

Dans les genres archégosaure, keraterpeton, lepterpeton, les
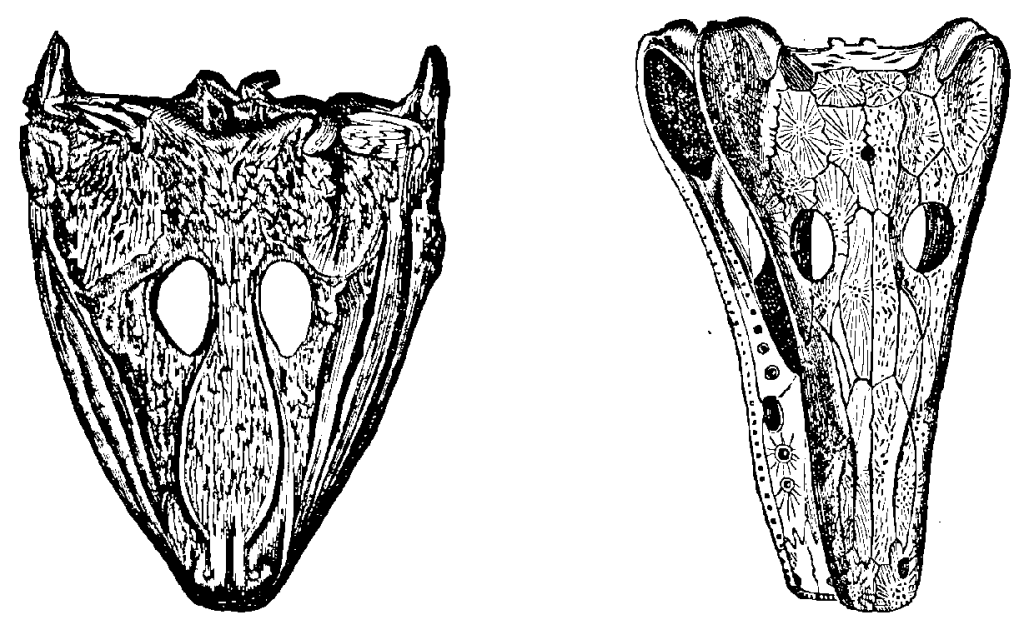

Fig. 258-259. - Tètes de labyrinthodontes. Archégosaure et mastodontosaure.

doigts sont au nombre de cinq à chaque patte, les tarses et le carpe restant à l'état cartilagineux. Chez l'archégosaure, les deux paires de membres, sensiblement de mème grandeur, sont dirigées en arrière et devaient servir à la natation. Ces os étaient d'une grande simplicité; les éléments osseux envahissaient imparfaitement leurs cartilages, de sorte que leur tissu était peu dense et facile à comprimer. C'est pour cette raison qu'en passant à l'ètat fossile ils se sont souvent déformés. Cette disposition décéle une grande infériorité d'organisation, car c'est principalement à l'extrẻmité des os que les muscles et les ligaments s'insèrent; elle parait indiquer des membres qui n'avaient que des mouvements généraux. 
Comme on vient de le voir, les labyrinthodontes comprennent un grand nombre de types distincts. larmi les groupes européens les mieux étudiés nous pouvons citer les mastodontosaures, les capitosaures, les metopias, les trematosaures, les zygosaures, les archégosaures, les rhinosaures. Bien que nous les connaissions encore fort incomplètement, les découvertes faites dans ces dernières années permettent cependant d'indiquer à larges traits les mœurs probables de ces étranges créatures.

Le corps devait être lourd et massif. Comme chez les anoures (grenouilles, crapauds, etc.) et chez les urodèles (salamandres, tritons, etc.) les membres, surtout les membres postérieurs, étaient trop faibles pour soutenir le corps, de telle sorte que le ventre trainait a terre. Les labyrinthodontes, du reste, devaient passer la plus grande partie de leur existence dans les marais, les étangs, les lacs, qui découpaient si largement le sol aux époques du carbonifère, du permien et du trias. Ils se trainaient parfois sur l'argile molle du rivage, qui a, dans certains cas, conservé l'empreinte de leurs pas et la trace laissée sur la vase par leur queue. C'est ainsi qu'en France des empreintes de chiroterium ont été reconnues à Saint-Valbert (Meurthe), dans une carrière où l'on exploite le grès vert, à la limite mème de minces couches de grès et d'argile qui alternent entre elles au-dessous de gros blocs rouges. Des empreintes du mème animal ont été recueillies dans les grès bigarrés de Lodève (Hérault). Le Muséum de Paris en possède de très beaux échantillons.

Certains labyrinthodontes devaient atteindre une taille vraiment extraordinaire. Dans les formations triasiques ont été trouvés des crânes mesurant jusqu'à $1^{\mathrm{m}}, 30$ de longueur, ce qui fait supposer des animaux de plus de six mètres de long. Ceux des terrains permiens de l'Ohio et de l'Illinois étaient moins grands (').

Le caractère des dents et la structure du crâne, si semblables comme organes de préhension et de mastication aux parties correspondantes des crocodiliens, montrent clairement que nous avons affaire à des animaux voraces. Les affinités amphibiennes des laby-

1. Brehm et Sauyage. Les Reptiles et les Batraciens. 
rinthodontés et la présence d'un appareil branchial chez la larve indiquont aussi quo ces ètres étaient entièrement aquatiques durant la première partie de leur existence. Les proportions du crâne et la faiblesse des membres de toutes les espèces carbonifères connues autorisent à admettre qu'elles fréquentaient l'eau et y cherchaicnt los éléments nécessaires à leurr subsistance. L'analogie avec les amphibiens actuels nous amène à supposer, d'autre part, que les labyrinthodontes étaient fluviatiles plutôt que marins. Le caractère des dépôts dans lesquels leurs restes sont inhumés confirme cette appréciation.

Jusqu'en 1867, on n'avait encore retrouvé en France aucun reptile primaire, à l'exception de l'aphẻlosaure, découvert à cette époque-là auprès de Lodève, quoique dès 1847 on eût mis au jour l'archégosaure dans le permien de Lébach (Prusse Rhénane), et que dès l'année 1710 un médecin de Berlin, nommé Spener, ait, sur l'invitation de Leibniz, décrit un protérosaure tiré des schistes permiens de la Thuringe. Aujourd'hui nous connaissons, dans notre contrée, le protriton, le pleuronoura, l'actinodon, l'euchirosaure, le stéreocharis, tous extraits du permien des environs d'Autun. "L'abondance des reptiles qu'on a retirés de couches où l'on n'en avait jamais rencontré jusqu'en ces dernières années, dit M. Gaudry (') prouve combien nous devons prendre garde d'attribuer à la nature des lacunes qui n'existent que dans nos esprits ignorants. Les plus anciens reptiles connus appartiennent aux terrains carbonifère et permien, c'est-à-dire à la partie supérieure des formalions primaires. Tandis que les invertébrés ont été nombreux dans les temps siluriens et que les poissons, plus élevés que les invertébrés, ont eu leur règne dès l'époque dévonienne, les reptiles, supérieurs aux poissons, ne se sont multipliés qu'à partir de la période carbonifère. Il y a là des faits favorables à l'idée d'un développement progressif du monde animal. »

Parmi ces reptiles (ou, pour mieux dire, ces batraciens), signalons une salamandre à queue courte, le protriton petrolei $\left({ }^{2}\right),(f g .260)$ de M. Gaudry. « Jusqu'à présent, dit-il, l'époque primaire paraissait

1. Fossiles primaires, p. 252.

2. Etymologie : Pro, avant, Tritor, salamandre aquatique. Lns schistes qui renferment le protriton sont exploités pour en tirer du pétrole. 
avoir été caractérisée par des reptiles distincts des batraciens actuels; on les avait décrits sous le nom, tantôt de lahyrinthodontes, tantôt de ganocéphales, tantôt de stégocéphales. Il m'a semblé que le protriton, comme aussi un petit fossile d'Allemagne, l'apateon, et un autre des États-Unis, le raniceps, ne différaient pas autant des batraciens. Voici les raisons qui m'ont frappé : pour tous les paléontologistes, le principal caractère des labyrinthodontes est d'avoir les os placés derrière les yeux (post-orbitaires, post-frontaux, sus-temporaux) si développés qu'ils s'unissent pour former un toit continu; chez les batraciens, ces os sont très réduits ou supprimés, de sorte que les cavités des yeux sont relativement si grandes qu'il en résulte une forme de tête très différente. Dans le protriton, le os situés en arrière des yeux sont bien moins développés que chez les labyrinthodontes, et les orbites ont une grandeur qui rappelle l'apparence des batraciens. Un autre caractère important des labyrinthodontes, c'est la forme bizarre de leur ceinture thoracique, avec un grand entorsternum sur lequel s'appuient des clavicules (épisternum), élargies en avant. Or je n'ai pu déconvirir d'entorsternum ossifié chez le protriton, et les clavicules n'ont point l'élargissement qui est si remarquable chez les labyrinthodontes. Ce qui distingue encore les labyrinthodontes, ce sont des côtes très grandes, compliqućes; au contraire, chez le protriton, le système costal est simplifié comme chez la plupart des batraciens. Enfin, les labyrinthodontes des temps primaires avaient sous le ventre un système d'écailles tout à fait curieux, tandis qu'à en juger par sa fossilisation, le corps du protriton était aussi nu que celui des batraciens. G'est pourquoi cet animal m'a paru un reptile, dans lequel ne se sont pas encore accusées les divergences qui ont caractérisé le groupe des labyrinthodontes ; j'ai pensé qu'il s'écartait moins du type commun des reptiles anallantoijdiens actuels, et notamment des salamandres.

« On ne peut manquer d'être frappé, ajoute le même naturaliste, de la remarque que les petits fossiles d'apparence salamandriforme se trouvent dans les mêmes terrains où l'on rencontre les labyrinthodontes. Ainsi, l'apateon a été recueilli dans des couches semblables à celles de Lebach où l'archègosaure abonde; dans le terrain de Dracy-Saint-Lorys, près d'Autun, on voit, à côté des pro- 
triton, l'actinodon et l'euchirosaure; en Bohême et en Saxe, MM. Fritsch, Geinitz et Deichmüller ont découvert, outre le branchiosaure, des animaux tels que le dawsonia et le melanerpeton pulcherrimum, qui semblent des labyrinthodontes. En présence de ces coïncidences, il est naturel de penser que, parmi les petits fossiles d'aspect salamandriforme, plusieurs doivent représenter l'état jeune des labyrinthodontes. Mais il n'est pas toujours facile de distinguer les différences dues à l'âge et les différences spécifi-

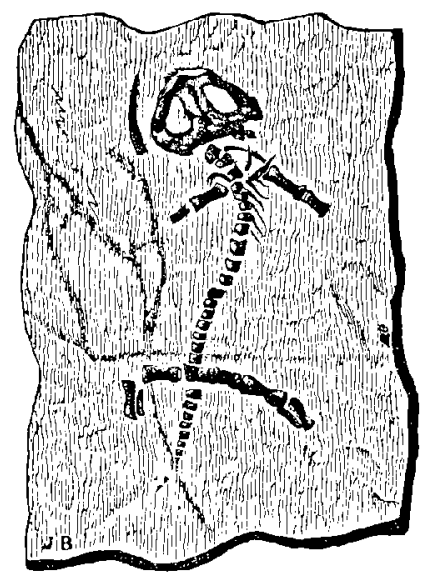

Fig. 260. - Restes fossiles du protriton petrolei.

ques chez des animaux qui ont pu être sujets à des métamorphoses, comme le sont plusieurs des batraciens actuels ».

La plus grande espèce de labyrinthodonte est connuo à la fois par ses ossements et par l'empreinte de ses pattes, assez semblables à une main d'homme dont les doigts courts et le pouce écarté seraient terminés par des griffes. Auprès de Lodève, les vestiges de pas sont accompagnès de ceux d'une queue traînante. Cet animal, moitié salamandre, moitié crocodile, avait le corps recouvert d'une carapace de fines écailles cornées. Ses membres étaient courts, mais robustes; la disproportion relative entre le train de derrière et cclui de devant marque les allures d'un reptile sauteur, avec des facons plus lourdes que celles des modernes batraciens. On peut se faire une idée de ces animaux, les plus anciens des vertébrés terrestres : peu actifs, voraces, croqueurs de petites proies, rôdant sur le sable humide, protégés par une armure impénétrable, rois de 
la création à une époque où il suffisait d'être solidement charpenté pour obtenir le sceptre, ils n'avaient à redouter d'ennemi d'aucun genre, puisqu'il ne s'agissait encore ni d'intelligence, ni de rapidité, ni n'énergie, et que l'instinct lui-même se réduisait à l'accomplissement des actes indispensables à l'entretien et à la propagation de l'espèce. La vie de pareils ĉtres s'écoulait dans sa monotonie à suivre les eaux dans leurs alternatives d'envahissement et de retrait; ils respiraient et se mouvaient à l'air libre, mais sans s'écarter beaucoup du voisinage de l'élément qui avait été leur premier berceau.

Le type des labyrinthodontes était ancien lors du trias qui en marque l'apogée; on le recontre, déjà reconnaissable, dans le terrain carbonifére. Toutefois, à cette époque reculée, on tronve à côtẻ de lui un autre type à la fois plus imparfait, plus ambigu et plus voisin du point de départ: e'est celui des ganocéphales. Ce type nous fait toucher au point où les reptiles, déjả peut-être organisés pour une respiration aérienne, n'avaient pas encore cessé d'être nageurs pour devenir marcheurs. Ces ganocéphales sont, à vrai dire, des labyrinthodontes moins avancés. L'ossification de leurs vertèbres est imparfaite, la disposition ainsi que la structure de leurs dents les rapprochent de plusieurs poissons. Leur taille (comme il arrive presque toujours lorsque l'on a sous les yeux les types primitifs d'une série) est modeste à côté de cclle des labyrinthodontes du trias. Le plus grand des ganocéphales, l'archégosaure ne ruesurait pas plus d'un mètre de long. Ses membres étaient faibles et plutôt disposés pour nager ou ramper que pour la marehe; ils se terminent pourtant par des extrémités munies de doigts distincts. Ses habitudes étaient carnassières comme celles des labyrinthodontes. L'archégosaure était à ceux-ci ce qu'est à la grenouille le type des salamandres, des tritons et des protées, qui tous s'arrètent à certains degrés de la métamorphose, et demeurent plus ou moins tètards durant toute leur vie (').

Ces faits offrent de grands enscignements pour l'histoire de l'évolution. Quand on voit les vertèbres incomplètement formées dans l'archégosaure et mème dans l'actinodon et l'euchirosaure,

1. De Saporta. Le Monde des Plantes avant l'apparition de l'homme. 
qui, à certains égards, sont des ètres assez perfectionnés, on no peut se défendre de l'idée que l'on surprend le type vertébré en voie de formation, au moment où va s'achever l'ossification de la colonne vertébrale. Lorsque l'on examine les os des membres de l'archégosaure et de l'actinodon, avec leurs extrémités creuses, autrefois remplies par du cartilage, ne pouvant exécuter que des mouvements généraux, il est naturel de penser qu'ils indiquent des animaux dont l'évolution n'était pas torminée. « Ricn n'est plus remarquable dans le squelette de l'hylonatus, écrit le géologue canadien Dawson, que le contraste entre les formes parfaites et belles de ses os et leur condition imparfaitement ossifiée; cette circonstance soulève la question de savoir si ces spécimens ne représentent pas les jeunes de quelques reptiles de plus grande taille. $>$

Comme le savant paléontologiste du Canada, M. Gaudry pense que ces os représentent un état de jeunesse; seulement il distingue deux sortes de jeunesse : la jeunesse des individus, et la jeunesse de la classe ¿̀ laquelle ils appartiennent. "A l'époque primaire, les batraciens et les reptiles étaient jeunes; plusieurs de leurs types étaient peu avancés dans leur évolution; c'est pour cela que, même dans les individus adultes, quelques-uns de leurs caractères pouvaient refléter ceux des reptiles actuels à l'état jeune ou même à l'état embryonnaire; ce sont là des applications des idées qui ont été mises en avant par Louis Agassiz sur les rapports de l'embryogénie et de la paléontologie. „

On a représenté ci-dessous ( $f g$. 261), d'après M. Sauvage ('), l'une des espèces de labyrinthodontes européens les mieux étudiés, celle des mastodontosaures, à tête courte, plate, large et de forme parabolique, aux mâchoires bien armées: la mâchoire supérieure portait deux rangées, dont l'externe ne comptait pas moins de cent dents. Ces reptiles ont pris leur plus grand développement à l'époque du trias, puis ont disparu sans laisser de descendants. Sur lo dessin, l'un de ces animaux est vu de dos, l'autre, à demi plongé dans l'eau, nous montre les plaques qui garnissent la poitrine. On remarque dans ce paysage, à gauche, des équisetum et des calamites, à

1. Édition française des Reptiles de Breнm. Paris, Baillière, 1885. 
droite des fougères arborescentes, plantes contemporaines des labyrinthodontes, de la période carbonifère à l'époque triasique.

Les labyrinthodontes, auxquels paraissent se rattacher les divers types qui viennent d'ètre décrits, ont été l'objet de discussions nombreuses dans le camp des géologues, et l'on n'est pas encore d'accord aujourd'hui sur leur véritable caractère. Nous les retrouverons dans les temps qui vont suivre, au début de l'époque secondaire. On a remarqué avec raison que lorsque Cuvier a classé l ss pièces fossiles du gypse de Paris, il a pu attribuer chacune à son espèce parce qu'il a eu pour se guider les êtres de la nature actuclle qui ont des affinités avec ccux des temps tertiaircs; tandis que l'examen des animaux récents ne peut jeter qu'une lumière bien affaiblie sur des créatures d'une anssi immense antiquité que celles des temps permiens. Que de milliers et de milliers de siècles ont passé depuis! Pour les habitants de la Terre contemporains de la formation de la houille ou du nouveau grès rouge (revoir le tableau de la p. 259) le siècle de Pharaon et de Moïse, celui de Romulus et des citoyens du Latium, celui de Jésus et de saint Paul, celui de Gharlemagne, celui de Louis XIV, le nôtre, étaient éloignés à une telle distance dans l'avenir que l'imagination la plus audacieuse n'aurait certainement pu atteindre jusque-là. De mème, nul ne saurait prévoir, à notre époque actuelle, les siècles qui se lèveront sur cette Terre dans cent mille ans, cinq cent mille ans, un million, cinq ou dix millions d'années. Une telle vue est écrasante pour la pensée. Pourtant pendant longtemps encore, sans doute pendant des centaines de milliers et des millions d'années, la vie terrestre continuera à progresser et à se perfectionner, et les habitants de ces âges futurs, aussi supérieurs à nous, sans doute, que nous le sommes aux premiers reptiles, auront de la peine à se représenter l'état actuel de nos paysages, de nos plantes, de nos animaux, de notre humanité avec toutes ses œuvres... 0 soleil ! il faut ' que notre mémoire soit bien courte pour nous imaginer qu'il n'y a rien de nouveau sous tes rayons!

Les végétaux de la période permienne sont, comme les animaux, le développement de ceux de la période carbonifère, développement dans le sens de la transformation des espèces, mais amoin- 
drissement dans les dimensions des géants houillers. Les grandes sigillaires avec leurs stigmaria, les cordaïtes aux larges feuilles

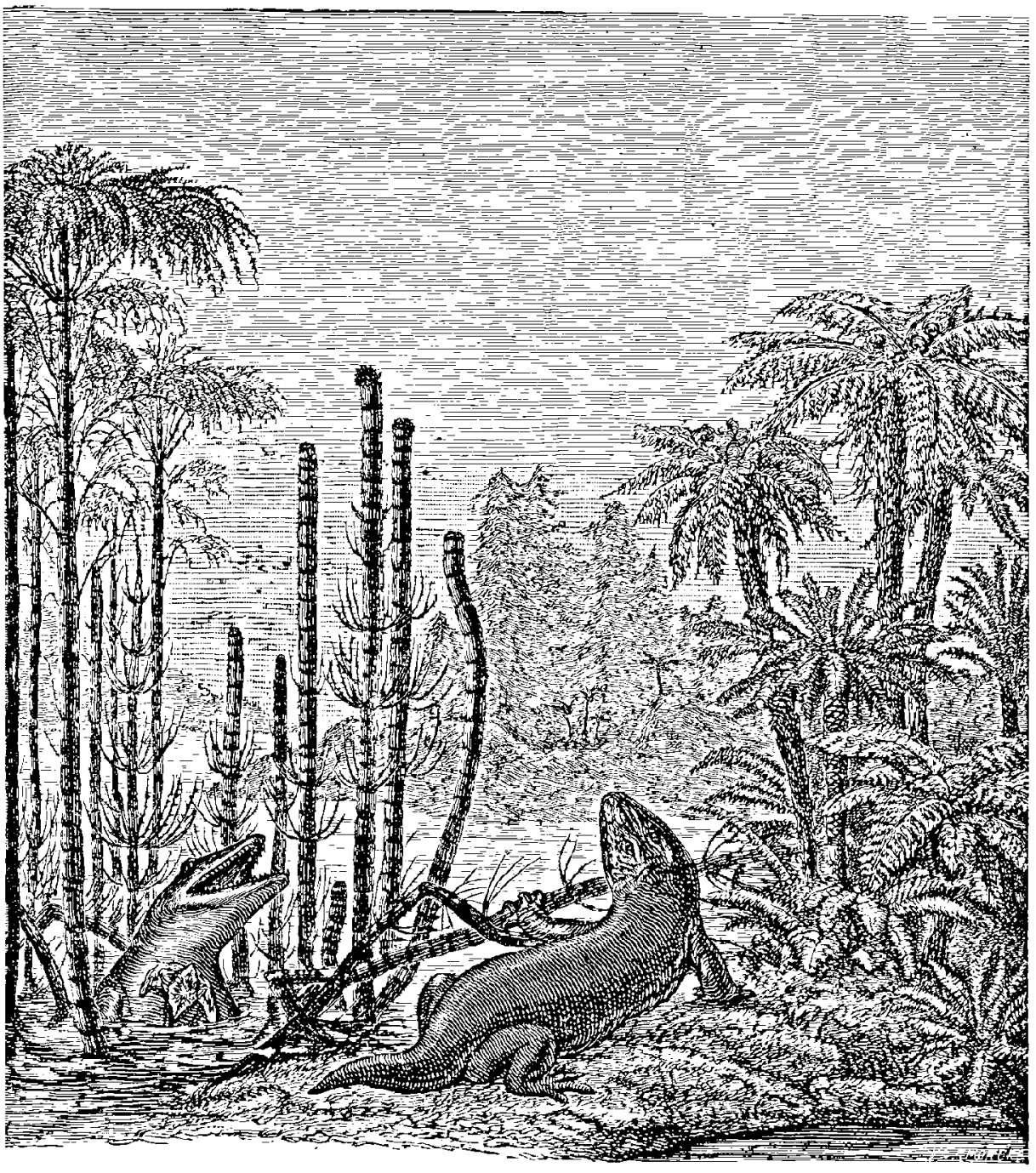

Fíg. 26I. - Les LABYRINтно оNTES : mastodontosaures

persistent encore pendant des siècles; mais bientôt ces formes caractéristiques disparaissent, pour faire place aux conifères. Les walchia envahissent les forêts et se substituent aux cryptogames en pleine décroissance. Ces conifères annoncent leurs successeurs de l'époque actuelle. Les formes changent. On devine les feuilles, 
presque les fleurs et les fruits des âges füturś. Mais qu'il y a ¡loin encore pour arriver à nos élégances végétales: actuelles ! Les temps primitifs sont finis pourtant. La nature va inaugurer les

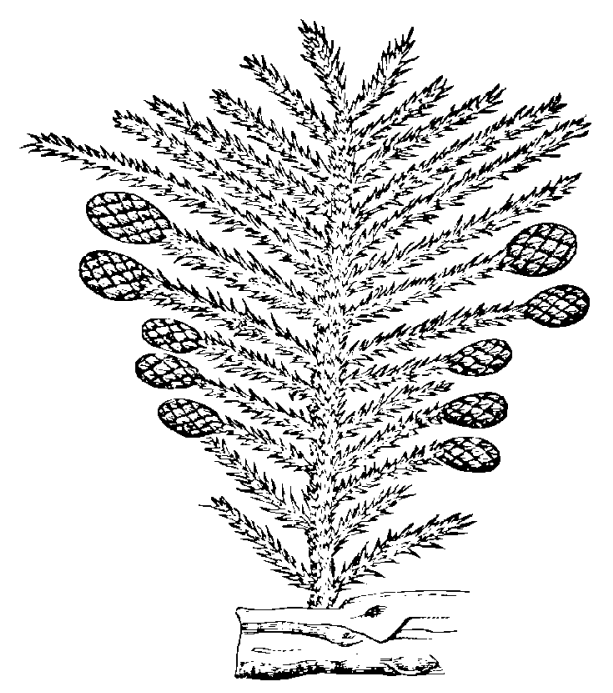

Fig. 262. - Les plantes de la période permienne. Conifères. Rameas de walchia.

grands jours de l'époque secondaire: la création entre dans une nouvelle phase, qui donne un magique essor à la vie et prépare les richesses de l'organisation moderne. 
LIVRE IV

IAGE SHCONDAIRE

IRIS - LILLIAD - Université Lille 1 
IRIS - LILLIAD - Université Lille 1 


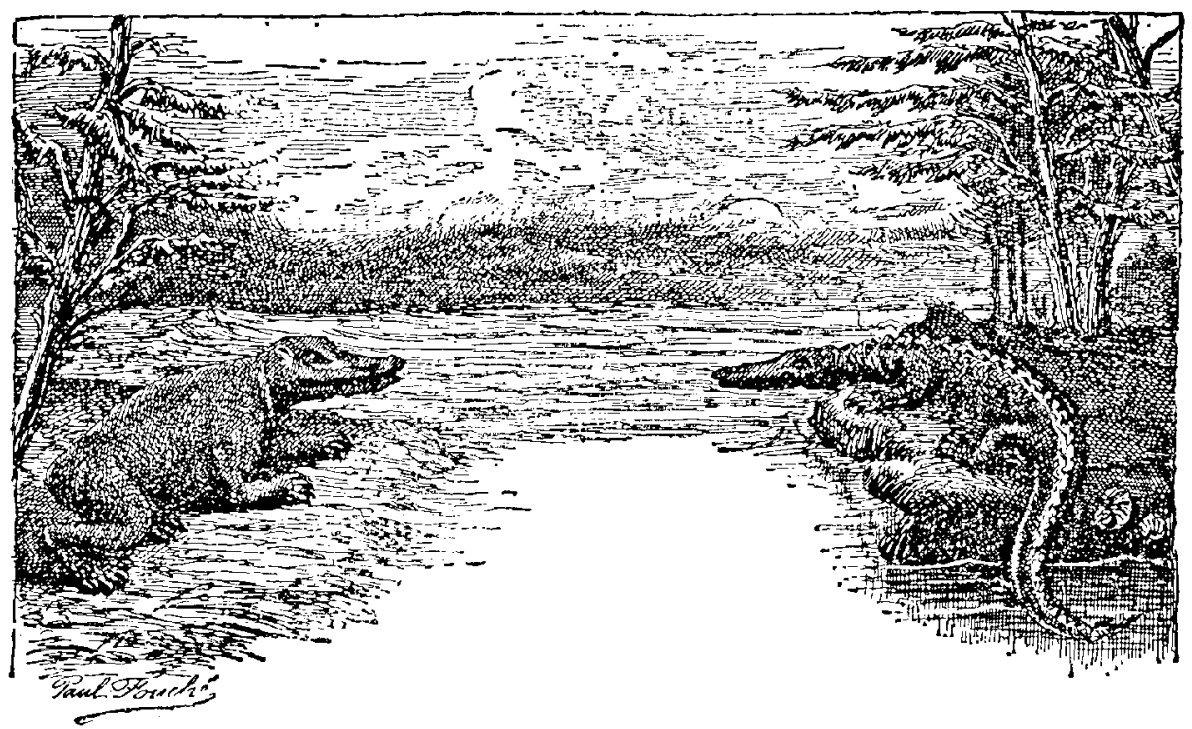

CHAPITRE PREMIER

LA PÉRIODE TRIASIQUE

L'atmosphère est purifiée. Le soleil, moins immense et moins nébuleux qu'aux siècles passés, commence à resplendir dans un ciel bleu. Les éruptions du foyer interne, de porpliyres, de trapps et de mélaphyres, qui avaient succédé aux convulsions primilives $\mathrm{du}$ monde naissant et avaient interrompu à plusieurs reprises le dépôt de sédiments houillers et permiens, sont devenues plus rares et plus calmes; les fentes du globe ne laissent plus passer la chaleur interne avec la même facilité, elles sont remplies de filons éruptifs qui se refroidissent eux-mẻmes. La population végétale et animale, qui des eaux avait envahi les rivages et les plaines bassos, s'élève en mème temps que, par la série des contractions du globe en voie de refroidissement, des plissements et des dislocations qui en résultent, le relief des terrains s'accuse davantage et fait émerger de plus en plus haut des îles de plus en plus vastes, presque continentales. Les plantes, moins nourries par l'eau et par l'atmosphère, gardent leurs dimensions géantes de l'époque houllère et commencent à se diversifier; voici les cycadèes et les conifères. Il n'y a pas encore, toutefois d'arbres à saisons, les saisons elles-mèmes n'existant pas encore. Les reptiles vont dominer sur la teire ferme. Dans les mers, les mollusques se multiplient, surtout les céphalo- 
podes de la famille des ammonitidés, qui apparaissent nombreux dès le début de l'ère nouvelle, dont ils caractériseront toutes les phases. Les poissons suivent un dèveloppement analogue; ils cossent d'ètre seulement cartilagineux, et un nouveau lype sort du premier, celui des poissons osseux. L'œuvre do la nature s'étend, s'agrandit et se diversifie.

L'ensemble de l'ère secondaire représente un progrès considérable et incontcsté sur l'ensemble de l'ère primaire. Mais ce n'est pas à dire pour cela que cette ère ait commencé, pas plus que l'ère primaire issue de l'ère primordiale, par une création soudaine de certains types animaux ou végétaux ou par un bouleversement quelconque dans les éléments de la planète. On l'a compris : entre une époque de la nature et celle qui la précède ou celle qui la suit, il n'y a pas plus de saut brusque,' de solution de continuité, qu'entre le dernier jour d'une année et le premier de l'année suivante, entre la dernière heure de notre vingt-neuvième année et la première de notre trentième. Et la Nature n'a pas les raisons apparentes qui nous invitent quelquefois à nous « faire » plus âgés tant que nous n'avons pas franchi le cap de la vingtième année, et plus jeunes lorsqu'avançant en âge nous regrettons de voir si vite envolés les beaux jours (passés inappréciés) du printemps et de l'été. Elle marche, toujours en avant, - toujours jeune, elle, ou plutôt affranchie des effets de l'âge pendant une durée si longue que pour nous sa jeunesse semble éternelle. - En fait, la Terre a commencè et elle finira; sa vie planétaire se compose aussi d'années et de jours; ces années et ces jours se suivent comme les nôtres, graduellement, et non par saccades; l'ère secondaire succède à l'ère primaire et la continue.

Tout etre porte en soi la tendance au progrès. Quelle que soit sa situation, il désire mieux, et ce désir est la cause et la raison d'être de son activité. La plante cherche, vaguement mais avec énergie, la lumière la plus favorable à son épanouissement, les sucs nourriciers les plus succulents pour ses racines. Le poisson vogue vers l'eau préférée, remonte les fleuves vers leur source. L'insecte choisit le meilleur miel ou le raisin le plus mûr. L'oiseau veut pour son nid la mousse la plus fine, le crin le plus souple, la situation la 
plus commode. Le chien épie les volontés de son maitre et cherche à lui plaire. Dans le règne végétal comme dans le règne animal, les qualités extérieures et intérieures, l'éclat des couleurs, qui fait préférer certaines fleurs aux insectes et les prédispose à la fécondation, qui, d'autre part, joue aussi un ròle important dans le choix des époux chez les insectes, les oiseaux, les mammifères, etc.; les odeurs, dont l'influence est loin d'ètre indifférente; la foree musculaire et nerveuse ; la nature de l'alimentation et le caractère qui en résulte; mille causes diverses agissent en faveur du progrès par suite de cette tendance au mieux dont tout ètre est doué. Supprimez cette tendance, ce désir, cette aspiration, vous brisez le ressort du moivement, et la nature entière, depuis la plante jusqu'à l'homme, tombe dans le marasme le plus inerte. Sans ce don intime et suprème, la vie elle-même perd son intérêt, sa raison d'être, l'humanitè s'arrête, ou pour mieux dire l'humanité n'existe pas, car elle serait restèe enfermée dans l'antique chrysalide du monde antérieur à elle. Tout manifeste, tout proclame l'ascension. C'est la loi générale et particulière. L'enfant n'a qu'un but : grandir; le lycéen aspire pendant dix ans à son émancipation ; la jeune fille, charmante en son adolescence, n'est point satisfaite : elle veut être “ dame; " la jeune épouse attend avec un inquiet bonheur la naissance de son premicr-né; le père de famille prépare pour ses fils une situation désirée supérieure à la sienne; le soldat convoite les galons, le colonel compte mourir général; le travailleur espère un avenir plus doux; le fonctionnaire escompte d'avance son avancement; l'ambiticux quête les places et les honneurs; l'avare s'enrichit comme s'il ne devait jamais mourir; le gourmand savoure d'avance la composition de ses repas; le député voit en rêve le portefeuille d'un ministère; le cardinal ne refuserait la tiare que par une feinte humilité; le savant étudie sans cesse, altéré de l'inconnu, désespéré parfois de ce qui reste à connaitre; l'artiste aspire à s'approcher de plus en plus de la beauté suprême; le penseur prévoit, dans un avenir qu'il espère prochain, une humanité plus parfaite que la nôtre; et ainsi, par toutes ses passions, par tous ses désirs, par toutes ses aspirations, dans ses plaisirs comme dans ses peines, l'homme marche et progresse, et loin mème d'être jamais satisfaits de ce que la vie actuelle 
peut nous donner, nous ne bornons pas à cette terre la sphère de nos aspirations et nous nous sentons appelés à les continuer au delà, dans une ascension plus haute et plus belle. G'est cette tendance divine, inhérente à l'atome, à l'être le plus élémentaire, à la cellule, au protoplasma; c'est cette part de divin, que la nature visible, émanation de la Force invisible, possède en soi; c'est cette aspiration vers l'Infini, notre pèrc, qui cause et détermine lo perfectionnement perpétuel des ètres, la transformation graduelle des espèces, et qui, dans l'histoire entière de la Terre, nous montre un progrès continu depuis les premiers âges jusqu'à nos jours.

En assistant aux évènements de l'âge secondaire, nous allons constater de plus en plus l'absolue vérité de cette loi universelle. Tout le système de la vie va prendre un dévoloppoment graduel incessant.

Cette époque se partage en trois périodes bien distinctes par leurs caractères, la période triasique, la période jurassique, et la période crétacée.

La première a été nommée triasique, parce que les terrains qui la représentent se sont montrés, à l'origine de l'étude de ces terrains, partagés en trois étages : le grès bigarré, le muschelkalk ou calcaire conchylien et le keuper, dans lequel on rencontre les marnes irisées, ou pour mieux dire, bariolées. On voit, en effet, ces trois étages, régulièrement posés l'un sur l'autre, en Souabe, en Franconie, en Lorraine, et aillcurs; mais cette division, qui comporte un étage marin intercalé entre deux formations d'eau douce, est en dẻfaut sur un grand nombre de points, notamment en Angleterre, dans les massifs montagneux des Alpes, de l'Himalaya et de la Californie. De plus, on trouve souvent ce système triasique intimement lié au permien, ce qui confirme l'unitè de développement organique que nous signalions tout à l'heure. Gertaines couches peuvent manquer, mais jamais l'ordre n'est interverti, jamais le grès bigarré n'est au-dessous du calcaire à coquilles, comme jamais le jurassique n'est au-dessus du crétacé.

Le seconde période des temps secondaires a reçu le nom de période jurassique, parce que la chaîne du Jura, qui s'est soulevèe plus tard, est en grande partie composée de terrains que les mers 


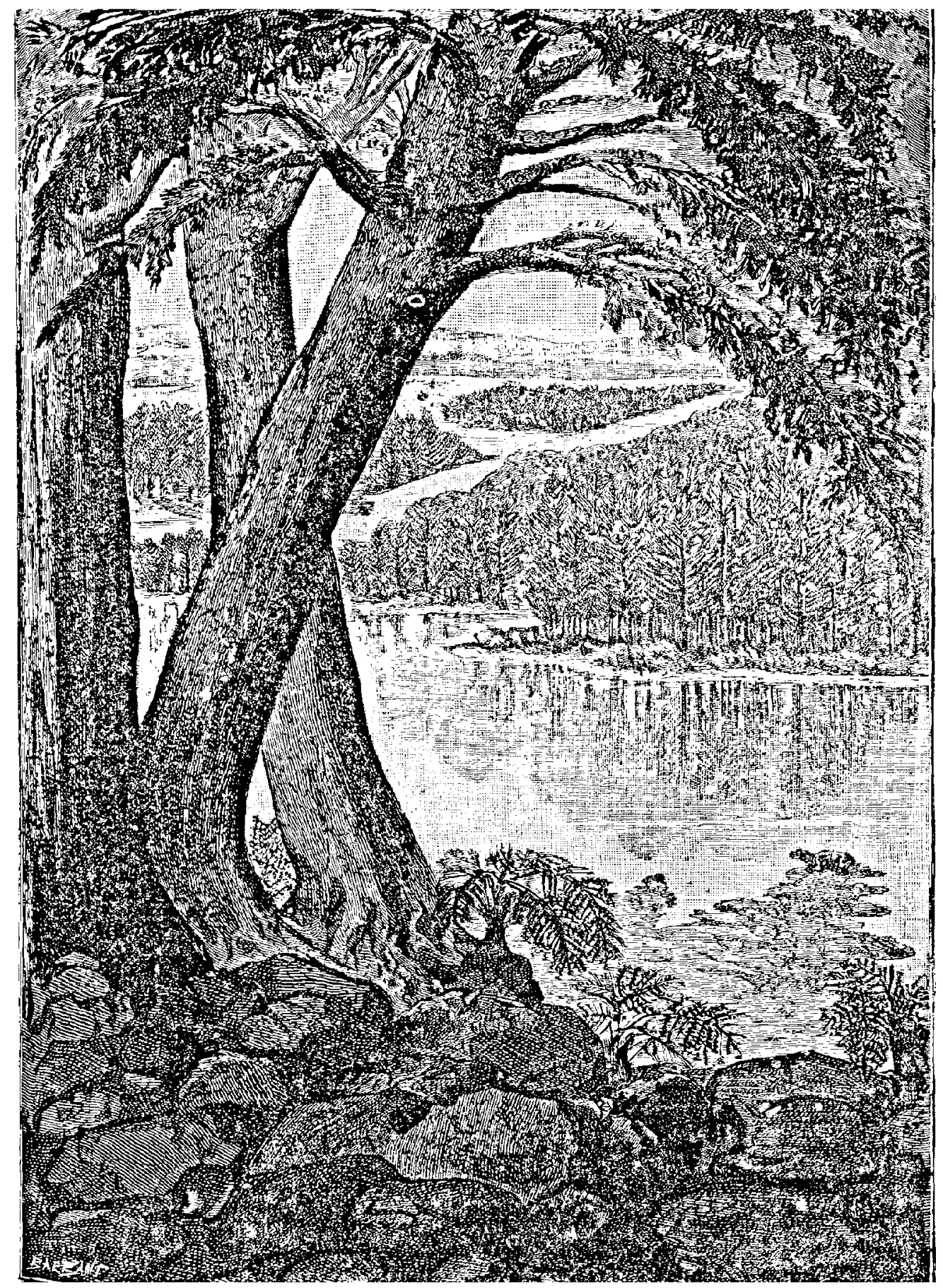

PAYSAGE UE L'EPOQLE TRIASIQUE (PÉRIODE CONCHYLIENNE).

Haidingera ol forát de Vultziz.

LE MONDE AYANT LA CREATION DE LHOHME 
ont déposés pendant cette période. Ces terrains sont caractéristiques d'une formation importante et très répandue. Cette période se subdivise en deux parties distinctes : le lias et l'oolithe.

La troisième période a été nommée crétacée, parce que les terrains que la mer a déposés à cette époque sont presque entièrement ormés de craie. On la subdivise en trois séries, le systéme crétacó inférieur, le moyen et le supérieur. (Revoir, à ce propos le tableau général de la page 259.)

Ainsi, succédant aux périodes des temps primaires, les périodes des temps secondaires se présentent dans l'ordre chronologique suivant :

\section{AGE SECONDAIRE}

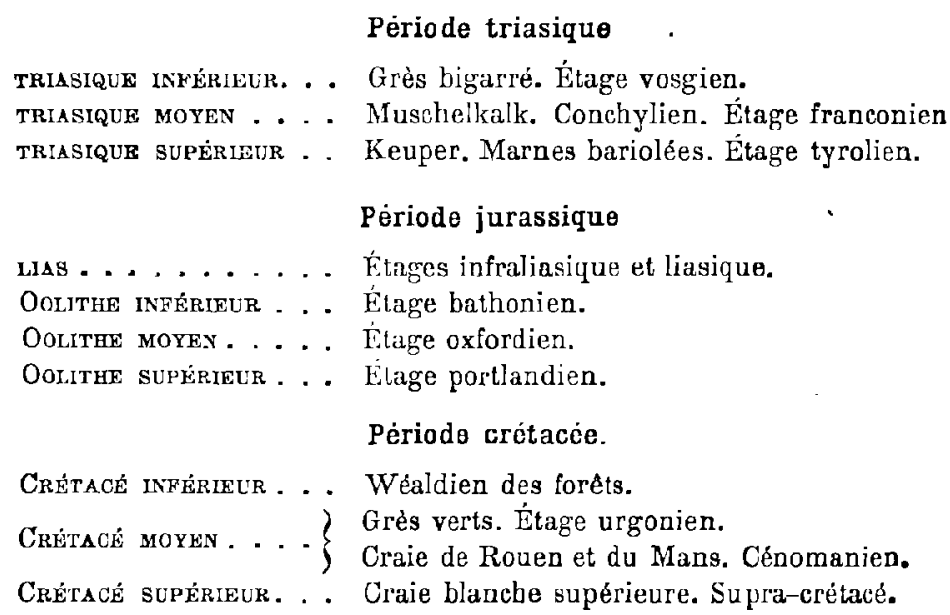

Nous allons étudier dans ce même ordre chronologique ces phases consécutives de l'histoire de la Terre.

La période triasique, qui inaugure l'ère secondaire, a vu se déposer, disions-nous, trois espèces de terrains, le grès bigarré, le calcaire à coquilles et le keuper. Le premier se présente, avec une abondance remarquable, dans les Vosges; le second, dans les mèmes conditions, on Franconie; et le troisième dans les Alpes du Tyrol. C'cst pourquoi on donne quelquefois à ces trois étages les titres respectifs de vosgien, franconien et tyrolien.

Dans quelles conditions ces terrains se sont-ils formés? «A l'ouverture de la période triasique, écrit M. de Lapparent, les mers intéricures où s'étaient déposés, dans le nord de l'Allemagne et de 
l'Angleterre, les sédiments marins du permien supérieur, sont asséchées, et c'est au sud, dans la région méditerranéenne, qu'il faut aller chercher le régime pélagique. Mais bientôt, de cette méditerranée largement ouverte, des golfes se détachent vers le nord, et le mouvement d'invasion marine atteint sa plus grande amplitude à l'époque franconienne, où la Lorraine et le bord oriental du plateau central sont baignés par la mer ou plutôt par des mers, en communication sans doute difficile avec l'Océan proprement dit. Bientôt, du reste, les eaux marines se retirent au sud et à l'est, et le régime des lagunes, peut-être même des étangs, prévaut à l'époque tyrolienne sur toute la France, toute l'Angleterre et la majeure partie de l'Espagne. Les conditions pélagiques se retrouvent à l'est de cette dernière contrée, en Italie, depuis la Sicile jusquaux Alpes vénitiennes, dans le pays de Salzbourg et la région des Carpathes. En un mot, c'est la méditerranée permo-carbonifère, un peu déplacée vers le nord, moins étendue à l'ouest et se reliant, comme auparavant, avec les dépressions de l'Oural et de l'Asie centrale. Sur tout ce territoire, où les ammonitidés avaient fait leur première apparition au sommet du permien, cette grande famille de céphalopodes prend une remarquable extension, et des circonstances semblables se retrouvent dans l'Amérique occidentale, ainsi que dans les régions arctiques, tandis que dans l'Afrique australe et en Australie, le trias reprend un facies continental analogue à celui de l'Europe. »

Ges divers terrains de l'époque secondaire se distinguent parfaitement les uns des autres, sont de composition toute différente, et se sont formés à des milliers de siècles d'intervalle. On a cependant le droit de les comprendre dans une même période de formation, car les plantes et les animaux qu'ils renferment ont le même caractère dans les couches supérieures et inférieures. Dans le grès bigarré, on trouve les mêmes espèces que dans le muschelkalk et le keuper, et l'on en suit mème un grand nombre jusqu'au crétacé. Pendant toute cette période, la surface terrestre ne s'est pas radicalement modifiée, mais elle présente des différences essentielles, relativement à la période précédente.

Tout d'abord, et en grand nombre, nous rencontrons les plantes que nous connaissons déjà, sous les anciennes formes et en espèces 
noùvelles, c'est-à-dire les fougères, les roseaux, les joncs, les équisétacées, les lycopodes. Mais, remarque caractéristique, les grandes espèces des deux dernières familles disparaissent, se rapprochent beaucoup des plantes actuelles, ou du moins offrent a vec elles certaines analogies, et ne s'en distinguent plus que sous le rapport de la dimension.

La famille des jones se présente abondamment, non plus par couches considérables de matières végétales carbonisées (celles-ci font à peu près défaut, dans la deuxième plase de la transforma-

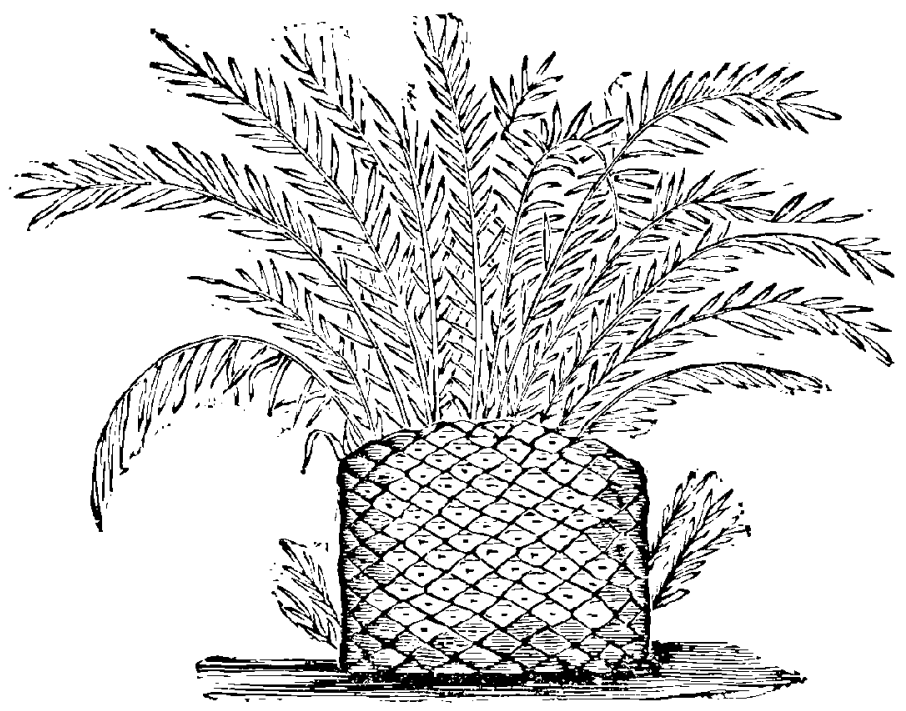

Fig. 265. - Cycadées de la période triasique

tion de l'écorce terrestre, dans les tèrrains secondaires), mais sous forme de nombreuses empreintes que recèlent de puissantes couches de grès.

Une plante qui, dans les époques antérieures, notamment pendant la formation houillère, se présente en quatre espèces, et en compte aujourd'hui quarante; apparait dans la formation secondaire en quantités tellement extraordinaires, que l'on peut dire qu'elle en est en quelque sorte le trait caractéristique: c'est la famille des Cycadées. (Le Cycas revoluta est encore aujourd'hui l'un des plus prócieux ornements de nos serres). Cette plante se trouve dans le terrain triasique en vingt, dans le jurassique en trente, et dans le crétacé en quinze espèces différentes, c'est-à-dire en 
soixante-cinq, ou vingt-cinq de plus qu'elle n'en comprend aujourd'hui. La figure précédente donne une idée de la forme générale des végètaux de cette famille.

Ce groupe de plantes, allié de prés aux palmiers, trahissant une origine tropicale, part du terrain houiller pour traverser, en s'élevant, tous les autres terrains (sauf le calcaire conchylien, qui n'en renferme pas), et se multiplie à la fois comme genre et comme individu. Mais il prouve, ainsi que les calamites et les fougères, que l'organisation des végétaux, dans les périodes successives qui
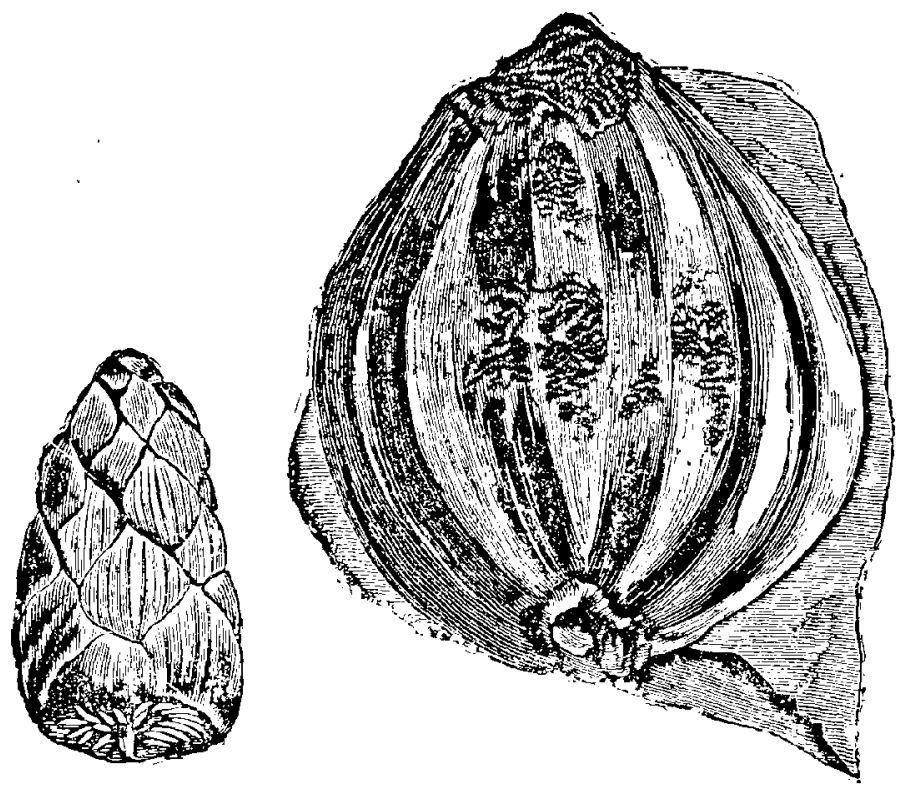

Fig. o6 - Fruits de cycadées, pétrifiés

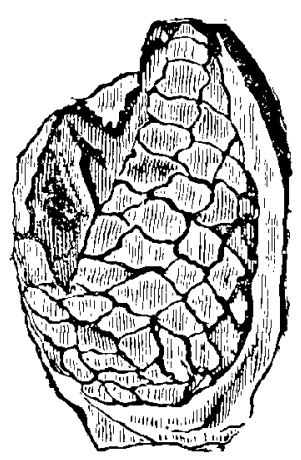

ont dû s'écouler pour la formation des divers terrains, a subi une métamorphose partielle, quoique la nature soit restée fidèle à la grande loi de son développement, c'est-à-dire que les formes imparfaites se reproduisent sans interruption et en des représentants toujours nouveaux, tant que la surface terrestre conserve le mème caractère qui, à l'origine, dans sa grossièreté primitive, excluait les organismes plus parfaits.

C'est ainsi que, jusqu'a l'heure actuelle, on voit, dans les terrains qui leur conviennent, se continuer les fougères et les équisètacées; c'est ainsi encore que l'on peut suivre la forme des 
cycadées qui, dans toutes les périodes de transformation de la Terre, depuis les couches secondaires jusqu'à l'époque où nous vivons, apparaissent en telle abondance, que les pétrifications de leurs fruits, de leur feuillage et de leur corps tout entier, se retrouvent un peu partout.

La figure 266 représente divers fruits, de cycadées fossiles dont le principal offre l'aspect d'une noix de coco. Ces cycadées atteignaient une hauteur de dix à douze mètres : les plantes actuelles de cette espèce mesurent rarement plus d'un mètre. Aujourd'hui, les cycas arborescents sont remplacés par les formes analogues, mais bien plus belles, des palmicrs.

Une preuve manifeste de la modification du sol se lit dans les groupes liasiques et jurassiques. Là, nous rencontrons déjà quelques plantes à floraison, et tout d'abord les conifères, dont les fouilles sont aciculées, c'est-à-dire cylindriques et pointues comme des aiguilles, et dont les fruits à forme conique, pommes de pin, pignons, etc., ont inspiré le nom donné à l'espèce. Dans la châne de montagnes qui s'étend entre Adersbach et Kudowa, tout près du village de Radowenz, en Bohème, on a découvert, en 1857, toute une forêt dans laquelle dominent ces arbres pétrifiés. Dans le terrain houiller, aux environs de Pilsen (Bohême), on a mis à nu des tigas de huit mètres de longtieur sur un mètre de diamètre, tantôt couchées, tantôt debout, et pétrifiées de la même manière; on suppose que ce sont les eaux siliceuses 'qui les ont ainsi transformées.

Les arbres de cette famille dénotent l'existence d'un terrain sec et d'un climat moins chaud; la Terre avait dù perdre en partie son caractère marécageux et insulaire; elle avait vu s'élever à sa surface des collines et des montagnes : la simultanéité des fruits et des troncs complets des conifères avec les palmiers, qui demandent l'humidité et la chaleur, tandis que les premiers préfẻrent un sol sec et une température plus fraiche, nous conduit, des coteaux et des collines, aux montagnes, où l'on trouve les conifères, même dans les régions tropicales.

Nous pouvons conclure de là qu'il existait des chaincs de montagnes couvertes de bois touffus de conifères, peut-être des plateaux enclavés dans l'intérieur des terres, tandis que les cycadées, 
les fougères, les lycopodes, mèlés de palmiers et de liliacées, entouraient les rives de ces vastes terrains inférieurs. Ia vie organique parait s'ètre accumulée surtout dans les ravins de ces collines boisées, car c'est principalement dans les bassins isolés qu'on en rencontre les restes.

Parmi les diverses espèces de conifẻres, nous trouvons surtout en abondance des araucarias, dont les formes sont d'une singulière beauté. Nous en représentons ici une branche, telle qu'on les trouve mutilées à l'état fossile. A l'état vivant, les araucarias portent leurs branches enroulées régulièrement autour du tronc, dans la forme verticillée, et constituent ainsi un type d'une remarquable élégance.

Parmi les arbres caractéristiques de ces forêts de l'âge secondaire, signalons aussi les voltzia, élégants conifères d'un aspect arsez étrange ( $f g .268$ ) et les pterophyllum aux feuilles échelonnées (fig. 269), ainsi que les haidingera, conifères très répandus pendant la période conchylienne, aux rameaux et au feuillage inclinés, portant des feuilles dans le genre de celles de nos dammara, et dont l'imposante structure devait offrir un aspect analogue à cclui de nos cèdres actuels. On a essayé de représenter plus

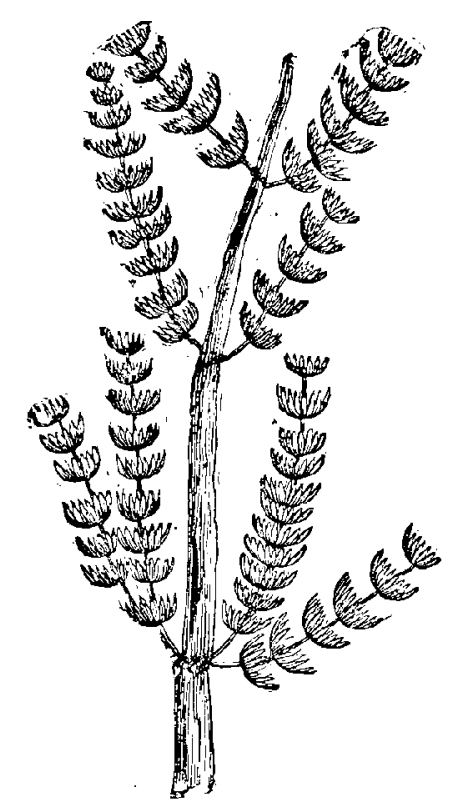

Fig. 267.

Branche fossile d’araucaria. haut(p. 489) un de ces paysages. Mais les richesses vógétales admirèes aux beaux jours de l'époque carbonifère ont fait place à une indigence relative; ce ne sont plus ces forèts profondes aux arbres géants, aux solitudes infinies, aux ombres impénétrables. Les végétaux sont plus clair-semés, les terrains sont plus accidentés, la lumière se joue sur des tapis de verdure et flotte dans les clairières. Les types de la houille ont disparu, mais les « angiospermes $₫$, c'est-àdire les plantes qui comprennent à elles seules les neuf dixièmes de la végétation actuelle, ne sont pas encore formées, à part quel: ques rares « monocotylèdones ». La flore ne comprend toujours 
que des « cryptoz unes » et des « gymnospermes », les premières étant représentéus par des fougèros, des préles, etc., les secondes, par des cycadées et des conifères. On remarque sculement, sur tout l'archipel marin qui existait alors à la place de l'Europe, que la végétation des rivages et des bas niveaux diffère de celle des collines et des sommets : en bas, les fougères aux frondes largement développées ou délicatement découpées, les équisétacées ct
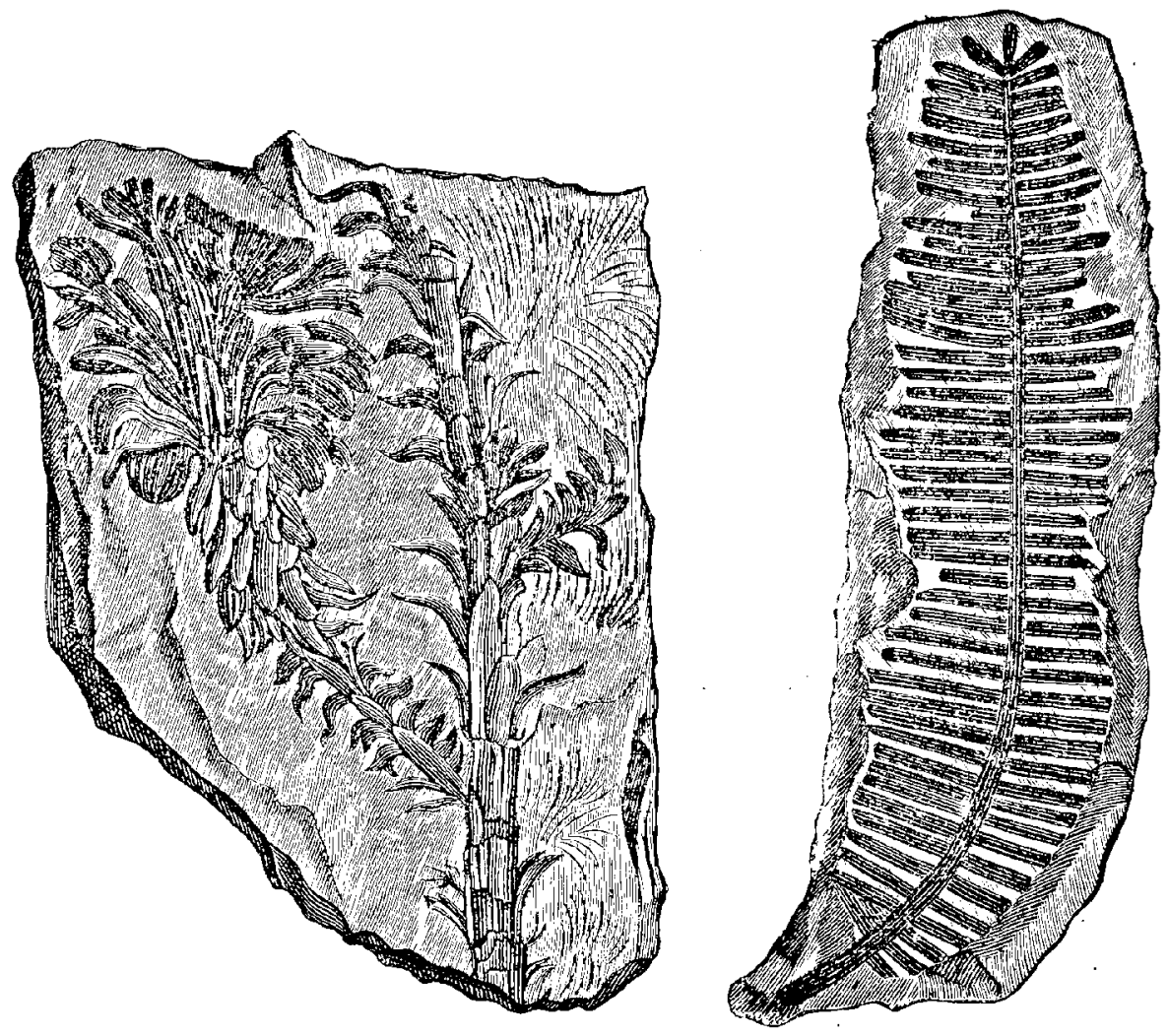

Fig. 268-269. - Les végétaux de la période triasique.

Voltziz heterophylla et Pierophyllum Juegeri

les conifères primitifs; en haut, sur les terrains plus élevés et plus. secs, des fougères aux frondes maigres et coriaces, des zamites, parmi les cycadées, et les conifères géants qui formaient la masse principale des forèts montagneuses.

Les grès qui couronnent maintenant les sommets des chaines secondaires des Vosges, sur une épaisseur de cinquante à soixante mètres, et qui reposent sur cinq cents mètres d'épaisseur de pou- 
dingue - le tout représentant le premier étage de la formation triasique - sont remplis de plantes terrestres témoignant que les forêts de cette époque étaient encore occupées par des fougères arborescentes, mais avec une grande abondance de cycadées et de conifères voisins de nos cyprès actuels. Les cyprès, qui ne subissent pas l'inflience des saisons, et que le culte des morts a choisis pour abriter les tombes d'une permanente mais sombre verdure, les

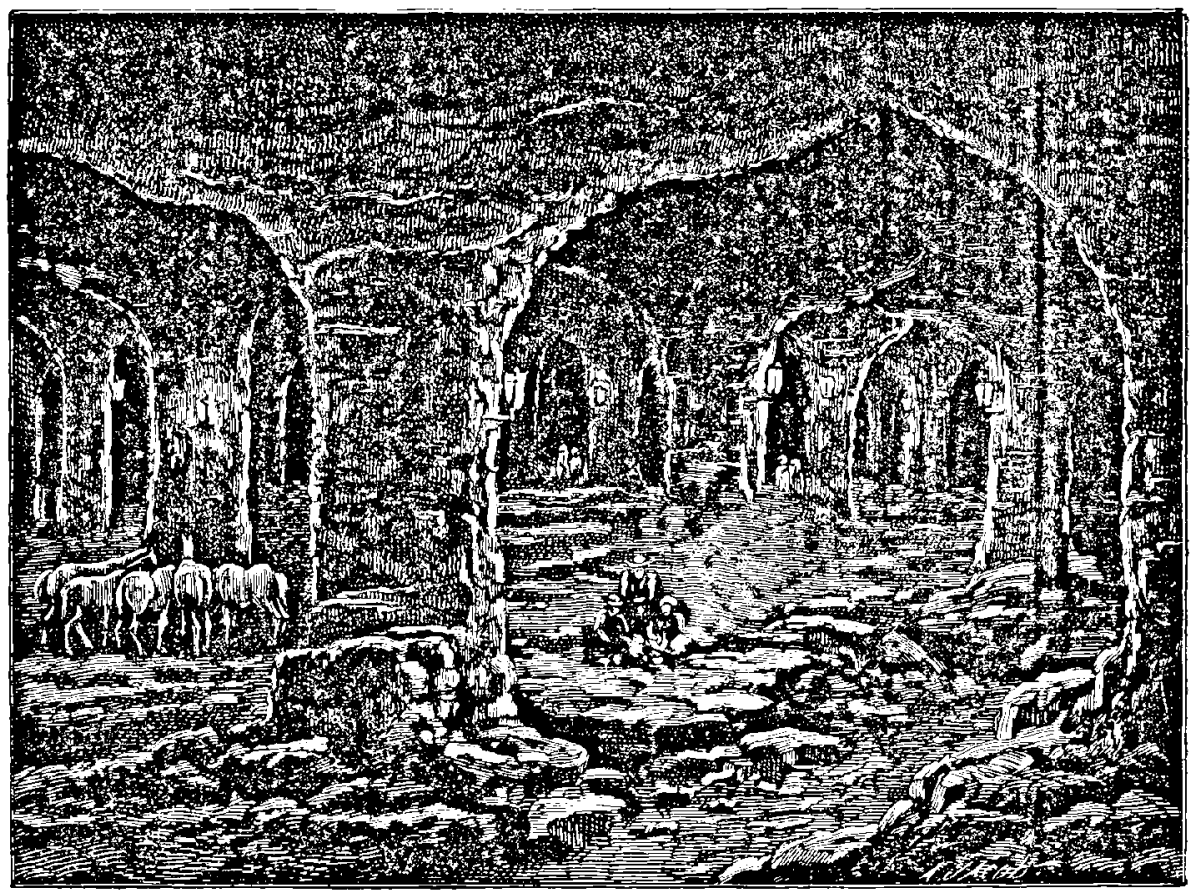

Fig. 270. - La formation triasique. Mines de sel de Wieliezka en Pologne.

pins aux branches étendues, ces arbres monotones et sévères, sont les plus anciens de ceux qui existent de nos jours, car les fougères et les prêles de l'époque primaire n'ont plus aujourd'hui que des représentants herbacés. Nous sommes encore loin des arbres à fruits - même sauvages. Ces grès vosgiens de la période triasique renferment aussi des équisetum voisins de nos prêles actuelles, végétaux des marécages et des étangs dans lesquels se sont déposés les sables du grès bigarré.

Le troisième étage - le plus récent - de la série triasique, celui des marnes bariolées, est quelquefois désigné sous le nom d'étage 
saliférien parce qu'on y rencontre beaucoup de gypse et de sel gemme déposé par amas souvent considérables. En Lorraine, en Souabe, dans le Wurtemberg, en Franconie, en Suisse, ces couches de sel gemme constituent en certains points des mines très épaisses et très riches. A Dieuze (Lorraine) on ne compte pas moins de treize couches superposées sur une épaisseur de cinquante mètres. Ces dépôts salifères triasiques se prolongent dans le Jura, où ils alimentent les nombreuses sources salées de la région, notamment à Lons-le-Saulnier, qui leur doit son nom. Dans le célèbre gîte sàlifère de Stassfurt, la puissance du sel gemme, mélangé de sulfate de magnésie et de chlorure de potassium, atteint cent soixante-dix mètres d'épaisseur. Cette même masse se prolonge jusqu'au-dessous de Berlin, où une couche de sel de 1550 mètres d'èpaisseur a été constatée, arrivant à quatre-vingt-dix mètres seulement au-dessous de la surface du sol.

L'absence presque complète des fossiles marins, dans les dépôts argileux qui terminent le trias, la fréquence des plantes terrestres, l'abondance du gypse et du sel, écrit M. Vélain, nous indiquent que les parties centrales de l'Europe où ces marnes irisées sont très répandues étaient alors couvertes par des eaux peu profondes, dont le degré de salure était tel qu'elles ne pouvaient contenir aucun ètre vivant. La mer Morte, les grands lacs salés d'Asie et d'Afrique, en partie recouverts par une croûte de sel, nous donnent un exemple de ce que devait être l'Europe septentrionale à cette époque. Les grandes masses d'eau océaniques s'étaient alors retirées dans les parties méridionales; elles occupaient la région des Alpes. On en a la preuve dans ce fait que déjà, quand on s'approche, en France, du plateau central, on constate que le calcaire marin de la division moyenne ne s'est pas étendu jusque-là et que les marnes irisées reposent directemont sur les grès bigarrés. On le retrouve plus bas, dans le département des Basses-Alpes, dans l'Hérault, dans le Var, aux environs de Toulon; de là on le suit sur tout le pourtour des Alpes, où il prend un grand développement. Dans cette région, le trias, tout entier, est représenté uniquement par des dépôts marins, par de grandes masses de calcaires compacts, souvent marmoréens, qui renferment alors un nombre considérable de fossiles. C'est là, dans ces assises calcaires qui s'étendent sur des milliers de 
mètres de puissance, qu'on peut bien juger de la faune marine triasique.

Les gisements du terrain saliférien les plus remarquables en France sont ceux de la Meurthe, de la Moselle, du Jura (Poligny et Salins), du Doubs, de l'Indre, du Cher, de l'Allier, de la Nièvre, de Saóne-et-Loire, de la Haute-Saône, de la Haute-Marne et des Vosges.

Chacun sait que le sel est un des minéraux les plus importants. A l'état de sel gemme, il forme des gisements entiers, et se rencontre en grande quantité dans l'intérieur des terrains de l'époque secondaire. En Transylvanie, il y a des montagnes salines qui ont plusieurs lieues de longueur, présentant des parois à pic de plusieurs centaines de pieds d'élévation, entic̀rement formées de sel gemme. A Cardona, sur le versant sud des Pyrénées, on voit un gisement de sel dont la masse au-dessus du sol s'élève à près de cent mètres de hauteur. Ces dépôts sont tellement déchirés et déchiquetés par les pluies, qu'avec leurs pyramides, leurs cornes, leurs pointes, leurs fondrières, on croirait voir un glacier; et la production du sel est tellement abondante que cette mine passe pour inépuisable, quoiqu'on l'exploite depuis des siècles (il en est fait mention dès l'an 1103). On admire là une montagne de sel de plusieurs centaines de mètres de hauteur. Les chaînes salines au sud et au nord de l'IIimalaya présentent des masses de sel plus considérables encore. A Kallabaugh, la route, sur un long parcours, est taillée dans des rochers de sel de trente mètres d'élévation. Mais ces masses gigantesques ne sont rien, comparées aux montagnes de sel qui entourent le lac de Titicaca, dans les Andes péruviennes; ce lac a une longueur de trois cent cinquante kilomètres.

Le sel se dissolvant aisément dans l'eau, le voisinage des montagnes salines présente souvent des lacs d'eau salée. L'eau de la mer aussi est salée, quoique les fleuves y amènent constamment de l'eau douce. Le sel marin provient de la combinaison du sodium et du chlore, éléments qui paraissent appartenir en propre à la constitution de l'eau primitive.

Partout où l'eau de mer s'évapore, le sel se dépose; sur un grand nombre de rivages, il est recueilli par évaporation. Nous ne savons pas si tous les dépôts de sel ont eu cette origine, ou si certaines couches se sont produites dans l'écorce du globe par d'autres 
phénomènes; mais un grand nombre de gisements, par exemple ceux de la Suisse, s'expliquent par l'évaporation de la mer. Les mollusques trouvès dans les roches calcaires qui avoisinent ces gisements de scl, prouvent qu'ils doivent leur origine à des dépôts marins.

Lorsqu'on pénètre dans une mine de sel, on est toujours impressionnẻ par l'aspect étrange de ces grottes souterraines. Cà et là les galeries s'èlargissent en de grandes chambres ou cavernes; leur centre est quelquefois occupé par un petit ètang; leurs parois et leurs voùtes étincellent de myriades de brillants cristaux de sel. Ces « chambres salines » sont assurément l'une des curiosités les plus remarquables de ces formations, et produisent un effet singulier lorsqu'on les visite à la lueur des torches (").

Les gisements allemands présentent une remarquahle analogie de conformation avec ceux de la Suisse septentrionale; on en peut conclure qu'ils ont été déposés à la mème époque et de la même manière. Le sel du Wurtemberg, dont les couches atteignent de dix à vingt mètres, est de même nature que le sel marin.

Pourtant la mer n'est peut-être pas la seule cause de ces curieuses roches de sel. " A Dieuze, fait remarquer M. de Lapparent, ce minéral offre des cavités avec bulles mobiles; il est mélangé d'argile bitumineuse, de sulfates de chaux et de soude, d'un peu de sulfate de magnésie; mais il ne contient ni chlorure de

1. Parmi les mines de sel les plus remarquables du monde entier, signalons celles de Wieliezka, près de Cracovie, en Pologne, au pied des Karpathes (fig. 270). Elles ne mesurent pas moins de trois mille mètres de longueur du nord au sud et douze cents mètres de largeur de l'est à l'ouest, à une profondew de quatre cents mètres au-dessous de la surface du sol. C'est une succession de vastes souterrains, une ville immense avec ses rues, ses avenues, ses places publiques, ses cabanes pour les mineurs et leurs familles : des centaines $\mathrm{y}$ sont nés et $\mathrm{y}$ finissent leurs jours. Il $\mathrm{y}$ a des chapelles pour le service du culte, et certaines galeries sont plus élevées et plus larges que des églises. Un grand nombre de lumières y sont toujours entretenues et leur flamme réfléchie de toutes parts sur les murs de sel, les font paraítre tantôt clairs et étincelants comme le cristal, tantât brillant des plus belles couleurs. On y trouve un lac que les visiteurs ne manquent pas de visiter en barque. La lueur vacillante des torches, la nacelle glissant en silence sur les eaux, les coups de pioche redoublés, les explosions de la poudre qui fait éclater des quartiers de sel, éveillent alors dans l'ame l'idée d'un monde infernal et la frappent d'une sorte de terreur religieuse.

La quantité de sel qu'on a extrait de ces mines depuis leur découverte, vers le milieu du XIII' siècle, s'élève à plus de six cent millions de quintaux.

Les mines de sel de la Suisse ne fournissent pas moins de 590000 quintaux par an. 
magnésium, ni trace d'iode ou de brome. Aussi Élie de Beaumont a-t-il fait ressortir combien il était peu probable que ce sel füt le résultat d'une évaporation naturelle survenue dans des lagunes
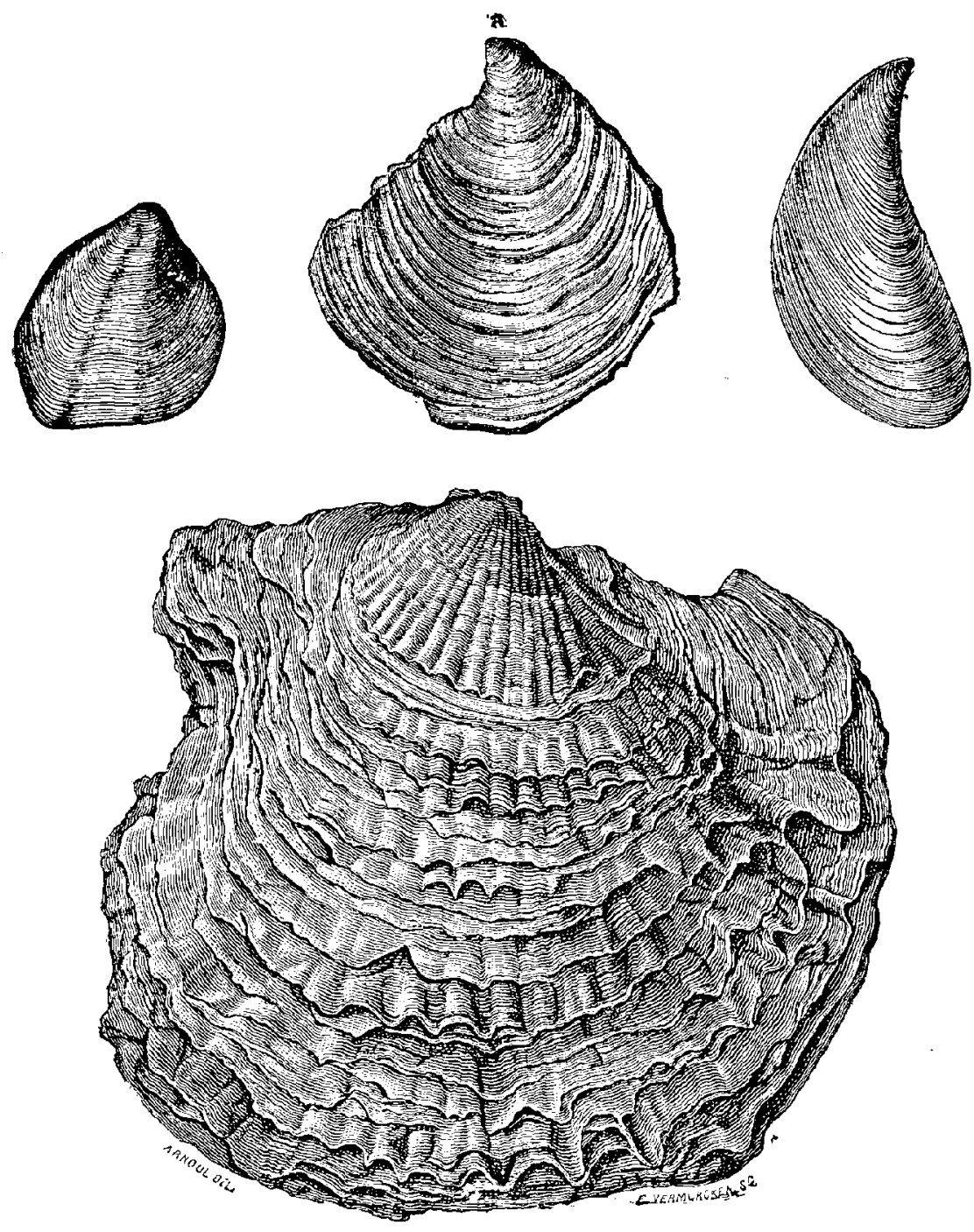

Fig. 271, - Iluitres fossiles de la période triasique.

marires; au contraire, il a indiqué l'analogie que présentent ces gisements avec certains produits immédiatement dérivés de l'activité ćruptive. Des couches de marnes et d'argile, avec gypse et anhydrite, séparent les conches de sel. Le gypse forme des amas plus 
nombreux et plus petits que ceux du sel gemme, et chacun d'eux affecte la forme d'un gros tubercule, autour duquel les marnes encaissantes sont relevées en vouttes et parfois renversées. Co gonflement s'explique si l'on admet que le gypse soit dù à une épigénie de calcaire par des émanations sulfureuses. $»$

A l'époque de la formation du sel, il y eut de nombreuses fluctuations marines, et le fait que l'on rencontre des couches de muschelkalk au-dessus des gisements salins indique qu'après l'évaporation de l'eau et la formation des bancs de sel, la mer est revenue sur les endroits desséchés et y a déposé ce calcaire et des glaises. Les animaux renfermés dans le muschelkalk nous fournissent quelques notions sur l'époque de la formation des couches salines. Ils nous apprennent égalementà connaître la faune marine de ces temps reculés.

Dans les salines suisses, Oswald Heer a trouvé d'importants spécimens de la faune de cette époque, notamment une écrevisse marine à longue queue et à carapace tuberculée, des étoiles de mer, des encrines ou lis de mer. Sur le bord de la Reuss, les roches sont remplies d'encrines. Ces animaux vivaient en colonies, écrit le savant naturaliste suisse, et ce devait ètre un curieux coup d'œil qu'un banc de rocher habité par des familles entières de lis de mer, avec leurs pieds minces et allongés, s'épanouissant au sommet comme une tulipe, tandis que de cette cupule finement sculptée sortaient les tentacules comme une gerbe de cils déliés.

Pendant que vivait ce genre complètement étranger à notre faune actuelle, de nombreux mollusques apparaissaient aussi. Ils se rapprochaient beaucoup plus des espèces actucllement vivantes, plusieurs appartenaient à des genres existant encore. Parmi ces espèces, on distingue la lima lineata, reconnaissable à ses deux grandes valves en forme de cornes et profondément striées, un peigne plat et poli et une avicule fort répandue. Les univalves ne sont pas rares, et la plupart appartiennent à des genres gui vivent encore : ainsi la turbonille, plusieurs espèces de troques et de natices, et un beau nautile, dont on a souvent trouvé de grands échantillons qui mesurent jusqu'à un pied de diamètre.

L'ammonite à corne (ceratites nodosus) est, le premier représentant de la famille des ammonitides, actuellement éteinte. Les 
ammonites et les nautiles appartiennent au groupe des céphalo. podes, qui occupent le premier rang dans la classe des mollusques , et se font remarquer par la construction cloisonnée de leurs coquilles. Ces nombreux mollusques servaient de nourriture aux poissons et aux amphibies dont les diverses espèces peuplaient la mer.

La faune terrestre étail pauvre au temps des marnes keupériennes. Heer a cherché en vain des insectes dans les couches helvétiques; les argiles schisteuses ont fourni deux espèces de coléoptères. Près de Richen, dans le grès bigarré, on a trouvé de grandes empreintes d'écailles provenant d'un gigantesque labyrinthodonte, et le squelette d'un petit saurien voisin des salamandres. A Rheinfelden, on a découvert une espèce de crocodile, le sclerosaure armatus, et des écailles de la tête du grand mastodonsaure. On a retrouvé de nombreux sauriens dans le keuper du Wurtemberg; le plus commun est le belodon Plieningeri, qui ressemblait beaucoup au gavial de l'Amérique tropicale; c'est la mème mâchoire, longue, étroite, et armée de grandes dents. Gressly a mis au jour, à Liestal, de grands os creux qui ont sans doute appartenu à une espèce de tératosaure d'une taille énorme.

Il est probable que la mer triasique a envahi tout le pays de la Suisse occupé maintenant par la mollasse; toutefois ses dépôts n'ont encore été signalés, dans la Suisse ceutrale, qu'à la chaine du Stockhorn. On rencontre des bancs de calcaire et de grès bigarré au Spietzfluh sur les bords du lac de Thun; ils renferment de nombreuses pétrifications et forment la limite du trias. Ils appartiennent au gisement rhétien.

Les dépôts de la mer triasique prennent plus d'importance à la frontière sud-est de la Suisse et dans les localités de la Savoie qui l'avoisinent.Un filon de gypse et de chaux carbonatée va de Bex à Morillon, en Savoie, et a Villeneuve; plus loin, de Meillerie, au bord du lac de Genève, et sur les bords de la Dranse, an-dessus de Thonon, on rencontre les gisements rhétions qui, dans la direction sud, peuvent être suivis jusqu'à l'Arve; or acquiert ainsi la preuve de la présence de la mer triasique en Savoie par l'existence de plusieurs couches de cette époque qui parcourent ce pays.

Remarquons encore qu'une large bande de roches triasiques 
part du Tyrol et du Vorarlherg, de Vadutz et de Triesen, et aboutit au Rhin, sans toucher à la Suisse; elle s'ètend au nord et à l'est sur les montagnes frontières du Prättigau (à trois mille mètres audessus de la mer : Scesaplana). De là, les roches triasiques s'étendent sur le pays de Davos jusqu'à Oberhalbstein sur l'Albula jusqu'en Engadine, ou elles recommencent à Ponte pour continuer jusqu'à Sulsana et de là, à l'est, jusqu'à Scarlthal et Münsterthal. Les montagnes calcaires qui occupent le côté droit de la vallée de

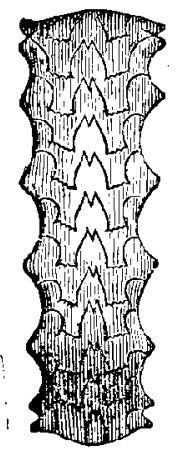

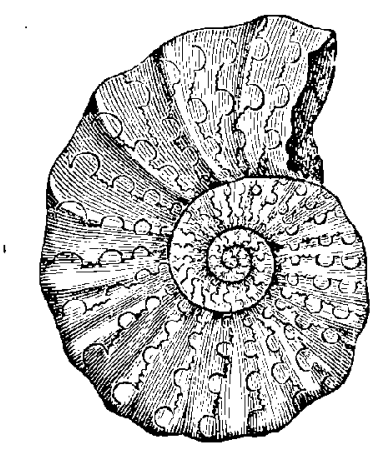

Cêratite nocosus.

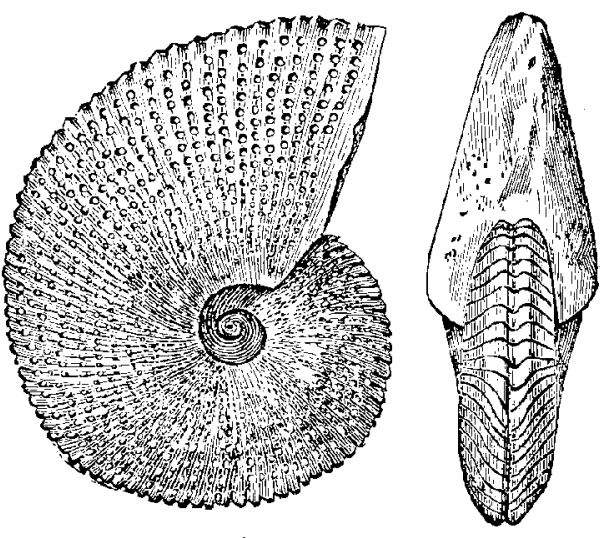

Ammonite Aon.

Fig. 272-273. - Ammonites de la période triasique.

l'Engadine, depuis Ponte jusqu'à Remus, appartiennent aussi à cette formation.

Cetle région n'ćtait donc pas immergée pendant l'époque keupérienne, tandis que la mer recouvrait le reste des Alpes ou se déposait, la formation triasique, ainsi que le prouvent les bactryllies, les algues et les coquilles marines qu'elles renferment. Ces débris appartiennent soit au muschelkalk, soit au keuper, et, suivant la nature de la roche et leur composition organique, permettent de reconniâtre plusieurs étages de dépôts.

On a trouvé dans ces roches les restes de cinquante-cinq espèces d'animaux marins qui ne laissent aucun doute sur leur origine; on y remarque non seulement l'encrinus liliiformis, l'halobia lommelii, si fincment strié, et l'halobia obliqua, mais plusieurs chemnitzia, l'ammonite luganensis et scaphitiformis, etc. ; on y trouve encore d'autres mollusques et coquillages qui caractérisent le trias, 
et prouvent que la faune triasique était répandue sous los mêmes formes en Allemagne, en Suisse et en Italie.

On a vu plus haut que l'une des plus importantes productions du trias a été le sel ; lo gypse cst aussi cn grande partie de formation triasique. On le trouve entre le muschelkalk et le keuper; par exemple, à Bâle-Campagne, dans le Jura argovien de Staffelegớ, à

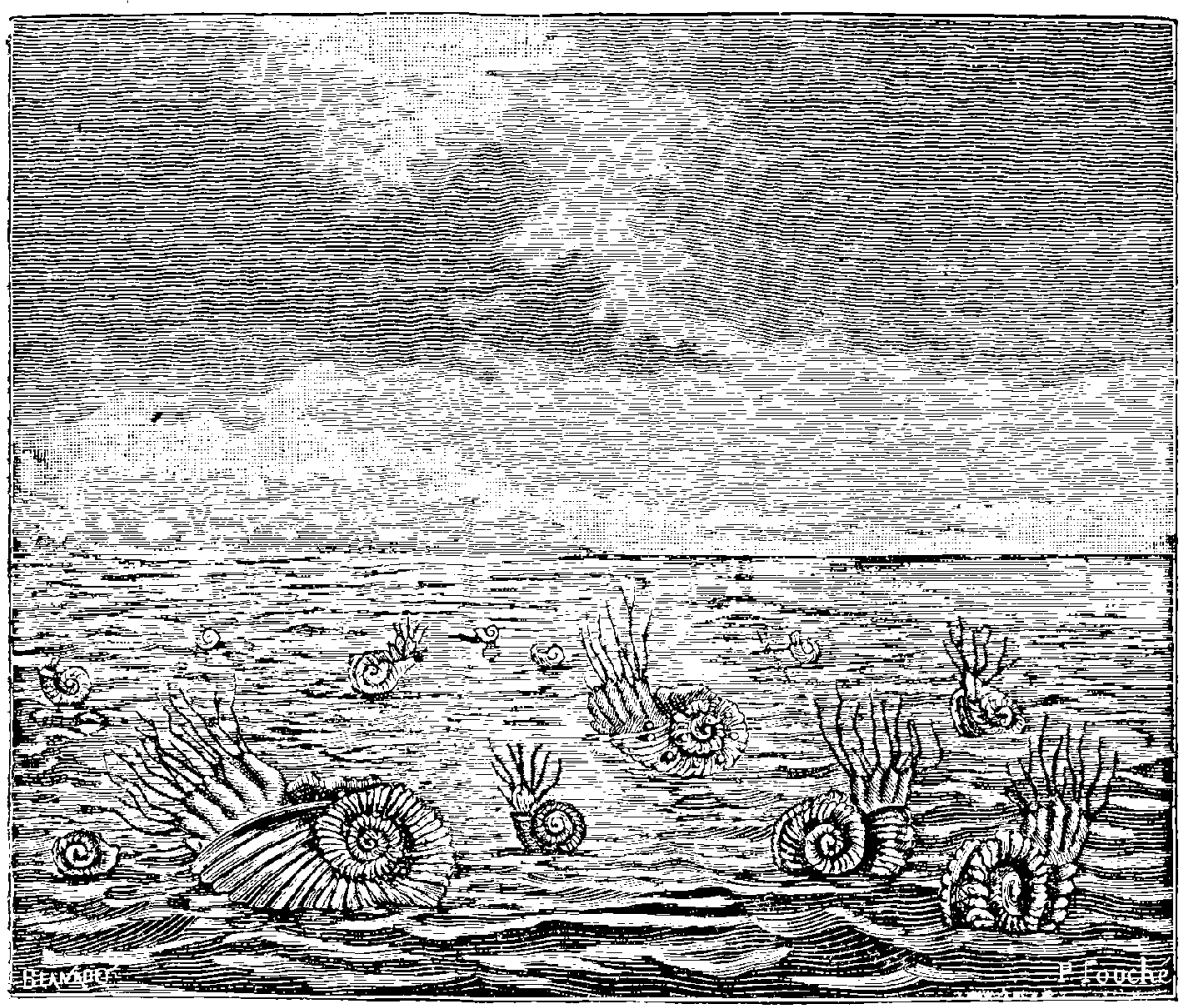

Fig..274. - Les ammonites des mers triasiques

Mabsbourg, à Niederwenịngen, Baden, Mullingen, Birmensdorf, Gebensdorf, Munsterthal, pour la Suisse seulement. Ces gypses renferment cà et lì des sulfates do soude et de magnésie; ces sels, dissous dans l'eau, fournissent des eaux minérales purgatives. “ Ces eaux, écrit Oswald Heer, sont, par leur nature, un objet de commerce; il y a, du reste, d'autres sources minérales fort riches qui proviennent de la formation triasique, par exemple, les eaux estimées de Baden qui, jaillissant d'une très grande profondeur, proviennent 
rraisemblablement de la formation keupérienne. L'eau sulfureuse de Schinznach et l'eau iodée de Wildegg prennent probablement leur source dans les gypses du trias. L'époque triasique nous a donc légué de grandes richesses; ses terrains renferment du sel et du gypse et ses eaux minérales ont reçu diverses applications physiologiques utiles. Le trias fournit en outre de riches matériaux de construction, et par sa décomposition même donne, sous forme de marne, un engrais estimé; les localités keupériennes se distinguent par leurs grasses prairies, leurs champs fertiles et leurs vignes productives; partout le trias assure le bien-être des populations.

«La dolomie seule fait exception; lorsque les pluies ont décomposé cette roche, il ne reste qu'un sable perméable à l'eau et stérile. Là où le terrain est exclusivement formé de dolomie, comme dans les montagnes calcaires du Vorarlberg et dans les vallées latérales de l'Engadine, la vègétation est fort pauvre, les arbres et les buissons sont rabougris, les prairies et les pâturages ne sont recouverts que d'une herbe clairsemée et les régions élevées sont complètement arides. Nous possédons en Suisse quelques localités dolomiriques (ainsi la vallée de "ifora qui conduit de Saint-Giacomo à la Munsterthalalp) où la végétation manque complètement, et depuis le bas de la vallée jusqu'au sommet déchiré des montagnes, cellessi n'offrent que le spectacle navrant de la désolation et de la mort (4).

Dans le Jura salinois, le keuper se compose de trois assises : selle du bas est salifère et épaisse de cent mètres; celle đu milieu, qui est gypsifẻre, mesure cinquante mètres; enfin l'assise supórieure, avec schistes et calcaires, à cypricardia, posidonia, avicula, présente une épaisseur d'une trentaine de mètres. C'est dans l'assise califère que l'on rencontre les cristaux de gypse et de polyhalite, qui font défaut dans l'assise gypsifère. Le gypse de l'assise moyenne est très régulièrement stratifié : M. Marcou attribue sa formation sinsi que celle du sel gemme, à des sources qui se seraient fait jour tans la mer keupérienne.

Aux environs d'Autun et de Châlon-sur-Saône, la base du trias est formée par une puissante assise d'arkose, tantôt meuble,

(1).0s waw Heira. Le Monde primitif de la Suisse. 
tantôt, par exemple à la Coudre, sur la lisière de la forêt de la Pla noise, imprégnèe de silice au point d'être comme vitrifiée et fondue. Cette assise, exploitée pour les verreries quand elle est meuble, contient, à Laives, des empreintes de labyrinthodontes. Le muschelkalk parait représenté par huit à dix mètres de grès marneux et de marnes vertes avec calcaire dolomitique. Enfin le keuper est bien développé vers Couches-les-Mines, sous la forme de marnes bariolées avec rognons de calcaire saccharoïde et de gypse. Ce dernier est exploité dans la vallée de la Dheune, et la présence du se] dans cet étage est indiquée par la source salée de Santenay.

Dans l'Auxois, le dépôt du keuper, formé d'argiles bigarrées alternant avec des arkoses, a été marqué par des épanchements siliceux, de nature calcédonieuse, qui forment au milieu des argiles et des grès des nappes très étendues, des amas lenticulaires allongés ou encore d'énormes masses irrégulièrement distribuées.

A l'état de grès rouges et de marnes, le trias affleure d'une manière plus ou moins discontinue, sur la bordure du plateau central de la France. On en trouve des vestiges près d'Alais, entre le système permo-carbonifère et le lias, dans le golfe de l'Aveyron, autour de Saint-Affrique, de Rodez et d'Espalion, puis entre Saint-Antoine et Villefranche-d'Aveyron.. Après quoi, pour le revoir, il faut suivre la lisière septentrionale du plateau, dans le Berri, où la composition du système est la mème que dans la Nièvre.

En Provence, les massifs anciens des Maures et de l'Esterel servent, au sud, d'appui à une bande triasique, qui en est séparée par les grès rouges permiens. Gette bande s'étend de Toulon à Antibes, et l'on y reconnait les trois divisions habituclles du trias lorrain (4).

Dans le Gard, trente mètres de schistes et d'arkoses métallifëres supportent quinze mètres d'un calcaire magnésien à minerai de fer pyrite et galène, que couronnent cent quinze mètres de grès et de marnes gypsifères bariolées, avec calcaire caverneux.

Près de Lodève, à Fozières, des empreintes d'un labyrinthodonte se rencontrent dans un grès que les auteurs rapportent au grès bigarré.

1. De Lapparent. Traité de Géologie. 
Le trias des Corbières a, d'après M. Magnan, une puissance de 500 à 600 mètres. Le grès bigarré y existe sous la forme de grès poudingues de colorations diverses. Ce même terrain affleure en divers points de la région pyrénéenne, notamment au sud de Bayonne.

A l'extrémité opposée de la France, la région ardennaise parait avoir formé, à l'époque triasique, une contrée continentale et accidentée, oủ les agents d'érosion entrainnaient, dans des lacs intérieurs, des blocs, des galets, du sable et de l'argile. Quelques restes de ces dépôts sont seuls parvenus jusqu'à nous, presque tous remarquables par leur couleur rouge. Ce sont ceux de la haute vallée de la Semoïs et des environs de Malmedy. L'ensemble, disposé en couches horizontales ou faiblement inclinées, mesure cent cinquante mètres d'épaisseur et forme, sur les rives de la Warge, de beaux escarpements qui ressemblent aux alluvions d'un fleuve.

Les circonstances continentales qui, dans les Ardennes, ont caractérisé la période triasique, peuvent ètre appliquées à tout le nord de la France. La destruction des terrains plus anciens y a donné naissance 1 des poudingues dont on observe quelques affleurements dans l'Artois. Tel est le poudingue à ciment rougeâtre et à galets calcaires, accompagné de grès et d'argiles rouges ou jaunes qui, dans le Pas-de-Calais, à Fléchin, Febvin, Audincthun, repose en discordance sur les affleurements sporadiques du svstème dévonien.

Près de Douai, des puits creusés pour les recherches de houille ont rencontré un conglomérat formé de très gros débris de calcaire compact, de dolomie carbonifère et de psammites du condros, empâtés dans une masse argileuse. Ce dépôt a les allures d'un amas de blocs éuoulés.

Plus au sud-ouest, les dépôts jurassiques et crétacés du bassin de Paris empèchent de rien voir, et le trias n'apparait plus que sur les bords du Cotentin, où il est formé de graviers, de poudingues, de sables, de grès et de marnes rouges, dont l'épaisseur ne paraît pas dépasser soixante mètres. Cet ensemble est la continuation des dépôts triasiques du Somerset et du Devonshire, et parait correspondre seulement à la partie supérieure de l'étage keupérien.

Ainsi, on peut supposer qu'à l'époque triasique tout le bassin de Paris (auquel se joignait l'Angleterre) formait une région de grands 
lacs, venant aboutir à une mer dont le rivage occidental, lors du dépôt des sédiments franconiens, s'étendait de Luxembourg à Autun (De Lapparent.) (').

Dans le massif des. Alpes occidentales, le trias affecte un facies

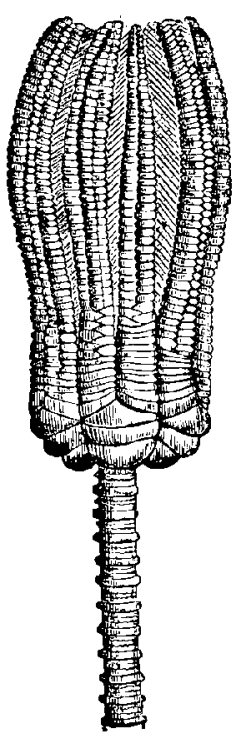

F'ig. 275.

F́chinodermes

de la période triasique,

Crinoides : encrize en furmo

de iys.

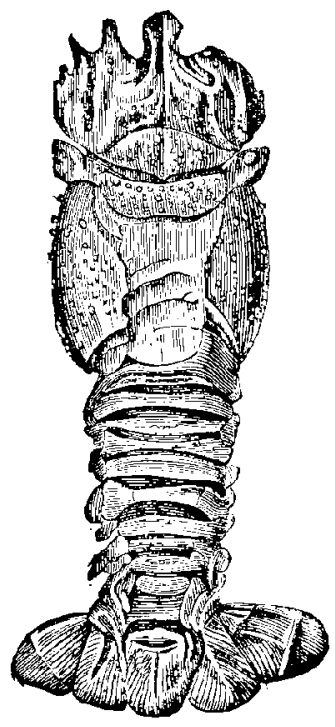

Fig. 276. - Crustacés de la période triasique.

Pomphiz seuoril.

spécial, qui l'éloigne scnsiblement du type franconien ou vosgien.

1. Sur le versant occidental des massifs cristallins de l'Oisans, le système triasique, gẻnéralement très mince, se compose de gypse, d'anhydrite, de dolomie et de sel gemme avec grès et schistes argileux bariolés. Mais de l'autre côté de la chaîne de Belledome, ce système acquiert subitement une épaisseur considérable. Les grès bigarrés deviennent assez durs pour avoir été, à tort, qualifiés de quartzites. Le tunnel de Modane les traverse sur trois cents mètres. Au-dessus viennent des calcaires magnésiens avec quelques fossiles, représentauts atrophiés du muschelkalk; enfin le tout est couronué par de puissants dépots de gypse et d'anhydrite, souvent imprégnés de sel (Moutier's, Bourg-SaintMaurice).

Au lieu d'être intercalés dans des argiles, les gypses se trouvent dans des schistes gris lustrés, remplis de mica; cette bande de schistes, qui forme le bassin de Queyras et les vallées de la 'arentaise, se poursuit en Piémont et dans les Grisons. Son épaisseur, de Bardonndehe à Modane, dépasse 4000 mètres. Un fait géologique particulièrement remarquable est limmense augmentation d'épaisseur du trias lorsqu'on a franchi la ligne des massifs cristallins allant des Alpes-Maritimes aux Alpes hernoises par le mont Blane et l'Oisans. On peut conclure que le trias de cette partie des Alpes s'est déposé dans des détroits encaissés, soumis à un phénomène d'enfoncement continuel. 
Pour complèter cette esquisse de la physionomie générale de la formation triasique, nous ajouterons encore, avecl'éminent géologue français, que c'est dans le nord-ouest de l'Angleterre que le trias atteint sa plus grande puissance (1500 mètres). Là aussi s'observent les plus gros cailloux roulés, parmi lesquels abonde le quartz. C'est donc vers le nord ou le nord-ouest que parait devoir ètre cherché le continent qui a fourni les matériaux des conglomérats triasiques. Le trias anglais repose d'ailleurs indifféremment sur le permien, le carbonifëre, même le cambrien; en outre, les marnes bariolées débordent souvent les assises inférieures.

Dans les comtés du centre, l'épaisseur du système est de 950 mètres. Il n'y a d'ailleurs aucune discordance de stratification sérieuse entre les termes qui le composent, de telle sorte qu'il est rationnel d'admettre que l'étage franconien y trouve sa représentation. Du reste, la disparition du facies calcaire de l'étage franconien est progressive à mesure qu'on s'éloigne de la Lorraine.

C'est dans le conglomérat dolomitique, épais de six à quinze mòtres, qu'on a découvert les ossements des thécodontosaures antiques, des palœosaures cylindrodon et platyodon, avec des dents de ceratodus. La même assise a fourni, dans le pays de Galles, des traces de brontozoum. Le grès du Keuper contient des ossements et des empreintes de pas de labyrinthodontes, ainsi qu'un poisson, dysteronotus cyphus. Le sel gemme se présente dans l'étage en masses lenticulaires rougeâtres atteignant jusqu'à soixante mètres d'épaisseur.

Sur la côte méridionale du Devonshire, à Budleigh Salterton, le conglomérat triasique est formé de galets de quartzites siluriens et dévoniens qui paraissent avoir été empruntés à des roches primaires, dont l'affleurement serait actuellement masqué pas les caux de la Manche.

On peut remarquer encore que dans l'Amérique du Nord le trias affleure en trois régions distinctes : celle des Apalaches, celle des Montagnes Rocheuses, où il offre un type voisin du facies arénacé de l'Europe septentrionale, et la région du Pacifique, où ses caractères sont ceux des depôts alpins. Le trias des Alpalaches forme des bandes étroites, mais qui se prolongent, surtout dans 
le Connecticut, avec des caractères uniformes sur de vastes étendues. C'est un grès d'un rouge brun, parfois constitué à l'état de véritable arène granitique, avec schistes et conglomérats, ayant au moins 1000 mètres de puissance et présentant de nombreuses traces de clapotement des vagues, ainsi que des empreintes de gouttes de pluie.

Les traces de labyrinthodontes abondent dans le Connecticut, ou

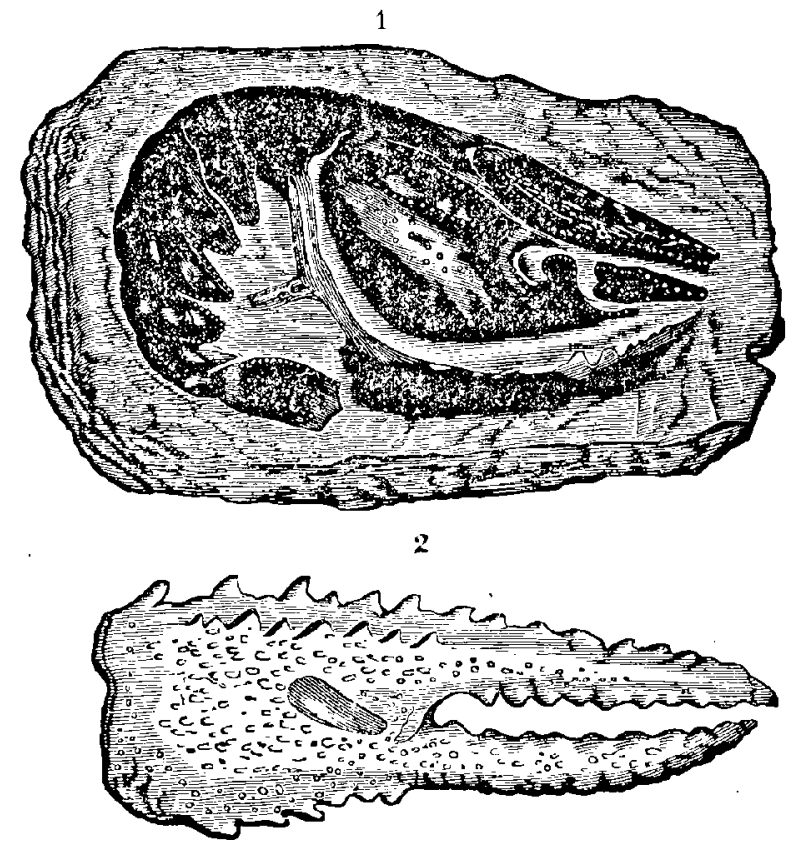

Fig. 277. - Crustacés de l'ẻpoque triasiqque. Les premiures écrevissus et lours pinces.

l'on compte plus de 12000 empreintes. Les géologues américains ont également signalé dans cet étage un petit mammifère didelphe, le dromatherium sylvestre, qui serait le plus ancien représeritant connu do cette classe. A l'est des Montagnes Rocheuses, le trias est constitué par des grès rouges, des marnes bariolées gypsifëres, et quelques assises magnésiennes. Son épaisseur varie entre 600 et 1800 mètres ( ${ }^{4}$ ).

D'après ce tableau d'ensemble, nous voyons que la formation triasique occupe une place importante dans les terrains de sédi-

I. A. me Lapparent, Traite de Géologie. 
wents et marque uno phase significative dans l'histoire de la transformation des espèces. En inaugurant l'âge secondaire, elle apporte dans le monde des éléments biologiques nouveaux, et ici comme dans la longue série des âges primaires, l'ohservateur de la nature peut constater un parallélisme constant entre le développement logique de la vie, tel que nous l'avons défini plus haut (Livre II, chap. iII) et les découvertes paléontologiques faites dans la succession des terrains.

Le règne animal se développe dans ses branches supérieures, lentement et graduellement. Un grand nombre des espèces d'invertébrés (zoophytes, mollusques et annelés) avec lesquelles nous

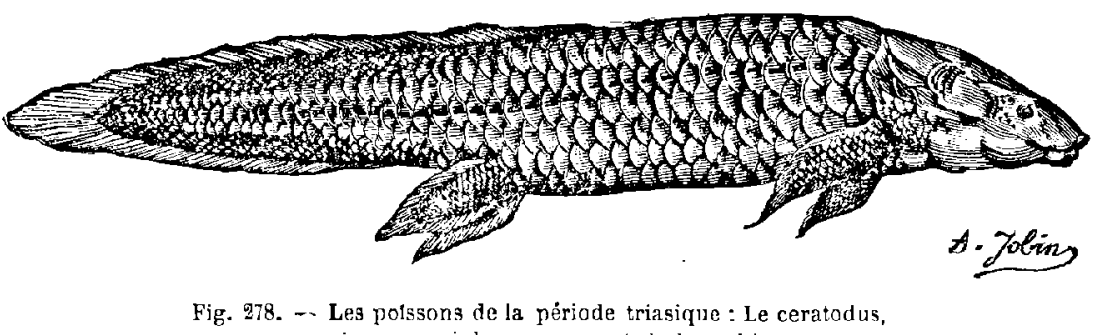
poisson muni de poumons et de branchies.

avons fait connaissance, ont disparu de la scène du monde pour faire place à de nouveaux etres.

On remarque, parmi les zoophytes, que le nombre restreint des genres de crinoïdes est en quelque sorte compensé par l'abondance extraordinaire des individus de l'encrinus liliiformis ( $f i g .275$ ), dont les articles remplissent des assises fort épaisses et fort étendues dans lo calcaire conchylion du trias normal. C'est l'un des fossiles les plus caractérisques de ces terrains. Nous avons déjà fait connaissance avec ces êtres en ètudiant les origines des espèces à l'époque silurienne (p. 237). Ce type est en décadence. D'autres espèces ont complètement disparu. Les fameux trilobites, notamment, se sont évanouis pour toujours. En rcvanche, les ammoxites, nés pendant les siècles permiens, prennent une rapide extension. Les ammonites étaient des mollusques céphalopodes, dont les coquilles spirales offrent les plus grandes variétés comme dimensions et comme dessins. Ils ont régné pendant toute l'époque secondaire, puis ont disparu. Aux temps triasiques domi- 


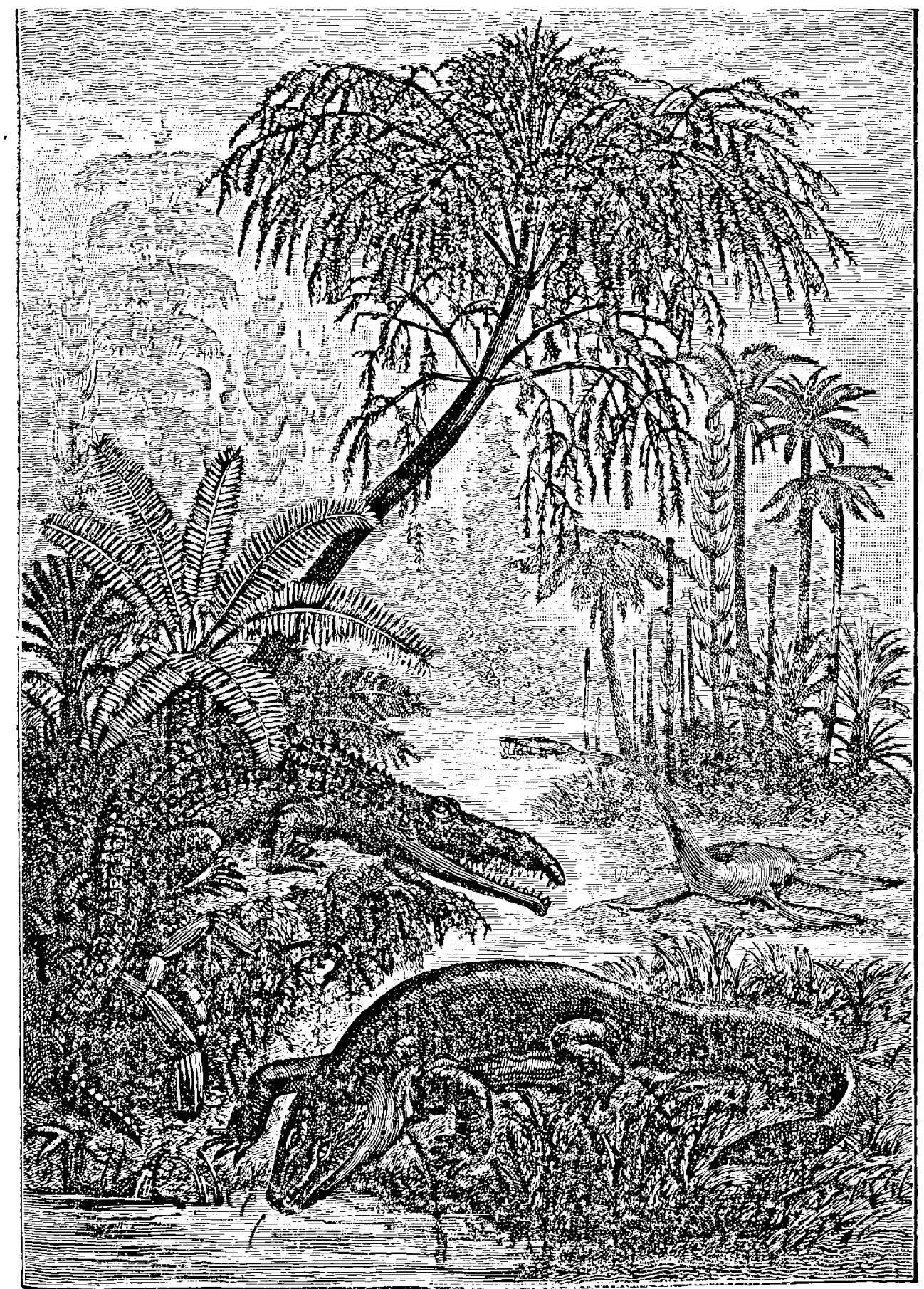

LES HABITANTS DE LA PÉRIODE THIASIQUE C CAHUSALRE, BLLODUN, NOTHOSAURE.

LE MONDE AVANT LA CRÉATION DE L'HOMME

65 
naient les ammonites Aon, les cératites noueux (fig. 272-273). Sans doute, avaient-ils eu pour ancètres les nautilides que nous avons rencontrés pendant la période dévonienne (p. 386, ( $f g .191)$, ou quelque mollusque plus ancien encore dont les nautilides, comme les ammonites, seraient descendues. Aux temps triasiques, les nautilides sont en décadence : on retrouve encore des orthoceras et des goniatides.

Les ammonites sont reconnues depuis longtemps par les géologues, et l'antiquité même avait deviné, par l'inspection de ces coquilles fossilles, les anciennes métamorphoses de la terre et des mers. Leur nom vient de la ressemblance de leurs volutes avec les cornes de bélier qui accompagnent la figure symbolique sous laquelle Jupiter Ammon était représenté.

C'est surtout pendant les temps jurassiques que les ammonites prendront leur plus grande extension. A la fin de la période, on en trouve qui atteignent les dimensions des roues d'une voiture!

Les brachiopodes se diversifient comme les céphalopodes. Aux spirifer du dévonien (p. 384), aux productus du carbonifère (p. 464), s'ajoutent maintenant des térébratules et des rynchonnelles, que nous trouverons plus spécialement caractéristiques des mers jurassiques. Tous ces coquillages se rencontrent aujourd'hui dans le deuxième étage de la formation triasique, dans l'étage conchyliçn, essentiellement marin.

Les acéphales manifestent encore un progrès plus développé, et nous pouvons en dire autant des gastéropodes; désormais ces deux classes priment toutes les autres dans l'embranchement des mollusques. - On doit y porter une attention d'autant plus grande qu'en définitive, ce sont surtout les coquilles de ces différentez espèces de mollusques qui caractérisent les terrains, attendu qui: ces coquilles sont très nombreuses et très répandues, généralement intégralement conservées, tandis que les ossements de grands animaux sont rares et plus ou moins endommagés. - La famille des ostracées (huitres) fait son apparition en compagnie de nombreux acéphales des genres pecten, posidonia, cardita, lima, myophoria, etc. Apparues pendant la période triasique, à l'origine même des temps sccondaires, les huitres vivront d'âge en âge et deviendront contemporaines de l'humanité. Elles constitueront mêrne 
l'une des premières ressources de son alimentation sur les bords de la mer.

Dans l'embranchement des articulés, les crustacés donnent naissances à l'ordre des décapodes, parmi lesquels on peut remarquer la famille des macroures, dont quelques-uns, les pemphix ( $f g .276$ ) caractérisent les dépôts du trias. On a retrouvé des carapaces entières d'écrevisses fort bien conservées. La plus grande différence qui les distingue des nôtres consiste dans leur force. Leurs pinces, garnies de dentelures aiguës ( $f g .277$ ), leur fournissaient les moyens de défense indispensables contre les monstres voraces qui infestaient les eaux.

Les poissons semblent rester stationnaires. \& La faune ictyologique n'est point en progrès. Presque absolument particulier au trias normal, les poissons appartiennent, comme précédemment, aux sous-classes des placoïdes et des ganoïdes. Parmi ces derniers, on ne signale guère que des rhombifëres. v(Contejeav.) - « Les poissons sont des ganoïdes à queue moins dissymétrique et à colonne vertébrale plus complètement ossifiée que chez les ganoïdes paléozoïques. Avec eux se montrent des représentants du groupe actuel des dipnoés, curieux par la constitution de leurs nageoires, qui rappellent les membres des cétacés, et pourvus, en outre des branchies, de poumons qui leur permettent de vivre dans la vase desséchée : de ce nombre est le ceratodus, ce genre singulier qui semble s'ètre conservé jusqu'à nos jours dans les rivières australiennes. Enfin, si les poissons osseux font encore défaut, les squales, ślaciens et cestracions, sont représentés par acrodus, hybodus, saurichthys. 》 (DE LAPPARENT.)

On le roit, parmi les poissons de la période triasique, c'est le ceratodus ( $f g .278$ ) que nous pouvons considérer comme typo de l'époque, type assez étrange, pourvu de branchies comme les poissons ordinaires et de poumons comme les animaux à respiration aérienne - et de dents plates profondément incisées sur les bords. Le plus curieux peut-ètre encore est que ce poisson se soit perpétué jusqu'à nos jours, et ait été retrouvé récemment dans les rivières de l'Australie où il atteint jusqu'à $1^{\mathrm{m}} 20$ de longueur.

Les vertébrés les plus élevés en organisation de la faune triasique, sont des batraciens et des reptiles. On ne devine encore 
ni le chien, ni le singe, ni l'homme. Les labyrinthodontes que nous venons d'étudier pendant la période permienne, restent les souverains du monde : chirotherium, trématosaures, mastodonsaures, etc., accompagnés de sauriens nageurs : placodus, nothosaures, simosaures, etc. Les dinosauriens arrivent. Ces gigantesques reptiles avaient les membres postérieurs très puissants, pouvaient se tenir debout, et quoique possédant des mains à cinq doigts bien distinctes à leur membres antéricurs, n'avaient cependant que trois doigts à leurs énormes pieds (les deux autres doigts restant

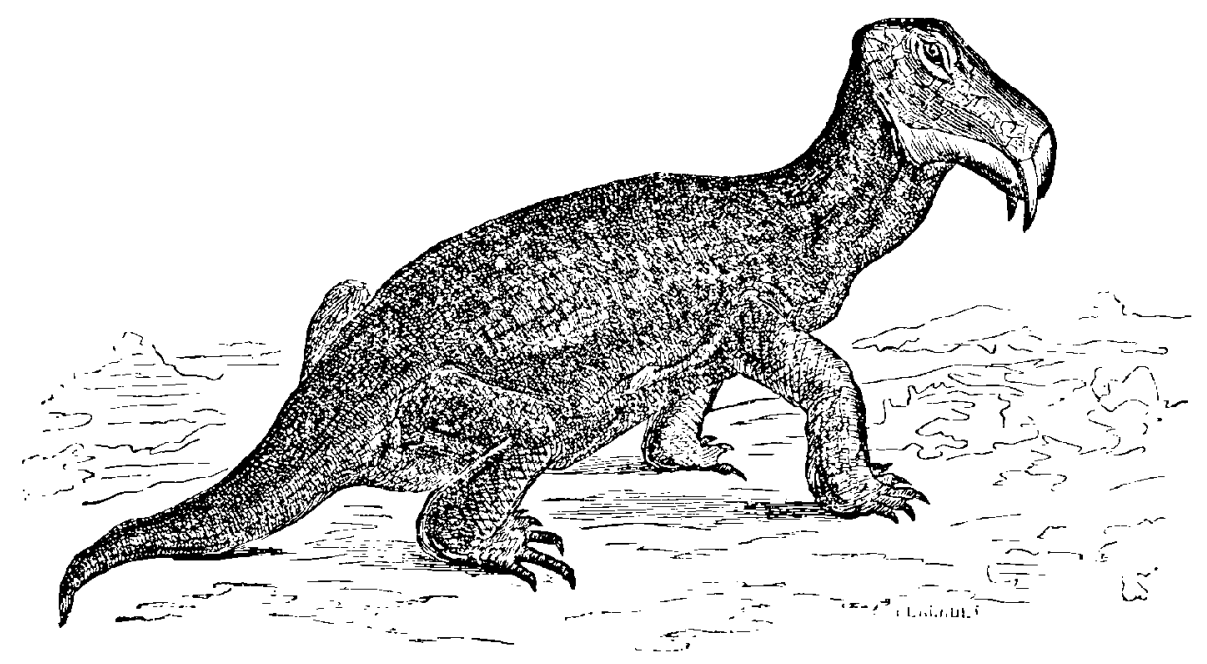

Fig. 280. - Le dicynodonte, reptile de l'époque triasique (Afrique australe).

cachés dans l'anatomie du membre). A ce groupe de reptiles triasiques qui marchaient en gardant la station verticale, appartiennent le megadactylus, le clepsysaure, le bathygnathus, etc., et probable. ment aussi le brontozoum dont on voit plus loin (fig. 282) une empreinte recueillie dans le grès du trias supérieur, en même tomps que des gouttes de pluie tombées lì sans doute au moment mème du passage de l'animal et conservées aussi dans la pétrification. Cette pierre d'apparence vulgaire, ce fossile d'aspect insignifiant, nous conserve ainsi comme une photographie de la scènr depuis si longtemps disparue dans l'histoire des àges. Il semble que l'on revoie l'énorme reptile, aux immenses enjambées, surpris par l'orage, fuyant le long de la plage unie du rivage et 
laissant l'empreinte de ses pas sur l'argile molie qui les conservera pour l'édification des géologues de l'avenir!

Ces pattes à trois doigts avaient inspiré l'idée d'oiseaux gigantesques, et l'on était ainsi conduit à admettre que les oiseaux auraient été contemporains de la période triasique. Plusieurs traités classiques de géologie présentent même depuis longtemps ces traces sous la désignation d'empreintes de pas d'oiseaux. Mais on n'a découvert aucun fossile d'oiseau dans ces terrains, et, d'autre part,

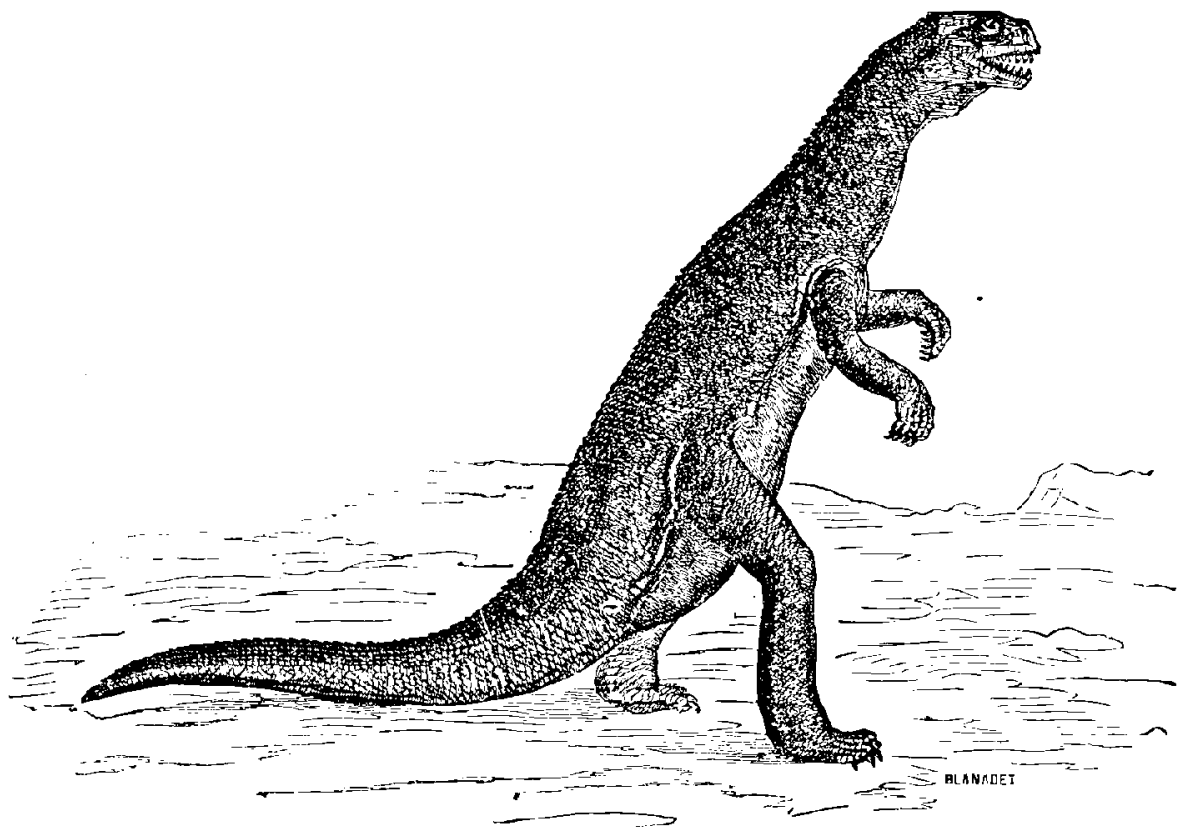

Fig. 281. - Le zanglodon, dinalısauriten de l'éloque triasique (Europe).

on connait les reptiles bipèdes qui peuvent avoir laissé ces traces de leur passage. La dimension de ces empreintes obligeait d'ailleurs à imaginer, dès la naissance de la classe des oiseaux, des êtres d'une stature colossale. Les oiseaux n'apparaitront qu'à la période jurassique.

Parmi les reptiles des temps triasiques, signalons aussi des thériodontes, précurseurs des mammifères monotrèmes.

Les dinausoriens et les sauriens nageurs vont régner en maitres pendant les siècles jurassiques, et nous allons en faire une étude spéciale dans le cadre même que la nature leur a donné pour 
rovaume. Pourtant, parmi ceux de la période triasique, plusieurs peuvent ètre présentés dès maintenant à l'édification de nos lecteurs. On reconnaitra entre autres (p. $513\left({ }^{4}\right)$ les capitosaures qui, comme tous les autres labyrinthodontes, tenaient, quant à l'aspect et a l'allure, le milieu entre les crocodiles et les salamandres. C'étaient bien de vrais batraciens à mœurs essentiellement aquatiques et se nourrissant de poissons. Depuis le permien jusqu'au keuper inclusivement ces formes étaient abondantes. Le belodon, un des premiers crocodiliens, se distinguait par l'aplatissement latéral et la hauteur de la mâchoire supérieure dont l'extrémité ètait recourbée en crochet. Dents coniques verticales, corps recouvert d'une cuirasse encore plus puissante que celle des crocodiles. Trouvé seulement dans le keuper supérieur du Wurtemberg.

Les nothosaures, précurseurs des plésiosaures, existent dans tout le trias. Le nothosaure mirabilis est surtout abondant dans le muschelkalk. Il est probable que, quoique marin, il se rapprochait des estuaires et remontait les cours d'eau.

Les dicynodontes ( $f g .280)$ offrent quelque rapport avce les tortues par la conformation générale de la tête, à part les dents

1. Ces dessins ( $/ g$. 279 à 28l) sont dus à l'habile crayon de M. Josıv, l'érudit naturaliste qui sait exhumer des fossiles les êtres endormis depuis tant de millions d'antées, et leur redonner la vie des anciens áges en les rétablissant au milieu de leurs propres paysages.

Faune et flare triasiques, plus spécialement keupériennes (fig . 279).

Fıune. - Capitosaurus nasutus, de l'ordre des labyrinthodontes (au premier plan et tout prêt à regagner l'eau; tête de 80 à 90 centimètres environ). - Belodon Kapfi (synon. Phytosaurus, Nicrosaurus), se ratlache aux formes primitives de l'ordre des crocodiliens, tête de 1 mètre environ et plus; également au premier plan, se glissant sur une éminence au milicu d'un fouillis de fougères et de cycadées, etc.). - Nothosaurus mirabilis au second plan. Conformé comme les plésiosaures mais à trone plus large. Pouvait avoir de trois à cinq mètres de long.

Flore. - Acthophyllum speciosum. Lycopodiacée gazonnante remplissant les fonctions des graminées aquatiques de nos jours dont elles avaient le port au premier plan, autour du capitosaurus). - Les fougères appartiennent aux genres pecopteris, neuropleris et clathrophyllum. - Plus loin, derrière le nothosaure, des fougères arborescentes du genre danocopsis et tæniopteris. - Calamites Meriani (ramifications disposées en parasol), dont le feuillage est identique avec le schizoneura Meriani. - Equisetum Munsteri et arenaceum, rameaux verticillés et dressés. - Les cycadées sont représentées par les pterophyllum Meriani et Jageri. - Tout au fond et moins distincts, arbres de la famille des conifères représentés par les genres voltzia, widdringtonites et albertia. Ces arbres présentaient par leur port toutes les transitions entre les cryptomeria, les araucaria et les dammara de nos jours. 
canines qui rappellent celles des mammifères. Par plusieurs points de leur organisation, ils se rapprochent des mammifères autant que des reptiles. (Tous de l'Afrique australe, décrits par Owen.)

Le zanglodon ( $f g .281)$ contemporain du belodon et des labyrinthodontes du keuper, était un dinosaurien carnassier gigan tesque, mais de forme relativement élancéc. Il paraît, d'après Kapff et d'autres, que la tète connue sous le nom de teratosaurus et trouvée dans le mème terrain, doit être rapportée au zanglodon.

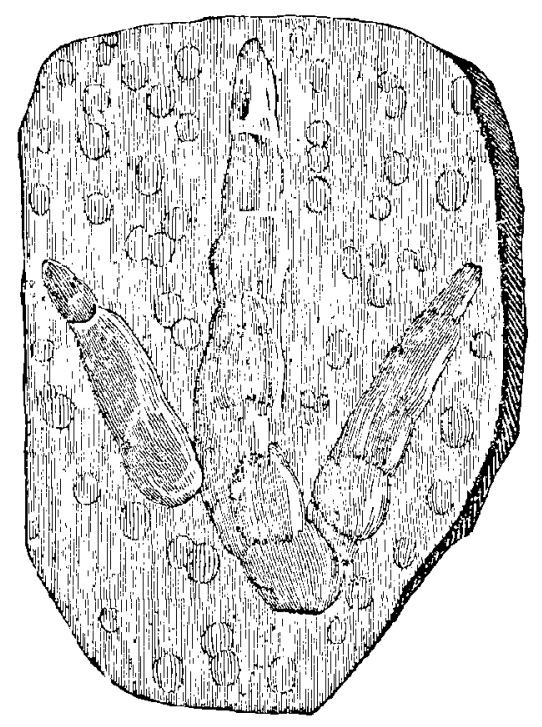

Fig. 282 - Empreintes de pas du brontozoum giganteum (période triasique) avec empreintes de gouttes de pluie.

Les animaux triasiques étalaient pour la plupart des formes entièrement étrangères à notre monde d'aujourd'hui. C'étaient en premier lieu des bipèdes, très éloignés par leurs dimensions comme par leurs formes du type des oiseaux actuels, mais qui ne sont encore guère connus que par l'empreinte de leurs pas, dont l'enjambée accuse parfois des dimensions quadruples de celles de l'autruche. Le nombre et la disposition des doigts rérèlent pour d'autres de telles singularités qu'en l'absence du squelette on ne sait comment les définir. Parmi les reptiles, les uns rappellent les tortues, les autres les lézards ou les crocodiles, ou bien encore, comme les dicynodontes, dont les mâchoires étaient armées de dé- 
fenses recourbées dans le genre de celles des morses, ils présentent les caractères mélangés de ces divers groupes.

Les dolichosaures, moitié lézards, moitié serpents, marquent le moment où ceux-ci ont commencé à se détacher du tronc commun des lacertiens; plus loin en arrière, les lacertiens se perdent comme ordre distinct, et l'on observe des types qui joignent les lézards aux iguanes et les monitors aux crocodiles. Les crocodiles eux-mèmes modifient leurs caractères ostéologiques pour en revêtir d'autres que l'on n'observe maintenant chez eux que dans la vie fotale. Les labyrinthodontes enfin se rapprochent des batraciens et même des poissons. Cette famille de reptiles est, comme nous l'avons vu, l'une des plus anciennes, des plus singulières et des plus ambiguës du monde primitif. Sa grande taille, l'armure de plaques osseuses qui recouvrait son corps, sa tête cuirassée empêchent de reconnaître de vrais batraciens dans les animaux qu'elle comprenait. Les labyrinthodontes respiraient par des poumons, au moins à l'àge adulte, marchaient sur le sol, succédaient à d'autres reptiles qui avaient des habitudes plus aquatiques. Ils représentent probablement un état particulier que la classe entière des reptiles a dù traverser autrefois avant de devenir terrestre. Cela ne prouve pas que les reptiles aboutissent originairement aux batraciens proprement dits, mais on peut affirmer qu'ils ont dù émerger d'une souche typique opérant, à l'exemple des batraciens, le passage d'une organisation purement aquatique à une organisation d'abord amphibie et finalement terrestre. (De Saponta.)

Deux grands faits s'imposent ici à notre attention : la période permienne nous a fait assister à la naissance des reptiles; la période triasique nous montre, à côté des sauriens qui se développent et vont régner en maîtres, la naissance des mammifères, qui s'inaugurent par l'arrivée des marsupiaux.

La naissance des mammifères! C'est le premier gradin de l'escalier magique qui doit conduire à l'humanité.

Les reptiles, les sauriens géants de l'époque secondaire, représentent la force. Les mammitères commencent l'ère du sentiment. Dans les destinées de la Terre, tous ces sauriens formidables sont condamnés à périr; ils ne portent pas en eux la flamme du progrés intellectuel; aucune de ces espèces si puissantes n'arrivera à l'âge 


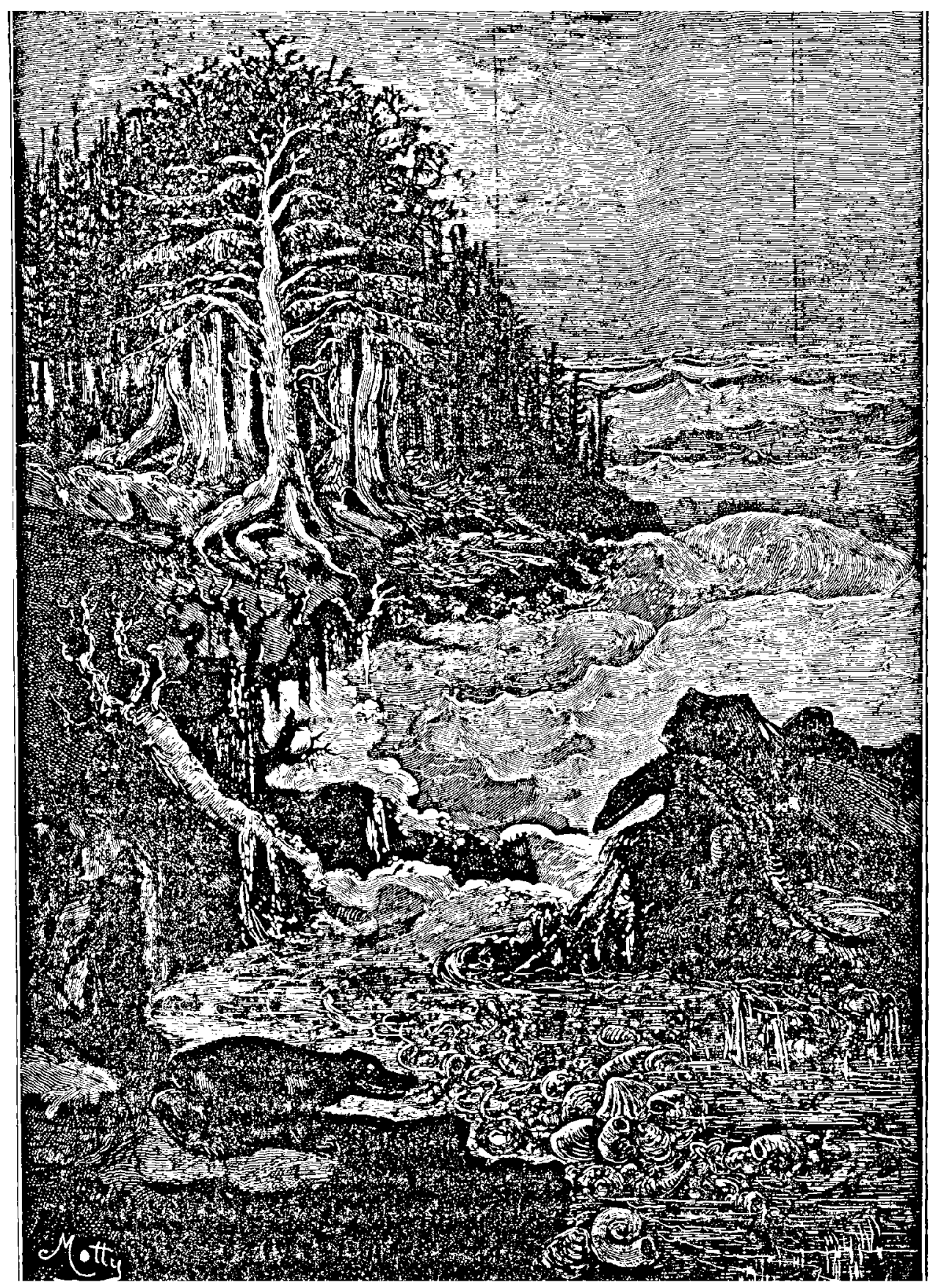

SCÈVE DE L'ÉPOOTE TAIASIQUE (PÉRIONE CONCHYLIENNE).

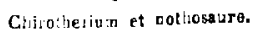

LE MUNDE aVANT LA CREATION DE h'HOMME 
de l'humanité. Les humbles marsupiaux qui s'éveillent en ce moment à la lumière du jour sous le soleil de la période triasique vont commencer la famille, vont aimer. Jusqu'à l'époque à laquelle nous arrivons l'amour n'était pas né sur la Terre : zoophites, mollusques, crustacés, insectes primitifs, poissons, batraciens, reptiles, n'ont pas aimé. Ils n'ont encore su pondre que des œufs, qu'ils ne couvent même pas eux-mêmes, dont ils abandonnent le sort aux bons soins de la nature. Les premier's mammifères qui viennent de naître ne pondent presque plus. Nous disons 'presque, et ce n'est point là une forme littéraire: l'ornithorynque pond encore. Mais, insensiblement, d'ovipares les êtres deviennent vivipares.

Humble origine! Des mammifères sans mamelles. Des petits qui viennent au monde à l'état d'œuf sans coque, pour ainsi dire non formés, et qui ne sont finis qu'après leur naissance! C'est bizarre, mais c'est ainsi. La nature veut nous témoigner sous toutes les formes la marche graduelle de la création.

La première découverte qui ait été faite de restes fossiles de mammifères appartenant à l'époque secondaire est celle de la mî̀choire trouvée en 1818 dans les terrains jurassiques (oolithe inférieur) de Stonesfield près Oxford (Angleterre). Cette mâchoire fut reconnue par Guvier comme caractérisant un petit mammifère de l'ordre des marsupiaux, ce qui jeta le plus grand trouble dans le camp des géologues, aux yeux desquels il paraissait impossible d'admettre l'existence de mammifères avant l'époque tertiaire. Owen fit remarquer que le genre auquel avait appartenu cette mâchoire offrait une grande aflinité avec un marsupial d'Australie, le myrnecobius. On trouve aussi, dans ce mème schiste de Stonesfield une autre mâchoire désignant un opossum, et, en 18こ4, une autre ayant appartenu à une espèce toute différente à laquelle on donna le nom de stereognathus. D'autre part, en 1847, on reconnut dans ie trias supérieur de Stuttgard la dent d'un petit mammifère appelé microlestes. Depuis, ce tcrain, ainsi que le trias supérieur du somersetshire et de la Caroline du Nord ont fourni un certain nombre d'autres mâchoires fossiles ayant également toutes appartenu à de petits marsupiaux ou à des insectivores de degré inférieur.

Le dromatherium sylvestre a été découvert (sa mâchoire seule- 
ment, $f g$. 284) par le géologue américain Emons, dans le grès rouge de la Caroline du Nord: c'est un petit marsupial, voisin des myrmécobies de l'Australie. Nos lecteurs savent que les marsupiaux constituent précisément la classe la plus simple, la plus primitive, la plus imparfaite des mammifères, dont la famille la plus élérnentaire, celle des monotrèmes, Il'est représentée aujourd'hui que par deux especes, habitant toutes deux la Nouvelle-Hollande et la

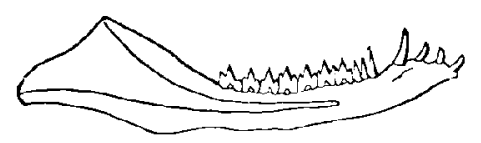

Fig. 281. - Plus ancien reste fossile de mammifère trouvé jusqu'à ce jour. Màchoire inférieure de dromatherium sylvestre. Trias de la Cároline da Nord.

terre de Van Diémen, qui en est voisine : l'ornithorynque (voy, fig. 81, p. 184) et l'échidna hystrix. Ces deux étranges espèces sont les derniers survivants d'un groupe autrefois très riche qui, durant l'âge secondaire, représentait seul l'ordre des mammifères ot d'où, sans doute, toutes les espèces ultérieures sont descendues par voie de différenciation el de perfectionnement.

Les marsupiaux (') tirent leur nom d'un sac en forme de bourse que la femelle porte sur son ventre et dans laquelle les petits restent longtemps après leur naissance. Dans cette poche arrivent de petites mamelles, ou plutôt des mamclons rudimentaires, auxquels se greffent les nouveaux-nés. Ces petits, chez tous les Inarsupiaux, naissent dans un état d'imperfection qu'on ne rencontre chez aucun autre mammifère. Ils sont nus, aveugles et sourds. La femelle les prend avec ses lèvres et les dépose dans sa bourse. Là, ils se greffent chacun à un mamelon et y restent adhérents jusqu'à ce que leurs membres et leurs organes des sens se soient déveJoppés. La bourse marsupiale est done comme un second utérus dans lequel s'achève leur évolution. Larsqu'ils ont pris un certain accroisscment, les petits se détachent du sein, mais ils n'abandonnent pas pour cela l'abri protecteur que leur offre la poche abdominale. S'ils en sortent parfois, ils se hâtent bien vite d'y rentrer, et l'on peut dire que c'est dans cette pache qu'ils passent toute

1. Etymologie: marsupium, bourse. 
leur enfance. Ainsi plus d'un' animal de cet ordre n'a qu'une gestation d'un mois, tandis que le produit de cette gestation séjournera six ou huit mois dans la bourse. Chez le kanguroo géant, sept mois se passent depuis le moment oú le petit y est déposé jusqu'à celui où il montre sa tête pour la première fois; et ce n'est que neuf semaines après cette première apparition qu'il commencera ì sortir. Pendant neuf semaines encore, le jeune kanguroo vit tantôt au dehors, tantôt au dedans de la poche marsupiale.

Dans cette espèce, le petit vient au monde le trente-neuvième jour. La mère le prend dans sa bouche, ouvre sa hourse avec ses pattes de devant et greffe le petit être à l'un de ses mamelons. Douze heures après la naissance, le petit kanguroo n'a encore que 32 millimètres de long, et ne peut être comparé qu'aux embryons des antres animaux. C'est une masse molle, transparente, vermiforme; les yeux sont fermés; le nez et les oreilles sont à peine indiqués, et les membres sont loin d'avoir leur forme. Il n'y a pas la moindre ressemblance entre cet être et sa mère. Les membres antérieurs sont d'un tiers plus longs que les postérieurs; la queue est courte et recourbée entre les pattes de derrière. Il pend au mamelon comme un corps inerte; il est même incapable alors de tèter : le lait, par suite d'une disposition organique particulière, lui est versé directement dans la bouche par le mamelon; ce n'est que plus tard qu'il exercera lui-même la succion.

Il reste ainsi huit mois à se nourrir du lait de sa mère; de temps ì autre, cependant, il montre la tête, mais il n'est pas encore capable de se mouvoir tout seul. Le naturaliste Owen enleva un petit de quatre jours du mamelon pour savoir si un ètre aussi imparfait pourrait de lui-mème retrouver le sein, ou si la mère l'y remettrait. Voici quel fut le résultat de son expérience. Le petit enlevé, une goutte de liquide blanc apparut au mamelon. Le petit s'agita, mais ne parut pas faire d'efforts pour s'attacher à la peau de la mère, et il fut absolument impuissant à se mouvoir. On le déposa au fond de la poche et on l'abandonna à la mère. Celle-ci se montra très irritée, se courba, gratta la face externe de sa bourse, l'ouvrit avec ses pattes, y plongea la tête et l'y promena de divers côtés. Finalement, ce petit mourut, la mère ne l'ayant pas rattaché, et aucun gardien n'ayant voulu se charger de le rétablir à son poste. 
Il résulte des observations les plus récentes que le jeune kanguroo, lorsqu'il a atteint une certaine taille, s'accroît très rapidement. Il sort alors sa tête, ses petits yeux regardent de tous côtés, ses petites pattes se promènent, et il commence à manger. La mère le soigne avec tendresse, mais se montre moins craintive qu'auparavant. Au commencement, elle ne souffre pas qu'on tente de le voir et, à plus forte raison, de le toucher. Elle éloigne même le mâle que la curiosité pousse à voir son rejeton : elle répond aux tentatives qu'il fait pour satisfaire son envie, par un murmure de mauvaise humeur et même par des coups. Une fois que le petit a montré la tête, elle cherche moins à le cacher. Celui-ci est d'ailleurs craintif, un rien le fait aussitôt rentrer au fond de la bourse où il prend toutes les positions imaginables; il en laisse sortir tantôt la tète, tantôt les pattes de derrière ou la queue. C'est un spectacle curieux que de voir la mère, lorsqu'elle veut se déplacer, forcer son petit d gagner les profondeurs de la bourse, en lui donnant de petits coups avec ses mains. Au bout d'un certain temps, le jeune kanguron abandonne la poche marsupiale et saute autour de sa mère; mais, au moindre indice de danger, il arrive en toute hâte et se précipite la tête la première dans sa cachette; en un instant il se retourne et, certain maintenant d'etre à l'abri de tout péril, regarde au dehors avec une expression comique (').

Il y a chez les marsupiaux, comme dans toutes les familles de l'immense règne animal, les plus grandes variétés physiques et intellectuelles. La sarigue opossum, par exemple, parait beaucoup plus intelligente que les kangourous. En chasse, on voit cet animal se dresser tout droit, regarder autour de lui, flairer à droite et à gauche, et se mettre en course :

Maintenant, écrit Audubon, ne le perdez pas de vue; au pied de cet arbre majestueux, il a fait halte, il tourne autour du noble tronc en cherchant parmi les racines couvertes de neige, et trouve au milieu d'elles une ouverture dans laquelle il s'insinue. Quelques minutes s'écoulent et le voilà qui reparait, tirant après lui un écureuil déjà privée de vie : il le tient dans sa gueule, commence à monter sur l'arbre et grimpe lentement. Apparemment qu'il n'a pas trouvé la première bifurcation à sa convenance, peut-être s'y croirait-il trop en vue, car il monte toujours

1. Brem. La Vie des animaux. 
jusqu'à ce qu'il ait trouyó un endroit où les branches, entrolacées avec des vignes sauvages, forment un épais berceau; là il se fait une place commode, s'arrange à son aise, enroule sa longue queue autour d'une des jeunes pousses et, de ses dents aiguës, déchire le pauvre écureuil qu'il tient avec ses griffes do devant.

Les beaux jours du printemps sont revenus; les arbres poussent de vigoureux bourgeons; mais l'opossum est presque nu et semble épuisé par un long jeune. Ilvisite les bords des criques et prend plaisir a voir les jeunes grenouilles - dont il se régale en attendant. Cepondant le phytolacca et l'ortie commencent à développer leurs boutons tendres et pleins de jus, qui lui seront une précieuse ressource. Lappel matinal du dindon sauvage frappe délicieusement ses oreilles, car il sait, le rusé, qu'il va bientôt entendre la voix do la femelle, et qu'il pourra la suivre à son nid, pour sucer ses œufs, qu'il aime tant! Et tout en rôdant ainsi à travers les bois, tantôt par terre, tantôt sur les arbres, de branche en branche, il entend aussi le chant d'un coq; et son cœur tressaille d'aise, en se rappelant le bon repas qu'il a fait l'été dernier dans une ferme du voisinage. Doucement, l'cil attentif, il s'avance et parvient à se cacher jusque dans le poulailler.

Honnète fermier, pourquoi aussi l'an passj, avez-vous tué 'tant de corneilles? Oui, des cormeilles; et par-dessus le marché, pas mal de corbeaux! Vous en avez fait à votre guise, c'est tant mieux! Mais maintenant courez au village, achetez des munitions, nettoyez votre vieux fusil, apprêtez vos trappes, et recommandez à vos chiens paresseux de faire bonne garde; car voici l'opossum. Le soleil est à peine couché, mais l'appétit du maraudeur est toujours évẹillé. Entendez-vous le cri de vos poules? Il en tient une, et des meilleures, et il l'emporte sans se gêner, le fin compère. Qu'y faire maintenant! Oui, guettez le renard et le hibou, et félicitez-vous encore une fois à la pensée d'avoir tué leur ennemi, et votre ami à vous, lo pauvre corbeau. Sous cette grosse poule, n'est-ce pas, vous aviez mis, il y a huit jours, une douzaine d'œufs; allez les chercher à présent. Elle a eu beau crier et hérisser ses plumes, l'opossum les lui a ravis l'un après l'autre.

La femelle de l'opossum peut être citée comme un modéle de tendresse maternelle. Plongez du regard au fond de colte singulière poche où sont blottis ses jeunes petits, chacun altaché à son mamclon. L'excellente mère! non seulement elle les nour rit avec soin, mais elle les sauve de leurs ennemis; elle les emporte avec elle, comme fait le chien de mor avec sa progéniture; d'autres fois, à l'abri sur un tulipier, elle les cache parmi le fenillage. Au bout de deux mois, ils commencent à pouvoir se subven ir à eux-mêmes; chacun alors a reçu sa leçon parliculiere qu'il lui faut désormais pratiquer. Mais, supposez que le fermier ait surpris l'opossum sur le fait, égorgeant l'une de ses plus belles volailles; exaspéré, furieux, il se rue sur la pau- 
vre bête, qui sachant bien qu'elle ne peut résister, se roule en boule et reçoit les coups. Plus l'autre curage, moins l'animal manifoste l'intention de se venger; et il reste là sous les pieds du fermier, ne donnant plus signe de vie, la gueule ouverte, la langue pendante, les yeux fermés, jusqu'à ce.que son bourreau prenne le parti de le laisser en se disant : Bien sùr, il est mort. Non! lecteur, il n'est pas mort. Seulement, il faisait le mort; et l'ennemi n'a pas plutòt tourné les talons, qu'il se remet, petit à petit, sur ses jambes - et court pour regagner les bois.

Une autre espèce, le Philander Énée, du Brésil, n'est pas inoins curieuse. Cet être vit presque exclusivement sur les arbres, et.ne descend sur la terre que pour y chasser. Sa queue prenante lui permet de grimper facilement, de s'accrocher partout, et, quand il se repose, il commence toujours par prendre un point d'appui solide en l'enroulant autour d'une branche. Sur le sol, il marche mal et lentement; il sait cependant y attraper de petits mammifères, des insectes, des crustacés, notamment des écrevisses, dont il fait sa nourriture de prédilection. Dans les branches d'arbres, il poursuit les oiseaux et pille leurs nids; il se nourrit aussi de fruits. Il rend parfois visite aux basses-cours, et y égorge les poules et les pigeons.

La femelle met bas de cinq $\dot{a}$ six petits informes, qui s'attachent à ses mamelons et y pendent comme des fruits à un arbre. Lorsqu'ils sont couverts de poils, ils montent sur le dos de leur nourrice et s'y tiennent en enroulant leur queue autorar de la sienne. Mème lorsqu'ils sont presque adultes, alors qu'ils n'ont plus besoin du lait maternel, ils restent encore avec leur mère, se réfugient sur son dos au moindre danger, se font emporter par, elle dans un lieu plus sûr. G'est à cet aspect que l'animal doit le nom d'Énée qui lui a èté donné. Lorsqu'elle est effrayée, la mère hérisse son poil, pousse des siffements, et répand une odeur très désagréable.

Mais arretons-nous dans cette excursion chez les descendants des premiers mammifères. Qu'il nous suffise d'avoir appréciè leur etat rudimentaire comme vivipares, et de reconnaître que pourtant ils inaugurent réellement le règne des animaux supérieurs. Les facultés intellectuelles et affectives sont nées. Elles ne s'éteindront plus. 


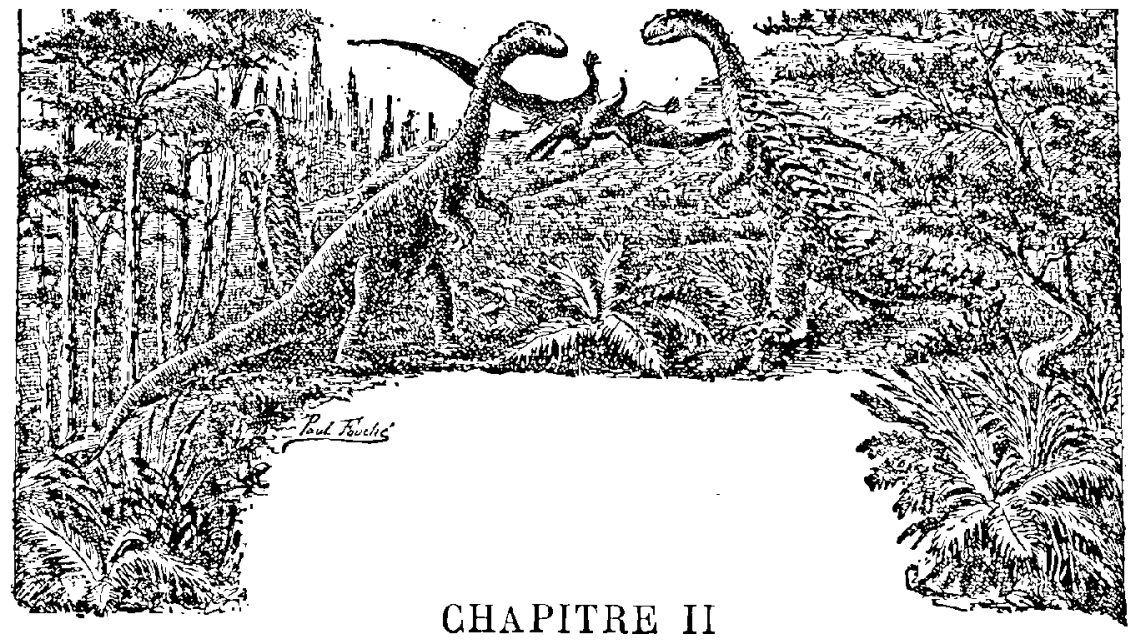

IA PERIODE JURASSIQUE

Lo règne des sauriens géants.

Nous arrivons en ce moment à l'ćpoque la plus extraordinaire de tous les temps qui ont précédé l'arrivée de l'homme sur la Terre. Lne mer immense s'étend encore sur la France presque tout entière, sur la plus grande partie de l'Europe et de l'Asie, sur de vastes régions de l'Afrique et des deux Amériques, aujourd'hui élevées à des centaines et des milliers de mètres au-dessus du niveau do l'Océan. Dans ces mers règnent des animaux gigantesques et bizarres dont aucun descendant n'existe plus de nos jour's. Plus avancée qu'aux temps primaires vers son état actuel, la planite semble à certains égards en différer davantage, parce que sa biologie subit une bifurcation qui ne présage en aucune façon ce qu'elle deviendra aux temps tertiaires et quaternaires. Un habitant de Mars (planète sans doute peuplée d'humains dès cette époque) ou un indigène de la Lune (monde probablement habité avant la Terre) qui aurait visité notre patrie au temps des reptiles jurassiques n'aurait certainement pu supposer que le jour arriverait oú sortis des eaux, les bas-fonds de la mer deviendraient le séjour de brillantes eités humaines telles que Paris, Londres, Vienne ou New-York. Dans ces mers nagent les lourds ichthyosaures aux yeux énormes, aux formidables mâchoires; les plésiosaures aux longs cous qui ramaient avec leurs larges pattes, plongeaient dans les 
profondeurs marines et reparaissaient aussitôt à la surface; les téléosaures, crocodiles monstrueux de dix mètres de longueur, dont la gueule fendue jusqu'à deux mètres d'ouverture pouvait engloutir des animaux de la taille du bocuf; les hyléosaures, à la carapace cuirassée, qui infestaient les rivages, tandis que sur les iles émergées, au pied des collines, au bord des mers, dans les fleuves et les lacs, au sein des bois ornés de fougères, de cycadées,

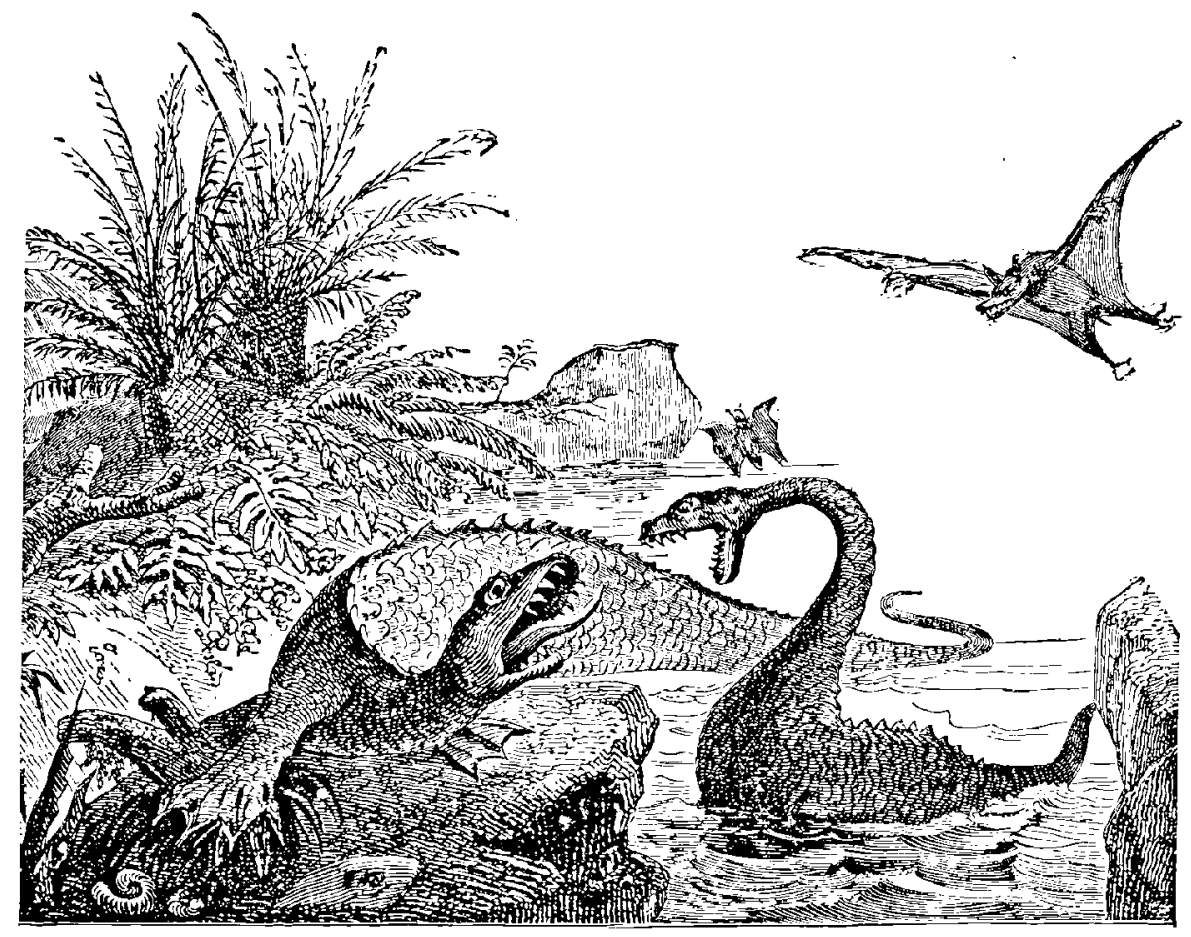

Fig 286. - Scène de la période jurassique. Ichthyosaure, plésiosaure, ptérodactyles.

d'araucarias, de conifères variés, vivaient les innombrables phalanges de dinosauriens qui, durant les temps secondaires, précédèrent dans la domination du monde les mammifères tertiaires : atlantosaures, gigantesques quadrupèdes herbivores de trente mètres de longueur; brontosaures, sauropodes du même ordre, dont la taille alteignait de quinze à vingt mètres; diclonius, reptiles bipèdes de douze à quinze mètres de longueur; stégosaures, autres bipèdes de dix mètres; iguanodons, bipèdes à pattes d'oiseau; comme les diclonius, rivalisant de taille avec eux, et les théropodes 
carnivores : mégalosaures, cératosaures, labrosaures, amphisaurides, compsognates, etc., reptiles de toutes formes et de toutes tailles, dont plusieurs étaient moitié crocodiles et moitié oiseaux, et dont l'étrange population devait faire de la mer et de la terre, des rivages et des bois, un monde fantastique dont aucune scène de l'animalité actuelle ne peut nous donner l'idée. A tous ces ètres, qui semblent autant d'essais informes de la force vitale, ajoutons, au-dessus d'eux, les énormes ptérodactiles aux ailes membraneuses qui sautaient dans le ciel et venaient s'abattre sur les rivages au milieu des cris rauques de toute cette population, et les innombrables oiseaux à dents qui traversaient l'espace à toute vitesse pour se précipiter sur leurs proies..., et nous aurons une faible image des spectacles que notreplanète devait offrir pendant ces siècles depuis si longtemps évanouis.

Les paléontologues qualifient avec raison cet âge de l'ère des reptiles. Et pourtant, combien ces sauriens et ces dinosauriens sont loin par leurs formes, leurs membres et leurs allures du sens que l'on attache généralement au mot reptile / Ces êtres ne rampaient pas. Ce n'étaient ni des serpents, ni des vipères, ni des couleuvres; c'étaient plutôt des lézards gigantesques, les uns marchant à quatro pattes, les autros se tenant de préférence sur leurs pattes de derrière et adoptant la position verticale, et quels lézards ! dix, quinze, vingt, trente mètres de longueur, et peut-ètre plus encore! Ces reptiles aux membres puissants ont été les ancêtres des crocodiles et des lézards tertiaires, qui, eux-mêmes, ont été les ancêtres des serpents, comme nous l'avons vu dans notre exposition générale du développement de la vie (p. 109-113). Les pattes ont graduellement disparu. - Les oiseaux aussi ont eu les reptiles pour ancêtres.

Cette riche période jurassique a dù s'étendre sur une très longue durée. Au commencement, immédiatement après les dernicrs sédiments triasiques, se sont déposés d'abord des sables devenus grès, puis, des marnes chargées de carbonate de chaux. On y rencontre beaucoup de fossiles, surtout des coquilles, ammonites, etc. Ces premières couches ont reçu le nom de couches liasiques, du mot anglais lias (qui ne veut rien dire du tout). Au-dessus d'elles se sont déposées des couches d'une autre nature, principalement 
des calcaires à l'aspect finement granulé qui donne l'idée d'agglomérations d'œufs de poissons. A cause de cette ressemblance, ces calcaires ont reçu le nom d'oolithiques (étymologie : wov, œuf, et 7.60\%, pierre). Il en résulte que les terrains de la période jurassique se partagent en deux grands systèmes, le lias et l'oolithe. Chacune de ces deux divisions principales se scinde à son tour en plusieurs subdivisions, car il y a un grand nombre de couches, différentes au point de vue minéralogique comme au point de vue des fossiles, de déposées pendant les longs siècles de cet âge. On peut signaler les suivantes :

PRINCIPALES DIVISIONS DE LA PÉRIODE JURASSIQUE

10 Système liasique.

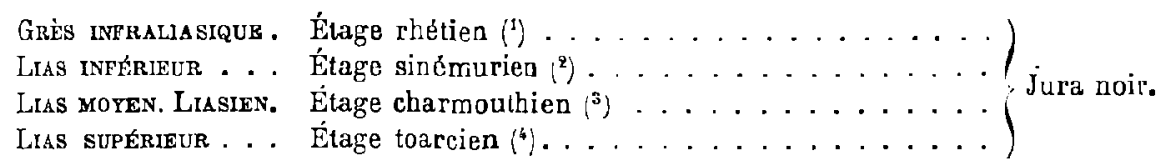

20 Système oolithique.

OoLithe mfériecr. . Étages bathonien $\left(^{(}\right)$et bajocien $(\diamond) \ldots \ldots \ldots \ldots$. . . Jura brun.

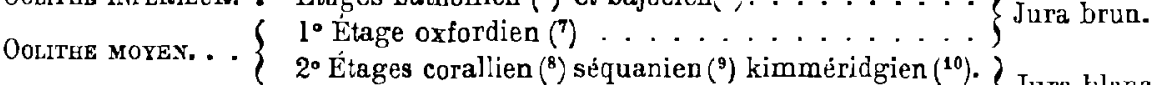
Ooliter scṕrRteur . Étages portlandien $\left.{ }^{11}\right)$ purbeckien $\left.\left({ }^{12}\right) \ldots \ldots \ldots\right\}$ Jura blanc.

Il y a encore d'autres subdivisions; mais évitons toute complication ainsi que toute fatigue d'esprit inutile. Comme ensemble, remarquons que ces couches géologiques deviennent de plus en plus claires, passant graduellement du foncé au blanc, à mesure qu'on s'élève vers la formation crétacée, posée, comme nous l'avons vu, sur la formation jurassique. Aussi leur donne-t-on également le nom de jura noir, jura brun et jura blanc.

1. Ce terrain est remarquable dans lès Alpes rhétiques.

2. Abondant aux environs de Semur.

3. De Charmouth (Angleterre).

4. De Thouars (Deux-Sèvres).

5. Très développé aux environs de Bath (Angleterre).

6. De Bayeux.

7. D'Oxford (Angleterre).

8. Remarquable par les vestiges de coraux qu'ıl renferme.

9. Facile à étudier dans le bassin de la Seine : Meuse, Haute-Marne, Côte-d'Or, Yonne, etc.

10. De Kimmeridge (Angleterre). - 11. De Portland (Angleterre). - 12. De Purbeek (Angleterre). 
Ces différentes couches prèsentent des épaisseurs trés diverses suivant les localités. Ainsi, par exemple, dans le département de la Haute-Marne, qui est sorti des eaux pendant la période crétacée, le grès infraliasique est très faible, le lias inférieur (sinémurien) a cinq mètres d'épaisseur, le liasien 91 mètres et le lias supérieur (toarcien) 53 mètres ; l'oolithe inférieul (bajocien) mesure 30 mètres au plateau de Langres et en Bourgogne (calcaire à entroques), l'oxfordien, cinq à six mètres seulement, l'oolithe marneux 70 mètres; l'étage corallien (souvent enchevètré avec le séquanien) y est faible et clairsemé; le calcaire portlandien se montre avec des ćpaisscurs de 80 à 150 mètres. Au contraire, on trouve, en d'autres points, le grès infraliasique épais de 12 mètres en Lorraine, de 24 à Kédange, de 60 dans le Luxembourg, de 700 en Scanie; le lias inférieur mesure 160 mètres dans le Yorkshire; le lias ou jura noir de la Souabe offre une épaisseur de cent mètres; l'oolithe inférieur a 60 mètres aux environs de Bath, l'argile de Kimméridge atteint, en deux couches, 350 mètres dans le comté de Lincoln, etc.

Au commencement de la periode jurassique, unc grande partie de la France, une grande partie de l'Europe mème, reste ensevelie sous les eaux. Depuis les àges lointains de la mer silurienne, oú déjá les massifs granitiques de la Bretagne, de la Vendée, de l'Auvergne étaient émergés et formaient des ìles à peine revêtues d'une misérable végétation, plusieurs fois la mer s'est retirée, et plusieurs fois elle est revenue. Pendant la période triasique, une vaste méditerranée s'étendait, découpée en golies, sur la France, l'Angleterre, l'Espagne et l'Italic, baignant les rives orientales de l'Auvergne et s'étendant par la Lorraiue jusqu'en Allemagne. Au début de la période du lias, au contraire, la mer est retirée à l'est, laissant à sec tor te _a région francaise et une partie de l'Allemagne; mais elle ne tarde pas à revenir baigner la France tout entière, ne laissant à sec que les îles des terrains anciens, sans communication les unes avec les autres, telles que l'Armorique, le plateau central, les Vosges et le massif primitif des $\Lambda$ lpes. Ces alternatives peuvent ètre lues par l'historien de la Terre sur les sédiments et leurs fossiles. Elles sont dues a des mouvements d'affaissement et d'exhaussement dans l'écorce du globe, analogues à ceux qui se produisent de nos jour's 


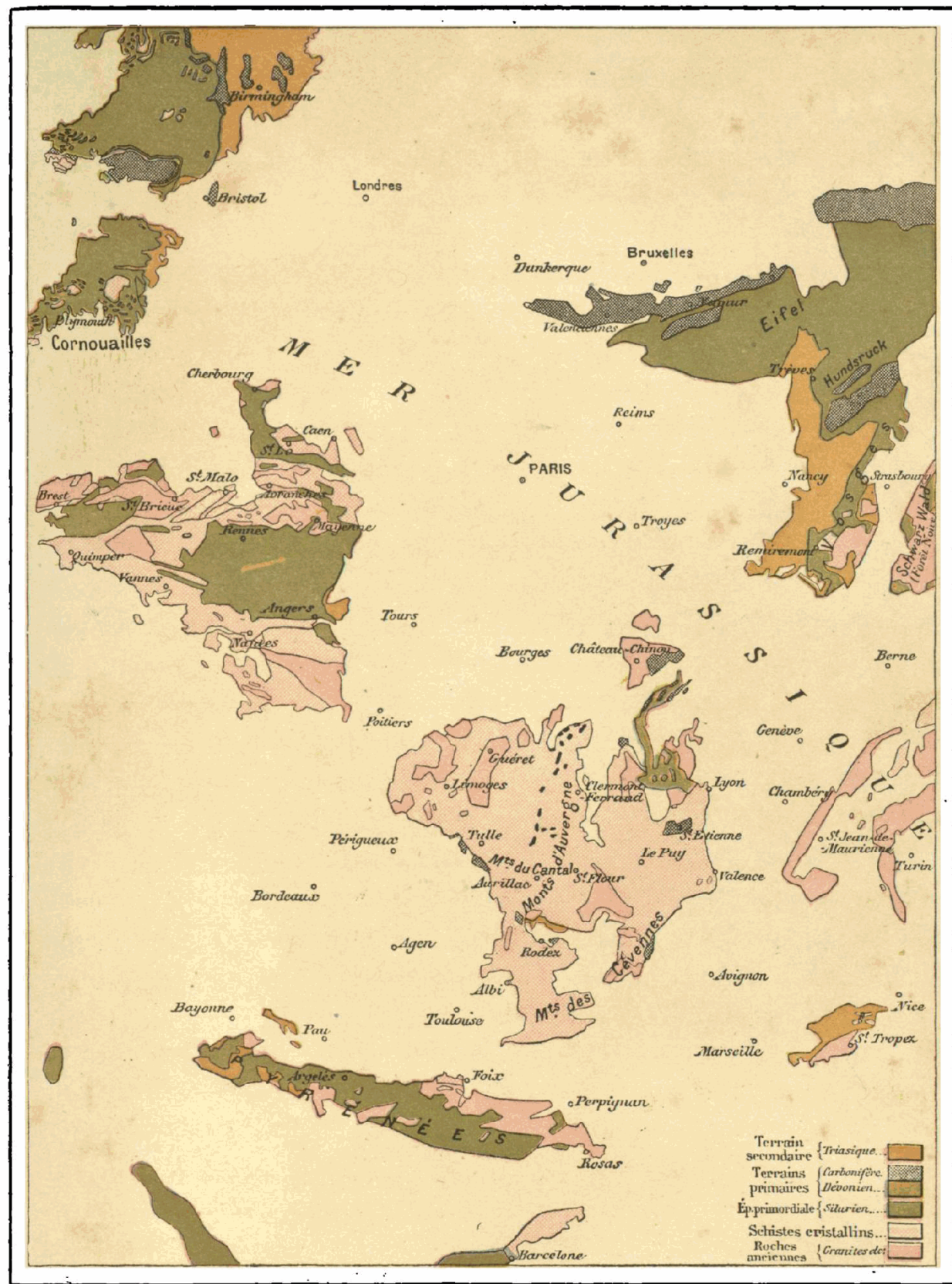

Grave' par E'Allorieu, R. Iavin \&ü. Paris.

FORMATION GRADUELLE DES TERRAINS

Imprimerie A. Lahure

FRANCE

Terrains primitifs, primaires et triasiques 
IRIS - LILLIAD - Université Lille 1 
et que nous avons longuement étudiés dans un chapitre précédent (précisément à cause de leur application géologique permanonte), mouvements lents, graduels, qui insensiblement ont à plusieurs reprises transformé la géographie de notre planète. Des centaines de milliers d'années gisent dans ces archives de l'enfance du globe.

On peut se former une idée de l'aspect géographique de nos contrées au commencement de la période jurassique, par l'examen de suotre carte géologique $n^{\circ} 6$, représentant les terrains graducllement émergés pendant les temps primaires et l'empldcement ir plus probable des régions qưi: étaient alors ensevelies sous les eaux. Avant que les terrains qui composent aujourd'hui le Jura, les Alpes, - d'Altorf à Sion, Aoste, Madane, Briancon, Gap, Digne, Tende, bandes découpées comme des îles dans le terrain primitif, - le plateau de Langres, une partie de la Bourgogne, la Haute-Marne, la Meuse, la Meurthe, la Côte-d'Or, le Nièvre, le Cher, la Vienne, les Deux-Sèvres, une partie de l'Orne et du Calvados, fussent soulevés (nos lecteurs peuvent suivie cetle formation jurassique sur notre carte géologique de la France) ('), la contrée sur laquelle resplendit. depuis plus de mille ans la civilisation francaise devait offrir l'aspect grographique dessinc: sur la carte ci-dessus. La mer s'étendait sur l'emplacement de Paris, Tours, Bourges, Poitiers, Saintes, Pirigueux, Bordeaux, Agen, Páu, Avignon, Chambéry, Genève, Berne, Bâle, Nancy, Troyes, etc. Elle couvrait toutes ces régrions, de Londres a Paris, à Bruxelles, à Bordeaux et à Marseille. Tel était l'étal de la France pendant la première partie de l'époque jurassique, pendant la période du lias.

1. Placement des cartes géologiques dans oette Édition. (Ces cartes sont toutes coloriées, pour la distinction des terrains).

Carte 1. Carte géologique de la France, p. 204.

- 2. Carte géologique de l'Europe, p. 220.

- 3. Formation graduelle des terrains. Fance. Terrains primitifs, p. 236.

- 4. Torrains émergés en Europe à l'époque do la mer silurienne, p. 252.

- 5. Coupe générale de l'écorce du glabe, p. 260.

- 6. Formation graduelle des terrains. Faxce. Terrains primitıfs, primaires et triasiques, p. 532.

- 7. Formation graduelle des terrains. France. Terrains primitifs, primaires, triasiques et jurasstques (au chapitre suivant).

- 8. Formation graduelle des terrains. France. Terrains primitifs, primaires et secondaires (au Livre suivant). 
Pendant la seconde partie de cette époque, pendant la période oolithique, l'affaissement du sol cesse pour faire place à un lent et graduel exhaussement. Vers le milieu de la période oolithique, on voit les régions maritimes qui séparaient les llots du terrain primitif s'élever au-dessus du niveau des eaux et souder le plateau central de la France; d'une part, à la Vendée et à la Bretagne; d'autre part, aux Vosges et à la Belgique. A la fin de la période jurassique, toutes ces régions autrefois ensevelies sous les eaux sont soulevées à une certaine hauteur.

En Angleterre, les terrains jurassiques forment une large hande traversant la région sud de la Grande-Bretagne, du nord-est au sud-ouest; cette bande est un prolongement de celle qui est disposée en ceinture autour du bassin de Paris. La mer jurassique s'est donc étendue sur toute cette partie de l'Angleterre comme sur la France.

Mais à la fin de l'époque jurassique, cette partie de l'Angleterre était émergée, comme le Jura, le plateau de Langres, l'Argonne et toute la ceinture dont nous avons parlé. De plus, des régions actuellement ensevelies sous les eaux de la Manche étaient également émergées, notamment entre Portland et Boulogne. La France était alors soudée à l'Angleterre, et là, où roulent aujourd'hui les caux de la Manche, s'étendait un continent couvert de lacs, entourés d'une riche végétation dans laquelle dominaient les cycadées, les fougères, les conifères, et qui étaient habités par de grands reptiles herbivores, notamment par des iguanodons, ainsi que par des troupeaux de marsupiaux. Sur cette terre disparue, se préparait la formation lacustre et terrestre connue sous le nom de purbeckienne, dont l'ile de Purbeck, sur la côte anglaise, non loin de Portland (Dorsetshire), en face de Cherbourg, présente le type géologique ainsi que les principaux fossiles.

Ainsi, tandis que le début de l'époque jurassique avait été marqué par un abaissement du sol d'une partic de la France, la fin de cette même époque a été contemporaine d'un exhaussement qui a fait émerger au-dessus des eaux une partie du nord de l'Europe.

Avant cet exhaussement, pendant le règne de la mer jurassique, une grande quantité de coraúx Rorissaient en France et en Angleterre. Les récifs coralliens sont intimement liés aux forma- 
tions oolithiques. Le sable calcaire que la marée rejette sur les plages des récifs de coraux ne tarde pas à ètre cimenté par les eaux d'infiltration; tantôt, les grains sont faiblement agglutinés et l'on peut reconnaitre l'enduit calcaire qui en opère la réunion par points; tantôt, le sable est devenu du calcaire solide, mais sans qu'on cesse de distinguer les petits grains de sable. Quelquefois, les sables sont mélangés de cailloux empruntés à l'ille qui borde le récif. On peut observer actuellement ce mème genre de formation oolithique et corallienne, dans l'íle de l'Ascension, à Oahu, et sur plusieurs points de l'Océan Pacifique.

On trouve les restes de ces récifs coralliens dans le Jura, sur une épaisseur de 40 à 60 mètres (aux environs de Gray et de Besancon), dans l'Yonne, en Provence, dans les Basses-Alpes, dans le Dauphiné, aux environs de Grenoble, - où ils sont représentés par de puissantes masses de calcaires blanes remplis de polypiers, avec leur cortège habituel d'oursins, de dicéras et de nérinées, - en Normandie et en Angleterre, où trois divisions du corallien se montrent nettement, au-dessus de l'oxfordien, sur la côte de Weymouth.

Le fait que les coraux vivaient, à l'époque jurassiquc, en France et en Angleterre, prouve que le climat équatorial s'étendait jusqu'au-delä du $55^{\mathrm{a}}$ degré de latitude, circonstance absolument incompatible avec l'existence de glaces au pôle nord. La végétation fossile donne le même témoignage, puisque des plantes tropicales, cycadées, fougères, vivaient alors jusqu'en Sibérie, jusqu'au $71^{\mathrm{e}}$ degré de latitude. Done à cette époque-là les saisons et les climats n'étaient pas encore bien marqués, probablement à cause de la prédominance des mers sur les régions polaires.

Sans doute, il est difficile de rétablir exactement les alternatives de retrait et d'envahissement de la mer. Les comparaisons géologiques permettent cependant de conclure que, comme on l'a vu plus haut, l'Europe, au commencement du jurassique, n'était qu'un archipel composé d'îles plus ou moins développées. A l'époque du lias, le plateau central de la France restait encore séparé du massif de la Vendée à l'ouest, de la région des Vosges et d'une partie des Alpes au nord-est et au sud-est, par les détroits.d'une ner libre (carte $\mathrm{n}^{\circ} 6$ ). A la fin de l'oxfordien, ces îles s'étendent et se soudent, d'une part par l'isthme de Poitiers, d'autre part par celui de la 
Cûte-d'Or. Au corallien, les trois bassins qui se partagent la France, celui de Paris au nord, celui de l'Aquitaine au sud-ouest, celui du Rhône au sud-est, n'ont plus de communications directes, les détroits de Poitiers et de la Côte-d'Or se trouvant fermés. Ce mouvement d'exhaussement, bien évident surtout dans la partie occidentale et septentrionale de l'Europe, s'accentue à la fin du jurassique. La France se soude à l'Angleterre, et sur l'emplacement actuel de la Manche s'établit un vaste continent, sur lequel les espèces animales et végétales sont surtout lacustres (dépót de Purbeck), ce qui montre que ces terres n'étaient pas fort élevécs et qu'elles restèrent longtemps soumises à de fréquentes incursions de la mer. Pourtant on y retrouve un grand nombre de plantes et d'animaux d'eau douce; les calcaires d'eau douce alternent avec les calcaires marins sur une épaisseur de 125 mètres : la période a donc été d'une longue durée. En France, le Boulonnais présente la mème formation. Il y avait également des lacs d'eau douce dans le Jura.

Si l'on compare à notre carte $n^{0} 6$, qui représente la formation des terrains jusqu'au commencement du jurassique, la carte dessinée par M. Contejean ( $f g .288$ ) dans l'intention de représenter l'état de 'a France à la fin du jurassique, on remarquera que dans celle-ci le soulèvement jurassique s'étend d'une part jusqu'à Boulogne, d'autre part jusqu'à Caen et Cherbourg (et à l'Angleterre par un isthme ponctué sur la carte). Ensuite une partie de ces terrains sont redescendus sous les eaux, non toutefois sans qu'une grande partie de la Manche ait été émergée, sous forme continentale, depuis Portland jusqu'à Boulogne.

Nous avons vu toxt à l'heure que le corallien est représenté dans le midi de la France, Provence, Basses-Alpes, Dauphiné, par de puissantes masses de calcaires blancs remplis de polypiers. Là, il est recouvert immédiatement par le crétacé. On en conclut qu'après la période corallienne, pendant les siècles où se sont formés les dépôts kimméridgiens et portlandiens, ce sol était hors de l'eau et qu'il est resté émergé jusqu'à l'arrivée de la mer crétacée. Ce sont là des documents géologiques qui permettent de reconstruire ces cartes rétrospectives.

A la période jurassique succède la periode crétacée. Dès le début 
de cette nouvelle période, tout change de nouveau dans la distribu. tion des terres et des mers. Le mouvement d'exhaussement du sol de la France, de l'Angleterre, du nord de l'Europe, qui avait été le trait dominant des temps oolithiques, s'arrête et fait place à un mouvement contraire. Une partie notable de l'Europe septentrionale descend sous les eaux et ne reçoit plus de dépôts que ceux où l'action sédimentaire est sensiblement dépassée en intensité par

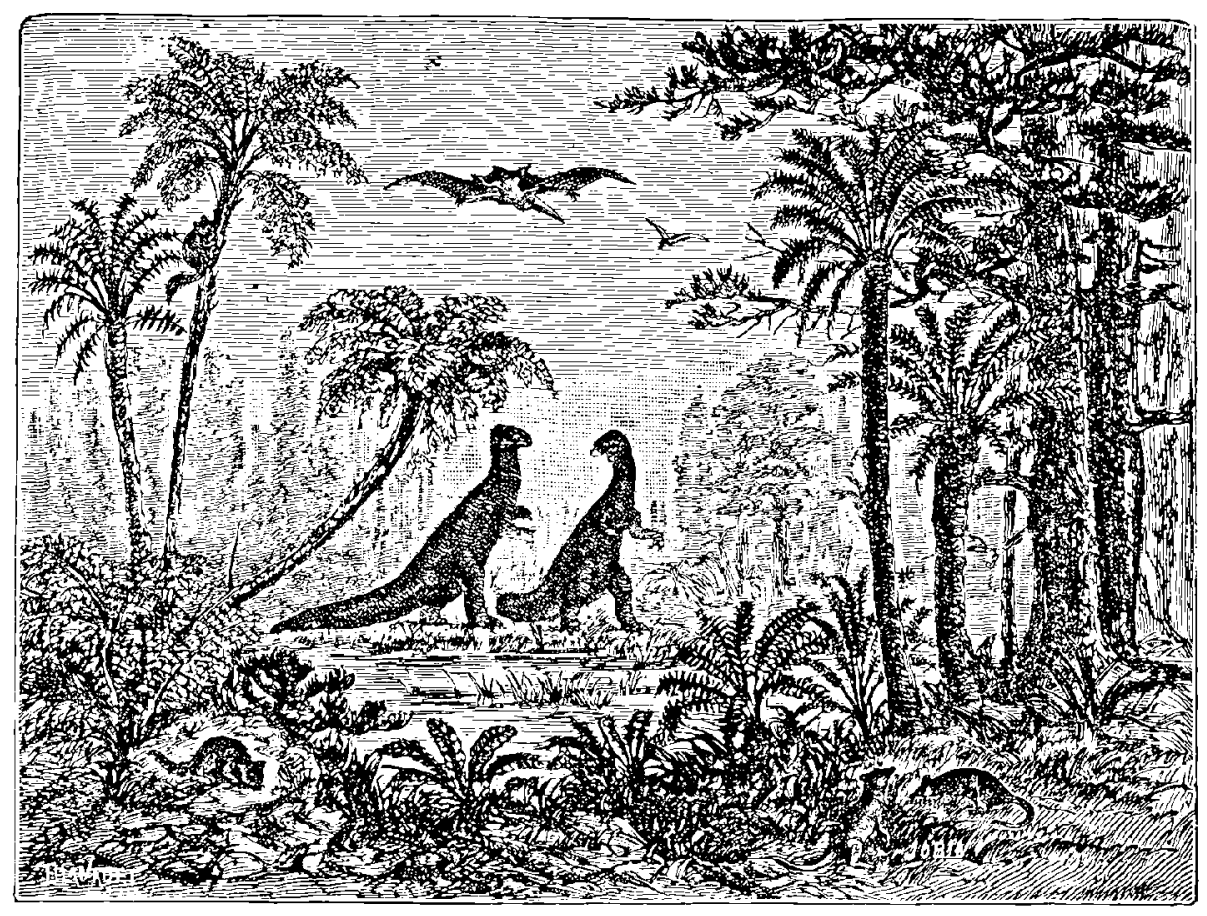

Fig. 287. - L'émersion du sol de la Manche à la fin de la période jurassique, et ses principaux habitants.

(Marsuplaux, iguanodons, ptérodactyles, au miliea des tougêres.)

celle des organismes microscopiques de l'Océan. C'est un temps de calme pendant lequel les infiniment petits travaillaient au fond des mer's et préparaient la formation de la craie, qui est presque uniquement composée de leurs débris, sur plusieurs centaines de mètres d'épaisseur. En France, une vaste mer baignait la base du Jura, se reliant d'une part avec la mer parisienne, d'autre part avec une mer méridionale s'ètendant jusqu'aux régions de la Méditerranée actuelle. Le midi de la France, qui était élevé au- 
dessus des eaux depuis la période corallienne, s'est de nouveau abaissẻ et a fait partie d'une vaste mer s'étendant sur tout lesud de l'Europe. A cette époque, le plateau central, complètement émergé, soudé d'une part aux Vosges et de l'autre à la Vendée, s'opposait à toute communication entre cette mer méridionale et la mer parisienne, qui s'avançait jusqu'au sud de l'Angleterre. L'ouverture de la période crétacée a donc été marquée par un remaniement considérable de la carte du monde et par le retour de la mer sur des régions qu'elle avait longtemps abandonnées. Cette invasion marine paraît avoir atteint son maximum lors du dépôt de la craie blanche.

L'examen géologique nous permet de reconnaître les régions où, le fond de la mer s'étant élevé, la terre a pris la place de la mer ; mais il ne nous permet pas facilement de déterminer les portions de terres qui ont été changées en mer, attendu que le sondage géologique du fond des mers est loin d'ètre fait. Nous ne pouvons done pas nous flatter de la prétention de rétablir avec cortitude l'état de la France ou l'état de l'Europe pour quelque époque géologique particulière. Ce que nous polivons faire de plus précis, car nous possédons les documents suffisants pour y parvenir, c'est do construire des cartes géologiques représentant les formations successives des terrains et leur émersion graduelle au-dessus du niveau de la mer. Ainsi, nos différentes cartes représentent, en fail, l'émersion des terrains de nos contrées: $1^{\circ}$ à l'époque de la mer silurienne; $2^{\circ}$ au commencernent de la mer jurassique; $3^{0}$ à l'époque de la mer crétacée; $4^{\circ}$ vers le milieu de l'àge tertiaire. Mais on serait dans la plus grande erreur d'en conclure que cette émersion progressive du continent franęais a passé régulièrement par ces quatre phases seulement. Loin de là, entre chacune de ces cartes on pourrait en intercaler plusieurs autres qui seraient toutes différentes, et qui, à l'exception des terrains primitifs restés presque tous en relief depuis l'époque silurienne et dessinant comme l'ossature de nos pays, montreraient des retours de la mer en un très grand nombre de points, d'abord exhaussés, puis abaissés, mais élevés de nouveau et encore submergés.

Si l'on considère, par exemple, le soulèvement des massifs des montagnes les plus importantes, telles que les Alpes, les Pyrénẹes, etc., on voit que ces soulèvements ont été soumis à bien des 
alternatives. Les roches primitives des Alpes, granite, gneiss, schistes cristallins ne portent au-dessus d'elles aucun terrain de sédiment primordial et primaire: elles étaient donc émergées pendant les périodes laurentienne, cambrienne, silurienne, dévonienne et carbonifère. Elles ont dủ subir un mouvement d'affaissement pendant la période permienne, car elles portent des sédiments anthracifères concordants avec les schistes cristallins. Pendant le dépôt du permien, les Alpes formaient une région littorale qui s'abaissa pour recevoir des sédiments de dolomies, de gypses et d'autres roches du trias. Ce mouvement d'affaissement n'a pas été général, mais particulier à certains points, et l'on constate au début de la période jurassique une série d'oscillations qui finit par un affaissement complet au-dessous du niveau de la mer. Alors, sur les Alpes englouties se déposent les sédiments oolithiques, entièrement marins, puis les sédiments de la période crétacée, dont les derniers seuls indiquent une tendance à l'émersion sous forme d'ìles, sur l'emplacement des chaines intérieures actuelles. Autour de ces îles, longtemps peu développées, se déposent les sédiments marins éocènes, du commencement de l'âge tertiaire. Mais ces chaînes intérieures continuent à s'élever et forment bientôt, au milieu de la mer éocène, un continent exposé par sa mobilité à de puissantes érosions et dont les débris vont s'entasser dans les couches de la mollasse, où les altcrnatives marines et terrestres accusent l'instabilité des rivages.

A peine la mollasse est-elle consolidée que l'effort de dislocation atteint son apogée, et les couches miocènes sont violemment rcfoulćes sans que la période pliocène, avec le début de laquelle ce mouvement coincide, puisse laisser d'autres traces que des dépôts torrentiels sur les flanes des montagnes et de petits bassins à lignite à une certaine distance. Ainsi le soulèvement des Alpes a été, si l'on peut s'exprimer ainsi, une cuvre de longue haleine, et il n'y a pas identité d'âge entre les chaines successives qui partagent ce massif en plusieurs régions distinctes. Les chaînes intérieures. sont d'âge éocène ou peut-être crétacé; celles qui suivent datent $\mathrm{du}$ début $\mathrm{du}$ miocène, et celles $\mathrm{du}$ bord sont pliocènes. Cette succession même n'est pas absolue, et il a pu se produire, à la faveur de l'un des ridements, des golfes profonds par lesquels 
la mer s'avançait dans les chaines intérieures déjà formées ('). On en a le tèmoignage par un dépôt nummulitique au sein des Alpes occidentales. L'histoire des Alpes orientales n'est pas idientiquement la mème que celle des Alpes suisses : leur émersion est devenue définitive à l'époque du crétacé supérieur, et déjà, dans les derniers temps de la période oolithique, elles formaient une chaîne d'iles, le long de laquelle a eu lien l'empiètement transgressif de la mer cénomanienne. Le redressement des chaìnes éocènes paraît s'y ĉtre accompli un peu plus tôt que dans les Alpes centrales. La séparation des deux massifs s'opérait alors comme aujourd'hui sur l'emplacement de la vallée du Rhin. Depuis le silurien jusqu'au carbonifère, la contrée située à l'est du Rhin est restée en partic immergée, tandis que l'ouest formait un continent de roches primilives, probablement en relation avec les Vosges, le plateau central et la Forêt-Noire. Puis les Alpes orientales s'affaissent et de riches faunes triasiques s'y succèdent, pendant que la plus grande partie des Alpes occidentales reste émergée. A la fin de cette période, la mer rhéticnne cnvahit la région suisse qui va dès lors s'abaisser de plus en plus. Le principal soulèvement des Alpes occidentales est le résultat d'une série de mouvements, lents ou saccadés, qui se sont succédés pendant le dépôt de la mollasse. Cies mouvements, en redressant sur les flancs des premières chaines alpines les assises inféricures et moyennes de cette formation, rejetaient peu à peu, en dehors de la zone montagneuse, les eaux où se formaient les couches supérieures, et donnaient naissance à des bassins d'eau douce au fond desquels se sont déposés des argiles à lignites.

De même que les Alpes, les Pyrénées sont le résultat d'efforts de dislocation plusieurs fois renouvelés. Toutefois, la chaine des, Pyrénées est beaucoup plus simple comme structure que celle des Alpes; elle ne présente qu'un seul massif de terrains anciens qui forme l'axe de la chaine, mais dont les deux versants sont loin d'ètre constitués de la même manière. Le versant français est beaucoup plus raide et plus abrupt que le versant espagnol; les dislocations et les contournements y sont aussi nombrenx que com.

1. De Lapparent, Traité de Géologie. 
pliqués. Sur le versant espagnol, les couches sédimentaires forment, en général, des paquets séparés les uns des autres par des failles, zans que les couches y soient très écartées de l'horizontale. Le.

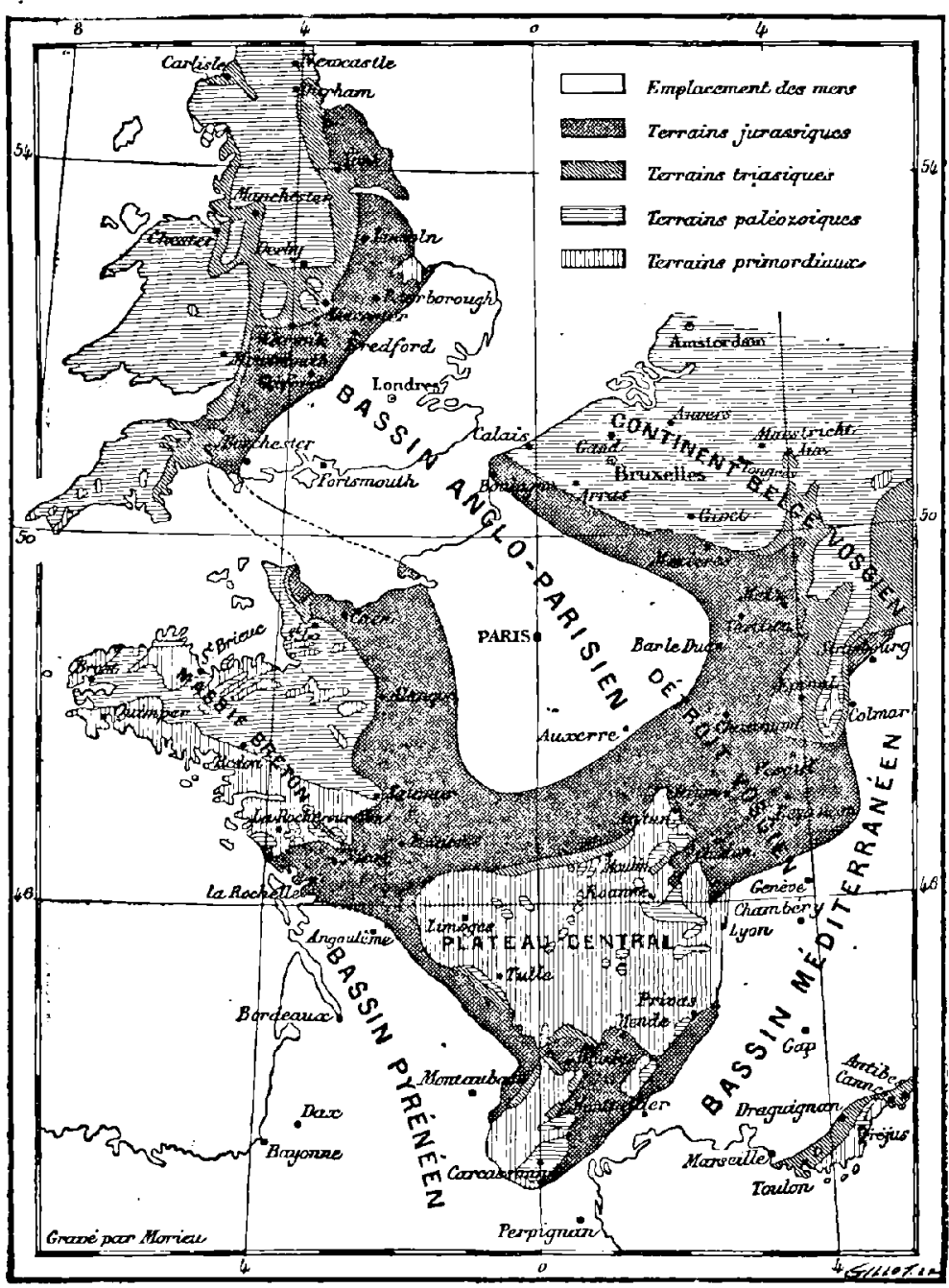

Fig. 288, - La France et l'Angleterre à la fin de l'époque jurassique (D'apross M. Cootejean.)

premier mouvement de soulèvement semble s'être produit avant le dépôt des couches carbonifères, car les schistes cristallins portent des assises primaires concordantes avec eux. Ensuite apparait, en discordance avec la sćrie précćdente, une suite continue qui va de l'étage houiller jusqu'aux couches infracrétacées. Ici s'est produit 
un nouveau mouvement, introduisant une discordance entre la série précédente et celle des couches suivantes, du crétacé à l'éocène: A la fin de l'éocène, un mouvement plus considérable que tous les précédents se produit et donne aux Pyrénées leur principa relief. Nous avons vu que le soulèvement définitif des Alpes a étć précédé par la formation de puissants conglomérats de la molasse, indices d'un sol que sa mobilité rendait très accessible à l'érosion; de même le soulèvement des Pyrénées a eu pour prélude des dépôts de poudingues (Palassen, etc.). Les assises nnummulitiques ont été portées à une grande hauteur dans la chaîne pyrénéenne où, sans être'sensiblement disloquées, elles atteignent 3352 mètres au Mont-Perdu. C'est pendant la formation des derniers dépôts éocènes qu'ont eu lieu les principales dislocations des Pyrénées (').

Ainsi, le soulèvement définitif des Pyrénées s'est opéré dans les premiers siècles de l'âge tertiaire, vers la fin de la période éocéne; il en a été de mème de celui des Apenniñs, qui a la mème direction. Le soulèvement définitif des Alpes, au contraire, a eu lieu dans les derniers siècles de l'àge tertiaire, vers la fin de la période miocène.

Ce sont là des faits qui sont aujourd'hui suffisamment déterminés. Il semble difficile d'admettre que l'âge relatif des montagnes puisse être lu de la sorte dans les archives du monde primitif; pourtant l'investigation des géologues, à la tête desquels notre reconnaissance doit nommer Léopold de Buch, Élie de Beaumont et Constant Prévost, y est parvenue. La première idée qui vient à l'esprit à l'aspect d'une montagne est qu'elle est sortie de terre par suite d'une impulsion verticale dirigće de bas on haut, à la manière des volcans. Cependant, lorsqu'on sait que le globe terrestre s'est nécessairement contracté en se refroidissant, on sent qu'il n'a pu le faire sans donner naissance à des plissements, à des vides internes, à des voùtes, à des dislocations de l'écorce extérieure, et quo ces dislocations ont nécessairement produit des montagnes. Lorsqu'on analyse la structure des montagrnes, on constate que la plupart du temps, au centre des massifs, la roche primitive surgit à travers les déchirures des étages sédimentaires, et vicnt former les cîmes

1. De Lapparent, Truilé de Géologie. 
culminantes. Tout terrain sédimentaire s'étant déposé, comme nous l'avons vu, au fond des eaux, en couches plus ou moins horizontales, ne peut se présenter cn couches inclinées que s'il a été soulevé par suite d'une dislocation postérieure à son dépôt. Une chaine de montagnes est donc, comme ligne de relief, plus jeune que les couches qu'elle a redressées. Mais elle est plus ancienne que celles qui sont venues se déposer horizontalement sur ses flancs. Nous avons vu, dans un chapitre précédent, que les choses se passent encore de nos jours de la mème façon. La principale cause de la formation des montagnes est la contraction lente et séculaire du globe. C'est cette formation actuelle des montagnes qui donne naissance aux tremblements de terre non volcaniques. L'état d'instabilité du noyau pâteux fait que, presque partout, le sol de la planète est en oscillation lente (4).

Chaque siècle le niveau du sol est soulevé dans certaines de ses parties et déprimé dans d'autres; il en est de même du lit de la mer. Par suite de ces changements incessants et des causes météorologiques, l'écorce terrestre, remaniée d̀ plusieurs reprises, a pris des formes toujours nouvelles, depuis qu'elle est habitée à sa surface par des êtres organisés et que le lit de l'Océan a été soulevé à la hauteur des montagnes les plus élevées. L'imagination est portée à s'effrayer, quand elle s'arrète à la considération de toules les irrégularités qui, à partir de cette époque, se sont produites dans la croûte terrestre. Toutefois, si l'on tient compte du temps que ces irrégularités ont pu mettre à s'accomplir, il n'est plus nécessaire pour les expliquer de troubler le calme ordinaire de la nature. On voit, d'ailleurs, que le résultat de ces changements est, en général, insignifiant, car les chaines de montagnes les plus hautes n'apportent qu'une modification presque insensible à la sphéricité parfaite du globe. Ainsi, le Gaorisankar, bien qu'il s'élève à 8840 mètres au-dessus du niveau de la mer, ne devrait être représenté sur uu globe de $1^{\mathrm{m}} 44$ de diamètre que par un grain de sable d'un raillimètre d'épaisseur.

On peut donc regarder les inégalités superficielles du globe

1. Voy. notre Revue mensuelle d'Astronomie populaire. Il ne se passe guère de jours sans que des tremblements de terre non volcaniques fassent sensiblement osciller le sol. Les montagnes continuent à se former - et à se défolmer. 
comme étant très peu considérables, et leur distribution, à une époque quelconque, pent être considérée, en géologie, comme une circonstance temporaire; sous ce rapport, cette variation d'altitude pourrait être comparée à la hauteur et à la forme que présente le cône du Vésuve, dans l'intervalle de deux éruptions. Quelque peu importante, toutefois, que puisse être l'inégalité de la surface du globe, relativement à sa masse totale, il n'en est pas moins vrai que c'est de la position et de la direction de ces faibles inégalités que dépendent principalement l'état de l'atmosphère, ainsi que le climat général et local.

L'âge d'une dislocation se détermine d'après celui des terrains qu'elle affecte. Si deux assises sédimentaires reposent immédiatement l'une sur l'autre, de telle sorte que leurs couches, inclinées les unes et les autres, ne fassent cependant pas le mème angle avec l'horizon, il est clair qu'on y doit voir la trace de deux redressements successifs, dont l'un a été antérieur et l'autre postérieur au dépôt de l'assise la moins ancienne. Une cassure est toujours plus récente que le dépôt des terrains qu'èlle a brisés et dont. l'âge fournit ainsi une limite inféricure pour l'époque de la dislocation. Comme, de plus, les accidents d'un même district obéissent en général à la loi de direction, tel accident, mal défini parce qu'il n'affecte qu'un petit nombre de couches, peut être légitimement rapporté au mème âge que d'autres de même alignement, affectant un plus grand nombre d'assises. C'est une analyse délicate à poursuivre dans chaque cas particulier, en s'aidant de tous les caractères que l'observation permet d'enregistrer.

S'il est possible d'arriver à définir avec quelque précision l'âge d'une dislocation élémentaire, il est beaucoup plus difficile de déterminer l'époque de la formation d'une grande ligne de relief. A vrai dire, il n'est guère de chaines de montagnes dont la structure ne porte l'empreinte de révolutions successives séparées les unes des autres par des intervalles de repos plus ou moins complet

Quand une importante ligne de hauteurs se forme, elle modifie puissamment le domaine continental, rejette au loin certaines mors et change, en un mot, d'une manière appréciable la carte de la région. C'est done cette carte qu'il faut reconstituer à diverses époques rapprochées, pour pouvoir reconnaitre à quel moment les. 
contours océaniques ont subi les modifications les plus profondes. Mais il ne suffit pas, pour cela, de noter soigneusement les points où l'on cesse d'observer telle ou telle formation marine ou lacustre. Il faut encore tenir compte des parties plus ou moins considérables que l'érosion a fait disparaitre, et n'accepter, comme indices d'un rivage, que les formations qui, d'après la nature de leurs éléments minéraux ou celle de leurs fossiles, affectent un caractère incontestablement littoral.

« On comprend aisément les difficultés d'une telle tâche, dironsnous avec un éminent géologue, si l'on songe que certains rivages ont disparu sans laisser de traces. La restitution des anciens rivages, fondée sur une exacte détermination des formations littorales, est le préliminaire indispensable des études orogéniques de détail. Or cette restitution ne peut ètre entreprise qu'à titre de résumé final des documents fournis par les cartes géologiques à grande échelle. Il ne s'agit pas, comme on le fait souvent, de donner une idée générale de la disposition respective des terres et des eaux à une certaine époque, par exemple. Il faut que ces contours maritimes s'appliquent avec rigueur à un moment bien déterminé de l'histoire géologique, c'est-à-dire au début ou à la fin d'un étage. Poser ce programme, c'est dire que l'heure d'une exacte détermination de l'âge des dislocations successives n'est pas encore venue, et qu'il convient d'attendre que les relevés géologiques de détail si activement poursuivis de nos jours, aient dit à peu près leur dernier not »('). Jusqu'à présent nous devons nous borner à apprécier aussi justement que possible la formation successive des terrains, puis essayer de bien nous rendre compte de l'ètat de la nature terrestre aux époques correspondantes à ces formations.

Nous ne pouvons, sans compromettre la clarté de ces études, empièter sur les formations de l'époque tertiaire pour compléter ce que nous aurions à dire ici des alternatives d'exhaussement. et d'affaissement des Alpes, des Pyrénées, des diverses chaînes de montagnes, ainsi que des changements dans la configuration géographique des mers et des terres. Nous y reviendrons en décrivant ces formations ultérieures. L'important ètait de nous former

1. De Lapparent, Traité de Géologie. 
une idée exacte de ces changements géographiques et d'attribuer aux cartes rétrospectives la valeur relative qui appartient à chacune d'elles, sans aller au delà de la note exacte de ces documents.

L'intérêt capital qui nous frappe dans la contemplation de ces époques disparues réside surtout dans La vie qui les caractérisait, et certes aucune époque ne pourrait rivaliser avec celle que nous visitons en ce moment pour l'étrangeté des formes dominantes de cette population. C'est avec une curiosité mêlée de stupeur que nous voyons aujourd'hui apparaitre devant nous les reptiles gigantesques de l'époque jurassique, notamment les ichıthyosaures et les plésiosaures, caractéristiques de cette faune.

On peut dire des reptiles qu'ils représentent le passé; ils ont pendant de longs siècles régné en maîtres à la surface du globe; on voit apparaitre une longue série d'animaux appartenant à des formes absolument disparues, en comparaison desquels les reptiles qui vivent aujourd'hui sont de véritables pygmées. Certains reptiles de l'époque secondaire peuvent être salués comme les plus gigantesques de tous Ies animaux terrestres connus : leur taille était supérieure à celle des éléphants et des cétacés; on connait à cette époque des fémurs de plus de deux mètres de haut, ce qui indique des bêtes d'une force si colossale qu'elle dépasse toute imagination. Des groupes entiers, dont rien dans la nature actuelle ne peut nous donner une idée, ont parcouru les océans, ont habité la terre ferme ou les marécages; ils ont disparu sans retour et sans laisser de descendants; certains de ces groupes sont à ce point isolés qu'ils diffèrent plus de nos animaux actuels que le serpent ne diffère du crocodile ; c'est par centaines que l'on cornmence à connaitre ces anciens reptiles qui ont pendant longtemṕs joné à la surface du globe le rôle de nos mammifères; on en trouve de carnassiers. d'herbivores, d'insectivores, de frugivores; ils sont partout, sur lá terre ferme, au sein des eaux et dans les airs. Si l'époque primaire a pu, à juste titre, être appelée le règne des poissons, on peut dire de l'époque secondaire qu'clle a vu le summum du développement des reptiles.

Les étranges animaux qui font, pour ainsi dire, passage des reptiles aux batraciens, s'ćtcignent, et à tout jamais, dans les assises 
inféricures des formations jurassiques, les reptiles proprement dits sont, par contre, à leur sommet d'épanouissement; ils sont représentés par tous les grands groupes que nous avons à l'époque actuelle, à l'exception du groupe des serpents qui n'apparaîtra que quand les premiers reptiles auront perdu leurs pattes. On trouve, en outre, des animaux de types absolument inconnus dans notre faune et qui ont disparu sans retour pendant l'époque crétacée (').

Les plus anciennement connus de ces reptiles secondaires sont les ichthyosaures, ear Scheuchzer, dès 1708, signale des vertèbres trouvées dans le lias d'Altdorf. Mais, comme nous le verrons plus loin, la nature de ces êtres si bizarres n'a été déterminée que dans la première moitié de ce siècle.

Les ichthyosaures $\left({ }^{2}\right)$ avaient les vertèbres d'un poisson, la tôte d'un lézard, le museau d'un marsouin, les dents d'un crocodile, le sternum de l'ornithorynque et les nageoires de la baleine. On en connait un grand nombre d'espèces différentes, parmi lesquelles plusieurs présentent une taille de dix et mème douze mètres. Ils sont extrêmement nombreux dans les terrains jurassiques, surtoul aux niveaux inférieurs. Leur tête (fig. 289), ètait longue et pointue, munie d'ycux énormes, leurs dents étaient pleines, longues, coniques et pointues $(\kappa g .291)$, et fort nombreuses, car on a trouvé des mâchoires munies de cent quatre-vingt dents, qui se remplaçaient indéfiniment, comme chez les crocodiles. L'allure générale des ichthyosaures devait rappeler celle de nos cétacés actuels.

Abstraction faite de l'ensemble formidable de la structure de ce monstre, ses yeux, de la grosseur d'une tête humaine, devaient lui donner un aspect tout à fait terrifiant. A l'intérieur de l'orbite, on remarque un cercle, composé de 13 à 17 lames osseuses, qui servaient probablement de support au blanc de l'œil, à cause de sa grande dimension; l'ouverture du cercle livrait passage à la lunnière. Ce système organique, qui se rencontre dans les yeux de plusieurs oiseaux, dans ceux des tortues et des lézards, sert à repousser en avant la cornée transparente, ou à la ramener en arrière, de façon à diminuer ou à augmenter sa courbure, et à

1. Brehm et Sautage. Les Reptiles.

2. Étymologie : ‘范, poisson; azuca, lézard. 
permettre ainsi la perception successive des objets $\dot{a}$ de petites et à de grandes distances, c'est-à-dire à faire alternativement, et selon les besoins de l'animal, office de lunette de myope ou de presbyte. A partir des yeux, le crâne acquicrt un volume considérable; le front s'élève pour s'aplatir de nouveau à l'arrière; les os font saillie au milieu et des deux côtés jusqu'à l'occiput, en laissant ouvertes les cavités qui abritaient l'appareil musculaire destiné $\grave{a}$ faire mouvoir la vaste et longue mâchoire inférieure.

A cette énorme tête, il fallait un puissant soutien ; c'est l'office que remplissait le cou, gros et court, et dont les vertèbres s'avancaient dans l'intérieur de la tête, tandis que la mâchoire inférieure se mouvait librement en avant et au-dessous d'elles. Les prolonge-

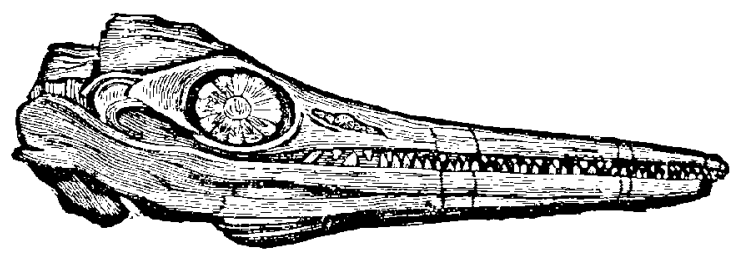

Fig. 283. - Tête fossile d’ichthyosaure.

ments épineux qui forment la colonne vertébrale vont en grossissant à partir de la tête jusqu'au milieu du dos ; ils servaient d'appui aux cordons musculaires qui s'étendaient le long de la colonne vertébrale, entre colle-ci et les côtes, cordons qui avaient probablement la grosseur d'un câblc. Les vertèbres mêmes sont à peu près circulaires, plates et garnies d'échancrures pour les ligaments cartilagineux par lesquels elles sont reliées entre elles. La crète de l'épine dorsale, laquelle, chez d'autres animaux, est pour ainsi dire soudée aux. vertèbres, n'y adhère que faiblement chez celui-ci, au point qu'on ne la retrouve tout entière que lorsque le squelette, enseveli dans la marne ou dans l'argile, s'est pétrifié avec le terrain même

Chez les animaux de notre époque, le nombre des vertèbres est si bien déterminé qu'il sert de caractère distinctif des familles; chez les sauriens, au contraire, il varie, ce qui indique un céveloppement imparfait : il ne s'était pas encore formé de type constanl; l'épine dorsale se compose tantôt de 110, tantôt de 120, 
voire mème de 145 vertèbres, dont 45 forment la racine d'autant de côtes, qui entourent tout le ventre.

La queue a de 80 à 85 vertèbres, dont les premières se conltinuent, des deux côtés, par des prolongements en forme de demi-côtes, allant en diminuant et cessant au point où cesse la

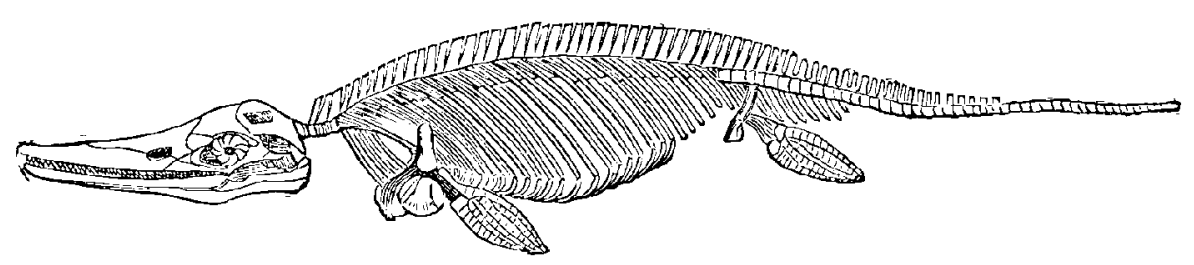

Fig. 290. - Squelette fossile de l'ichthyosaure.

crête du dos; à partir de là, la queue devient tout à fait ronde.

Les pieds, palmés, rappellent les nageoires de la balcine, avec celte différence qu'ils ont un plus grand nombre de doigts; mais ceux-ci se composent, comme la main de l'homme (moins le

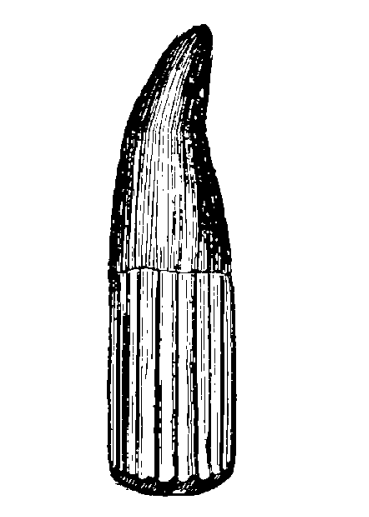

Fig. 291 - Dent d'ichthyosaure.

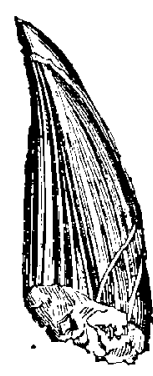

Fig. 298. - Dent de plésiosaure.

pouce), d'une série de phalanges, reliées entre elles par des muscles et des ligaments cartilagineux. Ces pieds semblent faits plutôt pour nager que pour marcher, mais ils ont pu servir aux deux usages

Les quatre membres de l'ichthyosaure étaient cuirassés comme un gantelet, tandis que le reste du corps restait dépourvu d'armure défensive (').

1. La chappente osseuse de ces membres est très reconnaissable sur la gravure qui précède ( $f i g$. 290) : les membres de devant s'insèrent à l'omoplate, ceux de derrière à la 
Le grand nombre et la surface biconcave des vertèbres permettent de conclure à une très grande agilité, grâce à laquelle ce monstre, si lourd en apparence, atteignait aisément sa proie. Si la longueur des quatre membres parait insuffisante, par contre la structure des vertèbres caudales et leur comparaison avec celles des poissons à corps élancé, indiquent que la queue de l'ichthyosaure était munie de larges et fortes nageoires, placées verticalement, comme chez tous nos poissons, et non pas horizontalement, comme chez la baleine; on comprend qu'à l'aide d'une pareille rame et de la forme allongèe de son corps il ait pu fendre l'eau avec rapidité.

On peut vair à la nouvelle galerie de paléontologie du Muséum de Paris un curicux fossile d'ichthyosaure dans. le scin duquel se trouve encore enfermé un petit ichthyosaure parfaitement formé. La mère et l'enfant sont, admirablement conservés ( $f g$. 293). La paléontologie a donné là une preuve directe, prise sur nature, que ces reptiles étaient vivipares.

Cet ichthyosaure a été trouvé par le naturaliste Chaining Pearce, dans le terrain liasique du Somersetshire; ce squelette fossile étajt couché sur le ventre. Surpris par quelque cataclysme, l'animal avait été recouvert do sable, pétrifié depuis lors avec tout ce qu'il renfermait, moins les parties molles. En enlevant avec précaution l'argile durcie, on a mis à nu toute la face ventrale du monstre : elle était parfaitement conservée, ainsi que toute la charpente osseuse.

Mais quel ne fut pas l'ćtonnement du naturaliste, en découvrant, dans la cavité du bassin de l'ichthyosaure, un autre animal de même espèce, en miniature, dont le squelette était couché tout du long, la tête tournée vers la queue de l'animal-mère, et à moitié emprisonné par l'os du bassin, comme si la mère avait été soudain foudroyée avec son produit.

Le fait de la découverte d'un embryon fossile dans le corps pétrifiẻ de sa mère est si prodigieux, qu'avant de l'admettre on n'a

hanche, chacun par un seul os trìs solide, qui se termine par une cavité d'où partent deux os; à la deuxième articulation, il s'en ajoute un troisième, puis successivement un quatrième et un cinquième; les membres de devant ont en plus, extérieurement, une série de petites phalanges, qui paraissent avoir formé un sixième doigt; le nombre des phalanges varie, de l'un à l'autre doigt, de 13 à 17 . Les membres de devant étaient composés, au total, de $90 \mathrm{os}$, les membres de derrière de 60 seulement. 
pas manqué de le scruter en tous sens; toute vérification faite, on n'a pu conserver aucun doute sur sa réalité. Ainsi que nous l'avons dit, le grand squelette a été dégagé de bas en haut, ce qui suffit déjaj pour exclure l'idée que le petit squclette aurait été amené là par alluvion; il est tout aussi inadmissible que le grand squelette soit tombé sur le petit, déjà enseveli dans la vaso, et lui ait fait contracter la position d'un embryon qui va naitre. La supposition que le petit animal ait été dévoré par le gros el soit venuainsi se placer à l'orifice du tube intestinal, se réfute d'elle-mème, puisque ce petit est tẹllement frêle que sa faible charpente (qui a d'ailleurs tous les caractères de celle de l'ichthyosaure) eùt été broyée dans l'estomac du gros monstre, - en supposant mème que les dents l'eussent laissée intacte. - Remarquons maintenant que la qualité de vivipare est inhérente à l'ordre des ichthyosauriens; les requins, qui ont aussi le gros intestin contourné en spirale, sont également vivipares, de mòme que plusieurs familles do scrpents, - les vipères, entre autres, dont le nom même indique cette propriété (viviparæx, par opposition à oviparæx, couleuvres qui pondent des œufs), les salamandres et quelques autres reptiles.

Quand nous retrouvons ainsi les vestiges de cette vie lointaine, quand nous'retrouvons, dit Buckland, dans le corps d'un ichthyosaure la nourriture qu'il venait d'engloutir un instant avant sa mort, quand l'intervalle entre ses côtes nous apparait encore rempli des débris de poissons qu'il a avalés il y a bien des centaines de millions d'années, tous ces intervalles immenses s'évanouissent en quelque sorte; les temps disparaisient, et nous nous trouvons, pour ainsi dire, mis en contact avec tous les événements qui se sont passés à ces époques incommensurablement éloignées, comme s'il s'agissait de nos affaires de la veille (').

Remarque assez curieuse, on n'a pas trouvé d'ichthyosaure dans les terrains secondaires des États-Unis. Cette absence a éti longtemps un des faitś paléontologiques les plus remarquables;

1. Il est très curieux de voir à quel degré de perfection la connaisisance de ces espèce: antiques, depuis si longtemps disparues, a été portée. Ainsi, par exemple, on sait ce que mangeaient les ichthyosaures, quelles espèces d'animaux ils dévoraient; on sait comment était construit le tube intestinal par lequel se terminaient leurs organes digestifs. Ces connaissances sont dues à la découverte de certaines concrétions, nommées copro- 
car, jusqu'en 1879, pas le moindre ossement de ce genre n'avait été rencontré de l'autre côtè de l'Atlantique. A cette époque, lo professeur Marsh en obtint un spécimen presque complet, mesurant trois mètres de longueur, provenant du jurassique de la région des Montagnes-Rocheuses, mais dépourvu de dents. Les vertèbres, les côtes et les autres portions du squelette pouvaiont à peine être distinguées des parties correspondantes d'un individu du genre Ichthyosaurus, et en beaucoup de points le crâne s'accordait aussi avec celui de ce dernier. Les prémaxillaires étaient proéminents; les susmaxillaires réduits; l'orbite vaste et défendue par un anneau sclérotique. Et cependant il n'y avait pas de dents; mieur que cela, une gouttière dentaire faisait mẻme défaut. Lo savant paléontologiste américain propose d'appeler le nouveau saurien «Sauranodon » ou saurien sans dents.

Quoiqu'on ait examinè dès 1708, comme nous l'avons vu, des restes fossiles d'ichthyosaures, on n'a commencé à les étudicr que vers 1814; c'est cette année-là que sir Everard Home publia ses premiers travaux sur les ossements qui venaient d'ètre découverts dans le lias des environs de Lyme-Régis, sur la côte de Dorset. En 1816 et 1818, de nouvelles pièces furent retrouvées an mème endroit, et en 1819 un squelette entier. En 1824, Cuvier publia un mémoirc complet sur la restauration de ce singulier reptile. Depuis, on en a trouvé en plusieurs couches du liasique et du jurassique, mais jamais à partir du milieu du terrain crétacé. On en distingue quatre espèces principales : l'ichthyosaurus communis, la plus grande de toutes (douze mètres), dont les dents sont striées et en forme de couronne conique; l'ichthyosaurus platyodon, chez lequel les dents sont comprimées; l'ichthyosaurus tenuirostris, qui a le museau long et mince; et l'ichthyosaurus intermedius, qui ressemble à la première espèce, mais a les dents plus aiguës et moins profondément striées.

Plus étranges encore et souvent plus gigantesques que les ich-

lithes (xorfos, excrément; $\lambda t \theta 0 \xi$, pierre), conservées à l'ètat fossile avec les squelettes des animaux. L'examen attentif des coprolithes de l'ichthyosaure y a fait reconnattre distinctement des écailles de poissons, des dents, etc. Par la forme des écailles, on a su déterminer l'espèce à laquelle appartenaient les poissons dévorés : on est mẻme parvenu à stablir que l'ichthyosaure dévorait des animaux de sa propre espèce. 
thyosaures, les plésiosaures (') ćtaient leurs contemporains perldant les siècles dont nous écrivons l'histoire. Leur forme est bizarre: que l'on se figure une baleine dont le tronc serait continué par un cou ressemblant au corps d'un serpent, le tout terminé par une tète extrêmement petite, comparativement à la grandeur de l'animal; tels sont les plésiosaures qui, par certains points de leur organisation, participent tout à la fois des crocodiles, des sauriens, des tortues, des cétacés, tout en conservant des caractères qui leur sont absolument particuliers. Certaines espèces courtes et ramassees rappellent un peu les ichthyosaures. La taille de ces Plésiosaures

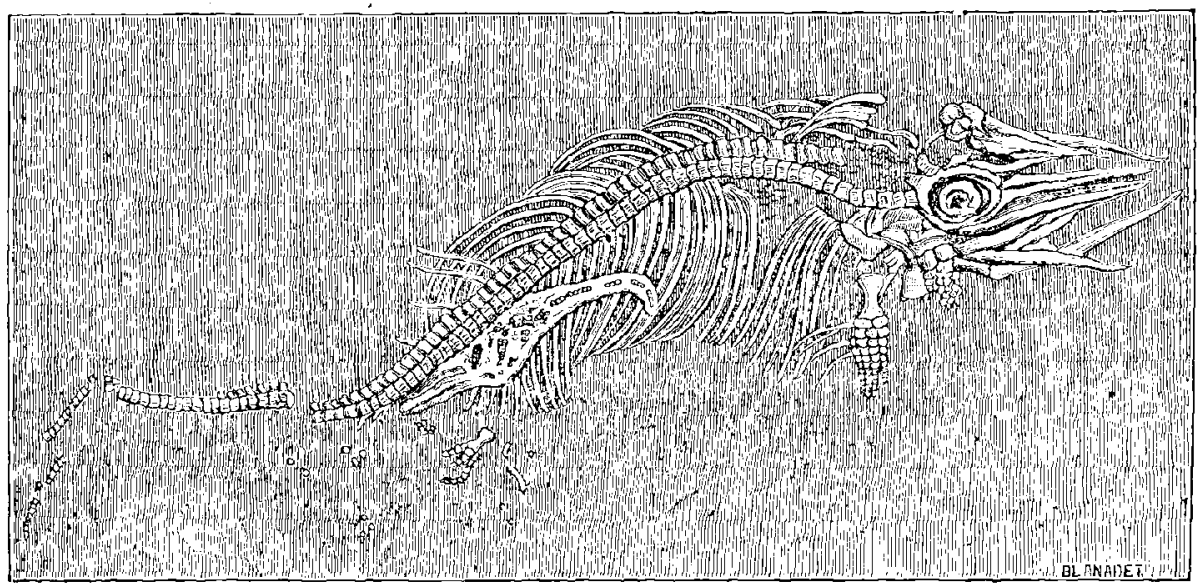

Fig s93. - Petit ichthyosaure conservé fossile dans le seln de sa mère. (Muséutn de Paris.)

devait être énorme : leurs dents ont plus d'un pied de longueur, et certains os de la cuisse sont plus grands qu'un homme de moyenne taille! Des animaux que l'on connait sous le nom de cétiosaures étaient non moins redoutables; leur fémur avait plus d'un mètre et demi de long, ce qui semble indiquer des animaux de dix-huit mètres de grandeur. Que nos reptiles actuels sont des pyormèes en comparaison des animaux de ces anciens âges; qu'ils paraissent petits lorsqu'on les met en parallèle avec ces primoldiaux!

Ces rois des mers jurassiques habitaient la haute mer; leurs membres, au nombre de quatre, aplatis comme des rames, étaient

1. Étymologie. $\pi \lambda \eta s_{5}$, voisin, oxupa, lézard.

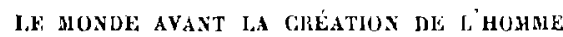


essentiellement conformés pour une natation d'autant plus puissante qu'elle était favorisée par la forme de la queue, haute et comprimée, qui leur tenait lieu de gouvernail. En raison de leur respiration aérienne, ils devaient nager, non dans la profondeur, mais à la surface des caux, comme le cygne et les oiseaux aquatiques. Recourbant en arrière leur cou long et flexible, ils dardaient de temps à autre leur tête robuste et armée de 'dents tranchantes, pour saisir les poissons. Ces animaux étant probablement vivipares, comme les ichthyosaures; ils se nourrissaient de proie vivante, que pouvaient saisir leurs dents nombreuses et souvent acérées.

Les premiers plésiosaures ont été trouvés aussi dans le lias d'Angleterre; c'est vers 1821 que Conybeare et De la Bêche en donnèrent la première description. Un squelette entier fut déconvert en 1824. Ils vécurent, comme les ichtyosaures, pendant la période liasique et jurassique et jusqu'au milieu de la période crétacée, non seulement dans les mers anciennes de l'Europe, mais encore dans celles de l'Amérique, de la Nouvelle-Zélande et de l'Australie. On en a déjà dislingué 73 espèces différentes, dont 24 đans les terrains crétacés. La moitié supérieure des terrains jurassiques français ont donné 1/t espèces, qui ont été principalement trouvées aux environs du IIavre et de Boulogne-sur-Mer.

En 1839, le naturaliste anglais Richard Owen découvrit un reptile non moins gigantesque que le plésiosaure, auquel il donna le nom de pliosaure, qui diffère du précédent en ce qu'il a le cou moins allongé, beaucoup plus court et rentré dans les épaules, comme l'ichthyosaure. Malgré cette différence, le pliosaure appartient au tỵpe des plésiosaures.

Vers la même époque, Hermann de Meyer, en Allemagne, faisait connaitre des reptiles provenant de la partie inférieure des terrains secondaires et trouvés dans les couches triasiques. Ces animaux, désignés sous les noms de nothosaures, pistosaures, simosaures, offrent aussi de nombreux rapports aver les plésiosaures. On voit là, comme dans les diverses races actuelles de chiens, si différentes de tailles et de formes; combien en histoire naturelle la qualification d'espèce est proche voisine de celle de race ou de variété, et combien il est difficile de l'enfermer dans des limites absolues. 
Nos lecteurs se rendront compte de l'aspect des ichthyosaures et des plésiosaures, non seulement par les fossiles que nous en arons reproduit, mais encore par les dessins qui ont poyr but de les reconstituer à l'état vivant. Notre figure 286, page 529, en donne une idée, que l'aquarelle de notre planche I (frontispice) rend d'une façon plus saisissante encore : dans cette aquarelle, le plésiosaure et l'ichthyosaure sont au milieu de la scène et ont pour compagnons des êtres non moins étranges, à la description desquels nous arrivons précisément en ce moment.

Les dernières découvertes de la paléontologic montrent en effet

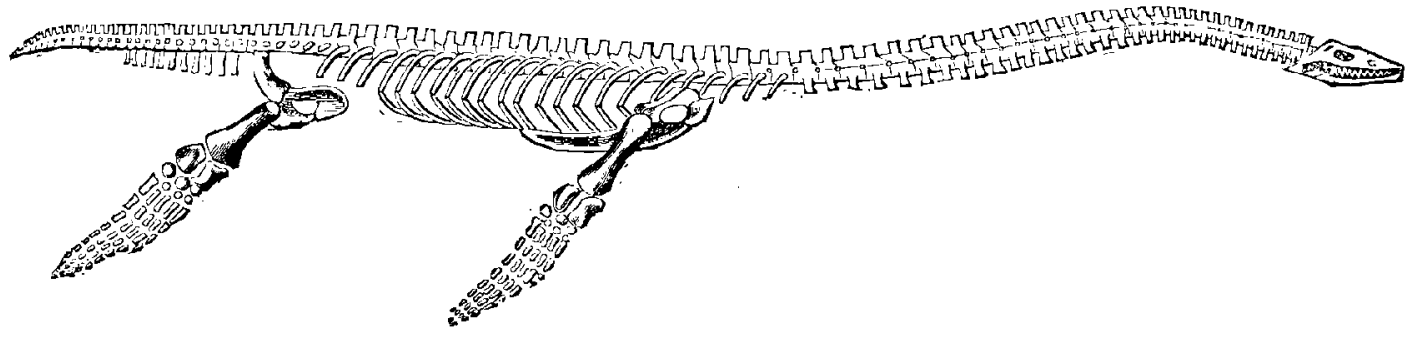

Fig. 294. - Squelette restauré du plésiosaure.

que les animaux dont nous venons de parler ne sont pas encore les plus extraordinaires de ces périodes antiques de l'histoire de la Terre. Nous pouvons avouer que les êtres les plus bizarres qui aicnt jamais cxisté sur notre planrite sont assurément encore les dinosauriens de l'époque jurassique.

Comme leur nom l'indique ('), c'étaient de terribles êtres, qui, précédant les mammifères, régnèrent sur la terre et sur la mer, et surent prendre une extension et une souveraineté comparables à celles des mammifères actuels. Les uns étaient carnivores et les autres herbivores; ils se nourrissaient des plantes croissant au sein des forêts profondes et se dévoraient entre eux. Depuis le trias jusqu'à la.fin de l'époque crétacée, ils ont dominé le monde, tour à tour contemporaius des ichthyosaures, des plésiosaures, des téléosaures, des mosasaures, etc. Les découvertes récentes permettent aujourd'hui de se reconnaitre au milieu de tous leurs débris fossiles, de reconstituer les principales espèces ct d'établir

I. Étymologie : òswón, terrible, étrange, prodigieux, sxupx, lézard. 
des groupes dans cette étrange population des siècles secondaires. Tout d'abord, il est naturel de les grouper en deux classes : les herbivores et les carnivores. Dans chacune de ces deux classes nous signalerons les espèces principales :

\title{
DINOSAURIENS
}

\author{
Berbivores \\ t. - Sauropodes (a pieds de lízards). \\ Espéces principales : Atlantosaure, Brontosaure. - Diplodocus. - Morosaure. - \\ Cétiosaure \\ iI. - stégosaures (sauriens a carapace). \\ Espéces principales : Stégosaure commun, Diracodon, Omosaure. - Scélidosaure, \\ IIylæosaure.

$$
\text { III. - ornithopodes (a PIEDS d'OIsEAdX). }
$$ \\ Espéces principales : Iguanodon, Camptonotus. - Hypsilophodon. - Hadrosaure.
}

\section{Carnivores.}

IV. - THEROPODES (A PIEUS DE CARNIYORES).

Espèces principales : Mégalosaure, Allosaure. - Cératosaure. - Labrosaure. Zanelodon. - Amphisaure. - Colurus. - Compsognathe.

Prenons une idée rapide de chacun de ces genres :

Dans la première série, remarquons les atlantosaurcs et les brontosaures, véritables géants de la faune secondaire, Les premiers atteignaient trente mètres de longueur et les seconds environ seize mètres. C'étaient de gigantesques quadrupèdes herbivores. les plus grands quadrupèdes qui aient jamais existé : on peut en juger (fig. 297) par la comparaison de ses dimensions avec celles de l'éléphant. Le brontusaure était plantigrade et avait cinq doigts aux quatre pattes; sa tête était remarquablement petite, plus petite que chez aucun autre vertébré connu; il avait le cou long et flexible, le trone court. Probablement amphibie. Le paléontologue américain Marsch en a restauré le squelette que nous reproduisons plus loin ( $($ g. 298). Selon toute apparence, c'était une bète lente et stupide, dont le poids devait s'élever à trente mille kilogrammes. L'animal marchait à la facon des ours actuels, et chaque empreinte de ses pas occupait environ 90 centimètres carrés.

Le diplodocus mesurait quatorze mètres de longueur. Fort ressemblant au brontosaure quant aux membres et à l'allure; petite tête, narines au sommet, mœurs aqualiques, dentition 
réduite, pas de dents au fond de la mâchoire; herbivore. Cerveau minuscule, comme celui de tous les dinosauriens.

Le cétiosaure a laissé des fémurs fossiles de $1^{\mathrm{m}} 70$ de haut; ce que l'on connaît de la tête et de la colonne vertébrale atteint douze mètres, ce qui représente un animal de seize à dix-sept mètres de long! Ils pouvaient vivre sur la terre ferme et se réfugier dans les marais ou à l'embouchure des grands fleuves, habitant généralement

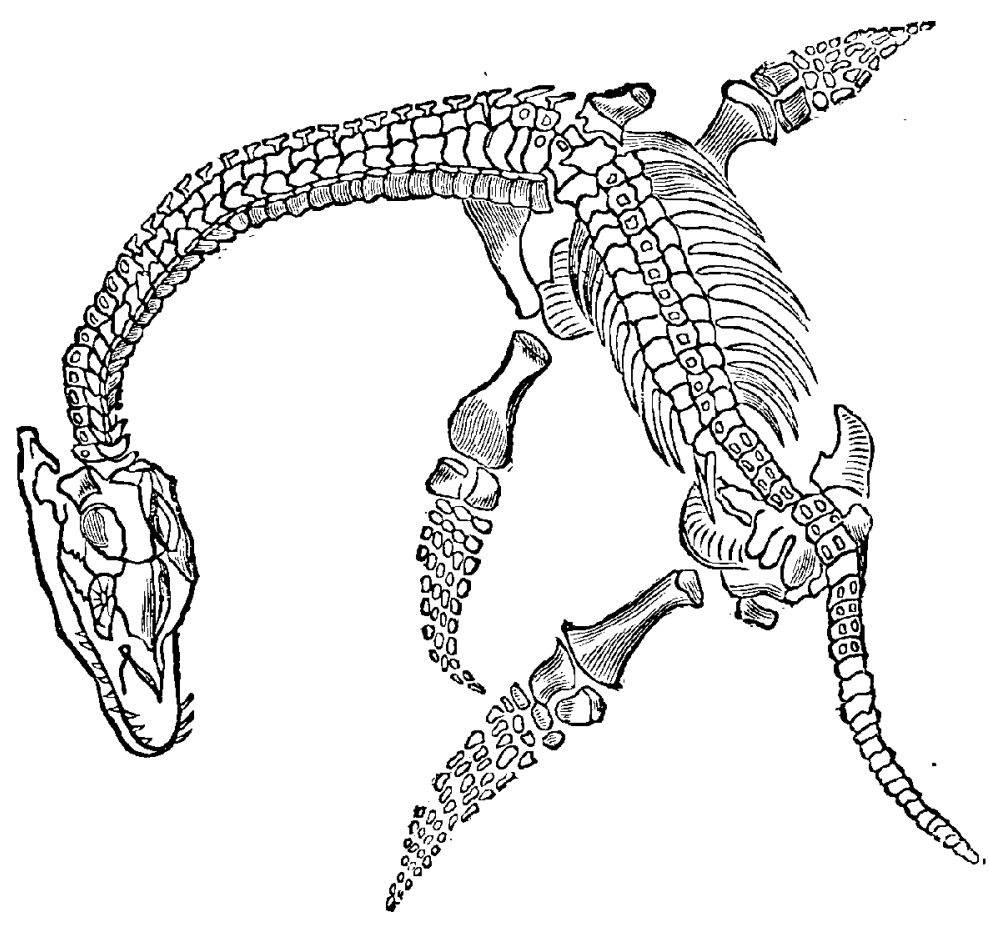

Fig. 205. - Fossile du plésiosaure macrocéphale.

parmi les fougères, les cycadées, les arbustes de conifères, circulant au milieu des forêts peuplées d'insectes et de petits mammifères. Herbivore.

“C'est parmi les sauropades, écrit M. Sauvage, que se trouvent probablement les plus gigantesques de tous les animaux terrestres; à en juger par les débris déjả retrouvés, certains d'entrc eux devaient atteindre plus de 35 mètres de long!»

Les stégosaures étaient des reptiles bipèdes atteignant une taille, de dix mètres environ de longueur; les membres antérieurs sont 
leaucoup plus courts et moins forts que les membres postérieurs; sinq doigts devant et derrière; petite tête, cerveau minuscule, beaucoup moins volumineux mème que la moelle épinière du bas Le la colonne vertébrale. Aquatique et se nourrissant de plantes. Leur corps était protégé par une armure composée de plaques et d'épines dont quelques-unes mesuraient jusqu'à 63 centimètres.

Parmi les ornithopodes, ou reptiles à pieds d'oiseaux, les plus remarquables sont sans contredit les iguanodons. Nous allons y revenir en détail. Mais complétons le tableau général des dinosauriens.

L'hypsilophodon avait la taille d'un grand chien. C'était un animal quadrupède, digitigrade et pourvu de quatre doigts fonctionnels devant et derrière. Son régime, comme le montre la dentition, qui occupait les mâchoires d'un bout à l'autre, était herbivore. Dépourvu de tout arme offensive ou défensive.

Le diclonius avait environ treize mètres de long. Il était bipède Les membres antérieurs se trouvant beaucoup plus courts que les postérieurs, comme un grand nombre des espèces de cetle époque), l.ligitigrade, avait quatre doigts à la main et trois au pied. Sa tète mesurait $1^{\mathrm{m}} 18$ de longueur. Elle est extrèmement aplatie de liaut en bas et, vue de dessus, offre un contour qui rappelle d'une manière étonnunte celui de l'ornithorynque. L'extrémité des mâchoires était revêtue d'un bec corné, tandis que le fond de la gueule renfermait deux mille soixante-douze dents. Le squelette a une longueur totale de $11^{\omega} 50$ environ.

Parmi les théropodes, avee le cératosaure, nous abordons les dinosauriens carnivores. Cet animal avait environ six mètres de long. Il était bipède, dans les mèmes conditions que les stégosaures tes orni thopodes. La dimension antéro-postérieure de sa tête est l'environ 60 centimètres; les mâchoires nous présentent des dents lortes et tranchantes d'une extrémité à l'autre. Ainsi que le rhinoréros, il portait sur le nez une puissante corne. Le mégalosaure itait un bipède de la même classe. Il habitait, ainsi que le tératosaure, les estuaires et les marais et se nourrissait de poissons.

Un type voisin, l'allosaure, également bipède et digitigrade, nous montre trois orteils et quatre doigts. Les membres postérieurs, qui portent seuls le poids du corps, sont terminés, 
comme chez les sauropodes, stégosaures et ornithopodes, par de petits sabots. Les membres antérieurs, qui doivent servir à retenir la proie, sont garnis de griffes acérées.

Le compsognathe ne mesurait guère qu'un pied de long. Il avait trois doigts fonctionnels devant et derrière. Particulièrement intéressant à cause de ses relations avec les oiseaux. Comparés aux sauropsides actuels, les dinosauriens sont apparentés, d'un côté aux lacertiliens et aux crocodiliens; de l'autre, aux oiseaux. Le compsognathe est jusqu'd présent le plus oiseau des dinosauriens. Il parait, comme le morosaure (animal voisin du brontosaure), avoir été vivipare (').

Le compsognathe a été trouvé dans les schistes lithographiques de Solenhofen, en Bavière, qui se sont déposés un peu avant la fin des temps jurassiques; ces schistes à grains fins, formés sous des eaux peu profondes et tranquilles, nous ont laissé des animaux d'une admirable conservation, des poissons, des insectes et jusqu'à des êtres complètement mous, tels que des étoiles de mer et même des méduses. "L'animal de Solenhofen, dit M. Sauvage, est de petite taille et se fait remarquer par la disproportion entre les membres de devant et ceux de derrière, ces derniers fort longs, les autres très courts; les vertèbres antérieures sont convexes en avant, concaves en arrière; le cou, très long, est surmonté par une tête assez semblable à eelle des oiseaux; les dents sont nombreuses; les pattes de devant et celles de derrière ne portent que trois doigts; un os du pied, l'astragale, est soudé avec le tibia, ainsi qu'on le voit chez les oiseaux. Le compsognathe, en un mot, bien qu'il soit reptile, est certainement un des dinosauriens ayant le plus d'affinités avec les oiscaux; c'est un de ces ètres comme nous commencons à en connaitre, qui pendant les temps anciens, semblent avoir relié les divers groupes les uns aux autres, comme si ces derniers avaient eu une origine commune. »

Donnons maintenant une attention spéciale aux iguanodons, qui ne sont bien connus des géologues que depuis l'étonnante et précieuse découverte faite récemment en Belgique de toute une compagnie do ces dinosaurions enscvelis et merveilleusement con-

1. L. Dollo. Revue des questions scientifiques, 1885 
servés. Nous résumerons dans ce récit la savante description qu'en a donnée M. Dollo, naturaliste du Muséum de Bruxelles [en compagnie duquel nous avons été heureux de visiter (octobre 1885) ces intéressantes et curieuses reliques des siècles disparus].

La première découverte de restes d'iguanodons date de 1822 . Cette année-là, Gédéon Mantell, naturaliste anglais, recueillait, dans la formation wealdienne de Tilgate Forest (comté de Sussex),

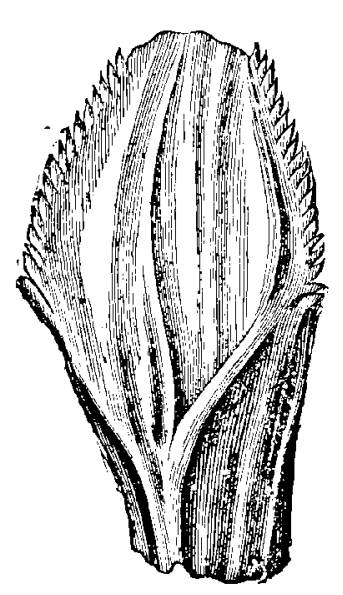
les premières dents de l'animal auquel on devait donner, quelques années plus tard, le nom d'iguanodon. Ces dents étaient si remarquables qu'elles auraient frappé, par leur apparence singulière, l'observateur le plus superficiel. Elles ne pouvaient, d'ailleurs, être confondues avec des dents de crocodiles, de mégalosaures et de plésiosaures, seuls reptiles dentés rencontrés jusqu'alors dans ces terrains. Trois ans plus tard, le même naturaliste crut pouvoir les assimiler à celles d'un iguane, et il en fut si fortement frappé qu'il Fig. 2936. - Dent d'iguanodon. déclare inutile d'insister plus longtemps sur leurs concordances, et propose d'appeler l'animal à dents d'iguane, iguanodon.

Le genre iguanodon était ainsi créé sur l'inspection d'une dent.

Neuf ans s'écoulèrent avant qu'on pût mettre la main sur une série d'os de quelque importance accompagnant des dents d'iguanodon. En 1834, on en mit au jour quelques fragments fossiles, mais il faut arriver jusqu'à l'année 1868 pour voir l'animal à peu près complètement décrit par Huxley.

Jusqu'a la découverte de Bernissart, on n'avait pas encore recueilli d'iguanodons entiers. On possédait des notions exactes sur la position de ce saurien dans l'échelle des êtres, mais on manquait encore de connaissances précises sur sa longueur totale, sur les proportions des diverses parties de son corps, sur son crâne, sur sa ceinture scapulaire et sur ses membres antérieurs.

Le 7 mai 1878, M. Van Beneden, professeur à l'Université de Louvain, annonçait, à l'Académie de Belgique, qu'une quantité considérable d'ossements de reptiles gigantesques venait d'être ren- 
contrée, à 322 mètres de profondeur, dans la fosse Sainte-Barbe du charbonnage de Bernissart, village situé entre Mons et Tournai, près de la frontière française. L'illustre paléontologiste insistait sur le mauvais état de conservation des fossiles et les rapportait dubitativement au genre Iguanodon. Avec ces débris s'en trouvaient beaucoup d'autres, notamment des restes de tortues, de crocodiles, do poissons, et un nombre considérable de plantes.

Cette extraction présentait de nombreuses difficultés : l'exécution était délicate et coùteuse, tandis que le résultat demeurait incertain. On remarqua d'abord que la galerie de reconnaissance avait

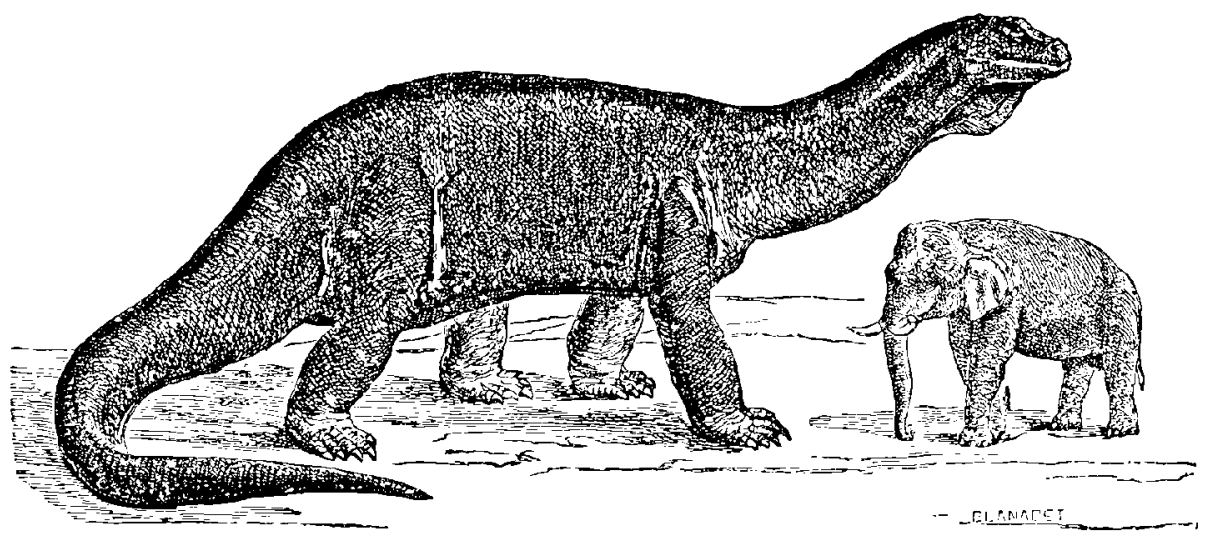

Fig. 997. - Forme et grandeur probables de l'atlantosaure: le plus grand des animaux qui aient jamais existé (longueur : 35 mètres).

traversé un iguanodon de part en part et l'avait détruit, depuis la tète jusqu'au bassin, de manière à ne laisser subsistcr intacts que les membres postérieurs et la longue queue de l'animal. Toutefois, les travaux de déblaiement, entrepris pour l'enlèvement des fossiles, mirent à découvert d'autres traces, qui furent poursuivies à leur tour, et, hicntôt, on acquit la conviction que l'individu traversé par la galerie était loin d'être seul, et que des squelettes complets pourraient être exhumés.

A mesure que l'on avançait dans l'extraction, on rencontrait de nouveaux débris et, dans les matériaux de déblai eux-mêmes, on ramassa tout un monde de petits reptiles, de tortues, de poissons et de végétaux. Finalement, après trois années d'un pénible labeur, et de déblais entrepris entre 322 et 356 mètres de profondeur, la 
science put compter à son actit vingt-neuf iguanodons, dont un bon nombre complets, cinq crocodiles, une salamandre, et des milliers de poissons et de végétaux (').

Par leur forme générale, leur port, leur allure, ils rappellent le kanguroo, mais un kanguroo gigantesque. Leur tête est petite rela. tivement et ressemble à celle des équidés.

Avec ces iguanodons, on a découvert, avons-nous dit, de nombreux restes de tortues terrestres et fluviatiles atteignant jusqu'à quatre mètres de long, et plusieurs centaines de poissons dont les espèces sont toutes d'eau douce.

Un cours d'eau douce traversait done la crevasse de Bernissart; mais, d'après l'alternance de ses dépôts avec les argiles noirâtres, on peut conclure qu'il dépendait de crues périodiques. En dehors de ces crues, la crevasse devait former un marais : la végétation l'indique, ainsi que les fossiles animaux. Son fond était occupé par une boue ou limon bourbeux dans lequel venaient s'enfouir les débris de fougères amies de l'humidité, qui croissaient au bord de ce marécage. Les gigantesques iguanodons, en voulant la traverser, s'y sont

1. Si la découverte de cette importante série d'êtres éteints avait été difficile, leur extraction le fut encore davantage, et on ne put la mener à bonne fin qu'avec les plus grandes précautions. Les ossements n'avaient, en effet, aucune consistance et tombaient en poussière aussitôt qu'on les dégageait. Dans le but d'obvier à ce grave inconvénient, on eut recours à un procédé qui rappelle un peu celui qu'emploient les jardinier's pour transplanter du gazon. De mene qu'ils n'arrachent pas les brins dherbe les uns après les autres pour les transporter tour à tour, mais détachent successivement par plaques la terre qui porte ce gazon, de -même fit-on pour les os des iguanodons. On découpa par blocs l'argile qui renfermait les ossements, et c'est dans cet état qu'on décida d'extraire ces derniers de la galerie et de les amener à la surface. Or ces blocs, dont plusieurs mesuraient $1^{\mathrm{m}} 50$ en longueur et en largeur sur une hauteur de 0 $0^{\text {m }} 60$, étaienl exposés, à cause de leurs dimensions, à tomber en morceaux. C'est ce qu'il fallait éviter à tout prix. Pour y arriver, on imagina de les entourer d'une enveloppe rigide en les noyant dans du platre. Le bloc était ainsi enduit sur quatre de ses faces, après quoi on l'ammenait jusqu'au sol. Là, on le consolidait par des ferrures annulaires, et on terminail son revêtement en recouvrant de plåtre ses deux extrémités. Insuite, le bloc recevait un numéro, et tous les blocs appartenant à un même animal, élaient marqués d'une lettre commune: on évitait de cette façon de mettre la tête d'un individu sur le corps d'un autre, etc. En outre, un plan indiquant la situation des différents blocs de chaque spécimen fut soigneusement dressé, de manière à pouvoir les placer plus tard exactement dans les positions relatives qu'ils occupaient, alors qu'ils faisaient encore partie intégrante de la couche argileuse.

Cela fait, les blocs, dont le poids total ne s'élevait pas à moins de 110000 kilogrammes, enveloppés dans leur gangue de plâtre, furent mis daus des tapissières et transportés par ehemin de fer à Bruxelles, où ils arrivèrent sans encombre au Musée d'histoire naturelle. 
enfoncós complètement; et c'est grâce à cette circonstance que leurs squelettes entiers ont pu être conservés pendant des milliers de sic̀cles et que nous pouvons les posséder aujourd'hui dans leur intégrité. On les a retrouvés couchés sur le côté, et plus ou moins déformés par la pression des terres sous lesquelles ils sont restés ensevelis.

Ce n'est pas là d'ailleurs un cas isolé. On a mis au jour, dans le limon pliocène de Dursart (Gard), des éléphants qui s'y étaient enfouis de la même façon. Malgré la distance de temps énorme qui sépare les deux dépôts, il existe un rapport évident entre leurs tombes respectives : la consistance et la couleur se ressemblent. Seulement, dans le Gard, on trouve des feuilles de chêne tandis qu'en Belgique, ce sont des fougères caractéristiques, propres à une localité envahie par l'eau.

Trois espèces d'iguanodons sont aujourd'hui bien caractérisées : l'Iguanodon Prcstwichi, l'Iguanodon Mantelli ct l'Iguanodon Bernissartensis.

I. L'Iguanodon Bernissartensis mesure $9^{\mathrm{m}} 50$ du bout du museau à l'extrémité de la queue et, debout sur ses membres postérieurs, attitude qu'il avait en marchant, - s'élève à $4^{\mathrm{m}} 36$ au-dessus du sol.

Sa tète est relativement petite et très comprimée suivant lo diamètre bilatéral. Les narines sont spacieuses et comme cloisonnées dans leur. région antérieure. Les orbites sont de grandeur moyenne, allongées suivant la verticale. L'extrémité des mâchoires, supérieure et inférieure, est édentée; elle était vraisemblablement revêtue d'un bec corné. Le reste de ces organes est garni de 92 denls, dont la structure indique un régime herbivore. Comme chez les reptiles actuels, les dents se remplaçaient indéfiniment, c'est-à-dire qu'aussitôt que l'une d'elles était usée, une autre lui succédlait.

Le cou est modérément long et contient, sans compter le proatlas, dix vertèbres qui, sauf la première, portent toutes une paire de petites côtes. Il devait ètre très mobile.

Le tronc est composé de 24 vertébres solidement réunies par des tendons ossifiés, derniers restes de la musculature si développée chez les serpents et servant dans ceux-ci à produire les mouvements latéraux de la colonne vertébrale.

La queue est un peu plus longue que le reste du corps; elle a 5 mètres et renferme 51 vertèbres. Elle est très comprinée latéralement, rappelant celle du crocodile.

Les membres antérieurs sont plus courts que les postérieurs. Ils sont 
massifs et puissants, et se terminent par une main à cinq doigts. Le premier doigt, ou pouce, de celle-ci, a sa phalange unguéale transformée en un énorme éperon, qui, revêtu de sa corne, devait être une arme terrible. Le second, le troisiène et le quatrième doigt possèdent chacun trois phalanges, dont la dernière, ou unguéale, porłait un petit sabot corné. Le cinquième doigt, qui est très long et fort singulier, était probablement opposable comme notre pouce, permettant ainsi àl'iguanodon de saisir et de rapprocher éventuellement de lui les branches des arbres dont les fruits servaient à sa nourriture.

Les membres postérieurs sont les plus volumineux, et leur structure rappelle celle des pattes d'oiseaux.

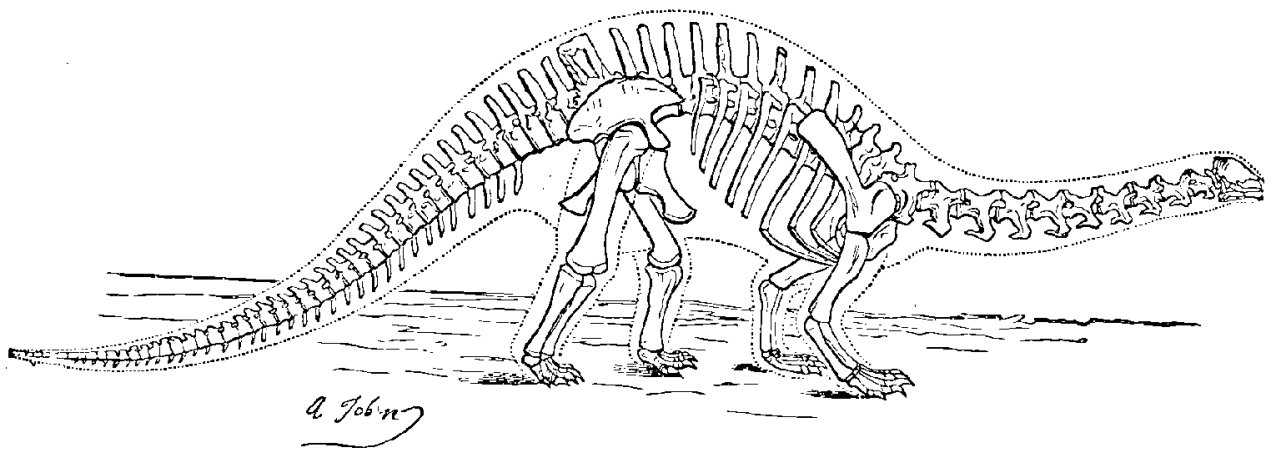

Fig. 298. - Animaux de la période jurassique : le brontosaure (1/125 de grandeur naturelle).

II. L'Iguanodon Mantelli, se distingue surtout de l'Iguanodon Bernissartensis par les caracteres suivants :

$1^{0}$ Il r'a que cinq à six mètres, au lieu de dix mètres;

$2^{\circ}$ Il n'a que cinq vertèbres au sacrum, au lieu de six;

$3^{0}$ I es narines sont beaucoup plus spacieuses.

III. L'Iguanodon Prestwichi se fait remarquer par la présence de quatre vertèbres seulement au sacrum et par la moins grande complication de ses dents.

Nous pouvous maintenant nous représenter les iguanodons comme des animaux amphibies, qui se nourrissaient de végétaux. . Ils coupaient ces derniers avec le bec corné qui terminait leurs mâchoires, et la trituration se faisait dans l'arrière-bouche à l'aide des 92 dents, continuellement renouvelées, dont nous avons parlé plus haut. Ils étaient probablement aquatiques. Les circonstances dans lesquelles les dinosauriens de Bernissart ont été trouvés, montrent que ces animaux devaient vivre au milieu de marécages etsur les bords d'une rivière. 
Étant donné que les iguanodons passaient une partie de leur existence dans l'eau, nous pouvons nous figurer, à l'aide d'observations faites sur le crocodile et sur l'amblyrhynchus (grand lézard marin des îles Gallapagos), deux modes de progression de notre dinosaurien, très différents l'un de l'autre, au sein de l'élément liquide.

Quand il nageait lentement, il se servait des quatre membres et de la queue. Voulait-il, au contraire, avancer rapidement pour

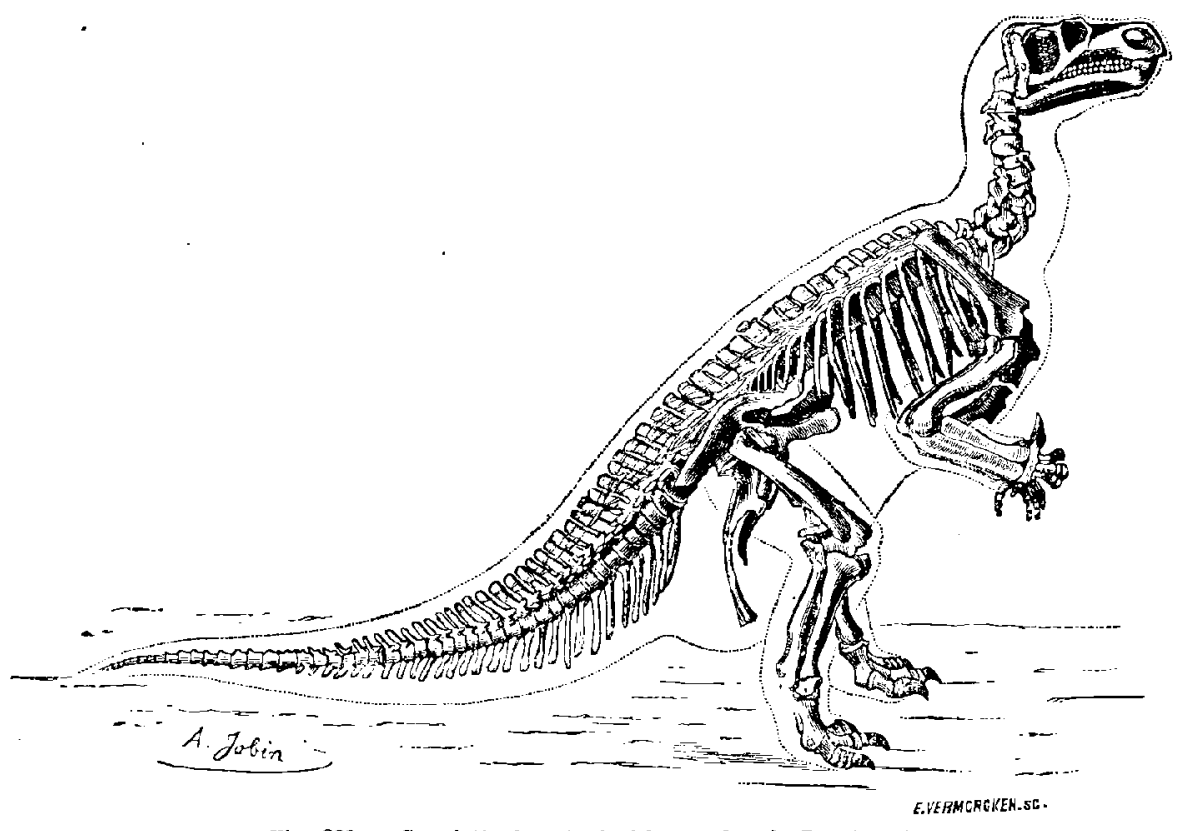

Fig. 299. - Squelette du principal iguanodon de Bernissart.

échapper à ses ennemis, il ramenait ses membres antérieurs - les plus courts - le long du corps, et se servait uniquement de son appendice caudal. Dans ce dernier mode de progression, il est clair que plus les pattes de devant sont petites, plus elles se dissimulent aisément et moins, par conséquent, elles causent de résistance au déplacement de l'animal dans l'eau. La conformation de tous les mammifères aquatiques donne le même témoignage.

A terre, ces animaux marchaient à l'aide des membres postérieurs seuls. En d'autres termes ils étaient bipèdes à la manière de l'homme et d'un grand nombre d'oiseaux, et non sauteurs comme les kangourous. De plus ils ne s'appuyaient point sur la queue, mais la laissaient simplement traîner. 
Les iguanodons étant herbivores devaient servir de proie aux grands carnassiers de leur époque. D'autre part, ils séjournaient au milieu de marécages. Parmi les fougères qui les entouraient, ils auraient vu difficilement, ou pas du tout, arriver leurs ennemis. Debout, au contraire, leur regard pouvait planer sur une étendue considérable. Dehout encore, ils étaient à même de saisir leur agresseur entre leurs bras courts mais puissants, et de lui enfoncer dans le corps les deux énormes éperons vraisemblablement garnis d'une corne tranchante, dont leurs mains étaient armées (').

Nos lecteurs se rendront compte de la stature de ces êtres bizarres par le squelette fossile gravé plus haut ( $f g .299)$ et mieux encore certainement par le beau dessin de la page 569, qui représente la rencontre d'un iguanodon et d'un mégalosaure dans une foret jurassique wéaldienne $\left(^{2}\right)$.

Tout récemment, cette année mème (1885), M. Dollo a restauré un nouveau reptile trouvé dans le crétacé du Hainaut et auquel il a donné le nom de hainosaure, "saurien de la Haine» (rivière), pour correspondre au terme de mosasaure " saurien de la Meuse » déjà donné à des reptiles du mème ordre. La longueur du crâne mesure $1^{\mathrm{m}} 55$, et la longueur totale du reptile devait être de treize mètres. C'est, jusqu'à présent, le plus grand des mosasauriens connus $\left(^{3}\right)$.

La tête du mosasaure, qui ne mesure pas moins de $1^{\mathrm{m}} 30$ de long et peut atteindre jusqu'à $2^{\mathrm{m}} 50$, ressemble à celle des monitors. Les mâchoires sont garnies de dents acérées. Le cou renfer-

1. L. Dollo. Revue des Questions scientifiques, Bruxelles, 1885.

2. Ce dessin, dủ au crayon de M. Jobı̃ (du Muséum de Paris), rétablit ces deux reptiles dans le cadre de leur époque. Le mégalosaure, qui est carnassier, est dans une atilude agressive. L'iguanodon (herbivore) se tient de son côté sur la défensive, tout prèt à faire usage du terrible éperon de son pouce.

La végétation est formée d'espèces appartenant aux genres suivants :

Fougères : Scleropteris, Lanatopteris, Stachypteris, etc.

Cycanḱes : Pternphyllum, Otozamites, Sphenozamites, etc. (Plantes ou petits arbres a tronc simple et formant le soubassement des bois.)

Coniteres : Brachyphyllum, Pachyphyllum, Palyssia Widdringtonia, Araucaria, Baiera. (Arbres de haute futaie rappelant les Sequoia, les Araucarias d'Australie, les Cyprès, les Ginckos. - Il y avaił même déjà de véritables Pins.)

3. Les premiers musasaures ont été recueillis dès l'année 1766, en Hollande, à Maestricht, au bord de la Meuse, par Drouin, officier qui s'intéressa à acheter ces ossements fossiles à mesure que les carriers les découvraient. Hoffmann, chirurgien de la garnison. 
mait vraisemblablement dix vertèbres au maximum et présentait sans doute les proportions de celui des ichthyosaures. La main, à cinq doigts, était terminée par des phalanges unguéales dépourvues de griffes et possédait la structure de la nageoire. Le plus long doigt portait six phalanges; le plus court, quatre. M. Marsh figure le pouce comme en ayant trois. Les membres postérieurs sont semblables aux antérieurs dans leur organisation, mais un peu plus faibles en volume. L'armure dermique consistait en plaques de deux centimètres environ : ces plaques, lisses sur la face interne, étaient imbriquées; on ignore le mode exact de leur distribution sur le corps de ces colosses.

Somme toute, dit M. Dollo, les mosasaures étaient des reptiles qui devaient extérieurement avoir l'aspect des dauphins, de grands marsouins, par exemple. Ils s'en distinguaient aisément cependant:

continua les recherches commencées par Drouin et réunit un assez bel ensemble de matériaux, que Pierre Camper acquit, en 1782, à la mort de son possesseur.

Lorsque l'armẻe française s'empara de la ville de Maestricht, en 1793, Kléber envoyá au Jardin des Plantes de Paris la tête fossile du mosasaure, qui était alors entre les mains du chapitre de l'Église. Faujas de Saint-Fons l'étudia et crut reconnaître dans l'animal de Maestricht, comme on l'appelait alors, un énorme crocodile. Cette tête mesure deux mèlres de longueur.

Cuvier décrivit le crâne et la colonne vertébrale, en même temps qu'il apprécia sainement les rapports zoologiques du mosasaure. Il ne put, faute de documents, établir sûrement la véritable nature des membres. Néanmoins, il reconnut qu'ıls devaient constituer des sorles de nageoires qu'il compare à celles des dauphins et des plésiosaures.

En 184I, sir R. Owen vint mettre à côté du mosasaure classique un nouveau genre, le leiodon, caractérisé par ses dents. Cette découverte augmenta le nombre des formes, mais l'ostéologie du groupe resla, ou peu s'en faut, stationnaire.

Un peu plus tard (1845), Goldfuss présenta comme une espèce nouvelle un mosasaure américain, dont le squeletle est aujourd'hui conservé à Bonn. Ce travail, tout en nous gratifiant d'un type inédit, fit avancer considérablement notre connaissance génèrale du sous-ordre.

11 se produisit alors un grand silence, à la suite duquel les fouilles étonnantes exécutées de l'zutre côté de l'Atlantique complétèrent, d'une manière inespérée, les renseignements fragmentaires recueillis auparavant.

Le professeur Cope, dans son grand ouvrage sur les vertébrés crélacés (1875), donna les diagnoses de trois genres nouveaux (Platecarpus, Clidastes, Sironectes), représentant ensemble vingt et une espèces.

Enfin le professeur Marsh, qui possède à présent les resles de quatorze cents individus du sous-ordre des mosasaures, fixa (1872) d'une façon définitive la structure des ceinlures scapulaire et pelvienne ainsi que des membres. Huit ans plus tard (1880), il décrivit le sternum. On lui doil encore la découverte de la nature des téguments. Enfin, il caractérisa cinq genres nouveaux (Baptosaurus, Edestosaurus, Holosaurus, Lestosaurus, Tylosaurus), auxquels M. Dollo a ajouté les genres Pterycollasaurus et Plioplatecarpus. 
parce que leur corps, au lien d'être nu, comme celui des dauphins, était recouvert de petites plaques osseuses; par la présence de deux paires de nageoires, tandis que ces cétacés n'en ont qu'une seule paire; par la circonstance que leur queue était comprimée latéralement et non de haut en bas, et par la position subterminale de leurs narines, qui n'étaient point transformées en évents. - Nous les retrouverons plus loin, à la période crétacée.

D'un autre côté, aux Ėtats-Unis, M. Marsh a restauré récemment aussi (1884) un nouveau reptile trouvé dans le jurassique et auquel il a donné le nom de macelognate. C'est une espèce de tortue à dents et à bec corné, les dents étant au fond de la mâchoire.

A tous ces ètres déjà si variés il faud rait encore ajouter les champsosaures, dont on discute en ce moment même la vraie conformation. Nous avons fait connaissance, d'autre part, en visitant l'époque triasique, avec les singuliers dicynodontes ( $f g .280$ p. 516) de l'Afrique australe. Nous en retrouverons encore d'autres à l'époque crétacée. Le naturaliste Cotta appelait ces dominateurs \& les hauts barons du royaume de Neptune, armés jusqu'aux dents et recouverts d'une impénétrable cuirasse, vrais flibustiers des mers primitives. „Pourtant tous ces reptiles ne sont pas encore les plus étranges de cet âge si bizarre, car nous n'avons pas encore parlé des reptiles volants, les ptérodactyles, ni des oiseaux à dents, les odonthorithes.

Tous ces ètres semblent combler l'hiatus qui, dans la nature actuelle, sépare les plus parfaits des reptiles, les crocodiles et les tortues, des mammifères inférieurs, des marsupiaux et des moins oiseaux parmi les oiseaux, tels que l'autruche, l'émen, le casoar. Ils sont si loin des reptiles que l'on devrait former pour eux une sous-classe distincte, égale en valeur à celle que l'on admet pour les reptiles actuels ; les différences qu'ils présentent avec nos reptiles sont de beaucoup supérieures à celles que nous constatons entre les tortues et les serpents, par exemple, pour prendre les deux termes extrêmes de la série. Nous ne connaissons des dinosauriens que le squelette; il est probable que s'il nous était donné de savoir quelle était leur organisation, comment se faisait leur circulation, quel était lour mode de développement, nous n'hésiterions pas à en former une classe intermédiaire entre celle des mammifères 


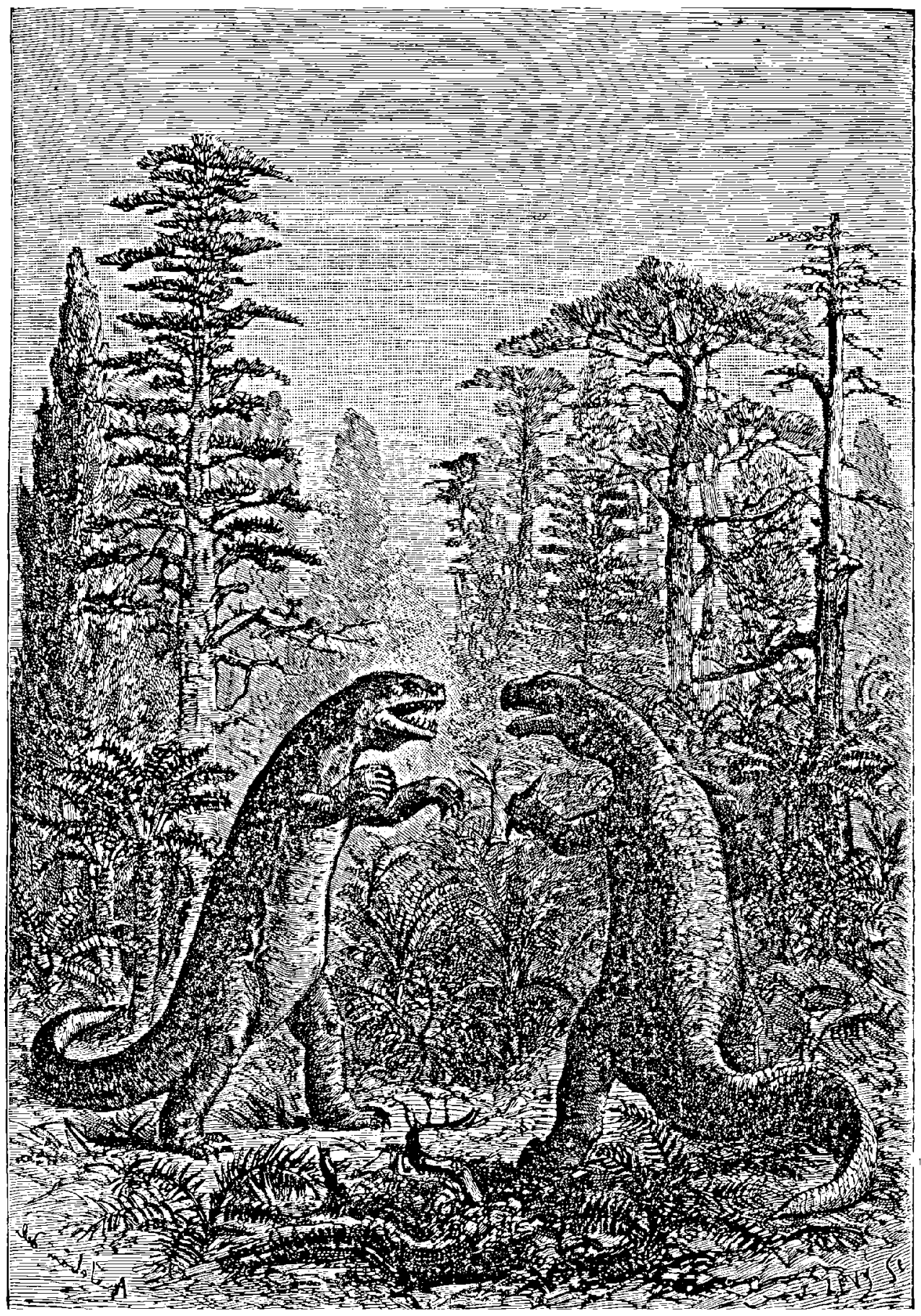

IES ROIS DE LA TERRE A LÉPOQUE JURASSIQUE.

Iguanodon et Mégalosaure dans une forēt de fougèrcs, de cycadées et de conifêres.

LE MOXde aVANT La CRÉation DE L'HOMHE 
et des oiseaux et celle des reptiles proprement dits. L'on commence à entrevoir parmi ces animaux des types très différents indiquant des ordres tout aussi distincts que le sont ceux des pachydermes, des ruminants, des carnivores parmi les mammifères.

La grandeur et la forme du crâne sont très différents suivant les type sexaminés. Ce crâne, d'ahord allongé comme celui des crocodiles chez les dinosauriens triasiques, se raccourcit chez les animaux "plus récents. Chez certains animaux, comme l'hipsilophodon, les os orbitaires sont en connexion avec les frontaux, comme chez les mammifères et chez beaucoup d'oiseaux. Le cerveau est essentiellement reptilien et parfois extrèmement petit. Les os intermaxillaires sont séparés; les branches de la mandibule ne sont unies que par du cartilage et non soudés. La composition du crâne ressemble par certains points à ce que l'on voit chez les crocodiles et chez les sauriens.

Le régime ayant été très varié chez les dinosauriens, la forme des dents diffère considérablement suivant les types examinés. Les carnassiers, tels que le mégalosaure, avaient des dents fortes et tranchantes, crénelées sur les bords; les maxillaires étaient armés de ces dents, qui devaient être redoutables. Les herbivores tels que l'iguanodon, le vectisaure, le laosaure, l'hypsilophodon, avaient leurs maxillaires garnis de dents admirablement disposées pour couper et broyer; ces dents s'usaient comme celles des mammifères herbivores acluels, et se remplaçaient indéfiniment, c'està-dire qu'aussitôt que l'une d'elles était usée, une autre lui succédait; il existait, ce qu'on ne voit pas chez les reptiles actuels, des mouvements de la mâchoire, comme chez les ruminants de notre époque pour permettre aux dents de broyer les aliments; la grundeur des trous et des canaux par lesquels passaient les nerfs montre que ces animaux avaient des lèvres molles et des joues sans lesquelles la mastication des aliments eut été complètement impossible. Les hadrosaures, qui sont des herbivores, avaient les dents disposees en plusieurs rangées formant, par l'usure, une surface hroyante en forme de damier. Chez les herbivores qui ont été groupés sous le nom d'ornithopodes, les intermaxillaires ne portaient pas de dénts; il en est de mème de l'extrémité de la mâchoire 
inférieure qui était vraisemblablement revêtue d'un bec corné à l'aide duquel l'animal coupait les bourgeons et les feuilles dont il faisait sa nourriture.

Les temps secondaires, pendant lesquels vivaient ces singuliers et gigantesques dinosauriens nous présentent vraiment le règne des reptiles. C'est alors que ce groupe arrive à son rnaximum de développement. Les mammifères sont très chétifs à cette époque et représentés seulement par les plus inférieurs d'entre eux; les dinosauriens semblent avoir joué alors à la surface du globe le rôle que les grands carnassiers et les grands herbivores y jouent actuellement; mais tandis que les mammifères ont toujours été en se développant, de telle sorte qu'ils offraient déjà ver's la fin des temps tertiaires, le magnifique épanouissement que nous voyons aujourd'hui, les reptiles ont été sans cesse en diminuant d'importance; les animaux supérieurs l'ont peu à peu emporté sur les êtres d'une organisation moins parfaite. A la fin de l'ère secondaire les dinosauriens disparaissent à tout jamais et sans laisser de descendance; ils n'ont pu se plier aux nouvelles conditions d'existence qui leır étaient imposées et ils sont morts, alors que les mammifères avançaient, au contraire, chaque jour davantage vers les types les plus élevés ( $\left.{ }^{(}\right)$.

Pendant l'époque du jurassique supérieur, nos contrées devaient être découpées de lagunes, de marécages, d'estuaires fréquemment inondés; ces localités privilégiées avaient une végètation plus riche et plus variée que les parties montucuses; là poussaient de grandes fougères, aux frondes coriaces, tandis que les pentes et les hauteurs étaient recouvertes de plantes se rapprochant des pandanées, d'araucaria, de cycadées aux semences en formes d'amandes, nourriture des dinosauriens herbivores de l'époque. Il en était de même au commencement de la période crétacée, alors que se formaient les terrains wealdiens.

On a vu plus haut que les dinosauriens ont disparu vers le milieu des temps crétacés; cette disparition a eu pour cause les changements considérables qui se sont, à cette époquc, opérés dans la température. " Jusqu'à présent, écrit Contejean, la distribution, à la surface du globe, des animaux et des plantes, et, en même temps,

1. E. SAuvage. Les Reptiles, édition française de l'ouvrage de Bremrr. 
la nature des genres et des familles qui composent les faunes et les flores, indiquent, à toutes les époques précédentes, une température uniforme et élevée, non excessive à l'équateur, et au moins tropicale jusque sous le $76^{\circ}$ degré de latitude nord. En un mot, sur tout le globe régnait le climat de la zone torride actuelle. Durant cette longue suite de siècles, il ne semble pas que la chaleur ait subi les moindres fluctuations; tout au plus a-t-on essayé d'indiquer, d'après l'aspect des sédiments, les périodes de sẻcheresse et d'humidité relatives. Vers le milieu de l'époque crétacée, les choses pren-

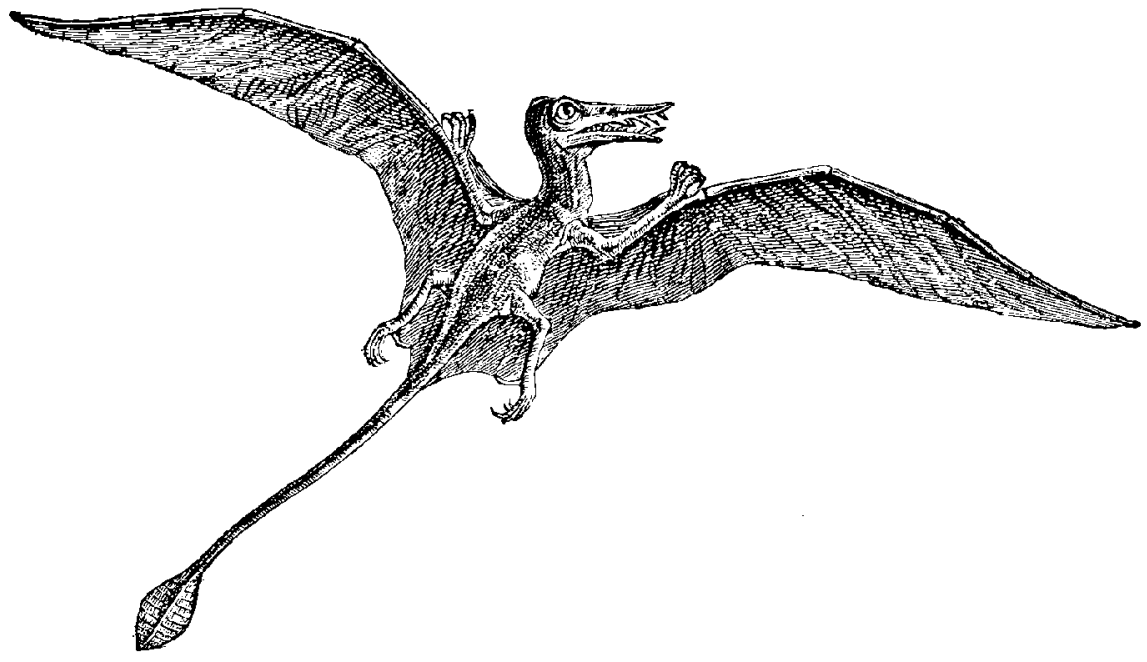

Fig. 301. - Le Khamphorynque.

dront une autre tournure, et l'on commencera à apercevoir les premiers indices d'un refroidissement dans le nord des continents. Ces indices sont l'absence de récifs 'et la lareté des coraux sur l'emplacernent de I'Europe, l'absence et la rareté des rudistes au nord du $45^{\mathrm{e}}$ degré de latitude; enfin l'apparition, dans les mèmes paracres, des familles végétales (amentacées, acérinées, et quelques autres), qui ne pénètrent qu'exceptionnellement dans les régions tropicales. »

Cette opulente époque jurassique est bien propre à nous faire apprécier l'étendue de la fécondité de la nature, car la Terre de cette époque était étrangement différente de celle de nos jours. Il est utile parfois d'envisager le cosmos au point de vue vivant et d'appliquer 
les enseignements de la nature terrestre à notre conception générale de l'Univers. Ceux qui nient l'existence de la vie à la surface des autres mondes, pourraient s'instruire et agrandir leurs idées sans sortir de notre patrie.

Ainsi, par exemple, examinons (fig. 303) (") un paysage d'araucariées et de cycidées, au milieu duquel circulent le gigantesque stégosaure au corps revêtu de plaques osseuses et d'épines lui formant une puissante armure, aux membres antérieurs singuliè-

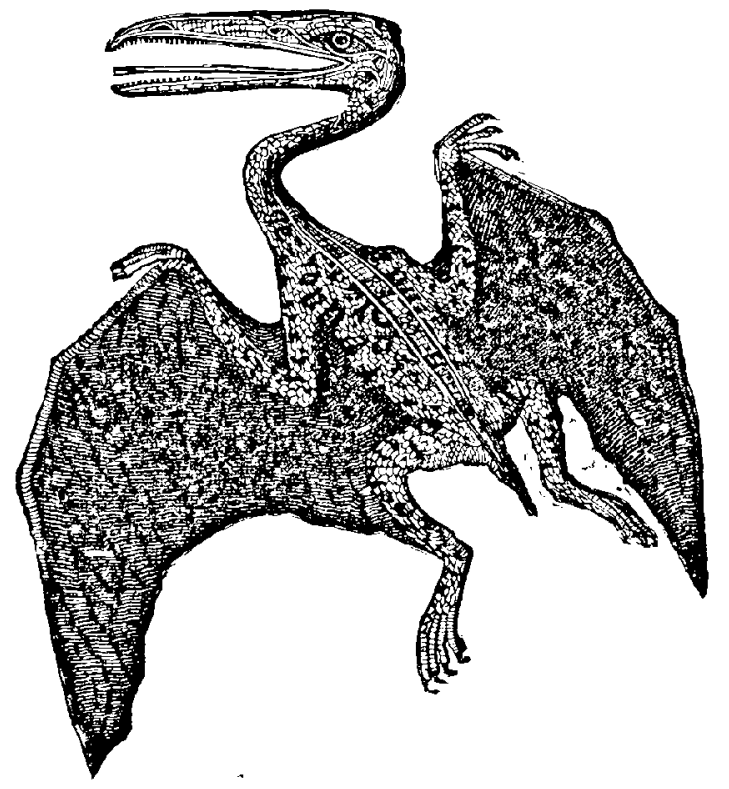

Fig. 302. - Le Ptérodactyle.

rement courts, - le compsonote, autre dinosaurien non moins grotesque, - et les étranges reptiles volants, les ptérodactyles.

N'est-ce pas là un monde tout diffẻrent du nòtre? Qui l'eût osé inventer si l'on n'en avait découvert les fossiles? Ces hahitants de l'époque secondaire ont tous disparu avec la fin des temps crétacés. Sur le globe entier régnait alors le climat de la zone torride actuelle; on a retrouvé jusqu'aux plus hautes latitudes les mêmes plantes et les mèmes animaux. C'est l'âge des reptiles, et quels reptiles! Le brontosaure atteignait, nous l'avons vu, une taille de

1. D'après Bremu, Reptiles, édition française de E. Sauvage. 
seize mètres et devait peser trente mille kilogrammes! L'atlantosaure était plus gigantesque encore. Le cétiosaure d'Europe ne le cédait guère en puissance à ses émules de l'Amérique : on en juge facilement quand on sait que l'os de la cuisse atteint jusqu'à $1^{\text {m }} 70$ de haut, et que ce que l'on connait de la tête et de la colonne vertébrale a douze mètres, ce qui donne un animal d'environ seize à dix-sept mètres. Les iguanodons atteignaient dix mètres; le plus grand porte une tête de $1^{\mathrm{m}} 20$ et ses pattes de devant surpassent $2^{\mathrm{m}} 50$ de hauteur. "Que l'on se représente de tels animaux, écrit M. Zaborowski, reposant sur leur train do derrière. Leur tête devait atteindre la cime des arbres. Quel aspect terrifiant aurait leur masse prodigieuse se mouvant dans le monde rabougri, étriqué, de nos climats! A peine dépasserions-nous leur cheville. »

Sans parler même de tout l'ancien monde des ichthyosaures, des plésiosaures, des labyrinthodontes, des paléothériums et de leurs émules de la faune antique, la période des dinosauriens suffit pour nous témoigner de la variété et de la diversité des productions de la force vitale, même sur notre seule et médiocre petite planète. La nature répond elle-mème à ceux qui mettent en doute sa fécondité, et nous n'avons rien à ajouter à ses propres paroles.

Ni les bètes imaginaires inventées par les mythologies de tous les peuples, ni les chimères srimaçantes sculptées par les artistes du moyen âge dans les gargouilles des cathédrales, ni les fantômes créés par la peur dans les siècles les plus sormbres oú la pensée humaine semblait sommeiller et rèver, ne pourraient rivaliser avec les enfantements fantastiques de la nature terrestre pendant tous ces essais informes à l'origine des quadrupèdes et des mammifères. Il semble que la nature ait tout essayé en des proportions colossales avant de se décider pour les formes qui devaient un jour aboutir à l'humanité.

Pendant que les mers étaient sillonnées par de gigantesques reptiles, ichthyosaures, plésiosaures, pliosaures, nothosaures, dont rien dans la nature actuelle ne peut donner la moindre idée, dirons-nous avec M. Sauvage, pendant que sur la terre ferme régnaient en maîtres les dinosauriens, les plus curieux peut-être de tous les animaux que nous aient légués les anciens âgros, les airs étaient peuplés d'êtres non moins étranges, ni oiseaux, ni reptiles, pré- 
sentant ce curieux caractère d'ètre à la fois des oiseaux dépourvus de plumes et armés de dents, et des reptiles à sang chaud, ne pouvant ni nager ni marcher. "Ce sont bien là les dragons de la fable, et l'imagination la plus déréglée ne peut enfanter, dans ses plus grands écarts, une collection de monstres qui n'aient vécu à l'époque jurassique $n$ (').

« Ce n'ètait pas seulement par la grandeur que la classe des reptiles annonçait sa prééminence dans les anciens temps; c'était encore par des formes variées et plus singulières que celles qu'elle revêt de nos jours. En voici qui volaient non pas par le moyen de leur côtes comme les dragons, ni par une aile sans doigts distincts comme celle des oiseaux, ni par une aile où le pouce seul aurait été libre, comme celle des chauves-souris, mais par une aile soutenue principalement sur un doigt très prolongé, tandis que les autres avaient conservé leur brièveté ordinaire et leurs ongles. En même temps, ces reptiles volants, dénomination presque contradictoire, ont un long cou, un bec d'oiseau, tout ce qui devait leur donner un aspect hétéroclite $\gg\left({ }^{2}\right)$.

Ces animaux étranges sont les ptérodactyles. Leurs mâchoires, qui sont courtes et robustes, sont garnies de dents à leur extrémité antérieure, tandis que la màchoire se prolonge en une sorte de bec, probablement revêtu de corne, et dépourvu de dents chez les rhamphorhynques et chez les dimorphodons. Par leur disposition, leur mode d'implantation; ces dents rappellent bien mieux ce que l'on voit chez les singuliers oiseaux à dents des terrains crétacós des États-Unis, tels que l'hesperornis, qu'à ce qui existe chez les reptiles proprement dits $\left.{ }^{3}\right)$.

Les ptérodactyliens étaient des animaux au vol puissant et rapide; aussi chez eux le membre antérieur est-il complètement modifié et disposé en vue de cette fonction.

1. Contejsan. Éléments de géologie et de paléontologie.

2. G. Cuvier. Recherches sur les ossements fossiles.

3. Une découverte des plus intéressantes faile dans les grès verts de Cambridge, en Anglelerre, grès verts qui apparliennent à la partie supérieure des terrains crélacés inférieur's, a été celle du moulage naturel de la cavité erânienne d'un ptérodactyle. Cette pièce si intéressante a été éludiée par Seeley, et lui a montré que le cerveau ressemblait à celui des oiseaux, du hibou, en partieulier; les hémisphères cérébraux ont le même développement; le cervelet et les nerfs optiques sont ceux de l'oiseau plutat que ceux du reptile. 
Chez les oiseaux, qui sont les animaux aériens par excellence, les ailes sont formées de plumes raides fixées par leur base à une sorte de moignon aplati et presque inmobile; les deux os de l'avant-bras ne peuvent tourner l'un sur l'autre, et le poignet ou carpe ne se compose que de deux petits os placés sur un même rang; la main n'est constituée que par un pouce rudimentaire, un petit stylet représentant le doigt externe, et un doigt médian composé de deux phalanges. L'organe du vol est tout autre chez les mammifères aériens, tels que les chauves-souris. Chez ces dernières c'est un repli de la peau qui sert à frapper l'air, et pour le soutenir les doigts prennent une longueur extrême.

Comme plusieurs autres animaux de cette époque, le ptérodactyle présente un mélange de caractères bien différents. Le cou, formé de sept vertèbres ccrvicales, dénote un mammilëre; les membranes qui servent au vol et s'étendent entre les pieds de devant et ceux de derrière, appartiennent à une famille déterminée de mammifères, celle des vespertiliens, tandis que, d'après la structure du pied, on doit ranger le ptérodactyle parmi les reptiles, les mammifẻres ayant à tous les doigts le même nombre de phalanges; les reptiles, au contraire, et notamment les sauriens, ont le plus petit nombre de phalanges au doigt qui occupe la place du ponce, et une phalange de plus à chaque doigt suivant, jusqu'au dernier, qui en a une de moins que le précédent.

Le ptérodactyle, ayant exactement cette conformation des doigts, est donc classé avec les sauriens; c'était une sorte de lézard volant, de grandeur modérée, ct insectivore, à en juger par la quantité d'insectes que l'on découvre à proximité de ses débris, entre autres des libellules d'une très belle espèce et qui formaient probablement sa principale nourriture.

On a constaté que le ptérodactyle était dépourvu d'armure défensive et mème de poils, les empreintes qu'il a laissées n'en portant aucune trace. Notre figure 304 fera juger de sa dimension, relativement à celle de la chauve-souris.

Dans ces schistes lithographiques de la Bavière qui nous ont fourni tant d'animaux intéressants, tant de spécimens remarquables par leur admirable état de conservation, on a trouvé, en 1873, un rhamphorynque sur lequel l'aile est intacte. Cet échan- 
tillon, qui a été étudié par le professeur Marsh, montre que l'aile était une membrane sembiable à celle des chanves-souris, lisse et finement réticulée. La membrane s'attachait, en dedans, dans toute l'étendue du bras; le cinquième doigt, très allongé, la soutenait

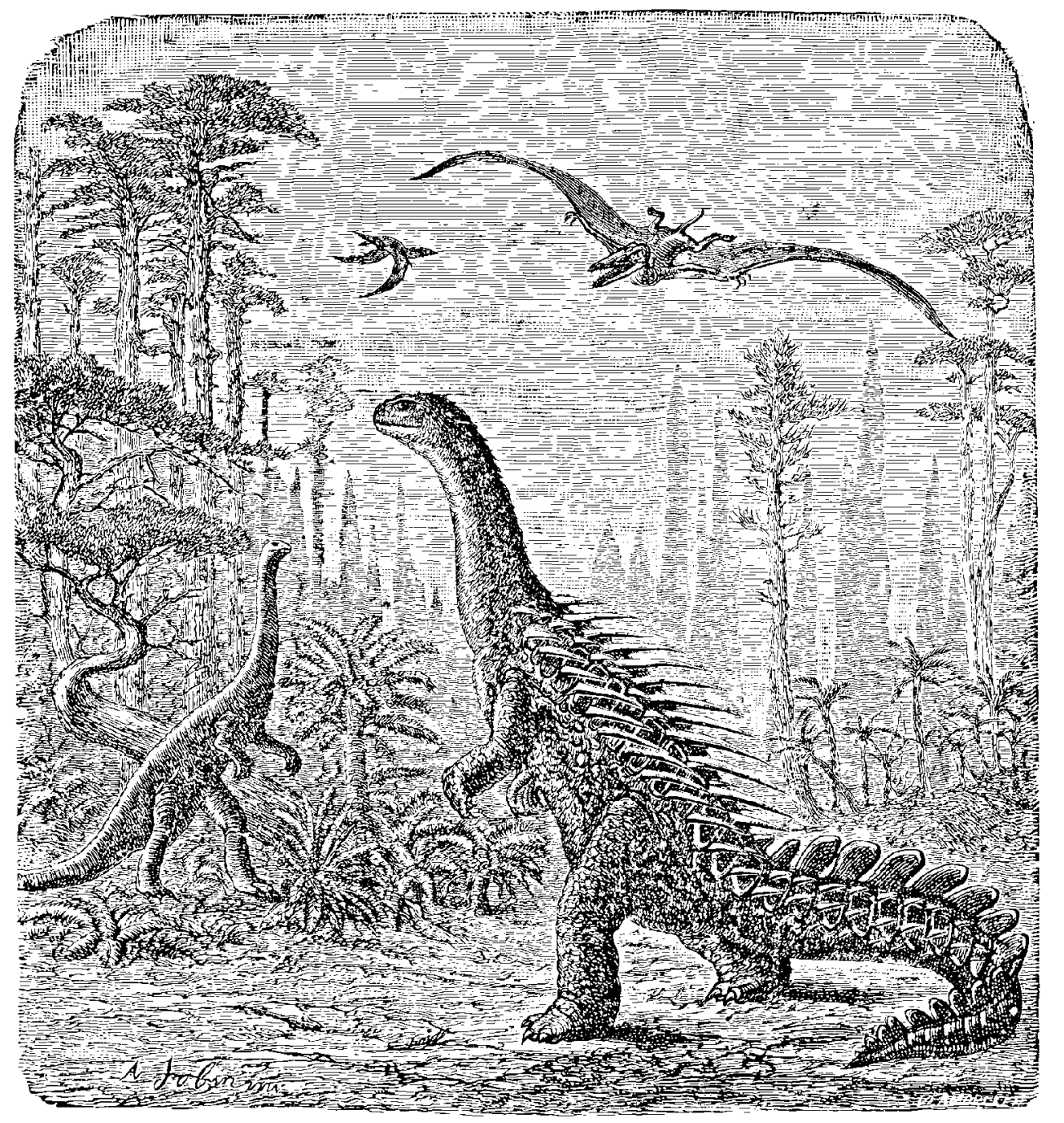

Fig. 303. - Les dinosauriens ; Stégosaure et Compsonate, dans un paysage d'araucariées.

jusqu'à la base de la queue. Celle-ci était très longue, et les vertèbres en étaient retenues par des tendons ossifiés; le singulier appareil que l'on voit à l'extrémité de la queue du rhamphorhynque remplissait évidemment le rôle de gouvernail et servait à prendre le vent. 
Les caractères que nous venons d'indiquer sont tellement particuliers, qu'il n'est pas surprenant que les ptérodactyliens - qui ont été désignés aussi sous le nom de ptérosauriens et d'ornithoscélidiens - aient été considérés tantôt comme des oiseaux, tantôt comme des reptiles, tantôt comme des animaux intermédiaires entre ces deux dernières classes. L'analyse des fossiles a singulièrement modifié la notion classique que nous avons recue des divers groupes d'animaux; nous connaissons des oiseaux ayant des dents comme les mammifères et des mammifères ayant un bec comme les oiseaux; certains êtres sont si étranges qu'ils ont pu être alternativement regardés, par les anatomistes les plus compétents, comme des reptiles ayant des plumes ou comme des oiseaux ressemblant à des reptiles par une grande partie do leur squelette. C'est que les groupements en classes, en ordres, en fámilles telles que nous les admettons dans nos classifications, n'existent pas en réalité dans la nature; il y a un enchainnement continu, sinon réel, du moins virtuel des êtres, les uns par rapport aux autres; chatnons d'une mome chaine, ils se relient entre eux. Si les dinosauriens représentent, on quelque sorte, la transition entre les reptiles, les oiseaux et les mammifères, les ptérodactyliens relient intimernent les reptiles aux oiseaux et se placent plus près de ceux-ci que des reptiles proprement dits. - De même que les dinosauriens, les ptérosauriens n'ont encore été trouvés que dans les formations secondaires, aussi bien en Europe que dans l'Amérique du Nord. Eux aussi, comprement des lypes très divers (').

Les ptérodactyles jurassiques de nos contrées avaient la taille de moineaux, de grives et de pigeons. Mais aux Etats-Unis, Marsh a trouvé dans les terrains crétacés du Kansas, des ossements qu'il rapporte au genre ptéranodon et qui ont appartenu à des animaux dont les ailes devaient avoir six à sept mètres d'envergure! Ces bêtes monstrueuses devaient être bien communes anx Etats-Unis, pendant l'époque crétacée, car le naturaliste américain assure qu'il existe dans les collections de Yale-College à New-Haven, dans le Connecticut, des ossements de près de six cents ptéranndons gigantesques.

Cette population étrange des temps secondaires a commencé,

1. Breum et E. Sauvage. Les Reptiles. 
comme nous l'avons vu, avec les labyrinthodontes. Aux formes singulières, il faudrait ajouter les cris sauvages de tous ces reptiles. Quels devaient ètre les beuglements et les hurlements de ces dinosauriens!.Quel devait être le coassement du labyrinthodon, cette grenouille gigantesque, au bord des lacs saumâtres? Un bœuf se mettant à coasser!

Tous ensemble allèrent porter le ravage dans le monde paisible des mollusques. Ils en broient les coquilles nacrées et se repaissent de poissons et de reptiles. Nul être ne pent résister à leurs mâchoires de carnivores; ils deviennent les souverains du monde.

Quelle faune bizarre et fantastique! La sculpture et la peinture, chez los anciens et les modernes, ont agrandi le monde réel en inventant des êtres qui n'ont jamais pu exister. Pense-t-on que les sphynx des Égyptiens, accroupis sur le sable, les centaures, les faunes, les satyres des Grecs, les griffons moitiẻ hindous, moitié perses, les goules du moyen-âge, les anges-serpents de Raphaël, ne pussent trouver d'analogues dans les ètres vivants qui ont peuplé la terre en ces temps antiques. Il semble, au contraire dirons-nous avec Edgard Quinet, que les reptiles dinosauriens, les iguanodons, les plésiosaures, pourraient rivaliser avec les dragons à la gueule enflammée de Médée, les serpents volants avec les serpents de Laocon, les plus anciens ruminants et les grands édentés, mylodon, mégathérium, avec les taureaux couronnés de Babel, les mammifères incertains, les mystérieux dromathériums et dinothériums avec les sphynx gigantesques de Thebes, les ichthyosaures avec les hydres d'Hercule et les harpies d'Homère, les cheval hipparion aux pieds digités avec les chevaux de Neptune ou avec le monstre de Rubens à la crinière soulevée, à la croupe colossale. On aimerait à voir et entendre l'ancêtre des chiens, l'amphicyon, hurler au carrefour de la création des mammifères tertiaires. Si les artistes grecs et modernes étaient réduits à imaginer des alliances de formes impossibles, l'artiste n'aurait, an contraire, qu'à puiser dans le monde organisé; il aurait l'avantage de trouver sous la main des formes toutes préparées dans l'atelier de la nature; il pourrait ainsi être réaliste tout en dépassant les limites du monde actuel, ce qui semble le but suprème de l'art.

Tout être a son cadre naturel. De mème que, de nos jours, il 
est difficile de se représenter le chameau sans l'associer au désert, il est également difficile de ne pas associer les crocrodiliens de l'âge jurassiqne à la forme de la terre jurassique dont ils étaient les seuls habitants. Ils s'aventurèrent sur la plage. Mais quelle terre trouvèrent-ils devant eux? Basse, marécageuse, étroite, la petite île liasique ne sollicitait d'aucun être un effort puissant pour en prondre possession. Quand le troupeau des sauriens s'était trainé sur la vase, aucune proie ne l'atlirait, il s'arrètait. Une patte informe, courte, palmée, l'arrière-bras serré au corps, suffisait pour occuper et visiter le banc de terre informe, étroit, qui, tour à tour noyć et submergé, offrait un séjour amphibie à une vie amphibie. Et comme, sur cette vase desséchée, oú chacun se trainait lentement, il n'y avait pas de péril à éviter, il n'y avait aussi ni nécessité ni de désir de fuir et de se hâter. G'est dans ce sens que l'on peut dire que cette antique figure du globe impose sa forme et ses habitants.

Cette forme fut celle des reptiles. Là où le sol manquait, le mode de progression terrestre ne pouvait se développer. Il n'était besoin ni de marcher, ni de courir, ni de voler; il suffisait de ramper. Avec les sauriens, se hasardaient les tortues; comme il s'agissait pour elles de se poser à terre, et que cette terre n'ètait qu'un point, elles n'eurent pas besoin de se hâter; sur cette terre rampante, elles n'eurent qu'á ramper pour conquérir leur domaine; elles recurent là comme un sceau d'immobilité.

Sur cette langue de terre, si la patte, le pied ne pouvaient se développer par le mouvement et la rapidité, comment l'aile auraitelle pu acquérir sa puissance? La nécessité de l'aile ne se comprend que lorsque de grands espaces terrestres s'ouvrent à l'horizon, qu'il faut les traverser pour atteindre une proie visible de loin, ou pour changer de climats par les migrations vers une autre contrée.

Mais sur les plages perdues des temps jurassiques, quel ètre avait besoin de prendre l'essor pour parcourir un si étroit domaine? Aussi les oiseaux manquent encore. Lorsqu'un premier vostige d'aile parait, c'est l'aile d'un reptile, le ptérodactile, avec la gueule dentée d'un saurien, et deux ailes membraneuses. C'est assez pour lui car il ne s'agit pas de traverser de vastes océans pour aborder 
des continents qui n'existent pas encore; il ne s'agit pas de plonger

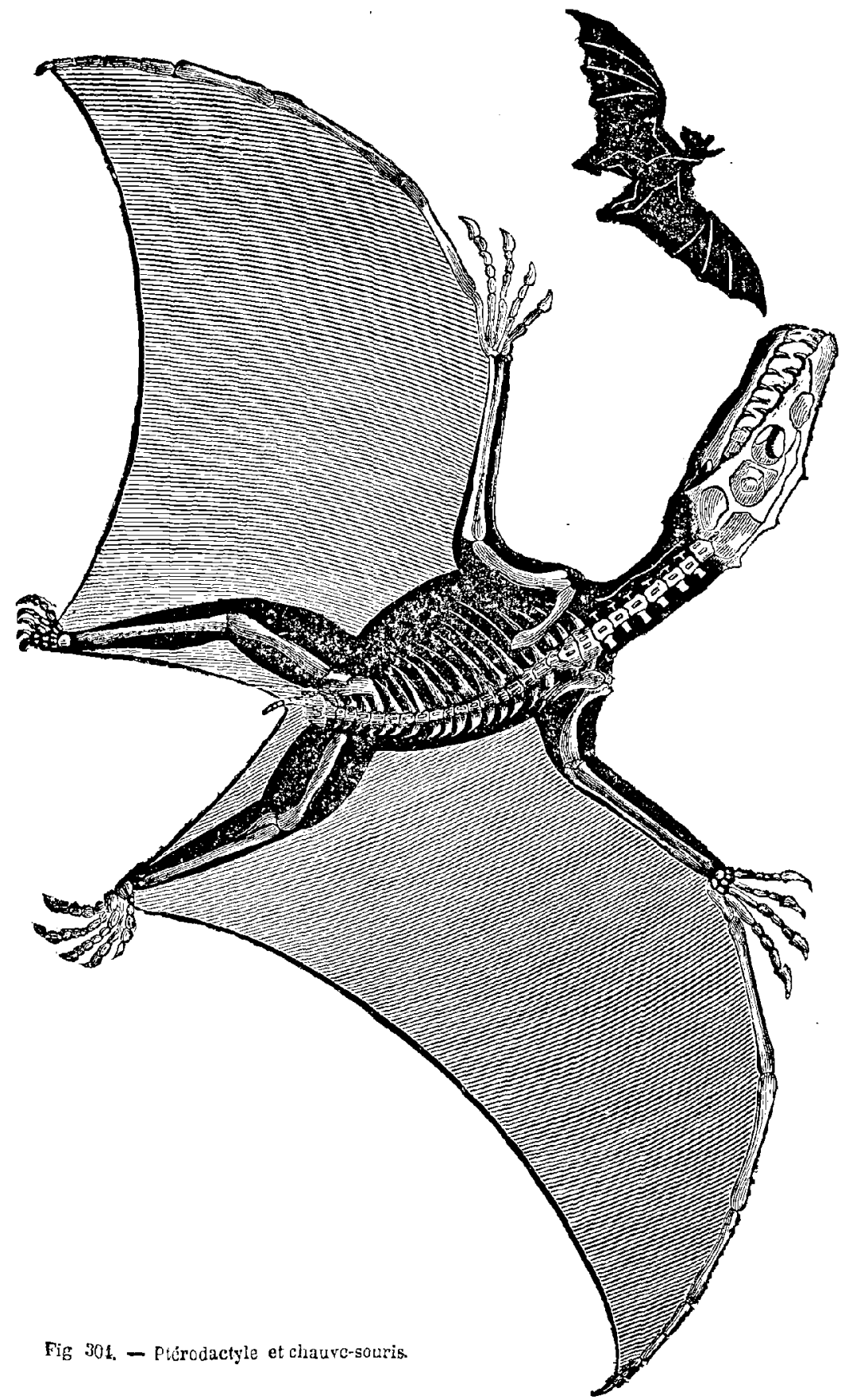

en un clin d'œil du haut d'un roc inaccessible dans une vallée 
béante. Il n'y a encore ni montagnes, ni vallées, mais un sol uni, rare, rampant, échancré, oủ tous les objets sont rapprochés. Que le reptile, caché dans le marécage puisse happer au vol un essaim de libellules où quelque grand scarabée, cela suffit à son premier instinct de mouvement.

Le temps du vol véritable n'est pas encore venu; l'aile ne se déploiera, dans sa grande envergure, qu'avec le déploiement et l'envergure des terres fermes, avec le soulèvement des montagnes, l'approfondissement des vallées, le changement des climats, des températures, l'émersion des archipels et des continents qui offriront des lieux de repos pour les vastes traversées et un but aux migrations lointaines.

Ainsi les âges du monde ne s'écoulent pas sans laisser une figure vivante d'eux-mèmes. Ils s'impriment d'une manic̀re ineffacable dans les créatures qui se succèdent. Ils revivent en elles. Chaque moment de la durée s'est pour ainsi dire fixé dans un type, dans une espèce, une famille, qui le représente. Si le désert disparaissait, il serait encore figuré dans le chameau. A ce point de vue, la série des êtres organisés reproduit, de nos jours, la série des grandes époques écoulées. Chaque végétal, chaque animal, ramené à son type, est comme une date fixe dans la succession des événements qui forment l'histoire du globe ( $\left.{ }^{4}\right)$.

Pourtant cette merveilleuse époque jurassique, la plus considérable et la plus féconde de toute l'histoire terrestre, n'a pas seulement vu apparaitre cette population formidable et fantastique des dinosauriens et des reptiles ailés; il appartenait à ses destinées de färe un pas de plus encore dans la marche de la création, d'aller plus loin dans le progrès que toutes ces manifestations de la force; elle a eu le privilège de donner naissance à l'oiscau, - non pas, sans doute, i l'hirondelle ou au rossignol, mais à l'oiseau rudimentaire: à l'oiseau primitif.

Ce fut une belle découverte, que celle de la première plume d'oiseau-fossile. Elle date de 1860 et a été faite dans les terrains jurassiques supéricurs de la Bavière, dans la pierre lithographique de Solenhofen/ Les géologues doutaient de l'authenticité de cette

\section{Edgard Quinet. La Création.}


plume, quand l'année suivante on trouva, dans ce même calcaire, et tout près de l'endroit où la plume avait été recueillie, une partie du corps de l'oiseau primitif, qui reçut le nom d'archéoptéryx ( $\left.{ }^{(}\right)$. Plusieurs années s'écoulèrent avant qu'il füt possible d'obtenir des notions plus complètes. Owen, en 1863, donna une première description; Evans, en 1865, fit paraitre une notice nouvelle. En 1877, un nouveau spécimen, beaucoup plus beau et plus complet, fut trouvé à quatorze kilomètres du point où lo premier avait été découvert. Le premier spécimen a été acheté par le Muséum de Londres, le second par celui de Berlin. L'examen de celui-ci a montré que le crâne a déjà la forme caractéristique de celui de l'oiseau, mais qu'il est muni de mâchoires garnies de dents logées

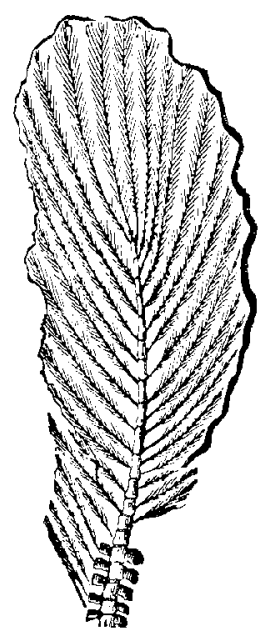

Fig. 30:. dans des alvéoles. La grosseur de cet'oiseau primitif est celle d'un pigeon.

La queue est particulièrement remarquable. Elle est très longue, formée par vingt vertèbres portant chacune une plume de chaque côté. C'est, par ses vertèbres, une queue de roptile plutôt qu'une queue d'oiseau. Du reste, par son organisation, l'archéoptéryx vient précisément se placer dans la lacune qui séparait les reptiles des oiscaux. On savait depuis longtemps déjà que les oiseaux sont des reptiles transformés; mais on n'avait pas encore eu do fessiles contemporains de cette transformation. L'archéoptéryx est, à tous les points de vue, l'une Queue de larchéoptéryx. des découvertes les plus importantes qui aient été faites en paléontologie.

Et pourtant ce reptile-oiseau n'était encore quo le prélude des découvertes récemment faites aux États-Unis sur les premiers oiseaux fossiles, découvertes si considérables que l'ouvrage dans lequel sont consignées les principales, et qui n'est en quelque sorte que le catalogue anatomique des pièces examinćes, formo un énorme volume in-folio $\left({ }^{2}\right)$ contenant plusieurs centaines de figures

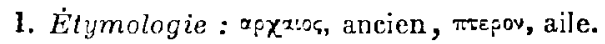

2. O.-C. MAksH. Odontornithes, a monograph of the extinct toothed birds of north America. Washington, 1880. 
de paléontologie. Dans cet immense travail du professeur Marsh, beaucoup trop spécial et trop technique pour que nous entreprenions même de le résumer ici, nous choisirons comme types intéressants des spécimens que l'on trouvera au chapitre suivant, en visitant la période crétacée, dans laquelle ils ont acquis tout leur

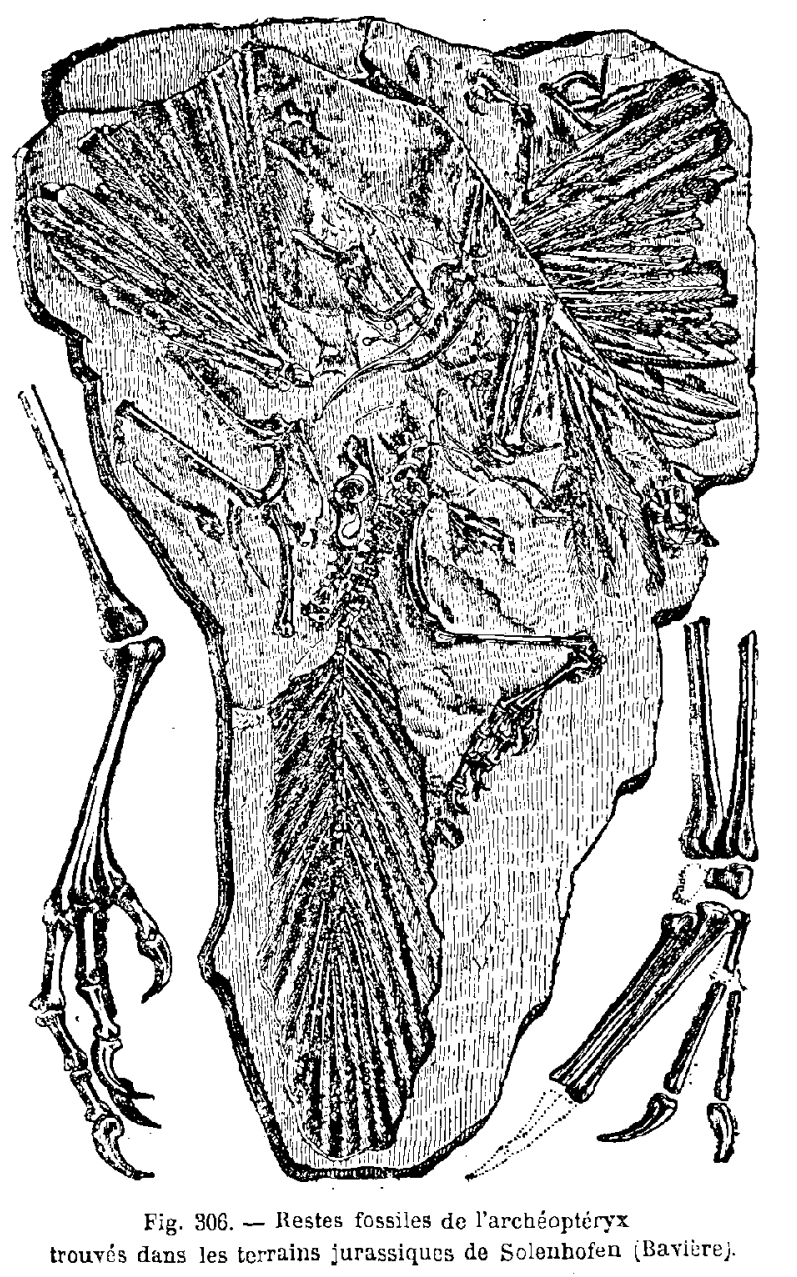

développement. Tous ces oiseaux $\dot{a}$ dents, (plus d'un millier) ont été découverts en compagnie de ptérodactyles do vingt-cinq pieds d'envergure, de mosasaures, de sauropodes et de stégosaures gigantesques.

D'après M. Marsh, on rencontre dans le jurassique de l'Amérique de très petits dinosauriens dont les os séparés du squelette ne peuvent 
pas ètre distigués de ceux des oiseaux des mêmes couches quand le crâne manque. Quelques-uns d'entro eux vivaient sur les arbres et ne différaient des oiseaux que par l'absence de plumes. Comment la naissance de celles-ci a-t-elle été provoquèe? « Nous en avons une indication, dit M. Marsh, dans le vol du galéopithèque, des écureuils volants, des lézards volants et des grenouilles volantes.

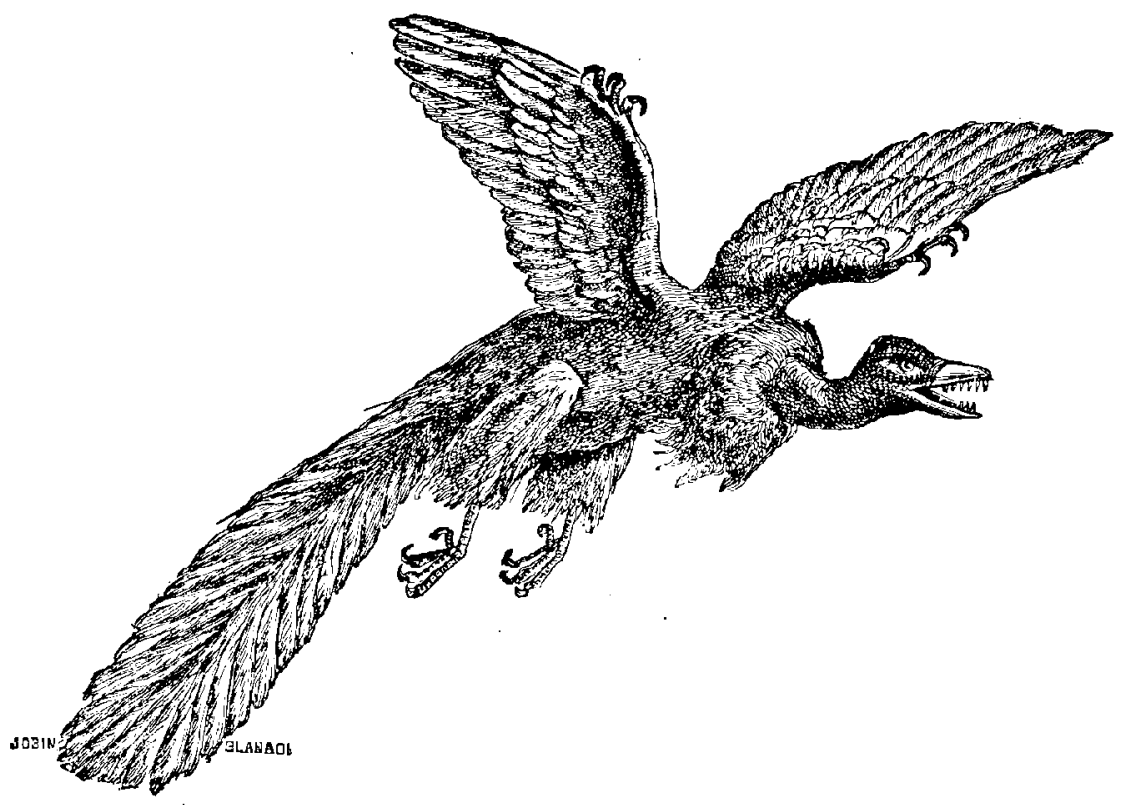

Fig. 307. - L'Archéoptéryx (plus ancien oiseau fossile découvert).

Dans les oiseaux primitifs, vivant sur les arbres, et qui sautaient de branche en branche, des plumes, mème rudimentaires, sur les membres antérieurs, auraient été un avantage, car elles auraient tendu à allonger un saut vers le bas ou à amortir la force d'une chute. Comme les plumes croissaient, le corps serait devenu plus chaud et le sang plus actif. Avec un nombre de plumes plus grand encore se serait accru le pouvoir du vol, etc. L'augmentation d'activité aurait eu pour résultat une circulation plus parfaite, etc. ”

Le Ramphorynchus peut sans doute donner une assez bonne idée de ces petits dinosauriens volants.

L'embryogénie, d'ailleurs, a démontré depuis longtemps l'homologie existant entre les écailles, crêtes, piquants, etc., des reptiles, et les moignons, en forme de verrues, qui apparaissent, chez 
l'embryon des oiseaux, comme premiers vestiges dú plumage. Ce n'est pas une hérésie scientifique d'admettre qu'il y ait eu des reptiles revêtus de plumes; et tel était peut-ètre le cas du compsognathe et de l'archéoptéryx. D'après l'étude faite par M. Vogt sur le second exemplaire mis au jour, ce premier des oiseaux avait sans doute le corps nu, car il ne portait, outre les plumes des ailes, que des culottes comme nos faucons actuels et une collerette semblable à celle des condors. Bien plus, l'aile elle-mème n'était chez lui guère autre chose que le résultat de cet emplumement particl. Voici ce que dit ce naturaliste de l'exemplaire qu'il a étudié :

Il possède, à chaque main, trois doigts, longs, efflés, armés d'ongles crochus et tranchant. Le doigt radial ou pouce est le plus court; les deux autres sont presque d'égale longueur; le second est cependant celui qui l'emporte. Ces deux doigts étaient évidemment réunis ensemble par des aponévroses tendineuses et serrées. Le pouce est composé d'un métacarpicn et de deux phalangos, et los autres doigts d'un métacarpicn et de trois phalanges.

Les rémiges étaient fixées au bord cubital de l'avant-bras et de la main, sans qu'on puisse remarquer, dans le squelette, une adaptation particulière dans ce but. Le pouce était libre, comme les dcux autres doigts, et ne portait point d'aileron. Qu'on enlève un moment, par la pensée, toutes les plumes, et on aura devant les yeux une main tridactyle de reptile, telle que le compsognathe et beaucoup d'autres dinosauriens paraissent l'avoir eue, à en juger par la trace de leurs pas. Je soutiens qu'aucun savant auquel on montrerait le squelette de l'archéoptérix seul et sans plumes ne pourrait soupçonner que cet être ait été muni d'ailes pendant sa vie.

Nous suivrons plus loin l'évolution des oiseaux en étudiant les phases de l'époque tertiaire.

Le monde des inscetes, dont nous avons salué l'apparition dès les jours déjà lointains de l'époque carbonifẻre (V. plus haut, p. 389), va en se multipliant rapidement pendant la période jurassique, et surtout en se développant vers les espèces plus parfaites. Ici encore la grande loi du progrès se manifeste comme dans tout l'ensemble du règne animal. Nous avons vu (p. 456) que les insectes primaires ont appartenu aux espèces inférieures, orthoptères, névroptères et hémiptères (blattes, grillons, sauterelles, termites, libellules) et qu'on n'a pas encore trouvé dans ces terrains anciens de 
débris d'insectes appartenant aux ordres plus élevés des hyménoptères, des diptères ou des lépidoptères, abeilles, fourmis ou papillons. Dans les sédiments les plus anciens de la période jurassique, dans le trias, Oswald Heer a mis au jour, en Suisse seulement, deux mille échantillons représentant 143 espèces, qui se partagent ainsi :

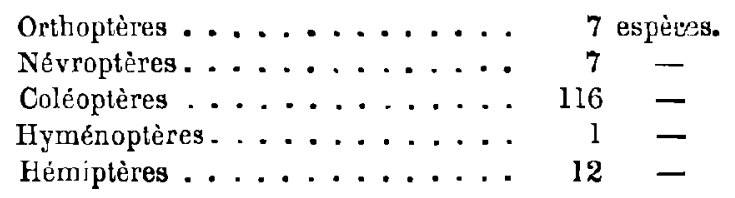

On voit que les coléoptères forment la grande majorité. Ces insectes fournissent la moitié des espèces fossiles, et nous démontrent par leur existence même que la terre ferme était occupée par des forêts. La famille de beaucoup la plus nombreuse est celle des buprestes; elle offre en même temps les plus grandes formes.

Nos lecteurs pourront remarquer ici $(f g .308$ et 309) une aile de scarabée et une de libellule fossiles, recueillies dans les terrains oolithiques de Stonesfield, près Oxford.

La richesse de la faune entomologique est une prenve que la terre ferme avait à cette époque une vaste étendue, et qu'ici nous n'avons plus seulement sous les yeux les petites îles de la mer liasique. L'existence des insectes aquatiques (libellules, coléoptères, etc.), qui étaient si nombreux, révèle la présence de fleuves ou de bassins d'eau douce. Nous savons que toutes les petites îles de l'Océan ne donnent asile qu'à fort peu d'animaux aquatiques : ainsi les îles Canaries, Madère, les Açores, n'en possèdent qu'un petit nombre. La raison en est simple : les ruisseaux sont trop petits et presque complètement desséchés à certaines époques de l'année, ce qui nuit aux conditions d'existence des animaux d'eau douce. Il faut fu'une île ait une certaine étendue pour que les ruisseaux n'y tarissent pas. Tout en admettant qu'à l'époque jurassique il tombait probablement beaucoup plus de pluie que de nos jours, et que cette pluie se répartissait plus uniformément pendant l'année que dans les îles que nous venons de nommer, la quantité des insectes d'eau douce que nous retrouvons nous porte à croire que ces îles étaient fort grandes.

En Angleterre, ainsi que chez nous, pendant l'époque jurassique, Je petites cicadelles sautillaient dans les broussailles, les libellules 
se balançaient dans les airs, tandis que les blattes et les termites cherchaient leur nourriture dans les forèts, que les punaises des hois donnaient la chasse à d'autres petits animaux, et que de joyeux essaims de gyrines s'ébattaient à la surface de l'eau.

Là aussi pullulaient les sauterelles aux bruits stridents et pe: harmonieux. G'était déjà là pourtant la cigale d'été chantée pa: Homère.

On peut croire, par analogie avec d'autres classes d'animaux, que les insectes primitifs devaient avoir une taille remarquable ot des formes plus ou moins différentes des formes actuelles. Nous avons vu, en effet, dès l'époque carbonifère ( $p .{ }^{4} 5 \bar{\tau}$ ), la grrandeur

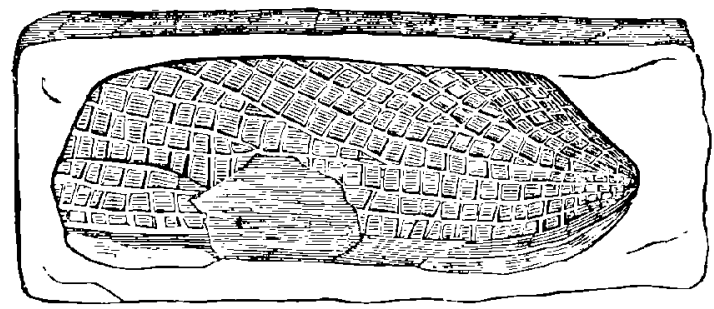

Fig. 308. - Llytre de scarabée conservée dans les terrains oolithiques.

géante du titanophasma. Mais dès les temps jurdssiques les.insectes offrent les mêmes dimensions que les nôtres.

Si nous observons la proportion numérique des familles, nous verrons qu'elle dénote un climat chaud; nous rappellerons entre autres les buprestes, qui sont nombreux, ainsi que les termites et les blattes; nous remarquerons aussi que parmi les premiers on trouve des formes rraiment tropicales, et que les blattes ont bien plus d'analogie avec celles des zones chaudes qu'avec les nôtres. Il en est de mème pour les végélaux. Les cycadées ainsi que les grands roseaux et les fougères à nervires réticulées n'habitent que les zones chaudes et torrides.

D'autre part, les araucaria s'avancent depuis les zones chaudes jusqu'aux tempérées, et le thuya jusqu'aux latitudes Nord, néanmoins, parmi les conifères, ces deux arbres sont ceux qui descendent le plus au midi; ils ne modifient donc pas l'hypothèse que nous avons énoncée plus haut, quoique leur présence seule ne permette pas de conclure à un climat chaud. Ce n'est pas l'air seulement, mais aussi la mer qui avaient sous nos latitudes une tem- 
pérature plus élevée que de nos jours; les ammonites, proches parentes des nautiles qui vivent actuellement dans les Indes, en sont une preuve, ainsi que les pentacrinites, qui ne se trouvent que sur les côtes des Antilles.

Ainsi les insectes, déjả très nombreux et très variés à l'époque jurassique, donnent le mòme témoignage que les autres espèces animales et végétales en faveur de la température de ces anciens climats. Nous en aurons un témoignage plus direct tout à l'heure par les coraux des mers jurassiques. Mais avant d'oublier ces insectes et surtout ces coléoptères antiques, remarquons que chez

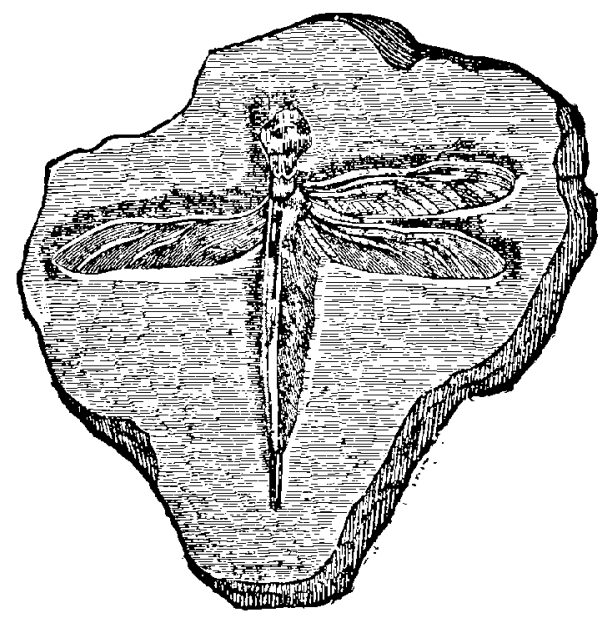

Fig. 309. - Libellule fossile de la période jurassique.

eux aussi nous pouvons observer des faits importants en faveur de l'adaptation des espèces aux conditions d'existence. Ainsi, par exemple, les insectes qui vivent dans l'eau sont en petit nombre, comparativement à ceux qui pullulent sur la terre; quant à ceux qui vivent dans la mer, ils sont d'une rareté excessive : ces articulés en effet ne sont pas organisés pour la vie marine, et ils sont remplacés au sein des mers par l'immense population des crustacés. Pourtant il y a des insectes qui passent une grande partie de leur vie sous la mer. Écoutons un instant ce récit d'un observateur :

Dans un voyagre que je fis, en 1822, écrit Audouin, sur les côtes de la Loire-Inférieure et de la Vendée, je visitai plusieurs des îles de l'Océan dans le but de récolter des crustacés et d'autres animaux marins. J'étais un jour, dans le courant de septembre, occupé à explorer l'île de Noirmoutiers, et j'avais profité d'une marée très basse pour m'avancer dans 
le lit de la mer jusqu'à la distance d'environ deux cents toises, lorsque je fus inopinément frappé par la présence, au milieu de ces profondeurs, d'un très petit animal que je reconnus aussitôt pour un insecte. Il courait précipitamment à la surface des pierres, sur les fucus, sur les éponges et sur les autres corps marins que l'eau venait à l'instant d'abandonner et qui ćtaient encore mouillés par la dernière vague.

Au premier abord, je soupçonnai que ce petit insecte qui, évidemment appartenait à la famille des carabignes dont, on le sait, toutes les espèces sont carnassières, et constamment terrestres, se trouvait là accidentellement, et que peut-êtro moi-même je l'y avais transporté. Cependant, à tout hasard, et comme il me parut curienx, je lo saisis. J'étais revenu de mes premières recherches lorsque j'en fus de nouveau distrait par la rencontre d'un second individu, puis d'un troisième. Plus loin j'en trouvai un quatrième et ailleurs beaucoup d'autres. En moins de six minutes, j'en recueillis jusqu'à dix..... Je revins le lendemain au moment où la mer commençait à baisser, afin de suivre graduellement le flot à mesure qu'il s'éloignait. D'abord je fus très surpris, malgré l'activité de mes recherches, de ne rencontrer aucun de ces insectes sur le terrain qui découvrait en premier. Ce ne fut qu'après avoir dépassé le niveau des marées ordinaires et avoir atteint celui des basses mers, que je commençai à les observer..... Ce jour-là je fus mieux favorisé que la veille. J'en vis plus d'une quinzaine, mais au lieu de les saisir je m'attachai à les étudier dans leur manœuvres et je me décidai à ne pas abandonner la place qu'ils ne l'eussent quittée eux-mêmes.

Bientôt j'eus lieu de m'applaudir de ma constance. En effet, je pus me convaincre qu'aussitôt que la mer laissait à dócouvert l'endroit occupé par un de ces insectes, il en profitait pour se mettre immédiatement en course et parcourait avec agilité la surface humide du sol; mais dès que la maréc commençait son mouvement d'ascension et à l'instant où le flot allait couvrir le sol, je vis à plusieurs reprises ces petits insectes, au lieu de chercher leur salut dans la fuite, s'empresser de se cacher sous quelque pierre voisine qui, à l'instant était submergée et recouverte par une masse d'eau toujours croissante.

Il était donc hors de doute : $1^{\circ}$ que ces petits animaux ne quittaient pas le fond de la mer pour gagner la côte; $2^{\circ}$ que pendant tout le temps de la marée, c'est-à-dire au moins durant six heures, ils restaient dans son fond et recouverts, suivant les localités, par vingt, trente ou quarante pieds d'eau.

Il en résulte que ces petits êtres ne peuvent respirer librement l'air qu'à des intervalles très êloignés, pendant fort peu de temps, et que leur vie sous-marine est infiniment plus longue que leur vie aérienne. Mais la nature, qui est d'autant plus prévoyante lorsqu'il s'agit de la conservation des êtres, que ces êtres sont exposés à de plus grands dangers, a 
donné à notre petit insecte le moyen de s'entourer d'une bulle d'air, et de plus, elle a fait en sorte qu'elle ne puisse que très difficilement leur échapper.

Si l'on examine à l'œil nu et mieux encore à l'aide d'une loupe la surface de ses élytres, sa tête, son corselet, ses antennes, ses pattes, tout son corps enfin, on voit qu'ils sont couverts de poils dont plusieurs atteignent une assez grande longueur.

Si ensuite, comme je l'ai expérimenté un grand nombre de fois, on fait passer immédiatement cet insecte de l'air dans l'eau de la mer, on remarque que chacun de ses poils retient une petite couche du fluide élastique qui, réunie d'abord en petits sphéroïdes, forme bientòt un petit globule, lequel entoure son corps de toute part, et qui, malgré l'agitation qu'il se donne en courant dans l'eau, au fond ou contre les parois du vase où on l'a placé, ne s'échappe jamais..... Toujours notre insecte emporte avec lni une petite conche d'air; et quand il se cache sous une pierre, il s'y trouve momentanément dans les conditions deș insectes placés librement dans l'air.

L'insecte étudié par Audouin était l'æpus marinus; depuis, en 1848, Charles Robin a découvert à Dieppe une nouvelle espèce dont le $\mathrm{D}^{\mathrm{r}}$ Laboulbène a retracé l'histoire; les observations sur l'æpus Robini sont venues confirmer celles d'Audouin; mais celles que le $D^{r}$ Coquerel a pu faire depuis à Brest sont plus complètes encore; plus heureux que ses devanciers, il a découvert la larve.

L'æpus Robini, dit-il, comme M. Robin l'avait observé, ne se rencontre que sous les pierres fortement adhérentes au sol, dans les endroits recouverts d'un gravier grossier"et toujours au-dessous des limites des marées. J'en ai trouvé près de trois cents individus dans ces conditions et jamais au delà. Quand la mer vient de se retirer, et que le sable est encore détrempé, on n'en voit pas un seul; ils sont alors cachés dans de petits trous et à une assez grande profondeur. Ils r'en sortent que lorsque le sol commence à être moins humide, et on les voit accourir avec la plus grande vitesse, dès qu'on soulève la pierre qui leur servait d'abri.

L'existence de ces curieux insectes est donc entièrement dépendante du phénomène de la marée. Ils demeurent engourdis sous l'ẹa tant que la mer est haute, et ne sont actifs et libres que lorsqu'elle se retire. Et si, par une perturbation des lois physiques, l'Océan venait à découvrir nos côtes avec moins de régularité, l'espèce qui nous occupe périrait sans doute; exemple intéressant de ces harmonies admirables qu'on retrouve à chaque pas dans l'étude des lois de la nature. Il n'est pas sans intérèt de remarquer encore que cet insecte ne se rencontre pas sur les bords de la Méditerranée où il n'y a pas de marée. Je l'ai cherché bien des fois sans succès sur les côtes de la Provence. 
Cet exemple, emprunté précisément à l'ordre des coléoptères, l'un des plus anciens parmi les fossiles, est bien propre à nous instruire sur les origines des espèces. L'être change pour s'adapter à
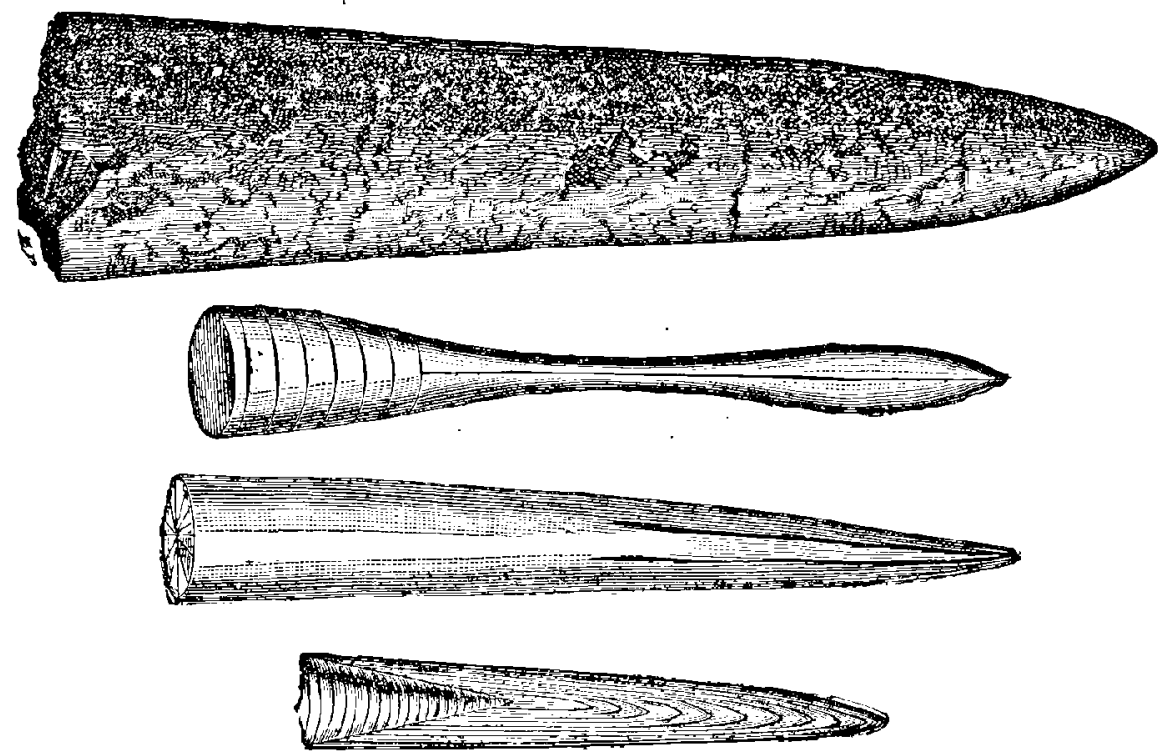

Fig. 310. - Divers rostres de bélemnites des terrains jurassiques.

de nouvelles conditions d'existencẹ. Il en a été de même pour les insectes devenus aveugles qui habitent les cavernes : leurs poils se sont allongés, la sensibilité tactile ayant remplacé la sensibilité

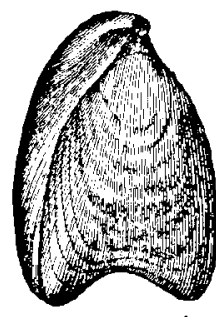

Fig. 311. - Térébratula digona. (Grandear eatarelle.)

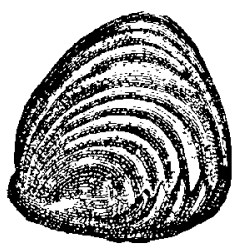

Fig. 312 - Rynchonelles rues de différents côtés. (Grandeur naturello,

optique. Mais revenons à l'époque jurassique et complétons-en la description générale. Nous avons passé en revue toute la population de cette époque; il nous reste encore à parler des mollusques et des espèces inférieures qui continuent à subsister malgré le progrès. Et pourquoi ne subsisteraient-elles pas? Celles dont les con- 
ditions d'existence ne changent pas, celles qui demeurent, par exemple, au fond des mers, ne changent pas elles-mèmes. D'autre part, la force vitale de la planète n'est pas épuisée . nous n'avons aucune preuve que le protoplasma ne continue pas à se former et à donner naissance aux organismes primordiaux.

Nous avons vu, au début de ce chapitre, que le terrain jurassique affleure à la surface du sol sur une partie importante de nos contrées (Voy. la carte géologique de la France, p. 204). Une bande remarquable s'étend de l'ouest à l'est, en allant en s'élargissant

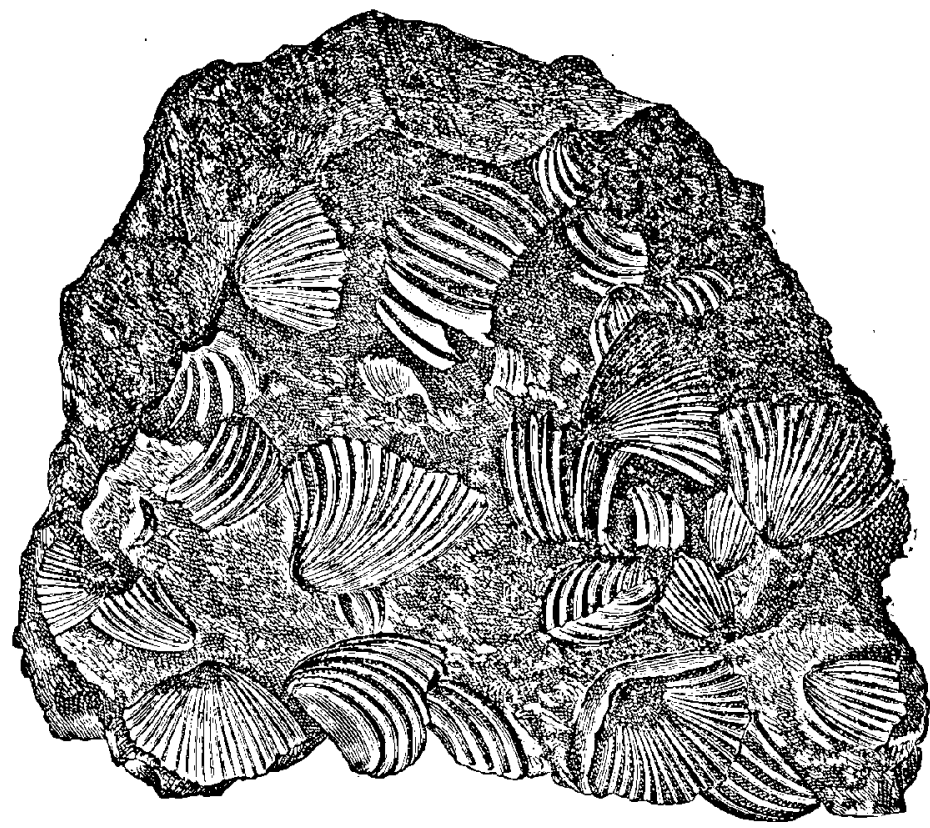

Fig. 313. - Fragment de bloc uniquement composé de rynchonelles agglomérees.

considérablement lorsqu'on approche du Jura et de l'Argone: on la suit facilement de La Rochelle à Nevers, Dijon, Langres, Chaumont, Neufchâteau, Nancy, Metz, Luxembourg, ainsi que sa bifurcation vers le sud-est par le Jura et les Alpes. La richesse de ce terrain en fossiles fait que la plupart des enfants jouent dès leurs premières années, sans le savoir, avec la géologie et la paléontologie. Celui qui écrit ces lignes a en ce moment sous les yeux toute une collection commencée dès ces premiers jeux d'autrefois sur les collines de la Haute-Marne, du plateau de Langres et des bords de la Meuse. On y remarque d'abord une quantité de « qrilles » (/gg. 310) de 
toutes grandeurs, depuis un et deux centimètres jusqu'à quinze et vingt de longueur. Ces « quilles» noires et pointues sont appelées «pierres du tonnerre »par les vignerons. On les a considérées aussi comme des jeux de la nature, des concrétions pierreuses, des stalactites, des dents de poissons, et quelquefois aussi on leur a donné le nom de "griffes du diable », etc.; elles sont si nombreuses qu'il n'y a, pour ainsi dire, qu'à se baisser pour en prendre. Ces pierres coniques pointues sont tout ce qui reste d'un mollusque céphalopode marin très répandu dans les mers de cette époque, ce sont des rostres de bélemnites: nous aurons lieu tout à l'heure de les étudier plus spécialement. Il y en avait tant, qu'on

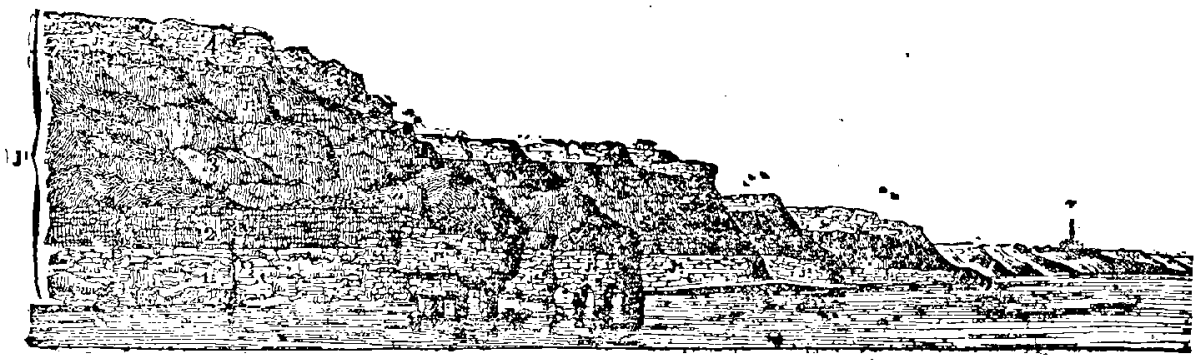

Fig. 314. - Terrains jurassiques moyens visibles sur les falaises du Calvados. v. Vierpille. - vv. Saint-Laurent. - vvv. Sainte-Honorine. J'. Elega oolithique inférielr: 1. Oolitbe Inférieure. - 2. Calozire argileux. - 3. Argile de Port en Bessin. - 4. Calcaire de Caen ou grande oolithe.

les rencontre par tas énormes (on peut voir dans les collections géologiques du Muséum de Paris une plaque de schiste provenant du lias d'Angleterre sur laquelle on compte plus de neuf cents rostres de bélemnites réunis dans un espace de cinquante centineètres carrés). Ces morceaux étaient d'ailleurs d'une conservation facile sur le fond de la mer, lequel, soulevé depuis, les a portés avec le sol sur lequel nous marchons aujourd'hui à trois, quatre et cinq cents mètres de hauteur (pour ne parler que de nos pays). Avec ces rostres de bélemnites, les fossiles les plus communs que la nature place elle-même dans le panier d'une collection d'enfant sont les térébratules ( $f i g .311)$ et les rynchonelles ( $f g .312)$. Un peu moins grosses que des noyaux d'abricots, ces coquilles pétrifiées offrent des formes qui ne sont pas sans élégance. Les premières sont allongées en amandes, l'une des deux valves empiétant sur l'autre par son sommet, les secondes ont les deux valves emboi- 
tées sur des plans différents par des échancrures hermétiquement fermées. On les trouve parfois aussi en telles quantités que des blocs de pierre de plusieurs kilogrammes sont entièrement formés d'une agglomération exclusive de ces coquilles juxtaposées et

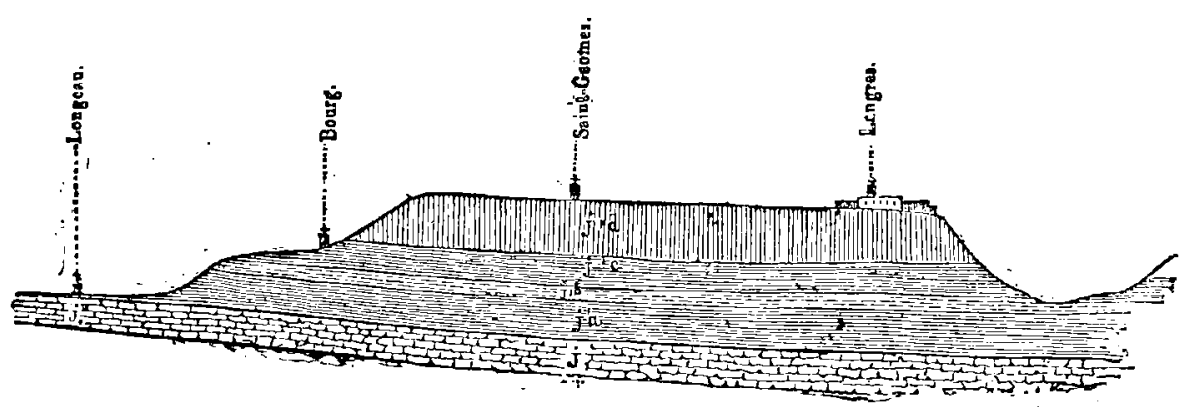

Fig. 810. - Coupe prise dans les terrains jurassiques moyens (Langres à Longeau\}.

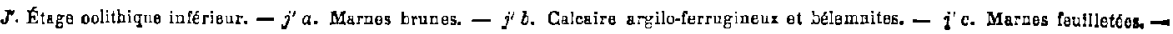
$j$ ' $d$. Calcaire de entroques, pointes d'oursins, ete.

que l'on peut facilement les détacher les unes des autres car elles ne sont reliées entre elles par aucun mastic. Les térébratules et les rynchonelles ( $f g .312$ ) étaient des mollusques brachiopodes, très répandus aussi dans les mers jurassiques.

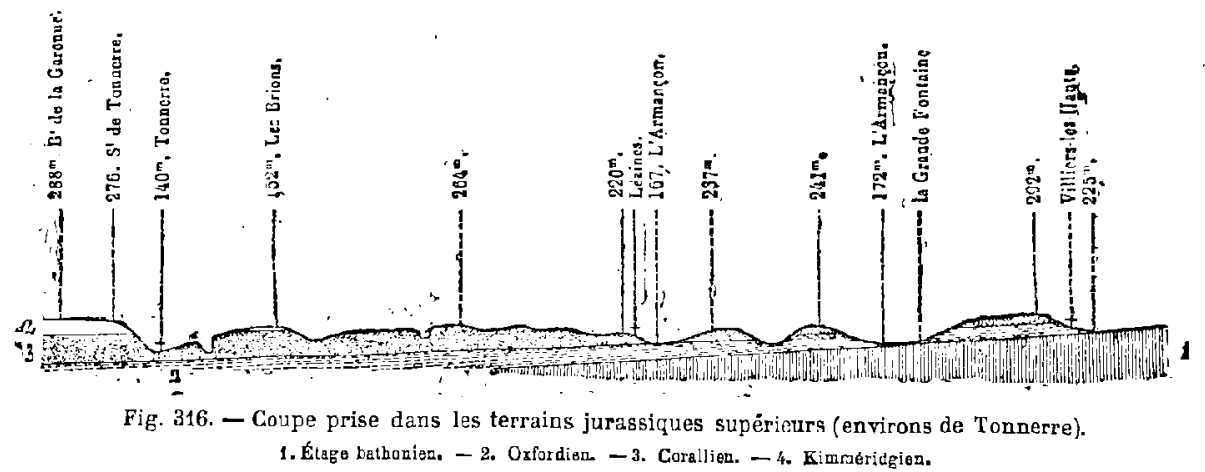

On a dessiné ici (fig. 313) d'iprès nature et de grandeur naturelle, un fragment d'un bloc d'un kilogramme choisi dans la petite collection dont nous parlions tout à l'heure, uniquement composé de rynchonelles adhérentes ensemble en une mème roche (').

1. Elles sont si communes que le balast de la voie ferrée de Langres à Neufchâteau en est pour ainsi dire pavé par places, notamment au pied de Bourmont · la vie rapide de nos jours humains circule sur les momies de millions d'êtres pétrifiés qui nous rappellent ces lointaines époques dont personne ne verra le retour. 
Les pétrifications d'huitres sont plus rares dans ces terrains, cependant la même collection enfantine en possède plusieurs, ainsi que des oursins. - Tous ces terrains appartiennent à l'étage oolithique inférieur, an bathonien. La Mense comme la Marne prennent leur source dans ces coteaux, sur les versants desquels on trouve aussi des gryphées, des ammonites, des peignes, des polypiers, etc., et coulent depuis les premiers âges de l'humanité sur

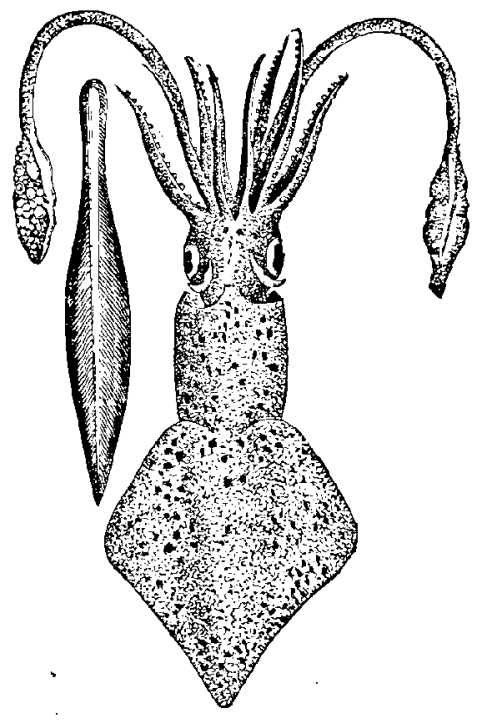

Fig. 317.

La seiche actuelle et son osselet.

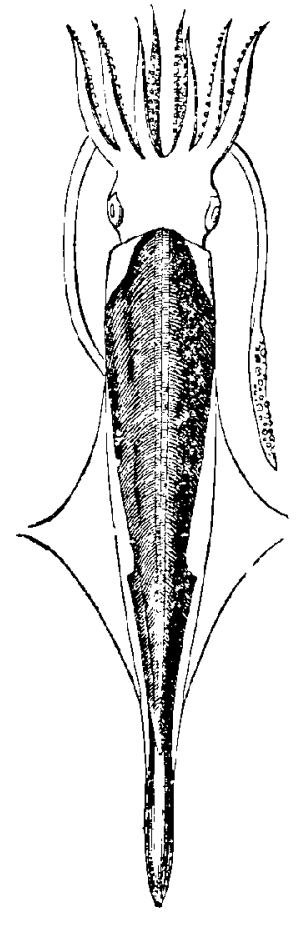

Fig. 318.

Bélemnite res.aurée.

ce sol que la mer jurassique recouvrait de ses ondes. - Tous y avons trouvé aussi des morceaux de bois pétrifié, dont nous possédons divers spécimens: il y a eu lá, aux temps jurassiques, des rivages et des forèts. Qui pourrait dénombrer les oscillations et les plus légers frémissements de l'épiderme de l'ètreTerre?

Un autre lambeau de terrain jurassique part de la Loire, à l'est d'Angers, pour s'élever directement au nord en s'épanouissant sur 
les départements de l'Or'i e et du Calvados par Argentan et Caen (').

En Normandie, sur la côte du Calvados, les argiles inférieures particulièrement riches en fossiles, épaisses de 60 mètres et dépourvues de minerai de fer, affleurent au niveau de la mer auprès de Dives, sous la falaise des a Vaches-Noires ». Les argiles qui suivent alternant avee des banes de calcaires noduleux, sont de meme remplies de fossiles : l'ammonites cordatus, une grande huitre dilatée, etc., forment des bancs entiers. Au pied de ces falaises dénudées, qui s'éboulent constamment sous les attaques des flots, on peut recueillir aisément les nombreuses espèces fossiles contenues dans ces argiles oxfordiennes. Les ammonites, à l'état pyriteux (sul-

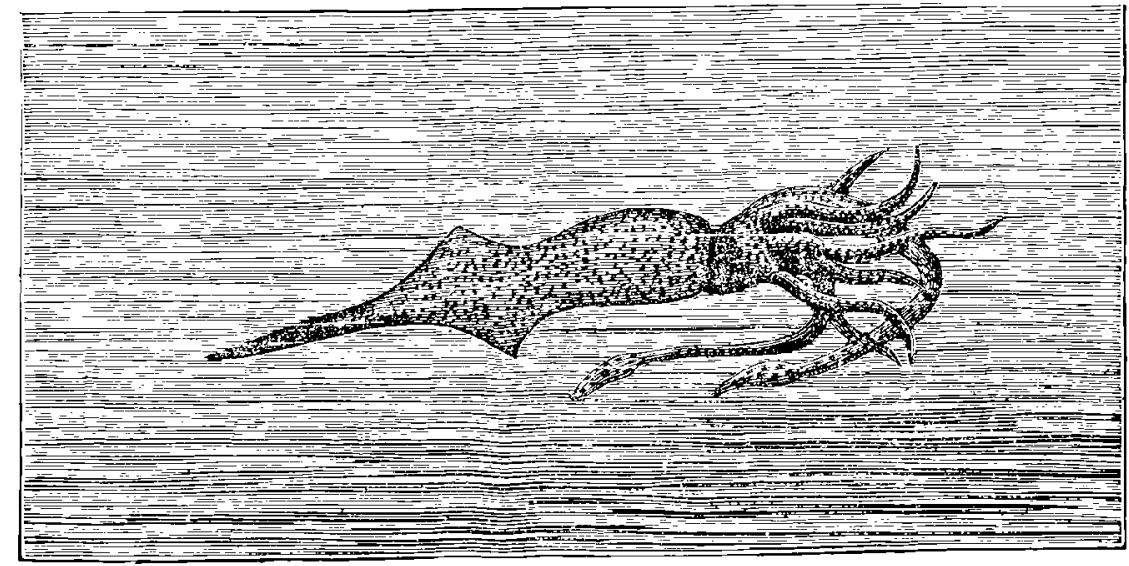

Fig. 319. - Bélemnite nageant.

fure de fer), brillent d'un vif éclat et sont bien conservées; des huitres de diverses formes, des trigonies à grosses côtes, des téré-

1. Nous avons visité ces formations de Normandie au mois de juin 1885, en compagnic de M. Vimont, le savant el laborieux fondiateur de la Société scientifique Flammarion d'Argentan, auquel nous devons un grand nombre de fossiles trouvés par luimème dans les terrains secondaires et primaires de l'Orne, qui y sont simultanément représentés, depuis le silurien jusqu'au jurassique. Il y a là un contraste des plus frappants : le voyage de Bagnols à la vallée d'Auge est à la fois des plus pittoresques et des plus instructifs. Les eaux de l'époque quaternaire ont creusé les riches vallées du pays d'Auge. Fn se plaçant sur les hauteurs, par exemple sur la colline de Montreuil-la-Combe, non loín de Trun - où un observatoire météorologique serail admirablement plaeé on domine toute la contrée et l'on se rend compte à première vue des rapports et des harmonies qui rattachent la préparation géologique des siècles antédiluviens aux productions de la terre et à l'état actuel de l'humanité. 
bratules, sont particulièrement abondantes. Toutes ces espèces se voientrégalement dans la falaise, disposées au milieu des argiles par cordons alignés dans les niveaux successifs.

Beaucoup moins étendue que celle de l'est de la France, cette
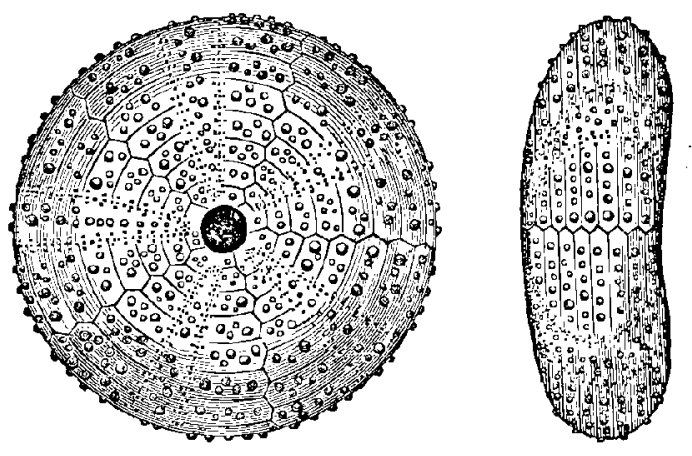

Fig. 320. - Oursins de la période jurassique.

iangue jurassique n'en est pas moins du plus haut intérêt pour l'étude de la géologie. On peut en dire autant de celle de la Pro-
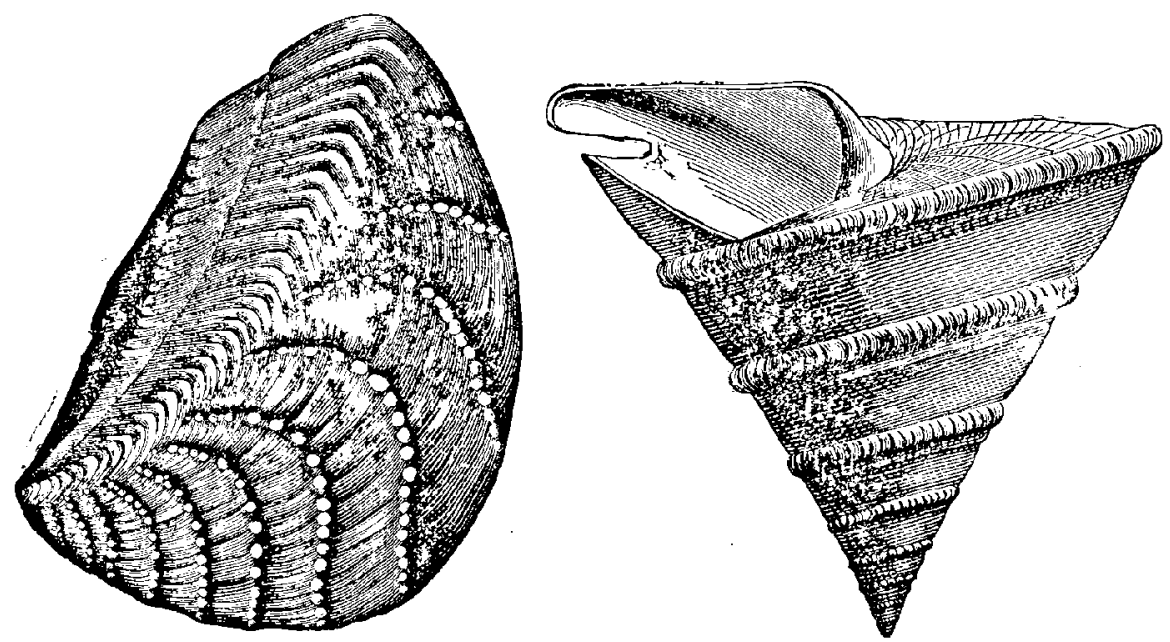

Fig. 321-322. - Mollusques acéphales et gastéropodes de la période jurassique.

Trigonia clavellata et pleurotomaria conoz̈dea.

vence. L'espace nous manque ici pour les décrire en détail; cependant quelques vues et coupes de terrains seront fort utiles pour compléter ce que nous en avons dit aux débuts de ce chapitre, et dans ce but nous avons reproduit plus haut quelques-unes de celles 
qui illustrent la « Description géologique de la France, » due aux travaux de Dufrénoy et Élie de Beaumont. L'une ( $f g$. 314) nous met sous les yeux les terrains jurassiques moyens (étage oolithique inférieur) que l'on voit sur les côtes du Calvados, entre Vierville, Port en Bessin et Avranches, couches superposées qui donnent un aspect si pittoresque à ces falaises. Une autre (fig. 315) représente nne coupe des mêmes terrains faite dans le département de la Haute-

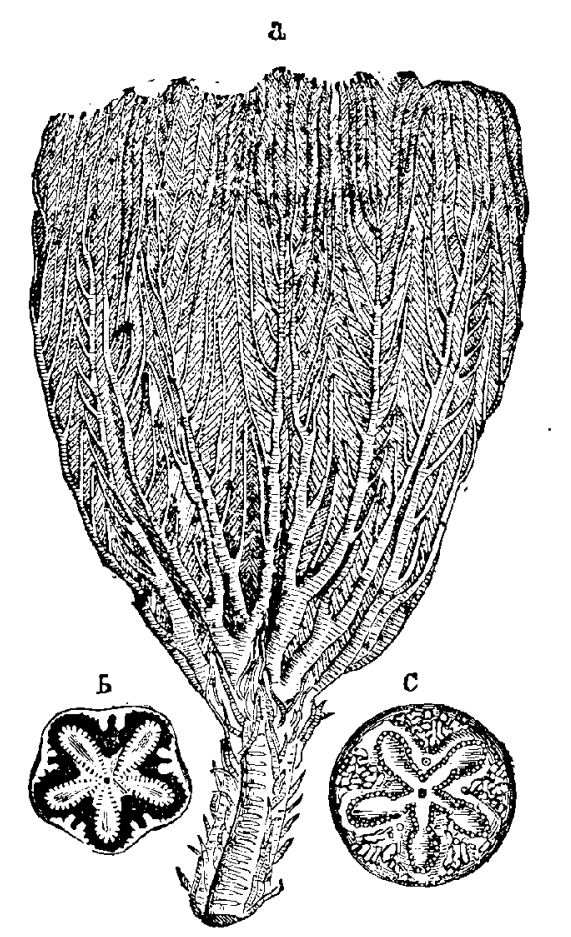

Fig 323. - Crinoïdes de la période jurassique.

l'entacrinus fescicinlosus. - a. Grandeur naturolle. $-b$, c. Articles do la tige grossis,

Marne, sur le promontoire qui s'avance comme un cap de Longeau à Langres, à 473 mètres d'altitude, et dans les flancs duquel la Marne prend sa source, à 381 mètres d'altitude. Une troisième (fig. 316) atteint les étages supérieurs de l'époque jurassique, les étages bathonien, oxfordien, corallien et kimméridgien, dans une coupe faite en Bourgogne aux environs de Tonnerre. Ces coupes complètent fort utilement la classification des terrains donnée plus haut (p. 531).

Mais revenons aux êtres vivants do ces lointaines époques. 
Nous parlions tout à l'heure des bélemnites et des pierres pointues qu'elles ont laissées. C'étaient des mollusques céphalopodes voisins des grands calmars artucls, qui vivent dans la haute mer, seiches, poulpes, pieuvres, elc. Les bélemnites étaient
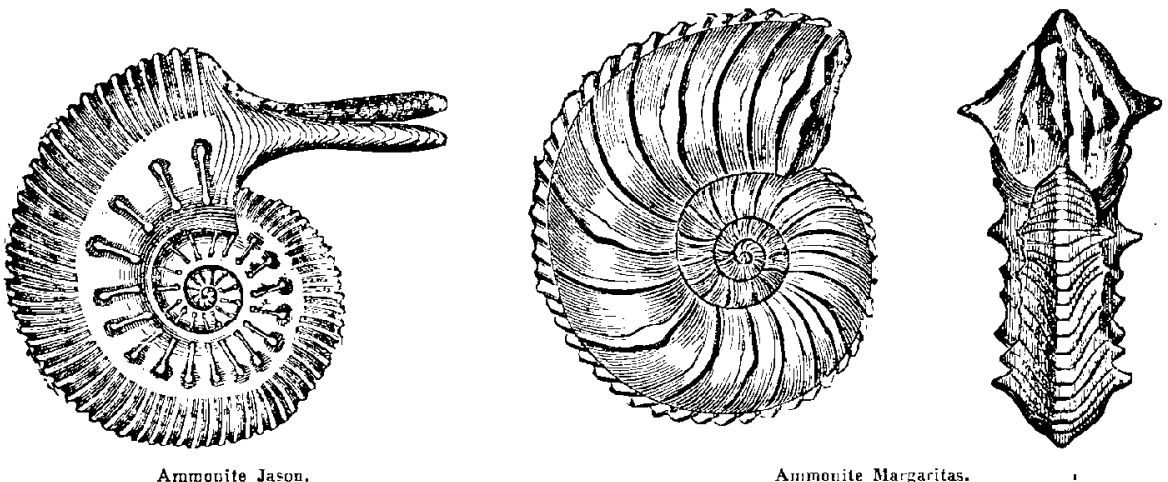

Fig. 321. - Mollusques céphalopodes de la période jurassique.

les pienvres des océans sccondaires. Tout le monde connait les sépias, non seulement pour les avoir mes aux bords de la mer ou dans les aquariums, mais encore par l'encre de couleur connue

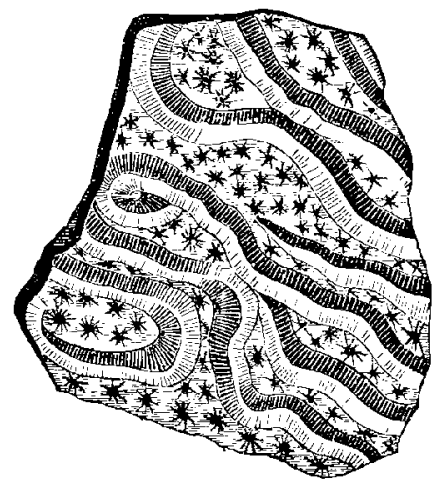

Comoseris vermieularis.

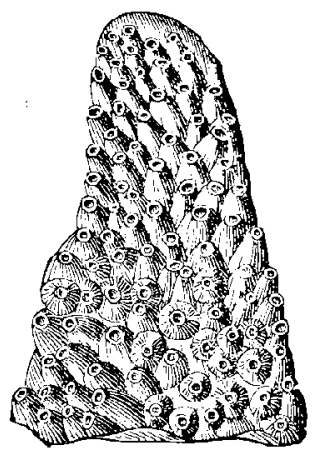

Lobocoenia obelise us.

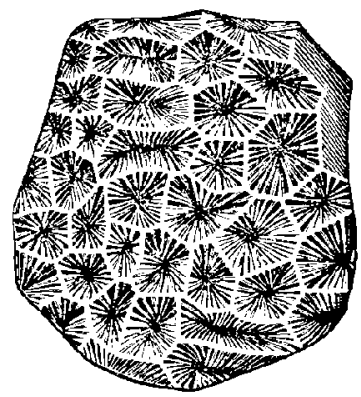

Latomeandra Daridsoni.

Fig. 32ù - Débris fossiles des coraux vivant en France a l'époque jurassique.

sous leur nom et par les os de seiche que l'on donne aux oiseaux de volière pour aiguiser leur bec ou dont on se sert pour la fabrication de la sandaraque. Les bélemnites sécrétaient comme les seiches une encre foncée que l'on a mème retrouvée dans la poche de l'animal à l'état de poussière fossile et dont on a pu s 
servir pour exćcuter des dessins avec cette sépia vieille de millions

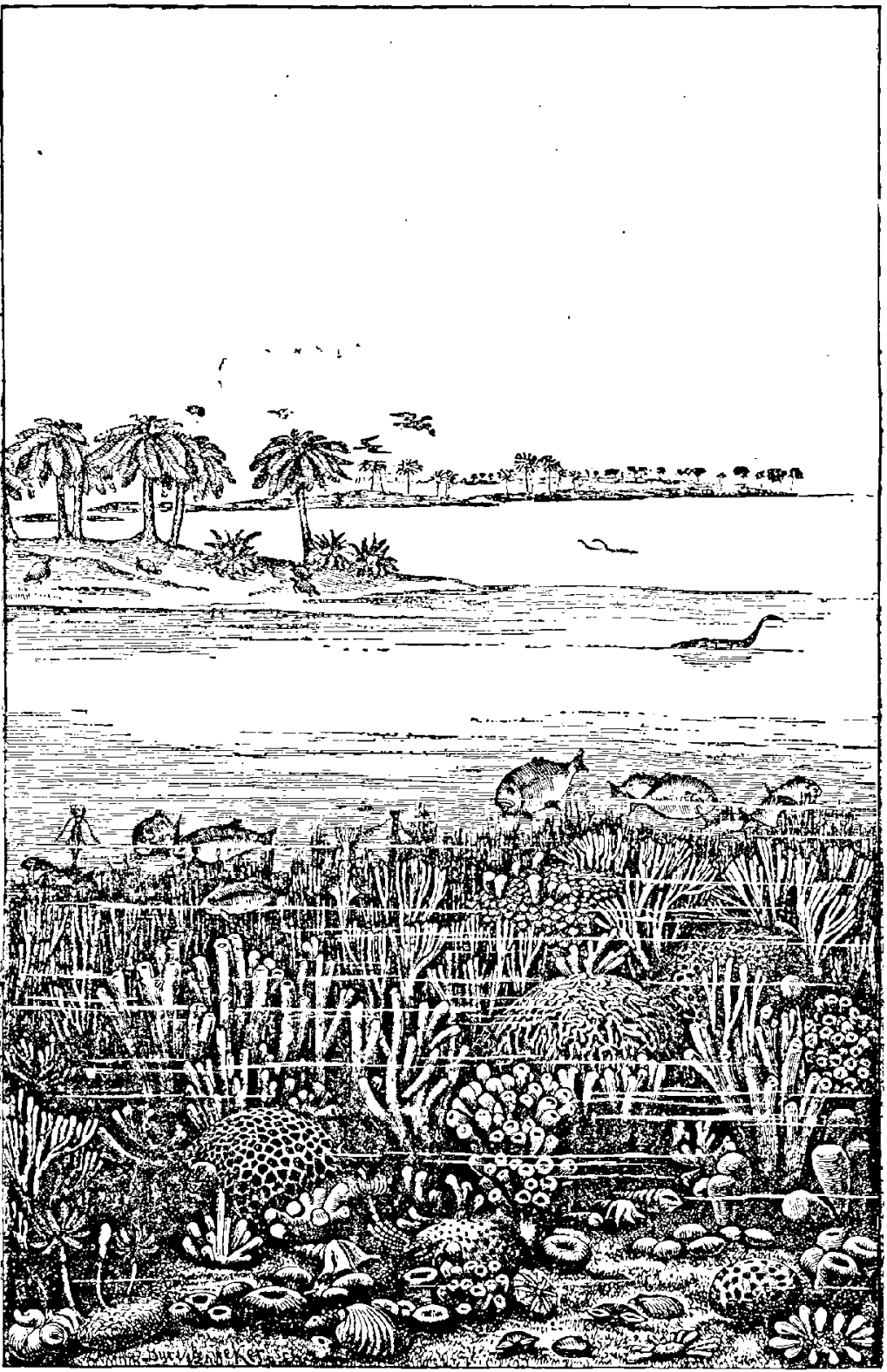

Fig 326. - La France, Jura, Franche-Comté, Buurgogne, à l'époque de la mer jurassique d'après Oswald Herr.

d'années. D'après les recherches spéciales de Blainville et de d'Orbigny, on sait aujourd'hui que les bélemnites atteignaient parfois LE MONDE aVANT La CRÉation de L'HOMME 
une taille de deux mètres. On en connaît cinq espèces principales. G'était un céphalopode bon nageur, qui devait surtout nager à reculons, dans la position horizontale représentée ( $f g$. . 319). C'est dans les terrains jurassique que les bélemnites atteignent leur maximum. 11 n'en existe plus depuis longtemps.

Les céphalopodes à tentacules, les ammonitides surtout, sont en progrès pour atteindre leur maximum pendant la période crètacée, où nous allons bientôt les retrouver. Signalons parmi les plus curieuses, l'ammonite Jason ( $/ g$. 324). Au nombre des acéphales et gastéropodes de cette époque, remarquons aussi les trigonia clavellata $(f g .321)$ et les pleurotomaria conoïdea $(f g .322)$. Les oursins sont nombreux et variés $(f g .320)$. Les crinoïdes atteignent un second et dernier maximum : désormais ils ne feront plus que décliner. A certains niveaux et en certaines contrées ils formaient de véritables champs sous-marins et leurs entroques constituent presque à elles seules des assises d'une grande épaisseur et d'une grande étendue dans le Jura de la Bourgogne et de la FrancheComté. Les principaux genres sont les pentacrinus ( $f g$. 323), les apiocrinus, les millcricrinus, les isocrinus. Ils avaient en général une tige longue et droite et un calice formé de pièces très épaisses ; les bras étaient libres et quelquefois trés rameux. Tous ces mollusques ont laissé leurs vestiges dans les terrains que nous étudions en ce moment, et en les ressuscitant par la pensée nous pouvons nous rendre compte de la population antique de ces mers.

Mais ce qui peut encore le plus nous frapper ce sont assturément les récifs de coraux qui ont caractérisé les derniers siécles de la période jurassique el qui ont donné à un étage tout entier le nom d'étage corallien. Cet étage est remarquablement développé dans la Meuse, où il mesure de cent vingt à cent cinquante mètres d'épaisseur, dans le Jura, en Suisse, en Provence, en Dauphiné, en Bourgogne, et cn Normandie, vers Trouville. Dans toutes ces régions, les calcaires oolithiques, qui forment le cortège habituel des récifs coralligènes, sont très fréquents, ainsi que des calcaires compacts à grains fins, indice assuré de dépôts effectués dans les grands fonds, loin de l'agitation des vagues. Le terrain corallien se montre généralement constitué de puissantes assises ḋe calcaires hlancs massifs, formés 
de coraux, les uns hrisés, les autres ayant encore conservé la position qu'ils occupaient au temps de leur développement. Inférieurs en puissance aux récils de nos mers tropicales, ceux de l'étage corallien l'emportaient cependant de beaucoup en superficie puisqu'on les rencontre à toutes les latitudes. On trouvera ici les

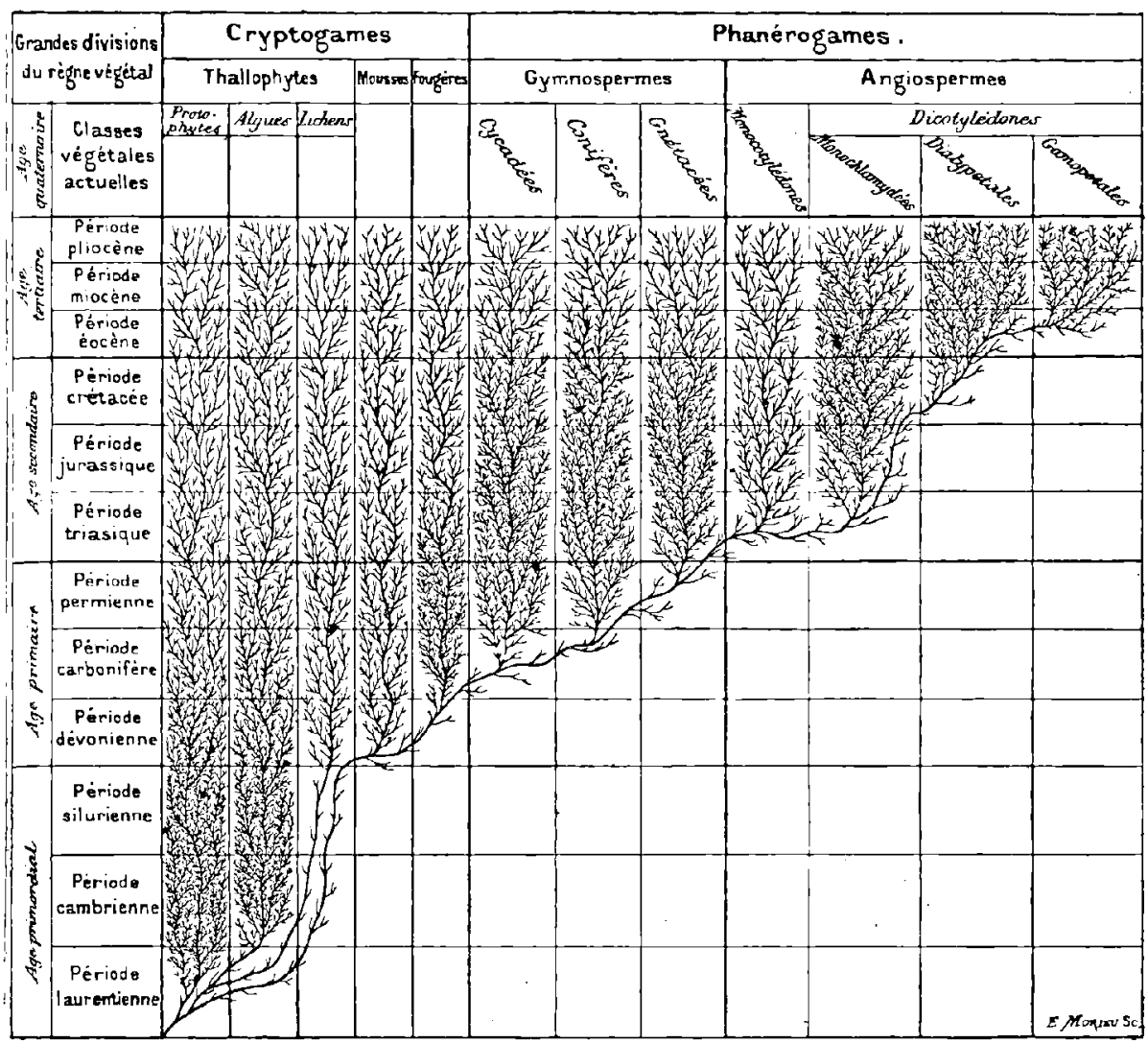

F1g. 327. - Arbre généalogique du règne végétal.

principaux spécimens (fig. 325) laissés dans ces terrains par les divers polypes du corail.

Nous signalerons, avee le naturaliste suisse Oswald Heer, les banes de coraux qui parsemaient la mer jurassique dans les eantons de Bâle, de Soleure et de Berne, jusqu'à Porrentruy et en France. Ces bancs de coraux, écrit-il, ont joué en Europe un rôle semblable à celui des coralliaires actuels de l'Océan Indien et des mers du Sud. C'est une question intéressante et un problème à résoudre que 
la distribution exacte et la configuration des bancs de coraux dans les mers jurassiques de l'Europe.

On peut se demander s'ils étaicnt recouverts par les eaux $0: 1$ s'ils émergaient et formaient des îles, comme on on voit en gran't nombre dans les mers du Sud ; les deux cas existaient. En Suiss', dans le canton de Bâle, le calcaire corallien est recouvert d'ur dépôt de charbon très peu important à la vérité, mais qui nons révèle un continent; près de Dänikon, dans le voisinage d'Olten, on a trouvé une belle fronde de zamite. Dans le Jura occidental, les îles madréporiques étaient couvertes de végétation comme on en a eu la preuve par la présence de belles feuilles de cycadées trouvées au Mont Risolux et près de Dorche. Dans les environs de Lyon, il y avait une île madréporique avec une forèt de cycadées, car il n'est pas rare d'y rencontrer çà et là de grandes et belles feuilles de cet arbre.

Nous avons reproduit plus haut ( $f g .326)$, d'après Oswald Hecr, un très beau paysage marin qui donne une juste idée des îles madréporiques du Jura et de l'aspect que devaient avoir les antiques atolls de notre pays. On y remarque des fles couronnées du zamite feneonis; des tortues sortant de la mer et gagnant la grève pour y déposer leurs œufs, des ptérodactyles volant vers le rivage et, dans le voisinage du littoral, des plésiosaures au long cou, cherchant leur nourriture. Dans les profondeurs de la mer nous distinguons toute une forêt de coralliaires et la faune variće qui les accompagnait.

Ajoutons enfin, pour compléter cette description générale de la plus curieuse de toutes les époques de l'histoire antć-humaine, quo le monde des plantes ne présente pas pendant les diverses phases sucessives de l'époque jurassique, depuis le lias inférieur jusqu'à l'oolithe supérieure, des formes caractéristiques aussi tranchées que le monde animal. Les espèces primitives s'éteignent lentement pour faire place à une végétation plus riche et plus diversifiée. C'est une ère de transformation. Les cryptogames dominent encore : fougères, prêles, etc.; mais les phanérogames angiospermes (cycadées conifères) commencent à s'imposer (voy. l'arbre généalogique du règne végétal, $f i g .327$ ), au rang horizontal de la période jurassique). Il n'y a pas encore de saisons ni de climats : les 


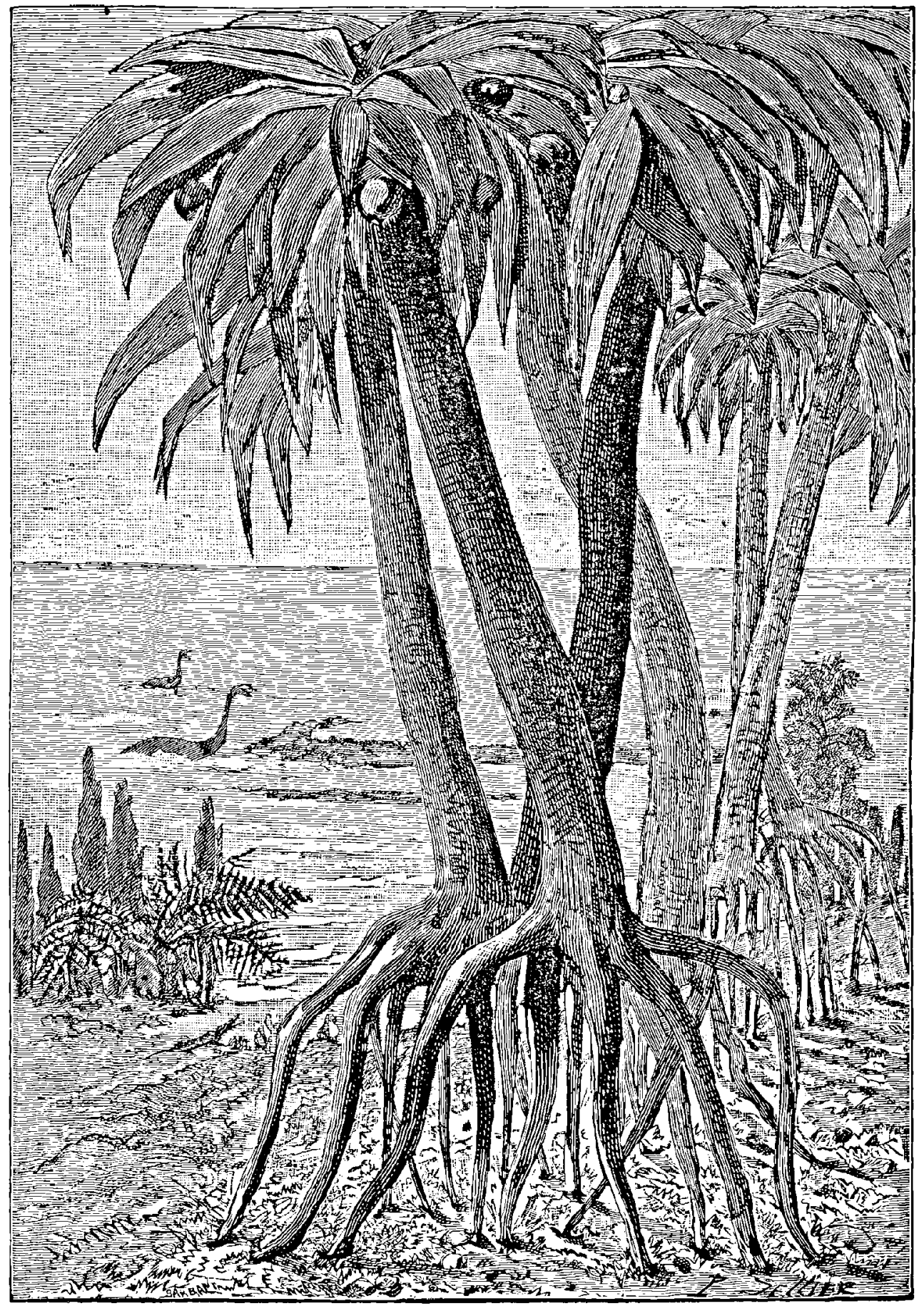

FIG. 328. - AU BORD DE LA MER PENDANT LA PERIODE JURASSIQUE, 
mêmes espèces végétales se retrouvent de l'équateur à la Sibérie et au Spitzberg. En France mème, sur les bords de la mer qui couvrait les régions où Paris fut fondé depuis, on aurait pu voir des paysages analogues à celui qui a été dessiné ci-contre : au premier plan des pandanées aux racines aériennes, des cycadées au tronc bas, et, au loin', nageant sur les eaux, les plésiosaures aux longs sous.

La période crétacée, qui succéde à la période jurassique, va compléter pour nous cette antique histoire des temps secondaires. 


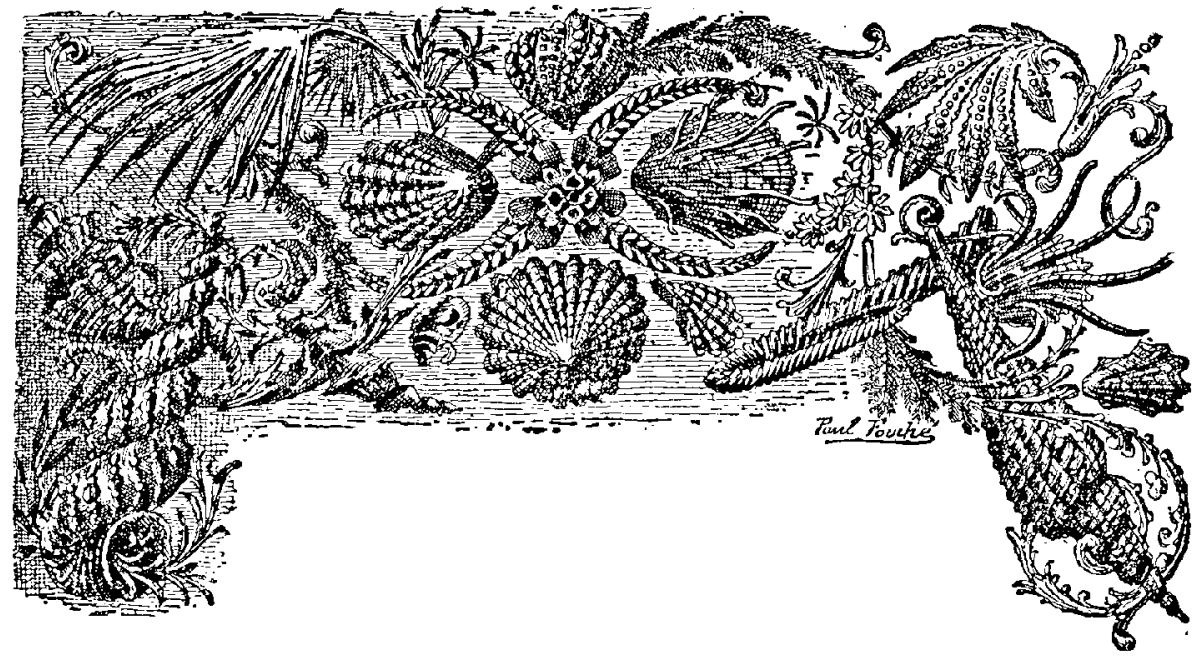

CHAPITRE III

\section{LA PERIODE CRÉTACÉE}

Si vous voulez bien, cher lecteur, retourner les feuillets de cet ouvrage jusqu'à la page 265 et considérer avec quelque attention la figurc qui représente la coupe du puits artésien de Grenelle à Paris, vous aurez sous les yeux la meilleure introduction à l'étude que nous sommes aménés à faire en ce moment ensemble de la dernière période de l'ère secondaire, de la période crétacée.

Sur cette figure vous remarquerez, depuis 41 mètres au-dessous du niveau du sol parisien jusqu'à 506 mètres de profondeur, de la craie, encore de la craie, et toujours de la craie. Or toute cette craie s'est déposée au fond de la mer, lorsque la mel couvrait ces régions, actuellement habitées par l'homme, à l'époque à laquelle nous arrivons dans cette histoire des transformations graduelles de notre planète.

Cet épais massif de craie qui passe an-dessous de Paris est une sorte de fond de cuvette irrégulière dont les bords se relévent et viennent affleurer à la surface du sol à une certaine distance tout autour de la grande cité, comme on s'en rend compte bicn facilement sur la coupe de la page 272 et sur le plan de notre carle géologique de la France : le terrain crétacé affleure le long d'une bande que l'on peut tracer d'Arras à Saint-Quentin, Reims, Châlons-sur- 
Marne, Vitry-le-François, Troyes, Sens, Auxerre, Bourges, Tours, Loudun, Le Mans, Dreux, Rouen, non sans irrégularités dues aux remaniements de la carte causés par les formations tertiaires. C'est cet affleurement de la craie sur une vaste étendue qui a donné à la Champagne pouilleuse son aridité et sa stérilité bien connues: sur des milliers d'hectares, la terre végétale de la surface n'a pas plus de quinze à vingt centimètres d'épaisseur, aucune végétation de quelque importance n'y peut croitre, les vallées seules restent vertes et quelque peu fertiles; lorsqu'on passe en ballon au-dessus de ces contrées, les prés étroits qui bordent les cours d'eau semblent des rivières qui serpentent sur un sol jaunâtre et aride, si singulièrement échauffé par le soleil que la réverbération suffit pour dilater l'aérostat et lui donner plus de force ascensionnelle, tandis que lorsqu'on traverse les rivières ou les canaux on rencontre des courants d'air frais qui changeraient la route de l'aérostat si l'on ne jetait du lest pour passer par-dessus. Cette vaste formation crayeuse se retrouve en d'autres points de la France; elle affleure, par suite d'un relèvement local, tout près do Paris, dans les collines de Meudon, Bellevue, Bougival : une demi-heure d'exploration dans les carrières qui bordent la colline de Bellevue suffit pour récolter un nombre considérable de coquilles fossiles, mais friables et crayeuses comme les terrains qui les renferment (nous en avons en ce moment sous les yeux, recucillis par nous-mèmes il y a quelques jours). On la retrouve à Mantes, au Mans, à Gisors, dans la pittoresque colline de Canteleu, près de Rouen : le long des rives de la Seine, de Vérnon au IIavre : épaisse de cinquante mètres, elle forme à elle seule toute la partie supérieure des falaises du cap de la Hève ( $f g .131$, p. 285). Ici, c'est l'étage cénomanien. Dans le Boulonnais et en Angleterre, c'est l'étage turonien; mais c'est toujours le terrain crétacé. On peut dire que la Manche s'est creusée son lit à travers la craie: nous avons vu, au chapitre des transformations actuelles du sol, qu'elle continue à l'élargir.

Cette même formation crayeuse peut être étudiće en bien d'au tres régions, par exemple de Saintes à Cahors, sur les deux versants des Pyrénées, surtout sur l'espagnol, dans les Alpes françaises, sur la rive droite du Rhin, en Allemagne, en Angleterre, en Algórie, en Palestine, dans l'Amérique du Nord, au Groënland, en un mot un 
peu partout sur la surface du globe, les mêmes causes ayant produit 'es mêmes effets, à part quelques différences de détail, moins importantes toutefois qu'on ne serait porté à le croire d'après les dis-

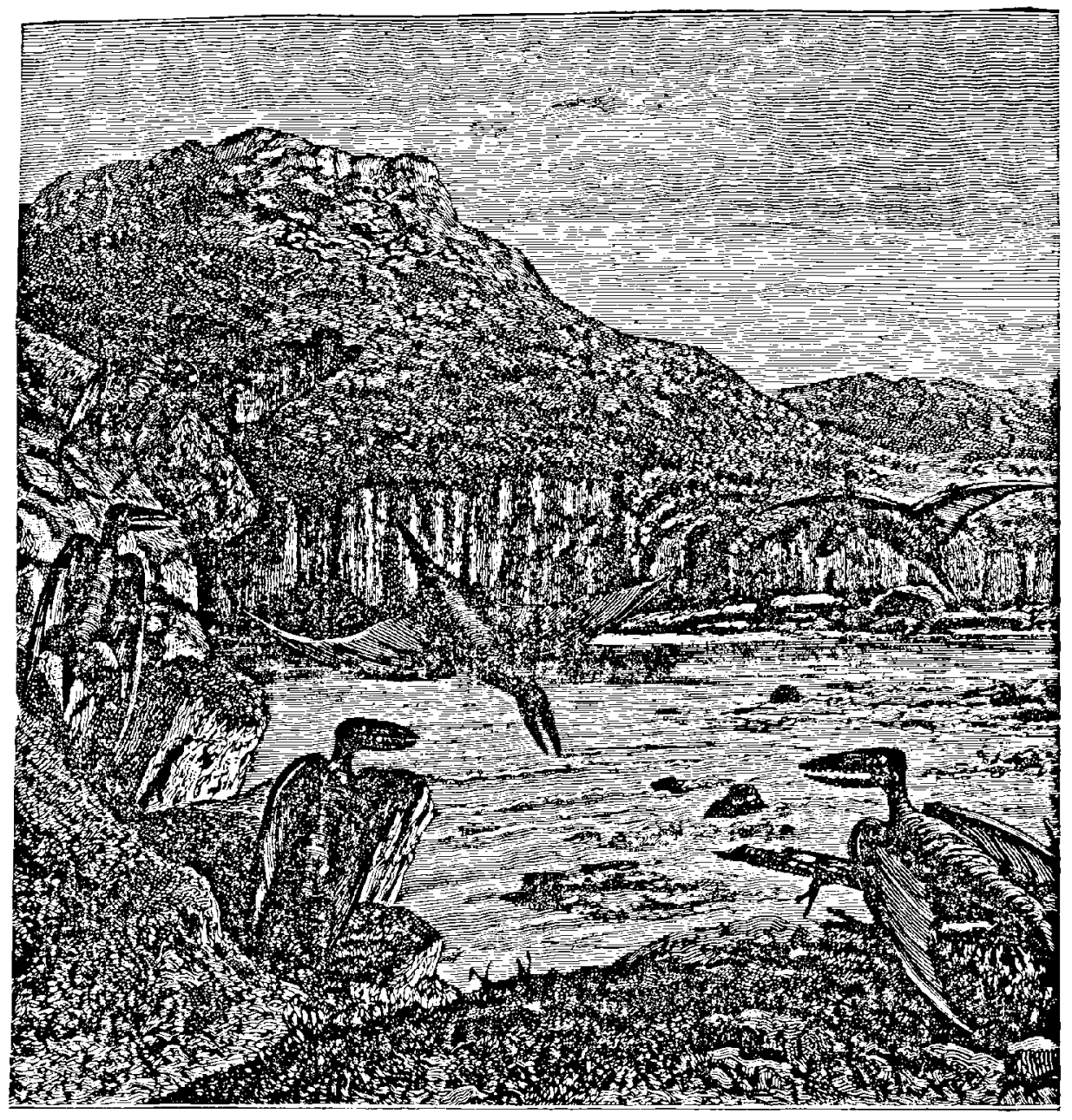

Fig. 329. - Les ptérodactyles.

tinces géographiques, car jusqu'à la période crétacée notre plazète n'a connu ni les climats ni les saisons.

Comme exemple de cette formation, outre la coupe du puits artésien de Grenelle et les falaises du cap de la Hève, on peut encore remarquer la coupe $(f g .330)$ prise dans les Pyrénées, sur le versant francais, près des Bains-de-Rennes. On n'y compte pas

LE MONDE AVANT La CRÉation de L'HOMME

19 
moins de vingt-cinq couches de calcaires et de marnes appartenant à la période crétacée, superposées et relevées. Ces couches marines reposent sur les sédiments wealdiens d'eau douce.

De même que les formations antérieures, les terrains crétacés ont pris naissance au fond des eaux. Toutes les contrées à la surface desquelles ce terrain affleure étaient sous les flots, comme celles qui le renferment, à une profondeur quelconque, lorsque ces dépôts de craie se sont effectués. Ainsi, par exemple, à l'èpoque crétacée, une mer assez vaste s'étendait sur toute la région dont nous venons d'esquisser les contours, aux environs de Paris, depuis Bar-le-Duc à l'est jusqu'au Mans à l'ouest, et depuis Bourges au sud jusque snr l'Angleterre et au delà. Une autre couvrait une partie des Pyrénées, les Alpes maritimes, le Dauphiné, la Savoie, Ie Périgord. La chaine du Jura s'est soulevée avant la période crétacée. La date du soulèvement de la Côte-d'Or est en général fixée entre la période jurassique et la période crétacée; mais d'après des recherches nouvelles (') elle présente, en plusieurs endroits de la lẻvre affaissée, des dépòts kirnméridjo-portlandiens, plus récents par conséquent que les calcaires coralliens, et, ce quí est plus réeent encore, des sables albiens (á Marsaunay-le-Bois, Saint-Julien, Clénay, Brétigny, et sur les flanes du mont Affrique, à 550 mètres d'altitude). Le soulèvement de la Côted'Or a done eu lieu après la période albienne.

Notre carte géologique $n^{0} 7$ représente l'aspect probable de la France à ectte époque : les terrains primitils, primaires, triasiques et jurassiques sont formés, chacun suivant son âge chronologique; mais le terrain crétacé n'existe pas encore et est en formation sous Ia mer partout où nons la voyons ici. La seule incertitude qui reste dans notre esprit à l'égard de cette distribution des terres et des caux à une époque déterminée, ćest qu'il est possible que certains points des mers actuelles, Manche, Océan, Méditerranée, aient été émergés alors et soient redescendus depuis sous les eaux, et que certains golfes ou détroits aient existé en vertu de quelques affaissements locaux, la restitution des anciens rivages comportant plusieurs éléments en discussion, comme nous l'avons vu plus haut (p. 545). Mais l'ensemble ne pouvait s'éloigner beaucoup de

1. M. J. Martin. Comptes rendus de l'Académie des sciences, 1885. 
l'aspect gènéral de la carte, et le fait qui nous intéresse le plus en ce moment, celui de l'existence de la mer sur les pays que nous habitons. aujourd'hui, est incontestable.

Comme son nom l'indique, le terrain crétacé est le gisement par excellence de la craie. Il renferme cependant, surtout à sa base, des calcaires compacts et des argiles; mais les roches peu cohérentes, les sables ou les grès faiblement cimentés et surtout la craic, dominent de beaucoup à la partie supérieure. En général les roches crétacées sont plus claires de nuance, plus détritiques, plus fraiches, en un mot, que les roches jurassiques; les fossiles ne sont pas aussi complètement transformés et paraissent plus jeunes que dans ce dernier terrain.

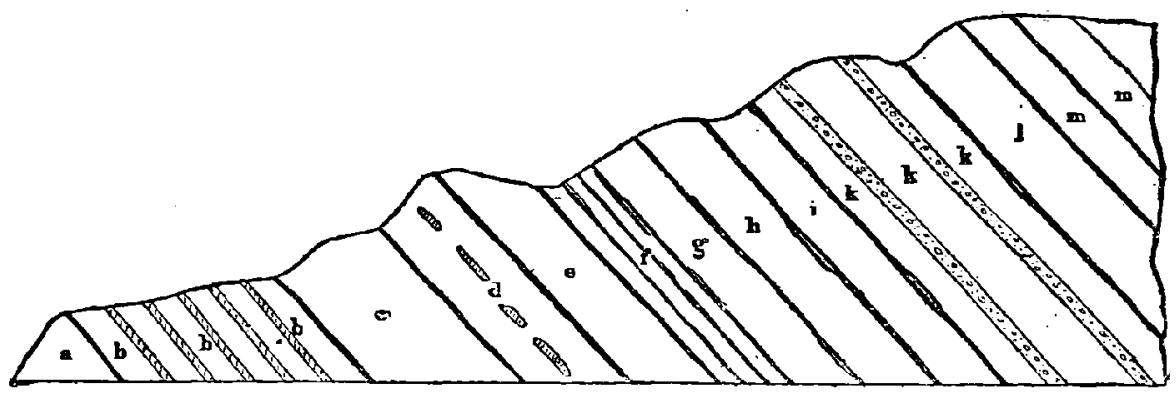

Fig. 330. - Coupe prise dans les terrains crétacés (Pyrénées : Bain-de-Rennes).

a. Ceicalre sacetaroĩde avec dicérates. - b. Marnea noires schisteuses, avec petites couches de calcaire compect et contenart dos ammonites, des exogyia. - c. Calcaire corpact, avec ostrea cristata, exogyra siauata, ex. columba. - $d$ Grès siliceux evec

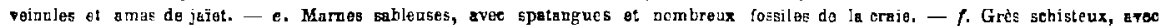
expreintes végétales et pelites couches de lignite. - g. Calcaire avec bippurites. radiolites, polypiars et contenant quelquas miliolites. - h. Calcaire a miliolites ot nommulites. - i. Marnes arec spstangaes et autres fossiles de la craie. - $k$. Alternance de marnes rougeátres, de calcaire compact cristallin et de poudingue calcaire. - l. Calcaire a miliolites et marnes rougeâtres, m. Marnes noires a miliolites, nummuliteñ, etre. .

Sans faire absolument défaut, le fer, le gypse, la dolomie, le sel gemme, sont fort rares dans la formation crétacée, où abondent, au contraire, les rognons de silex pyromaque, qui ont, dans la craie blanche, leur principal gisement. L'épaisseur' maximum de ce terrain dépasse deux mille mètres. Presque entièrement marine, la formation renferme cependant, à divers niveaux, des assises d'eau douce, plus développées que celles du terrain jurassique, et fournissant quelquefois des lignites exploitables. En Angleterre el ailleurs, elle débute par des argiles et des sables, déposés dans des lagunes analogues à celles où se formait l'étage de Purbeck. Les oscillations du sol ont continué à se manifester pendant toute la durée de l'époque, de façon que les mers empiétaient dans certaines régions, où 
se constituaient des dépôts d'une grande épaisseur, et laissaient à sec d'autres lieux, où des étages entiers font défaut. Cependant le mouvement d'ascension continue dans l'Europe occidentale; les bassins maritimes occupent à peu près les mêmes emplacements qu'à l'èpoque jurassique, mais diminuent insensiblement en surface. Il en résulte que les faunes et les sédiments diffèrent de plus en plus, même à des distances fort rapprochées, et deviennent comparables à ce qu'ils étaient à l'époque silurienne. Au contraire, dans l'Amérique du Nord, la mer envahit le littoral de l'Atlantique, et pénètre fort avant à l'ouest du Mississipi, où des dépôts d'une grande étendue témoignent de sa présence ( $\left.{ }^{4}\right)$.

Ces terrains se présentent, en général, sous forme de plateaux élevés, constituant le plus souvent des plaines arides et sèches ou des monticules aux pentes arrondies. Ils forment, presque partout, des zones concentriques aux grandes bandes jurassiques que nous avons décrites, et viennent s'appuyer sur elles, on s'enfonçant sous les terrains tertiaires, qui les recouvrent dans la région des plaines. En quelques points, ils dejpassent ces limites et viennent reposer sur le terrain houiller, ou même sur des couches schisteuses redressées, plus anciennes, ce qui nous indique que des mouvements assez considérables du sol ont encore eu lieu à cette époque.

Les mers, dans lesquelles ils se sont déposés, couvraient encorc une grande partie de l'Europe, mais leur configuration n'était plus la même qu'à l'époque jurassique. L'époque crétacée a été marquée par un retour de la mer sur des espaces qu'elle avait depuis longtemps abandonnés. C'est ainsi que la France méridionale, émergée depuis le corallien, s'est trouvée de nouveau sous les eaux et a fait partie d'une vaste mer qui s'étendait dans tout le sud de l'Europe.

$\Lambda$ cetto date, le plateau central; complètement émergé, soudé d'une part aux Vosges et de l'autre à la Vendẻe, s'opposiat à toute communication entre cette mer méridionale et celle qui, largement étendue dans le nord, couvrait le bassin de Paris et se prolongeait dans le sud de l'Angleterre. Ce fait important permet d'expliquer Ies grandes différences que l'on remarque entre les terrains crétacé: du nord et ceux du midi de la France.

1. Contrusan. Éléments de Géologie et de Paléontologie. 


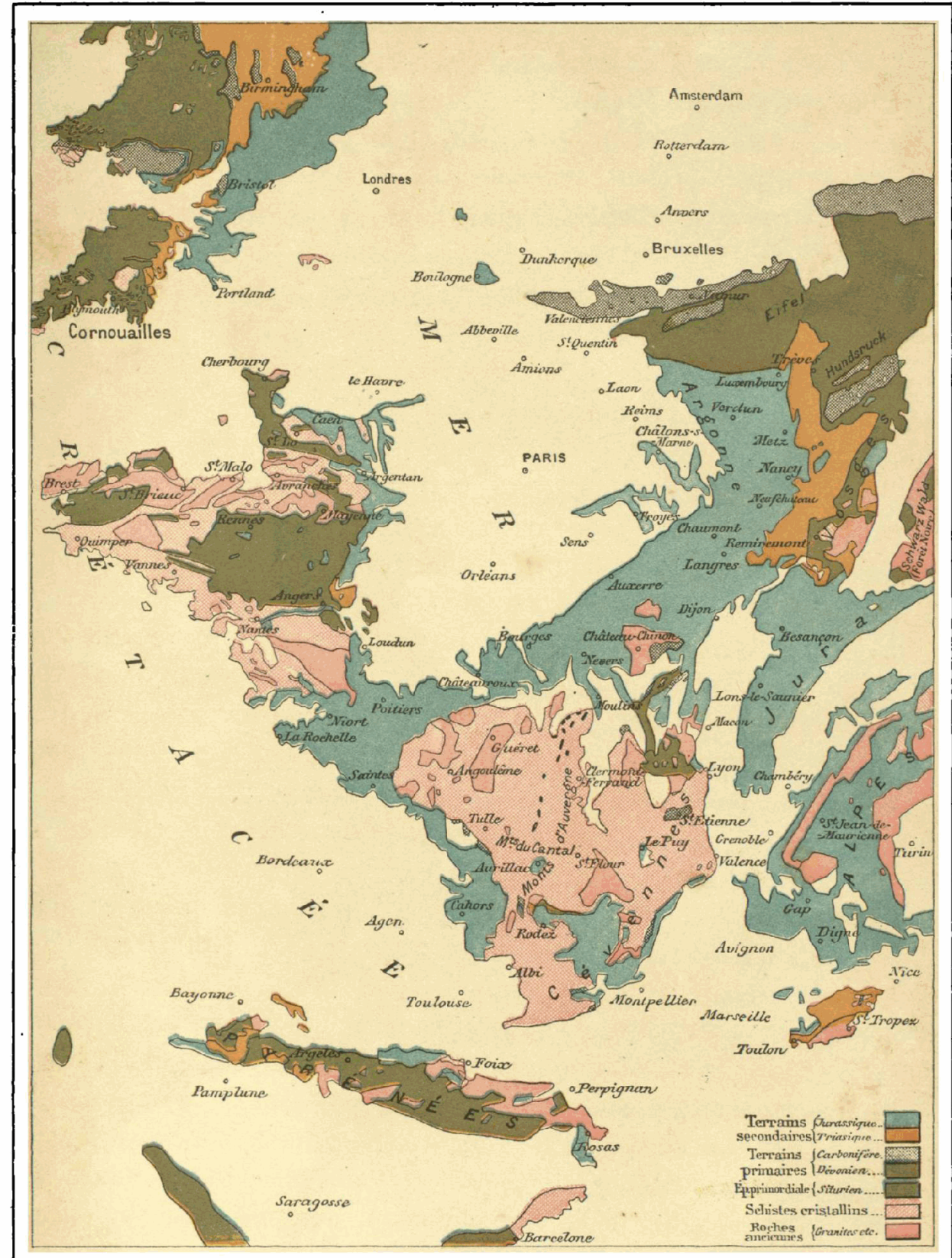

Gravé par E.Alorieze, R. Fowin 45, Paris.

Imprimerie A. Lahure

FORMATION GRADUELLE DES TERRAINS

FRANCE

Terrains primitifs, primaires, triasiques et jurassiques 
IRIS - LILLIAD - Université Lille 1 
La période crétacée se partage, comme la jurassique, en deux parties bien distinctes. De mème que dans les terrains jurassiques nous avons distingué le lias de l'oolithe, de même, dans les terrains crétacés, il convient de distinguer le système infracrètacé du crétacé proprement dit. Le premier, qui succède immédiatement au jurassique, ne contient pas de craie mais des calcaires, des sables et des argiles qui offrent de grandes analogies avec les sédiments jurassiques. Ces deux grandes séries, l'infracrétacé et le crétacé, se partagent à leur tour chacune en plusieurs ètages :

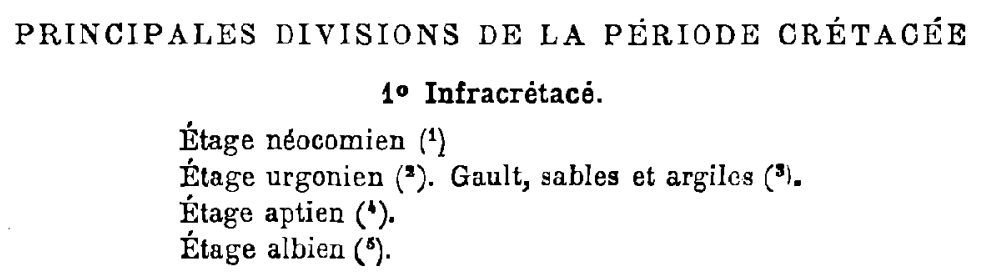

\section{Crétacé.}

Élage cénomanien ( $\left.{ }^{6}\right)$.

Étage turonien ( 7 ).

Étage sénonien ( ${ }^{(8)}$ et campanien (अ).

Étage danien (10) et garumnien (14,

La période infracrétacée se relie étroitemiat. par l'ensemble de ses caractères, à celle qui l'a précédée. La flore, où dominent les cycadées et les conifères et où les dicotylédones angiospermes sont encore inconnues, est une flore jurassique. Si des pins, des sapins et des cèdres s'y montrent associés aux types tropicaux, cette association prévaut aussi bien près du pôle, au Groënland, que dans l'Europe centrale, et atteste que les climats devaient offrir encore une grande uniformité. Toutefois, on ne peut manquer d'être

1. Ainsi nommé de Neuchâtel (Neocomium), en Suisse, où il est exploité pour les constructions.

2. D'Orgon, près d'Arles.

3. G'est le fond du puits artésien de Grenelle, et e'est un précieux réservorr pour les eaux d'infiltration. Ces argiles sont employées en Angleterre à la fabrication de tuiles et les ouvriers les ont qualifiées du nom peu distingué de gault.

4. D'Apt, où il est très développé.

5. Du département de l'Aube.

6. Du Mans.

7. De la Touraine (tuffau).

8. De Sens (craie blanche). - 9. Craie de la Champagne. - 10 et 11. Craie du Danemark et de la Haute-Garonne. 
frappé de ce fait que les formations des polypiers qui, pendant la période oolithique, s'avançaient jusque dans le Yorkshire par plus de $50^{\circ}$ de latitude ont sensiblement reculé vers le sud, car les calcaires à réquiénies (caprotines), qui sont pour la période infracrétacée, l'équivalent des calcaires à dicérates, ne se montrent guère que dans la zone méditerranéenne. Il ne semble donc pas excessif d'en conclure que déjà les conditions tropicales, qui seules conviennent aux formations coralligènes, avaient abandonné la partie septentrionale de notre hémisphère. L'empire de la terre ferme, durant cette période, parait avoir appartenu aux grands dinosauriens bipèdes, pourvu de caractères mixtes qui les font participer à la fois des mammifères, des oiseaux et des reptiles. Quant aux animaux marins, à part la prépondérance relative des céphalopodes à tours déroulés, on peut dire qu'ils ne font que continuer les types oolithiques ( ${ }^{(1)}$.

Les terrains crétacés commencent par des calcaires, des sables et des argiles, qui ont encore quelque analogie avec les sédiments jurassiques; c'est seulement dans les assises supérieures que se montre la craie véritable.

Le gault est reconnaissable à sa couleur foncée et se voit de loin tranchant par ses bandes sombres sur les teintes claires des roches qui l'environnent. C'est un ealcaire ou un grès tantôt vert, tantôt noir, renfermant une quantité de graines vertes qui lui ont fait donner le nom de grès vert. Ces grains sont composés d'un silicate de fer oxydulé; c'est par leur oxydation même qu'ils donnent à la pierre cette couleur sombre. Le gault renferme, par places, de nombreux rognons qui contiennent probablement du phosphate de chaux. Il est très répandu dans la zone alpine de la Suisse orientale, surtout au Sentis, au lac de Wallenstadt, à Pragel, près de Seeven, et jusqu'à Unterwald; il manque au contraire dans les Alpes bernoises et lucernoises; on le retrouve dans la vallée du Rhône et dans la Savoie, où il attcint de grandes proportions. A la perte du Rhône, il prend l'apparence d'un gris vert clair; il en est de mème à Sainte-Croix, dans le Jura, où il est recouvert par une argile bleue.

4. De Lapparent. Traité de Géologie. 
Le fait que l'on rencontre partout de ces grains dans le crétacé, et surtout dans le gault anglais, doit provenir d'une cause générale qui a présidé à leur formation et à leur disparition. Pendant l'époque crétacée il a dù se produire, à deux reprises, une riche formation de fer provenant de l'intérieur de la terre et qui s'est répandue dans toute l'Europe sans que nous soyons, pour le moment, en état de donner une explication plausible de ce phénomène.

La puissance de la craie dans le bassin de Paris est considérable; dans les falaises de la Manche elle surpasse cent mètres ; elle s'accroit en épaisseur dans l'intérieur du bassin ; ̀̀ Paris, les sondages pour es puits artésiens ont rencontré la craie sur une profondeur de 460 mètres; elle se divise en deux parties principales: la première, composée de craie d'abord noduleuse avec silex blonds, la seconde de craie blanche, avec silex zonés, renfermant, à divers niveaux, des oursins cordiformes de la famille des spatangues, et surtout les Micrasters, qui sont caractéristiques de cette première masse.

C'est à la craie à micraster que l'on doit entre autres les falaises de Dieppe et colles si singulièrement découpécs ditrtretat. On la retrouve dans l'intérieur des terres, en Picardie, elc.

Tous ces étages crayeux dessinent dans le bassin de Paris, antour des terrains tertiaires qui en occupent le centre, une large plaine ondulée, disposée en fer-à-cheval, dont les deux branches ouvertes viennent aboutir sur la côte normande, d'une part entre Dieppe et le Tréport, et de l'autre entre Boulogne et Calais. Ces deux bandes crayeuses se poursuivent au travers de la Manche et viennent de nouveau affleurer sur la côte anglaise, où elles forment ces grandes falaises blanches, de chaque côté de Douvres, qui sont visibles de France par un temps clair. L'Anglcterre leur doit son nom d'Albion. La craie s'y développe de mème, autour des terrains tertiaires, sur lesquels la ville de Londres est établie, en formant une région de collines arrondies, qui portent les noms de Downs. Tous ces terrains - Orléans, Paris, Dieppe, Londres - étaient donc sous les eaux à l'époque à laquelle nous sommes actucllement arrivés dans cette histoire de la Terre. Dans les environs de Paris, à Meudon, on voit aussi, au-dessus de la craie blanche, un calcaire jaune formé de petits grains arrondis et de débris de fossiles, désigné sous le nom de 
calcaire pisolithique; ce calcaire pisolithique, qui représente le dernier dépôt de l'époque crétacée, renferme un mélange d'espèces crétacées et d'espèces tertiaires. On y rencontre notamment, avec des ananchytes, de grands cérithes, comparables au cerithium giganteum que nous trouverons, très abondant, dans le terrain tertiaire parisien.

Ce même calcaire crétacé peut être observé à l'état de lambeaux isolés, adossés à la craie, en plusicurs points des environs de Paris. Il prend ainsi un caractère littoral très prononcé et témoigne, par sa distribution, d'un changement notable survenu dans les conditions du bassin parisicn, primitivement occupé par la mer crétacée. Gette mer, qui venait du nord, s'est retirée successivement, de telle facon que toutes ces masses crayeuses que nous venons de définir sont disposées en retrait les unes au-dessus des autres. Après le dépôt du calcaire pisolithique qui, lui-même, est limité à une petite étendue, toute cette partie nord de la France était émergée ( $\left.{ }^{4}\right)$.

Comment se sont formées ces épaisses couches de craie, qui atteignent cinq cent, mille et deux mille mètres d'épaisseur? Par sédimentation, par dépôts au fond des eaux, comme les précédents terrains, mais pourtant d'une façon bien différente. La craie est du carbonate de chaux. Ce carbonate de chaux était en dissolution plus ou moins saturée dans les eaux des mers primitives, puisque des quantités innombrables de crustacés s'en sont servis pour construire leurs coquilles calcaires. Dans ce milieu liquide, sensiblement calcaire, les foraminifères, les polypiers, les rudistes pullulaient et formaient d'innombrables populations. Que devenaient, après leur mort, les corps de ces animaux, grands et petits, mais ordinairement d'une petitesse microscopique? La matière animale destructible disparaissait, au sein de l'eau, par la putréfaction; il ne restait que la matière inorganique indestructible, c'est-ḋ-dire le carbonate de chaux, formant le test de leur enveloppe. Ces dépôts calcaires s'accumulèrent en épaisses couches sur le bassin des mers ; ils s'agglutinèrent bientòt en une masse unique, et formèrent un lit continu au fond des eaux. Ces couches se superposant, augmentant par la suite des siècles, ont fini par constituer des terrains: i ce sont nos terrains calcaires actuels.

1. Св. Vélals. Géologie straligraphiqua. 
Prenez un microscope, et, muni de cet œil artificiel, examinez un fragment de craie; vous n'y verrez plus une poudre informe et grossières, mais tous les grains vont prendre une forme régulière. Voici des fragments de coquilles, des ammonites lilliputiennes, et toute une armée de foraminifères $(f g .331$ à 333$)$. Tout ce monde des eaux antiques apparaît sous le microscope; ce massif de craie n'est pas autre chose que l'entassement séculaire de ces populations marines d'un autre âge!

Les coquilles de foraminifères forment à elles seules des chaînes

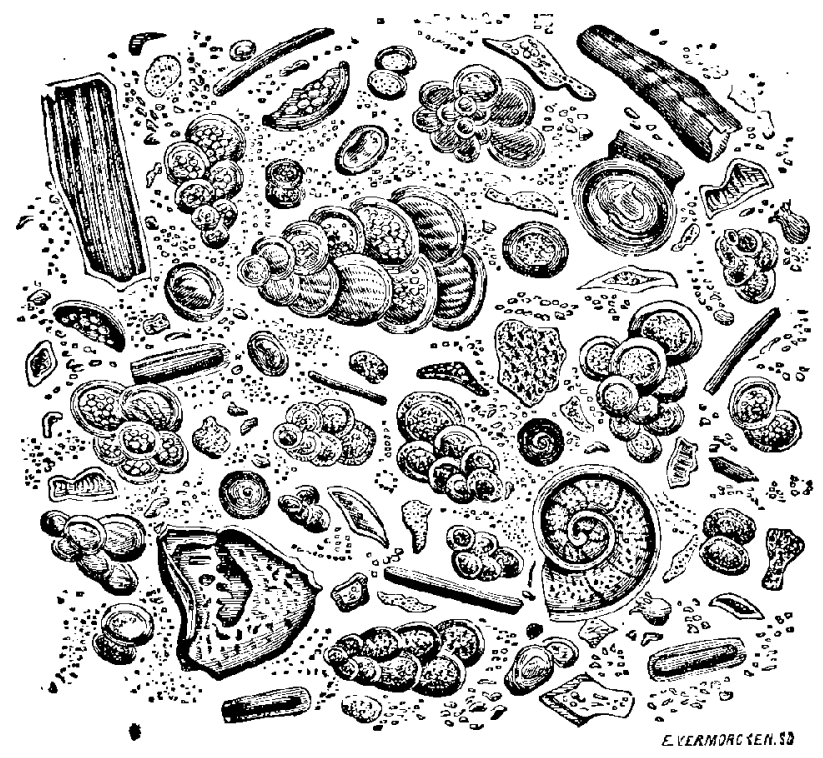

Fig, 331. - Fragment de craie vu all microscope.

entières de collines élevées et des banes immenses de pierres à bâtir. Les foraminifères sont des coquilles marines à plusieurs loges dont les plus grandes atteignent tout au plus deux millimètres de diamètre, et dont cependant on est parvenu à distinguer près de huit cents espèces différentes. Combien n'a-t-il pas fallu de ces petits ètres pour que leurs débris accumulés forment des bancs de craie d'une aussi vaste étendue! Le calcaire grossier des environs de Paris est, dans certains endroits, tellement rempli de ces dépouilles, qu'un centimètre cube des carrières de Gentilly, carrières 
d'une grande épaisseur, en renferme au moins vingt mille; ce qui donne par mètre cube le chiffre énorme de vingt milliards.

Quand nous passons prè d'une maison en démolition ou d'un édifice que l'on construit et que nous sommes enveloppés par un nuage de poussière qui pénètre dans notre gosier, nous avalons souvent, sans nous en douter, des centaines de ces infiniment petits. On donne aussi à ces fossiles microscopiques le nom de milioles parce que leur volume ne dépasse pas celui d'un grain de millet et même est souvent moindre.

Une observation de M. Defrance donne une idée de la petitesse

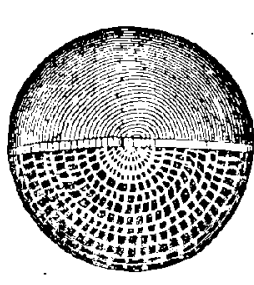

Fig. 332.

Les nummulites de là pierre à bảtir. de la miliole des pierres, espèce dont est principalement composé le calcaire grossier employé à la construction. Il a reconnu qu'une case d'une ligne cube de capacité pouvait en contenir jusqu'à quatre-vingtseize!

Celles-ci étaient tellement nombreuses dans les mers parisiennes, qu'en se déposant elles ont formé des montagnes que l'on exploite aujourd'hui pour la construction de nos villes. La plupart des pierres des habitations de Paris ne sont même composées que de petites carapaces de miliolides entassées et étroitement liées arec elles; aussi peut-on dire, sans hyperbole, que notre splendide capitale est bâtie en coquilles microscopiques. Arrètez-vous à Paris devant un mur quelconque de pierres de taille, par exemple rue de Rivoli, au Palais-Royal, etc., vous reconnaitrez non seulement les grains de ce calcaire, mais aussi, en bien des points, les coquilles parfaitement visibles à l'œil nu. La pierre dite de Laon est forméo d'un amas considérable de nummulites, charmantes espèces de forme lenticulaire, à cellules très nombreuses disposćes en spirale, espèces non microscopiques.

Les pyramides d'Égypte sont construites avec des pierres analogues et fondées sur des roches de calcaire nummulitique. Nous avons déjà vu plus haut que les anciens prenaient pour des lentilles pétrifiées les débris tombés à la base. Ce nom de nummulites vient de leur ressemblance avec de petites pièces de monnaie (étymologie : nummularius). 
Les foraminifères ont donc sécrété une partie du sol sur leque? nous marchons, des maisons qui nous abritent et des édifices que nous léguons à la postérité. Chaque animalcule a fourni son grain solide, chaque type a déposé sa couche imperceptible. Les espèces qui vivent encore aujourd'hui préparent en silence, au sein de l'Océan, des pierres de taille pour la construction des générations futures.

Ehrenberg, qui a examiné bien des centaines d'échantillons de vase recueillie dans toutes les mers, a étudié entre autres les boues ramassées à des profondeurs de trois à einq cents mètres dans les sondages exécutés à l'occasion de la pose d'un câble télégraphique. Presque généralement les polythalames s'y trouvent dans une porportion considérable, ce qui n'a guère lieu de surprendre après qu'on les a vus apparaître en masses dans des points peu profonds du littoral. Le naturaliste bérlinois a trouvé souvent, dans les coquilles retirées avec les sondages, des restes du corps mou de l'animal. Il a cru devoir en conclure que ces animaux vivent en réalité dans ces profondeurs lointaines, et que leur multiplication, par masses considérables, contribue à niveler graduellement sur place les vallées sous-marines.

Les plus grands de tous les foraminifères, les nummulidés, ont joné un grand rôle à diverses époques géologiques, dit Pouchet. On les rencontre en quantité prodigieuse dans les terrains secondaires et tertiaires, et ils ont tellement abondé parmi les mers qui recouvrirent quelques-uns de nos continents, que par leur simple agrégation, leurs carapaces calcaires forment d'imposantes montagnes.

Dans une vaste étendue, ces caquilles constituent absolument toute la chaine arabique qui longe le Nil; là, elles sont tellement nombreuses et tellement tassées qu'il n'existe presque aucune gangue pour les lier. En diverses régions de la haute Égypte, le sol du désert ne consiste qu'en un épais matelas de nummulites, dans lesquelles glisscnt et s'enfoncent profondément les pieds des voyageurs et des chameaux.

Tout le terrain de la ville de Richmond et du district environnant, dans l'État de Virginie, en Amérique, se compose d'une couche de diatomées fossiles, de près de dix mètres d'épaisseur, appartenant 
à des espèces qui vivent encore aujourd'hui dans la mer Glaciale. Par contre, on a découvert, dans les lacs d'eau douce de l'Afrique occidentale, de semblables organismes vivants, d'une espèce qui est connue, à l'état fossile, en Suède et en Norwège, sous le nom de farine minérale.

Le duché de Lunébourg est généralement considéré comme une lande sablonneuse, ce qui n'est rrai que pour certaines parties superficielles; les terrains situés à quelque profondeur se composent, sur une étendue de plusieurs centaines de licues carrées, d'une couche de diatomées, ayant une épaisseur de dix à vingt mètres. La couche de diatomées du Brandebourg, sur laquelle est bâtie la ville de Berlin, a une épaisseur encore plus considérable: elle atteint quarante à cinquante mètres; mais clle est moins pure que celle du Lunébourg; il s'y trouve beaucoup d'autres organismes et aussi des matières inorganiques.

Ce que l'on connaît sous le nom de farine minérale, schiste à polir, tripoli, etc., dans différents pays, notamment aux environs de Bilin, en Bohème, n'est autre qu'une masse de coquilles siliceuses d'êtres microscopiques. Humboldt raconte même que certaines peuplades des Antilles en font une friandise, consistant en petits rouleaux d'une pâte préparée avec ces infusoires, et séchée au feu pour en former une sorte de gâteau.

Ces ètres microscopiques sont répandus dans toutes les contrées du globe, depuis les pôles jusqu'à l'équateur. Tous les êtres organiques de notre époque sont diversifiés selon les climats ; les diatomées, au contraire, ne paraissent ressentir l'influence ni du froid ni de la chaleur: les espéces trouvées en Chine et au Japon ont été reconnues identiques avec celles qui vivent dans la mer Baltiqque. La Nouvelle-Hollande, dont tous les produits organiques se distinguent de ceux de l'ancien continent, possède des espèces qui sont répandues dans les régions torrides de l'Afrique et de l'Asie, aussi bien que dans les contrées froides de l'Europe et de l'Amérique; les espèces que l'on a découvertes dans les sources chaudes de Carlsbad se montrent aussi dans le voisinage des pôles; celles, enfin, qui vivent à la surface de la mer ont également été trouvées, au moyen de la sonde, à une profondeur de six cents mètres, où elles subissaient une pression de 60 atmosphères. 
Or, comme nous l'avons vu, les couches les plus anciennes de l'écorce terrestre, celles qui, aussitôt après le refroidissement de la surface, ont été déposées par la mer encore en ébullition, ces couches-là, disons-nous, ronferment déjà des diatomées analogues aux espéces actuellement vivantes. Les animaux les plus énormes du monde primitif, les atlantosaures, les brontosaures, les monstrueux crocodiles et lézards volants, les mammouths ont tous disparu de la nature vivante, sans laisser d'autre trace que leurs débris fossiles. Les imperceptibles diatomées, au contraire, ont survécu à toutes les révolutions du globe, à toutes les luttes des éléments déchaînés: leurs descendants peuplent encore ces mèmos mers

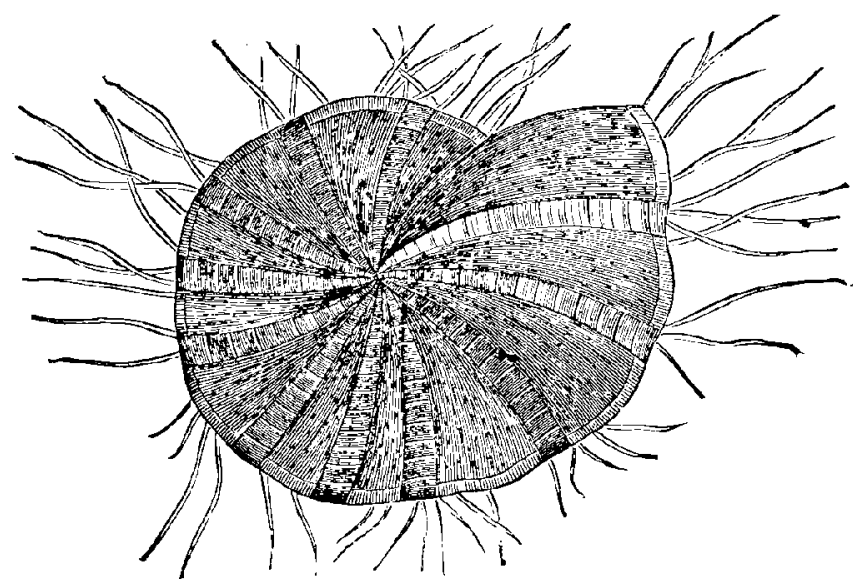

Fig. 333, - Miliole de la pierre a bãtir (calcaire grossier) très grossie. Polystomella strigillata.

qui ont englouti les ossements des animaux 'gigantesques, dont pas un seul n'est resté pour reproduire sa race. Si, d'une part, l'extrème petitesse des diatomées explique leur force de résistance, d'autre part leur puissance inouie de reproduction fait comprendre leur importance pour l'économie de la nature.

Ces organismes se multiplient par scission. D'un de ces corpuscules, il s'en forme soudain deux, dont chacun grossit, se fend à son tour, en forme encore deux, et ainsi do suite, à tel point qu'on a pu établir, par une observation attentive, que dans des circonstances exceptionnelles, une seule diatomée peut produire en quarante-huit heures un million, et, dans l'espace de quatre jours 150 billions d'individus de son espèce. Seulemenl, ils ne vivent 
pas longtemps; mais leurs débris restent. Une reproduction si énorme n'a pas lieu ordinairement; cependant en certaines conditions, elle peut se constater à vue d'œil. La vase qui se dépose dans le port de Pilau (près de Kœnigsberg, en Prusse) est à moitié composée d'organismes microscopiques; elle nécessite une activité incessante pour le curage du port, attendu que les nouveaux dépôts remplissent tous les ans un cspace de 14000 pieds cubes. Si l'on n'y mettait obstacle, le port deviendrait impraticable, et au bout d'un siècle on aurait là une couche de diatomées d'un million et demi de mètres cubes.

Dans le sable de la mer on trouve fréquemment de petits coquillages; dès les premières années du siècle dernier, deux savants italiens, Bianchi et Beccaria, se donnèrent la peine de compter le nombre des coquilles contenues dans une once de sable de la mer Adriatique, aux environs de Bologne : ils en trouvèrent 1120 . Beccaria constata que des collines entières de la terre ferme, au sud de Bologne, sont formées exclusivement de ces coquillages. Mais à cette époque, oủ l'on avait l'habitude de mettre sur le compte dn déluge tous les phénomènes analogues, on ne comprit qu'imparfaitemeut l'importance géologique de ce fait.

Jans le courant de ce siècle, longtemps avant les sondages faits en vue de la pose du câble transatlantique, on avait établi qu'une grande partie du fond de la rógion septentrionale de l'Atlantique est constitué par un dépôt désigné aujourd'hui sous la dénomination de " vase des globigérines. \Il est formé de coquilles de petits foraminifères appartenant principalement au genre globigerina; à l'état sec, cette vase offrait à peu près l'apparence d'un sable fin; les petites coquilles se détachant les unes des autres, ont permis de reconnaitre qu'elles constituaient presque exclusivement ce dépôt. Quand on recueillait, à l'aide d'un procédé spécial, des échanlillons de la inasse du fond située un peu plus profondément, on trouvait les coquilles de globigérines brisées et soudées ensemble, de telle sorte qu'elles formaient un limon presque uniforme, dans lequel on pouvait néanmoins distinguer encore un grand nombre de coquilles intactes et de fragments parfaitement reconnaissables. La masse entière était constituée presque uniquement par du carbonate de chaux, et la seule roche qui 
aurait pu provenir de là eût été une pierre calcäire. On a conclu de ces observations que sur une vaste étendue de la région septentrionale de l'Atlantique et sur beaucoup d'autres parties de la surface terrestre, il a dû se déposer des rochos calcaires de ce genre. D'autres observations ont montré que c'était presque le même matériel qui composait la craie, et il paraît établi, d'une manière indéniable, que le dépôt qui continue à s'effectuer encore aujourd'hui est identique à la craie.

Ces petits étres ont exercé une action plus puissante que celle des forces plutoniennes et volcaniques les plus formidables. Les unes et les autres n'ont pu que soulever du centre à la surface ce qui existait déjà, ou bien le détruire ou le bouleverser. Les polypes, au contraire, construisaient, créaient, et agissant lentement, mais sans cesse, étaient parfaitement aptes à transformer, dans le cours de millions d'années, la face de la planète. Sthleiden dit à ce sujet, avee autant de vérité que de justesse : « Les modifications de la surface terrestre sont en partie l'ouyrage d'animaux et de végétaux que, d'ordinaire, on croit destinés seulement à se faire porter et nourrir par la terre, leur mère commune; et, chose merveilleuse, ce ne sont pas les masses colossales des baleines et des éléphants, ni les trones puissants des chènes, des figuiers et des boababs, mais bien les polypes, gros comme une tête d'épingle, les polythalames, imperceptibles à l'œil nu, les plus petites plantes microscopiques dont tous les marais recèlent l'existence ignorée, qui ont exercé une action efficace sur la strurture de la terre ».

Nous contemplons avec admiration une longue suite de montagnes, couvertes de vastes forèts de chênes et de hêtres, et nous passons dédaigneusement devant l'écume verdâtre d'une flaque d'eau stagnante; et pourtant, dans cette écume méprisée se meut tout un monde de petits êtres, occupés à construire des montagnes. Il en est ainsi dans la mer, où une force productrice inépuisable couvre sans cesse les rochers d'ètres qui construisent des rochers nouveaux, et ces ètres sont des animalcules tellement petits, qu'ils se dérobent à l'œil humain.

Ainsi la craie est surtout un produit de l'activité organique. Elle est composée de particules calcaires amorphes auxquelles sont associées un grand nombre de carapaces microscopiques de fora- 
minifères appartenant surtout au genre globigerina. Elle varie d'ailleurs beaucoup dans sa composition; tantôt elle s'associe avec de l'argile et devient marneuse, tantôt elle se charge de grains verts ferrugineux (glauconie); c'est la craie glauconieuse. Quand elle est dure et compacte, on lui donne le nom de craie blanche; la craie est dite tufacée quand elle est jaune et sablonneuse.

La craie renferme quelques substances accidentelles, parmi lesquelles on peut citer le silex et le sulfure de fer. Le silex, en particulier, est fréquent dans la craie blanche qui forme la partie supérieure du terrain crétacé, où il se présente disposé par rognons noduleux plus ou moins arrondis, souvent très irréguliers, alignés par cordons, espacés de un à deux mètres au travers de la masse crayeuse. Ces silex, de nature calcédonieuse, résultent de la concentration de la silice autour de corps organiques en décomposition, dont le squelette était siliceux, tels que les spongiaires.

Leur coloration varie : les uns sont gris et zonés, les autres blonds et transparents, d'autres sont complètement noirs. Ces dictinctions offrent cet intérêt pårticulier de permettre d'établir des niveaux dans la masse crayeuse.

Le sulfure de fer se présente fréquemment sous la forme de baguettes ou de globules à texture fibreuse, d'un jaune d'or (pyrite jaune), ou d'un blanc argentin (pyrite blanche) éclatant.

S'il n'est pas nécessaire d'admettre que la craie se soit formće à une grande profondeur, on doit du moins reconnaitre que son dépôt a dû être exempt de troubles et que les rivages voisins n'y ont apporté aucun élément. Ce dépôt s'est d'ailleurs accompli avec lenteur; car il n'est pas rare de trouver des oursins sur le test desquels des individus de crania se sont librement développés pour servir, à leur tour et après la mort de l'animal, de surface d'attache à des serpules. Plusieurs générations d'animaux marins se sont donc succédé au mème point avant qu'il se déposât, sur le fond, une quantité de boue crayeuse un peu épaisse.

La faune crétacée est la continuation de la faune jurassique, avec une tendance vers les progrès destinés à etre réalisés pendant l'époque tertiaire. On connait déjà près de six mille espèces caractéristiques de cetté époque. Les types secondaires y dominent, mais vers la fin apparaissent déjà les types tertiaires. C'est toujours la 


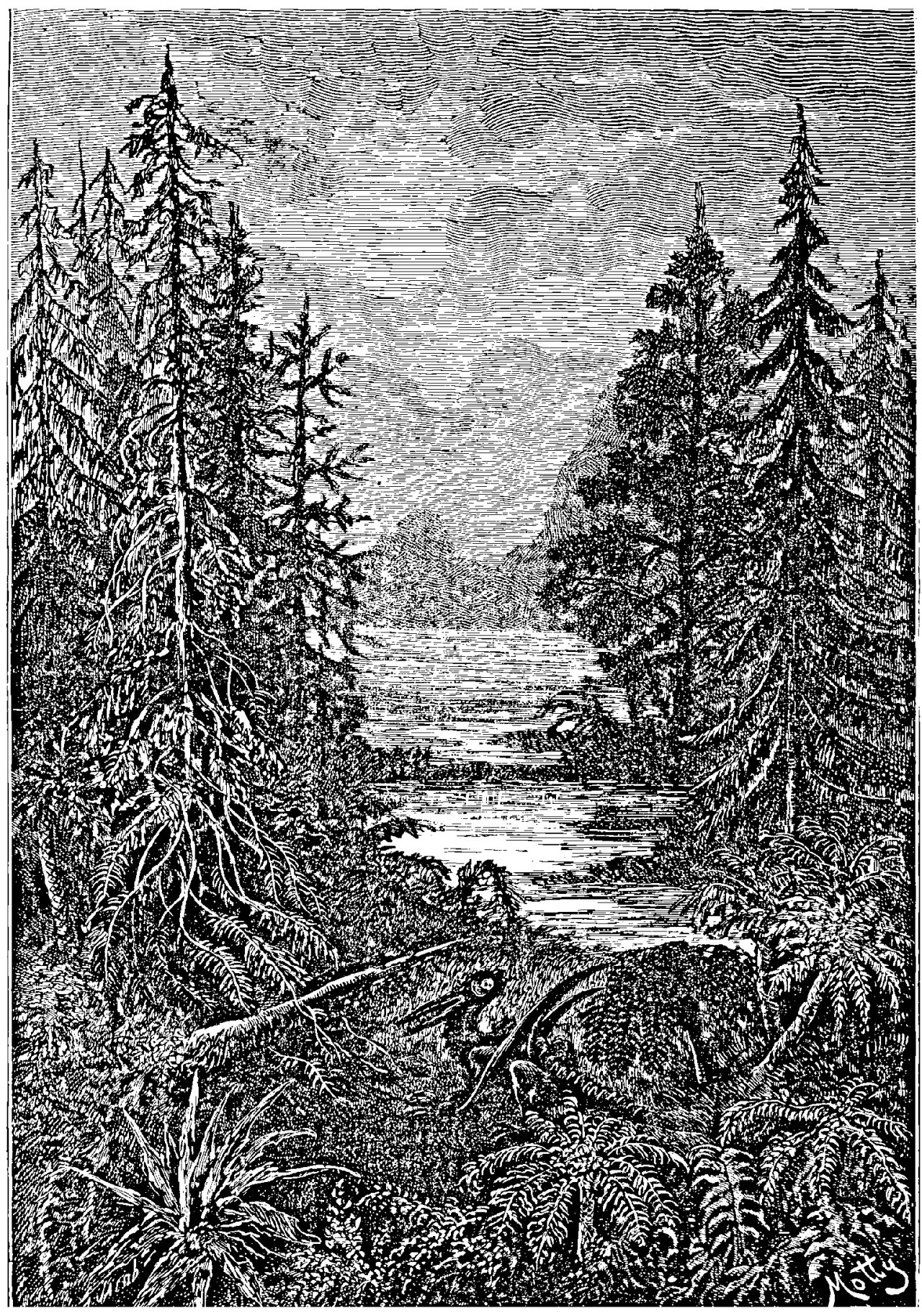

UNE FOUET AUX PREMIERS SIÉGLES DE LA PB́BNODE GRETACELL.

LE MUNDE aVaNt La CRÉtion DE L'HOMME 
mẻme loi de continuité qui s'est mise d'elle-mẻme en évidence dans tout le cours de cet ouvrage.

Parmi les classes inférieures de l'animalité, nous avons déjà signalé le grand et remarquable développement des foraminifères qui succéda à celui des polypiers et des spongiaires de l'étage corallien. Les coraux ne construisent plus de récifs dans nos contrées, et vers la fin de la période abandonnent tout à fait les mers septentrionales, ce qui doit correspondre avec un abaissement de température. Les stellérides se maintiennent davantage; les échinides sont en progrès (signalons, parmi les coquilles caractéristiques de ces terrains, le micraster cor-anguinum ( $f g .335)$, que l'on trouve communément dans le bassin de Paris). Les mollusques bryozoaires se multiplient, surtout dans les étages supérieurs. Les brachiopodes s'enrichissent d'espèces nouvelles, notamment des térébratulines ( $f g .336$ à 338), différentes des térébratules, et dont plusieurs espèces existent encore aujourd'hui dans nos mers profondes. Certaines couches sont très riches en huitres. Les acéphales et les gastéropodes se développent aussi, donnant naissance à la curieuse famille des rudistes, caractéristique du terrain crétacé, dans les limites duquel elle se trouve absolument renfermée.

Les rudistes sont des mollusques assez bizarres, qui ont exercé la patience et la sagacité des naturalistes au moins autant que les bẻlemnites. Massive et irrégulière, leur coquille ressemble à une grosse corne allongée, à un trone de cône, le tout généralement criblé de perforations tubulaires. Les principaux genres de rudistes sont les hippurites $(f g .339)$, les sphérulites, les radiolites, les caprines ( $f g .340)$, les caprotines. Leurs espèces vivaient souvent en colonies agglomérées, formant des banes très étendus oú des indiviuns de tout àge se souderent lés uns aux autres par la substance même de la coquille. Elles abonident dans le crétacé du sud-ouest de la France et n'ont guère dépassé au nord le $45^{\circ}$ degré de latitude, nouvel indice d'un abaissement probable de la température. On retrouve aujourd hui de beaux types ae ces récifs anciens encore en place, et tels qu'ils se sont formés sous l'influence des courants sous-marins qui accumulaient en certains points les amas de ces animaux divers. Bien n'est plus curieux que cet assemblage de rudistes encore perpendiculaires, isolés ou en 
groupes, que l'on apereoit aux flancs de cortaines montagnes, principalement en Provence. Il semble, dit Alcide d'Orbigny, que la mer vienne de se retirer et de montrer encore intacte la faune sous-marine de cette époque telle qu'elle a vécu. En effet, ce sont des groupes énormes d'hippurites en place, entourés des poly-
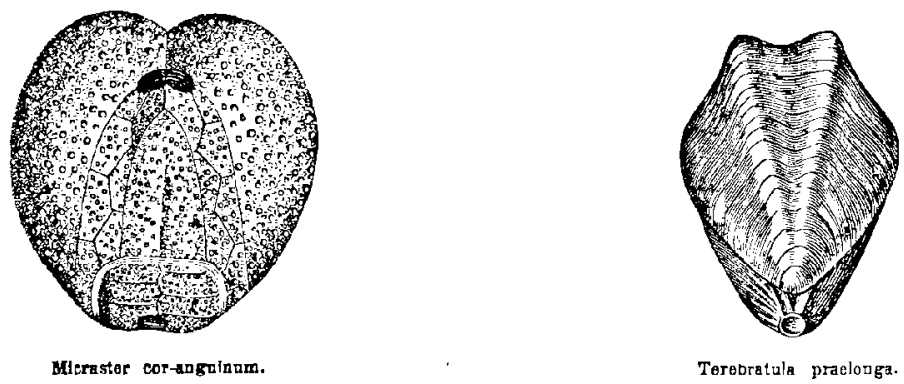

Fig. 335-336. - Fossiles du terrain crétacé.

pier's, des échinodermes, des mollusques, qui vivaient réunis dans ces colonies animales, analogues à celles qui vivent sur les récifs des coraux des Antilles et de l'Océanie. Pour que cet ensemble nous ait été conservé, il faut qu'il ait été d'abord couvert subitement de sédiments lesquels, en se détruisant aujourd'hui par suite
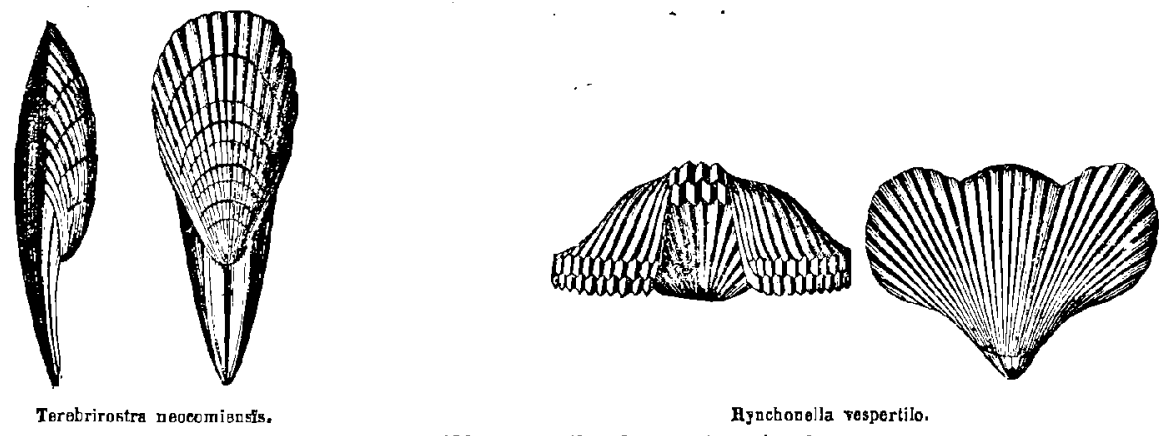

Fig. 337-338. - Fossiles du terrain crètacé.

des agents atmosphériques, nous découvrent dans ses plus secrets détails cette nature des temps passés.

Les ammonitides atteignent leur ère de souveraineté avec une profusion des types les plus variés. Le genre ammonite proprement dit prime tous les autres comme aux temps jurassiques; il serait long d'en décrire les formes même principales; signalons pourtant l'ammonite inflatus ( $f g .341$ ) et l'ammonite radiatus ( $f g$. . 342), qui 
peuvent assurément compter parmi les plus remarquables. Elles disparaissent ensuite pour toujours. Les bélemnites sont encore représentées par les genres actinocomax (pleines) (fig. 343) et

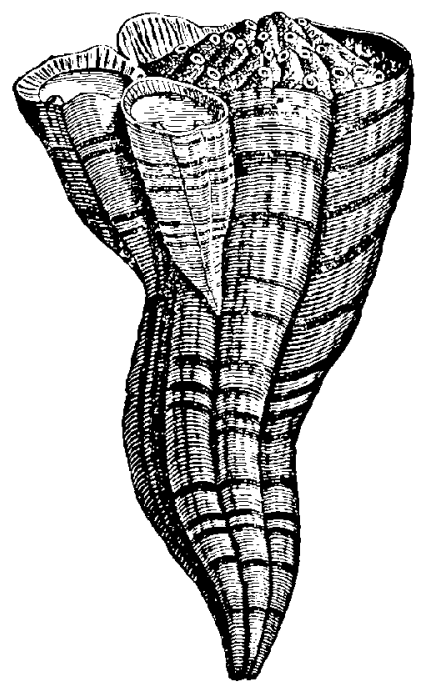

Fig. 339. - Groupe d'hippurites Toucasianus à différents âges.

belemnitella mucronatus (creuses) ( $f g .344)$. On les rencontre souvent ovales et écrasécs. Au-dessus du terrain crétacé, oủ elles

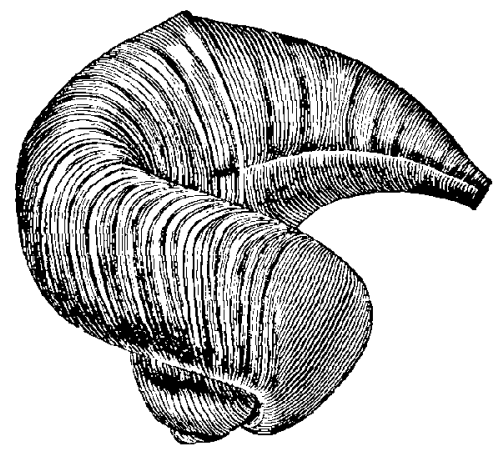

Fig. 340. - Rudiste du terrain crétacé. Caprina adversa.

commencent à ètre rares, on ne trouve plus ni ammonites ni bélemnites, de sorte que la seule présence de ces fossiles suffit pour donner la certitude que la formation du terrain qu'on examine n'est pas antérieure à l'époque du trias, ni postérieure à celle de la craie. C'est avec raison, on le voit, que les géologues considèrent 
les coquilles comme les médailles commémoratives des grandes

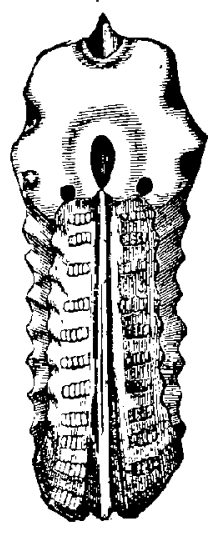

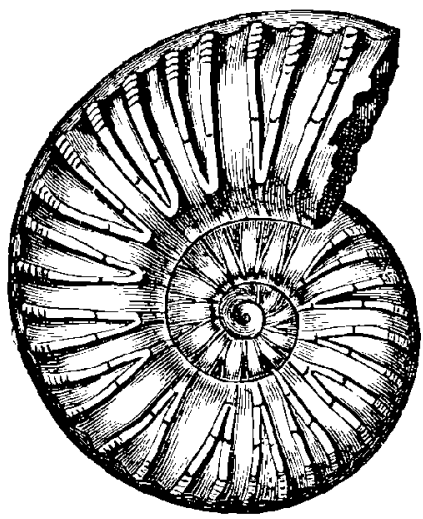

Ammonjtes indatue,

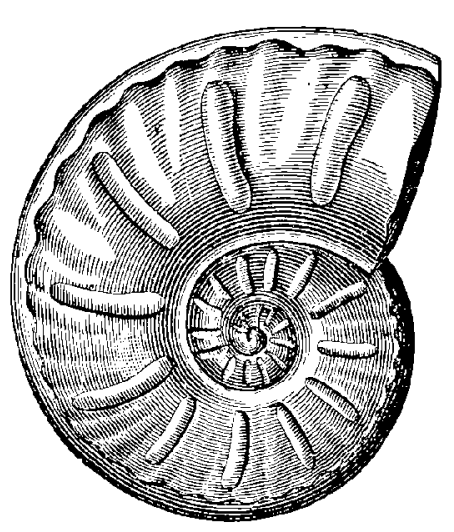

Ammonites rad alus.

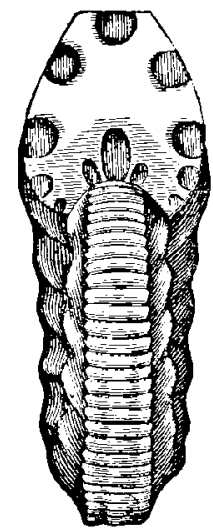

Fig. 341-342. - Ammonites du terrain crétacé.

époques du globe. Colui qui trouverait une bélemnite dans un

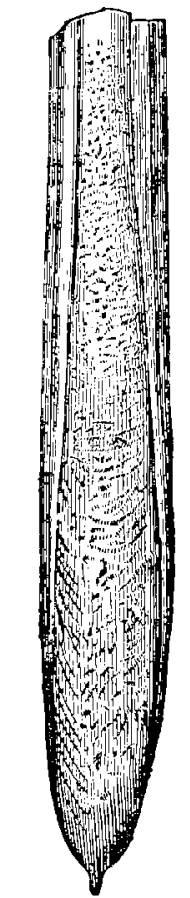

Actinoconax (pleine)

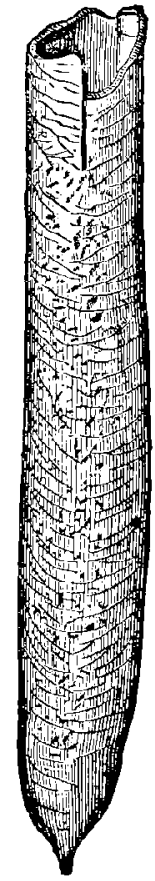

Belemnitella (crense).

erétacé.

terrain houiller ferait une découverte analogue à celui qui irouverait une phrase de francais daus un manuscrit de Cicéron. 
C'est dire qu'il y aurait là un anachronisme absolument impossible.

De même que pendant l'époque jurassique, les mollusques forment encore ici le contingent le plus important de la population des mers crétacées. Les céphalopodes rivalısent par le nombre de leurs espèces avec ceux de l'époque jurassique; si les ammonites n'atteignent pas le mème chiffre, les nautiles, en revanche, sont devenus plus nombreux; avec les turrilites, baculites, ptychoceras et les hamites apparaissent des genres entièrement nouveaux. Les nombreuses formes de ce groupe à coquilles droites, recourbées et

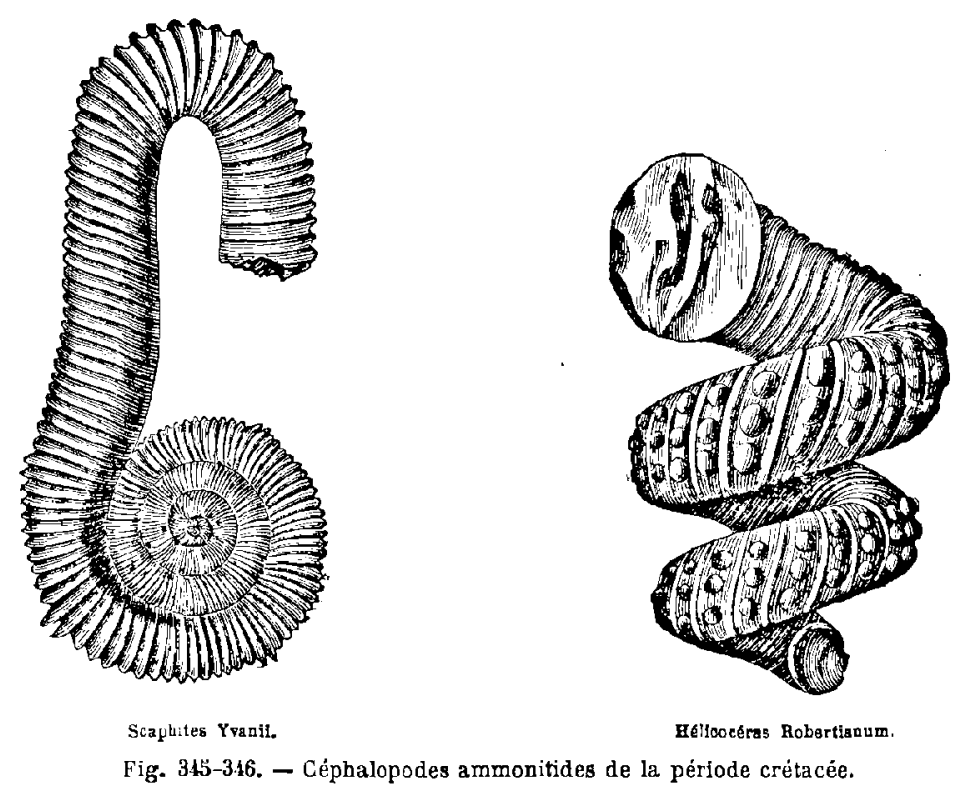

enroulées seulement à leur extrémité caractérisent en général l'époque crétacée. Cette famille possédait déjà dans la mer jurassique une remarquable richesse de formes; cette modification des genres continue pendant la période crétacée et de nouveaux types viennent même s'y ajouter. L'ammonite n'est plus sculement enroulée cn spirale sur un même plan, type que nous avons vu dans le Jura; elle prend dans le crétacé l'aspect de cornes, de bâtons, elle s'enroule en ris ou à la façon des escargots. Ainsi donc, avant de disparaitre pour toujours des faunes vivantes, ce remarquable type de mollusque possédait encore une grande variété de formes.

Parmi les classes supérieures de l'animalité, nous pouvons 
observer la transformation lente des poissons et des reptiles. Les poissons ganoides sont en décadence et ont fait place aux genres à écailles cornées, aux téléostéens. Les reptiles qui ont caractérisé le jurassique s'éteignent peu à peu. Dans la seconde moitié de la période crétacée, on ne trouve plus ni ichthyosaures, ni plésiosaures, ni ptérodactyles. Les dinosauriens sont encore représentés par les iguanodons, les mégalosaures, les hyléosaures, les pélorosaures, et surtout par les giganlesques mosasaures. Les crocodiles, descendants des sauriens du jurassique, font leur apparition pour durer jusqu'à nos jours.

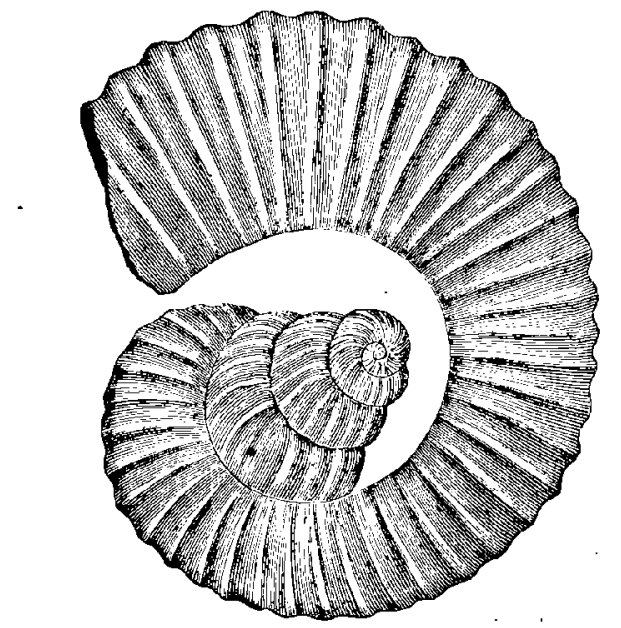

Fig. 347. - Céphalopode ammonitide de la période crétacée. Hétéracéras Emericianum.

Les poissons et les amphibies ne paraissent pas avoir été nombreux, quoiqu'on trouve èd et là quelques restes. Parmi les premiers, les squales sont remarquables; on en a découvert six espèces en Suisse, ils appartiennent à des genres dont quelques-uns vivent encore de nos jours, tels que les oxyrhina et les odontaspis; d'autres, aux genres otodus et corax, qui sont spéciaux à la craie et à la mer tertiaire. Nous retrouvons la famille des ganoïdes représentée comme à l'époque jurassique, par le genre pycnodus avec cinq espèces, dont une a èté observée al Sentis, à la perte du Rhône et au Salève; une autre est commune dans le néocopien du Jura; cnsuite viennent les genres sphænodus et gyrodus. 
M. Pictet a décrit quatre espèces de poissons à forme de harengs, qu'il a trouvées dans le néocomien des Voirons; ils sont proches parents des genres élops et mégalops des tropiques. Parmi ces harengs et ces squales, les poissons de l'époque crétacés s'écartent de ceux de l'époque jurassique et se rapprochent de la faune actuelle.

Les reptiles marins achèvent leur règne. Si quelque obser. vateur, quelque esprit, quelque regard pensif avait pu contempler alors les régions où la grande cité parisienne resplendit aujourd'hui et pénétrer les profondeurs de la mer au fond de laquelle se déposaient les banes crétacés que nous avons remarqués dans la coupe géologique du puits artésien de Grenelle, ce précurseur de l'humanité future aurait vu dans ces eaux les poissons antiques de cette époque, les macropoma, les gyrodus, les belenostomus, les lepidotus, en compagnie des céphalopodes, des hippurites, des oursins, des éponges, vivant de cette existence primitive qui ne laisse rien deviner des destinées futures de la Terre, el dominés par les gigantesques reptiles aquatiques de la surface, notamment par le fameux mosasaure décrit à la période précédente et qui règne jusqu'aus derniers temps de la mer crétacée. C'est ce que nous avons essayé de représenter dans le dessin de la page suivante.

Les oiseaux prennent graduellement possession de l'atmosphère. Aux archéoptérix de l'époque jurassique succèdent les oiseaux $\dot{a}$ dents avec lesquels nous avons dèjà fait connaissance, les ichthyornis, les hesperornis, etc.

Le plus ancien et le mieux connu de ces oiseaux primitifs est l'hesperornis regalis. Il parait avoir été abondant vers le milieu de la période crétacée. C'était un oiseau aquatique. Il habitait les rives de la mer qui s'ètendait alors sur l'Amérique du Nord; il était très grand et pouvait ressembler à un énorme pingouin. Ses ailes ètaient réduites à un seul osselet styliforme représentant l'humérus; son sternum aplati et sans carène ressemblait à celui des autruches, et son omoplate ainsi que l'os coracoïde rappelaient à la fois les ratitæ et les reptiles dinosauriens. Mais ses membres postérienrs, avec leurs pattes palmées, étaient très robustes, et il avait une forte queue qui, composée de douze vertébres dilatées latéralement en torme de rame ou de palette horizontale, devait constituer un puissant organe de locomotion. 


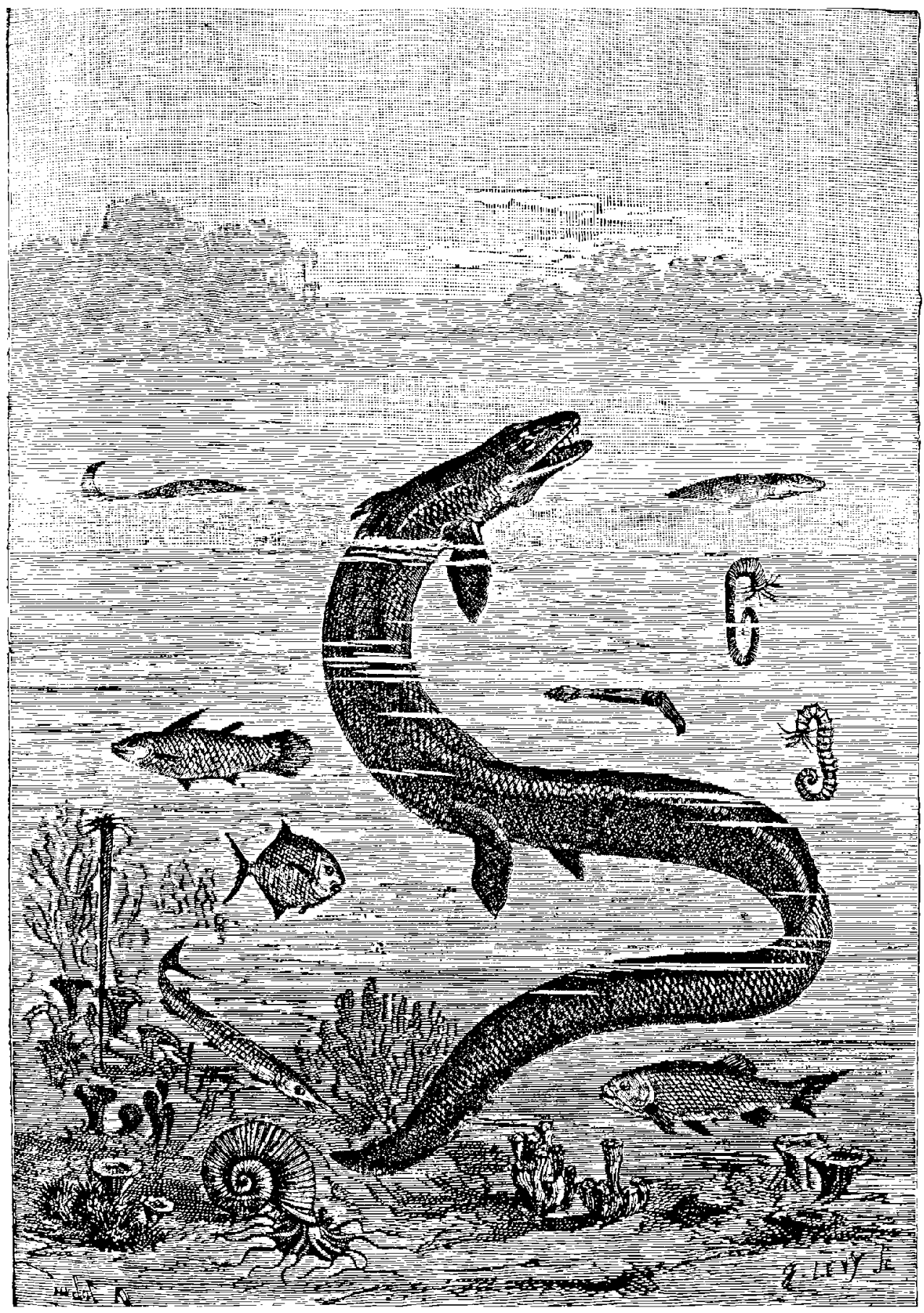

LA RÉGIOK DE PARIS PENUANT LA MER CRÉTACEE, FIN DU RËGNE DU GAAND USASAUBE.

LE MONDE AVANT LA CREATION DE L'HOMME

80 
Le bec était pointu comme celui du plongeon ou de la cigogne. La mâchoire supérieure portait quatorze dents sur le maxillaire et n'en portait pas à sa pointe, sur le prémaxillaire; la mûchoire inférieure en portait au contraire sur son bord entier, trente-trois de chaque côté, et ses deux branches, réunies par une articulation cartilagineuse, pouvaient peut-ĉtre se dilater afin de permettre à l'animal d'avaler des proies volumineuses, comme chez les serpents. Caractère essentiellement reptilien : les dents sont implantées avec de fortes racines dans une rainure commune; elles sont couvertes d'un émail lisse, coniques, à pointe dirigée en arrière, c'est-à-dire qu'elles sont propres à saisir les aliments, comme chez les reptiles, et non à les mâcher.

Le cerveau était aussi tout à fait reptilien par sa petitesse.

Cousin de l'hesperornis regalis, mentionnons l'ichthyornis. Les caractères qui le séparent du précédent le rapprochent do nos oiseaux actuels. Il est encore reptile par le cerveau, petit comme dans l'hesperornis, et par ses vertèbres biconcaves, mais il est oiseau par tout le reste. Il a en particulier des ailes bien développées. Sa taille ne dépasse pas celle du pigeon et du corbeau, et il ètait analogue à nos hirondelles de mer.

La comparaison de ces divers oiseaux primitifs conduirait à penser que des différences essentielles les séparent, et que les oiseaux ne sont pas dérivés d'une seule branche reptilienne, mais de plusieurs.

Grâce à sa faculté de franchir les étroites limites où notre vie actuelle est enfermée, notre esprit peut embrasser cette longue période crétacée qui, pour se dérouler, a peut-être exigé un million d'années.

Si nous nous arrètons par la pensée à l'époque néocomienne et que nous parcourions les côtes de nos mers, nous rencontrerons en plusieurs endroits de grandes masses d'animanx que l'océan a jetées sur le rivage. Maintes espèces se présenteront à notre regard; nous rencontrerons partout les formes étranges des bélemnites, dont la queue se termine en forme de fuseau, des ammonites et diverses espèces de céphalopodes.

Si notre esprit nous transporte à une époque postérieure, celle de l'urgonien, séparée de la précédente peut-être par cent mille années, et parcourt les"mêmes localités, nous serons étonnę́s de pe. plụs 
rencontrer les céphalophodes qui, pendant la période néocomienne, formaient un des joyaux de la faune en égayant les bords de la mer par leurs brillantes coquilles nacrées; ces demeures admirablement distribuées en compartiments et de formes si diverses, tout cela a disparu, sauf quelques rares débris. Cependant nous trouvons ici et là, le long des rives, quelques banes de coraux.

$\mathrm{Si}$, cent mille ans plus tard, pendant le gault, nous visitons les mèmes côtes, nous les voyons couvertes de nombreux oursins, de bivalves, d'univalves; les céphalopodes ont changé de livrée et ne sont plus les mèmes que pendant le njocomien; nous aurons lieu de nous étonner de voir non seulement de nouvelles espéces, mais en

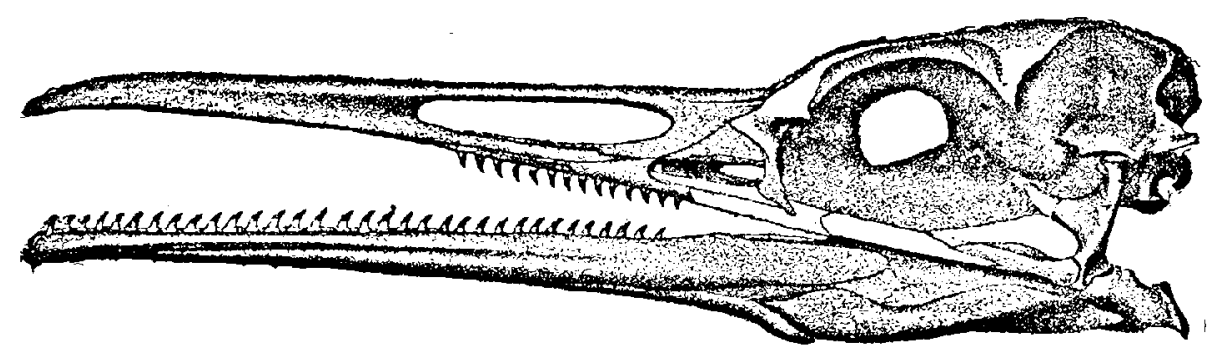

Fig. 348. - Tête d'oiseau à dents (crétacé des États-Unis).

partie aussi de nonveaux genres, tels que les turrilites et les hélioceras. Les mêmes proportions subsistent encore cependant quant au caractère général du mélange des espèces.

Ainsi, cetle faune marine a conservé le cachet de chacun des étages de l'époque crétacée. Si, pendant cette époque, nous avions visité cent fois, à des intervalles de dix mille années, les rives de ces mers, nous aurions peut-être pu suivre les modifications successives de la faune qu'elies renfermaient, et nous aurions eu la démonstration que toutes ces fúunes avaient cntre elles une foule de rapports intimes et variès; nous aurions pu de la sorte contempler vivants et animés les étres innombrables qu'on a retrouvés, enfouis depuis tant de siècles. (Oswald Heer.)

Aucun fossile nouveau ne montre de progression dans les mammifëres, dont les plus rudimentaires sont des espèces nées, comme nous l'avons vu, pendant la période liasique.

Ce qui frappe, ce qui confond, dans les myriades de siècles accu- 
mulés des mers jurassiques et crétacées, c'est de voir les éternités s'ajouter aux éternités, l'incommensurable à l'incommensurable,

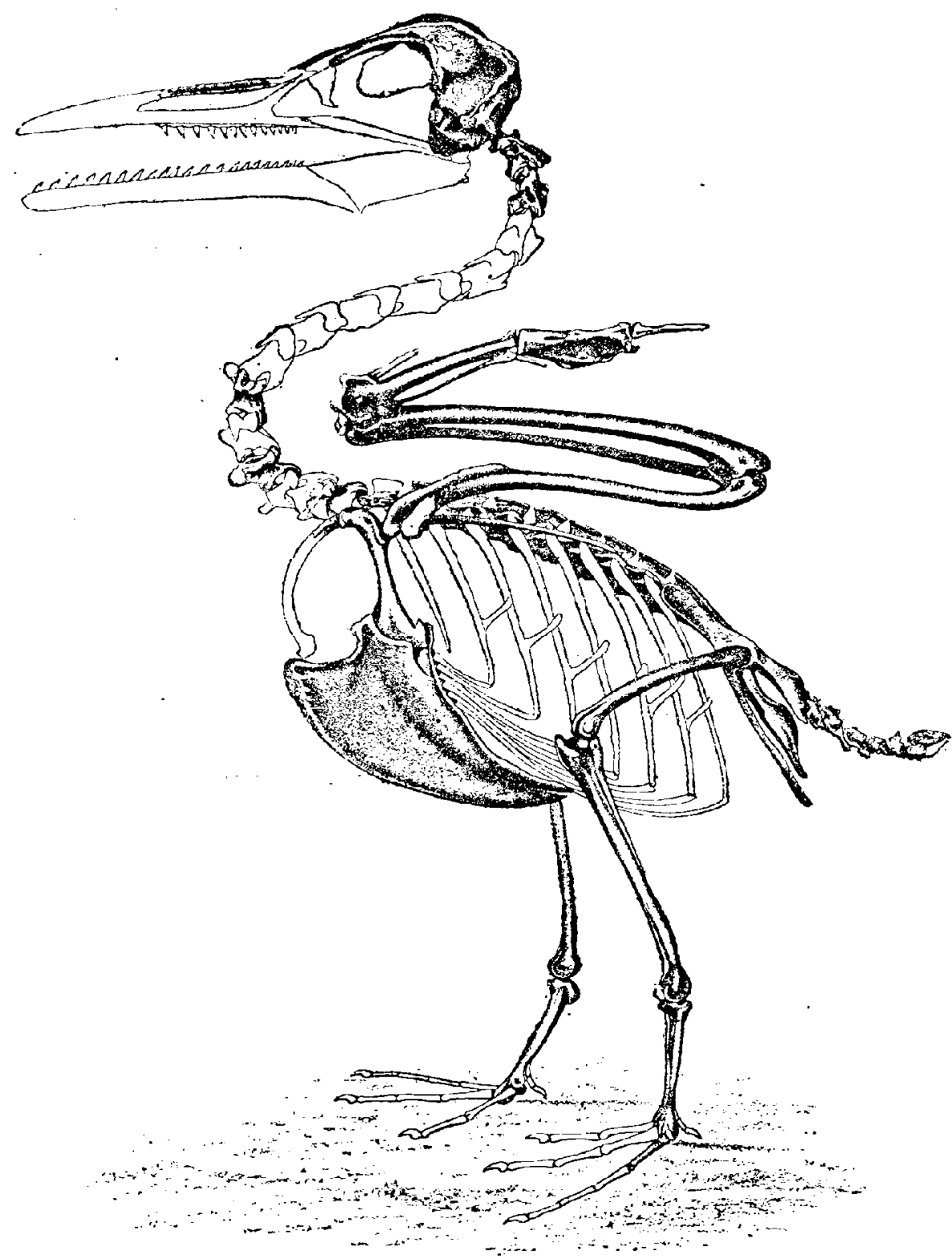

Fig. 349. - Les oiseaux à dents de la période crétacée.

L'Ichthgorols Victor de l'Amérique du Noris.

sans quo la nature sorte du type des reptiles. Elle multiplie les sauriens : elle en grossit, amplifie les formes; elle s'obstine dans 
ce type dont elle épuise les variétés, puis, par degrés, elle l'abandonne.

Dẻjả pourtant le type des mammifères et celui des oiseaux existaient quelque part, ébauchés dans les abimes de l'époque du trias; ils y sont comme égarés, tant ils sont rares. Et s'ils n'ont pu se développer et envahir la scène, ce n'est pas que le temps leur ait manqué pour se transformer de génération en génération, c'est

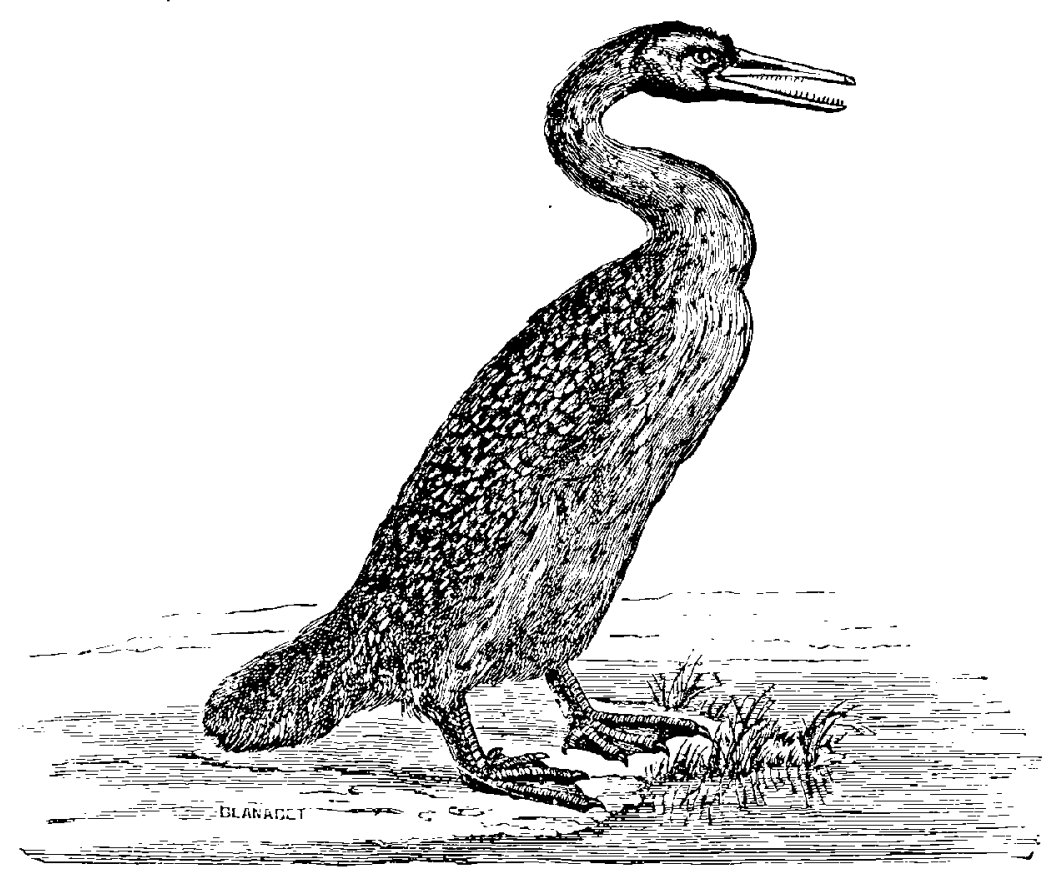

Fig. 350. - Les oiseaux à dents : l'Hesperornis regalis.

qu'à travers le changement des temps, la figure du monde ne changeait pas. Le type des terres fermes restait insalubre; il marquait de son sceau une faune insulaire.

En vain les siècles s'accumulaient, ils ne pouvaient donner aux organisations vivantes le caractire continental qui manquait encore au globe. Les petits rongeurs insectivores restaient dans les ìles jurassiques ce que leurs analogues sont dans les iles de l'Océanie. Tout au plus ils s'élevaient à l'ordre inférieur des kangourous didelphes de la Nouvelle-Zélande.

Le morcellement, l'éparpillement, la rareté des terres oppo. 
saient une barrière invincible au développement des marnmifères terrestres, car ceux-ci pour s'élever aux grandes espèces, ont besoin d'un vaste espace. Nomades, il leur faut un monde à parcourir herbivores, des paturares toujours nouveaux. On ne peut imaginer les grands carnassiers sans troupeaux d'herloivores et ces troupeaux sans vastes plaines herbacées. Cliaque organisation vivante suppose ainsi une certaine forme du monde qu'elle réfléchit. Au chameau, répond le déscrt; ail cheval, les steppes; au chamois, à la chèvre, les monts escarpés; à l'éléphant, au rhinocéros, les immenses forêts; à la giriufe, l'oasis; au bœuf, les plaines vieroges; à l'hippopotame, les fleuves d'eau douce. Chacun de cos genres de mammifères est conforme à une certaine figure du globe; tous ensemble supposent une variété inépuisable dans la conformation des terres, principalement l'étendue telle que peut la fournir un continent.

Au licu de cela, resserrez le continent dans l'étroite enceinte d'une île, multipliez cette île tant que vous le voudrez, parsemez-en à profusion le vaste océan, imaginez partouţ une terre étroite, basse, uniforme. Il est impossible de concevoir, dans ces limites, la formation, la production, l'apparition des grands mammifères, qui n'aurait aucun rapport avec le monde insulaire dont ils étaient entourés. Tant que le globe ne s'élève pas de la forme insulaire à la forme continentale, la faune ne peut s'élever du reptile au mammifère, bien moins encore à l'homme.

Si vous trouviez quelque part, dans une ile, les restes fossiles d'un grand mammifère, il faudrait en conclure qu'il n'y est pas indigène, mais qu'il y a été apporté ou que l'ỉle a été détachée d'un continent. La seule vue des ossements fossiles d'éléphants et de rhinocéros découverts à Palerme dit assez que la Sicile a fait autrefois partie d'une vaste terre ferme. Pour tirer cette conclusion, il n'est pas besoin de comparer les dépôts sous-marins. Le grand mammifére exclut l'île, comme l'île exclut le mammifòre.

Ne nous étonnons donc pas que les mers jurassiques et crétacées n'aient pu produire des types absolument nouveaux dans les ètres animés, puisqu'elles ont gardé, à travers les métamorphoses des rivages, le même type dans la configuration du globe. $\mathrm{A}$ la surface de ces iles toutes semblables, qui émergent l'une après l'autre, devaient se perpétuer des reptiles insulaires qui, sans doute, 
se transformaient insensiblement, mais qui ne pouvaient sortir des conditions uniformes où ils étaient enfermés (').

On le voit, la fin des temps secondaires signale la disparition du monde ancien et l'arrivée d'un monde nouveau. Les restes fossiles deviennent pauvres; ceux des mammifères peuvent presque être considérés comme nuls. C'est un crépuscule qui précède une aurore.

Il en est de mème du monde des plantes. Le nombre connu des espèces végétales particulières au crétacé ne dépasse guère trois cents. Ce sont encore des fougères, des conifères qui dominent. Mais elles ne tardent pas à faire place à des espèces nouvelles. Le caractère de la flore crétacée consiste dans l'apparition des plantes dicotylédones angiospermes. Dès lors la flore européenne présente la juxtaposition de deux catégories de types, les uns destinés à disparaitre ou à être refoulés vers le sud, les autres devant former le fonds de notre végétation indigène. Ainsi les peupliers, les hètres, les lierres, les châtaigniers et les platanes y sont associés aux palmiers, aux lauriers, aux pandanées.

Les conifères jurassiques étaient pour la plupart des arbres élevès, plusieurs de première grandeur. Les unes ressemblaient aux araucaria ou mème faisaient légitimement partie de ce genre, les autres offraient l'aspect de nos cyprès, avec des rameatux plus forts et plus vigoureux; d'autres enfin, n'offraient que des rameaux raides et des tiges nues ou peu divisées. Les feuilles de ces derniers se réduisaient aux proportions de simples écailles mamelonnées étroitement contiguës et dessinant à la surface des parties anciennes une mosil̈que à compartiments réguliers, dont l'âge ne faisait qu'accroitre le périmètre.

Lors du wealdien, premier terme de la craie ou, si l'on préfère, dernier terme de la série oolithique, la soudure continentale est évidente, et l'émersion effectuée sur une grande échelle, s'accuse sur une foule da points: en Angleterre, dans le nord de l'Allemagne, dans le Jura et ailleurs, par l'extension des eaux lacustres ou fluviatiles dont le rôle devient très considérable. Ce sont là les indices avant-coureurs de la révolution végétale qui se prépare.

L’évolution organique à laquelle les dicotylédones dúrent leur

1. Edgard Quinet. La Création. 
existence et ensuite leur extension s'accomplit sans doute sous l'influence de conditions très diverses. Mais il est aujourd'hui certuin qu'elle s'est produite pendant l'époque crétacée.

Partout alors les dicotylédones ou végétaux à feuillage, auparavant inconnus, sont devenus dominants ; partout une révolution, aussi rapide dans sa marche qu'universelle dans ses effets, favorise, l'introduction de cette catégorie de plantes et partout aussi les cycadées et les conifères, jusqu'alors les dominateurs incontestés du règne végétal, tendent à décroître et à reculer.

Les dicotylédones abondent dans l'Allemagne cénomanienne,

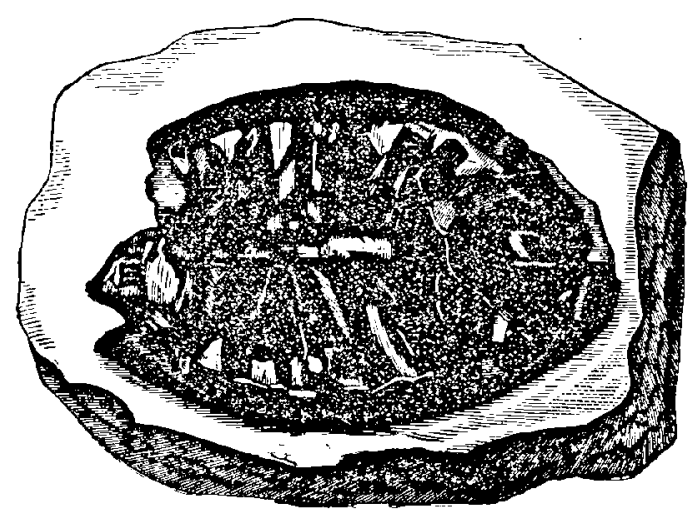

Fig. 351 - Tortue fossile de la période crétacée.

en Moravie, en Saxe, en Bohème, en Silésie, entre $49^{\circ}$ et $50^{\circ}$ de latitude. Au sein de cette région, situće alors à proximité des plages d'une mer septentrionale, les plantes à feuillage présentent un mélange curieux de genres éteints, de genres devenus exotiques et tropicalix, et de genres demeurés européens ou du moins encore indigènes de la zone boréale extra-européenne. Lo genre credneria est un excmple des premiers ; le genre hymenea, qui fait partie du groupe des légumineuses césalpiniées, atteste la présence des seconds. Ces types, fixés dès lors dans leurs traits principaux, n'ont plus donnè lieu par la suite qu'à d'insignifiantes variations.

Le platane, le lıêtre, le chc̀ne, le châtaignier, ont èté trouvés, en Amérique comme en Europe, dans les sédiments de la période crétacée. On le voit, ce sont les précurseurs du monde végetal moderne. 
Les premiers palmiers qu'on ait encore signalés, en ne tenant pas compte des fausses indications souvent appliquées à des vègétaux de la flore carbonifère, étrangers en réalité à cette classe, se

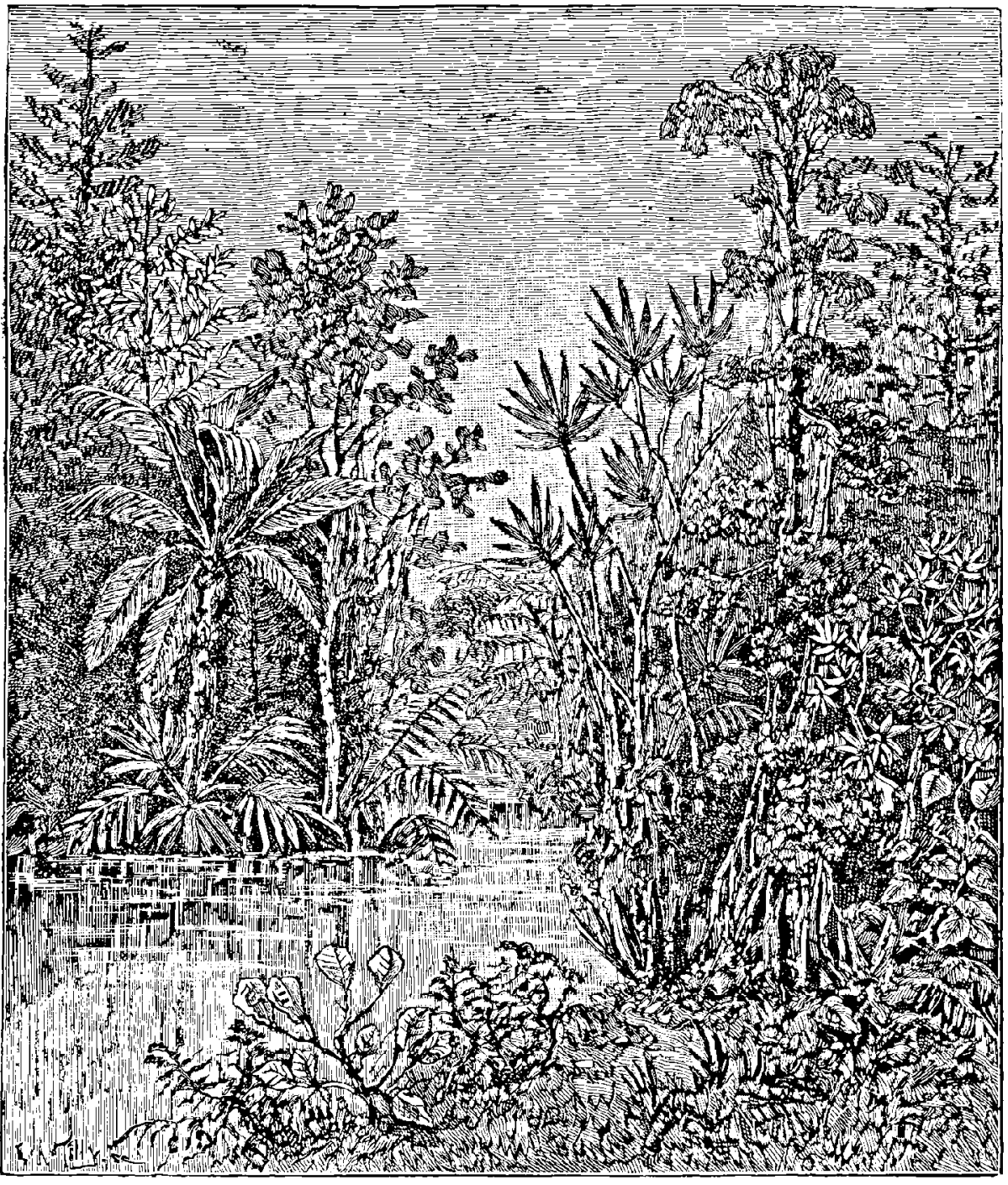

Fig. 3̋2. - Paysage végétal de la période crétacée, en Rohème, n'alırès M. de Saporta.

montrent en Europe dans la seconde moitié de la période crétacée.

Ce type tenait le milieu entre celui des palmicrs à frondes pinnées, comme les dattiers, et celui des palmiers à frondes flabellées, comme le sont les sabals. La plupart des palmiers portent

LE HONDE AVANT LA CRÉATION DE L'HOMME. 
dans leur enfance des trondes construites sur ce modèle, avant de prendre leur entier développernent et de revetir leur forme définitive. Il est curieux d'observer un type semblable à l'origine du groupe, et l'exclusion de ce groupe des régions arctiques constitue également, comme nous l'avons fait remarquer précédemment, $u$ précieux indice de l'abaissement de la température commençant se prononcer dans l'extrême nord.

Un gisement cénomanien de plantes terrestres a été découvert Atané (Groënland), par Nordenslijoeld. On y observe un bambou, une cycadée, des fougères de la tribu subtropicale, des gleichéniés et des angiospermes parmi lesquelles domine un peuplier voisin du populus euphratica en compagnie de figuiers, de magnolias, etc. Des pins, des sequoia, un gingko complètent ce curieux ensemble, d'où les palmiers sont absents, tandis qu'à la mème époque on en observe en Silésie et en Provence. Ce fait semble indiquer que la distinction des zones de climats commençait alors à se dessiner, au moins pour la région polaire.

"L'existence simultanée de deux séries qui nous semblent maintenant destinées à s'exclure, écrit M. de Saporta, avait sans doute alors sa raison d'être. En dépit de la chaleur, certainement tempérée par l'humidité et probablement assez uniforme, elles pouvaient vivre associées dans un ensemble des plus harmonieux. L'ampleur presque générale des formes végétales de cette époque annonce un temps et des saisons favorables au développement du monde des plantes, et ces conditions expliquent très bien l'extension rapide des divers types qui se partagent la classe des dicotylédones. La plupart d'entre eux effectivement, si l'on s'attache aux familles que l'on rencontre le plus ordinaircment à l'état fossile, remontent jusqu'à cet âge et avaient, dès lors, les caractères qui les distinguent encore. La seconde moitiè de la craie peut être considérée, comme le point de départ de la végétation particulière à notrel zone, de même que le temps des houilles a marqué celui du règne végétal tout entier. Dès le cénomanien, en effet, commence une évolution à l'aide de laquelle les tribus nouvelles vont en se multipliant et en se différenciant dans une proportion toujours croissante.

a Le climat européen, nous devons lo constater, a varié à bien des reprises, et par là s'explique la prépondérance alternative, 
dans le cours des temps tertiaires, des associations d'espèces au feuillage maigre et coriace et des associations distinguées par l'ampleur de leurs organes appendiculaires. Les choses se passent encore de mẻme sous nos yeux; les différences de région à région, . d'une station à une autre station, retracent le tableau de celles que le temps fit naitre et qui se succédèrent sur notre sol. De cette sorte, les phénomènes que nous observons maintenant, en comparant entre eux certains points de la surface terrestre, se sont manifestés autrefois à travers la suite des âges. Les procédés de la nature sont, au fond, restés les mèmes. Elle a réussi de tout temps à plier les organismes sous l'influence des milieux, et de cette influence elle a fait sortir une force susceptible de réveiller les tendances à la variabilité, inhérentes à tous les êtres vivants. C'est là une action d'autant plus énergique qu'elle est permanente et qu'enfin elle s'applique à des organismes fixés au sol, comme les végétaux, qui la subissent sans ètre capables de s'y soustraire par la fuite ('). D

Nous reproduisons plus haut ( $f g .352)$, d'après l'éminent botaniste français, un paysage végétal de la période crétacée, reconstitué d'après les types reconnus dans l'étage cénomanien, en Bohême. On s'aperçoit que le monde s'avance vers notre époque. Ce ne sont plus les prêles et les calamites de la période dévonienne, les lougères des temps carbonifères (comparez le paysage de la page 425), les sigillaires, les lépidodendrons ( $\mathrm{p}$. 441), ni les haidingera et les voltzia de la période triasique (p. 489 et 513). On approche des aspects modernes. Mais ce ne sont encore ni nos paysages tropicaux, ni nos bois tempérés de chênes, de hêtres, d'ormes ou nos bosquets de tilleuls, de peupliers ou de saules.

Cependant, nous venons de le voir, les espèces modernes sont nées : elles n'auront plus qu'à se séparer des anciennes. Les sequoia, les pins, les bambous, les figuiers, les magnolias, les palmiers, les platanes, les peupliers, les chènes, les tilleuls, les châtaigniers, les hêtres, les saules, le lierre, etc., existent déjà. La Terre de l'homme se prépare. Si le lecteur veut bien se reporter encore à l'arbre généalogique du règne végétal publié plus haut (p. 603),

1. De Saporta. Le Monde des plantes avant l'apparition de l'homme. 
il verra que le développement de cet arbre s'est continué régulièrement comme celui du règne animal et que, précisément pendant la période crétacéc, le rameau des dicotylédones dialypétales s'est détaché pour donner naissance aux branches supérieures du règne végétal. Nous avons dès lors des variations de saisons, des arbres dont le feuillage tombe en hiver et se renouvelle au printemps, des aspects changeants que le regard humain contemplera dans l'avenir, des perspectives au-dessus desquelles la pensée s'étendra et se reposera, des sites qui charmeront l'artiste et le rêveur. Les hôtes des forêts antiques ont disparu. Les iguanodons grotesques, les reptiles grimpeurs au vol fantastique, les sauriens géants, tout ce monde informe, rude, grossier, sans élégance et sans grâce, est maintenant enseveli dans les couches fossilifères. Au-dessus de leurs tombes gazouilleront les oiseaux, frémiront les insectes, voleront les papillons et, dans le calme de la nature, les rayons du soleil illuminent les premières fleurs. Le cri sourd, rauque et sans suite, de li brute qui s'agite de loin en loin est couvert maintenant par mille voix modulées sous le souffle des passions changeantes. A l'isolement morne des premiers êtres a succédé la vie en troupeaux, précurseur de la vie en société. Les marsupiaux ont créé le sentiment de la sollicitude pour les petits. Des soins intelligents et gracieux sont devenus une des conditions et la sauvegarde de l'existence des oiseaux. Les plantes, comme les animaux, se sont elles-mèmes singulièrement embellies; elles vont bientôt offrir, avec des fleurs brillantes, des fruits savoureux. La température est plus modérée, l'air plus pur, le ciel plus beau. La Terre marche vers la perfection. L'humanité s'éveillera bientôt - dans quelques milliers de siècles - avec ses aspirations supérieures, mais aussi avec les instincts animaux de son origine, avec ses ongles, ses dents, ses appétits grossiers, ses armes, son budget de la guerre et ses armées permanentes. 
LIVRE V

LAGE TERTIAIRE

IRIS - LILLIAD - Université Lille 1 
IRIS - LILLIAD - Université Lille 1 


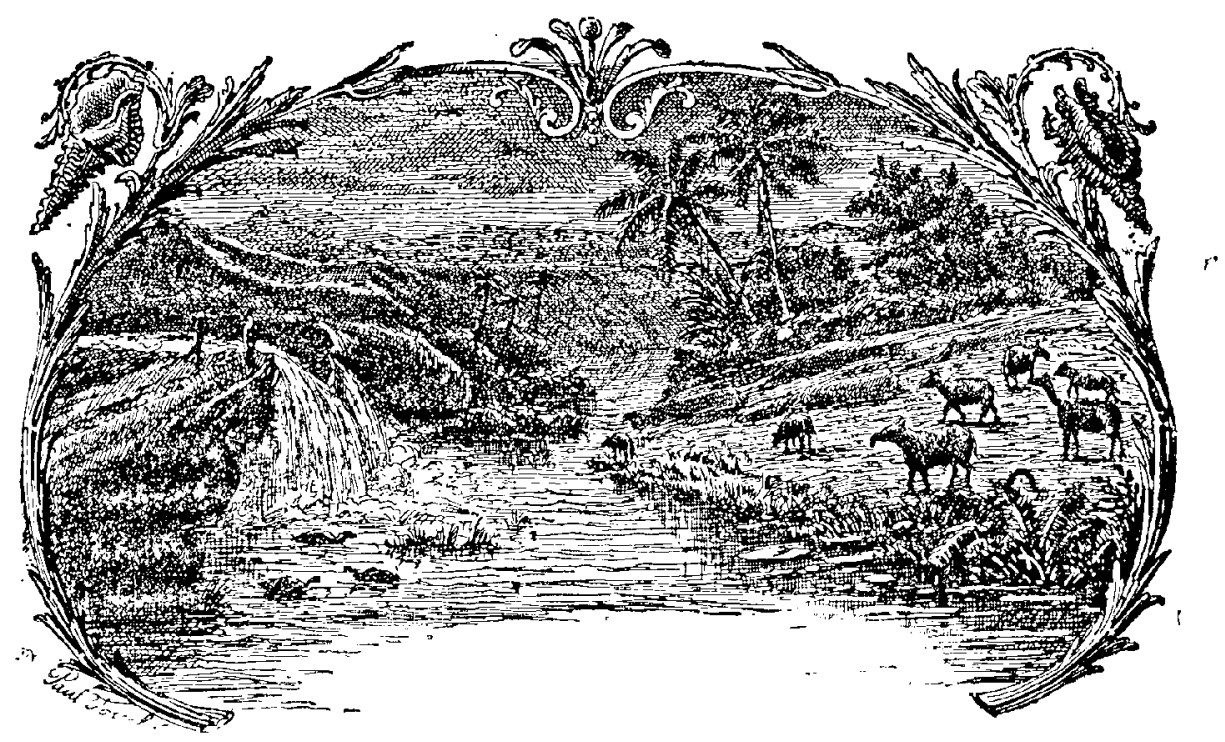

GHAPITRE PREMIER

\section{LA PÉRIODE ÉOCENE}

Les années ont succédé aux années, les siècles ont suivi les siècles; des milliers, des myriades de siècles ont passé sur la face du monde depuis les origines de la création terrestre. A l'âge cosmique de la formation de la planète, antéricur à toute vie, a succédé l'âge primordial, l'ère des organismes primitifs, des êtres sans tête, dépourvus de sens et d'organes, des plantes sans feuilles, sans fleurs et sans fruits, monde insensible, aveugle et muet. Longtemps après, émanant des premiers par voie de perfectionnement, apparureut les ètres un peu plus avancés de l'âge primaire: les mollusques, les crustacés, les poissons, toujours sourds et muets, mais non plus aveugles. Nous avons assisté ensuite à l'éclosion des reptiles et des arbres à feuilles persistantes qui caractérisent les trois grandes périodes de l'âge secondaire, et déjà, vers la fin de cet âge, nous avons salué l'apparition des reptiles-oiseaux et celle, plus importante encore, des mammifères primitifs, les marsupiaux. Ainsi, lentement, progressivement, graduellement, l'histoire de la nature nous a conduits au vestibule des temps tertiaires, où nous pénétrons en ce moment, qui seront couronnés par le plus grand de tous les progrès organiques terrestres, par l'apparition de l'humanité. 
L'ère tertiaire, dirons-nous avec M. de Lapparent, peut ètre définie d'un mot : c'est celle où les conditions physiques et biologi. ques, jusqu'alors remarquablement uniformes, se sont différenciẻes au point de produire la variété qui caractérise l'ère moderne. A la fin des temps crétacés, l'Europe, réduite à un petit massif central et pourvue d'un faible relief, commençait à prononcer un mouvement d'émersion. A travers de nombreuses vicissitudes, ce mouvcment va désormais s'accentuer et les diverses phases en seront marquées par le soulèvement de hautes chaines de montagnes. Tandis qu'au voisinage de la dépression méditerranéenne, les dépôts garderont en général le caractère marin, dans les contrées septentrionales une large part sera faite à l'élément lacustre ou saumâtre et peu à peu la mer sera rejetée dans ses limites actuelles. La zone chaude, après avoir longtemps défendu l'intégrité de son domaine, reculcra tout à fait vers le sud; il suffira bientôt de la différence de la latitude qui sépare la Provence de l'Angleterre pour passer d'une flore subtropicale à des forêts de conifères, en attendant que le refroidissement polaire gagne de proche en proche et entraine la retraite de tous les végétaux qui ne peuvent s'accommoder des longs hivers.

L'accroissement des masses continentales et la variété des conditions qu'elles offrent désormais se traduisent par un changement notable dans les launes et les flores terrestres. On y voit apparaitre cette complication organique qui caractérise le progrès physiologique, comme la division du travail est le signe du perfectionnement des civilisations matérielles. Les mammifères, longtemps atrophiés, se développent avec une vigueur extraordinaire et prennent possession du globe, tandis que le monde végétal déploie, avant l'invasion finale des froids septentrionaux, une ampleur et une diversité jusqu'alor's inconnues. Le règne des gymnospermes est fini, la prépondérance appartient aux palmiers et aux arbres à saisons, dont le milieu de l'ère tertiaire verra l'apogée. Dans les mers, les céphalopodes ne jouent plus qu'un rôle restreint, les brachiopodes sont pauvrement représentés et la famille des ammonitides a dit son dernier mot. En revanche, les lamellibranches abondent et avec eux les gastropodes, dont le développement s'explique par le caractère littoral de la plupart des formations de i'époque désormais émergées. Dans les régions plus franchement 


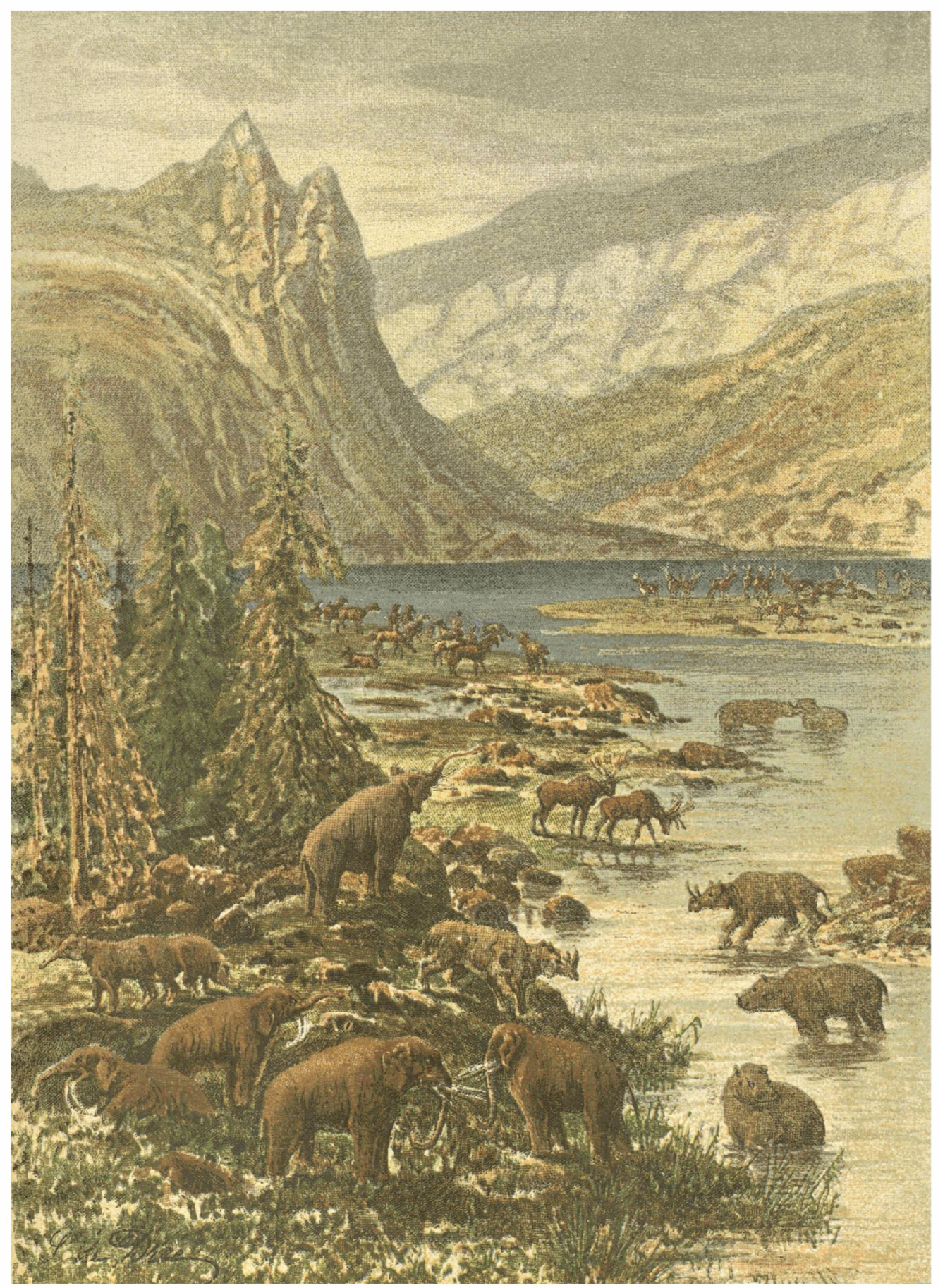

Chromotypographie SGAP.

PAYSAGE D'EUROPE A L'ÉPOQUE TERTIAIRE 
IRIS - LILLIAD - Université Lille 1 
marines, les foraminifères prospèrent, du moins au début de la période, et édifient des assises calcaires qui deviennent la forme tertiaire du régime méditerranéen comme les bancs à rudistes en avaient été la forme secondaire. Les faunes locales se multiplient, sous l'empire de conditions extérieures chaque jour plus diversifiées, préparant la variété des provinces zoologiques modernes.

En même temps, l'activité intcrne, endormie pendant de longs siècles, se réveille en donnant lieu, sur toute la surface du globe, à des manifestations grandioses dont les phènomènes volcaniques actuels ne sont plus qu'un écho très affaibli. Les anciennes failles de l'écorce se rouvrent; de nouvelles crevasses prennent naissance, et, sur les parois des unes et des autres, les émanations internes déposent des matières divęrses où dominent l'or et l'argent. Ainsi, peu à peu, la Terre se prépare pour recevoir dignement l'être qui doit régner en maitre à sa surface (').

Cette époque inaugure l'ère des phénomènes volcaniques; pour la première fois, les roches ignées se montrent bulleuses et boursouflées, et surgissent accompagnées de cendres et de scories, qui témoignent d'un énorme dégagement de gaz. Vers la fin de la période apparaissent les volcans à cratères. En France, le PlateauCentral s'entr'ouvre et livre passage aux basaltes et aux trachytes. Ces derniers forment de nos jours, en Auvergne, des montagnes comme le Puy-de-Dôme et le Mont-Dore, qui atteignent de 1500 à 1800 mètres d'altitude. Il en a été de même sur toute la surface du globe. En Europe, la plaine centrale de l'Allemagne, la Hongrie et la Transylvanie sont les régions où ces éruptions ont été les plus actives.

Encore plus incessants qu'aux époques immédiatement antérieures, les mouvements d'oscillation du sol sont démontrés par les innombrables alternances d'assises d'eau douce et d'eau marine, presque pendant toute la durée de l'époque tertiaire. Au commencement de cet âge, les terres formes avaient à peu près gardé leur ancienne configuration, etl'on reconnait encore les trois bassins franẹais, dont les isthmes seulement ont gagné en largeur; mais bientôt les continents se trouvent définitivement émergés et arrivent, peu à

1. A. dr Lapparent, Traité de Géologie.

LE MONDE AFANT LA CRÉATION DE L'HOMME 
peu, à leur configuration actuelle. C'est à cette époque que les Alpes, l'Hirnalaya et les Cordillères ont acquis leur gigantesque hauteur.

Les roches tertiaires sont extrèmement variées. Elles consistent en sables, plus ou moins purs, quelquefois cimentés de manière à fournir des grès de diverse consistance; en marnes, en argiles, en calcaires. Le gypse, le sel gemme, les minerais de fer, le soufre, les rognons siliceux, les lignites y abondent et forment quelquefois des lentilles ou des amas fort importants. Plusieurs roches proviennent directement des profondeurs du globe, d'où elles ont été injectées, dans des bassins plus ou moins circonscrits : tels sont les sables, les argiles et les fers sidérolithiques du Jura bernois, et peutètre les grès de Fontaineblcau. Parfaitement horizontales et encore plus intactes que dans les formations antérieures, les assises tertiaires ne se montrent guère rompues et soulevées que dans les montagnes. La puissance du terrain tertiaire dépasse quelquefois 3000 mètres, mais peut-être n'est-il complet nulle part (').

A l'époque où se forma ce terrain tertiaire qui, en se soulevant, donna à la France, encore reliée cependant à l'Angleterre, à peu près sa configuration actuelle, la vie végétale et animale prend ses derniers développements. Dégagées des formes archaïques particulières aux époques précédentes, la flore et la faune ressemblent tellement à l'état actuel que l'on a pu dire, avec raison, que nous vivons encore à l'époque tertiaire. Cette flore et cette faune nouts sont, du reste, mieux connues que celles des époques antérieures, et elles renferment un grand nombre de types qui n'ont pas été conservés dans les terrains plus anciens où ils existaient probablement.

On voit la faune des reptiles se rapprocher de colle des temps actuels, notamment chez les vrais batraciens, grenouilles et salamandres; des tortues, des crocodiles, des lézards et des serpents, apparaissent les derniers, descendance modifiée des lézards. Les oiseaux ont laissé des débris assez nombreux.

Co sont les mammifëres qui donnent à la faune tertiaire son principal caractère. Tous les ordres y figurent. Ce sont d'abord les pachydermes appartenant à des genres éteints et quelques carnas-

1. Contedenn. Géologie et Paléontologie. 
siers, quelques chiroptères, quelques rongeurs; les proboscidiens apparaissent ensuite, avec les amphibies, les ruminants, les insectivores, les quadrumanes et très probablement les bimanies.

La période tertiaire a été ainsi marquée par l'établissement définitif des continents actuels, mais il convient d'ajouter que l'ensemble des dépôts qu'elle comprend répond à une si longue durée, qu'il serait inexact de croire que la distribution des terres et des mers soit demeurée stable dans toute leur étendue. Le sol, au contraire, surtout au début, a été soumis à des oscillations incessantes, qui ont eu pour effet de transformer les golfes en lagunes, puis de les mettre à sec. Les eaux atmosphériques, en s'accumulant dans les dépressions, ont constitué des lacs, autour desqucls une riche végétation, composée, cette fois, de plantes voisines de celles de nos foréts actuelles, s'est établie. Cet état de choses a duré jusqu'à ce qu'un mouvement en sens inverse ramenât les eaux marines sur les espaces qu'elles occupaient autrefois. Ge sont ces mouvements alternatifs d'exhaussement et d'affaissement.qui ont progressivement donné aux continents leur configuration actuelle ( $\left.{ }^{4}\right)$.

Les terrains tertiaires occupent, généralement, les parties basses des continents, et reposent en stratification discordante sur les terrains secondaires. Dans les pays de plaine, leurs couches restées sensiblement horizontales, c'est-à-dire dans les conditions originelles de leur dépôt, se correspondent exactement dans les coteaux qui séparent les vallées. Ces terrains ont beaucoup moins de consistance que les roches des terrains plus anciens; ce sont des argiles molles et plastiques, des sables pulvérulents ordinairement très purs, parfois consolidés sous forme de grès. Les calcaires terreux, gènéralement tendres, faciles à tailler, fournissent d'excellentes pierres à bätir. La fréquence des travertins, c'est-à-dire de ces calcaires ,concrétionnés et celluleux qui se forment principalement quand des eaux chargées de calcaire tombent en cascade, indique l'abondance des sources et par conséquent des pluies.

L'épóque tertiaire se divise en trois périodes, caractérisées chacune par des dispositions stratigraphiques spéciales ainsi que par des faunes distinctes, oủ la fréquence des espèces actuelles s'accuse

1. VÉLAIN. Géologie stratigraphique. 
de plus en plus : $1^{\circ}$ Terrain tertiaire inférieur: Eocène (aurore des espèces actuelles); $2^{\circ}$ Terrain tertiaire moyen : Miocène (moins d'espèces actuelles); $3^{\circ}$ Terrain tertiaire supérieur : Pliocène -(plus d'espèces actuelles) ( ${ }^{*}$ ).

Ces trois divisions principales, proposées par Lyell et acceptées depuis longtemps, tendent à se rnodifier et à se subdiviser avec les progrès des études géologiques. Quelques géolognes mème lui préfèrent un nouveau partage en périodes un peu différentes : ils appellent paléocènes les premiers dépôts tertiaires, oligocènes ceux qui leur ont succédé (pris sur l'éocène et sur le miocène) et néogènes ce qui reste $d u$ miocène et du pliocène pour compléter l'époque tertiaire. Nous ne nous éloignerons pas sensiblement des deux systèmes de divisions, et nous garderons les termes les plus généralement employés, en conservant le premier classement et en partageant la première période en deux, sous les désignations de paléocène et d'oligocène. L’ère tertiaire ‘se présente dès lors sous l'aspect suivant :

\section{ÉPOQUE TERTIAIRE}

Pèriode éocène.

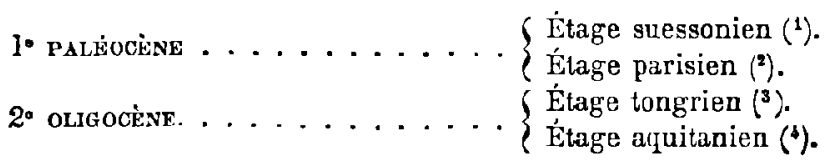

Période miocène.

MIOCĖNE INFÉRIEUR. . . . . . . . E Étage langhien (\$).

Mocìne MOYen . . . . . . . . . Étage helvétien, mollassique (\%)

MIOOĖNE SUPÉRIEUR . . . . . . . Ítage tortonien (7).

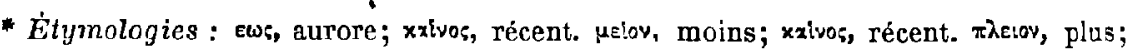
xaivos, récent. Ces dénominations, quoique plus poétiques, ne sont guère plus heureuses que celles des terrains primaires et secondaires.

1. Sables du Soissonnais, argiles et lignites d'Épernay, marnes de Meudon.

2. Calcaire grossier de Paris, calcaire lacustre de Saint-Ouen, sables de Beauchamp.

3. Argile et sables de Tongres en Limbourg.

4. Calcaire de l'Aquitaine. Meulières de Montmorency.

5. Ainsi nommé des langhue, collines italiennes. Sables et grès de Fontainebleau

6. Couches marines de la mollasse suisse.

7. Argiles de Tortone, en Italie. 
Période pliocène.

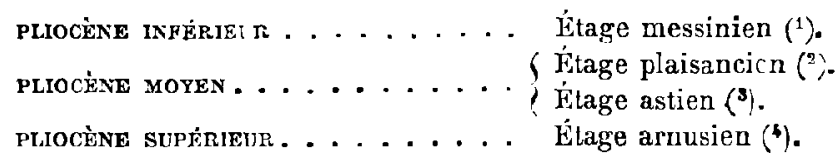

Ces étages ou horizons se reconnaissent partout où ils existent par leur nature minéralogique et par leurs fossiles, et ils sont désignés sous des noms rappelant les pays où ils ont été le mieux étudiés. Cependant on sent bien là que la langue de la géologie n'est encore que provisoire. Telle qu'elle est, elle a déjà peine à subsister. Quelle raison, par exemple, de donner le nom d'une province de Russie, d'Angleterre, de Suisse ou de France à un terrain qui se trouve disséminé sur tout le globe? Pourquoi imposer le nom de langhien à des grès que l'on rencontre à Fontainebleau, ou d'aquitanien aux meulières de Montmorency? A une science qui nait, il fallait une langue improvisée; chacun a donné le nom de son pays comme le premier qui s'offrait à lui. Mais la confusion commence à s'établir entre des dénominations qui souvent n'ont eu d'autre origine que le hasard.

Quoiqu'il en soit, nous allons essayer de revivre un instant au milieu de ces époques disparues, en suivant l'ordre de leur développement historique. Visitons d'abord la période éocène.

La nature nous fait assister à de grandioses transformations gèognostiques. Comme s'il s'agissait d'un simple jeu plusieurs fois renouvelé, la mer couvre et découvre tour à tour des contrées qui semblent aujourd'hui le domaine fixe de l'humanité, inonde de vastes régions, se retire et revient encore. La période éocène a vu se produire les premiers efforts des continents et en particulier de l'Europe, pour conquérir leurs dimensions et leurs reliefs actuels. Déjà, vers la fin des termps crétacés, un mouvement d'émersion marqué avait succédé à la grande dépression de la craie. Les sédiments éocènes attestent, dès le début, la lutte de l'Océan et de la terre ferme, surtout dans les contrées du Nord, où abondent les

1. Correspondant ì la formation de la mer Caspienne.

2. Invasion marine subapennine : Plaisance, ete.

3. Desséchement du bassin du Rhône.

4. Zone de l'elephas meridionalis du val d'Arno, en Italie. 
formations d'eau douce, destinées à s'étendre de plus en plus au Sud jusqu'à l'époque du soulèvement des Pyrénées.

Mais cette lutte n'a pas lieu dans le bassin de la Méditerranée, oủ les formations marines gardent quelque chose du caractère particulier qui distinguait cette région pendant les périodes antérieures; c'est-à-dire qu'on y voit dominer, se prolongeant sur de grandes étendues, des calcaires à la construction desquels les petits mollusques ont pris une part notable. Seulement ce n'est plus à des dicérates ni à des rudistes que cette tâche est dévolue ; c'est à de simples protozoaires et surtout aux nummulites, qui ont donné leur nom à l'ensemble du système éocène méditerranéen ou terrain nummulitique.

A cette époque, une méditerranée quatre ou cinq fois plus vaste que la nôtre, la mer nummulitique, traversait diagonalement l'Europe, allant de Nice en Crimée, en suivant la direction de la chaîne des Alpes, qui ont, depuis, relevé ses dépôts.jusqu'à lcurs sommets. A la place des Alpes il n'y avait alors que des îlots.

L'Europe offrait alors une physionomic tout africaine. Sous l'influence d'une mer chaude, touchant au tropique vers le Sud, s'établit un régime de saisons sèches et brûlantes, alternant avec des saisons pluvieuses et tempérées, la température moyenne annuelle ètant d'environ $25^{\circ}$ sous la latitude de la Provence. Alors se trouve réalisée la plus grande élévation thermique que l'Europe ait connue dans les temps tertiaires. Les palmiers abondent en France, les cocotiers et des arbres analogues prospèrent en Angleterre où les arbres à saisons semblent encore relégués sur les hautéurs, d'où ils ne descendront qu'à la fin de l'éocène. La période s'achève à peu près dans ces conditions, sans que les régions les plus voisines du pôle cessent de nourrir une végétation qui témoigne d'une moyenne annuelle supérieure d'une vingtaine de degrés à celle que l'on constate de nos jours dans les mèmes parages (').

C'est d'ailleurs à ce moment que l'activité interne commence à se faire sentir, surtout par des éruptions de roches serpentineuses, qui accompagnent le soulèvement des Pyrénées et celui des Apennins, tandis que, plus au nord, d'abondantes émissions sulfureuses et ferrugineuses arrivent jusqu'à la surface.

1. A. ne Lajparent, Traité de Géologie 


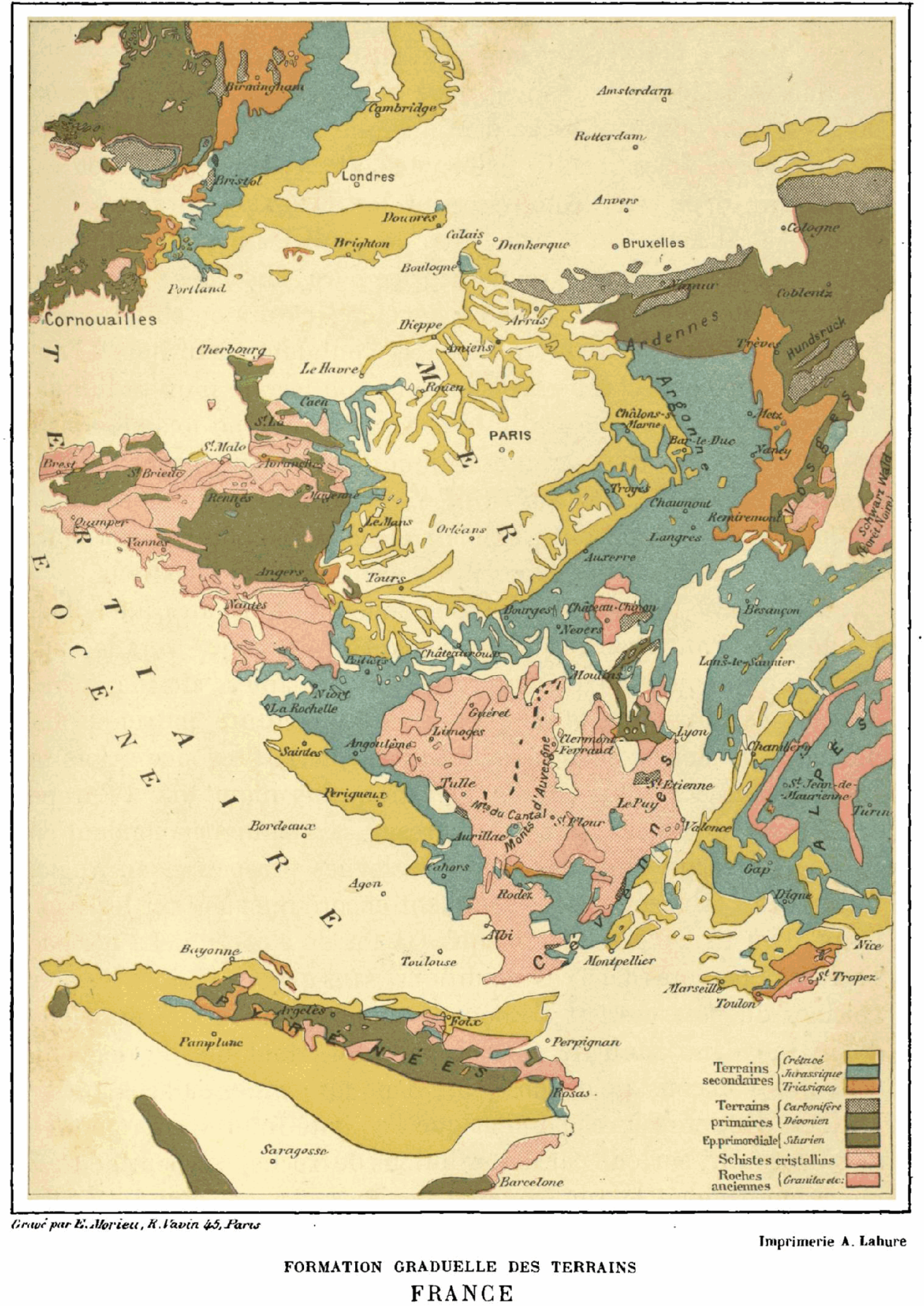

Terrains primitifs, primaires et secondaires 
IRIS - LILLIAD - Université Lille 1 
Le terrain tertiaire inférieur est très développé dans les environs de-Paris; il se poursuit dans l'est, en Belgique, et au nord-onest, en Angleterre. Trois capitales, Paris, Bruxelles et Londres sont ainsi ettablies sur des dépôts de cet âge. La Manche n'existait pas à cette époque; la Bretagne, reliée à la presqu'ìle de Cornouailles, fermait, de ce côté, le golfe anglo-parisien, qui s'ouvrait largement à l'est, en passant au-dessus des Ardennes, pour s'étendre suŕ la Belgique.

Dans le bassin de Paris, l'éocène, devenu classique, se compose d'une alternance, fréquemment répétée, de couches marines et lacustres qui viennent se ranger dans les trois divisions suivantes:

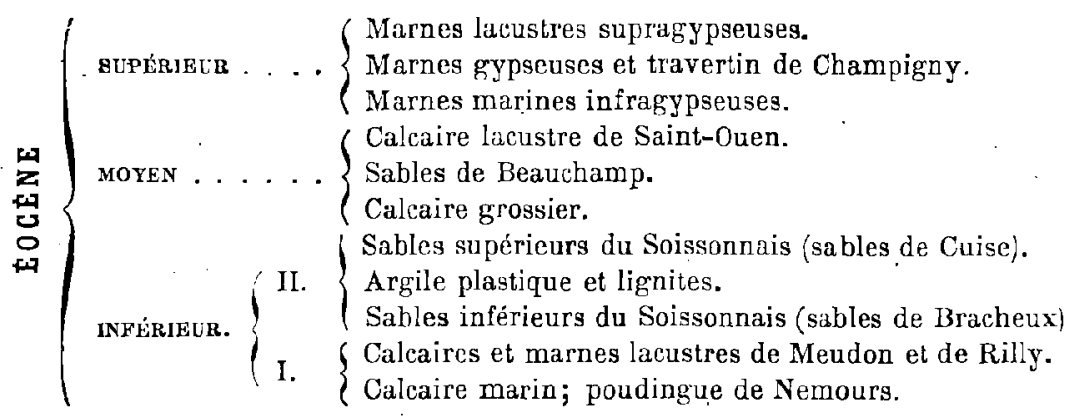

Nous décrirons ces diverses formations avec quelques détails parce qu'elles sont très développées et d'une observation facile dans nos contrées, surtout aux environs de Paris. Voici leur succession chronologique d'après M. Vélain (1) :

Commençons par la base, par les couches les plus anciennes.

Éock̀ne INFÉRTFUR. - I. Calcaire marin et formation lacustre de Rilly. - Les couches les plus inférieures de l'éocène sont représentées dans les environs immédiats de Paris, notamment à Meudon, où elles recouvrent le calcaire pisolitique qui termine le terrain crétacé, par des marnes blanches, onctueuses, strontianifères, renfermant : à la base, des nodules calcaires avec fossiles marins au sommet, des concrétions blanches qui contiennent des mollusquos d'cau douce et terrestres. Elles attestent ainsi que le bassin de Paris, envahi au début par des eaux marines, a été plus tard en partie émergé et recouvert par des eaux douces. Cette formation marine de la base, qui révèle, pour les premiers siècles de l'éocène, une nouvelle invasion de la mer, est encore bien indiquée, plus au sud, par un cordon de galets roulés, aujourd'hui cimentés par de la

1. Géologie stratigraphique. 
silice et transformés en un poudingue épais (poudingue de Nemours), qui trace bien la limile de cette invasion de la mer. Dans l'est, en Belgique, ces dépôts marins, mieux accusés, donnent lieu à un calcaire sableux, très coquiller, renfermant une belle faune marine. Au-dessus se développe, connme à Meudon, un calcaire lacustre, rempli de coquilles terrestres. Ce même calcaire se développe à Reims; à Rilly, il atteint plusieurs mètres de puissance et se montre particulièrement riche en fossiles. Plus loin, auprès de Sézanne, il se présente sous la forme d'un travertin, adossé à une falaise crayeuse qui marque, en ce point, la limite de l'emplacement occupé par cet ancien lac, où venaient se déverser des sources incrustantes actives, qui, du haut de la falaise de craie, se précipitaient en cascades. Dans ces eaux ruisselantes, trés ombragées, vivaient de nombreux mollusques, avec des insectes qui se sont trouvés pétrifiés et sont si bien conservés, dans ces calcaires incrustants, qu'on reconnait tous les détails de leur organisation.

II. Sables du Soissonnais. - La mer est venue ensuite recouvrir toute l'étendue du golfe anglo-parisien, elle y a déposé des sables glauconieux, remplis de coquilles marines, très répandus dans les environs de Bracheux, où ils se signalent par l'abondance d'une grande espèce d'huitre, qui forme des bancs entiers.

Argile plastrque et lignites. - Le golfe où se sont déposés ces sables était ainsi très étendu. Tne émersion du bassin anglo-parisien qui a suivi, accentuée surtout de l'est, a amené l'établissement, au centre. de ce bassin, dans les environs immédiats de Paris, d'un lac où se sont déposées des couches d'argile exploitées à Vaugirard et à Issy, pour briques et poterics, à Montercau, où cllo est plus pure, pour faïcnce et porceIaine. Ces argiles à lignites sont bien plus étendues que l'argile plastique inférieure. Il en est de même en Angleterre, oì les sables et les argiles à lignites, reliés à ceux du Soissonnais, sont surmontés par des argiles brunes tenaces (London clay), dont l'épaisseur peut atteindre 150 mètres à Londres. L'argile de Londres offre cet intérèt particulier de renfermer des coquilles marines appartenant à des genres qui ne vivent que dans les mers chaudes; avec ces fossiles on rencontre là un grand nombre de tortues, plus de soixante espèces de poissons, enfin de nombreux ossenents de mammifères, ainsi que des fruits très gros, comprimés, anguleux, assez analogues aux noix de coco, qui doivent avoir flotté à la surface des eaux avant de s'ensevelir dans les dépóts vaseux, où nous les retrouvons aujourd'hui en un parfait état de conservation. On a retrouvé de ces fruits des tropiques dans la vase maruo-sableuse du Trocadéro, en faisant les travaux de terrassement antérieurs à l'exposition de 1867 : Paris était alors un estuaire chaud, voisin de la mer, qui, du reste, allait y revenir.

Sables supérieurs du Soissonnais. - Alors que ces dépỏts argileux s'ef- 
fectuaient, d'une part dans le sud de l'Angleterre oì ils représentent une formation d'estuaire, de l'autre en Belgique où ils appartiennent à une mer plus profonde, le bassin de Paris était encore immergé : les sables. fins, jaunes et souvent glauconieux, qui recouvrent, dans le Soissonnais, les argiles à lignites, et qui annoncent un retour de la mer dans cette région, renferment une grande abondance de nummulites.

Ces sables sont hien développés au nord-est de Paris, notamment dans la vallée de l'Aisne ou ils atteignent 50 mètres d'épaisseur. En Belgique, ils prennent, au-dessus de l'argile des Flandres, une importance encore plus grande. Cette mer nummulitique est ainsi venue de l'est; passant sur les Flandres, elle a pénétré dans le bassin de Paris, par un détroit correspondant à la vallée actuelle de l'Oise, et ne s'est pas étendue au delà des environs immédiats de Paris. A Vaugirard, à Vanves, les sables glauconieux qui recouvrent les fausses glaises appartiennent à la série du calcaire grossier et marquent le début de l'éocène moyen.

ËOcÈNE MOYEN. - Calcaire grossier inférieur. - Le calcaire grossier comprend un ensemble varié de calcaires fossilifères, fournissant d'excellente pierre pour les construclions, dont l'épaisseur moyenne est de 30 à 35 mètres; à la base, on remarque des sables grossiers, avec petits galets de silex noirs et grains verts de glauconie, souvent agglutinés par du calcaire, contenant avec des dents de squales, de petits polypiers, et surtout une nummulite d'assez grande taille, qui devint très abondante dans le calcaire grossier proprement dit.

Ces sables glauconieux marquent d'une façon constante le début de cette formation marine qui, cette fois, va s'étendre dans le sud-est de l'île de France, bien au delá des limites atteintes par les sables de Cuise.

Au-dessus, se développe un calcaire à texture grossière, très coquillier, pétri de nummulites, à ce point que, dans le Soissonnais, on le désigne sous le nom de pierre a liards; il contient, avec de grosses bivalves, des oursins et surtout une grande cérithe qui devient caractéristique de ce niveau.

Au delà de la saillie de l'Artois, on trouve, épars à la surface du sol, depuis Saint-Quentin, le Catelet jusqu'à Lille, des blocs siliceux à nummulites lovigata, emballés parfois dans des argiles rouges bariolées, et offrant alor's l'aspect de véritables meulières. Ce sont là les derniers témoins d'une couche, aujourd'hui démantelée, qui nous indique que la mer du calcaire grossier inférieur s'étendait de ce côté et se poursuivait en Belgique par un détroit qui, longeant la haute vallée de la Somme, traversait le département du Nord dans toute son étendue.

Calcaive grossier supérieur. - Le calcaire grossier supérieur, plus complexe, perd le caractère franchement marin des assises précédentes et représente une formation d'estuaire. Il comprend, à la base, un horizon d'eau douce, intercalé entre deux bancs marins caractérisés chacun par 
l'abondance des cérithes, qui se montrent là associées à des gastéropodes d'eau saumâtro. Le calcaire d'eau douco contient des limnées, des paludines avec des coquilles terrestres; il s'entremêle parfois d'argiles ligniteuses qui renferment une belle flore d'un caractère tropical très prononcé, attestant la présence, autour de ce lac, des palmiers à éventails. C'est également là qu'on rencontre le lophiodon.

La mer du calcaire grossier, se retirant de plus en plus vers le nord, cette séric se termine par lits minces de calcaires compacts ou siliceux, alternant avec des marnes feuilletées, quelquefois magnésiennes, désignées sous le nom de caillasses, oì les fossiles font le plus souvent défaut.

Sables de Beauchamp. - Après ces alternances de formations lacustres et marines qui mettent fin au calcaire grossier, un retour offensif de la mer dans le bassin de Paris a donné lieu à des dépôts sableux, dont la faune diffère peu de celle du calcaire grossier. Avec un grand nombre d'espèces communes aux deux horizons, on trouve, comme espèce spéciale, une nummulite nouvelle.

Calcaire de Sainu-Ouen. - Après le dépôt de ces sables, le golfe du bassin de Paris, déjà rétréci à la fin du calcaire grossicr, se ferme à son embouchure et se transforme on un lac d'eau douce, ou se déposent alors des calcaires et des marnes, avec lits de silex intercalés, dont l'épaisseur peut atteindre une vingtaine de mètres. Ce calcaire lacustre s'étend sur de grandes surfaces au nord de Paris, dans le Valois, et renferme des limnées et des planorbes, avec quelques coquilles terrestres. A la fin de l'éocène, les formations d'eau douce ont ainsi prédominé dans le bassin de Paris.

Éocìne supérIeur. - Marnes gypsifères. - L'éocène supérieur se compose d'une longue série de marnes jaunes feuilletées, avec lits de gypse intercalés; ces dépôts, qui peuvent atteindre jusqu'à 60 mètres, sont encore, en majeure partie, d'origine lacustre. A la base, une première série de marnes gypsifères peu épaisses est directement appliquée sur le calcaire de Saint-Ouen. Au-dessus, se développent les marnes gypsifères proprement dites, où le gypse se présente en trois masses principales de forme lenticulaire. Les deux premières sont épaisses de quatre à cinq mètres en moyenne; la dernière est de beaucoup la plus étendue et la plus épaisse : elle atteint vingt mètres à Montmartre. Le gypse s'y présente sous l'aspect saccharoïde, et présente de romarquables divisions prismaliques comparables à celles des basaltes, qui ont valu à cette masse le nom de hauts piliers. Toute cette partie supérieure, franchement lacustre, se termine par des marnes pyriteuses et bleuâtres à la base, très blanches à la partie supérieure.

G'est dans la haute masse qu'on a rencontré tous ecs pachydermes, paléothériums, anoplothériums, etc., avec lesquels nous allons bientôt 
faire connaissance, et qui doivent ètre considćrés comme les animaux caractéristiques de l'éocène supérieur.

Telle est la succession des sédiments pétrifiés pendant la période éocène, facile à étudier, comme on le voit, dans nos régions francaises. Remarquons, en complétant cette description sommaire, que ces roches ont joué un rôle important dans les constructions humaines. Si la pierre à bâtir n'existait pas, on peut se demander sous quelle forme les habitations, les monuments, les villages, les villes auraient été édifiés. L'humanité tient non seulement au règne animal et au règne végétal, mais au règne minéral lui-même, qui se reflète dans les formes de son activité et dans son histoire.

On se rendra compte de cette succession assez compliquée de terrains par le tableau de la figure 354, dù à M. Stanislas Meunier. Il faut supposer ces couches placées au-dessus de celles qui ont été représentées dans la coupe du puits aitésien de Grenelle (p. 265): elles sont restées dans les régions que les eaux n'ont pas dévastées. Mais ce que ni la description ni le dessin ne peuvent rendre, c'est. Ja durée que représentent ces alternatives de mers, de terre forme et de lacs, qui, pendant cette seule période, se sont succédé sur ces régions de la France où nous vivons aujourd'hui : des centaines de milliers d'années! Les cours d'eau diluviens de la fin de l'époque tertiaire et de l'époque quaternaire, dont on a pu prendre une idée par lí largeur de la Seine aux temps préhistoriques (p. 348), ont creusé les vallées à l'état où nous les voyons aujourd'hui... et, comme nous l'avons vu, les niveaux continuent de changer de nos jours.

Pour se former une idée de l'extrême variété qui signale la période éocéne, on peut remarquer que la partic inférieure de la formation teltiaile est représentée, dans le bassin de Paris, par une vingtaine d'horizons parfaitement distincts, possédant tous quelque trait minéralogique on quelques fossiles particuliers, et dont les assises sont tantôt marines et tantôt d'eau douce; au contraire, elle consiste presque uniquement, dans les Pyrénées, le Midi de l'Europe et jusque dans la Chine, en un énorme massif d'un calcaire compact entièrement marin, d'aspect jurassique, où pullulent les foraminifères qui l'ont fait appeler calcaire à nummulites, et où les fossiles se trouvent différemment associés. Dans tous les bassins on observe d'ailleurs des passages de fossiles entre les divers étages ou horizons, 
et en général ces passages sont d'autant plus nombreux que le niveau dans le terrain se trouve plus élevé. Aussi, l'époque tertiaire se distingue-t-elle mieux de l'époque crétacée que des suivantes : un grand nombre d'espèces miocènes passent à l'étage pliocène, et les mers actuelles, la Méditerranée, par exemple, nourrissent encore une telle quantité de mollusques pliocènes que la démarcation n'est pas facile à établir entre les sédiments tertiaires et ceux de notre époque. $\Lambda$ joutons encore que les dragages récents ont amené la découverte d'un grand nombre d'espèces tertiaires que l'on croyait éteintes, et qui n'en prospèrent pas moins dans les profondeurs de la mer.

Les régions polaires, aujourd'hui désertes et glacées, étaient alors couvertes, comme aux tèmps secondaires, d'une riche végétation forestière; mais on remarque une tendance au froid. Ce ne sont plus des plantes tropicales, mais des platanes, des tilleuls, des châtaigniers, des hètres, des sapins, des bouleanx, des noisetiers. Ces arbres se dissémineront plus tard vers nos contrées, lorscu'elles seront assez refroidies. Mais alors la chande France, l'Allemagne, la Belgique, l'Angleterre, étaient couvertes de palmiers!

Lenlement, graduellement, de siècle en siècle, d’âge en âge, la Vie s'est développée en se diversifiant et en progressant toujours. Les invertébrés de l'âge primordial ont donné naissance aux vertébrés. Aux mollusques ont succédé les poissons, aux poissons les reptiles aquatiques, à ceux-ci les amphibiens, et des reptiles se sont dégagés les oiseanx. Issus des amphibiens, les monotrèmes, les marsupiaux ont commencé le règne des mammifères qui, durant l'âge tertiaire, ont acquis la domination définitive du mondc. Nous allons assister au développement de cette classe d'êtres supérieurs, qui va donner naissance aux divers ordres : pachydermes, ruminants, carnivores, rongeurs, lémuriens, singes et hommes.

Nul tableau n'est plus instructif peut-être que celui qui représente la correspondance chronologique entre ce développement graduel du règne animal et la succession des époques géologiques. $\mathrm{Si}$ nos lecteurs veulent bien s'y arrèter un instant ( $f i g .355$ ) et l'ètudier, ils auront sous un même coup d'œil la synthèse de cette grande histoire.

Les ordres actuels des poissons existaient déjá pendant la période 
crétacée et probablement mème antérieurement; la période de leur évolution a été le dévonien et le carbonifère. Les ordres actuels des

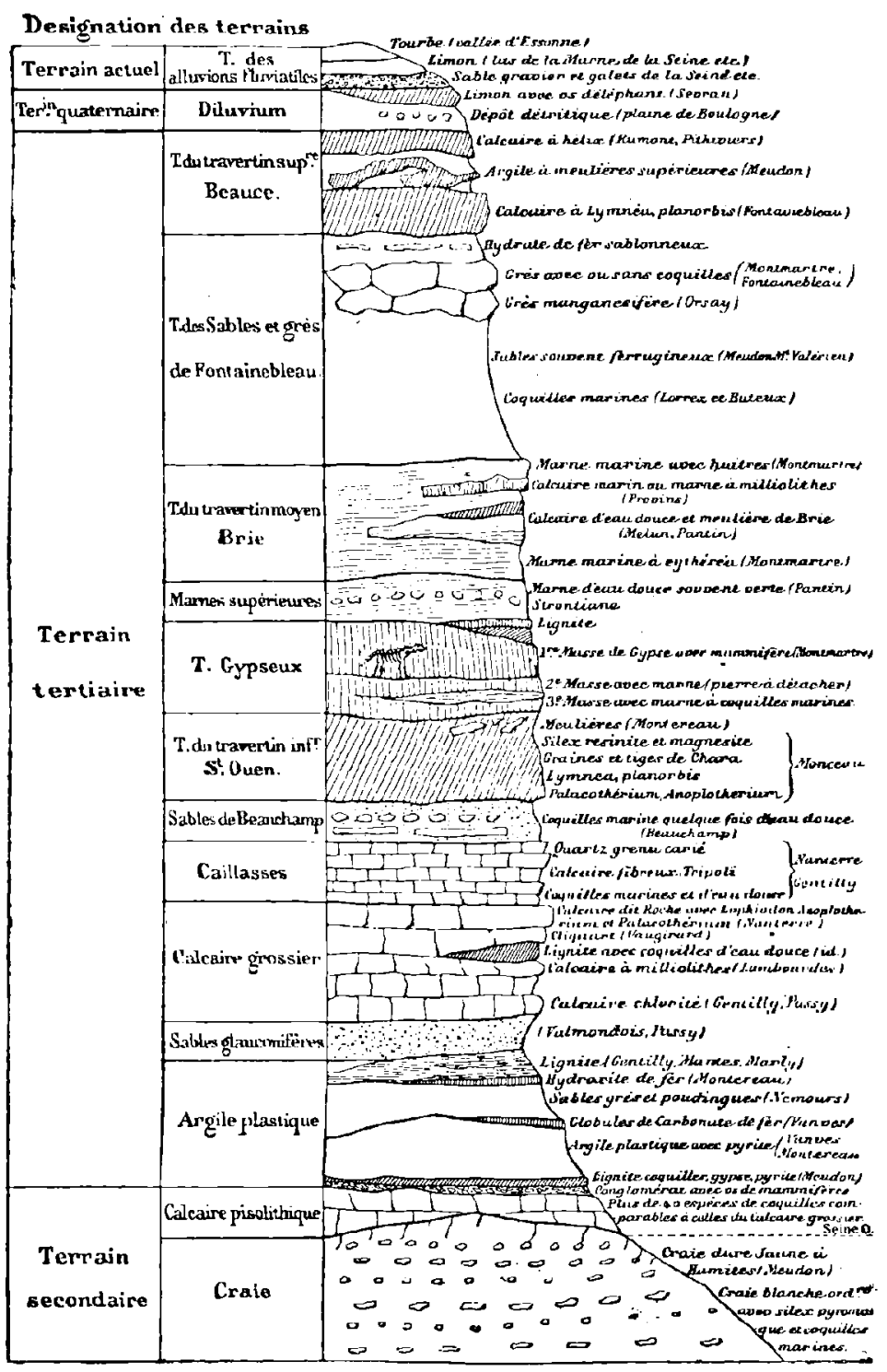

Fig. 354. - Tableau génẻral des terrains parisiens.

reptiles étaient tous établis avant l'éocéne; la période de leur évolution s'étend à travers les trois âges mésozoïques et spécialement le permien... Les ordres actuels des mammifères n'ont été complè- 
tement constitués que pendant la période miocène; dans l'éocène, ils étaient en voie de différenciation et se montrent peu ou point distincts les uns des autres.

Les reptiles sont nombreux dans l'éocène des États-Unis, bien qu'ils soient singulièrement déchus de leur suprématie pendant la période secondaire. On no trouve plus de dinosauriens terrestres, et les ptérosauriens ne volent plus dans les airs : ces ètres ont disparu avec les mers jurassiques et crétacées qu'ils habitaient. Ce sont désormais des crocodiles, des tortues et des lézards, qui prennent leur place, et les serpents font leur première apparition sur le continent américain. Les crocodiles appartiennent déjà aux types actuels : M. Cope en distingue une douzaine d'espèces. Les tortues sont plus variées : on en connaît quarante-trois espèces. Parmi les sauriens, le champsosaure est identifié au simcdosaure, ce type ayant existé sur les deux continents. Quant aux serpents, on n'en connaît encore que six espèces éocènes.

On a retrouvé dans les dépôts des mers éocènes des raies de toute espéce, y compris la torpille ou raie électrique, reconnaissable à ses nageoires disposées en cercle tout autour du corps. Des torpilles ont été découvertes aux environs de Vérone, dans le mont Bolca, célèbre par ses nombreux fossiles; elles s'y présentent avec des dimensions beaucoup plus considérables que celles des torpilles qui habitent aujourd'hui la Méditerranée. Les espèces fossiles ont aujourd'hui leurs représentants presque exclusivement dans les mers australes; tcl, par exemple, l'ostracion quadricornis (fig. 357), remarquable par la singulière disposition de ses yeux, fixés sur de véritables cornes.

Aix, en Provence, est également une localité célèbre pour ses poissons fossiles. On y rencontre surtout une espèce de carpe (lebias cephalotes), qui se distingue des autres carpes par sa bouche garnie de dents. Cette espèce existe encore de nos jours dans les eaux douces de la Provence. Elle comprend de petits poissons, longs d'un pouce, que l'on trouve réunis par centaines dans un fragment, gros comme la main, du schiste qui les renferme à l'état fossile. Le naturaliste Agassiz en a dessiné dans son excellente iconographie des poissons fossiles; la figure 356 a èté gravée d'après ses dessins. 


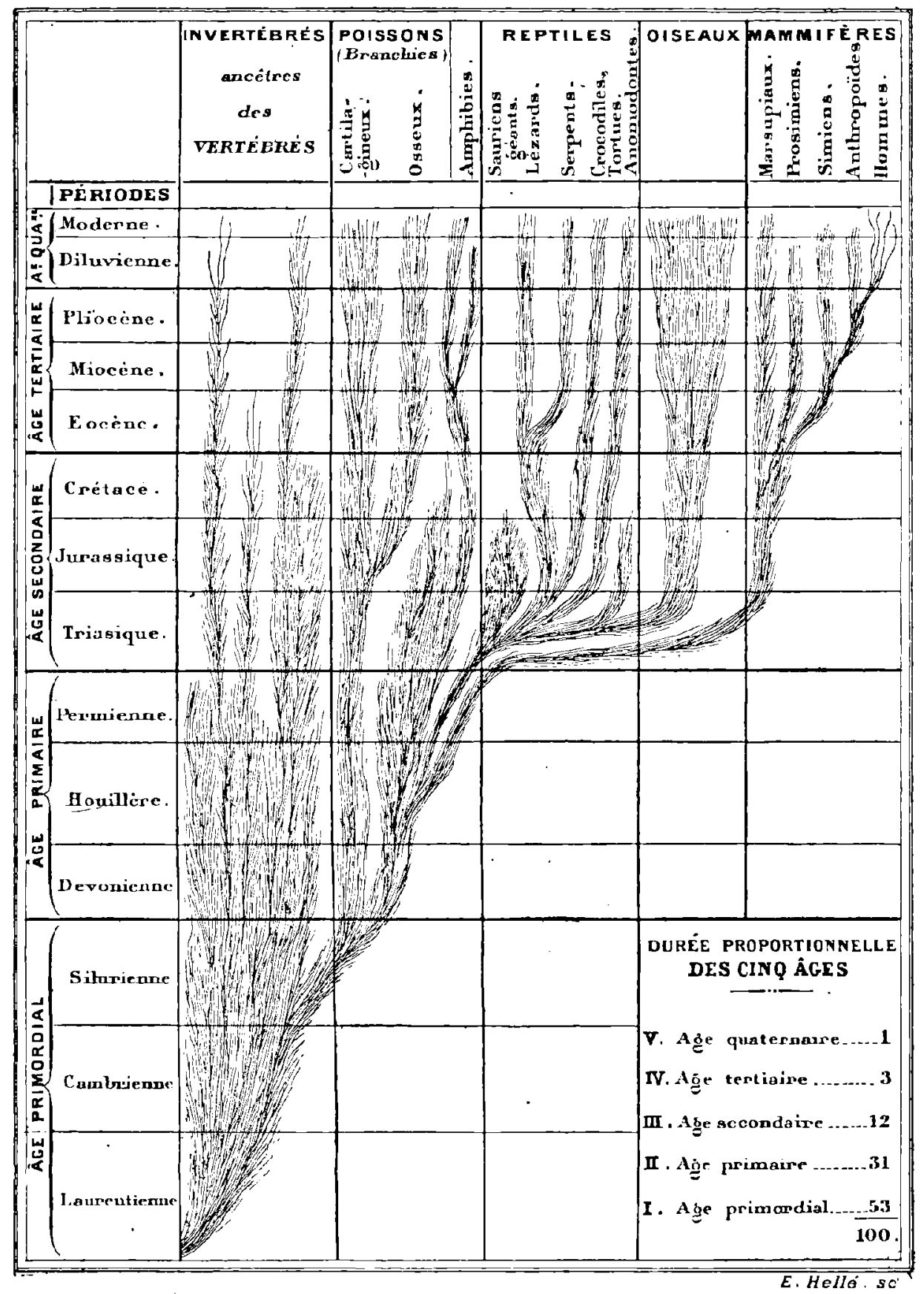

Fig. 3ij. - Correspondance entre le développement du règne animal et la succession des époques géologiques. 
Signalons, parmi les poissons les plus curieux de cette époque, le platax altissimus ( $\mathrm{fg}$. 358).

Les oiseaux, dont nous avons salué l'apparition avec l'archéoptẻryx, semblent se dégager définitivement des reptiles. La figure 359 représente une curieuse empreinte qui a été trouvée dans

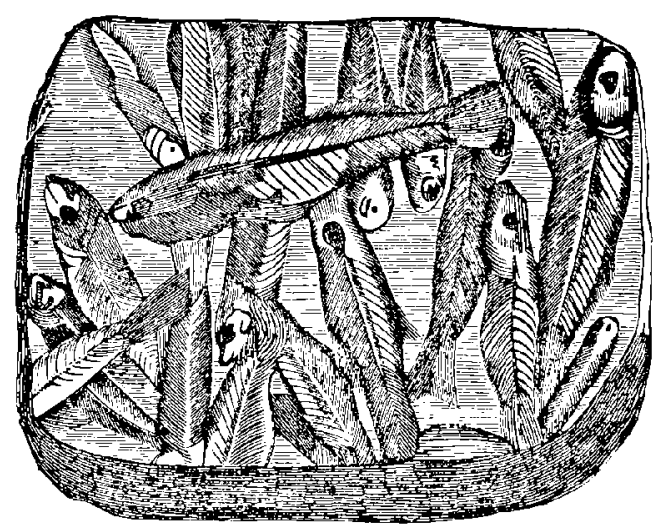

Fig. 3ä6. - I'oissons fossiles conservés sur une plaque de schiste.

les couches inférieures de la colline de Montmartre. Ce sont les restes d'un être ailé offrant l'aspect et l'organisation de nos oiseaux actuels, et que l'on a nommé oiseau de Montmarlre.

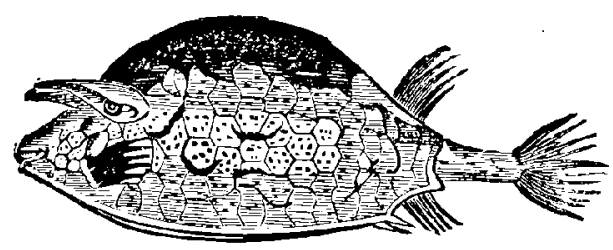

Fig. 3ذ7. - Les poissons de la période éocine (ostracion quadricornis)

Cet ètre ailé n'avait que des dimensions médiocres. Il en est autrement d'un oiseau qui à été découvert en 1855 par M. Gaston Planté, dans les couches éocènes de Meudon : le gastornis parisiensis. Le tibia de l'oiseau a seul été découvert; mais la dimension de cet os assure à l'animal une envergure considérable.

Nous verrons les oiseaux prendre tout leur développement penpant la période géologique suivante : la période miocène.

Comme nous l'avons déjà remarqué, ce sont les mammifères qui caractérisent essentiellement l'ère tertiaire. Nous avons assisté 
plus haut à leur naissance dans l'ordre primitif et rudimentaire des marsupianx. Ces mammifères inférieurs ont précédé dans nos pays les placentaires; après y avoir vécu pendant les temps secondaires, ils y sont devenus rares pendant l'époque éocène et ils ont disparu au milieu de l'époque miocène. M. Gaudry pense que plusieurs d'entre eux se sont transformés en placentaires. « Ceux qui n'ont pas

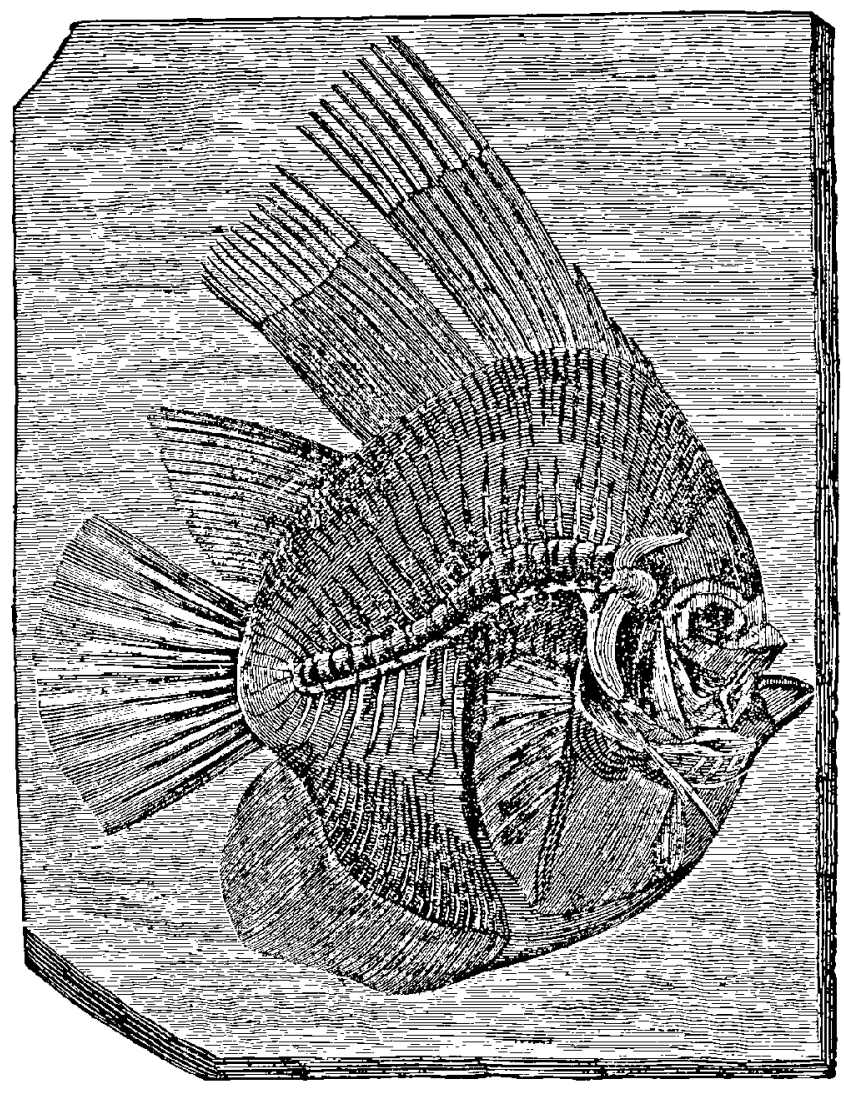

Fig. 3ö8. - Les poissons de la période éocène (platax altissimus).

subi de changement ou qui n'ont pas émigrè ont eu des désavantages dans la lutte pour la vie. Quels que soient, en effet leur courage et leur sollicitude maternelle, leurs petits, ètres chétifs, venus avant terme, sont plus exposés aux attaques des bêtes de proie que ceux des placentaires et surtout des ruminants et des pachydermes qui arrivent au jour dans un état très parfait. En outre, les marsupiaux ne peuvent traverser les fleuves avec leurs petits dans leur poche ou 
sur leur dos sans risquer de les voir asphyxier dans l'eau; les placentaires, dont les petits viennent au jour dans un état assez avancé pour qu'ils puissent courir et nager, n'éprouvent pas les mèmes difficultés. Comme la destinée des herbivores est d'aller de campagnes en campagnes cueillir les plantes que chaque saison fait épanouir, les herbivores ont dù ètre plus gênés que les marsupiaux carnivores, soit par les bras de mer, soit par les fleuves; c'est peut-être là une des raisons pour lesquelles ils ont disparu plus tôt de nos contrées, car il est digne de remarque qu'on n'a signalé encore dans nos terrains tertiaires aucun véritałle marsupial herbivore, tandis qu'on y rencontre des débris de marsupiaux carnivores $n$.

Pendant la première moitié des temps tertiaires, il y a eu à Paris, en Auvergne, en Vaucluse, en Suisse, des animaux qui ressemblaient extrèmement aux sarigues actuels. On ne peut douter qu'ils aient eu une organisation analogue, car Cuvier a retrouvé en place chez l'un d'eux les os appelés os marsupiaux, qui servent à maintenir la poche où logent les petits. Cette découverte est une de celles qui sermblent avoir le plus intéressé notre grand anatomiste; avant d'avoir vu le bassin, il était persuadé qu'il portait des os marsupiaux, parce que l'étude des dents et du squelette lui avait révélé des ressemblances avec les sarigues. Cuvier admettait une loi qu'on appelle la loi de connexion des organes; il pensait que la présence d'un organe entraîne un autre organe, et voyant un animal du gypse de Montmartre, qui avait des dents comme les sarigues, il assurait d'avance qu'il devait aussi avoir des os de marsupiaux comme les sarigues. Au moment de creuser la pierre pour mettre à nu le bassin, il réunit quelques amis afin de les faire assister à la découverte des os marsupiaux; la réussite de son opération fit admirer une foís de plus sa jerspicacité anatomique.

Cependant, remarque M. Gaudry, « Cuvier aurait pu n'être pas toujours aussi heureux; il faut prendre garde d'exagerer la loi de connexion des organes. L'illustre fondateur de la paléontologie, croyantà l'immutabilité des espèces, supposait qu'un chien est constamment chien, qu'un sarigue est constamment sarigue. Je ne pense pas qu'il en ait forcément été ainsi ; un animal peut avoir eu à la fois les caractères d'un genre et ceux d'un autre genre, les caractères d'un 
ordre et ceux d'un autre ordre. Il est même possible qu'il ait formé un intermédiaire entre les deux principales divisions de la classe des mammifères ». On en a eu la preuve par les reptiles-oiseaux et les dinosauriens. Cette loi de continuité, déjà établie dans tous les précédents chapitres de cet ouvrage, s'affirme ici mieux que jamais.

La population éocène offrait comme caractère essentiel une remarquable abondance et une grande variété des divers genres de pachydermes, qui manquent entièrement parmi les quadrupèdes de nos jours; ceux de cette époque se rapprochaient plus ou moins des tapirs, des rhinocéros et des chameaux. Ces genres, dont la décou-

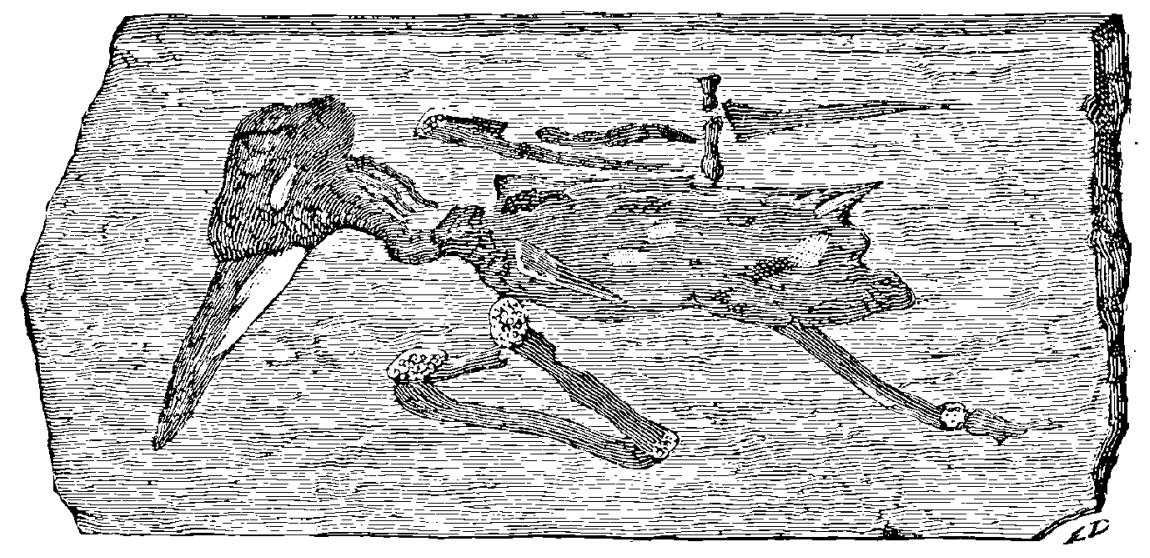

Fig. 359. - Restes fossiles d'oiseau trouvés à Montmartre (1/2 gr. nat.).

verte entière est due à Cuvier, sont: les paléothériums, les lophiodons, les anaplothériurns, les anthracothériums, les chéropotames, les adapis. Décrivons-les sommairement.

Les paléothériums ( $\left.{ }^{(}\right)$ressemblaient aux tapirs par la forme générale, par celle de la tête, notamment par la brièveté des os du nez, qui annonce qu'ils avaient, commo les tapirs, une petite trompe; enfin par les six dents incisives et les deux canines ḋ chaque mâchoire; mais ils ressemblaient aux rhinocéros par leurs dents mâchelières, dont les supérienres étaient carrées, avec des crêtes saillantes diversement configurées, et les inférieures en forme de doubles croissants, et par leurs pieds, tous les quatre divisés en

1. Etynologie : $\pi x \lambda \alpha .0 \varsigma$; ancien; $\theta_{n}=6 \%$, animal. 
trois doigts, tandis que dans les tapirs ceux de devant en ont quatre (').

C'est un des genres les plus répandus et les plus nombreux en espèces dans les terrains de cet âge.

“ Nos plâtrières des environs de Paris en fourmillent, écrivait Cuvier : on y trouve des os de sept espèces. La première (paleotherium magnum), grande comme un cheval; trois autres de la taille d'un cochon, mais une avec des pieds ètroits et longs; une avec des pieds plus larges; une avec des pieds encore plus larges et surtout plus courts; la cinquième espèce, de la taille d'un monton, est bien plus basse et a les pieds encore plus larges et plus courts; une sisiẻme est de la taille d'un agneau, et a des pieds greteles, dont les doigts latéraux sont plus courts que les autres; enfin une septième n'est pas plus grande qu'un lic̀ve $»$.

On a trouvé aussi des paléothériums dans d'autres contrées de la France: au Puy-en-Velay, dans des lits de marne gypseuse; aux environs d'Orléans, dans des couches de pierre marneuse; aupris d'Issel, dans une couche de gravier ou de mollasse, le long des pentes de la Montagne-Noire. Mais c'est. surtout dans les mollasses du département de la Dordogne que le paléothérium a été rencontré non moins abondamment que dans nos plâtrières de Paris.

Les lophiodons se rapprochent encore un peu plus des tapirs que ne font les paléothériums, en ce que leurs dents màchelières inférieures ont des collines transverses comme celles des tapirs. Ils en diffèrent cependant par certains détails.

Cuvier en a découvert jusqu à douze espèces, toutes de France, ensevelies en des pierres marneuses formées dans l'eau douce, et

1. Nous donnons plus loin (fig. 361) le squeletle du grand paléothérium, et ici $(f g .360)$ l'animal restauré. On peut voir à la nouvelle galerie de paléontologie du muséum de Paris un immense bloc de pierre dans lequel le squelette presque entier de cette espèce de rhinocéros a été conservé. On l'a découvert dans la carrière Michel, à Vitry-sur-Seine, près de Choisy-le-Roi. Pour l'obtenir dans son entier, il a fallu tailler n bloc de pierre long de $2^{\mathrm{m}} 45$, large de $\mathrm{I}^{\mathrm{m}} 30$ et épais de $8^{\mathrm{m}} 25$, au fond d'une galerie souterraine dont il formait le toit. Ce bloc est dressé de sorte que l'animal est à peu près debout comme dans l'état de vie; mais quand le squelette a été trouvé, il était couché horizontalement dans la pierre.

Loin d'etre lourd el presque massif, comme on le pensait, le paléothérium était un animal d'un port assez élégant, dont l'encolure était peut-être aussi allongée que celle diu cheval, et qui semble assez exactement modelé sur le même type que le lami. 
remplies de limnées et de planorbes, qui sont des coquilles d'étang et de marais. La plus grande se trouve près d'Orléans, dans la mème carrière que les paléothériums; elle approche du rhinocèros. Il y en a dans le même lieu une autre, plus petite; une troisieme se trouve à Montpellier; une quatrième près de Laon; deux près de Bichsweiller, en Alsace; einq près d'Argenton, en Berry. On en a trouvé ègalcment près de Gannial.

Ces espèces diffèrent entre elles par la taille, qui dans les plus

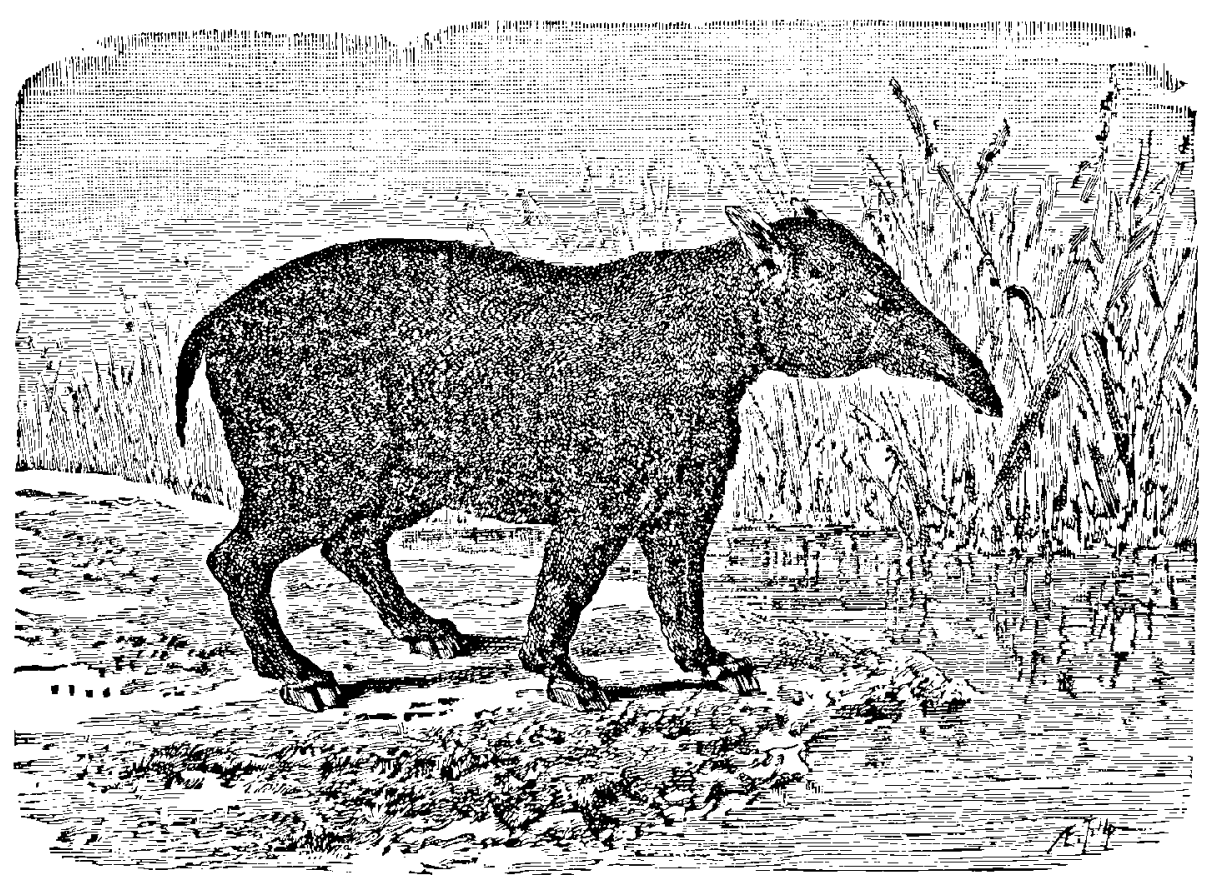

Fig. 3øn. - I.e grand paléothérium, marmmifêre pachyderme de la période éocène (1/20 de gr. nat.).

petites devait égaler à peine celle d'un petit agneau, et par des détails dans les formes de leurs dents, qu'il serait trop long d'exposer ici. On a recueilli un grand nombre d'ossements fossiles de lophiodons dans les couches supérieures du calcaire grossier de Paris.

Les anoplothériums, retrouvés surtout dans les plâtrières des environs de Paris, présentent certains caractères qui ne s'observent dans aucun autre animal: des pieds à deux doigts dont les métacarpes et les métatarses demeurent distincts ct ne se soudent pas 
en canons comme ceux des ruminants, et des dents en série continue et que n'interrompt aucune lacune. L'homme seul a les dents ainsi contiguës les unes aux autres, sans intervalle vide.

Ce genre extraordinaire, qui ne peut se comparer à rien dans la nature vivante, se subdivise en trois sous-genres: les anoplothériums proprement dits, dont les molaires antérieures sont encore assez épaisses, et dont les postérieures d'en bas ont leurs croissants à crête simple; les xiphodons, dont les molaires antérieureś sont, minces et tranchantes, et dont les postéricures d'en bas ont vis-àvis la concavité de chacun de leurs croissants une pointe qui prend aussi en s'usant la forme d'un croissant; les dichobunes, dont les croissants extérieurs sont pointus, et qui ont ainsi sur leurs arrièremolaires inférieures des pointes disposées par paires.

L'anoplothérium le plus répandu était un animal haut comme un sanglier, nais bien plus allongé, et portant une queue très longue et très grosse, en sorte qu'au total il avait à peu près les proportions de la loutre, mais plus en grand. Il est probable qu'il nageait bien et fréquentait les lacs, dans le fond desquels ses os ont èté incrustés par le gypse qui s'y dẻposait.

Le xiphodon était svelte et léger comme la plus jolie gazelle.

Le dichobune avait la taille du lièvre. Outre ses caractères sousgénériques, il diffère des anoplothériums et des xiphodons par deux doigts petits et grẻles à chaque pied, contigus aux deux grands doigts.

Le genre des anthracothériums est à peu près intermédiaire entre les paléothériums, les anoplothériums et les cochons. Deux de ces espèces ont été trouvées dans les lignites de Cadibona, près de Savone. La première approchait du rhinocéros pour la taille; la seconde était beaucoup moindre. On en rencontre aussi en Alsace et dans le Velay. Leurs dents mâchelières ont des rapports avec celles des anoplothériums; mais ils ont des canines saillantes.

Le genre chéropotame vient de nos plâtrières, oủ il accompagne les palćothériums et les anoplothériums, mais il est beaucoup plus rare. Ses molaires postérieures sont carrées en haut, rectangulaires, en bas, et ont quatre fortes éminences coniques cntourées d'éminences plus petites. Ses canines sont petites. La taille était celle d'un cochon de Siam. 
Le genre adapis a offert une espèce de la taille du lapin : iI vient aussi de nos plâtrières, et devait tenir de près aux anoplothériums.

Ainsi voilà près de quarante espèces de pachydermes de genres entièrement éteints; et dans des tailles et des formes auxquelles le règne animal actuel n'offre de comparables que trois tapirs et un daman (').

Ce grand nombre de pachydermes est d'autant plus remarquable, que les ruminants, aujourd'hui si nombreux dans les genres des cerfs et des gazelles, et qui arrivent à une si grande taille dans ceux des boufs, des girafes et des chameaux, ne se montrent presque pas dans les terrains dont nous parlons.

Mais nos pachydermes n'étaient pas pour cela les seuls habitants des pays où ils vivaient. Dans nos plâtrières, du moins, nous trouvons avec eux des carnassiers, des rongeurs, plusieurs sortes d'oiseaux, des crocodiles et des tortues; et ces deux derniers genres les accompagnent aussi dans les mollasses et les pierres marneuses du centre et du midi de la France. Signalons notamment une chauvesouris découverte à Montmartre, et du genre des vespertilions.

Montmartre a aussi donné les os d'un renard, différent du nôtre, et qui diffère également des chacals, des isatis et des renards d'Amérique; ceux d'un carnassier voisin des ratons et des coatis, mais plus grand; ceux d'une espèce particulière de genette, et de deux ou trois carnassiers problématiques.

Les crocodiles de l'âge dont nous parlons se rapprochent de nos crocodiles vulgaires par la forme de la tête, tandis que dans les bancs de l'âge du Jura on ne voit que des espèces voisines du gavial. Les tortues de cet âge sont toutes d'eau douce ; les unes appartiennent au sous-genre des émydes; et il y en a, soit a Montmartre, soit surtout dans les mollasses de la Dordogne, de plus grandes que toutes celles que l'on connaît vivantes; les autres sont des trionyx, ou tortues molles. Ce genre, que l'on distingue aisément à la surface vermiculée des os de sa carapace, et qui n'existe aujourd'hui que dans les rivières des pays chauds, telles que le Nil, le Gangc, l'Orćnoque, était très abondant sur les terrains qu'habitaiẹnt les

1. Cuviar. Discours sur les révolutions du globe. 
palćothériums. Il y en a une infinité de débris ì Montmartre, et dans les mollasses de la Dordogne et autres dépôts de graviers du midi de la France.

Les lacs d'ean douce autour desquels vivaient ces divers animaux, et qui recevaient leurs ossements, nourrissaient, outre les tortues et les crocodiles, quelques poissons et quelques coquillages. Tons ceux que l'on a recueillis sont anssi étrangers à notre climat, et mème aussi inconnus dans les saux actuelles, que les paléothériums et les autres quadrupèdes leurs contemporains. Les poissons appartiennent mème en partie à des genres inconnus.

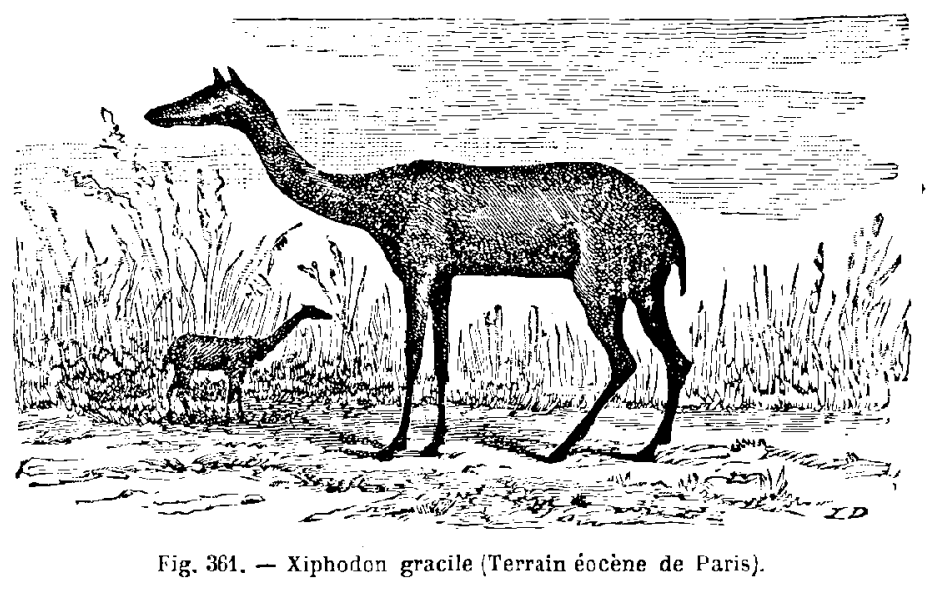

$\Lambda$ insi l'on ne peut douter que cette population, que l'on pourrait appeler d'àge moyen, cette première grande production de mammifères, n'ait été en partie détruite; et en effet partout od l'on en découvre les débris il y a au-dessus de grands dépôts de formation marine, en sorte que la mer a envahi les pays que ces races habitaient, et s'est reposée sur eux pendant un temps assez long.

Tout récemment, en 1884, M. le docteur Lemoine a découvert dans le terrain éocène inférieur des environs de Reims, un mammifère auquel il a donné le nom de "pleuraspidotherium ». Cet animal se rapprochait des marsupiaux et du paléothérium.

Tout récemment aussi, en établissant le nouveau chemin de fer de Saint-Cloud à Marly-le-Roi, on a mis au jour sur une grande étendue l'élage géologique des sables de Fontainebleau avéc les marnes coquillières. Au milieu de cette tranchée, M. Chouquet a 
trouvé, parmi de nombreux débris fossiles, quatorze côtes d'un poids et d'un volume vraiment extraordinaires. Ces côtes sont longues de 43 centimètres, et elles sont aussi épaisses que larges. M Gaudry soupconne qu'elles ont dû appartenir au plus gros mammifère marin qui ait été encore découvert aux environs de Paris. Cet animal an lédiluvien devait se rapprocher de notre lamantin actuel, grand cétacé herbivore, plus connu sous le nom de «bouf marin ». Les nageoires se composent de cinq doigts qui forment de véritables mains. Les femelles portent sur la poitrine deux grosses mamelles.

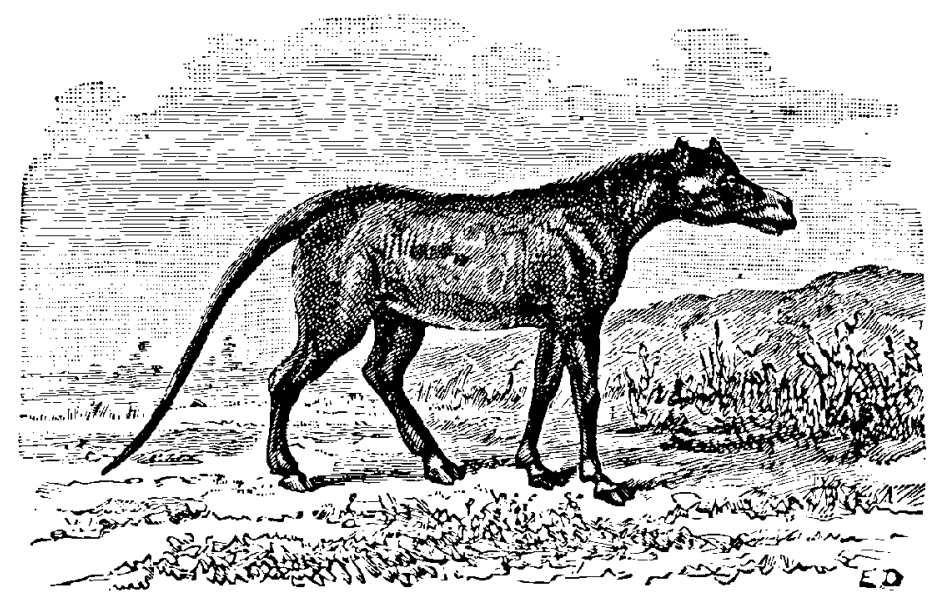

Fig. 362. - L'anoplothérium, mammifère pachyderme de la période éocène (1/20 de gr. nat.).

L'énorme lamantin devait avoir une cage thoracique énorme. On ne connait aucun animal muni de côtes aussi lourdes et aussi grosses.

Mais c'est aux Etats-Unis que ces terrains ont récemment offert les plus belles richesses à la paléontologie. Depuis l'établissement du chemin de fer qui traverse l'Amérique, de l'Atlantique au Pacifique, des contrées jusqu'alors fermées à la civilisation et à la science ont été explorées. On y a trouvé une multitude d'animaux fossiles dont plusieurs sont très différents de ceux d'Europe.

La région du Wyoming, comprise entre les Montagnes-Rocheuses, à l'est, et la chaine de Wahsatch, à l'ouest, est une de celles qui réservaient le plus de surprises aux paléontologistes. A l'époque éocène, la mer qui l'avait occupée pendant l'époque crétacée a été remplacée par de vastes lacs d'eau douce, sur les bords desquels 
s'est épanouie une riche végétation et s'est développée la famille des gigantesques pachydermes auxquels on a donné le nom de Dinocératidés. M. Marsh vient de publier un grand ouvrage sur ees étranges créatures ('); nous l'avons sous les yeux : il est encoro plus volumineux et plus riche en documents que celui dont nous avons parlé plus haut sur les oiseaux à dentś.

L'inspection des crânes de dinucératidés explique pourquoi on leur a donné leur nom ( ${ }^{2}$ ). Jamais on n'avait vu de têtes aussi cornues : les os du nez portent en avant deux petites protubérances osseuses; les maxillaires produisent au-dessus des canines deux fortes protubérances; une troisième paire de protubérances encore plus grosses et plus extraordinaires est formée par les pariétaux; elles se continuent avec une énorme crête qui borde le haut de la partie postérieure de la tête. Quel pouvait ètre l'aspect d'une pareille tête à l'état vivant? On a essayé de reconstituer cet étrange animal sur le dessin de la page 677.

Le cerveau n'est pas moins étonnant; il laisse complètement à découvert les lobes olfactifs ainsi que le cervelet, et il est plus petit que dans aucun autre mammifère; il a l'aspect d'un cerveau de reptile. La petitesse du cerveau est un caractère propre à plusieurs mammifères du tertiaire inférieur; cet organe a pris plus de développement chez les genres du tertiaire moyen et surtout chez ceux de l'époque actuelle. Comme il y a en général une relation entre le développement du cerveau et celui de l'intelligence, on peut croire que les anciens mammifères ont eu moins d'intelligence que ceux d'aujourd'hui.

L'animal fossile qui, par ses membres et sa dentition, se rapproche le plus des dinocératidés, est le coryphodon; mais cet animal est encore bien éloigné des dinocératidés. Malgré leur taille énorme et certaines dispositions de leurs membres, les grandes bêtes cornues des Western-Territories ne peuvent être rapprochèes des proboscidiens, car elles n'avaient ni trompes, ni incisives supérieures, et, bien que leurs pattes présentent quelque ressemblance avec celles des éléphants, elles en diffèrent à plusieurs égards. En réalité,

1. MARsH. Dinocerata, a monograph of an extinct order'of gigantic mammals, Washington, 1884.

2. Elymoloyie: Setwós, terrible; xépas, corne. 
les dinocératidès sont des êtres qui, après avoir.contribué à donner une physionomie assez bizarre au monde éocène, ont disparu sans laisser de postérité.

On éprouve quelque étonnement en voyant apparaître, dès l'époqlie du tertiaire inférieur, des bètes si puissantes, car les recherches qui ont été faites dernièrement en Amérique, comme celles qui ont eu lieu en Europe, n'avaient jusqu'à présent fourni que des mammifères secondaires assez chétifs ( $\left.{ }^{4}\right)$.

De 1870 à 1883, M. Marsh est parvenu à recueillir les restes de plus de deux cents individus de dinocerata, sans compter les innombrables fossiles appartenant à d'autres groupes. On en connait déjà près de trente espèces différentes. C'est sur l'étude de ces magnifiques matériaux qu'est basée sa belle monographie.

Comme nous l'avons dit, le cerveau est un des organes les plus curieux des dinocerata : il est plus petit que dans aucun autre mammifere connu. Il n'est même pas plus gros que l'ensemble de toute la colonne vertébrale. Au surplus, l'évolution du cerveau, pendant les temps tertiaires, a obéi, d'après M. Marsh, aux lois suivantes :

1. Tous les mammiferes tertiaires avaient de petits cerveaux.

2. Il y a eu accroissement graduel du cerveau pendant les temps tertiaires.

3. Cet accroissement portait surtout sur les hérnisphères.

4. Dans quelques groupes, les circonvolutions cérébrales deviennent plus complexes.

Les vertèbres cervicales des dinocerata ressemblent à celles des proboscidiens, mais elles sont plus longues. Le cou entier était d'un tier's plus grand que celui de l'éléphant. Une trompe était donc inutile puisque la tête pouvait atteindre le sol. Les os des membres sont en général très solides, de même d'ailleurs que tout le squelette,' à l'exception d'une partie du crâne. Les membres antérieurs ont une ressemblance générale avec ceux des proboscidiens. Les pattes de devant sont plus volumineuses que celles de derriere.

Si l'on compare le dinoceras à quelques-uns des plus grands mammifères ongulés d'aujourd'hui, on observe qu'il présente cẹr-

1. Albert Gaudry. Comptes rendus de l'Académie des sciences, 19 octobre 1885. 
taines ressemblances avec le rhinocéros et certaines autres avec l'éléphant. Quant aux dimensions, il est intermédiaire entre les deux. Par plusieurs autres points, il rappelle aussi l'hippopotame. La petitesse remarquable du cerveau et la lourdeur des membres indique un animal se mouvant lentement, peu adapté à se soustraire aux changements de climat, et condamné par conséquent à périr à la suite de ceux qui marquèrent la fin de la période éocène.

Les mammifères de l'époque tertiaire nous offrent des conditions particulièrement favorables pour étudier les questions relatives à l'évolution. Ces êtres, dont la peau est le plus souvent délicate, nue ou couverte seulement de poils, n'ont eu leur complet développement que lors de l'extinction des énormes reptiles secondaires, auxquels une peau coriace et quelquefois cuirassée donnait des avantages dans la lutte pour la vie. Pendant la plus grande partie des temps tertiaires, les mammifères ont été très différents des animaux actuels; ils étaient encore en pleine évolution.

Arrètons-nous un instant sur les pachydermes qui ont eu pour tombeaux les carrières à plâtre des environs de Paris. Montmartre et Pantin furent leur dernier refuge. Chaque bloc qui sort de ces carrières renforme quclque fragment d'un os de ces mammifères, et combien de millions d'ossements ont été détruits avant que l'attention se füt portée sur cette étude!

Les pachydermes se partagent en deux groupes principaux : ceux à doigts impairs, tels que les rhinocéros et les tapirs, et ceux à doigts pairs, tels que les cochons et les hippopotames. De nos jours, quel que soit celui de ces deux groupes auquel elles appartiennent, les espèces de pachydermes sont pour la plupart isolées les unes des autres et, sous ce rapport, elles forment un contraste avec l'ordre des ruminants, dont plusieurs membres se ressemblent tellement qu'il est impossible de tracer leurs limites génériques. Assurément, les pachydermes modernes ont dù contribuer à faire repousser l'idée que les espèces différentes sont descendues les unes des autres; mais comme M. Gaudry l'a fait remarquer, lorsque nous pénétrons dans les temps géologiques, nous voyons les lacunes se combler : « Les espèces se montrent si rapprochées les unes des autres qu'il est difficile d'échapper à la pensée que ces ressemblances prouvent ùne parenté commune. » 
Comme exemple de pachydermes actuels qui paraissent dérivés d'espèces tertiaires, on peut citer les rhinocéros. Ceux de ces animaux qui habitent l'Afrique sont assez différents de ceux qui vivent en Asie; par conséquent, il n'y a pas licu de supposer qu'ils descendent directement des uns des autres. Il est au contraire naturel de penser qu'ils proviennent de leurs prédéces-

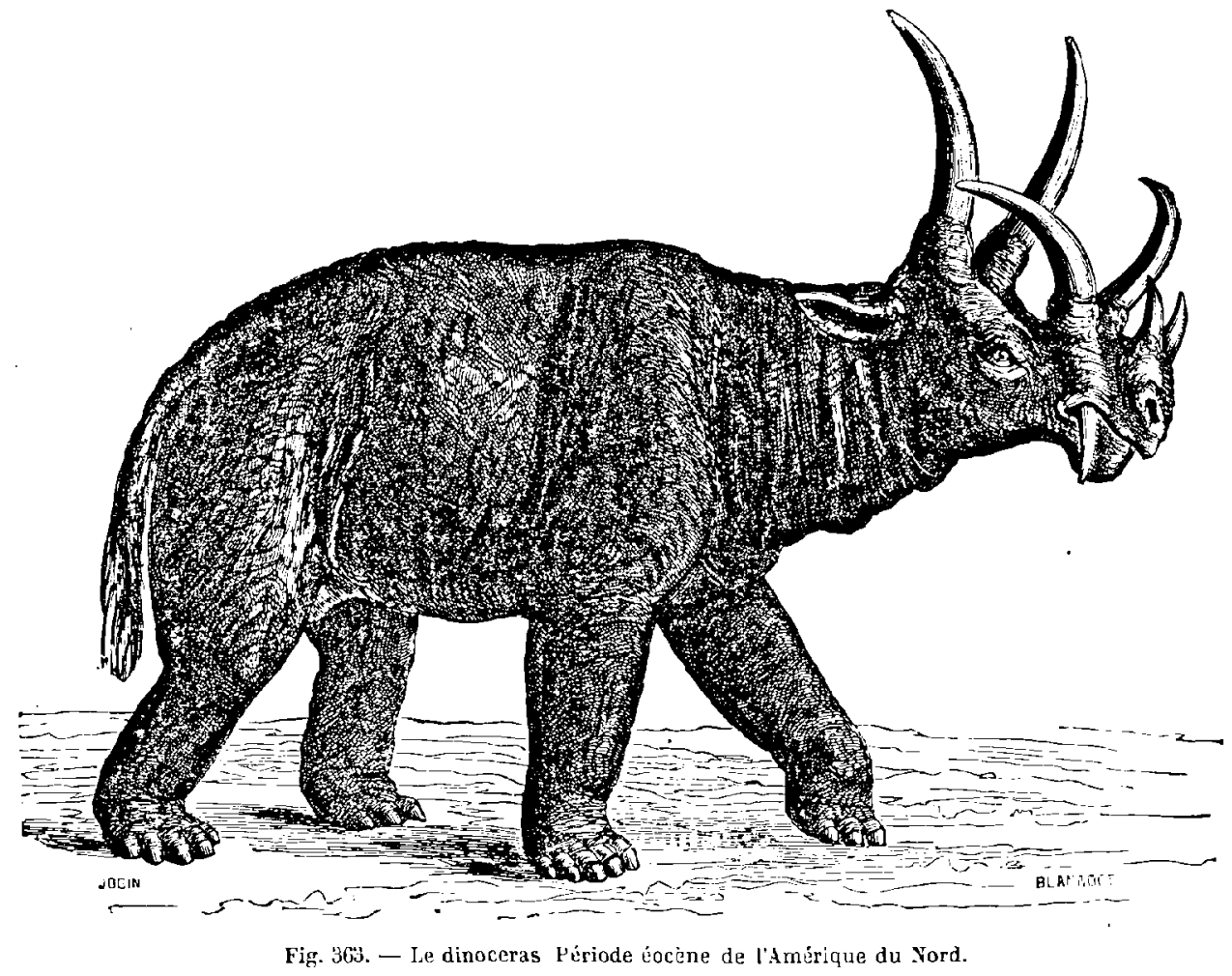

seurs tertiaires, car ils s'en rapprochent extrèmement; les rhinocéros actuels d'Asie rappellent les rhinocéros Schleiermacheri de Pikermi, d'Eppelsheim et de Sansan; le rhinocéros bicorne d'Afrique a une étonnante ressemblance avec le rhinocéros pachygnathus de Pikermi.

Les rhinocéros ne remontent pas très loin dans les âges tertiaires; ils ont été précédés par les acérothériums, les paléothériums, les paloplothériums. Le trone et les membres de ces animaux offrent de remarquables ressemblances. C'est sur l'examen du crâne et de la dentition que leurs distinctions génériques ont été basées; 
leurs diffẻrences ne sont pas tellement tranchées qu'on ne puisse concevoir qu'ils sont descendus d'ancêtres communs.

Afin que nos lecteurs puissent juger par eux-mêmes de cette parenté, nous reproduisons plus loin ( $f g .364$ et 365), d'après M. Gaudry, les squelettes fossiles dont la comparaison établit une similitude véritablement révélatrice de leur descendance. Le premier est celuj du paléothérium magnum de l'éocène supérieur; le second est celui du rhinocéros pachygnatus du miocène supérieur. Ainsi s'établit par une série d'observations différentes la doctrine moderne de la transformation des espèces.

Il faut bien avouer que la soudaine apparition des grands mammifères, paléothériums, anoplothériums, dans le terrain tertiaire, aux flancs de la colline de Montmartre, était faite pour causer aux géologues le même étonnement que l'apparition des pyramides d'Égypte, des grands temples de Palmyre, de Poestum et de la Grèce dans le désert, à un esprit sans culture.

Le premier sentiment des peuples qui ont rencontré les temples, les pyrąmides, les dolmens, a été d'en attribuer la construction à des êtres inaginaires, génies, démons, fées, qui remplacent la puissance évanouie des civilisations antiques. De là le grand nombre de légendes, de superstitions, de poésies populaires qui s'attachent à chacune des ruines du désert.

En vain les découvertes nouvelles ont montré les divers degrés par où l'homme a passé, combien d'ébauches, de tâtonnements, de formes, de genres de vie, ont servi d'intermédiaires entre l'âge de pierre et l'âge de fer, par combien d'états antérieurs a été préparée chacune des stations humaines; combien les peuplades aryennes ont précédé de loin l'épanouissement du sanscrit et du zend; comment par delà chaque antiquité se révèle une antiquité plus lointaine, par delà chaque génération une autre génération, et combien de siècles de siècles pèsent dejà sur ceux que nous prenons pour les premiers-nés de la première journèe du monde humain. En vain ces intermédiaires sont placés sous nos yeux, l'habitude de l'esprit l'emporte.

Ne nous étonnons pas si, à la première révélation des grands ossements des mammifères épars dans la période tertiaire, une stupeur semblable a envahi l'intelligence. Ici, l'esprit humain était 
mis véritablement au défi de dénouer l'énigme. Comment les plus sages, les plus savanti, les plus méthodiques, ne se seraient-ils pas contentés de répondre d'abord : “Ceci dépasse les facultés humaines. Ne tentons pas l'impossible. Les grandes organisations dont nous venons de découvrir les ruines ont été dès l'origine ce qu'elles furent plus tard. Elles sortent toutes achevées de la main du Créateur. En demander davantage, c'est outrepasser les limites de notre entendement. Prenez garde au vertige : arrêtez-vous. Ne cherchez. pas à voir Dieu face à face. »

Voilà, en d'autres termes, ce que répondait Cuvier, qui avait ouvert ces abimes nouveaux à l'intelligence. Mais, comme le dit avec raison Edgard Quinet, il était impossible que la curiosité humaine, ainsi attirée et repoussée en mème temps, se renfermât toujours dans une si grande prudence.

L'impossibilité de l'ancienne solution éclatait. Cornment consentir à se représenter le chène surgi tout à coup de sa hauteur centenaire? Comment, en un çlin d'œil, aurait-il enfoui ses racines sous terre.

Comment le lion se serait-il élancé du néant sans avoir été lionceau?

Et l'homme, qu'il fallait se représenter adulte, vers l'âge de trente ans, sans mère, sans berceau, sans enfance, déjà plein de forces et même d'expérience! Car il en faut pour le moindre mouvement, pour la plus petite action, pour le plus simple usage des sens. Que ferait cet homme de trente ans, subitement apparu, qui ne sturait ni voir, ni toucher, ni entendre? Que lui serviraient ses bras viguureux s'il ne savait pas saisir, ses yeux s'il ne savait pas regarder, juger la distance; ses pieds, s'il ne savait pas marcher? Sa force mème se tournerait contre lui.

La solution devait venir, comme nous l'avons vu, de divers points à la fois. Tout d'abord on aperçoit çà et là des enchainements qui peuvent servir de fils conducteurs. A côté de leurs différences, les ètres qui se sont succédé dans les diverses époques ont suuvent gardé des traits de ressemblance. Etant les derniers venus de la création, nous n'avons pas assisté à leur naissance; d'Archiac disait : "Nous sommes comme les éphémères qui meurent au soir du jour qui les a vus naitre, nous n'avons pas eu le temps de con- 
templer les métamorphoses du monde organique ». Cependant lorsque nous étudions les débris enfouis dans les couches terrestres, les analogies que nous découvrons entre les animaux des temps présents et leurs prélécesseurs nous portent souvent à admettre leur parenté. Par exemple, on trouve à l'état fossile des hyènes, des civettes, des chats, des éléphants, des rhinocéros, des tapirs, des cochons, des cerfs, des gazelles, des diuphins, des rorquals, etc., qui se distinguent à peine des espèces actuelles, on est porté à supposer qu'ils en sont les ancêtres, attendu que leurs différences ne

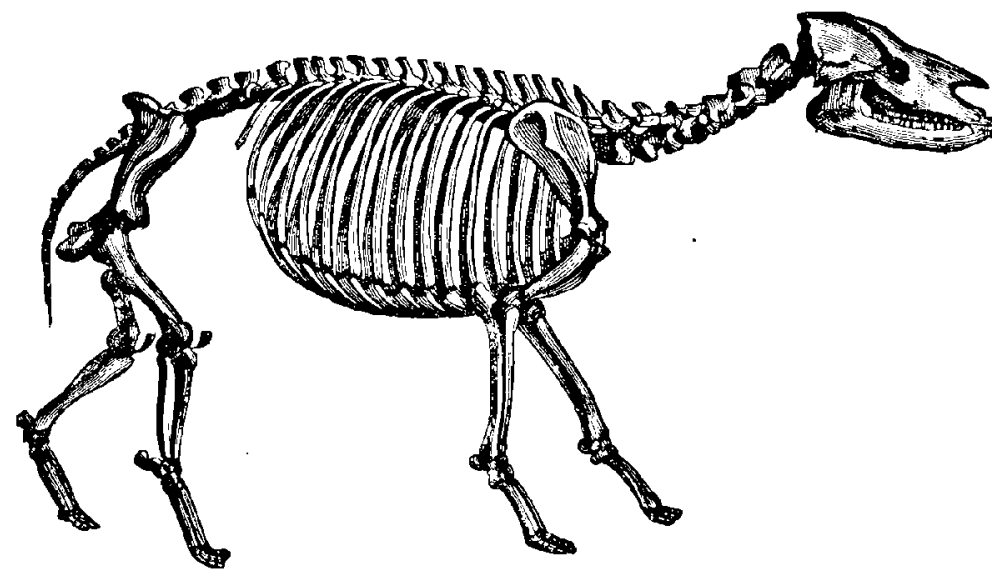

Fig. 361. - La transformation des especes : sqquelette du paléothërium

dépassent guère celles des races issues d'une même origine; dans les temus géologiques aussi bien que dans les temps actuels, les espèces se sont fractionnées en races, et il est impossible de dire où commence l'espèce, où s'arrète la race.

Ce ne sont pas seulement les espèces d'un mème genre qui ont des indices de parenté. " Quand je remarque, écrit M. Gaudry, que le cheval a succédé à l'hipparion, l'éléphant au mastodonte, le rhinocéros au paléothérium, le tapir au lophiodon, la loutre au lutrictis, l'hyène à l'ictithérium, le chien à l'amphycion, le semnopithèque au mésopithèque, etc., je pense que ces genres ont eu des liens étroits, car la somme de leurs ressemblances l'emporte infiniment sur celles de leurs différences. Si je crois à la parenté d'animaux de genres distincts, je crois aussi à celle des animaux d'ordres distincts; en effet, je vois des ruminants, des solipèdes remplacer 
des pachydermes qui s'en rapprochent tellement que nul ne peut tracer la limite des ordres des pachydermes, des solipèdes et des ruminants. Ainsi il me semble que les paléontologistes sont autorisés à dire qu'ils ont découvert de nombreux liens de parenté entre les animaux actuels et les mammifères qui les ont précédés dans les temps géologiques.

“ $\Lambda$ mesure que j'ai étendu mes observations, ajoute l'éminent naturaliste, je me suis confirmé dans la croyance que les ètres n'ont point paru isolément sur la Terre, sans liens les uns avec

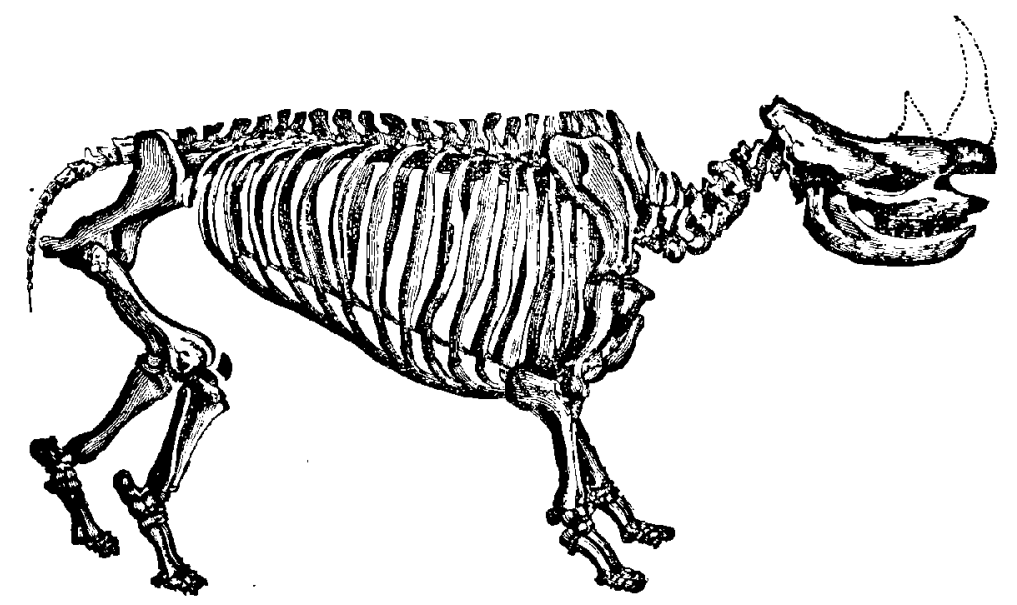

Fig. 365. - La transformation des espèces : squelette de rhinocéros.

les autres; j'ai pensé que, sous l'apparente diversité de la nature, domine un plan où l'Étre infini a mis l'empreinte de son unité. Dès lors, l'idée de découvrir quelque chose de ce plan a dirigé mes recherches paléontologiques $»$.

-Cette loi de la nature s'affirme de plus en plus, à mesure que nous avançons dans l'histoire de la Terre. A mesure que les milieux changent, les espèces vivantes changent en mème temps.

Les nouveaux venus de la période éocène no rampent plus, ils marchent, ils courent, ils bondissent, ils ne se tiennent plus attachés à la vase d'un marécage. Ils sont maitres de la terre et semblent la connaitre, car ils errent au loin en troupeaux.

Les uns grimpent sur les arbres et vont au bout des branches ronger les fruits que la flore tertiaire vient de mûrir pour eux; 
d'autres s'élancent de rocs en rocs sur la cime des montagnes nouvellement émergées; presque tous ont dépouillé l'armure écailleuse des reptiles. Ce sont les mammifères à peau épaisse garnie de poils. Aucune barrière ne les arrète; quand un sol est èpuisé, ils vont plus loin. C'est l'anoplothérium, le xiphodon, le paléothérium.

Il y en a déjà qui creusent la terre et qui la fouillent de leurs groins énormes; d'autres déracinent les arbrisseaux de leurs longues dents d'ivoire. La plupart, comme l'anoplothérium, sont entièrement désarmés. Sans défense, ils ont apparu sur une terre, où l'ancienne population rampante ne pouvait rien contre eux. Leur force, leur puissance est dans les quatre jambes déliées qui, en un moment, les portent au bout de l'horizon.

Ce que nous appelons centre de création, peut-on dire avec Edgard Quinct, est une constitution nouvelle du globe qui se réflèchit à la longue dans les mœurs, les habitudes, les instincts et la figure des êtres : tous sont plus ou moins entrainés au changement par cette nouvelle distribution de la terre et des eaux, par l'élévation des montagnes et l'arrivée du froid sur les hauteurs; chaque figure nouvelle du monde s'imprime dans la forme de chaque être, et les êtres changent tous plus ou moins.

Nous allons en avoir une nouvelle preuve.

La région du Jura et une notable partie des abords du plateau central de la France sont recouverts, en un grand nombre de points, par une formation très spéciale, à laquelle l'abondance du minerai de fer en grains a fait donner le nom de terrain sidérolithique. Ce terrain date de la seconde moitié de la période éocène (oligocène inférieur de M. A. de Lapparent). Les dépôts de phosphorite ou phosphate de chaux, si répandus dans le Quercy, constituent un ensemble analogue, à beaucoup d'égards, à la formation sidérolithique et paraissent, comme elle, appartenir, au moins en majeure partie, à l'oligocène inférieur. Ces dépôts renferment un nombre considérable de fossiles, surtout de mammifères.

Or ces phosphorites du Quercy ont fourni un genre particulièrement intéressant comme intermédiaire entre les marsupiaux et les placentaires: c'est un carnivore que M. Filhol a signalé sous le 
nom de cynohyœnodon ('). M. Gaudry l'a inscrit sous celui de proviverra $\left({ }^{2}\right)$.

M. Daubreee, qui a été l'un des premiers à attirer l'attention des naturalistes sur les phosphorites du Quercy, a rapporté de ces curieuses formations un crâne remarquable qui a été spécialement ètudié par M. Gervais. " Le moule de la cavité crânienne, dit ce naturaliste, montre que les hémisphères étaient pourvus de circonvolutions multiples, disposées longitudinalement, peut-être au nombre de quatre, et dont les deux intermédiaires offriraient des commencements de sinuosités; quant au cervelet, il était fort et complètement à découvert ». Le nom de thylacomorphus, sous lequel ce crâne a été inscrit, montre que dans l'opinion du savant professeur du Muséum, il annonçait des affinités avec les marsupiaux.

On a trouvé aussi dans le tertiaire inféricur, un carnivore qui appartient à un tout autre type que tous les précédents : ses dents ne sont pas coupantes; elles indiquent le régime omnivore des ours; cet animal est l'aretocyon $\left({ }^{3}\right)$ du grès de la Fère; il est le plus ancien de tous les mammifères connus jusqu'à présent dans les terrains tertiaires. D'habiles paléontologistes l'ont cru voisin des ratons et l'ont rangé parmi les placentaires; mais $M$. Gervais a récemment reconnu qu'il se rapprochait des marsupiaux par la forme de son cerveau et par la grandeur des trous palatins.

En présence de ces remarques, on peut se demander si les placentaires ne sont pas les descendants des marsupiaux. "Cette interrogation doit paraître bien naturelle aux embryogénistes, dit à ce propos M. Gaudry, car pour concevoir le passage d'un marsupial à un placentaire, il suffit de supposer que l'allantoïde s'est agrandie. Quand je réfléchis que le ptérodon, l'hyœnodon, la paléonictis, la proviverra, l'arctocyon ont vécu à l'époque où les marsupiaux ètaient sur le point de disparaitre de nos pays pour faire place au règne des placentaires, quand d'autre part je considère que ces carnassiers ont à la fois des caractères de marsupiaux et de placentaires, je suis porté à croire qu'ils sont les descendants

1. Animal qui tient à la fois des chiens ou des cynodons et des hyœnodons : xuwv, chien; uxwa, hyène; 3. Étymologie : xpxros, ours; xuwv, chien. 
des marsupiaux des temps secondaires, chez lesquels auraient persisté certains caractères des parents. $刃$

Des réminiscences de l'état marsupial se retrouvent même chez des animaux qui ont les apparences de vrais placentaires; ainsi l'amphicyon, qui appartient à la famille des chiens, a le méme nombre d'arrière-molaires supérieures que les marsupiaux, et son humérus ressemble plus à celui de ces animaux qu'à celui des chiens. Le cynodon est voisin des chiens et des civettes.

Il semble donc naturel de conclure que les etres actuels sont une dérivation des êtres des temps passés. L'histoire d'une époque a en partie sa raison d'être dans l'histoire de l'époque qui l'a précédée.

La période éocène a vu la naissance des lémuriens ou prosimiens, de ces étres que les naturalistes classaient encore naguère parmi les singes, mais qui ne méritent pas ce titre et semblent plutôt intermédiaires entre les chéiroptères et les singes. On se rendra compte des différences qui séparent les lémuriens des singes si l'on remarque qu'aux premiers appartiennent les makis; les loris, les galagos, les tarsiers, les galéopithèques, tandis qu'aux seconds appartiennent les sajous, les cynocéphales, les macaques, les cercopithèques, les semnopithèques, les gibbons, les orangs-outangs, les chimpanzés et les gorilles. La distinction est grande, comme on le voit, les quadrumanes comprennent donc deux groupes bien séparés : celui des lémuriens et celui des singes.

La première mention d'un lémurien fossile a été due à Rütimeyer. En 1862, parmi les fossiles éocènes recueillis dans le sidérolithique d'Egerkingen, près de Soleure, le savant professeur de Bâle rencontra un morceau de mâchoire pourvu seulement de trois molaires, dans lequel il sut découvrir un lémurien; il le désigna sous le nom de cœnopithecus (').

En 1873, Delfortrie a signalé dans les phosphorites du Lot une tête presque entière d'un lémurien primitif auquel il a donné le nom de palœolemur.

Plus récemment, M. Filhol a trouvé dans ces mèmes terrains la tête d'une seconde espc̀ce du même genre, qui se distingue par sa

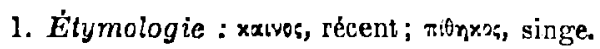


dimension plus grande et surtout par son allongement. Le même naturaliste a fait connaitre un bien plus petit lémurien qu'il a appelé necrolémur.

" En examinant les espèces découvertes dans les phosphorites, écrit M. Guudry, je me suis demandé si les lémuriens n'auraient pas eu une communauté d'origine avec plusieurs des pachydermes éocènes. Une telle question doit paraitre plus naturelle aujourd'hui que MM. Alphonse

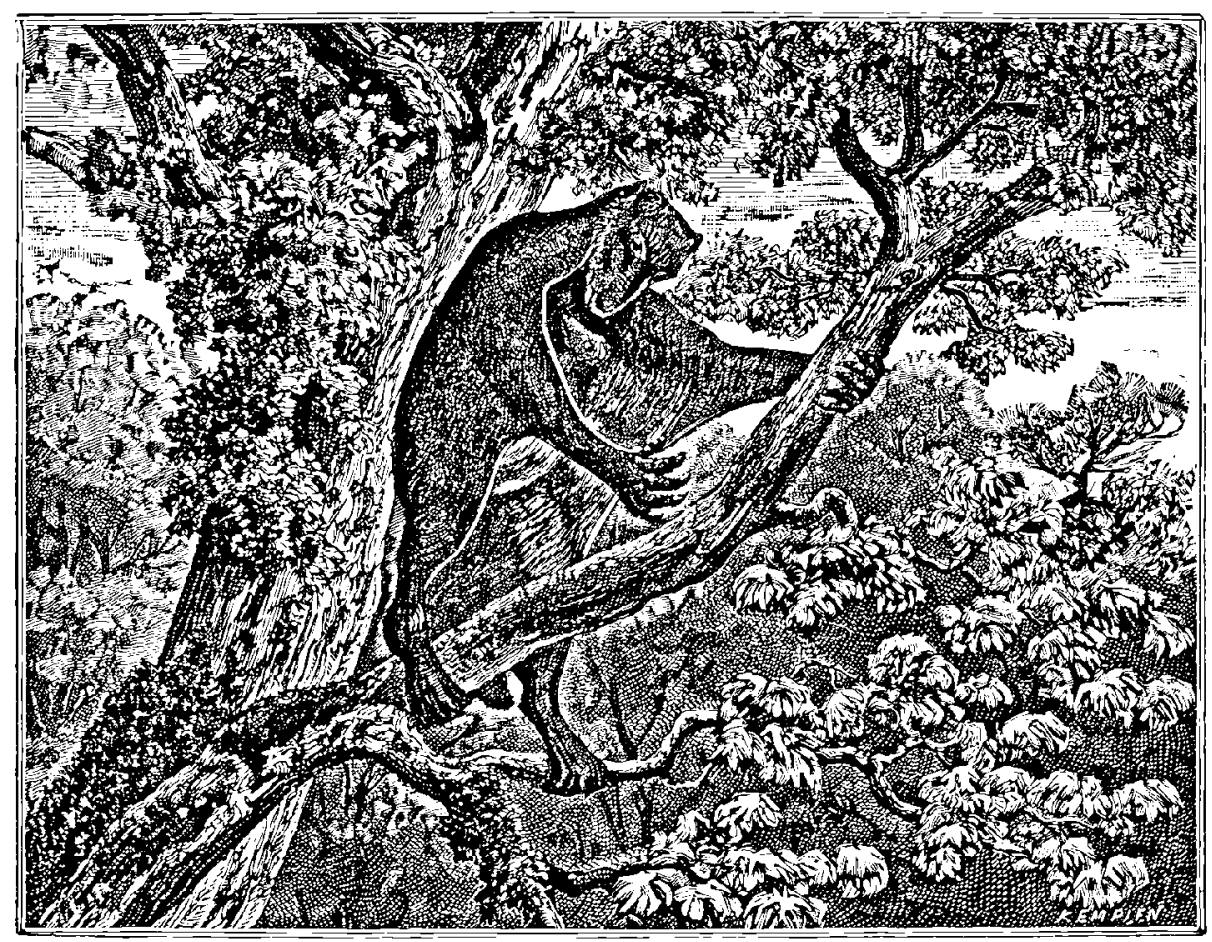

Fig. 366. - Le galéopithèque, lémurien de la période éocène.

Milne-Edwards et Grandidier, dans leur grand ouvrage sur les mammifères de Madagascar, ont prouvé combien les lémuriens ont d'analogie avec les ongulés. Pour montrer que plusieurs des anciens lémuriens ont eu des caractères entre ceux des lémuriens actuels et ceux des pachydermes éocènes, il suffit de mentionner les circonstances de leur découverte. Quand M. Delfortrie eut achevé d'étudier le crâne du potit lémurien du Lot, il voulut bien me l'envoyer en communication; en même temps il m'adressa plusieurs échantillons qui avaient été trouvés dans les phosphorites. Parmi ces échantillons, il y avait une mandibule, qui me rappela une pièce du gypse de Paris dont la détermination m'avait autre- 
fois beaucoup préoccupé, j'avais reconnu qu'elle ressemblait à une mandibule décrite par M. Gervais sous le nom d'aphélothérium, mais il était bien difficile d'aller plus loin et de dire à quel groupe l'aphélotherium devait être rapporté. La comparaison des mandibules de ce genre avec les pièces découvertes par M. Delfortrie et les màchoires des lémuriens vivants, m'apprit que les échantillons du savant naturaliste de Bordeaux et les mâchoires d'aphélothérium provenaiont sans doute d'une mème espèce de lémuriens. Je me souvins en méme temps qu'il y avait dans l'éocène supérieure un fossile dont la détermination n'était pas moins embarrassante que celle de l'aphélothérium : ce fossile, e'est l'adapis parisiensis; il me vint à la pensée que l'adapis était également du mème genre que le lémurien des phosphorites. Je suis encouragé à croire que cette opinion est vraisemblable, parce qu'elle a été adoptée par MM. Gervais et Filhol. Si elle est fondée, elle fournit la preuve qu'autrefois les lémuriens ont été moins éloignós des pachydermos qu'ils ne le sont aujourd'hui, car Cuvier a rangé l'adapis parmi les pachydermes. M. Gervais a provisoirement classé aussi l'aphélothérium près des pachydermes; on ne concevrait pas que des naturalistes, d'une première habileté, eussent fait ces rapprochements, si les lómuriens n'avaient pas eu anciennement des traits de ressemblance avec les pachydermes.

Ainsi, malgré la pauvreté des découvertes, on saisit déjà la parenté qui a dû faire descendre les lémuriens des pachydermes. M. Gaudry est aussi d'opinion, après l'examen des mâchoires trouvées, que, comme les lémuriens, les singes peuvent aussi descendre des pachydermes.

Comme on le voit, suivant la progression organique observée depuis le commencement du monde terrestre, les lémuricns sont arrivés en leur temps, pendant la période éocène, et nous verrons les véritables singes apparaitre pendant la période suivante. Natre figure 366 représente l'un de ces lémuriens ou prosimiens, l'un des plus curieux assurément, le galéopithèque ('), encore voisin des chéiroptères. Le caractère physiologique le plus remarquable de ces êtres indécis, c'est la membrane en forme d'ailè qui fonctionne comme parachute et leur permet, non de voler comme les chauvessouris (autres mammifères voisins), mais de se soutenir dans les airs. Il est peut-être regrettable que l'humanité ne descende pas des galéopithèques. Avec le progrés des fonctions et des organes, elle serait sans doute parvenue à voler.

1. Étynılogie : $\gamma \alpha \lambda \eta$, chat; $\pi \cdot 0 \eta \bar{s}$, singe. 
La fin des temps éocènes, désignée sous la qualification de période oligocène, a vu à ses débuts le principal soulèvement des Pyrénées et, à son déclin, celui des Alpes principales. La configul'ation géogr'aphique se modifie. Déjà nous avons remarqué qu'une invasion marine venant du Nord s'est fait sentir, en France, jusque dans le Gâtinais, dans la vallée du' Rhin jusqu'à Bàle, tandis que, dans les régions méridionales, le domaine maritime semblait plutôt reculer vers le Sud. Sous l'influence de cette mer septentrionale, le climat européen devient plus tempéré et moins extrême.

Après cette première phase, la mer se retire vers le Nord, et toute l'Europe, ou à peu près, devient terre ferme. C'est une époque de grands lacs, aussi bien dans la Beauce et la Limagne qu'à Manosque, en Provence, près de Narbonne, en Languedoc, en Savoie, en Suisse, enfin en divers points de l'Allemagne, de l'Autriche, de l'Italie et de la Grèce. En méme temps, l'Allemagne du nord voit prédominer les lagunes tourbeuses, favorables à la production des lignites. L'extension des lacs et l'abondance des dépôts d'eau douce, ainsi que l'opulence des formes végétales, attestent l'humidité croissante du sol, jointe à une chaleur égale et modérée. Les arbres à saisons prenment visiblement leur essor dans cetle seconde phase, sans toutefois exclure les palmiers, qui prospèrent encore au delà du 50 parallèle, c'est-à-dire au nord de Paris, ni les camphriers, dont la limite boréale dépasse le $55^{\mathrm{e}}$ degré. La période se termine par un mouvement qui provoque l'assèchement des grands lacs et fait naître sur le sol un régime fluvial, bientôt accentué par l'invasion de la mer mollassique.

C'est probablement à l'éocène qu'il convient d'attribuer les gisements de lignites avec plantes fossiles, découverts au Groënland, par $70^{\circ}$ de latitude nord, ainsi que dans le Canada septentrional, l'Islande et le Spitzberg. Ces gisements contiennent, d'après Heer, 9 grandes fougères, 31 conifères, 11 monocotylédones et 93 dicotylédones, noyers, platanes, hètres, chênes, érables, peupliers, etc.

Le refroidissement $d u$ globe avant commencé par les pôles, il est assez logique de considérer cette flore, malgré ses espèces miocènes, qui d'ailleurs ne forment pas plus du quart de l'ensemble, comme antérieure à la flore miocène européenne, c'est-ì-dire à la raigration vers le Sud des plantes qui devaient caractériser cette 
dernière. Le point le plus septentrional oủ l'ensemble végétal qui nous occupe ait été observé est la terre de Grinnel, située vers le $82^{\circ}$ parallèle. Sur ce point, le sapin argenté et le cyprès chauve croissaient à côté du peuplier et du bouleau, auprés des lacs couverts de nénuphars, nymphœa arctica; c'est-à-dire que le climat de l'époque, à quelques pas du pôle, était celui des Vosges actuelles. Mais les magnolias y faisaient défaut, tandis qu'ils existaient alors au Groënland, par $70^{\circ}$ de latitude. La moyenne annuelle du Grọënland septentrional devait être de $+12^{\circ}$ centigrades, c'est-à-dire celle de la Californie, tandis qu'à $80^{\circ}$ de latitude, régnait au Spitzberg une moyenne de $+8^{\circ} \dot{\mathrm{a}}+9^{\circ}$. En outre M. de Saporta a fait remarquer que la flore du Groënland offre un parallélisme remarquable avec celle de l'éocène inférieur parisien. Aussi est-il d'àvis que les diverses flores arctiques ont précédé les nôtres et ont émigré en Europe et en Amérique, tandis que les palmiers, qui se sont montrés pour la première fois en Europe à l'époque crétacée, n'ont jamais pénétré dans l'intérieur du cercle polaire (').

Quoique nous soyons entrés dans l'ère moderne de l'histoire de la Terre et que l'époque tertiaire soit récente relativement à l'antiquité secondaire, cependant les changements géographiques arrivés depuis cette époque sont loin d'être insignifiants. Le géologue Charles Lyell a construit une carte fort intéressante et dont nons donnons ici un extrait $(f g .367)$, destinée à représenter l'étendue de la surface qui, en Europe, a été couverte par la mer depuis le commencement de la période éocène. Dans cette carte, les parties ombrées comprennent, outre la mer actuelle, tout l'espace dont la submersion est manifeste par les dépôts qu'on y retrouve. Cet espace ombré, il est vrai, n'a jamais pu être complètement immergé en même temps, mais ses diverses parties l'ont été successivement, ou sont passées plusieurs fois et alternativement de l'état de terre sèche à celui de mer, suivant les oscillations du sol. Les places laissées en blanc représentent des surfaces actuellement sèches et qui l'ont toujours été (sauf leur occupation par des lacs d'eau douce) depuis la première partie de la période éocène.

Un volt sur cette carte que, depuis cette époque, la mer est re-

1. A. de Lapparent. Traité de Géologie. 
venue à Paris, à Londres, à Bruxelles, à Berlin, à Vienne, etc. On voit aussi un bras de mer aller de Bordeaux à Montpellier, à Lyon,

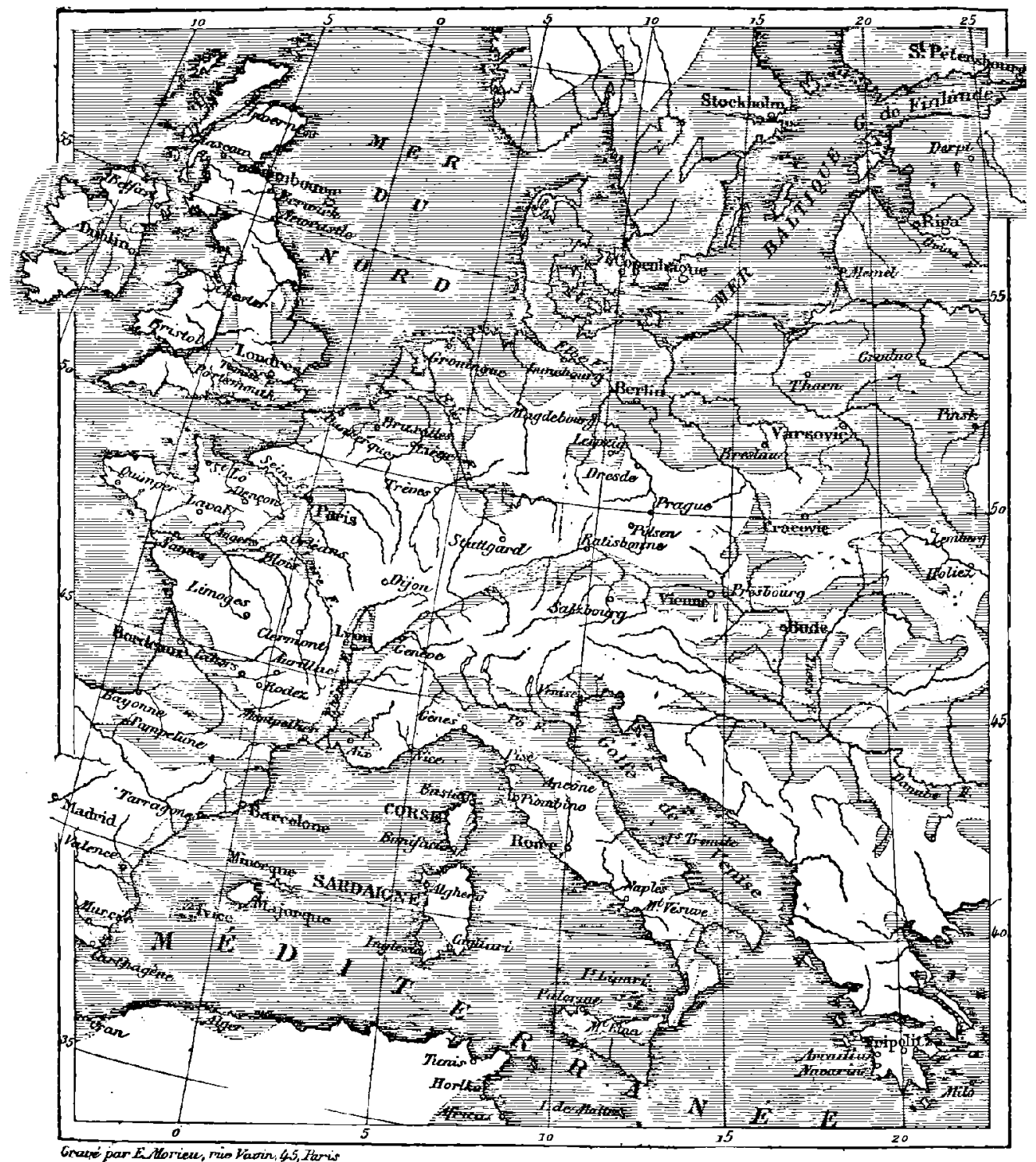

Fig. 367. - Carte montrant l'étendue de la surfuce qui a étí couverte par la mer depuis le commencement de la période écéne.

à Genève et jusqu'en Autriche. Nous avons vu plus haut, au chapitre des transformations actuelles du sol, que ces oscillations de la surface terrestre se continuent de nos jours et que la mer gagne 
de nouveau à l'ouest et au nord de la France, en Belgique, en Hollande, au sud de la Suède, etc., tandis qu'elle se retire au nord de la presqu'ŝle scandinave aux embouchures du Pô, du Nil, du Rhône, etc. Ainsi notre planète se transforme d'âge en âge, elle aussi, comme tous les etres qui l'habitent.

Pour compléter la physionomie générale de la période, ajou. tons, comme déjà nous l'avons remarqué; que c'est vers les derniers temps de l'éocène, que les Pyrénécs ont acquis leur principal relief dans le soulèvement qui a porté les assises nummulitiques à 3352 mètres de hauteur. Les Apennins sont de la mème époque, c'est-à-dire de la fin de l'éocène, des temps oligocènes. Les Alpes, au contraire, n'ont atteint leur plus grande hauteur que pendant la période miocène, dont l'étude va faire l'objet du chapitre suivant. 


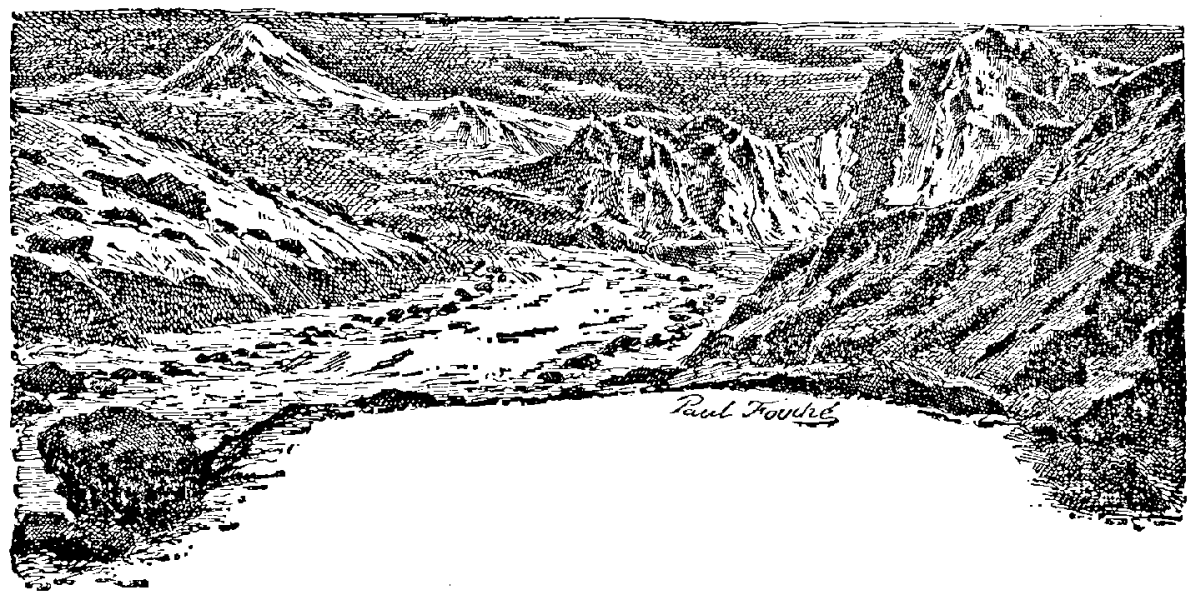

CHAPITRE II

LA PÉRIODE MIOCÉNE

La période miocène, l'ère moyenne de l'âge tertiaire, succède aux temps dont nous venons d'esquisser l'histoire, cn continuant de faire avancer le monde organique et le monde inorganique vers l'état dans lequel nous les voyons aujourd'hui. C'est pendant cetto périodo nouvelle que la géographie a pris ì peu près sa forme actuelle, que les Alpes, s'exhaussant jusqu'à la hauteur des neiges éternelles, comme les Pyrénées l'avaient fait à la période précédente, mar'quent l'Furope occidentale de son relief définitif et qu'au centre mème do la France les éruptions de basalte jaillissant de l'antique plateau granitique central, préparent les volcans d'Auvergne qui vont jeter leurs flarmmes au milieu de nos contrées. - Cette période prodnit aussi les mammifëres supérieurs, les singes. Progrès immense!

Dans le Gantal, les éruptions volcaniques élèvent au-dessus du massif granitique primitif, déjà porté à huit et neuf cents mètres d'altitude, des montagnes qui, de nos jours encore, malgré les érosions considérables dont le temps les a dénudées, atteignent dix-huit et dix-neuf cent mètres. Les dinothériums et les hipparions ont été témoins de ces éruptions et ont laissé leurs restes dans les gravier's qui recouvrent ces basaltes éruptifs. La sortie du basalte miocène a été suivie, après une période de repos, pendant laquelle le relief de la contrée s'est modifiè par érosion, d'épanchements visqueux de nature domitique, exploités aujourd'hui comme pierre à bâtir. En- 
suite un cratère s'est ouvert entre les lacs de Murat et d'Aurillac. Une énorme brèche s'est formée, à laquelle ont succédé d'épaisses coulées de basaltes porphyroïdes qui ont brûlé les forèts développées sur les flancs de la montagne. Puis un cratère s'ouvrit et rejeta jusqu'à vingt et trente kilomètres de distance une pluie de cendres qui, ensevelissant la végétation du voisinage, donna naissance aux cinérites du Cantal. Ces mouvements volcaniques ont duré jusqu'à la période pliocène, pendant laquelle se sont ouverts à leur tour les volcans du Mont-Dore et des Puys.

Pour la première fois, la terre sernble véritablement sortie des eaux. Ce ne sont plus ces linéaments qui sillonnaient cà et là les étendues maritimes; ce sont maintenant des masses émergées qui offrent une large base au développement de la vie terrestre. Les Alpes ne sont encore, il est vrai, que des collines. Pourtant onze piliers ont surgi des eaux, premier soubassement, ou plutôt colonne vertébrale de l'Europe centrale, car ces illes alpines s'unissent entre elles et marquent le dessin des terres inférieures.

Entre le Jura déjà parvenu à moitié de sa hauteur, et les Alpes naissantes, la mer persiste dans un golfe étroit; elle bat de ses flots leur double rivage; elle accumule à leurs pieds de nouvelles coquilles et de nouveaux siecles; mais elle ne pourra effacer les deux lignes si fièrement tracées des Alpes et du. Jura.

Longtemps incertaine de son domaine, la Méditerranée s'avance et se retire par la vallée du Rhône, la Suisse, la Bavière jusqu'à la mer Pannonienne. La mer des Indes communique avec la Méditerranèe par-dessus l'Égypte d'Isis encore submergée. Mais, quoiqu'elles fassent, il y a de vastes espaces que ces mers ne peuvent reprendre: il faut qu'elles s'accoutument à leur lit actuel.

On devine la Grèce, qui n'est point séparée de l'Asie Mineure. Voici un long segment échancré, mutilé, l'épine dorsale de l'Italie, où les places de Rome et de Florence manquent encore. L'Afrique s'unit à l'Europe par l'isthme émergé de Tunis à Gênes et par celui de Gibraltar. Au nord, la terre ferme s'étend de l'Oural à l'Angleterre, et elle se prolonge par continents et archipels (Atlantide?) jusqu'aux rivages des deux Amériques.

La période miocène a vu s'accomplir, dans la géographie de l'Europe, des changements notables. Dès le début, les grands lacs 


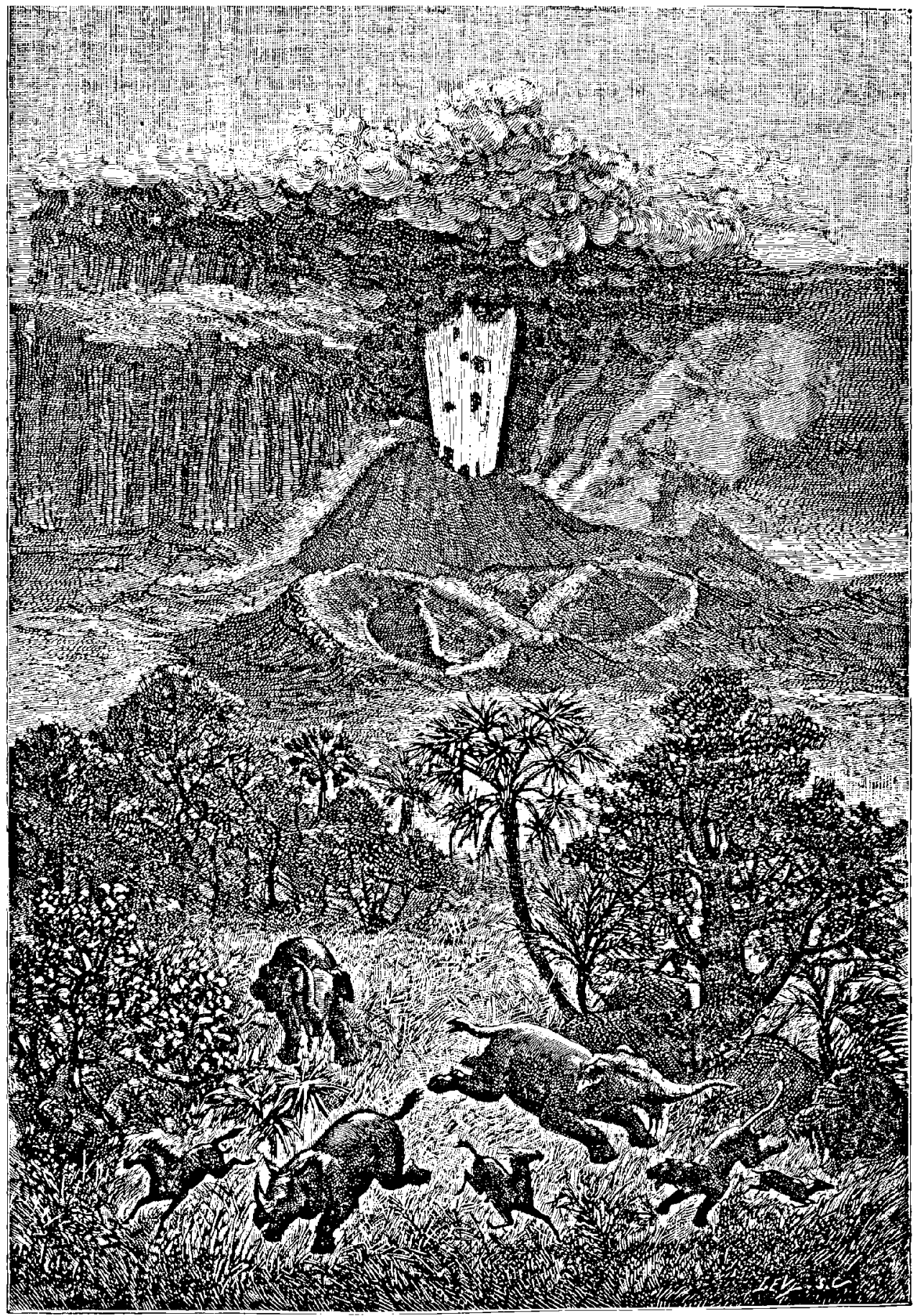

LES YOLCANS TRANGAIS HENDANT LA PEKIOUE HLOCENE 
qui existaient à la fin de la période éocène perdent leurs eaux, sans doute par suite d'un mouvement du sol en relation avec les prémisses du soulèvement alpin. Les vallóes fluviales se dessinent et, sur le sol français, des graviers de transport se substituent aux dépôts lacustres de la Beauce. Bientôt le relief s'accentue davantage et la mer de la mollasse ou mer helvétienne envahit une notable partie de l'Europe occidentale. Cette mer pénètre en France, par la vallée de la Loire, jusqu'aux portes de Blois, et l'un de ses bras va rejoindre la Manche par l'Ille-et-Vilaine, isolant l'Armorique devenue ile. La mer se répand dans la vallée du Rhône, couvre une partie de la Suisse et de l'Autriche, longeant ce qui forme anjourd'hni le pied des Alpes, se répand sur l'Asie Mineure orientale jusqu'à l'Euphrate et au lac Ourmiah. Par cette mer, l'Europe est découpée en une sorte d'archipel indien, où les conditions deviennent éminemment propres à l'épanouissement du monde végétal. Aussi ce dernier, dans son ensemble, ne s'est-il jamais montré plus opulent. L'hiver est encore particulièrement doux, ne suspendant jamais d'une manière complète l'activité de la végétation, et, quand la période s'achève, le camphrier garde encore le privilège de fleurir, dès le mois de mars, sur les bords du lar: de Constance, comme il le fait de nos jours à Madère. Pour retrouver les associations végétales de la période miocène, il faudrait aujourd'hui descendre de 25 à 30 degrés vers le Sud. S'il y avait déjà une différence manifeste entre la végétation des terres voisines $\mathrm{d} u$ pôle et celle de nos régions, du moins les glaces ne faisaient pas sentir leur influence et l'Islande était couverte de riches forèts. En mėme temps, les manifestations volcaniques se multipliaient et l'Auvergne, la vallée du Rhin, la Hongrie, le versant occidental des Montagnes-Rocheuses et bien d'autres pays encore devenaient le théâtre de prodigieux épanchements de roches éruptives. - Les volcans d'Italie, le Vésuve, les champs phlégréens, l'Etna, en Sicile, sont de l'âge quaternaire. - Enfin l'écorce terrestre ètait partout en mouvement et ses efforts pour conquẻrir une situation d'équilibre finirent par dresser au milieu des airs les hautes chaines des Alpes, des Cordillères et de l'Himalaya (').

1. A. de Lapparent, Traité de Géologie. 
Yous avons vu pilus haut que pendant l'époque éocène l'Europe offrait déjà un continent d'une vaste étendue et parcouru par de nombreux bras de mer. Une distribution à peu près semblable rógnait aussi durant la période molassique. Une île immense qui comprenait tout le territoire alpin actuel, s'était agrandie. A l'Ouest, cette île s'étendait jusqu'au sud de la France et elle était en connexion directe par le Piémont avec la presqu'ile italienne. A l'Est, elle comprenait tout le pays qui s'étend jusqu'au $35^{\mathbf{e}}$ degré de longitude, et se prolongeait vers le Sud par la Dalınatie jusqu'en Grèce. $\mathrm{Au}$ Nord elle était bornée par la mer qui formait là une grande baie, couvrait les plaines de la IIongrie et traversait. toute l'Europe centrale par un bras relativement étroit. A l'Est, nous voyons la mer hongroise en communication avec 'le Grand Océan; elle s'étendait sur la Russie méridionale; la mer Noire, la mer Caspienne et la mer d'Aral n'en sont que de faibles restes. Cet océan couvrait probablement l'est de l'Oural et se rèpandait sur les vastes plaines de la Sibèrie, séparant l'Europe de l'Asie par sa réunion avec la mer polaire.

J'autre part, la mer miocène s'étendait sur l'Arménie et l'Asie Mineure orientale, et se trouvait en communication avec la Méditerranée, ainsi que le prouvent les nombreux fossiles communs ¿ tous ces pays. En revanche, le détroit des Dardanelles était fermé, et la mer Égée n'existait pas. La Grèce formait un continent qui se prolongeait jusqu'en Asie Mineure : les îles de l'archipel égéen sont les montagnes d'un pays qui s'est enfoncé plus tard. Si nous tournons nos regards du côtè du Sud, nous verrons que la Méditerranée se réunissait à l'Océan Indien en couvrant l'Égypte; elle s'étendait sur la Mésopotamie où elle était probablement en communication avec l'océan aralo-pontique. La mer mollassique ne couvrait pas la ligne même des Alpes, comme la mer nummulitique, mais roulait ses flots tout autour de ce relief qui s'aceentuait.

La flore et la faune du Maroc et de l'Algérie ayant par leurs traits fondamentaux et par une certaine communauté des espèces, une grande analogie avec celles des côtes européennes, on a pensé depuis longtemps que ces pays étaient autrefois reliés les uns aux autres par. des isthmes tels que ceux qui existaient a Gibraltar et probablement aussi entre la Corse et la Sardaigne; en effet, ces pays touchaient d'une part aux côtes méditerranéennes et d'autre part à l'Afrique. 
Cette hypothèse serait confirmée par les restes d'os que l'on a découverts récemment en Sicile et qui nous apprennent que l'éléphant africain, l'hippopotame et la hyène tachetée vivaient en Sicile, et que par conséquent ce pays avait sans doute été en communication avec l'Afrique avant la formation actuelle.

L'emplacement actuel de la mer Baltique devait vraisemblablement être à sec et en communication avec la Scandinavie primi-

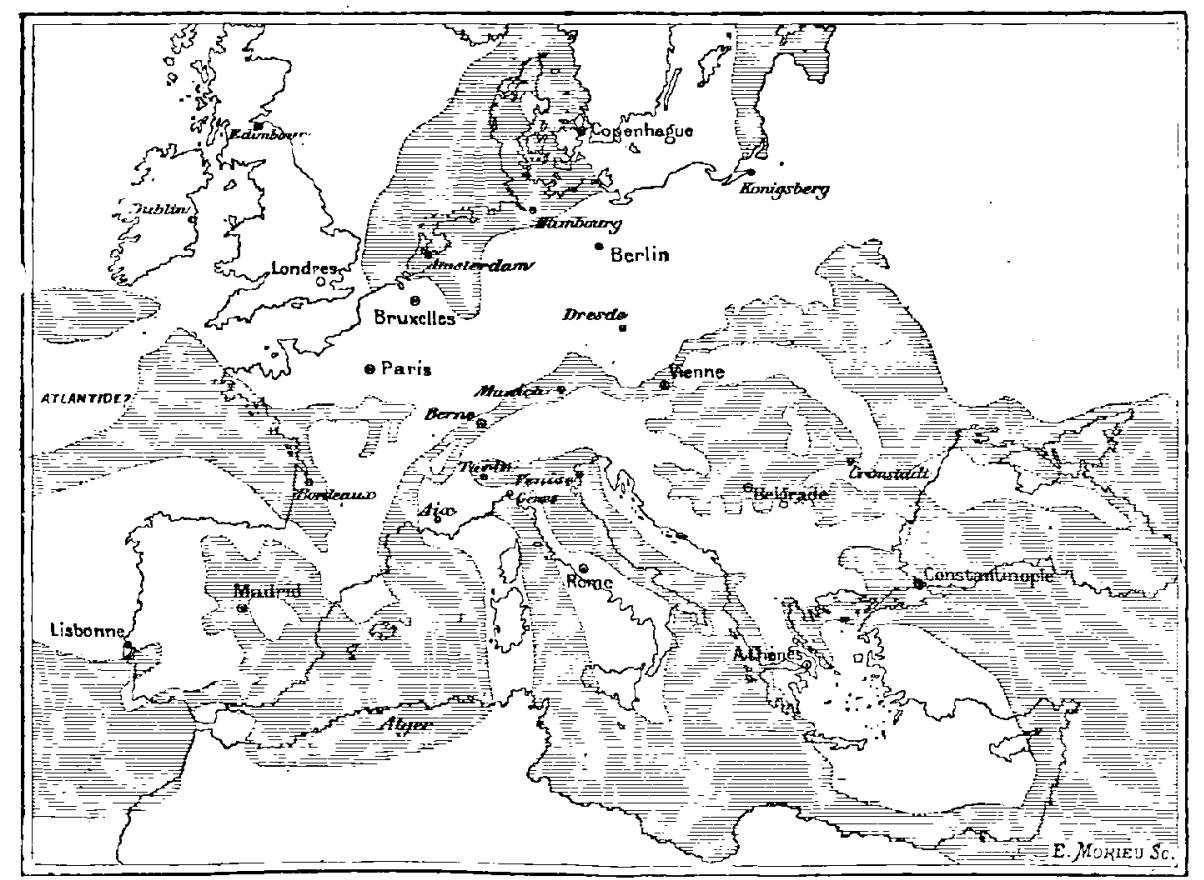

Fig. 370. - L'Europe centrale à l'époque de la mer mollessique (miocène moyen)

tive; cette mer cst la patrie du succin, ou ambre jaune, qui n'est autre chose que le produit des conifères de l'époque tertiaire.

Le Danemark, la Hollande et le nord de la Belgique étaient immergés et la mer s'avançait jusqu'à Cologne; d'autre part, la formation géologique des côtes de Bretagne et d'Angleterre, et la nature du sol anglais nous autorisent à croire que ces deux pays communiquaient directement. Il est vraisemblable aussi que les îles Britanniques ne représentent, comme déjà nous l'avons remarqué, qu'une faible partie d'un grand continent qui, traversant l'Océan Atlantique, aurait rejoint l'Amérique. 
C'est l'exhaussement du relief des Alpes, opéré après la mer

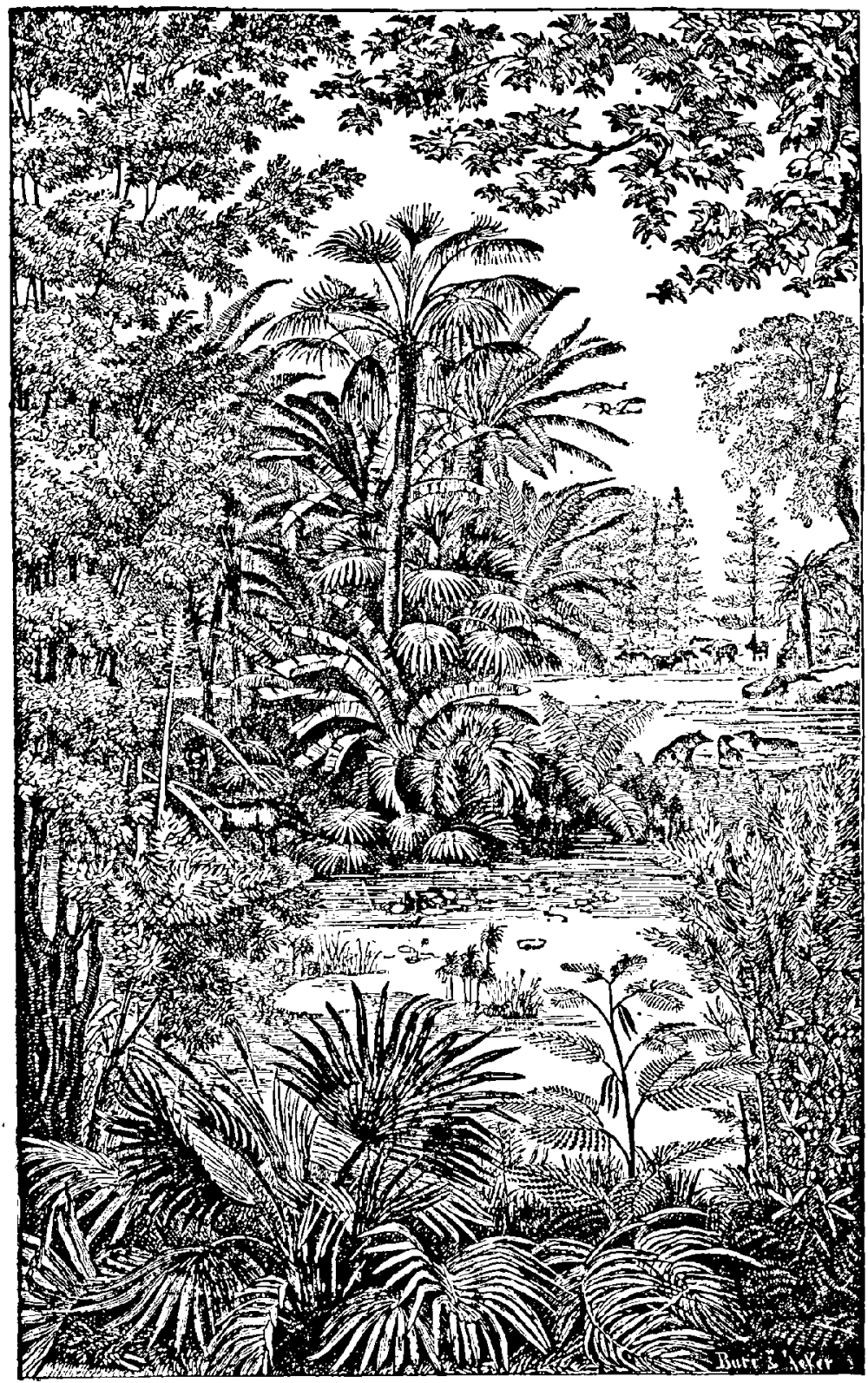

Fig. 371. - Paysage de la période miocène à La lsanne, d'après Oswald Heer.

mollassique, qui a donné à l'Europe son relief, et par là sa configuration géographique. Quelques centaines de mètres de différence 
(souvent quelques dizaines) suffisent pour mettre la mer a la place de la terre et réciproquement. Les terrains que nous avons vu se former graduellement sur nos cartes géologiques ont subi plusieurs fois depuis leur formation des mouvements d'abaissement et d'exhaussement qui tour à tour les ont immergés et émergés. L'état qui vient d'être décrit pour le milieu de la période miocène nous donne une carte ( $f g .370$ ) bien différente assurément de la carte actuelle, et pourtant cette configuration géographique a prècédé immédiatement la nôtre avant l'exhaussement des Alpes. A mesure qu'elles se sont élevées, celles-ci ont progressivement repoussé la mer dans ses limites actuelles. A l'ouest, le continent atlantique qui, selon toute probabilité, occupait une partie de I'Océan Atlantique est descendu sous les flots et l'Océan est venu rejoindre la mer du Nord en ouvrant le détroit de la Manche.

Comme nous l'avons vu (p. 652), le système miocène peut ètre subdivisé en trois étages: l'inférieur ou langhien correspond à la période d'émersion, avec régime fluvial, qui a précédé l'invasion de la mer mollassique. L'étage moyen ou helvétien comprend les conches marines des faluns de la Touraine et de la mollasse suisse. Enfin dans l'étage supérieur ou tortonien viennent se ranger les couches contemporaines des argiles de Tortone, en Italie, et nolamment la plupart des dépôts du bassin de Vienne et de la Galicie.

Au début du miocène, une grande mer est arrivée sur Paris par le nord-est et est venue occuper le bassin de Paris, où ses dépôts sableux ont donné lieu aux sables de Fontainebleau; cette mer, contournant la Normandie, entame à peine l'Angleterre dans le sud; au nord-est elle couvre encore une bonne partie de la Belgique, puis bientôt cette mer se retire à son tour, et súr son emplacement s'établit un grand lac, très étendu dans.le sud, óu se dépose le calcaire de Beauce.

Les sables de Fontainebleau sont extrêmement curiẹux à visiter sur le sommet de ces collines. On croirait que la.mer est retirée d'hier. Leur étage est situé entre deux formatiọns d'eau douce, le calcaire de Brie au-dessous, le calcaire de Beauce audessus.

Ensuite, pendant le miocène moyen, les eaux douces - ont déposé les sables de l'Orléanais, au milieu desquels ont été conservés 
sous la forêt d'Orléans actuelle, les dinothériums et les mastodontes. Plus tard la mer est revenue à l'ouest de Paris et a donné naissance aux faluns de la Touraine, de l'Anjou, du Maine, de la Bretagne, du Cotentin et du Bordelais. Ces faluns sont des dépôts marins composés de coquilles brisées, de polypiers, de bryozoaires mélangés d'une certaine quantité de sable silicenx plus ou moins grossier. A cette époque, la mer a également laissé les mèmes dépôts dans le golfe de I'Aquitaine, dans le Bordelais et dans la vallée du Rhône. En Provence et en Dáuphiné, elle a déposé des calcaires.

C'est à cette mème époque que la mer a envahi la Suisse presque entière, au-dessus des Alpes non encore élevées (petites îles). Le nom de « mollasse » a été donné aux terrains - ce sont principalement des grès - qui ont èté formés au fond de la mer helvétienne (miocène moyen). On peut presque dire que le terme « miocène moyen » a la mème signification que celui de “ mollasse. »

Les dépôts de cette époque sont très considérables et s'élèvent maintenant sur le bord des Alpes en montagnes assez hautes, entre autres la Speer (2 000 mètres) et le Rigi (1 800 mètres) au-dessus de la mer. Vers le nord, le terrain mollassique est moins élevé ; on peut en conclure que l'eau trouva son écoulement dans cette direction en formant des fleuves et des ruisseaux qui se sont fait jour par de larges et profondes vallées. Les roches qui se déposèrent pendant cette époque sont des grès, de la marne, du nagelfluh et du calcaire. (Le nagelfluh consiste en cailloux roulés de toutes les grosseurs qui sont cimentés ou réunis les uns aux autres par une marne arénacée ou par du grès.)

Tandis que le calcaire joue un rôle important dans les dépôts jurassiques et crétacés, il n'occupe qu'un rang médiocre dans les sédiments mollassiques. Les conditions qui ont présidé à la formation des puissantes masses calcaires font défaut dans cette nouvelle période; nous ne retrouvons plus ces myriades de petits ouvrier's marins qui travaillaient sans relâche à la construction de l'écorce terrestre. - On rencontre fréquemment du lignite dans les gisements mollassiques.

Le retrait de la mer mollassique a été marqué, au sud-est de la. France; par le plus grand événement géologique dont cette 
contrée ait jamais été le théâtre : la constitution définitive du puissant massif montagneux des Alpes date, en effet, de cette époque. Ces hautes montagnes ont acquis leur principal relief, $\grave{i}$ la suite de mouvements postérieurs au dépôt de la mollasse, qui se trouve violemment refoulée sur ses bords. Pendant le miocène supérieur, l'Europe septentrionale s'exhausse graduellement.

En étudiant une localité spéciale particulièrement riche en fossiles végétaux et animaux caractéristiques de cette période, la localité d'OEningen, située en Suisse, près du lac de Constance, Oswald Heer a, depuis longtemps déjà, merveilleusement reconstitué toute la vie de ces siècles antiques.

Le savant naturaliste suisse a ressuscité la flore tertiaire de nos contrées dans ses espèces végétales essentielles. Il a retrouvé notamment des sequioas, des cyprès, des graminées (entre autres du riz et du millet), des roseaux, la plupart de nos herbes et de nos buissons actuels, huit espèces différentes de peupliers, une espèce de tremble, des charmes, des noisetiers, des chènes, des ormes, dix-sept espèces de figuiers, vingt-cinq de lauriers, des camphriers, des banksia aux fruits en amande, des frênes, des lianes, des renoncules, des clématites, de la vigne, des magnolias, des myrtes, des tilleuls, des acacias, des mimosas, des érables, des houx, des noyers, des cerisiers, des pruniers et des amandiers. Mais on n'a encore retrouvé ni pommiers ni poiriers.

Comme plantes caractéristiques de cette époque, nous avons reproduit plus haut (fg. 371), d'après le laborieux naturaliste suisse, le paysage remarquable qui représente l'aspect du site de Lausanne à l'époque miocène. On y voit, réunis ensemble, des palmiers, des acacias, des chènes, des charmes, des noyers, des pins, des houx. Des rhinocéros, des tapirs, des crocodiles, sont attirés par la fraicheur de l'eau. Le climat des vallées de la Suisse et de la France centrale devait être alors celui de la Louisiane ou du nord de l'Afrique : $20^{\circ}$ à $21^{\circ}$ comme moyenne, pendant le miocène inférieur, et celui de Madère, Malaga, Sicile $\left(18^{\circ}\right.$ à $190^{\circ}$ ) pendant le miocène supérieur. Le mélange des plantes tropicales avec les tempérées indique des hivers doux et des étés pas trop chaux : climats marins. Les végétaux retrouvés montrent qu'en même temps la température s'abaisse dans le nord. Au Spitzberg elle est déjà descendue à $+8^{\circ}$ 
et il en est de mème au Groënland, où l'on a retrouvé des magnolias, des sequoias, des peupliers, des châtaigniers, des chênes et mẻme de la vigne. Aujourd'hui la température moyenne de ces contrées est de $7^{\circ}$ à $8^{\circ}$ au-dessous de zéro. Les arbres tempérés, sapins, chènes, peupliers, etc., descendent à cette époque dı nord
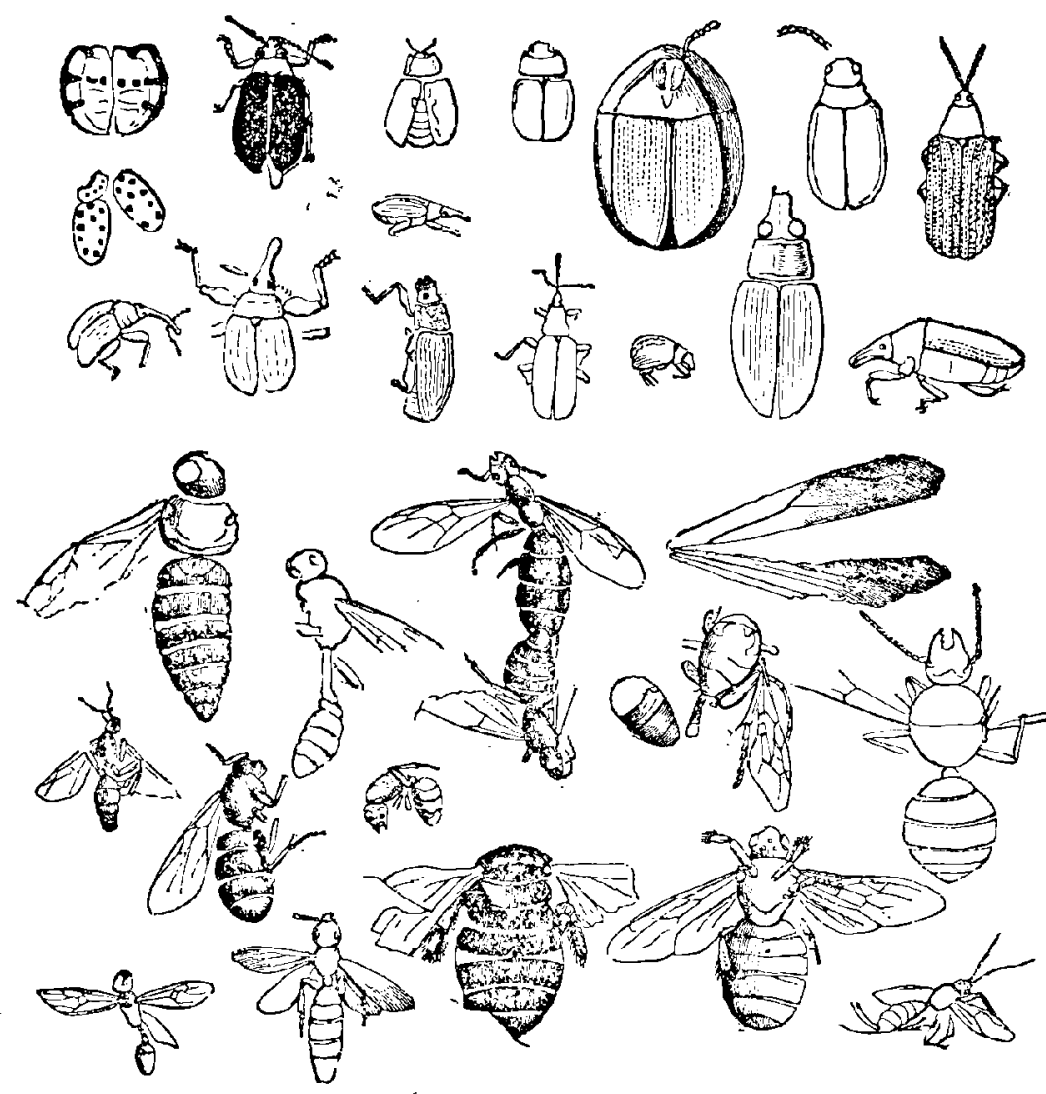

Fig. 372. - Insectes de la période miocène retrouvés à l'état fossile.

dans nos contrées, commençant par occuper les montagnes, dont la température est plus fraîche. Les palmiers ne se rencontrent plus que dans les plaines et les vallées. Climats et saisons s'établissent. Les insectes retrouvés donnent le mème témoignage.

Dans les époques primitives, comme de nos jours, les insectes ont fourni le contingent principal du règne animal. Malgré leur petitesse et la fragilité de leur organisation, il nous est parvenu un si grand nombre d'espèces qu'il ne peut y avoir aucun doute à cet 
égard. Oswald Heer a réuni 876 espèces de fossiles de cette période. Ces insectes se divisent ainsi : 543 coléoptères, 20 orthoptères, 29 névroptères, 81 hyménoptères, 3 lépidoptères, 64 diptères et 136 hémiptères. Les plus nombreux sont donc les coléoptères; viennent ensuite les hémiptères, les névroptères et les diptères. Les lépidoptères sont les plus faiblement représentés.

Parmi les hyménoptères, ce sont les fourmis, et parmi les diptères les cousins qui sont les plus communs, comme de nos jours.

On trouvera ici $(f g .372)$, d'après Oswald Heer, une intéressante collection de ces insectes de la période miocène. On remarque d'abord des coléoptères, parmi lesquels plusieurs types de coccinelles ou " bêtes à bon Dien » et un grand nombre d'insectes que l'on rencontre de nos jours dans les champs et les prairies. On voit au-dessous divers spécimens d'hyménoptères tombés dans l'eau du lac d'OEningen au moment même de leurs ébats et fossilisés au fond du lac pour les collections des géologues futurs; on y reconnait des abeilles, des bourdons, des guêpes, des fourmis: Les papillons sont plus rares : on en rencontre pourtant dans ces terrains. Ce sont les derniers venus des insectes - les plus parfaits - et les plus heureux sans doute.

Les insectes sont un résumé de l'histoire de la vie terrestre : leurs métamorphoses rappellent la succession des âges; le papillon est le contemporain des flęurs, tạndis que la chenille rappelle par son aspect, par ses instincts et par ses armes, les périodes primaires et secondaires; la métamorphose accomplie aujourd'hui en quelques mois résume des millions d'années.

Los espèces primitives sont presque restées ce qu'elles étaient. Le grillon, la blatte des temps cabonifères ont survécu aux transformations du globe en persistant dans leurs mœurs et leur régime : nous les retrouvons aujourd'hui blotlis près des fours de boulangers ou des fourneaux des antiques cuisines, se chauffant comme au temps de la température houillère et dévorant la farine moderne comme autrefois la farine des cycadées et des équisétacées. Ils cherchent la chaleur etévitent la lumière, ne sachant pas, sans doute, que le monde a beaucoup changé depuis leurs forêts primitives.

Dans le murmure confus des insectes nous devons reconnaitre l'écho des âges évanouis. Il n'v avait encore ni oiseaux, ni voix, 
ni chant, les élytres de la cigale, de la sauterelle, du grillon, les bourdonnements de ce vague murmure des champs et des bois $\dot{a}$ la fin d'une journée d'été, répandent dans l'air tiède des bruits confus qui ne sont pas encore des voix, mais qui pourtant nous parlent de ces temps primitifs. L'ombre du soir leur rappelle à tous l'époque crépusculaire qui leur a donné naissance.

Nos connaissances sur les insectes fossiles sont dues surtout aux recherches de M. Charles Brongniart, Grand'Eury, Fayol (paléontologie française), Oswald Heer (fouilles d'OEningen). Avant de quitter les fossiles d'OEningen, souvenons-nous que cette célèbre localité géologique, si riche en fossiles de tout ordre, insectes, poissons, reptiles, etc., avait déjà, au siècle dernier, frappé le monde des naturalistes par une découverte problématique assez bizarre.

C'est lá, en effet, que l'on trouva, en 1725, ce fameux fossile qui bouleversa le monde savant - et l'autre - pendant plus d'un demisiècle, et qu'un pieux naturaliste, Scheuchzer, crut reconnaittre pour un homme fossile et qualifia du titre d'homo diluvii testis, a homme témoin du déluge n. C'était, en réalité, le squelette en mauvais ètat d'une énorme grenouille, ou pour mieux dire d'une salamandre, reptile dont la taille atteignait $1^{\mathrm{m}} 26$ de longueur.

La tête, la colonne vertébrale, les bras, les jambes, - pour les naturalistes de ce temps-lá, - étaient ceux d'un squelettc humain. Pendant assez longtemps, ce préadamite fit grand bruit; mais, bien qu'on invoquât à l'appui de son existence la découverte, sur les côtes de la Guadeloupe, de véritables squelettes humains pétrifiés, on finit par reconnaître sa nature réelle, grâce à l'anatomie comparée. On constata que les fragments trouvés à OEningen avaient appartenu à une salamandre gigantesque, ce que ne tarda pas à confirmer la découverte, sur les bords du Rhin et au Japon, de squelettes complets de ces animaux antédiluviens. Et quant aux " hommes fossiles » de la Guadeloupe, il fut reconnu que la pétrification de ces squelettes avait été produite par de l'eau qui, s'infiltrant à travers la mince couche de terre d'un cimetière (établi depuis la conquête de l'Amérique par les Européens), avait enduit les ossements d'une sorte de tuf calcaire.

-... Scheuchzer en avait pourtant fait l'objet d'une dissertation spéciale. Cette dissertation était accompagnée de la figure sur bois 
de l'Homme témoin du déluge. Scheuchzer revint sur ce sujet dans un autre de ses ouvrages, Physica sacra. "Il est' certain, écrivait-il, que ce schiste contient une moitié, ou peu s'en faut, du squelette d'un homme; que la substance même des os, et, qui plus est, des chairs et des parties encore plus molles que les chairs,

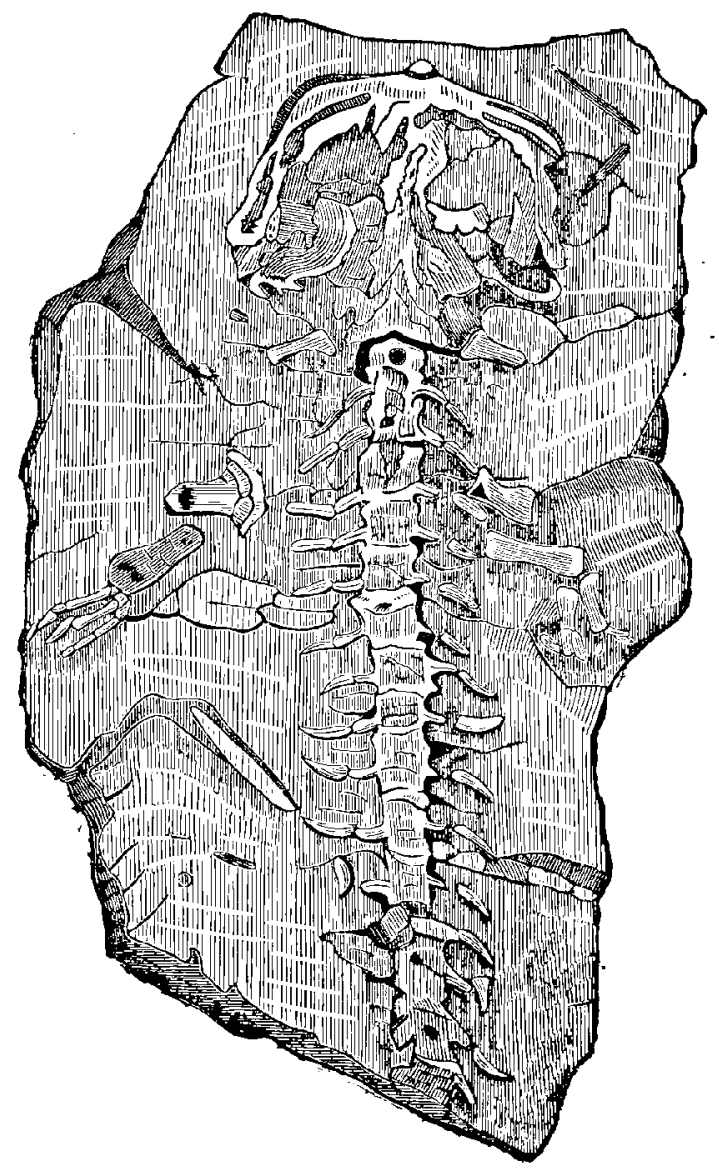

Fig 373 - L'homme témoin du dẻluge, de Scheuchzer (1725).

Fussile de salsinandre.

sont incorporées dans la pierre; en un mot, quéc'est une des reliques les plus rares que nous ayons de cette race maudite qui fut ensevelic sous los eaux. La figure nous montre le contour de l'os frontal, les orbites avec les ouvertures qui livrent passage aux gros nerfs de la cinquième paire. On y voit des débris du cerveau, du sphénoïde, de la racine du nez, un fragment notable de l'os maxillaire et des vestiges du foie $»$. 
Et notre pieux auteur de s'écrier, en prenant cette fois la forme lyrique :

D'un vieux damné déplorable charpente,

Qu'à ton aspect le pécheur se repente!

Le lecteur a sous les yeux la figure du fossile du schiste d'OEningen $(f g .373)$. Il est évidemment impossible de trouver dans ce squelette ce que voulait y voir l'enthousiaste savant.

Prenez, disait Guvier à ce propos, un squelette de salamandre et

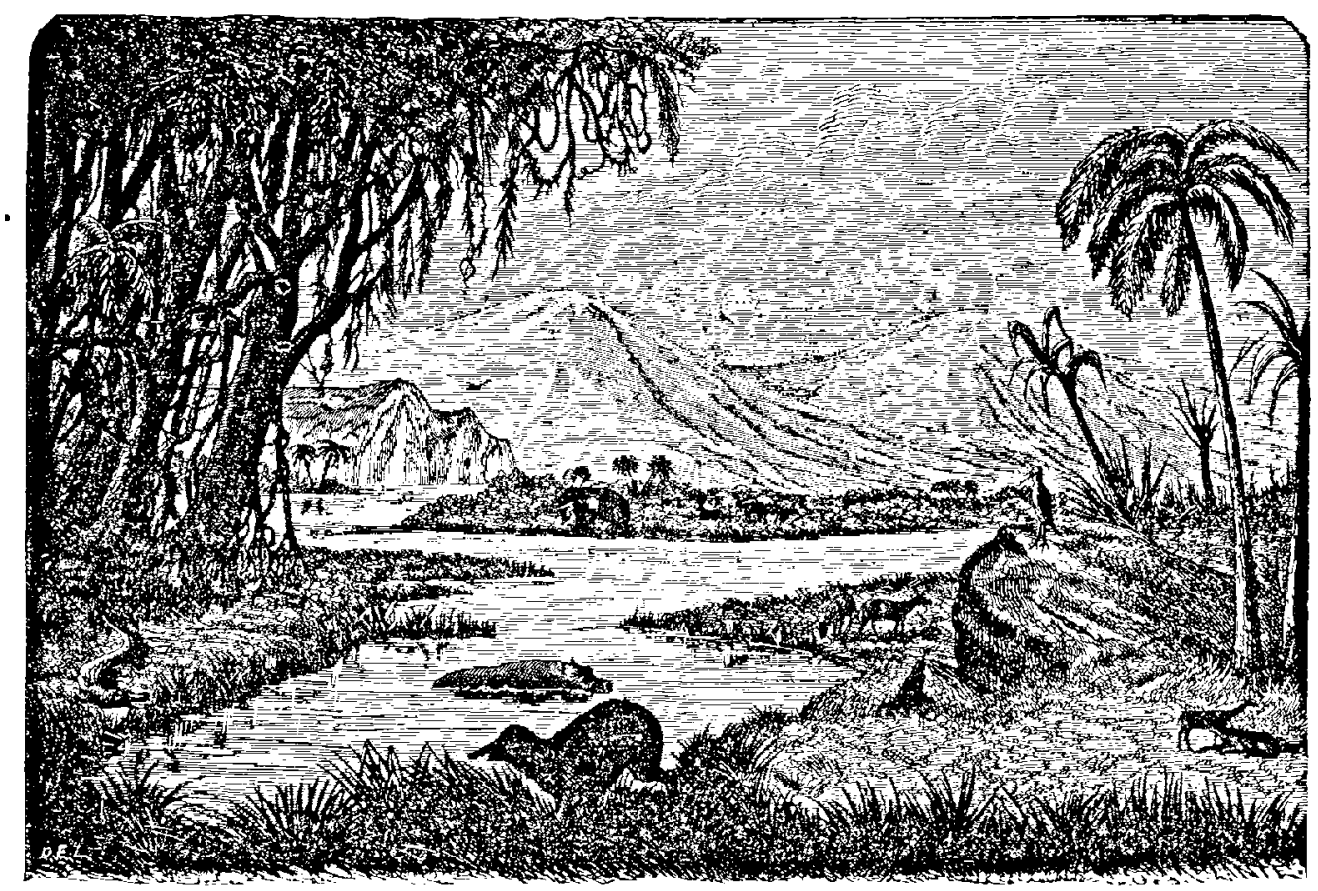

Fig. 374. - Paysage de la période miocène en France.

placez-le à côté du fossile, sans vous laisser détourner par la différence de grandeur, comme vous le pouvez aisément en comparant un dessin de salamandre de grandeur naturelle avec le dessin du fossile réduit au sixième de sa dimension, et tout s'expliquera de la manière la plus claire. Je suis persuadé même, ajoutait-il, que si l'on pouvait disposer du fossile, et y chercher un peu plus de détails, on trouverait des preuves encore plus nombreuses dans les faces articulaires des vertèbres, dans celles de la mâchoire, dans les vestiges de très petites dents, et jusque dans les parties du labyrinthe de l'oreille.

Notre grand naturaliste eut la satisfaction de procéder lui-même LE MONDE AVANT LA CRÉatION DE L'HOMye 89 
à l'examen dont il avait parlé pour la confirmation de ses vues. Se trouvant à Harlem, il demanda au directeur du Musée de faire creuser la pierre qui contenait le prétendu homme fossile, afin d'y mettre à découvert les os qui pouvaient encore y rester cachés. L'opération se fit en présence du directeur du Muséc et d'un autre naturaliste. Un vrai dessin du squelette de la salamandre avait été placé près du fossile par Cuvier. Il eut la satisfaction de reconnaitre qu'à mesure que le ciseau creusait la pierre, les restes que ce dessin avait annoncés d'avance apparaissaient au jour.

Ainsi la salamandre d'OEningen, un instant métamorphosée en homme fossile, retomba dans l'oubli d'où elle avait été exhumée, et il en a été de même d'un grand nombre de découvertes apocryphes sur le même sujet. Les véritables restes d'hommes fossiles n'ont été reconnus qu'en notre siècle, comme nous le verrons plus loin.

G'est aussi pendant cette mème période miocène que l'oiseau, non plus seulement l'oiseau-reptile, mais l'oiseau véritable, a pris définitivement possession de l'atmosphère et du monde aérien. Ce n'est plus seulement l'archéoptéryx qui voletait dans les bois de cycadées, sans s'éloigner de la lagune ni chercher des sommets qui manquaient encore. D'immenses contrées se déroulent, liées l'une à l'autre par des isthmes. Qui les visitera le premier, si ce n'est l'oiseau? Il a des yeux perçants pour découvrir les lointains, et ces lointains se prolongent, et la terre s'étend et les continents se développent à mesure qu'il avance. Il faut qu'il se donne, au lieu de cette aile engourdie de l'archéoptéryx, une aile infatigable.

Voilà la puissance du vol née de la forme nouvelle de la Terre. L'oiseau était emprisonné dans l'âge jurassique. Il ne pouvait, déployer ni sa force, ni son instinct, aussi son aile n'était qu'un bras dont il s'aidait pour se soutenir plutôt que pour fendre l'air. Le monde tertiaire se déroule devant lui; il poursuit cet horizon qui fuit toujours; son instinct lui est révélé, il se confie à la vaste étendue. Un type nouveau éclate avec un univers nouveau. Qu'il y a loin de lá au mollusque silurien, au reptile jurassique!

L'oiseau I poésie vivante! le vol absolument libre, l'aile et son essor aérien, la liberté au-dessus du monde, le chant, le nid, l'amour, l'œuf, le berceau! tout à la fois.

La nature vivante était restée muette jusqu'à la fin des temps 
primaires. Aux bruits des flots, des vagues, du vent dans le feuillage, de l'orage, de la foudre, des ouragans et des tempètes, les mollusques, les poissons, les crustacés étaient restés sourds. Les insectes commencèrent à bourdonner, les cigales frappèrent leurs élytres, les grenouilles coassèrent, les premiers mammifères gémirent, les sauriens géants beuglèrent ou crièrent. Mais nul ètre n'avait encore chanté.

Voici l'oiseau, voici le ciel bleu, voici les fleurs. Décidément, la terre se forme. Bientôt l'humanité pourra naître à son tour.

Doux progrès, sois le bienvenu! Tu nous parles mieux que toutes les évolutions antérieures, tu résumes en toi seul la loi générale de la création; en t'appréciant, nous sommes plus instruits que par toute l'histoire de l'humanité mème. Tu nous apprends, tu nous prouves que dans l'œuvre divine tout marche vers le beau, vers la lurnière et vers l'harmonie. Inquiète préparation du nid, douces et mystërieuses sensations de la couveuse, naissance et éducation des petits: n'est-ce pas ici l'œuf de l'humanité ellemême?... Hélas ! c'est peut-être même un symbole trop beau: l'humanité n'a pas d'ailes !

Pendant l'époque miocène, les oiseaux sont très nombreux. Dans les terrains fossiles du département de l'Allier, M. Alphonse Milne-Edwards n'a pas découvert moins de soixante-dix espèces d'oiseaux différentes, appartenant à des groupes très variés, notamment des pélicans, des grues, des marabouts, des flamants, des ibis, des hirondelles salanganes, des perroquets, des couroucous : ces oiseaux indiquent un climat plus chaud que le nôtre; le centre de la France devait ressembler au centre actuel de l'Afrique. La figure précédente reproduit, d'après M. Contejean, l'aspect probable de ces paysages.

Le progrès se développe dans toutes les branches du règne animal. Nous avons vu plus haut (p. 665) que les mammifères pachydermes, lophiodons, paléothériums, anoplothériums, sont issus, selon toute probabilitė, des mársupiaux, au commencement de la période éocène. Les pachidermes, à leur tour paraissent avoir donné naissance aux ruminants, d'une part, aux carnivores d'autre part.

L'étude de la paléontologie nous montre, comme nous l'arons 
vu, des espèces fossiles qui peuvent être les ancêtres des espèces des carnivores actuels; de plus elle commence à nous révéler des traits d'union entre des genres qui paraissent aujourd'hui très séparés les uns des autres. Tous les animaux que l'on réunit sous le nom de carnivores sont loin d'avoir le même régime : le lion est un mangeur de chair fraîche, l'hyène dévore les cadavres, certains ours sont aussi omnivores que les cochons. De là résultent des différences considérables dans la forme des dents; plus un animal est carnivore, plus ses dents sont coupantes et plus ses carnassières sont grandes; quand son genre de vie se rapproche des omnivores, ses dents tuberculcuses, qui servent à broyer, prennent de l'importance. Les membres des carnivores présentent aussi des différences considérables correspondant à celles de leur genre de vie; l'ours, qui court peu et grimpe aux arbres, ne peut avoir les mèmes membres que le chien, animal coureur; les pattes avec lesquelles le lion déchire ses victimes ne doivent pas être faites comme celles de l'hyène. Les nombreuses variations des carnivores ont permis de diviser ces animaux en six familles :

$\begin{array}{ll}\text { Ours, } & \text { Martes, } \\ \text { Chicns, } & \text { Hyènes, } \\ \text { Civettes, } & \text { Chats. }\end{array}$

Les savantes études de M. Gaudry établissent que ces familles ont entre elles bien des liens d'affinité et de parenté. Ainsi malgré la séparation qui parait exister entre le chien et l'ours, on connait des carnivores fossiles qui rendent possible l'idée d'une parenté entre ces animaux. Tel est, par exemple, l'amphicyon ('); ce quadrupède, qui est un des fossiles les plus caractéristiques du milieu de l'époque tertiaire, appartient certainement, ainsi que son nom l'indique, au groupe des chiens; cela est si vrai que les paléontologistes sont quelquefois embarrassés pour distinguer les restes d'amphicyon d'avec ceux des chiens. Cependant l'amphicyon était plantigrade et peut-ètre grimpeur comme les ours, au lieu que les vrais chiens sont digitigrades, coureurs et non grimpeurs.

Il y a un genre fossile chez lequel les affinités avec les ours sont encore plus marquées que chez l'amphicyon, c'est l'hyœnarctos $\left(^{2}\right)$ trouvé dans le miocène moyen de Sansan.

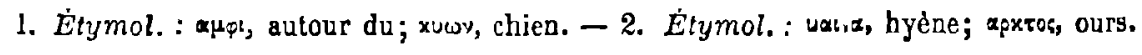


Les hyènes sont aujourd'hui assez distinctes des civettes; mais il n'en a pas toujours été ainsi : par l'examen des dents, la paléontologie nous montre le passage des hyènes aux civettes.

Les carnivores des temps actuels se lient $\dot{a}$ ceux des temps passés; mais, de même que beaucoup d'herbivores se sont éteints sans arriver jusqu'à nos jours, on doit croire aussi que certains carnivores ont eu leur règne dans les temps géologiques et sont

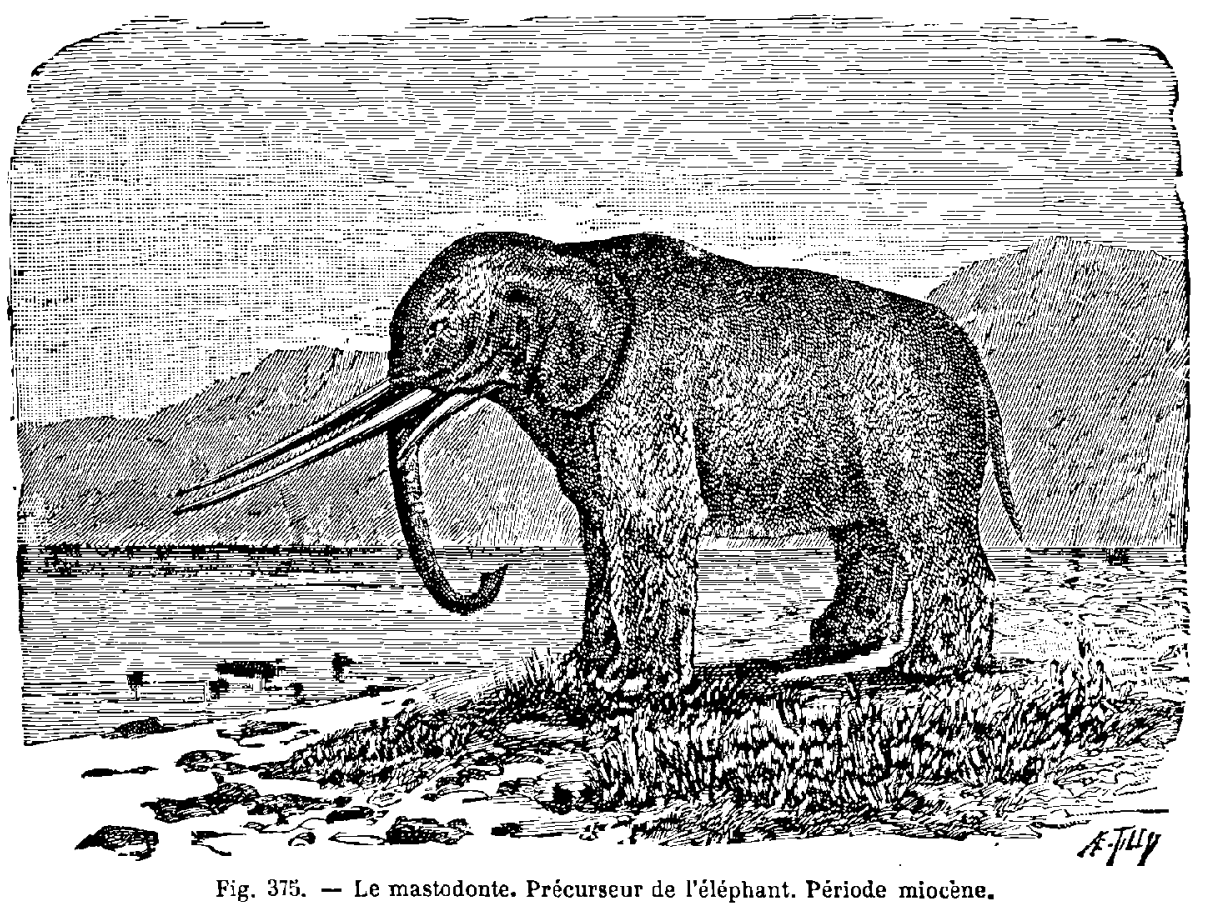

morts sans laisser de postérité. M. Gaudry cite comme exemple le machœrodus (4); ainsi que son nom l'indique, cet animal avait des canines allongées et aussi tranchantes que des lames de poignard, avec lesquelies il devait enlever des lanières dans le cuir épais des pachydermes; aucune bète de notre époque ne parait être la descendante de ce terrible carnivore.

Nous avons déjà vu que c'est dans cette même période miocène que les mammifères paraissent avoir atteint leur plus haut degré de développement. Dès l'époque langhienne, on voit s'effacer, chez les

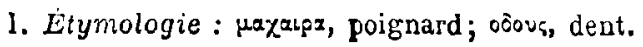


placentaires terrestres, les quelques caractères qui les reliaient encore aux marsupiaux. Les proboscidiens apparaissent avec les genres pachydermes dinothérium et mastodonte, que nous pouvons considérer l'un et l'autre comme précurseurs des éléphants, avec lesquels ils offrent d'ailleurs les plus grandes ressemblanices.

Le dinothérium (") est le plus grand des mammifères terrestres qui ait jamais vécu. Longtemps on ne posséda de cet animal que d'incomplets débris, qui conduisirent Cuvier à le ranger à tort parmi les tapirs. La déconverte d'une mâchoire inférieure presque complète, armée d'une défense dirigée en bas, vint démontrer plus tard que cet être mystérieux était le type d'un genre nouveau et des plus singuliers. Toutefois, comme on connaissait des animaux de l'ancien monde dont les mâchoires supérieures et inférieures étaient toutes les deux garnies de défenses, on crut pendant quelque temps qu'il avait pu en être de même pour le dinothérium. Mais, en 1836, des fouilles faites à Eppelsheim (Hesse-Darmstadt) mirent au jour un crâne presque entier ne portant que les deux défenses de la màchoire inférieure. D'après l'ensemble des membres retrouvés, son aspect devait offrir une grande ressemblance avec celui du mastodonte.

Le mastodonte $\left({ }^{2}\right)$ a d'abord été découvert en Amérique, an siècle dernier, et Buffon avail donné à ce grand fossile le nom d'éléphant de l'Ohio. Guvier lui donna celui de mastodonte.

Le mastodonte de la période miocène avait quatre défenses, lcs plus petites étant placées à la mâchoire inférieure.

De tout temps on a trouvé des ossements d'éléphants fossiles, mastodontes, etc., et ce sont ces ossements qui ont donné naissance aux histoires fabuleuses de l'exhumation de squelettes d'anciens géants; car dans un temps où l'anatomie avait fait si peu de progrès, l'amour du merveilleux pouvait d'autant mieux s'emparer de pareils événements pour accréditer des idées qui frappent l'imagination, que l'éléphant est un animal dont le squelette présente (aux dimensions près) assez de ressemblance avec celui de l'homme. On composerait un volume entier des histoires d'ossements fossiles de grands quadrupèdes que l'ignorance ou la fraude ont fait passer pour des débris de géants humains. La plus

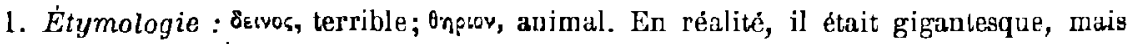
non terrible. - 2. Étymologie : بzsтos, mamelon; odous, dent. 
célèbre de toutes cst celle du squelette que, sous Louis XIII, on a présenté pour celui de Teutobochus, cet antique roi des Cimbres qui combattit contre Marius. Voici ce qui donna lieu à ce conte.

Le 11 janvier 1613, on trouva dans une sablonnière, près du château de Chaumont, en Dauphiné, entre les villes de Montricaux, et Saint-Antoine, des ossements dont plusieurs furent brisés par les ouvriers; un chirurgien de Beaurepaire, nommé Mazurier, averti de cette découverte, s'empara des os, et résolut d'en faire son profit; il prètendit les avoir trouvés dans un sépulere long de trente pieds, sur lequel était écrit теuтовоchus Rex; il ajoutait avoir découvert en meme temps une cinquantaine de médailles à l'effigie de Marius. Il inséra tous ces contes dans une brochure propre à piquer la curiosité du public, et parvint à montrer pour de l'argent, tant à Paris que dans d'autres villes, les os du prétendu géant. Gassendi cite un jésuite de 'Tournon comme l'auteur de la brochure, et montre que les prétendues médailles antiques étaient controuvées; quant aux os, dont le Muséum de Paris est devenu possesseur, ce sont des os de mastodonte (comme on le voit au premier coup d'œil à la forme des dents), et non pas des os d'éléphant ainsi qu'on l'avait: supposé quand on n'avait pour guide, dans cette détermination des débris, qu'une espèce d'inventaire des différentes pièces qui furent montrées en public, et quelques vagues indications des formes, éparses dans les écrits des médecins et chirurgiens qui prirent part à la discussion pour combattre ou soutenir les assertions mensongères de Mazurier.

Des faits semblables, mais mieux observés et décrits avec plus de précision à mesure que leur date est plus récente, nous conduisent jusqu'au dix-huitième siècle. A cette époque le progrès des sciences naturelles ne permit plus de inéprises aussi grossières que celle dont il vient d'être question : lorsqu'on trouva des ossements d'éléphants, on les prit pour ce qu'ils étaient; mais on se persuada qu'ils avaient été ensevelis sous le sol au temps des Romains.

Le mastodonte, dont l'apparition est de date miocène, est le précurseur et probablement l'ancêtre de l'éléphant. M. Gaudry a admirablement montré comment les dents du mastodonte le plus ancien se sont graduellement modifiées jusqu'à celles de l'éléphant 
actuel. Le doute n'est plus permis sur ce point. On voit l'espèce se transformer insensiblement d'un type parfait d'omnivore en

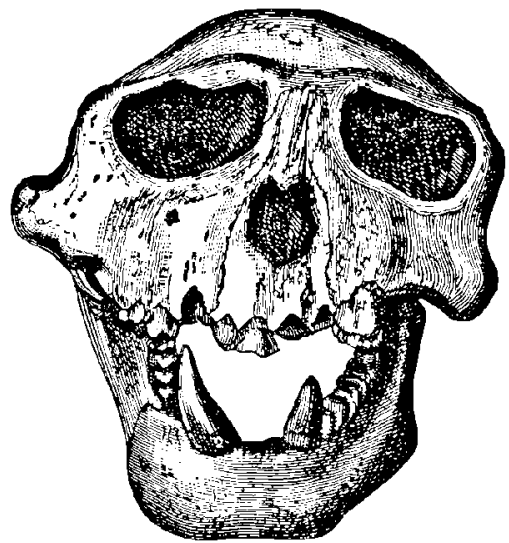

Fig. 376. - Crảne du singe mésopithèque de la période miocène.

un type non moins parfait d'herbivore. Le progrès marche dans l'ordre intellectuel comme dans l'ordre physique, car nos lecteurs

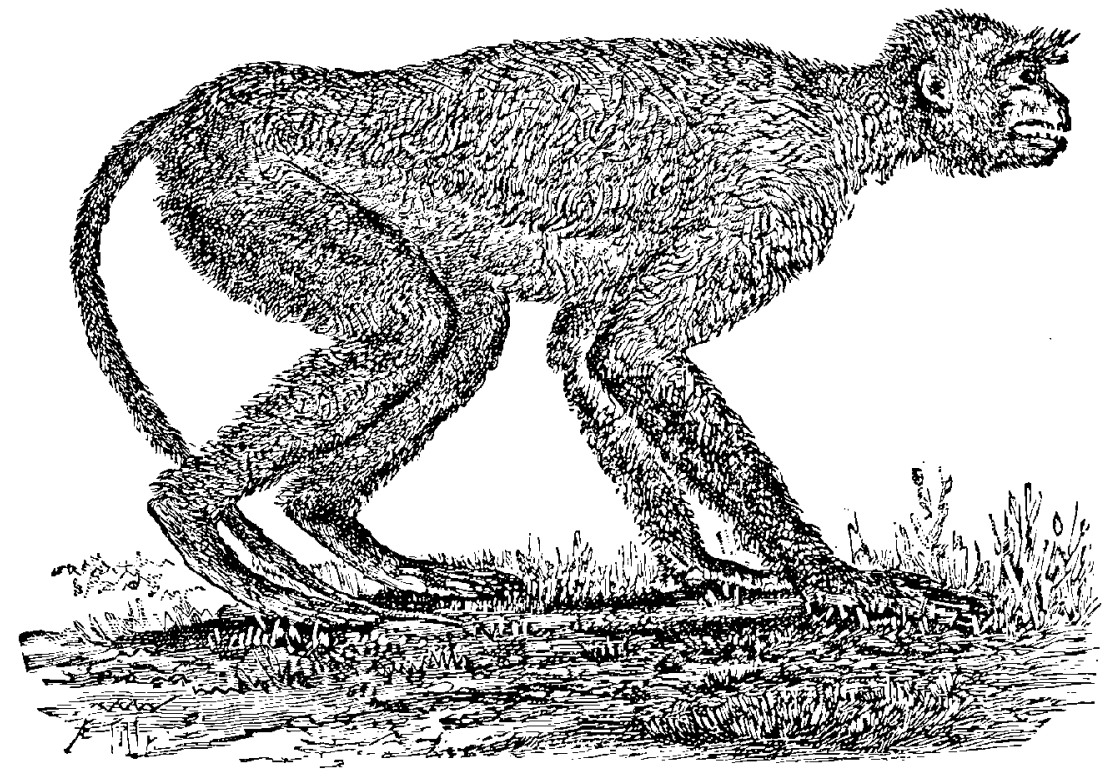

Fig. 377. - Singe mésopithèque de la période miocène en Grèce.

savent que l'éléphant est l'un des animaux les plus intelligents et l'un des meilleurs.

Comme nous l'avons dit, pendant la période miocène tous les 
ordres de mammifères sont représentés, pachydermes, carnassiers, cheiroptères, rongeurs, proboscidiens, amphibies, ruminants, insectivores, quadrumanes. Les plus caractéristiques sont ceux que nous venons de signaler, les dinothériums et les mastodontes. Ils étaient accompagnés d'un grand nombre d'autres habitants des bois, des campagnes et des rivages, tels que : l'antracothérium, pachyderme armé d'incisives et de canines tranchantes qui pouvaient servir

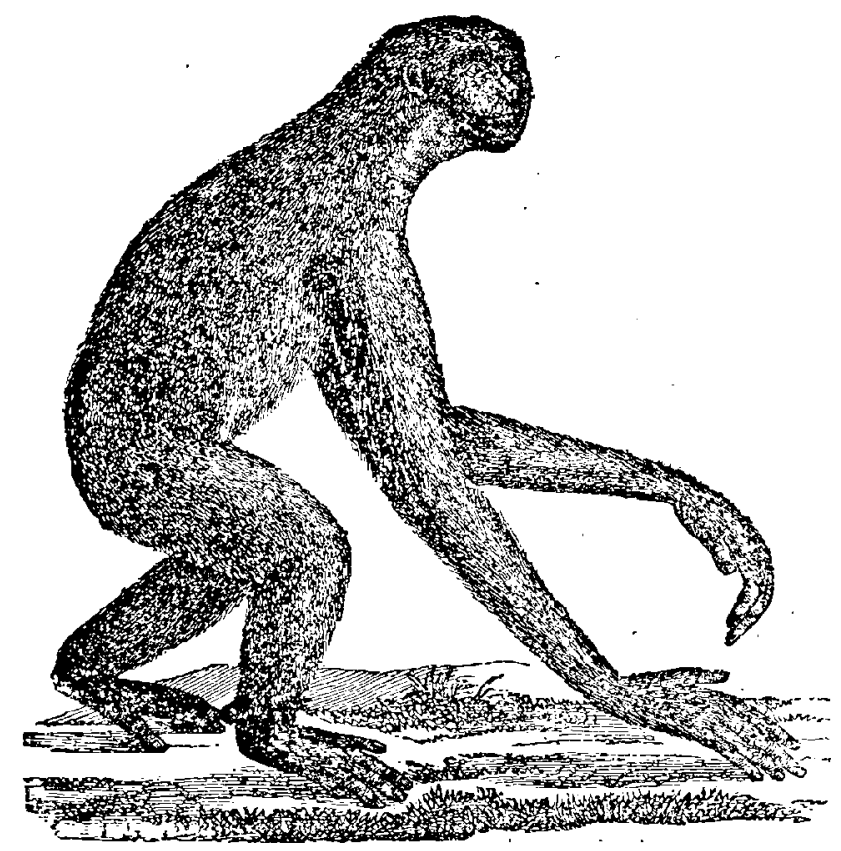

Fig. 378. Le siamang, singe gibbon de la période miocène.

d'instruments de défense (on en trouve les ossements dans le calcaire de Beauce). Les tapirs et les rhinocéros se montrent, ainsi que les premiers ancêtres des ruminants. Dans la Grèce seule, qui faisait alors partic d'un continent, M. Gaudry a mis au jour einquante et une espèces différentes, parmi lesquelles nous signalerons, outre les singes dont nous parlerons tout à l'heure, des hipparions, des antilopes, des gazelles, des girafes, des sangliers, des chats sauvages, des civettes, etc. Un édenté aux doigts crochus a reçu le nom d'ankilothérium. Un animal qui parait être moitié ours, moitié chien et mème un peu chat, a recu le nom de simocyon. Une sorte de girafe dont le cou est peu allongé a reçu le nom de helladothérium. 
Deux ruminants qui.se rapprochent de nos chèvres ont reçu les noms de paleoceras et tragoceras. A tous ces contemporains de la période miocène, il faudrait encore ajouter les castors, les marmottes et un grand nombre d'échassiers.

Nous avons signalé plus haut (à la période èocène, p. 686) los recherches de M. Gaudry sur l'origine des singes par les pachydermes et la naissance des lémuriens pendant cette période. Quelle que soit cette origine, les principaux types de singes se montrent constituós dès le milieu de l'époque miocène : on trouve dans les terrains de cette époque les singes ordinaires et les singes anthropomorphes.

Le premier singe fossile que l'on ait connu est le semnopithecus subhimalayanus, rencontré en 1836 par Baker et Durand, dans le miocène supérieur de l'Himalaya; il avait la grandeur d'un orang-outang. Bientôt aprés, Falconner et Cautley ont extrait des mèmes terrains une autre espèce plus petite de semnopithèque. M. Gervais a signalé à Montpellier quelques pièces qu'il a attribuées également à un semnopithèque. Une mâchoire do macaque a été tirée du pliocène du Val d'Arno.

On a trouvẻ dans les lignites d'Elgg, en Suisse, une belle mâchoire de singe munie de ses dents, caractérisant un singe de la famille des catharrhiniens. Cette mâchoire offre la plus grande analogie avec une autre màchoire simienne découverte à Sansan, près d'Auch (Gers), par M. Lartet, et doit se rapporter à la même espèce de singes. M. Gervais en a fait un genre spécial éteint, le pliopithèque, tandis que M. Rütmeyer estime que c'est un gibbon iridien, un hylobate; en tous cas, ces derniers singes, sans queue et à bras longs, sont ceux avec lesquels il a le plus d'analogie. D'après M. Rütmeyer, ce gibbon primitif serait un proche parent, certainement un ancêtre, du siamang de Sumatra.

M. Albert Gaudry a recueilli à Pikermi les restes de vingt-cinq individus du genre mésopithèque; d'après tous ces matériaux, on peut se faire une idée de son aspect et de ses mœurs (voy. fig. 376 et 377). Son angle facial de $\mathbf{5 7}$ degrés semble indiquer un singe dont l'intelligence était dans la bonne moyenne; ses dents montrent qu'il n'était pas essentiellement frugivore, mais qu'il se nourrissait de bourgeons de feuillages. L'égalité de ses mombres de 
devant et de derrière prouve que c'était plutôt un marcheur qu'un grimpeur; il vivait en petites troupes. La connaissance que nous avons des diverses parties du squelette de mésopithèque a révélé que ce singe forme la transition entre deux genres actuellement vivants, entre les semnopithèques et les gibbons, et c'est pour cette raison qu'on l'a nommé mésopithèque (').

La découverte des singes fossiles du groupe anthropomorphe est due à M. Gaudry. En 1835, il a signalé à Sansan le pliopithèque $\left({ }^{2}\right)$, animal probablement voisin des gibbons. Plus tard, il a décrit le dryopithèque $\left({ }^{3}\right)$; on n'en possède malheureusement que la mâchoire inférieure et l'humérus. « Le dryopithèque, dit l'éminent professcur, était un singe d'un caractère très élevé. Il se rapprochait de l'homme par plusieurs particularités. Sa taille devait ètre à peu près la mème; ses incisives ètaient petites; ses arrièremolaires avaient des mamelons moins arrondis que dans les races européennes, mais assez semblables aux mamelons des molaires d'Australiens; on a supposé que la dernière molaire poussait après la canine, comme la dent de sagesse chez l'homme. A côté de ces ressemblances, il y a une différence qui frappe dès que l'on compare une mâchoire humaine à la mâchoire du dryopithèque : dans une mâchoire humaine, où la première arrière-molaire est plus forte que chez le dryopithèque, la canine et les prémolaires sont au contraire plus faibles; celte différence est d'une importance considérable, ear le raccourcissement des dents de devant est en rapport avec le peu de saillie de la face, et par conséquent est une marque de la supériorité humaine; ce qui caractérise essentiellement la tête de l'homme, c'est un développement extrême des os qui entourent l'encéphale, siège de la pensèe, et une diminution des us de la face tellement grande qu'au lieu de former un museau, ils ne sont plus que la façade de la tête. "Ainsi, de progrès en progrès, dans les règnes organiques qui peuplent la Terre, s'achève la préparation au règne humain.

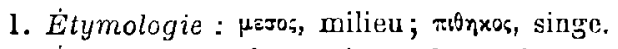

2. Etymologie : $\pi \lambda \in i o v$, plus; $\pi$ tonxos, singe.

3. Étymologie : Spus, chène; $\pi .8 \mathrm{n} \times 0$ s, singe 


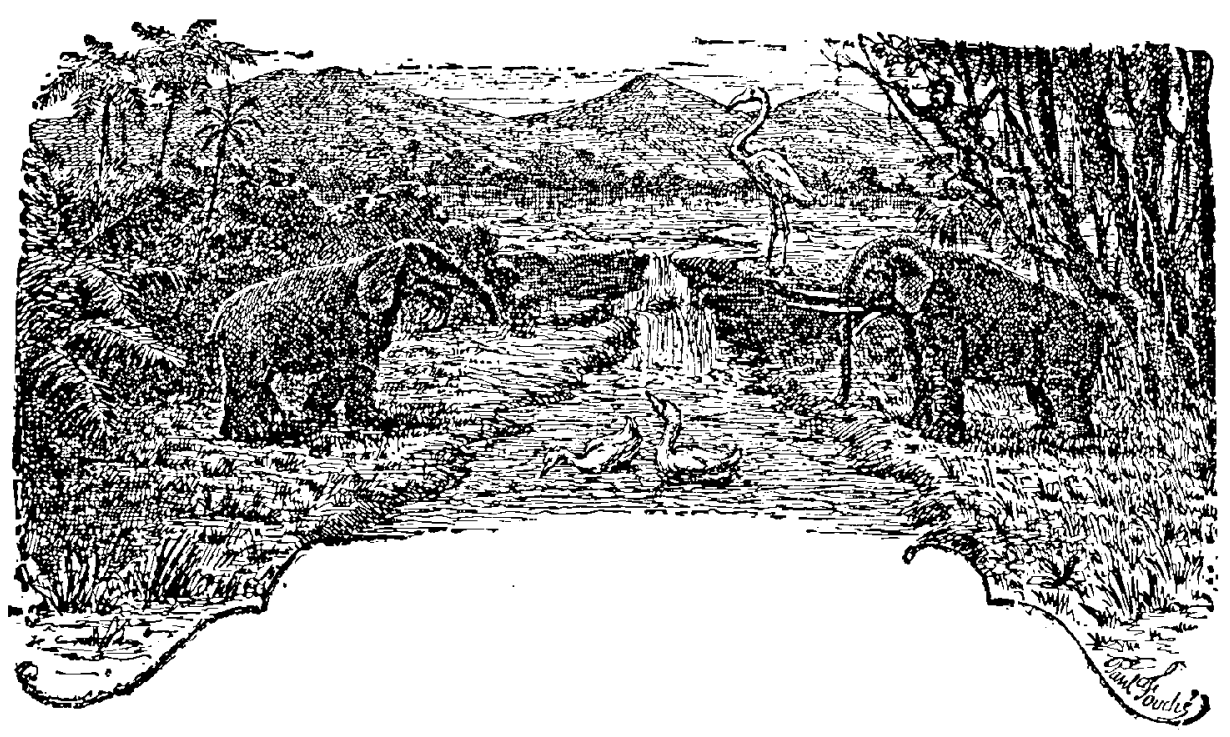

GHA PITRE III

LA PERIODE PLIOCENE

La troisième et dernière période de l'ère tertiaire a reçu, comme nous l'avons vu, le nom de pliocène. Assez in timement liće à l'époque actuelle pour que quelques auteurs ne croient pas devoir l'en distraire, elle offre cependant une individualité distincte et représenie un ètat de choses assez différent de celui qui prévaut de nos jours. Sans doute, vers la fin de la période, les contours des configurations des mers et des continents s'éloignaient peu de ceux des configurations actuelles. Toutefois, sur plus d'un point, les sédiments de cet âge sont aujourd'hui inclinés et portés à des hauteurs notables, et la faune dont ils ont conservé les débris, antérieure au refroidissement des régions boréales, marque plutôt la fin que l'inauguration d'une ère.

Au début de la période pliocène, la géographie des régions méditerranéennes a subi une modification passagère, mais considérable. En effet, les premiers sédiments de cet âge accusent des conditions plutôt saumâtres que marines. Des couches à congéries, répandues sur divers points de la Provence, de l'Italie et de la Gorse, en même temps qu'elles occupent des espaces considérables dans l'Europe orientale, attestent qu'alors la Méditerranée ne s'avançait pas au delá du méridien de la Sardaigne et que toute sa partie orientale 
avait fait place à une série de mers caspiennes sur les bords desquelles royageaient librement de grands troupeaux d'herbivores. Mais bientôt le relief de la région s'accentue, la continuité du régime marin se rétablit et la mer avance, par de longues échancrures, au delà des estuaires actuels de nos fleuves, notamment dans la vallée du Rhône et dans celle du Pô. En France, la mer pliocène s'est avancée jusqu'aux portes de Lyon, en Italie le long des Apennins,

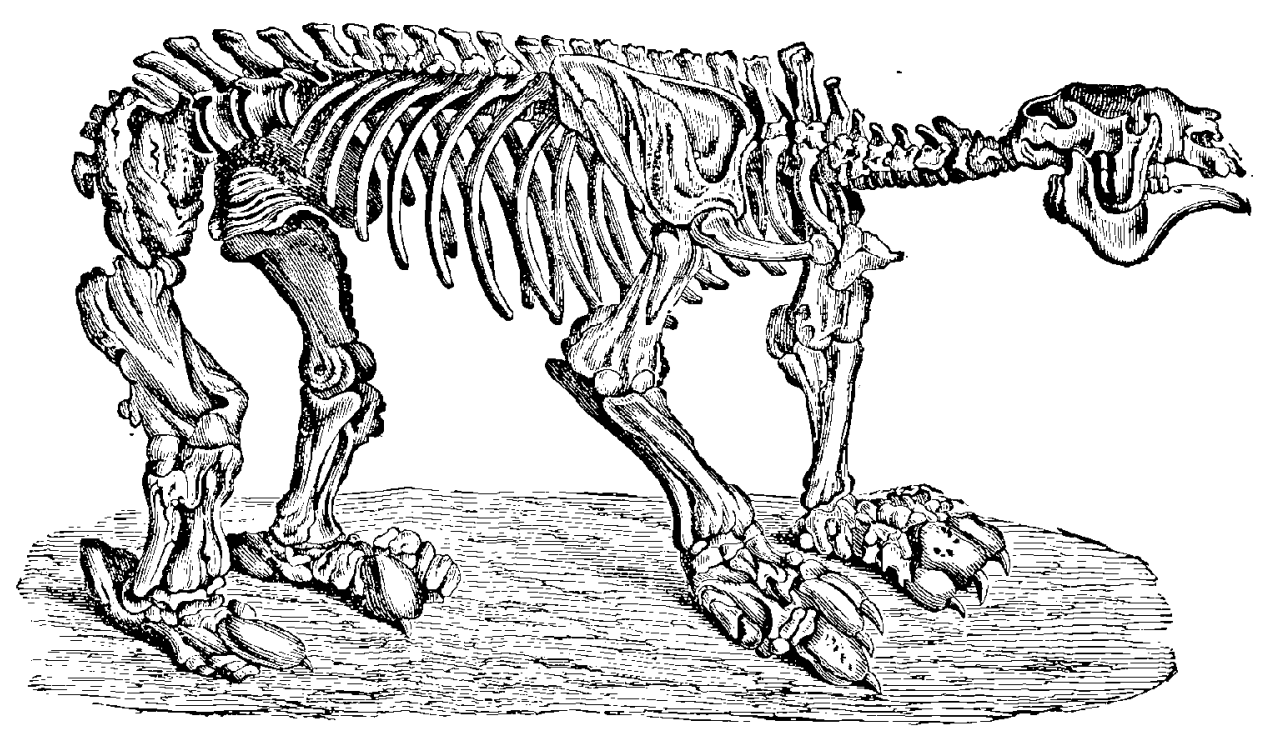

Fig. 380. - Squelette fossile du mégathėrium.

surtout dans la Ligurie centrale; Rome, les collines du Vatican et et du Montc Mario étaient alors sous les flots, destinées dans le mystère des âges à leur gloire future. On retrouve, sous le Vatican mème, les coquilles pliocènes datant de plusieurs milliers de siècles avant l'ère que les croyances chrétiennes attribuaient naguère encore à la création du monde.

A cette même époque aussi, d'imposantes manifestations volcaniques prolongent l'activité éruptive de la période miocène. « Un climat relativement très doux permet à l'Europe de nourrir une végétation oủ les types des riches forèts du Nord sont associés à ceux des îles Canaries et des confins de la région caucasienne. Mais la température s'abaisse peu à peu, en mẻme temps que la mer se retire; la flore s'appauvrit pour ne plus rien acquérir désormais; 
les espèces les plus délicates émiqrent vers le Sud, et les palmiers ne se trouvent plus qu'à des latitudes inférieures de dix degrés à celles qu'ils atteignaient lors du miocène. Enfin, la période s'achève avec une flore qui, assez riche encore pour fournir une abondante nourriture à de gigantesques herbivores, ne contient plus en chaque point, d'espèces qu'il ne soit aujourd'hui facile de retrouver en descendant de quelques degrés vers l'équateur (').»

La période miocène a marqué l'apogée de la splendeur et de la richesse du règne végétal en Europe. La póriode pliocène en commence le déclin : la chaleur se perd, la végétation s'appauvrit pour tonjours.

Insensiblement, la mer se rotire des $\Lambda$ ipes soulevées, de la Suisse, de la France entière. Dans la vallée du Rhône, elle se retire à Valence, puis à Montélimart, puis à Orange; comme l'emboucliure du Rhône, celles du Pò et du Danube se montrent à l'état de golfes. Nos contrées prennent graduellement leur configuration géographique et les fleuves leurs directions.

Pendant la première partie de la période pliocène, la prépondérance parmi les animaux terrestres, appartient sans conteste aux herbivores. Les mers miocènes viennent de se dessécher, ou plutôt de se transformer en grands lacs salés, autour desquels se développe une abondante végétation de graminćes. Sur ces herbages se promènent les innombrables troupeaux d'antilopes, de cerfs, d'helladothériums, de girafes, de palæotragus, de palæoreas, dont les fossiles de Grèce, de Suisse et de France ont révélé l'existence. A ces animaux s'associcnt l'hipparion, le mastodonte et le singe mésopithèque.

Dans l'ensemble de la période, la nature se rapproche de plus en plus de ses aspects modernes. La végrétation de nos contrées voit disparaître les palmiers et revèt un caractère tempéré, non seulement par ses arbres, mais encore par ses arbustes et par ses fleurs. Après avoir conservé quelque temps les sequoias et les bambous, l'Europe se peuple d'espèces très voisines de celles qu'elle possède aujourd'hui, mais destinées à reculer vers le sud dans les âges suivants. La flore pliocène témoigne d'un climat déjà plus froid. Les différences climatériques entre le nord et le sud de l'Europe

1. A. de Lapparent. Traité de Géologie. 
commencent à s'accentuer; c'est ainsi qu'un palmier (Chamørops humilis), associé à des chènes (Quercus lusitanica) qui ne se rencontrent plus que dans le sud de l'Espagne, se maintenait dans les environs de Marseille, tandis que l'érable, le peuplier, le noyer et le mélèze élaient prépondérants dans le centre de la France, offrant quelques types dont les identiques doivent ètre aujourd'hui

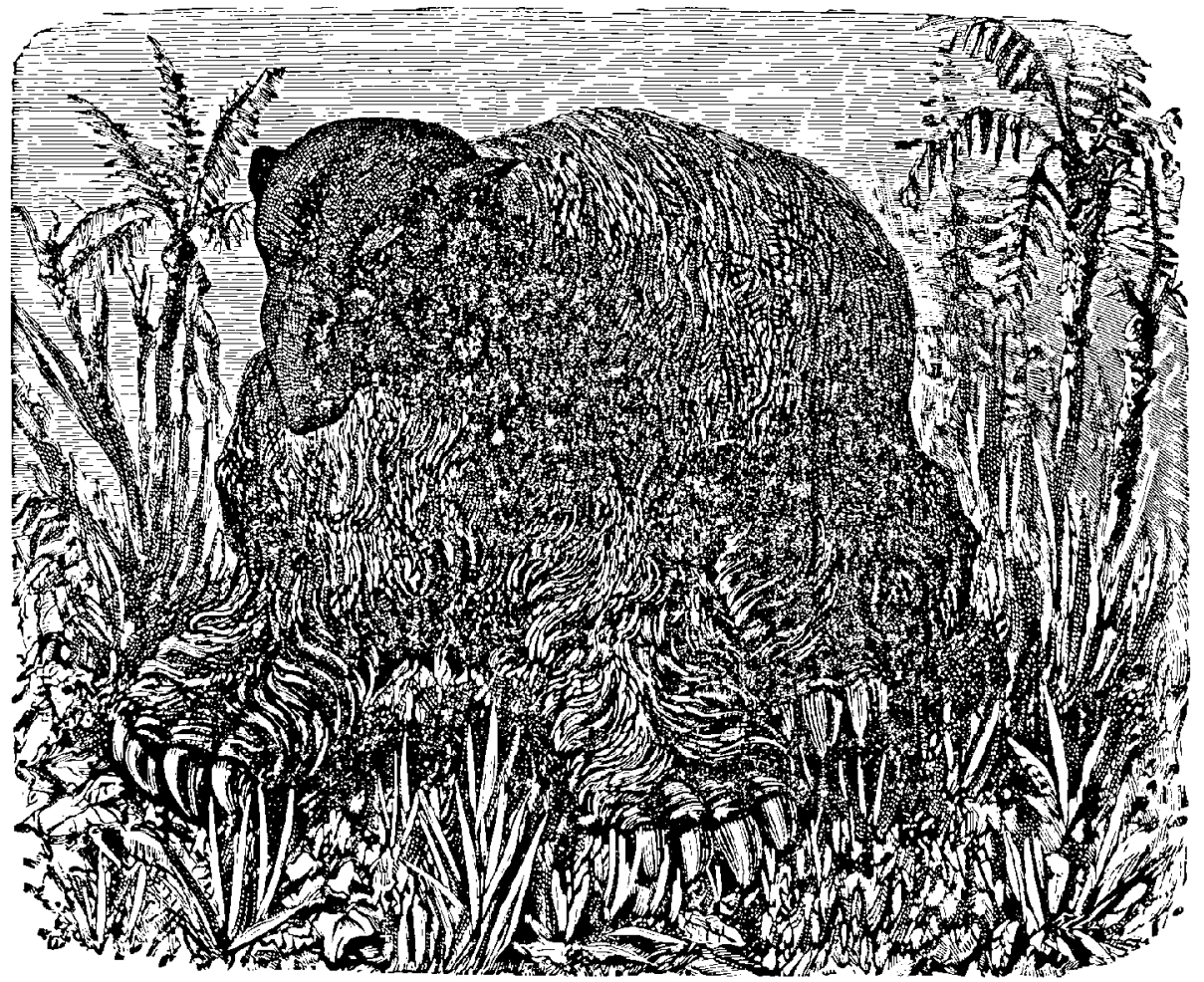

Fig. 381. - Le mégathérium (période pliocène de l'Amérique du Sud).

demandés à la flore de l'Algérie, à celle du Portugal ou même dı Japon. Plusieurs des espèces végétales du pliocène européen sont anjourd'hui indigènes des grandes forêts d'Amérique.

Le règne animal voit le développernent et le progrès des mammifères; de nouveaux mastodontes remplacent les anciens pour disparaitre bientòt à jamais.

Le mastodonte, que nous avons étudié dans la période précédente, vivait encore à l'époque pliocène. La figure 383 représente un squelette fossile de l'espèce qui vivait à cette époque, le Mas- 
todonte de Turin, qui n'avait que les deux grandes défenses de la mâchoire supérieure. Le mastodonte qui vivait pendant la période miocène avait quatre défenses, comme on l'a vu plus haut.

Les dinothériums sont èteints; les éléphants se perpétueront par de nouvelles espèces (mammouth on elephas primigenius) qui assureront la durée du genre jusqu'à nos jours; les hippopotames,

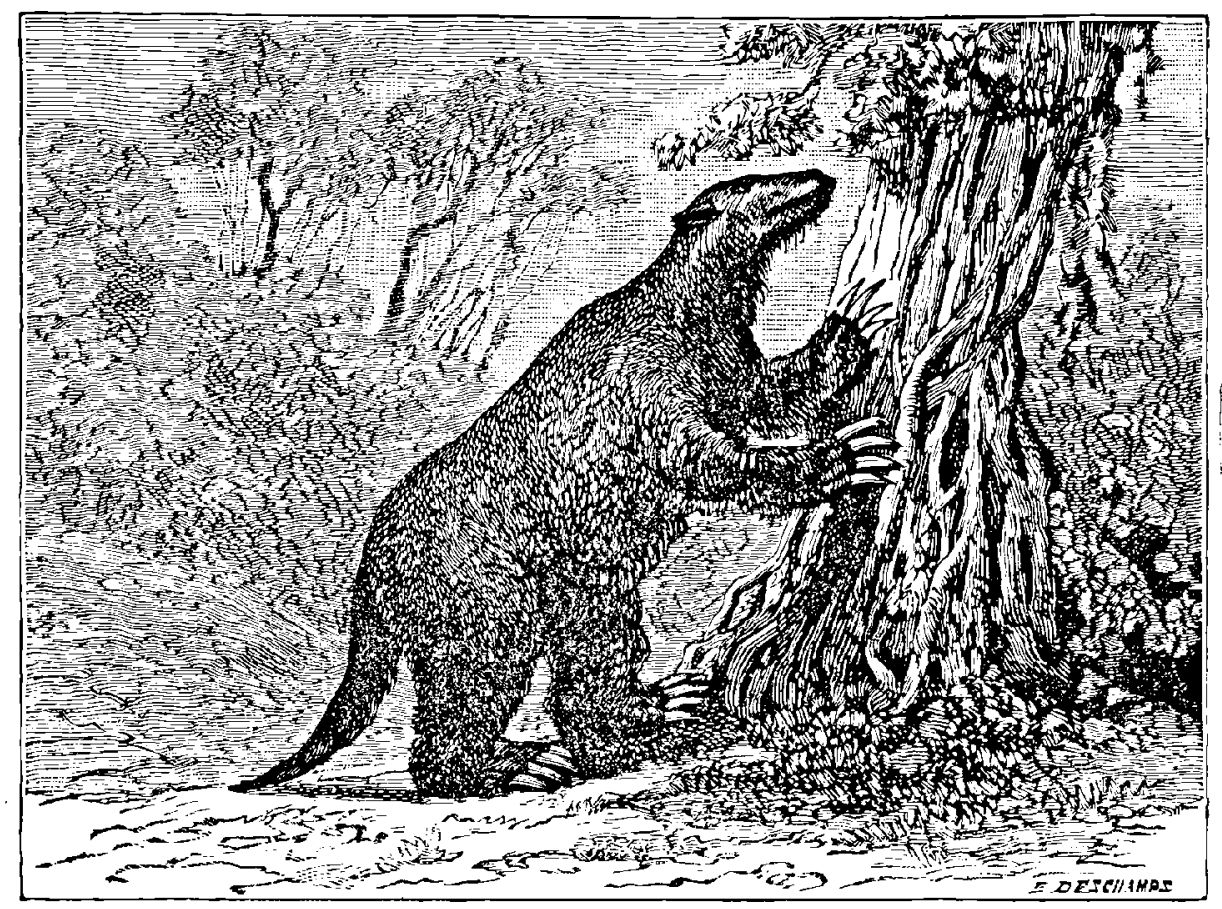

Fig. 382. - Le mylodon (période pliocène de l'Amérique dı Sud).

les rhinocéros se multiplient, ainsi que les tapirs et les chameaux. On voit arriver des bœufs énormes, qui vivent en troupeaux dans les forèts de nos contrées; des cerfs à grands bois, des ours, des hipparions et des chevaux (plus petits que ceux de nos jours). On assiste aussi à la naissance de nouvelles espèces de singes; mais les singes quittent bientôt l'Europe, devenue trop froide, pour aller vivre en Afrique.

Dans le nouveau continent on remarque, parmi les mammifères les plus curieux de cette époque, le mégathérium, découvert dans le Paraguay, à Buenos-Ayres, appartenant à l'ordre des paresseux; d'une allure gauche et bizarre, il était herbivore et mesu- 


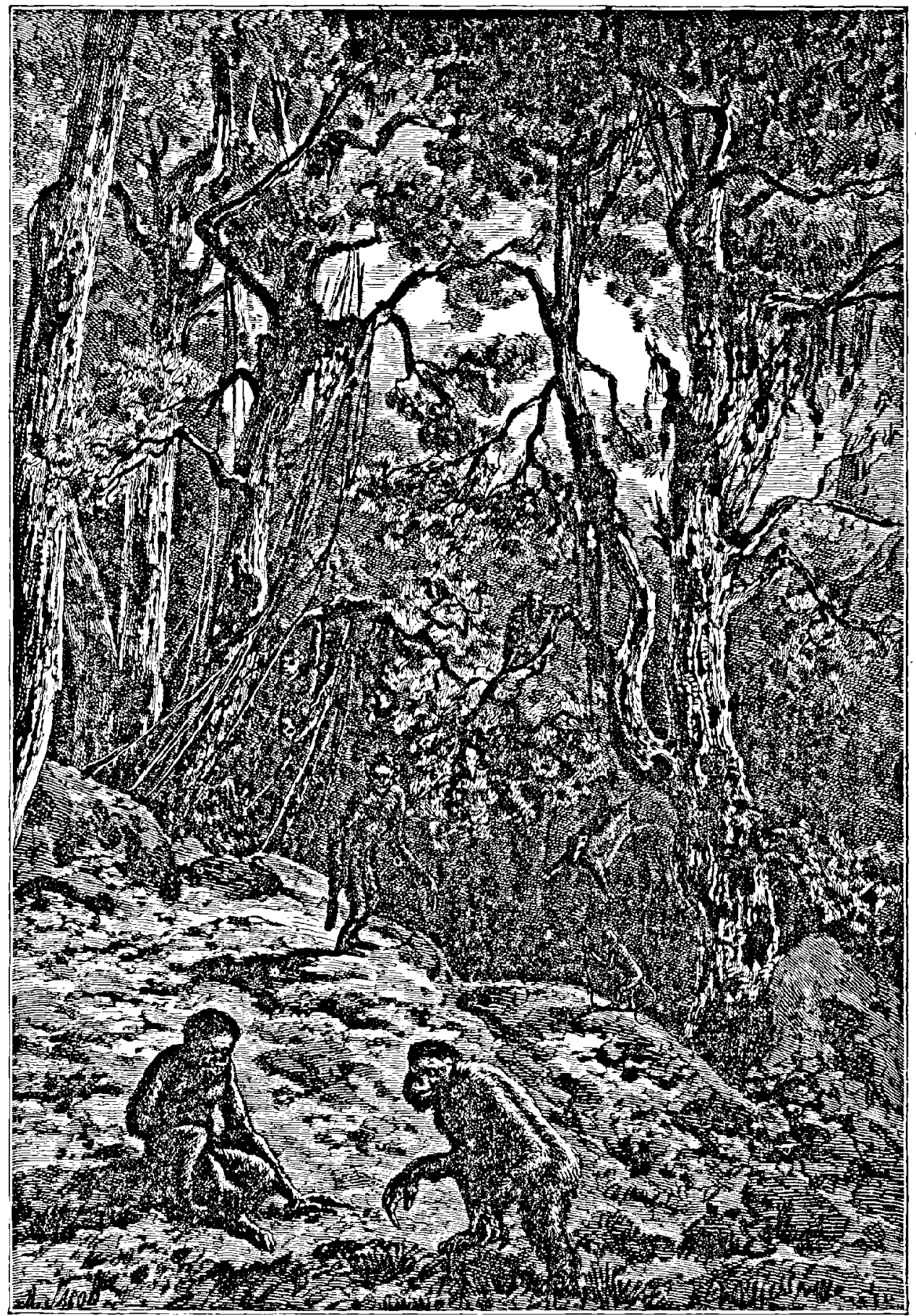

HAgITANTS DE LA GRÉCE, DE LA SCISSE, DE LA PROVENGe, AOX PREYLERS SIÉGLES DE L'ÉPOQUE PLIOGÉNE.

LE YONDE AVANT LA CRÉtion DE L LOMBE 
rait deux mètres et demi de hauteur; son squelette est conservé au Muséum de Madrid. Adjoignons lui son contemporain, le mylodon, qui se nourrissait surtout des feuilles des arbres et des bourgeons. Il était un peu moins grand que le mégathérium et portait aussi des sabots et des griffes à chaque pied. - Mais revenons aux habitants de nos contrées.

. Les grands proboseidiens dominent, surtout l'elephas méridionalis, dont les incursions s'étendent jusqu'en Angleterre; à la fin du pliocène, les mastodontes disparaíssent de l'Europe pour survivre plus longtemps en Amérique. Les rhinocéros et les hippopotames sont à leur apogée, les cerfs et les bœufs se montrent: tous ces herbivores attestent la grande abondance de la nourriture végétale.

On peut voir à la nouvelle galerie de paléontologie du Muséum de Paris le squelette fossile de l'elcphas meridionalis, découvert en 1872 a Durfort (Gard) par M. Gazalis de Fondouce; sa hauteur est de $4^{\mathrm{m}} 10$ et la plus grand largeur du crâne atteint $1^{\mathrm{m}} 65$.

G'est aussi à l'époque pliocène que le plus grand de tous les cerfs prend naissance; ses ossements ont été trouvés dans les Indes, au sein des monts Sivaleks, oủ les habitants adorent l'antique idole connue sous le nom de Siva; aussi l'a-t-on désigné sous le nom de sivatherium.

Le sivatherium avait la taille de l'éléphant; il appartenait au genre des cerfs : c'est donc le cerf le plus gigantesque qui ait jamais existé. Il ressemblait à notre élan actuel, mais il était beaucoup plus gros et plus massif. Sa tête présentait une disposition que l'on n'a trouvée sur aucun animal connu: elle était armée de quatre bois, dont deux au haut du front, et les deux autres, plus grands, plantés à la région des sourcils. Ces quatre bois, très divergents, devaient donner à ce cerf colossal un aspect des plus étranges.

L'histoire géologique des ruminants est très différente de celle des pachydermes. Ceux-ci ont eu leur règne dans nos contrées pendant la première moitié des temps tertiaires, et on n'en voit plus aujourd'hui que des reliquats isolés. Au contraire, les ruminants ont eu leur règne dans la seconde moitié des temps tertiaires, ct de nos jours encore leur ordre est très florissant.

Les plus anciens ruminants qui ont été trouvés en Europe sontle 
xiphodon, le dichodon, et l'amphiméryx; les deux derniers sont imparfaitement connus; quant au xiphodon, on peut dire qu'il a autant de titres à etre classé parmi les pachydermes qu'à être rangé parmi les ruminants. En Amérique, les ruminants paraissent s'être multipliés plus tôt qu'en Europe; cependant, à la fin des temps éocènes, ou même al commencement de l'époque miocène, la plupart de leurs espèces avaient conservé quelques caractères do pachydermes.

Iorsque nous voyons les ruminants se développer pendant

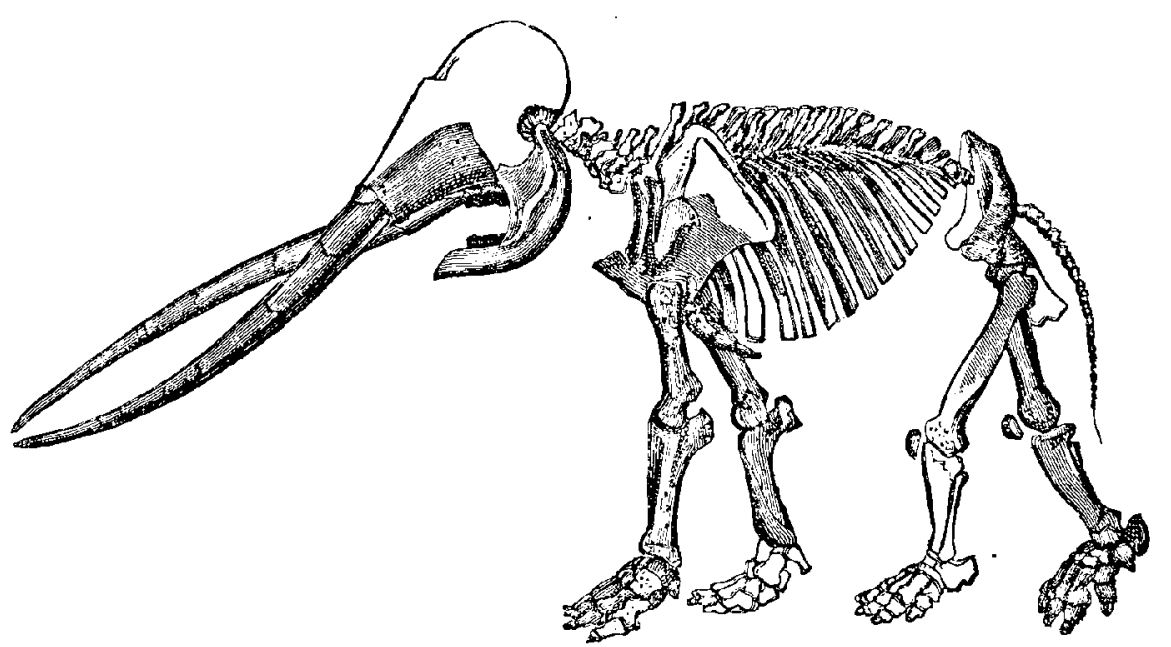

Fig. 384. - Squelette fossile du mastodonte du musée de Turin.

l'époque tertiaire au fur' et à mesure que les pachydermes diminuent, il est naturel de penser qu'ils pourraient être des pachydermes transformés. Or, c'est précisément là la conclusion que M. Gaudry a déduite de la comparaison des dents, à ce point mème qu'il est difficile de décider quels sont les genres de pachydermes qui ont le plus de titres à être regardés comme les ancêtres des ruminants.

La tardive extension des herbivores, soit solipèdes, soit ruminants, cst un fait très digne d'ètre noté; elle favorise la doctrine du développement progressif. Comme ce sont les herbivores qui forment les grands troupeatix, leur arrivée indique un accroissement de fécondité dans la nature. Ce n'est pas seulement par leur nombre, c'est aussi par la vivacité de leurs allures, la rapidité de 
leur course qu'ils donnent de l'animation aux campagnes. Pour s'en emparer, les carnivores sont obligés de mettre en jeu toute leur intelligence et leur force. Du contraste des efforts que font les herbivores ct les carnivores pour assurer leur vie, les uns en évitant les attaques, les autres en poursuivant leur proie, il résulte une somme d'activité que le monde n'avait pas eue dans les anciennes époques. Les herbivores constituent aussi un progrés au point de vue esthétique, car les solipèdes rivalisent de beauté avec les ruminants; plusieurs d'entre enx, comme le zèbre, le daw, le conagga, ont des robes magnifiques; quelques-uns ont une allure particulièrement noble, tous sont élancés et de formes gracieuses ( $\left.{ }^{(}\right)$.

A cette époque aussi, vivait l'hipparion, ancètre probable dn cheval, qui en différait par certaines particularités tirées du mode de plissement de l'émail dans les dents et surtout par ce fait qu'on pourrait lui refuser le nom de solipède, parce qu'au lieu de posséder à chaque pied un seul sabot, il en possédait trois, dont deux latéraux atrophiés. (La réduction des cinq doigts en un seul n'était pas encore complète.) En examinant son squelette (fig. 386), on devine du reste, en lui, l'allure et la noblesse du cheval.

Chaque époque de l'histoire du monde a été marquée par des ètres qui lui ont donné une physionomie spéciale; aprés leurs épanouissements, ils ont disparu. Ainsi a été produite cette perpétuelle diversité qui charme les géologues en leur révélant une infinie puissance d'activité.

Si maintenant nous essayons de tracer un résumé de l'époque tertiaire, d'après tout ce que la géologie et la paléontologie ont pu nous apprendre, nous devons, avec M. Contejean, nous figurer des continents assez étendus, exhaussés de montagnes déjà élevées, mais toujours fort disséminées. En Europe, les grandes terres ressemblaient sans doute aux régions planes ou ondulées de l'intérieur de l'Afrique; elles étaient semées de lacs et de marécages, et nourrissaient une végétation luxuriante. D'immenses troupeaux d'herbivores parcouraient ces savanes à demi noyées sous les eaux, aussi nombreux et plus variés que les troupes d'éléphants, de zèbres et d'antilopes de l'A frique centrale. Les rhinocéros, les tapirs, divers

1. Albert Gaudry. Mammiferes tertiaires. 


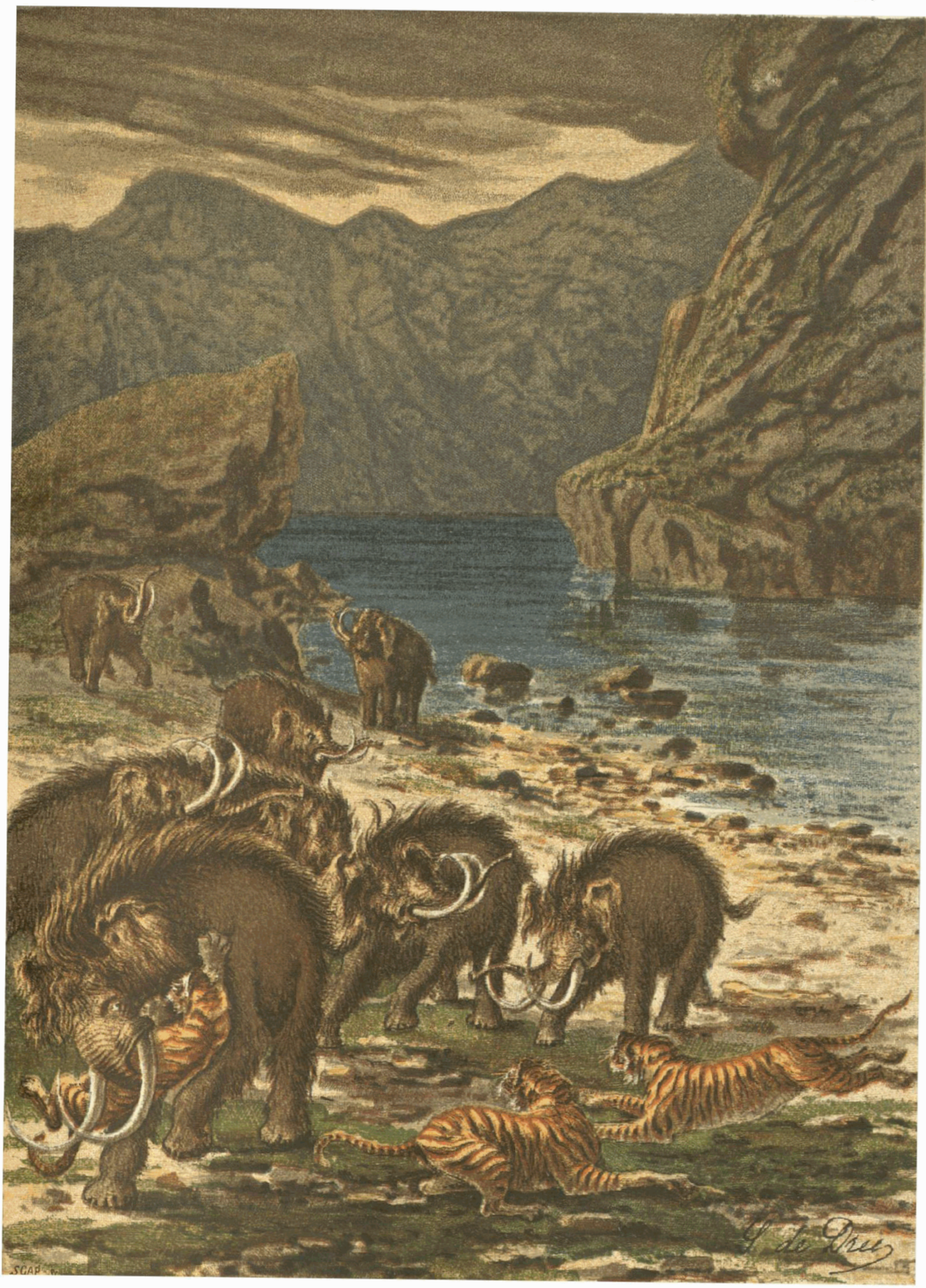

Chromotypographie SGAF.

LA FRANCE AVANT L'HOMME

COMBat de Mammouths ET De chats Géants 
IRIS - LILLIAD - Université Lille 1 
sangliers, des antilopes, des anchitériums semblables aux chevaux, paissaient dans les mèmes régions que les paléothériums, les anthracothériums, les helladothériums, les sivathériums, les mastodontes, non moins remarquables par la bizarrerie de leurs formes que par celle de leurs noms. De nombreux carnassiers venaient modérer

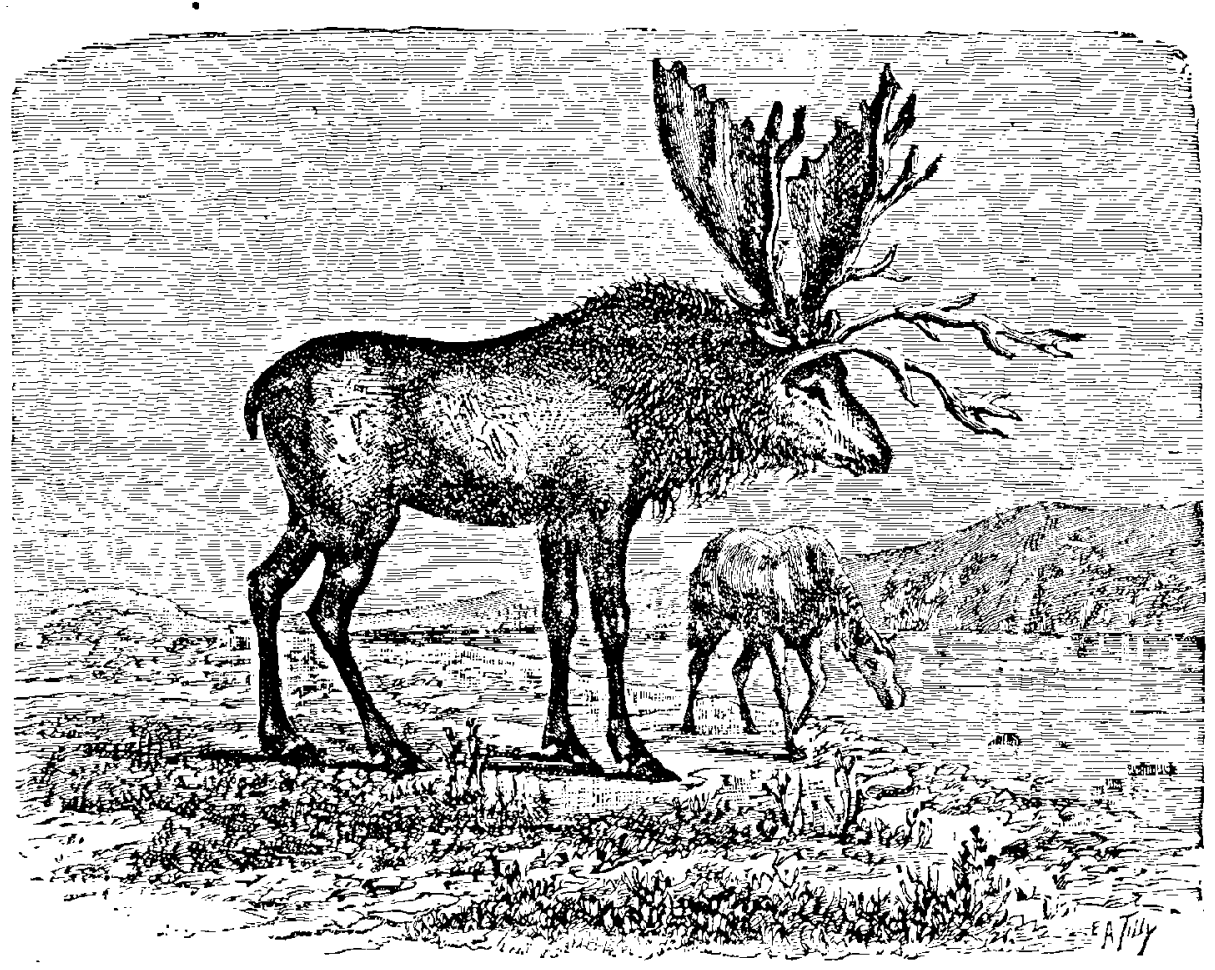

Fig. 38. - I e sivathérium, cerf-colosse des temps pliocènes.

ce que cette population aurait pu présenter de trop exubérant. Des oiseaux coureurs, semblables à l'autruche, traversaient les plaines acides, de grands lézards, des serpents de diverses sortes se glissaient entre les arbres des forêts hantées par une population assez variée de singes précurseurs de l'homme. Des insectes et des oiseaux de toute espèce sillonnaient les airs. Repaires de crocodiles, les lacs et les marécages nourrissaient aussi des poissons analogues à ceux de nos rivières. Sur les rivages des mers se trainaient des phoques et des lamantins; et les océans, peuplés de dauphins, de baleirıes et de cachalots, étaient ravagés par des squales énormes. Dans son ensemble, la nature avance lentement vers l'ordre des choses actuel. 
Peut-etre, comme nous le verrons bientôt, l'hornme existait-il dejà, à l'état primitif et sauvage, mais il ne connaissait pas encore le chemin de l'Europe et vivait au milieu des forêts de l'Asie méridionale, inconscient de ses destinées autant que de sa propre existence. Il est né à son heure, après les singes anthropoïdes, orangs, chimpanzés ct gorilles.

A la fin de la période, la température est à peu près ce qu'elle est de nos jours; les mastodontes, les tapirs, les singes ne se rencontrent plus en Europe, mais en Afrique et an midi de l'Asie.

La création du monde est continue. La découverte des vestiges enfouis dans l'écorce terrestre nous apprend qu'une constante harmonie a présidé aux transformations du monde organique. Quels que soient les fossiles dont nous entreprenions l'étude, la beauté de la nature se révéle à nous.

Cette beauté de la nature qui apparait à toutes les époques est le secret de l'entraînement que subissent tant de naturalistes dont la vie est vouće aux recherches paléontologiques et dont l'esprit trouve dans ces recherches un charme toujours renaissant. Lorsque Georges Cuvier put, dans sa pensée, redonner l'existence aux quadrupédes du. gypse de Paris, il dut éprouver de singuliers mouvements d'ćtonnement et de plaisir; là où s'étend aujourd'hui notre grande ville, il pensait voir des lacs où se baignaient les anoplothériums; sur leurs rives bordées de palmiers, il apercevait des paléothériums d'espèces et d'allures variées, s'entre-croisant avec les chœropotames et les dichobunes; d'élégants xiphodons et des amphiméryx couraient dans les plaines; à côté d'eux, de plus petits animaux de différents ordres contribuaient à donner de la diversité aux paysages; c'étaient des écureuils, des sarigues, des chauves-souris et différentes espèces de singes, notamment les anthropoïdes, précurseurs de notre race.

« J'ai compté parmi les meilleurs moments de ma vie, écrit M. Gaudry, les mois que j'ai passés dans le ravin de Pikermi, à extraire les débris des quadrupèdes qui animaient autrefois les campagnes de la Grèce. En vérité, ces animaux de Pikermi devaient former de magnifiques spectacles : ici des singes gambadaient, là errait l'énorme ancylothérium, aux doigts crochus. Les plaines étaient au loin couvertes de troupeaux d'hipparions et de rumi- 
nants; les cornes de ces animaux présentaient des dispositions variées; les unes étaient en forme de lyre, d'autres rappelaient celles des gazelles actuelles, d'autres encore ressemblaient à celles des chèvres. Avec ces bètes aux allures légères, contrastaient de lourds rhinocéros et d'énormes sangliers. Enfin, au milieu d'animaux si divers, on voyait un rassemblement de puissants quadrupédes. Quelle ampleur de formes et quelle variété sur le théâtre de la vie! Bètes géantes et innombrables de likermi, la pensée de vos imposantes cohortes a souvent transporté mon esprit; je

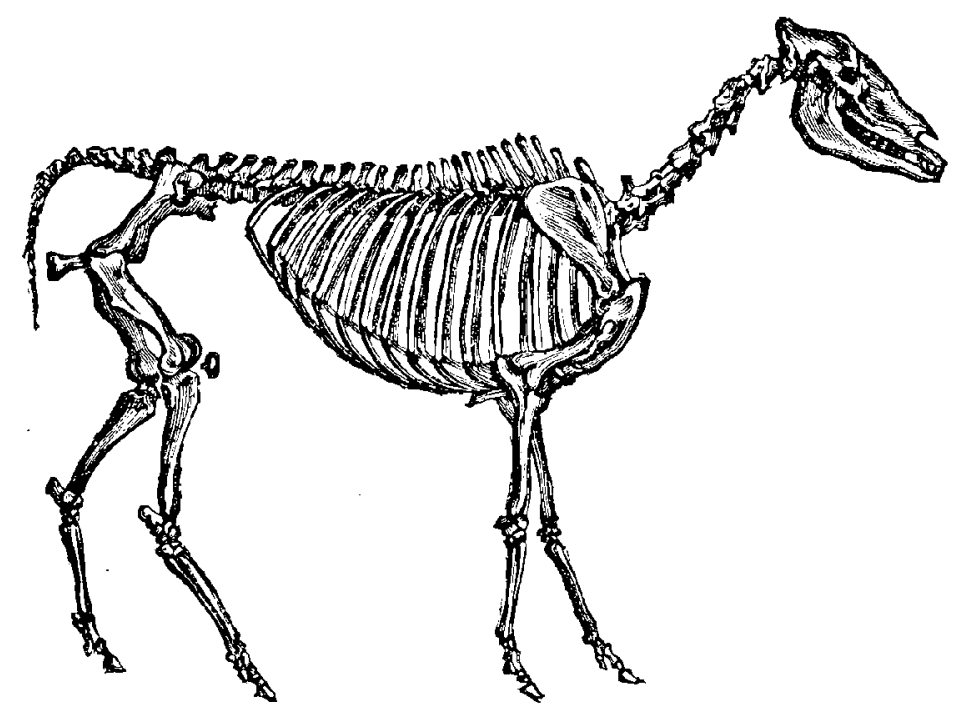

Fig. 386. - Squelette fossile de l'hipparion, ancêtre probable du cheval. (1/20 gr. nat.i

ne puis songer à vous sans m'élever jusqu'à l'Artiste infini dont vous êtes l'ouvrage, et sans lui dire merci de nous faire assister aux grandes scènes qui semblaient réservées pour lui seul, jusqu'au jour oủ a été soulevé le voile sous lequel la paléontologie était cachée...

« Des trésors de poésie sont enfouis dans l'écorce de notre globe. Combien d'hommes qui ont soif du beau, éprouveraient de douces jouissances s'ils se mettaient à la recherche des sources mystérieuses de la vie! Combien s'en vont par des chemins ou ils cueilleront des fruits insipides et quelquefois amers, qui seraient heureux en scrutant les merveilles de la nature! A ces.hommes, je dirai : 
vencz nous aider, notre science a de quoi charmer les âmes des arlistes aussi bien quo les âmes des philosophes.»

Ce sont là de belles pensées, dignes des hautes contemplations qui les ont inspirées. L'étude de la nature restera toujours la plus captivante et la plus profonde des études; ses tableaux, ses perspectives, ses harmonies charmeront toujours nos esprits. N'est-ce pas pour nous une émotion agréable que de voir revivre en quelque sorte devant nous tous ces siècles depuis si longtemps disparus, et d'assister ainsi à la création du monde, création qui n'est qu'une seule et même œuvre, continue depuis la nébuleuse terrestre jusqu'à nos jours. Grâce aux travaux des paléontologistes, nous avons pu ressusciter ces êtres pétrifiés et les rétablir dans leurs anciens domaines; nous avons vu la mer prendre plusieurs fois la place de la terre, et la face du monde changer avec tous ces êtres d'une époque ḋ l'autre; une étude attentive des sciences physico-chimiques et des sciences biologiques nous a même permis de suivre l'œuvre de la création sans lacunes séparatrices entre le monde inorganique et le monde organique, et de remonter aux origines mèmes de la vie. Ainsi pour nous, désormais, quelque progrès que fassent dans l'avenir toutes les sciences, quelque incomplètes que soient encore aujourd'hui les notions sûrement acquises, nous avons une idée exacte de la marche de la nature et de l'œuvre de la création.

A la fin de cette ère tertiaire, nous avons parcouru toutes les phases de cette a histoire naturelle ๖. La création est terminée, puisque l'homme est en germe dans les anthropoïdes et que la tendance au mieux, but supréme de l'existence de tout ètre, va faire progresser ces anthropoïdes et les élever au rang d'hornmes sauvages. C'est là une vaste question, que nous examinerons rigoureusement sous tous ses aspects au Livre suivant, et elle y sera à sa place, attendu que c'est à l'aurore de l'ère quaternaire que l'humanité paraît s'ètre dégagée de l'animalité. En ce moment, à la fin de l'époque tertiaire, elle ne mérite pas encore son nom. Dans les buis existent des familles de grands singes, semnopithèques, orangs, gorilles, chimpanzés. L'éléphant, l'hippopotame, le rhinocéros, le cerf, le cheval, le chat sauvage, le chien sauvage, le loup, l'ours, l'hyène, le tigre, le lion, en un mot, les espèces modernes, 
contemporaines de l'âge de l'humanité, existent dans la nature, au milieu d'une végétation analogue à celle qui revêt encore aujourd'hui la surface de la Terre. Montagnes et vallées, alpes couvertes de neiges, vallons ombragés, sources et ruisseaux, cascades et fleuves, forêts vierges, prairies aux herbes puissantes, sables stériles et déserts, climats et saisons, troupeaux pâturant, oiseaux chanteurs dans les bois, douces clairières, rayons et ombres, pluies et soleils, fleurs des champs, fruits sauvages, tout est formé, tout est prẻt pour la race conquérantc. L'ancien monde est mort. Le monde moderne cst né. 
IRIS - LILLIAD - Université Lille 1 


\section{LIVRE VI}

LAGE QLATERNAIRE

IRIS - LILLIAD - Université Lille 1 
IRIS - LILLIAD - Université Lille 1 


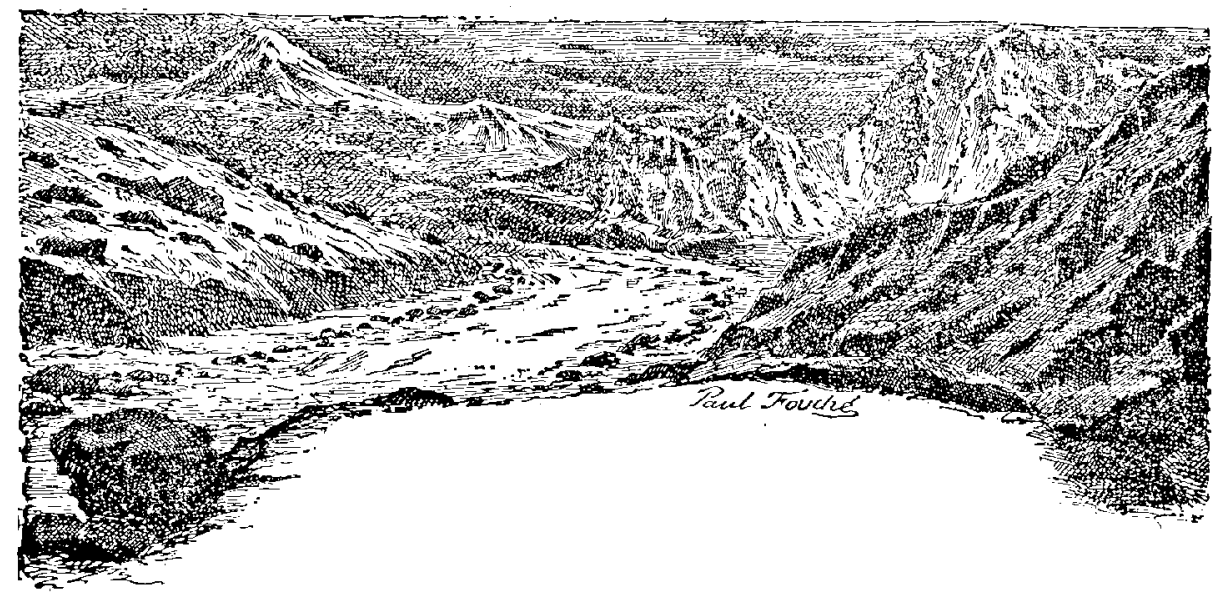

GHAPITRE PREMIER

LE QUATRIEME AGE DE LA VIE TERRESTRE

ET LES PREMIERS JOURS DE I'ERE AGTUELLE

Avec le quatrième âge de l'histoire de la Terre nous entrons dans l'ère moderne, dans l'état actuel de la création sur notre planète. Cependant le commencement de cet âge date de loin déjà, de plus de cent mille ans assurément, et bien des évènements se sont accomplis dans la géographie physique, dans la distribution des terres et des mers, dans les climats, dans les manifestations de la vie, depuis les premiers siècles de cette ère moderne, dont l'histoire entière de l'humanité n'est que le dernier chapitre, - le plus important et le plus glorieux de tous, mais, jusqu'à présent, le plus court. - L'humanité intellectuelle ne date que d'hier.

Les débuts de l'époque quaternaire ont été marqués par un événement météorologique considérable, un changement momentané de climat qui, en imprimant, dans toute la zone tempérée, une activité extraordinaire en précipitations atmosphériques, a donné naissance à des glaciers immenses, à des pluies et à des phénomènes d'érosion et d'alluvionnement considérables. Comme conséquence de ce changement, de grandes nappes de neiges et de glaces ont couvert les massifs montagneux, ainsi que les régions septentrionales, produisant, dans les diverses parties du monde, un refroidissement marqué, avec lequel l'âge des grands cours d'eau a pris fin. Plus tard seulement, la température s'est radoucie et 
le régime actuel s'est établi avec l'âge des tourbières et des habitations lacustres. De cette manière, tandis que, de nos jours, l'action des glaciers, des rivières et de l'atmosphère sur la surface terrestre est réduite à des proporlions presque insignifiantes, cette action a suffi, au début de l'ère moderne, pour répandre sur de vastes étendues des dépôts parfois très épais.

L'âge quaternaire a débuté par le refroidissement général qui -ui a valu le nom d'époque glaciaire. Dans la péninsule scandinave, l'abaissement de la température se trahit par l'aspect des roches, qui sunt striées et quelquefois polies par les anciens glaciers jusqu'au niveau de la mer; il se reconnaît encore à des traînées de blocs erratiques accompagnées d'argiles, de sables et de graviers qui se trouvent disséminées sur tout le pourtour méridional de la péninsule, rayonnant autour d'un point des Alpes scandinaves voisin de l'emplacement actuel de Stockholm, et ne s'arrêtant, dans l'Europe centrale, qu'à une ligne qui passerait à peu près par Vikaltkoï, Coula, Cracovie, Breslau, Leipzig, Hanovre, Arnheim, et le nord de l'Angleterre. Tous les matériaux, ainsi disséminés, ont traversé l'emplacement de la Baltique et de la mer du Nord, et proviennent. des Alpes scandinaves; ils ont reçu des géologues étrangers le nom de drift. Mèmes stries, même drift sur le nouveau continent; seulement les marques de l'action glaciaire s'étendent beaucoup plus au sud, et s'observent jusque vers le $39^{\circ}$ degré de latitude, dans la Pennsylvanie, l'Ohio, l'Indiana, l'Illinois et l'Iowa; ce qui montre que les lignes isothermes existaient déjà avec leurs inflexions actuclles. Les trainées glaciaires renferment. des débris de mollusques qu'on ne retrouve plus que dans les contrées circumpolaires. Tout récemment (Académie des sciences, 11 janvier 1886), le terrain glaciaire a été également signalé dans l'Afrique équatoriale, en Assinie, par $5^{\circ}$ de latitude nord et $5^{\circ}$ de longitude ouest.

On rencontre des témoignages de cette curieuse époque un peu partout. Arrètons-nous un instant sur nos contrécs, sur la France, l'Italie et la région des Alpes.

Les glaciers anciens, comme les glaciers actuels, ont laissé des traces irrécusables de leur passage; un rapide coup d'œil jetè sur la longue chaîne des Alpes et dans les vallées qui s'ouvrent à leur pied, suffit pour nous montrer le développement de ces mers de glace et 
les espaces parcourus qui, pour quelques-unes, ont été de plus de 400 kilomètres.

Il faut se représenter, avant tout, les cimes de nos montagnes beaucoup plus élevées qu'elles ne le sont actucllement. L'une des dernières oscillations du sol, vers le déclin de l'époque tertiaire, avait achevé l'exhaussement le plus important de notre système de montagnes. Le calcul du volume des roches que les courants fluviatiles et surtout glaciaires ont arrachées à ces sommets pour aller combler au loin de profondes vallées, indique pour ces monts une élévation de plusieurs centaines de mètres supérieure à celle qu'ils présentent actuellement.

Du Mont-Blanc, du Mont-Rose, du Splugen, du Gothard, du Brenner, du Mont-Viso, du Mont-Cenis, en un mot, de toute la chaine des Alpes, ces glaces sont descendues et ont envahi les vallées et les plaines en vertu de leur force propre d'expansion. La, nature du sol pouvait offrir des obstacles à la marche d'un glacier et mème en faire dévier le cours; dans ce cas, le sol résistant apparaît proiondément creusé parfois, mais surtout rayé, poli et moutonné par le frottement de ces débris de roches dures que la glace retient enchâssés et qu'elle entraîne dans son cours. Mais lorsque le terrain n'ètait formé que d'anciennes alluvions, les ondes glacées se sont facilement frayé un passage et ont atteint des distances énormes.

Ces courants de glace, pareils aux courants des caux, ont déposé à leurs côtés et à leur extrémité ces amas de boue, dite glaciaire, qui forment de vraies collines ou moraines, et ont semé cà et là sur leur parcours les blocs erratiques, énormes parfois, dont la présence dans nos contrées a été, de tous temps, l'objet des plus ćtranges légendes.

Les anciens géologues désignent encore tous ces matériaux erratiques sous le nom de diluvium, terme légué par la théorie ancienne et erronée du déluge universel auquel leur transport était attribué.

C'est en suivant ces dépôts morainiques, qui diffèrent essentiellement des alluvions anciennes par le manque absolu de stratificátion et par ces pierres anguleuses et striées qu'ils contiennent, que l'on pcut tricer, avec certitude, l'étendue des anciens bassins glaciaires. 
Par les rayures qu'ils ont gravées sur les ruchers sous-jacents ils ont marqué eux-mêmes les directions qu'ils ont suivies dans leur progression.

Aujourd'hui, dirons-nous avec M. Chantre, on sait quels ont èté les anciens glaciers des deux versants des Alpes, et quel a été leur parcours. Sans parler des glaciers de la Reuss, de la Linth et de tant d'autres de l'intérieur de la Suisse, citons l'immense glacier du Rhòne qui, depuis le Valais, s'est étendu jusqu'au collines lyonnaises. Il a été, pour ainsi dire, le centre de tout le réseau glaciaire formé par les glaciers inférieurs de l'Arve, de l'Isère, du Drac et de la Romanche, et a environné tout le versant Ouest-Nord et Nord-Est des Alpes. Il s'est, en outre étendu, d'un côté, jusqu'au delà de Lyon, et, par une autre branche projetée au nord, il s'est approché des Vosges par le Jura. Sa masse de glace, après avoir rempli les vallées entre les Alpes et le Jura, au sortir de l'étroit débouché du Bugey et du Dauphiné, s'est étendue en éventail, et sa dernière moraine frontále s'est étalée en demi-cercle depuis Bourg, au plateau de la Bresse, aux collines lyonnaises et aux environs de Vienne.

Sur le versant italien, les anciens glaciers ont été très nombreux, mais aucun d'eux n'a atteint les proportions gigantesques du glacier du Rhône, puisque la glace n'a jamais dépassé les rives du Pô. Les glaciers de la Stura, de la Maira, de la Vraita, du Pó, du Pellice, en partant des Alpes-Maritimes, sont plus considérables si on les compare à ceux des régions du Nord et du Nord-Est. La Doire Ripaire a porté ses moraines jusqu'à Rivoli, près de Turin; la Doire Baltée s'est avancée jusqu'à Ivrée, oủ ses moraines terminales forment presque un cercle. Le glacier du Tessin, au cours -tortueux, s'est ètendu depuis le Gothard jusqu'au delà du lac Majeur; celui de l'Adda s'est prolongé jusqu'à Monza; le glacier' de l'Oglio a atteint le petit lac d'Iseo, et, enfin, tout à fait à l'extrémité orientale de la chaine des Alpes italiennes, on signale les glaciers de l'Adige, de la Brenta, de la Piave, dont le premier, le plus considérable, réunissait à lui seul tous les glaciers du Tyrol, et, depuis le Brenner, s'ètendait jusqu'au Sud du lac de Garde.

Quoi de plus imposant que cette masse mouvante de glace, descendant le long des pentes de ces monts gigantesques, gagnant peu 
à peu les vallées et les plaines, n'étant arrètée par aucun obstacle; moutonnant et rayant les roches inférieures, et laissant sur son passage, semblables à des digues immenses, cette suite de collines morainiques latérales et frontales, qui montrent jusqu'à quel niveau elle a pu s'élever? Et quelle force devait avoir ce courant

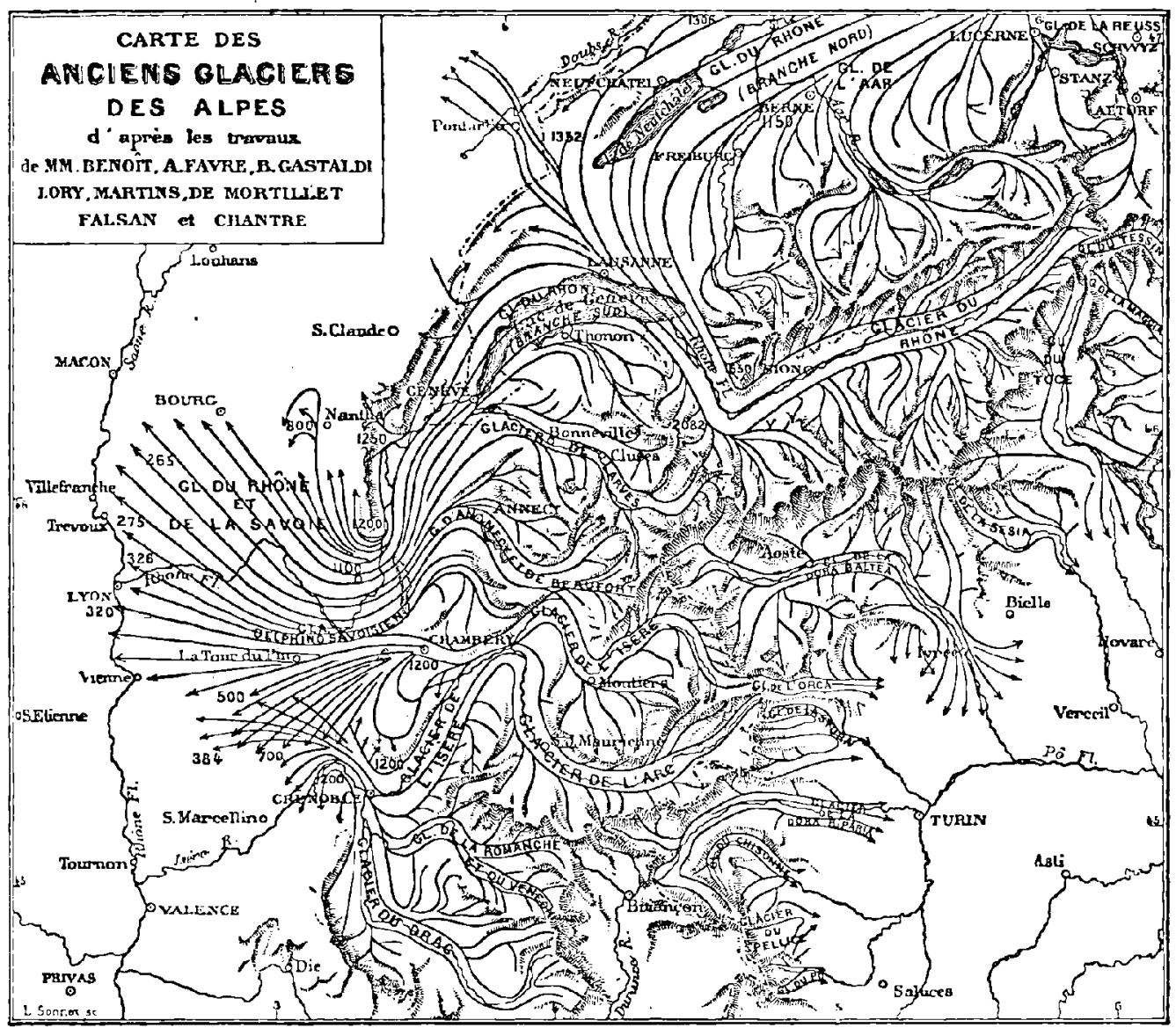

Fig. 389. - Extension des glaciers des Alpes jusqu'a Lyon et au Mảconnais,

glaciaire pour trainer à des distances prodigieuses des blocs énormes de pierres granitiques et autres, arrachés au mont où ils avaient pris naissance! Il n'est pas rare de rencontrer à de grandes distances de nos sommets alpins des roches cubant plusieurs centaines de mètres, gisant sur un sol de nature bien différente, telles, par exemple, la pierre de la «Mule du Diable », bloc erratique de 624 mètres cubes, provenant de la Maurienne, et gisant à Artas, entre Bourgoin et 
Lyon, la Ficrro de Rancé, à Villards-les-Dombes, bloc de granit de cent mètres cubes, provenant du col du Bonhomme, à la base sud du Mont-Blanc, et tant d'autres parsemés sur toute l'étendue glaciaire, dont l'origine et la nature sont parfaitement reconnues.

De même que le navire sillonne la mer, portẻ par les flots, les blocs erratiques atteignaient les plaines, les vallées et le sommet des collines, portés par les ondes de glace.

D'ąilleurs, quel autre agent assez puissant aurait pu opérer un tel déplacement? Toutes les autres données que l'on a invoquées pour l'expliquer n'ont point résisté à l'observation- exacte, et encore moins celle qui attribuait le transport de ces matériaux glaciaires aux déluges ou à des débầcles dé lacs.

En effet, quelle masse d'eau assez colossale, an cours assez torrenticl, aurait pu faire glisser ces blocs le long des hautes montagnes, les pousser à travers des espaces immenses, et les hisser souvent sur les plateaux et au sommet des collines, où on les voit encore fréquemment, perchés les uns sur les autres, en équilibre, formant de véritables pyramides? Quelque violente qu'elle eût pu être, toute la fureur d'une mer n'aurait pu obtenir un pareil résultat. Mais pendant que des savants de toutes les écoles rompaient des lances pour faire triompher leur's théories plus ou moins étranges, de simples bergers donnaient la clé du grand problème.

L'humble chasseur de chamois, le montagnard Perraudin, de la vallée de Bagnes dans le Valais, révélait le premier à M. de Charpentier que les glaciers avaient dù être anciemement beaucoup plus grands, et étaient descendus de la cime et des flanes des montagnes en transportant avec eux ces masses de roches granitiques qu'ils y avaicnt arrachées. Plus tard, de simples bûcherons expliquaient la même théorie comme on explique un fait très naturcl. Donc rien danormal dans la marche des glaciers. Cette révélation fut la base des recherches et des études de M. de Charpenticr, et scrvit de guide sûr à tous ceux qui entreprirent depuis de développer et d'approfondir cette importante question.

Le climat devenu plus sec, moins uniforme, l'évaporation moins abondante, lès glaciers furent de moins en moins alimentés; par suite, leur volume diminua peu à peu, et atteignit les proportions qu'on leur connaît actuellement. 
Ce travail de retrait, lent et intermittent, a donné lieu à la formation d'autres moraines secondaires, parallèles aux terminales, qui marquent les différentes stations de ces mers de glace dans leur marche en arrière.

Si quelques points de. détail restent incertains, l'ensemble des faits est suffisamment démontré pour qu'il soit impossible de nier qu'à l'aurore de l'époque quaternaire, il s'est produit, surtout au centre de l'Europe, une grande extension glaciaire. En présence de la thérie rationnelle et positive, basée sur celte démonstration de faits purement physiques, les traditions bibliques, la légende du Déluge universel érigée en théorie diluvienne, no se soutenant que par l'intervention du surnaturel, de l'incompréhensible, sont enfin tombées. Fant-il encore croịe à l'extermination de la race humaine pendant cette époque (à l'exception cependant des hôtes privilégiés de l'arche miraculeuse) et à la submersion totale par conséquent de tout ce qui germait et vivait dans le sein et à la surface de la Terre? Sin réponse à cette antique légende, la paléontologie nous montre l'homme vivant partout aux bords de ces masses de glace, chassant le renne, l'antilope saïga, Ie cheval et même le mammouth. Partout, à la limite des régions glaciaires, on retrouve des traces de son séjour et les débris nombreux de son petit mobilicr primilif répondant aux besoins principanx de la vie. Je son côté, la paléontologie végétale et animale a prouvé, par ses dernières découvertes, qu'à cette époque, faune et flore vivaient en face de ces glaciers, et tímoignaient mème d'un climat relativement tempéré.

La grande extension des glaciers quaternaires a été commune $\dot{a}$ toutes les régions du globe ot, de nos jours encore, d'importants et de nombreux glaciers se forment et se meuvent dans des conditions identiques, sinon dans des proportions aussi vastes, sur toutes les grandes chaines de montagnes, non seulement de l'Europe, mais du monde entier, principalement au Caucase, à l'ilimalaya, aux Andes de Patagonie, oủ le fleuve de glace s'étend jusqu’à la mer, et à la Nouvelle-Zélande, où les blocs de glace qui se détachent du glacier tombent au milieu d'une végétation luxuriante de fongeres arborescentes. Notons. encore que lia lalitude de toutes ces contrées ne dépasse guère $40^{\circ}$. Un firoid excesșif n'est donc pas nécessaire pour produire el alimenter un 
glacier, et sa présence n'influe pas sur les contrées environnantes au point d'y paralyser toute la vie organique.

Les glaciers dominant toujours le sommet de nos monts, il suffirait d'une légère modification dans la température pour leur faire reconquérir leurs anciennes proportions.

Toutefois, il n'est pas probable que nous soyons jamais les témoins d'un tel fait, étant donnée la lenteur d'un courant de glace relativement à la rapidité si grande du courant de la vie humaine. C'est peut-être là une des causes les plus puissantes qui nous empêchent, trop souvent, de concevoir les phénomènes les plus grandioses do la nature (4).

Les géologues admettent généralement qu'après une première époque de froid, à laquelle correspondent le polissage des roches du nord des continents, le drift, la première extension des glaciers et peut-être les alluvions de la Bresse et de la Crau, il y eut une élévation de température, marquée par un premier retrait des glaciers, par la dissémination des blocs erratiques du Jura et par le diluvium de la vallée du Rhône. Ensuite un retour du froid amena la réapparition des glaciers. C'est à cette deuxième période glaciaire qu'on rapporte le limon de la vallée du Rhin et du nord de la France. La température se relève ensuite peu à peu, et dès qu'elle ne diffère plus de celle qui règne aujourd'hui, l'époque quaternaire cède la place à l'état actuel.

Il semble donc que nous puissions nous représenter ces âges anciens comme une époque de grandes perturbations climatériques. Des pluies, d'une violence et d'une continuité extraordinaires, inondaient les terres fermes de véritables déluges. Elles recouvraient tout le sol émergé de nappes d'eau qui s'écoulaient vers les niveaux inférieurs en suivant les pentes, creusant peu à peu les vallées d'érosion, et charriant en mème temps les matériaux diluviens abandonnés sur le pourtour des massifs montagneux. Ces eaux retombaient en neiges dans le voisinage des pôles, aussi bien que sur les cimes élevées. Grâce à la vapeur d'eau, aux nuages et aux pluies de neige, au moins autant qu'à l'abaissement de la température, ces glaciers envahirent bientôt les montagnes et formèrent

1. Ernest Cinantre. Revue monsuelle d'Astronomie populaire, septembre 18385. 
autour des pôles des vastes bordures se développant graduellement. Pendant les débâcles, des radeaux de glace flottante transportèrent au loin des blocs erratiques, qu'il n'est pas toujours facile de distinguer de ceux qui ont abandonné les glaciers. Les torrents courent à plein bord, leur lit se creuse de plus en plus. Réfugiés sur les plateaux élevés et dans les cavernes, les animaux continuent néanmoins à se propager. Beaucoup sont victimes de la fureur des éléments; cependant leurs espèces se succèdent et se remplacent comme aux époques antérieures. Insensibles à toutes les catastrophes, les animaux marins continuent au fond des eaux leur tranquille existence. Après un grand nombre d'alternances de froid et de chaud, de pluies et de débâcles, dont on arrivera sans doute à determiner le nombre el la durée relative, les climats finissent par demeurer stationnaires et les temps actuels commencent. Mais les phénomènes dont il a été question ne sont pas les seuls qui aient marqué l'èpoque quaternaire. Le désordre de la nature se trouvait compliqué par de violents mouvements du sol. C'est, en effet, à cette époque, que des montagnes énormes, telles que les Cordillères, prennent leur relief, et il est évident qu'un pareil exhaussement, mème en le supposant aussi lent que possible, n'a pu s'effectuer sans amener de grandes perturbations sur d'immenses surfaces.

En mème temps, beaucoup de plages s'affaissent ou se soulèvent, la Baltique et la Méditerranćo prennent leur forme moderne, le canal de la Manche s'ouvre et les îles Britanniques se séparent du continent ( $\left.{ }^{\mathbf{1}}\right)$.

Si l'existence d'une ou même deux périodes glaciaires est incontestablement démontrée par le fait des blocs erratiques transportés par les glaciers, par les stries et rayures visibles le long des routes suivies par ces transports et par la conservation des animaux mêmes, ensevelis dans ces glaces (rhinocéros, mammouths, etc.), la cause de cette production de glace et de cette immense extension du froid n'est pas encore déterminée avec certitude.

Plusieurs causes sont possibles. Et d'abord le Soleil qui nous donne la lumière et la chaleur peut, comme heaucoup d'autres soleils de l'immensité, subir des fluctuations d'éclat et voir parfois

1. Ch. Contejean. Géologie et Paléontologic. 
diminuée l'intensité de son rayonnement. L'astronomie nous a fait connaître l'existence d'un grand nombre de soleils variables, parmi les millions d'étoiles qui parsèment les champs de l'infini, et plusieurs d'entre ces astres deviennent mème en certaines périodes complètement invisibles par l'extinction temporaire de leur lumière. Notre solcil, n'étant qu'une étoile, peut, lui aussi, être une étoile variable, se couvrir de taches immenses, perdre une partic de sa lumière et de sa chuleur rayonnantcs, et, pendant des années, des siècles même, laisser la Terre et les autres planètes de son système rouler dans l'espace en ne recevant plus qu'uno chaleur insuffisante et stérile. Le résultal de cet abaissement de température serait celui qui se produit en hiver : le froid, la neige, la glace. Un tel hiver pourrait être rigoureux, général, et durer plusieurs siccles. Puis, l'astre du jour ayant repris son éclat, le printemps sera revenu, avec la fonte des neiges, les pluies, les cours d'eau, la végétation nonvelle et le cours naturel des choses.

On peut objecter à cette explication que rien ne prouve que notre soleil, malgré ses taches périodiques bien comnes, soit variable à ce degré, et que la période glaciaire n'a pas éteint la vie terrestre. Cependant elle reste plausible, car il suffirait d'une différence do quelques degrés dans la chaleur recue pour expliquer l'extension des glaciers constatée par la position des blocs erratiques.

Une seconde explication a été demandée à la variation de l'excentricité de l'orbite terrestre. Nos lecteurs savent (Les Étoiles, p. 773) que I'ellipse décrite annuellement par la Terre dans son cours autour du Soleil se gonfle et se dégonfle tour à tour, qu'elle est parfois à peine différente d'un cercle — comme dans 23980 ans, par exemple - et parfois très allongée - comme il y a 850000 ans. - La variation s'étend depuis 0,0033 , comme chiffre minimum de l'excentricité, jusqu'à 0,0717 comme chiffre maximum, c'est-àdire que daris ce second cas olle est 22 fois plus forte que dans le premier. Actuellement, cette excentricité est de 0,0168 : telle est la distance du centre de l'ellipse au foyer, en fonction du demi grand axe, soit, en kilomètres, $148000000 \times 00168$, ou 2486400 . La différence entre le périhélie et l'aphélie est done actuellement de 4972800 kilomètres : la Terre est de toute cette quantité plus près du Soleil le $1^{\text {er }}$ janvier que le $1^{\text {er }}$ juillet, et l'hémisphère aus- 
tral, alors tourné du côté du Soleil, a un été plus chaud que le nôtre, çui n'est tournè vers le foyer qu'à l'aphélie.

Mais il y a une compensation produite par la différence des durécs: la période estivale dure huit jours de moins dans l'hérnisphère austral que dans l'hémisphère boréal, notre planète ne mettant que 179 jours pour aller de l'équinoxe de septembre à celui de mars et en employant 186 pour aller de l'équinoxe de mars à celui de septembre. Cette différence de 187 heures en faveur de notre hémisphére compense la distance, d'autant plus que, par suite du plus long espace de temps pendant lequel le pôle aretique reste incliné vers le Soleil, le nombre des houres du jour dépasse dans les régions horéales le nombre des heures de nuit qui prédominent. La compensation est-elle complète ? Dans l'état actucl de nos connaissances, il serait léméraire do l'aftirmer comme de le nier.

$\Lambda$ son maximum d'ẹcentricité, la distance du contre de l'orbite. terrestre au foyer s'élève à $148000000 \times 0,0747$, soit à 11055600 kilomètres. La différence entre le périhrélie et l'aphélie s'élève done alors a plus de 22 millions de kilomètres. Les quaritités de chaleur recues au périhélic et à l'aphélie sont alors entre èlles dans lo rapport de 26 à 19. La diffírence do durée entre la section de l'orbite du côté du périhélic et colle du côté de l'aphólie subit une augmentation corrélative, la Terre voguant d'autant plus vit: qu'elle est plus proche du soleil et d'autant moins vite qu'elle est plus éloignée; à l'éporgue de la plus grande excentricité, la søetion périhélique est parcourue on 16't jours et l'aphéliquo en 201.

L’hémisphère terrestre tourní vers lo Solcil à l'époque du périhélie a ses étés plus chauds et plus courts, ses hivers plus longs et plus froids. L'hémisphère tourné vers le Soleil à l'époque de l'aphélie a ses ètés moins chands et plus longs, ses hivers plus courts et moins froids. Si, lors d'une grande excentricité, les hivers son! très longs et très froids, la rapidité des étés, quelque chauds qu'ils puissent être, peut n'être pas suffisante pour fondre les neiges et les glaces du sol gelé (comme il arrive en Sibérie), mais seulement etre cause d'une évaporation active qui ne fera qu'accroitre la quantité de vapeur d'eau, les pluies, les brouillards et les neiges. D'ailleurs, sans vapeur d'eau, pas de neiges possibles. L'hiver de 
notre hémisphère arrivant à l'aphélie pendant une période de grande excentricité serait bien préparé pour une période g]aciaire. Or l'excentricité a été très forte de l'an 210000 à l'an 100000 avant notre ère. Les saisons faisant le tour de l'année en 21000 ans, il se pourrait qu'il y eût eu pendant cette période cinq phases glaciaires pour chaque hémisphère, l'intensité de chacune d'elles dépendant d'ailleurs de la direction des courants, des exhaussements continentaux et de plusieurs autres causes.

Cette seconde explication de la période glaciaire est plus probable que la première; mais elle parait avoir plutôt aidé le phénomène que l'avoir produit à elle seule, en coïncidant, il y a un millier de siècles, avec une transformation géographique et climatologique que M. de Lapparent définit comme il suit.

Quelles qu'aient été les phases diverses de l'époque quaternaire, il est évident que la première et la majeure partie de sa durée a été marquée dans les régions accidentées de notre hémisphère, par la grande extension des glaciers, et en dehors des montagnes, par l'extrême activité des agents d'érosion et d'alluvionnement. Or ces deux phénomènes ne sont que deux manifestations différentes d'une même cause, qui est l'exagération momentance des précipitations atmosphériques. Pour substituer aux cours d'eau de nos contrées des fleuves coulant à pleins bords dans des lits larges de plusieurs kilomètres ; pour permettre sur toutes les pentes un ruissellement capable de donner naissance au loess; pour alimenter les sources qui produisaient les tufs de Moret et de Cannstadt; pour garnir les cavernes d'un épais revêtement de stalagmites, il fallait que la pluie fùt infiniment plus abondante que de nos jours, et cela dans toute la zone qui s'ćtend depuis le Sahara jusqu'au centre de l'Angleterre, comme depuis la Louisiane jusqu'aux grands lacs américains.

Ge troisièmo mode d'explication est confirmé par l'exameu de la faune quaternaire : les innombrables ossements de pachydermes dont le diluvium du Nord est rempli, disent assez quelle abondante végétation, conséquence d'un climat doux et humide, devait s'offrir aux herbivores.

On sait d'ailleurs qu'aux époques antérieures, de très grands lacs d'eau douce occupaient les vallées des principaux fleuves en 
Europe, ainsi que le versant occidental des Montagnes-Rocheuses en Amérique. L'entretien de ces napes d'eau suppose un régime particulièrement humide, dont celui de l'époque quaternaire peut n'avoir été que la continuation.

Mais ce qui tombe en pluie sur les régions de faible altitude prend, dans les montagnes, la forme neigeuse. L'établissement

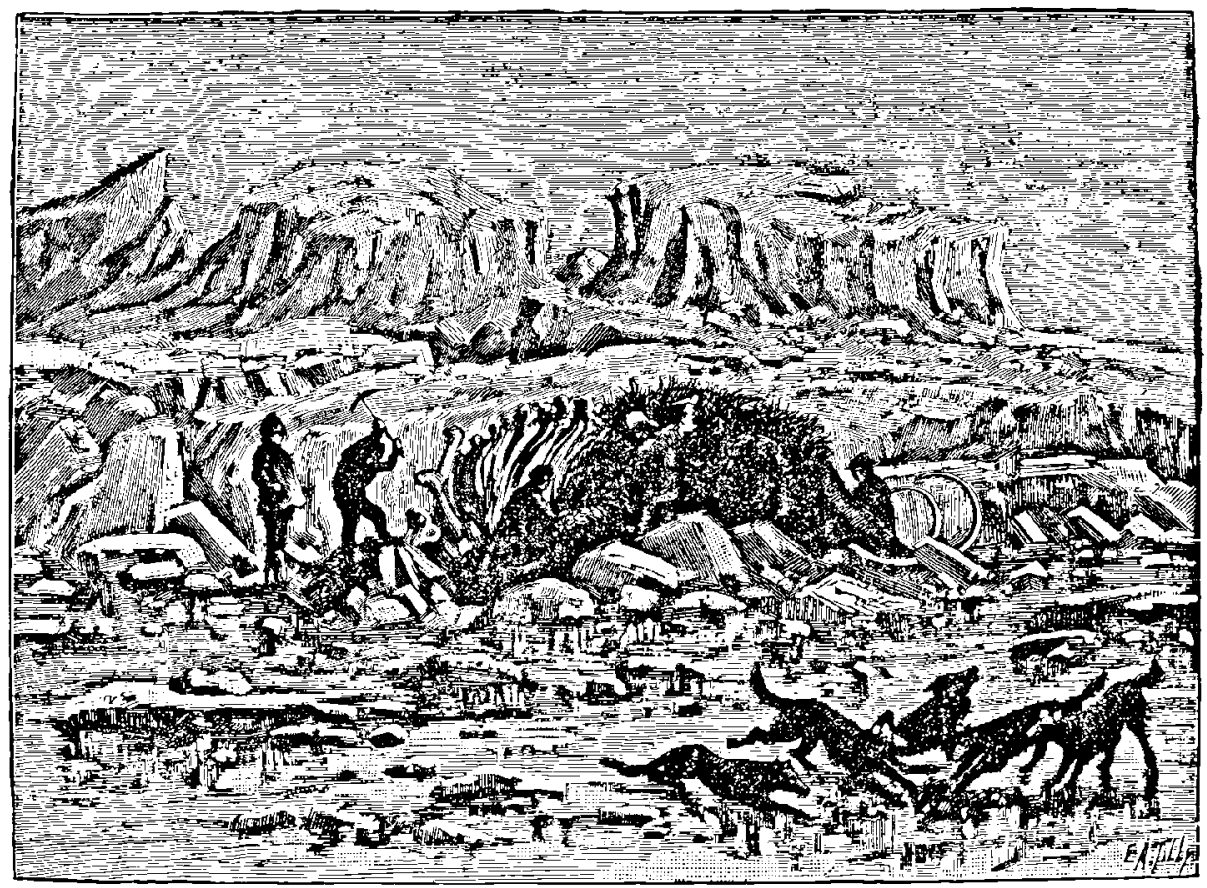

Fig. 389. - Mammouth retroupé au milieu des glaces de la Sibérie, avec sa chair et sa peau.

d'un régime humide a donc eu pour conséquence nécessaire la formation de champs de révé, et par suite, celle de grands glaciers. Cette formation, impossible auparavant (si ce n'est peut-être, depuis l'éocène supérieur dans la région pyrénéenne), faute de condenseurs suffisamment importants, a pu se faire dès la fin du pliocène, c'est-à-dire au moment où les Alpes et tant d'autres chaines venaient d'acquérir leur principal relief. Ce n'est donc pas le froid qui a fait naitre le régime glaciaire; à lui seul, le froid est impuissant à nourrir des glaciers, comme en témoignent suffisamment par 5000 et 6000 mètres d'altitude, les plateaux dénudés du 
Tibet. C'est la combinaison d'une grande humidité atmosphérique avec l'existence, jusqu'alors à peu près inconnue, de condenseurs montagneux, aussi importants par leur masse que par leur relief absolu; condenseurs d'autant plus actifs qu'au début, la masse der Alpes; par exemple, était plus grande de tout ce que les érosions lui ont arraché depuis, en mème temps que l'altitude des sommets pou. vait étre, par suite d'un relèvement momentané de la région, supérieure de plusieurs centaines de mètres à ce qu'elle est aujourd'hui.

On voit donc que le ruissellement et les grands cours d'eau dans les plaines, d'une part, les grands glaciers dans les montagnes, d'autre part, ont été deux phénomènes nécessairement concomitants, et c'est pourquoi plus d'un auteur a voulu, non sans raison, substituer au mot, souvent employé, de période glaciaire, celui, plus général et tout aussi significatif, de période pluviaire.

Sans doute, les progrès du refroidissement polaire, qui avaient commencé à se faire sentir nettement dès le milieu de l'ère tertia're, u'ont pas été tout à fait étrangers à ce résul'at; mais il n'eus. sent pi.s suffi, à beaucoup près, et l'étude des dépóts quaternaires des régions tempérées, de celles qui échappaient à l'influence du voisinage immédiat des glaciers, atteste que de l'elephas meridionalis à l'elcphas antiquus et de celui-ci à l'elephas primigenius la transition s'est faite graduellement, sans qu'il y ait eu, dans cet intervalle, une subite invasion du froid.

Partant de ces prémisses, reportons-nous au moment où les grandes montagnes venaient d'acquérir leur relief, c'est-à-dire au début de la période pliocène.

Déjà, depuis longtemps, l'émersion de l'Europe se préparait; il n'y avait plus guère, en France et en Angleterre, que des lacs d'eau douce et, dès l'époque langhienne, la plus grande partie du nord de la France, définitivement émergée, subissait, sous forme de soubresauts successifs, le contre-coup des mouvements orogéniques voisins. Un régime hydrographique devait donc nécessairement s'y établir, et les premiers rudiments de nos cours d'eau commençaient à y creuser leurs lits. La période pliocène n'a pu qu'accentuer le mouvement, en y faisant participer les régions montagneuses de nouvelle formation. Aussi ces dernières, où les détails du relief avaient certainement commencé à se dessiner dès le début de leur soulève- 
ment, ont-elles été, à l'époque pliocène, le théâtre d'une activité dont tèmoignent, entre autres dépôts, les conglomérats du bassin du Rhône et less alluvions anciennes de la Suisse. Il est donc permis de penser que, quand le pliocène prit fin, les principales vallées étaient déjà découpées jusqu'au cœur des massifs et avaient leur fond tapissé d'alluvions et de graviers, tandis que, sur les plateanx, s'étalaient déjà les plus anciens limons. Les bassins de réception des neiges, aussi bien que les cananx d'écoulement des glaciers, étaient constitués all commencement de l'époque quaternaire et, pour les remplir de grandes masses de glaces il a suffi qu'il arrivât dans nos régions occidentales des courants d'air plus abondamment chargés d'humidité qu'aux époques précédentes.

L'étude de la distribution des anciennes formations glaciaires fournit un puissant argument en faveur de l'hypothèse qui en attribue l'origine à une exagération, dans le sens de l'humidité, des conditions climatériques actuelles. En Angleterre comme en Scandinavie et en Amérique, les districts où l'on remarque aujourd'hui les plus fortes chutes de pluie ont été à l'époque quaternaire les centres de dispersion des plus grands systèmes de glaciers. Au contraire, la région de l'Amérique située dans le Wisconsin et connue sous le nom de Driftless Area, à cause de l'absence du dépôt erratique, est justement celle oủ, de nos jours, les précipitations atmosphériques sont le moins abondantes.

En un mot, l'humidité et l'altitude ont été les dcux grands facteurs du phénomène glaciaire, et ce qui prouve bien que l'innuence de la température gènérale n'a été que secundaire, c'est ce fait que, sur une partie considérable de la Cordillère américaine, les districts d'où les glaciers ont actuellement disparu ont une température moyenne plus basse que celle des régions où la glace s'est conservée. La sécheresse de l'air a donc été plus efficace comme agent d'ablation, que le froid comme agent d'alimentation.

D'après M. de Lapparent, la cause principale de l'extension des glaciers, à l'époque quaternaire, semble devoir être cherchée dans des changements de climat déterminés par des circonstances géographiques du même ordre que celles qui, en donnant naissance au courant chaud de l'Atlantique, ont si fortement dévié vers le Nord les isothermes de l'Europe occidentale. 
$\Lambda$ la fin de la période pliocène, et pendant l'époque quaternaire, le Suhara, l'Arabie, la Perse, ces pays aujourd'hui désolés par la sécheresse, étaient soumis à un régime de pluies intenses, faisant naitre des alluvions d'une puissance extraordinaire. Ce régime s'étendait encoro plus loin vers l'Est, sur les déserts actuels de la Mongolie et, dans les bassins pourvus d'un large débouché, comme celui du fleuve Jaune, il donnait lieu à d'énormes accumulations de

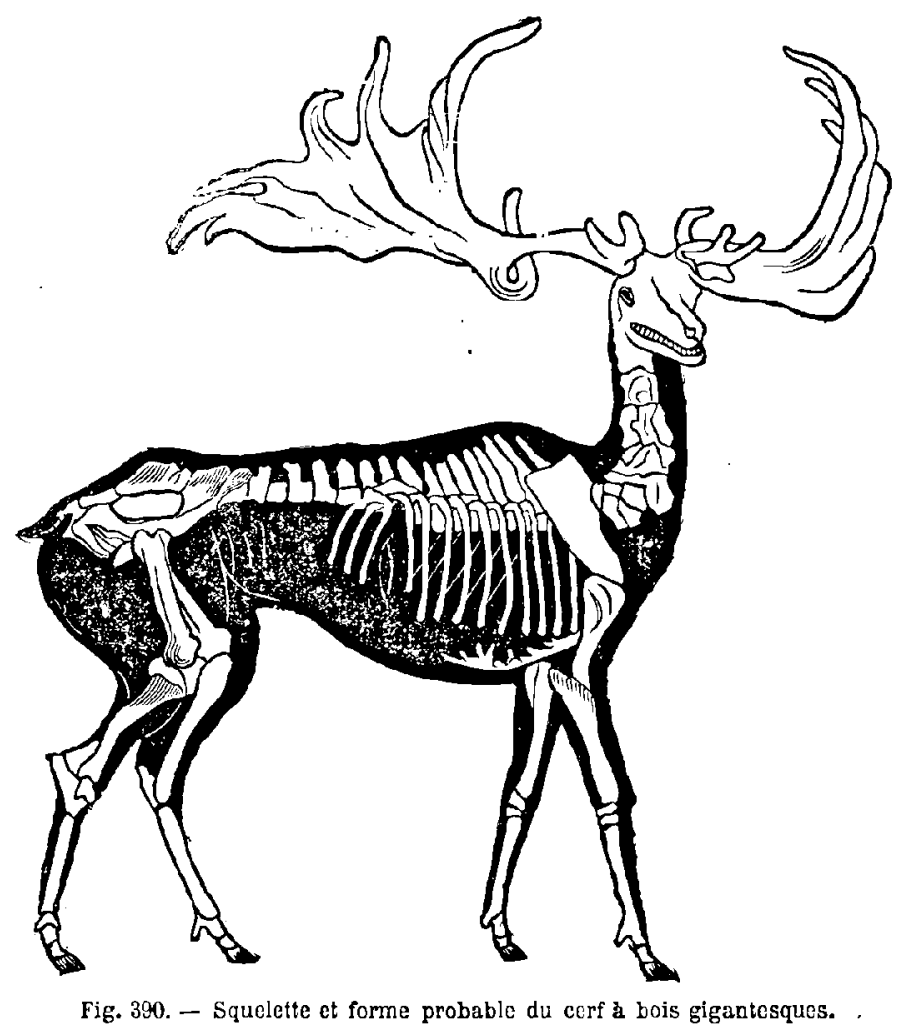

loess. Il est certain que la zone pluvieuse s'est déplacée vers le Nord, et sans doute ce déplacement se fait encore sentir, car le littoral méditerranéen de l'Afrique et de l' $\Lambda$ sie Mineure est singulièrement déchu des conditions climatologiques favorables qui en faisaient sous la domination romaine, une terre si fertile. En revanche, le climat de la Gaule et de la Germanie est loin de justifier la réputation de sévérité que lui ont fait les anciens historiens or les vents, qui produisent la sécheresse ou l'humidité, dépendent avant tout de la distribution des mers et des terres et leurs changements 
de régime doivent coïncider avec des variations d'ordre géographique. La disparition de l'Atlandide a dì apporter une modification considérable dans les courants. Cette époque a été aussi celle des volcans de France, d'Espagne et des bords du Rhin.

Dans ces variations géographiques, lc relief du sol n'a pu rester absolument fixe; du reste, nous avons vu plus haut qu'il n'est pas

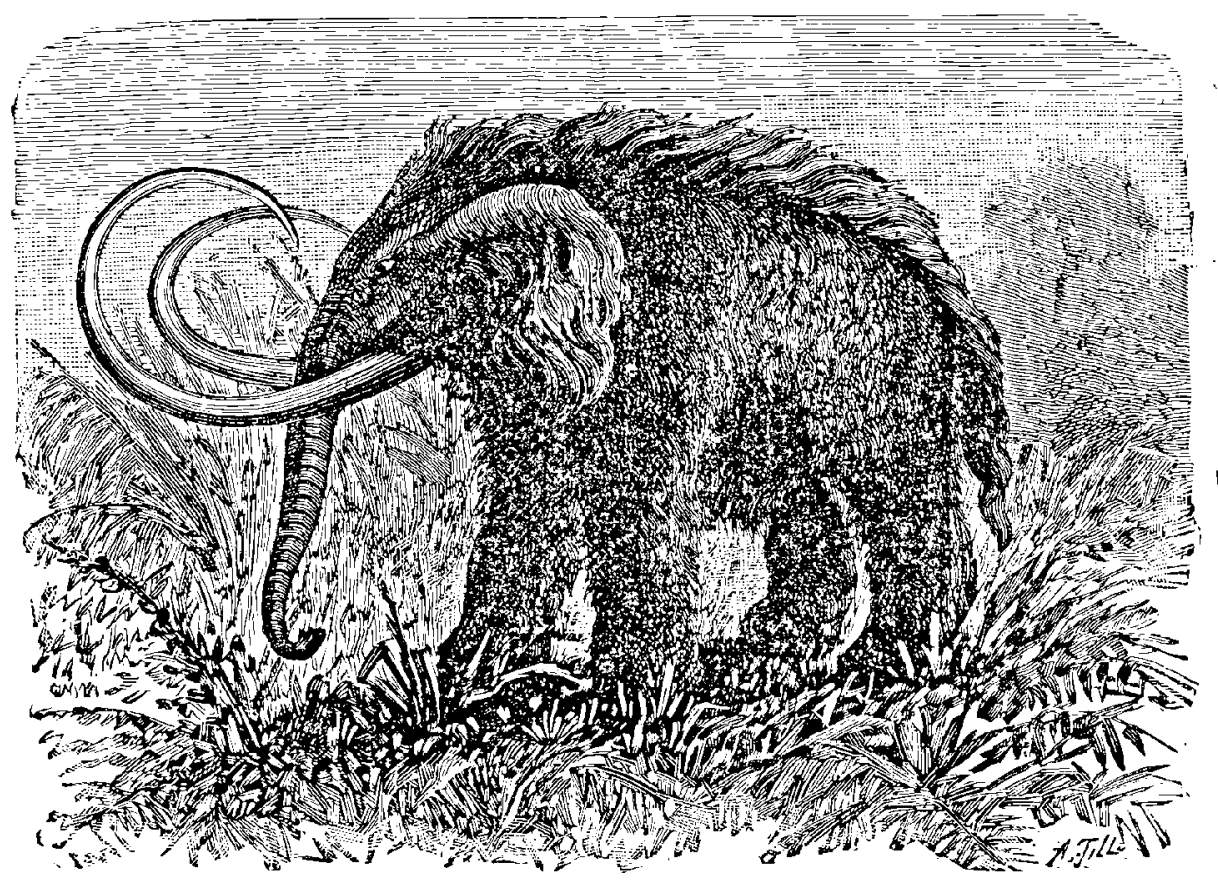

Fig. 391, - Le mammouth, elephas primigenius.

encore stable aujourd'hui. Quelques centaines de mètres de plus dans le relief général du nord de l'Europe suffiraient pour avoir diminué la température au degré caractérisé par l'extension des glaciers.

Ainsi peut s'expliquer cette fameuse époque glaciaire, dont le dénouement fut l'époque diluvienne qui laissa à la surface des vallées ces dépôts désignés aujourd'hui sous le nom de diluvium. Tous les dépôts postérieurs aux terrains tertiaires, et qui forment les parties les plus superficielles de l'écorce terrestre, se distinguent des formations précédentes en ce qu'ils n'offrent plus, en général, les caractères de sédiments effectués tranquillement au sein de grandes masses d'eau, mais plutôt ceux de dépôts irréguliers, 
résultant d'un transport rapide, plus on moins violent, par des eaux courantes.

Ces dépôts, généralement meubres, limoneux ou caillouteux, se composent, à la base, de couches ou d'amas irréguliers de gros galets roulés, entremélés de sables et de graviers, qui reposent toujours sur un sol profondément raviné.

Dans le haut, les graviers diminuent de volume, et passent à des sables grossiers qui deviennent de plus en plus fins. Ces sables sont alors zonés, entremèlés de petits lits de cailloux, ils deviennent terreux et se mélangent avec des limons jaunes, souvent fort épais, qui recouvrent le tout.

On reconnaît là tous les caractères des alluvions, c'est-à-dire des dépôts effectués dans les eaux courantes. On les rencontre dans les plaines, sur les plateaux, sur les pentes des collines; ils remplissent aussi les vallées, mais dans une situation telle, que leur masse, au lieu d'être augmentée par les eaux actuelles, tend à diminuer tous les jours, étant creusée et sillonnée continuellement par les rivières modernes qui y établissent leur lit et les remanient, en donnant lieu à de nouveaux dépôts, très distincts.

Cette disposition est la mème partout; ils s'échelonnent ainsi, à diverses hauteurs, depuis le fond des vallées jusqu'au sommet, en constituant des terrasses successives qui représentent les diverses phases du creusement des vallées. Mais leur composition présente certaines différences, qui tiennent à la diversité de la constitution géologique des contrées qui en ont fourni les matériaux. Ainsi, dans les alluvions anciennes de la vallée de la Seine, on remarque de nombreux blocs roulés de granite et de porphyre qui viennent du Morvan, où ils ont été arrachés par un cours d'eaul, qui suivait le tracé actuel de l'Yonne et se déversait comme elle dans la vallée de la Seine; tandis que, dans la vallée de la Marne, ces mèmes alluvions sont principalement composées de galets calcaires et de silex roulés, provenant des plaines crayeuses de la Champagne et du plateau jurassique de Chaumont et de Langres.

Ces graviers et ces sables renferment, en grand nombre, des ossements pour la plupart brisés, ayant appartenu à des espèces aujourd"hui perdues, ou bien à des espèces analogues à celles qui vivent actuellement, mais dans des lieux bien éloignés de ceux où 
se trouvent leurs ossements. Ainsi, on rencontre là, dans toute l'Europe, des débris d'éléphants gigantesques (elephas primigenius), de grands rhinocéros, qui portaient deux cornes sur le nez (rhinocéros tichorhinus), avec des ossements nombreux de chlevaux et de grands ruminants (corfs à grandes cornes, daims, élans, oœufs, etc.). Des dents et des portions de squelettes de tigres (felis spelæa), d'hyènes (hyæna spelæe) et d'un grand ours (ursus spelæus), qui atteignait la taille d'un bœuf, indiquent également que les carnassiers étaient nombreux dans la faune quaternaire. Des hippopotames (hippopotamus major) vivaient aussi, en Europe, dans les grands fleuves de cette époque. Toutes ces espèces sont aujourd'hui éteintes; parmi les espèces émigrées figurent le renne (cervus tarandus) et le glouton (gulo luscus), aujourd'hui retirés dans la zone glaciale (').

Le marnmouth était répandu dans tout l'hémisphère boréal, et non pas seulement en Asie, où l'on en a trouvé les premiers débris. Depuis Otto de Guérike, l'inventeur de la machine pneumatique, qui fut témoin, en 1663, de la découverte d'ossements fossiles, défenses prises alors pour des cornes; depuis Leibnitz qui s'avisa de composer de ces débris un animal étrange, fantastique, portant une défense (en guise de corne) au milieu du front, et une donzaine de molaires longues d'un pied, depuis les nombreuses trouvailles faites en Allemagne, en Russie et en Sibérie pendant tout le siècle dernier, les mammouths ont cessé d'ètre des animaux fabuleux, grâce surtout aux discussions auxquelles de nouvelles et fréquentes découvertes ont donné lieu dans notre siècle.

On sait que sur les rives de la Léna et dans les glaces de la Sibérie, il n'est pas rare de retrouver, non seulement l'ivoire fossile (employé dans le commerce depuis un temps immémorial), mais encore des cadavres entiers conservés avec la chair, la peau et la fourrure.

Le musée de Saint-Pétersbourg possède l'un des plus beaux spécimens retrouvés, un squelette entier mis au jour en 1804, au milieu des glaçons de la Léna. Il ne mesure pas moins de six mètres de hauteur, et ses défenses recourbées atteignent quatre mètres de longueur. Le mammouth était beaucoup plus grand que l'éléphant.

(1) С. VÉLalN. Géologie straligraphique. 
Ces rencontres ne sont pas très rares, et tout récemment encore les glaces en ont rejeté un nouveau presque aussi gigantesque que celu;, du musée de Saint-Pétersbourg.

Parmi les rhinocéros, remarquons le rhinocéros tichorinus,' ainsi nommé parce qu'une cloison osseuse séparait ses deux narines. C'est le rhinocéros aux narines cloisonnées, qui joua un grand rôle en ces siècles antiques et dont on retrouve les ossements fossiles un peu partout. Ses cornes ont donné lieu à bien des légendes, notamment au fameux «Oiseau Rock » du moyen âge que l'on prètendait trouver dans le sein de la terre, et aux têtes de dragons de l'ancien temps. La reconnaissance anatomique de ce fossile date de 1772, année pendant laquelle le naturaliste Pallas put étudier un squelette entier fraichement retiré des glaces, sur les bords d'un affluent de la Léna - et non seulement un squelette, mais un cadavre presque entier, chair; peau, poils et téguments. - Le corps du rhinceśros tichorinus était couvert de poils, et sa peau n'offrait pas les callosités rugueuses de celle qui recouvre aujourd'hui notre rhinocéros d'Afrique.

Un des plus magnifiques animaux antédiluviens a dù ètre aussi le cerf-géant, dont les débris se présentent très fréquemment en Irlande, dans les environs de Dublin, entremèlés de coquillages, à la hautcur de soixante-dix mètres au-dessus du niveau de la mer, aussi bien que dans les dépôts et les tufs calcaires qui s'étendent sous les immenses tourbières, et dans la tourbe mème, au niveau de la mer. Près Curragh on tronve des squelettes de cerf-géant par monceaux accumulés dans un espace restreint, comme s'il y on avait eu des troupeaux entiers d'ensevelis. Il est à remarquer que tous les individus s'y présentent dans la même attitude : la tête hautè, le cou tendu, les bois rabattus sur le dos, comme si, enfoncés dans le terrain marécageux, ils s'étaient efforcés de humer l'air. le plus longtemps possible.

Le genre éléphant parait avoir suivi la progression marquée successivement par les espèces suivantes :

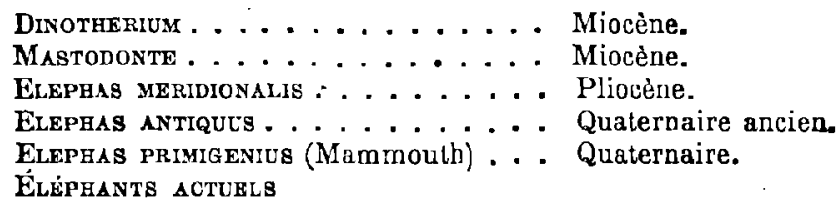




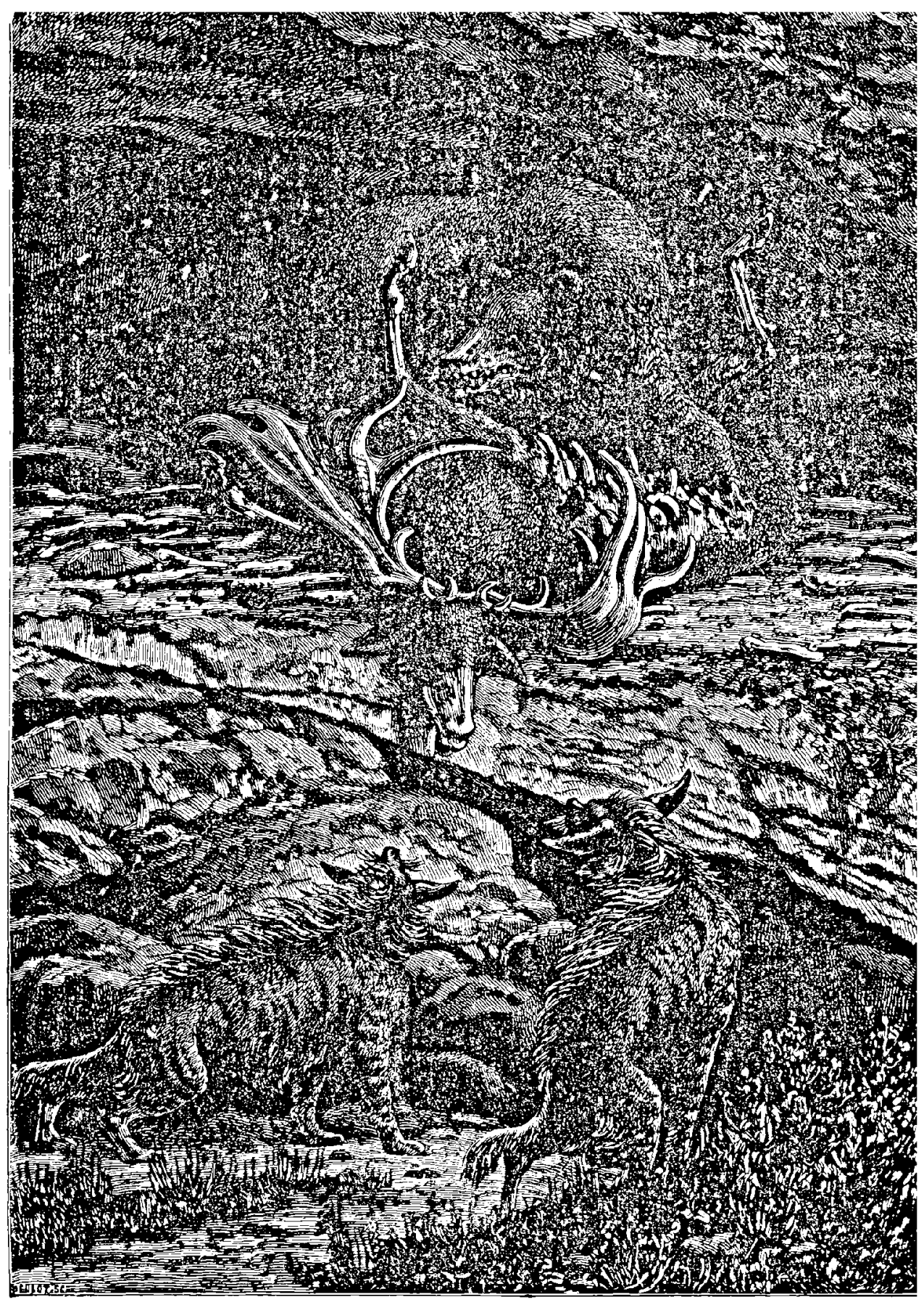

LES CONTEMPORAINS DE L'HOMME PRIMITIF : LUULS DES GAVERAES

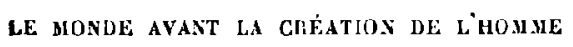


Au commencement de l'âge quaternaire, l'elephas meridionalis a disparu pour faire place à son successeur immédiat l'elephas antiquus. Celui-ci régnait en souverain sur la faune de nos contrées, et ses troupeaux se promenaient paisiblement au milieu des

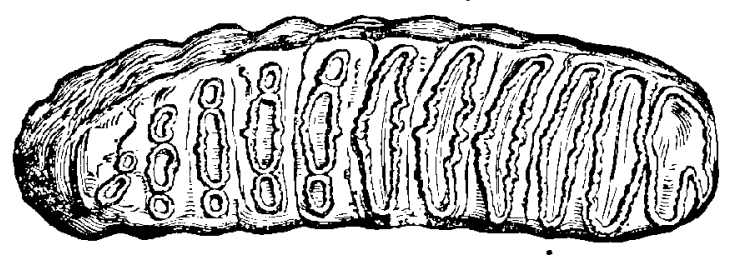

Fig. 393. - Dent molaire de l'elephas antiquus, 1/3 de grandeur naturelle.

forêts immenses qui s'étendaient sur les régions oủ Faris resplendit de nos jours ('). L'inspection des dents, entre autres ( $\mathrm{kg}$. 393 et 394) a conduit les naturalistes à conclure que la seconde espèce est une

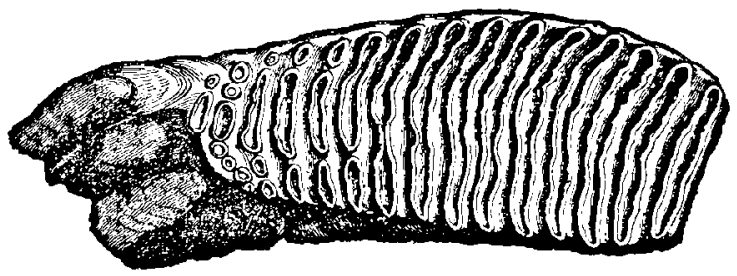

Fig. 394. - Dent molaire du mammouth (alvéoles serrées, transformation de la dent de l'elephas antiquus), $1 / 3$ de grandeur naturelle.

transformation de la première, due surtout au changement de nourriture.

L'clephas antiquus caractórise le premier âge de l'ère quaternaire, l'elephas primigenius le second àge, plus froid, le rhino-

1. Au moment où nous mettons la dernière main à cet ouvrage ( 2 édition: février 1886 ), un lecteur des premières liviaisons, M. Tony Giroudon, nous apporte une défense presque entière d'elephas antiquus trouvée en novembre 1885, aux portes de Paris, à Livry (Seine. et-Oise), dans une carrière à plâtre, à 45 mètres de profondeur. Cette défense, droite et très légèrement recourbẻe, mesurait environ $1^{\text {m5}} 50$ de longueur. Quoique passée elle-même à l'état de plâtre et d'une trop facile désagrégation, on y reconnaît à première vue le couches concentriques de l'ivoire, et le fossile est resté intact. L'animal était couché là, dans le gypse, depuis cent mille ans peut-être.

L'elephas antiquus et l'elephas primigenius ètaient très répandus dans nos contrées. Nous remarquions encore dernièrement, chez un de nos camarades d'enfance M. J. Legrand, à Montigny et à Bourmont (Haute-Marne), une magnifique collection de curieux spécimens trouvés en divers points de l'est et du centre de la France 
céros tichorhinus le troisième âge, et le renne le quatrième. Cette appréciation se rapporte à l'Europe. La faune est sensiblement différente en Amérique.

Une grande quantité des animaux terrestres actuels existaient dès le commencement de la période pendant la durée de laquelle beaucoup de types nouveaux se tormèrent. Il $\mathrm{y}$ a donc un passage tout à fait insensible de la faune quaternaire à la faune contemporaine; aussi les deux époques sont-elles plutôt séparées par la cessation des phénomènes physiques et climatériques de la période glaciaire et diluvienne, et par l'inauguration de la tranquillité actuelle que par une différence dans la faune et dans la flore. Cela est d'autant plus manifeste, que si les animaux contemporains remontent souvent à l'époque quaternaire, et mème à l'époque tertiaire, plusieurs espèces quaternaires n'ont pris fin que dans les temps modernes. Le mammouth a survécu aux dernières catastrophes, l'urus existait encore, il n'y a pas fort longtemps, dans les forêts de la Gaule et de la Germanie, et l'aurochs n'a pas encore tout à fait disparu de celles de la Lithuanie et du Caucase.

En Europe, les mammifères quaternaires étaient des ours, des lions, des hyènes, des rhinocéros, des éléphants, des cerfs, des bœufs, presque tous de taille gigantesque; puis des insectivores, des rongeurs, des carnassiers, des ruminants, des chevaux, des sangliers, etc., dont la plupart subsistent encore. L'ours des cavernes ètait grand comme un cheval, l'éléphant laineux ou mammouth dépassait de beaucoup ses congénères actuels, il portait des défenses énormes recourbées un peu en spirale; le cerf des tourbières, aux bois palmés, avait au moins la stature de nos bœufs, et certaines espèces de bœufs atteignaient des dimensions extraordinaires. Ce mélange d'animaux des contrées froides et tempérées avec d'autres que nous sommes habitués à regarder comme habitants des pays chauds, n'a plus rien d'étonnant, depuis que l'on sait que le mammouth et le rhinocéros à narines cloisonnées étaient revêtus d'une épaisse fourrure de laine et de crins, ainsi que le témoignent les spécimens trouvés dans les glaces de la Sibérie. Il est donc naturel de rencontrer à la fois, dans le midi de la France, les débris des ours et des hyènes des cavernes, des rhinocéros, du mammouth, de l'autruche, du cheval. du renne, du glouton, et 
même du bœuf musqué des régions arctiques. La durée de cette époque glaciaire a èté considérable; les animaux terrestres s'en sont ressentis et, pour vaincre les rigueurs du climat, ils se sont recouverts d'une épaisse fourrure.

En Arnérique, les dépôts diluviens sont très étendus et, de plus, particulièrement riches en ossements; mais cette faune présente avec celle que nous venons de voir en Europe, de grandes différences. Ainsi, dans les limons et les tufs calcaires qui recouvrent les immenses plaines de la Plata, dans l'Amérique du Sud, qu'on nomme les Pampas, on trouve un nombre considérable de mammifères, dont

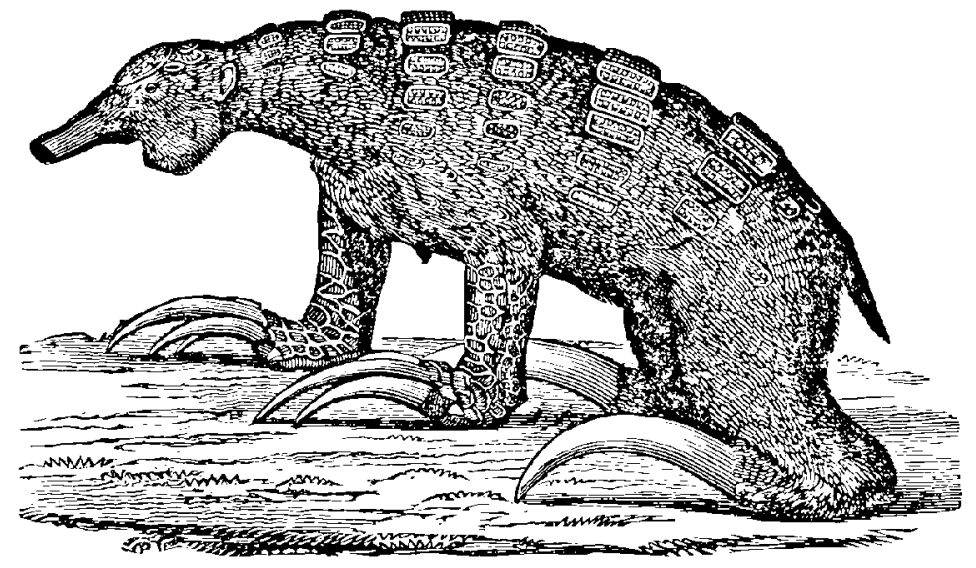

Fig. 395. - Le mégalonyx, mammifêre édenté quaternaire du continent américain.

tes squelettes sont pour la plupart entiers, et parmi lesquels on remarque surtout d'énormes édentés, tels que le mégathérium et le mylodon, avec lesquels nous avons fait connaissance pendant la période pliocène en Europe, et tels que le singulier mégalonyx (fig. 395) plus spécial au continent américain. On y rencontre aussi des tatous géants, dont le plus remarquable était le glyptodon, associés à des castors, à des chevaux, à des tapirs, etc., tandis que les grands animaux les plus fréquents et les plus remarquables de la faune quaternaire européenne, le mammouth, le rhinocéros, lours des cavernes, l'hippopotame, manquent complètement.

Le glyptodon ( $f g .396$ ) était un tatou géant, mesurant plus de trois mètres de long; il était enveloppé et protégé par une cuirasse évaisse, composée de pièces osseuses solidement ajustées. 
En Australie, les mammifères quaternaires ètaient exclusivement des marsupiaux; il en est de mème aujourd'hui, mais leurs représentants actuels ne sont que des nains par rapport aux espèces d'autrefois.

Enfin, dans la Nouvelle-Zélande, les mammifères faisaient presque défaut comme aujourd'hui ; ils étaient remplacés par des oiseaux géants, les moas (dinornis), qui pouvaient atteindre quatre mètres de hauteur et dont les œufs, longs de 32 à 3 ' centimètres, avaient une capacité de neuf litres.

Ces faits sont importants, ils nous montrent qu'aux temps

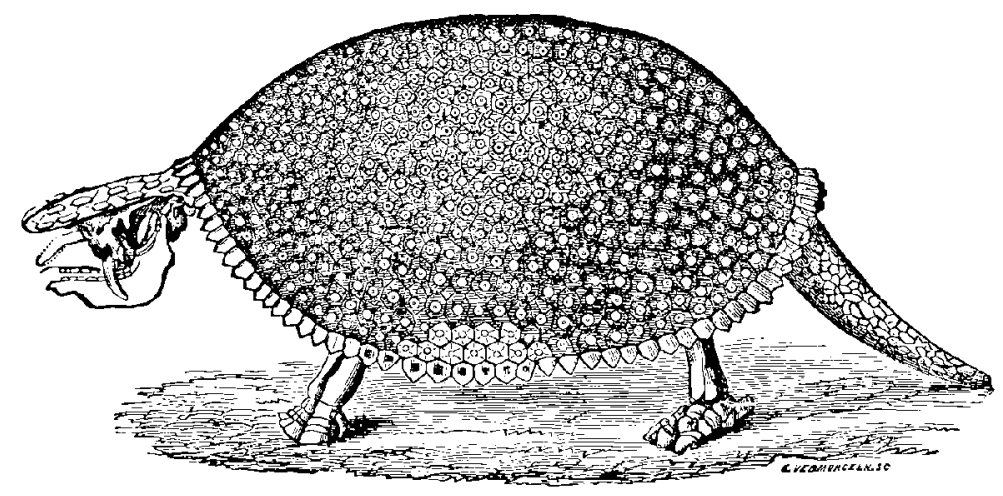

Fig. 396. - Squelette restauré du glyptodon (Amérique du Sud).

quaternaires, les distinctions entre les diverses faunes, qui sont si marquées à l'époque actuelle, étaient déjà bien accusées.

Nous nous occuperons au chapitre suivant de l'époque de l'apparition de l'homme; mais nous pouvons dire dès maintenant qu'on a recueilli dans le diluvium et dans les cavernes du commencement de l'époque quaternaire non seulement des silex taillés. des os faconnés, des croquis d'animaux et une foule de restiges de l'industrie grossière des premiers âges, mais encore des restes fossiles de l'homme lui-même. Les premiers hommes ont donc assistè aux phènomènes que nous venons de dècrire; ils ont contemplé les inondations diluviennes, ont été témoins de la prodigieuse extension des glaciers, ont vu s'élever des chaînes de montagnes, ont pu observer la formation d'un grand nombre d'espèces animales. Mais ils n'étaient pas encore observateurs. Tout ce qui s'est con- 
servé dans la mémoire de l'humanité, c'est un vague souvenir des périls auxquels elle était en butte, et des animaux qui menaçaient son existence. Les monstres et les géants abondent dans les premiers récits, et les traditions de tous les peuples mentionnent des inondations et des déluges singulièrement travestis par la fable. Ce n'est pas ici le lieu de chercher à débrouiller l'histoire encore si obscure des premiers âges de l'humanité; constatons seulement, avec le géologue Contejean, qu'on a trouvé les vestiges de races humaines diverses ; que les plus anciennes paraissent se rapprocher des populations les plus dégradées de l'Afrique du Sud et de l'Australie, et que plusieurs étaient anthropophages : “ Ce n'est que lentement, et à la suite des siècles, que l'humanité s'est peu à peu élevée de la sauvagerie à la barbarie, puis à la civilisation; il faut done absolument renoncer au rêve si séduisant d'un édénisme, pendant lequel notre espèce, sortie parfaite des mains du Créateur, aurait joui d'une félicité sans égale. »

L'usage de la pierre a précédé celui des métaux, et dans cet âge de pierre, on peut, en raison du degré de perfection plus au moins grand des outils de silex employés, constater deux ères principales: la première, dite paléolithique, oi les instruments de pierre sont simplement taillés, la seconde, dite néolithique ou de la pierre polie, parce que ces instruments, plus finement travaillés, sont le plus souvent polis.

Il est désormais prouvé que l'homme existe sur la terre depuis une époque très reculée. Les documents écrits ne nous ramènent qu'à cinq ou six mille ans en arrière, les restes les plus anciens des édifices bâtis à une époque antérieure, et qui sont anssi des archives de pierre, datent peut-ètre de vingt siècles auparavant, mais par delà cette bien courte période historique, comprenant à peine la durée de cent cinquante générations successives, s'étend la période, certainement beaucoup plus longue, de la tradition pure. Alors, dirons-nous avec Élisée Reclus, l'humanité, naissant à la conscience d'elle-même, rattachait les siècles aux siècles par les légendes, les hymnes, les formules symboliques, les souvenirs des grands événements. Migrations, guerres de races, alliances, exterminations, conquêtes du travail, s'incorporaient dans la religion mème, et, sous une forme de plus en vlus altérée, se transmettaient 
d'âge en âge, comme l'hẻritage des peuples. Plus anciennement encore, dans le lointain inconnu des temps, nos ancètres vivaient de la vie des bêtes fauves dans les forèts et les cavernes. La tradition non moins quo l'histoire, est muette sur cette période de la raco humaine; mais les assises de la terre, interrogée de nos jours par les anthropologistes et les géologues commencent à nous révéler à la fois l'existence et les mœurs de ces aïeux naguère inconnus.

Tant de débris humains, tant de produits de l'industrie primitive ont été découverts dans les derniers temps, qu'il ne reste plus do doute relativement à la longue durée de notre espèce. Non seulement nos barbares aïeux habitaient les forêts en mẻme temps que le bison, mais avant cet âge, ils vivaient aussi pendant la période glaciaire, quand la France et l'Allemagne avaient l'aspect de la Scandinavie actuelle et que les rennes, aujourd'hui relégués dans le voisinage de la zone boréale, parcouraient les glaciers des Alpes et des Pyrénées. Antérieurement encore, à une époque où le climat curopéen, qui plus tard devait tellement se refroidir, était au contraire beaucoup plus chaud que de nos jours, l'homme des cavernes avait pour contemporains des espéces de rhinocéros et d'éléphants, maintenant disparues, et déjà des artistes, humbles devanciers des Phidias et des Raphaël, s'essayaient à graver sur leurs outils des figurines de femmes et des images de mammouths et de cerfs, qui se sont conservés dans l'argile des grottes. Avant cette époque, l'homme se retrouve encore, luttant pour la domination contre un redoutable ennemi, le grand ours des cavernes, dont il nous a laissé ègalement des dessins sur la pierre; et plus loin, dans l'immense profondeur des âges, d'autres restes, ceux des éléphants antiquus et méridionalis, nous apprennent que nos ancètres étaient déjà nés durant une période de la vie terrestre que l'cn croyait naguère avoir été séparée de l'épocue actuelle par une série de brusques revouvellements (').

Telle a été la dernière des périodes géologiques esquissée dans ses grandes lignes. Le but de cet ouvrage étant atteint par l'arrivée du genre hımain antérieurement à cette époque même, ce n'est

1. Étisée Recius. La Terre, II, p. 625. 
'pas ici le lieu de nous étendre sur l'histoire spéciale de l'époque quaternaire et sur celle des premiers âges de l'humanité. Pour nous, notre mission; dans ce long travail, était de montrer comment, par la succession des espèces, la nature a progressivement conduit la vie depuis le protoplasma.jusqu'à l'homme, sur une planète devenue habitable après àvoir été nébuleuse et soleil. C'est à nos lecteurs à décider s'ils ont maintenant entre les mains tous les témoignages conquis par la science pour donner enfin la solution du grand problème.

Ce splendide sujet des premiers àges de l'humanité vá faire l'objet d'un 'ouvrage plus spécial, qui succédera tout naturellement à celui-ci, et qui sera dù à la plume si compétente de M. Emile Cartailhac, le savant directeur de la Revue des matériaux pour l'histoire primitive et nalurelle de l'homme. Nul auteur n'était mieux préparé que ce savant anthropologiste pour préscnter au public désireux de s”instruire sur ces àges antiques, si mystérieux encore, un ouvrage populaire exposant les documents déjà innombrables qui ont été reconnus et recueillis, depuis un quart de siècle surtout, sur l'état primitif du genre humain. Aussi est-ce avec un véritable bonheur que nous voyons M. Cartailhac préparer la publication de ce magnifique ouvrage, qui continuera celui-ci sous un aspect qui nous intéresse de plus près encore, puisqu'il a pour sujet l'humanité elle-même et sa primitive histoire.

Notre devoir personnel n'est pas encore complètement accompli, pourtant. Avant de clore ce volume, il importe que nous résumions sous un aspect général l'ensemble de tout ce qui a été dit depuis les premières pages, et que nous sachions en dégager la grande inconnue; la question finale de la Création de l'Homme. Nos lecteurs sont entièrement préparés pour le faire eux-mêmes. Le fruit est mùr : il suffit d'étendre la main pour le cueillir. Et c'est là le vrai fruit de l'arbre de la science, auquel il n'est plus interdit de toucher, comme dans la légende, gracieuse mais un peu trop inexacte, du paradis terrestre. 


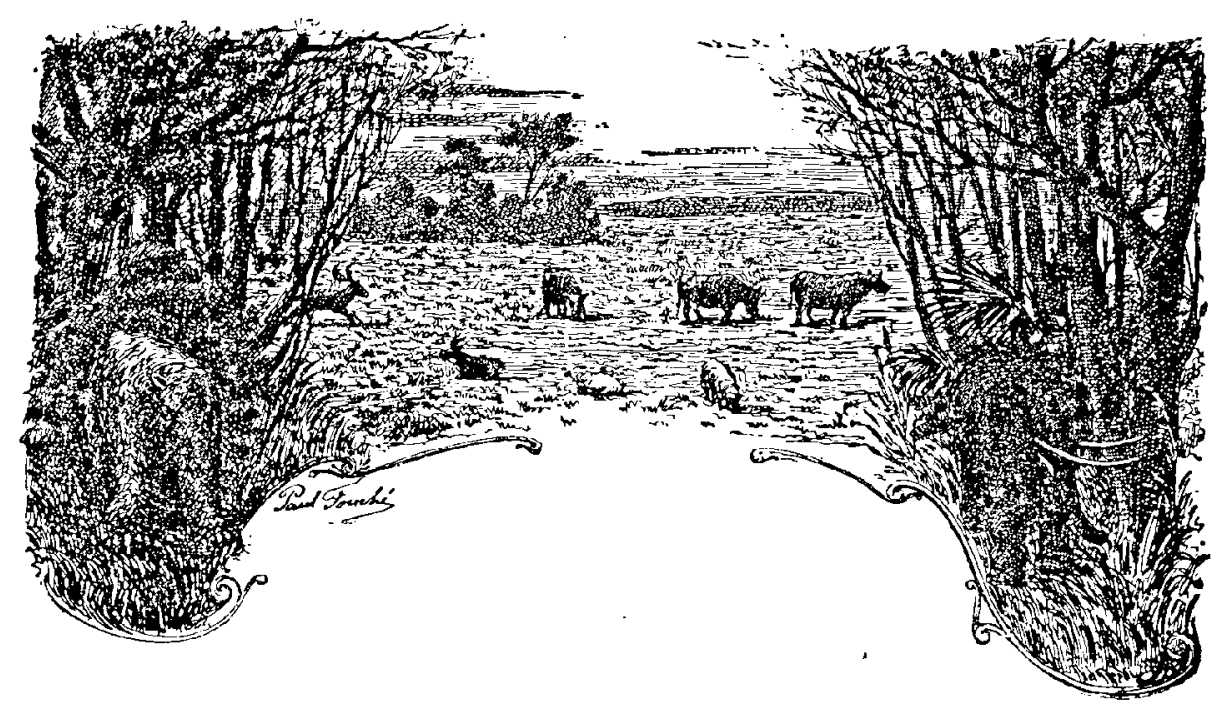

LA CREATION DE L'HOMME

Au titre de cet ouvrage, Le Monde avant la création de l'homme, on pourrait substituer celui de Monde avant l'apparition de l'homme, et il a semblé à plusieurs critiques éclairés de la littérature et de la science que le second serait plus exact que le premier. Dans la conception scientifique actuelle que nous pouvons nous former de la création des choses et des ètres, les deux expressions sont absolument synonymes. L'étude de la nature nous a montré, dans toul le cours de cet ouvrage, que le sens autrefois attribué à ce mot de création est purement imaginaire et que l'on n'observe nulle part de création directe. Jamais on n'a vu quelque chose sortir de rien. Non seulement pas un être animé, le plus élémentaire soit-il, pas une plante, pas un brin de mousse ne nait de rien, mais encore pas la moindre concrétion minérale, pas la moindre molécule, et même pas la moindre quantité de chaleur, de lumière, d'électricité; aucune force comme aucun atome ne sort du néant. Il faut donc laisser aux théologiens qui y tiennent encore le soin de défendre ces conceptions surannées : elles appartiennent à l'âge de l'enfance de l'humanité, et le mieux que nous puissions faire est de les oublier dans le musée des reliques, que l'on ne ' visite plus qu'au point de vue du sentiment de la curiosité historique. Pour l'esprit sincère qui, sans aucune idée préconçue et sans embarras pusillanimes, étudie librement le spectacle splendide de 
l'univers vivant, cet univers est, dans toutes ses parties, une évolution progressive des choses et des étres. Nous devons done entendre le mot création dans le sens de création naturelle. Compris de la sorte, le titre « création de l'homme » est aussi exact et plus légitime que celui d'apparition. L'homme n'est pas apparu subitement, il a été graduellement créé par les forces naturelles.

Ce n'est point à dire pour cela que l'étude positive de la nature nous autorise à nier l'existence d'une Cause première, agissant d'une manière permanente dans l'œuvre de l'évolution de l'univers, force invisible régissant le développement des êtres et des choses dans un dessein spirituel dont le but nous est présentement inconnu. Il importe à l'éclairement de nos esprits d'upprécier à leur juste degré les limites de la science. Ceux qui prétendent que l'on ne sait rien et qu'il est inutile d'étudier sont des hommes habiles, instruits ou non eux-mêmes, qui trouvent bon d'exercer une influence facile sur des personnes faibles, préparées à abandonner entre leurs mains la conduite de leur conscience. En fait, on sait quelque chose, et toute âme juste doit ètre pénétrée de reconnaissance envers les chercheurs de tous les siècles qui ont consacré leur existence entière au travail, et dont les labeurs ont donné à l'humanité les richesses intellectuelles et matérielles de la science et de Ia pensée. Mais si l'on sait quelque chose, on ne sait pas tout, et la science expérimentale a des limites. Elle ne peut pas encore trancher la question si importante de l'existence de Dieu et de l'immortalité de l'âme, et surtout elle ne peut pas la trancher par la négative. C'est le devoir de tout penseur, qui a le respect de la vérité, de dire franchement ce qu'il sait, et de tenir en garde ceux qui l'écoutent contre toute conclusion exagérée et étrangère à la science. Les religions qui prétendent raconter la création de l'homme par les mains d'un magicien divin et qui fondent toute l'histoire de l'humanite sur la pointe d'une pyramide renversée, font peut-être un prodige d'équilibre; mais il est certain qu'elles sont dans l'erreur la plus complète. Les systèmes philosophiques qui nient au nom de la science l'existence de l'âme humaine et prétendent écraser sous le poids d'un matérialisme grossier les plus nobles aspirations de l'humanité, font peut-être parade d'une certitude bien déguisée; mais ils ne voient qu'un côté de la création, et non lo 
plus beau. Sans doute il est difficile de se dégager de toute chaine, d'apprécier les choses telles qu'elles sont et de penser librement. Mais c'est là, en vérité, le plus grand mérite que nous puissions avoir, et le plus noble exercice que nous puissions faire des facultés intellectuelles que nous avons recues. Et c'est l'un des derniers progrès de la civilisation, dont nous ne saurions trop sentir le prix, de pouvoir aujourd'hui penser et parler selon notre conscience, sans hypocrisie comme sans châtiment de la part d'une société à la fois fausse, fourbe et ignorante. Il est enfin permis d'être sincère. Pourtant tout le monde ne l'ose pas.

La création naturelle de l'homme, tous nos lecteurs l'ont dẻjà compris, ne commence pas historiquement avec le titre de ce chapitre; elle remonte, par ses origines, aux premières pages de ce volume. G'est insensiblement, graduellement, progressivement, que l'évolution des êtres est parvenue au point où nous la voyons actuellement dans l'humanité. Il serait aussi impossible de dire quand l'homme a commencé, que de dire quand la rose a commencé. Contemplez cette rose magnifique, aux pétales multipliés, de nos jardins modernes, respirez son parfum exquis, admirez les nuances si tendres et si délicates de cette chair végétale, et cherchez sa naissance. Vous remonterez à la rose sauvage, vous remonterez à l'aubépine; mais ce n'est plus la rose. Cherchez la naissance de la pèche, à la fois si belle et si succulente; cherchez la naissance du chasselas doré dont chaque grain emprisonne des rayons de soleil; cherchez la naissance du lis ou de l'orchidée; en remontant aux origines, vous perdez insensiblement de vue l'objet de votre recherche. De la Terre actuelle, couverte des produits de l'humanité militante, parsemée de champs, de prairies, de cités, de villages, de routes, de chemins de fer, vous remontez insensiblement à la Terre des iguanodons, des dinosauriens, des labyrinthodontes, aux âges primaires, à la nébuleuse. Tout n'est que transition, transformation, évolution.

Entre minuit et midi, la différence est grande, le contraste est absolu. Décidez cependant à quelle heure, à quelle minute, à quelle seconde, à quel moment précis le jour a commencé. Il en est de môme de l'homme.

Observant l'humanité dans son état actuel, nous avons une 
tendance à croire qu'elle a toujours été telle que nous la voyons. Pourtant nous assistons nous-mèmes à son évolution et nous pouvons nous rendre compte de la rapidité avec laquelle tout change. Dans moins d'un siècle nos descendants ne s'imagineront pas facilement l'époque à laquelle il n'y avait ni chemins de fer ni télégraphes, et pourtant c'est d'hier. Nous jetons une lettre à la poste pour Madrid, où elle arrive le lendemain, et en traversant la grare d'Orlćans, nous lisons sans admiration sur le wagon-poste : "PArrsPýḱxÉEs ». Notre mémoire est courte et notre indifférence est bizarre. Charlemagne saluerait une conquète plus grande que celle de tout son empire, s'il ressuscitait une heure seulement dans l'express qui fond de Paris sur Rome en 34 heures ou dans celui qui vole de l'aris à Constantinople en 60 heures; il n'en croirait pas ses yeux et encore moins sa raison, si quelque ingénieur essayait de lui expliquer que c'est tout simplement de la vapeur émanée de quelques litres d'eau bouillante qui produit cette merveille. Nous voyons des villes, des maisons confortables fermées par du verre, des boulevards, des théatres, des académies, des églises; nous voyons des étoffes, děs costumes, des meubles; nous entendons de la musique, nous lisons des journaux et des livres, et nous sommes portés à croire que tout cela a toujours existé. Mais, au contraire, en fait, tout n'est arrivé que successivement.

L'homme s'est fait ce qu'il est aujourd'hui, comme il se fait actuellement ce qu'il deviendra demain. Corps, esprit, mœurs, idées, langage, tout change, et très vite. Charlemigne n'entendrait déjà plus la langue que l'on parle aujourd'hui à Paris. Que dis-je, Charlemagne? Saint Louis, qui rendait la justice sous un chène du bois de Vincennes, ne comprendrait plus le français. Insensiblement l'lomme a acquis ses idées, son langage, ses facultés intellectuelles; insensiblement il a produit ses ceuvres diver'ses; insensiblement l'humanité est devenue ce qu'elle est. Encore devrions-nous dire l'humanité civilisée; car il existe sur notre planète, notamment dans l'Afrique centrale, au sud de l'Amérique et dans les îles de l'Océan Pacifique bien des groupes d'ètres nommés humains et qui n'en ont guère que la forme. Et quelle forme! Ces sauvages primitifs, incapables de toute conception intellectuelle, moins intelligents yue plusieurs de nos animaux domestiques, rebelles à tonte éduca- 
tion, sans mémoire historique, sans calendrier, vivant au jour le jour, incapables de compter au delà des cinq doigts d'une main, brutes et barbares dans tous leurs actes, n'allant pas plus loin dans le sentiment de la famille que certaines espèces de singes, d'oiseaux ou même de kangourous, ces sauvages (dont on peut apprécier les types en visitant les salles d'anthropologie du Musẻum d'histoire naturelle de Paris, depuis les Boschismans jusqu'à la Vénus hottentote), ces êtres primitifs ne doivent assurément pas encore être inscrits dans les rangs de l'hụmanité dont nous célébrions tout à l'heure l'avancement intellectuel.

La parenté de l'homme avec les organismes qui l'ont précédé dans l'ordre de la vie terrestre est démontrée par des faits absolument incontestables. Ces faits, nombreux et divers, peuvent être classés en plusieurs séries, éloquemment concordantes : $1^{\circ}$ l'anatomie comparée montre l'identité de construction du corps humain avec celui des espéces animales les plus élevées dans la hićrarchie zoologique, depuis le squelette jusqu'aux organes et jusqu'aux moindres détails du corps; $2^{\circ}$ la physiologie établit que l'organe le plus caractéristique de l'espèce humaine, le cerveau, s'est progressivement formé et développé dans les espèces animales pour aboutir graduellement et sans transition brusque au corveau humain; $3^{\circ}$ l'observation de l'intelligence des animaux prouve qu'ils possèdent, à un degré moindre, toutes les facultés intellectuelles de l'homme, ordinairement en un état très rudimentaire, mais quelquefois développées d'une manière remarquable; $4^{\circ}$ cette parenté physique et morale de l'homme avec les animaux supérięurs a laissé de plus des traces irrécusables dans les organes atrophiés qui existent dans l'organisme humain, hẻritage des ancètres primitifs, et dans les taits d'atavisme ou de retour de l'homme vers ses origines; $5^{\circ}$ l'embryologie constate que, maintenant encore, tout être humain passe, dans le sein de sa mère, par les phases animales antérieures et, qu'avant d'ètre humain, chacun de nous a été œuf, reptile et quadrupède; $6^{\circ}$ la géologie et la paléontologie établissent qu'en réalité c'est bien ainsi que les choses se sont passées; puisque les êtres dont on retrouve les fossiles, depuis les zoophytes et les mollusques jusqu'à l'homme, progressivement et se perfectionnant sans cesse, montrent un arbre grandissant des 
racines au sommet et un parallélisme complet entre l'ordre logique indiqué par la physiologie et la succession réelle des espèces dans l'histoire du monde. De ces diverses séries, qui comprennent l'ensemble des observations scientifiques auxquelles nous pourons recourir pour la solution du grand problème, la sixième a fait l'objet de cet ouvrage tout entier, et nos lecteurs en ont apprécié surabondanment l'intérêt et la valeur. Les cinq autres ont déjá été esquissées dans leurs grandes lignes lorsque nous avons étudié les origines et la progression de la vie; il importe cependant de placer sous nos yeux leurs arguments essentiels et d'essayer ensuite de découvrir de quelle espèce animale l'humanité s'est dégagée et vers quelle époque s'est accomplie cette importante transformation.

Et d'abord, nous disons que l'anatomie comparée établit une identité de construction entre le corps humain et celui des animaux supérieurs. C'est ce que tout le monde sait aujourd'hui. Il n'est personne qui n'ait vu, au naturel ou en modèles, soit dans les musées, soit dans les collections, soit mème simplement anx étalages de bouchers ou de charcutiers des animaur écorchés, bœufs, veaux, moutons, porcs, chevreuils, etc., et sans être nécessairement pour cela grand observateur, on ne peut pas ne pas avoir remarqué l'analogie qui existe entre la position des principaux organes de ces corps avec celle des organes du corps humain. Ce premier coup d'œil poussé un peu plus loin conduit aux éléments de l'étude anatomique, et si l'on pénètre jusqu'à l'examen spécial des organes : cerveau, cœur, poumons, membres, tête, dentition, yeux, orcilles, mains, etc., on constate très vite que dans tous ses détails notre corps est construit absolument sur le même modèle que celui des mammifères supérieurs. Si l'on va plus loin dans l'examen et que l'on cherche, parmi ces mammifères supérieurs, quels sont ceux dont l'organisation anatomique et physiologique offre la plus grande ressemblance avec la nôtre, on ne tarde pas à constater que ce sont les singes.

C'est là un fait que nulle objection de sentiment ne peut détruire. Est-ce à dire que ce rapprochement suffise pour établir. que nous descendions du singe? Assurément non. Et puis, il faudrait d'abord examiner à quel singe on peut offrir la palme. 
N'allons pas si vite. Mais ne fermons pas les yeux pour cela. Notre corps est construit comme celui des animaux supérieurs. Si l'homme avait été l'objet direct d'une création spéciale, étrangère à celle des autres espèces vivantes, cette ressemblance organique n'aurait aucune raison d'être. Elle serait mème étrange, inexplicable et humiliante, surtout inexplicable, si l'homme avait été créé à l'état de perfection angélique. Au contraire, elle s'explique tout naturellement si nous appartenons à l'arbre de la vie terrestre.

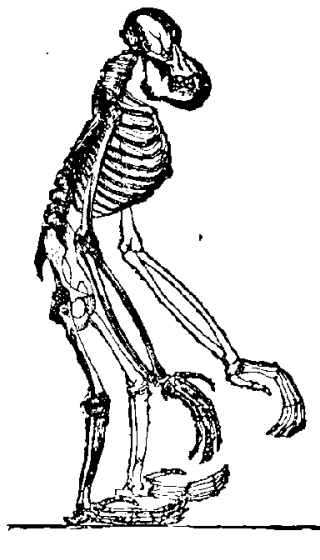

OAAKG.

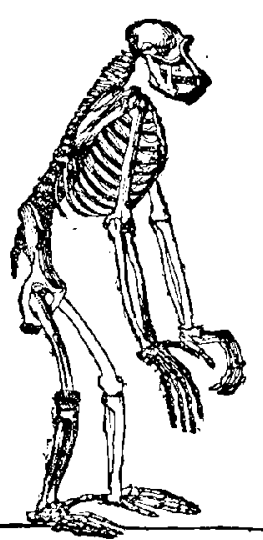

CEIYPANZE.

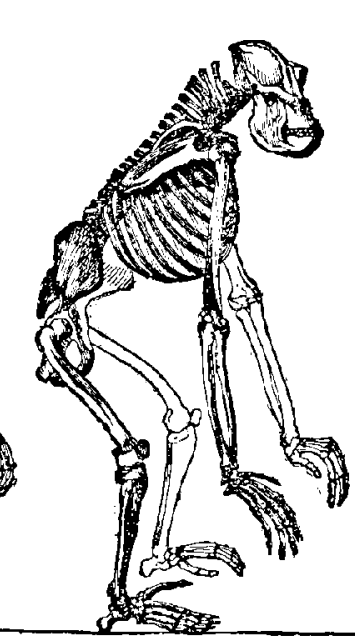

GORILI.Z.

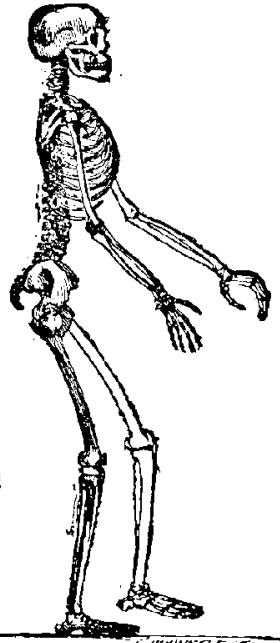

HOMXE.

Fig. 398. - Squelettes comparés de l'orang, du chimpanzé, du gorille et de l'homme.

Si nous comparons au squelette humain celui des singes les plus voisins de l'homme par leur organisation, nous avons sous les yeux la figure ci-dessus, qui est bien significative par elle-même. On ne saurait refuser de convenir que la ressemblance entre ces squelettes est grande. La stature générale, les côtes, les jambes, les bras, la colonne vertébrale, la tête laissent une impression de ressemblance hien réelle. Des différences de détails se manifestent. Lo crâne des singes est bestial, les bras sont très longs, et surtout la stature humaine, droite, verticale, est empreinte d'une certaine noblesse à laquelle ne pourraient prétendre les autres. Mais ne sent-on pas comme une ascension graduelle du squelette animal vers la noblesse humaine? Comparez un squelette de quadrupède : chien, cheval ou lion (voyez par exemple $f . g .386, p$. 727) avec celui 
de l'orang, et vous sentirez qu'il y a plus de distance entre le cheval ou le lion et le singe, qu'entre le singe et l'homme. Pourtant le lion peut être considéré comme l'un des animaux supérieurs; son visage, son regard, sa fierté, son aspect (fig. 399) n'ont-ils pas déjà presque quelque chose d'humain?

$\mathrm{Si}, \mathrm{du}$ squelette nous allons plus loin et considérons l'ensemble de l'organisation corporelle; si, allant encore un peu plus loin, nous observons l'organisation intellectuelle, la vie et les mœurs des singes, la ressemblance avec l'humanité, surtout avec les races inférieures, va s'accuser avec une évidence de plus en plus marquée. Sans doute, c'est plutòt par les vilains côtés qu'ils nous

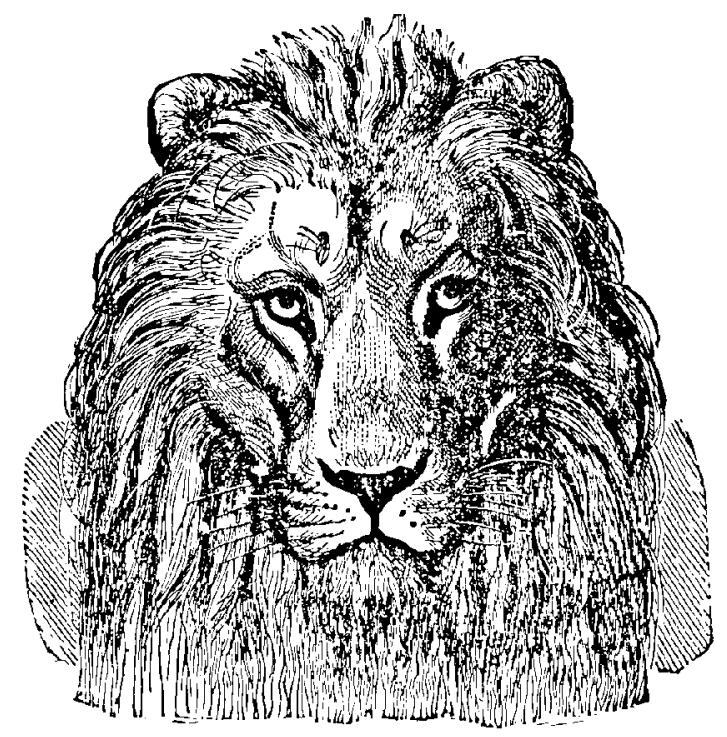

Fig. 393. - Tete de lion du Senuaar, vue de face.

ressemblent; mais ils ne manquent ni de finesse ni d'esprit. Écoutons à ce propos l'un des meilleurs observateurs, Brehm, qui pourtant ne parait pas les aimer beaucoup. Le lecteur qui lira, avec attention, la description suivante, prise sur nature, recevra l'impression qu'entre le singe et l'homme non civilisé il n'y a qu'une différence de degré.

L'on ne peut nier, écrit ce naturaliste, qu'ils ne soient méchants, nadlicieux, perfides, rageurs et furieux, haineux, sensuels sous tous les rapports, querelleurs, batailleurs, despotiques, irritables et moroses, en un 
mot, soumis à toutes les passions les plus détestables; ils éprouvent un malin plaisir à faire toutes sortes de mauvais tours; mais il faut recou naître aussi qu'ils manifestent souvent de la prudence et de la gaîté, de la douceur et de la bonté, de l'amitié et de la conflance; ils sont sociables,

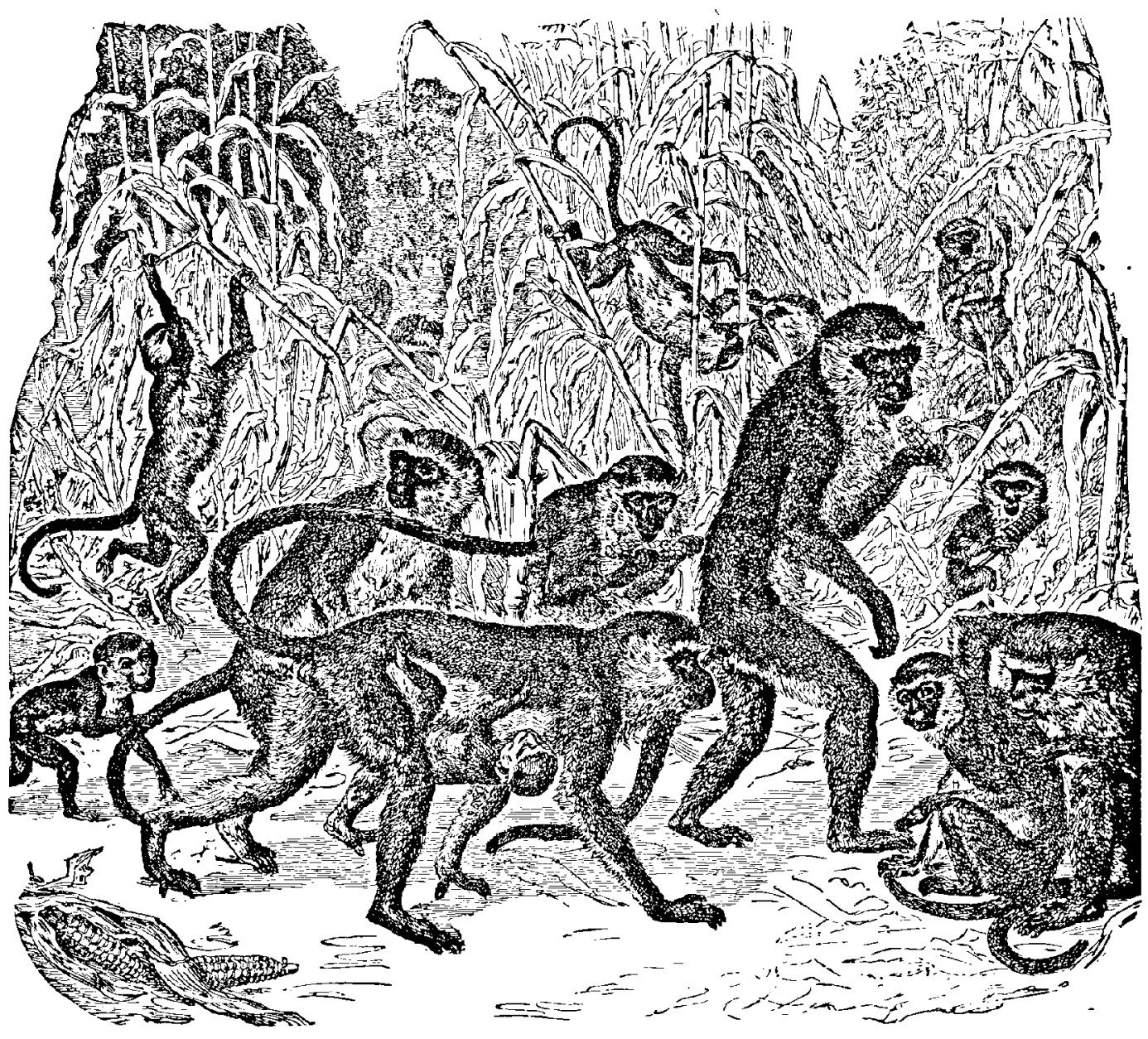

Fig. 400. - Singes cercopithèques en maraude.

courageux, dévoués à leurs semblables qu'ils défendent vigoureusement, même contre des ennemis supćrieurs en forces. Tous montrent une certaine grandeur dans leur amour envers leurs enfants, dans leur compassion pour les ètres faibles, non seulement dans leur race ou dans leur famille, mais pour les petits d'espèces ou mème de classes différentes.

La vie sociale de ces animaux est pleine d'attraits pour l'observateur. Peu d'espèces de singes vivent solitaires; la plupart d'entre elles se réu-

I.E MONDE AYANT LA CRÉATION DE L'HOMME 
nissent par bandes. Chacune de ces bandes choisit un domaine fixe, plus ou moins étendu, toujours dans les contrées les plus favorables sous tous les rapports et surtout sous celui de l'alimentation. Lorsque la nourriture manque, la bande pousse plus loin. Les forèts voisines des lieux habités par l'homme et dans lesquelles se trouvent des plantations de mais, de cannes à sucre, de bananes, des arbres fruitiers, des melonnières, sont pour eux un véritable paradis. Ils ne dédaignent pas non plus les villages, où la superstition grossière défend à tout le monde de châtier ces voleurs impudents. Lorsque la bande est tombée d'accord sur l'endroit où elle doit se fixer, la véritable vie de singe commence avec ses plaisirs et ses agréments, ses disputes et ses batailles, ses besoins et ses misères. Le mâle le plus fort de la troupe en devient le conducteur, le guide, mais ce n'est pas le suffrage des autres individus de sa société qui lui confère cet honneur; il est contraint de l'acquórir à force de luttes et de combats contre les autres vieux mâles ses rivaux. Les dents les plus longues et les bras les plus puissants, chez les singes comme chez les hommes, décident de la victoire. Quiconque ne veut pas se soumettre de bonne grace y est contraint par la force. L'empire est done au plus fort; le plus sage est celui qui a les plus longues dents. Cela s'explique, du reste, par ce fait que les singes les plus forts sont généralement les plus âgés, et les jeunes sont bien obligès de se reconnaitre inexpérimentès devant eux. Le guide exige une obéissance absolue et il l'obtient dans toutes les circonstances. Sultan jaloux et brutal, il s'arroge un droit exclusif sur toutes les femelles, éloigne celles qui s'oublient; aussi peut-on dire qu'il est le père de sa troupe.

Lorsque la colonne devient trop nombreuse, une partie s'en détache sous la direction d'un aulre mâle devenu assez fort pour lutter avec le chef, et une nouvelle lutte commence pour la direction générale des intérêts de la société qui vient de se former. Il y a toujours lutte là où plusieurs visent au mème but. Chez les singes, il ne se passe pas un jour sans disputes et querelles : il suffit d'observer une troupe pendant quelques instants pour voir que la discorde règne au milicu d'elle sans cause

- apparente.

Le guide exerce son emploi avec beaucoup de dignitė. L'estime qu'il a su conquérir, exaltant son amour-propre, lui donne une certaine assurance qui manque à ses sujets; ceux-ci lui font toujours la cour. On voit mème des femelles s'efforcer de recevoir de lui la plus grande faveur qu'un singe puisse accorder ou obtenir : elles mettent tout leur zèle à débarrasser son pelarge des parasites incommodes, et il se prète à cette opération avec une grotesque majesté. Fn retour, il veille fidèlement au salut commun. Aussi est-il, de tous, le plus circonspeet; ses yeux errent constamment de côté et d'autre; sa méliance s'étend sur tout, et il arrive presque toujours à découvrir, à temps, le danger qui menace sa colonie. 
Le langage des singes paraît êtro assez varié, du moins chaque espèce exprime-t-elle par des sons différents ses diverses impressions; l'observateur parvient bien vite à reconnaître la signification des sons que pousse un guide pour conduire son troupeau, et le cri plein de terreur qui ordonne la fuite. Ce cri, qu'il est difficile de décrire et encore plus d'imiter, consiste en une série de sons courts, saccadés pour ainsi dire, tremblants et discordants, que les contractions de la figure rendent encore plus expressifs. Dès qu'il se fait entendre, toute la bande prend la fuite. Les mères rappellent leurs petits, qui s'attachent rapidement à elles; puis, chargées de leur doux fardeau, elles gagnent au plus vite le premier arbre ou le rocher voisin. Le vieux singe prend les devants et indique le chemin, que toute la bande suit avec la plus grande confiance; et quand la halte et le calme du guide annoncent que tout danger est passé, la bande se réunit de nouveau, rehrousse chemin et va achever le pillage que l'on avait empêché d'accomplir.

Cependant tous les singes ne fuient pas devant l'ennemi; les plus forts se défendent contre les carnassiers les plus redoutables et même contre l'homme, plus terrible pour eux; ils livrent alors des combats dont l'issue est souvent douteuse. Les grands singes, par exemple les cynocéphales, possèdent dans leurs dents des armes si terribles, qu'ils peuvent bien accepter la lulte avec l'ennemi qui se présente scul, tandis que les singes de petite taille se défendent en masse et se secourent mutuellement avec une fidélité digne d'éloges. Les femelles ne se battent que lorsqu'elles sont forcées de défendre leur vie ou leur petit; dans ce cas, elles font preuve de tout autant de bravoure que les mâles. Ia plupart des singes combattent à l'aide de leurs mains et de leurs dents, ils déchirent et mordent; cependant quelques auteurs ont avancé qu'ils se servent quelquefois de branches cassées, en guise de bâtons. Ce qu'il y a de certain, c'est que, du haut de leur refuge, ils lancent des pierres, des fruits, des morceaux de bois sur leurs adversaires. Aucun indigène, surtout lorsqu'il n'a pas d'arme à feu, ne se mesure avec le cynocéphale. Les orangs, et notamment les gorilles, sont si forts et si dangcreux que, lorsqu'un chasseur est aux prises aver l'un deux, il ne peut se servir de son fusil que pour la défense et ne peut jamais l'employer à l'attaque. La rage excessive des singes, qui décuple leurs forces, est beaucoup à craindre, et leur grande adresse enlève trop souvent au chasseur l'occasion de leur porter un coup mortel.

A l'état de nature, chaque espèce fait bande à part; toutefois, quelques-unes de celles qui sont très voisines et presque semblables, se supportent et font société. En captivité, toutes les espèces vivent en bonne amitié, et on observe alors les mêmes lois de domination que dans une colonie libre. Le plus fort a toujours de l'empire sur les autres. Ies grandes espèces s'occupent des espèces plus petites et les mâles rivalisent 
avec les femelles pour les soigner. Les femelles des grandes espèces recrutent même de jeunes enfants ou de petits mammifẻres qu'elles peuvent porter sur leurs bras. Autant le singe est méchant contre tous les animaux, autant il est aimable et doux envers les enfants ou d'autres pupilles; aussi, l'amour maternel des singes est-il devenu tout à fait proverbial. Naturellement, cet amour s'observe surtout envers leurs propres petits.

Le nouveau-né n'est pas beau; mais ce petit monstre fait los joies do

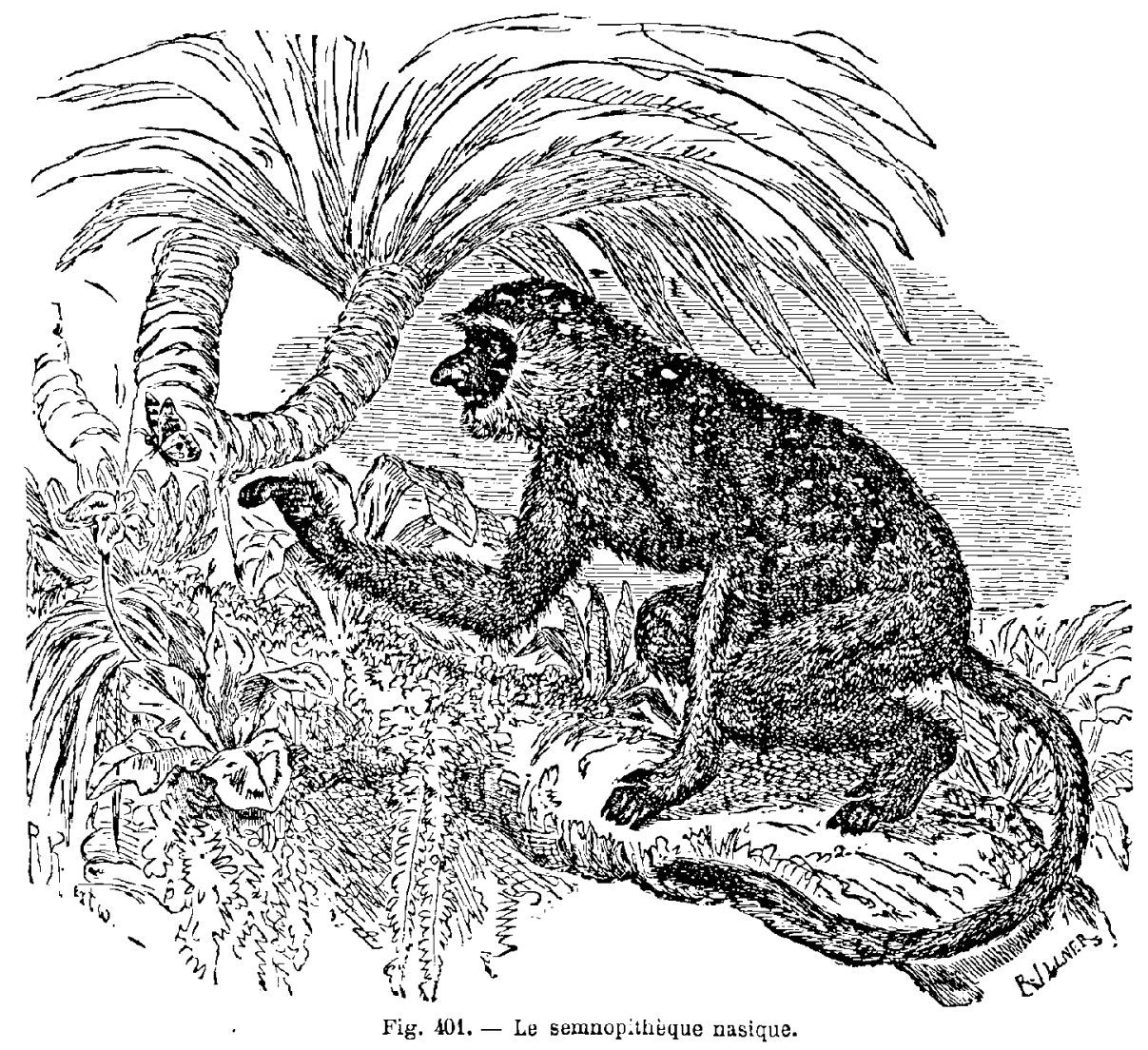

sa mère, qui le caresse et le soigne avec tant de démonstrations, que ce grand amour en paraît ridicule. Quelque temps après sa naissance, le jeunc singe se suspend avec ses deux mains de devant au cou de sa mère, tandis yue ses mains de derrière embrassent les flancs de celle-ci; il prend ainsi la position la moins gènante pour la nourrice et la plus commode pour téter. Derenu plus grand, il saute, à la première alerte, sur les épaules ou sur le dos de ses parents.

Le petit être est d'abord insensible à toutes los caresses de sa mère, qui n'en est que plus aimable envers lui. Elle s'en occupe constamment. Tantôt elle le lèche, tantôt elle l'épouille; elle le presse contre son cour 
ou le prend dans ses deux mains pour mieux le contempler, elle le replace au sein, ou le balance dans ses bras comme si elle voulait l'endormir... Au bout de quelque temps le petit singe devient plus indépendant et prend un peu plus de liberté. Sa mère le laisse maître de ses mouvements

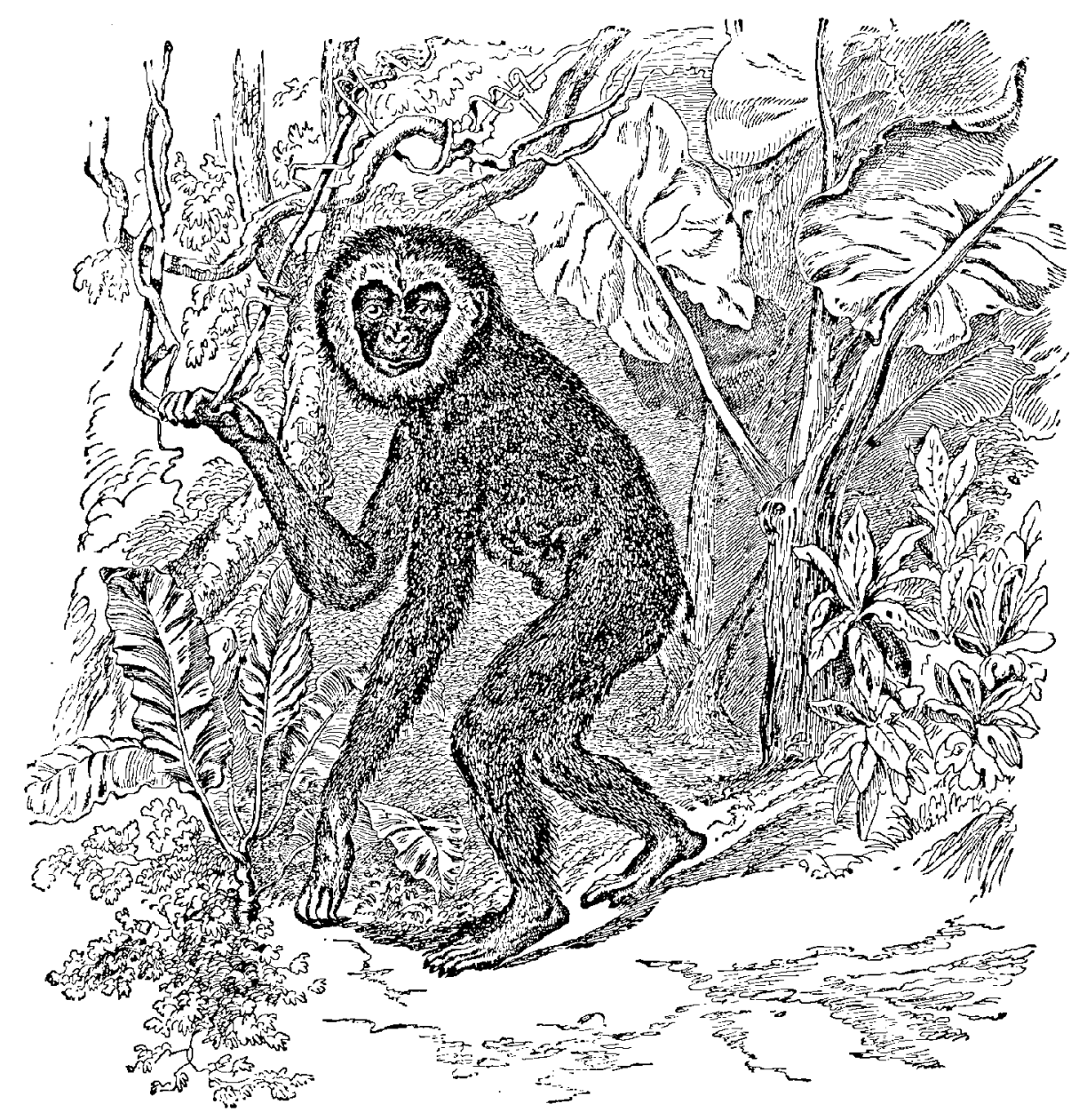

Fig. 402. - Le gibbon oa.

et lui permet de s'ébattre avec les autres singres de son espèce, mais elle ne le quitte pas un instant des yeux, suit tous ses pas, surveille ses actes et ne lui permet que ce qui ne peut lui nuire. Au moindre danger, elle se précipite sur lui en poussant un cri particulier, qui est une invitation à venir se réfugier dans ses bras. Lorsqu'il désobéit, ce qui arrive rarement - les jeunes singes étant en général très soumis - elle le punit en le pinçant ou en le secouant, quelquefois même, en lui donnant de vrais soufflets. 
Dans la captivité, la mère partage fidèlement ce qu'elle mange avec son petit, prend part à tout ce qui lui arrive et lui donne de touchants témoignages d'affection. La mort de ce petit entraîne fatalement la sienne; le chagrin que lui cause cette perte la tue (1). Lorsqu'une mère meurt, un individu quelconque de la bande, mâle ou femelle, adopte l'orphelin et lui témoigne presque autant d'amour qu'à sa propre progéniture.

Quelques voyageurs ont fait une peinture des combats des nègres avec le gorille, réellement épouvantables à les en croire; ceux qui vont chercher l'ivoire craignent au plus haut degré le gorille et redoutent surtout sa manière d'attaquer. Les indigènes prétendent que lorsque des chasseurs cheminent tranquillement en troupe à travers la forêt, un gorille suspendu à l'une des branches inférieures d'un arbre, saisit habilement l'un d'eux par la nuque, l'attire vers lui, l'entraîne jusqu'au sommel de l'arbre, où il l'étrangle sans qu'il puisse seulement pousser un cri, et le laisse retomber inerte sur le sol. Des nègres sortent quelquefois horriblement mutilés d'un combat qu'ils ont eu à soutenir avec ces terribles animaux et dont ils sont sortis vainqueurs. Lorsque le gorille est entouré de sa famille, il attaque sans être provoqué, et le combat entre l'homme et lui se termine ordinairement par la mort de l'un des combattants; malheureusement, presque toujours, c'est l'homme qui succombe. Il est plus difficile de s'emparer d'un jeune gorille que d'une dizaine de chimpanzés. Les femelles se sauvent avec leurs petits sur les arbres dès que les chasseurs s'approchent, tandis que les mâles se préparent immédiatement au combat. Leurs grands yeux verts étincellent, leur crin se dresse, ils grincent des dents, poussent un cri aigu que l'on peut exprimer par kahi! kahi! et se précipitent avec fureur sur l'ennemi. Lor'squ'on manque le gorille, on ne peut même plus se servir du fusil comme d'une massue; le singe furieux le tord ou le brise facilement avec ses dents. G'est aussi avec ses dents qu'il déchire le chasseur. Il n'est donc pas étonnant de voir passer pour un héros dans sa tribu, le nègre qui a réussi à tuer un gorille, et l'on ne doit pas être surpris de voir les indigènes refuser de procurer au poids de l'or un gorille vivant aux voyageurs européens.

Les indigènes croient que ces grands singes sont de véritables

1. Les singes pourraient parfois donner des leçons à l'humanité. Au moment où nous corrigeons cette épreuve ( 1 re édition: novembre 1885), nous venons précisément de lire le fait suivant, qui vient de se passer dans le département du Nord :

- Au mois d'août dernier, la femme Gorin, d'Herbignies, avait vendu pour 40 francs ses trois enfants : Clovis, agé de neuf ans; Clarisse, sept ans, et Clémence, cing ans, a des saltimbanques qui se rendaient à la foire de Lille.

* Pendant toute la durée de la foire, les pauvres enfants, exploités par les saltimbanques, durent mendier dans les rues de Lille, et quand là récolte n'était pas suffisante, les coups ne se faisaient pas attendre. Lassé de cctte misérable vie, Clovis se sauva, emmenant avec lui sa scur Clarisse, et tous deux parvinrent à retrouver le chemin d'Herbignies, où ils revinrent après avoir mendiẻ sur les chemins. Quand la mère vit revenir ses deux enfants, 
hommes, et qu'ils font seulement semblant d'ètre si féroces et si bètes parce qu'ils ont peur de devenir esclaves et d'ètre forcés de travailler. $\hat{E}$ tre esclave c'est, pour le véritable Africain, le sort le plus affreux. Ils prétendent aussi que les âmes de leurs rois habitent après leur mort le corps des gorilles, et que si ceux-ci les haïssent et les tourmentent, c'est par une vieille habitude.

Paul Du Chaillu a doṇné des renseignements très étendus et pleins d'intérêt sur le gorille. Ge qu'il en raconte confirme une partie des faits généraux que nous venons d'indiquer. Empruntons-lui les témoignages les plus intéressants pour la question qui nous occupe.

Le tableau suivant, que trace Du Ghaillu, de la rencontre d'un gorille à la mort duquel il prit part, donnera une idée de l'impression que doit produire ce terrible quadrumane.

Pendant que nous rampions au milieu d'un silence tel que notre respiration en sortait bruyante, la forêt retentit tout entière du terrible cri du gorille. Les broussailles s'écartèrent des deux côtés, et nous fûmes en présence d'un énorme gorille mâle. Il avait traversé le fourré à quatre pattes; mais quand il nous apercut, il se redressa de toute sa hauteur, ct nous regarda hardiment en face. Il se tenait à une quinzaine de pas de nous. C'est une apparition que je n'oublierai jamais. Il paraissait avoir près de six pieds; son corps était immense, sa poitrine monstrueuse, ses bras d'une incroyable énergie musculaire. Ses grands yeux gris et enfoncés brillaient d'un éclat sauvage, et sa face avait une expression diabolique. Tel apparut devant nous ce roi des forèts de l'Afrique.

Notre vue ne l'effraya pas. Il se tenait là à la même place, et se battait la poitrine avec ses poings démesurés, qui la faisaient résonner comme un immense tambour. C'est leur manière de défier leurs ennemis. En mème temps il poussait rugissement sur rugissement.

elle les mit brutalement à la porte et leur fit entendre que leur devoir était de retourner chez ceux à qui elle les avait vendus.

« Les pauvres petits, éplorés, durent se remettre à courir les chemins, et, il y a quelques jours, M. Dutertre, professeur au collège d'Avesues, trouva Clovis mourant de fairn et de froid auprès d'un mur. Il emmena chez lui l'enfant, qui raconta en pleurant sa dramatique histoire. M. Dutertre, révolté, se hata de prévenir l'autorité et une enquête a été ouverte.

* Le petit Clovis ne sait pas ce que sont devenues ses deux soeurs : la plus jeune, Clémence, doit être encore avec les saltimbanques; quant à Clarisse, qui avait suivi son frère jusqu'à Herbignies, on pense qu'elle a été recueillie dans une ferme des environs d'Aresnes. "

De tels faits, qui ne sont pas absolument rares dans l'espèce humaine, se passent de commentaircs. Hier aussi, les journaux rapportaient l'histoire d'un récidiviste qui vient d'assassiner un passant, sans le connaitre, et sans aucun but, tout simplement pour etre envoyé à la Nouvelle-Calédonie. Non, notre espèce n'est pas aussi éloignée de l'animalité qu'on aimerait à le croire. 
Le rugissement du gorille est le son le plus étrange et le plus effrayant qu'on puisse entendre dans ces forèts. Cela commence par une sorte d'aboiement saccadé, comme celui d'un chien irrité, puis se change en un grondement sourd qui ressemble littéralement au roulement lointain du tonnerre, si bien que j'ai été parfois tenté de croire qu'il tonnait, quand j'entendais cet animal sans le voir. La sonorité do ce rugissement est si profonde qu'il a l'air de sortir moins de la bouche et de la gorge que des spacieuses cavités de la poitrine et du ventre. Ses yeux s'allumaient d'une flamme ardente pendant que nous restions immobiles sur la défensive. Les poils ras du sommet de sa tête se hérissèrent, et commencèrent à se mouvoir rapidement, tandis qu'il découvrait ses canines puissantes en poussant de nouvcaux rugissements de tonnerre. Il me rappelait alors ces visions de nos rêves, créations fantastiques, ètres hybrides, moitié hommes, moitié bêtes, dont l'imagrination de nos vieux peintres a peuplé nos régions infernales. Il avança de quelques pas, puis s'arrêta pour pousser son épouvantable rugissement; il avança encore et s'arrêta de nouveau à dix pas de nous : nous fimes feu et nous le tuâmes.

Le rảle qu'il fit entendre tenait à la fois de l'homme et de la bête. Il tomba la face contre terre. Le corps trembla convulsivement pendant quelques minutes, les membres s'agitèrent avec effort, puis tout devint immobile; la mort avait fait son ceuvre. J'eus tout le loisir alors d'examiner l'énorme cadavre; il mesurait cinq pieds huit pouces, et le développement des muscles de ses bras et de sa poitrine attestait une vigueur prodigieuse.

Il est de principe chez tous les chasseurs qui savent leur métier, dit ailleurs Du Chaillu, qu'il faut réserver son feu jusqu'au dernier moment. Soit que la bête furieuse prenne la détonation du fusil pour un défi menacant, soit pour toute autre cause inconnue, si le chasseur tire et manque son coup, le gorille s'élance sur lui, et personne no peut résister à ce terrible assaut. Un seul coup de son énorme pied, armé d'ongles, éventre un homme, lui brise la poitrine ou lui écrase la tête. On a vu des nègres, on pareille situation, réduits au désespoir par l'épouvante, faire face au gorille et le frapper avec leur fusil déchargé; mais ils n'avaient pas mème le temps de porter un coup inoffensif, le bras de leur ennemi tombait sur eux de tout son poids, brisant a la fois le fusil et le corps du malheureux. Je crois qu'il n'y a pas d'animal dont l'attaque soit si fatale à l'homme, par la raison méme qu'il se pose devant lui face à face, avec ses bras pour armes offensives, absolument comme un boxeur, excepté qu'il a les bras bien plus longs, et une vigueur bien autrement grande que celle du charrpion le plus vigoureux que le monde ait jamais vu.

Jamais la femelle n'attaque le chasseur; cependant des nègres m'ont dit'qu'une mère qui a son petit avec elle, se bat quelquefois pour le défendre. C'est un spectacle charmant qu'une mère accompagnée de son 
petit qui joue à côté d'elle. J'en ai souvent guetté dans les bois, désireux d'avoir des sujets pour ma collection; mais, au dernier moment, je n'avais pas le cour de tirer. Dans ces cas-là, mes nègres muntraient moins de faiblesse : ils tuaient leur proie sans perdre de temps.

Lorsque la mère fuit la poursuite du chasseur, le petit s'accroche par les mains autour de son cou, et se suspend a son sein, en lui passant ses pètites jambes autour du corps.

A l'histoire du gorille vivant en liberté, du Chaillu a joint l'étude qu'il a pu faire sur des jeunes dont il a tenté l'éducation.

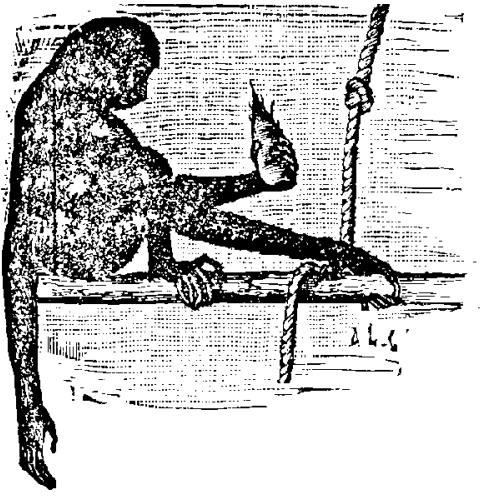

Fig. 403. - La gourmandise.

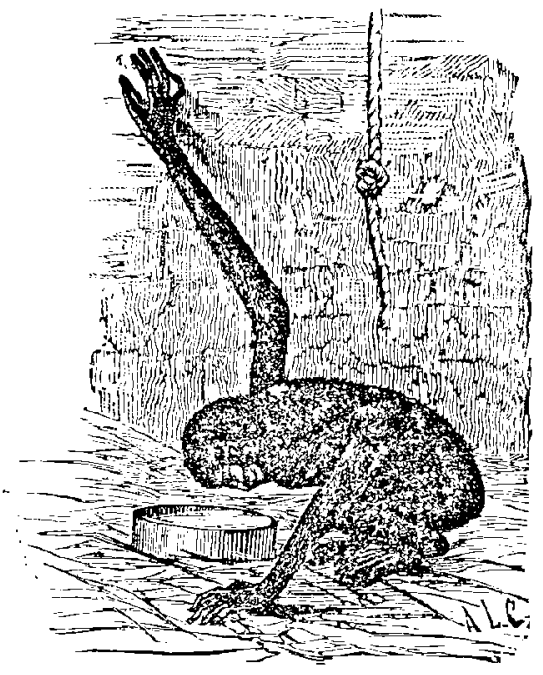

Fig. 404, - Le premier miroir.

Quelques chasseurs, qui avaient été battre les bois, écrit-il, me ramenèrent un jeune gorille vivant. Jo ne puis décrire les émotions que je ressentis à la vue de ce petit animal qui se débattait pendant qu'on le trainait de force dans le village. Ce seul instant me récompensa de toutes les fatigues et de toutes les soulfrances que j'avais endurées en Afrique.

C'était un petit être de deux à trois ans, qui avait deux pieds six pouces, aussi farouche d'iilleurs et aussi indocile que s'il eùt atteint tout son développement.

Mes chasseurs, que j'aurais embrassés, l'avaient pris dans le pays. Ils allaient, au nombre de cinq, gagner un village, près de la côte, et traversaient sans bruit la forèt, lorsqu'ils entendirent un cri qu'ils reconnurent aussitôt pour celui d'uu petit gorille qui appelait sa mère. Tout, du reste, était silencieux dans la forêt; il était près de midi; ils se décidèrent à se porter du côté d'où venait le cri, qui se fit entendre une seconde fois. Le fusil à la main, ils se glissèrent tout doucement dans un fourré épais où devait être le petit gorille; quelques indices leur 
firent reconnaître que la mère n'était pas loin; il y avait mème à croire que le mâle, le plus redontable de tous, se trouvait aussi aux environs. Pourtant les braves gens n'hésitèrent pas à tout risquer pour prendre, s’il était possible, un sujet vivant, sachant quelle joie me ferait cette capture.

Ils virent remuer les buissons; ils se faufilèrent un peu plus avant, silencieux comme la mort, et retenant leur respiration. Bientôt ils aperçurent, spectacle bien rare mème pour ces nègres, un jeune gorille assis, mangeant quelques graines à peine sorties de terre; à quelques pas étail aussi la mère, assise de même et mangeant du mème fruit. Ils se décidérent à tirer; il était temps, car au moment où ils levaient leurs fusils, la vieille femelle les aperçut: ils n'avaient plus qu'à faire feu, sans un instant de retard. Heureusement, ils la blessèrent à mort.

Elle tomba. Le petit gorille, au bruit de la décharge, se précipita vers sa mère, et se colla contre elle, se cachant sur son sein, et embrassant son corps. Lés chasseurs s'élancèrent avec un hourra de triomphe; mais leurs cris rappelèrent à lui le petit animal qui, lâchant te corps de sa mère, s'enfuit vers un arbre et grimpa avec agilité jusqu'au sommet où il s'assit.

Nos gens étaient bien embarrassés pour l'atteindre; ils ne se souciaient pas de s'exposer à ses morsures, et, d'un autre côté, ils ne voulaient pas tirer sur lui. A la fin, ils s'avisèrent d'abattre l'arbre et de jeter un pagne sur la tête du petit; ce qui n'empêcha pas un des hommes d'être mordu grièvement à la main, et un autre d'avoir la cuisse entamée.

On construisit une petite cabane de bambous très forte, avec des barreaux solidement fixés et assez espacés pour que le gorille pùt être vu et voir lui-même au dehors. Il fut jeté de force là-dedans; et pour la première fois je pus jouir tranquillement du spectacle de ma conquête. G'était un jeune mâle, qui, évidemment, n’avait pas encore trois ans ; tout à fait en état de marcher seul, il était doué pour son âge d'une force musculaire extraordinaire. Sa face et ses mains étaient toutes noires, ses yeux moins enfoncés que ceux des adultes. Les poils de sa chevelure commencaient juste aux sourcils et s'élevaient au sommet de la tête, où ils étaient d'un brun rougeâtre, pour redescendre des deux cótés de la face jusqu'à la mâchoire inférieure, en dessinant des lignes assez pareilles à nos favoris.

Quand je vis le petit camarade solidement enfermé dans sa cage, je mapprochai pour lui adresser quelques paroles d'encouragement. Il se tenait dans le coin le plus reculé ; mais, dès que j'avançai, il rugit et s'élança sur moi, et, quoique je me fusse retiré le plus vite possible, il réussit à saisir mon pantalon qu'il déchira avec un de ses pieds; puis il retourna vite dans son coin. Cette attaque me rendit plus circonspect; pourtant je ne désespérais pas de parvenir à l'apprivoiser. Mais il ne tarda pas à mourir (').

1. Du Challuv. Paysages et Aventures dans l'Afrique équatoriale. 
Les nègres se considèrent comme les cousins des orangs. Ils voient dans le chimpanzé un membre d'une race humaine particulière, que sa mauvaise conduite a fait rejeter hors de la société des lommes et que sa persistance dans le mal a fail descendre peu à peu au degré d'abjection dans lequel il vit actuellement. Gette considération n'empèche nullement ces indigènes de manger les singes qu'ils parviennent à tuer.

Le capitaine Grandpret cite l'histoire d'un chimpanzó femclle qui donnait les preuves les plus remarquables d'une intelligence développée.

Elle se trouvait sur un vaisseau qui devait la conduire en Amérique. On lui avait appris à chauffer le four, et elle s'acquittait de cet emploi à la satisfaction générale; elle prenait un soin particulier pour empêcher les charbons ardents de tomber sur le sol et reconnaissait très bien quand le four avait atteint le degré de chaleur voulu. Elle allait ensuite avertir le boulanger par des signes très expressifs; aussi celui-ci se fiait-il entièrement sur son aide et ne surveillait-il jamais le feu. Elle savait rempiir toutes les fonctions d'un matelot avec autant d'adresse que d'intelligence, hissait le cáble de l'ancre, serrait les voiles, les liait solidement et travaillait de manière à contenter tous les matelots, qui finirent par la considérer comme un compagnon. Malheureusement, cette magnifique bète mourut avant son arrivéc en Amérique, par suite de la cruauté du pilote. Celui-ci l'avait maltraitée, sans tenir compte des prières qu'elle semblait lui adresser. Elle joignait les mains en suppliante, pour toucher le cœur de son persécuteur; mais le barbare n'avait pas de cœur, et le langage si expressif de cet intelligent animal ne le touchait point. Il per sista dans sa cruauté grossière. La pauvre bête supporla patiemment ses mauvais traitements, mais à partir de ce moment, elle refusa toute espèco de nourriture, et cinq jours après, elle mourut de faim et de douleur. Tout l'équipara la pleura comme si un matelot était mort.

Brosse avait amené deux chimpanzés en Europe, un mâle et une fomelle, qui se mettaient à table comme des humains, mangeaient de tout et se servaient du couteau, de la cuillère et de la fourchette. Ils buvaient de toutes nos. boissons; le vin et l'eau-de-vie leur plaisaient surtout. Lorsqu'ils avaient besoin de quelque chose, ils appelaient les mousses; s'ils éprouvaient un refus de leur part, ils se fâchaient, les saisissaient par le bras, les mordaient et les jetaient à terre. Lo mâle étant tombé malade, lè médecin du bord le saigna; plus tard, dès qu'il se sentait indisposé, il tendait le bras au médecin.

Le chimpanzé qui fut élevé par Buffon marchait presque toujours debout, même lorsqu'il portait des objets très lourds. Il avait l'air triste et sérieux, 
tous ses mouvements étaient posés et raisonnables. Il n'aviit aucun des hideux défauts des cynocéphales, et n'était pas aussi espiègle que le sont en général les cercopithèques. Une parole ou un signe de son maître sulfisait pour le faire obéir. Il offrait le bras aux personnes qui venaient visiter Buffon, et se promenait avec elles; il se mettait à table, connaissait l'usage de la serviette, s'essuvait la bouche chaque fois qu'il avait bu, se versait lui-mème du vin et trinquait avec ses voisins. Il se cherchait une tasse avec sa soucoupe, y mettait du sucre, versait du thé et le laissait refroidir

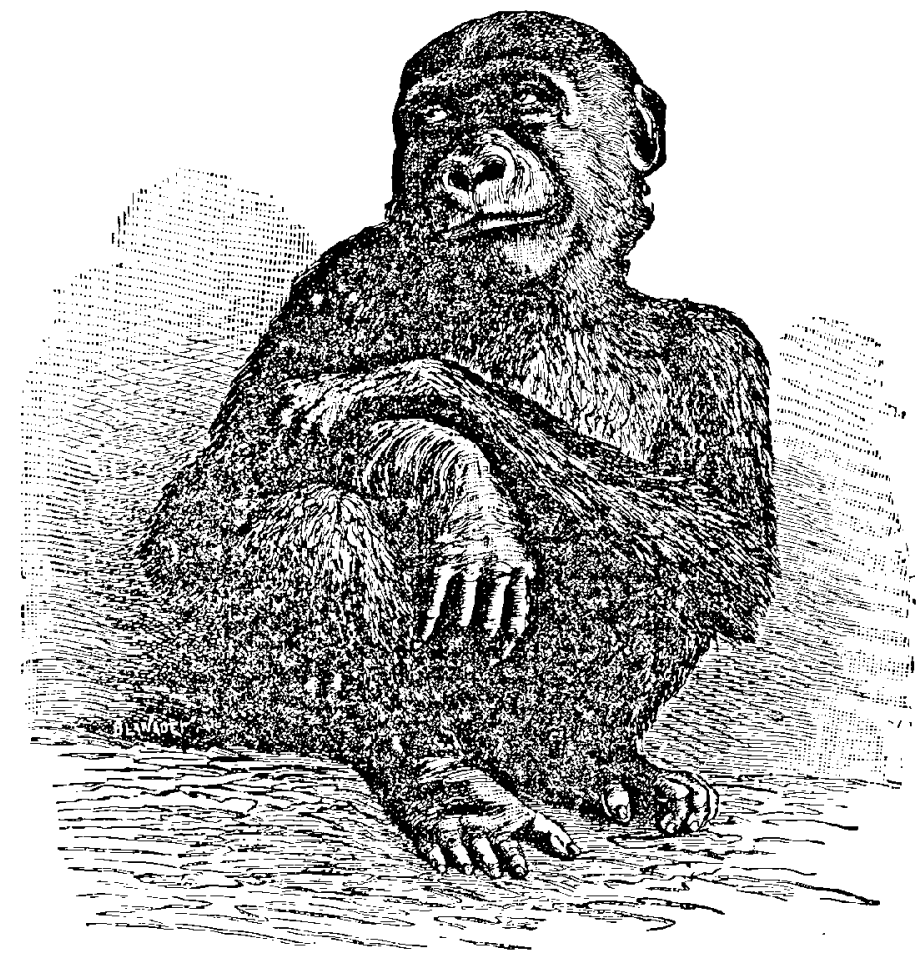

Fig. 40\%. - Le gorille du Muséum de Paris un mois avant sa mort (pholographie directe).

avant de boire. Jamais il ne faisait de mal à personne; au contraire, il s'ipprochait avec beaucoup de convenance des visiteurs, et témoignait tout le plaisir qu'il éprouvait à ètre caressé. Tous les amis de Bufron aimaient son domestique et lui apportaienl des biscuits et des fruits. Malheureusement, la phtisie l'enleva en moins d'un an.

Le docteur Traill avait amené en Angleterre un chimpanzé qui n'aimait pas la marche verticale et s'appuyait toujours sur les mains. Il était timide, mais devenait familier avec les personnes qu'il voyait souvent. Quand il avait froid, il s'enveloppait d'une couverture. Un jour, on lui 
présenta une glace, qui fixa immédiatement son attention; à sa grande mobilité habituelle succéda le calme le plus absolu. Il examinait avec curiosité le merveilleux instrument et restait muet d'étonnement. Il interrogeait son ami du regard, examinait de nouveau le miroir, tournait tout autour, considérait son image et cherchait, en touchant le miroir, à s'assurer s'il avait réellement sous les yeux un être de chair et d'os comme lui, ou bien s'il ne voyait qu'une simple apparence; en un mot il fit absolument ce que font les peuples sauvages lorsqu'on leur présente pour la première fois un miroir $\left({ }^{1}\right)$.

Il est vraiment dommage que la phtisie enlève si rapidement les chimpanzés et les gorilles que l'on éloigne de leur pays natal. Peu de temps après leur arrivée en Europe, ils commencent $\dot{a}$ tousser et deviennent plus tristes. A mesure que la maladie fait des progrès, leur calme et leur douceur paraissent augmenter; bientot ils font réellement pitié à voir. Ils penchent la tête en avant comme les personnes dont les poumons sont altaqués, toussent de temps en temps et posent leurs mains sur leur poitrine malade; leurs yeux brun foncé prennent une si grande expression de douleur, que l'homme ne peut les voir sins ètre ému. Ordinairement ils succombent à cette terrible maladie dès la première année et rarement dans la seconde; notre climat rigoureux ne peut jamais rendre leur belle patrie à ces heureux enfants du Midi ( $\left.{ }^{2}\right)$.

On a souvent essayé de conserver de

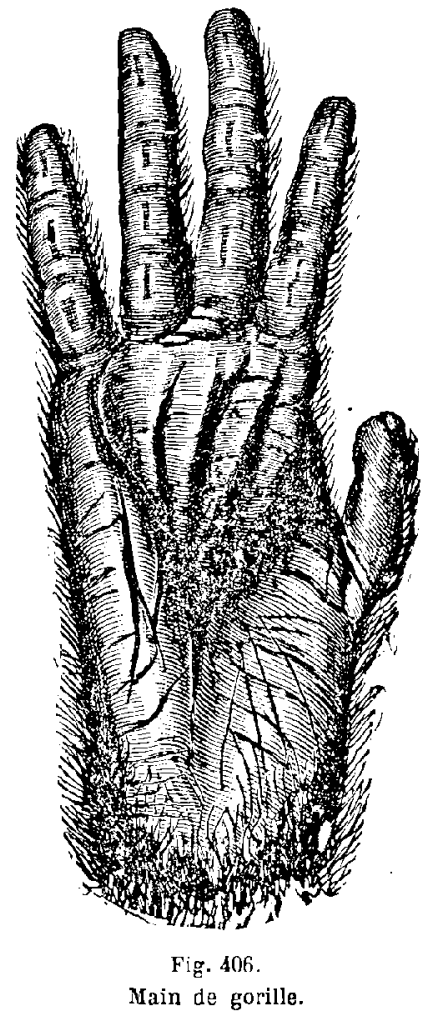
jeunes gorilles au Jardin des Plantes de Paris; les observations confirment tout ce qu'on vient de lire, et malheureusement aussi l'impossibilité de les voir vivre longtemps sous nos climats. La figure 405 représente, d'après üne photographie, le dernier que l'on y a possédé. Dans ce grand sentiment de mélancolie, n'a-t-on pas l'impression de l'exilé regrettant la patrie?

1. On a pu remarquer plus haut ( $f g .403$ et 401$)$ deux petits dessins pris sur nature, au Jardin des Plantes de Paris, de charmants petits singes révélant déjà quelques vestiges non déguisés de sentiments tout humains.

2. Bкенм. L'Homme et les Animaux. 
L'examen de la main du gorille ( $f g .406$ ) parle aussi bien que celui de sa tête en faveur de la ressemblance humaine. On pourrait presque y faire de la chiromancie.

Quelques mots encore sur une autre espèce, l'orang-outang. G'est un animal très doux et trés pãisible. Il n'est pas timide et ne fuit pas devant l'homme, qu'il regarde au contraire avec beaucoup de calme. Parmi les nombreuses observations que nous possédons sur les mœurs de ce singe (en captivité), on doit signaler celles que F. Cuvier a faites sur une jeune femclle qui a vécu un mois au château de la Malmaison, en 1808.

Cet animal employait ses mains comme nous employons généralement les nôtres. Il portait le plus souvent ses aliments à sa bouche avec ses doigts; mais quelquefois aussi il les saisissait avec ses longues lèvres, et c'était en humant qu'il buvait, comme le font tous les animaux dont les lèvres peuvent s'allonger. Il se servait de son odorat pour juger de la ature des aliments qu'on lui présentait et qu'il ne connaissait pas, et il paraissait consulter ce sens avec beaucoup de soin. Il mangeait presque indistinctement des fruits, des légumes, des œufs, du lait, de la viande, et il aimait beaucoup le pain, le café et les oranges; une fois il but, sans en être incommodé, tout le contenu d'un encrier tombé sous sa nain. Il ne mettait aucun ordre dans ses repas, et pouvait manger à toute heure, comme les enfants.

Nous avons dit que pour manger, il prenait ses aliments avec ses mains ou avec ses lèvres; il n'était pas fort habile à manier nos instruments de table, et à cet égard il était dans le cas des sauvages que l'on a voulu faire manger avec nos fourchettes et nos couteaux; mais il suppléait par son intelligence à sa maladresse; lorsque les aliments qui étaient sur son assiette ne se plaçaient pas aisément sur sa cuillère, il la donnait à son voisin pour la faire remplir. Il buvait très bien dans un verre, en le tenant entre ses deux mains. Un jour, qu'après avoir reposẻ son verre sur la table, il vit qu'il n'était pas d'aplomb et qu'il' allait tomber, il plaça sa main du côté où ce verre penchait, pour le soutenir:

Presque tous les animaux ont besoin de se garantir du froid, et il est bien vraisemblable que les orangs-outangs sont dans ce cas, surtout dans la saison des pluies. J'ignore quels sont les moyens que ces animaux emploient dans leur état de nature pour so préserver de l'intempérie des saisons. Notre animal avait été habitué à s'envelopper dans ses couver. tures, et il en avait presque un besoin continuel. Dans le vaisseau, il prenait pour se coucher tout ce qui lui paraissait convenable. Aussi lorsqu'un matelot avait perdu quelques hardes, il était presque toujours sûr 
de les retrouver dans le lit de l'orang-outang. Ie soin que cet animal prenait de se couvrir nous mit dans le cas de nous donner encore une très belle preuve d'intelligence. On étendait tous les jours sa couverture sur un gazon devant la salle à manger, et après ses repas, qu'il faisait ordinairement à table, il allait droit vers ce vêtement, qu'il plaçait sur ses épaules, et revenait dans les bras d'un petit dómestique pour qu'il le portât dans son lit. Un jour qu'on avait retiré la couverture de dessus le gazon et qu'on l'avait suspendue sur le bord d'une croisée, pour la faire sécher, notre orang-outang fut comme à l'ordinaire pour la prendre, mais de la porte ayant aperçu qu'elle n'était pas à sa place habituelle, il la chercha des yeux et la découvrit sur la fenètre; alors il s'achemiua près d'elle, la prit et revint comme à l'ordinaire pour se coucher (').

Ces relations prises sur nature, qu'il serait facile de multiplier, et qui pourraient s'étendre sur plusieurs volumes de la dimension de celui-ci, mettent, croyons-nous, sous le jour d'une évidence peu contestable les rapports physiques et moraux qui rattachent les races simiennes supérieures aux races humaines inférieures. Les rapports purement physiques ont été démontrés par les analogies du squelette et par les enseignements de l'anatomie comparée. Ceux-ci, à certains égards, nous paraissent plus importants encore. L'âme humaine s'est graduellement formée comme le corps.

Cette double ascension physique et morale de l'animalité vers l'humanité a été corrélative du développement du cerveau. C'es' là aussi un fait de la plus haute importance à reconnaître. Les sauriens, les dinosauriens, les' quadrupèdes et les mammifères de l'époque secondaire sont tous remarquables par l'exiguïté de leur cerveau. Cet organe de la pensée s'accroit pendant les temps tertiaires pour arriver graduellement jusqu'au cerveau des singes supérieurs. La loi est générale, quoiqu'il y ait diverses exceptions chez certaines espèces d'oiseaux, chez les souris, etc., mais l'accroissement est remarquable dans l'ensemble du développement du règne animal. Ce n'est pas que le degré de l'intelligence soit toujours en rapport avec le volume et le poids du cerveau; nous verrons tout à l'heure que c'est plutôt avec le nombre et la profondeur des circonvolutions cérébrales; cependant, le cerveau étant

1. Geoffroy Saint-Hilaire et Frédéhio Cuvier. Histoire naturelle des mammifères. 
l'organe de la pensée, on conçoit que le développement de la pensée se soit fait corrélativement avec l'accroissement de l'organe.

Le poids du cerveau est, en moyenne, de 1485 grammes pour l'homme européen, et de 1262 pour la femme de la même race. Il s'agit ici des tailles moyennes également. Le volume et le poids du cerveau étant naturellement en rapport avec la taille du corps tout entier, le poids absolu ne doit jamais être considéré indépendamment de la taille du corps auquel il a appartenu. La différence du poids entre le cerveau masculin et le féminin a surtout pour cause la mème différence entre le poids de l'homme et celui de la femme. L'homme européen pèse en moyenne 70 kilogrammes et la femme 65; la taille moyenne de l'Européen est de $1^{\mathrm{m}}, 65$ et celle de la temme de $1^{\mathrm{m}}, 53$; la taille de la femme est à celle de l'homme comme 93 est à 100 , et le poids des cerveaux comme 85 est à 100 . Toute proportion gardéc, la cervelle féminine est donc en réalité un peu plus légère que le cerveau masculin.

Le cerveau s'accroît, toutes choses égales d'ailleurs, avec le travail et l'activité dont il est le siègo. Son poids, que nous venons de voir égal à 1405 grammes pour l'homme européen adulte, varie depuis 2000 grammes jusqu'à 1000 . On en a même trouvé de supérieurs et d'infẻrieurs à ces deux limites, mais il s'agissait sans doute là de cas pathologiques.

On voit que, chez l'Européen, le poids du cerveau est environ le $50^{\circ}$ du poids total du corps normalement constitué (ni obèse ni étique).

Ce poids diminue à mesure qu'on descend dans l'ordre intellectuel, comme l'indiquent les mesures suivantes :

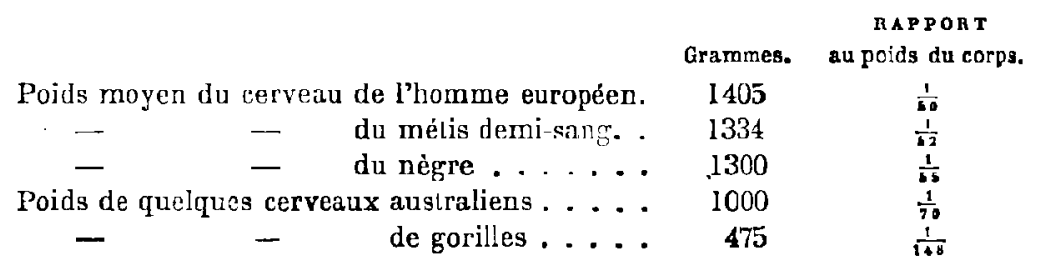

Ces diffẻrents êtres offrant à peu près la même taille et le même poids, les proportions sont à peu près celles que nous avons inscrites dans la seconde colonne. Ces proportions diminuent lorsqu'oun 
examine d'autres mammifères, éléphants, chiens, chevaux, lions, tigres, boufs; voici quelques-uns de ces rapports :

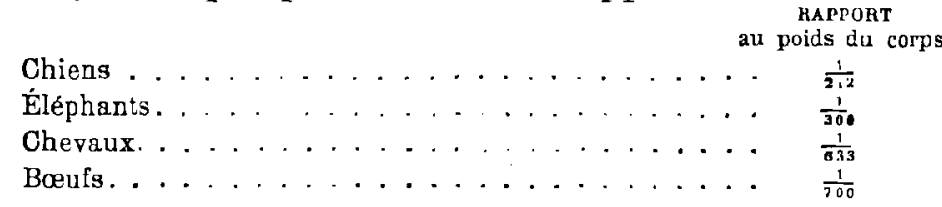

Mais, comme nous le remarquions tout à l'heure, ces rapports

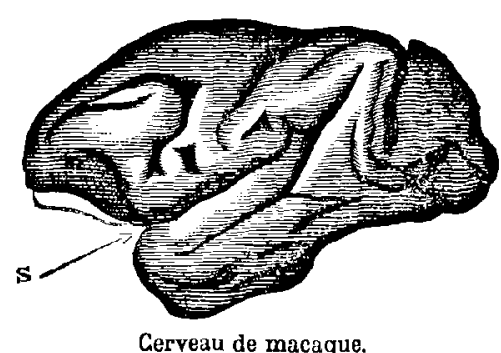

Cerveau de macaque.

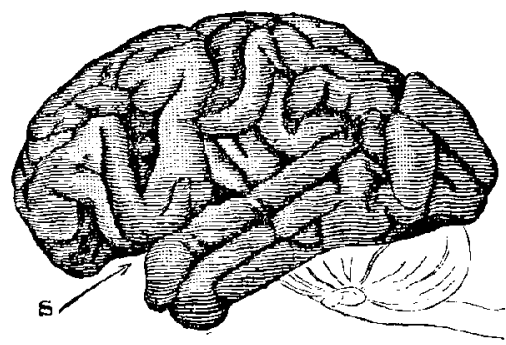

Cerveau de chimpanzé.

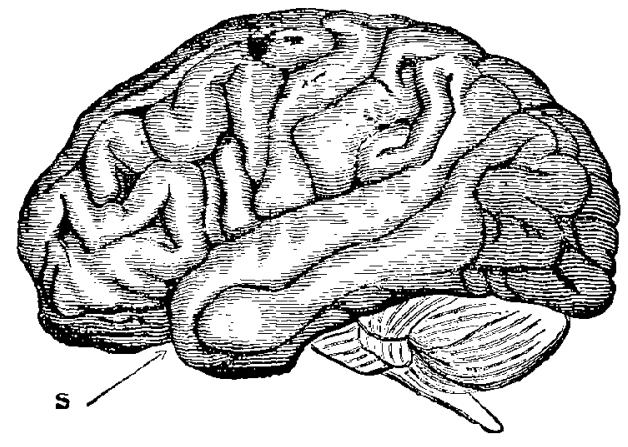

Cerveau de la Vénus hottentote.

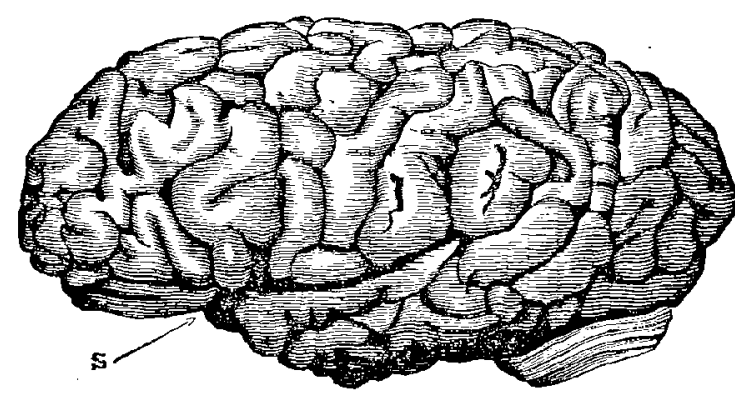

Cerveau du mathématicien Gauss.

Fin. 4O7. - Ies circonvolutions du cerveau et l'intelligence.

S. - Partage du cervean par in scissuro de Sylvias.

ne suffiraient pas pour apprécier le degré intellectuel : il faut leur ajoindre la nature des circonvolutions. Examinez par exemple le 
cerveau humain européen, vous remarquerez, à première vue, les nombreuses circonvolutions qui le caractérisent. Sans entrer dans aucun détail anatomique, qu'il nous suffise de dire qu'en thèse générale les cerveaux qui travaillent ont les circonvolutions plus marquées, plus tourmentées que ceux qui restent inertes. L'âme pétrit en quelque sorte la substance cérébrale. On sait que les actes de pensée, d'initiative personnelle se passent dans la substance grise qui constitue l'écor'ee des hćmisphères cérébraux et que les sensations se transmettent par les fibres dont l'ensemble forme la masse blanche centrale. Nos lecteurs savent aussi que le cerveau est partagé en deux hémisphères symétriques, que l'hémisphère gauche préside aux mouvements du côté droit et le droit à ceux du côté gauche, et que le premier a une prééminence importante sur le second : il est plus lourd, plus riche en circonvolutions, plus actif dans les opérations de la pensée, et, fait plus grave, c'est en lui (dans la troisième circonvolution frontale gauche) que réside la facultẻ du langage : un accident dans cette localité du cerveau supprime la parole ou apporte dans le langage les troubles les plus extraordinaires.

Plus il y a de substance grise et de surface sur laquelle elle puisse se développer en couche continue, et plus les opérations intellectuelles acquièrent de puissance; dans ce but, la surface se plisse, se contourne, de manière à multiplier son étendue. Tel est l'office des circonvolutions, renflements allongés et tortueux, séparés par des sillons plus ou moins profonds. Leur développement en nombre a pour conséquence la diminution de chacune d'elles en particulier. Des circonvolutions grosses et simples sont un signe de faible intelligence, dans quelque race humaine que ce soit; les circonvolutions petites et à plissements nombreux sont un signe de grande capacité intellectuelle.

Les petites espèces de mammifères ont le cerveau plus développé que les grandes (relativement à leur taille); la souris, par exemple a, par rapport à son corps, plus de cervean que l'homme. Mais ces espèces ont le cerveau entièrement lisse, pas de circonvolutions. L’organisation atteint le même résultat par deux procédés dont chacun à son importance.

Si l'on compare au cerveau humain celui des espèces qui sont 
anatomiquement et physiologiquement les plus voisines de nous, on constate que le nombre des circonvolutions s'accroit depuis les espèces de singes les plus inférieures jusqu'à l'homme. L'ouistiti, le plus inférieur de tous, a le cerveau absolument lisse; le macaque présente quelques circonvolutions; le nombre en augmente rapidoment d'espèce en espèce, et, tout à coup, presque sans transition, chez les anthropoïdes, chimpanzés, orangs et gorilles, elles se révèlent avec leurs merveilleuses complications. Les circonvolutions essentielles, seules communes à tous les cerveaux humains, se retrouvent, sans exception, sur les cerveaux de l'orang et du chimpanzé. Il y a un abime entre le cerveau du ouistiti et colui du chimpanzé; il n'y a qu'une nuance entre celui-ci et le cerveau humain; comparez, du reste, les dessins de la figure 407. Ce sont là des faits. Celui qui, pour une raison ou pour une autre, refuse de les reconnaitre, est un aveugle volontaire.

La comparaison des diverses races humaines et des singes donne des résultats analogues, si nous examinons la capacité crânienne et l'angle facial :

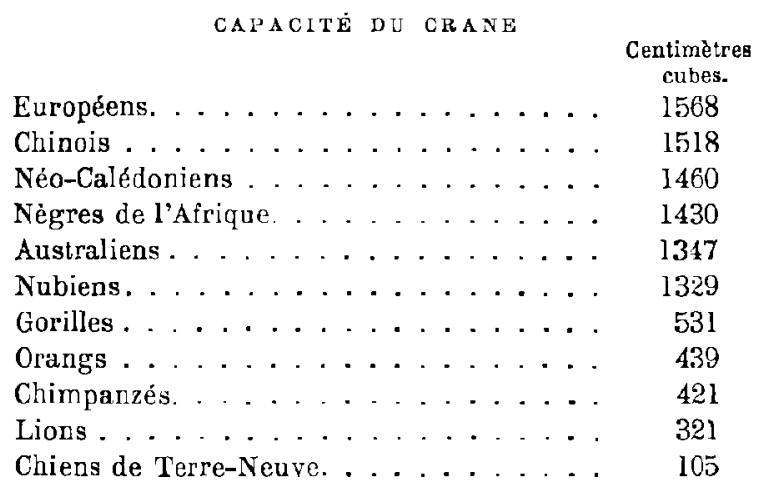

On a remarqué que les crânes du douzième siècle trouvés dans les anciens cimetières de Paris, sont un peu plus petits que ceux des Parisiens actucls. La proportion est de 1504 contimètres cubes à 1558 .

L'angle facial est d'autant plus ouvert que le front est plus développé, et que la race est plus intelligente. Voici quelques mesures :

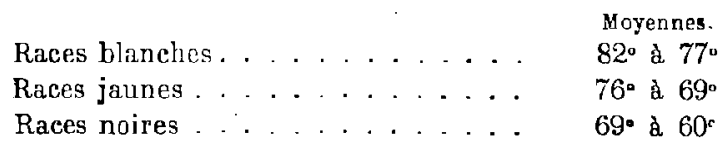


Celui des Français est, en moyenne, de $78^{\circ}$; celui des Chinois, de $72^{\circ}$; celui des Néo-Calédoniens, de $70^{\circ}$; celui des nègres de l'Afrique occidentale, de $67^{\circ}$; celui des Boschimans, de $60^{\circ}$.

Les races humaines inférieures établissent une transition physique et intellectuelle entre les singes anthropoïdes et les races européennes. Les exemples ne manquent pas de races placées si bas qu'on les a tout naturellement rapprochées des singes. Ces races, beaucoup plus près que nous du véritable état de nature, méritent par cela mẻme toute l'attention de l'anthropologiste et $d u$ linguiste qui, tous deux, peuvent aller chercher chez elles la solution de problèmes insolubles ailleurs. C'est pour n'avoir pas étudiè les caractères physiologiques de ces races, qu'on est tombé dans d'étranges méprises.

L'exemple le plus souvent cité est celui des indigènes de l'Australie. " Ils ont toujours montré une profonde ignorance, disent Lesson et Garnot, un véritable abrutissement moral... Une sorte d'instinct très développé pour conquérir une nourriture tonjours difficile à obtenir, semble avoir remplacé chez eux plusieurs des facultés morales de l'homme. Si la police anglaise n'y veillait de fort près, ils braveraient chaque jour, dans les villes des colonies, les lois de la décence publique, sans plus de souci que des singes dans une ménagerie. »

Hale écrit qu'ils ont presque la stupidité de la brute, qu'ils ne savent compter que jusqu'à quatre, quelques tribus jusqu'à trois. " La faculté de raisonner, dit-il, paraît chez eux très imparfaitement développée. Les arguments dont font usage les colons pour les convaincre ou les persuader, sont souvent de ceux qu'on emploie avec les enfants ou les gens presque idiots.

Quoy et Gaymard, racontent ainsi leur entrevue avec ces popula. tions misérables : « Notre présence leur causait une sorte de gaité; ils cherchaient à nous communiquer leurs sensations avec une loquacité à laquelle nous ne pouvions répondre, car nous n'entendions pas leur langage. Dés que la rencontre s'opérait, ils venaient à nous les premiers, en gesticulant et en parlant beaucoup; ils poussaient de grands cris et, si nous leur répondions sur le mème ton, leur joie était extrême. Bientôt l'échange de nom avait lieu, et ils ne tardaient pas à demander à manger en se frappant sur le ventre. Le 
tableau que ces voyageurs avaient devant elx est tellement triste et navrant qu'ils ajoutent aussitôt, comme par acquit de conscience : "Cependant, ils ne sont point stupides. 》 Non, sans doute, mais ils ne semblent mème pas mériter l'épithète de : " malin comme un singe. "Ils ne sont point stupides, et voilà tout.

Les Australiens ne sont pas seuls dans ce cas; Bory de SaintVincent nous a tracé un tableau à peu près aussi triste des habi-

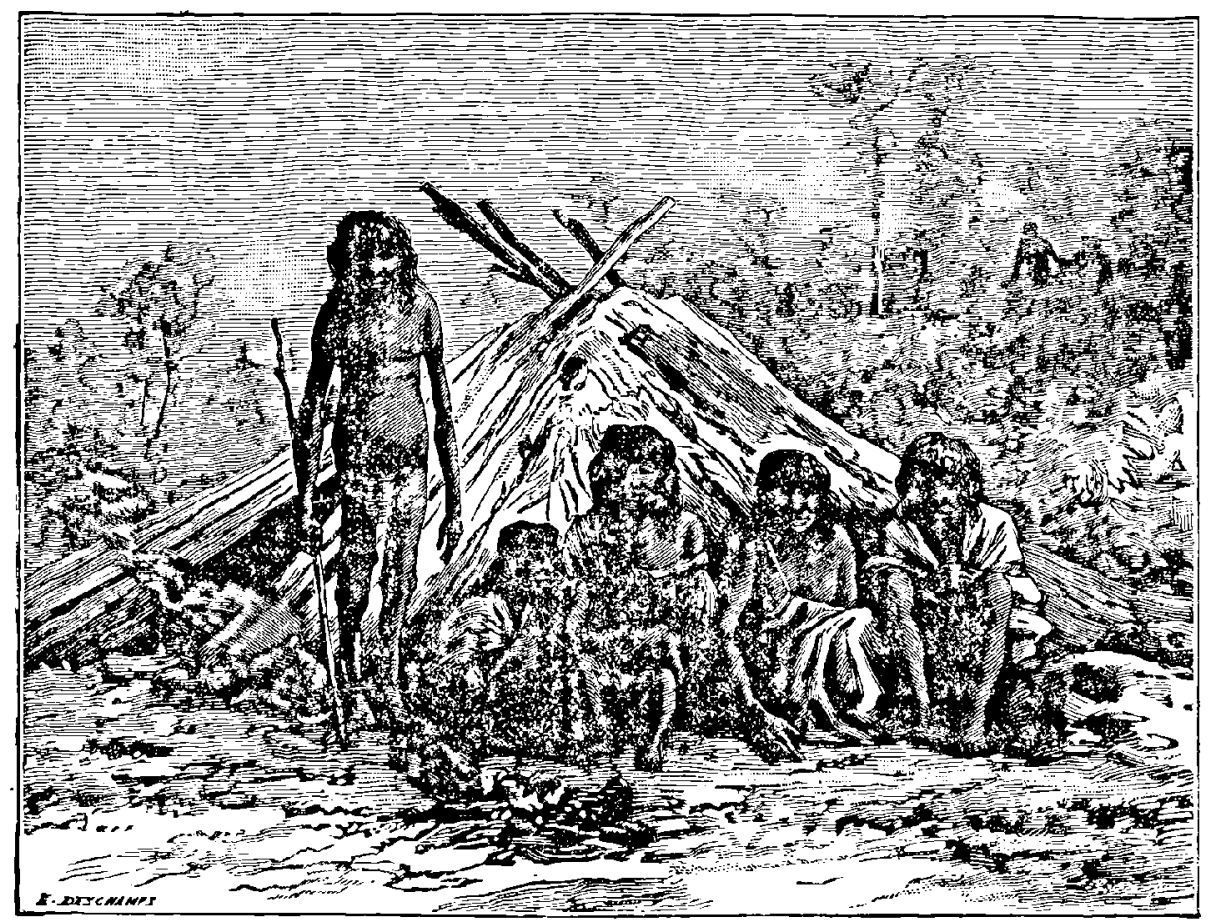

Fig. 408. - Les races primitires actuelles. Patagons, en 1882.

tants du sud de l'Afrique, beau et fortile pays. A l'extrémité de l'Amérique du Sud, en Patagonie, les Fuégiens sont tout aussi misérables et aussi primitifs.

A l'autre extrémité du monde, sur ce continent de glace qui cnvironne le pôle boréal, nous retrouvons la mème abjection.

John Ross, perdu dans les glaces, se trouva en présence d'une peuplade qui n'avait jamais vu un Européen. Le navigateur anglais, d'une religion profonde, était dans les meilleures conditions pour envisager avec indulgence les seuls êtres à portée de son affection, et 
cependant,... observateur attentif et scrupuleux, sincère avant tout, il dut désespérer de trouver dans ces âmes l'étincelle vivifiante qu'il y cherchait. « L'Kskimau, dit-il, est un animal de proie, sans autre jouissance que celle de manger; dépourvu de tout principe, sans aucune raison, il dévore aussi longtemps qu'il peut, et tout co qu'il peut se procurer, comme le vautour et le tigre. » Et plus loin : \& L'Eskimau ne mange que pour dormir, et ne dort que pour remanger aussitôt qu'il le peut. »

Nous allons descendre encore, trouver des hommes tels que ceux qui les ont vus, ont pu dire que dans les branches touffues ou les ombres des forêts, ils auraient été embarrassés pour décider s'ils avaient devant eux des singes ou des hommes. Et, qu'on y fasse attention, ce n'est pas dans des terres pauvres ou reléguées au bout du monde, que vivent ces déshérités de la forme humaine, c'est sur le continent asiatique même, au sud de la chaîne de l'Himalaya, au centre de l'Indoustan, dans ces régions qui ont été le berceau de quelques grandes espèces de singes, ̀̀ l'époque sans doute où les iles de l'archipel indien reliées à l'Asie ne formaient qu'un immense continent, patrie de la race malaise.

Piddington, établi au centre de l'Indoustan, raconte lui-même qu'il vit arriver avec une bande d'ouvriers Dhangours qui venait chaque année travailler à la plantation, un homme et une femme d'étrange aspect, et que les Dhangours désignaient sous lo nom de peuple-singe.

lls avaient un langage à part. Autant qu'on en put apprendre par signes, ils vivaient bien au delà des Dhangours dans les forêts et les montagnes et n'avaient que peu de villages. Il paraitrait que l'homme s'était sauvé avec la femme à la suite de quelque accident, peut-être d'un meurtre volontaire. Ce qui est certain, e'est que les Dhangours les avaient recueillis perdus dans les bois, épuisés et presque morts de faim. Ils disparurent une nuit, au moment où Piddington se disposait à les envoyer à Calculta. Piddington décrit ainsi l'homme : Il était petit, avait le nez plat, des rides en demicercles couraient autour des coins de la bouche et sur les joues; ses bras étaient disproportionnellement longs, et l'on pouvait voir un peł de poil roussâtre sur sa peau d'un noir terne. Blotti dans un 
coin obscur ou sur un arbre, on eut pu se tromper et le prendre pour un grand orang-outang.

Piddington avait beaucoup voyagé, avait vu tour à tour des Boschimans, des Hottentots, des Papous, des Alfours, les indigènes de la Nouvelle-Hollande, de la Nouvelle-Zélande et des Sandwich, ce qui lui donnait une certaine expérience d'observateur.

Le nom que les Cafres donnent à l'Ettre divin témoigne qu'ils n'avaient autrefois aucune idée de rien de scmblable. Ce nom est Tixo et son histoire est trop curieuse pour n'être pas rapportée; c'est un composé de deux mots qui, ensemble, signifient le genou blessé. C'était, dit-on, le nom d'un médecin ou sorcier célèbre parmi les Hottentots et les Namaquas, il y a quelques générations, en conséquence d'une blessure qu'il avait reẹue au genou. Ayant été tenu en grande réputation pour son pouvoir extraordinaire pendant sa vie, le GenouBlessé continua d'ètre invoqué, même après sa mort, comme pouvant encore soulager et protéger; et, par la suite, son nom devint le terme qui représenta le mieux à l'esprit de ses compatriotes leur confuse conception du Dieu des missionnaires.

Pour les Eskimaux, dès 1612, Whitebourne écrivait « qu'ils n'avaient aucune connaissance de Dieu, et ne vivaient sous aucune forme de gouvernement civil ». Et nous pouvons joindre à ce témoignage déjà ancien les lignes suivantes du journal de John Ross qui habita longtemps au milieu d'eux : " Comprirent-ils quelque chose de tout ce que j'essavai de leur apprendre, leur' expliquant les choses les plus simples de la manière la plus simple que je pus m'imaginer? Je ne saurais le dire. Aurais-je mieux réussi si j'avais mieux compris leur langue? j'ai beaucoup de raisons pour' en douter. Qu'ils possèdent quelque rudiment d'une loi morale écrite dans le ceur, je ne saurais le nier, et de nombreux traits de leur conduite le montrent; mais au delà de ces indices, je n'ai jamais pu arriver $\dot{a}$ une conclusion satisfaisante. Quant à leurs opinions sur les points esseritiels dont j'aurais pu déduire l'existence d'une religion, je ne suis jamais parvenu mème à asseoir une conjecture qui valût la peine d'etre rapportée. Force me fut, pour le moment, d'abandonner toute tentative en désespoir de cause. » Ce fragment est d'autant plus important qu'on y croit sentir à chaque mot le chagrin d'un homme qui n'a pas trouvé dans le 
cœur d'autres hommes un écho fraternel à ses sentiments les plus chers (').

Un grand nombre d'hommes primitifs vont entièrement nus. Le docteur Schwcinfurth, dont on connait les expéditions récentes au cœur de l'Afrique, rapporte que chez les Dinkas, entre autres, « un

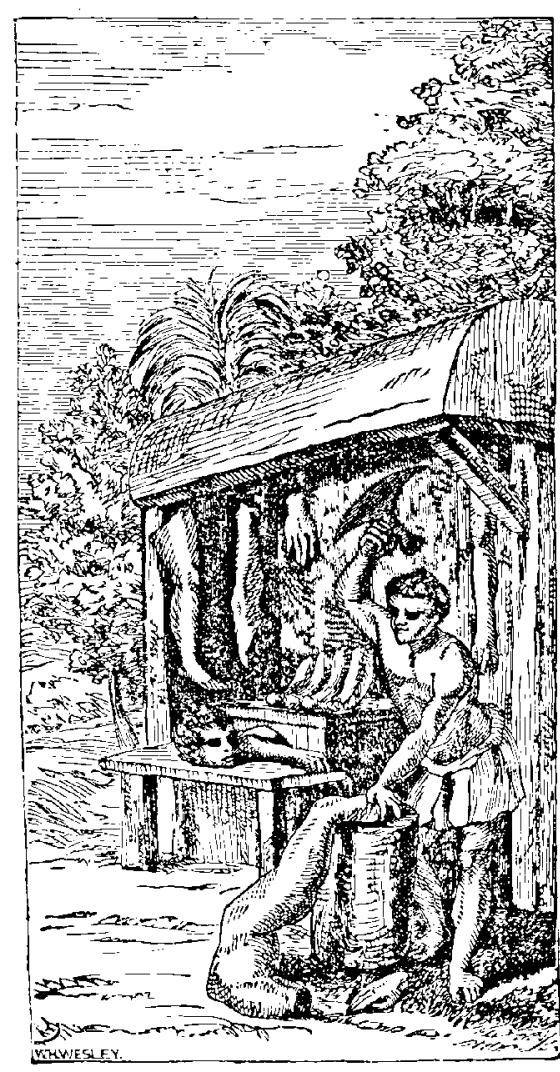

Fif- 409

Boucherie humaine dans l' $A$ frique centrale, en 1598 , d'après le voyage de Pigafetta. appareil quelconque, si restreint qu'il soit, parait indigne du sexe fort ». Les Nubiens, qui portent une légère ceinture, sont traités de femmes par les Dinkas, dont les femmes, en effet, portent des tabliers de peaux. Les Chillouks et les Diours, autres tribus de l'Afrique centrale, n'ont pas d'autre costume que celui de la nature et vont entièrement nus comme les Dinkas. La couleur de leur peau est celle dn chocolat. Les uns se taillent les incisives en pointes pour mieux mordre leur adversaire, tandis que d'autres se les arrachent pour obëir à la mode. Les Bongos portent une ceinture, mais leurs femmes « re. fusent opiniâtrément toute parcclle de cuir ou d'étoffe »: une branche souple et garnie de feuilles ou un petit bouquet d'herbe compose toute leur garde-robe. Les uns et les autres se mettent aux bras

et aux jambes, quelquefois an cou, de lourds anneaux de fer ou de cuivre, et les femmes, à peine mariées, se percent la lèvre inférieure dans laquelle elles font entrer d'énormes chevilles de plus en plus grosses atteignant jusqu'à deux et trois centimètres de diamètre. Les Bongos n'ont pas la moindre conception de l'immortalité. Toute

1. Georges Ponchet. De la Pluralite des races humaines. 
religion, dans le sens que nous donnons à ce mot, leur est étrangère. En dehors du terme « loma », qui signifie également heur et malheur, ils n'ont pas dans leur idiome un seul équivalent du mot divinité. Ils appellent bien loma-gobo le dieu des Turcs dont ils ont entendu parler, mais pour eux, ce motest synonyme de chance.

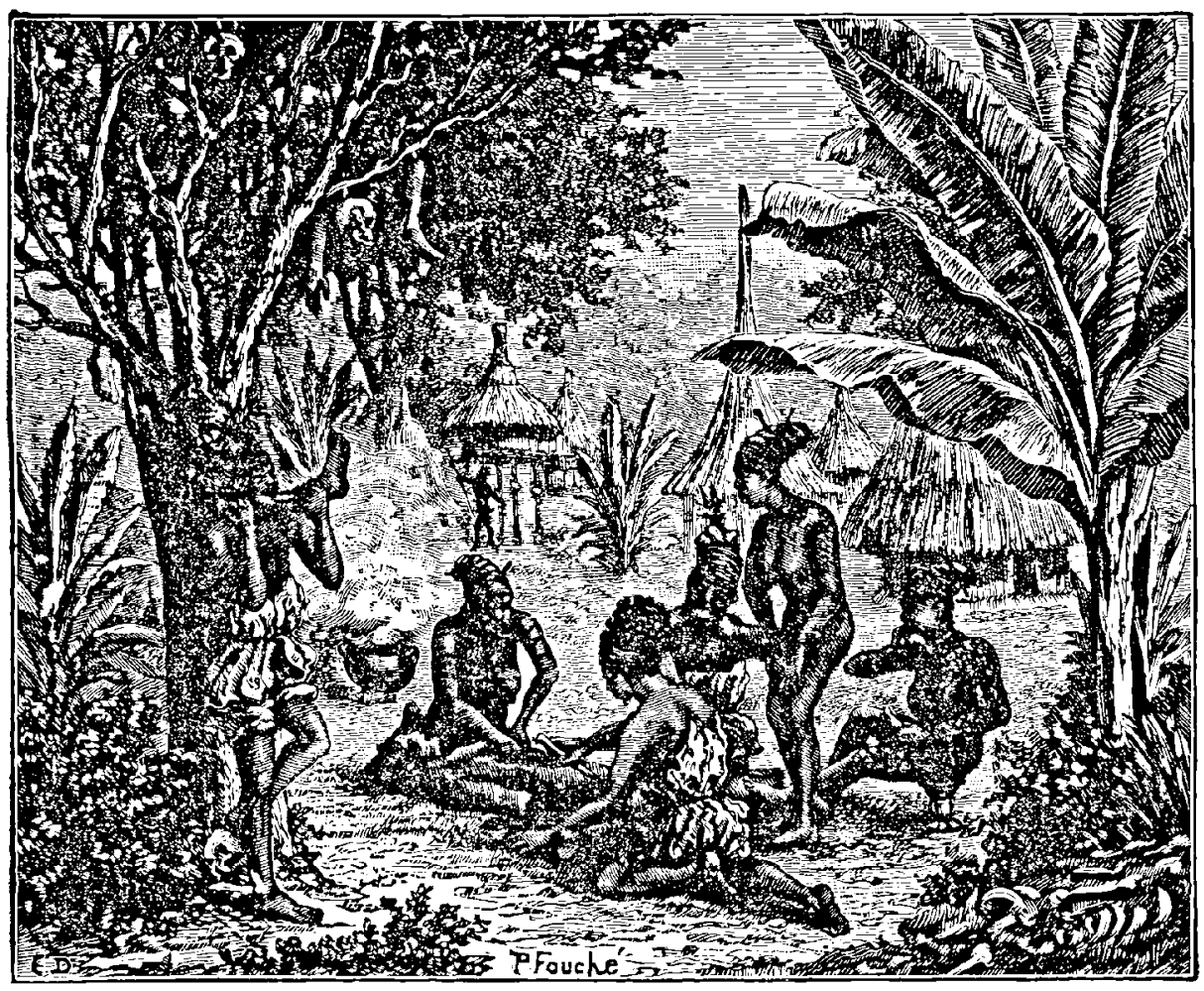

Fig. 410. - Anthropophages de l'A frique centrale, en 1870, daprès le voyage de Schweinfurth.

Lorsqu'ils reviennent de la chasse sans avoir rien pris, ils disent: " loma nyan », “ je n'ai pas de chance ». Les termes les plus ordinaires par lesquels nous exprimons des idées abstraites leur manquent d'une manière absolue; chez eux, les équivalents des mots esprit, âme, immortalité, infini, temps, espérance, pensée, réflexion, sentiment, couleur, odeur, etc., n'existent pas, et il en est de mème chez toutes ces races inférieures. Leur langage n'est en quelque sorte qu'une imitation plus ou moins bien combinée. Ainsi le chat se nomme mbriahou; ronfler se dit marougòun; une boule, koulloukoûle; une cloche, gùlongolo, etc. Les noms des 
individus sont des noms d'animaux ou de plantes. Chez les Diours, le mode de salutation le plus noble est de cracher l'un sur l'autre, et le crachat est toujours parfaitement accueilli.

Les Niams-Niams portent généralement une ceinture disposée d $r$ manière à simuler une queue. A côté d'eux, les femmes a-bang. n'ont pour tout costume qu'un lambeau d'écorce de figuier granil. comme la main. Les Niams-Niams sont encore anthropophages; lours hameaux ont toujours à leur entrée des poteaux et des arbres servant à l'exhibition des trophẻes de chasse et de guerre. $\propto$ Il y avait là, raconte Schweinfurth dans son voyage, des massacres d'antilopes de maintes espèces, des têtes de sangliers, de petits singes, de babouins, de chimpanzés, auxquelles s'ajoutaient des crânes d'hommes, les uns dans leur enticr, les autres par fragments : tout cela pendait aux branches comme les étrennes ì celles d'un arbre de Noël. Enfin, témoignage non équivoque d'anthropophagrie; on voyait près des huttes, dans les débris de cuisine, des os d'hommes qui portaient des traces évidentes de la hache ou du couteau; et aux arbres voisins étaient accrochées des mains et des pieds à moitié frajs qui répandaient une odeur révoltante. L'hospitalité en pareil cndroit n'avait rien d'engageant; toutefois, surmontant notre répugnance, nous nous installâmes du mieux possihle $n$.

Cette région de l'A frique centrale, habitée par ces hommes primitifs, parait être aussi la patrie des chimpanzés. Du moins, le voyageur que nous venons de citer a-t-il rencontré là un nombre considérable de crânes dans les hameaux, et les Niams-Yiams leur font-ils une chasse habituelle dans toutes les forêts du pays. Les indigènes assurent, de mème que ceux de l'ouest de l'Afrique, que ces singes à forme humaine enlèvent les femmes et les jeunes négresses et qu'il est trés difficile de les leur reprendre. " Ces troglodytes se défendent avec rage : acculés dans un coin, ils arrachent les armes des mains des agresseurs, et, à leur tour, en usent contre l'ennemi. »

Voisins des Niams-Niams, les Mombouttous mettent en pratique l'anthropophagie à un plus haut degré que ceux-ci, non par besoin, car ils ont à leur disposition un grand nombre d'animaux, mais par pure gourmandise. Elle est habituclle chez eux, lorsqu'ils peuvent 
avoir des victinies sulus la main( $\left.{ }^{4}\right)$. Ils sont entourés de tribus noires plus inférieures qu'eux encore dans l'ordre intellectuel et social; et leur font une chasse assidue, comme ailleurs aux singes ou comme aous le faisons en Europe pour le gibier. Les curps de ceux qui

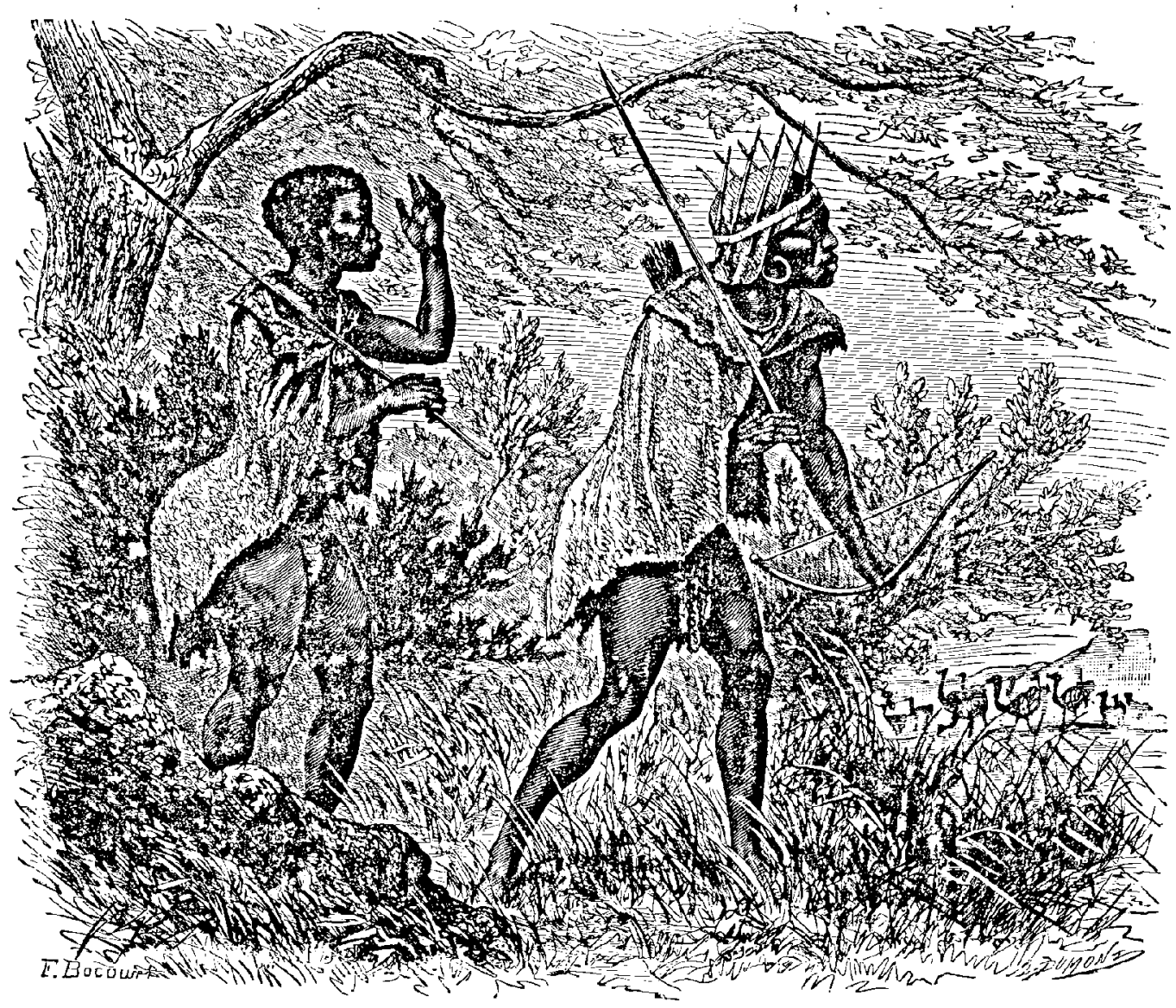

Fig. 411, - Boschismans à la chasse.

tombent sont immédiatement découpés en morceanx, taillés en longues tranches, grillés sur place et emportés comme régal. Les

(1) On a rappelé plus haut (fig. 410) celte scène de cannibalisme d'après le texte mème de lauteur. Ce n'est point nouveau. On trouve dans les voyages de Pigafetta, rédigés sur les manuscrits de Lopez, qui visila au XVI' siècle le Congo et l'Afrique centrale, la figure 409, qui n’a peut-etre qu'un défaut, celui d'avoir dessiné la race blanche du lieu de la race noire. L'anthropophagie est ancienne dans l'humanité. Humboldt rapporte que dans les pays où l'on fait, rotil des singes pour la cuisine, la transition du singe à l'homme parait à peine sensible. 
prisonniers sont conservés, parqués comme des moutons et égorgés les uns après les autres comme viande fraiche. Les enfants sont réservés en friandise pour les chets. "Pendant notre séjour, dit Schweinfurth, on tuait tous les matins un enfant pour la table du roi (Mounza). Un jour, passant près d'une case où se trouvait un groupe de femmes, je vis celles-ci en train d'échauder la partie. inférieure d'un corps humain, absolument comme chez nous on échaude et l'on racle un porc après l'avoir fait griller. L'opération avait changé le noir de la peau en un gris livide. Quelques jours après, dans une autre case, je remarquai un bras d'homme suspendu au-dessus du feu ». En cuisine, on se sert surtont de graisse humaine : c'est le beurre frais des fins gourmets.

a La polygamie règne sans réserve. L'union matrimoniale de la famille n'existe guère que pour la forme. Les femmes elles-mèmes sont d'une obscénité révoltante. Elles vont entièrement nues, comme les Bongos, dont un bouquet de feuilles constitue le seul voile, mais leur nudité à elles est différente et reste sans excuses $»$. Tout cela est plus singe qu'humain.

Les Ounyariézi des grands lacs peuvent être réunis aux tribus qui précèdent. Naguère encore, ils laissaient leurs morts sans sépulture, se contentant de les jeter dans quelque fourré pour les faire dévorer par les hyènes; aujourd'hui un certain nombre imitent la coutume des Arabes et enterrent leurs morts. Près du cadavre d'un chef on enterre vivantes trois esclaves pour lui épargner les horreurs de la solitude! Toutes les cérémonies de ces populations sont accompagnées de libations copieuses.

Parmi les races inférieures de l'Afrique, on peut citer aussi les Hottentots et les Boschismans. Les premiers se distinguent par leur petite taille, leur peau d'un jaune sale, leur physionomie repoussante; leurs cheveux sont noirs, longs, laineux et insérés par petites touffes, de telle sorte que, lorsqu'ils commencent à pousser, ils forment des petites masses de la grosseur d'un grain de poivre. Ils ont le crâne petit et très allongé, le front étroit, mais élevé.

La face du Hottentot présente un aspect tout particulier : elle al une forme triangulaire très accusée, ce qui tient à la saillie des pommettes et au rétrécissement du bas de la figure jusqu'au runton. Cette forme fait paraître la tête maigre et trop petite pour le 
corps. Les yeux sont obliques comme chez les Chinois, avec lesquels les Hottentots ont une certaine ressemblance due à la saillie des pommettes et à la couleur de la peau. Le nez est extrèmement épaté, les narines très grosses et les mâchoires fort saillantes; la bouche est grande et entourée de lèvres retroussées et volumineuses.

Chaque tribu nomme un chef dont les pouvoirs sont limitès; en cas de guerre, chacun combat à sa façon, sans être guidé par des chefs militaires. Ils ont les sens fort développés; à la trace la plus fugitive, ils reconnaissent les hommes et les animaux qui y ont passé, et devinent à première vue à quelle race, à quelle tribu un homme appartient.

Il serait facile de pousser plus loin ces relations. Qu'il nous suffise d'avoir compris, par l'observation directe, que ces tribus inférieures de l'humanité, ces ètres matériels, grossiers, ignorants, inaptes à toute abstraction morale, scien tifique ou artistique, sont plus rapprochés de leurs voisins les chimpanzès, les orangs et les gorilles que de la race intellectuelle à laquelle nous devons des esprits tels que Newton, Leibniz, Kepler, Archimède, Phidias, le Dante, Shakespeare, Léonard de Vinci, Pascal, d'Alembert, Raphaël, Mozart, Chopin, Hugo et leurs émules à différents titres. Et remarquons que déjà il devient très difficile de trouver des races primitives naturelles, car depuis longtemps les voyageurs et les missionnaires ont infiltré un peu partout les idées appartenant au. progrès de notre civilisation supérieure. Sans doute, on pourrait, à certains égards, contester la supériorité de notre propre état intellectuel et moral. Aux religions les plus pures on peut reprocher les infamies les plus grossières : aux chrétiens les horreurs, les crimes, les supplices de l'inquisition et des guerres de religion; aux musulmans les tueries et les mutilations qui ont ensanglanté leurs conquêtes; aux gouvernements les plus sages de l'Europe, l'ignominie de la paix armée, le sang qui coule aux quatre veines de l'humanité, la diplomatie qui suce le sang des citoyens, etc., etc., et, un peu partout, le règne avoué ou hypocrite du droit du plus fort. Sans doute, un habitant du système de Sirius ou de quelque monde véritablement intellectuel ne ferait pas une bicn grande différence entre les Européens, 
les Américains, les Asiatiques d'une part, et les tribus australiennes ou africaines dont nous venons de parler, et peut-être envelopperaient-ils tous les habitants actuels de notre planète dans la même pitic. Mais enfin, tout est relatif. Il n'est pas contestable que nous sommes moins imparfaits que ces tribus sauvages et que nos intelligences vivent dans une sphère supérieure à la leur. Le résultat de cette étude a été de nous montrer les rapports qui relient l'humanité au règne animal, dont elle s'est difficilenent et lentement dégagée.

On a dit que, comme l'humanité a pris possession de la planète et a dominé le règne animal tout entier par l'exercice de ses facultés supérieures, de même nous pourrions craindre que le jour vienne où une nouvelle race sortît de terre, autant supérieure à nous que nous le sommes aux autres mammifères, et nous asservità san tour comme nous avons dominé les races infërieures. L'idée a été discutée et célébrẻe en différents ouvrages de toutes les langues. C'est là une erreur. Les races ne sortent pas de terre. L'humanité de l'avenir ne sera certainement pas la nôtre ; mais elle se sera formée progressivement, elle sera le développement insensible de ce que nous sommes. G'est nous qui aurons grandi, qui serons devenus plus sages, qui aurons supprimé l'asservissement physique et moral de l'homme, et qui aurons créé, par le bien futur, le règne de la lumière et de la liberté.

Ainsi, on ne saurait trop le répéter, et la question est hors de cause, l'homme occupe par son intelligence la première place dans la série des êtres; il règne donc à juste titre sur tout ce qui a vie sur sa planète. Mais, il faut aussi le reconnaitre, il ne présente pas de différence radicale avec ses plus proches voisins, les singes anthropoïdes. Anatomiquement, ce sont les mêmes organes, construits et disposés de la mème facon et ne s'écartant que par des nuances secondaires les pieds, les mains, la colonne vertébrale, le thorax, le bassin, les organes des sens, tout est organisé de mème; le cerveau dans sa structure et ses circonvolutions est aussi identique physiologiquement, ce sont encore les mẻmes fonctions s'exerçant d'une manière unique; leurs maladies enfin sont semblables. Toutes les différences physiques sérieuses résident dans le volume du cerveau, qui est trois fuis plus développé chez l'homme.. et dans ses propriétés dont la 
pondération et coordination donnent à celui-ci le jugement, la raison et l'intelligence, qui sont le plus beau fleuron de sa couronne. Au paint de vue moral, nous avons reconnu la gradation de l'esprit depuis les animaux jusqu'à l'homme. Mais la question suivante s'impose tout naturellement ; parmi les quatre genres dont les singes anthropoïdes se composent, en est-il un qui soit plus voisin de l'homme?

Le gibbon doit être mis de côté. Par ses circonvolutions cérébrales et l'ensemble de sa colonne vertébrale, il est réellement supérieur, mais par les proportions de ses membres, l'étroitesse de son bassin, Ia disposition de ses muscles, il ètablit la transition aux pithéciens.

L'orang occupe également une place défavorable par quelques caractères anatomiques qui lui sont propres, par les proportions de son squelette, par ses pieds et ses mains défectucux; mais il se relève par ses circonvolutions cérébrales, par son angle facial, par ses côtes, par ses dents, et peut-être aussi par son intelligence.

Le chimpanzé a pour lui la richesse des circonvolutions cérébrales, les proportions de son squelette, la disposition de ses fémurs et la physionomie générale de son crâne.

Le gorille enfin a en sa faveur le volume du cerveau, la direction de son regard, sa taille, les proportions générales de ses mem. bres, la disposition de ses muscles, de sa main, de son pied, de sor. bassin; mais il a treize paires de côtes, une colonne vertébrale défectueuse, et des canines fort longues.

Chacun des trois grands singes anthropoïdes se rapproche plus ou moins de l'homme par certains caractères, mais aucun ne les réunit tous. De mème, dans les races humaines inférieures, aueune n'est plus particulièrement indiquée, pas même la race boschismane, comme descendant d'un anthropoïde; elles ne font que s'en approcher plus ou moins par tel ou tel caractère. Nous pouvons done penser que l'homme ne descend d'aucune des espèces actuelles de singes : il n'est que cousin germain de l'anthropoïde; l'ancêtre commun est au delà (').

1. Nous avons vu que l'embryologie prouve que l'homme et les mammifères passert dans le sein de leur mère par les phases ancestrales et que chacun de nous a été pendant quelques jours reptile, quadrupède, etc. X̧ous avons vu également (livre II, ehop. $\mathrm{I}^{\text {er }}$ ) que les organes atrophiés restent encore dans notre organisme comme témoignages du passé. On a discuté de longue date si l'embryon humain est pendant quelque temps doue d'une véritable queue, munie de vertèbres comme celle des singes et des quadrupèdes. 
Les singes d'Amérique diffèrent de ceux d'Afrique, d'Asie et d'Europe en ce qu'ils ont le nez aplati, de telle sorte que les narines ne sont pas dirigées en bas, mais en dehors; on les nomme à cause de cela singes platyrrhiniens. Les singes de l'ancien monde (orangs, gorilles, chimpanzès, etc.), au contraire, ont une mince cloison nasale et leurs narines sont dirigées en bas comme chez l'homme, et on les appelle pour cela catarrhiniens. En outre, ceux-ci ont la mème dentition que l'homme : chaque mâchoire portant quatre incisives, deux canines et dix molaires, en tout trente-deux dents, tandis que les singes américains ont quatre molaires en plus, c'esta-dire trente-six dents. Nous devons en conclure qu'il y a eu une dérivation ancienne dans la généalogie des singes et que l'espèce humaine (les Américains autochtones comme tous leurs frères) descend des singes catharriniens de l'ancien continent. Mais aucun des singes actuels ne peut être considéré comme notre souche ancestrale. Depuis longtemps les ancètres pithécoïdes de l'homme ont disparu. Peut-être le dryopithèque, auquel M. Gaudry a attribué la possibilité d'avoir taillé les silex, était-il assez proche parent de cet ancèire, dont le règne remonte à plus de cent mille ans.

Conclusion : l'homme est le dernier produit de la vie terrestre, le couronnement actuel de tout l'arbre généalogique du règne animal, le dernier-né et le plus parfait des mammifẻres, et, en définitive, un singe perfectionné et transformé.

Cette idée froisse et révolte ceux qui se plaisent à entourer d'une auréole brillante le berceau de l'humanité, et si nous mettions notre

Cetle question vient d'être définitivement résolue. A la séance de l'Académie des Sciences du 8 juin dernier (1885), M. H. Fol a montré que l'embryon humain de 5 millimètres el demi c'est-à-dire de 25 jours, porte 32 vertèbres; que celui de 9 à 10 millimètres, c'est-à-dire de 35 à 40 jours, possède 38 vertèbres. Or, on sait que le squelette humain n'a que 24 vertèbres. Ces additions caudales n'ont qu'une existence éphémère. Déjà sur les embryons de 12 millimètres, c'est-à-dire de six semaines, la trente-huitième, la trenteseptième et la trente-sixième se confondent en une seule masse, el la trente-cinquième elle-même n'a plus des limites parfaitement nettes. Un embryon de 19 millimètres n'a plus que 34 vertèhres. Il résulte de ces faits que l'embryon normal, pendant la cinquième et la sixième semaines de son développement, est muni d'une queue incontestable, régulièrement conique, composée de vertèbres et détachée du corps.

Remarquons encore que tous les enfants sont de véritables et charmants petits singes, quant à leur esprit d'imitation perpétuel, auquel ils doivent leurs premiers progrès dans la vie. 
gloire dans notre généalogie et non dans nos propres œuvres, nous pourrions en effet nous croire humiliés. Mais qu'est-ce pourtant que ce nouvel échec à notre amour-propre, en comparaison de celui que l'astronomie nous a déjà infligé? Lorsqu'on fixait la Terre au centre du monde et qu'on croyait l'univers créé pour la Terre et la Terre pour l'homme, notre orgueil pouvait être satisfait. Cette doctrine géocentrique par rapport à la Terre et anthropocentrique par rapport à l'homme, était parfaitement coordonnée, mais elle s'écroula le jour où il fut démontré que notre planète n'est que l'humble satellite du Soleil, qui lui-mème n'est qu'un des points lumineux de l'espace : c'est ce jour-là et non pas aujourd'hui que l'homme fut vraiment rappelé à la modestie. Ce n'était plus pour lui que le Soleil se levait chaque matin, que la voûte céleste allumait chaque soir ses feux innombrables; la création n'était plus faite exprès pour lui, pas plus que pour les habitants de tout autre monde de l'infini.

De mème que ce paysan qui avait rêvé l'empire du monde, il se réveillait dans une simple chaumière. Ce n'est pas sans regret qu'il se vit ainsi diminué; longtemps le souvenir de son rêve évanoui vint troubler sa pensée, mais il fallut se résigner, s'habituer à la réalité, et aujourd'hui il se console de n'être plus ce roi de la création en songeant qu'il est réellement le roi de la T'erre (').

Cette royauté incontestée, il a le droit d'en être fier. Mais en quoi cst-elle menacée ou amoindrie par la connaissance de la transformation graduelle des espèces? Sera-t-elle moins réelle s'il l'a conquise par lui-même ou s'il la tient de ses premiers ancêtres? Loin d'humilier le berceau de notre race, la doctrine nouvelle nous ennoblit, en montrant à l'homme qu'il a acquis lui-même sa valeur par son travail et par l'exercice de ses facultés.

D'excellents esprits, animés des meilleures intentions, nous ont parfois exprimé le regret de nous voir heurter certaines idèes reçues, certaines croyances respectables. A leurs yeux, ces considerations philosophiques paraissent déplạcées dans un ouvrage de science ou d'instruction populaire, et elles nuisent au succès du livre en

\section{ToptNard, Anthropologie.}

LE MONDE AVANT LA CRÉATION DE L'HOMME

101 
l'empêchant de se répandre indistinctement parmi l'entière généralité des lecteurs. Nous saisirons cette circonstance pour donner ici quelques mots d'explication.

Très certainement, la Science, considérée en elle-même, l'astronomie, la géologie, la paléontologie, a sa valeur intrinsèque absolue. Mais le but du savoir est d'éclairer l'esprit. Un astronome, un géologue, un naturaliste, qui connait à fond tous les arcanes de sa science de prédilection, peut fort bien garder, malgré tout, un esprit fermé et, tout en étant très instruit, ne pas savoir penser. Or, la plus haute faculté humaine est la faculté de penser, de juger, d'abstraire, de généraliser, en définitive, d'appliquer le savoir au jugrement. Un astronome qui admet le miracle de Josué manque de logique, et sa science ne lui sert à rien, ni à lui, ni à ceux auxquels il l'enseigne. Un anthropologiste qui admet la crẻation d'Ève tirće d'une côte d'Adam, ou, plus simplement encore, la création d'Adam et d'Éve en dehors de la généalogie naturelle des êtres vivants, est dans le mème cas que son confrère, etc., etc. Sans qu'il soit nécessaire d'entrer ici dans une série d'applications superflues pour l'intelligence de nos lecteurs habitucls, nous déclarons qu'à nos yeux la science qui n'éclaire pas l'esprit, qui ne le guide pas, qui ne l'affranchit pas graduellement des erreurs de l'ignorance, est moins utile, moins recommandable, moins digne de respect que celle qui remplit entièrement son devoir d'émancipatrice. Certes, nous savons personnellement que cette conduite n'est pas sans périls; nous nous voyons attaqué par des écrivains (dont beaucoup sont de mauvaise foi, il est vrai) qui prétendent que nos ouvrages ont pour but (!) de blesser. des croyances chères à un grand nombre, et nous constatons que certains esprits intolérants défendent par la presse ultramontaine, par leur bons conseils voire mème au confessionnal - de lire et de propager nos ouvrages. Jamais aucun sentiment d'intérèt matériel n'a guidé aucun acte de notre vie. Et alors même que l'apostolat de la vérilé devrait nous conduire à n'avoir pour lecteurs qu'une minorité d'élite, nous n'hésiterions pas à parler selon notre conscience. D'ailleurs, il faut bien l'avouer, ce ne sont jamais les hommes de science qui ont ouvert le feu. Mais il y a des esprits aussi orgueilleux qu'ils sont étroits, qui, dans un cerveau muré, à travers lequel aucune impression ne peut 
passer, s'imaginent pourtant penser réellement; ils n'ont rien appris ni rien oublié; ils travestissent constamment l'histoire pour se donner raison; ils prétendent aujourd'hui que Galilée n'a jamais étè condamné et que la croyance au mouvement de la Terre n'a jamais été tenue pour hérétique; ils passent leur temps depuis dix-huit siècles à torturer la Bible pour lui faire dire ce qu'elle n'a jamais voulu dire; et dès qu'une découverte importante est faite dans les sciences, dès que les savants mettent en lumière, comme résultat de laborieux efforts et de persévérants travaux, une vérité qui touche de près ou de loin à l'histoire de la création dont ils se prètendent les seuls interprètes, ils se mettent à clamer comme des paons en déployant un plumage superbe et en s'imaginant que leurs cris empêcheront la Terre de tourner. S'ils se taisaient, s'ils ne s'occupaient que de moraliser les esprits et de les diriger vers le bien avec tolérance et charité, il y a longtemps que les savants, les penseurs, les philosophes s'abstiendraient de répondre à des attaques et à des prétentions qui n'existeraient plus. Mais non. Ils continuent à parler avec un dédaigneux mépris de questions dont ils ignorent le premier mot, à travestir les plus laboriẹuses conquêtes de la science et à publier dans leurs sermons des affirmations d'une telle audace, que l'on se demande parfois si vraiment ils croient eux-mèmes à ce qu'ils avancent. C'est contre ces énergumènes de toutes les religions (tristes défenseurs d'un principe plus noble qu'eux) qu'il est du devoir de tout honnète homme de réagir lorsque les circonstances s'en présentent.

Sans doute, un certain nombre de nos lecteurs, fixés dans leur foi, ne se préoccupent en aucune taçon des remarques philosophiques auxquelles nous faisons allusion ici, et ils ont raison, car s'ils sont satisfaits dans leur conscience, pourquoi se troubleraientils! On peut prendre dans nos ouvrages l'instruction scicntifique qu'ils comportent sans se croire obligé de nous suivre dans les déductions qui nous paraissent en émaner logiquement. La science en elle-mème est indépendante de toute opinion religieuse, ces opinions étant surtout une affaire de sentiment dérivant de l'éducation premic̀re que nous avons reçue et du milieu dans lequel nou avons vécu. On peut done s'instruịre dans toutes les branches du savoir humain sans cesser d'ètre catholique, protestant, grec ortho- 
doxe, israélite, musulman, boudhiste, etc., etc. Il y a mème des savants qui se vantent d'être athées, ce qui ne les empèche pas d'ètre de véritables savants. Pour nous, Dieu est inconnaissable, et celui qui nie son existence nous parait aussi complètement dans l'erreur que celui qui s'imagine l'enfermer dans un culte quelconque. Le but suprème de la science nous parait être de nous élever à lui par un idéal de plus en plus pur, en nous affranchissant de tous les poids de la matière, en nous faisant mieux concevoir l'essence des forces immatérielles qui régissent l'univers et l'emportent vers un but inconnu. $\Lambda$ ce titre-là, le savant est l'ennemi de tout fanatisme et de toute intolérance, le défenseur de la liberté de conscience, l'apôtre de la lumière et du progrès. Il doit avoir le courage de ses opinions et préférer toujours, sans réflexion, l'intérèt de la vérité à son intérêt personnel. La devise empruntée à Juvénal par J.-J. Rousseau doit rester dans son cœur : Vitam impendere Vero, " consacrer sa vie à la Vérité ».

Mais revenons à l'homme primitif.

Ainsi la nature elle-même nous enseigne par toutes ses voix que l'homme descend du singe, que le singe descend du marsupial, le marsupial de l'amphibien, l'amphibien du poisson, le poisson de l'invertébré, l'invertébré du protoplasma, le protoplasma du règnè minéral. Nous avons suivi cet arbre de vie naissant et grandissant à travers les âges, depuis l'époque primordiale inorganique jusqu'à l'ère actuelle. Assurèment, il reste encore bien des lacunes dans une synthèse aussi nouvelle d'un ensemble de sciences nouvelles clles-mèmes, puisque ces sciences modernes ne datent pas encore de plus d'un siècle; mais telle qu'elle est, notre synthèse nous a permis de concevoir les grandes lignes de l'histoire naturelle de la création.

Arrivés au point où nous sommes, nous pouvons nous demander maintenant à quelle date remonte l'apparition de l'humanité sur la Terre.

Cette question est beaucoup plus complexe qu'elle ne le paraît à première vue. Si, par le mot « Humanité » nous entendons la faculté caractéristique de cette race qui domine aujourd'hui la planète, l'existence de l'esprit humain, on peut répondre que l'humanitẻ date d'hier, de quelques milliers d'années seulement, du commen- 


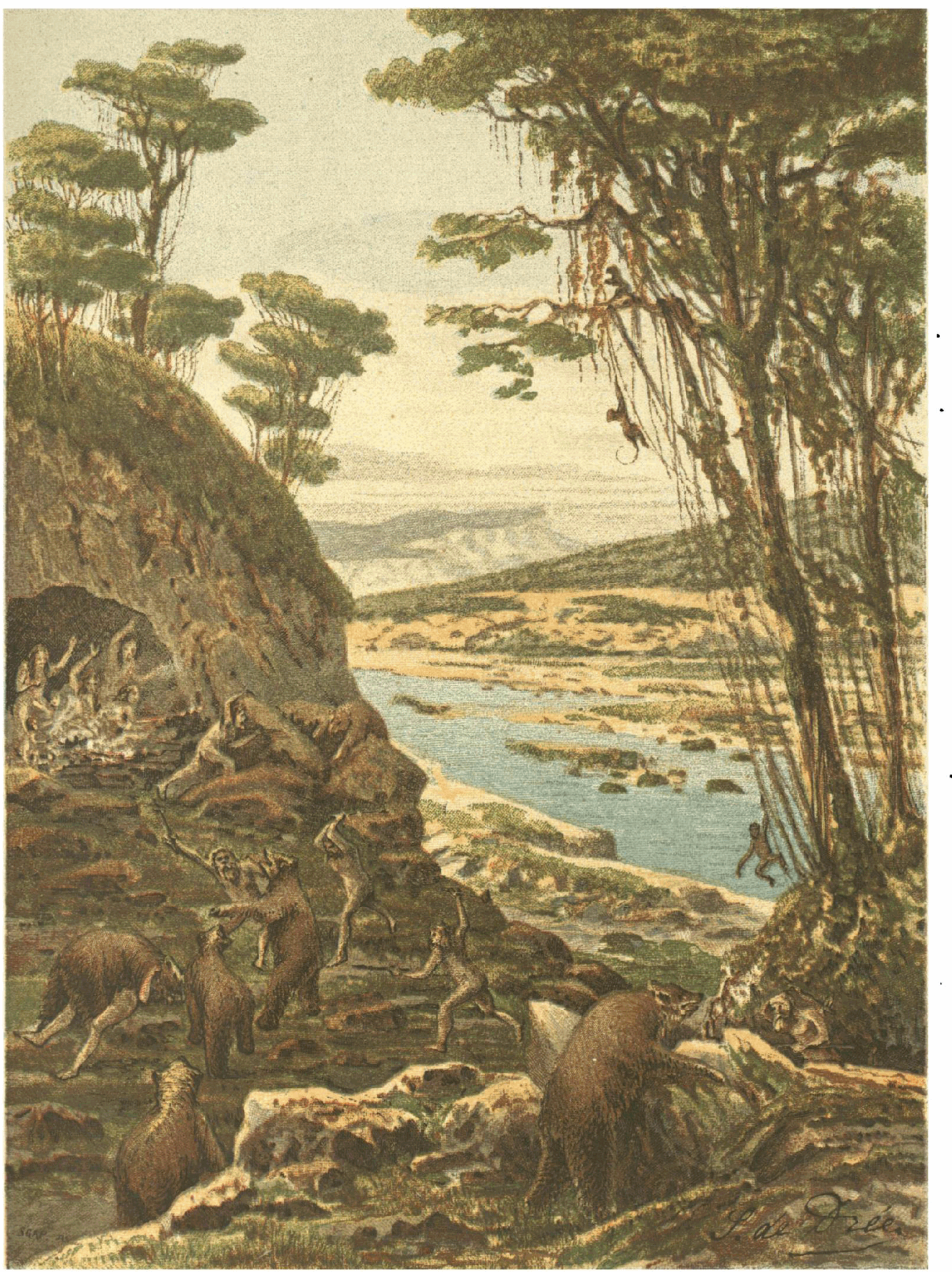

Chromotypographie SGAP

\section{LES PREMIERS AGES DE L'HUMANITÉ ÉPOQUE DE L'OURS DES CAVERNES}


IRIS - LILLIAD - Université Lille 1 
cement de l'histoire, qui ne remonte pas mème à dix mille ans, mème pour l'Esypte antique, le plus ancien peuple dont nous possédions des documents historiques authentiquos. Tant que l'humanitè n'a pas 'eu l'écriture, le langage écrit, elle n'a pas existé historiquement. Les tribus inférieures qui, actuellement encore, sont sans langage écrit - et mème presque sans langage parlé - ne font pas partie de l'humanité pensinle et agissante. Le langage écrit est le plus grand progrès que l'hurnanitè primitive ait accompli, et c'est lui, sans contredit, qui l'a lancée dans sa véritable voie intellectuelle. Le premier langage écrit a été lrès rudimentaire, et avant lui, le langage parlé était plus rudimentaire encore.

Nous avons aujourd'hui la preuve que l'homme primitif est antérieur de plusieurs dizaines de milliers d'années à l'âge de l'humanité historique, car on a retrouvé déji un grand nombre de types de l'homme fossile.

Non pas pourtant depuis longtemps. C'est en 1823 seulement qu'Amy Boué présenta à Cuvier des ossements humains trouvés par lui dans le loess du Rhin, aux environs de Lahr, dans le pays de Bade. Cuvier qui avait, comme nous l'avons vu, un système arrêté par des idées théoriques préconçues sur la nature de la création et sur l'immutabilité des espèces, se refusa à les admettre comme fossiles, et ce refus eut une action funeste sur le progrès de la science.

Cela n'empècha pas des restés d'hommes fossiles d'être découverts, en 1828, dans l'Aude, par Tournal ; - en 1829, dans le Gard, par Christol ; - en 1833, en Belgique, par Schmerling; - en 1835, dans la Lozère, par Joly; en 1839, dans l'Aude, par Marcel de Serres; - en 1844, au Brésil, par Lund, etc., etc. Mais la science officielle objectait, a priori, que les restes humains ou les objets fabriqués par l'homme trouvés dans ces terrains quaternaires y avaient été amenés par des ealx ou par des éboulements.

Fn 1847, il y eìt un grand coup porté à la question par les efforts vigoureux et indépendants de Boucher de Perthes, qui, dans des carrières de graviers situées près d'Abbeville, recueillit une quantité considérable de silex travaillés de mains d'hommes.

Mais il faut arriver jusqu'en 1861 pour voir le fait de l'homme fossile affirmé hors de doute par le délhlaiement de la grotte d'Aurignac, dù à M. Lartet. Ici, le doute n'était plus possible. Cette 
grotte, ou mieux cet abri, était fermée au moment de la découverte par une dalle apportée de fort loin. M. Lartet découvrit dans cette grotte les ossements de huit espèces animales sur neuf qui caractérisent essentiellement les terrains quaternaires. Quelques-uns do ces animaux avaient été évidemment mangés sur place; leurs os, en partie carbonisés, portaient encore la trace du feu dont on retrouvait les charbons et les cendres; ceux d'un jeune rhinocéros tichorinus présentaient des entailles faites par des outils de silex et avaient été rongés par des hyènes dont on retrouva des vestiges. Ajoutons que la position de cette grotte la mettait à l'abri de tout apport dû au diluvium. Ces faits établirent que l'homme primitif a vécu au milieu de la faune qualernaire, utilisant pour sa nourriture jusqu'au rhinocéros et suivi par la hyène de cette époque qui profitait des débris du repas. La coexistence de l'homme et de ces espèces fossiles était démontrée.

L'année 'suivante, une découverte capitale vint confirmer les faits antérieurement acquis. Le 28 mars 1862, M. Boucher de Perthes eut le bonheur de déterrer lui-mẻme, dans le diluvium gris de la vallée de la Somme, à Moulin-Quignon, près d'Abbeville, une mâchoire humaine, sans doute fort incomplète, mais néanmoins bien précieuse : elle provient d'un homme quaternaire.

Il y aurait plus. En 1868, M. Laussedat a présenté à l'Académie des sciences une mâchoire de rhinocéros provenant du miocène de Billy (Allier), sur laquelke se voit une entaille que plusieurs naturalistes ont pensé avoir été faite par l'homme. M. l'abbé Delaunay a rencontré dans le miocène de Pouancé (Maine-et-Loire) une côte d'halithérium, portant des entailles qui ont été également attribuées à l'action humaine; M. Garrigou a émis l'opinion que certains ossements trouvés à Sansan avaient été brisés par l'homme. M. le baron de Ducker a exprimé la même croyance au sujet d'ossements trouvés à Pikermi. Mais ces entailles peuvent avoir été faites par des carnassiers ou même par de simples frottements. Un prètre géologue, l'albbé Bourgeois, mort en 1878, a trouvé dans le miocène de Thenay, près de Pontlevoy (Loir-et-Cher), des silex qu'il regarde comme ayant été taillés par un être plus intelligent que les animaux actuels, et son opinion a été partagée par des anthropologistes très habiles. 
D'après ces derniers témoignages, auxquels il scrait facile d'en adjoindre un grand nombre d'autres, il semble que nous devrions ètre autorisés à admettre aussi l'existence de l'homme tertiaire miocène. Cependant nous croyons que les documents ne suffisent pas encore pour cette affirmation. M. de Quatrefages, M. Hamy, admettent que les silex de Thenay ont été taillés par des hommes. M. Bourgeois, M. Gaudry, M. de Mortillet, pensent qu'ils peuvent l'avoir été par des singes. Dans cette hypothèse, le précurseur de l'homme serait le dryopithèque ou quelque anthropomorphe de ce genre. Mais les opinions restent contradictoires sur le fait lui-même de décider si, oui ou non, ces silex sont vraiment taillés. Pour nous, très profane dans la question et sans compétence spéciale sur ce point, ils ne le sont pas: nous en avons trouvé d'analogues en cherchant dans des tas de pierres naturelles; de plus, chacune des discussions faites chaque année sur ce même sujet dans les sessions de l'Association française pour l'avancement des sciences a apporté de nouveaux doutes; enfin, d'après l'examen géologique de la région faite à la dernière rémnion de Blois, le terrain dans lequel se trouvent ces gisements de silex serait encore plus ancien qu'on ne l'avait cru; l'assemblée a été disposće à le considércr comme tertiaire inférieur, c'est-à-dire comme éocène. Lá présence d'objets travaillés, c'est-àdire d'œuvres d'ètres intelligents dans l'éocène est diflicile à admettre, car non seulement les espèces, mais tous les genres de cette époque sont différents des genres d'animaux actucls; on n'y rencontre encore ni vrais ruminants, ni solipèdes, ni proboscidiens, ni singes.

Les silex signalés à Otta, près de Lisbonne, et à Puy-Courny, près d'Aurillac, ne sont pas plus démonstratifs : leur gisernent est certainement miocène, mais il n'est pas sûr qu'ils soient taillés.

Il y a, du reste, des considérations d'ordre général qui ne permettent guère de faire remonter l'existence de l'homme à une époque aussi lointaine. "A quelque point de vue que l'on se place, remarquerons-nous avec M. de Lapparent, l'homme ne peut apparaitre que comme le couronnement du monde organique, après que le règne végétal et le règne animal ont recu l'un et l'autre tous leurs développements. Or, à l'époque miocène, ces développements sont encore trop incomplets pour que la présence de 
l'homme sur la Terre ne soit pas considérée comme un véritable anachronisme; et cela suffit à nos yeux pour permettre de rejeter des faits aussi insuffisamment établis que ceux qui précèdent."

Actuellement, il est impossible de douter de l'existence de l'homme dès l'origine de l'époque quilternaire et., sans doute mème, dès la fin de l'époque tertiaire. La transformation simienne à laquelle nous devons d'exister date très probablement de la période

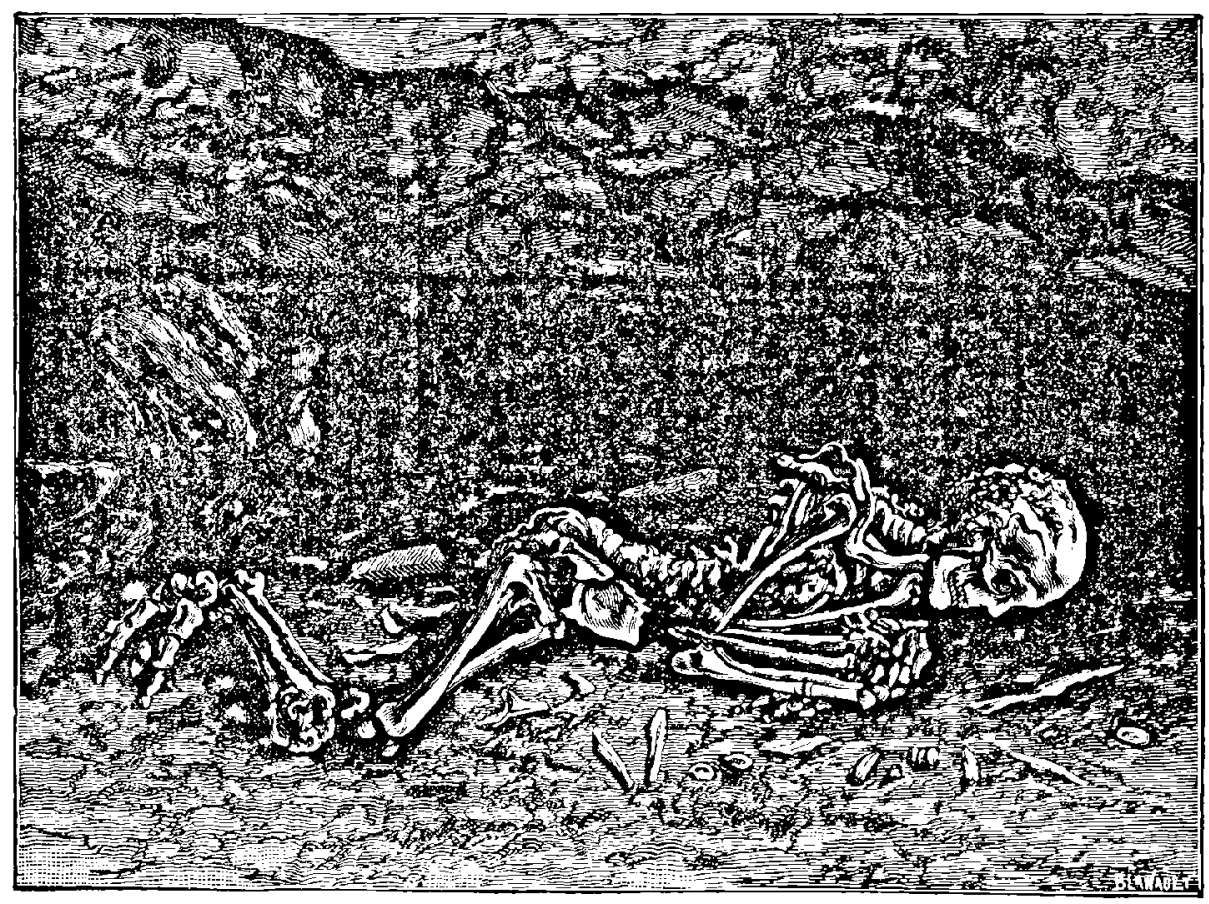

Fig. 412, - L'homme fossile trouvé en 1872, dans une caverne, à Menton, actuellement au Muséum de Paris.

pliocìne. Il serait long d'exposer ici tontes les découvertes faites, tant de restes humains fossiles que de silex taillés ou d'objets fabriqués par l'homme primitif. Au musée de Saint-Germain, on peut admirer tout un monde exhumé, grâce aux travaux persévérants de l'archéologie préhistorique. Au musée de Bruxelles, il n'y a pas moins de quatre-vingt mille silex taillés de mains d'homme, et plus de quarante mille ossements d'animaux contemporains de l'homme primitif. On a déjà pu classer la succession de ces races humaines disparues; les unes ont été contemporaines de l'ours des 
cavernes, d'autres du mammouth, d'autres du renne, et d'autres enfin de l'auroch. Le remarquable homme fossile de Menton, trouvé il y a une dizaine d'années par M. Rivière dans une grotte voisine de la frontière française ( $f g .400$ ), parait ètre de l'âge du rchne. L'année dernière, étant à Nice, nous avons été nous-mème témoin de nouvelles fouilles faites en ce même point par M. Wilson, consul des Etats-Unis.

Ces documents, toutefois, ne suffisent pas encore pour nous permettre de définir l'homme primitif. Du reste, comme le remarque M. de Quatrefages, le type primitif de l'espèce humaine a nécessairement dù s'effacer et disparaitre. A elles seules, les migrations forcées et les actions de milieu devaient amener ce résultat. L'homme a traversé la distance de l'époque tertiaire à l'époque quaternaire; peutètre son centre d'apparition n'existe-t-il plus; en tout cas, les conditions y sont tout autres qu'au moment ou l'homme débutait. Quand tout changeait autour de lui, l'homme ne pouvait rester immuable.

Nous ne connaissons pas l'homme primitif; nous le rencontrerions que, faute de renseignements, il serait impossible de le reconnaitre. Tout ce que la science naturelle permet de dire à son sujet, c'est que, selon toute apparence, il devait présenter un certain prognathisme et n'avait ni le teint noir, ni les cheveux laineux. Il est encore assez probable que son teintse rapprochait de celui des races jaunes et accompagnait une chevelure tirant sur le roux. Tout enfin conduit à penser que le langage de nos premiers ancêtres n'a d'abord consisté qu'en monosyllabes et en onomatopées.

Avant qu'ils eussent inventé la charrue, la bèche, le pilon, le moulin, le four, la cuve, le tonneau, l'écuelle, la cuiller, la fourchette, le couteau, etc., avant qu'ils eussent fait la première invention, les ètres qui sont devenus des hommes, mais qui alors n'étaient que des animaux peu raisonnables et peu perfectionnés, vivaient dans les bois et dans les cavernes, cherchant leur nourriture (que persońne ne venait leur apporter) comme leurs contemporains, amis ou ennemis, les singes, les loups, les tigres, les chevaux sauvages, les éléphants, les ours, les hyènes, les chacals, les castors, etc. Le titre d'homme leur convient-il? Il ne le semble pas. Se défendre des pieds, des mains et de la tête, quand on est attaqué, ce n'est pas en- 
core là le propre de l'homme, car le singe le fait. Prendre un fruit et le jeter à la tête de son adversaire, le singe le fait aussi. Saisir une branche $\dot{a}$ terre, ou bien en casser une (exprès ou non) et en frapper l'altaquant, le singè le fait encore. Protéger la mère et les enfants, presque tous les animaux en prennent souci. Le premier acte de perfectionnement de l'espèce a dù être tout à fait élémèntaire. Une pierre pointue, acérée, aura servi mieux que les ongles et les dents pour couper une peau d'animal assommé. Des ètres très intelligents pour l'époque auront pu remarquer que les pierres tranchantes et pointues valaient micux que les rondes pour íendre quelque chose, et ils s'en seront servi à leur avantage. Ils auront èté imités ou pillés par d'autres, sans souci de la propriété future des brevets d'invention. Plus tard, des indigènes, non moins sauvages assurément, mais plus intelligents encore, auront remarqué que le choc d'une pierre contre une autre faisait des morceaux, dont plusieurs étaient tranchants ou pointus. L'animal, candidat à l'humanité sans le savoir, inaugurait ainsi les âges primitifs de la pierre zaillée dont on retrouve aujourd'hui les documents épars un peu partout. La découverte du feu, par le frottement du bois sec, a été à elle seule un progrès immense.

De mème que l'organisme corporel de l'homme, son organisme intellectuel, si l'on peut s'exprimer ainsi, s'est formé graduellement et progressivement par l'animalité elle-mème. Si le corps humain est le fruit de l'ascension de la nature à travers toutes les phases du règne animal, l'esprit humain en est la fleur, et lui aussi a été graduellement acquis et développé. Les animaux supéricurs ont une intelligence digne d'être comparée à celle de l'homme, de la sensibilité, de l'entendement, de la mémoire, de la volonté, des fantaisies, en un mot des facultés essentiellement intellectuelles. Ce n'est qu'une question de degrés. La nature entière est construite sur le mệme plan et manifeste l'expression permanente de la même idée.

Il y aurait des volumes entiers à écrire sur l'intelligence des animaux - et en effet, il y en a de considérables publiés sur ce grand sujet - et nous ne pouvons nous étendre ici sur les développements qui se présentent à l'esprit.

Le point essentiel était d'appeler l'attention de nos lecteurs sur 
le fait de l'intelligence des animaux. Chacun peut, soit par ses propres observations, soit par celles qu'il connait, compléter son jugement et apprécier comme il mérite de l'étre ce caractère intellectuel des races antérieures à la nôtre. L'âme humaine n'est pas plus isolée que le corps du reste de la nature : elle s'est graduellement formée dans la série des âges.

D'autres considérations non moins intéressantes pourraient encore être ajoutées à toutes les précédentes et combler en quelque sorte la mesure déjà pleine de notre argumentation. Mais il est impossible que la conviction des esprits libres et impartiaux ne soit pas irrévocablement arrêtée depuis longtemps. Comment cependant nous refuser à considérer encore, ne serait-ce qu'à titre de curiosité, les ressemblances souvent si singulières qui se remarquent assez fréquemment entre certaines têtes, certaines physionomies humaines, et certains types animaux? N'y a-t-il pas là comme une sorte d'écho du passé, comme une sorte de retour, d'atavisme vers les formes antérieures? Les ressemblances humaines avec les singes, surtout dans les races inférieures, sont trop évidentes pour que nous nous y arrêtions davantage. Mais dans notre propre race blanche, distinguée et hautement civilisée, il n'est pas très rare de remarquer sur les figures el même dans les caractères de certains individus des rapports incontestables avec certains animaux, tels, par exemple, que le lion, le chat, la fouine, l'oiseau, le reptile, le poisson même. Jetez, par exemple, un coup d'cil sur les dessins originaux dans lesquels un peintre éminent, Gharles Lebrun, s'est plı, dès le siècle de Louis XIV, à représenter les rapports typiques entre humains et animaux il scrait assurément difficile de se soustraire à l'impression de l'authenticité des ressemblances. Quant aux caractères - de noblesse - de perspicacité - de sottise - d'emportement - de servilité - de bonté - de méchanceté - de désintéressement - d'avarice - de bestialité, etc., etc., accusés par les physionomies, il n'est pas nécessaire de les étudier dans les cuvres de Lavater pour les reconnaitre chaque jour autour de soi.

L'homme ne s'est dégagé que lentement, insensiblement, de sa grossièreté primitive. Le plus grand pas dans la voie du progrès intellectuel et artistique n'a pu être fait tant que les besoins maté- 

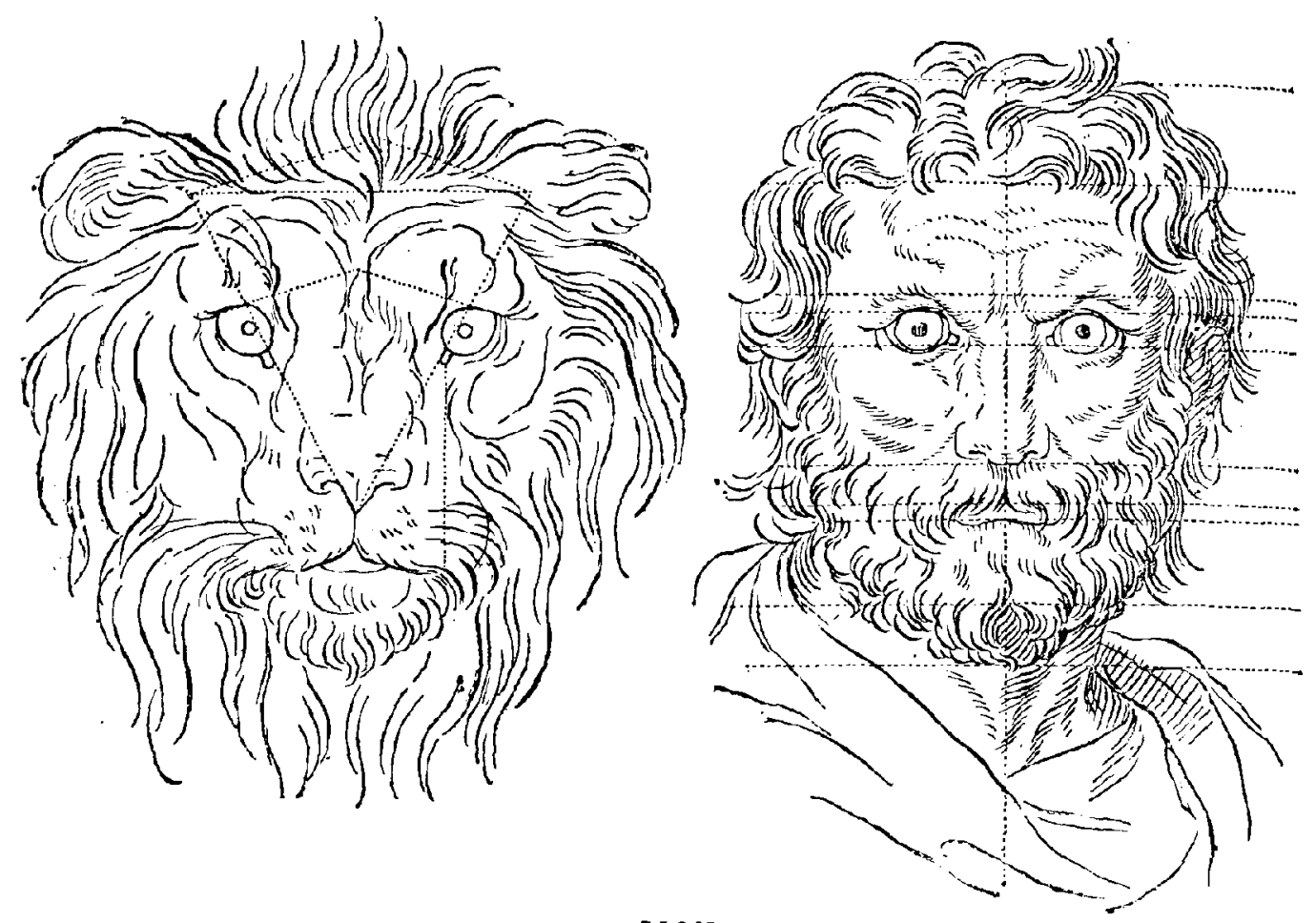

LION
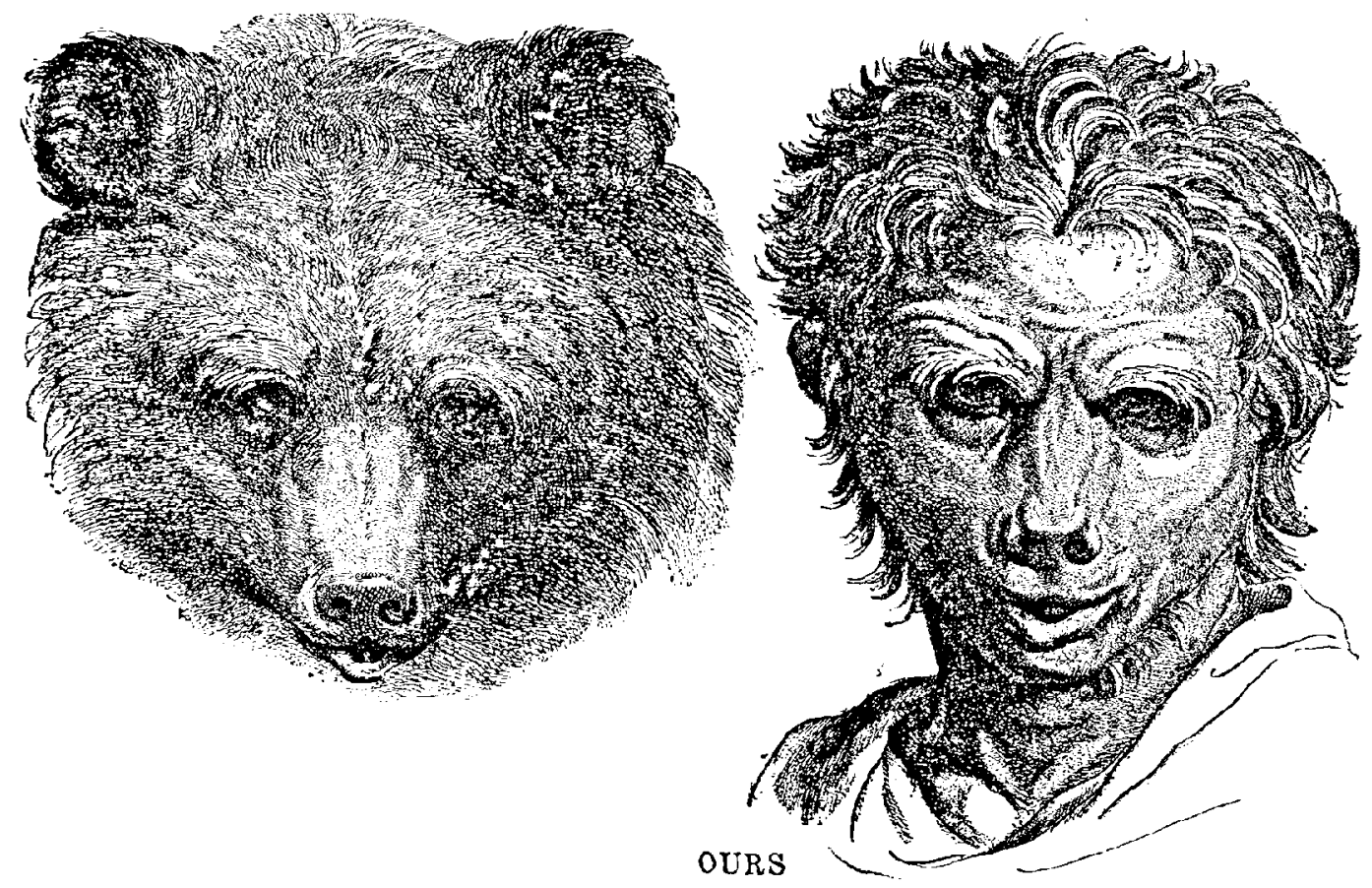

BESSEMBLANCES HUMAINES ET ANIMALES, PAR GIIARLES LEBRUN 

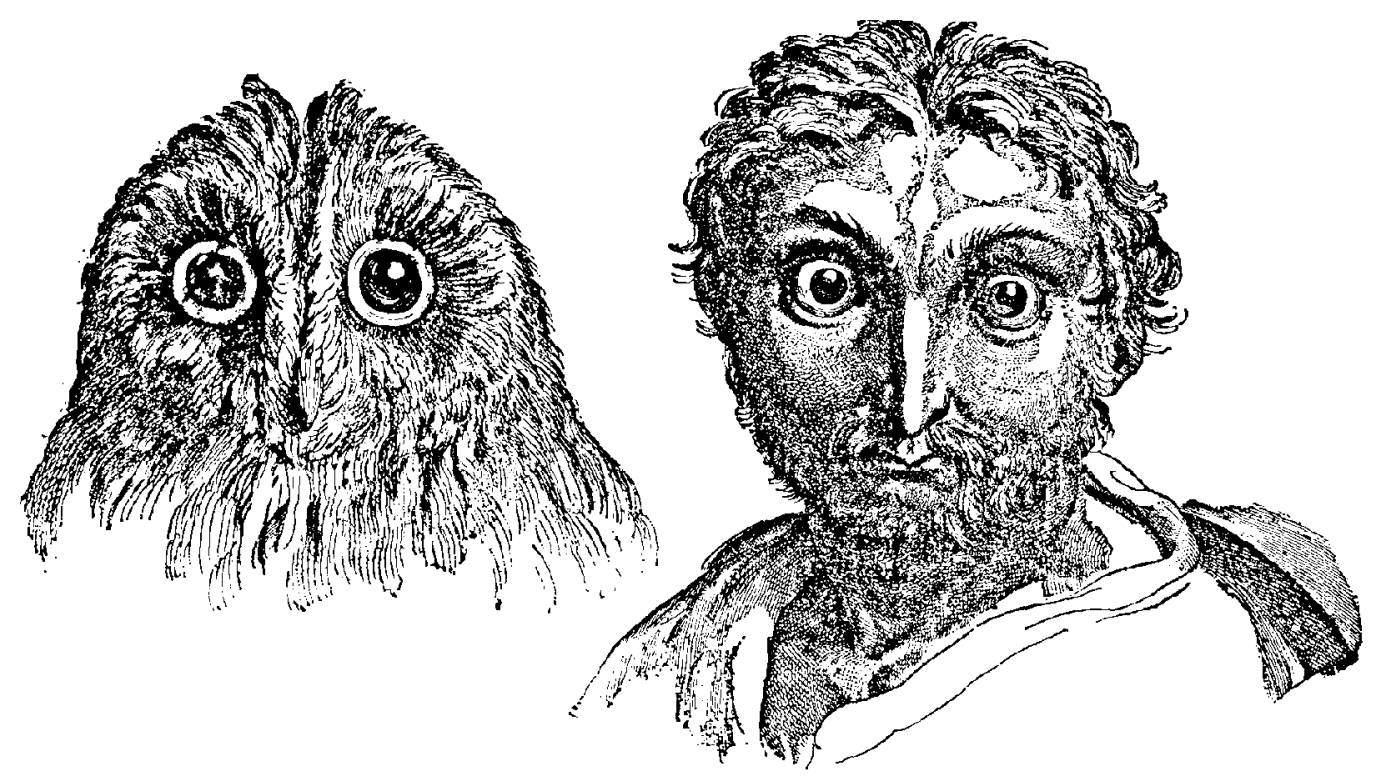

HIBOU

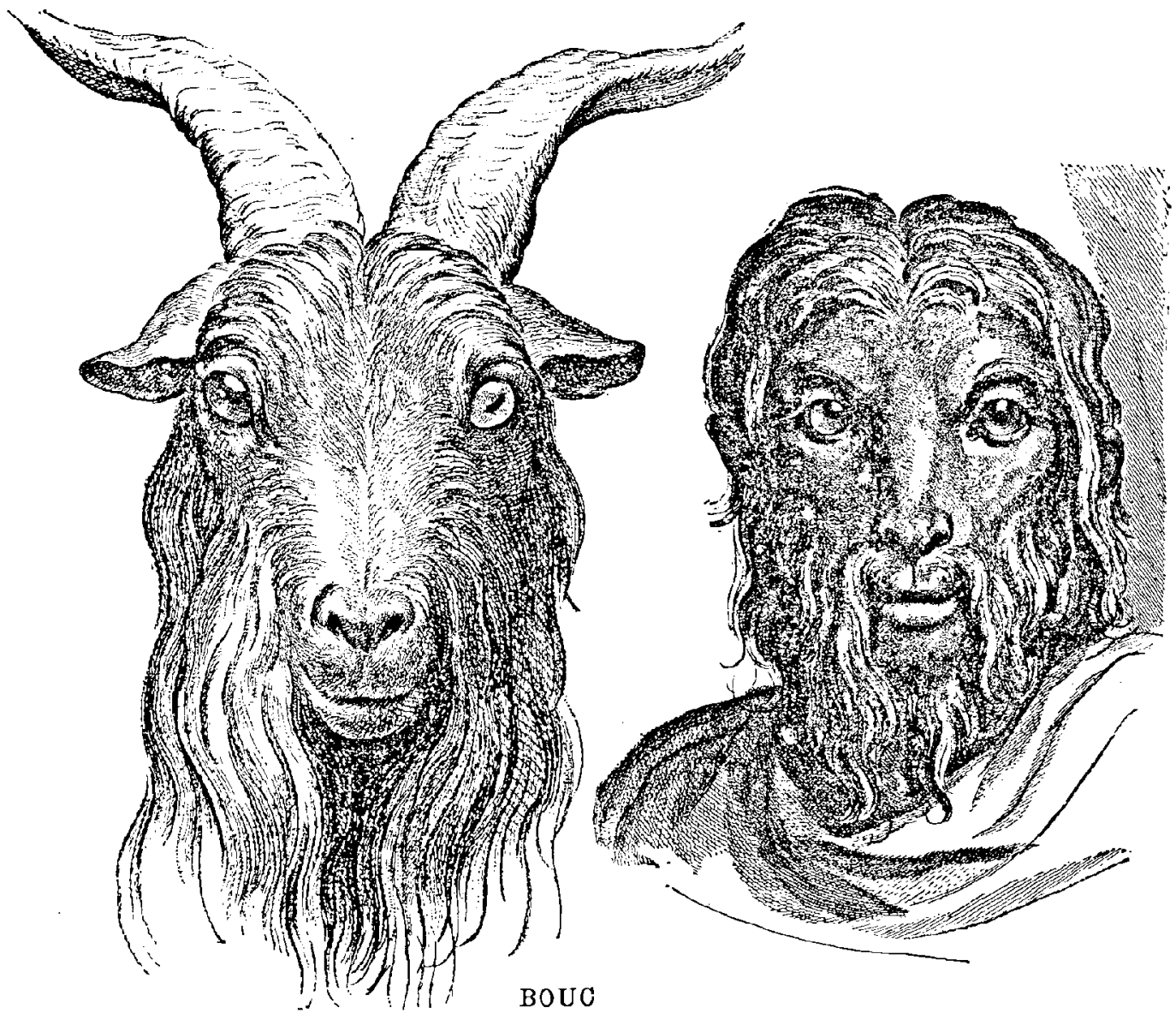

MESSEMBLANCES HUMAINES ET ANIMALES, PAR LHARLES LERRUN 

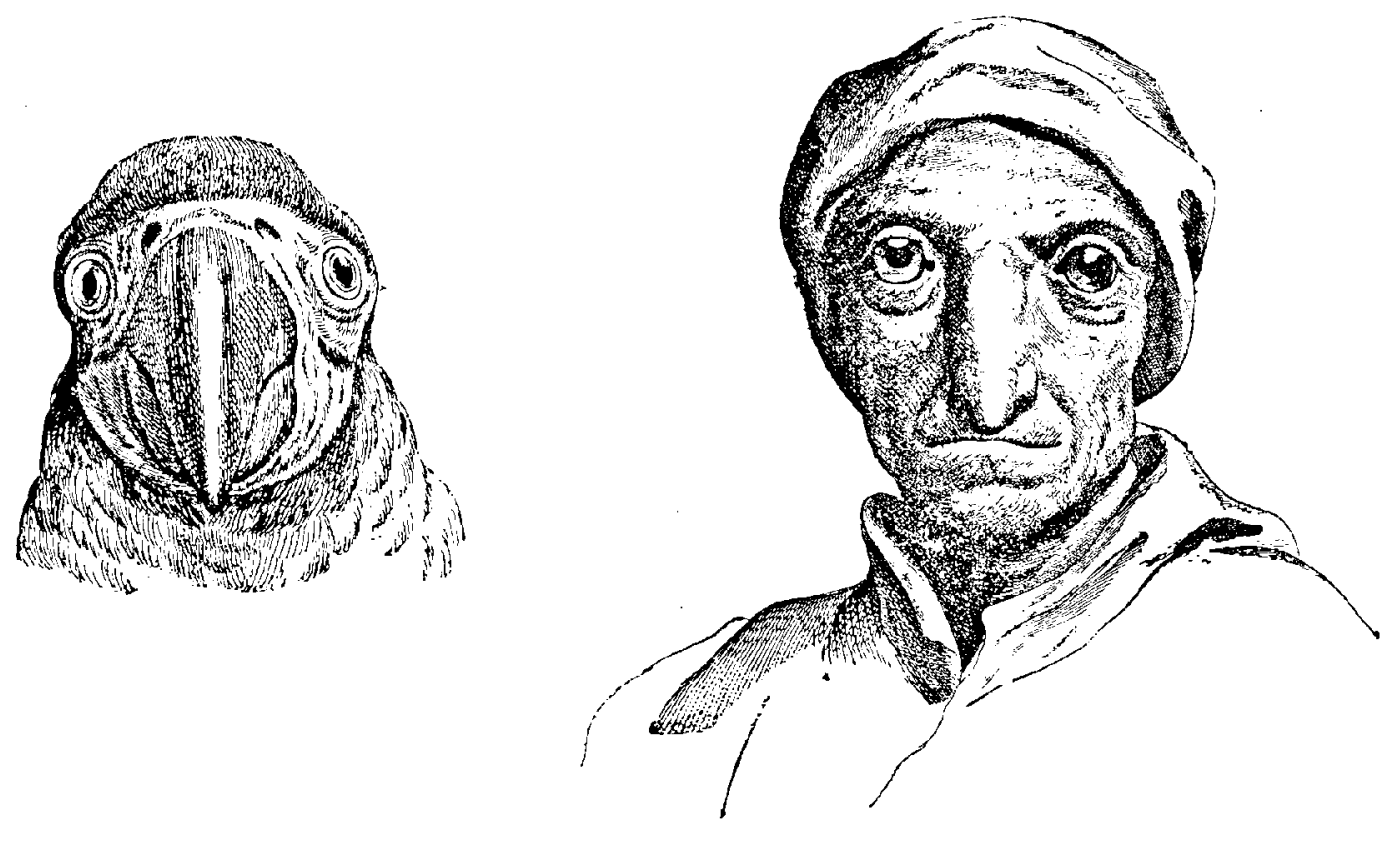

PERROQUET
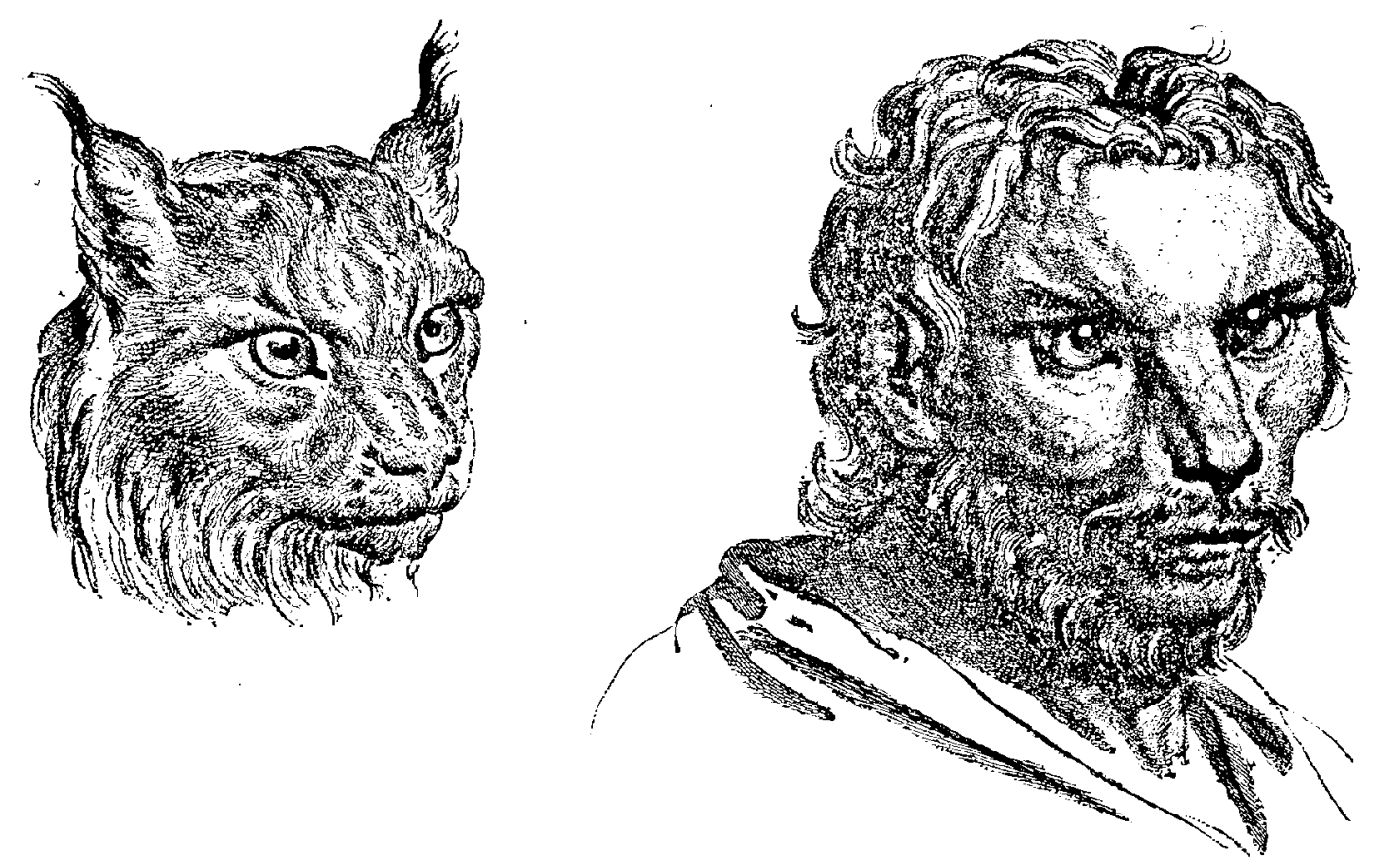

CHAT

RESSEMBLANCES HUMAINES ET ANTMALES, PAR GHARLES LEBRUN 


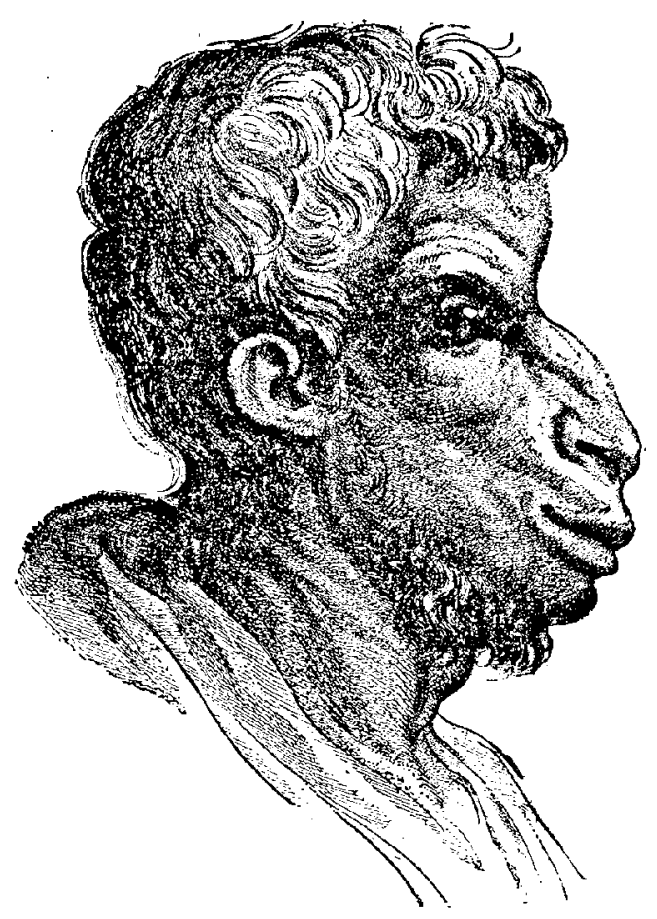

CHAMEAU

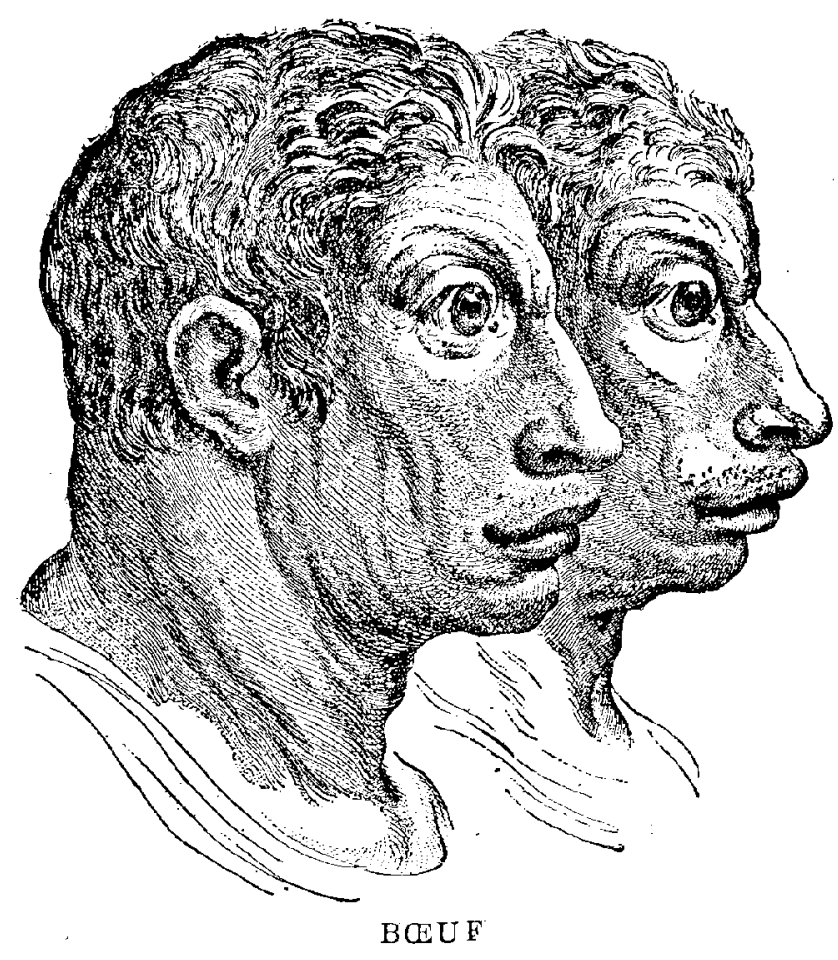

RESSEMLANCES HLMAINES ET ANIMALES, PAB CHAHLES LEBBUN 
riels et la lutte pour l'existence ont imposé leur dur et constant labeur. C'est à la faveur de circonstances heureuses, d'un climat plus doux, au milieu des fruits nouveaux d'une terre plus fertile, en une ère de prospérité et de tranquillité, que la matière a quelque jour cédé le pas à l'esprit. Le premier homme qui a dessiné une tête de mammouth, une silhouette de cerf, un portrait, sur quelque corne polie, le premier qui a composé un bouquet de fleurs sauvages pour l'offrir à sa bien-aimée, le premier qui chanta la plus simple mélopée des âges d'enfance ou qui sut faire résonner une eorde harmonieuse, le premier artiste, le premier contemplateur, le premier rêveur, n'avait, à ce moment-là, ni faim ni froid. L'humanité pensante n'a pu s'éveiller que sous la douce température d'une contrée fertile, également éloignée des glaces polaires et des bêtes féroces des tropiques. C'est la famille humaine ainsi favorisée du ciel qui ouvrit l'ère du progrès. Les autres, moins privilégiées par leur situation, forcées de combattre sans trève pour vivre et pour se défendre, n'ont pu avancer que bien peu. Mais sous les rayons enchanteurs d'un soleil tempéré, au milieu des bois animés par le langage des oiseaux, devant les clairières fleuries et parfumées, la sève humaine s'épura sous la chair des adolescents, et la fleur du sentiment vint s'élever et briller au-dessus de la rude écorce du passé.

Peut-être l'épuration animale, le dégagement de l'origine simienne, le perfectionnement dans la beauté physique, le développement du goût, l'insatiable désir du mieux, sont-ils dus, non à l'homme proprement dit, mais à la femme. Maître par la force, dès les familles simiennes, comme nous l'avons vu, et même chez certains quadrupèdes, subvenant aux besoins des siens, protecteur et défenseur, le mâle était chargé de préoccupations incessantes. Du lever au coucher du soleil, et pendant la nuit comme pendant le jour, c'est lui qui protège, qui surveille, qui cherche la nourriture, végétale ou animale, qui dirige une expédition s'il s'agit de fruits à cueillir (singes), ou qui fond sur sa proie s'il s'agit d'un animal à manger (carnassiers). Chez les singes comme chez tous les animaux supérieurs, la femelle est en gẻnéral affranchie de ces travaux exté rieurs. Qu'elle soigne le mâle et les petits, voilà tout ce qu'on lui demande. Elle a donc tout le temps de songer. Ce n'est 
pas là un vain mot, chez les singes comme chez les lions ou chez les oiscaux - mais surtout chez les mammifères. Elle reste au logis, et quelque rudimentaire que puisse ètre son cerveau, il fonctionne. A quoi pense-t-elle?

Son sentiment est plus développé que celui du mari. Elle est mère. Dès leur naissance, scs enfants lui ont coùté des souffrances. Elle les nourrit de son lait. Elle les airne. Sa fonction est d'aimer. Dès l'origine simienne et animale la plus reculée, les cellules de son cerveau se sont ainsi disposées naturellement. Elle est faite pour le sentiment, et c'est le sentiment qui la fait vivre. Telle est sa nature; tel est son caractère essentiel.

L'affection, quelque élémentaire qu'on la suppose dans l'origine, ne vit pas sans retour. Si la mère aime ses enfants, à leur tour elle veut en être aimée, elle les protège tendrement, et au moindre danger, c'est dans ses bras qu'ils se réfugient. C'est d'elle qu'ils reçoivent les premières lecons et c'est à elle qu'ils donnent leurs premiers baisers. Si la femme aime son mari, elle entend que son mari l'aime, car il ne lui semble pas possible d'aimer sans ètre aimée. Nous nous demandions tout à l'heure à quoi pense la femme. C'est à être aimée.

Lhomme, lui, peut penser à tout autre objet; il peut être ambitieux, chercher la fortune, s'aventurer à la guerre ou à la chasse, s'adonner au jeu ou au vin, s'occuper d'études absorbantes, s'abandonner aux jouissances sensuelles, etc., etc. Son cerveau, lui aussi, s'est organisé spécialement. Son premier devoir lui paraît toujours, comme au temps des ancêtres simiens, de subvenir aux besoins de sa famille, et il sent, lorsqu'il y manque, qu'il est à côté des lois de la nature. Lui aussi a besoin d'aimer. Mais il ne passe pas sa vie absorbé dans cet unique sentiment.

Née pour aimer et pour être aimée, la femme doit plaire, être belle, charmer. C'est là aussi, comme conséquence, sa fonction primordiale et sa perpétuelle tendance. Dès que son cerveau a été suffisant pour concentrer cette idée, ses cellules cérébrales se sont organisées dans ce sens. Elle commence son règne; car elle règne, en fait, sur l'homme, et depuis cent mille ans au moins, e'est dans ce but qu'elle travaille. L'homme a disséminé ses efforts; il a inventé les sciences, les philosophies, les religions, les gouvernements politiques et militaires, les lois, les écoles, les arts, l'inLE MONDE AYATT LA CRÉATION DE L'HOMME 
dustrie; la femme n'a eu qu'une passion dominante : être aimée et régner par l'amour. Elle y a réus:i. Aujourd'hui l'homme est à ses pieds. Chez les animaux, c'est le mâle qui est le plus beau, le mieux paré, le plus élégant, le plus brillant par ses charmes extérieurs. Comparez le coq à la poule, le paon ou le faisan à leurs femelles, les oiseaux entre eux, les insectes, les quadrupèdes, les mammifères, le lion à la lionne, le tigre à la tigresse, etc., etc., partout le mâle est supérieur en beauté à la femelle. Il en était de même à l'origine de l'humanité (chez les sauvages, ce sont les hommes qui se tatouent avec le plus de soins, qui se mettent le plus d'ornements aux orcilles, au nez, aux bras, aux chevilles). En poursuivant sans cesse le même but, la femme a changé le cours de la nature.

Ses yeux ont acquis une plus grande douceur en mème temps qu'une expression plus captivante, ses bras arrondis ont reçu leur souplesse, l'épiderme s'est adouci, satiné, son visage est devenu plus noble, sa chevelure plus soyeuse et plus longue, les pieds et les mains se sont faits plus petits, son corps a senti se modeler ses formes élégantes, et insensiblement, comme la lumière de l'aurore, Ève s'est élevée, dominante et splendide dans la beauté du jour. Charmé par ces perfections nouvelles, l'homme a constamment choisi pour compagnes les plus belles et les plus séduisantes, et celles-ci devenues mères de préférence aux moins privilégiées, ont donné naissance à leur tour à des filles choisies plus tard sous une inspiration analogue. Dans l'humanité, c'est l'homme qui choisit, et telle est la cause principale du progrès dans la beauté fíminine et, comme conséquence, dans la beauté humaine tout entière. Dans le règne animal, ce sont les mâles qui font de la coquetterie autour des femelles pour étre agréés, et ce sont les plus beaux - et les plus forts - qui entretiennent et développent l'espèce. Il en est de mème chez les singes et dans les tribus sauvages. Dans l'humanité, la femme a particulièrement soigné sa beauté. si, plus tard, elle a inventé les vêtements et les modes, c'est encore inspirée par un sentiment de coquetterie habilement dissimulé.

Cette fonction essentielle de la femme - l'amour - est accompagnée comme conséquence d'une passion dominante, la jalousie. Le désir, le besoin d'être souveraine, de dominer, de briller, ont été 
et sont, malgrè des ombres, une cause favorable au progrès et au perfectionnement de l'espèce. La femme veut être belle, veut posséder un beau mari, veut avoir de beaux enfants. Qu'elle s'en rende compte ou non, c'est là son désir le plus intime et le plus naturel. Si elle ambitionne la fortune ou quelque position supérieure donnée par la gloire de son mari, c'est surtout pour briller. L'homme, à son tour, est forcẻ de la suivre dans l'élégance, d'adoucir des angles un peu durs, de soigner sa personne, d'affiner son esprit, et, tout en gardant la supériorité primitive que lui donna la force et que lui conserve l'exercice incessant de sa raison, de ne pas trop se laisser dépasser par l'esthétique féminine. De là l'adoucissement des mœurs, le perfectionnement du langage, la naissance des beaux-arts. Sans l'influence de la femme, la musique, le théâtre, la peinture, la sculpture, l'architecture mème, comme l'ameublement et la décoration des habitations diverses, les temples eux-mèmes, les églises, les religions aussi, la poésie, en un mot tout ce qui dans les œuvres humaines est inspiré par le sentiment et par le goùt scrait certainement resté en un état très rudimentaire. Une émulation incessante a poussé l'homme en avant, et ses facultés intellectuelles en ont reçu un de leurs développements les plus précieux.

A ces qualités extérieures lentement acquises par la persévérance féminine se sont unies, dans le même progrès, des qualités in térieures émanées comme les précédentes de la mème origine, du sentiment d'affection. La femme est devenue d'une extrème tendresse, d'un dévouement profond pour tout ce qui souffre, et son besoin d'aimer la rend capable de se consacier sans réserve au bien de l'humanité entière. Elle a soif de l'idéal, et lorsqu'elle ne trouve pas dans l'amour ou dans la maternité la satisfaction de ses ardeurs spirituelles, souvent elle se plonge et se noie dans le mysticisme religieux plutôt que de renoncer à ses aspirations.

Nous devons done reconnaitre à a la plus belle moitié du genre bumain $D$, une part très importante dans le progrès physique et moral de notre espèce. Si nous ne sommes plus des singes, c'est en grande partie à la femme que nous le devons: elle n'a pas voulu rester dans cet état qui finit par lui parattre ridicule. Ce n'est pas qu'il n'y ait plus d'atavisme. Malgré tous les progrés accomplis, on rencontre encore quelquefois, en Éurope, en France, à Paris mème, 
des têtes qui ne pourraient certainement pas renier leur origine. Mais il faut avouer que ces physionomies malhrureuses sont plus fréquentes dans le sexe masculin. Du reste, on n'y accorde pas une attention démesurée : « l'homme » a encore le droit d'être laid.

La distinction des sexes a donc exercé une influence heurense sur le progrès. Si la reproduction des ètres avait continué de s'effectuer par bourgeonnement ou fissiparité, comme elle a eu lieu primitivement pendant des millions d'années, chez les organismes inférieurs, il n'y aurait pas eu de sexes sur notre planète, et les ètres eussent été tout différents de ce qu'ils sont. Ils u'auraient certainement pas progressé comme ils l'ont fait. Il n'y aurait pas eu d'amour, et l'amour a tout embelli, élevé, purifiè.

Pendant que l'esthétique féminine agissait en faveur de la beauté, de l'élégance, de la finesse matérielle et intellectuelle, du bon goùt, de l'éducation des enfants et du progrès moral dins la famille, le travail de l'homme agissait en faveur des arts extérieurs, du perfectionnement des outils nécessaires à l'entretien de la vie; il inventait successivement les instruments de pierre, d'abord grossièrement taillés, marteaux, haches, couteaux, têtes de flèches ou de lances, grattoirs pour les peaux écorchées, aiguilles d'os ou de corne; puis ces outils se sont perfectionnés à l'âge de la pierre polie; on avait trouvé le moyen de faire du teu en frottant du bois sec dans un trou creusé dans une pierre; on construisit plus tard des instruments en bronze et en fer. Tout cela d'abord fut bien primitif, comme on le constate sur les quantités d'uljets retrouvés. Mais insensiblement la faculté d'invention s'accroît elle-mème dans le cerveau humain. Lorsqu'on eùt remarqué la germination de certaines plantes utiles, on inventa la charrue, les semailles et la moisson; mais il fallut bien longtemps se contenter de ce qu'on trouvait sous la main avant de songer à l'avenir. Un lloc d'arbre tombé fut longtemps la première table, et longtemps les lèvres et les mains précédèrent l'invention des écuelles de bois ou de terre ou celle des cuillers et des fourchettes. Longtemps aussi des feuilles mortes, des branches d'arbres, des cavernes, précédèrent la plus humble cabane de terre et d'herbe. La pèche commença par celle des coquilles, notamment des huitres, dont on retrouve les écailles lans les anciens séjours de l'homme. La navigation comnıença par 
un tronc d'arbre creusé. Quelques animaux, l'éléphant, le renne, le cheval, le bœuf, purent être apprivoisés, domestiqués, utilisés (l'homme avait été précédé par les fourmis qui avaient su domestiquer leurs troupeaux de pucerons). Dans tous ces travaux qui ont pour but de rendre la vie matérielle moins difficile et plus sùre, on voit jusqu'à présent peu d'abstraction. La faculté de penser se développe, mais lentement. On compte peut être déjà jusqu'à cinq, avec les doigts, peut-être jusqu'à dix, mais c'est tout. On est encore sauvage et barbare, on s'assomme entre soi sans pouvoir encore raisonner et s'expliquer (les armes sont nombreuses et variées dans les outils primitifs). On ne fait pas encore de combinaisons bien longues et tout jugement est sommaire. On parle, mais quel langage! par interjections, par monosyllabes. Les langues monosyllabiques ont été les premières parlées, et on en retrouve encore aujourd'hui la descendance dans les langues parlées par les races aînées. Les langues agglutinatives, plus perfectionnées sont venues ensuite, et en dernier lieu les langues à flexion. Le langage est sans doute l'un des plus grands progrès qui, des singes anthropomorphes ont fait des hommes sauvages; mais il ne faut pas oublier que le langage ne consiste pas essentiellement dans la voix, mais plutôt dans la faculté d'exprimer ses idées. Or la plupart des animaux possèdent cette faculté : les chiens savent bien se faire comprendre de nous-mèmes; le langage antennal des fourmis parait assez riche, etc. Plus tard, le langage s'est développé, diversifié, enrichi, parallèlement avec les idées, et a scrvi lui-même au développement des idẻes. Le langage écrit n'est arrivé que beaucoup plus tard. Il est tout récent, comme l'histoire, at ne date pas de plus de six ou sept mille ans.

Tel fut l'homme préhistorique. Mérite-t-il le titre d'номме? Sans doute, et nous lui devons d'etre ce que nous sommes. Mais qu'il y a loin de cet être essentiellement matériel à celui qui pour nous représente réellement le type de l'humanité, à l'homme pensant! Qu'il y a loin de ces sauvages aux Égyptiens des premières dynastir's, à Moïse et aux prophètes, aux Grecs contemporains d'Homère, d'Ilésiode, de Thalès ou d'Archimède! L'humanité historique ne date que du trentième siècle avant notre ère - Hoang-Ti en Cihine, Abraham en Mésopotamie, les Hindous chantés par lo 
Zend-A vesta - peut-être du quarantième ou du quarante-cinquième siècle, de l'époque des Égyptiens de la cinquième dynastie. Mais, nous qui parlons aujourd'hui, en France, en Italie, en Europe, 'qu'étions-nous alors, il y a six mille ans, lorsque déjà cette antique civilisation brillait dans la vallée du Nil, lorsque déjá l'écriture et l'histoire existaient pour une race religieuse et réfléchie? Nos ancêtres en étaient encore à l'âge de la pierre - non polie - et vivaient au milieu des bois, sur les rives de la Seine; de la Loire et du Rhône, en compagnie de l'ours des cavernes, du rhinocéros, de l'éléphant, de l'hippopotame, ne se préoccupant point encore des grands problèmes de la métaphysique ni des petites questions de la politique. Ils vivaient au jour le jour, rudes, grossicrs et assez barbares.

On ne peut préciser de date pour l'apparition de l'humanité, puisque cette apparilion n'a pas été subite et que notre race s'est graduellement formée. Les documents manquent d'autre part pour indiquer la contrée où ce progrès s'est manifesté. Cependant nous avons de bonnes raisons de penser que l'humanité primitive, possédant un rudiment de langage, vivant à l'état d'associations, sachant se fabriquer des instruments de pierre, dessiner sur la corne, etc., date de plus de cent mille ans, et nous pouvons aussi placer cette origine du progrès humain définitif en Asie, vers la région du Golfe Persique, d'où la race intelligente s'est répandue sur le monde.

Le caractère psychique essentiel de l'homme est sa faculté $d$ 'abs. traction, et c'est mème là le propre de l'âme humaine. Supprimez cette farulté, l'homme redescend à l'état d'animal. Mais cette faculté aujourd'hui caractéristique est relativement récente, et nous pouvons signaler les phases de son développement. Les mathématiques, par exemple, sont à juste titre considérées comme l'une des manifestations les plus élevées de l'esprit humain, surtout dans leurs applications transcendantes aux plus profonds problemes de l'astronomie. Or il n'est pas difficile d'en suivre la filic̀re. On a commencé par l'arithmétique élémentaire, par les doigts de la main, jusqu'à dix, et telle est mème l'origine de la numération décimale. Pour les mesures de longueur, nn a pris le pied, le pas, la coudée (du bout de la main au cou le), pour les mesures de profondeur la brasse, toutes dimensions empruntées au corps humain. Dans 
l'écriture cunẻiforme des Chaldéens, les nombres sont tout simplement représentés par des trous (autant de trous que d'unités jusqu'à dix, et combinaisons au delà). Chez les Grecs, les chiffres ne sont autres que les lettres de l'alphabet surmontées d'un accent: $x^{\prime}=1, b^{\prime}=2, \gamma^{\prime}=3$, etc., jusqu'à 20 ; au delà on combine les lettres. La géométrie a sans doute commencé par l'arpentage et l'architecture. L'arithmétique et la géométrie élémentaires sont aussi anciennes qu'elles sont simples, et elles dépassent à peine les facultés de certains animaux (abeilles, fourmis, pies, corneilles, castors, chiens, etc.). Les vraies mathématiques paraissent n'avoir commencé qu'avec Thalès et Pythagore, au sixième siècle avant notre ère, comme développement de l'arithmétique et de la géométrie égyptiennes. Comme corps de doctrine, par démonstrations inattaquables, la géométrie ne date que d'Euclide, au point de vue de la mèthode, et d'Archimède comme science de mesure; les sections coniques, devenues plus tard si fécondes, datent d'Apollonius de Perge, l'algèbre a commencé avec Diophante, l'astronomie de précision (relative) avec Hipparque et Ptolémée, la démonstration du véritable système du monde date de Copernic, la connaissance des mouvements est due à Képler, et celle des lois à Newton, l'astronomic physique commence avec la lunette de Galilée, l'application de l'algèbre à la géométrie appartient à Descartes, les logarithmes, qui rendent tant de services dans les calculs, ont été inventés par Neper, la théorie des nombres n'a jamais été poussée aussi loin que par Fermat, le calcul différentiel a èté inventé par Leibniz, le calcul intégral a été développé par Jean Bernoulli et Euler; Lambert, Clairaut, d'Alemhert, Lagrange, Laplace, Leverrier, ont dònné les derniers développements à la mécanique céleste. Tout cela est d'hier. La philosophie astronomique ne date même pas d'hier: elle est à peine fondée, c'est à peine si l'on commence aujourd'hui à étudier les conditions de la vie sur les autres mondes, à sentir la vie animer l'univers immense et à apprécier le rang de notre planète dans la vie universelle et éternelle. On le voit, nous pouvons suivre historiquement, pas à pas, les progrès de l'esprit humain. Ce que nous venons de dire pour les mathématiques et l'astronomie, pourrait l'être, tout aussi facilement, pour la physique, bour l'optique, pour la chimie, pour toutes les sciences, pour 
tous les arts, pour toutes les cuvres de l'esprit. Ce qui fait que parfois le progrès ne parait pas aussi manifeste, c'est que dans certains cas, comme dans la sculpture, la peinture - la médecine peutètre - le changement n'est pas remarquable depuis deux mille ans; mais on ne réfléchit pas que deux mille ans, c'est un jour. Ln fiit, pour celui qui remonte aux origines, impartialement, sans aucun parti pris et de bonne foi, tout ce qui constitue aujourd'hui la valeur matérielle, intellectuelle et morale de l'humanitéa élé acquis successivement par le long travail des siècles. Dans les sciences les plus modernes mème, dans les inventions les plus nouvelles, dans les applications los plus ingénieuses, l'esprit le mieux doué, le plus instruit, le plus laborieux et le plus adroit, ne crée pas: il se sert des éléments qui lui sont fournis par l'état actuel de la science pour faire un pas de plus et aller plus loin. Ainsi marche, ainsi a toujours marché le Progrès.

Certes, l'humanité actuelle est encore loin d'être parfaite. Nous n'avons pas encore l'âge de raison. Tant qu'on verra des gouvernements agir comme ils le font; le suffrage universel se faire représenter par les fruits secs de tous les clochers; les Chambres incapables de discerner le faux du vrai, le juste de l'injuste; les esprits les plus avancés aveugles sur l'idéal; le droit grossier du plus fort; les armées permanentes; le ministère le plus absorbant de chaque nation s'appeler le ministère de la guerre; le travail de rous spolié par des impôts toujours grandissants; les administrations routinières; les parasites de tout ordre; les fortunes scandaleuses et les misères abrutissantes; les vols et les assassinats - tout cela produit par un ordre humain mal équilibré - on ne pourra se vanter d'appartenir à une race véritablement intelligente. Mais son avancement passé est un sùr présage de son progrès futur. Certes, l'ignorance est encore très générale; il y a encore aujourd'hui beaucoup d'humains qui ne pensent pas, qui vivent sans rien chercher, sans rien savoir, sans avoir aucune idée, ni de la constitution de l'univers, ni de la planète qu'ils habitent, ni de l'histoire de l'humanité; larves étranges d'une race en formation! Cependant le monde marche. Sciences, arts, littérature, goùt, morale, tout s'élève malgré les lourdauds. Le règne de l'esprit arrive. Le sentiment du bien s'affirme comme celui du vrai; la vertu, comme le savoir, agrandit 


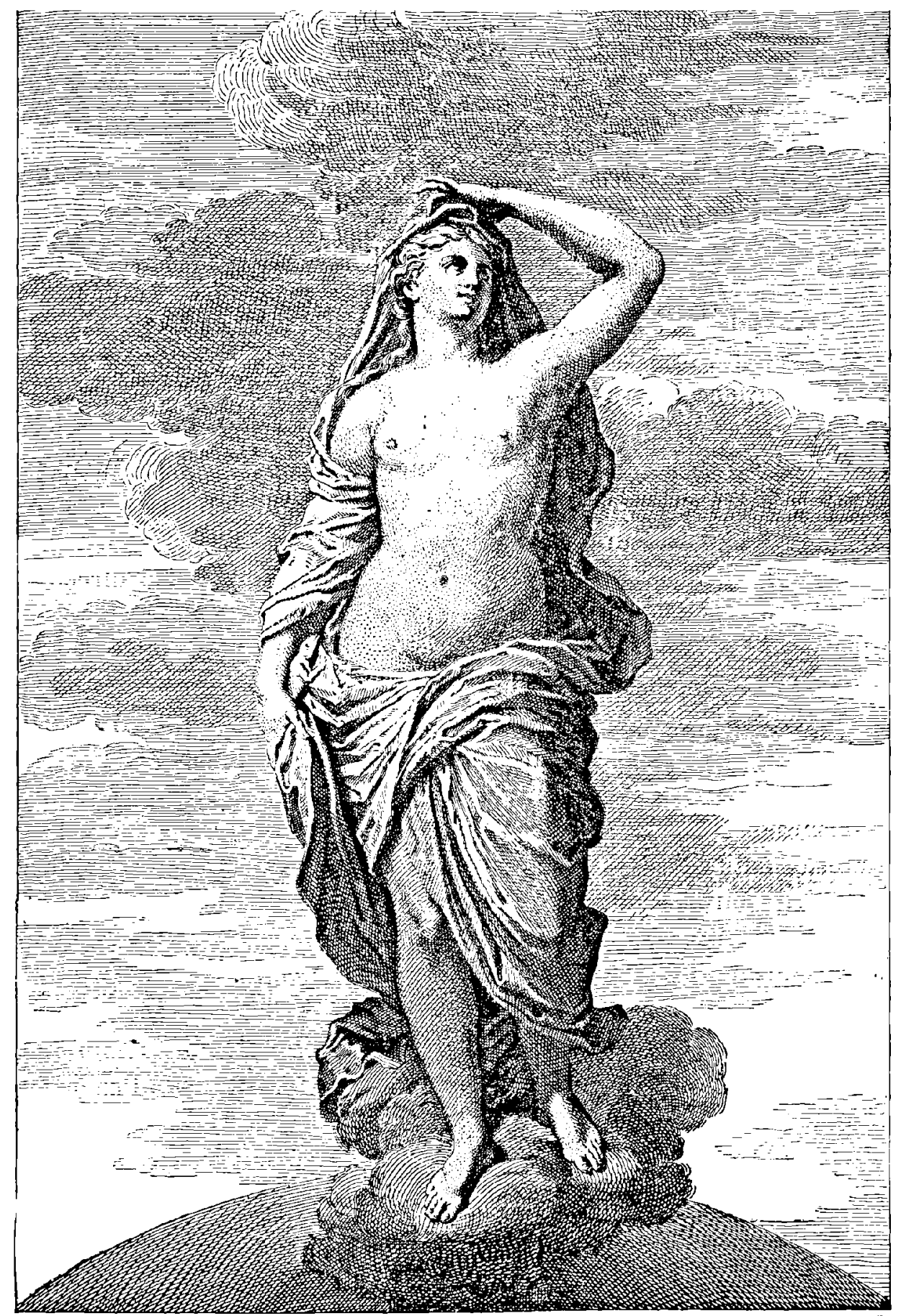

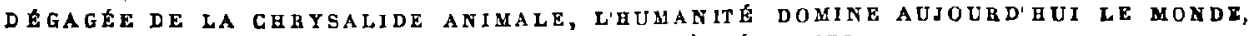
, ASPIRANT AU PROGRË ÉTERNEL

LE MONDE AVANT LA CRÉatION DE L'HOMME 
l'homme et le purifie. Il est doux de reconnaitre dans l'histoire des âmes telles que celles de Jèsus, Socrite, Platon, Marc-Aurèle ou Vincent de Paul, dont le bienveillant souvenir repose la pensẻe. Nous pouvons saluer l'ère définitive de la race humaine terrestre. Notre planète avance. Dégagée de la chrysalide animale, l'Humanité domine aujourd'hui le monde, aspirant au progrès éternel.

Tel est l'état actuel des connaissances humaines sur les grandes questions qui ont de tout temps inquiété la pensée des mortels, sur l'éternel problème des origines du monde, de la vie et de l'humanité ('). Nous avons fait nos efforts pour exposer dans cet ouvrage la synthèse de ces connaissances, avec la sincérité la plus absolue et sans être jamais détourné de la contemplation directe des choses par aucun esprit de système. Nous espérons n'avoir rien omis d'important dans cette synthèse, ayant puisé directement aux sources d'informations les plus sùres, pour toutes les questions de détail qui, au sein de ce vaste ensemble, s'éloignaient le plus de l'ordre habituel de nos travaux, c'est-à-dire de l'étude générale de l'univers à laquelle notre vie a été consacrée. Il serait long de citer toutes ces sources; mais en dehors de nos recherches astronomiques sur les origines du monde, en dehors de nos observations directes sur les fossiles, sur la géographie physique et sur les transformations du sol, nous devons tout particulièrement signaler, parmi les ouvrages spéciaux auxquels nous avons eu le plus souvent recours : le nouveau Traité de géologie, de M. A. DE LAPPARENT (édition de 1885); la Géologie et Paléontologie, de M. Сн. Contejear; les Enchainements du Monde animal, de M. Albert Gaudry; le Monde des Plantes avant l'apparition de l'homme, de M. de Saporta; les Colonies animales, de M. Ĺdyond Perrier; les Merveilles de la nature, de Brenm (édition de M. E. Sauvage); l'Histoire de la Création naturelle, de HaEckes; les Leçons sur l'homme, de CarL Vogr; la Géologie slraligraphique, de M. CH. VéLain; les Comptes rendus de l'Académio des sciences de Paris,

1. L'ouvrage qui fait suite à celui-ci, La Création de l'homme et les premiers áges de l'humanilé, et qui, dans le principe, devait etre écrit par M. Cartallasc, a été rédigé par $M$. pu Cluuziou, l'érudit auteur de l'Art national: il va être publié immédiatement à la suite de ces dernières pages et sous la même forme. 
de l'Académie de Belgique, etc; les publications américaines du géologue Marsh, les publications anglaises de Huxley, Waldace, Darwin, Crold; les publications allemandes de Brehm et Haeckel, ouvrages récents auxquels il 'n'est que juste d'ajouter des ouvres plus anciennes et non moins riches en documents, telles que le Monde primitif de la Suisse, d'Oswald HeEn; l'Origine des espèces, de Darwin; les Principes de géologie, de LyelL; l'explication de la Carte géologique de la France, par Dufrévoy et Élie de Beaumont; les travaux de Cuvier, Geoffroy Saint-Hilaire et Brongniart; la Philosophie zoologique, de Lamarck, etc., etc. Nos lecteurs ont pu remarquer encore un grand nombre d'autres sources mentionnées dans le cours de ce volume.

Sans doute, la géologie proprement dite, la paléontologie, la zoologie, l'histoire naturelle, la physiologie végétale, l'anatomie comparée, l'embryologie, l'anthropologie, sont des études en apparence bien étrangères à l'astronomic, et la sublime science du ciel est si vaste en elle-mème que l'esprit le plus laborieux d'un seul homme a déjà beaucoup de peine à la bien connaitre. Il était donc assurément téméraire pour un astronome d'entreprendre une tâche telle que celle-ci. Mais comment se défendre de l'attrait excrcé par ces grands problèmes d'origines? Comment rester étranger à toutes ces merveilleuses découvertes d'une science qui grandit tous les jours? On commence par vouloir se rendre compte de l'origine du monde au point de vue purement astronomique. Ensuite, lorsqu'on est à peu près satisfait des lueurs que la science du cosmos apporte sur le berceau de la Terre et qu'on assiste à la première condensation des eaux, à la formation de l'atmosphère, à l'émersion des premières îles, on ambitionne de savoir comment les premiers organismes sont venus au monde... et ainsi de suite jusqu'à l'état actucl de la nature, y compris le règne de l'humanité. Tout se touche, tout s'enchaine. Et puis, le hasard, la fantaisie, certains souvenirs d'enfance, ne sont peut-être pas de vains mots, comme on peut en juger par la petite anecdote suivante, qui n'a qu'un tort, celui d'ètre un peu personnelle. Mais je la raconte telle qu'elle est en terminant.

Avant d'entrer à l'Observatoire de Paris, comme élève-astronome il y a longtemps de cela : en 1858 - l'auteur de cet ouvrage avait été sur 
le point d'entrer (d'après les encouragements de M. Pasteur) au Muséum d'histoire naturelle, et déjà avec un gros manuscrit sous le bras, marnuscrit de cinq cents pages, illustré de cent cinquante dessins et portant pour titre ronflant: Cosmogonie univenselde, ou Histoire de la création Co gros manuscrit est mème double, l'un, de la main de l'auteur, très barbouillé de ratures, l'autre, beaucoup plus élégant, de la main de sa sœur. En 1857, date la rédaction de cet essai de jeunesse, l'auteur comptait trois lustres, comme on disait au siècle dernier, soit quinze ans, et sa sœur treize.

Get ouvrage était resté oublié dans une ombre aussi légitime que discrète, bien anéanti par le soleil de l'Astronomie, lorsqu'il y a quelques années, le frère de l'auteur - on voit que l'anecdote ne sort pas de la famille, et c'est en cela qu'elle est un peu personnelle - fut conduit, à propos de transactions de librairie, à acquérir l'ouvrage bien connu de Zimmermann sur Le Monde avant la création de lhomme. Mais cet ouvrage datant de plus d'un quart de siècle, il était désirable de ne pas le publier sans une revision qui le mît au courant des grands progrès accomplis.

On le voit, l'auteur n'a fait que revenir a à ses premières amours * en entreprenant cette revision. Seulement, il a été conduit, par la force même des choses, à outrepasser le but. Les connaissances nouvelles acquises par la science depuis vingt-cinq ou trente ans, sont telles que pas une seule page de l'œuvre, alors remarquable, 'du naturaliste allemand, n'a pu rester dans cet ouvrage-ci, qui est absolument nouveau dans toutes ses parties : pas une seule page! Le titre seul est resté. Encore, à certains égards, si l'on y tenait beaucoup, pourrait-on lui substituer celui de Monde avant $l$ apparition de Chomme.

Par son origine même, ce livre pourrait donc être considéré comme le premier que l'auteur ait préparé, la Pluralité des Mondes habités n'ayant été écrite qu'en 1861.

Ce petit récit, véridique dans ses moindres détails — et facile à vérifier d'ailleurs pour ceux que cette vérification intéresserait n'a d'autre but que de nous excuser de notre grande témérité d'avoir entrepris une telle cuvre, en expliquant les causes qui nous y ont conduit, et qui nous y avaient prédisposé d'ancienne date. II n'a, au fond, ce petit récit, rien de bien encourageant. Il nous ouvre en perspective que dans un nouveau quart de siècle, plus ou moins, la science aura fait de nouveaux progrès devant lesquels cette édition-ci paraîtra à son tour antédiluvienne. L'auteur lui-mème sera déjà fossile ou à peu près. Un nouveau soleil, celui du vingtième siècle, éclairera le monde. Et les fils de ce siècle pro- 
chain marcheront en avant, étonnés sans doute de nos réticences actuelles, qui nous semblent, à nous, des témérités.

Hélas! c'est l'histoire de toutes choses. Mais pourquoi dire hélas / Soyons heureux, au contraire, de la continuité du progrès. Naguère encore, je passais en ballon au-dessus de Paris, et je voyais sous un méme coup d'œil, ces milliers, ces millions d'êtres humains, courant fort affairés dans les rues, sur les places publiques, occupant les villes, les villages, les champs, les ateliers, cir. culant à la vapeur dans les trains multipliés ou les navires, préoccupés de mille désirs, de mille besoins, de mille querelles, - troupeaux ou armées - s'agiter, travailler, rire, pleurer, aimer, souffrir... et je me disais : $\propto$ D'aujourd'hui en cent ans, il y aura là autant de monde, et encore davantage; mais tous ceux-ci seront dans la tombe; qu'est-ce que la vie, et à quoi sert-elle? „ Eh bien! elle sert au progrès, au progrès individuel et au progrès de l'humanité. Soyons heureux de mourir pour faire place à d'autres. Nous ne sommes peut-être que les iguanodons de l'humanité future.

Oui, le progrès est la loi de la nature; toutes les pages de cet ouvrage en sont un constant témoignage; le but attractif de toutes les tendances de l'esprit humain est la recherche de la Vérité. Tout le reste n'est qu'ombre. La destinée de chacun de nous est de nous élever de plus en plus dans la sphère intellectuelle. Sans doute, l'avenir a plus de nuages que le passé : il reste encore enveloppé de mystères; mais hier encore la création des choses et des êtres nous paraissait aussi impénétrable que leur destinée. Maintenant, déjà quelques voiles sont écartées, et nous commençons à distinguer de quelle façon ces phases se sont produites. C'est là un garant et une espérance en faveur du progrès de notre savoir. Bientôt peut-être nous saurons résoudre l'énigme de la vie future comme nous avons commencé à voir se dissiper les brouillards qui cachaient le passé. Gardons pour devise : vÉRITÉ I LUMIÈRE I ESPÉRANCE l... Et continuons de vivre dans le divin monde de l'esprit.

FIN. 
IRIS - LILLIAD - Université Lille 1 


\title{
TABLE ALPIIABÉTIQUE
}

\author{
DES MATIÈRES
}

Annèlides, animaux primitifs, 298 à 230 .

Action des cours d'eau sur le sol, 279 a 348 ; des infiniment petits sur la création des roches, 8Q23.

Actuelle (Période), son déreloppement, 89; les transformations actuelles du sul, 279 a 368 .

Affaissements du sol, 304 a 344,533 a 546 .

Agents atmosphériques, 205, 206.

Ages de la Terre, 4, - primordial, secondaire, tertiaire, quaternaire, 22, 23. - Tableau de leurs développements progressif́s, 89. - L’àge primordial, 83 a 252 ; - durêe des divers åges, 290 ; - revue des Áges, $240,242,243$;-Áge primaire, 2533482 ; - tableaux des âges, des cơches, des terrains et de l'écorce terrestre, 258 a 261 ; - Âge secondaire, 483 a 644 ; - tertiaire, 645 a $729 ;-$ quaternaire, 733 a 829 .

Air, sa formation, $74 ;$ - son influence sur la transformation des espices, $\$ 6,98$; - sa composition, 122,123 ; - son épuration, 247 \& 249.

Algues, premieres plantes, 224, 296, 230, 247, 438.

Alluvions des fleuves, 290,748 a 751 .

Alpes, leur ancienneté, 236 à 238 ; - leurs stratifications, 538 a 546 ; - leurs soulèvements, 630,691 a 700 .

Ame chez les êtres supórieurs, 196.

Ame humaine. Son existence dans la théorie du transformisme, 197, 199, 810, 822.

Amibes, 140, 141.

Ammonites, 491 ; - du trias, 502 à 505, 512, $514 ;-$ du crétacó, 629 \& 631.

Amphibies, 22, 81 .

Amphicyon, 708.

Amphiméryx, 723 .

Angleterre, érusion de ses rivages, 322 a 325 , $338,339$.

Animal, classification du règne, 87, 88, 113.

Animaux, leur création, 6 a 8. - Premiers animaux, 22, 23; - sans sexe, 92, 23. - Les animaux ont toujours été distincts des végétaux, 154. - Êtude détaillée des premiers animaux terrestres, 221 a 252; - développement des animaux primaires, 387 ; - du trias, 512 a 527.

Anoplothèrium, 670.

Anthracothérum, 670.

Anthropophages, 792.

Araucaria, 430, 495, 571.

Arbre généalogique du règne animal, 113, 118, 663 ; du regne régetsl, 437,603 .
Arbres (Les premiers). Epoque déronienne, 390 a 395. - Apbres géants de la période carbonifłre, 438 \& 454.

Arcachon, transformation des rivages, 330 a 332 . Archéoptérix, le premier oiseau, 23, 582 à 586. Ardoises, leur formation, leur disposition, 78, 79. Argentan, terrain jurassique, 597.

Argiles, leur décomposition, 78, 597, 613, 6556 . Argileux (Dépỏts), 206.

Asconsion de la pie, 145.

Aspect de la Terre durant la période primitive, $80,82,85,86$.

Assises géologiques, 265, 270 a 273.

Astéries, leur formation, 177.

Atmosphère primitive, $22,66 .-$ Combinaisons des substances contenues dans l'atmosphère primitive, 72, 74.-A tmosphère de vapeurs, 86 ;sa condensation, 200, 201, 205, 247 ; - atmosphère car'bonifère, 406, 410; - triasique, 485.

Atomes vivants (Hypothèse des) a l'origine de la nébuleuse solaire, 122.

Atrophio d'organes derenus inutiles, 100 a 110.

Atterrissements des fleures, 289 a 306.

Attraction des molécules de la nébuleuse solaire, $20,22$.

Auvergne (Volcans), 691.

Azoiques, roches primitives, 207.

Bacilles, 151

Bactéries, 151. - Nombre par mètre cube d'air, 153.

Bagnoles (Orne), les plus anciennes plantes du silurien inférieur, 244, 245.

Basalte, 691 .

Bathonien, étage jurassique, 490.

Batraciens de l'époque permienne, 465 a 480 , - du trias, 515.

Bélemnites du jurassique, 592 a $602 ;-$ du crétacé, 629 .

Bilobites, 223, 224.

Blocs erratiques, 734 a 749.

Bøufs du pliocène, $720 ;-$ du quaternaire, 7555.

Brachyphyllum gracile, 224, 226.

Bretagne, modifications de son sol, 312 a 314 , 319 aे 325.

Calamites du déronien, 391 a 394 ; - du carbonifère, 412, 518.

Calamodendrons du carbonifère, 449, $44,452$. 
Calcaire, composition, 286 ; - pierre, 261, 488, 611 \& $624 ;-$ du tertiaire, 651 a $659 ;-$ calcaire miocène, 699.

Calendrier terrostre, 4.

Calvados, envahissement de la mer sur les cótes, 311,319 ; - soulèvement durant la période jurassique, 533.

Cambrien (Terrain), son développement, 89 ; époque cambrienne, 223 a 227 ; - terrain, 218 ; — son eprisseur, 221.

Cantal, voleans du miocène, 692 .

Carbonate de chaux, ses produits, 261.

Carbonifére (Póriode), 396 a 459.

Carrières, couches superpoş́es, 269.

Cénomanien, étrgre du irétacé moyen, 490.

Cerf a bois gigantesque, 648 .

Cerveaux des races humaines, 783 a 789 ; - des singes, 787.

Chaine des etres vivants, 10, 11.

Chaleur et mouvement, 38 40. - Chaleur propre de la Terre aux premiers ages de notre globe, 75. - Action de la chaleur sur les premières couches du globe, 78, - Son influenco sur la transformation des espéces, 99, 100.

Chóropotame, 670.

Chondrites antiques, 226, 297.

Chute des pattes chez les lézards, 109, 110.

Classification du règne auimal, 87,88 ; - des terrains, $255 £ 278$.

Climats Absence de climats aux premiers ages de la Terre. 75, 76. 227; - action des climats sur le sol, 367 ; - les anciens climats, 398 \& 408 ; du temps jurassique, $335,604,606$; - du crétacé, 613;- de l'éocène, 648, 649; - du miocène. 700,$701 ;-$ du pliocène. 716 \% $720 ;-$ de l'ếpoque glaciaire, 733 a 749.

Clyménie, 386.

Cœur de tortue continuant de battre après avoir été arrarhé, 189

Gomètes ragahondes, 1516.

Composition de la houille, 412.

Conclusions sur le progrès perpétuel des êtres, 821 à 839 .

Condensations planétaires, 54, 55; - de l'atmosphère primitive, 72, 74; - du Soleil, $400,401$.

Conglomérats, 206, 162.

Coniferes, 3. 44, t52, 481, 482, 494, 495, 496, $5666,604613,639$.

Corail, 230; - iles de coraur, 363 a 360 , 534, 53., 604 a $604,614$.

Cordaites du rarhonifère, 452, 481.

Cordouan, яffaissement du sol, 317, 318, 320, 321.

Cosmique, matière priniture, 48, 122. 123.

Couches d'eau uniformément répandues à la surface du glolie terrestre, 77 ; - des roches primutives, 78, 79, 85; - fossiliferes, 259 à
261; de sédiment, 262 à 278 ; - de bouille, 420 \& 424.

Coupo générale de l'écorce du globe, 261; - du puits de Grenelle, 265, 270 h 273 ; - coupe d'une lle de coraux, 363 a 365 ; - d'un terrain houiller, $\$ 19$ a 421 ; $-\mathrm{du}$ jurassique, $591,595$.

Cours d'eau, leur action sur le sol, 279 a 348 ; - de la périoda glaciaire, $733,734,740$ à 749 .

Craie, sa composition, 156, 206; - ses gisements, 611 a 624.

Crass rostris, 3 .

Creation des animaux, hỵpothèses inadmissibles, 7, 8, 10. - Métamorphoses continuelles, 15. - Création des êtres vivants. fissiparité, aelfs, $1 \pm 8$ h $130 ;-$ du monde se continue, 726 b 729 ; - de Ih)mme, 762 a 829 .

Crétacé (Terrain), son développement. $89 ;-$ ses étages, 488, 490; - période crétacée, 607 a 644 .

Crinoīdes, 233, 234, 237, 599.

Cristallisation des calcaires, 206, 207.

Crocudiles, 671.

Crustacts (Premiers), 22, 230, 232, 238, 239 ; de l'époque dévonienne, 381 a 384 ; - carbonifère, 455; - du tries, 515

Cryptogames des mers primitives, 22\%, 296; du terrain houiller, 427, 428,444, 481. Plantes inférieures, leur naissance, 426.

Cycadees, 3, 444, 445, 452, 492, 493, 494. 496, $518,566,571,604 ;-$ du crétacé 613, 640.

Cycles de l'bistoire organique de la Terre, 258 a 261.

Cyprès, 197.

Darwinisme, 110 a 119.

Décomposition des granits, 77 ; - des urgiles, $78 ;$ - des roches, 262.

Deltas, leur formation, 279 a 309 .

D nsité des roches, de la Terre, 202.

Dents Preuves du transformisme, 718, 754.

Depóts qui se forment dans l'Océan, 262, 263.

Depressions du sol, 306 a 344 .

Doveloppement et progession de la vie, 144 a 199369 \& 395.

Dévonien (Terrain), son déreloppement, 89, 257; - période dévonienne, 369 a 395.

Diatomees leurs diverses formes, 152 à 156.

Dichobune, 670.

Dichodon. 723 .

Dieu Sun existence n'est pas mise en péril par la thériedu transformisme, 197 a $199 .-$ Lo Dieu de la science, 15, $762,804$.

Diluvium. 734 a 749 .

Dimorphodon macronyx, 3.

Dinoceratidés, 674, 675.

Dinornis de la Nouvelle-Zélande, 757. 
Dinosauriens, 517, 5ว̆5̈; - espèces principales, 556 \& 571.

Dinothérium du quaternaire, 691, 710, 752.

Dislocations du noyau terrestre, 76 à 79.

Dives, atterrissements, 300.

Dolomie, 506, 508, 539.

Dunes, villages ensevelis, 317,326 a 328.

Dryopithéque (Singe), $2,715$.

Dureo des époques géologiques, 220.

Eaux, leur première condensation, 72 a 74, 76, 77. - Influence de l'eau sur la transformation des espèces, 91 n 96. - Action des eaux, 205; - eaux hahitées, 241, 247. - Eraporation des eaux, 287 à 289 ; - de la période glaciaire, 740 aे 749 .

Eaux minérales, 505 a 307 .

Éboulements des montagnes, 355 a 369.

Écume siliceuse, 203.

Électricité atmosphérique des premiers ages de la Terre, 78, 77, 89; - action de l'électricité sur la progression de la matiore, 135.

Elémentaire (0rganisme), 190 a 143.

Éléphants, 710, 711. 720, 722, 746, 751 à 755. Leur succession généalogique et leur transformation, 752

Embouchure des fleuves, leurs modifications, 279 a 310 .

Emplacement futur de nos grandes villes, 16.

Empreintes géologiques, 223 a $228 ;-$ de pas, 469,519

Envahissements de la mer, 309.

Éocène (Terrain), son déreloppemeut, 89; - période éocène, 617 a 690 .

Éopteris Morieri, la plus ancienne plante connue, 2469.8.

Epaisseur des terrains, 220, $2 \% 9$ a 261,506 , $507,532,611$.

Époques, 4; - primordiale, 82 \& 252 ; - primaire, 255 a 482 ; - secondaire, 485 h 644 ; - tertiaire, 647 à 729 ; - quaternairo, 733 a 829.

Équisétacées du dóronien, 391 a 393 ; - du carbonifere, 139, 410, 499, \$18.

Érosion des rivages, 290, :08; - des collınes, 691. Erratiques, blocs de la période glaciaire, 734 a 749.

Éruptives (Roches), 276, 277, 691 a 700.

Especes. Preures de Ieurs tansformations, 91 a 119,677 aे 684,707 k 715 .

Esprit (Comment arriva l'), 195, 197, 523, 777, 798.

Étages anciens, 218 \& $220 ;-d u$ secondaire: triasique, 490; - jurassique, 531 ; - crétacé, 613 ; - du tertiaire, $659,653$.

Etats (Trois) des corps, 72.

Etoiles des quatre types, 62,63 .

Etres (Premiers) 22:- Porenté et noité organi- ques, 103 à 119 ; - Formation des organes, 116, 117; - leur matière organique composante, $126 ;-$ premiers ètres, 371,$372 ;-$ évolution, 677 à $684 ;$ - l'homme règne au premier rang, 797 a 799

Europe dans les temps reculés, 3 ; - a l'ẻpoque jurassique, 533 a 535 ; - a l'époque tertiaire, 663 a 659,689 a $700 ;-$ miucène, 716 \& 729 .

Évolution des espèces, 91 a 119, 677 a 681,707 715 .

Falaises, 205, 206; - Action de la mer, 980 a 337; - du Calrados, 594.

Falun du miocène, 699.

Fauno. Tableau de ses déreloppements progressifs, 89; - période carbonifère, 454 a 459 ; - permienne, 463 a 480 ; - du trias, 518 ; du jurassique, 546; - du crétacé, 6924 à 639; — do l'éocìne, 667 a 686 ; - du miocéne, 695 à $698 ;-$ du pliocène, 718 a $728 ;-d u$ quatern ire. 748 a 759.

Fécondation des plantes, 433 ; - des animaux, 149, 174, 182.

Feldspath dans la composition des roches, 77, $20: 3$.

Femme (La), son rôle dans la vie de l'homme et son action dens le progrès, 816 a 891 .

Fer, 201 à 203 ; - sulfure de fur, 624 .

Figures naturelles singulières, 208, 209, 212, 213. Filons éruptifs, 277.

Fissiparité des organismes inférieurs, 128, 129.

Fleuves, leurs atterrissements, 290 à 306 .

Flore. - Tableau de son dóveloppement progressif, 89 ; - première flore, 225,226 ; - de l'époque carbonifere, 410 a 420,438 a $454 ;-$ du trias, $518 ;-$ du tertiaire, $648,651,688$, $700,701,717,718$.

Fontainobleau, sables du miocène, 698,699

Foraminifères, 156, 157, 616 a 624, 649

Forêts primitives, 390 à 395 , - houillères, 408, 423.438 a 454.

Formation du système solaire, 48 a 63 ; - des anneaux nébuleux, 54, - de la Lune, 66, 67; durée de la période de formation des planètes, $71 ;$ - de l'atmosphere terrestre, 72, 73, $74 ;-$ formation des terrains, 202 a 207 , 255 a 278 ; de la houille, 410 a 454 ; - des terrains, 544, 545,610 a 615 .

Fossiles. Langage des fossiles ressuscités, 6,7 . Goutles de pluies fossiles, 80. - Examen des fossiles, 117. - Les plus anciens fossiles, 207 a 217. - Arbres fossiles, $409,410,448,450$; - du crétacé, 627 a 641 ; - d'OEningen, 703 a. $706 ;-\operatorname{singes,} 314,815$.

Fossilisation, sa theorie, 201 a 20 .

Fougère arborescente, $3 ;-$ du déronien, 391 
z $394 ;-$ du carbonifère, 412, 440 a 443 , 446, 447, 450,453; - de l'Age secondaire, $492,496,497,518 ;-d u$ jurassique, 566 , 571.

Fractures dans l'écorce du globe, 273 a 278.

France a l'époque silurienne, 236, 237; - a l'époque jurassique, 532 в $546,601,602$; - crétacée, 607 à 616 ; - bocène, 619, 650; miocène, 716 a 722 .

Franconien, étage triasique, 190.

Froid de l'espace, 66, 71.

Galéopithèque, 685.

Galets rejetés en cordons, à Cayeux, 330, 331 ; - du terrain houiller, 414, 415 ; - du trias, 508,510 .

Gange, ses atterrissements, 300,304 .

Garonne, ses alluvions, 298.

Gault (A rgile), 611, 615.

Gaz lumineux, 38, 42; - substances gazeuses de I'atmosphère primitive, $74 ; \rightarrow$ faible densité des gaz de Ia nébuleuse solaire, 120.

Gazeux (Etat) de la Terre, 201

Généalogique (Arbre) de la vie terrestre, 113, 118 ; - du règne végétal, 137.

Génération des êtres inférieurs, 126; - sans sexe, avee sexe, alternonte, 130 ; - chez les vers, 173, 174; - les annélides, les insectes, 174 a 176 ; - les astéries, les mollusques, 177 ; - les oviparcs, 180 183; - les vivipares, 183.

Genèse de la Terre, 4, 7, 15, - des mondes, 29 a 47 ; - Jupiter en sa genèse, 62, 63; - genèse terrestre, 138.

Genève(Lac de), se diminution graduelle, 309, 303.

Eéologiques (Couches), 24. - Examen des fossiles, 117 ; - explorations, 222,223 ; - épaisseur des couches des terrains géologiques, ㄴ59, 260 ; - du puits de Grenelle, 260 , 270 à 273 ; constitution du cap de la Heve, 285

Germes primitifs de la vie, 129 ; - hypothèse de W. Thomson, 195.

Gibraltar, la naissance du détroit, 339.

Glaciaire, période, 733 a $\mathbf{7 6 0}$.

Glaciers, 734 à 749.

Globo terrestro aux premiers ages, 74 is 77 ; - épaisseur des couches, coupe, 259, 260.

Glyptodon, 756 .

Guoiss, sa position dans le sol, sa composition, 78,201 \& 205.

Goutte d'huile au repos, en mouvement, 60,61 . - gouttes de pluies fossiles, 80, 516.

Granit. Apparition de ce minéral, 77. - Sa composition, 77. - Sa désagrégation primitive, 78, 201 a 203, $205,207$.

Grave, affaissement de ce rivage, 318, 319.

Grenello, puits artésien, 265, 270 a 273.
Gràs, 201, 202, 206. - Variétés de grès, 206 ; grês rouge, 462 ; - bigarré, 488; - triasique, $496,497$.

Guerres dans l'avenir, 18.

Gypse, ses gisements, 501, 502, 505, 506 .

Habitants de la Terre aux premiers áges 371.

Harmonie universelle, 578 a $5 \times 2$.

Havre (Le), son histoire gélogique, 281.

Herbivores du pliocène, 718 a 724 .

Hermaphrodismo des animaux inférieurs, 129, $130,172$.

Hève (Cap de la), 285.

Hipparion, ancêtre probable du cheval, 691, 724.

Historre de la Terre a sa formation, 20,22 ; - de l'Homme primitif, 804 à 810 .

Hollande, ses affaissements, 315 a 317,319 .

Hommo, ses ancêtres, 6, 7. - Variétés de la race humaine, 10 a 12 - Son apparition, 23. - L'univers et l'homme, 29 - Physionomie humaine, 116, 117. - L'homme prinitif du pliocène, 726; - de lis période glaciaire, 737 a 760 ; 一 sa crésation intellertuelle par les progrés, 761 a 829 ; - diflélence entre les races, 788 a 797 . - Les premier's hommes, 804 d 810 . - Ressemblance de l'homino et de certains animaux, 811 a 817.

Homo diluvii testis, 703 .

Houjlle, 400 i 4:34.

Houillère (Période), son dévelonpement, 89, 396 h 459; - Iorêts houillères, 408 a 411 .

Huitres fossiles du trias, 501.

Humanité dans les siècles futurs, 16, 19; - sa marche constante, 19, 20; - 747, 798, 842 a 826.

Hydre ou polype d'eau douce, 162 a 166, 230.

Ichthyosaure, 546 a $\mathbf{5 5 4 .}$

Iguanodon, 559 a $\mathbf{5 6 6 .}$

Immortalité de l'âme, 199, 822.

Inclinaison de l'axe des planètes, 57 à 59 ; des couches de schiste, $78,79,85 ;-$ des roches, $269,270$.

Industrie humaine a l'époque quaternaire, 757 à 760.

Influences de l'eau sur la transformation des espèces, 91 \& 96 ; - de l'air, 96 a $98 ;$ - de la lumière, 98, 99; - de la chaleur, 99, 100.

Infusoires microsropiques dans toutes les mers, 140; - leurs organismes, 141;-leurs débris fossiles, $156,616,6 \pm 4,649$.

Insectes, les premiers, 387 à 391 ; - du carbonifêre, 455 a 459 ; - du jurassique, 586 a 592 ; - du mincène, 701 à 703 .

Intelligence des enimaux, 193, 811; - Faible intelligence des races inférieures, 194, 195, 788.

Intolérance de certains esprits, 801 a 804.

Invertébrés, Ieur arbre généalogique, 113. 
Jersey, affaissement da sol, 310,311 .

Joncs ítu déronien, 394; - de l'age secondaire, 492

Jaurs. Premiers jours de la Terre, 1 i 26, 240, 241.

Jupiter, inclinaison de son axe, 57. - Monde de la Genèse, 62, 63.

Jurassique ,Terrain), son développement, 89 ; ses étages, 488, 490; - la période jurassique, 528 a $6 \cup 6 ;-$ ses principales divisions, 531.

Kangourou, 184, 523.

Labyrinthodontes de la période permienne, 470 a $4 \times 10$; - du trias, 510, 511, 516, 518.

Lacs de la période éucène, 687.

Lacustre, formations tertiaires, 655,656 .

Langues. Orisine, 821.

Laurentienne (Epoque), 218 a 223; - terrain, 218 ; - sun épaisseur, 221.

Lẻmuriens, sinyes inférieurs, 684, 714.

Lepidodendı ous, arbres gigantesques, 40, 41, $443,446,449,453$.

Lias, étage jurassique, 490, 331.

Lignite. 611, 656, 687 .

Littoral flançais, ses modifications, 279 a 368 .

Loire, ses ulluvions, 298.

Lophivdon, 668, 669.

Lumieı, son influence sur la transformation des espicues, 98, 99.

Lune, qée de la Terre, 59, 66, 67; - ses marées, 68,$64 ;-$ son óloignement du globe terrestre, 70 ; - son action sur les marées terrestres, 73 .

Lycopodes du dévonien, 391 a 394 ; - du carbonitère, 411, 412; - de l'âge secondaire, 492, 518.

Mains de différents êtres organisés, 105.

Mammifères, leur succession, 89; - première apparition, 520 a $527,637,638$; - du terrain éocèue, 648, 664 686; - marins, 673; du niocène, 713 ; - du pliocène, 719 a $7 \pm 9$; - du quaternaire, 751 a 757. - La naissance des numumultères, 520.

Mammouth de la Léna, 751, 752.

Marbre, sa formation, 206.

Marées lumaires et lerrestres, 59,67 ; - marées primitives, 68, 69; - action des marées sur le ralentissement de la rotation de la Terre et de Ia Lune, 70; - marées primitives, 75, 76, 82, $85,2116,227$.

Marnes du trias, 488, 497, 503, 506, 507, 510;du tertiaire, $\mathbf{6 5 8}$.

Marsupiaux, 23, 184, 520 a 527, 683, 684, 7.77.

Mastodontes a l'étage miocène, $710,711,719$; du quatrrnaire, 752.

Matière orgauique des otres, 126.
Méditerranèe, sa formation, 692 à 696 .

Méduses, leur formation, 166, 167, 168, 169

Mégalonyx, 7ธั6.

Mégalosaure, 3 .

Viegathorium, $720,729$.

Mer primitivo, 22, 74; - son eppasseur, 77 ; organismes vivant au fond, protoplasma, 132 a 134 ; - effets des mers primitives, 205206 , - du miocène, 694, 695; - du pliocène, $717,718$.

Mésopithéque (Singe), 2, 712 à 715.

Hotamorphoses que subissent les animaux et les pluntes sous certaines influences, 91 ¿ 119.

Métaux-Apparition du fel', de l'or, argent, cuivre, étain, $78 ;-$ premiers métaux, 201.

Mica, base des roches azoiques, $77,78,205$.

Micaschiste, roche primitive, 78, 79, 201, 205, 207.

Microbes, 131; - atmosphériques, 151.

Microscopiques (Infusoires) répandus partout, 140

Microzymas, 130, 131.

Mines de houille, 115 a $424 ;$ - de sel, 497 a 502 Mineraux, 261.

Miocène (Étage), son déreloppement, $89 ;-$ ṕrivde, 691 a 715 .

Modifications que subit la Terre, 19, 14, 15, 30, 279 a 369 ; - des océans, 301, 302; éboulements des collines, 355 a 362 .

Molécules de l'époque primordiale, 122, 123.

Mollasse, terrain helvétique, 699, 700.

Mollusques, leur formation, 177, 178, 2429 a 231 ; - du dévonien, 384 \& 388 ; - du carbonifèrc, 454,$455 ;-$ du trias, 512,$514 ;-d u$ jurassique, 592 à 602 ; - du crétacé, 630.

Mondes, leur genèse, 29 a 47 ; - leur commencement, 48 a 63 . - Le monde de Saturne, 56.

Manère, etre le plus simple, 127, 130 à 132, 136, 137; - dimensions des monères, 141, 142.

Montagnes, leur formation, 205 ; - leurs ébeslements, $3 \mathrm{~J}^{5}$ a 362 ; - leur structure, 538 a 54 .

Mont-Saint-Michel, son affaissement, 307 a 311 .

Moraines de la période glaciaire, 734 a 749 .

Morieri (Eapteris), la plus ancienne plante cannue, $246,248$.

Mouches de la période miocène, 700 a 702.

Mousses du carbonifère, 439, 440 .

Mouvement et chaleur, 38. - Mourement d'une goutle d'huile, 61 ; - da sol permien, 462 ; piriode gluciaire, 741.

Mulo du Diable, bloc erratique, 737, 738.

Multiplication des espèces, 128, 129.

Murchisonites fossiles, 226, 227.

Mylodon robustus, 720 .

Naissance de la Terre, 24; du système solunte, 48 à 63 ; - de la Terre, 64 a 81 ; - de lo pensée chez les animaux infépieurs, 149; - 
des poissons. 369 395; - des mammiferes, 520 ; - de l'áme humaine, 810.

Nature (Époques de la), 255 a 278 ; - son étude, 727 i 729,761 \& 764 .

Nautile, 386.

Nébulouse primitive, 29 a 47. - Nébuleuse d'0rion, 36 b38; - d'Andromède, 40, 41; - du Lion, 41, 42, 49; - du Dragon, 43; du Verseau, 44, 45; - des Chiens de chasse, 49. - La néhuleuse solaire vue de la Terre, 400 iो 404.

Nébulosité gazeuse de la Terre, 20, 122; - des planètes, 45, 48, 49. - Pâle nébulosité de la Terre, 64, 65, 66. - Atmosphere de la Terre, 86.

Niagara, recul de la cataracte, 340 a 345 .

Kil, ses alluvions, $299,300$.

Noct,luque miligire, 160.

Normandie, affaissement de son sol, 306 i 337 .

Ocóans, leurs transformations séculaíres, 300 à $302,340$.

CEningen, fossiles remarquables, 703 \& 707.

Cuf des etres organisés, 129, 182.

Oiseaux. Premiers oiseaux, 23, 582 a $586 ;-$ du crétacé, 63z à $637 ;-$ de l'èocène, 664, 667; - du miocène, T06, 707.

Ondulations pétrifiées, 80, 82; - de l'écorce du globe, 273 a 278.

Dolithe, ses trois êtages jurassiques, 490, 531.

Organes atrophies devenus inutiles, 100 a 110

Organisme élémentaire, 120 a 143. - Les premiers organismes, 1 y a a 129 ; - leur formation dans les eaux primitives, 132 \& 135 , 157 \& 159 . - Organisues des vertébrés, 180 2182. - Apparition des organismes primitifs, 201,221 a 230.

Origine des condensations planétaires, 54, 55. - Les origines de la vie, 83 a 143. - Rénumé des origines, 142; - origine des terraius de sédiment, 205 à 208 ; - origine de l'homme, 800.

Orne, soulèvement durant la périodo jurassique, 5.33; - jurassique, 597.

Oscillations lentes du sol, 331 a $343,611,649$ a b52.

Ours res cavernes, $753,755$.

Ovipare, ar'ıgine de la génération vivipare, 181.

Oxfordien, étage jurassique, 490.

Pachydermes, 671, 675 a 681 ; - transfor niés, 723.

Paléontol gie, sa eréation et son développement. 217, $218,707,739$. - Tableáu des périodes palénntulu iquues, 258

Paléothérium, 667 a 669 .

Faléozoiques, dépỏts, 207.
Parenté organique des êtres, 105 a 119.

Parıs dans les temps reculés, 2, 3; - dans l'avenir, 16; - suhmersions océaniques, 24; vallée de la Seine, 270, 271; - sous les eaux, 329; - aux temps préhistariques, 344, $346,348,349,63 ̈ 5$ в $661,673,676,687$.

Pas, enıpreintes, 169.

Pattes, leurs transformations, 109 a 119.

Paysages de l'époque bouillèe, 408, 453; triasique, 48y; - crétacée, 641; - miocêne, 697.

Pénéen (Terrain), son développement, 89.

Ponseo chez les animaux inférieurs, 149; - chez l'homme, 191, 779, 810, 822.

Périodes planétailes, 4; - primordiale, 22; silurienne, 22. - Duréo de la période primordiale, 80; - des trilobites, des grands sauriens et des mammiferes (tableau), 89. Période laurentienne, 218 a 223; - cam brienne, 223 a 227 ; - silurienne, 228 \& $2 \% 2$; - durée minima des póriodes terrestre, 290 ; tableaux des périoules, 2:58, 2:19, 260, 261; période dévanienue, 369 a 395 ; - carbonifère, 396 a $4 . ; 9$; - permienne, 460 a 482 ; triasique, 485 a 327 ; - jurassique, 528 a 606 ; - crétar'é, 607 à 644 ; - éocène, 647 a 690 ; - mincène, 691 a 715 ; - pliocène, 716 a 729 .

Permien (Terrain). son dévelıppement, 89; périnde permienne. 460 a 482 .

Pétrifications les plus vieilles du monde, 80, 82; - des orgunismes, $217,210,212$ a 215.

Phanérogames. plantes supérieures, leur naissance, 437.

Phenoménes qui ont amené la période glaciaire, 740 \& 749

Phosphorescence des equx, 160.

Thosphorites du Quercy 682 a 686 .

Physionomie humame, $116,117,810$.

Pierre. Age de la piarre taillée, 758.

Piyeon ahlatiou des lobes cérébraus d'un), 187

Placentaires, t883.

Plauètes, leur histuire. leur formation, 30 \& 47 ; leu, s dimensions, 33; - leurs vitesses sur leurs oibites, 52; - inclinaison do leurs axcs. 57 a 60): - durée de leur période de formation, 71; - effets des ayeuts atuospbériques sur la Terre, 2ub. 206.

Plantes. Etres élémelutaires, 191 a 193, tiuiles des prrmitres plantes, 220 à $282 ;$; prenières plautes du dóvonien, 390 a 395 ; du terrain houiller, 438 a 4304 ; - du permien,

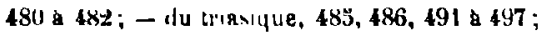
- du créta é. 6.39 a ti4t; - leur dércloppement génétugrịue 6013; - la naissince des crilloyllies, 420; - des phandrogames, 4.7.

Plésiosaure, 3, 549, 553 a 555. 
Pliocéne (Êtage), son développement, 89 ; - période, 716 a 729 .

Pluies des premiel's áges, 76, 77, 80, 205; Gouttes (Issiles, 80; - pluies de l'éroque silurieme, 246 ; - Artion dissolvante des pluies, 262; - hautpur de pluie, 287; - leurs effets sur le sol, 3,55 \& 360,362 ; - de l'époq̣ue glaciaire, 740 a 749.

Po, action de ses equx, atterrissements, 296 a 298.

Poissons. Premiers poissons, 22; - les vertébrés pt les invertébrés, examen de leurs organismes, 179, 180; - la naissınce des poissons, 349 a 345; - в l'époque carhonifere; $\$ 004$, - peruienne, 463, 465; - du trias, 515; du crétace, 631,632 ; - de l'éorène, $66 \%, 664$.

Polaires, rógions primitives, 227, 228; - du tertiaire, 6 bio.

Pôle, température aux premiers jours de la Terre, 75 ; - plantes de l'śpoque carbonifere dens la zone polaire, 406, 40T.

Polypes d'eau douce, 162 à 165.

Portlandien, étage jurassique, 490.

Poudingues, leur formation, 206.

Pouzzole. Temple de Jupiter, 346 a 359.

Prehistorique (Ifomme), 80t a $810 ;-820$ a 829 .

Premuer jours de la Terre, 1 ; - naissance dè la Terre,4;- premier's êtres, 2., 23; - absence de saisons et de climats, 7o, $76 ;-$ preniere's fles et moutannes, 77, 78;- premières platules et premiers animaux, 200 à $292 ;$ - primiers poissons, 372 a 383 ; - animaux, 387,388 ; manmiferes, 522 à 527 .

Primaire (Aqe), sa durée, 220 ; - période primaire, 22, 78; - épaisseur de sa couche, 220; - élude de lâge primaire, 25ä a 489; - tableaux, 2.58 a 261 ; - fin des temp primaires, 460 a 482.

Primitil (Terrain), 78;- sa compositian, sa position en Europe, 79; - germes primitils, l2..

Primitive Ner), 29; - matiere cosmique primitive, 48 ; - commencemeut du monte, 63 a 82 ; - asplert de la surface terrestre a l'éproque primitive, 80, 82, 85, 86;-roches primitives, 201 , 207 ; - plantes, 390 a 395 .

Primordial (Aye), sa durée, 4 ;- épnqua primordiale, zyz; - narées primordiales, $7 \mathrm{i} ;-$ - lurée de l'époijue prinordiale. 80; - température terrestre, 8.;; - elude développre de l'áge primordial, 8z a 2az; - Epaissecur et durée, zz0, 221. 258 в 261

Proboscidiens ilu pliocène, 792.

Profession de foi, 145 a 1!!9, 8

Progres, sa marrhe roustante, 18, 14.5, 2:1; ; sa tendanle, 486 a tax; - lai du progrès dalss la création de l'homme, 810 a 8 !:

Progression de la vio terrestre, 144 a 199 , Lifo, 251.
Prosimiens, 686 .

Protistes, êtres intermédiaires, 158 à Ifi0.

Protoplasma, première substance vivante, 131, 13⿻, 1.00, 151; - progres du protoplasma, 157 \ 159 .

Protozoaires. leur arbre généalogique, 113; dans les calcaires, 206.

Ptérodactyles, 3, 568, 573 \& 582.

Pyrenees, leurs affaissements et soulévements, 538 a $542,654,659,690,691$.

Quartz, base des roches primitives, 77, 205.

Quaternaire (Age), sa durée, 220 ; - terrain, 89 ; - son épaisseur, 220 , 2059 à 261 ; — àge, 733 a 829 .

Races, variátós de la race humaine, 11 ; - diffśrences eutre les races humaines, 788 a 797 .

Radiolaires de la Méditerranée, 141; - de la craie, $156,157$.

Ralentissement du mourement de la Terre, 59, 70.

Ramphorynchus, 3.

Reculver, empiètements de la mer, 323 a 325.

Refroidissement du globe terrestre, 71, 74 is 77,85 ; - premiers terrains défosés sur le globe terrestre re roidi, 201 a 206 ; - refroidissement des vapeurs terre-tres, 200,$201 ;-$ du globe teriestre, 542, 543, 687, 6\%8; - refroidissement a l'ẹpołue glatiaire, 733 a 736 .

Regne animal, sa classification, 87; - son orjfine, 136; - son dóveloppement, 147, 387, $512,563$.

Règne végôtal, son origine, 132, ge1, 245: son développement, $390,396,603$.

Reptiles - Premiers re|tiles, 22. 23; - du terrain permien, 466 a $480 ;-$ du trias, 515 à $520 ;-$ leur règne, $5 \pm 8$ à $606 ;-$ du crétacé, 632

Ressemblances humaines et animales, 811.

Résurrection des especes disparues, 4, 6, 7.

Rhinocéros, 677, 678, 720, 751 . 7.9.

Rhòne, truvail de ses eaux, 290 a

Rivages, leurs variations, 279 a 368 .

Roches primitives, 77, 78, 201 d 203, 905, zut; - crécacées, 611 ; - dú zertiaire, 630, 6 6̆1.

Rynchonelles, 592, 593, 627.

Sables du crétacé, $614 ;$ - du tertiaire, 6.36 \& 6.39 ; - du miocène, 698.

Saisons absence de saisons aux premirrs âges de la Terre, 7i, 407. - Prensière applaction des saisols, 6144, 60to.

Salamandre fossile d'OEningen, 703 a 707 .

Saturne et ses anneaux, $\mathbf{5 6}$.

sauriens. Tableau de leur développement, 89 ; - 
du trias, 520. - Règne des sauriens géants, 528 à 6.6.

Sauterelle décapitée vivant au bout de quinze jours, 185 \& 187 .

Schiste, sa composition, sa disposition, son apparition, 78 a 80 . - Schistes bleus, inclinaisun de leurs couches, 78,79 ; - dépôts argileux, 206; - schistes laurentiens, $221 ;-d u$ trias, 509 .

Science et sentiments, science et vérité, 198, 199.

Scorpion fossile, $249,250$.

Secondaire (Age), sa durée, 220; - son épaisseur the couche, 220, 259 \& 261 ; - age secondaire, 482 a 644 .

Sédiments, leur arigine, 205 a 208 ; - les plus anciens, 218, 219 ; - les dépôts de sédiment, $262,2063,266$ aे $278,543,655$ aे 659 .

Seine aux preniers jours de la Terre, 2 ; - sa vallée, coupe de son bassin, 270 a $272 ;-$ son embouchure, 280 a 286 ; - action de ses eaux, 298; - aux temps préhistoriques, 348, 349.

Sel, sa formation, 497 a 502 .

Sélection naturelle, 110 \& 119.

Sentiment (La naissance du), 522, 64k, 707, 783 .

Serpents Plemiers serpents, 199.

Sexe des premiers organismes, 126 a 129.

Sigillaire, $3 ;-$ du déronien, 391 a $394 ;-d u$ carbonifére, 412, 440, 441, 445, 446, 447, 449 .

Silex du crétacé, 611, 624; - du tertiaire, 650 ; - taillés du quaternaire, 757 .

Silice, écume siliceuse, 203, 205 ; - produits de ls silice, 261 ; - silice du tertiaire, 650,651 .

Silurienne (Yériode), 22; - son développement, 89 ; - époque silurienne, 228 a 252 ; - terrain, 218 ; - son épaisseur, 221 ; - soulèvements, uniformité de température, 236 ; parties de l'Europe qui émergent, 236, 237.

Simocyon, 713.

Singes. La naissance des singes à l'époque miocène, 712, 726. - L'homme et les singes, 767, 768. - Vie, coutumes et mœurs des singes, 768 a 783 ; - fossiles, 686 , 714. - ancêtres de l'homme, 799; - singes anthropomorphes, 800 .

Sivathérium du pliocène, 792; - du quaternaire, 752.

Socièté scientifique Flammarion d'Argentan géologie de l'Orne, 597.

Sol, ses transformations actuelles, 279 a 368 .

Solaire (Système), plau général, 32 ; - sa formation, 48 a 63,120 a 122 .

Soleil, son aspect, sa marche, 14 ; - le Soleil éteint, 18; - nébuleuse solaice, 20, 22, 29 a 17; - le Soleil dans les âges futurs, 47; Terre et Soleil, 66, 67; - le Soleil aux premiers jours de l'époque primordiale, 85, 86, 120 à 122, 228 à $230 ;-$ du déronien, 393 ;
- ses dimensions successives à l'époque carbonifere, 400 a 409 ; - lors de la période triasique, $455 ;-$ glaciaire, 741 \& 744.

Solidification de la croute terrestre, 76 a 78 ; - du granite, 203.

Soulèvements des époques primordiales, 76 a 79, 85, 235, 236, 268 a 278 ; - de la Suède, 331 a $334 ;-$ en Europe, 306 à 335 ; - sur le globe, 335 à 339 ; - duraut la période jurassique, 533 a 546 ; - tertiaire, 649, 690 a 700 ; - glaciaire, 741.

Spectroscope, son utilité, ses révélations, 123 Squelettes de singes et d'hommes, 767,768 .

Stratification des terrains, 269, 270, 271; - dc la houille, 414 a 429 ; - étages tertiaires, 65 느.

Submersions des terrains, 312 a 314.

Suedde, soulèvements et affaissements du sol, 331 à 334,338 .

Sulfure de fer, 624 .

Superposition des couches terrestres, 259 \& 261.

Systèmo solaire, 39; - sa formation, 48 a 63 ;faible densitó des gaz primitifs, 120.

Tableau des animux prinaires, 387; - général des terrains parisiens, 661 .

Température excessive de la Terre aux premiers ages, 4,$71 ;-$ température unifirme des poles et de l'équateur, $75 ;$ - température élevée des eaux a l'epoque primordiale, 76, 77, 203; température terrestre, 85 ; - température a l'époque silurienne, 236 ; - à l'époque houillère, 408; - à l'époque glaciaire, 733 a $73 \%$, 740 a 749 .

Tempêtes, leurs effets, 355.

Temps. Durée des époques géologiques, 220.

Térébratules, 592, 627.

Terrain primitif, 78; - bancs superposés, 79; - les plus anciens terrains d'Europe, 79; - premiers terrains déposós sur le globe minéral primitif, 200 a 204, 206; - terrains secondaires, $490 ;$ - tertiaires, 652 ; - quaternaires, 744. - Épaisseur comparative des terraius, 268; - leur classification générale, 258; - leur anciennetê, 202 à 204,218 à 220.

Terre, premiers jours de la Terre, 1; - ages de la Terre, 4 ;- la Terre daus cent mille ans, 12 ; - dans les áges futurs, 16; - nébuleuse terrestre, 20, 22; - naissance de la Terre, 24;bistoire de la Terre, 30; - inclinaison de l'axe de la Terre, 57 ; - ralentissement de son mourement, 59 ; - naissance de la Terre, 64 a 81 ; - absence de climats et de saisons aux premiers âges de la Terre, 75, 76; - dislocation du sol, 78, 79; - archivos de la Terre, 80;développement de la faune et de la flore aux àges successifs (tableau), $89 ;-$ la Terre a l'état 
de soleil, 120, 123; - origine de la rie sur la Terre, 142; - Terre végétale, 261.

Terrestre, refroidissement du noyau terrestre, 74 ; - aspects successifs du globe terrestre, 74 a 78 ; - chaleur terrestre aux premiers àges de la Terre, 75, 76; - aspoct de la surface terrestre à l'épnque primordiale, $80,8 \%$, 86; - arbre généalogique de la vie terrestre, 113, 118; - la vie terrestre, 138 a 140 ; - son quatrieme âge, 733 a 760 .

Tertiaire (Age), sa durée, 220; - son développement, 89, 220, 259, 261; - opoque tertiaire, 61.5 a 729

Tibre, action de ses eaux, 298.

Tyrolien, étage triasique, 490.

Transformations des especes, 91 a 119 ;végétaux , 91,92; - amphibies, 92 i 95 ; - oiseaux, 95, 96; - des forces naturelles, 148, 149; - actuelles du sol, 279 a 368 ; - évolution des espèces, 677 a 684 ; preuves du transformisme, 90 à 118, 708 .

Tremblements de terre, 361 a 366 .

Triasique (Étage), son développement, 89;période, 485 à 527 ; - ses étages, 488, 490.

Trilobites. Leur périodo do développement, 89, 230 aे $232,238,239$.

Tripoli, sa composition, 206.

Uniformité de température ax époques anciennes, 75, 236, 408.

Unité organique des êtres, $10 \ddot{3}$ à 119.

Univers, 20, 29. - L'uuivers et l'homme, 29. Développement de la vie, 138 ; - revue de l'univers, 242.

Uranolithes, 66, $120^{\circ}$.

Urgonien, étage du crétacé moyen, 490.

Vallées, leur formation, 659.

Vapeurs atmosphériques des premiers âges de ha Terre, 20, 22, 74, 75, 85, 86, 203, 204 .

Variations des ricages, 979 a 368 .
Végétal. Règne, naissance, développoment et arbr généalogique, 224, 390, 429, 603.

Végétaux. Influences diverses sur leurs transformations, 91 a 100 - Les régétaux ne sont pas les ancêtres des animaux, 154 ; - les premiers végétaux, 390 à 395 ; - leurs organes, 428 a 438 ; - du terrain houller, 438 k 454 ; - du permien, 480 a $182 ;-$ du triasique, 485, 486, 491 à 497 ; - du crétacé, 639 a 644.

Vers de terre, indécisions primitives de la génération, 173.

Vertébrés, leur arbre généalogique, 113. - Vertébrés mammifêres, 113; - vertébrés de toute sorte, 180 ; - constitution de leurs organismes, 181 ; - du trias, 515 a 527 ; - dérelop'pement, 547 et suiv.

Vésuye, 350,694 .

Vido de l'espace, avant la formation de la nébulcuse solaire, 120.

Vie, ses origines, 85 à 143, 147. - Arbre généalogique de la rie terrestre, 113, 118. - Les germes de la vic, 12. ; - leur apport sur la Terre, 125. - La vie sur la Terre, 138, 139. - Résumé des origines de la vie, 144. - Déreloppemenl de la vie, 144 a 199. - Ce qu'est la vie, 146 a 149. - Progression de la vie, $243,244,257,258, \$ 69$ a 395,660 a 664 ; le quatrième âge de la vie terrestre, 733 a 760 .

Vitalité des éléments organiques, 185.

Vivipares descendant des ovipsres, 183.

Volcans de l'époque tertiaire, $649 ;-$ periode miocène, 691 a 694.

Vosgien, êtage géologique, 490 .

Walchia, 452, 481

Wéaldien des forêts, crétacé inférieur, 490.

Xiphodon, 670, 723.

Zoophites primitifs, 238 ; - du trias, s12. 


\section{TABLE: DES FIGURES}

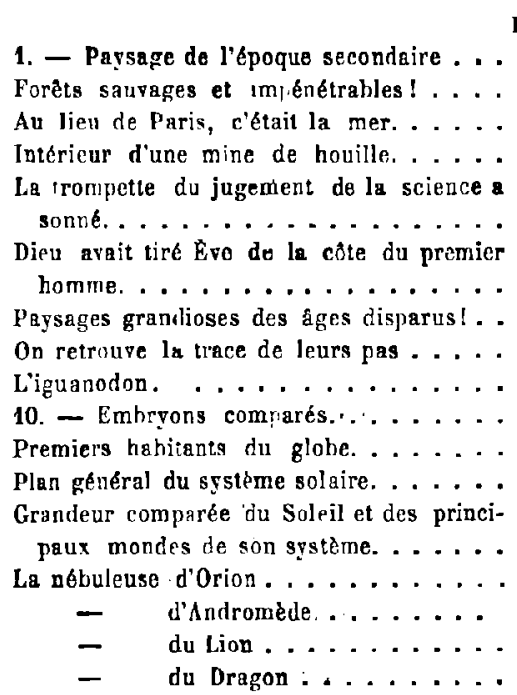

90. - Les anneaux nébuleux ...... La nébuleuse des Cbiens de chasse.... Formation d'anneaux nébuleux. . . . . . Le monle de Saturne. . . . . . . . . . Inclinaison comparée de l'axe de la Terre et de l'axe de Jupiter . . . . . . . . . . . Inclinaison comparée de l'axe de la Terre et de l'axe de vénus. . . . . . . . . . Jupiter est un monde en sa genঠse. . . . . 30. - Les premiers jours de la Terre... La Terre brillait dans l'espace. . . . . . Le Soleil et la Terre vus de loin formaient ane étoile douhle. ..........

La Lune, plus proche de la Terre, produisait des marées formidables. . . . . . .

La formation de l'atmosphère. Première condensation des equx...........

Treniers soulevements de la croute terrestre. . . . . . . . . . .

Empreintes fossiles de gouttes de pluies tombées il y a des millions d'années. . . Scories to tant sur le glohe en fusion. . 40 - Développenents progressifs de la flore et de la laune aur áges successifs de la Terrs. . . . . . . . . . . . Métamorphose d'un animal aquatique. . . . Les êtres qui ont précếdé l'hommo. ....
Pages.
Pages.

Exemple de transformation des races. . . : 101 Inité organique el pareuté des étres. $\therefore 105$ Transformation des espéces. La chuto des pattes ................ 109 Arhre génßalngi ifue de la vie terrestre . . . 113 Suus l'immense soleil des premiers âges l'enu, l'eau partuut, l'eau toujours : dans son sein va germer la vie. ....... 121 Les monères. ........... 197 50. - Prrmiers stades de la création d'un mamnifè e............ 129

Propngation d'un infusoire par division spon-

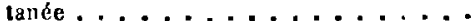
Protoplosma recueilli dans les profondeurs de la mer. ............ 133 Assnciation de moneres. .......... 137 Infusoires élémentrires. Monades. Volvoces. 140 L'astension de la vie. . . . . . . . 145 Mirrohes tmosphériques......... 151 60. - Bacilles, bactéries. . . . . . 151

Diverses formes de diatomées. . . . 1 1;9 k 153 Coquilles de la craie prise sur une carte de visite glacée. ............. 157 Protistes, étı'es intermédiaires. . . . 158-1- 199 On cruit voir une nalade glissant sur les ondes et faire jaillir la phosphorescence. 161 70. - L'hydre d'esu douce et son modo de loconotion............. 163 Hydraires d'eau doure. . . . . . . . 165 La formution des méduses. . . . . . . 167 Polypes divers. . . . . . . . . . . 168 La méduse Hhirostome. ........ 169 Polypier du corail. .......... 171

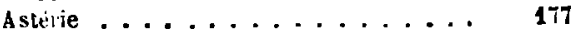
L'anuhyoxus. premier poisson ..... 179 La lamproie. .............. 179 80. - La génération vivipare vient de la génération ovipare............ 181 Marsuviaux, preuiers mammifères . . 184 Sicute elle décapitée. .......... 185 Pigeon après l'ublation des boes cérébraux.................. 189 Premiers terrajus dépnosés sur le globe. . . 201 A wathes portant de siugulieres tigures naturelles ............... 208 Curieuser pierres arborisées. . . . . . . 209 Ardosses portant des pétrifications .... 212 
Collection de fossiles gravés dès 17à1 . Pages. 213 90. - Les plus anciens dépóts sédimentaires 221 Organismes problématiques des anciennes

mers. .............. 223-224

premières plantes ........... 20. 20

Les plus anciennes plantes, algues, etc. 226 \$ 248

Empreinte fossile de plante primitive. . . 227

100. - Les plus anciens animaux ... 928 a 230

Le trilohite .............. 232

Le pterigotus ............. 233

Echinodermes............ 237

Les premiers jours de l'époque silurienne. 242

110. - Les plus anciennes plantes. . . . 248

Le plus ancicn animal connu. ......

Épaisseur comparative des terrains géolo-

giques. .. ............

Coupe du puits artésien de Grenelle....

Mode de formation des terrains de sédi-

ment. . . . . . . . . . .

Soulevement des terrains de sédiment ...

line carriere; couche de roches superpo-

sées. ...............

Exemple do soulevement et des inclinaisons

qui en résultent. ............

Soulèvement des terrains stratifiés .....

120. - Coupe au travers de la vallée de la

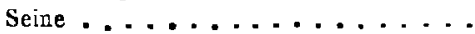

Coupe du bassin de la Seine, du puits arté-

sien de Grenelle (Paris) au plateau do

Langres. . . . . . . . . . . .

Ondulations, soulevements et fractures de

l'écorce du globe. ...........

Exemples de fractures .

Couches relevées sur une masse éruptive. - 276

Exemples de filons éruptifs ì travers les ro-

ches stratifies...........

Lembouchure de la Seine. . . . . . .

130. - L'embouchure de la Seine, il y a

quatre cents ans : avant la fondation du

Harre...............

lo cap de la Hère...........

Falaise méditerranéenne. . . . . . .

lalaise de l'Océan. . . . . . . . .

L'embouchure du Rhône. .........

Les cordons littoraux et le lent retrait de la

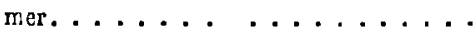

Voie romaine de Beaucaire à béziers. . .

Diminution graduelie de la mer à l'embouchure du PO...

- $\quad$ a l'embouchure du

Tibre......

a l'embouchure du Nil.......

140. - Diminution graduelle du lac do

Genéve par les atterrissements du Rhone.

Le Mont-Saint-Michel. .........
La baie du Mont-Saint-Michel aux hautes et basses mers. ............. 307 Carte des envahissements de la mer. . . 309

Submersion de la ville d'ls. . . . . . . 313

Villages de Zélande engloutis sous l'irruption de la mer............ 317

Les envahissements de la mer la pointe de Grave..............

Le phare de Cordouan et son tle au seizicme siècle.............. 320

Le phare de Cordouan aujourd'hui. . . . 321

Rivage rongé par les flots à Gallipoli . . 323

150. - L'église de Reculver en 1781 . . 344

Vue de l'église de heculver en 1834. . . 39

Village enseveli sous les dunes. . . . . 328

260 Paris sous les eaux, .......... 329

265 Plage de galets rejetés en cordons par la

mer, a Cayeux (Somme)........ 331

Etat actuel et déplucement rapide du cap Ferret, pris d'Arcachon ........ 332

Soulèvements et affaissements constatés en Suède................... 334

Forêt en voie de submersion sur les rivages de la Suède. . . . . . . . . . .

Carte générale des soulèvements et affaissements du sol en roie d'accomplissement.

Le détroit de Gibraltar, autrefois et aujourd'hui .............. Recul graduel de la cataracte du Niagara. . 160. - Vue à vol d'oiscau des chutes du Niagara.............. 311

Chutes du Niagara .......... 345

La Seine aux temps préhistoriques. . . . 348 - sur l'emplacement de Paris aux temps préhistoriques......... 349 277 Le temple de Sérapis a Pouzzole. . . . 352 281 La tempette............. 333 Dégradation produite par les eaux a travers la voie romaine de Soissons a Senlis. . 356 283 Un tremblement de terre. . . . . . . 361 283 170. - Coupe verticale à travers une ille de coraux .............. 363

289 Une tle de coraux. . . . . . . . . 365

293 Les premiers poissons. ...... 374 à 379 Principaux habitants de la Terre pendant la période dévonienne......... 37

293 180. - Transformation de la queve des poissons ................ 380 207 Crustacés de la période désonienne. . 381 a 383 Mollusques brachiopodes de la période dé-

299 vonienne. ...............384 a 386 190. - Développement et varjation des animaux primaires a travers les âgos. . . 387 Les premiers insectes. . . . . . . . 389

303 Les plus anciennes plantes. . . . . . . . 390 305 Débris fossiles de plantes primitives. . . 391 


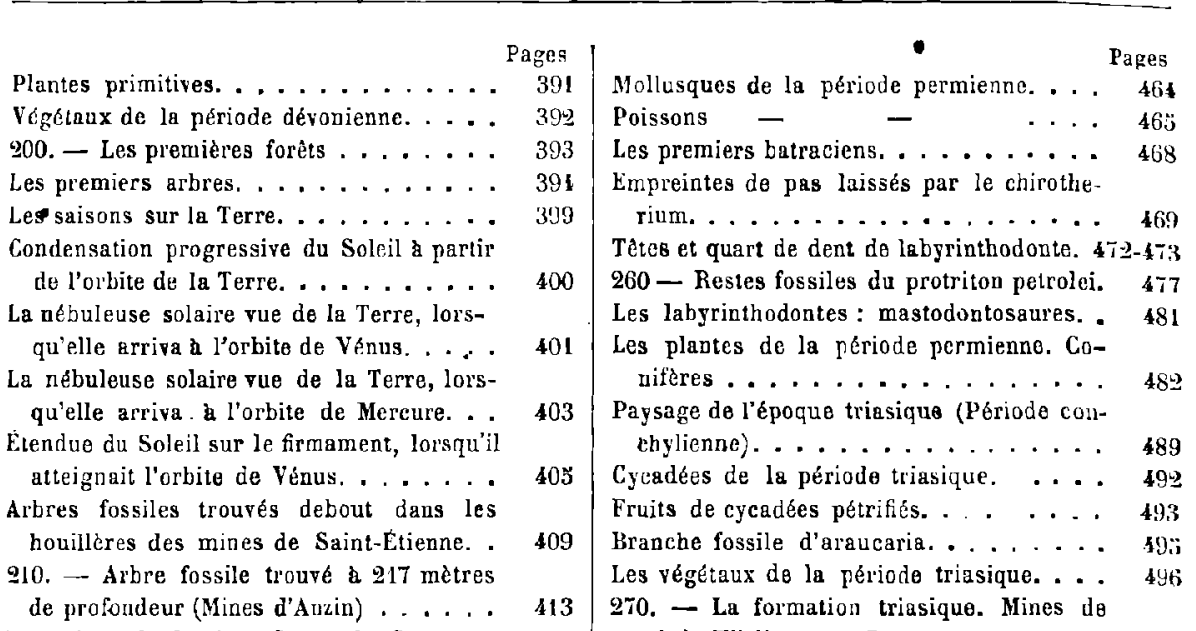

Les mines de houille. Coupe du Creuzot a

Montchanin .............

Les mines de houille. Coupe de St-Gervais.

Position des couches de houille da la carriere de Fins (Allier). . .......

Coupe de la coucho de houille de Montcenu-

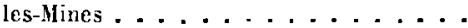

Forêt de l'époque carbonifêre. .......

Feurs de boswellia, de coriandre, d'aiglemoine et de pavot..........

920. - Fleur de kalmia . . . . . . .

l.a fícondation régétale. ........

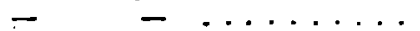

Arbre généalogique du règne végétal. . .

Lessouia fucescens (Algues). .......

Equisetum sylvaticum et polytrichum... . Rameau fossile de lepidodendron. . . . Les albres géants de la période carbonifère. Empreinte fossile de fougère . . . . . . 230 . - Ecorce et écailles du lepidodendron (2 fig.) ............

Fragment et moelle pétrifiée d'un calamodendron (2 fig.). .........

Ecorce fussile de sigillaires . . . . .

Empreintes fossiles (2 fig.) . . . . . .

Racines de sigillaire . . . . . . .

Fougère arborescente. .........

Rameau fossile dastérophylite equisetiformis. ...............

940. - Lepidodendron et sigillaire . . . Rameaux fossiles de fougères (2 fig ). . . Un paysage de l'époque houillère ..... Brachiopodes, oursins et crinoides de l'époque carbonifère. ..........

Arajgnée et myliapodo fossiles . . . . . . 200 - Insectes de l'énoque carbonifere

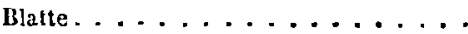
Insectes de l'époque carbonifère. Proto-

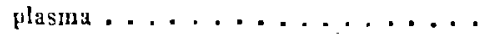

477 sel de Wielieztia en Pologne.... Ammonites - - $\quad$ - $\quad$. . 504 Les ammonites des mers triasiques ... 421 Echinodermes et crustacés de la période triasique...............

421 Les premières écrevisses et leurs pinces. .

497 Poissons de la période triasique: le ceratodus ..............

Les labitants de la période triasique : capitosaure, belodon, nothosaure. . . . . 280. - Le dicynndonte, reptile de l'epoque triasique. .............. Le zanglodon, dinosaurien de l'époque

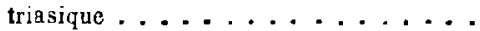
Empreintes de pas du brontozoum gigan-

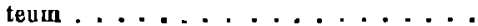
Scène de l’époque triasique. . . . . . $\mathrm{Plus}$ ancien reste fossile de mammifire trouvé jusqu'à ce jour ......... Scène de la póriode jurassique: ichthyosaure, plésiosaure, ptérodactyles ....

L'émersion du sol de la Manche a la fin de la période jurassique et ses principaux habitants .............. La France et l'Angleterre a la fin de l'époque jurassique........... \$ 511 Tête fossile d'ichthyosaure. . . . . . 5 \$ 48 290. - Squelette fossile de l'ichthyosaure. - $\quad 549$ Dents d'ichthyosaure et de plésiosaure. . 549 Petil ichthyosaure conservé fossile dans le sein de sa mère. ......... \$ \$ 533 Sipuelette restauré de plésiosaure. .... 5\%̃ Fossile du plésiosaure macrocéplhale. . . 587 Dent d'iguanodon. .......... 560 Forme et grandeur probable de latlantosaure................ 561 Animaux de la póriode jurassique : le broatosaure............. 561 


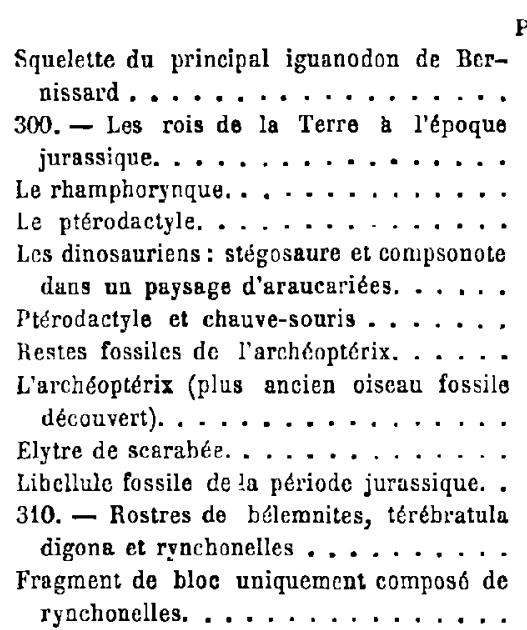

Terrains et coupes jurassiques. . . . . 594-39

Seiche et bélemnite . . . . . . . . 896

Bélemnite nageant. . . . . . . . . . 597

390. - Oursins et mollusques de la période jurassique............. Crinơde de la période jurassique. . . . . . Mollusques céphalopodes et débris fossiles de coraux de la période jurassique. ... France : Jura, Franche-Comté, Bourgogne a l'époque de la mer jurassique..... Árbre généalogique du règne végétal ... Au hord de la mer pendant la période jurassique. ............ Les ptérodactyles ............ 330. - Coupe prise dans les terrains crétacés ................

Fragment de craie vu au microscope. ... Miliole de la pierre à bátir . . . . . . . Une forêt aux premiers siècles de la période crétacée............

Fossiles du terrain crétacé. Micraster, terebratules. . . . . . . . . . . . Fossiles du terrain crétacé. Hippurites. . 310. - Fossiles du terrain crétacé. Rudiste, ammonites, belemnites . . . . . . . .

Céphalopodes ammonitides de la périodo crétacée. . . . . . . . . . . 630-631

La région de Paris pendant la mer crétacée. . . . . . . . . . .

Tête d'oiseau à dents. . . . . . . . . . Les oiseaux a dents de la période crétaḉe................ 350. - L'Hesperornis regalis. . . . . . . Tortue fossile de la période crétacée. ... Paysage végétal de la période crétacée en Bohême. ..............

Tableau général des terrains parisiens. . Correspondance entre le développement du
Pages. règne animal et la succession des époques geologiques. .......... 663 Poissons de la période éocéne . . . . . 664-663 Restes fossiles d'oiseau trouves a Montmartre. . . . . . . . . . 667 360. - Le grand paléothérium . . . . . kik9 Le xiphodon gracile .......... fi L'anoplothérium . . . . . . . . . . . 6 :73 Le dinoceras. . . . . . . . . . . 6 677 Transformation des espèces: squelette de paléothérium. . . . . . . . . . . . 680

Transfurmation des espèces: squelette de

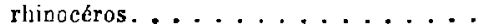

Le galéopithéque, lémurien de la périodo

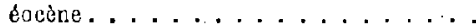

Carte montrant l'étendue de la sulface qui a été couverte par la mer depuis le commencenent de la période éocène. . . . . Les volcans français pendant la période miocène............... 370. - L'Europe centrale à l'époque de la mer mollassique. ...........

Paysange de la période miocène à Lausanne ...............

Insectes de la période miocène retrouvés a l'état fossile ............. Le prétendu homme témoin du délu Paysage de la période miocène en France. Le mastodonte. Précurseur de l'élêphaut . .

Cláne et singe mésopithèque de Ia période miocène. ............. 712

Le siamang, singe gibbon de la période miocène. ............ 713 380. - Squelette fossile du mégathérium. . 717 Le mégathérium. .......... 719 Le mylodon.............. 720

Habitants de la Grece, de la Suisse, de la Provence, aux premiers siècles de l'époque pliocène ............. Squelette fossile du mastodonte du musíe de Turin ............. 7 . 7 . Le sivathérium, cerf-colosse . . . . . . 725 Squelette fossile de l'bipparion (ancêtre probable du cheval) ............ 792 Carto des unciens glaciers des Alpes. . . . 737 390. - Mammouth retrouvé au milieu des glaciers de Sibérie. . . . . . . 745 Sqquelette et forme probable du cerf à bols gigantesque............. 748 Le mammouth, elephas primigenius . . . I $\quad$ it9 Les contemporains de l'hornme primitif. . . 759 Le mégalonyx............. Tis Squelette restauró du glyptodon. ...... $\mathbf{7 3 7}$ Squelettes comparés de l'orang, du chimpanzê, du gorille et de l'homme . . . . 767 Téte de lion du Sennar. . . . . . . . 768 


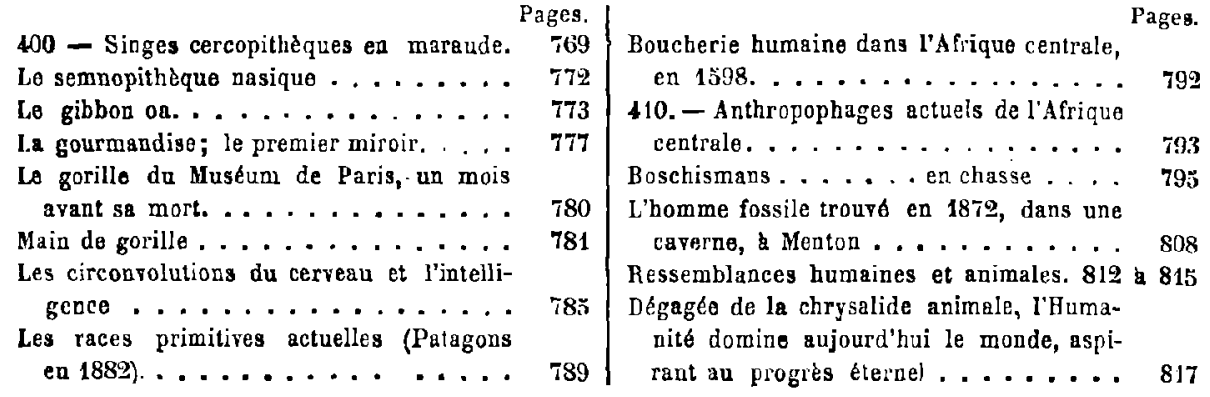




\title{
TABLE DES MATIÉRES
}

\author{
CHAPITRE PRÉLIMINAIRE
}

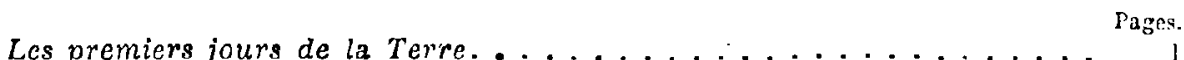

\section{LIVRE PREMIER}

Chapitres,

Lo commencement du mondo.

I. - La genèse des mondes. Les nébuleuses. . . . . . . . . . . . . . .

II. - La formation du système solaire . . . . . . . . . . . . . . . . . 48

III. - La naissance de la Terro................... 64

\section{LIVRE II}

L'Age primordial.

I. - Les origines de la vie. - Parenté et filiation des étres. - Arbre généalogique de la vie terrestre. - Transformation séculaire des

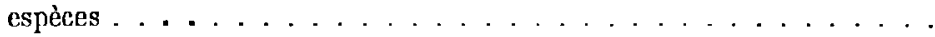

II. - Les origines de la vie. - Comment la vie a-t-elle commencé? L'organisme élémentaire. . . . . . . . . . . . . . . . . 120

IIL. - Développement et progression de la vie . . . . . . . . . . . . . . 144

IV. - Premières plantes et premiers animaux. - Les plus anciens fossiles. — Périodes laurentienne, cambrienne et silurienne . . . . . . . 200

\section{LIVRE III}

\section{L'Ago primaire.}

I. - Les époques de la nature. - La formation des terrains. - Leur

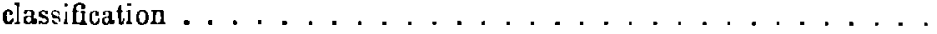

II. - Les transformations actuelles du sol. - Variation des rivages. Embouchures et deltas. - Action des cours d'eau. - Oscillations lentes. - Soulèvements. - Dépressions. - La Terre et la Mer. La nature continue son cuvre. . . . . . . . . . . . . .

III. - Le développement de la Vie. - La naissance des poissons. - La période dévonienne. . . . . . . . . . . . . . . . .

IV. - La période carbonifòre. - Développement du règne végétal. - Iles et continents. - Climats insulaires. - Absence de saisons. - La nébuleuse solaire. - L'atmosplère, la chaleur et l'humidité. - Les plantes et les arbres. Forêts antiques. Animaux qui les habitaient.

V. - Fin des temps primaires. - La période permienne. - Batraciens

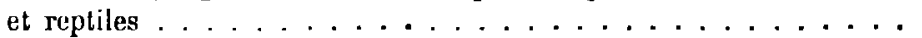




\section{LIVRE IV}

\section{L'Age secondaire.}

Chapitres.

I. - La période triasique. - Mollusques, crustacés, poissons, amphibies: batraciens, reptiles, labyrinthodontes. Premiers mammifères ; marsupiaux. . . . . . . . . . . . . . . .

II. - La periode iurassique. - Le règne des sauriens géants. Ichthyosaures, plésiosaures, dinosauriens, atlantosaures, brontosaures, iguanodons, mégalosaures, reptiles volants, ptérodactyles. . . . . . .

III. - La période crétacée. - Les derniers sanriens, les premiers oiseaux, oiseaux ì dents. Progrès corrélatif du régne végétal et du règne

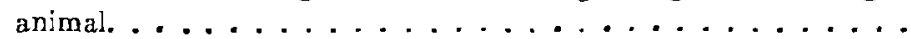

Pages

\section{LIVRE V}

\section{L'Age tertiaire.}

1. - La période éocène. - Développement des mammifères. Pachydermes, paléothériums, lophiodons, anoplothériums, dinocéras. Apparition des lémuriens ou singes inférieur's ..............

II. - La période miocène. - Mammifères supérieurs, hipparions, chevaux, mastodontes, éléphants, singes. .............. III. - La période pliocène. - Fin des temps anciens. Les précurseurs de

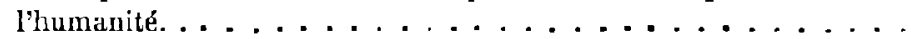

\section{LIVRE VI}

\section{L'Age quaternaire.}

I. - Le quatrième áge de la vie terrestre et les premiers jours de l'ère

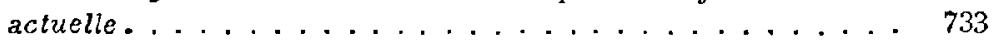

II. - La création de l'homme.................. $76 \mathrm{I}$ 


\section{PLAGEMENT DES PLANCHES DANS GETTE ÉDITION}

\section{CARTES GEOLOGIQUES}

(Ces cartes sont toutes coloriées pour la distinction des terrains.)

Carte 1. Carte géologique de la France ................ 204

- 3. Formation graduelle des terrains. FRANCE. Terrains primitifs. . 236

- 4. Terrains émergés en Europe à l'èpoque de la mer silurienne. . 252

- 5. Coupe générale de l'ècorce du globe. . . . . . . . . . . . . 260

- 6. Formation graduelle des terrains. FRANCE. Terrains primitifs, primaires et triasiques. . . . . . . . . . . . . 532

- 7. Formation graduelle des terrains. FRANCE. Terrains primitifs, primaires, triasiques el jurassiques. ............ 612

- 8. Formation graduelle des terrains. Fravce. Terrains primitifs, primaires et secondaires. . . . . . . . . . . . .

\section{PAYSAGES (Aquarelles).}

Planches.

I. - Scène du monde primilif pendant la période secondaire . . . Frontispice.

II. - Une forêt de l'époque carbonifère . . . . . . . . . . . . . . . 408

III. - Paysage d'Europe à l'époque tertiaire. . . . . . . . . . . . . . . . 648

IV. - La France avant l'homme. Combat de mammouths et de chats géants. 724

V. - Les premiers áges de l'humanité. Époque de l'ours des cavernes. . . 804

Cartes et tableaux géologiques Insérés dans le texte.

Développements progressifs de la flore et de la faune aux áges successifs de la terre............................ . . . . 89

Arbre généalogique du règne animal................. 113

Coupe du puits artesien de Grenelle, à Paris. . . . . . . . . . . . . . . 265

Carte générale des soulèvements et affaissements du sol......... 337

Arbre généalogique du règne végétal. . . . . . . . . . . . . . . . . 437

Tableau général des terrains parisiens. . ................ . . . . . . . . . . . . . . . .

Correspondance entre le développement du règne animal et la succession des époques géologiques. .................... 663

Carte montrant l'étendue et la surface terrestre qui, en Europe, a été couverte par la mer depuis la période éocène. . . . . . . . . . . 689

L'Europe centrale à l'époque miocène. . . . . . . . . . . . . . . . 696

Extension des.glaciers des Alpes à l'époque glaciaire. . . . . . . . . 737

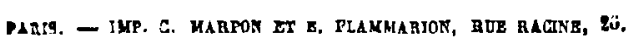

